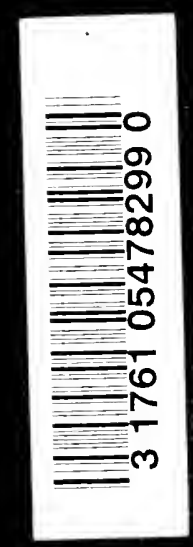



Digitized by the Internet Archive in 2007 with funding from Microsoft Corporation 



\section{PRINCIPLES OF \\ STRATIGRAPHY}

BY

AMADEUS W. GRABAU, S.M., S.D.

PROFESSOR OF PALEONTOLOGY IN COLUMBIA UNIVERSITY
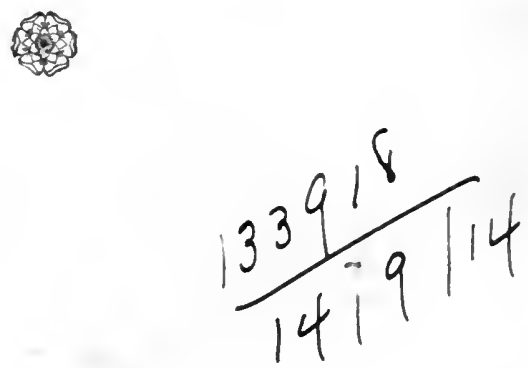

NEW YORK

A. G. SEILER AND COMPANY

1913 
Copyright, I9I3, BY

A. W. GRABAU

All rights reserved 
PRINCIPLES OF
STRATIGRAPHY 


\section{COMPANION VOLUMES OF THIS WORK North American Index Fossils \\ (Invertebrates)}

By Amadeus W. Grabau, Professor of Palæontology in Columbia University, and HeRvey WoodBuRN SHIMER, Assistant Professor of Palæontology in the Massachusetts Institute of Technology. 2 vols. Vol. I, r909, 853 pages and r2 ro text figures; Vol. II, I9Io, 909 pages and 727 text figures.

The volumes contain brief descriptions of the genera and species of North American fossils most important for the determination of geological horizons, and keys for class work in the genera. They are suitable worker, in determining tology, and as an aid to the zons. Owing to thing his fossils and finding his horiliterature, a come widely scattered condition of the becomes an indisrehensive treatise like the present equipment. The Stratiole adjunct to the geologist's sary of Term Fossils, and the of great value.

Large octavo, cloth bound, \$12.00 int, for the two volumes.

\section{In preparation \\ Manual of Stratigraphy}

By Professor Amadeus W. Grabau,

A discussion of the geological formations, with especation of "Principles of Stratigraphy."

A. G. Seiler \& Co., 1224 Amsterdam Ave., New York 


\section{ERRATA}

Part changed in italic

PAGE

54, 7 lines from top, change Eggleston to Egleston

56, 16 lines from top, change Pumpelli to Pumpelly

86,7 lines from top, change silvestris to sylvestris

90,16 lines from top, change primogenius to primigenius

97, reference 96 , change Tolman, C. E., to Tolman, C. $F$.

224, 26 lines from top, change Skagar to Skager

236, I 7 lines from top, change Barent to Barents

268, reference 66, change Sorbey to Sorby

294, 23 lines from top, change Philipps to Phillips

296, 6 lines from top, for shatter marks put chatter marks

299, reference 23, change Philipps to Phillips

310 , Io and 11 lines from bottom, change Abyssolyth to Abyssolith

377,14 lines from top, change Pterigotus to Pterygotus

392, 4 lines from top, change Woods Holl to Woods Hole

474, 15 lines from bottom, change Cymapolia to Cymopolia

534, 4 lines from bottom, change Yantzi to Yangtse

543,5 and 7 lines from bottom, change Solefluction to Solifluction

554, 7 lines from top, change Askabad to Ashkabad

591, I4 lines from bottom, change Molasse to Mollasse

6I4, 2 lines from bottom, change Dantzig to Danzig

639, reference 45 , change Philipps to Phillips

684, 16 lines from bottom, change Reed to Reeds

689 , reference 80 , change Reed to Reeds

743, 3 lines from top, initial letter c to be capital C

830,3 lines from top, change Chonoplain to conoplain

893, bottom line, change Equador to Ecuador

905, 4 lines from bottom, change R. D. Chamberlin to R. $T$. Chamberlin

941, 8 lines from bottom, change Dadoxylen to Dadoxylon

1034, 4 lines from top, change Bothryolepis to Bothriolepis

1038, top line, change $Æ$ pyornys to $Æ$ pyorn $i$ s

105I, 8 lines from top, change Orinoko to Orinoco

1076, 7 lines from bottom, change Chili to Chile

1086, 7 lines from bottom; change Valient to Valiant

1096, reference 22, change Roth, I. to Roth, $J$.

1099, Foot note 1, 2 lines from bottom, change Philips to Phillips

1 108, column headed Founder, change Conybear to Conybeare 

TO

JOHANNES WALTHER

A LEADER IN THE

FIELDS OF KNOWLEDGE

HEREIN EXPLORED 


\section{ACKNOWLEDGMENTS.}

To the many among my colleagues and students who have rendered assistance in the production of this work I wish to tender heartiest acknowledgments. Of those whose helpful attitude aided the early stages of my labors I zeant especially to mention Alpheus Hyatt and Robert Tracy Jackson, leaders in American Palcontology, and further, William Otis Crosby, Nathaniel Southgate Shaler, William Morris Davis and Jay Backus Woodzeorth, masters all of inorganic geology, and known as such in both hemispheres. More recently my colleagues at Columbia University, Professors James F. Kemp, Douglas Wilson Johnson, and especially Charles Peter Berkey have put me under obligations by helpful suggestions and criticisms. My graduate students, too, during the last ten years have aided me more than many of them perhaps realize, for only a teacher can know the help and inspiration that comes from daily contact with eager and, above all, inquiring minds, such as our splendid body of American graduate students furnishes. May these pages recall to them the many spirited discussions, in which they usually bore their part so zell.

To one of them, Miss Marjorie O'Connell, A.M., instructor in Geology in Adelphi College, Brooklyn, my special thanks are due for the careful and critical attention given for a period of a full year or over to both mamiscript and proof, and to the verification of the literary references, and the endeavor, by patient library research, to make the bibliographies as serviceable as possible. To her prolonged search of the literature for available material, I also owe many important references which I would otherwise have missed. And, finally, she has to her credit the very complete index of this volume. One other I may mention by name, Mr. George L. Camnon, of Denver, Colorado, whose broad conceptions of the principles of classification have rendered our discussions highly profitable.

Finally, I cannot forbear to mention my many foreign friends who, by word of mouth or by their writings, have led me into paths replete with interest and profitable adventure. To their willingness to guide me in my studies within their home-lands, and to discuss the problems which interested us in common, I oze many stimulating hours. Some, like Kittl of Vienna, Koken of Tïbingen, and Holsapfel of Strassburg, have since passed away, and I may think of them here in sorrow. To the many, however, who still hold high the torch of learning, these pages bring a greeting from the land which has yet much to learn from the culture, and the devotion to Pure Science, so characteristic of the European leaders in the Earth Sciences. And he, to whom these pages are inscribed, will know that the days spent in his inspiriting companionship in field and study are among the potent infuences which helped to shape the character of this book. 


\section{PREFACE}

This book is written for the student and for the professional geologist. It aims to bring together those facts and principles which lie at the foundation of all our attempts to interpret the history of the earth from the records left in the rocks. Many of these facts have been the common heritage of the rising generation of geologists, but many more have been buried in the literature of the science, especially the works of foreign investigators, and so have generally escaped the attention of the student, though familiar to the specialist. Heretofore there has been no satisfactory comprehensive treatise on lithogenesis in the English ianguage, and we have had to rely upon books in the foreign tongue for such summaries. It is the hope of the author that the present work may, in a measure, supply this need.

The book was begun more than fifteen years ago, and the material here incorporated has been collected and sifted during this interval. From time to time certain phases of the work have been published, and these in a revised form have been included in the book. The first of these, on Marine Bionomy, appeared in I899, the latest, on Ancient Deltas, in I9I3. Much of the material has, however, not appeared in print before. The principles and data herein treated have for years been considered and discussed in a course of lectures on the "Principles of Geology," given jointly by Professor Berkey and myself at Columbia University. Some of the problems which have taken form during these discussions have been chosen as subjects for more extensive investigations by members of the classes, and the results of a number of these have already appeared in print.

My own interest in the problems, and especially the principles of Orogenesis and Geodynamics, goes back to the days when, as a student, I listened to the illuminating expositions of that versatile and accomplished exponent of rational geology, Professor William Otis Crosby, at the Massachusetts Institute of Technology. It was at this time also that Alpheus Hyatt and the other eminent naturalists who foregathered at the fortnightly meetings of the Boston Society of Natural History, discussed the problems of Biogenesis, and evolved the working principles which have since guided the in- 
vestigations of the "Hyatt School" of Palæontologists. Later, at Harvard University, under the leadership of the unforgettable Shaler, and guided by that keenest of analysts, William Morris Davis, and by the others of that brilliant coterie of Harvard Geologists and Palæontologists-Wolf, Woodworth, Jackson, Ward, Daly, Jaggar, and others-the principles of Lithogenesis, Glyptogenesis, and Biogenesis formed daily topics of discussion, and many of that group of eager students, who took part in these discussions, here laid the foundations for subsequent achievements in these fields. It was at this time also that we in America first became acquainted with those monumental contributions to Lithogenesis and Biogenesis, that had been and were being made by the then Haeckel Professor of Geology and Palæontology at Jena, Dr. Johannes Walther, now Professor of Geology and Palæontology at Halle. The Einleitung in die Geologie als historische Wissenschaft had appeared only a few years before, and its influence in shaping geologic thought, especially among the younger men, was just beginning to be felt. The Lithogenesis der Gegenvart presented such a wealth of facts concerning the origin of sedimentary rocks, that attention began to be diverted from the problems of the igneous rocks which had heretofore almost exclusively occupied petrographers, and "Sediment-Petrographie," or the petrography of the sedimentary rocks, attracted more and more of the younger geologists, especially in Germany and France. In the latter country the works of Cayeux and Thoulet led the way, while in Britain Mackie and Goodchild applied the principles of eolian deposition to the interpretation of British strata, and Sorby, Phillips and many others accumulated a wealth of facts and inferences.

It was at this period, too, that the attention of geologists and especially stratigraphers was first seriously directed toward the desert regions of the world and the phenomena of extensive subaërial deposition. Here, again, Walther led the way in that classic, Die Denudation in der Wiiste, followed in 1900 by his epoch-making book, Das Gesetz der Wiistenbildung, which, in its revised second edition, appeared in I9I2. It is, of course, true, that important studies of desert regions were made earlier, notably those of von Zittel on the Libyan desert (I883), but the significance of the desert deposits in terms of stratigraphy was first fully appreciated within the last decade. That the importance of the desert as a geological factor has become widely recognized, is shown by the numerous recent studies, especially those on the Kalahari by Passarge, and those on the Asiatic deserts, by Sven Hedin, Pumpelly, Huntington, and others. 
It is during this same decade that the Sciences of Glyptogenesis and Geomorphology have come into being, notably through the labors of Davis in America, and of Suess and Penck in Europe. Suess's Antlitz der Erde began to appear, it is true, in I883, but it is only in recent years that this work has been readily accessible to most American students, through the medium of the English translation by Sollas and Sollas (1904-1909). Penck's Morphologic der Erdoberflïche appeared in 1894, but did not become well known in this country until much later. It was, however, Davis's publications in this country, chiefly during the early nineties of the last century, which gave the great impetus to the study of land forms, and especially of the influence of erosion on their production. The concept of the peneplain, of the cycle of erosion, of the sequential development of rivers and erosion forms on the coastal plain and on folded strata, and others chiefly due to him, have become of incalculable value to the stratigrapher. The more recent development of the idea of desert planation by Passarge and Davis, has opened further promising fields to the stratigrapher, who seeks to interpret the record in the strata by the aid of modern results achieved by universal processes.

The science of earth deformations, or Orogenesis, also received renewed impetus during the last decade, in the work of Bailey Willis in this country (Mechanics of Appalachian Structure, 1893), and the researches of the European geologists on the deformations of the Alps and other great mountain chains. True, this field had been opened up in a masterful way by Heim, when in 1878 he published his Mechanismus der Gebirgsbildung, and by Suess in his earlier studies, but such work was of the nature of pioneer investigations. In the Face of the Earth, too, emphasis is laid on deformation as the principal agent in the production of the diversified surface features of the earth.

In the field of Correlative Stratigraphy the past decade has likewise seen striking advances. The publication of the Lethrea falls into this period, and so does Marr's comprehensive little volume, The Principles of Stratigraphical Geology, not to mention the elaborate recent texts of Haug. Kayser, and others, or the numerous publications of Government surveys, and of individual contributors. That questions of correlation have reached an acute stage in American Geology is manifested by such recent publications as the Outlines of Geological History and Ulrich's Revision of the Palcozoic Systcms, and the numerous papers accompanying or called forth by these. Finally, Palæogeography, as a science, is of very recent development, most of the works of importance having ap- 
peared in the last five years. In America Schuchert and Bailey Willis are the acknowledged leaders, while in Europe many able minds have attacked the problems of Palrogeography from all angles.

It is thus seen that this book was conceived during the period of initial reconstruction of our attitude toward the problems of geology, and that its birth and growth to maturity fell into that tumultuous epoch when new ideas crowded in so fast that the task of mastering them became one of increasing magnitude and, finally, of almost hopeless complexity. To summarize and bring together the ideas of the past decade, and focus them upon the point of view here essayed, is probably beyond the power of one individual. Nevertheless, the attempt to present the essentials of the new geology for the benefit of those who, grown up with it, have perhaps treated it with the lack of consideration usually bestowed on a contemporary, as well as for those who will carry on the work during the next decade or two, cannot but serve a useful purpose. May this attempt be adjudged not unworthy of its predecessors, nor unfit to stand by the side of its contemporaries.

Scarsdale, New York,

The first of November,

One thousand nine hundred and thirteen. 


\section{TABLE OF CONTENTS}

\section{CHAPTER I.}

PABE

General Introductory Considerations... . . . . . . . . . .

The Earth as a Whole........................... I

I. The Atmosphere.......................... I

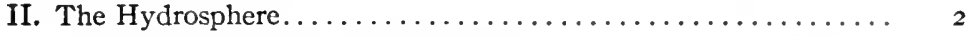

Transgression and Regression................. 3

The Terrestrial Part of the Hydrosphere............ 4

III. The Lithosphere........................... 5

The Mean Sphere Level (6); The Continental Block (7); Isostacy

(9); Thickness of the Earth's Crust (Io); Material of the Earth's Crust (12); Deformation of the Earth's Crust (Dias-

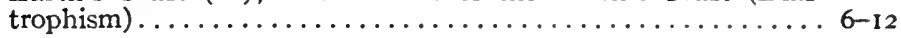

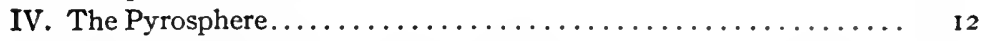

V. The Centrosphere...................... I3

Temperature of the Earth's Interior (13); Increase of Density. . 13-15

VI. The Organic or Biosphere...................... 6

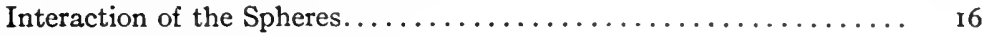

Sculpturing Processes..................... I6

Definition and Subdivision of Geology ................ I9

Table of Division of Geological Time.............. 22

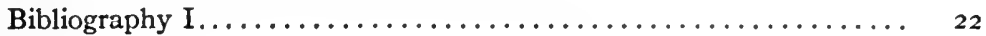

\section{A. THE ATMOSPHERE.}

\section{CHAPTER II.}

Constitution, Physical Characteristics, and Movements of the Atmosphere; Geologic Work of the Atmosphere.......... 24 Composition of the Atmosphere...................... 24

Nitrogen; Oxygen; Argon; Carbon Dioxide; Water Vapor (25); Absolute and Relative Humidity (26); Source of Water Vapor

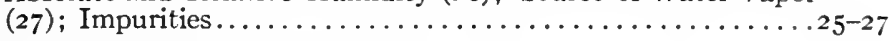

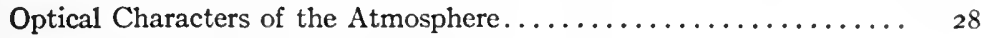

Light; Diffusion of Daylight................. 28 
Temperature of the Atmosphere.

Distribution of Heat within the Earth's Atmosphere..... 30

Geological Work of Heat and Cold-Changes in Temperature

(3I); Insolation and Radiation; Frost Work............. 31-34

Chemical Work of the Atmosphere.................. 34

Oxidation (35); Red and Yellow Colors of Soil due to Oxidation

(36); Oxidation of Organic Compounds. . . . . . . . . . . 35-37

Hydration; Kaolinization (37); Dehydration; Carbonation

(38); Laterization (39); Influence of Temperature on Rock

Decomposition..................................

Movements of the Atmosphere. Winds................ 40

Isobars; Direction of Movements of the Air (41); Influence of

Continents on Winds (44); Sea Breezes; Land Breezes; Mon-

soons...............................

Cyclones and Anticyclones (46); Whirlwinds and Tornadoes.....46-47

The Influence of Mountains on Winds (47); Mountain and

Valley Winds (5o); Velocities of Wind.............47-50

Eolation or Mechanical Work of the Atmosphere............ 5I

Wind Erosion and Translocation................ 52

Corrasion (52); Facetted Pebbles (54); Deflation (55); Character

and Amount of Deflational Denudation (57); Distance of Eolian

Transportation (58); Volume of Dust Falls (60); Sorting and

Rounding of Sand Grains by Wind ................

Condensation and Precipitation of Atmospheric Moisture........ 62

Dew, Frost, Clouds and Fogs; Rain, Snow and Hail. ......62-63

Amount of rainfall (63); Relation of Evaporation to Rain-

fall (65); Influence of Winds and Topography on Rainfall

(66); The Equatorial Belt of Calms and Variable Winds

(67); Latitude and Precipitation; Periodicity of Rainfall. .63-7I

Electrical Phenomena of the Atmosphere.............. $7^{2}$

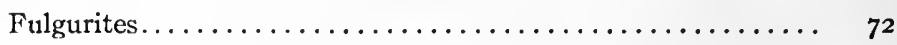

Climate; Climatic Zones, Present and Past............... 74

Solar Climates, Climatic Belts or Zones.............. 74

Physical Climate......................... 75

1. Marine or Oceanic Climate; 2. Coast or Littoral Climate;

3. Interior Continental Climate; 4. Desert Climate; 5.

Mountain Climate................... $75^{-77}$

Climatic Provinces (77); Climatic Types based on Separate Atmospheric Factors and on Agents (78); Climatic Zones of the Past (78); Neumayr's Climatic Zones of the Jurassic (79); Discussion of the subject of Climatic Zones...................

Rhythm of Climatic Changes (82); Indication of Climatic Changes

(83); Topographic Evidence of Change of Climate (83); Stratigraphic Evidence of Change of Climate (84); Organic Evidence of Change of Climate (85); 1. Plants; 2. Animals...........82-87

Displacement of the Earth's Axis as a Cause of Climatic Changes. 90

Origin of the Atmosphere. . . . .

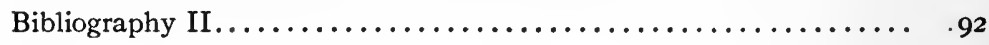




\section{B. THE HYDROSPHERE.}

\section{CHAPTER III.}

MoRPHOLOGY ANd SURdivision OF THE Hydrosphere............ 99

A. The Marine Division of the Hydrosphere.............. 99

Regional Subdivisions of the Sea................. 99

I. Intercontinental Seas or Oceans. ................ 100

Bathymetric Zones of the Sea (I00); Conformation of the Ocean Floor (IOI); Features and Extent of the Continental Shelves (I03); Table Showing Distribution Area and Depth of the Principal Continental Shelves (I03); Subordinate Features of the Continental Shelf (104); Features of the Suboceanic Elevations and Depressions......................... 100-105

II. Intracontinental Seas. . . . . . . . . . . . . . . . .

A. Independent Seas (I07); I. The Mediterraneans (I07); Interoceanic Medilerraneans (I09); 2. Epicontinental Seas (I09);

B. Dependent Seas, Funnel Seas................107-112

Summary of Classification. .................... I 13

B. The Continental Division of the Hydrosphere........... I15

III. Continental Seas or Lakes................... 115

Classification of Lakes and Lake Basins............. I16

Classification of Lake Basins................. I16

A. Deformational or Tectonic Basins........... 118

B. Constructional Basins (I20); Volcanic Basins; Chemical Basins; Organic Basins; Detrital Basins......... I 20-121

C. Destructional Basins (122); Volcanic; Chemical;

Fluviatile; Glacial; Deflation; Artificial. .......... 122-1 23

D. Obstructional or Barrier Basins (124); Tectonic; Vol-

canic; Chemical; Ice; Organic; Detrital..........124-126

Classification of Lakes as a Whole.............. 128

IV. Rivers............................. 129

Simple or Monogene Rivers................ 130

I. Consequent Streams; II. Insequent Streams; III. Overflow Streams; IV. Glacial Streams; V. Subterranean Streams.......................... I30-133

Polygene Rivers...................... I33

Relative Ages of Rivers and River Systems.......... I35

Aging of Rivers by Accident; Revival and Rejuvenation

of Rivers............................ $35^{-1} 37$

V. Underground Water (Ground Water)............. 138

-Classification of Ground Water (138); General Course of

Meteoric Water (139); Porosity of Rocks (140); The Water

Table; Depth and Quantity of Ground Water........... $388^{-141}$

Bibliography III............................. 143 
CHAPTER IV.

Composition and Physical Characters of the Hydrosphere....... I 45

Composition of the Hydrosphere.................... 145

I. Salinity of the Sea....................... I45

Table Showing the Salinity of the Sea (146); Variation in the Distribution of the Salt Content of the Oceans and Intracontinental Seas (149); Variation in Salinity in Bay of Danzig (I5I); Table Showing the Bathymetric Variations of Salinity

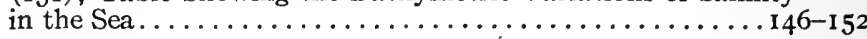

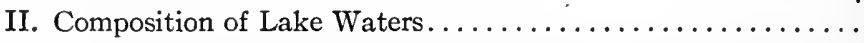

Table of Salinity of Various Lakes (154); Table Showing Vertical Range of Salinity in Dead Sea (156); Analyses of Types of Lake Water (157); Table in Percentage of Total Solids of Composition of Various Types of Natural Waters (I58); Composition of Saline Lakes in Percentage of Total Solids (159); Table of Average Composition of Lake Waters.... I54-161

III. Composition of River Water................ I6

Table Showing the Amounts in Permille of the Principal Elements and Compounds occurring in Various River Waters (162); Table Showing Salinity of other Rivers (162); Table of Total Solids carried in Solution in Tons per Year (164); Table Showing the Amounts of the Different Salts carried in Solution in one Cubic Mile of Average River Water. . . . . 162-164

IV. Composition of Spring Water................. I65

Table of Composition of Rain Water near London (165); Impurities in Rain Water; Solids in Rain Water (I66);

Composition of Spring Water from the Sahara.........165-167

Classification of Natural Waters; Gases and Organic Matter in

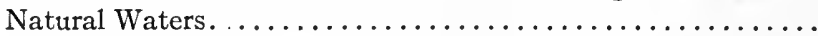

Table of Analyses of Spring and Well Waters (1 70); Composition of Dissolved Air in Rain Water at Different Temperatures (170); Gases in a Liter of pure Water.........170-171

Organic Matter (172); Table of Organic Matter in Various

Streams in Percentage of the Total Solids........... 172-173

Chemical Work of the Natural Waters............. 174

Solution; Cementation; Hydration; Oxidation; Carbonation... I75-1 79

Density and Specific Gravity of the Hydrosphere........... I79

Variation in Osmotic Pressure in the Sea Water........... I 80

Temperature of the Hydrosphere................. I 81

Freezing Point of Water; Heat Capacity of Water......... I8I

Warming of the Water Body; Average Surface Tempera-

ture; Vertical variation of Temperature........... $182-183$

Temperature of the Sea.................. I 84

Horizontal and Vertical Distribution of the Temperature in the Three Great Oceans (1 84); Temperature of the Mediterraneans and Epicontinental Seas Dependent on the Large Oceans (189); Temperatures of Dependent Seas (19I); Temperatures of the Arctic Ocean and its Dependencies (192); Mean Temperatures of the Oceans and Intracontinental Seas; Eutectic Temperatures (193); Range of Temperature of the Oceans................... 84 -194 
Temperatures of the Terrestrial Waters.................

Temperatures of Lakes, etc. (195); Classification of Lakes

According to Temperature (196); Freezing of Lakes (197);

Normal and Excessive Temperatures of Streams and of

Ground Water (199); Freezing of Rivers; Freezing of Ground Water (200); Mechanical Work of Freezing Ground Water (200); Thermal Springs (200); Magmatic or Juvenile

Waters........................ 195

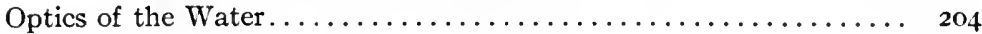

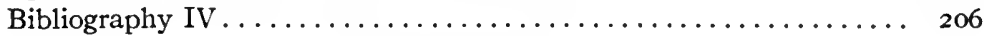

\section{CHAPTER V.}

Movements of the Hydrosphere and their Geological Effects....

Table Showing Relationships Between Wind Velocities and

Wave Height (213); Table Showing Relationship Between Mean Wave and Wind Velocities (2I4); Relation Between Length and Height of Wave (214); Classification of Waves (2I4); The Swell or Ground Swell (2I5); Depth of Wave Activity (216); Waves in Shallow Water (217); Destructive Work of Waves (220); Rounding and Sorting of Detritus

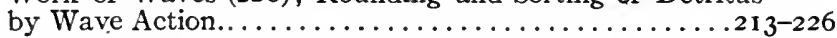

Tides................................... 226

Comparison of Tides and Waves (228); Interference of

Tides; Tidal Scour and Transportation.............228-23

Marine Currents.......................... 23I

Currents of the Oceans (23I); The Atlantic Ocean; the Arctic Ocean; the Pacific Ocean; the Indian Ocean...........23I-238

Currents in Mediterraneans and Epicontinental Seas........ 239

Marine Currents in Relation to Migration and Dispersal, Past and Present (243); Depth of Current Action.............243-244

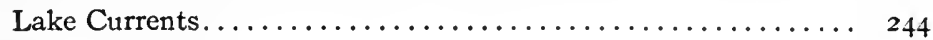

River Currents. . . . . . . . ................. 244

Velocities of River Currents (245); Erosive Power of Rivers (246); Rate of Erosion; Transporting Power of

River Currents......................245-247

Table Showing Transportation of Material by Rivers (248); Table of Velocities Required to stir up Bottom Material (248); Table Showing the Size of Rock Fragments Moved by Different Velocities of Currents.... 248-249

Sorting Power of Rivers (252); Rounding of Sand Grains. . 252-253

Table Showing Coefficient of Psephicity of Minerals in Air and Water (255); Table Showing Rounding of Sands of Moray Firth (256); Table Showing Rounding of

Sands of Culbin Dunes.....................255-256

Movement of Underground Waters............... 257

The Underflow (258); Rate of Flow of Underground Water (259); Table Showing Permeability of Various Soils (259); Pervious and Impervious Strata (260); The Deeper Zones

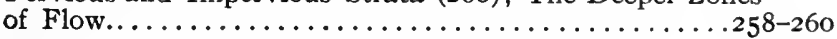
Springs......................... $26 \mathrm{r}$ 
Water in the Solid Form ......................

Kinds of Movement of Solid Water (262); Rate of Movement; Wasting of the Glaciers; Erosive Work of Ice; Transportation by Ice....................262-265

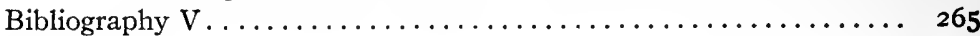

\section{THE LITHOSPHERE. CHAPTER VI.}

Classification of the Rocks of the Earth's Crust. ............

Subdivision of rocks.......................... 269

I. The Endogenetic Rocks................... 271

I. The Pyrogenic or Igneous Rocks (Pyroliths) ......... 274 Composition Groups (274); Textural Groups (275); Water and Ice as Igneous Rocks (278); Metamorphic Derivatives of Igneous Rocks.................................... 749

2. The Atmogenic or Atmospheric Rocks (Atmoliths)...... 279

I. Snow; II. Firn or Névé; III. Snow Ice or Glacial Ice.. 279

3. The Hydrogenic Rocks (Hydroliths) ............. 280

4. The Biogenic Rocks (Bioliths) ............... 280 Caustobioliths (28I); Sapropelites, Humus and Humuliths, Liptobioliths........................ $28 \mathrm{I}$

Subdivision of Hydrogenic and Biogenic Rocks.......... 28

Textures of Amorphous Hydrogenics (28I); Textures of

Biogenic Rocks (281); Table of the Principal Types of

Hydrogenic and Biogenic Rocks...............281-282

Spherytes, Granulytes and Pulverytes............. 283

Oöliths, Pisoliths, Rogensteine, etc.............. 283

II. The Exogenetic or Clastic Rocks. . . . . . . . . . . . 284

Textural Groups (285); Size of Grain (286); Table of Standard Sizes of Rock Fragments (287); Types of Sands Based on

Origin (288); Composition of Clastic Rocks...........285-29o

I. The Pyroclastics (290); 2. The Autoclastics (29I); 3. The Atmoclastics (292); 4. The Anemoclastics (293); 5. The Hydroclastics (294); 6. The Bioclastics.................290-296

Summary of "Sedimentary Rocks"................. 296

The Cosmoclastic Rocks. . . . . . . . . . . . . . . . . . . 297

Special Rock Terms........................... ${ }^{2} 97$

Rock Terms Emphasizing Composition (297); Autoch-

thonous and Allochthonous Deposits..............297-298

Bibliography VI. . . . . . . . . . . . . . . . . . . . 298

\section{CHAPTER VII.}

Structural or Tectonic Features of Rock Masses. Original Structures and Lithogenesis of the Pyrogenic Rocks.......... 3 o I

The Pyrogenic Rocks....................... 30I

Intrusive Igneous Bodies.................... 302

Igneous Versus Sedimentary Contact (309); Contacts of subterranean or abyssal masses (309); Contacts of hypabyssal or injected masses................... 309-3 10 


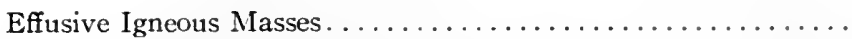

Features of Basal Contact of Lava Sheets (3II); Features of Upper Surfaces of Lava Flows (3I3); I. Basic Lavas;

2. Acid Lavas...........................

Minor Structural Characters of Volcanic Rocks............

Flow Structure; Stratification of Flows; Columnar Struc-

ture; Variation in Grain....................... $17-319$

Bibliography VII. . . . . . . . . . . . . . . . . . . .

\section{CHAP'TER VIII.}

Structure And Lithogenesis of the Atmogexic Rocks.......... 322

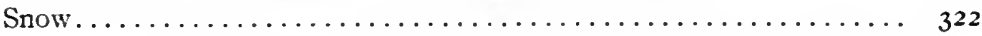

Height of Snow-line (322); Altitude of Snowfall and of Snow-

line (323); Conversion of Snow into Ice............ 322-323

Glaciers (Kinds and Character) ..................... 323

Stratification of Ice (326); Shear Zones and Flow Struc-

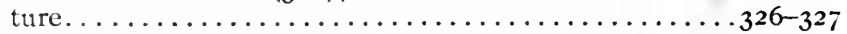

Bibliography VIII. . . . . . . . . . . . . . . . . . . 327

\section{CHAPTER IX.}

Original Structures and Lithogenesis of the True Aqueous or Hy-

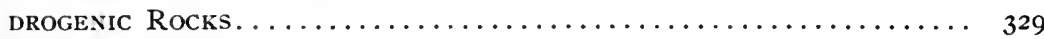

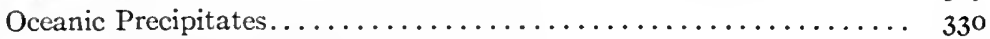

Chemical Deposits of the Deep Sea............. 330

Chemical Lime and Magnesia Deposits............... 33 I

Chemical Precipitation of Carbonate of Lime and Magnesia in

the Ocean (33I); Table Showing Proportion of Dolomites to Limestones in the Geological Series (333); Oolites and Pisolites of Chemical or purely Hydrogenic Origin...............3 1 I-336

Deposits in Enclosed or Nearly Enclosed Basins......... 338

Chemical Limestone Depnsits of Lakes in Arid Regions (338);

Older Deposits of this Type.................... 338-34I

Limestone Deposits from Rivers................ 34 I

Deposits of Lime by Springs (342); The Onyx Marble.....342-344

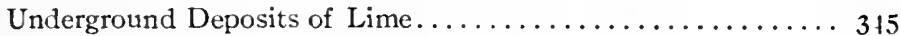

Method of Deposition of Lime from Solution............ 346

Deposits of Marine Gypsum and Salt............... 347

Experiments of Usiglio (348); Table Showing the Order of

Separation of Salts from Sea Water............... 348-349

The Bar Theory of Ochsenius (350); The Bitter Lakes of

Suez an Example (352); The Karabugas Gulf........350-35t

Natural Salt Pans (35t); Evaporation of Cut-offs from the

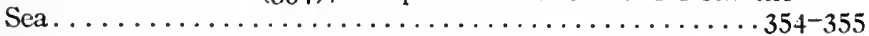

Non-calcareous Terrestrial Precipitates.............. 356

Salt Lakes and Salinas (356); The "Salitrales" of Patagonia...356-360

Deposits of Sodium Sulphate and Carbonate........... $36 \mathbf{I}$ 
PAGE

Table Showing Successive Crystallization resulting from

the Evaporation of the Waters of Owens Lake....... 362

Borax and Borates (363); Deposits of Nitrates (364); Other Min-

crals Deposited under Desert Climates...............363-365

Origin of the Saline Deposits. . . . . . . . . . . . . . . . . 365

Sources of Sodium Chloride (366); Marine; Leaching of Salt

from Older Formations and its Segregation (366); Sources of

Calcium Sulphate (368); Sources of Alkaline Carbonates

(369); Sources of Boric Acid and Borates and of Nitrates. . 366-37o

Summary ............................. 370

Ancient Salt Deposits............................ 371

The Stassfurt Salts (37I); The Siluric Salts of North America

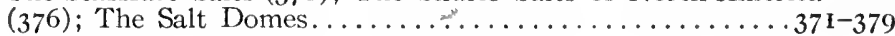

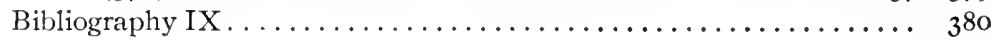

\section{CHAPTER X.}

\section{Morphology and Lithogenesis of the True Organic or Biogenic}

Rocks. Zoogenic Deposits........................ 384

Coral and Other Reefs............................. 385

Characters and Development of Modern Coral Reefs........ 386

Types of Modern Coral Reefs................ 386

Factors Limiting the Distribution of Modern Coral Reefs (389);

Depth of Water; Intensity of Light; Temperature; Other Phys-

ical Conditions............................ 389-392

Composition and Structure of the Reef (393); Materials Composing the Reef (393); Structure of Coral Reefs (396); Cavernous character of reefs (40I); Characters of Epicontinental reefs. .393-402

Theories of Origin of Types of Coral Reefs (407); Subsidence

Theory of Darwin (408); Evidence of Subsidence (409); The Spreading Ring Theory of Murray (4IO); Multiple Origin of

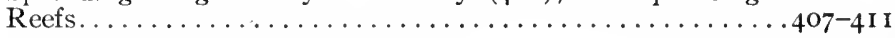

Rate of Growth of Reef Organisms.............. 4II

Compacting Agents of the Coral Reef............. 4 I 3

Destruction of the Coral Reefs (4I4); Formation of Coral and other Organic Lime-Sand and Mud................ 4I4

Fossil Coral and Stromatopora Reefs............. 4 I 7

Cambric and Pre-Cambric (4I7); Ordovicic.......... 4I7-4I 8

Siluric (4I8); Niagaran Reefs of Wisconsin (418); Siluric Reefs of

Gotland (420); Upper Siluric Reefs of North America......418-422

Devonic Coral Reefs (423); Lower Devonic Reefs of Konjepruss,

Bohemia (423); The Onondaga Reefs of New York (424); Middle

Devonic Reefs of Michigan (426); Devonic Reefs of the Attawapishkat River, Canada (430); Middle Devonic Reefs of the Eifel and Belgium.......................... $43^{-4} 43^{0}$

Mississippic Reefs (43I); Mississippic Reefs of Belgium; Missis-

sippic Reefs of Great Britain . . . . . . . . . . . . . .

Fossil Reefs of Bryozoa and other Organisms............ 433

Bryozoan Reefs of the German Zechstein (433); The Triassic Reefs of the Tyrol (434); The Jurassic Reefs of Solnhofen (437); The Sponge Reefs of the Swabian Jura (442); Miocenic Reefs of the Austro-Russian Border (442); Pliocenic Bryozoa Reefs of

Kertch............................... $433-443$ 
Bedded Reefs.............................. 444

Loss of Structure through Alteration of Reef Limestones. . . . . . 445

Ball-stone Reefs........................... 446

Structures Formed by the Growth of Shell Colonies........... 447

Tepee Buttes (447); Other Examples..............447-449

Bedded Zoögenic Deposits........................ 449

Crinoidal Limestones (449); Shell Limestones (449); Calcareous and Siliceous Oozes........................ 449-450

I. The Calcareous Oozes (450); Recent Foraminiferal Oozes (450); Fossil Foraminiferal Oozes (453); Zoögenic Oölites (455); Recent Pteropod Oozes; Fossil Pteropod Oozes; Entomostracan Oozes; Coccolith and Rhabdolith Oozes. . . . . .450-456 2. The Siliceous Oozes (457); Radiolarian Oozes (457); The Jurassic Radiolarite of the Alps (459); Recent Diatomaceous Oozes (460); Fossil Diatomaceous Earths of both Fresh and

Salt Water Origin.........................

Phosphate Deposits; Guano..................... $46 \mathrm{I}$

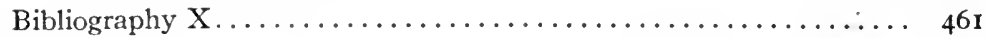

\section{CHAPTER XI.}

Character and Lithogenesis of Organic or Biogenic Rocks (ConTinued). Phytogenic Deposits...................... 467

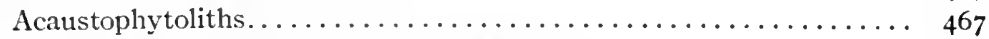

Deposits formed by Lime-Secreting Algæ............. 467

Modern Marine Forms (467); Order Cyanophyceæ or Blue-Green

Algæ (467); Phytogenic Oölites (467); Order Chlorophyceæ or Green Algæ (469); Order Phæophyceæ or Brown Algæ (470); Order Rhodophyceæe or Floridæ; Red Algæ (470); Lime-secreting Algæ of Fresh Water........................ $467-471$

Fossil Phytoliths of Algous Origin............... 471

Fossil Oöliths (47I); Rogensteine of the Bunter Sandstein

$\left(47^{2}\right)$; Alteration of Oölites.................... $47^{\mathrm{I}-473}$

Sphærocodium and Girvanella Deposits; Fossil Nullipores;

Fossil Chara........................... 474-475

Travertine and Siliceous Sinter formed by Algæ in Hot Springs... 475

Method of Lime Deposition by Plants............... 475

Separation of Siliceous Sinter by Plants............. 476

Vegetal Deposits (Caustophytoliths)................ 478

Petrographical Types of Vegetal Deposits............. 478

Sapropeliths (478); Petroleum (480); Sapanthraconyte or Cannel

Coal (481); Jet (482); Black Shales (483); Sapropelcalcilyths

Sapropelsilicily th and Sapropel-ferrilyths............... $480-484$

Recent Humuliths....................... 485

Marine Marshes (487); Conversion of Salt Peat into Coal

(493); Mangrove Marshes. . .................. 487-494

Fresh Water Swamps (494); Lake Swamps (495); Rivers and

Estuarine Swamps...................... 494-497

Terrestrial Bogs (50I); Forest Moors; Upland Bogs or High

Moors; the Arctic Tundras..................... 50I-507 
Peat in the Tropics......................... 509

Fossil Humuliths......................... 510 Lignite; Brown coal; Bituminous Coal; Anthracite; Graphite.........................

Ancient Moors (5II); Black Soil and Shales of Humulithic Origin (5I3); Burial of Peat Deposits (5I4); Liptobioliths. .5II-5I7 Allochthonous. Vegetal Deposits (518); Marine Vegetal Deposits 518

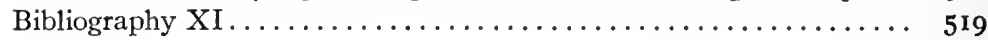

\section{CHAPTER XII.}

Original Characters' and Lithogenesis of the Exogenetic Rocks. The Pyroclastics and the Autoclastics. . . . . . . . . . . . . . 52

Pyroclastic Rocks......................... 524

Modern Pyroclastics (524); Organic Remains of Modern Pyroclastics (525); Older Pyroclastic Deposits.............. 524-525

Autoclastic_Rocks............................. 527

Classification of Autoclastic Rocks................ 527

Fault Breccias (528); Intraformational Breccias (529); Fracturing and Piling up of Material; Distortion of Layers in Gliding. . 528-530

Glacial Deposits (531); Character of Modern and Pleistocenic

Glacial Deposits (531); Ancient Glacial Deposits (534); The Pre-Cambric Tillite of Canada; Cambric Glacial Deposits; the

Permic Glacial Deposits........................... 53I-535

Endolithic Brecciation......................... 536

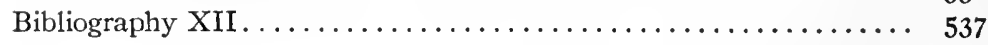

CHAPTER XIII.

Original Structure and Lithogenesis of the Atmoclastic and Anemo-

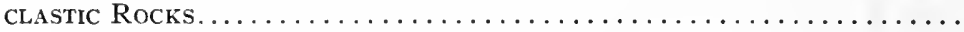

A. Atmoclastic Rocks .............................

Characteristics and Occurrence of Modern Atmoclastic Forma-

tions......................................

Texture of Atmoclastic Rocks (542); Movement of Atmoclastic Material (543); Slow Movements of Rock and Soil; Rock and Soil Creep; Solifluction or Rock Flow (543); Rock Slides and

Falls (545); Rock Slides Started by Earthquakes.......... 542-546

Ancient Examples of Rock Streams and Slides (546); Mackinac

Limestone Breceia ............................... 546-547

Residual Soils............................. 548

B. Anemoclastic or Eolian Deposits. Anemoliths............. 549

Source of Matcrial of Eolian Deposits............... 549

Textural Types of Anemoliths; General Characteristics of Modern

Eolian Deposits..............................

Sorting of Material according to Size and Specific Gravity;

Size of Grain in Eolian Deposits; Rounding of Sand Grains;

Stratification and Cross-bedding of Eolian Deposits.... 552-554 


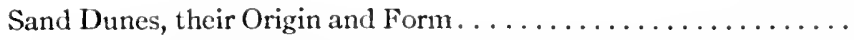

Types of Sand Dunes; (I) Strand Dunes; (2) Lake Shore Dunes; (3) River Flood Plain and River Bottom Dunes;

(4) Inland or Desert Dunes. . . . . . . . . . . . 557-56I

The Forms of Dunes (563); Origin of Intercalated Dust and Clay Layers, and of Clay Balls in Sand Dunes; Peat and Lignite Deposits in Sand Dunes (564); Transgressive Relation of

Dune Sands to Subjacent Formations............. . 563-565

Examples of Older Eolian Deposits............... 565

The Loess as an Example of a Dust Deposit; Fossils and

Concretions in the Loess; Cenozoic and Mesozoic Loess-like

Deposits; Palæozoic Loess-like Deposits.......... 565-569

Older Deposits of Dune Types............... 570

Volcanic Dust Deposits.................... 572

Special Indicators of Eolation................. 572

Calcareous and Other Non-Siliceous Eolian Sands (573); Recent and Tertiary Examples (573); Older Examples (577); Possible

Application to the Chalk Beds (577); Dunes of Gypsum..... 5 573-578

Bibliography XIII.......................... 578

\section{CHAPTER XIV.}

Original Structure and Lithogenesis of the Continental Hydro-

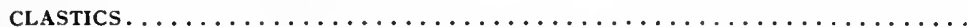

River-laid Clastics or Potamoclastics. . . . . . . . . . . . . . .

Alluvial Fans (583); Form and Extent of Modern Alluvial

Fans (583); Basins Filled by River-washed Waste....... 583-587

River Flood Plains..................... 588

Cross-bedding of Torrential Sediments (590); Thickness and Composition of River Deposits (590); Depth of Compound Continental Deposits (592); Chatter or Pereussion Marks (592); Organic Remains in Torrential Deposits (592); Distance to which Material may be Carried by Rivers (594); Purity and Rounding of Fluviatile Deposits (594); Form of River Pebbles (595); Overlap Relations of River Deposits............................. 590-597

Flood Plains of Glacial Streams (597); River and Flood Plain

Deposits from Continental Ice-sheets............ 597-598

I. Torrential Moraine or Kame Deposits; 2. The Frontal or Apron Plain; 3. The Esker; 4. Glacial Sand Plains........................... 598-600

Consolidated Sand Plains; The Nagelfluh of Salzburg... 60 I Playas or Takyrs and Salinas (602); Preservation of Footprints, ete., in Subaērial Deposits (604); Other Structural Characters.602-605

Normal Paludal and Lacustrine Clastic Deposits................ 605

Deltas.................................607

Form and Rate of Growth of Deltas (608); Thickness or Depth of Deltas (609); Delta Slopes (610); The Bird-foot Delta of the Mississippi (6Io); Structure and Composition of the Delta (6I2); Organisms of the Delta (6I5); Gaseous Emanations of Deltas (615); Cementation of Delta Deposits 
(6I6); Modification of the Delta Surfaces (6I6); Relation of Delta-building to Crustal Movements (6I 7 ); Effect of Subsidence (6I8); Effect of Elevation (6I9); Deltas Merging into Desert Deposits....................608-619

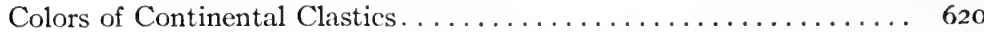

Alternation of Red Beds with Those of Other Colors; Original Red Color of Sediments...............623-625

Examples of Older Continental Hydroclastics. . . . . . . . . . . . 626

Cenozoic or Tertiary Examples.................... 626

Mesozoic Examples of Continental Hydroclastics........... 63I

The Potomac Formation; The Red Beds of North America;

Triassic Red Beds of Eastern North America, and of

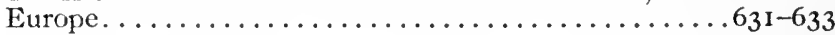

Palæozoic Delta Deposits....................... 635

Bibliography XIV.......................... 637

\section{CHAPTER XV.}

\section{Structural Characters and Lithogenesis of the Marine Hydro-} CLASTICS.................................. 641

Subdivision of the Areas of Marine Deposition..............

I. The Littoral District; 2. The Bathyal District; 3. The

Deep Sea or Abyssal District...................

Murray and Renard's Classification of Marine Deposits (643); Krümmel's Classification of Marine Deposits (644);

A New Classification of Marine Deposits ...........643-545

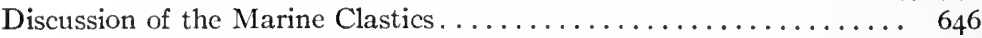

The Littoral District and Its Deposits. .............. 646

The Shore Zone (Inter Co-tidal Zone; Littoral Zone in a

Restricted Sense)............................

Facies of the Shore Zone (648); I. Rocky Cliff Facies (648); 2. Bouldery Facies (648); 3. Gravel Facies (649); Organic Remains in Pebble Beds (650); 4. Sandy Facies (65I); Marine Arkoses (652); Sorting of Sands and Gravels by Waves (653); Organic Remains in Marine and Lacustrine Sands (654); 5. Muddy Facies (655); Flocculation and the Conditions of Mud Deposition (655); Table Showing Rate of Settlement of Solid Matter in Fresh and Salt Water $(656) ; 6$. Organic Facies. . . . . . . . . . . . 648-657

Subaqueous Solifluction (657); Accessory Features of Subaqueous Gliding...................... 657-660 The Permanently Submerged or Neritic Zone (Flachsee, Shallow Water or Thalassal Zone)............... 66

I. The Estuary (66I) ; 2. The Marginal Lagoon or Barachois (665); 3. The Epicontinental Seas and Mediterraneans

(666); 4. The Ocean Littoral or the Neritic Zone..... . 66I-667

Deposits of the Bathyal District................... 668

Table Showing Kinds and Distribution of Bathyal Deposits (668); 'Table of Analyses of Muds, of Terrigenous and of Volcanic Origin....................668-669 
The Blue or Slate Colored Mud; The Red Mud; The Green Mud; Green Sand; Table of Analyses of Glauconite from Various Horizons.....................668-670 Deposits on Lee Banks and at the Edge of the Continental

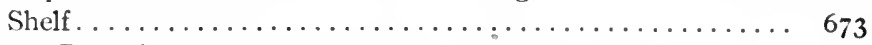
Abyssal Deposits........................ 674

Abyssal Deposits of Pelagic Origin (674); Abyssal Deposits of Terrigenous Origin (676); The Red Clay (676); Analyses of Deep Sea Deposits (677); Table of Analyses of Deep Sea Deposits (677); Older Deposits that have been Considered of Deep Sea Origin (678); Concretions of the Deep Sea (678); Cosmic Deposits of the Deep Sea (679); Submarine Volcanic

Deposits.....................................674

Interruptions of Marine Sedimentation............ 680

Persistence and Variation in Thickness of Marine Strata...... 682

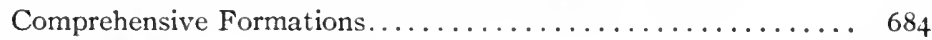

Bibliography XV............................. 685

\section{CHAPTER XVI.}

Characters and Lithogenesis of the Bioclastic Rocks.......... Work of Herds of Animals in the Present and the Past; Work of Burrowing Animals; Destructive Work of Fish and Marine Invertebrates; Work of Earthworms and Lobworms; Work of Ants and Termites; Comparison of Work of Earthworms and Ants; Summary of Work of Ants in Soil and Subsoil; Destructive Work of Plants. . . . . . . . . 691-695

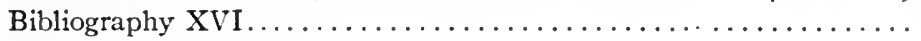

\section{CHAPTER XVII.}

Summary of Original Features of Clastic Rocks..............

I. Stratification; Definitions of Stratum; Types of Stratifica-

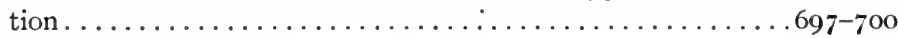

2. Cross Bedding................. 7ol

a. Delta Type (702); b. Cross-bedding of Torrential Deposits (702); Cross-bedding of Eolian Deposits (703); c. Comparison

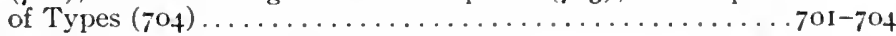
3. Beach Cusps (706); Fossil Beach Cusps (707); 4. Wave Marks $(708) ; 5$. Rill Marks.................. 706-708

6. Mud-cracks, Sun Cracks or Desiccation Fissures........ 709 Playa Surface (709); Permanent Lake Surface (709); River Flood Plains (710); The Shore Zone (710)...... 709-710

7. Clay Galls (Thon-gallen) (7II); 8. Clay Boulders (7II); 9. Rain Prints (712); 10. Ripple Marks $(712)$; 11. Impressions of Animals and Plants in Transit.................. $71_{1-714}$ 12. Application of these Structures in Determining Position of Strata.............................. 715

13. Rounding and Sorting of Sand Grains and Wearing of Pebbles............................... 7 I5 
PAGE

14. Characteristics of Inclusions in Sand Grains........ 7 I6

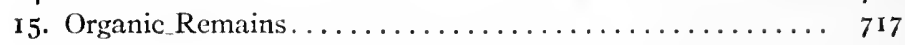

I6. Concretions..................... 718

Accretions (719); Intercretions (719); Excretions (720);

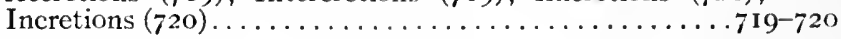

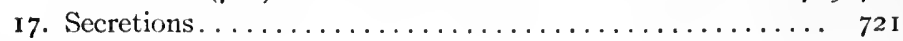

Bibliography XVII ..................... $72 \mathrm{I}$

\section{CHAPTER XVIII.}

Overlap Relations of Sedmentary Formations............ 723

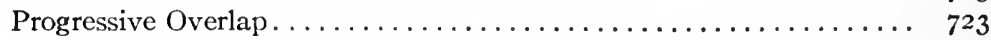

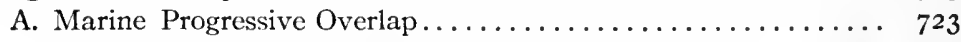

I. Rising Sea-level or Positive Diastrophic Movement....... 724

I. Transgressive Movement. . . . . . . . . . . 725

a. Rate of Depression Equals Rate of Supply (725); Older Examples $(\mathbf{7 2 8})$; b. Rate of Depression Exceeds Rate of Supply...........................

2. Regressive Movements................ 732

c. Rate of Depression is Exceeded by Rate of Supply.... $73^{2}$

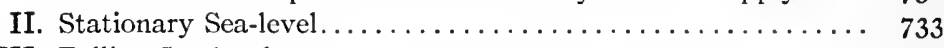

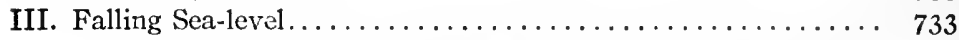

Characteristics of Regressive Deposits (734); Burial of Retreatal Sandstone by Subsequent Transgressive Movement. 734-735

Examples of Intercalated Sandstones from the Palæozoic and

Mesozoic; Formations of North America............. 738

The Saint Peter Sandstone (738); The Dakota Sandstone. 738-739

B. Non-marine Progressive Overlap................ 739

The Pottsville Series, a typical Example of Non-marine Progressive

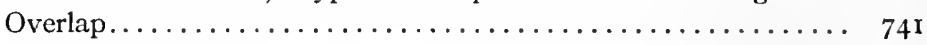

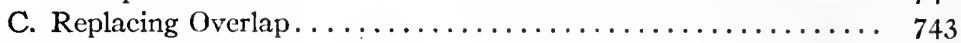

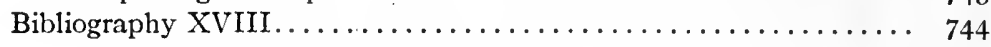

\section{CHAPTER XIX.}

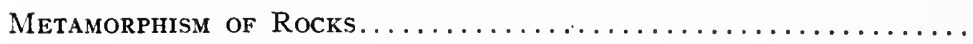

General Definitions (746); The Forces Producing Metamorphism (746); The Region of Metamorphism (747); Characteristics of the Zones of Metamorphism (747); Kinds of Meta-

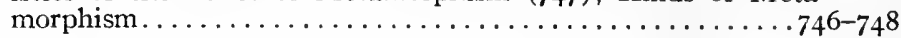

Static Metamorphism or Diagenism.................. 750

I. Lithification or Induration $\ldots \ldots \ldots \ldots \ldots \ldots \ldots \ldots \ldots \ldots \ldots \ldots \ldots \ldots$

Lithification or Induration of Clastic Rocks (75I); I. Welding (75I); 2. Cementation (753); Quartzites and Novaculites (755); Lithification of Clastics Largely a Supra-marine Process...75 $1-755$

II. Recrystallization. . . . . . . . . . . . .

Pressure Phenomena due to Recrystallization (Enterolithic

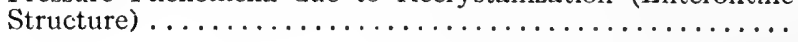


III. Dolomitization of Limestones. . . . . . . . . . . . . .

IV. Replacement of Limestone by Silica. Iron Oxide, etc. $(762)$;

V. Desalinification $(763)$; VI. Formation of Concretions $(763)$;

VII. Hydration and Dehydration . ................ $762-765$

Contact Metamorphism or Aethoballism.............. 765

I. Pyrometamorphism (765); 2. Hydrometamorphism (766);

3. $\Lambda$ tmometamorphism $(767) ; 4$. Biometamorphism ..765-768

Dynamic or Pressure Metamorphism, or Symplirattism........ 768

The Terms Slate, Schist and Gneiss (770); General Terms for Metamorphic Rocks (771); Variation in Metamorphism of Strata $\left(77^{2}\right)$; Age of Metamorphic Rocks. ..........770-773

Bibliography XIX............................. 773

\section{CHAPTER XX.}

Deformation of Rock Masses........................... 776

Endogenetic Deformations....................... 777

I. Endolithic Brecciation $(777) ; 2$. Enterolithic Structure $(778) ; 3$. Contraction Joints, Basaltic Jointing ........777-778

Deformation Due to Extraneous Causes-Exogenetic Deformations. 779

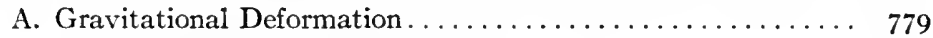

a. Structures due to Movements............... 779

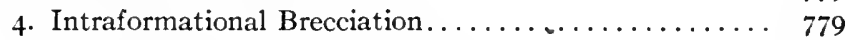

5. Subaquatic Gliding Deformation........... 780

Examples of Fossil Subaqueous Solifluction (78I) A.

Miocenic Sublacustrine Glidings of Oeningen (78 $\mathrm{r}$;

B. Jurassic Deformations (781); C. Triassic Examples (782); D. Devonic Examples (782); E. Ordovicic Examples $(783)$; F. A Cambric or Earlier Example .... . 78 $1-784$

6. Surface deformations Due to Creep ............ 785

b. Deformations due to Vertical Pressure of Overlying Rock Masses $(785) ; 7$. Squeezing Out of Layers; 8. Shaliness; 9.

Slatiness................................ $785-786$ c. Of Complex Origin $(786) ;$ io. Pressure Sutures and Stylolites $(786)$; I I. Cone in Cone................ $786-788$

B. Tectonic or Orogenic Deformations.............. 789

d. Deformations Resulting in Fractures and Related Struc-

tures............................ 789

I2. Joints (789); Minor Characters of Joints; Feather

Fractures; Dendritic Markings; Widening of Joints....789-79 I

13. Earthquake Fissures (792); 14. Slaty Cleavage (793);

15. Fissility (794); 16. Schistosity (794); 17. Gneissoid

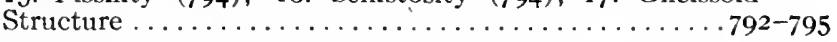

e. Deformation due to Folding and to Folding and Erosion.. 795

18. Folding (795); a. Anticlines (795); b. Synclines (795); c. Isoclines (796); d. Fan Folds (798); e. Monoclines (798); Anticlinoria and Synclinoria (799); Geosyncline and Foredeep ................................... 795-799

Relation of Dip Strike and Outcrop (800); Strike as Affected by Pitching Axis of Folds (806); Folding as Indications of Unconformity (815); The trend of the Appalachian Folds....................800-807 
I9. Domes and Basins. ......................... 808

f. Deformation due to Dislocation of Strata. Faulting.... 8 ro

20. Faults.......................... 8

Features Shown in Section of Faults (8I2); Features Shown in Surface Appearance of Faults, i.e. Map Features of Faults (813); Classification of Faults (8I3); With Reference to Direction; With Reference to Movement; With Reference to Cause..............812-8I4

Terms Applied to Rock Masses Formed by, or Bounded by Faults, but not Topographically Distinguishable from Surrounding Masses (8I5); Terms Applied to the Topographic Expression of Faults...............

Secondary Features due to Erosion (8I6); Stratigraphic Significance of Faults (8I7); Faults as Indications of Unconformity (8I9); Relation of Folds, Faults, Cleavage, Fissility and Joints............. 816-8 19

C. Contact Deformations........................ 820

2I. Prismatic Joints due to Contact with Igneous Masses

(820); 22. Insolation joints. . . . . . . . . . . . . 820-82 I

D. Structures in Part due to Deformation and in Part to Erosion. 82 I

23. Disconformity and Unconformity (82I); Disconformity (Parunconformity, Pænaccordanz) (822); Unconformity

(Clinunconformity; Discordanz) (824)........... 82 I-82.4

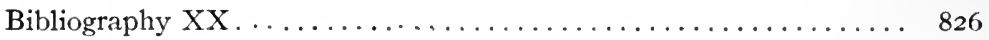

\section{CHAPTER XXI.}

The Principles of Glyptogenesis or the Sculpturing of the Earth's

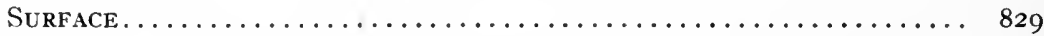

The Cycle of Erosion..................... 829

A. Erosion Features in Undisturbed Strata.............. 830

I. The Coastal Plain ....................... 830

Dissection of the Coastal Plain (83I); Deposition in Dissected Coastal Plain; Effect of Dissection and Peneplanation of Coastal Plain Strata on Outcrop............ 83 I-833

Ancient Coastal Plains Showing Cuesta Topography....... 835

Minor Erosion Forms of Horizontal Strata.......... 839

B. Erosion Features in Disturbed Strata. . . . . . . . . . . . . . 846

2. The Monocline $(840)$; 3. Erosion Features of the Structural Dome $(8+\mathrm{I}) ; 4$. Erosion Features of the Anticline $(843)$; 5. The Basin $(846) ; 6$. The Syncline $(847) ; 7$. Erosion Features in Faulted Strata $(847) ; 8$. The Completion of the Cycle $(847) \ldots \ldots \ldots .840-847$

The Peneplain $(8+7)$; 'The Relation of the Peneplain to Sedimentation; Dissection of the Peneplain; Age of the Peneplain;

High-level Plains of Arid Regions. . . . . . . . . . . . $847-85^{2}$

C. Minor Erosion Features...................... 856

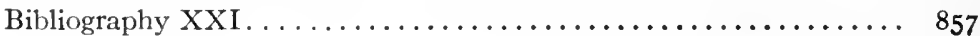




\section{THE PYROSPHERE.}

CHAPTER XXII.

General Summary of Pyrospheric Activities............... 859

Volcanic Activities.......................... 859

Types of Volcanic Activities................... 859

Subdivision with Reference to Location. . . . . . . . . . 859

Explosive Eruption (860); Terrestrial Type (860); The Cinder Cone; Material of the Cinder Cone; The Forms of the Cinder Cones; Consolidation of Cinder Cone; Submarine Explosive

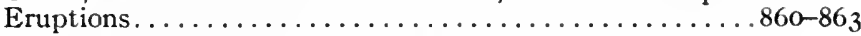

Extravasative Eruptions (865); Terrestrial Type; Fissure Eruption; The Lava Dome; Acid Lava Domes; The Spine of Pelée................................ $865^{-870}$

Composite Lava and Cinder Cones (87o); Submarine Cones; Mud Volcanoes.......................... 870-872

Dissection of Volcanoes (874); Special Erosion Features. . . . . 8 874-875

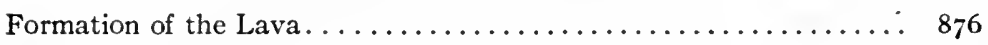

Bibliography XXII....................... 878

\section{E. THE CENTROSPHERE OR BARYSPHERE.}

\section{CHAPTER XXIII.}

Diastrophism, or the Movements Taking Place Within the Earth's

Crust and Their Causes......................... 880

Classification of Earth Movements................... 880

Classification of Seismic Disturbances (88I); The Volcanic or Pyroseismic Type of Earthquake; The Tectonic or Dislocation

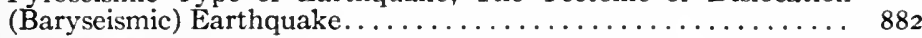

Surface Manifestations of Baryseismic Disturbances......... 883

Rifting (883); Filling of the Fissures, Sandstone Dikes (884); Craterlets (885); Fossil Examples (886); Slipping (887); Block Movement (887); Disruptive Effects of Earthquakes (888); Effects of Earthquakes on Topography (888).....883-888

Submarine Earthquakes and Seaquakes (889); Airquakes (89I);

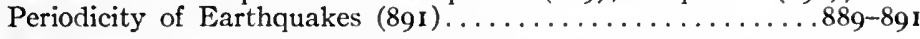

Movements due to Displacement or Migration of the Poles (891); The Pendulation Theory (892); Determined Migrations of the Poles................................ 89 $1-899$

Earth Movements and Geosynclines (900); Geosynclines, the Sites of Orogenic Disturbance (902); Foreshortening of the Crust (903); Height of the Folds (903); Character and Thickness of the Deformed Mass.............................. 900-904

Changes due to Extra-Telluric Influences............. 906 Bibliography XXIII.......................... 908 


\section{F. THE BIOSPHERE.}

\section{CHAPTER XXIV.}

Subdivision of the Biosphere. Claśsification and General Morpho-

logical Characters of Organisms...................... Plants and Animals as Indicators of the Age of the Period in Which They Occur.......................... 9I I

Classification of Plants and Animals.................. 912

Naming of Genera and Species (912); Pryority and Synonymy (9I4); Synonymy (9I5); Manuscript Names, List Names; Nomina Nuda (917); Generic Names as Synonyms,

Types (918); Terms Used for Specific Types (918); Generic

Types.................................918-920

Selection of the Genotype or Type Species of a Genus (920);

Union of Genera into Group of Higher Taxonomic Value. .920-92 I

Sub-families; Families: Super-families; Sub-orders; Orders;

Groups of Higher Rank; Faunas and Floras ..........92 I-922

Table I, Subdivisions of the Plant Kingdom (922); Table

II, Subdivisions of the Animal Kingdom . . . . . . . . . 922-925

Brief Summary of the Morphological Characters of the Phyla of

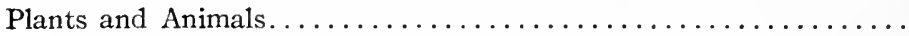

A. Plants (933); Phylum I, Protophyta (933); Phylum II, Thallophyta (934); a. Algæ (935); b. Fungi (937); c. Lichens (937); Phylum III, Bryophyta (937); Phylum IV, Pteridophyta (938);

Phylum V, Spermatophyta (94I) ................. 933-941

B. Animals (942); Phylum I, Protozoa (942); Phylum II, Porifera (Sponges) (942); Phylum III, Coelenterata (942); Phylum IV, Molluscoidea (943); Phylum V, Mollusca (944); Phylum VI, Platyhelmintha and Phylum VII, Vermes (946); Phylum VIII, Arthropoda (947); Phylum IX, Echinodermata (949); Phylum X, Protochorda (950); Phylum XI, Vertebrata (950); Pisces (95I);

Amphibia (952); Reptilia (952); Aves (954); Mammalia (955)..942-955

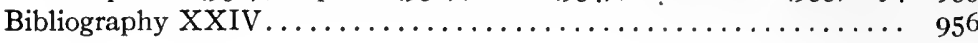

\section{CHAPTER XXV.}

Biogenetic Relations of Plants and Animals. . . . . . . . . . . . 958

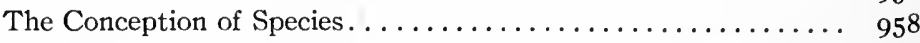

The Mutations of Waagen.................... 960

Mutation Theory of De Vries................... 962

Orthogenesis and the Concept of Species............. 963

Acceleration and Retardation in Development (Tachygenesis

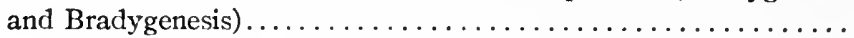
Illustrations of Orthogenetic Development (964); Origin and Development of Characters the Important Question; Rectigradations and Allometrons..............964-970

Nomenclature of Stages in Development............. 970

Ontogenetic Stages and Morphic Stages (970); Simple

Organisms (970); Colonial Forms..............970-973 
Intracolonial Acceleration and Retardation (973); Atavism or

Reversion............................. $973-974$

Parallelism and Convergence in Development (Homœogenesis). . 976 Bibliography XXV............................. 979

\section{CHAPTER XXVI.}

Physical Characteristics of the Injhabitable Earth. Bionomic

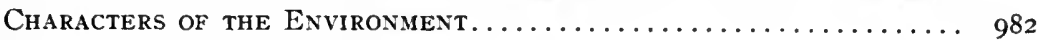

I. The Littoral District................... 983

A. Marine (983); B. Fresh Water (987); C. Terrestrial

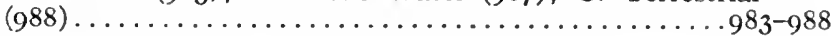

II. The Pelagic District................... 988

A. Marine (988); B. Fresh Water (988); C. Terrestrial

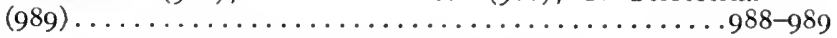

III. The Abyssal Life District. ................... 990

A. Marine; B. Fresh Water and C. Terrestrial......... 990

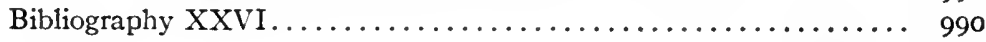

\section{CHAPTER XXVII.}

Bionomic Classification of Plants and Animals............. 99 I

Subdivisions (991); Primary Divisions; Secondary Divisions.... 99 I

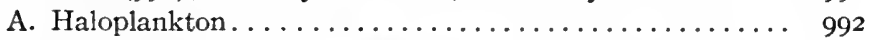

I. Holoplankton (992); 2. Meroplankton (993); 3. Pseudoplankton (994); 4. Epiplankton (994); B. Halonekton (996);

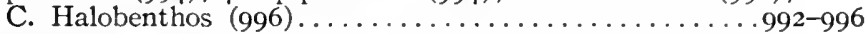

D. Limnoplankton (997); E. Limnonekton (Helionekton, Potamonekton); F. Limnobenthos (Heliobenthos, Potamobenthos)........................... $997-998$

G. Atmoplankton; H. Atmonekton; I. Atmobenthos...... 998

Bibliography XXVII......................... 999

\section{CHAPTER XXVIII.}

Bionomic Characteristics of Plants and Animals.............. I000

A. Bionomic Characters of Plants.................. I000

Protophyta (1000); Thallophyta (I00I); (Alga, Fungi, Lichens);

Bryophyta and Pteridophyta (I003)................. I000-1003

Spermatophyta........................... 1004

Ecology and Ecological Adaptations of Spermatophytes..... I005

I. Hydrophytes and Hemihydrophytes; 2. Xerophytes;

3. Bog Xerophytes; 4. Tropophytes; 5. Hygrophytes;

6. Sciophytes; 7. Halophytes; 8. Calcicole and Calcifuge

Plants............................... I006

B. Bionomic Characteristics of Animals............... 1007

I. Protozoa (I007); (Foraminifera; Radiolaria); II. Porifera (I008);

III. Coelenterata (Ioog) (Hydrozoa; A nthozoa); IV. Molluscoidca

(IOI4) (Bryozoa; Brachiopoda); V. Mollusca (IOI 5); (Pelecypoda;

Scaphapoda and Amphineura; Gastropoda; Pteropoda; Cephalopoda) 
VI. Platyhelmintha; VII. Vermes................ I023

VIII. Arthropoda (I025); Crustacea (I025); (Trilobita; Phyllopoda; Copepoda; Ostracoda; Cirrepedia; Phyllocarida; Schizopoda; Stomatopoda; Sympoda; Decapoda; Arthrostraca); Acerata (I028); (Merostomata; Arachnida; Pantapoda); Myriopoda and Insecta (1030) .............................. I025-1030

IX. Echinodermata (rozr); Cystoidea and Blastoidea; Crinoidea; Asteroidea; Ophiuroidea; Echinoidea; Holothuroidea........1031-1033 X. Protochordata....................... 1033 XI. Vertebrata (I033); Osiracoderma (I033); Pisces (I034); Amphibia (1035); Reptilia (1036); Aves (1037); Mammalia

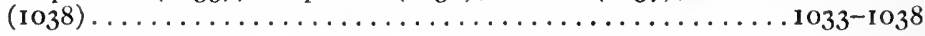
Bibliography XXVIII ...................

\section{CHAPTER XXIX.}

Chorology or the Principles of the Geographical Distribution of Plants and Aximals. . . . . . . . . . . . . . . . . .

Dispersal and Migration (IO4I); Barriers to Migration and Dispersal (I042); Faunal Groups.................... 104 I-1044

Factors Governing Dispersal and Migration........... 1044

Inorganic Factors; the Medium................ 1044

Composition of Medium (1044); Stenohalinity and Euryhalinity; Quantity of Air (1045); Volume of Water (ro47),

I044-1047

Climate............................. 1047

Climate and Temperature (I047); Currents (1048); Topog-

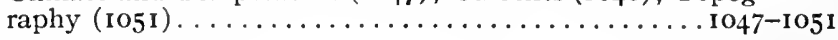

The Organic Factors. . . . . . . . . . . . . $105^{2}$

Biogeographical Provinces..................... 1053

Marine Provinces (I055); Former Marine Geographic Provinces (1057); Present and Former Biogeographic Provinces of the Land (1058); Fresh Water Biotic Provinces (1059) . 1055-1059

Relicts (I062); Relict Faunas and Lakes (I062); Marine Relicts,

Bipolar Faunas (1065); Terrestrial Relicts (1066)......... I062-1066

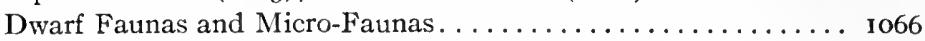

Bibliography XXIX............................ 1069

\section{CHAPTER XXX.}

Fossils, their Character and Mode of Preservation.......... 1073

Definition and Limitation of the Term Fossil........... 1073

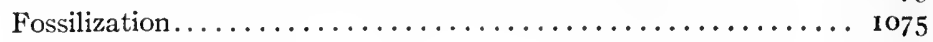

Types of Fossil ......................... 1076

I. Actual Remains..................... 1076

Preservation of Soft Tissues (I076); Preservation of Hard

Structures and of Petrified Remains............. 1078 Petrifaction of Non-mineral Substances (I080); a. Replacement of Soft Animal Tissue; b. Petrification of Plants ............................ 1080 
Petrifaction of Mineral Structures (1082); a. Protozoa (I082); b. Sponges and Hydrozoans (1082); c. Silicification of Corals (I083); d. The Brachiopod Shell (I083); e. Shells of Molluses ( 1084 ); f. Crustaceans Merostomes, Insects, etc. (I086); g. Echinoderms (I086); h. Verte-

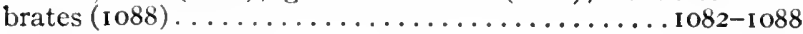

Excessive silicification................. I089

Molds and Casts...................... 1089

2. Tracks, Trails and Burrows of Animals........... Iogo

3. Artificial Structures..................... 1093

4. Coprolites.......................... 1093

Mechanical Deformation of Fossils................ $109+$

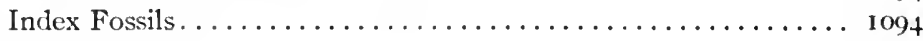

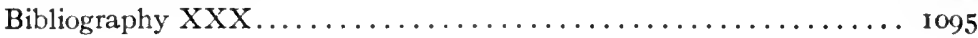

\section{G. PRINCIPLES OF CLASSIFICATION AND CORRELATION OF GEOLOGICAL FORMATIONS.}

\section{CHAPTER XXXI.}

Nomenclature and Classification of Geologic Formations. . . . . . . 1097

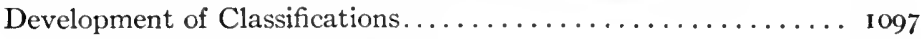

Selection of the Type Section................. I 100

Time Scale and Formation Scale.............. 1 102

Subdivision of Time and Formation Scales (I I03); I. International Geological Congress (1104); II. Dana's System (I I06); III. United States Geological Survey......... I I03-ı I06 Unification of Terminology ( 1 I 07 ); Local Stages and Substages I 107 Principles Governing the Naming of Formations (1 I09); Selection of Names for Systems, Series and Stages (Groups)......... I I o9-I I I Mapping (I I 12); Mapping on Formational Basis (I I I2); Mapping on Faunal Basis (III3); Mapping of Discontinuous Formations

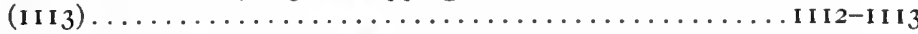

Types of Geological Maps (I I I5); Formation and System MIaps (I I I5); Intermediate Maps (I I I5); Notation of Formations on Map (III6); Legend (III6) ............. III5-1II6

Continuous and Discontinuous Mapping........... II 7

Sections; Types of Sections..................... 1117

The Length of Geological Time................. 1 18

Bibliography XXXI..................... III9

\section{CHAPTER XXXII.}

Correlation, Its Criteria and Principles. Paleogeography...... i i 2 I

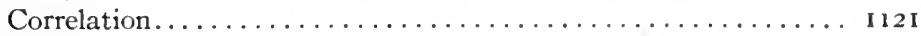

History of Development of Methods of Correlation....... I I I I Chronological Equivalency; Contemporaneous and Homotaxial Formations (II2t); Contemporaneity of Faunas (I 125); Prenuncial Faunas; Colonies............ I $24^{-1126}$ Standard or Type Section (I 127); A Double Standard. 1 I 27-I I 29 
Methods of Correlation................... I129

I. Superposition (I I29); 2. Stratigraphic Continuity (II3I); 3. Lithic Character (II32); 4. Organic Contents

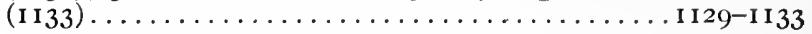

a. Index Fossils (I I 33); b. Grade of Index Fossil (I I34); c. Correlation by Equivalent Stages in Development (I I35); d. Correlation by Faunas and Floras. Representative Species (I I36)............... II33-II36

5. Correlation by Unconformities and Disconformities

(1137); 6. Correlation by Regional Metamorphism

(I I39); 7. Correlation by Diastrophism......... II39-II4I

Palæogeography and Palæogeographic Maps............. I I 44

Types of Palæogeographic Maps (I 145); Construction of

Palæogeographic Maps........................ I I $4,5-1146$

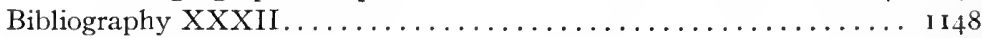

Index................................... II I 


\title{
PRINCIPLES OF STRATIGRAPHY
}

\author{
CHAPTER I. \\ GENERAL INTRODUCTORY CONSIDERATIONS.
}

STRATIGRAPHy in its broadest sense may be defined as the inorganic side of Historical Geology, or the development through the successive geologic ages of the earth's rocky framework or lithosphere. Its relation to other branches of geologic science may be made clear by a few brief considerations regarding the earth as a whole, and a short survey of the science of geology and its subdivisions.

\section{THE EARTH AS A WHOLE.}

The earth as a whole may be vicwed as a central mass or sphere of unknown material surrounded by a number of envelopes. For convenience sake in discussion, these envelopes may be considered as continuous shells or hollow spheres, the outer ones more or less intimately interwoven with the upper part of the rocky crust. They may be grouped into the inorganic and the organic spheres. Beginning with the outermost of the inorganic, the following are recognized: I. Atmosphere or sphere of gas and vapor; II. Hydrosphere or sphere of water; III. Lithosphere or the rock sphere or solid part of the earth. Below the known crust of the earth is the zone of volcanic activities and the seat of lava formation. This is called the Pyrosphere, IV, and it merges upward into the lithosphere (III) and downward into the Centro- or Barysphere, V, which occupies the unknown center of the earth and the nature of which is in doubt. Permeating more or less all of these spheres. except the last two, is the organic or Biosphere. VI, the living envelope of the earth. A brief summary of cach may first be given.

I. THE ATMOSPHERE. This consists of a mechanical mixture of nitrogen about 79 parts, and of oxygen about 21 parts (by volume), with small quantities of carbon clioxide (about 0.03 part of the whole) and some of the rarer elements. Besiles this it nearly always contains a variable amount of aqueous vapor together with other impurities, such as dust, organic matter, etc. Its weight at 
sea-level is about 15 pounds (I 4.7 pounds)* per square inch, or about a ton per square foot, and this is spoken of as the normal atmospheric pressure or one atmosphere. It becomes more tenuous upward; above 50 miles from the earth's surface it becomes so excessively thin that it is incapable of producing measurable pressure, or of deflecting perceptible amounts of sunlight. (Davis6:13.) $\dagger$ Above 100 miles it practically ceases to exist so far as observations have been made, though it is supposed that it might extend in an excessively attenuated state to the limit of the earth's gravitative control, which is at about 620,000 miles from the surface of the lithosphere. (Chamberlin and Salisbury-4, i:6.)

II. THE HYDROSPHERE. This is a fairly continuous envelope, concentrated chiefly in the larger depressions of the lithosphere, where it constitutes the oceans, but also permeating the upper part of the earth's crust as a more or less continuous layer. The surficial extent of the sea water on the earth is estimated at 36I.I million square kilometers, while the total land surface is estimated at 148.8 million square kilometers. This makes a ratio of land surface to sea surface of I: 2.43 or $29.2 \%$ land and $70.8 \%$ sea (Krümmel-I7, i:8), , or in round numbers the sea surface is 2.5 times that of the land. When taken in hemispheres, the northern one has $60.7 \%$ water and the southern $80.9 \%$ (I7, i:I3). The greatest known depth, that of the Nero deep, opposite the island of Guam in the Ladrone Islands east of the Philippines, is 9,636 meters ( $5,269 \cdot 13$ fathoms or 3 I,6I5 feet). The area of the ocean bottom below 4,000 meters comprises about I 85 million square kilometers, that below 5,000 meters of depth 72 million square kilometers or about half the area of the dry land ( $1 / 5^{\text {th }}$ of the sea surface); that below 6,000 meters about 5.4 million square kilometers or about the area of European Russia. Among the greater deeps, which are more circumscribed, we have that of the Marian depression opposite the Marian or Ladrone Islands (in which the Nero deep occurs) with an area of 49,000 square kilometers (equal in area to Sardinia and Sicily) below 7,000 meters and about 22,500 square kilometers below 8,000

\footnotetext{
* I.0333 kgm. per sq. cm., or the weight at sea-level of a column of mercury $760 \mathrm{~mm}$. (29.92 I inches) high.

$\dagger$ The Arabic figure refers to the number of the article in the bibliography at the end of the chapter, the italicized number refers to the page.

$\$$ Penck in Scobel's Geographisches Handbuch makes the surface area of the water 366 million square kilometers, and that of the land 144 million square kilometers, including the Antarctic continent, which has an estimated area of 8 to 9 million square miles, giving in percentages $71.8 \%$ water and $28.2 \%$ land, a ratio approximately of $2.3: \mathbf{I}$.
} 
meters. In the southern Pacific the Tonga deep has an area of 123,000 square kilometers below 7,000 meters, and 63,000 square kilometers below 8,000 meters, while the Kermadec deep to the south of it has 137,000 square kilometers below 7,000 meters, and 78,000 square kilometers below 8,000 meters. The maximum depths of these two depressions are 9,427 and 9,4I3 meters, respectively. (Krümmel-I 7, i :85.) The total area of the oceanic depressions below 6,000 meters is given by Penck as 10.6 million square kilometers, and by Krümmel as 5.4 million square kilometers. Taking the area of the seas as a whole at 36r, I00,000 square kilometers, and evening out the irregularities of the bottom, so as to obtain a mean depth, we find this to be approximately 3,680 meters or 2,012 fathoms (see further under lithosphere). Various estimates as to the volume of the sea water as a whole have been made. The most recent of these, given by Krümmel, places it at I,330 million cubic kilometers. The weight of the sea water may be calculated from this by taking its average density, increased in the deeper portions by pressure, as 1.04, the result being $1.3832 \times 10^{18}$ metric tons or in round numbers $138 \times$ IO ${ }^{18}$ metric tons.*

Transgressions and Regressions. Two types of alternation of the level of the hydrosphere are recognized: the local and the universal. The former is due to slight up or down warpings or faultings of parts of a continent with resulting local retreat or advance of the sea. The effects of such a change will be noticed only locally and will at best be of slight amount. An example of this is shown in the periodic rising and sinking of the land in the Gulf of Naples as recorded in the ruins of the temple of Jupiter Serapis, near Pozzuoli (Lyell-18, ii Chapter XXX); or, in the Scandinavian region, where, during the last century, an area of 300,000 square kilometers rose on the average 0.7 meter, making a total elevated mass of 2 Io cubic kilometers.

The second type of change is one that affects the entire surface of the ocean, and is best explained by a bulging up or a sinking down of the sea bottom, the result of which will be a universal rise of the sea-level and transgression over, or fall and retreat from the edge of the land. For these latter movements Suess (27, ii:68o; 28, ii :534) has proposed the term: "Eustatic Movements." The sinking of the sea bottom and consequent lowering of the level and withdrawal of the water from the land constitute negative eustatic movements, while elevation or bowing up of the sea bottom with

* The metrie ton contains I,000 kilograms, equivalent to 2,204.6 pounds avoirdupois. 
accompanying rise and transgression cause positive eustatic movements. A third type of movement must be considered. If we regard the continents as crustal blocks of a lighter specific gravity than the suboceanic crustal blocks, the former being squeezed upward by the downward pressure of the suboceanic blocks, it is conceivable that a single continental block like that of the Americas might be squeezed upward, while the other continental blocks would remain stationary, and yet at the same time there need be no marked change in the altitude of the suboceanic blocks with reference to the stationary continental blocks. As a result there will be a widespread emergence, or negative movement of the sea, so far as the rising land block is concerned, while at the same time the resultant displacement of the water will cause a transgressive or positive movement of the sea with reference to the stationary blocks. Thus a retreatal movement in one continent may be correlated with a transgressive one in another continent. Such differential movements may even affect different parts of the same continental block, if the movement is an unequal or tilting one, and this would account for transgression of the sea over one section of a continent at a time when retreatal movements characterized another part.

The Terrestrial Part of the Hydrosphere. The terrestrial or extra-oceanic part of the hydrosphere is chiefly found in the ground water and in the streams, lakes and ponds of the earth's surface. Since the porosity of the rocks constituting the earth's surface region varies greatly, the quantitative distribution of the water also varics. The ground water is probably chiefly confined to the upper six miles of the earth's crust, and here we have a diminishing porosity from 5 per cent. or over at the surface to zero at the depth of six miles. It has been estimated on this basis that the rock of the earth's surface contains enough water to form a layer nearly 800 feet deep (Chamberlin and Salisbury-4:221), but other estimates make this layer much thicker, that of Slichter being 3,000 to 3,500 feet $(25: 15)$. Van Hise, on the other hand, has shown that the amount is much less, and is, according to his estimate, sufficient to make a layer only 69 meters or 226 feet thick over the continental area $(30: I 28-I 29,570-57 I)$. Kemp has called attention to the fact that in the deep mines no water is encountered below a moderate depth. "In several important instances of this class, as well as in many mines of smaller depth, it is possible to impound all the water within a short distance, it may be within 500 feet of the surface. Below this level the workings are dry, and in not a few cases dusty." (15:I6.) He con- 
cludes that something like 2,000 feet appears to be the limit to which ground water descends, while in some regions it ceases at 500 feet. From this it is estimated that the amount of water present would produce a layer over the surface of the earth between $5^{\circ}$ and Ioo feet deep. Fuller $(7: 6 I, 62,72)$ calculates the exact figure at 96 feet, which would be acceptable were it proven that the data on which his calculations are based are ascertained with equal exactness.

III. THE LITHOSPHERE. This is the solid framework of the earth. It is a nearly perfect oblate spheroid with a polar diameter of 12,713.5 kilometers (7,899.7 miles) and an equatorial diameter of $12,756.5$ kilometers (7,926.5 miles), corresponding to a meridional circumference of about 40,008 kilometers (24,860 miles), an equatorial circumference of 40,076 kilometers (24,902 miles), and a surface area of 5 Io million square kilometers (I96,940.700 square miles). As already noted, the land surface is scmething over 29 per cent. of this, or about I48.8 million square kilometers. The greatest elevation of the land above sea-level (Mt. Everest) is 8,840 meters, which is nearly 800 meters less than the greatest known depth of the sea $(9,636$ meters). Of the entire earth's surface not over three million square kilometers of area lie more than 4,000 meters, nor over half a million square kilometers more than 5.000 meters above sea-level. The following table shows the percentages of land within successive strata of 100 meters (Penck2I, i:I45):

Between o and 200 meters, each interval of 100 meters contains $14.6 \%$ of the land, or a total of .............................

Between 200 and 500 meters, each interval of 100 meters contains

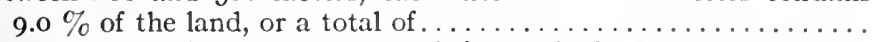

Between 500 and $\mathrm{I}, 000$ meters, each interval of 100 meters contains

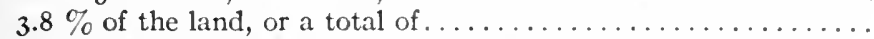

Between 1,000 and 2,000 meters, each interval of Ioo meters contains

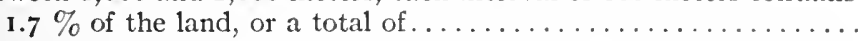

Between 2,000 and 3,000 meters, each interval of 100 meters contains

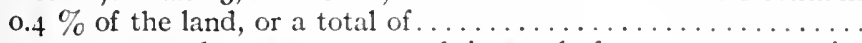

Between 3,000 and 4,000 meters, cach interval of 100 meters contains o.I \% of the land, or a total of.

Between 4,000 and 8,840 meters, each interval of 100 meters contains $0.04 \%$ of the land, or a total of.

$29.2 \%$

$27.0 \%$

$19.0 \%$

$17.0 \%$

$4.0 \%$

1.0\%

I.9\%

$99.1 \%$

It is thus seen that more than one-half of the earth's surface $\left(5^{6}\right.$ per cent.) lies below the 500-meter contour, and that more than half this lies below the 200-meter contour. Very different values 
have been reached by de Lapparent, Heiderich and Murray, as shown in the following table (Penck-21, i:I5O):

\begin{tabular}{|c|c|c|c|c|c|c|c|}
\hline $\begin{array}{l}\text { Percentage of } \\
\text { land surface }\end{array}$ & $\begin{array}{c}\text { Below } \\
\text { o m. }\end{array}$ & $\begin{array}{c}\text { From } \\
0- \\
200 \\
\mathrm{~m} .\end{array}$ & $\begin{array}{c}\text { From } \\
200- \\
500 \\
\mathrm{~m} .\end{array}$ & $\begin{array}{c}\text { From } \\
500- \\
\text { I,OOO } \\
\text { m. }\end{array}$ & $\begin{array}{c}\text { From } \\
\text { I,000- } \\
2,000 \\
\text { m. }\end{array}$ & $\begin{array}{c}\text { From } \\
2,000- \\
3,000 \\
\text { m. }\end{array}$ & $\begin{array}{c}\text { Above } \\
3,000 \\
\text { m. }\end{array}$ \\
\hline de Lapparent. & & I 8.00 & 20.00 & 47.0 & 14.00 & \multicolumn{2}{|c|}{ I } \\
\hline Heiderich... & 0.08 & 13.40 & 37.96 & 28.5 & $17.8 \mathrm{I}$ & I.95 & 0.30 \\
\hline Murray....... & 0.00 & 14.60 & 38.00 & 25.8 & 19.80 & 1.40 & 0.40 \\
\hline
\end{tabular}

The mean elevation for all continents is given by Sir John Murray as 2,250 feet (686 meters), and the mean or average depth of the ocean as 3,840 meters (2,IOO fathoms). Penck (2I II II; $22: I 7)$, on the other hand, finds the mean elevation of the continents and islands to be 735 meters and the mean depth of the ocean 3,650 meters. The mean depth of the ocean has more recently been calculated as 3,680 meters (precisely 3,68I meters) by Krümmel ( $17: 144$ ), who also assumes the mean altitude of the land at approximately 700 meters. More recently still Penck has given these figures as 3,680 meters and 710 meters, respectively $(22: 125)$. With a land area of 148.8 million square kilometers, the volume of the land mass above sea-level becomes ro4.2 million cubic kilometers. From these figures the following ratios are deduced: mean height of land to mean depth of sea $=700: 3,680=$ $\mathrm{I}: 5.25$; area of land to $\mathrm{sea}=\mathrm{I} 48.8: 361.2=1: 2.43$; volume of

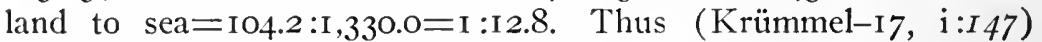
it would take nearly $\mathrm{I} 3$ times the volume of the land rising above sea-level to fill the sea, three times that volume to fill the Atlantic Ocean, 23/4 times that volume to fill the Indian Ocean, and $61 / 2$ times to fill the Pacific Ocean.

The Mean Sphere Level. If we regard the land mass as a whole, we may represent it by a prismatic block (tetragonal) composed of that portion which lies above mean ocean depth. plus that portion rising above sea-level, giving a height of $3,680+700=$ 4,380 meters, a base of I 48.8 million square kilometers, the present area of the land surface, and a volume of $65 \mathrm{r} .8$ million cubic kilo- 
meters; ${ }^{*}$ while the sea may be represented by a prismatic block (tetragonal) having twice that volume $(1,330.0 \div 65 \mathrm{I} .8=2.04)$. If, then, we were to flatten out all irregularities of the sea bottom by cutting down the land block sufficiently to fill them, or, in other words, if we distribute the land biock of $6_{5} \mathrm{I} .8$ million cubic kilometers over the entire surface of the earth, 509.950,000 square kilometers, according to Bessel, it would raise the mean level of the ocean floor by the quotient of $65 \mathrm{I} .8 \div 509.9=1.278$ kilometers. The level of the earth's crust would therefore be $-3,68 \mathrm{I}+1,278=-2,403$ meters, or approximately $-2,400$ meters ( $-\mathrm{I}, 3 \mathrm{I} 3$ fathoms) below the present sea-level. This is called the mean sphere level (mittlere Krustenniveau), which Penck originally placed at $-2,500$ meters ( -1.367 fathoms), but more recently at 2,400 meters $(22: 125)$. Mill (19:I83), using the figures of Sir John Murray for height of land and depth of ocean cited above, finds the mean sphere level to be $-2,560$ meters or - r,400 fathoms, while Romieux (24:99\%) from the same data finds it to be approximately $-2,360$ meters (- I,290 fathoms). For the whole earth, 222 million square kilometers lie above this mean sphere level and 288 million square kilometers below it. If we assume a smooth lithosphere, the surface of which would correspond to the mean sphere level, and the available sea water (I,330 million cubic kilometers) were uniformly spread over this surface, we would have an approximate but uniform depth of 2,600 meters ( 1,422 fathoms) for the universal ocean $(\mathrm{I}, 330.0 \div 509.0=$ 2.608 kilometers). The oceanic areas below this depth of 2,400 meters (or approximately I,300 fathoms) constitute the abysmal areas; those above this to the edge of the continental shelf (200meter or approximately Ioo-fathom line) the transitional areas (die aktischen Regionen of Penck) and those above this level (-200 meters to $+8,840$ meters) as the continental area (Penck). $\dagger$

The Continental Block. The conception of a continental block was introduced by $\mathrm{H}$. Wagner $(3 \mathrm{I}: 749)$ for the mass of land (222 million square kilometers in basal area) which rises above the mean crustal level. This he divides into: I. The continental slope (Kontinentalabhang), between the median sphere level and the

* If we represent the continental mass as a prismatic block with a square base of $148,800,000$ square kilometers of area, a side of $12,198.36$ kilometers, and a height of 4,380 kilometers, on the scale of $1 / 1,000,000$, we would have a block of square base 12.2 meters on the side, and $4.38 \mathrm{~mm}$. in height and nearly one-fifth of this or $0.83 \mathrm{~mm}$. would represent the part above sea-level.

f In the original classification by Dr. Hugh Robert Mill, the line between the transitional and the continental areas was drawn at sea-level. 
clge of the continental shelf, i. $\mathcal{e}$., between -200 and $-2,400$ meters depth. 2. The continental platform (Kontinentaltafel), between -200 meters below and $+\mathrm{I}$,Ooo meters above sca-level; and 3. The culminating land region (Kulminationsgebiet) from I,OOO meters to 8,840 meters above sea-level. The abysmal regions are divided into (a) the deep sea platform (Tiefseetafel), between the median sphere level $(-2,400$ meters $)$ and - 5,000 meters depth; and (b) the depressed region (Depressions sebiet), below

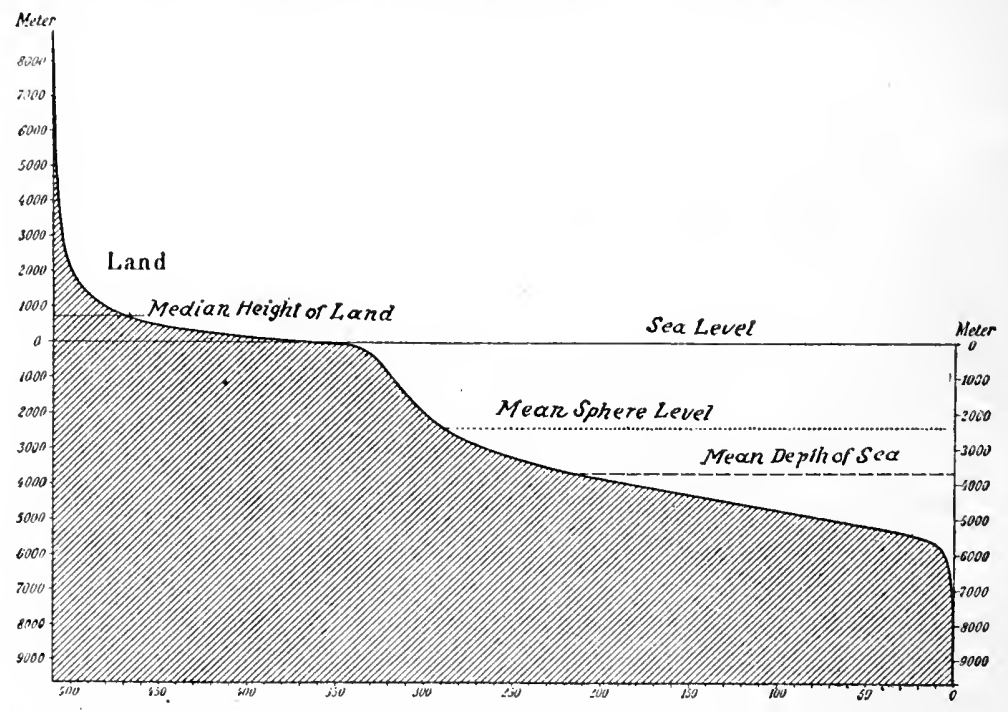

Million square kilometers.

FIG. I. Hypsographic curve, showing subdivisions of the hei hts of the land and of the depths of the sea. (After Krummel.)

- 5,000 meters. A more satisfactory dividing line is placed by Krümmel at 5.500 meters. (Fig. I.) The continental block has roughly the form of a star surrounding the north pole, and extending its rays southward. (Penck-22:12I.) Two principal divisions of these rays are recognizable, the Old World and the New World, of which the first is divided into three continents, Eurasia, Africa, and Australia, and the other into two: North America and South America. The divisions are brought about by deep indentations from the sea, constituting the mediterraneans. Besides the five continents mentioned, there is the continent of Antarctica, still little known, but larger than Australia in area. The two main divisions of the continental block are separated by the "arctic mediterranean." 
In some respects, as has already been stated, it might serve our purpose better to consider the main land groups as three separate continental blocks, namely; the Old World block, comprising the continents of Eurasia, Africa and Australia; the New World block or the two Americas, and the Antarctic block. On the basis of such division we may consider that we have four great oceans separating these blocks one from another, namely, the Atlantic, the Pacific and the Arctic* separating the Old and the New World blocks, and the Indian Ocean separating the Old World from the Antarctic block. These oceans would then be the intercontinental divisions of the sea, while the divisions of these masses into continents, as ordinarily understood, would be accomplished by mediterraneans, which may then be regarded as intracontinental in character.

Isostasy. Carrying out this idea, we have to consider the sea

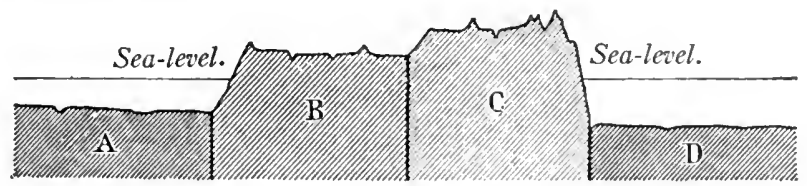

FIG. 2. Diagram illustrating the relationships between the denser suboceanic crustal blocks $\mathrm{A}$ and $\mathrm{D}$ and the light or terrestrial crustal blocks $\mathrm{B}, \mathrm{C}$, when in static equilibrium. (After Penck.)

as divided into four great blocks corresponding to the four oceans, including the Arctic. If we divide the crust into continental and suboceanic masses or crustal blocks, we must consider that these masses are in static equilibrium, due to the greater density of the material of the suboceanic masses, as shown by pendulum experiments. Penck (22:I25-126) illustrates these relations by comparing these masses with boards of equal thickness, but of different weights floating upon water. Those of heavier wood will sink deeper than those of lighter wood, and may be taken to represent the suboceanic masses. This static equilibrium of the blocks of the earth's crust constitutes the phenomenon of isostasy, and indicates

* It must, on the other hand, be considered that the Arctic Ocean has the character of a mediterranean, in that its abyssal portion is everywhere scparated from that of the sea as a whole. In fact, at the present time, not only is the 2,400-meter line continuous within the Arctic, but this is equally true of the I,ooo-meter line, the depths between North America, Greenland, Iceland, and Northern Europe not going below this. That the Arctic Ocean is one independent depressed earth block similar to those forming the three great oceans can hardly be doubted. The peculiarities which differentiate it from the other oceans are due largely to its location at the earth's axis, and to its extensive covering of ice. 
that these differences are of fundamental value, and that hence the great relief features of the earth's surface have been persistent since the earliest time (Fig. 2). Where the isostatic equilibrium is disturbed by erosion of the higher less dense masses, and by the transference of the product to the denser block, a compensatory deep-seated transference of material by flow must occur, from the denser to the lighter, which is accompanied by a sinking of the upper part and surface of the denser block and a corresponding rise above the level of compensation of the upper part and surface of the less dense block. (Hayford-13:I99.)

Thickness of the Earth's Crust. In considering the top of the lithosphere as representing the surfaces of a series of elevated and depressed crustal blocks, we naturally assume that the thick-

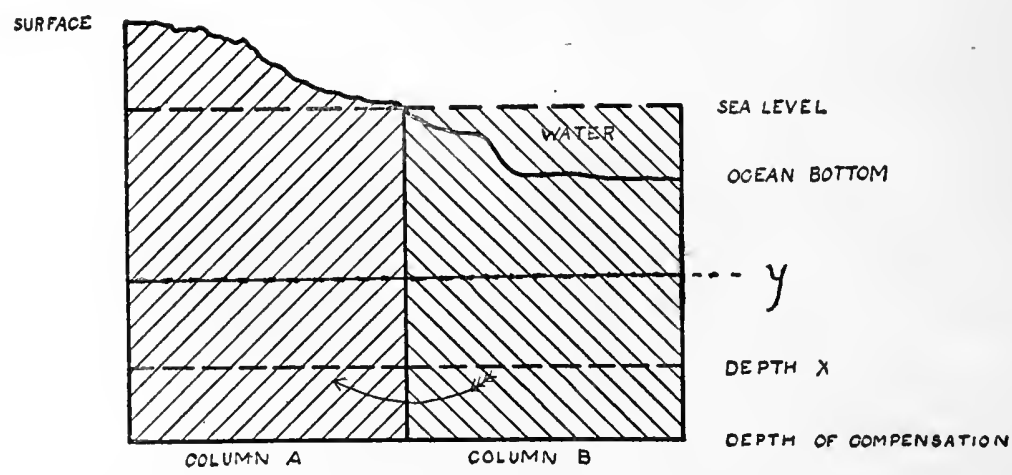

FIG. 3. Diagram illustrating the conception of isostatic equilibrium and its adjustment with change in surface. (After Hayford.)

ness of the crust is measured by the height of these blocks. Since they are considered to be in a state of isostasy, it follows that, if these masses were divided into prismatic columns of equal basal area, the pressure due to gravity at the bases of these columns would be the same. The depth at which this state of equilibrium is found is the depth of compensation. From calculations made by the Coast and Geodetic Survey on numerous observations scattered over the United States, the conclusion has been drawn that the most probable depth of compensation is 76 miles, and that it is practically certain that it is not less than 62 nor more than 87 miles. (Hayford-12:77-78; I3:200.) This assumes a uniform position of the level of compensation with reference to depth. In Fig. 3. adapted from Hayford, columns $\mathrm{A}$ and $\mathrm{B}$ have been assumed to contain equal masses. There is complete isostatic equilibrium and 
the pressures at the bases of the two columns are equal. But, since the heights of the columns are unequal, it follows that their densities must also be unequal, the shorter coltumn, ls, having the greater density. If the mass is unequal in the two columns, isostatic compensation is incomplete. At any plane, as $x$, above the level of compensation, the pressure of the two columns will not be the same, since the mass above this point differs. The mass of column A will be greater than that of column $B$, and hence the pressure of $A$ at $\mathrm{x}$ will be greater than that of $\mathrm{B}$. If now, through erosion, material from the higher column A is transferred to the lower column $\mathrm{B}$, the height of the two columns will be changed, and hence the pressure at their bases will not be the same, but greater in $B$ than in A. So long as A remains higher than B, any plain, as $y$, cutting $A$ and $B$ near the top, will leave $A$ heavier than $B$. If, then, the weight of $\mathrm{B}$ becomes greater than $\mathrm{A}$ at the base, owing to the loading of $\mathrm{B}$, while at $\mathrm{y}$ it is still less than $\mathrm{A}$, owing to its lesser mass, it follows that at some intermediate point, as at $x$, it will be uniform. This is the "neutral level," which, however, rises as the load on $B$ increases and as $A$ is lowered by erosion. Below the neutral level $x$ there will be an excess of pressure in the column $\mathrm{B}$ over that of column $\mathrm{A}$, and this excess of pressure will increase as the neutral level rises, through continued erosion and deposition. When the pressure becomes greater than the natural resistance of the material can balance, a transference or flow of the material from $\mathrm{B}$ to $\mathrm{A}$ will take place below the neutral level. This transfer of material will be accompanied by an elevation of the upper part and surface of $A$, and a sinking of the upper part and surface of $B$. unless there is a compensatory change in volume of material. Chemical changes in the mass relieved by erosion may cause further expansion in volume, and consequent further rise of the stirface, but lowering, of temperature throughout the entire block, due to the lowering of the surface by erosion and the invasion of surface temperatures into regions originally bclow the surface and therefore of much higher temperatures, will cause a slow, but continued shrinking of the mass. Hayford assumes an approximate shrinking from this cause of the crustal column of 76 miles, to the amount of 30 feet for every 1,000 feet eroded (13:204). In like manner, blanketing of the mass by deposition will cause a rise in temperature and consequent expansion and increase in volume. If the changes due to variations in the temperature overbalance those due to the causes with opposite effects, as may be the case in the course of a long time, the regions of erosion may subside, as in the event of the submergence of a peneplain, while regions of former deposi- 
tion may rise. It thus appears that the adjustments within the earth's crust and the forces responsible for the geological changes recognizable on the surface of the earth are confined to the upper 76 miles of the earth's mass, or about $1 / 53$ of the radius. This we may, therefore, regard as the crust of the earth, bearing in mind, however, that there is no marked line of separation between the crust and the subcrustal part. It is within this crust, and chiefly within its upper part, that we find the seat of vulcanism; that the minor disturbances recorded as earthquakes, etc., occur; that the ground water circulates, and that the crushing and flowage of rocks take place, and it is by changes in the crust as thus defined that the rise and fall of land masses and sea bottoms take place. It is of course possible that the source of some of our basic volcanic rocks is deeper than 75 miles. Thus the density increase in the earth cited below suggests that basalts are derived from depths of 105 to I37 miles.

Material of the Earth's Crust. Only the material of the lighter blocks of the earth's crust, $i$. $e_{\text {. }}$, those constituting the continental masses, is open to observation, and constitutes the "rocks of the earth's crust." The average specific gravity of this material is 2.2 to 3 (average 2.6), while that of the earth as a whole is about 5.6. This difference is accounted for by assuming that the material constituting the interior of the earth (centrosphere) has a higher specific gravity than the earth as a whole. It is clear that if the continental and suboceanic crustal blocks are in the condition of static equilibrium, the latter must consist of heavier or denser material than that of the known surface.

Deformation of the Earth's Crust. (Diastraphism.) The larger deformations of the earth's crust consist in the sinking of the suboceanic crustal blocks, or the rise of the continental blocks, or vice versa. These are designated epeirogenic (continent-making) movements. Minor diastrophic changes result from local warpings, either up or down, from faultings, or foldings of the strata. These are designated as orogenic (mountain-making) movements, resulting in the formation of mountains. Local rising of the land, even though unaccompanied by visible foldings, must be considered as bowing or folding on a large scale, and it often precedes the formation of folded mountains, as shown by the successive elevations of the Appalachian Old Land (recorded in the successive continental fans), which preceded the folding of the strata at the end of Palæozoic time.

IV. THE PYROSPHERE. This is an indefinite region in the lower part of the earth's crust, or below it, and designated as dis- 
tinct because it is the zone of fusion and of the formation of volcanic matter. Its existence is revealed by the manifestation of volcanic phenomena, and it passes insensibly on the one hand into the Lithosphere and on the other into the Centrosphere, of which it may indeed be a part. Its depth varies for different rocks, and it cannot be regarded as constituting a continuous sphere, as do the others so far discussed. Its consideration as a distinct sphere is rather more for the sake of convenience of discussion.

V. THE CENTROSPHERE. So far as actual observation is concerned, the greater part of the geosphere is unknown to us. Beyond the relatively insignificant thickness represented by the known part of the earth's crust or lithosphere open to observation, and the inferred pyrosphere, there is the vast mass of the earth's interior, forever withdrawn from direct observation and approachable only in an indirect manner. This is the centrosphere which may be the ultimate storehouse of the earth's internal heat. The following diagram (Fig. 4), adapted from Crosby,* will serve to illustrate the relation between the known and the unknown parts of the earth. The diagram represents a sector of the earth, two degrees or about I 40 miles broad. It is drawn to a radius of 75 inches, or a scale of $53 \frac{1}{3}$ miles to the inch. Assuming the crust to have a thickness of 75 miles, and the greatest depth of the atmosphere at roo miles, these would be represented by $13 / 8$ and $17 / 8$ inches, respectively. The extreme depth of the ocean is taken as 31,600 feet (o.II inches), the mean depth as 12,000 feet ( 0.043 inches), the mean height of land as 2,300 feet (o.009 inches) and the greatest height of land as 29,000 feet ( 0.03 inches). The length of radius on this scale being 75 inches, it follows that the two radii will meet at that distance from the surface of the water line, $i$. $e_{\text {., }}$ the distance to the center of the earth on this scale is $61 / 4$ feet from the line representing sea-level. This shows well the relative insignificance of the surface features as compared with the size of the earth as a whole.

Temperature of the Earth's Interior. (Günther-Io, i:328.) From observations in deep mines, artesian wells, etc., it appears that there is an increase in temperature downward, this being about $I^{\circ}$ Fahrenheit for every 53 feet vertical descent, or, in round numbers, $100^{\circ}$ per mile. $\left(2.5^{\circ}\right.$ to $3^{\circ} \mathrm{C}$. per 100 meters, or about one degree for every 40 meters.) Considerable variation is, however, shown in different mines or wells. Thus the Sperenberg bore hole in North Germany (south of Berlin), which went to a depth of

* Collections of Dynamic and Structural Geology in the Museum of the Boston Society of Natural History. 
$\mathrm{I}, 273$ meters $\left(3,492\right.$ feet), showed a rate of increase of $\mathrm{I}^{\circ} \mathrm{F}$. in 5 I.5 feet depth; the bore at Schladebach, Saxony (west of Leipzig), extending to a depth of 1,748 meters (5,630 feet), showed a rate of increase of $\mathrm{I}^{\circ} \mathrm{F}$. in 67.I feet, while the Calumet and Hecla mine

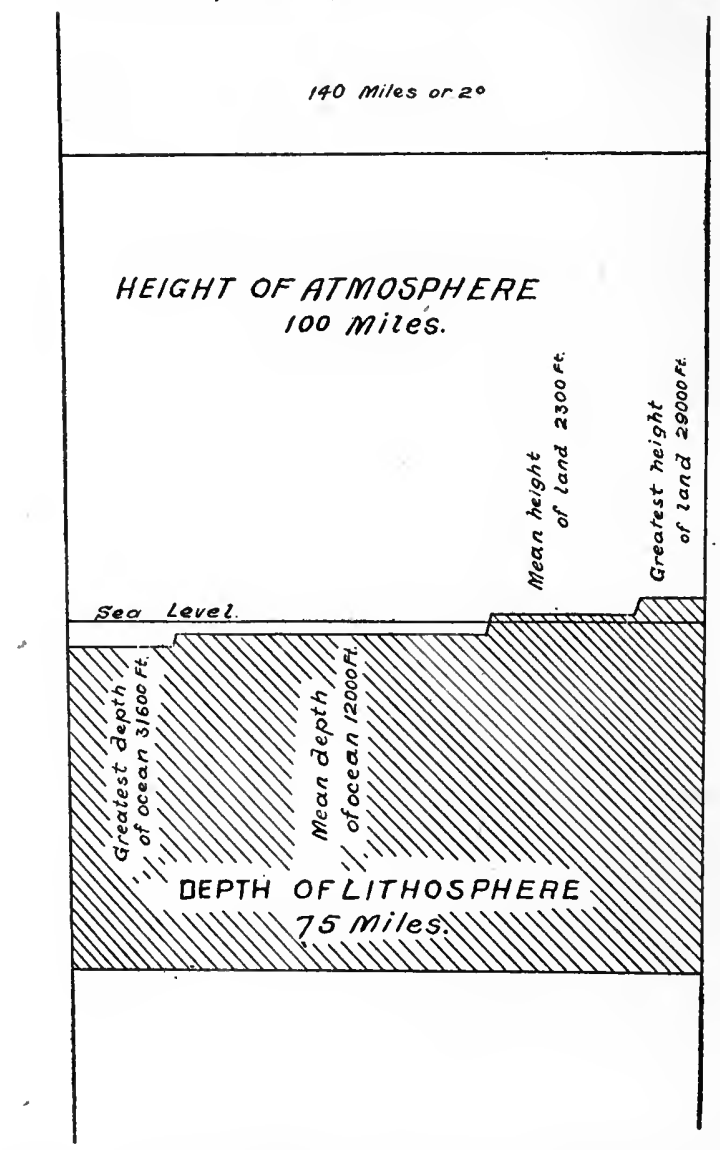

FIG. 4. Diagram illustrating the relation of the superficial features of the earth to the entire mass. Seale $\mathrm{I}$ inch $=53$ I-3 miles. Drawn to radius of 75 inches $(=4,000$ miles $)$.

of Northern Michigan, with a depth of 4,939 feet, showed a rate of increase of $\mathrm{I}^{\circ} \mathrm{F}$. in $\mathrm{IO} 3$ feet depth, though between 3.324 feet and 4.837 feet the rate of increase was as high as $\mathrm{I}^{\circ} \mathrm{F}$. in 93.4 feet. Other bores and mines show intermediate values.* In the Witwa-

* The deepest well yet completed is at Paruschowitz, Provinee of Silesia, whieh reached a depth of 2,003 meters $(6,57$ I.5 feet). 
tersrand mines, South Africa, the general rate of increase was $1^{\circ} \mathrm{F}$. for 250 feet, the temperature at $\mathrm{I}, \mathrm{OoO}$ feet being $68.75^{\circ} \mathrm{F}$., and at 8,000 feet $102.35^{\circ}(32: 820)$. These observations, however, are restricted to the thin outer layer or shell of the earth's crust, which does not exceed I/4000 of the earth's radius, and hence we are scarcely justified in extending this rate over the whole interior of the earth. If continued at the known rate, enormous temperatures would be met with at a depth of only a few miles. With a regular increase of one degree $F$. in 60 feet, we would get at the center of the earth a temperature of $348,000^{\circ} \mathrm{F}$., while at the regular rate of increase of one degree F. in 100 feet, we would get a temperature of $209,000^{\circ} \mathrm{F}$. at the center. $(4: 57 \mathrm{I}$.) On the other hand, we may, with Crosby (5:9), consider it as more likely that the increase in temperature is at a constantly diminishing rate, so that the interior temperatures do not exceed those with which we are acquainted on the surface.

InCREASE of Density. As already noted, the density of the earth as a whole is 5.6, while the median density of the known rocks of the earth's crust or lithosphere is only 2.6. Assuming a regular and steady increase in density, Helmert ( $14: 475$ ) has calculated that the density of the center of the earth is II,2. From this it is possible to calculate the depth at which any given density of $\operatorname{rock} \theta$ should prevail, according to the formula:

$$
h=r\left(I-\sqrt{\frac{I-\sqrt{0.082 I \theta+0.08}}{0.46}}\right)
$$

where $\theta$ is the given density, $h$ is the depth sought, and $r$ the radius of the earth $(\mathrm{r}$ (equatorial) $=3,959$ niles or 6,375 kilometers). (2I, i:442.) According to this formula (2I, i:443), andesites and trachytes with a specific gravity of $2.7-2.8$ would be derived from a depth of 73 to II 7 kilometers, basalts with a specific gravity of 2.9-3, from a depth of 169 to 221 kilometers. According to this calculation, rock-melting temperatures $\left(1,200^{\circ}\right.$ C. $)$ must exist at a depth of 73 kilometers, which would require a rate of increase of $\mathrm{I}^{\circ} \mathrm{C}$. in $6 \mathrm{I}$ meters. That the rocks at the depth at which the temperature of $1,200^{\circ}$. C. exists are not in a molten condition, is due to the fact that they are under the weight of the superincumbent rock mass, and that pressure raises the fusing point. Thus, according to the experiments of Carl Barus, as summarized by Clarence King ( $16: 7)$, basalt, which will melt at the earth's surface at a temperature of $1,120^{\circ} \mathrm{C}$., will require a temperature of $76,000^{\circ} \mathrm{C}$. $\left(136,800^{\circ} \mathrm{F}\right.$.) to fuse it at the center of the earth This 
raising of the fusing point by increased pressure has led to the assumption that, in spite of the great heat, the earth's interior is a solid mass. Dana and Crosby suggested that the earth might be regarded as a mass of solid iron from the center to within 500 miles of the surtace; others, however, still hold to the fluid theory of the earth's interior, more or less universally accepted at the beginning of the last century, while still others hold to the theory of a gaseous interior $(1: 395 ; 9: 58$; $10: 354 ; 33)$ with a zone of liquid matter transitional to the solid crust.

VI. THE ORGANIC OR BIOSPHERE. This is the sphere of living matter which permeates the atmo- and hydrospheres, and to some extent the upper strata of the lithosphere. Its two main divisions, the plants and the animals, are familiar. The first forms a nearly continuous mantle over the land and the shallower ocean bottoms, and may be spoken of as the phytosphere; while the second forms a less continuous, though more universally present animal sphere or shell, which may be designated the zoösphere.

\section{INTERACTION OF THE SPHERES.}

Of the known spheres, the lithosphere is the most stable, and the one retaining in a more or less permanent form the impressions received through the mutual interaction of the spheres upon each other. The cycle of change, as it affects the lithosphere, has been divided (II:I2) into: I. Lithogenesis, or the origin and development of the rocks; 2. Orogenesis, or their deformation (diastrophism, including epeirogenic elevations), and 3. Glyptogenesis, or the sculpturing of the lithosphere. In lithogenesis all the other spheres participate. Deformation or orogenesis may be referred especially to the influence of the centrosphere and to gravitative forces; while glyptogenesis is largely accomplished by the atmosphere and hydrosphere, with minor contributions of the biosphere and pyrosphere.

\section{Sculpturing Processes.}

It will be convenient to treat the sculpturing processes while discussing the characteristics of the spheres most actively engaged therein, leaving the larger aspects of the subject, $i$. e., the land forms due to sculpture, until we have considered in detail the processes of lithogenesis and orogenesis.

In its broadest aspects the sculpturing processes may be di- 
vided into the three phases: Erosion, Transportation, and Deposition. Erosion consists of Clastation,* or the breaking up of the rock masses in situ; and Ablation, or the separation of material from the main mass. The first process is accomplished to a large extent by atmospheric forces and hence is called weathering. It affects only the upper zone of the earth's crust, which is termed the zone or bclt of aceathering, while the zone beneath it is termed the belt of cementation. The processes of erosion may be tabulated as follows: $(8 ; 34: 573$.

\section{EROSION.}

I. Clastation (breaking up of rock material).

A. Physical or Disintegration.

I. Atmospheric (generally included under weathering).

a. Insolation and radiation.

b. Frost shattering.

c. Electrical (lightning) shattering, etc.

2. Hydrospheric, wave shattering, etc.

3. Pyrospheric, shattering by volcanic explosion.

4. Controspheric, shattering by earthquakes.

5. Biospheric, shattering by growing organisms, by man, etc.

B. Chemical or Decomposition.

I. Atmospheric (weathering in the narrower sense; oxidation, hydration, carbonation, etc.).

2. Hydrospheric (hydration, oxidation, etc.).

3. Pyrospheric (decomposition through the activities of eruptive masses; of fumaroles, etc.).

4. Biospheric (decomposition under influence of living matter, probably rare.)

II. Ablation (separating off, or removal of material).

A. Mechanical.

I. Denudation, removal of weathered or loose material, i. e., mantle rock.

a. by wind = deflation.

b. by streams =fluvial ablation.

c. by glaciers = exaration.

d. by waves, shore cutrents, etc.

e. by organisms.

*From Gr. $\kappa \lambda \alpha \sigma \tau \sigma s=$ broken, and ation . 
2. Corrasion, a filing process.

a. by wind = eolian corrasion.

b. by running water=river corrasion.

c. by ice = glacial corrasion.

d. by waves $=$ abrasion.

e. by organisms = gnawing, etc.

3. Quarrying (closely related to physical clastation).

a. by wind (rare) undermining (decapitation of erosion monuments), etc.

b. by running water $=$ undermining (recession of Niagara).

c. by ice=plucking, sapping.

d. by waves $=$ tunneling and undermining.

e. by organisms, plant-wedging, plucking, etc., man's work.

B. Chemichl.

4. Corrosion.

a. by air-or evaporation (snow, ice).

b. by water (aqueous corrosion)-or solution.

c. by heat-igneous corrosion or melting.

d. by organisms.

\section{TRANSPORTATION.}

I. MECHANICAL.

A. In SUSPENSION (in, and moving with the mass).

I. Atmospheric-by wind: eolian transport.

2. Hydrospheric.

a. by waves, ocean and lake currents, tidal current, undertow, etc.

b. by rivers. (fluviatile transport).

c. by ice, englacial till; ground moraine, etc.

d. carried by floating host-such as :

(I) floating dead organisms (stones held by floating trees, etc.).

(2) icebergs, shore ice, etc.

(3) rafts, ships, etc.

3. Pyrospheric-suspended in molten lava.

4. Biospheric-transported by animals either externally or internally.

B. BASALLY, by shoving, rolling, sliding, etc.

I. Atmospheric-rolling by wind, as sand of sand dune, etc. 
2. Hydrospheric-
a. by water currents.
b. by ice, terminal moraines, etc.
c. by snowslides, etc.

3. Centrospheric-purely under the influence of gravitation.

4. Biospheric-by man, and more rarely other animals.

II. Chemical: In solution.

I. Atmospheric-dissolved in air, as water-vapor, gases, etc.

2. Hydrospheric-dissolved in water, $c . g$., salt.

3. Pyrosphoric-in igneous solution.

4. Biospheric-as body constituents, etc.

\section{DEPOSITION.}

A. Mechinical.

I. Atmospheric-by wind, etc. Atmoclastic and anemoclastic deposits.

2. Hydrospheric-by water. Hydroclastic deposits.

3. Pyrospheric-by igneous action. Pyroclastic deposits.

4. Biospheric-by animals, including man. Bioclastic deposits.

B. Chemical.

I. Atmospheric-atmogenic deposits-snow, etc.

2. Hydrospheric-hydrogenic deposits, salt, gypsum, etc.

3. Pyrospheric-pyrogenic or igneous deposits.

4. Biospheric-biogenic deposits (coral rock), etc.

\section{DEFINITION AND SUBDIVISIONS OF GEOLOGY.}

Geology is the science of the entire earth. The common impression of the layman, that geology is the study of the lithosphere alone, is a misconception, based on the fact that the geologist concerns himself largely with the crust of the earth, since here he finds the record of the history he seeks to read. According to the division of the earth as a whole into a series of spheres, as already set forth, we may divide the science of geology as a whole into the following branches : 
Geology $\left\{\begin{array}{c}\begin{array}{c}\text { Inorganic } \\ \text { Atmology (Meteorology) }\end{array} \\ \text { Hydrology ..... } \\ \begin{array}{l}\text { Oceanography (Oceanology) } \\ \text { Limnology } \\ \text { Potamology } \\ \text { Pyrogeology (Vulcanology) } \\ \text { Organic } \\ \text { Biology............ }\end{array}\end{array}\right.$

Since no direct study of the Centrosphere is possible, no corresponding science has been developed. (See, however, Chapter XXIII.)

Each branch or science may again be treated under the following headings: dynamics, structure, and history or genetics. Dynamical geology in the broadest sense deals with the physical and chemical forces and their working. In the narrow sense, dynamical geology is dynamical lithology, or the working of the physical and chemical forces in and upon the earth's crust. Dynamical biology is designated physiology. Hydrology and atmology (meteorology) are largely a treatment from the dynamic point of view of the water and the atmosphere, respectively, dealing especially with the movements of these. Volcanic manifestations illustrate the dynamics of the pyrosphere, or pyrodynamics, while earthquakes illustrate the dynamics of the centrosphere, or rather their effect upon the lithosphere. The interaction of the spheres upon one another must here be considered as developing the exogenous dynamic forces. Thus the action of the atmosphere, hydrosphere, biosphere, and pyrosphere upon the lithosphere furnishes the exogenous dynamic products which are manifested chiefly in the clastic rocks; while the endogenous dynamic forces reside within the material of the earth's crust, and are manifested in chemical combinations, in crystallization, etc.

From the point of view of structure, structural lithology (structural geology in the narrower sense) deals with the composition and arrangement of the material of the earth's crust, and comprises : I, elements; 2, minerals (mineralogy) ; 3 , rocks (petrology, petrography, lithology in the narrower sense); 4, large structural features (geotectology or the study of the architecture of the earth's crust) ; 5 , the surface features (lithomorphology, physical geography). Structural biology comprises the study of: I, the cell (cytology) ; 2, the tissues (histology) ; 3 , the larger structures (anatomy); 
4, the form (biomorphology). etc. Structural hydrology comprises the study of composition (hydrochemistry), classification according to form (hydromorphology), such as occans, lakes, rivers, etc., each of which has developed a special science to which are applied the names oceanography (oceanology. thalassography), the hydrology of oceans; limnology, the hydrology of the lakes; and potamology, or the hydrology of the rivers. Structural atmology or meteorology considers the composition of the atmosphere, its density, etc. The composition and structure of the Pyrosphere is only indirectly ascertainable, while those of the Centrosphere fall into the realm of speculation.

The historic or genetic aspect of these sciences likewise affords an interesting series of parallels. Thus historical or genetic lithology, or the science of lithogenesis in its broadest sense, deals with the origin not only of the rocks as such, but also of the structures they exhibit, and must necessarily take account of the conditions under which they were formed. The study of the genesis of the stratified rocks is stratigraphy, which, however, is closely bound up with the other branches of the earth science, and cannot be made independent of them. Historical biology or the science of biogenesis is the science of organic evolution. It may be considered from the botanical side (phytogenesis), or from the zoölogical side (zoögenesis), with reference to the individual (ontogenesis) or to the race (phylogcnesis). Palcontology, or the science of the past life of the earth, traces the phylogeny back through the successive geologic periods, and is, therefore, the complement of neobiology, or the science of modern life, and further demonstrates the intimate relationship between the organic and the inorganic sciences. Hydrogenesis, atmogenesis, and pyrogenesis are branches of historical geologic science as yet little developed.

While stratigraphy is thus more especially the science of the genesis of the stratified series of rocks, it necessarily includes and is based upon the study of the rocks themselves, of their arrangement or structures, and of the morphology of the earth's surface during their formation. Thus it comprises the subject of Palaogeography, or the geography of former times, and it furthermore takes careful account of the physical conditions of the land and sea as indicated by the organic remains entombed in the strata. Nor can it leave out of consideration the various diastrophic movements and their results, during all the geologic periods; while igneous activities, in so far as they affected the strata of the earth's crust, also belong to the field of legitimate inquiry for the stratigrapher. In other words, stratigraphy is the science of the evolution of the 
lithosphere since the formation of the Archean rocks. The following table gives the larger divisions of this evolutionary history:

Table of the Divisions of. Geological Time.

Psychozoic or Quaternary time.......... $\left\{\begin{array}{l}\text { Recent or Holocenic } \\ \text { Pleistocenic }\end{array}\right.$

Cenozoic or Tertiary time............ $\begin{aligned} & \text { Pliocenic } \\ & \text { Miocenic } \\ & \text { Oligocenic } \\ & \text { Eocenic }\end{aligned}$

Mesozoic or Secondary time........... $\begin{aligned} & \text { Cretacic } \\ & \text { Comanchic } \\ & \text { Jurassic } \\ & \text { Triassic }\end{aligned}$

Palæozoic or Transition time........... $\begin{aligned} & \text { Permic } \\ & \text { Carbonic } \\ & \text { Mississippic } \\ & \text { Devonic } \\ & \text { Siluric } \\ & \text { Ordovicic } \\ & \text { Cambric }\end{aligned}$

Proterozoic (Eozoic) or Primary time (in Keweenawic part) Algonkian................. Huronic

Azoic (Archæozoic) or Primary time (in part) \{ Keewatic

Archæan..................... Laurentic

\section{BIBLIOGRAPHY I.}

1. ARRHENIUS, SVANTE. 1900. Geol. Fören. Forhandl. Vol. XXIţ.

2. BARUS, CARL. 1891. The Contraction of Molten Rock. American Journal of Science, 3rd ser., Vol. XLII, pp. 498-499.

3. BARUS, CARL. 1892. The Relation of Melting to Pressure in Case of Igneous Rock Fusion. Ibid. Vol. XLIII, pp. 56-57.

4. CHAMBERIIN, THOMAS C., and SALISBURY, ROLLIN D. 1906. Geology, Vol. I.

5. CROSBY, WILliAM OTIS. 1892. Dynamical Geology and Petrography.

6. DAVIS, WILLIAM MORRIS. 1899. Elementary Meteorology.

7. FULLER, MYRON L. 1906. Water Supply and Irrigation Paper, No. 160 .

8. GREgORY, J. W. I9II. The Terms Denudation, Erosion, Corrosion, and Corrasion. Geographical Magazine, Feb. I9I I, pp. I89-I95.

9. GÜNTHER, SIEGMUND. r89r. Lehrbuch der Physicalischen Geographie. Stuttgart. 
ro. GÚNTHER, SIEGMUND. I897. Handbuch der Geophysik. 2nd edit. Stuttgart. 2 volumes.

II. HAUG, EMILE. 1907. Traité de Geologie. T. I.

12. HAYFORD, JOHN F. 1909. The Figure of the Earth and Isostasy (and Supplementary Investigation). U. S. Coast and Gcodetic Survey.

13. HAYFORD, JOHN F. 19II. Vice-presidential address before section D of A. A. A. S. The Relation of Isostasy to Geodesy, Geophysics, and Geology. Science, N. S., Vol. XXXIII, Feb. Io, pp. I99-208.

14. HELMERT, F. R. 1884. Theorien der höheren Gcodesic. Leipzig, Vol. II.

15. KEMP, JAMES FURMAN. 1901. The Rôle of the Igneous Rocks in the Formation of Veins. American Institute of Mining Engineers. Richmond Meeting.

I6. KING, CLARENCE. 1893. The Age of the Earth. American Journal of Science, 3rd ser., Vol. XLV, pp. I-20.

17. KRU்MMEL, OTTO. 1907. Handbuch der Ozeanographic. Band I, 2nd edit.

18. LYELL, CHARLES. I 875. Principles of Geology. Twelfth edition, Vol. II.

19. MILL, HUGH ROBERT. I890. The Vertical Relief of the Globe. Scottish Geographic Magazine. Vol. VI, pp. I82-187, with map.

20. MURRAY, JOHN. 1888. On the Height of the Land and the Depth of the Ocean. Scottish Geographic Magazine. Vol. IV, p. I et seg.

21. PENCK, ALBRECHT. I 894. Morphologie der Erdoberfläche, Vol. I.

22. PENCK, ALBRECHT. I908. Die Erdoberfläche in Scobel's Geographisches Handbuch.

23. PENCK, A., and SUPAN, A. I889. Mittheilung über Murray's "Die Mittlere Höhe des Landes und die Mittlere Tiefe des Meeres." Petermann's Mittheilungen, Bd. XXXV, pp. 17-21.

24. ROMIEUX, A. I89o. Relations entre la deformation actuelle de la croute terrestre et les densities moyennes des terres et des Mers. Comptes Rendus des Seances de 1' academie des Sciences. Paris, T. CXI.

25. SLICHTER, CHARLES S. 1902. Water Supply and Irrigation Paper, No. 67. U. S. G. S.

26. STAPFF, F. M. I894. Ueber die Zunahme der Dichtigkeit der Erde nach ihrem Innern. Gerland's Beiträge zur Geophysik, Vol. II.

27. SUESS, EDUARD. r888. Das Antlitz der Erde, Bd. II.

28. SUESS, EDUARD. 1906. The Face of the Earth, Vol. II.

29. TUMLIRZ, O. 1892. Die Dichte der Erde, berechnet aus der Schwerrebeschleunigung und der Abplattung. Sitzungsberichte K. Acad. d. Wiss. Wien. Math. Nat. Klasse. CI, Abh. IIa, pp. 1528-1536.

30. VAN HISE, CHARLES R. 1904. A Treatise on Metamorphism. United States Geological Survey, Monograph, Vol. XLVII.

31. WAGNER, HERMANN. I894. Areal und Mittlere Erhebung der Landflächen sowic der Erdkruste. In Gerland's Beiträge zu Geophysik Bd. II.

32. WATSON, THOMAS L. I9I I. Underground Temperatures. Science, N. S., Vol. XXXIII, pp. 828-83I.

33. WOODWARD, R. S. 1889. Mathematical Theories of the Earth. Proceedings of the American $\Lambda$ ssociation for the Advancement of Science, pp. 59-63; American Journal of Science, 3rd ser. Vol. XXXVIII, pp. 337 et seq.

34. WALTHER, JOHANNES. I893-4. Einleitung in die Geologie als historische Wissenschaft. 


\title{
A. THE ATMOSPHERE.
}

\author{
CHAPTER II.
}

\begin{abstract}
CONSTITUTION, PHYSICAL CHARACTERISTICS AND MOVEMENTS OF THE ATMOSPHERE; GEOLOGIC WORK OF THE ATMOSPHERE.
\end{abstract}

\section{- COMPOSITION OF THE. ATMOSPHERE.}

As already noted, the atmosphere consists of a mechanical mixture of oxygen and nitrogen with some argon, the proportion in pure dry air being:

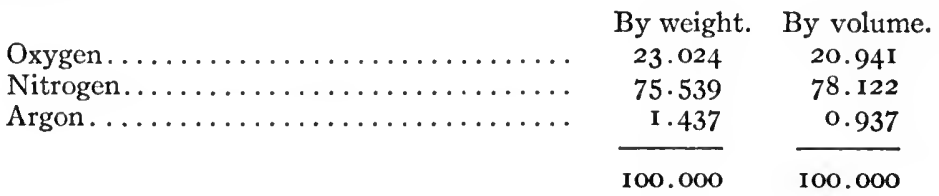

Air is always impure, water vapor and carbon dioxide, as well as various organic and inorganic impurities being generally present in variable quantities. The average volumetric composition of the gases of the atmosphere in parts per 10,000 is as follows $(29: 860)$ :

\begin{tabular}{|c|c|c|}
\hline & $2,065 \cdot 940$ & Ozone...... \\
\hline Nitrogen...... & $7,711.600$ & Aqueous vapor. \\
\hline Argon (about)... & 79.000 & Nitric acid...... \\
\hline Carbon dioxide...... & $3 \cdot 360$ & Ammonia............. \\
\hline
\end{tabular}

In addition to this there is often found free hydrogen, up to one part in 5,000 by volume (Gautier), methane, benzine and its homologues, etc. Other compounds are formaldehyde (2 to $6 \mathrm{gr}$. per IOO cu. meters), and sulphur compounds, especially $\mathrm{H}_{2} \mathrm{~S}$, which becomes oxidized to $\mathrm{SO}_{2}$. Sulphur dioxide is also derived from volcanoes and the combustion of coal, and has been found at Lille (France) to the extent of $1.8 \mathrm{cu} . \mathrm{cm}$. of $\mathrm{SO}_{2}$ in $\mathrm{I}$ cu. meter of air. It is returned to the ground as $\mathrm{H}_{2} \mathrm{SO}_{4}$ in rain water. So universally 
are water vapor and $\mathrm{CO}_{2}$ present, that we can speak of a triple atmosphere, one an intimate mixture of oxygen and nitrogen, and the other two of water vapor and $\mathrm{CO}_{2}$, respectively, diffused through the pure air atmosphere.

Nitrogen is the inactive element, though animals and plants appropriate it through the formation of nitrogenous compounds.

Oxygen, the active element of the atmosphere, is consumed by all animals and taken either directly from the air, or, in the case of water-living animals, from the water in which it is dissolved. Decaying organic matter consumes oxygen, and so do some minerals during the process of oxidation. Oxygen is supplied to the air by the growth of plant life, which breaks up $\mathrm{CO}_{2}$, using the carbon and setting part of the oxygen free. Volcanic vents also supply oxygen, while another source of supply is found in the deoxidation of minerals. Thus the quantity of oxygen withdrawn from the air is balanced by that supplied, so that the relative amount remains practically constant.

ARGon, first separated from the nitrogen of the air in 1895 , is like that element exceedingly inert, its power of combining with other elements being even less than that of nitrogen. It forms about 0.94 per cent. by volume, or $\mathbf{I} .44$ per cent. by weight, of the atmosphere. Other previously unknown gases in the atmosphere are: helium, I to 2 parts per million; neon, I to 2 parts per hundred thousand; krypton, I part in 20 millions; xenon, I part in I70 millions. These are as inert as argon.

Carbon Dioxide $\left(\mathrm{CO}_{2}\right)$. This is a relatively constant constituent of the air, making about 0.03 per cent. by volume, or three parts in Io,000 of the entire atmosphere. It is supplied to the atmosphere by the burning or decay of organic matter, by the respiration of animals, as well as by volcanic emanations and other agents. 'Artificial consumption of coal and other burnables furnishes a large supply of $\mathrm{CO}_{2}$ to the atmosphere, a ton of bituminous coal ( 75 per cent. of carbon) furnishing about $23 / 4$ tons of $\mathrm{CO}_{2}$ (Salisbury-83:515). Since the amount of $\mathrm{CO}_{2}$ in the air remains relatively constant, a quantity equal to that supplied [estimated at several billion tons a year (Salisbury)] must be removed from the air. The chief agents active in abstracting $\mathrm{CO}_{2}$ from the air are chlorophyll-forming plants, which, as already remarked, find in it the source of carbon for their tissues. Carbonization of mineral matter, or the combination of the $\mathrm{CO}_{2}$ with other elements, is another cause of the reduction of the amount of $\mathrm{CO}_{2}$ in the air.

WATER VAPOR. The water vapor of the atmosphere varies with temperature and other local conditions, and with the amount sup- 
plied. It is precipitated in the form of dew, rain, snow, frost, etc., and is constantly returned to the atmosphere by evaporation. In damp countries near the equator the amount of water vapor in the air may be 3 or even 4 per cent. by volume of the whole air. Thus at Batavia (Java), where the vapor pressure is $21 \mathrm{~mm}$., the amount of water in the air is 2.8 per cent. by volume. The composition of the air here is: $\mathrm{N} 76.8 \%, \mathrm{O} 20.4 \%, \mathrm{H}_{2} \mathrm{O} 2.8 \%$ and a few hundredths of a per cent. of $\mathrm{CO}_{2}$. At Allahabad (Persia) during the rainy season, 4 per cent. of water vapor by volume has been found in the air (calculated from the vapor pressure, which was $30.7 \mathrm{~mm}$.). In central Europe, even in summer, with a vapor pressure of about Io mm., the volume of water in the air amounts to only I.3 per cent. (Hann-40:74.)

Absolute and Relative Humidity. Expressed in weight of water, the amount which one cubic foot of air can hold is as follows: one-half grain of water at $0^{\circ} \mathrm{F}$., 5 grains at $60^{\circ} \mathrm{F}$., and II grains at $80^{\circ} \mathrm{F}$. At $60^{\circ}$ the amount which the air of a room $40 \times 40 \times$ I 5 $\mathrm{ft}$. can hold is nearly 20 pounds, or almost enough to fill a common water pail. The amount of moisture which the air contains is its absolute humidity. The percentage of moisture which the air contains at a given temperature, of that which it would contain at that temperature if it were saturated, is its relative humidity, which is $5^{0}$ when the air contains only half the amount which it could contain at saturation at that temperature. In the latter state the humidity is Ioo. The average relative humidity of the air on the land is perhaps 60 per cent., and over the ocean about 85 per cent. Below 65 per cent. the air becomes dry. In semiarid regions it ranges around 45 per cent., and in desert regions it ranges around 25 or 30 per cent.

At Ghadames (Hann-40:I5I), western Tripoli, the relative humidity for July is 27 per cent. and for August 33 per cent. The oasis of Kufra, in the heart of the Libyan desert, has a relative humidity of 27 per cent. in August, 33 per cent. in September, and 17 per cent. for the 3 P.M. August mean. The oasis of Kauar, in the heart of the Sahara, has a mean relative humidity of 27 per cent. in August. In the Punjab district of India, the relative mean humidity in May is $3 \mathrm{I}$ per cent. at Lahore, while at Agra, in the northwest province, it is 36 per cent. It must, of course, be borne in mind that the observations made in the inhabitable portions of the desert regions, $i$. $c_{\text {., }}$, the oases, give a much higher relative humidity than occurs in the open desert itself.

In the semiarid regions of southwestern United States, the following humidities occur: 


\begin{tabular}{|c|c|c|c|}
\hline Place & $\begin{array}{l}\text { Mean } \\
\text { annual } \\
\text { relative } \\
\text { humidity }\end{array}$ & $\begin{array}{l}\text { Mean } \\
\text { monthly } \\
\text { minimum } \\
\text { humidity }\end{array}$ & Month \\
\hline 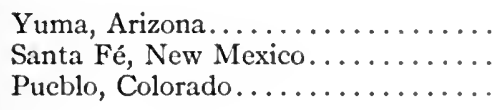 & $\begin{array}{l}42.9 \% \\
44.8 \% \\
46.2 \%\end{array}$ & $\begin{array}{l}34.7 \% \\
28.7 \% \\
37.6 \%\end{array}$ & $\begin{array}{l}\text { June } \\
\text { June } \\
\text { April }\end{array}$ \\
\hline
\end{tabular}

Death Valley, California, a typical American desert, showed a mean relative humidity of 23 per cent. for the five months from May to September in 1891 . In regions of summer rain the relative humidity is high, even far inland. Thus at Dorpat, Baltic Provinces of Russia, the mean relative humidity in summer is 73 per cent.; at Yeniseisk, Central Siberia, it is 70 per cent.

Source of Water Vapor. Evaporation is the chief source of the water vapor of the air. All exposed moist surfaces furnish water vapor to the atmosphere, the conversion of water into vapor constituting evaporation. Evaporation is, of course, most marked over large water surfaces, such as the oceans, the ultimate source of the water vapor, and over lakes, ponds, etc. It is estimated that the average amount of evaporation from the surface of the earth amounts to a layer 30 or 40 inches deep each year. (Some estimates make it 60 inches.) At this rate, if the water were not returned to the sea, the oceans would be dried up in from 3,000 to 4,000 years, while the lakes of the earth would probably be exhausted in a single year. The water evaporation from the surface of the Mediterranean and Black Seas is estimated as more than 226 cubic miles per annum. Evaporation may be going on from an approximately dry land surface, the moisture being drawn from beneath the surface. By such processes mineral matter held in solution within the pores of the rock is drawn to the surface, and there left on evaporation. Such is the origin of the brown desert varnish on rock surfaces, and the efflorescence of salt and alum found on many rocks. Snow and ice also evaporate, at a temperature below the melting point, for snow and ice slowly disappear, even in temperatures below $32^{\circ} \mathrm{F}$.

Other sources of water vapor are animal and plant respiration, and volcanic ejections, the latter often adding an appreciable amount.

ImpURities. The impurities of the atmosphere are in large part inorganic particles or dust. Organic matter, such as spores of plants, bacteria, etc., also abounds, but the dust is by far the most 
prevalent. In dust storms the amount is, of course, extreme, but ordinary air sometimes carries a surprising amount. Thus, in England, during the fogs of February, I89I, the amount of dust deposited on the previously washed glass roofs of the plant house at Kew was 30 grams to 20 square yards, while at Chelsea 40 grams were deposited over the same area. This represents 22 pounds to the acre, or six tons to the square mile. Of this amount, unconsumed carbon (soot) formed 42.5 and 39 per cent., respectively, and 41.5 and 33.5 per cent. was other mineral matter, including some metallic iron. (Hann-40:77; Russell-8I.)

\section{OPTICAL CHARACTERS OF THE ATMOSPHERE.}

Light. The three chief effects produced by the energy of the sun's rays are optical, thermal, and chemical. We may thus speak of light rays, heat rays, and chemical or actinic rays, bearing in mind that the difference of effect does not lie in the differences of the rays, but in the nature of the surface on which they fall.

The rays of the most importance to vegetal life are the luminous or light rays, $i$. e., the components of radiation near the red end of the visible spectrum, rather than at the blue and violet end. Experiments with monochromatic light on Mimosa pudica have shown that the plant thrives best in red light and least in blue. "The red and the yellow rays are the most active in promoting the respiration and the transpiration of the leaves and the assimilation of carbonic acid." (C. Flammarion, quoted by Hann-40:36.)

Diffusion of daylight. The sunlight on penetrating our atmosphere is scattered or diffused by the partictes of dust in the air, and thus the illumination of the whole atmosphere on the sunny side of the earth is produced. If it were not for the dust, it is probable that the sky would be black, the stars visible by day, and darkness prevail in all shady places, while those exposed to the sun would be illumined with dazzling brilliancy. The color of the sky and the sunset and sunrise tints are largely due to the presence of the dust. The very brilliant sunset effects of the autumn and winter of 1883 were due to the large amount of volcanic dust in all parts of the upper air, derived from the explosion of the volcano Krakatoa (between Sumatra and Java) from May to August, I883. (See the illustrations in Hann (39), opposite page 30.)

Diffused sunlight is of the greatest importance to plant life. It is the diffused light which pours over all portions of the plant equally, which benefits the plant as a whole by benefiting all its parts. 
Plants need less light as the temperature rises, and more as it falls.

\section{TEMPERATURE OF THE ATMOSPHERE.}

The chief source of atmospheric heat is the sun, while of much less significance is the internal heat of the earth. Other local causes, such as friction in landslides, etc., volcanic activities, fires, organic decay, etc., and movements of the atmosphere itself, locally warm the air, but these are generally of almost negligible significance.

The amount of heat received by the earth from the sun each year would, if equally distributed, melt a layer of ice about $\mathrm{I}_{4} \mathrm{I}$ feet thick over the entire surface of the earth, or evaporate a layer of water 18 feet deep; yet the amount received is less than I/2,000,000,000 of the heat given off by the sun. The space outside of our atmosphere is believed to have a temperature of $-273^{\circ} \mathrm{C}$. $\left(-459^{\circ} \mathrm{F}.\right)$, which would be the winter temperature (coldest month) of the polar regions of the earth if there were no atmosphere. The winter temperature of the equator would be about $+56^{\circ} \mathrm{C}$. $\left(+164.8^{\circ} \mathrm{F}.\right)$. The estimated summer temperature at the poles under the same condition would be $+82^{\circ} \mathrm{C}$. $\left(+2 \mathrm{I}\right.$ I. $6^{\circ} \mathrm{F}$.), while that at the equator at the same time would be only $+67^{\circ} \mathrm{C}$. $(+184.6 \mathrm{~F}$.), since the polar regions, owing to their continuous day in summer, would receive a greater amount of total heat. The minimum observed temperature is $-60^{\circ} \mathrm{C}$. and the maximum $+80^{\circ} \mathrm{C}$. The chief agents in retaining the sun's heat within the earth's atmosphere are the carbon dioxide and the water vapor, which act as thermal blankets. It has been estimated by Arrhenius (2) that if the amount of $\mathrm{CO}_{2}$ in the atmosphere were increased 2.5 to 3 times its present value, the temperature in the arctic regions must rise $8^{\circ}$ to $9^{\circ} \mathrm{C}$. and produce a clinate as mild as that of Eocenic time, so that magnolias would again grow in Greenland. On the other hand, if the $\mathrm{CO}_{2}$ were decreased to an amount ranging from 0.62 to 0.55 of its present value, a fall of from $4^{\circ}$ to $5^{\circ} \mathrm{C}$. would result and glacial conditions would again overspread the northern parts of the continents. These estimates have been seriously questioned, but the general fact that both $\mathrm{CO}_{2}$ and water vapor act as thermal blankets is established. Chamberlin $\left(1_{3}, 1_{4}, 1_{5}\right)$ has discussed in detail the bearing of these facts on former continental glaciation, his argument being that the abstraction of the $\mathrm{CO}_{2}$ from the atmosphere cluring the periods of extensive vegetal growth, $i$. e., the periods of coal formation, tended 
to refrigerate the climate. The amount of $\mathrm{CO}_{2}$ taken from the air in the known geologic periods and locked up in the coals and limestones of the earth has been variously estimated at from 20,000 to 200,000 times the present atmospheric content, or even more. Another factor favoring the consumption of $\mathrm{CO}_{2}$ is the extensive subterranean decomposition of the rocks following a period of elevation with its attendant fissuring of the rock and the deepening of the zone of circulation of surface waters. These, supplied with $\mathrm{CO}_{2}$ at the surface, are active in the carbonation of the decomposing rocks. "The solution of limestones and other carbonates is a further source of abstraction of $\mathrm{CO}_{2}$ from the atmosphere, since the original monocarbonates are changed to bicarbonates in the process of solution, the second molecule of $\mathrm{CO}_{2}$ being derived from the atmosphere. This is, however, a temporary abstraction, for on the redeposition of the limestone, either by chemical or organic agencies, the second molecule of $\mathrm{CO}_{2}$ is set free again. Hence periods of extensive limestone deposition must be periods of extensive supply of $\mathrm{CO}_{2}$ to the atmosphere, and this would have the effect of ameliorating the climate. It is important to note that extensive coal formation is dependent on the great expanse of land areas, while extensive limestone formation depends on the expanse of the sea. Extension of the land is accompanied further by an extension of the deep-seated circulation, and by decomposition and carbonation of the crystalline rocks, as well as by periods of solution of the carbonates. The two periods of great land expansion, followed by well-authenticated glacial periods, are the close of the Palæozoic and that of the Cenozoic. Other periods are the pre-Cambric, the close of the Siluric and the opening of the Devonic, the close of the Jurassic and opening of the Comanchic, and the end of the Cretacic. Periods of marine extension, on the other hand, with the formation of much limestone and the accompanying setting free of $\mathrm{CO}_{2}$, were the middle and early upper Ordovicic, the early Siluric (Niagaran), the Mississippic, the upper Jurassic, the mid-Cretacic, and in some regions the Eocenic and Oligucenic. Much evidence exists that these periods of extensive limestone formation were periods of mild and equable climates, very nearly uniform for all latitudes.

Distribution of Heat Within the Earth's Atmosphere. The sun's heat is distributed through the atmosphere by radiation, conduction, and convection. The heat which the earth receives from the sun is returned to the atmosphere by radiation. These non-luminous heat waves are much more readily absorbed by the air than the luminous ones which reach it from the sun. The atmosphere in contact with the land is further heated by conduction, provided the surface of the 
land is warmer than the air, and this warmer air will be distributed by the setting in of convection currents. The heated air expands and rises, while the heavier, colder air from above sinks down to take the place of that which has risen, pushing upward and outward, at the same time, the lighter air which still remains. Vertical and horizontal convection currents thus come into existence, and distribute the heated air in the atmospherc. The surface of the land is heated four or five times as fast as the surface of the water, due partly to the greater specific heat of the latter, the more ready absorption of heat by the land and its reflection by the water. The land radiates its heat more readily than the water, in which convection currents tend to distribute it, while at the same time the heat of the sun's rays penetrates more deeply into it than into the land, and a given amount of heat is distributed through a thicker layer of water than of land. All this shows that the temperature of the air over the land is heated more highly than that over the water, and conversely it is cooled more quickly than that over the water. Hence continental climates show greater annual extremes than those of the sea. As an example, two points in $62^{\circ} \mathrm{N}$. latitude are given, one at Thorshaven on the Faroe Islands, where the mean annual range is $7.9^{\circ} \mathrm{C}$. $\left(+3.0^{\circ} \mathrm{C}\right.$. in March, $+10.9^{\circ} \mathrm{C}$. in July) the other at Yakutsk, Siberia, where the range is $61.6^{\circ}\left(-42.8^{\circ} \mathrm{C}\right.$. in January, $+18.8^{\circ} \mathrm{C}$. in July).

Geological Work of Heat and Cold-Changes in Temperature.

This may be grouped under the heads of (a) insolation, or the exposure to the influence of the sun's rays by day; (b) radiation, or the loss of heat at night through cooling; and (c) congelation, or the work of frost.

Insolation and Radiation. Heating in general causes expansion of rock masses and decreasing density, while cooling causes contraction and an increase of density. Even water follows this rule down to a temperature of $+4^{\circ} \mathrm{C}$, when it reaches its maximum density, after which it expands. Naked rock surfaces may be highly heated by exposure to the sun during the day, especially in the rarefied air of high altitudes. This heating will affect the outer part only, owing to the poor conductivity of rock, and the resulting expansion will cause a surface layer to scale off from the cooler, less expanded mass below. On cooling at night, the outer layer loses its heat most rapidly, and the accompanying contraction causes the rock to break. Where changes of temperature are great and regular, as on exposed mountain summits, the surface may be characterized by scaling-off 
layers, as in Mt. Starr-King, California, or Mt. Monadnock, New Hampshire; or by breaking off of fragments of all sizes, which cover the mountain top to the frequent exclusion of solid ledges, as on Pike's Peak, Colorado; Mt. Adams, New Hampshire; Sugar Loaf Mountain, Brazil; Ben Nevis, Scotland; and most mountain summits. Such fragments, supplemented by those broken off by frost action, accumulate at the foot of every cliff and on every steep slope, forming the talus, the surface angle of which varies with the coarseness of the material. (See Chapter XIII.)

The best illustration of such disruption of rocks is seen in desert regions, where changes of temperature are very great. Livingston has described the disruption, with ringing sound, of the basalt masses in South Africa. Other examples are cited from Brazil and the Atacama desert of Chile, where the temperature in winter ranges from $-\mathrm{I} 2^{\circ} \mathrm{C}$. at $7 \mathrm{A.M}$. to $+37^{\circ} \mathrm{C}$. at I I A.M., and the summer temperature from $+5^{\circ} \mathrm{C}$. to $+55^{\circ} \mathrm{C}$. From tropical west Africa Pechuel-Loesche has recorded temperature ranges of $60^{\circ}$ to $84^{\circ} \mathrm{C}$. (Walther-I04:28 et seq.; also I03:556-557 and literature there cited.) Walther has found this shattering of rocks through insolation in limestone, flint, sandstone, porphyry, granite, gneiss, quartz, and other rocks. The crack penetrates gradually into the depths of the rock, so that half-broken pebbles are not infrequently found. Such cracks are visible in rocks of all sizes, from fragments as large as a nut to blocks of the dimensions of a house. In limestone and granites, Walther often found peripheral cracks which permitted the separation of concentric shells, varying in thickness from that of a sheet of paper in some limestones to shells $10 \mathrm{~cm}$. thick in some granites. In Brazil the range of temperature is considerably more than $100^{\circ} \mathrm{F}$., while in the northern United States it is $150^{\circ} \mathrm{F}$. $\left(-30^{\circ}\right.$ to $\left.+125^{\circ}\right)$ in half a year, with a diurnal variation often amounting to half that. (Shaler.)

Changes of temperature in like manner affect the individual mineral constituents of the rock, as well as their association in the rock. Since each mineral has its normal coefficient of expansion and contraction under a given influence of heat or cold, it follows that irregular stresses and strains are set up within a rock mass of relatively coarse-grained minerals such as a granite, and that this must lead to a slipping back and forth of the minerals upon each other with ultimate disruption or disintegration of the mass as a whole. Walther regards the difference of color of these mincrals as of especial significance ( $103: 556$ ), and Branner (Io) has also called attention to the fact that coarse texture likewise favors this type of disintegration. This is well shown in coarse granites of sub-arid 
regions such as Pike's Peak, the granite countries along the Colorado River in Arizona, the peaks of Mount Sinai, and many other mountain tops where taluses or screes of crystalline sand, made up of dissociated minerals of the granite, characterize the exposed mountain sides and fill up all the hollows. The feldspar of this sand is generally fresh and unclouded, the original crystals being scarcely altered. Such sands, reconsolidated with little assortment. give rise to peculiar arkoses in which the fresh feldspar crystals form the most striking feature, and may even cause the rock to be at first mistaken for an unaltered granite. Examples of this kind are found in certain parts of the Torridon sandstone (pre-Cambric) of the west of Scotland, and in other rocks. Granite bosses, wherever exposed, are generally marked by rounded surfaces, intersected perhaps by joint cracks into which the disintegration products have been washed, and which alone support vegetation, the granite surface being bare. Granite boulders exposed to the same forces will crumble into heaps of crystalline sand. Since the corners and angles of rock fragments are their most exposed portions, the first being attacked from three sides, it follows that disintegrating blocks will soon assume a rounded outline. Concentric exfoliation of the disintegrated outer portions of such rock masses is observable, the rock becoming a boulder formed in situ and often embedded in a mass of disintegrated and partly decomposed residual sand and soil. Branner, discussing the effect of these temperature changes on the rocks of Brazil, remarks: "The unequal contraction and expansion of the minerals composing the rock tend to disintegrate the entire mass, while the even annual and diurnal changes and the approximately even penetration of these clinges cause the rock to exfoliate or to spall off in layers of even thickness, like the coats of an onion, while the crevices opened in the rocks admit acids and gases and set up a train of reactions that sooner or later disinte-. grate and decompose the entire rock mass." (I0:28I.)

The individual minerals themselves may likewise be affected by this change in temperature, since there is differential expansion along the different crystal axes. A cleavable mineral like feldspar may thus become potentially shattered, innumerable fine rifts forming along the cleavage planes, which, though insufficient to cause the mineral to crumble, yet admit air and moisture and permit chemical decomposition within the crystal. In moist climates this is seen in the clouding of a feldspar crystal along the fine cleavage lines as seen in a thin section uncler the nuicroscope.

Disintegration, as here described, is always associated with a greater or less anount of chemical alteration, such as oxidation. 
hydration, etc., according to the state of the atmosphere. Where little moisture exists in the air, as in arid regions, the chief process by which the destruction of rock masses is effected is disintegration, supplemented, of course, by the mechanical work of the wind.

Branner (10:28I) has observed that the mica of Brazilian gneisses is an element of weakness, tending, both on account of its low conductivity and its form, to develop crevices along which the rocks exfoliate more readily.

Frost Work. Water, on freezing, expands one-tenth of its volume, and so becomes a powerful agent in destroying rock masses. The expansion of water in fissures on freezing is capable of prying off huge masses of rock, and in some cases much of the talus at the foot of the cliff is to be referred to frost action. Rock surfaces may by radiation cool below the freezing point $\left(0^{\circ} \mathrm{C}\right.$. or $32^{\circ} \mathrm{F}$.), so that moisture coming in contact with them freezes at once. This is often seen in high altitudes where moisture-laden winds strike a cold rock wall or cairn, with the result that the moisture is precipitated as ice. An interesting case of freezing in contact with cold rocks has been observed on the coast of Newfoundland, where the limestone cools more rapidly at the beginning of the winter than the seawater, which penetrates all the fissures at high tide, freezing there in contact with the cold rock and shattering the mass during the retreat of the tide. The constant repetition of this phenomenon results in covering the beach with freshly broken,-angular fragments. (Thoulet, Walther-I03:559.)

The creep of the soil on sloping surfaces has also been referred to frost action, the water in the soil freezing and converting the mass into an "earth glacier" (Kerr-54:345). The creeping downhill of this mass results in the bending over of the ends of the vertical or steeply inclined strata.

\section{CHEMICAL WORK OF THE ATMOSPHERE.}

The chemical activities of the atmosphere penetrate the upper layers of the lithosphere to the level of the ground water. This averages perhaps from 30 to 50 meters below the surface, though in many regions it is at the surface, while again, in arid regions it may be so much as I,Ooo meters or more beneath the surface. The belt thus produced, between the average level of the ground water and the surface, is the belt of demorphism, or in general the Belt of Weathcring. It is here that the chemical work of the atmosphere is most marked in destroying the rocks, this work consisting, so far 
as the atmosphere is concerned, in oxidation, hydration, and carbonation. Solution, which also goes on actively here, is to be regarded as the work of the ground water, rather than that of atmospheric moisture. The two agents are, however, so intimately related that it is impossible to draw a sharp line between them and their respective accomplishments.

Carbonation of silicates is on the whole the most characteristic reaction. This takes place on a vast scale, producing carbonates from the silicates, and setting free, thereby, silica or colloidal silicic acid. Hydration is the most extensive single reaction in this belt, while oxidation is very pronounced, owing to the free access of oxygen to the pores, from the absence of water. Solution removes many of the products of decomposition from this belt of weathering. and carries it away over ground or under ground. As a result of this, the volume of rock in the belt of weathering becomes greatly reduced, the resultant material in the end occupying only a small fraction of the volume it once had.

Oxidation. "The oxygen is chiefly utilized in the oxidation of iron, surphur, and organic material. In the upper part of the belt [of weathering], where oxygen is abundant, large amounts of hematite and limonite may be produced by the oxidation of the ferrous particles, but for the greater part of the belt of cementation, where oxygen is somewhat deficient, the ferrous oxide is oxidized only to the form of magnetite, since this requires, per unit of iron, only twothirds as much oxygen as to produce hematite and limonite." (Van Hise-100:606.) Magnetite may be directly oxidized into hematite, involving an increase in volume of 2.5 per cent. Hydration may occur simultaneously, changing the mineral to limonite with a corresponding increase in volume of 64 per cent. Iron carbonates are oxidized to ferric oxide, with a corresponding decrease in volume, owing to loss of $\mathrm{CO}_{2}$. This is 49 per cent., if hematite is the result, but only 18 per cent., if the carbonate is changed to limonite. Sulphides are oxidized to sulphites and sulphates. Sulphurous and sulphuric acids are formed, which may enter into various combinations. Sulphuretted hydrogen is a common result of the oxidation of iron pyrites, and, from the further oxidation of this, pure sulphur may be precipitated.

Some of the changes occurring may be expressed in the following formula (for others see Van Hise-100:21.7): $\mathrm{FeS}_{2}+6 \mathrm{O}=$ $\mathrm{FeSO}_{4}+\mathrm{SO}_{2}$. If the water is present, we may have:

$$
\mathrm{FeS}_{2}+3 \mathrm{O}+\mathrm{H}_{2} \mathrm{O}=\mathrm{FeSO}_{4}+\mathrm{H}_{2} \mathrm{~S} \text {. }
$$

The ferrous sulphate may be removed in solution or may fur- 
ther be oxidized into hydrated sesquioxide of iron or limonite and sulphuric acid, thus:

$$
{ }_{4} \mathrm{FeSO}_{4}+2 \mathrm{O}+7 \mathrm{H}_{2} \mathrm{O}=2 \mathrm{Fe}_{2} \mathrm{O}_{3}+3 \mathrm{H}_{2} \mathrm{O}+{ }_{4} \mathrm{H}_{2} \mathrm{SO}_{4} .
$$

In each of these reactions heat is liberated. Where $\mathrm{H}_{2} \mathrm{~S}$ is liberated, this may be further oxidized, especially in the presence of bacteria, and sulphur may result thus: $\mathrm{H}_{2} \mathrm{~S}+\mathrm{O}=\mathrm{H}_{2} \mathrm{O}+\mathrm{S}$. The sulphur may later be oxidized to sulphuric acid.

The cllange from sulphides to oxides without hydration involves a diminution in volume. A change to magnetite means a decrease in volume of 24 to 39 per cent., oxidation and hydration of pyrite, however, result in a total increase in volume of 3 per cent., while the increase in the case of pyrrliotite is 25 per cent.

Red and Yellow Colors of Soil Due to Oridation. Within the zone of active rock weathering, the iron compounds are transformed to ferric oxide or hydrate, if the amount of oxygen is sufficient. These iron compounds will impart their characteristic color to the soil, which will be yellow or red, according to the simultaneous occurrence or non-occurrence of hydration. Dehydration of ferric hydrates may likewise change the color of yellow soil to red, as is shown in brick-making, when the yellow clay on burning changes to a red brick. Crosby has attributed the contrast of the color of soils of high and low latitudes to the process of dehydration of the latter, partly due to the greater heat of the southern latitudes and partly to the greater age of the products of decomposition. He calls attention to the fact that the red color is mostly a superficial feature, varying usually from two to five feet in clepth, and rarely exceeding ten feet. The color is "usually reddest at, or near, the surface, changing downward gradually, more rarely airuptly, through various shades of orange to yellow; while occasional complete sections show the yellow changing through paler tints to gray or the color of the underlying hard rocks." (Crosby-20:77.) Russell has shown that the grains of the rock are encrusted by a ferruginous clay which contains both ferric oxide and alumina.

In Nicaragua, east of the continental divide, the red color is from 3 to Io meters deep. (Hayes-45:I28, I29.) The abundant vegetation lrere causes a transpiration of the moisture so that the soil is not saturated with water. On the western side of Nicaragua the color of the clay soil is blue, the iron being in the ferrous form. Here dry seasons alternate with wet ones, and the deeply cracked soil of the dry season is filled with the remains of vegetation, which thus become a powerful reducing agent within the zone of weathering. 
The red color of desert sands has frequently been remarked upon. It is che to a coating of iron oxicle over the rounded quartz grains. Phillips $(76)$ has determined the total amount of iron oxide of the coating of the sands in the Nefud desert of Arabia to be $0.2 \mathrm{I}$ per cent., while the sand itself, after the solution of the coating, still contained 0.28 per cent. of iron oxide, o.88 per cent. of clay and 98.53 per cent. of silica. Walther holds that the iron of the crust was also originally in the sand and has found its way to the surface of the grain under the intense heating of these grains from exposure to the sun. Similar conditions are rather widespread within the arid belt of the earth, and such coating of quartz sand grains may be considered as typical of desert sands, whether of recent origin or preserved in older formations.

Oxidation of Organic Compounds. (Van Hise-100:46I.) In the presence of water and bacteria, cellulose and other organic substances are oxidized with the production of a number of organic acicls, such as humic, ulmic, crenic, etc. (See Chapter IV.) Further oxidation of these acids results in the production of carbon dioxide and water. The artificial oxidation of carbon in the form of coal and other combustibles has become a factor of great importance. It is estimated that at the present time $1,000,000,000$ metric tons of coal are oxidized each year, and this, with an average of 80 per cent. of carbon, would produce a total of 2,933.333,000 metric tons of $\mathrm{CO}_{2}$ to be passed into the atmosphere each year. This is 0.1233 per cent. of the total amount of $\mathrm{CO}_{2}$ at present in the atmosphere. Continuing this rate of consumption of coal for 812 years, the amount of $\mathrm{CO}_{2}$ in the atmosphere would be doubled. (Van Hise-100:464.) The oxidation of nitrogen to ammonium nitrites and nitrates takes place in the presence of water and with the aid of bacteria. It is most marked in the tropics, where the nitrates of the soil sometimes amount to .30 per cent. of the mass.

Hydration. The chemical union of water with minerals is hydration, and the results are hydroxides. So far as hydration of minerals by atmospheric moisture is concerned, the process is a superficial one, but within the belt of weathering of the lithosphere it is a very extensive process due to the percolation of the ground water. It will be further considered under that heading. A comparatively low temperature favors hyclration of minerals, a temperature above $110^{\circ} \mathrm{C}$. at ordinary conditions of pressure will stay the process or even reverse it, dehydration being the result.

Kaolinization. The ordinary effect of the atmospheric moisture on the rocks is the attack upon the feldspars producing kaolin 
or clay. This commonly takes place in the presence of $\mathrm{CO}_{2}$, the formula for the alteration of orthoclase into kaolin and quartz being (Van Hise-100:389):

$$
2 \mathrm{KAlSi}_{3} \mathrm{O}_{8}+2 \mathrm{H}_{2} \mathrm{O}+\mathrm{CO}_{2}=\mathrm{H}_{4} \mathrm{Al}_{2} \mathrm{Si}_{2} \mathrm{O}_{9}+4 \mathrm{SiO}_{2}+\mathrm{K}_{2} \mathrm{CO}_{3} \text {. }
$$

The change to kaolin is accompanied by a volume decrease of 54.44 per cent.; the change to kaolin and quartz, as in the above reaction, by a decrease of 12.57 per cent. The change by hydration of hematite to limonite is accompanied by an increase in volume of 60.72 per cent., and may be expressed by the formula: $2 \mathrm{Fe}_{2} \mathrm{O}_{3}+{ }_{3} \mathrm{H}_{2} \mathrm{O}={ }_{2} \mathrm{Fe}_{2} \mathrm{O}_{3} \cdot 3 \mathrm{H}_{2} \mathrm{O}$. Hydration under the atmosphere often goes on so rapidly as to suggest slaking of quicklime. This has been observed by Merrill in the granitic rocks of the District of Columbia (66:188), and by Derby in the sedimentary rocks of railway cuttings in Brazil (Branner-6). In both cases the rocks exposed at the surface soon break into powder, although in fresh exposures they may be so strong as to require blasting.

Dehydration. The loss of combined water or dehydration is a phenomenon of regions of high temperature and low humidity. It probably occurs on the largest scale in regions of alternating wet and dry climate combined with high temperature. Such dehydration tends to change the limonite or göthite of the soil to hematite, with a corresponding change in color from ochery to red. Crosby, Dana, and Russell have attributed the red color of the soil of southern regions to this process of dehydration under the influence of high temperature and, to some extent, under that of age. Partial dehydration of such compounds as the zeolites, colloidal silicic acid, aluminum hydroxide, etc., may take place on a considerable scale in regions of high temperature and little moisture.

Carbonation. The atmosphere furnishes much of the $\mathrm{CO}_{2}$ which combines with the bases to form carbonates, either directly or indirectly through the mediation of plants. Like oxidation, it is thus a superficial phenomenon. As we have seen, the oxidation (decay) of the vegetable matter on the surface of the earth liberates much $\mathrm{CO}_{2}$, which may be taken up by the waters entering the soil and used for carbonation. The air, as already noted, contains about 3.4 parts by volume in Io,000 ( 4.5 by weight). Rain water contains from 0.22 to 0.45 per cent. (Merrill-66:I79) of the volume of the water or 0.00044 to 0.00089 per cent. by weight. In the pore spaces of soils much more $\mathrm{CO}_{2}$ exists, as shown by the following table by Boussingault and Lewy copied from Merrill $(66: 178)$ : 
$\mathrm{CO}_{2}$ in 10,000 parts

by weight.

Air from sandy subsoil in forest. ...........

38
I 24
I 30
I 46
270
543

Air from loamy subsoil in forest............

Air from surface soil of forest..............

Air from surface soil of vineyard............

Air from pasture soil...................

Air from soil rich in humus..............

543

The union which goes on continually of the $\mathrm{CO}_{2}$ with the minerals of the Belt of Weathering in the earth's crust is rather an accompaniment of the processes set going by the ground water, than a direct activity of the atmosphere. The use of $\mathrm{CO}_{2}$ in solution of limestones likewise belongs there. On liberation in the process of decarbonation, the $\mathrm{CO}_{2}$ commonly returns to the atmosphere.

Laterization. Laterite (Meigen-64; Clarke-17) is the product of rock decay in pluvial tropical regions, and is especially characterized by the high content of iron oxide. Its color is mostly a deep red, the iron being often so abundant as to form concretions of brown or red iron ore. The depth to which the lateritc extends may be very great, being over 300 feet in Brazil. Its areal extent is likewise great; thus, according to the estimates of von Tillo, it covers $49 \%$ of the surface of Africa, $16 \%$ of Asia and $43 \%$ of South America.

Typical laterite is characterized by the formation, during the process of decomposition, of a considerable amount of lydrous oxide of aluminum, chiefly in the form of Hydrargillite $\left(\mathrm{Al}_{2} \mathrm{O}_{3} \cdot 3 \mathrm{H}_{2} \mathrm{O}\right)$, whereas the ordinary products of rock decay in moist temperate climates are the hydrous silicates of aluminum. kaolinite $\left(\mathrm{H}_{4} \mathrm{Al}_{\mathbf{2}^{-}}\right.$ $\left.\mathrm{Si}_{2} \mathrm{O}_{9}\right)$, or its ferric equivalent, nontronite $\left(\mathrm{H}_{4} \mathrm{Fe}_{2} \mathrm{Si}_{2} \mathrm{O}_{9}\right)$. Often the laterite still shows the form or structure of the gneisses or other crystalline rocks from which it is derived.

The diminution or total disappearance of the silicic acid in combination with bases is one of the characteristic features of laterization. Thus the laterization of a dolerite near Bombay, India, involves a loss of $\mathrm{SiO}_{2}$ from $50.4 \%$ in the fresh to $0.7 \%$ in the weathered, while at the same time there is a proportional increase in the $\mathrm{Al}_{2} \mathrm{O}_{3}$ from $22.2 \%$ in the fresh to $50.5 \%$ in the weathered rock, and an increase in $\mathrm{Fe}_{2} \mathrm{O}_{3}$ from $9.9 \%$ to $23.4 \%$. In the kaolinization of an English dolerite in South Staffordshire, the change from the fresh to the altered rock includes a change in $\mathrm{SiO}_{2}$ from $49.3 \%$ to $47.0 \%$, in $\mathrm{Al}_{2} \mathrm{O}_{3}$ from $17.4 \%$ to $18.5 \%$, of $\mathrm{Fe}_{2} \mathrm{O}_{3}$ from $2.7 \%(+8.3 \% \mathrm{FeO})$ to $14.6 \%$, and so forth. Laterizatio: 
must be regarded as a further step in the decomposition of rocks, the silica being separated out and deposited elsewhere as agate or chalcedony. The alkalies likewise are carried away and the separation and redeposition of the iron, if present, also take place at an. carly moment.

While in the temperate climates the abundance of humus brings about the reactions which result in the kaolinization of the feldspars, the absence of this humus tends to subject the feldspars to the attack of non-acidulated waters, which under the influence of tropical heat produce a hydrolytic separation of the silicates with the formation of aluminum hydrate and alkali silicate, which separates further into alkali hydroxide and free silica.

\section{Influence of Temperature on Rock Decomposition.}

The influence of temperature on the decomposition of rocks is well shown by the fact that beneath the ever-moist moss cushions of Finland and the northern Urals, the granite shows undecomposed surfaces, solution being the only process active here. (von Richthofen-78:98.) This is due to the prevailing high degree of cold. The same thing is seen on the Kerguelen and the Crozet islands in the South Indian Ocean, where the cold humid climate has produced but little soil, whereas in tropical regions, as in the Samoan Islands, a deep brilliant red soil, the terra rossa, is produced. The soil of the Samoan Islands is deep and rich and is produced by the decomposition of a basaltic rock similar to that of the Kerguelen Islands, which there, however, is unaffected. (Russell-8o.)

\section{MOVEMENTS OF THE ATMOSPHERE.}

WINDS. The movements of the atmosphere are inaugurated by the inequalities in atmospheric pressure and are controlled to a large extent by the rotation of the earth. The normal atmospheric pressure at sea-level, or one atmosphere, is sufficient to balance the weight of a column of mercury in the barometer 30 inches, or 760 millimeters, high. As the pressure decreases the mercury falls, as it increases the mercury rises. At an elevation of 5,9ro feet above sealevel the mercury stands at 24 inches, at 10,550 feet at 20 inches, and at 16,000 feet above sea-level it stands at 16 inches. (Davis26: I3.) When air is heated it expands and so becomes lighter, and the same is true when air becomes saturated with moisture. Though temperature and humidity are causes of varying pressure, high temperature and high humidity, producing areas of low pressure, and conversely low temperature and humidity, producing areas 
of high pressure, the distribution of these over the earth's surface depends on a variety of factors, and is not coincident with regions of corresponding temperature and humidity. Areas of high pressure may also be produced by the crowding of warm rising air against the cooler upper layers, as is the case in the higher atmosphere of the equatorial belt.

IsOBARS. If the points of equal atmospheric pressure, due to unequal heating, at a given time were united into a series of continuous surfaces, they would form a series of superposed planes warped and dented into domes and ridges, and basins and troughs, in a more or less conformable manner. So far as the layers are afirected by the heating, those representing the highest pressure would lie below, and the successive surfaces upward would represent a regularly decreasing pressure. The elevations in these surfaces cover the areas of high pressure on the earth's surface, and these elevations, when localized, would be dome-like. The depressions similarly cover the areas of low pressure. Since pressures both higher and lower than 30 ( 30 inches of mercury) are found at sea-level, this surface must be regarded as a horizontal plane cutting the warped isobaric surfaces. The resulting lines of intersection are the isobars, and it will be observed that, where the sea-level cuts a local area of low pressure, $i$. e., a depressed area in the isobaric surfaces, the resulting isobars will be irregular closed curves of decreasing value toward the center, and crowded in proportion to the steepness of the slope or gradient, whereas a local high pressure area (a convex surface) will show closed curves of increasing value toward the center. Over much of the earth's surface the isobars are long, more or less parallel lines conforming in a general way to the direction of the parallels of latitude. The winds are the movements of the atmosphere from the regions of high to those of low barometric pressure, at the same level. This may be regarded as a movement down the isobaric slopes, and most readily and strongly down the steepest gradient.

Directions of Movement of the Air. Since the lower air of the equatorial regions is heated more than that of the polar regions by the direct action of the sun (insolation), it must expand most at the equator and, rising, produce a belt of low pressure around the globe. Into this will flow the winds from the region of greater pressure to north and south, along the bottom of the atmosphere, while at the same time the rising air crowds against the higher layers of the equatorial atmosphere which are not heated, and so produces a surface of high pressure in the upper part of the equatorial belt, with a poleward gradient down which the air will move. 
Thus a poleward movement of the upper air and an equatorial movement of the lower air are established, with a rising of the air at the equator and a descent in the polar regions. (Fig. 5.) This is the fundamental type of circulation of the atmosphere. This simple type of circulation is greatly modified, however, at any rate so far as the lower part of the atmosphere is concerned, by various factors, chief among which may be counted the rotation of the earth, the distribution of land and sea, the lateral pressure exerted by the expanding warm air of the equatorial region, and the crowding from the descent of the air in high latitudes, the subsidiary motions set going

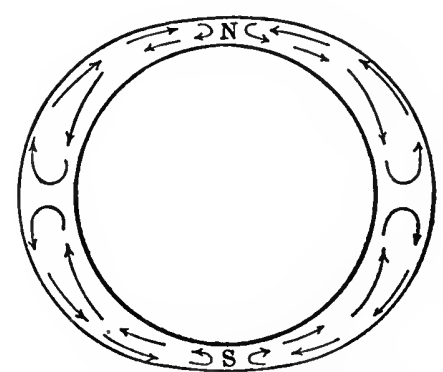

FIG. 5. Diagrammatic section of the earth and the enclosing atmosphere, illustrating the fundamental type of circulation in the lower atmosphere, established by unequal heating, as a result of differences in latitude. (After Salisbury-Physiography.)

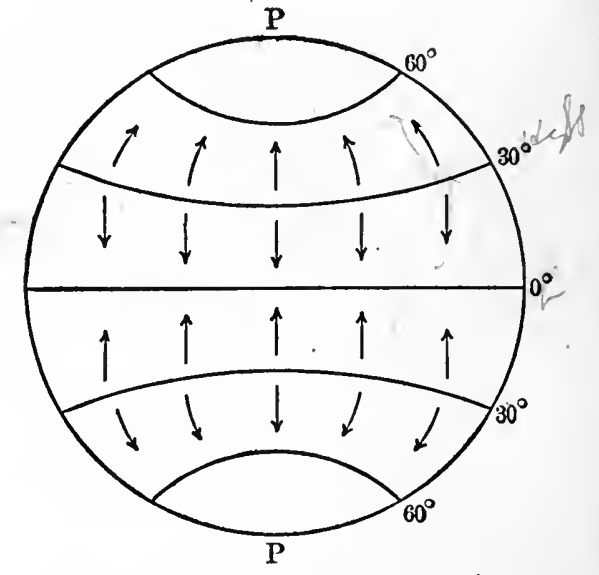

FIG. 6. Diagram showing the general movements which would take place in the lower air if there were no rotation. (After Salisbury.)

by the aspiratory action of the larger currents, etc. Considering that in each hemisphere there is, on the equatorial side, a rising mass of air, which turns poleward, while on the poleward side an equivalent current descends, and then flows equatorward, we have an intermediate area around which this circulation takes place, and these areas are belts of high pressure. Their location is approximately in latitudes $30^{\circ}$ N. and S., a location determined in part by the rotation of the earth. The center of this high pressure belt in the northern hemisphere is in $30^{\circ} \mathrm{N}$. lat., or a little less in January, with great expansion of the belt northward on the land. In July this center shifts north to about lat. $35^{\circ}$ and the belt is interrupted on land. The reverse is true for the southern hemisphere, where the summer conditions exist in January, with the center of 
the high pressure belt in about lat. $35^{\circ} \mathrm{S}$., while in July the center shifts to $30^{\circ}$ or less. (Fig. 7.) The shifting of the center of high pressure is, therefore, in harmony with the apparent motion of the sun.

The general distribution of pressure areas is somewhat as follows: I, an equatorial belt of low pressure; 2 , two belts of high pressure in about latitudes $30^{\circ} \mathrm{N}$. and $30^{\circ} \mathrm{S}$., respectively; and 3 , two high latitude areas of low pressure. In general there should thus be a horizontal movement of air in the lower part of the atmosphere from the extra-tropical belts of high pressure, both poleward

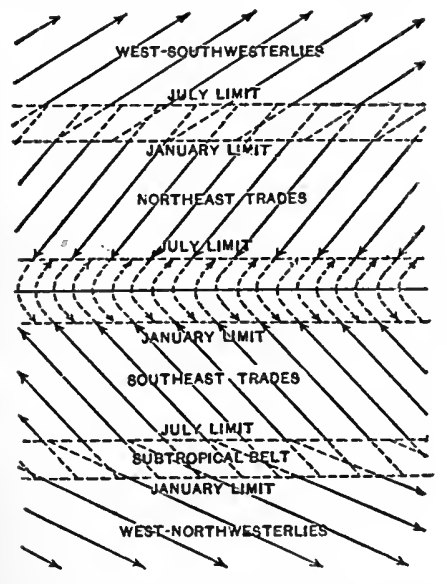

FIG. 7. Diagram illustrating the seasonal shifting of the wind zones. (After Davis.)

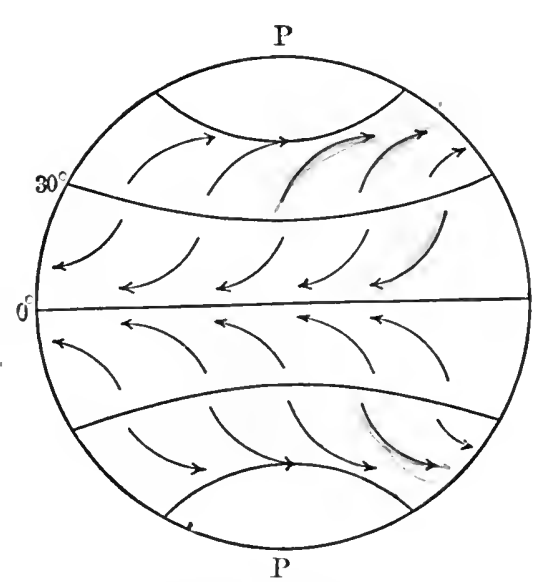

FIG. 8. Generalized diagram illustrating the deflection of the winds at the bottom of the atmosphere, due to rotation of the earth. (After Salisbury.)

and equatorward. (Fig. 6.) This motion is modified by the rotation of the earth, which causes a deflection of all currents to the right in the northern hemisphere and to the left in the southern. (Salisbury-83:603. Fig. 8.) As a result, the poleward winds in each hemisphere are turned toward the east, and so become w'esterly acinds, or southwest winds, in the northern hemisphere, and northwest winds in the southern hemisphere. The winds blowing equatorward will be deflected to the west, and so become casterly ainds, northeast winds in the northern and sontheast in the southern hemisphere. These are the most constant winds and are known as the trade winds? Where these currents meet at the equator, we have. the zone of equatorial calms, characterized chiefly by rising air 
currents. The center of this zone shifts with the sun, but remains near the equator. The prevailing zoinds or planctary arinds thus produced belong strictly to the lower part of the atmosphere. This is especially true of the trade winds, which appear to be confined to the lower Io,ooo feet, as shown by observations on the Peak of Teneriffe in the Canary Islands (lat. 28 ${ }^{\circ}$ ). The westerly winds of the higher latitudes, however, coincide with the general movement of the upper air, which, being poleward, is deflected to the east. Thus, as shown by the movement of the upper clouds, the direction of the upper winds is toward the east, and so a circumpolar whirl is instituted.

\section{Influence of Continents on Winds.}

Sea-Breezes. The chief disturbing factor of the planetary winds is the unequal heating of the atmosphere over the land and the water, as explained on p. 3I, which, in fact, is itself a cause of local winds. As the land, after the rising of the sun, is more quickly warmed in summer than the water, the air above the land expands upward, crowding against the upper air and so producing a seaward barometric gradient down which the air will flow. The resulting pressure over the sea and the relief of pressure over the land will cause a lower return current, the sea-breese, to flow landward. The velocity increases from the morning ( 8 or 9 A.M.) to the afternoon, reaching its maximum at the time of greatest air temperature. At first the sea-breeze blows, in general, at right angles to the coast, but as the air is drawn from greater distances off-shore, it comes under the influence of the deflective force of the earth's rotation and is turned to the right in the northern hemisphere and to the left in the southern hemisphere. Thus a sea-breeze on the eastern coast will change to a southeast wind in the northern and a northeast wind in the southern hemisphere, while a sea-breeze on the western coast changes to a northwest and a southwest wind in the northern and southern hemispheres respectively. Where the sea-breeze has the direction of the prevailing winds it often increases in the afternoon to the velocity of a gale. At Valparaiso "pebbles are torn up from the walks and whirled about the street" and business and shipping are interrupted. (Maury-63.) At evening the calm suddenly succeeds the uproar. Measurements on the Massachusetts coast have shown the velocity of the sea-breeze to be at first from 5 to $13 \mathrm{~km}$. per hour, reaching its greatest velocity of 16 to $30 \mathrm{~km}$. late in the afternoon. At Boston the average velocity is $23 \mathrm{~km}$. per hour at $3 \mathrm{P}$. M. on sea-breeze days. The height of the 
sea-breeze at Coney Island, New York, was found to be 150 meters in August, with a distinct seaward motion of the air at 200 meters. At Toulon, in the middle of October, I893, it was found to be 400 meters, with a distinct off-shore current at 600 meters. On the coast of California its height is about 2,500 meters.

Land-Brccass. These are generally much weaker than seabreezes. They result from the more rapid cooling of the land at night, involving a decrease in the pressure of the higher air and an inflow of warm air from the sea. This lowers the surface pressurd over the sea and increases that over the land, with the result that a surface current flows seaward from the land. As the land winds increase in length they will fall under the deflective action of the

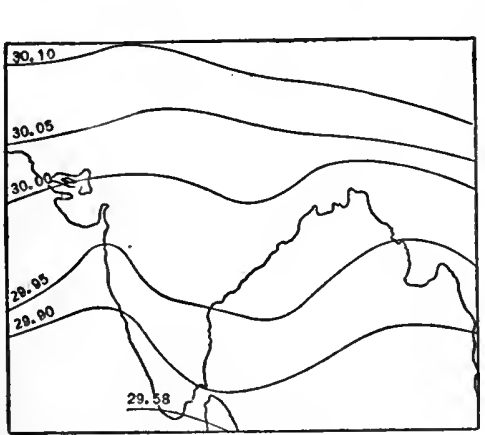

FIG. 9. The isobars of India for January. (After Bartholomew; from Salisbury.)

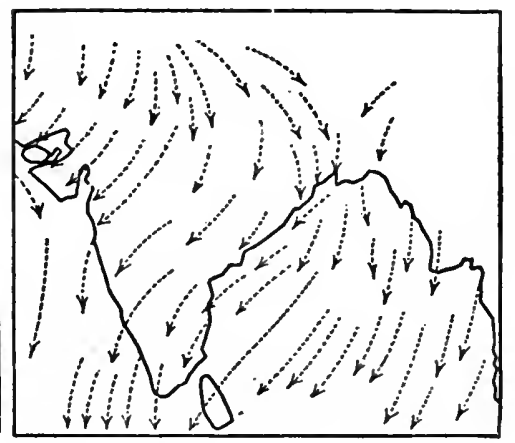

FIg. 10. Wind directions in India in winter. (After Köppen; from Salisbury.)

earth's rotation, and the breeze on the east coast will become a northwest wind on the northern and a southwest wind on the southern coast, while the land-breezes on the west coast will become southeast and northeast winds, respectively. The large lakes in like manner influence the formation of land- and lake-breezes, though not to the extent that oceans do.

Monsoons. These are the seasonal winds, brought about by the heating of the land during the summer and the cooling during the winter. These winds may be regarded as sea- and land-breezes acting continuously for nearly half a year each, and hence attaining great velocity. In the middle and higher latitndes of the northern hemisphere these seasonal winds may even entircly overcome the prevailing or planetary circulation, at least so far as the lower atmosphere is concerned, and may further exert a powerful influence on ocean currents. 
A glance at a chart of isobaric lines for January shows that Eurasia is a center of high pressure, and hence of air depression. The Indian Ocean is an area of low pressure and hence strong continental winds flow southward, and by the rotation of the earth are deflected to the west. Hence, over India we have northeast continental winds which harmonize with the trade winds and augment their effectiveness. In summer, on the other hand, Eurasia is a center of low pressure, centering in July over northwestern India, and hence the direction of the winds is a northward one, deflected to the northeast by the rotation of the earth. This is diametrically opposed to the direction of the northeast trade winds, which become

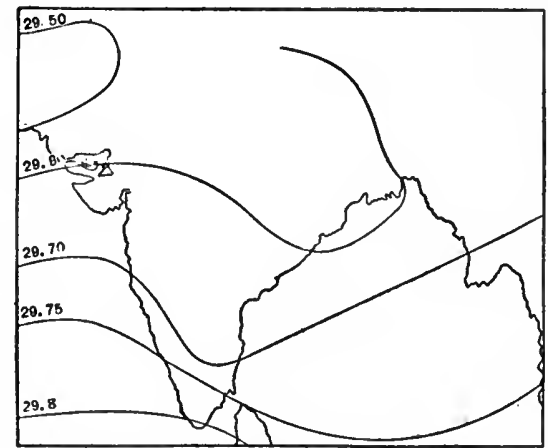

FIG. II. Isobars of India for August. (After Bartholomew; from Salisbury.)

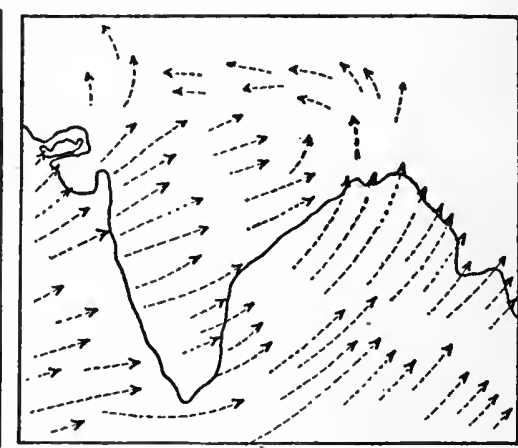

Fig. I2. Winds of India in midsumner. (After Köppen; from Salisbury.)

displaced by this more powerful southwest monsoon. The influence of these changes on the ocean currents will be noted later. Spain, which lies in the zone of westerly winds, furnishes another illustration of the importance of seasonal winds or monsoons. In winter the central plateau is characterized by low temperature and high pressure, and the winds blow outward, while in summer the reverse is true, the winds blowing toward the center. The importance of such winds in affecting the relative humidity of the climate and corresponding sedimentary deposits must not be overlooked.

\section{Cyclones and Anticyclones.}

An area of high barometric pressure produces an anticyclonic movement of the air, which passes out in all directions from it. In the northern hemisphere these winds are deflected to the right, making a clockwise circulation, while in the southern hemisphere deflection to the left produces a counter-clockwise circulation. Conversely, the low pressure areas are characterized by a cyclonic cir- 
culation, the winds flowing inward. In the northern hemisphere the course of the winds is counter-clockwise, the deflection being again to the right, while in the southern hemisphere the direction of the circulation is clockwise, the deflection being to the left.

\section{Whirlwindo AND TORnadoes.}

These are due to ascending air currents of a localized character caused by excessive heating of the air at one place. In desert regions these whirls often reach a hcight of $\mathrm{I}, 000$ feet or more, as shown by the whirling columns of dust. Rains of exceptionally heavy character, called cloudbursts, often result from the expansion of the air above and the consequent cooling. Tornadoes are whirlwinds of unusual strength and very small diameter. The air pressure at the center of the tornado is sometimes a fourth less than that of the surrounding region, while the velocity of the winc's has been estimated at from 400 to 500 miles per hour. Tornadoes are thus of exceptionally destructive character.

The Influence of Mountains on Winds. The air movements are locally modified to a considerable extent by mountains, which give them special characters, significant in their influence on climate. As an example, the fochn of Switzerland may be mentioned. (Hann-40:345.) This is a warm dry wind which blows down from the crest of the Alps with great violence from a sontheasterly, southerly, or, less frequently, a southwesterly direction, according to the trend of the valleys. The main valleys which trend southeast and northwest or south and north on the northern side of the central chain of the Alps are the most exposed to the foehn, while east and west valleys are seldom or never visited by it. The greatest frequency of these winds is between Geneva and Salzburg, where in the valleys the velocity of the wind, the rise in temperature, and the dryness are the greatest. In the upper portions of the valleys of the Rhine, the Linth, the Reuss, and the lower Rhone, the foehn sometimes attains the velocity of a gale. As it recedes from the mountains its violence decreases, and over the main part of the Swiss highland and the Jura, and along the northern frontier of Switzerland, it causes only a slight rise in temperature and corresponding decrease in humidity. These winds are most frequent in spring, when the snow disappears before their hot breath, and least so in summer. Ten years' observations at Innsbruck give the average number of foehn wind days for spring 17 . summer 5, antumn II.I, and winter 9.5; a total of 42.6 for the year.

While $(40: 349)$ the foehn is blowing north of the Alps, there 
is a calm on their southern side, with little if any-increase in temperature, and with high humidity. In most cases also, a few hours after the foehn has begun to blow, rain and snow begin to fall on the southern slopes and the summits of the Alps, the precipitation being often extraordinarily heavy; exceptional precipitation on the south often coinciding with extreme violence of the foehn on the north. The following table, copied from Hann, shows the average weather conditions which prevailed simultaneously at Milan, on the southern side, at Bludenz, Austria, in a tributary alpine valley of the Rhine, and at Stuttgart in the northern plains, during twenty winter days on which there were foehn winds. $(40: 350$.)

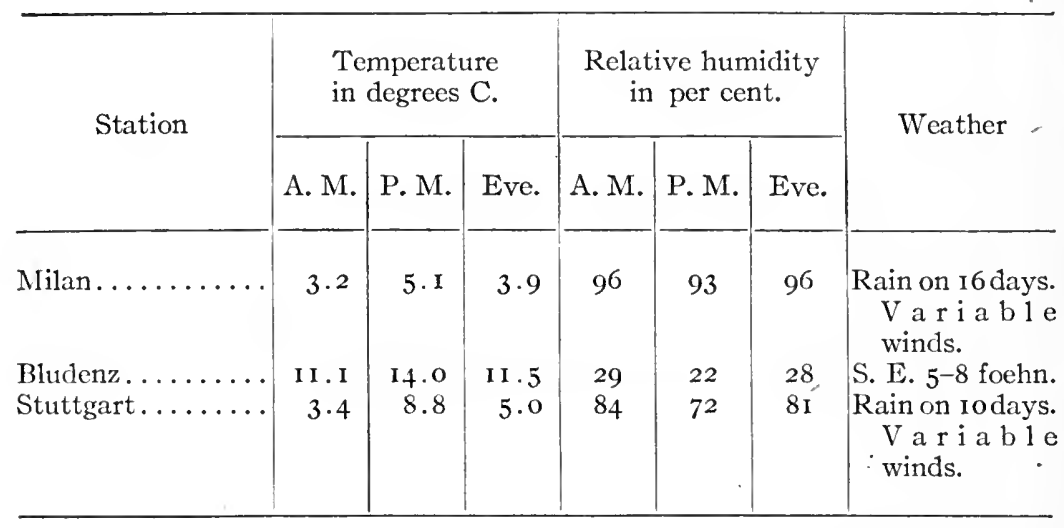

The high temperature of the wind and its dryness do not exist on the alpine summits, but are acquired during the descent on the northern side. They are not imported from the region to the south of the Alps. This is shown by the observations on the weather along the St. Gotthard Pass during the foehn of January $3 \mathrm{I}-\mathrm{Feb}-$ ruary I, I869, as shown in the following table. (Hann-40:350.)

\begin{tabular}{|c|c|c|c|c|}
\hline Station & $\begin{array}{l}\text { Altitude } \\
\text { (meters) }\end{array}$ & $\begin{array}{c}\text { Temperature, } \\
\text { degrees C. }\end{array}$ & $\begin{array}{l}\text { Relative } \\
\text { humidity, } \\
\text { per cent. }\end{array}$ & Wind \\
\hline 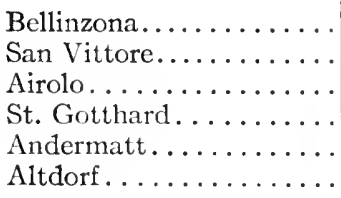 & $\begin{array}{r}229 \\
269 \\
1,172 \\
2,100 \\
1,448 \\
454\end{array}$ & $\begin{array}{l}+3.0 \\
+2.5 \\
+0.9 \\
+4.5 \\
+2.5 \\
+14.5\end{array}$ & $\begin{array}{c}80 \\
85 \\
\cdots \cdots \cdots \cdots \\
\cdots \cdots \cdots \\
\cdots \cdots \\
28\end{array}$ & $\begin{array}{l}\text { N. (rain). } \\
\text { S. and S.W. } \\
\text { N. and S. } \\
\text { S., 2-3. } \\
\text { S.W., 2. } \\
\text { S. (Foelnn). }\end{array}$ \\
\hline
\end{tabular}


The foehn winds are explained by the development of southerly winds which flow toward a region of low pressure in western Europe, because of the advance of barometric depressions or storm centers from the Atlantic. The air of the Alpine valleys is likewise drawn toward this region, and to.replace it the air rushes in from the summits, the wall of the Alps preventing any direct supply, and keeping the air calm on the south side of the Alps. Air carried up and expanding is cooled at the rate of $\mathrm{I}^{\circ} \mathrm{C}$. for every $\mathrm{I}$ oo meters, this loss of heat being the thermal equivalent of the work done by the air in increasing its volume against the pressure of the surrounding air. Conversely, air drawn down from a region of less to one of greater pressure will be compressed, and at the same time warmed at the rate of $\mathrm{I}^{\circ} \mathrm{C}$. for every $\mathrm{IoO}$ meters (or more exactly $0.99^{\circ} \mathrm{C}$. for every $100 \mathrm{~m}$.). Since the average rate of decrease of temperature with increase in altitude is in winter $0.45^{\circ} \mathrm{C}$. for every 100 meters, the air coming down from the mounitains increases in temperature $0.54^{\circ} \mathrm{C}$. in every IOO meters. This would give $13.5^{\circ} \mathrm{C}$. for a descent of 2,500 meters. The increase in temperature readily explains the fall in relative humidity, since the capacity of the air for moisture is greatly increased with but slight actual additions. Foehn winds of less magnitude sometimes occur on the south side of the Alps when the conditions are reversed. Similar winds have been recorded from the western coast of Greenland, where a warm, dry easterly or southeasterly wind blows across the ice-covered interior of Greenland and down onto the fiords of the western coast, raising the temperature on the average $12^{\circ}$ to $20^{\circ} \mathrm{C}$. above the mean in winter, and about $\mathrm{II}^{\circ}$ in spring and autumn. Iceland, New Zealand, Japan, and other countries have foehn winds, and the chinook wind, which blows eastward from the Rocky Mountains of North America in Wyoming, Montana, Alberta, and the Saskatchewan country, has a similar origin. The siroccos of Sicily (Palermo), the Algerian coast, the north coast of Spain, etc., are other examples of foehn winds, but the sirocco of Italy and the Dalmatian coast is a damp. muggy south or southeast wind in striking contrast with the cold, dry northerly winds of that region. These winds, the bora, rushing down from the high platean of the Istrian and Dalmatian coasts and then down the southerly slope of the Caucasus to the Black Sea (at Novorssiisk, Russia), are ice-cold blasts which apparently are not warmed by their descent. This is only apparent, however, since the initial temperature of these winds is so low that, in spite of the increase during the descent, they reach the warn coast of the Adriatic or the Black Sea as a cold blast. The bora occurs only where the 
back country is very cold as compared with the coast. The mistral, a stormy northwest wind blowing from the Cévennes in southern France, has a similar origin, descending from the cold central plateau to the warm Mediterranean coast.

Mountain and Vallcy Winds. . Where the general air movements are not too strong, a regular daily alternation of winds is observable in mountain regions, blowing up the valleys by day and down by night. Though not confined to valleys on the mountain sides, they attain their best development there. In the Hinalayas, the winds blow up the valleys from 9 A. M. to 9 P. M. and down the remainder of the night. Where the valleys open out into the plains, the winds often blow with great violence, particularly in winter. The upward flow during the day is explained by the increase of pressure at points distant from the slope, owing to the warming and rising of the air beneath these points and the expansion of the air at the same level on the mountain slope. This causes a movement of the air toward the mountain which must result in an upward flow of the current on the mountain side. At night the cool wind naturally flows down the slope, attaining its greatest velocity where it leaves narrow, cool valleys and enters broader, well-warmed ones.

Velocities of Wind. The velocity of the wind current varies enormously, from the frightful rate of 400 or 500 miles per hour obtaining in some tornadoes, to the gentle zephyr breeze of a fraction of a mile per hour. The average velocity for the winds* of the United States has been estimated at about 9.5 miles per hour (4.25 meters per second), and for Europe 10.3 miles per hour (4.60 meters per second). It is greater over the sea than over the land, where friction retards it, and greater in the upper air than at the earth's surface. The average velocity of the wind is also greatest in about latitude $50^{\circ}$. The following wind scale gives the velocities of the various types of wind according to Hann (40):

\begin{tabular}{|c|c|c|c|}
\hline \multirow[b]{2}{*}{ Number } & \multirow[b]{2}{*}{ Name } & \multicolumn{2}{|c|}{ Velocity } \\
\hline & & Meters per second & Miles per hour \\
\hline 0 & Calm. & & \\
\hline $\mathbf{I}$ & Light air. & 1.7 & $4 \cdot 0$ \\
\hline 2 & Light breeze. & $3 \cdot I$ & 7.0 \\
\hline 3 & Gentle breeze. & 4.8 & 10.5 \\
\hline
\end{tabular}

* For comparison see velocities of streams given on p. 245 . 


\begin{tabular}{|c|c|c|c|}
\hline \multirow{2}{*}{ Number } & \multirow{2}{*}{ Name } & \multicolumn{2}{|c|}{ Velocity } \\
\hline & & Meters per second & Miles per hour \\
\hline 4 & Moderate breeze. & $6.7^{\circ}$ & 15.0 \\
\hline 5 & Fresh breeze. & 8.8 & 20.0 \\
\hline 6 & Strong breeze. & 10.7 & 24.0 \\
\hline 7 & Moderate gale. & 12.9 & 29.0 \\
\hline 8 & Fresh gale. & 15.4 & $34 \cdot 5$ \\
\hline 9 & Strong gale. & 18.0 & 40.0 \\
\hline 10 & Whole gale. & 21.0. & 47.0 \\
\hline II & Storm. & 30.0 & 67.0 \\
\hline 12 & Hurricane. & 50.0 & I 12.0 \\
\hline
\end{tabular}

The following table by Mohn (67:I2I) gives the range in velocities and also the corresponding pressure. The values are somewhat different from those in the table by Hann.

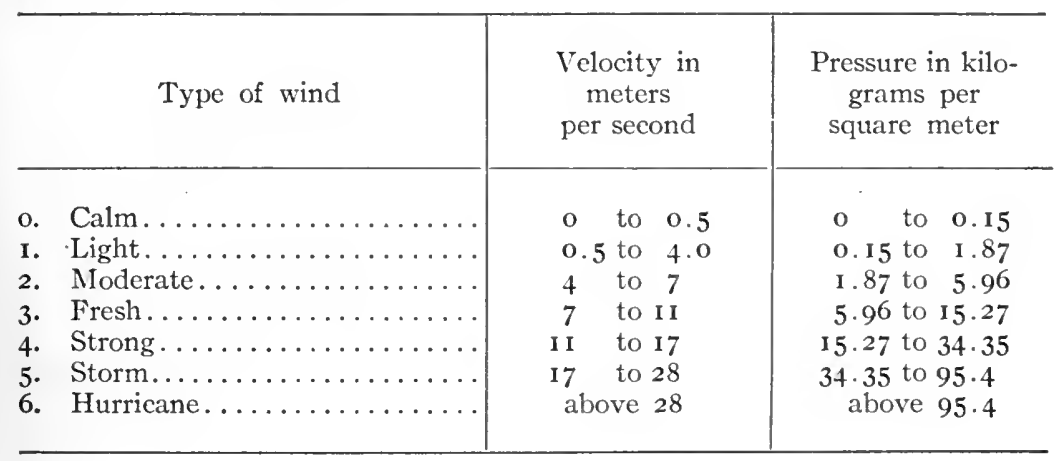

\section{EOLATION OR MECHANICAL IVORK OF THE ATMIOSPHERE.}

The mechanical work of the wind is expressed by the term colation, which is the process of the eartl sculpture by wind, the scouring by wind-driven sand, dust, and other substances, and the transportation and deposition of rock material by wind. It may be summarized as wind erosion or corrasion, as wind transportation or deflation, and as colian sedimentation. The last will be especially dealt with in Chapter XIII. 


\section{Wind Erosion and Translocation.}

Walther (IO2, IO4) has repeatedly insisted upon the importance of distinguishing the twofold process of denudation performed by the wind, namely, corrasion, or the abrasive process, and deflation, or the process of denuding by removal of mineral particles loosened by weathering. The latter is by far the more effective process, and applies not only to the immediate products of weathering, but to all the loose material of the earth's surface, fine enough to be subject to wind transportation.

Corrasion. Wind corrasion is accomplished by means of the material carried by the wind. Sand grains are the commonest and most effective agent in this respect, though blown snow crystals have a similar though less violent effect. Wind-corraded rocks usually have a smooth and highly polished surface, which, however, is frequently irregular, with the harder ninerals or bands projecting, or with cavities due to corrasion of the soft parts. Hard limestones often have their otherwise obscure bedding emphasized by the wearing of the softer layers; while hard fossils or concretions will appear in relief by the filing away of the surrounding softer rock. In the Libyan desert the blocks of Tertiary Operculina limestone are corraded by the wind in such a manner that the somewhat harder Foraminifera are filed out in relief, each resting on a pyramid or a needle of limestone, the latter often $2 \mathrm{~cm}$. long, and sometimes giving the rock the aspect of a pincushion stuck full of long pins. (Walther-106:4I4.) On the Libyan limestone plateau, where the surface is formed by an exceptionally hard siliceous lower Eocenic limestone bed, wind-carved furrows have been discovered, which extend in a N.N.W.-S.S.E. direction and vary in depth up to a meter. These were carved by the sand-laden winds which for thousands of years swept across this surface, with little or no variation of direction. (Walther-106:4I3, and Martonnc-62, pl. XXXIII, b.) Similar furrows, a foot or more wide, but shallow, occur in the surface of the late Siluric Anderdon limestone of western Ontario, and probably represent wind crosion under desert conditions during Lower Devonic time. They are covered with Middle Devonic sands, both siliceous and calcareous, about 12 feet thick, apparently free from fossils, and probably representing the somewhat reworked calcareous sands drifted across the old limestone plateat. These lower beds, chiefly brown dolomitic rocks, fill the fissures above referred to. (Grabau and Sherzer-36:44.) The yardangs of Central Asia (47) are groove-like hollows, sculptured out of ar- 
gillaceous rock surfaces, and separated by more or less fluted ridges. (Fig. I3.)

Such structures in an early stage are also found in the region near Biggs, Oregon.. What may be a similar structure is seen in the contact of the Upper Cambric Olenus limestones with the highest bed of the Ceratopyge limestone in central Sweden, the lower

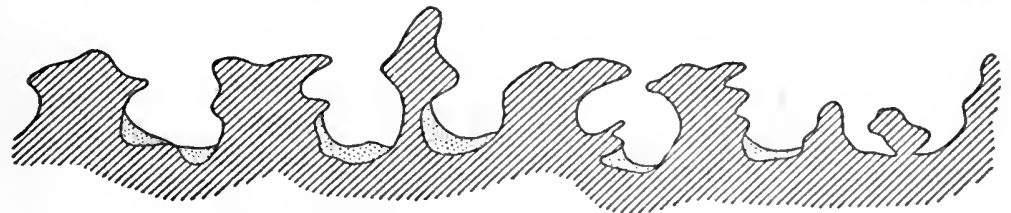

FIG. I3. Diagrammatic section of yardangs of Central Asia, the deeper depressions filled by sand. (After Sven Hedin.)

limestone surface being grooved irregularly, sometimes for a depth of a few centimeters, and the succeeding limestone filling the crevices. Other eolian erosion features are seen in the Bad Land topography of western North America, the remarkable sandstone pillars of the Bastei, in Saxony, the equally remarkable stone pillars

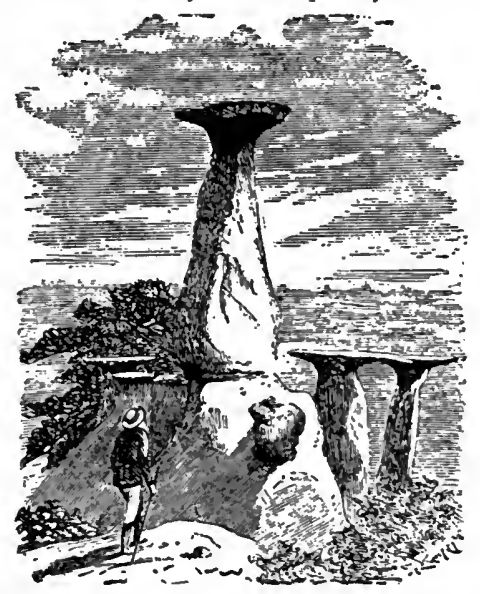

Fig. I4. Erosion columns in sandstone. The result of eolian erosion. Monument Park, Colorado. (After Hayden.)

of Tertiary sandstone, capped by harder iron-cemented layers, found in Monument Park, Colorado, and the similar erosion pillars or gour (singular gara) of Egypt. In part these are probably due to deflation of material previously disintegrated. (Fig. 14.)

The natural sand-blast in the San Bernardino Pass, in southern California, is so powerful that the modern telegraph poles of the Southern Pacific Railway are greatly damaged and have to be pro- 
tected by piles of rock and supplementary pieces placed on the windward side of the affected poles. The telegraph wires of the TransCaspian Railway between Aidin and Bala-ischem had to be renewed after eleven years, because their diameter had been diminished onehalf by the sand-blast corrasion. (Walther-104:52.) Even dust from the city streets blown against the tombstones of cemeteries will in time efface their inscriptions. (Eggleston-28:654-658.)

Facetted Pebbles. A highly significant and interesting result of sand corrasion on loose stones is the facetted pebble or windkanter. This generally has three or more faces ground flat, by the sand blown over it at different times, and these faces meet in sharp angles. These angles do not represent the direction of the wind at the time of cutting, but rather the more or less accidental meeting of faces cut at different times. Walther (I06) describes "Einkanter," Irr egular "Windkanter," "Dreikanter," and "Parallelkanter" from the Libyan desert, all formed by wind blowing in one direction only. The einkanter are arranged with the ridge at right angles to the wind direction, the single wind-cut face being-normal to and inclined toward that direction. This Walther regards as the normal type. The polyfacetted condition is brought about by the fact that the sand-laden wind-currents along the bottom of the atmosphere wind in and out among the pebbles strewn over the surface, cutting one here and another there, and so producing faces and angles which have no definite orientation. In some cases the undermining of a pebble on which one face has been cut and its subsequent rolling over, expose a new surface to the wind. (Davis24.) Of between 300 and 400 specimens observed by Wade (IOI) in the eastern desert of Egypt, 78 per cent. were set at right angles to the direction of the wind. He found the ridge to be more generally a curved one, and the face presented to the wind not a plane surface, but a gently curved one. Measurements taken on over fifty specimens showed that this surface makes an angle with the vertical, which varies between $40^{\circ}$ and $50^{\circ}$, most usually approximating $45^{\circ}$. Wade determined to his own satisfaction that the air currents were driven upward, carrying the sand against the pebble face. Undermining and consequent change of position of the pebble were found to be the cause of the cutting of the several facets, as postulated by Davis.

The presence of these pebbles in undisturbed condition in older formations is a reliable indication of the subaërial origin of the deposit. Davis (24) has used them to prove the undisturbed subaërial character of the apron plains of Cape Cod. They have also been found in the pre-Cambric Torridon sandstone of Scotland, the 
basal Cambric sands of Sweden, the Rothliegende of Germany, the Buntersandstein of Thuringia and elsewhere.

Deflation. This is by far the most important work of the wind, and its geological significance can scarcely be overestimated. The lifting of the material from the surface is largely the work of eddies and irregularities of movement of the wind, including many conflicting cross-currents. (Langley-57; 58.) The most important are, of course, the whirling eddies of whirlwinds and tornadoes, but many minor currents, due, in part, at least to the irregularities of the surface are active in lifting the dust and fine sand. The ordinary convection currents of the atmosphere carry this finer material up to great heights. The force (Free-33:35) which moves the particle is due to the direct impact of the wind plus the friction along its surface. The force of the direct impact varies with the velocity of the wind, and for a given velocity with the cross-section of the particle in the plane perpendicular to the direction of the wind, as well as with the orientation of the particle, and it is of course most efficient when a smooth plane is opposed to the wind. The resistance of the particle varies with its mass, i.e., its size and specific gravity, and to some extent its form. In general the velocity of the wind necessary to carry a spherical particle of given specific gravity varies as the square of the radius, and conversely the radius of a particle which can be supported by wind varies as the square root of the velocity. Thoulet $(94 ; 95)$ found that a uniform upward current of air will keep suspended quartz grains, the size of which varied with the velocity as follows:

\begin{tabular}{|c|c|}
\hline Velocity in meters per second & $\begin{array}{c}\text { Diameter of } \\
\text { quartz grain } \\
\text { in mm. }\end{array}$ \\
\hline $0.50 \ldots \ldots \ldots \ldots \ldots \ldots \ldots \ldots \ldots \ldots$ & 0.04 \\
\hline $1.00 \ldots \ldots \ldots \ldots \ldots \ldots \ldots \ldots \ldots \ldots \ldots$ & 0.08 \\
\hline 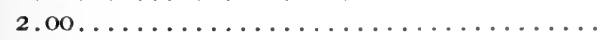 & 0.16 \\
\hline 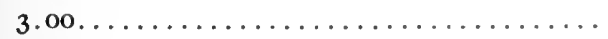 & 0.25 \\
\hline 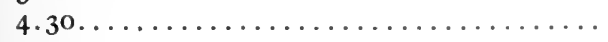 & 0.35 \\
\hline 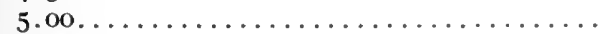 & $0.4 \mathrm{I}$ \\
\hline 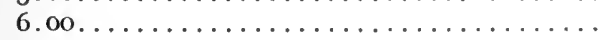 & 0.49 \\
\hline 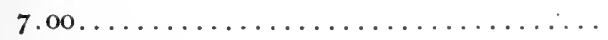 & 0.57 \\
\hline 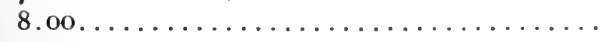 & 0.65 \\
\hline 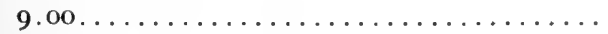 & 0.73 \\
\hline 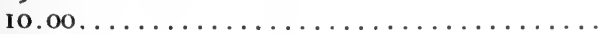 & $0.8 \mathbf{I}$ \\
\hline 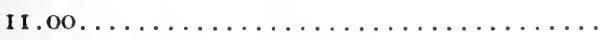 & 0.89 \\
\hline $12.00 \ldots \ldots \ldots \ldots \ldots \ldots \ldots \ldots \ldots \ldots$ & 0.97 \\
\hline $13.00 \ldots \ldots \ldots \ldots \ldots \ldots \ldots \ldots \ldots \ldots \ldots$ & 1.05 \\
\hline
\end{tabular}


From this Free deduced the formula $\mathrm{V}=\mathrm{Kr}$, where $\mathrm{K}$ is a constant for the conditions of experiment and $r$ the radius of the particle.

From numerous measurements Udden concluded that the "average largest size of quartz particles that can be sustained in the air by ordinary strong winds is about 0.I mm. in diameter" (Udden97), but the largest particle that can be transported (not held in suspension) is nearer $2 \mathrm{~mm}$. in diameter, while gravel the size of peas may in rare cases be carried along by the wind. This, however, represents the limit of ordinary deflation. (Walther-104: 97.) Much larger fragments, nevertheless, are rolled along by the wind, and sometimes even lifted and carried for some distance. Stones as large as a man's fist have been observed blown along by wind in the deserts of Sahara (Rohlfs), and Gobi (Przhevalsky), and Pumpelli saw stones 2 inches across blown by a storm in Turkestan. (Pumpelli-77:303.) A wind-blown pebble $2 \mathrm{~cm}$. in diameter was collected from the snows of Ben Nevis after a severe storm. (Murray and Renard-69:590, also Theobold-93:534535.) A remarkable case is reported by St. Metnier (66a: 440; 73: $247-248$ ) of a "rain" of limestone pebbles, whose diameter ranged from 25 to $35 \mathrm{~mm}$., which fell on June 6, I89I, in the Department of Aube, France. These pebbles are believed to have been transported $150 \mathrm{~km}$. Other pebble falls are recorded by various observers. Organisms, often of some size, are also known among the remarkable "solid" rains. Thus a fall of lichens was reported from Persia by De Candolle. Falls of small live fish have been reported from Madras, India, and were also observed at Singapore, in the Malay peninsula; at Winter Park, Florida, in June, I893; and at Tillers Ferry, South Carolina, in Igor. A turtle 6 inches by 8 inches, and a stone fragment $1 / 2$ inch by $3 / 4$ inch, both incased in ice, fell at Vicksburg, Mississippi, on May I I, I894. (Abbe cited by Free-33.)

Sokolow gives the following table of quartz sand grains moved by varying wind velocities, as derived from his experiments $(87: 12)$.

Strength of wind in meters per second.

Maximum diameter of

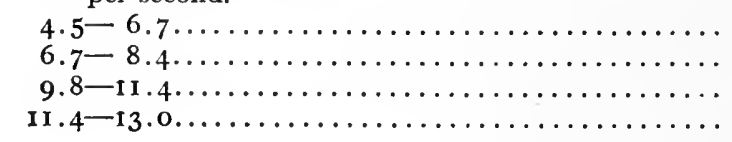
sand grains per $\mathrm{mm}$.
0.25
0.5
I.0
I. 5

These results are only approximate. Sokolow holds that eolian deposits with grains above 4 to $5 \mathrm{~mm}$. in diameter are not known. 
Character and Amount of Deflational Denudation. On the seashore and in the descrts all the dust and fine sand grains are blown away, leaving only the coarser sands and the rock fragments. The latter are characteristic of the stony desert, the Hamada type, which is found in many deserts the world over. The pebbles are generally smooth from wind wear, and may resemble water-laid deposits. That some pavements of this kind are due to water work is believed to be the case by some observers (Free-33:32, and works cited there). Not infrequently the surface of the pebbles is covered with the brown desert varnish, indicating that corrasion has come to an end for the time being. The desert varnish is a brown to black, often highly polished coating of iron oxide or hydrate, or of manganese oxide, which covers the stones and ledges of arid regions. The amount of the coating, which is seldom more than a small fraction of a millimeter thick, increases with the increase in aridity. Often it is developed only on the 11pper, exposed side of the stones of the Hamada, the under surfaces remaining uncoated. Chemically, the material forming the rind is a mixture varying from pure iron oxide to nearly pure manganese oxide, with all intermediate combinations. The formation of the rind begins with the absorption of moisture by the porous rock and the formation of various compounds, through the substances present in the rock or derived from without. The solutions formed are drawn to the surface by capillarity, and under the intense heat of the desert they evaporate, leaving the coating of oxide upon the surface. What appears to be a case of desert varnish in Palæozoic rocks is found in a layer of pebbles at the base of the Siluric iron ore deposit of Wisconsin. These rest upon an eroded surface of Ordovicic shale, and are succeeded by the iron ore.

A marked characteristic of many desert surfaces is the wealth of fossil organisms which are left behind after the disintegration and deflation of the rock mass originally containing them. Even if the original rock is only sparingly fossiliferous, a long-continued deflation will result in the concentration of a considerable number of specimens on the desert surfaces. (Walther-I04:38.)

Extensive eolian erosion, referable almost entirely to deflation of materials loosened by other agencies, is shown in the plateau country of western North America. The Jurassic sandstone of Utah shows this especially well, numerous isolated remnants or buttes testifying to the great extent of this work. The buttes themselves often show striking features, as in the case of Casa Colorado and Looking Glass Rock in Dry Valley, Utah. In the latter a large alcove or cavern has been hollowed out by the wind, a feature not 
uncommon in these sandstones where some parts are very friable. (Cross-21 : pl. 4, fig. 2.) Hollows of this type are very common in sandstones, especially where concretionary segregation of this iron oxide has left some of the sands in an unconsolidated condition. (See Chapter XVII.) Deflational erosion of rocks in moist temperate regions is shown by the classical example of the Heidelberg Schloss. The western tower of this castle, built in 1533 and partly blown up in 1689 , shows a narrow passageway, through which the wind blows with considerable force. The wall of this passage is built of heavy sandstone blocks, some of which have been hollowed out for a depth of $10 \mathrm{~cm}$., entirely by the blowing away of the disintegrated sand grains, the situation being such as to exclude corrasion.

Eolian erosion over wide areas is well shown in the Kalahari Desert of South Africa, where, according to Passarge, extensive plains have been produced by this agent, the amount of deflational work being often indicated by the butte-like "Inselberge" still rising above the plain as unconsumed remnants. (Bornhardt-8:37.) A similar origin has been advocated for a part at least of the desert plains or "bolsons" of southwestern United States. (Hill-50; Keyes-56.) That some of the extensive depressions of the earth's crust occupied by deserts owe their character to deflational work of the wind seems quite certain. In the Inselberg-landscape of South Africa the country rock is a crystalline rock, mostly biotite gneiss, biotite muscovite gneiss, garnet gneiss, and amphibolite. The residual peaks are harder rocks, chiefly pegmatite dikes and other rocks high in quartz. The individual Inselberge are separated by distances varying up to $25 \mathrm{~km}$. and over; the differences in height of various parts of this plain are not great, 80 meters having been found in a distance of over $150 \mathrm{~km}$. Sometimes the floor of the plain seems as smooth as a table top, the minor depressions being filled in by eolian deposits. Near the Inselberge, sometimes at their very bases, are heavy masses of talus, consisting of the products of recent rock decay, inaugurated probably by a change in climate to a more pluvial one. (Hecker-46.)

Distance of Eolian Transportation. Only the finest dust particles remain more or less permanently suspended in the air, or until washed out by rains. Most of the wind-borne particles travel by means of leaps and bounds of varying magnitude. The length of the leap depends upon the size and shape of the particles, the wind velocity, and to some extent on the topography of the country. From a number of analyses of wind-transported material Udden has constructed the following table of approximate maximum distances 
over which quartz particles of different dimensions may be lifted by moderately strong winds in single leaps. (Udden-99:65.)

Gravel (diameter from 8-1 mm.)*

A few feet.

Coarse and medium sand (diameter $\mathrm{I}-1 / 4 \mathrm{~mm}$. $\mathrm{I}-\mathbf{0 . 2 5}$ ).... Several rods.

Fine sand (diameter $\left.1 / 4^{-1 / 8} \mathrm{~mm} .0 .25-0.125\right) \ldots \ldots \ldots$ Less than a mile.

Very fine sand (diameter $1 / \mathrm{s}-1 / 16 \mathrm{~mm} .0 .125^{-0.0625}$ )...... A few miles.

Coarse dust (diameter $1 / 16-1 / 22 \mathrm{~mm} .0 .0625-0.03125) \ldots . .200$ miles.

Medium dust (diameter $1 / 32^{-1} / 6 \pm \mathrm{mm}$. 0.03125-0.015625).. I, 1,000 miles.

Fine dust (diameter $1 / 64 \mathrm{~mm}$. 0.015625 and less)......... Around the globe.

These theoretical distances are probably never realized, owing to the complex character of the wind currents and other factors.

Dust storms may often cover extensive areas and be the means of distant transportation of materials. Udden $(98: 196)$ records storms extending 300 and 400 miles in their longest observed direction. A Chinese dust storm is known to have existed simultaneously from Hankow to Chin-kiang, or over a distance of more than 450 miles, and for an unknown distance beyond in either direction. (Guppy-38.) On February 6 and 7, 1895, dust fell in Missouri which must have come from western Kansas and Nebraska, since all the intervening country was covered with snow and ice. On April 2, 1892, a yellow dust carried from the interior of China fell on the deck of a ship 95 miles west by south of Nagasaki, at least I,000 miles from its source; and dust storms from Australia have sometimes reached New Zealand, having been transported some I,500 miles. Dust believed to have been brought from the Sahara has been observed in northern Germany, and in England, some 2,000 miles distant. This is the so-called sirocco or tradewind dust, which, however, has little or no relation to the true sirocco. Volcanic dust carried to the upper air is likewise transported over great distances. Thus the dust formed by the eruption of Krakatoa in 1883 was projected so high into the air that, caught by the currents of the upper air, it was carried around the world repeatedly before settling. Some of this dust is said to have completed the circuit of the earth in 15 days. (Chamberlin and Salisbury-16:27.) This dust settled slowly all over the world and became incorporated in all contemporaneous deposits. Beds of volcanic dust in places 30 feet thick are known in Kansas and Nebraska, hundreds of miles distant from volcanoes which could have supplied the material. (Salisbury-82.) The following summary of volcanic dust transport is taken from Free $\left(33:\right.$ I $_{49-150)}$ : "Volcanic dust from Iceland has several times fallen in Scandinavia, in

* See table of sizes of sand grains, etc., in Chapter VI, page 287. 
northern Great Britain, and in Holland. Dust from Tomboro fell on Sumatra, a thousand miles away. Krakatoa ashes fell inches deep at distances of nearly $\mathrm{I}, \mathrm{OOO}$ miles from the volcano, and small quantities fell even in Holland. Dust from Colima in Mexico fell in February and March, 1903, at points over 200 miles north and east of the volcano, and the ash from Santa María in Guatemala in October, I9O2, covered all the northern part of that country and most of the states of Tabasco, Veracruz, and Oaxaca in southern Mexico. At Tapachula, 40 miles away, the ashes were 19.5 centimeters thick.

"Ash from Coseguina in Nicaragua in 1835 covered an area of I,500,000 square miles and even reached Jamaica, more than 750 miles away. The dust from the eruption of Cotopaxi in Equador in 1877 fell at Guayaquil, I50 miles away, to the amount of 3I5 kilograms on every square kilometer during the first thirty hours of the fall. Once 209 kilograms fell in twelve hours. The dust ejected by this same volcano in 1888 amounted to more than 2,000,ooo tons. On this occasion the dust cloud traveled 85 miles in six hours. At the eruption of Tarawera in New Zealand in 1886 , $1,960,000,000$ cubic yards of dust were discharged in five or six hours and covered a land area of over 6,000 square miles. Much more dust fell into the sea. Dust from the eruptions of La Soufrière and Pelée in 1902 fell plentifully all over the West Indies and especially at Barbados, 130 miles from Pelée and 225 from La Soufrière. Dust from the eruption of Pelée in I8I 2 is said to have reached the Azores. Dust from Vesuvius has been observed in Greece, in France, and in Austria."

Volume of Dust Falls. In 1863 a rain of dust occurred on the Canary Islands, the volume of which was estimated at 3,944,000 cubic meters. (Fritsch-34:212.) Free $(33: 98)$ reduces this to $5,900,000,000 \mathrm{kgm}$. or 6,500,000 tons. The dust fall in England on February 22, 1903, is said to have furnished 9,100,000,000 kilograms or $10,000,000$ tons of material, but the data are not wholly reliable. The great dust storm of March 9-12, 1901, however, brought to Europe $1,782,200,000$ kilograms or $1,960,420$ tons of dust, while North Africa received 1,500,000,000 kilograms or $1,650,000$ tons. This dust deposit thus covered at least 300,000 square miles of land surface, and I70,000 square miles of ocean, and, according to Walther, traveled in part at least a distance of 4,000 kilometers or 2,500 miles. Altogether 3,282,200,000 kilograms or $3,610,420$ tons of dust fell. For the European area (437,500 square kilometers or 168,437 square miles), the fall averaged a layer of dust $0.239 \mathrm{~mm}$. thick. Assuming the usual dust falls together with 
the exceptional ones to average this amount for every period of five years, we would get a deposit $4.78 \mathrm{~mm}$. thick in a century, while during the three thousand odd years during which such storms have been recorded, the total amount would be $143.4 \mathrm{~mm}$. or over $5^{\mathrm{I}} / 2$ inches of material brought from the desert. Dust fogs are characteristic of the Red Sea at certain seasons and are known on parts of the Atlantic reached by the winds from the desert. If dust-laden winds reach a district of more rainfall, or if their velocity is diminished, they will be relieved of their burden, and the dust will settle. This occurs in the steppe surrounding the desert, where the further transport of the material is in large measure prevented by the grassy vegetation. Thus the surface of the steppe is gradually built up by deposits of fine material derived often from great distances. Skeletons of terrestrial animals may readily be buried where accumulation is rapid, while along the water conrses leaves and shells of fresh water or land molluses may become entombed. The loess, discussed more at length below, is belicved to be an accumulation of this sort, and older deposits of this type are coming to be more generally recognized.

Sorting and Rounding of Sand Grains by Wind. The sands picked up by the winds on the shores ordinarily travel only at a slow and probably constantly diminishing rate inland. But the finer dust particles are blown away rapidly. If the sand consists of or contains minerals which are readily ground into dust, this dust will be blown away and the destructible minerals are thus removed from the dune sand. It is due to this destruction of other minerals that the dune sand of some coasts consists almost entirely of pure quartz grains.

During this movement, these dry sand particles are not only actively engaged in abrading whatever rocks or other objects are in their path, but they themselves are well rounded through mutual attrition. So perfect is this rounding of the grains in some windblown sands that even the lens will reveal no irregularities. (Walther-103: 795.) Since particles 0.I mm. or less in diameter are not reduced by mutual attrition in water, it follows that rounded grains below this size must in general be regarded as wind-worn grains. (The relative efficacy of wind and water as agents of rounding will be discussed in Chapter V.) The glassy character is, moreover, dimmed by this attrition, and the surface of the grains takes on the character of ground glass. Such sands may later be worked over by the waves of a transgressing sea or lake, and so become wellstratified waterlaid deposits with remains of aquatic organisms. Not infrequently shells are driven far up on the shore by the winds, 
and become buried in the sand dunes. (See, further, Chapter XIII.) Wind is a better sorter than water, hence pure quartz sands will be more commonly formed from crystalline rocks in arid regions. When the rock destroyed is a marine or other sandstone, the resulting sand requires comparatively little purification.

The sands of the Libyan desert are believed to have been derived from the destruction of the Nubian sandstone to the south, whence they were transported by wind to their present position on the Cretacic limestone plateaus of the desert. Grains of lime rock from the underlying foraminiferal limestones are noted in this sand, but otherwise it is pure quartz and well assorted as to size.

\section{CONDENSATION AND PRECIPITATION OF AT- MOSPHERIC MOISTURE.*}

The moisture of the atmosphere is condensed and precipitated in the form of frost or of clouds and fogs, rain, snow, or hail. Air is brought to the point of condensation of its moisture by being carried to regions of lower temperature, $i$. $e$., up the sides of mountains or to higher latitudes, by the influx of a cooler wind, by radiation, and by expansion. Convection currents will carry the air upward to cooler regions, or to regions where it can expand. Such currents are characteristic of the tropical belt of calms where precipitation occurs almost daily.

DEw. When the temperature of the air is lowered to such a point that, with a given absolute humidity, the relative humidity rises to IOO, the next step in cooling will cause the precipitation or condensation of some of the moisture. The temperature at which this takes place in any given case is the dew point. According to the absolute amount of water in the air, the dew point will vary in temperature, being high when there is a large amount of water in the air, and low when the amount is small. Radiation on clear nights may reduce the temperature of the rocks and vegetation to such an extent below that of the air, that moisture will condense in the form of dew, if the condensation temperature is above $32^{\circ} \mathrm{F}$. ( $0^{\circ} \mathrm{C}$.), or in the form of ice particles if the temperature is below that point. Moisture thus condensed has been observed by the author to cover the rocks and vegetation of the summits of the White Mountains with ice crystals in early August, these crystals, six inches long, jutting out into the teeth of the moisture-laden wind from the vertical

* For composition of rain water see Chapter IV. 
surface of the rock cairn. Similar crystals i 8 inches long have been reported from these summits.

Frost. Frost results from a condensation of the atmospheric moisture at a temperature below the freezing point, in contact with cold objects. It has the same relation to dew that snow has to rain. The atmospheric moisture freezing in the finer rock crevices becomes a powerful agent in causing rock disruption. The freezing of water in these fissures likewise acts as a powerful wedging agent (see, further, Chapter IV.)

Clouds AND Fogs. Clouds are the condensed atmospheric vapor remaining suspended in the air, and fogs are clouds resting upon the surface of the earth. When condensation takes place above the freezing point, the clouds and fogs will consist of water particles; if below that point, they will be ice particles, constituting air frost. Clouds form an effective thermal blanket, preventing radiation and the cooling of rock surfaces. In regions of much cloudiness, shattering of rocks by insolation is reduced to a minimum. The diameter of the droplets of water in clouds and fogs has been estimated at $0.0085 \mathrm{~mm}$., and it is owing to this small size that they remain suspended. The types of forms which clouds assume are: cumulus, thick clouds with horizontal base and more or less dome-shaped upper surface; stratus, horizontal sheets of lifted fog; nimbus, or rain clouds, of thick layers of dark clouds with ragged edges; and cirrus, high, thin, feathery, or fibrous clouds, often consisting of particles of snow or ice. Intermediate types are also recognized.

Rain, SNow, and Hail. The moisture of the atmosphere is precipitated as rain, snow, or hail, when the particles become heavy enough to fall. If they begin as frozen particles of snow in the upper air, they may melt on passing through a stratum of warmer lower air and so change to rain, or, if the air is dry, even evaporate. Thus snow may fall on the mountain top and rain in the valley, or no precipitation occur in the valley, while rain or even snow falls on the summits. When water falling as rain passes through a colder stratum of air, it may freeze, and hail will result. Hail also results from the enlargement of snow crystals which pass through a very moist atmosphere and so surround themselves with layers of ice.

Amount of Rainfall. Sir John Murray (68) estimates the total annual rainfall of the globe at $29.35^{\circ}$ cubic miles. Of this amount 2,243 cubic miles of rain falls on the inland drainage areas of the globe, such as the Caspian, the Sahara, and similar districts. Of this the Sahara alone gets 728.9 cubic miles, or an average of $31,106,860$ cubic feet per square mile of area, while the Kalahari 
desert gets I4.4 cubic miles, making an average of 34,26I,500 cubic feet per square mile. The inland drainage areas of Eurasia average 25,125,040 cubic feet and those of Australia only 23,986,540 cubic feet per square mile. The total of these inland drainage areas comprises about II,486,350 square miles, giving an average of $28,729,760$ cubic feet of rain per square mile of area. None of the water falling there reaches the sea. Most or all of this amount is returned to the atmosphere and often more, as shown by the shrinkage of inland lake basins such as Great Salt Lake of Utah. When the annual rainfall is under Io inches, desert conditions will prevail, and a "rainless" condition is assumed to exist. Thus the average precipitation along the Mexican boundary of the lower Colorado district is about 8 inches; on the Yuma and Colorado deserts it is only 2 or 3 inches. The total area of land thus affected at the present time is about $12,200,000$ square miles, and corresponds very closely in extent and position to the inland drainage areas of the world. These areas are distributed as follows :

\begin{tabular}{|c|c|c|c|}
\hline Continent & - & $\begin{array}{l}\text { Area in square } \\
\text { miles with less } \\
\text { than ro inches of } \\
\text { rainfall }\end{array}$ & $\begin{array}{l}\text { Percentage of } \\
\text { total area of } \\
\text { continent }\end{array}$ \\
\hline 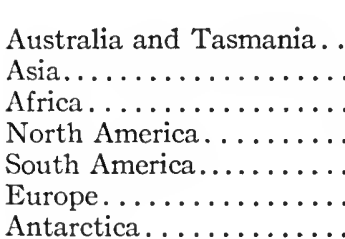 & 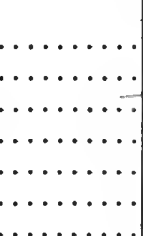 & $\begin{array}{r}1,196,250 \\
5,892,250 \\
3,221,000 \\
1,432,400 \\
333,050 \\
139,35^{\circ} \\
\end{array}$ & $\begin{array}{r}39.8 \\
36.3 \\
28.2 \\
17.0 \\
4.7 \\
3.7 \\
\end{array}$ \\
\hline Total....... & & $12,215,300$ & $\begin{array}{c}21.2 \% \text { total land } \\
\text { area } *\end{array}$ \\
\hline
\end{tabular}

The highest rainfall is recorded in Asia, where 437,500 square miles, or 2.7 per cent. of its total area, receive over 75 inches annually (averaging I I 3 inches), and in South America, where I,444,ooo square miles, or 20.5 per cent. of its total area, receives Ioo inches or over. The distribution of areas receiving over 75 inches of rainfall annually is as follows:

* Taking the total area of the land (see ante) as 148.8 million square kilometers or $57,460,777$ square miles. 
Square miles.

Asia-

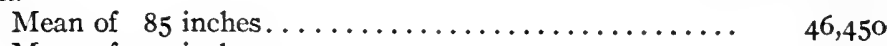

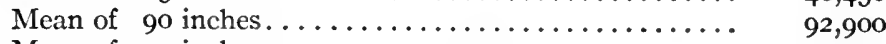

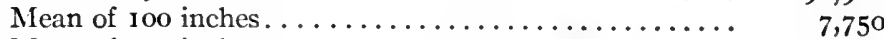

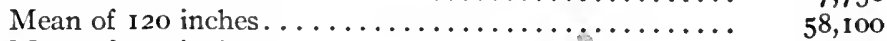

Mean of 170 inches..................... 232,300

Africa-

Mean of 100 inches.................... 201,300

Mean of 110 inches.................... 209,050

Java, mean of 110 inches.................... $54,200^{*}$

Sumatra, mean of 130 inches................. $185,800^{*}$

Celebes, mean of 120 inches.................. $77,400^{*}$

Borneo, mean of 100 inches. . . . . . . . . $290,35^{*}$

Philippines, mean of 90 inches................ 123,900*

Formosa, mean of 85 inches................. $\quad$ I5,500*

Japan, mean of 80 inches. . . . . . . . . .

North America-

Mean of 85 inches................... 92,900

Mean of 90 inches................... 69,700

South America-

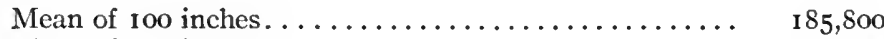

Mean of 120 inches. . . . . .

Mean of 130 inches..................... 135,500

Total area over 75 inches of rainfall annually..... 2,810,550

The rainfall of Europe does not exceed 75 inches, nor does that of Australia and Tasmania. The rainfall of the Antarctic ranges from 25 to 50 inches, that of Greenland from ro to 50 , and that of Iceland from 25 to 75 inches.

Relation of Eraporation to Rainfall. Measurements of rainfall and evaporation made in Russia have shown a steady decrease of the former from the coast to the interior, and a corresponding rapid increase of the evaporation. Thus at Kiev the rainfall is 53 $\mathrm{cm}$., while the evaporation is $48 \mathrm{~cm}$. At Astrakhan the precipitation is I6, and at Petro-Alexandrovsk it is only $6 \mathrm{~cm}$., while the corresponding evaporation at the two points is $74 \mathrm{~cm}$. and $232 \mathrm{~cm}$., respectively. The following table (p. 66), compiled by Murray, shows the annual rainfall and annual discharge for 33 rivers in different parts of the world, the difference between these representing the mean annual amount evaporated. Over the total area of the drainage basins of these rivers, comprising $13,272,000$ square miles, the annual evaporation amounts to about 8,000 cubic miles of water.

* Total area of the islands. 


\begin{tabular}{|c|c|c|c|c|c|}
\hline $\begin{array}{l}\text { Position } \\
\text { of } \\
\text { mouth } \\
\text { of } \\
\text { river }\end{array}$ & River & $\begin{array}{l}\text { Drainage } \\
\text { area } \\
\text { in } \\
\text { square } \\
\text { miles }\end{array}$ & $\begin{array}{l}\text { Annual } \\
\text { rainfall } \\
\text { in } \\
\text { cubic } \\
\text { miles }\end{array}$ & $\begin{array}{c}\text { Mean } \\
\text { annual } \\
\text { discharge } \\
\text { in cubic } \\
\text { miles }\end{array}$ & $\begin{array}{l}\text { Mean } \\
\text { ratio }\end{array}$ \\
\hline \multirow[t]{4}{*}{$50^{\circ}-60^{\circ} \mathrm{N}$. } & Rhine. & 32,600 & 19.500 & 10.100 & 2.049 \\
\hline & Oder & 51,100 & 14.700 & 2.500 & 5.803 \\
\hline & $N$ & $36,45^{\circ}$ & 10.355 & $3 \cdot 783$ & 2.737 \\
\hline & Vistula........... & 65,800 & I9.908 & 5.657 & $3 \cdot 508$ \\
\hline \multirow[t]{9}{*}{$40^{\circ}-50^{\circ} \mathrm{N}$} & St. Lawrence....... & 565,200 & 338.967 & 87.312 & 3.904 \\
\hline & Danube......... & 320,300 & 198.736 & $67 \cdot 511$ & $2.74^{6}$ \\
\hline & Po....... & 27,100 & 23.887 & $13 \cdot 322$ & 1. 794 \\
\hline & Volg & 592,300 & 152.384 & $43 \cdot 73^{6}$ & 3.484 \\
\hline & Sein & $23,25^{\circ}$ & 10.266 & $5 \cdot 469$ & 1.877 \\
\hline & Rho & 34,850 & 22.439 & 14.066 & 1.724 \\
\hline & Dniep & $197,45^{\circ}$ & 56.384 & 22.195 & 2.527 \\
\hline & $\ldots \ldots$ & 42,600 & 18.210 & 7.810 & $2.33^{2}$ \\
\hline & er........... & $30,95^{\circ}$ & 8.792 & 3.274 & 2.685 \\
\hline \multirow[t]{3}{*}{$30^{\circ}-40^{\circ} \mathrm{N}$. } & Yang-tse-kiang....... & 689,100 & 408.872 & 125.043 & $3.42 \mathrm{I}$ \\
\hline & ho......... & 387,150 & $117 \cdot 711$ & 28.591 & $4 \cdot 159$ \\
\hline & $\mathrm{N}$ & $1,293,050$ & 892.120 & $24 \cdot 334$ & 36.998 \\
\hline \multirow{4}{*}{$20^{\circ}-30^{\circ} \mathrm{N}$. } & $\mathrm{Pe}$ & 65,000 & 22.354 & 1.6 & I3.55I \\
\hline & nde......... & $\begin{array}{r}1,285,300 \\
232,300\end{array}$ & 073.064 & $\begin{array}{l}03 \\
76\end{array}$ & $\begin{array}{l}5.446 \\
8.966\end{array}$ \\
\hline & $\ldots \ldots \ldots \ldots$ & 360,050 & 104.416 & 26.032 & -4.886 \\
\hline & Gan: & $5^{88,45^{\circ}}$ & 548.791 & 43.263 & 16.169 \\
\hline \multirow[t]{4}{*}{$10^{\circ}-20^{\circ} \mathrm{N}$. } & Magdalena. . & 92,900 & I 16.746 & $59.45 I$ & I.964 \\
\hline & Iraw & I8I,950 & I 80.849 & 82.299 & 2.256 \\
\hline & Kist & $8 \mathrm{r}, 300$ & 61.025 & $14 \cdot 766$ & $4 \cdot 137$ \\
\hline & Goda & 154,850 & 95.924 & 16.841 & $5 \cdot 708$ \\
\hline N. & Orino & 429,700 & 603.397 & 122.242 & 4.936 \\
\hline Equator & Amazon........... & $2,229,900$ & $2,833.830$ & $527 \cdot 95^{I}$ & 8.009 \\
\hline \multirow[t]{2}{*}{$0^{\circ}-10^{\circ} \mathrm{S}$} & San Francisco...... & 212,900 & 218.459 & 22.197 & $9.84^{2}$ \\
\hline & Congo.............. & $\mathrm{I}, 540,800$ & I, 2 I 3.044 & 419.291 & 3.213 \\
\hline $20^{\circ}-30^{\circ} \mathrm{S}$ & 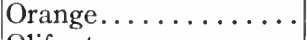 & 267,150 & 50.913 & 21.875 & 2.327 \\
\hline \multirow{4}{*}{$30^{\circ}-40^{\circ} \mathrm{S}$} & Olifant.... & 14,300 & 2.472 & 0.679 & 3.639 \\
\hline & De la Plata. & 994,900 & 904.687 & 188.740 & 6.091 \\
\hline & Uruguay ............ & 151,000 & r3o.890 & 32.136 & 4.073 \\
\hline & Total.... & $13,272,000$ & I0, 186.460 & $2,182 \cdot 485$ & \\
\hline
\end{tabular}

Influence of Winds and Topography on Rainfall. Winds blowing from higher to lower latitudes, $i$. e., from cooler to warmer regions, have their capacity for moisture increased and hence become drying winds. This is illustrated by the trade winds, which take up moisture from the oceans and the lowlands over which they blow. The Sahara, parts of Asia, and large parts of Aus- 
tralia, South Africa, and southern South America present such lowlands in the trade-wind zones, and hence are deserts. Indeed most of the great deserts of the modern world lie in the belts of lowland country swept by the trades outside the poleward limit of the equatorial rain belt, or roughly between latitudes $20^{\circ}$ and $30^{\circ}$. On the leeward western coasts of Australia, South America, and South Africa, these deserts extend directly to the edge of the sea. If these winds are forced to rise to greater altitudes, as is the case when a mountain range stretches across their path, they are cooled, and the moisture is condensed and may fall as rain or snow. Thus the windward sides of these mountains will be characterized by heavy rainfall, as illustrated by the eastern slope of the Andes Mountains. The southeastern trades of this region first lose a part of their moisture over the comparatively low Sierras of the east coast, where the rainfall is over 80 inches a year. Then, as they sweep over the Brazilian plains, the rainfall is less (between $4^{n}$ and 80 inclies per annum), to be increased again to over 80 inches as they rise in the Andes. After crossing the Andes, they descend, and being warmed both by compression during the descent (see page 49, foehn), and by contact with the warm surface of the lower region, they become drying winds, with the result that the narrow Pacific coastal strip, to leeward of the Andes, is a pronounced desert from near the equator to about latitude $30^{\circ} \mathrm{S}$. Cold ocean waters and prevailing southerly (drying) winds along shore further contribute to this result. The leeward sides of the mountains in the path of the trade winds are thus a region of little precipitation, dry savannas or deserts occurring, while the windward sides support a luxuriant vegetation. If the eastern coast mountains were higher, the winds after passing over them would become drying winds, and the plains of Brazil would be arid, rainfall becoming abundant again only as the winds rose over the Andes. Corresponding to such a distribution of rainfall, one would expect densely wooded areas on the eastern side and heavy torrent-laid deposits on the western borders of the two mountain chains, with semiarid or desert conditions between them. The latter might be characterized either by eolian erosion, or by deposition of wind-transported material, or by both. Some of the lofty islands of the Hawaiian group which lie in the northeast trade wind belt furnish other good examples of rainy windward and dry lee slopes, the latter in some cases being of a desert character.

The equatorial belt of calms and variable winds, $i . e$, the doldrums, is a region of exceptionally abundant rainfall, being one of the rainiest regions of the world, its average being about 100 inches 
per year. The cause of this rainfall is the rising and expansion of the air warmed near the surface, and the consequent cooling and condensation of its moisture. These precipitations are almost daily accompanied by thunderstorms, especially in the afternoon and evening. The belt shifts north and south with the position of the sun. Two maxima occur, one in April and one in November, lagging thus somewhat behind the vertical sun, the April maximum being the principal one. The minima between these are seldom rainless. This constitutes the equatorial type of rainfall. The tropical belt of calms, situated in about latitude $30^{\circ}$, but likewise shifting with the position of the sun, is a region of descending and hence compressing winds, which thus become warmed and have a drying effect.

From the shifting nature of the tropical rain belt with the change in position of the sun, the regions near its margin (or more than $10^{\circ}$ to $12^{\circ}$ from the equator) are subject to regular alternations of one wet and one dry season, the two rainy seasons having become merged, owing to the short interval between the periods of vertical sun in summer. This is followed by a single dry winter season. During this period the trade winds produce their drying effect, which continues until the equatorial rain belt again encroaches. This type of alternating abundant rainfall and draught is called the tropical type. The dry (winter) season lasts eight months in typical cases; the lowlands become parched and vegetation withers away, whereas during the shorter wet season grass and flowers will grow in abundance and all life take on new activity. The Soudan, between the Sahara and the equatorial forest of Africa, partakes alternately of the character of each; vegetation grows actively when the doldrums are over it (May to August), but when the trade winds blow the ground is dry and parched (December to March). The llanos of Venezuela have a dry season when the trade winds blow, $i$. $e$., during the northern winter, and an abundant rainfall from May to October. The reverse is the case in the campos of Brazil, situated south of the equator, where the rain falls from October to April, while the remainder of the year is dry. The overflow of the Nile results from the abundant rainfall in the Abyssinian Mountains when the equatorial rain belt migrates northward.

In the monsoon belts the rains follow the vertical sun, and there is thus a simple annual period similar to that of the tropical type. In summer the warm air flows inland from the sea, bringing much moisture, which is condensed and precipitated as the winds are forced to rise over mountains or highland plateaus. The heaviest precipitation in India is in the Khasi Hills (Assam) at the head of 
the Bay of Bengal, and at an altitude of 4,455 feet. Here the mean annual rainfall is between 400 and 500 inches. Along the southern base of the Himalayas it is 60 to Ioo inches, on the bold western coast 80 to 120 inches and over, and on the mountains of Burma I60 inches. (See map of Indian winds, Figs. Io and I2.) The prevailing direction of the rain-bringing monsoon of India is from the southwest, that of the Pacific coast of Asia from the southeast. In general, the eastern coasts in the tropics are the rainiest, though there are notable exceptions to this rule.

The westerly winds of both hemispheres (southwesterly in the northern and northwesterly in the southern), which blow poleward above the latitudes of $30^{\circ}$, have a corresponding effect on the rainfall, the precipitation occurring on the westerly side of the mountain ranges, while corresponding dryness prevails on the eastern. In general, bold west coasts on the polar side of latitude $40^{\circ}$ are very rainy, the precipitation being 100 inches or more a year in the most favorable situations. The interior of the continents, on the other hand, especially when well enclosed by mountains, or open only to the cool ocean winds which become warmed as they proceed, have only a slight rainfall of from io to 20 inches or less. The eastern coasts are drier than the western, but wetter than the interiors of the continents. The maximum rainfall occurs in winter over the oceans, islands, and west coasts of the continents, this being the season of strong westerly winds, when cyclonic stormis are most numerous and best developed. The cold lands, too, have a chilling effect on the inflowing damp air. In the interior of the continents high pressure prevails and the winds flow outward, while their low temperature at the start makes them drying winds as they proceed outward to warmer regions. This season is, therefore, the driest for the interior of the continents.

The greater part of the United States lies within this zone of prevailing westerlies, the direction for almost all the country being from the southwest. In winter these winds from the Pacific yield their moisture on reaching the cool lands, this occurring even at low altitudes, as a result of which the lowlands of California have a wet season. This condition also exists in summer in Washington and Alaska, while southern California has its dry season. Rising over the mountains back of the coast, the winds yield more moisture, so that all the regions west of the crest of the coast ranges are well supplied with rain and snow in winter. Beyond this range, and beyond the Sierras and Cascade Mountains further north, the winds descend and become warmer and drier, and here lie the semiarid lands of eastern Oregon and Washington, and the Great Basin with 
Great Salt Lake, the shrunken remnant of Lake Bonneville. In southern California the Mohave and Colorado deserts lie just east of the Coast Range. In the higher parts of the Rocky Mountains these winds again yield some moisture, but beyond these ridges they once more become drying winds, with corresponding semiaridity of the climate. The winds would continue so, and arid conditions would prevail throughout the entire interior of the continent, were it not for the aperiodic cyclonic winds which, passing over the country from east to west, cause moist air to flow from the Gulf northward to cooler latitudes.

If the south winds from the Gulf were shut out by a mountain range, the region to the northeast of it would likewise be of an arid nature. Such conditions seem to have existed in Triassic time in North America and western Europe. In North America the newly formed Appalachian ranges shut in the land on the Atlantic side, and their westward continuation in Arkansas, Oklahoma, and Texas formed a barrier against the winds from the south. Continuing through the region of the present Basin ranges, as the Palæo-Cordilleran Mountains, they formed the western arm of the system which embraced interior North America. To the south and west extended the Triassic sea with its marine limestone accumulations. Rising over the Palæo-Cordillerans in the southern region (Arizona, New Mexico), these winds became drying winds, as a result of which semiarid continental deposits were formed on the leeward side of these mountains. These are now found as extensive red sandstone deposits, partly of torrential, but perhaps more largely of eolian character, extending from Texas to Montana and Canada. They are heaviest in the Arizona region and extend eastward and northward into Colorado and Dakota, dipping under the Cretacic deposits of the Great Plains. They come to an end before reaching the Mississippi Valley, where Cretacic beds rest disconformably upon Permic. Over the whole eastern half of North America, west of the newly made Appalachian Mountains, no Triassic deposits are known, and erosion rather than deposition seems to have been active. This erosion probably was in part eolian, similar to that known in the Kalahari desert, but near the mountains precipitation was again abundant, so that river erosion characterized the mountain regions. Much of the drainage from these mountains must have escaped toward the northwest, where an arm of the sea entered during part of Triassic and later Jurassic time. Some of the continental deposits formed over the crystalline region of Canada and northern United States may have subsequently been reworked into the con- 
tinental Kootanay and Cretacic deposits, especially the widespread Dakota sandstone. As the west-winds descended on the eastern side of the new Appalachians, they again produced semiarid conditions, which favored the deposition of the continental Newark and Connecticut Valley sandstones and their extensions north and south, formations which to-day are represented only by fragments of what must have been formerly a very extensive piedmont deposit. Southward the condition seems to have been one of less aridity, possibly because the mountains were lower, or south winds from the Atlantic acted as modifiers, for here we find plant beds and coal deposits associated with the upper part of the formation. These same southwesterlies were also responsible for the extensive continental deposits of the Trias of western Europe. A mountain chain, the Armorican, extended northwestward from central France through Brittany, southern England and Ireland, thus lying directly in the path of the southwesterly winds. A second chain, the Variscian, extended eastward through southern Germany, around the Bohemian Mass on the north, and thence to the present Carpathians. These chains thus completely enclosed northern Europe on the south, and to the north of them were formed the extensive New Red sandstone deposits of England and the Bunter Sandstein with its desert features in Germany.

Latitude and Precipitation. Rain and snow decrease progressively from the equator polewards, the precipitation being comparatively slight, owing to the smaller capacity of the air for watervapor at the prevailing low temperature. and to the absence of local convectional storms. The western coast of Norway is an exception, since the rainfall is here much heavier. The precipitation is mostly in the form of snow, though rain falls in summer sometimes probably at all points. The snow of the polar regions is fine and dry: flakes are not formed at low temperatures, but the atmosphere is full of fine, glittering ice needles, which gradually descend to the earth even on clear days.

Periodicity of Rainfall. In a number of places, as for example India, observations have shown an apparent fluctuation in rainfall and temperature for a period of eleven years, corresponding to the sun-spot period or the periodicity of the earth's magnetic phenomena. A thirty-five-year period of oscillation has also been discovered and elaborated by Professor Brïckner (12) (Brückner cycle). The cycle varies from 20 to 50 years, but 35 is the average. The fluctuations of the rainfall between the dry and wet periods are most marked in the interior of the continents. 


\section{ELECTRICAL PHENOMENA OF THE ATMOSPHERE.}

By thunderstorms, or other electrical discharges in the atmosphere, some of its oxygen is probably converted into the allotropic modification ozone. Hydrogen dioxide and oxides of nitrogen are further formed, the latter yielding, with the moisture of the air, nitric and nitrous acids, which, when brought to the earth by rains, become agents of corrosion of the rocks. Both ozone and hydrogen dioxide are powerful oxidizing agents, and will transform organic matter suspended in the air into carbon dioxide, water, and probably ammonium nitrate.

Lightning may further act as a disrupter of rock masses. In Fetlar, one of the Shetland Islands, a solid mass of rock 105 feet long, ro feet broad, and in some places more than 4 feet high, was in an instant torn from its bed by lightning and broken into three large and several small fragments. "One of these, 28 feet long, I7 feet broad, and 5 feet in thickness, was hurled across a high point of rock to a distance of 50 yards. Another broken mass, about 40 feet long, was thrown still farther, but in the same direction, and quite into the sea. There were also many lesser fragments scattered up and down." (Hibbard-49:389.)

FULGURITES. When the electric spark strikes loose sand or rock, a coating of fused vitreous material may be formed, or a mass of vitreous drops or bubbles. More generally, slender tubes of fused material mark the path of the electric spark, especially in loose sand. These tubes, known as fulgurites * consist of fused grains, and range up to $2^{1 / 2}$ inches in diameter. They descend vertically. or obliquely into the rock or sand, occasionally branch, and diminish in size to a point. The summit of Little Ararat, which is exposed to frequent thunderstorms, is riddled with fulgurites, which here occur in a porous andesite and consist of irregular tubes having an average diameter of 3 centimeters, and being lined with a blackish-green glass. Humboldt obtained these fulgurites from trachyte peaks in Mexico, and found that in two cases at least the fused mass overflowed from the tubes onto the surrounding surface. Other cases of lightning-fused rocks have been reported in hornblende schist of Mont Blanc (De Saussure); in mica schist and limestones from the Pyrenees (Ramond; Arago); in basalt of Mount Thielson, Oregon, and Mount Shasta, California (Diller); in glaucophane schist of Monte Viso (J. Eccles); in gneiss of Lake

\footnotetext{
* For extended bibliography including the cases cited, see the article by Barrows (5) 1910.
} 
Champlain (Hallock), etc. Fulgurites in sand have been frequently described. These have been found in the sands of the Libyan desert (Gümbel), as well as in the sand and soil of moist climates. In Silesia, near Olkusz, 26 tubes were found in an area of 200 by 100 feet, most of them associated in groups. In Cumberland, England, near Drigg, fulgurites of exceptional size were found. Three of these tubes were found in a sand hillock within an area of fifteen square yards. One of them was traced perpendicularly to a depth of 40 feet, the basal part being much contorted and branched, owing to the presence of many small pebbles in the soil. The maximim diameter of this tube was $2 \frac{1}{2}$ inches.

The finer structure of the glass lining of the tube has been especially investigated by Julien (53). He finds that the bubbles which occur in such large numbers in the clear amorphous glass of the tube contain no water, these bubbles probably being formed by the expansion of heated air. The vesicles are elongated, and their longer axes disposed radially. All sand grains within a radius of a few millimeters were suddenly and completely fused. The inner wall is practically free from bubbles, and is a clear, shining glass, streaked and spotted with black and brown, according to the abundance of iron-bearing minerals. Externally the form is very rough, corrugated longitudinally and coated with partially fused sand grains. The outline is an irregularly branching one, due to the forking of the electric spark. The thickness of the wall varies from $0.1 \mathrm{~cm}$. or less to $0.5 \mathrm{~cm}$. or more, and the vesicles from less than $0.002 \mathrm{~mm}$. to $1.2 \mathrm{~mm}$. or over. The cross section is often nearly circular; at other times it is irregular. Sometimes the round hole is merely lined by a network of fused materials.

Of exceptional interest is a fulgurite described by Barrows (5) from the Raritan sands of New Jersey. It was found in a mass of sand fifty feet thick, resting on the South Amboy fire clay, and occurred 15 to 20 feet above the clay or from 45 to 55 feet from the surface formed by the Pensauken outwash gravels of Pleistocenic age. The fulgurite ran at a low angle to the horizontal for about I 5 feet parallel to the face of the bank. The length was about ig feet, including branches, and the diameter of the tube varied from $3.2 \mathrm{~cm}$. to $0.3 \mathrm{~cm}$. The position of this tube suggests that it was formed after part of the sand had been leposited and before the laying down of the upper part of the sand. If this is the case, these sands would have to be regarded as dune sands, since fulgurites will form only in comparatively dry media. This interpretation is not inconsistent with the character of the formation as a whole, which is of continental rather than of marine origin. Of course the tube 
may have resulted from a discharge entering the bank of sand since digging has exposed it, but it is difficult to understand why the discharge should run parallel to the face of the cliff.

It is obvious that fulgurites found in the older formations may have such relationships that they must be regarded as contemporaneous in age with the formation, in which case they would form valuable evidence for the continental origin of such formations.

\section{CLIMATE. CLIMATIC ZONES, PRESENT AND PAST.}

Climate is the average or sum total of weather conditions normal to a given region, while weather is only a single occurrence or event in that series of conditions, and of short duration. Climate may be classified as solar and physical, the latter comprising continental, marine, and mountain climates.

\section{Solar Climates. Climatic Belts or Zones.}

If the earth had a homogeneous land surface and no atmosphere, solar climate alone would prevail, the distribution of heat being solely according to latitude. Five zones of solar climate are recognized: the torrid or tropical, limited by the tropics of Cancer and Capricorn and divided by the equator, the two temperate zones, limited poleward by the arctic and antarctic circles, and the two frigid or polar zones centering at the poles. The torrid or tropical zone has the least annual variation in insolation, and may be called the zone of perpetual summer, while the polar zones have the greatest variation between summer and winter, and may be called the winter zones, summer being so short and cool that it may be neglected. The intermediate zones have about an equal distribution of seasons, summer in the northern corresponding to winter in the southern hemisphere. A somewhat different delimitation of the zones has been proposed by Supan, who suggests that the hot belt be limited by the two mean annual isotherms of $+68^{\circ} \mathrm{F} .\left(+20^{\circ} \mathrm{C}\right.$.) (the approximate polar limit of the trade-wind belts, and the polar limit of palms), and the polar limits of the temperate zones, by the two isotherms of $+50^{\circ} \mathrm{F} .\left(+10^{\circ} \mathrm{C}\right.$. ) for the warmest month (the approximate northern limit of the cereals and forest trees). This limit in the north is very near the northern boundary of the continent of North America and Eurasia, while in the south it passes through the southern extremity of South America. Africa lies almost wholly within the hot belt, and so does the greater part of South and all of Central America. The smaller size of the north 
polar climatic cap is due to the expansion of the land in that hemisphere. The greatest expanse of land lies in the north temperate zone.

\section{Pinysical Climate.}

This is the climate produced through modification of the solar climate by the physical characters of the earth's surface. The principal kinds to be considered are: 1, The marine or oceanic; 2, the coast or littoral; 3 , the continental or interior; 4 , the desert, and 5 , the mountain and plateau climates. Each of these has its peculiarities which in turn influence the distribution of plant and animal life. (See Chapter XXIX.)

I. Marine or Occanic Climate. Owing to the slow changes of temperature which the ocean water undergoes, the seasonal temperature changes are comparatively slight, while the times of occurrence of maxima and minima are retarded, a cool spring and warm autumn resulting. Relatively greater humidity, cloudiness, and heavier rainfall than is found on the land, are further characteristic of marine climates; and are explained by the greater evaporation over the sea. In the winter within the middle latitudes, there is excessive precipitation over the oceans, but the continental interiors are relatively dry. Air over the water is also purer and in more active motion than that over the land.

2. Coast or Littoral Climate. The coastal region shows the transition from the marine to the interior continental type of climate, and nay alternately partake of both, according to whether the prevailing wind is from the sea or from the land. The windward coasts are tisually well supplied with rainfall, especially in the tropics, while the leeward coasts, notably those in the tradewind zones, are usually dry; and the deserts may extend clear to the coast. This is the condition on the west coasts of South America, Africa and Australia. The cold shore currents and the prevailing long-shore winds further prevent precipitation. An exception to this general character of wet eastern and dry western coasts in the trade-wind zone is seen in the regions of the monsoons. Thus the west coast of India is abundantly watered by the wet southwest monsoon. A peculiarity of these monsoon countries is the threefold division of the climate such as characterizes India. In the winter little precipitation occurs, and the temperature is low, the monsoons blowing offshore. Then follows the hot transition period, which in turn is succeeded by the cooler and wet summer season, when the monsoon blows onshore. The monsoons of the 
eastern coast of Asia, the most northerly of such, likewise produce these results, the weather being cold, clear and dry in winter, and cool, cloudy and damp in summer.

3. Intcrior Continental Climates. In the interior of continents climatic changes are for the most part very pronounced. The annual temperature ranges become greater with increased distance from the shore, the coldest and warmest months in the northern hemisphere being January and July, respectively. There being less cloudiness over the land, the diurnal changes are greater than over the sea. These ranges are well shown by a comparison of the January and July temperatures of coast and inland stations in low and high latitudes.

\begin{tabular}{|c|c|c|c|c|}
\hline \multirow{2}{*}{ - } & \multicolumn{2}{|c|}{$\begin{array}{c}\text { January } \\
\text { temperature }\end{array}$} & \multicolumn{2}{|c|}{$\begin{array}{l}\text { July-August } \\
\text { temperature }\end{array}$} \\
\hline & C. & F. & C. & F. \\
\hline 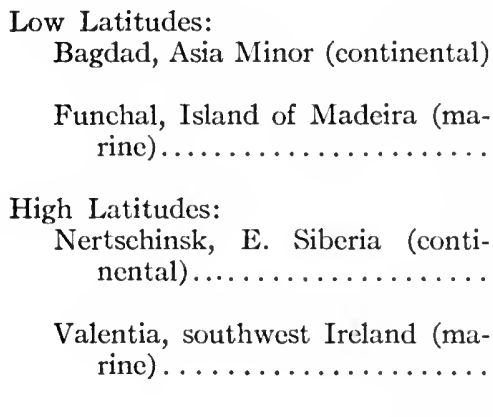 & $\begin{array}{l}+11 \cdot 5^{\circ} \\
\ldots \ldots \\
+15 \cdot 5^{\circ} \\
\cdots \cdots \cdots \\
-32^{\circ} \\
\ldots \ldots \\
+7 \cdot 5^{\circ} \\
\ldots \ldots \cdots\end{array}$ & $\begin{array}{l}\ldots \ldots \cdots \\
+53^{\circ} \\
\ldots \ldots 0^{\circ} \\
\ldots \ldots \\
-25.6^{\circ} \\
\ldots \ldots \\
+45.5^{\circ}\end{array}$ & $\begin{array}{l}+34^{\circ} \\
\ldots \ldots \\
+22 \cdot 5^{\circ} \\
\ldots \ldots \cdots \\
+22^{\circ} \\
\ldots \ldots \ldots \\
+16^{\circ} \\
\ldots \ldots \ldots\end{array}$ & $\begin{array}{l}\ldots \ldots \ldots \\
+93^{\circ} \\
\ldots \ldots \ldots \\
+72.5^{\circ}\end{array}$ \\
\hline
\end{tabular}

The mean range of many observations in widely distributed stations is $8.2^{\circ} \mathrm{C}$. for marine, and $39.0^{\circ} \mathrm{C}$. for continental climates. (Hann-40: I 42.)

The relative humidity of continental interiors is of course much lower than that over the sea or on the coast, but even in arid regions it may reach 20 per cent. or 30 per cent. The rainfall decreases in amount and frequency as we proceed inland, except where local topographic features act as modifiers. The winds average lower in velocity, and calms are more frequent over the land than over the sea. Continental winds are sometimes so well developed as to become monsoons. 
4. Desert Climate. This is characterized by excessive dryness, by great heat during the day, with accompanying strong convection currents resulting in high winds, and by relatively cool, clear and calm nights. The peculiarities of temperature and aridity are unfavorable to the growth of vegetation, except certain arlapted forms, and the general absence of plants further intensifies the climatic conditions. Rains are infrequent; parts of the Sahara are known to have been without rains for 10 or 15 years, and when they occur they are apt to be sudden downpours of great floods of water. Dust storms are characteristic of the daytime, when high winds blow, and it is then that deflation and the mechanical wear by drifting sands are chiefly accomplished. The rivers resulting from the sudden rainfalls, or fed by springs in the mountains, wither away, the water sinking into the parched ground or evaporating. Brackish sinks and lakes abound, and temporary playa-lakes suddenly come into existence and disappear by evaporation, leaving behind a characteristic, hard, mud-cracked surface. The plants protect themselves against animals by thorns, and guard against excessive evaporation by a reduction in the size of the leaves. The roots penetrate deep into the dry soil and subdivide extensively to obtain all the available moisture.

5. Mountain Climate. This is distinctive in all zones, and always contrasts strongly with that of the neighboring lowlands. There is a decrease in temperature, pressure and absolute humidity, and an increase in intensity of insolation and radiation, and generally an increase in the frequency and amount of precipitation. Pressure is reduced to about one-half that at sea-level, at an altitude of about 16,000 feet, while the zone of maximum rainfall lies at about 6,000 to 7,000 feet in intermediate latitudes. Inversions of temperature characterize mountains at night and during the colder months, the cold air flowing down the mountain sides to collect in the valleys below, and being replaced by warmer air above. Thus the diurnal and annual ranges of temperature are lessened, mountain summits having in this respect a climate more nearly resembling the marine.

\section{Climatic Provinces.}

Detailed consideration of climates leads to the recognition of a number of climatic types for the entire earth, the characters of these types being brought about by combinations of distinct climatic elements. Supan has established thirty-five types arranged in thirtyfive provinces as follows ( $\left.9^{1}: 23^{2}\right)$ : 
I. Eastern Continents and Island Regions with the following provinces :

I West European; 2 East European; 3 West Siberian; 4 East Siberian; 5 Kamtschatka; 6 Chinese-Japanese; 7 Asiatic highland; 8 Aral; 9 Indus; 10 Mediterranean; I-I Sahara; 12 Tropical Africa; I3 Kalahari; I4 Cape (of Good Hope); I5 East Inclo-Australian monsoon province; i6 Australian lake province; i7 Southwest Australia; 18 East Australian; 19 New Zealand; 20 Polynesia (tropical) ; 2 I Hawaii.

II. American Regions with the following provinces:

I Hudson Bay ; 2 Northwest Coast; 3 California ; 4 Highlands; 5 Atlantic; 6 West Indian; 7 Tropical Cordilleran; 8 Tropical South America ; 9 Peruan; 10 North Chilean ; i s South Chilean; 12 Pampas.

III. Arctic Regions with only one province:

I Arctic province.

IV. Antarctic Regions with only one province:

I Antarctic province.

Climatic Types, Based on Separate Atmospileric Factors and on Agents.

In considering the principal atmospheric factors, we may recognize several distinct types, which, however, vary with change in local conditions. The principal types based on factors are: (I) moist and (2) dry, (3) cold and (4) warm, (5) pluvial and (6) arid. Based on the agent infuenced by these factors, we may distinguish: ( I) glacial climates, when glacial conditions become widespread, and (2) interglacial climates, when glaciers dwindle; (3) fluvial and lacustrine climates, when there is an increase in precipitation and consequently a rise in streams and an extension of lakes, and (4) interfluvial and interlacustrine, or desert climates, when the reverse is true, lakes and rivers shrink and vegetation dries up. These terms are useful in discussing the prevailing character of ancient climates.

\section{Climatic Zones of the Past.}

The existence of climatic zones in the past was first suggested by Jules Marcou in 1860, who postulated their occurrence in Jurassic time to explain the "homozooidal belts" of that period. The Austrian geologist, Melchior Neumayr ( 70 ), attempted to prove this theory by palæontological and geological evidence, and his conclu- 
sions have been widely accepted in some quarters, and combated in others.

Neumay's Climatic Zones of the Jurassic. These from the north southward are as follows:

I. Boreal Zone. Characterized by the presence of the ammonite genera, Cardioceras, Oxynoticeras, and Virgatites, the belemnite Cylindroteuthis, and the pelecypod Aucella; also by the absence of reef-building corals, and of the ammonite genera: Phylloceras, Lytoccras. Simoceras, and Lissoceras, and the scarcity of the genera: Oppelia, Hecticoccras, Peltoceras, and Aspidoceras. The boundary between this and the next zone was placed at latitude $45^{\circ}$ in the Pacific, but further north in the Atlantic and Europe.

2. North Temperate Zone. This comprised especially the provinces of Central Europe, and was characterized by the rarity of the ammonite genera which attained their maximum in the two adjoining zones; and also by the appearance of reef corals, and the predominance of the ammonite genera: Oppelia, Reineckia, Peltoceras, and Aspidoceras. The boundary between this and the next zone was placed at latitude $32^{\circ} \mathrm{N}$. in the Pacific, but oscillated about latitude $40^{\circ} \mathrm{N}$. in the Atlantic and in Eurasia.

3. Equatorial Zone. This comprised in Europe the Mediterranean province and was characterized by the abundance of the ammonite genera Phylloceras, Lytoceras, and Simoceras, the belemnites Belemnopsis and Duvalia, and the brachiopod, Pygope. The boundary between this and the next zone was placed at about latitude $32^{\circ} \mathrm{S}$.

4. South Temperate Zone. This reproduced the characters of the north temperate zone.

\section{Discussion or the Subject of Climatic Zones.}

Of the zones mentioned above, the colder or boreal zone appears to be well established, but the differentiation of the warmer belt into three distinct zones is less generally supported by the evidence. In Europe the north temperate province of Neumayr represents. according to Haug (42), the shallow water zone of the warm belt. while the equatorial zone corresponds in general with the open and deep Thetys sea. The distribution of the genera in these provinces is due more to this difference in depth and the corresponding difference in temperature than to zonal distinctness. That annual changes of temperature existed in Jurassic time is shown by the development of annual growth rings in the stems of Abietinex of that period found on King Charles Land. ( $78^{\circ}$ N. lat.) (Gotan- 
$35: 44$.) (See, further, under Chapter XXIX.) Although the distribution of the genera of ammonites, as well as of corals, does not follow so rigidly the belt-like arrangement in extra-European countries as held by Neumayr, and although much of the distribution is explainable by difference in depth, still the probability of differentiation of the earth's surface into climatic zones is not to be altogether discarded. A part of the anomalous distribution of ammonites may certainly be explained by floatation (see Chapter XXVIII), while the deflection of the zonal boundaries, due to continental expansions or contractions, must also be considered. Finally, the influence of ocean currents in modifying the temperature of the water must not be neglected. Ortmann ( 7 I:267) especially emphasizes the occurrence of reef-building corals in the Russian Jura, in a region included in Neumayr's boreal zone, and insists that these indicate a tropical climate, but Neumayr contended that such occurrence was not sufficient evidence against his theory.

That climatic zones existed during Mesozoic times, if not earlier, is not at all an improbable supposition, though it may perhaps be questioned whether the differences between successive zones were always as great as now. That the air temperature as a whole was higher at times than now, probably through an increase in the carbon dioxide content and the consequent trapping of solar heat, is highly probable, and indeed seems far more reasonable than the assumption of a uniform climate over the entire earth. A universal rise in temperature of the air would permit a wider distribution of those marine types now restricted to the tropical water of to-day, for the present tropical temperatures would extend to higher latitudes. Even though the tropics under such conditions would be much more highly heated, it is questionable if the waters would be too hot for the existence of life. It would only be necessary for organisms living in the tropics to descend to greater depths, so as to escape the excessive surface temperatures. Nor must the possibility be overlooked that stenothermal modern forms may have had eurythermal ancestors; that, in other words, the descendants of once widely adapted classes of organisms, capable of existing under a great range of temperature, have now become restricted to a limited range, in the warmer waters of to-day.

It is a universally recognized fact that climatic conditions of greater severity existed in the recent geologic past, so that extensive portions of the northern continents became glaciated. The very fact that these glaciers extended over only part of the earth's surface shows the existence of climatic zones, the limit of glaciation marking the poleward limit of a milder belt. The southern 
limit of Pleistocenic glaciation in North America was at latitude $37^{\circ} 30^{\prime}$ in the Mississippi valley, while in Europe it did not extend below about $53^{\circ}$, though the Alps and other great mountain ranges were heavily glaciated. The high mountain areas of Asia (Lebanon, the Caucasus, the Himalayas and the mountains of Manchuria) were heavily glaciated, these glaciers reaching down to 4,500 feet A. T. in latitude $26^{\circ}$ in Bengal, and to 2,000 or 3,000 feet in the western Himalayas. (Coleman-19:348.) The Atlas Mountains of Africa and the lofty peaks under the equator all show an advance of the glaciers of several thousand feet lower than at present. A similar extent of glaciation of the southern hemisphere would not have reached any of the continents, except the southern end of South America and perhaps New Zealand. The greater expanse of ocean, however, with its more moderate climate, would favor a less extent of the Atlantic ice; and it may be questioned if the ice sheet which is known to have been much more extensive over the Antarctic continent extended much beyond its border. Patagonia, it is true, was widely glaciated south of latitude $37^{\circ}$, the ice reaching the sea. This may have been purely local, however. In the Andes, further north, even within the tropics, are old moraines, showing the extent of these glaciers 800 to 900 meters below their present position.

The now incontrovertible evidence pointing to glacial periods at various tines during the geologic history of the earth from preCambric time on, indicates not only repeated periods of greater cold in the earth's atmosphere, explainable by the reduction in the amount of $\mathrm{CO}_{2}$, but also the existence of warmer and colder zones, as shown by the limited extent of these glacial deposits. Indeed, it may be questioned if zonal arrangement of temperature has not always been the normal state of the atmosphere, and that the changes have only been toward a greater universal increase or decrease in temperature, the former pernitting expansion of tropical types of organisms, the latter the expansion of the cooler types, and culminating in many cases in periods of glaciation. Evidence of early glaciation has now been recorded from the Lower Huronian of Ontario, Canada (Coleman-19), the pre-Cambric (?) of Varanger Fjord, Norway (Reusch, Strahan-9o, etc.), and Spitzbergen (Gregory-37), the basal Cambric or pre-Cambric of the Yangtse canyon of China (IVillis-I08), of South Australia (Howchin, David-23, etc.), and Tasmania; of South Africa (Griquatown series, Rogers-79) and less definitely from North America and North Asia. The extent in the southern hemisphere was northward to $29^{\circ}$ in South Africa, and to $32^{\circ}$ or $33^{\circ}$ in South Australia, 
the movement being northward and the ice reaching sea-level. The evirlence of Permo-Carbonic glaciation is even more firmly established. This has been recognized in India, Australia and Tasmania, South Africa (Dwyka conglomerate and tillite) and South America. In India the indications of glacial occupancy have been traced from lat. $16^{\circ}$ or $17^{\circ}$ to lat. $34^{\circ}$ or $35^{\circ}$, and in Australia from lat. $20^{\circ} 30^{\prime}$ to lat. $43^{\circ} \mathrm{S}$. In the eastern Urals of Russia a Permic boulder conglomerate suggests glacial origin (Karpinsky) and a conglomerate of similar age in England has been regarded by Ramsay as glacial, though this has been disputed by others. In Prince Edward Island (F. Bain-3), Colorado (Cross), and eastern Massachusetts (Shaler) conglomerates of this age occur, which suggest a glacial origin. In the Antarctic region glacial deposits of this age have recently been found in the Falkland Islands (Halle$4 \mathrm{I}: 26.1$ ).

It is a remarkable fact that a center of Permic glaciation in the Old World seems to have been near the tropics, perhaps in the Indian Ocean (the old Gondwana land), for the movement in South Africa seems to have been southward, and in India northward, the movement in both cases being away from the equator. The evidence of transported rocks in eastern Massachusetts is, however, from the north and similar in extent to that of the Pleistocenic glacial transportation. So far as the evidence goes, a general refrigeration of the climate of world-wide extent may have occurred, and the development of an ice sheet in the tropics may be in part due to the great elevation of the land of that time and in part to the nature of supply of moisture to feed the ice sheet. (Philippi75.) For another suggested explanation, see Chapter XXIII.

\section{Rimythim of Climatic Changes.}

The course of climatic changes during geologic time passes from a rhythmically pulsating state, a climatic "strophe," to one of relative torpidity, the climatic "interstrophe." (Huntington-5I:362.) The pulsations of the strophe comprise a series of accentuations of certain climatic characters, such as glacial, fluvial, vegetal (when plant life spreads widely), or pluvial (when much rain falls). Each accentuation forms an arsis of the climatic strophe, the time of such accentuation being an arsial epoch. The thesis, or thesial epoch of the strophe, is the depression between the accented epochs, as in the case of interglacial or interfluvial epochs, intervegetal or interpluvial epochs. The growth in strength of the arses and theses of the strophe is a gradual one to the point when the acme is reached, 
after which a diminution will set in. The interval between two thesial epochs constitutes a short or strophic cycle, while the interval from the center of one interstrophe to that of another constitutes a grand or climatic cycle. (See diagram, Fig. 15.)

\section{Indication of Climatic Changes.}

Topograpiitc Evidence of Cilange in Climate. Since the angle of slope assumed by waste under arid conditions is much steeper than that assumed under pluvial climates (see postca Chapter XIV) and the material of the former is much coarser than that of the latter, it follows that traces of such conditions in a region now well watered suggest a former greater aridity. This is seen in alluvial fans of great radius and steepness of slope, such as those of the region near San Bernardino with radii of ten, twelve, or

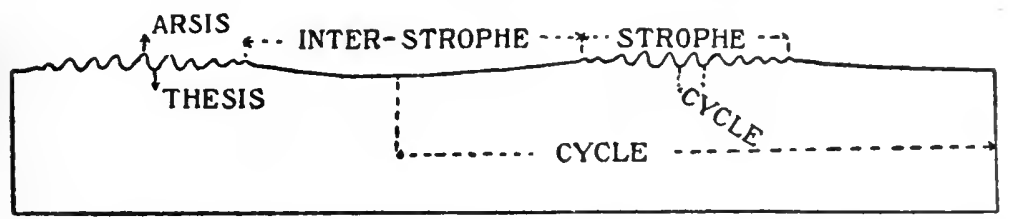

FIG. 15. Diagram illustrating progress of changes of climate during geologic time. (After Huntington.)

fourteen miles, and an elevation, at the head, of four, six, or seven hundred feet above the frontal margin. Such fans are characteristic of arid mountain regions, and their essential features will be recognizable in the topography of a region become more moist. The clogging by waste of deep-cut valleys, formed during a moist climatic period, as well as the formation of fans on the much dissected mountain slopes, is evidence of change from moist to dry climate. In the same manner the dissection of steeply graded valley floors and waste slopes shows a change from dry to moist climate, provided these features do not indicate increased elevation of the region. In lakes of a dry region the water would be low and their shores lined by alluvial fans, against which, on the change of the climate to moister conditions, the waters of the expanded lake would come to lie. This was the case in Lake Bonneville, the waters of which rested against the alluvial fans of the pre-Bonneville dry period. The present dry period is again characterized by the formation of such alluvial fans. The outlets of these lakes are further marked by the features of topographic youth. Evidences of 
former extensive sand dunes now covered over by vegetation must further be regarded as indicative of a change of climate.

Stratigraphic Evidence of Change of Climate. A careful consideration of the lithic characters of the strata of a given region may furnish evidence of changes of climate in the successive geologic epochs. Thus ancient alluvial fans and delta deposits intercalated between marine sediments are not only evidence of elevation followed by subsidence, but may also indicate a change in climatic conditions. This is especially the case when such alluvial fans are characterized by coarse waste, or by red color. The red color of such continental deposits as the Longwood shale of the late Siluric, the Catskill and Old Red sandstones of the Devonic, the Mauch Chunk of the Mississippic, and the Newark and Red beds of the Trias, have been regarded as indicating more or less arid conditions during the formation of those deposits. Huntington (5I) has described the alternations of red and green strata exposed in the uplifted and dissected bottom of the Pleistocenic lake Seyistan in eastern Persia. The red or pink strata are thick beds of clays, silts, and fine brown sands of a very continuous and uniform character, traceable for miles, even though varying in minor details. They show evidence of exposure to the air, under conditions which prevented extensive development of vegetation. The white or greenish layers, on the other hand, are solid beds of clay, lined above and below by somewhat more sandy films. These green clays were deposited during the periods of expansion of the lake, while the red beds indicate exposure to a dry climate followed by oxidation during periods of retreat, when arid conditions prevailed. There are here indicated ten epochs of expansion of the lake (the arsial cpochs) and ten of contraction (the thesial epochs). The Moencopie beds of Utah and Arizona (Permic) show a similar alternation of red and greenish beds and indicate a similar pulsation of the climate of the Permic.

Arid conditions are also shown by the arkose character of many rocks, as, for example, the Torriclon sandstone of western Scotland, where the feldspar crystals are scarcely weathered, and the Newark sandstone beneath the Palisades of the Hudson. Arid conditions are further indicated by the occurrence of beds of salt and gypsum, and the same thing is shown by extensive deposits of wind-blown, cross-bedded sands such as are found in the White River beds ( $\mathrm{Ju}$ rassic) of Arizona. The extensive development of coal swamps and marshes may indicate a change to cooler and moister climate, while tillites, coarse boulder conglomerates and striated rock and boulder surfaces indicate glacial conditions. 
Organic Evidence of Change of Climate. This is in many respects the most reliable, since organisms are the most sensitive indicators of climatic conditions.

I. Plants. Coal swamp vegetation, as indicative of cooler and moister climates, has already been referred to. The various types of swamp vegetation preserved in the peats of different countries, serve as an excellent index to the gradual change of climatic conditions since the last glacial period. Thus for Germany it has been ascertained that the first floral mantle following the retreat of the ice was of the tundra type without any true arboreal growths whatever. In many places a lower horizon, with the mountain or arctic dryas, Dryas octopetala, and the arctic divarf willow, Salix polaris, and a higher one, with Salix phylicifolia and S. reticulata, besides Dryas octopctala, can be determined. Aquatic plants are rare in this period, but several species of Potamogeton occur regularly in the upper beds, together with Myriophyllum spicatum, Hippuris vulgaris and Batrachium aquatile confervoides. During the Dryas period, even in the earliest epoch, the climate could not have been an arctic one in North Germany, for the aquatic plants require a July temperature of approximately $6^{\circ} \mathrm{C}$., and need 4 to 5 months with a temperature of at least $3^{\circ} \mathrm{C}$. in order that their seeds may ripen. The rapid amelioration of the climate during the Dryas period is shown by the presence of Phragmites communis in the upper layers formed during this period, followed by heavy deposits of decayed vegetation, indicating a rapid increase in the plant and animal life of the waters. With this appears the first arboreal vegetation with birches and pines.

The two epochs of arctic floras, $i . c$., the earlier colder one with Salix polaris and the later milder one with Salix reticulata, are recognized in many regions in Scania and elsewhere in southern Sweden. In Finland the arctic Dryas flora (Dryas, Salix polaris, Betula nana, Batrachium confervoides) and the moss Sphcrocephalus turgidus, characteristic of the modern arctic region, together with the arctic beetle Pterostichus vermiculosus, occur in a sandy deposit between Lake Ladoga and the Gulf of Finland, indicating a climate, during the period of the melting of the ice, comparable to that now found in northern Russia and the ncighborhood of the polar sea. The Sali.r polaris flora has also been found in Norway and Denmark, this arctic flora everywhere forming the first or tundra type of flora to appear during the period of melting of the glaciers. Gunnar Andersson lays especial stress on the occurrence of an aquatic flora with these arctic plants, which, though consisting of few species, is nevertheless rich in numbers. He con- 
cludes that "already in a period immediately after the melting of the ice ... the vegetation period was four months [in length] and the July temperature about $+6^{\circ} \mathrm{C}$. This increased, during the period of the tundras, to a season of five months' vegetation and a July temperature of $+9^{\circ}$ C." (Andersson-I : Xxv.) The arctic flora of these countries was followed by forests in which three trees, the pine (Pinus silvestris), the birch (Bctula odorata), and the asp or poplar (Populus tremula) became the dominant types. The July temperature at this time averaged probably $10^{\circ}$ to $12^{\circ} \mathrm{C}$. These first forest trees were, however, not uniformly distributed. Thus in the western regions the pines were absent, the birch and poplar alone predominating. This corresponds to the distribution of the trees in the present arctic region where Betula odorata forms the dominant forest tree around the fjords of South Greenland, in Iceland, the whole of Scandinavia and the peninsula of Kola to the White Sea. This may be explained by the greater humidity of this region. In Finland and North Germany the birch and pine occurred together in the first post-glacial forests, which represented the drier, more continental type of arctic forest, such as is found to-day in the remainder of the arctic regions, where forests, consisting primarily of pines (Pinus), spruces (Picea) and larches (Larix), abut against the treeless arctic plains.

With the increase in temperature, the coniferous woods were replaced by those requiring a higher summer temperature, such as small leaf lindens (Telia curopaa), hazel (Corylus avellana), maple (Accr platanoides), elm (Ulinus montana), etc. Finally, the oak (Qucrcus pedunculata) made its appearance, and displaced the pines almost entirely. Gunnar Andersson and others have furnished evidence from the former distribution of the hazel, oak, linden and several aquatic plants, to the effect that the increase in warmth culminated in a period of higher temperature than the present over the whole of western Scandinavia, and less markedly over North Germany. In northern Sweden the temperature during the warner period averaged $2.5^{\circ} \mathrm{C}$. higher than now, though the winter temperature could not have been higher than the present, for plants requiring a warmer winter apparently did not extend further north than they do now. In the central parts of southern Norway, Holmboe finds that the border line of the fir was once about 300 meters higher than at present. In general, the appearance of the spruce (Picea cxcelsa) in the northern and the beech (Fagus silvatica) in the southern part of the glaciated region seems to indicate a gradual deterioration of the climate of Europe since the maximum of post-glacial temperature. 
A similar succession of floras seems to have occurred in North America, but the evidence has not been fully gathered. Over the great plains of Canada, between the international boundary and the forest region which stretches northwestward through Manitoba and Saskatchewan and westward across Aberta, the climate on the melting of the glaciers was probably much like that of the barren lands farther north at the present time, where the mean summer temperature is below $10^{\circ} \mathrm{C}$., with permanently frozen subsoil and consequently a complete absence of trees. As the climate became warmer on the disappearance of the ice, it also became drier, so that forests were unable to grow and Sphagnum swamps unable to form.

Evidence of a warmer climate preceding the present has been obtained from the Atlantic coast, where the Talbot formation of Maryland and Virginia, believed to be post-glacial in age, holds a flora which is more characteristic of southern portions of the same region. Thus the bald cypress (Ta.rodium distichum), found fossil as far north as Long Branch, New Jersey, has its present northern limit in southern Delaware and on the eastern shore of Maryland; the loblolly pine (Pinus tada), also found at Long Branch, does not extend north of southern New Jersey at the present time, with its maximum -development west of the Mississippi; the tupelo (Nyssa biflora), found fossil in New Jersey, ranges to-day from North Carolina to Louisiana.

2. Animals. Marine and fresh-water mollusca are among the best available indicators of climatic changes, so far as species are concerned, which are stiil existing, and the geographic range of which is known. In the marine species it must, however, always be borne in mind that bathymetric distribution may counteract the influences of climate and that hence the evidence must be carefully scrutinized. Even better indications of change of climate are furnished by the distribution of land animals, especially insects and mammals, though this evidence is generally less readily available. Examples showing changes of fauma, most probably due to change of climate, have been obtained in numerous late glacial and post-glacial deposits. A highly significant section of these deposits has been studied by Jensen and Harder on the west coast of Greenland in the Orpiksuit fjord, Disko Island (about lat. $70^{\circ} \mathrm{N}$.). In the lowest clays occurs a fossil fauna with Balanus hameri, inclicating a period during which the climate was not high arctic, but rather resembled that of the present time. This is followed by a series of clay beds averaging 10 meters in thickness, with a rich fauna, anong which Mya truncata cf. ovata and Yoldia arctica must be noted, indicating that the climate gradually refrigerated until high arctic conditions 
existed. This period seems to have been characterized by subsidence. A period of elevation followed, with an increase in warmth, which reached its maximum when the land stood approximately io meters higher than at present. This is shown by the boreal molluscs Zirphea crispata and Anomia ephippium, together with Mytilus edulis, Tellina baltica, Littorina rudis, and $L$. palliata, mostly forms now common on the New England coast. With still greater elevation the climate again cooled, until it resembled that of the present time, the maximum elevation being 50 meters above the present sealevel. The first two formations probably were deposited during glacial time, while the succeeding deposits represent post-glacial time. The warm-water fauna has a wide distribution in the arctic, especially recognizable by the shells of Mytilus edulis, and often by Cyprina islandica and Littorina littorea. Some of the arctic localities where this fauna has been found fossil are the Franz Josef fjord, East Greenland, Spitzbergen, King Charles Land and Franz Josef Land. It has not yet been found in arctic North America.

Another fauna, found in parts of the arctic where it is now extinct, and indicating warmer conditions than now, is the Purpura fauna, with $P$. lapillus, Pecten islandicus, Zirphea crispata, $C y$ amium minutum and Skenea planorbis. This has. been found in northwestern Iceland, in a formation resting in some cases directly upon the peat beds with remains of the arctic birch, Betula odorata.

In North Germany a climate similar to the arctic one is indicated by late glacial or early post-glacial deposits, carrying the molluscs, Vertigo paracedentata, Succinea schumacheri, Planorbis arcticus, P. stroemi, Sphcrinu duplicatum and Anodonta mutabilis. Arctic conditions in Denmark and Sweden, while the ice still occupied a part of the land, are indicated by deposits containing at the base a fauna with the arctic molluses, Yoldia arctica, Tellina torelli, and $T$. loveni, which at present are restricted to seas where the temperature in the depths at which the species live scarcely rises above $2.5^{\circ} \mathrm{C}$. and frequently remains below $0^{\circ}$, even in the warmest months of the year. This corresponded to the time of the Salix polaris flora in Denmark. Higher up, together with a flora in which the birches predominate, occurs Anodonta cygnea, which has been held to indicate a July temperature of $13^{\circ}$ to $15^{\circ} \mathrm{C}$. Still higher follows the fauna with Zirphaca crispa, Mytilus edulis, Cyprina islandica, etc.

In northern New England and eastern Canada, the glacial till is followed by the lower Leda clays, the fauna of which (Leda sp., Saxicava rugosa, etc.) indicates a climate like that of southern Labrador. These are followed by the upper Leda clays and sands 
with Macoma fusca, which indicate a climate like that of the present St. Lawrence valley. The occurrence of relict colonies of Ostrea virginiana var. borealis and Venus mercenaria at various places in the maritime provinces, and in shell heaps along the New England coast as far as Casco Bay, Maine, indicates a period of warmer climate than the presert, since these species are now limited in their northward migration by Cape Cod. The extinction of this, and the character of the present fauna indicate a return to cooler conditions. Warmer water conditions inland are also indicated by the occurrence of Unios and other fresh-water molluscs in the gravels of Goat Island and the banks near the Falls of Niagara, some of which (Unio clavus, $U$. occidens, and $U$. solidus and the Margaritana) live to-day only in tributaries of the Mississippi to the south. Evidence of change of climate during Pliocenic times in Japan is indicated by the succession of molluscan faunas (Yokoyama-IIO). From beds regarded as of middle Pliocenic age, a molluscan and brachiopod fauna of decidedly boreal character has been obtained. In the Upper Pliocenic near Tokyo was obtained a molluscan fauna less boreal in character, though indicating still colder conditions than exist at the present time. Still higher beds, referred to the Pleistocenic (Diluvial), contain a molluscan and coral fauna, many species of which are now found only in much more southern localities, the China Sea, the Plilippines, and the tropical portions of the Pacific and Indian oceans. If the identifications of these formations as Pliocenic and Pleistocenic, respectively, are correct, the remarkable conclusion would have to be drawn that Japan actually had a warmer climate than to-day, while Europe and America were suffering glacial conditions. In order to bring Japan into harmony with the western world, we would have to assume that the deposits called Pliocenic on the basis of numerical preponderance of living species are actually later in age, $i$. $c$., are all Pleistocenic. Such an assumption is not unwarranted.

The Pliocenic or Crag faunas of England show a progressive refrigeration of the climate. The mollusca of the lowest of these, the Coralline Crag, still bears the stamp of a more genial climate than the present, in spite of the admixture of a few boreal types. In the next division, the Red Crag, the number of boreal species increases so as to form $10 \%$, while the succeeding Norwich Crag has a still greater percentage of northern forms. Finally, the highest, the Chillesford and Wegbourne Crags, have a really boreal or arctic molluscan fauna, including Tellina baltica, Saxicaz'a arctica, Mya arenaria, M. truncata, Cyprina islandica. Astarte compressa, A, sulcata, A. borealis, Turritella terebra, Trophon antiquus, Pur- 
pura lapillus, Littorina littorea, Buccinum undatum, etc., most of which still exist in arctic and subarctic regions.

The mammals of North America have furnished some evidence of the change in climate (Hay-43). Along the cold margin of the ice sheet ranged the northern Rangifer, Boötherium and Symbos, as shown by their remains. The giant beaver Casteroides lived with the now extinct horses, tapirs, mastodons, elephants, mylodon, and magalonyx in the southern States and continued there during the Pleistocenic period. It moved northward after the melting of the ice. The peccaries, apparently always lovers of a mild if not warm climate, now range from Arkansas to Patagonia. In the Pliocenic a species lived in Texas, while after the melting of the ice representatives of the family moved northward, their remains having been found in three localities upon the Wisconsin drift sheet, viz.: northern Indiana; near Columbus, Ohio, and at Rochester, New York. The hairy mammoth, Elephias primogenius, seems to have always lived near the margin of the ice sheet, but the Columbian elephant, E. columbi, was a denizen of warmer climates, yet its remains have also been found in deposits overlying the Wisconsin drift. The same is true of the mastodon, $M$. americanus, a denizen of mild climates, which has not only left its remains over the southern States, but which roamed northward during the warm postglacial period. The mammals also indicate a period of warmer climate, during which they ranged farther north than at present, which is a period of somewhat lower temperatures. This reduction, while fatal to many forms, was the cause of the survivors moving southward again.

\section{Displacement of the Earth's Axis as a Cause of Climatic Changes.}

That a change in the position of the earth's axis would bring about a change in climate, cannot be questioned, and this explanation has been suggested for the glacial conditions in Pleistocenic time. Davis (25) has outlined the climatic consequences of displacing the poles in such a way that the north pole would be located at Iceland, in latitude $70^{\circ} \mathrm{N}$. on the meridian of $20^{\circ} \mathrm{W}$., the following being some of the effects: "First, a rearrangement of shore lines in consequence of the adoption of new locations of polar flattening and equatorial bulging. ... Second, alteration in the paths of ocean currents, of which one of the most important would be the diminution of the volume of warm water transferred from the southern to the northern hemisphere by the oblique cross-equator current of 
the Atlantic, and thus the great loss of importance in the extension of the Gulf Stream into the North Frigid zone. Third, a change in the location of the wind and rain belts, their boundaries being shifted twenty degrees southward, in the meridian of Iceland, the same amount northward on the opposite meridian which passes somewhat east of New Zealand, and remaining essentially unchanged at the halfway points, which are located near the meridians of Ceylon and the Galapagos."

Such rearrangement of wind and rain belts "would tend not only to glaciate northwestern Europe and northeastern America, but would also place arid trade-wind climates on the northern side of the belt now occupied by the equatorial rains of Africa and South America, and at the same time place the equatorial rains on the northern margin of the arid land areas now found in the southern parts of these continents. On the adoption of the present location of the poles, the change would be reversed." The northern side of the equatorial rain belt in Africa and South America should then be found to possess topographic records of a wet climate recently succeeding a dry climate, and the features of the region south of the same belt should indicate a dry climate following a wet climate.

Professor Simroth, of Leipzig, in his book, Die Pendulations Theoric, I907 (86) has tried to explain some peculiar distributions of organisms in the present period by oscillations of the poles along the meridian of $10^{\circ} \mathrm{E}$. latitude ( $170^{\circ} \mathrm{WV}$. lat.). With an oscillation of $20^{\circ}$ back and forth this would bring the north pole at one time near Behring Strait, and at the other extreme in the Arctic Ocean, west of the northern end of Norway. If the former position was held in Pliocenic times, the Pacific side would be cool and gradually become warmer, with the change of the pole to the opposite position; while on the Atlantic side the change would be from warmer to cooler conditions terminated by glacial climates. Such conditions seem actually to have occurred, as shown by the gradual change from a warmer climate than at present at the beginning of Pliocenic time in Europe, to the glacial conditions in Pleistocenic time, and by a gradual increase in warmth on the Pacific side as shown by the Pliocenic deposits of Japan, until in the Pleistocenic the sun shone in the region of Noma $\left(35^{\circ} \mathrm{N}\right.$. lat.), "with about the same intensity as it now shines at least on the Ryukyus or the Bonin Islands." (Lat. $27^{\circ} \mathrm{N}$.) This explanation has found its most recent advocate in the brilliant palecontologist of the Imperial University of Tokyo, Professor Matajiro Yokoyama (Yokoyama-110:II6). Investigating this problem, G. H. Darwin (22) came to the conclusion that, if the earth is quite rigid, the pole may 
have moved about $3^{\circ}$ from its original position. If, however, the earth is plastic, as seems to be the case to a certain degree, so that it could readjust itself to the form of equilibrium, then there is a possibility of a cumulative effect, and the pole may have wandered $10^{\circ}$ or $15^{\circ}$ from its original position. This subject is more fully discussed in Chapter XXIII.

\section{ORIGIN OF THE ATMOSPHERE.}

According to the nebular hypothesis of earth origin, the atmosphere is merely the residuum of uncombined gases which were left behind when the globe assumed its solid form. To this are added various supplies, chief among which is the carbon dioxide from volcanic eruptions, the decay of organic matter, and the burning of coal. The Planetesimal hypothesis of Chamberlin, on the other hand, considering the earth as made up of aggregations of small solid bodies coming from space, derives the atmosphere from the small quantities of entangled or occluded atmospheric matter brought by these planetesimals. The pressure of the accumulating cold matter eventually produced sufficient internal heat to expel these gases. If the conception of an internal gaseous centrosphere can be entertained, the possibilities of addition to the atmosphere are greatly enhanced.

\section{BIBLIOGRAPHY II.}

1. ANDERSSON, J. G. 1910. Die Veränderungen des Klimas seit dem Maximum der letzten Eiszeit. Papers by Gunnar Andersson (summary also for North Italy, Greece), F. Wahnschaffe (Germany), G. van Baren (Netherlands), A. Rutot (Belgium), G. W. Lamplugh (Great Britain), H. Brockmann-Jerosch (Switzerland), T. Taramelli (Italy), E. Brückner and A. v. Hayek (Austria), L. de Lóczy, E. de Cholnoky, T. Kormos, P. Treitz, K. Gorjanovic-Kramberger (Hungary), G. Murgoci (Rumania), G. I. Tanfiljef (Russia), H. Lindberg (Finland), R. Sernander, Gunnar Andersson, G. de Geer (Sweden), V. Nordmann and C. G. Joh. Petersen (Denmark), Jens Holmboe, P. A. Ojen (Norway), G. Bardarson (Iceland), Wm. C. Alden, W. H. Dall, F. H. Knowlton, O. P. Hay (United States), G. F. Matthew, J. A. Dresser, Frank D. Adams, A. P. Coleman, J. B. Tyrrell, R. W. Brock, R. G. McConnell (Canada), Ad. S. Jensen, Poul Harder, Gunnar Andersson (North Polar Region), W. F. Hume (Egypt), M. Blanckenhorn (Syria, Palestine and Egypt), Sven Hedin (Persia), G. E. Pilgrim (India), A. W. Rogers (Cape Colony), R. v. Lendenfeld (Australia and New Zealand), C. Skottsberg (Patagonia and Terra del Fuego), R. Hägg (Southern South America), E. Philippi (South Polar Region). Stockholm.

2. ARRHENIUS, SVANTE. 1896. On the Influence of Carbonic Acid in the Air upon the Temperature of the Ground. Philosophical Magazine, Decade V, Vol. XLI, pp. 237-276. 
3. BAIN, F. 1887. On a Permian Moraine in Prince Edward Island. Canadian Record of Science, Vol. II, pp. 34I-343.

4. BARRELL, JOSEPH. I908. Relations between Climate and Terrestrial Deposits. Journal of Geology, Vol. XVI, Nos. 2, 3, and 4.

5. BARROWS, WALTER L. 1910. A Fulgurite from the Raritan Sands of New Jersey, with an historical sketch and bibliography of fulgurites in general. Columbia School of Mines Quarterly, Vol. XXXI, No. 4, July, pp. 29t-319. (Also Contributions Geological Department Columbia University, Vol. XX, No. Io.)

6. BATHER, F. A. I900. Windblown Pebbles in the British Isles. Proc. Geologists Association, June, p. 396. (With extended bibliography of older works.)

7. BAUER, MAX. 1907. Beitrag zur Kenntnis des Laterits, im besondern von Madagaskar. Neues Jahrbuch für Mineralogie, Geologie und Palæontologie, Fest. band, pp. 33-90.

8. BORNHARDT, W. I 898. Zur Oberflächengestaltung und Geologie Deutsch Ost. Africa. Berlin.

9. BOSWORTH, T. O. 1910. Wind Erosion on the Coast of Mull. Geological Magazine, Decade V, Vol. VII, pp. 353-355, pls. XXVIII, XXIX.

10. BRANNER, JOHN C. 1896. Decomposition of Rocks in Brazil. Bull. G. S. A., Vol. VII, pp. 255-314, pls. I-4. (For review and discussion see O. A. Derby, Journal of Geology, Vol. IV, pp. 529-540, I 896.)

II. BRANNER, JOHN C. I9II. Aggraded Limestone Plains of the Interior of Bahia, and the Climatic Changes Suggested by Them. Bulletin of the Geological Society of America. Vol. XXII, May, pp. 187-206.

12. BRUCKNER, EDUARD. I890. Klimaschwankungen seit I700. Wien. Zur Frage der 35 jährigen Klimaschwankungen. Petermann's Mittheilungen, 1902 .

13. CHAMBERLIN, THOMAS C. 1897. A Group of Hypotheses Bearing on Climatic Changes. Journal of Geology, Vol. V, pp. 653-683. British Association for the Advancement of Science, Report, 1897, pp. $644-647,1898$.

14. CHAMBERLIN, THOMAS C. I898. The Influence of Great Epochs of Limestone Formation upon the Constitution of the Atmosphere. Journal of Geology, Vol. VI, pp. 609-62I.

15. CHAMBERLIN, THOMAS C. I 899. An Attempt to Frame a Working Hypothesis of the Cause of Glacial Periods on an Atmospheric Basis. Journal of Geology, Vol. VII, pp. 545-584; 667-685; 75I-787.

16. CHAMBERLIN, THOMAS C., and SALISBURY, ROLLIN D. 1906. Geology, Vol. I.

17. CLARKE, FRANK W. 1908. The Data of Geochemistry. United States Geological Survey, Bulletin 330. Bulletin 49I, 2nd edition, I9I I.

18. CLOOS, H. I9I I. Wind und Wüste im Deutschen Namalande. Neues Jahrbuch für Mineralogie, Band XXXII, pp. 49 et seq.

19. COLEMAN, ARTHUR P. 1908. Glacial Periods and their Bearing on Geological Theories. Bulletin of the Geological Society of America, Vol. XIX, pp. 347-366.

20. CROSBY, WILLIAM OTIS. I89I. On the Contrast in Color of the Soils of High and Low Latitudes. American Geologist, Vol. VIII, pp. 72-8I.

21. CROSS, WHITMAN. 1908. Wind Erosion in the Plateau Country. Bulletin of the Geological Society of America, Vol. XIX, pp. 53-62, pls. 3-4. 
22. DARIVIN, GEORGE H. I876. On the Influence of Geological Changes on the Earth's Axis of Rotation. Proceedings of the Royal Society, Vol. XXV, pp. 328-332; also Nature, Vol. XV, I876-1877, pp. 360-36r.

23. DAVID, T. W. EDGEWORTH. 1907. Conditions of Climate at Different Geological Epochs with special reference to Glacial Epochs. Congrès Géologique International. Compte Rendu. Ioth session, Mexico, 1906, pp. 437-482. 9 plates.

24. DAVIS, WILLIAM MORRIS. 1893. Facetted Pebbles on Cape Cod, Massachusetts. Boston Society of Natural History Proceẹdings, Vol. XXVI, pp. I66-175, pls. I, II.

25. DAVIS, WILLIAM MORRIS. 1896. A Speculation in Topographis Climatology. American Meteorological Journal, April, I896.

26. DAVIS, WILLIAM MORRIS. I899. Elementary Meteorology. Ginn and Company, Boston.

27. DAVIS, WILLIAM MORRIS. 1905. The Geographic Cycle in an Arid Climate. Journal of Geology, Vol. XII, pp. 39I-407.

28. EGLESTON, THOMAS. I886. Transactions of the American Society of Civil Engineers, Vol. XV, pp. 654-658.

29. ENCYCLOPADIA BRITANNICA, Eleventh Edition, Vol. II, Article on Atmosphere, p. 860.

3o. EWING, A. L. I 884. An Attempt to Determine the Amount of Chemical Erosion Taking Place in the Limestone Valley of Centre County, Pennsylvania. American Journal of Science, 3rd series, Vol. XXIX, pp. 29-3I.

31. FERMOR, LEIGH. I9II. What is Laterite? Geological Magazine, Decade V, Vol. VIII, No. X, pp. 454-462; No. XI, pp. 507-516; No. XII, pp. 559-566.

32. FRECH, FRITZ. I906. Ueber die Klima-aenderung der geologischen Vergangenheit. Congrès Géologique International. Compte Rendu. Ioth session, Mexico, pp. 299-325.

33. FREE, E. E. I9II. The Movement of Soil Material by the Wind. Bulletin of the United States Department of Agriculture, No. 68. Bureau of Soils.

34. FRITSCH, KARL VON. I888. Allgemeine Geologie. Stuttgart.

35. GOTAN, SVENSKA. 1907. Die fossilen Hölzer von Köngi Karlo Land. Kongl. Svenska Vetenskaps-Akademiens Handlingar, Vol. XIII, No. IO.

36. GRABAU, AMADEUS W., and SHERZER, WILLIAM H. 1910. Monroe Formation of Southern Michigan and Adjoining Regions. Michigan Geological and Biological Survey, Publication 2, Geological Series 1.

37. GREGORY, J. W. 1907. Climatic Variations, their Extent and Causes. Congrès Géologique International. Compte Rendu. roth Session, Mexico, I906, pp. 407-426.

38. GUPPY, HENRY B. r88r. Dust Winds at Hankau. Nature, Vol. XXIV, pp. 126-127.

39. HANN, JULIUS. 1896. In Hann, Hochstetter and Pokorny. Allgemeine Erdkunde, Bd. I (5th edition).

40. HANN, JULIUS. 1903. Handbook of Climatology. Part I, General Climatology. Translated, with additional references and notes by Robert de C. Ward. 2nd edition. Macmillan Company.

41. HALLE, J. 1908. Geology of the Falkland Islands. Geological Magazine, N. S. Decade V, Vol. V, pp. 264-265.

42. HAUG, EMILE. 1910. Traité de Geologie. Tome I. 
43. HAY, OLIVER P. I9Io. On the Changes of Climate Following the Disappearance of the Wisconsin Ice Sheet. Veränderung des Klimas seit dem Maximum der letzten Eiszeit, pp. 37I-374.

44. HAYES, C. W. I897. Solution of Silica under Atmospheric Conditions. Bulletin of the Geological Society of America. Vol. VII, pp. 214-217.

45. HAYES, C. W. I899. Report of the Nicaragua Canal Commission. Appendix II, Geological Report.

46. HECKER, OSKAR. 1905. Zur Entstehung der Inselberglandschaften im Hinterlande von Lindi in Deutsch-Ost-Africa. Zeitschrift der deutschen geologischen Gesellschaft, Bd. LVII, Monatsbericht, pp. I75-179.

47. HEDIN, SVEN. 1904. Scientific Results of a Journey through Central Asia in 1899-1900. Stockholm, 1904, 1905, Vols. I and II.

48. HELLMANN, JOHANN G. G., and MEINARIUUS, WILHELM. 1902. Der Grosse Staubfall vom 9ten bis I2ten März, 1901, in Nord Africa, Süd und Mitteleuropa. Abhandlungen des königlichen preussischen meteorologischen Instituts, Vol. II, No. I, pp. 93 et seq. (I90I), Abstr. Meteorologische Zeitschrift, Vol. XIX, pp. I80-I84 (1902). Nature, Vol. LXVI, pp. 4I-42 (1902).

49. HIBBERT-WARE, SAMUEL. 1822. Description of the Shetland Isies. Quoted by Geikie, Text Book of Geology, 3rd edition, p. 328; 4th edition, p. 433 .

50. HILL, ROBER'T T. 1908. Growth and Decay of the Mexican Plateau. Engineering and Mining Journal, Vol. LXXXV, pp. 68I-688.

51. HUNTINGTON, ELLSWORTH. 1907. Some Characteristics of the Glacial Period in Non-Glaciated Regions. Bulletin of the Geological Society of America, Vol. XVIII, pp. 35I-388.

52. JENTZSCH, A., and MICHAEL, R. Ueber die Kalklager im Diluvium bei Zlottowo in Westpreussen. Jahrbuch der kōniglichen preussischen geologischen Landesanstalt, Band XXIII, pp. 78-92.

53. JULIEN, ALEXIS A. I901. A Study of the Structure of Fulgurites. Journal of Geology, Vol. IX, pp. 673-693.

54. KERR, W. C. I88I. On the Action of Frost in the Arrangement of Superficial Earthy Material. American Journal of Science, third series, Vol. XXI, article XLIV, pp. 345-360.

55. KEYES, CHARLES R. 1908. Rock Flour of the Intermont Plains of the Arid Regions. Bulletin of the Geological Society of America, Vol. XIX, pp. 63-92, pl. 5 .

56. KEYES, CHARI.ES R. 19ir. Mid-Continental Eolation. Bulletin of the Geological Society of America, Vol. XXII, pp. 687-7I4.

57. LANGLEY, SAMUEL P. I893. The Internal Work of the Wind. Smithsonian Contributions, 27, No. 884, 30 pages.

58. LANGLEY, SAMUEL P. I894. The Internal Work of the Wind. American Journal of Science, 3 rd series, Vol. XLVII, article V, pp. $4 \mathrm{I}-63$.

59. MANSON, MARSDEN. I899. The Evolution of Climates, Separate publication reprinted from the American Geologist, Vol. XXIV, pp. 93-120, 157-180, 205-209.

60. MANSON, MARSDEN. 1904. The Laws of Climate Evolution. American Geologist, Vol. XXXIII, pp. 44-57.

6r. MANSON, MARSDEN. 1907. Climats des Temps géologiques, leur developpement et leurs causes. Congrès Géologique International. Compte Rendu. roth session, Mexico, 1906, pp. 349-405. 
62. MARTONNE, E. DE. 1909. Traité de Géographie Physique.

63. MAURY, M. F. I874. The Physical Geography of the Sea. 15th edition, London.

64. MEIGEN, W. Geologische Rundschau, Bd. II, Heft 4, pp. 197-207.

65. MERRILL, GEORGE P. I 896. The Principles of Rock Weathering. Journal of Geology, Vol. VI, pp. 704-724, 850-87I.

66. MERRILL, GEORGE P. I897. A Treatise on Rocks, Rock Weathering and Soils. Macmillan and Company.

66a. MEUNIER, S. I891. Meteorologische Zeitschrift.

67. MOHN, H. I875. Grundzüge der Meteorologie.

68. MURRAY, SIR JOHN. 1887. On the Total Annual Rainfall of the Land of the Globe, and the Relation of Rainfall to the Annual Discharge of Rivers. Scottish Geographic Magazine, Vol. III, pp. 65-77.

69. MURRAY, SIR JOHN, and RENARD, M. A. I884. Volcanic Ashes and Cosmic Dust. Nature, Vol. XXIX, pp. 585-59I.

70. NEUMAYR, MELCHIOR. I883. Ueber klimatische Zonen während der Jura- und Kreidezeit. Denkschrift der kaiserliche Akademie der Wissenschaften. Wien, Vol. XLVII, pp. 277-3Io.

71. ORTMANN, ARNOLD E. I896. An Examination of the Arguments given by Neumayr for the Evistence of Climatic Zones in Jurassic Times. American Journal of Science, 4th series, Vol. I, pp. 257-270.

72. PASSARGE, SIEGFRIED. 1904. Die Inselberglandschaften im tropischen Africa. Naturwissenschaftliche Wochenschrift, No. XLII.

73. PENCK, ALBRECHT. I894. Morphologie der Erdoberfläche. 2 vols.

74. PFAFF, FR. 1872. Beiträge zur Experimentalgeologie. Zeitschrift der deutschen geologischen Gesellschaft. Bd. XXIV, pp. 40I-409.

75. PHILIPPI, E. I9Io. Ueber einige palaeoklimatische Probleme. Neues Jahrbuch für Mineralogie, Gcologie und Palaeontologie. Beilage Bd. XXIX, pp. I06-I 79 .

76. PHILLIPS, JOHN A. I882. The Red Sands of the Arabian Desert. Quarterly Journal of the Geological Society of London. Vol. XXXVIII, PP. IIO-II3.

77. PUMPELLY, RAPHAEL. 1908. Carnegie Institute of Washington, Publication 73, Vol. II.

78. RICHTHOFEN, FERDINAND, FREIHERR VON. rgor. Führer für Forschungsreisende. Berlin.

79. ROGERS, A. W. Geology of South Africa.

80. RUSSELL, ISRAEL COOK. I898. Subaërial Decay of Rocks and Origin of the Red Color of Certain Formations. Bulletin of the United States Geological Survey, No. LII.

81. RUSSELL, W. J. I885. Impurities in London Air. Monthly Weather Record, August, I 885 .

82. SALISBURY, ROLLIN D. I896. Volcanic Ash in Southwestern Nebraska. Science, N. S. Vol. IV, pp. 8I6-8I7.

83. SALISBURY, ROLLIN D. 1907. Physiography, Part III, The Atmosphere. (Henry Holt.)

84. SCHIAPARELLI, G. V. I889. De la Rotation de la Terre sous l'Influence des Actions Géologiques. Memoire présenté à l'observatoire de Poulkova, St. Petersburg. Reviewed in Petermann's Mittheilungen, Vol. XXVIII, I 892, pp. 42-45.

85. SHALER, NATHANIEL S. 1894. Phenomena of Beach and Dune Sands. Bulletin of the Geological Society of America, Vol. V, pp. 207-2I2. 
86. SIMROTH, HEINRICH. 1907. Die Pendulations Theorie. Leipzig.

87. SOKOLÓW, N. A. I 894 . Die Dünen. Bildung, Entwickelung und innerer Bau. Berlin. Translated by Andreas Arzruni. Berlin.

89. STUNTZ, S. C., and FREE, E. E. I9II. Bibliography of Eolian Geology. United States Department of Agriculture, Bureau of Soils, Bulletin No. 68, pp. $174-263$.

90. STRAHAN, AUBREY. 1897. On Glacial Phenomena of Palæozoic Age in the Varanger Fiord. Quarterly Journal of the Geological Society of London, Vol. LIII, pp. 137-146; plates VIII-X.

91. SUPAN, ALEXIS. 1903. Grundzüge der physischen Erdkunde. 3rd edition, Leipzig.

92. SUPAN, ALEXIS. Atlas of Meteorology.

93. THEOBOLD, —. I867. Jahrbuch schweizerischen Alpenkunde. Bd. IV, pp. $534-535$.

94. THOULET, J. I884. Experiences relatives à la vitesse des courants d'eau ou d'air susceptibles de maintenir en suspension des grains mineraux. Annales des mines, Tome V, pp. 507-530.

95. THOULET, J. 1908. De l'Influence du Vent dans le Remplissage du Lit de l'Ocean. Compte rendı I 46 , pp. I $84-1$ I 86.

96. TOLMAN, C. E. I909. Erosion and Deposition in the Southern Arizona Bolson Region. Journal of Geology, Vol. XVII, pp. I 36-I63.

97. UDDEN, JOHAN AUGUST. 1894. Erosion, Transportation and Sedimentation Performed by the Atmosphere. Journal of Geology, Vol. II, pp. 318-331.

98. UDDEN, JOHAN AUGUST, I 896. Dust and Sand Storms in the West. Popular Science Monthly, Vol. XLIX, pp. 655-664.

99. UDDEN, JOHAN AUGUST. I 898. The Mechanical Composition of Wind Deposits. Augustana Library Publications, No. I, 69 pages.

roo. VAN HISE, CHARLES R. 1904. A Treatise on Metamorphism. Monograph XLVII of the United States Geological Survey.

101. WADE, A. 1910. On the Formation of Dreikanter in Desert Regions. Geological Magazine, Decade V, Vol. VII, pp. 394-398, pls. XXXI, XXXII, text figures $1,2,3,4$.

102. WALTHER, JOHANNES. 189I. Die Denudation in der Wüste und ihre geologische Bedeutung. Untersuchungen über die Bildung der Sedimente in der agyptischen Wüste. Abhandlungen der Mathematisch, physicalischen Classe der königlich-sächsischen Gesellschaft der Naturwissenschaften, Vol. XVI, pp. 347-569; 99 figs., 8 plates.

103. WALTHER, JOHANNES. I894. Einleitung in die Geologie als historische Wissenschaft.

104. WALTHER, JOHANNES. 1900. Das Gesetz der Wüstenbildung, Berlin.

105. WALTHER, JOHANNES. 1903. Der grosse Staubfall von I9o I und das Loess problem, Naturwissenschaftliche Wochenschrift, Bd. XVIII, pp. 603-605.

106. WALTHER, JOHANNES. I9I I. Ueber die Bildung von Windkantern in der libyschen Wüste. Zeitschrift der deutschen geologischen Gesellschaft Monatsberichte, No. VII, pp. 410-4I7; figs. I-4.

107. WALTHER, JOHANNES, r912. Das Gesetz der Wüstenbildung, Leipzig Second edition.

ro8. WILLIS, BAILEY. 1907. Researches in China. Carnegie Institution Publication. 
109. WILLS, LEONARD J. 19I0. On the Occurrence of Wind-Worn Pebbles in High-I,evel Gravels in Worcestershire. Geological Magazine, Decade V, Vol. VII, pp. 299-302, pl. XXV.

I10. YOKOYAMA, MATAJIRO. I9II. Climatic Changes in Japan Since the Pliocenic Epoch. Journal of the College of Science, Imperial University of Tokyo, Vol. XXXII, article V, October, I9I I.

II I. ZITTEL, KARL A. VON. I883. Beiträge zur Geologie und Palæontologie der libyschen Wüste. Palæontographica, Vol. XXX, pp. I-CXLVII.

\section{Supplementary.}

112. HUMPHREYS, W. J. 1913. Volcanic Dust and other factors in the Production of Climatic Changes, and their possible Relation to Ice Ages. Bulletin of the Mount Weather Observatory, Vol. VI, pt I, W. B., No. 5I I, pp. I-34. 


\title{
B. THE HYDROSPHERE.
}

\author{
CHAPTER III.
}

\section{MORPHOLOGY AND SUBDIVISIONS OF THE HYDROSPHERE.}

The hydrosphere consists of the oceans and their prolongations into the land blocks, the lakes, the rivers, and the ground water. The oceans and their extensions into the land blocks constitute the marine portion of the hydrosphere; the lakes, rivers, and ground waters constitute the non-marine or continental portion. In the present chapter their morphological characteristics will be discussed, and an attempt will be made to outline a natural classification of the various subdivisions, based primarily on origin.

\section{A. THE MARINE DIVISION OF THE HYDROSPHERE.}

REGIONAL SUBDIVISIONS OF THE SEA. The classification of oceans and minor stubdivisions of the sea has attracted the interest of geographers from the earliest times. Many and varying systems of classification have been proposed, based on size, form, position with reference to the land, composition, origin, etc. Otto Krümmel $(23: 49)$ has published a very comprehensive system of the seas, in which he recognizes as primary divisions: (I) The independent, and, (2) the dependent types; the former comprising the oceans, the latter the mediterraneans-subdivided into (a) intercontinental, and (b) intracontinental mediterraneans-and the marginal seas. Added to these are: (3) the gulfs or bays, and (4) the straits. Two other subdivisions are made on the basis of ingression of the sea into existing depressions, with the subsidence of the land, forming ingression seas, gulfs, or straits; or, on the partial breaking down of the surface and sinking of fault blocks, permitting the sea to enter the land and forming tectonic seas, gulfs, or straits.

In a natural subdivision of the sea into basins, its relation to the continental blocks must be considered of primary importance, since 
it is on this relationship that the other characteristics are, in a large measure, dependent. As shown in the introductory chapter, the most natural view to take of the land mass as a whole is that it constitutes three continental blocks-the American; the Old World, comprising Europe, Asia, Africa, and Australia; and the Antarctic. These three great blocks are separated one from the other by the great divisions of the sea, the oceans, which, therefore, have an intercontinental location. These continental blocks and dividing oceans have certainly been distinct since the Mesozoic, and it is probable that they have been distinct since much earlier, possibly Palæozoic, time. It is, of course, true that America has at different times been united with Europe or with Asia on the north, and with Antarctica on the sonth, either by land bridges or by shallow submarine banks. But this docs not, therefore, destroy the essential independence of the three great blocks. If, then, we regard the oceans as the intercontinental bodies of sea water, and consider America and the Old World as distinct blocks, we have the following four:

\section{Intercontinentai. Seas or Ocenns.}

I. Pacific-between all three blocks, with a superficial area * of 166 million square kilometers.

2. Atlantic-between all three blocks, with a superficial area * of 82 million square kilometers.

3. Indian-between Old World and Antarctica, with a superficial area of 73 million square kilometers.

4. Arctic-between Old and New World, with a superficial area of about 14 million square kilometers.*

If, on the other hand, we consider, with Wagner, Penck, and others, the Old and New World together as one block, we must take the Arctic Sea from the list of oceans and place it as an intracontinental body among the mediterraneans.

Bathymetric Zones of the Sea. A strip of shallow sea surrounds each of the four great oceans and constitutes the belt of transition from the sea to the land. This is the littoral belt, the width of which corresponds to the width of the continental shelf. Similarly, a littoral belt outlines each group of oceanic islands, though this is generally very narrow. The depth of the littoral belt does not, perhaps, greatly exceed 200 meters (roughly, Ioo fathoms), and it corresponds very closely with the depth to which sunlight

* Exclusive of marginal bodies. 
ordinarily penetrates. The littoral belt is, therefore, the submerged edge of the continental area, and most of it forms the margins of the great oceans. The remainder of the oceans constitutes the abysmal or abyssal area, in the discussion of which we may include the steep transitional slopes between -200 meters and $-2,400$ meters (see ante). The upper zone of the ocean as a whole, irrespective of the position of the sea floor, forms the pelagic district, of especial importance in marine bionomy, under which heading it and the abyssopelagic zone will be more fully considered. (See Chapter XXVI.)

Conformation of the Ocean Floor. The ocean floor is characterized by elevations and depressions, often of great extent and
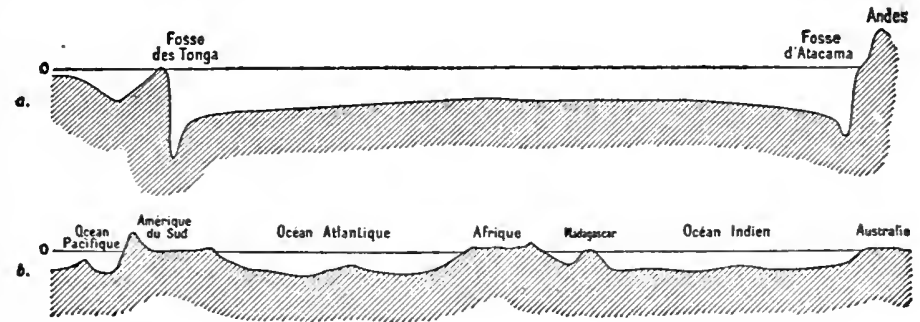

FIG. 16. (a) Diagrammatic cross-section of the Pacific Ocean near lat. $20^{\circ} \mathrm{S}$, showing two fore-deeps, the Tonga and the Atacama.

(b) A similar section across the South Atlantic and Indian oceans near lat. $24^{\circ} \mathrm{S}$. The Mid-Atlantic Rise is shown in section in the Atlantic. (After Haug.)

diversity. (Fig. I6.) The following terminology has been developed for these irregularities by the International Commission for submarine nomenclature $\left(39: 5_{5}\right)$ :

\section{Grand or Major Features, or Those of Wide Extent.}

I. Continental Shelf (G. Schclf. Fr. socle or plateau contincutal). The submerged border of the continents to the Ioo-fathom or 200-meter line, where the descent is abrupt.

2. Sub-oceanic Depressions.

a. Basin (G. Becken, Fr. bassin). Approaching a circular form.

b. Trough (G. Mulde, Fr. vallée). Elongated and broad depressions with gradually sloping sides.

c. Trench (G. Grabcn, Fr. razin). Long but narrow depressions along the continental border, with steep sides, of which the continental is higher than the marine. 
d. Prolongations of the basins or trough, comprising:

(I) Embayment (G. Bucht, Fr. golfe). Semicircular to triangular indentations of the land or of submarine elevations.

(2) Gully (G. Rinne, Fr. chenal). Elongated indentations of like character.

3. Sub-occanic elevations, either independent, or submarine prolongations of the land.

a. Rise (G. Schwellen, Fr. seuil). With very gradually ascending sides.

b. Ridge (G. Rücken, Fr. crête). Prolonged elevations with steep sides.

c. Plateau (G. Plateau, Fr. plateau). Elevations with steep sides and longitudinal and transverse dimensions of similar extent.

4. Deep (G. Tief, Fr. fosse). Abrupt depressions of the sea floor, e. g., Nero deep.

5. Height (G. Höh, Fr. haut). Abrupt elevations, generally on rises, ridges, or plateaus.

\section{Minor Features, or Those of Limited Extent.}

I. Elcvations.

a. Ridge (G. Rücken, Fr. crête). Long ridges of minor character, generally with an irregular surface, rising and falling.

b. Submarine hill or peak.

( I) Dome (G. Kuppe, Fr. dôme). Small, steep-sided elevations in depths of more than 200 meters.

(2) Bank (G. Bank, Fr. banc). Elevations above 200 meters but below i I meters, $e$. g., Porcupine Bank west of Ireland; Grand Bank south of Newfoundland.

(3) Reef or Shoal (G. Riff, Fr. récif or haut fond). Elevations to within II meters or less of the surface.

2. Depressions.

a. Caldron (G. Kessel, Fr. caldeira). Steep-sided depressions of slight extent.

b. Furrow (G. Furche, Fr. sillon). Canal-like depressions in the continental shelf, and more or less transverse to it, e. g., Ganges furrow. 


\section{Features and E.rtent of the Continental Shelves.}

Among the more prominent parts of the continental shelves we may mention the following (Krümmel-23:II3):

Table showing distribution area and depth of the principal continental shelves.

\begin{tabular}{|c|c|c|}
\hline Name and location & Area in sq. $\mathrm{km}$. & Depth \\
\hline \multicolumn{3}{|l|}{ I. Atlantic Ocean: } \\
\hline & & \\
\hline $\begin{array}{l}\text { Newfoundland shelf } \ldots \ldots \ldots \ldots \ldots \ldots \ldots \\
\text { Florida-Texas shelf } \ldots \ldots \ldots \ldots \ldots \ldots\end{array}$ & 345,000 & I $50-200 \mathrm{~m}$ \\
\hline Florida-Texas shelf.$\ldots \ldots \ldots \ldots \ldots \ldots$ & 385,000 & mostly less than \\
\hline Campeche shelf, Central America...... & 170,000 & do. \\
\hline Guiana shelf, So & 485,000 & do. \\
\hline South Brazil shelf.............. & 370,000 & do. \\
\hline Patagonia shelf. . & 960,000 & $50-100 \mathrm{~m}$. \\
\hline \multicolumn{3}{|l|}{ 2. Africa } \\
\hline Agulhas shelf, South Africa.. & 75,000 & mostly over \\
\hline \multicolumn{3}{|l|}{ 3. Europe } \\
\hline British shelf, including North Sea to & & \\
\hline Cape Skagen, Denmark, and south to & & \\
\hline Biarritz, Bay of Biscay ........... & $1,050,000$ & $\begin{array}{l}\text { mostly under } \\
100 \mathrm{~m} \text {. }\end{array}$ \\
\hline \multicolumn{3}{|l|}{ II. Arctic Ocean: } \\
\hline Norwegian shelf. & 93,000 & $200-300 \mathrm{~m}$. \\
\hline Iceland-Faroe shelf $\ldots \ldots \ldots \ldots$ & I I 5,000 & $200-300 \mathrm{~m}$ \\
\hline 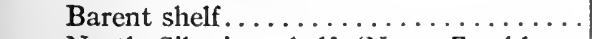 & 830,000 & $200-300 \mathrm{~m}$. \\
\hline North Siberian shelf (Nova Zembla to & & \\
\hline $155^{\circ} \mathrm{W}$. Long.) $\ldots \ldots \ldots \ldots \ldots \ldots$ & $1,330,000$ & $\begin{array}{l}\text { one-half under } \\
\text { 50 m. }\end{array}$ \\
\hline \multicolumn{3}{|l|}{ III. Indian Ocean: } \\
\hline Zambesi shelf, mouth of Zambesi River. . & 55,000 & $\begin{array}{l}\text { mostly under } \\
50 \mathrm{~m} \text {. }\end{array}$ \\
\hline \multicolumn{3}{|l|}{ 2. Asia } \\
\hline Bombay shelf, India $\ldots \ldots \ldots \ldots \ldots \ldots$ & $\begin{array}{r}230,000 \\
200,000\end{array}$ & $\begin{array}{l}50-100 \mathrm{~m} \text {. } \\
\text { mostly under }\end{array}$ \\
\hline 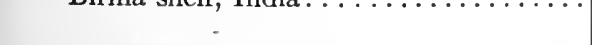 & & $100 \mathrm{~m}$ \\
\hline \multicolumn{3}{|l|}{ 3. Australia } \\
\hline $\begin{array}{l}\text { Northwest Australian shelf (N. W. Cape } \\
\text { to Melville Island) . . . . . . . . . . . . }\end{array}$ & 590,000 & $50-100 \mathrm{~m}$ \\
\hline South Australian shelf . . . . . . . . . . . & 320,000 & $50-100 \mathrm{~m}$ \\
\hline
\end{tabular}


Table showing distribution area and depth of the principal continental shelves-Continued.

\begin{tabular}{|c|c|c|}
\hline Name and location & Area in sq. $\mathrm{km}$. & Depth \\
\hline 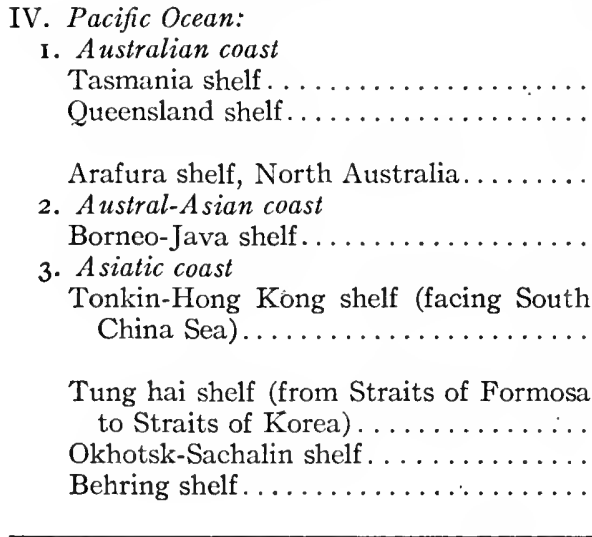 & $\begin{array}{r}915,000 \\
715,000 \\
1,120,000\end{array}$ & $\begin{array}{c}\text { mostly under } \\
\text { I00 m. } \\
\text { do. } \\
\text { 50-100 m. } \\
\text { one-half under } \\
50 \mathrm{~m} \text {. }\end{array}$ \\
\hline
\end{tabular}

Along the East Pacific (West American) border the continental shelf is extremely narrow; no specially defined portion of any size being recognizable.

Subordinate Features of the Continental Shelf. These are the minor elevations and depressions of which the banks and furrows are the most important. Of the former, the banks at the mouth of the English and St. George's channels are characteristic, the largest of these, the Labadie-Cockburn bank, having a length of 280 kilometers. These banks are submarine continuations of the old folds of southern Ireland, and on their surfaces are often found the shells of shore Mollusca, which do not live in the depth of water now covering the banks, showing a comparatively recent subsidence. On the other parts of the British shelf we have the great Dogger Bank in the North Sea. Bones of mammoth, rhinoceros, bison, urochs, and wild horse are not infrequently brought up from this bank, this, together with other facts, indicating depression, probably in glacial time, of a former land area. The Silver Pit furrow in this bank has been regarded by Jukes-Brown as the ancient continuation of the Rhine.

Examples of banks and furrows on the American coast are the Newfoundland banks, Great Bahama banks, Campeche bank, etc., and the St. Lawrence and Hudson furrows. 


\section{Features of the Sub-Oceanic Elevations and Depressions.}

Among the great sub-oceanic elevations the most extensive is the Mid-Atlantic Rise (Supan-38, plate 12), which extends from Iceland, over the Azores, southward to Tristan da Cunha, a distance of I4,00o kilometers and an area of Io million square kilometers. It is bounded by the 4,00o-meter line, and its width in the South Atlantic is approximately indicated by the longitudes of Ascension and St. Helena islands. From the temperatures found in the depressions on either side, and especially from the high temperature of the south African trough, it is thought that the axis of this rise nowhere

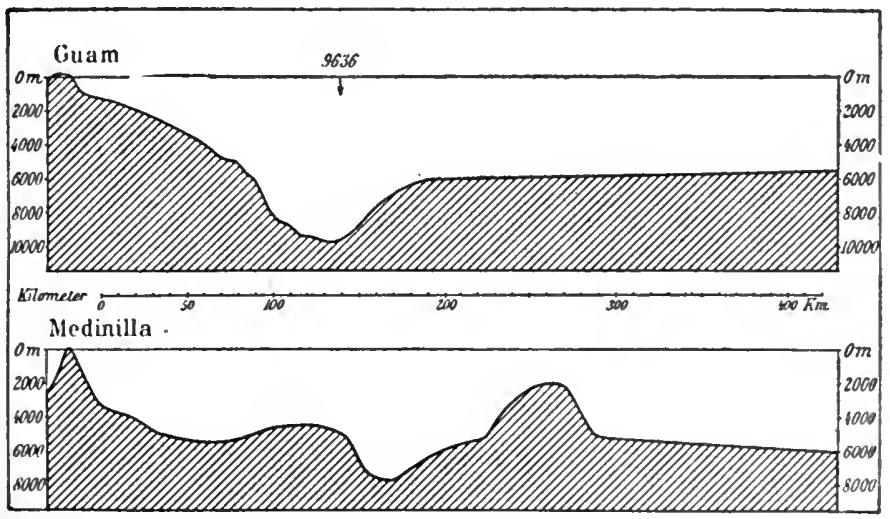

Fig. 17. Two cross-sections of the Marian Trench, a fore-deep in the western Pacific. The upper is east from Guam, and passes through the Nero Deep, 9.636 meters. The lower is east from Medinilla, and passes through lesser deeps, north of the preceding, and also shows a "ridge" east of the trench. (After Krümmel.)

falls below 3,000 meters. North of the equator it is less continuous than south of it. With its branches it divides the Atlantic Occan bottom into a number of great depressions: a North American basin of 13 million square kilometers area, a Brazilian and an $\mathrm{Ar}$ gentine basin with a combined area of 16 million square kilometers, a North African basin of 9 million square kilometers area, and a West African trough of I m million square kilometers area. This great Mid-Atlantic swell does not join the Antarctic continent, but between $30^{\circ}$ and $40^{\circ} \mathrm{S}$. lat. it has two branches-a northwestern one, the Rio Grande rise, nearly separating the Argentine and Brazil basins, and a western one, the Whales rise, which extends from Tristan da Cunla island to the South African continent, and ef- 
fectively cuts off the South African trough from the Antarctic cold waters. In the Pacific, west of South America, is the great Easter Island rise, with an area exceeding that of Africa. The South Indian Ocean shows two great swells or rises: the Kerguelen rise, from Antarctica and Australia, and the Crozet swell, or rise, extending southward from Africa. As examples of trenches, or Gräben, may be mentioned the Marian trench with the Nero deep, and the Japan trench with the Tuscarora deep. They are regarded as submarine fault or rift valleys, just as are those upon the land (e.g., Rhine Graben). 'The two cross-sections of the Marian trench here reproduced show their general characteristics (Fig. 17). Ridges are illustrated by the Wyville-Thomson ridge, between North Britain and the Faroe Islands, and the Faroe Island ridge, which separates the deep Arctic waters of the East Greenland Sea from the North Atlantic. The Wyville-Thomson ridge has its lowest point within 576 meters of the sea-level, and shows a number of notches of the wind-gap type, which suggest that it is a part of an old land ridge. The floor of the Faroe-Shetland gully, which terminates in this ridge, has a fairly uniform depression of 1,170 to I,I89 meters. As an example of a plateau may be mentioned the Blake Plateau, a nearly flat submerged tableland averaging 700 to 800 meters below sea-level, and bounded on the west by the steep slope rising to the Florida-Carolina shelf, and on the east by the equally steep slope descending to the North American basin. From this basin rises the small isolated Bermuda plateau, while the Pacific has in its central part the equally steep-sided Hawaiian plateat, both of which are well shown on Supan's map, above cited. The Pourtales plateau, south of Florida, with a depth of 90 to 300 fathoms ( $6_{5}$ to 549 meters), is an example of a small plateau bordering the continent.

\section{Intracontinental Seas.}

The continental blocks are divided into continents by arms of the sea penetrating deep into the land, or indented by shallow or deep marginal seas more or less land-locked or enclosed by islands. These are the intracontincutal seas, among which two types can be distinguished: the independent,* and dependent. Independent seas are more or less distinct from the oceans, lying in depressions which are independent of the main ocean basins, and separated from them by a rim, which may be largely submerged or may rise above sea-level, leaving only a slight superficial connection

* Not in the sense of Krümmel. See ante. 
with the ocean. These seas would become wholly independent if the surface of the ocean were lowered sufficiently, or, at the most, would remain connected with the oceans only by very narrow channels. Dependent seas are merely arms of the ocean extending into the land, without marginal rim, becoming progressively narrower and shallower the further they penetrate into the land. Seas of this type would merely become shorter on the lowering of the sea-level, but would always maintain their open connection with the oceans.

In each of these groups we may further distinguish a subordinate group in which an abyssal area is present, and another in which it is absent. Independent intracontinental seas with an abyssal area are called mediterraneans (Mittelmeere), while the shallow type, without the abyssal area, constitutes the true epicontinental sea.* Each of these types may further be divided into marginal seas, $i$. $e$., those largely enclosed by islands rising from a submerged rim, and land-locked seas, or those largely surrounded by the mainland.

\section{A. Independent Seas.}

I. The Mediterraneans. The land-locked mediterraneans are the most typical of this kind, and by some they are regarded as the only true mediterraneans. Examples of these are the Roman mediterranean (the Mediterranean of geographers; in reality, a double one, the western descending to 3,I I I meters off the coast of Sardinia, and the eastern to 4,404 meters south of Greece); the Black Sea, an extreme type with a maximum depression of $2,2+4$ meters: the Red Sea, 2,27 I meters; and the Mexican mediterranean, or Gulf of Mexico, 3,809 meters. An intermediate type between the land-locked and the marginal is seen in the Caribbean Sea, partly enclosed by islands, and in the group of Austral-Asian mediterraneans. $\dot{\dagger}$ This group comprises a number of distinct mediterraneans, each one of which, considered separately, would be classed as of the marginal type. The chief of these are: the South China Sea, with a maximum depth of 4,226 meters; the Celebes Sea, 5,II2 meters; and the Banda Sea, 5,226 meters. An example of an abnormal marginal mediterranean is found in the Tung-Hai, or East China Sea. This descends regularly from the shore to below the 200-meter line,

* This term was proposed by Professor Chamberlin, and made to include the littoral zone of the open ocean, which by no stretch of mcanings can be classed as a distinct sea. The present restriction of the term was proposed by the author in 1907 (18).

† Classed by Krümmel as a typical intercontinental mediterranean. 
and then rises abruptly in the chain of Lu-Tschu Islands, which bound it on the southeast. Its littoral belt occupies more than twothirds the width of the sea on the west or continental side, but is extremely narrow on the east or oceanic side, where the islands rise abruptly. The maximum depth within the chain is 9I4 meters. Typical marginal mediterraneans are found in the Japan Sea, 3,73 I meters; in Okhotsk Sea, 3,370 meters; and in Behring Sea, 5,369 meters-all on the east coast of Asia. The last of these is an example of a mediterranean in which the rim is in large part submerged, only islands bounding it on the south, east, and north. An example of a still more extreme marginal mediterranean is the Coral Sea, east of Australia, the deepest part of which descends to 4,663 meters, but of which the southeastern margin is largely composed of submerged reefs and shoals with deep channels between. From this a further step takes us to the oceanic deeps, already mentioned, as the extremes in one direction, while the land-locked type leads through the Black Sea type of nearly cut-off bodies to the completely enclosed deep continental seas or lakes, such as the Caspian. A subordinate type is found in the Adriatic, which is a dependent, not of an ocean, but of the Roman mediterranean. Only a small part of its bottom falls below the 200-meter line, its greatest depth being $I, 589$ meters. It is thus transitional to the epicontinental seas.

It is noteworthy that marginal mediterraneans, so characteristic of the western or Asiatic bordcr of the I'acific, are wanting on the eastern or American border. On the west Atlantic (east American) coast we have the Caribbean and Mexican mediterraneans already mentioned, and between them the smaller Yucatan basin, which descends to 6,269 meters south of Grand Cayman Island. The ridge between this and the Caribbean lies between Pedro and Rosalind banks and has a maximum depth of nearly $\mathrm{I}, 300$ meters. The Windward Canal between Haiti and Cuba has a maximum depth of 1,284 meters and the Mona passage between Porto Rico and Haiti, one of the entrances to the Caribbean, only 583 meters, though the main entrance, the Anegada Straits, between the Virgin Islands and Sombrero in the Lesser Antilles, is less than 2,000 meters, while the greatest depth of the Caribbean is 5,20I meters. The Florida Canal, the exit from the Mexican mediterranean, has a maximum depth of 803 meters. On the northern Atlantic we have Baffin Bay $(5,249$ meters), which, though also open to the Arctic Ocean, has its broader connection with the North Atlantic. On the East Atlantic coast no mediterraneans except the Roman, with its dependents the Adriatic and Black seas, occur, but epicontinental seas abound. 
The Indian Ocean has only the Red Sea as a contributory landlocked marginal mediterranean, in addition to which there is a very open and incomplete marginal mediterranean, the Burma or Andaman Sea, between the Malay peninsula and the Andaman and Nicobar Island groups. The maximum recorded depth here is 4,I77 meters, but much of its deeper part lies between 2,000 and 3,000 meters below sea-level. Whether or not mediterraneans exist off the southern borders of the three great oceans is at present unknown. The Arctic Ocean has only one large marginal mediterranean, but several epicontinental seas. The mediterranean type is represented by the East Greenland Sea, lying between Greenland and Scandinavia, and Iceland and Spitzbergen. This has a maximum known depth of 4,846 meters between North Greenland and Spitzbergen, its connection with the Arctic being by channels 2,000 meters deep. The deepest part of its submerged southern border is $55^{\circ}$ meters in Denmark Straits, but much of this border is shallow. (Fig. 18.)

Interoceanic mediterraneans. The East Greenland Sea and Baffin Bay are interoceanic mediterraneans, i. e., lying between the Atlantic and the Arctic, one belonging to each. Behring Sea is an interoceanic mediterranean which lies between the Arctic and the Pacific, but belongs to the latter. The Austral-Asian group is interoceanic between the Pacific and the Indian oceans, while the Red Sea has been artificially made interoceanic between the Indian and Atlantic systems by the building of the Suez Canal, and the Caribbean mediterranean will soon be placed in this class also.

In general, mediterraneans may be considered in the light of minute oceans, with the essential bathymetric zones found in these, $i$. e., abyssal, littoral, and pelagic. The characteristic independent ocean currents are, however, wanting, though parts or branches of these currents may occur, as, for example, the Gulf Stream in the Central American mediterraneans, and the branch streams entering the Roman mediterranean.

2. Epicontinental Seas. These are the shallow independent seas, the greatest depth of which does not pass much below 200 fathoms, or, if so, in only a few isolated spots. These have, therefore, only a littoral and a pelagic zone, the abyssal being absent. Both landlocked and marginal epicontinental seas occur; the former, when situated in a region of normal pluvial clinate, generally falling in percentage of salinity below that of the open sea, owing to the abundant influx of fresh water. Examples of the land-locked epicontinental seas are Hudson Bay in North America, and the Baltic with its branches, the Bothnian and the Finnish gulfs, in Europe. Both of these are tributary to the Atlantic system. Hudson Bay 
has a maximum depth of 228 meters in one spot, but otherwise is less than 200 meters deep; while the maximum depth of the Baltic is 249 meters east of Gotland, that of the Bothnian Gulf 294 meters

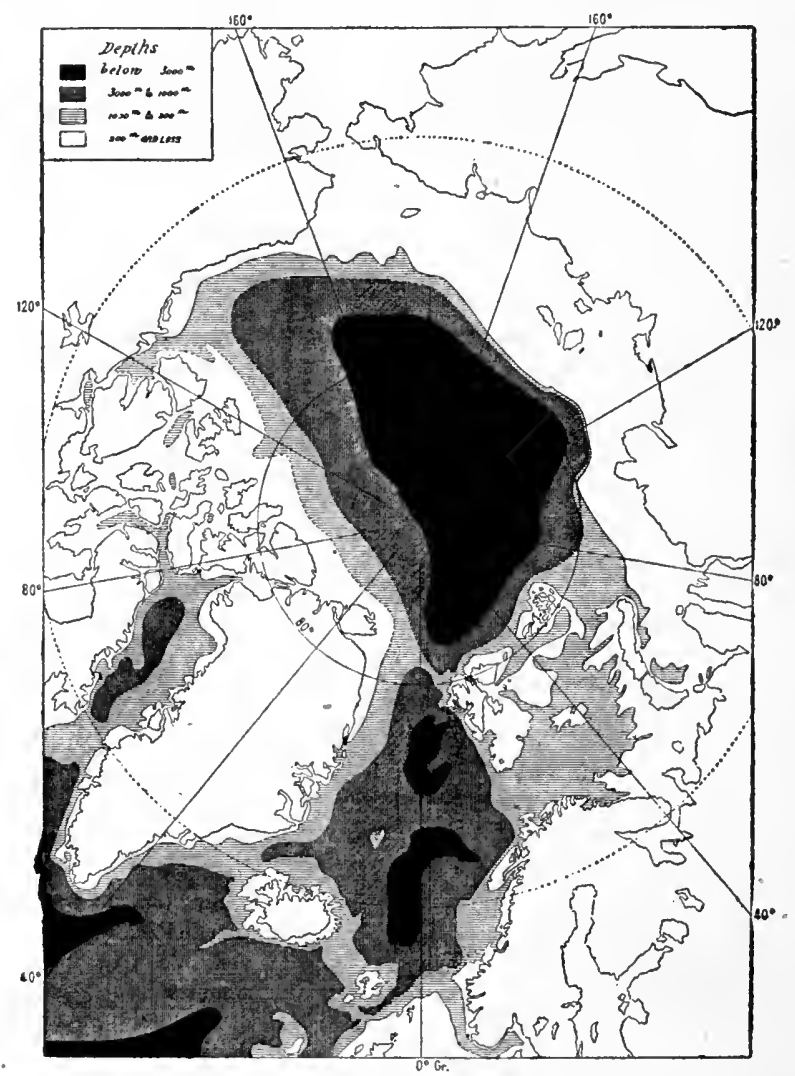

FIg. 18. Bathymetric chart of the Arctic Ocean. The deepest shade (solid) shows depths below 3,000 meters; the next (cross-hatching) between 3,000 and I,000 meters; the next lighter (horizontal lining) shows depths between $\mathrm{I}, 000$ and 200 meters, while the white color shows everything above the 200-meter line, including the lands. The character of East Greenland mediterraneans and the location of the Wyville-Thomson Faroe-Iceland and DenmarkStrait ridges is recognizable. The dotted circle is the Arctic circle. (After Nansen and Haug.)

opposite Hernösand, Sweden, and that of the Finnish Gulf I24 meters near its mouth. In each case these maxima lie in small depressions below the main floor of the water body. The deeper portions of the main floor of the Baltic average I50 to I70 meters, 
while much of the depth is less than Ioo meters. In the Bothnian Gulf the deeper parts lie between Ioo and 160 meters, while the greater part has a deptl of less than 90 meters. Finally, the Finnish Gulf, with the exception noted, does not reach the roo-meter line, while much of it has a depth of less than 50 meters. The Persian Gulf, with a maximum depth of 90 meters, is the only land-locked epicontinental sea tributary to the Indian Ocean, but several other Eurasian epicontinental seas of the land-locked type are tributary to the Arctic Ocean. The larger of these are the White Sea, with a maximum depth of 329 meters, but mostly above 200 meters, and the Gulf of Obi in Siberia. In the Pacific the only land-locked epicontinental sea is the Huang-hai or Yellow Sea, of China. This sea has a rather broad opening into the East Chinese Sea and its margin does not rise perceptibly above the general level of its floor, which is from 80 to 90 meters below sea-level. Still there are a few depressions of a little more than 100 meters, the maximum being Io6 meters, opposite the southern end of the Korean peninsula. The Gulf of Carpentaria in North Australia is another epicontinental sea partly land-locked, but with a broad opening toward the north. The average depth is from 50 to 60 meters, and this continues northward in the shallow Arafura Sea between Australia and New Guinea. Among the islands which separate this sea from the Banda mediterranean on the northwest are several deep holes, some of them descending below the 2,000-meter line.

On the eastern shore of the Pacific, Cook Inlet in Alaska and Georgia Straits in Britiol Columbia are examples of land-locked epicontinental seas of very small size. The latter has a hole 316 meters deep opposite Vancouver, but is generally quite shallow, as is also Cook Inlet. Another small water body of this type is San Francisco Bay, while marginal epicontinental seas of small size also occur on the coast of British Columbia and Alaska. An aberrant type of the marginal epicontinental sea is found in the Rann of Cutch, Bombay, west coast of India. This is very shallow, and as it lies within the belt of great evaporation, it has practically been converted into a salina or salt pan.

In the Arctic Ocean system are several epicontinental seas of the marginal type, besides the land-locked typés already mentioned (White Sea and Gulf of Obi). Melville Sound in Arctic North America is probably to be classed here, though its central area descends below the 200-meter line. The Kara Sea, behind Nova Zembla, is another but more open marginal sea, though in its western end a hole 730 meters deep is recorded. The largest sea of this class connected with the Arctic Ocean is the East Spitzbergen, or 
Barents Sea, lying between Spitzbergen on the west, Nova Zembla on the east, the North European coast on the south, and nearly closed on the north by the island group of Franz Josef Land. It has some depths as great as 370 meters, but is shallow for the most part, so that it is best classed as an epicontinental sea.

The North Sea and the Irish Sea are examples of marginal epicontinental seas on the North Atlantic border. The former is for the most part less than Ioo meters deep, but has some depths as great as 187 meters off the Orkneys, while the latter has a maximum depth of 124 meters, much of its bottom lying between 50 and 100 meters. The English Channel is an extreme case, approaching the dependent type; still it has a few deep holes descending to a maximum of 172 meters north of the Channel Isles. Its opening into the great North Sea at Dover Straits gives it, however, a peculiarity not possessed by other marginal bodies of this kind. In the South Pacific the Tasmanian Sea, between Australia and Tasmania, may be classed as a shallow, flat-bottomed, rather open epicontinental sea of the marginal type. Its greatest reported depth is 88 meters.

\section{B. Dependent Seas-Funnel Seas.}

A typical example of a dependent sea is found in the Gulf of California, between the Peninsula of Lower California and Mexico. The floor of this water body descends from zero at the head to 2,600 meters below sea-level at the motth, the descent being a regular one. At the same time the channel widens so that the form is that of a narrow funnel split lengthwise. This Funnel Sea (Trichter See, mare tuyau), as it may be called, will never become distinct, no matter how much the surface of the ocean is lowered; it will simply be shortened until, when the level has been lowered 2,600 meters, it becomes extinct. In form it resembles a broad river valley; indeed, if it were shorter and shallower it might be regarded as the estuary of the Colorado River, which enters its head.

An example of a broader funnel sea is found in the Bay of Biscay, which descends to near 5,000 meters at the mouth. Here a few deeper depressions may occur inside of the mouth, but the form is in all essentials that of a funnel sea.

The Bay of Fundy on the Atlantic is a shallow funnel sea, not descending below 200 meters at the mouth. It may be regarded as the littoral type of the narrow funnel seas, just as the Californian Sea may be regarded as the littoral-abyssal type of the same class. 
Of the broader, or Biscayan type, on the east Pacific border, only the Gulf of Panama need be mentioned as of sufficient size and importance. This descends to 3,665 meters. On the Atlantic border, besides the Biscayan, may be noted the Gulf of Guinea (to 4,000 meters), off the African coast. Of a special type is the Gulf of Cadiz (3,000 to 4,000 meters), as the funnel sea between Spain and Morocco is called. This has all the characters of a typical funnel sea of the Biscayan type, but opens by the Straits of Gibraltar into the Roman Mediterranean, making it more truly a funnel than Biscay. Of a similar type, though in form related to the Californian Sea, is the Gulf of Oman, connecting the Persian Gulf with the Indian Ocean (3,292 meters) and the Gulf of Aden, the continuation of the Red Sea (to $3,5^{8} 4$ meters).

An extreme case of the Fundy type is seen in the estuary of the Rio de la Plata, which has a depth of only 26 meters at the mouth. Neither the Arctic nor the West Pacific furnishes examples of dependent seas.

Examples of subordinate funnel seas, situated on a mediterranean instead of an ocean, are found in the Golfe di Taranto, southern Italy, and the Golfe du Lion, southern France. Both descend approximately to 2,000 meters at the mouth. Of the same character is the Gulf of Sidra on the north coast of Africa. All of these are of the Biscayan type. The Gulf of Suez at the head of the Red Sea may be taken as an example of a subordinate funnel sea of the Fundy type, though its channel is rather narrow and tortuous. The Gulf of Akabah, on the other hand, forming the east branch of the head of the Red Sea, is a subordinate mediterranean of the land-locked type.

An example of a complex funnel sea, approaching in some of its characters a mediterranean of the marginal type, is seen in the Gulf of St. Lawrence-the mouth of the river of that name. This descends regularly to 572 meters, but rises again from Cabot Straits outward to 4IO meters before falling off to deep water. It has two arms, one from north of Anticosti, the other separating Labrador and Newfoundland. A continuous deep channel is said to exist, however, and the valley is explained as a Tertiary erosion valley.

\section{SUMMARY OF CLASSIFICATION.}

The classification of seas may be summarized as follows:

I. Intercontinental seas or oceans.

Zones: Pelagic, littoral, abyssal.

Examples: Pacific, Atlantic, Indian, Arctic. 
II. Intracontinental seas.

A. Independent Seas.

I. Mediterraneans.

Zones: Pelagic, littoral, abyssal.

a. LAND-LOCKED.

Atlantic system: Roman, Black, Mexican. Indian system: Red Sea.

Subordinate: Adriatic, Akabah.

b. Marginal.

Pacific system: Australasian group, East China Sea, Japan Sea, Okhotsk Sea, Behring Sea.

Atlantic system: Caribbean.

Indian system: Andaman.

Arctic system: East Greenland Sea.

2. Epicontinental Seas.

Zones: Pelagic, littoral.

a. LAND-LOCKED.

Pacific system: Yellow Sea.

Atlantic system: Hudson Bay, Baltic group.

Indian system: Persian Gulf.

Arctic system: White Sea, Sea of Obi.

b. Marginal.

Pacific system: Tasmanian Sea, Carpentaria Gulf.

Atlantic system: North Sea, Irish Sea, English Channel.

Arctic system: East Spitzbergen Sea.

Kara Sea, Melville Sound.

B. Dependent Seas. Funnel seas.

I. Californian Type.

Zones: Pelagic, littoral, abyssal.

a. Closed Head.

Pacific system: Californian Gulf.

Atlantic system: Gulf of St. Lawrence.

b. Open Head.

Indian system: Gulf of Aden, Gulf of Oman. 
2. Biscayan Type.

Zones: Pelagic, littoral, abyssal.

a. Closed Head.

Atlantic system: Bay of Biscay, Gulf of Guinea.

Subordinate: Gulf of Taranto, Gulf of Lyons, Gulf of Sidra.

b. Open Head.

3. Fundyan Type.

Atlantic system: Gulf of Cadiz.

Zones: Pelagic, littoral.

a. Closed Head.

Atlantic system: Bay of Fundy, Rio de la Plata.

b. Open Head.

Indian system (Subordinate): Gulf of Suez. (Head artificially opened.)

\section{B. THE CONTINENTAL DIVISION OF THE HYDROSPHERE.}

\section{iII. Continental Seas or Lakes.}

Inland seas or lakes, $i$. $e$., water bodies entirely enclosed by land, may be classed as continental. They are either salt or fresh, depending on their location within the arid or the pluvial belts and on the relative amount of evaporation and precipitation. Salt lakes lying near the sea often have their surface below that of the ocean, as in the case of the Caspian Sea, the surface of which lies 26 meters below the level of the Black Sea, less than 500 kilometers distant; while the Dead Sea is 394 meters below the level of the Roman mediterranean, which is only 75 kilometers distant. The Sea of Aral, however, another salt sea in the same belt, is 48 meters above the Black Sea, with a maximum depth of 66 meters; while Balchash Sea, in the Great Steppe farther east, has an elevation of 274 meters, with a depth of 25 meters. In the region bounded by the Caspian, the Black, and the Mediterranean (Roman), are several small salt lakes varying from 940 meters to I,925 meters in elevation. In North America, Great Salt Lake has an elevation of 1,283 meters above the sea.

Fresh-water lakes all have their surfaces above or just at sealevel, though some of them have their bottoms far below sea-level. 
Such is the case with Lake Baikal in Siberia, which has an elevation of 520 meters and a depth of I,430 meters, its floor, therefore, descending 9 ro meters below sea-level.

Among the great American lakes, Ontario descends I 50 meters below sea-level, Huron $5^{2}$ meters, Michigan 88 meters, and Superior I 14 meters. The American Great Lakes drain their surplus waters through the St. Lawrence system into the Atlantic, and Lake Baikal through the Angara River into the Arctic. Lake Tanganyika, of East Africa, 780 meters above sea-level, has only an interrupted outward drainage, the removal of surplus water being by evaporation; but Lake Nyassa, 480 meters above sea-level, drains by the Schire and the Zambesi into the Indian Ocean. This lake has a maximum known depth of 786 meters ( 430 fathoms), its floor thus descending 300 meters below sea-level. Its length is about $35^{\circ}$ miles and its average width about 40 miles. Lake Tanganyika also passes below sea-level in its deeper portion. On the American continent, Lake Tahoe in the Sierras, with a depth of 1,654 feet, is second only to Crater Lake, Oregon, which has a depth of I,975 feet. Lake Superior has a maximum depth of only I,008 feet, while Lake Maggiore ( $\mathrm{I}, 004$ feet) and Lake Como ( $\mathrm{I}, 354$ feet), on the south side of the Alps, compare favorably with the American lakes in depth.

Classification of Lakes and Lake Basins. A genetic classification of lake basins differs from a classification of lakes as a whole because it deals only with the depression in which the lake is situated. Depressions of exactly similar characters, but without water, may exist, and would have to be taken account of in the classification of basins. Such "dry lakes" are, however, of no significance to the limnographer or to the bionomist. Again, the character of the water, whether salt or fresh, is largely a matter of climate, and has no relation to the lake basin. This is also true of the outlet or effuent, for if the number of affluents is small and evaporation lowers the lake sufficiently, it will lose its outlet, just as it may through a rise of the rim or other tectonic change. Such excess of evaporation generally brings about the salinifying of the water by the concentration of the mineral solute. (Davis-7; also Salisbury-33.)

\section{Classification of Lake Basins.}

In a natural classification of lake basins the agent active in their production is of first importance, and lake basins may, therefore, be classified in the first place as A. Lakes of Deformation, or 
Tectonic Lakes, B. Lakes of Construction, C. Lakes of Destruction, and D. Lakes of Obstruction. The further subdivision is as follows :

A. DEFORMATIONAL OR TECTONIC BASINS.

I. Fault basins.

2. Folded basins.

3. Warp basins.

4. Complex basins, great basins.

B. CONSTRUCTIONAL BASINS.

I. Volcanic: a. Crater lakes; b. depressions in lava flows.

2. Chemical: Hot spring and geyser basins.

3. Organic: a. Vegetal or swamp; b. coral reef lagoon.

4. Detrital: (Reconstructional).

a. Marine: ( I) Coastal plain depressions.

b. Lacustrine.

c. Fluviatile: (I) River flood plain lakes (oxbows); (2) delta lakes; (3) fan lakes.

d. Glacial : (I) Morainal kettle lakes; (2) drift sheet kettle lakes.

e. Atmospheric: (I) Land-slip basins; (2) dune lakes.

f. Artificial: Human constructions, etc., $\mathcal{c}$. g., builtup reservoirs.

C. DESTRUCTIONAL BASINS.

I. Volcanic: Pit craters, volcanic subsidence hollows.

2. Chemical:

a. Solution hollows and sink-holes.

b. Disintegration hollows.

3. Fluviatile:

a. Waterfall lakes.

b. Pot-hole lakes.

4. Glacial: Ice excavated rock tarns.

5. Deflation lakes, or wind excavated hollows.

6. Artificial excavations: Man-made excavations; mud wallows.

D. OBSTRUCTIONAL BASINS. Formed by damming a preexisting valley.

I. Tectonic barrier basins.

a. Warp barrier.

b. Fold barrier. 
2. Volcanic barriers

a. Volcanoes.

b. Lava flows.

3. Chemical: Tufa barrier basin.

4. Ice barrier basin.

5. Organically built barrier.

a. Coral reef barrier.

b. Vegetal growths.

6. Detrital barrier basin.

a. Marine and lacustrine (barrier beach).

b. Fluviatile, or river-built: Fan-delta barriers; marginal barriers (drift-wood barriers, etc.).

c. Glacial, or ice-built: Drift and morainal barriers.

d. Atmospherically built.

(I) Land-slip barrier.

(2) Dune barrier.

e. Artificial (built by organisms from foreign substances).

(I) Beaver dams.

(2) Man-made dams.

While pure types of these basins probably exist, the majority of lake basins are of a more complex order, falling under more than one class.

\section{A. Deformational or tectonic basins.}

These are due to faulting, folding, or warping, so as to produce a closed depression. I. Fault basins are not uncommon, the best examples being Albert and Summer Lakes of Oregon (Fig. I9), and perhaps Lakes Tanganyika and Nyassa of Africa (Fig. 20). 2. Lakes due only to folding or the formation of mountain trouglis are rare, but those in which folding takes a part are not uncommon in young mountain regions. Here belong, in part at least, Lake Baikal of Asia, Lake Nicaragua, and the western end of Lake Superior in Central and North America, respectively. 3. Basins due wholly to warping are unknown, but Lake Ontario is a warped river valley which is partly closed by drift deposits. 4. Great basins are produced when mountains arise all around a less disturbed area by combined folding, faulting, and warping, and thus leave this area surrounded by a rim, and in condition to become a lake. The size of this lake, when below the maximum possible for the lowest 
outlet, is determined by the relation between rainfall and evaporation. A typical example is found in the extinct Lake Bonneville (Gilbert-15), which extended along the western base of the Wasatch range for 300 miles. Its surface covered I9,750 square miles at the highest stage, and its hydrographic basin had an area

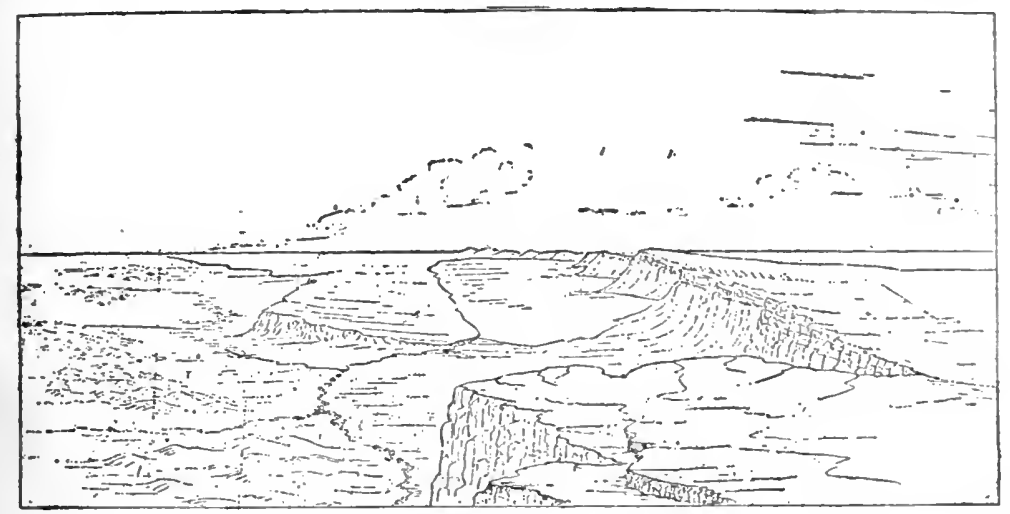

FIG. 19. Sketch of Albert Lake, Oregon, a fault-basin lake. (After Russell.)

of 52,000 square miles. By evaporation it has now been reduced to a body of salt water which in 1850 was 1,750 square miles in area, with a maximum depth of 36 feet-the Great Salt Lake of Utah. Another example in the same region is the extinct Lake Lahontan, which lay in what is now northwestern Nevada, with an arm extending into California, and with a length of 260 miles.

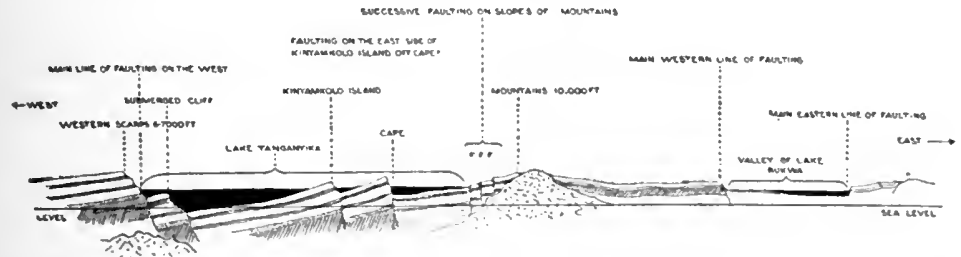

FIG. 20. Section through Lakes Tanganyika and Rukwa, from northeast to southwest. Vertical scale exaggerated five times. (After Moore.)

and enclosed an island 126 miles long and 50 miles broad. Most of the valleys occupied by the arms of this lake are deserts now, but some contain small lakes of more or less saline or alkaline waters, but not of concentrated brines. (Russell-31.) What appears to have been an enormous inland sea or lake of this type. but beginning as a cut-off from the sea, occupied, according to 
Walther (45:74-79), the greater part of Germany during the Middle Zechstein period (Permic), extending from the Urals on the east to the Armorican chain in France, Belgium, South England and Ireland on the west, and bounded on the south by the Bohemian mass, and the mountain chain (Vindelician) corresponding to the present Danube plain. In this sea the great salt deposits of North Germany were laid down from the complete evaporation of the waters. Fault depressions accompanying earthquakes also belong to this class.

\section{B. Constructional basins.}

I. Volcanic (pyrogenic) basins. These include $a$. crater lakes, where water is enclosed by the built-up rim of the crater, and $b$. depressions in a lava sheet produced at cooling and occupied by water. Examples of the former are Crater Lake of Oregon (in part a broken-down cone), the Soda Lakes of Nevada, and Lakes Albano and Nemi, near Rome, and Agnano and Averno, near Naples. Other lakes of this type occur in the Auvergne district of France, about Auckland, New Zealand, and in other volcanic regions. (Davis-7:380.)* Sometimes these lakes are hot, or contain gases fatal to animal life. In the Caucasus a lake of this class (Elbruz) lies at an elevation of 18,500 feet above the sea. Lakes in depressions in lava flows are probably not common, and when they are found they are mostly small.

2. Chemical (hydrogenic) basins. This class is limited to small ponds, or basins built by tufas in hot spring and geyser regions. The small tufa basins in mammoth Hot Springs of the Yellowstone region are typical examples. Examples of large size are so far unknown. (See Fig. 67, page 343.)

3. Organic (biogenic) basins. $a$. Basins built by the growth of vegetation in moist climates are not an uncommon feature in the peat bog regions of northern countries, though the larger ones of this class may be in part of the barrier type, the vegetable growth merely damming back waters in a preëxisting valley. A more perfect example of a phytogenetic or vegetal basin is seen in Lake Drummond in the Dismal Swamp of Virginia and North Carolina. (4I.) This lake was originally 22 feet above sea-level and 6 feet deep. It is completely surrounded and enclosed by a mass of peat and vegetable material with a maximum thickness of 20 feet. At present the lake is only 6 feet deep and only about 16

* Davis places them among obstruction lakes. 
feet above sea-level, owing to artificial drainage. The lake decreases to a few inches in the woods surrounding it. Although originally believed to have started in a depression in the underlying stratum, it is now entirely enclosed by, and owes its continuance to, a rim of vegetal material, and so is typical of this class. Lakes and ponds of this type due wholly to the growth of vegetation, abound in the tundra of Alaska, where they occur even on hillsides, which otherwise would be freely drained. (Russell-30:128.) $b$. Lake basins of animal or zoögenic origin are less common, but are represented by coral island lagoons, when their connection with the sea ceases or is reduced to a minimum. An elevation of the coral island or atoll would result in complete separation of the basin from the ocean, and a freshening of the water. Lakes apparently of this type have been reported from the coral islands of the Pacific.

4. Detrital (clastic) basins. These are built up by detrital material, which, though it is the product of rock destruction elsewhere, nevertheless produces constructional basins similar to the volcanic and the chemical, the material for the building of which is obtained from within the earth, and to the organic, the material for which is obtained from the air or the water. They may also be called reconstructional, since the material of old land forms is reconstructed into the new.

a. Marine detrital basins are depressions on the subcoastal plain, due to irregularity of arrangement of material. On emergence these will carry shallow lakes. Such are the lakes on the coastal plain of Buenos Ayres. (Davis-7:372.) b. Lacustrine detrital basins are those left in the irregular detrital deposits on the floors of large extinct lakes. Here belong many lakes remaining in the Great Basins, such as the successors of Lake Lahontan and Lake Bonneville and others. c. Fluviatile detrital basins comprise (I) those formed on river flood plains by irregular deposition, though these are always complicated by erosion, as in the case of oxbow lakes: (2) those formed by irregular deposition of deltas; and (3) those formed by irregular deposition on alluvial fans. Lake Pontchartrain, near the mouth of the Mississippi, is of the clelta-lake type. It has a surface of twenty by forty miles, but a depth of only 27 feet. Others are found on the Mississippi delta, the leltas of the Rhine, and elscwherc. (Davis-7.) Oxbows and other flood-plain lakes occur on most large rivers. while delta-fan basins, though small, are not uncommon. A combination of flood plain and delta basin is seen in the lakes, of the great alluvial plains of China. d. Morainal and drift kettle holes are common in the region affected by the Pleistocenic ice sheet. They are mostly small, though often 
proportionately deep for their size. Though mostly due to irregularity of deposition, many owe their chief characters to the cavingin of the sand upon the melting of an included ice block. $e_{1}$. Landslip basins are rare and small, forming in irregularities or depressions in the land-slide surface. $\mathrm{e}_{2}$. Hollows between dunes are common, but these, as a rule, hold no water, owing to the porousness of the sands. Examples of lakes held up by sand dunes are, however, abundant in Cherry county and elsewhere in the sand-dune region of Nebraska. f. Finally, artificial structures, such as built-up (not excavated or dammed) reservoirs, belong here.

\section{Destructional basins.}

I. Volcanic destructional. Of this type the most characteristic are the pit craters, or the more or less circular hollows produced by volcanic explosions, without the building up of a crater, or by subsidence. The Maare of the Eifel and elsewhere in Germany are typical examples, the largest of this type being the Laacher See, near Coblenz, with a diameter of a mile and a half and a depth of about 200 feet. Other examples are found in the Auvergne. Where the surrounding region is strewn with the pyroclastic ejectamenta, the basin may be regarded as due to explosion, as in the case of the Maare of the Eifel in general. In other cases subsidence after the removal of rock matter below may be the cause of the depression. Lake Balaton (Platten See) in Hungary is regarded as of this type. It is 50 miles long, 3 to ro miles wide and 40 feet deep.

2. Chemical basins of the destructional type include (a) solution basins, where limestone or gypsum has been removed by solution; some of the lakes in Florida may have originated in this way. Sink-holes, due to caving-in of the surface over caverns, also belong here. These are common in limestone regions. Lakes due to solution of underground salt deposits and to the caving-in of the surface are also of this type. An example of a recently formed lake of this class is the intensely saline Lake Illyés or Medve Lake, near Szovata, Hungary. Temporary solution lakes on glacier surfaces must also be included in this group. (b) Dccomposition and disintegration hollow's. These are of little significance, since they can be cleared out only by wind, ice, or other agency.

3. Fluviatile destructional basins are never of great size, for rivers cannot excavate large hollows, their chief work resulting in free drainage channels. Pot-holes, however, and the depressions gouged out by retreating waterfalls, are rock basins of this type. Pot-holes are mostly small, though exceptional cases have a diameter 
of 20 feet and a depth of 40 feet. Waterfall hollows also are limited in size. At Niagara a hollow nearly 200 feet deep, over three miles in length, and a thousand feet or more broad has been gouged out by the Horseshoe Falls. When Niagara goes dry, this will remain as a lake. A typical example of an existing lake of this type is Lake Thaxter of the St. Croix Dalles region in Minnesota. Along the course of most rivers are deeper reaches which represent stronger scour, and these may be converted into lakes. This is the case in some of the branches of the Nile, where, during the dry season, these pools contain water. In old river courses like that of the Oxus, an affluent of the Caspian, and the old course of the Huang-ho, such lakes are sometimes a characteristic feature.

4. Glacial rock basins. When a glacier gouges out the floor of its valley above the mouth, so as to leave the frontal rim actually ligher than some other parts of the basin, the conditions for the formation of a destructional lake basin are furnished. Such lakes are common in areas of recent glaciation and many of the lakes in the region of the Pleistocenic ice sheet invasion owe their existence partly to this cause. The Finger Lakes of New York are believed to be in part glacial rock-basins, and in part. due to obstruction.

5. Deflation basins. These result from the removal, by wind, of sand and dust from a disintegrating surface, in such manner as to leave a complete rock rim surrounding the area of remova!. This area will be deepened to the extent determined by the power of the wind to remove disintegrated material. Desert basins, in so far as they are not tectonic depressions, owe their character to this agent, since no other force (excepting man) can remove soil or sand from the enclosed basin. Playa lakes may occupy temporarily the lower depressions of these basins. Hollows excavated by wind carrying sand, though insignificant, should nevertheless be nentioned.

6. Artificial cxcavations. These are included for completeness sake, but need no further comment. Mud wallows, on the other hand, may be briefly discussed. In desert areas where elephants and other large creatures wallow about in pools. they produce hollows several meters deep. Rains washing down the sandy sides of these hollows widen the area affected. Thus if the hollow left after the filling is still I meter deep its diameter may be $25 \mathrm{~m}$. Continued wallowing will result in the formation of a depression 5 meters deep and 120 to 150 meters in diameter, such as are found in abundance at the present time in the drier districts. Their formation by animal erosion is often observed in the Kalahari and other deserts.

Where salty marl surfaces are covered by sand, these retain 
the moisture to which the buried salt surface is relatively impervious. Efflorescences of salt on the surface attract herds of animals who stamp the soil into powder, which then is carried away by wind. Water may gather in the resulting shallow depression, and this will attract more animals, and by their trampling of the soil and the deflation of the material large hollows are formed, which will be permanent lakes when the ground water level is reached. Such lakelets abound in the northern Kalahari. Where the surface of the Kalahari is formed by a porous limestone with efflorescence of salt, it is broken up by the hoofs of animals and blown away by wind. As water accumulates, in the shallow depressions, the animals coming to drink trample the rock into fragments. The finest particles are separated out by the water and settle as a layer of fine mud which, on the drying of the pool curls up, is powdered by the hoofs of the animals and blown away by the wind.

In a region where, through increasing aridity, vegetation dies out, the roots are grubbed after by animals, which thus begin the formation of a hollow, later subject to enlargement.

\section{Obstructional or barrier basins.}

These in all cases arise by an obstruction or dam placed across a valley which, but for this obstruction, would have free drainage. The principal types are the following. (Davis-7.)*

I. Tectonic barrier basins. These are brought about by warping, by folding, or by faulting. Warp barrier basins are produced by the deformation of an entire valley area by warping so as to reduce it from its continuous slope to a depression. Lake Ontario owes its existence in part to such warping, which has carried the upper part of the ancient river valley below sea-level, leaving the lower part considerably above it. (Grabau-I7:49.) Valleys dammed by folding are not uncommon in the Alps. Laggo Maggiore, Lake Lucerne and others have been classed here.

2. Volcanic barrier basins. These are formed by the growth of volcanoes so as to cut off a preëxisting valley, or by the damming of such a valley by a lava flow. Lake Kivu in the great rift valley of Africa is a good example of the first type. Formerly this drained northward into the Albert Edward Nyanza and the Albert Nyanza, with the valleys of which its own is continuous. A group of modern volcanoes, the Mfumbiro Mountains, dammed it

* Davis includes as obstructional many of those here classed as constructional, especially the detrital section. 
on the north and raised its level 2,000 feet, until it began to overflow southwarl across the gneiss rim into Lake Tanganyika. The watershed on the north has been raised by these (in part) still active volcanoes to something over 7,000 feet, while individual peaks of the barrier rise to great altitudes, the peak of Karisimbi reaching 14,000 feet and being often snow-capped. (Moore-26:8I.) (Fig. 21.) The valley of Lake Kivu is of tectonic origin. The extinct Tertiary Lake Florissant of Colorado was due to a lava dam. Lakes of this type are usually long lived. Navahoe Lake of Utah is held by a flow of scoriaceous lava.

3. Chemical (Hydrogenic) or tufa barrier basins are probably always of small size. Some of the smaller lakes of the Yellowstone

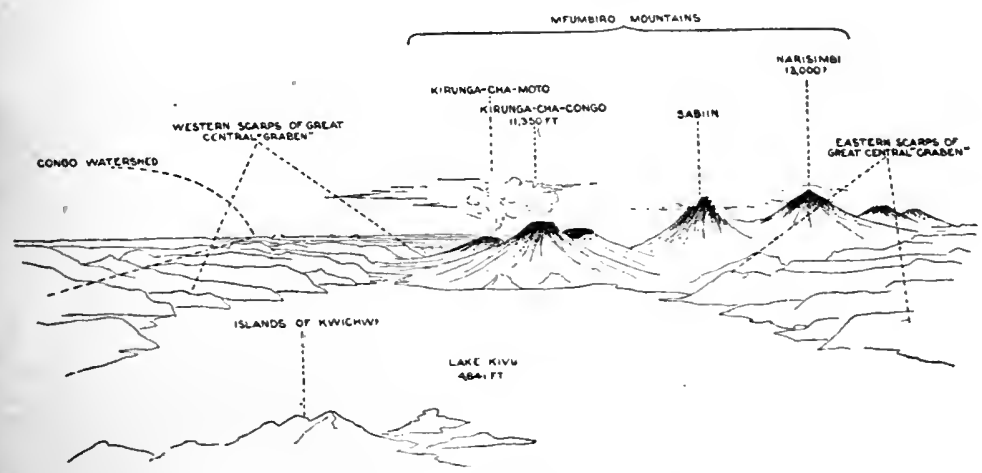

Fig. 2I. Sketch of Lake Kivu and the Mfumbiro Mountains of Africa. The lake lies in the great rift valley of Africa, and is dammed by volcanoes of recent origin. (After Moore.)

region appear to owe their existence, in part at least, to damming of valleys by hot springs or geyser deposits. The Plitvicer seas of Croatia are small lakes in a Karst valley dammed by tufa deposits. The same may be true of Lac de Brenets of the French Jura, which has a depth of 3 I. 5 meters. (Penck-28: 288.)

4. Ice barrier basins. Of these the Merjelen See in Switzerland is the best known existing example. An example of one now extinct is seen in Glen Roy (Agassiz-I :33) in the Highlands of Scotland. Here only the old wave-cut shore-lines remain in the "Parallel Roads," marking the successive changes in level of the lake which was held up by the glacier occupying the valley to which Glen Roy is tributary. Ice barrier lakes were abundant toward the close of the Pleistocenic ice age, when the continental glacier blocked northward draining valleys and converted them into tem- 
porary lakes. Examples of these are Lake Agassiz (Upham-40) on the Minnesota-Canadian border; Lake Passaic (Salisbury-33) of eastern New Jersey; Lakes Bouvé (Grabau-I6), Charles (Clapp3), Nashua (Crosby-4), etc., in castern Massachusetts; and Lake Shaler (Wilson-46) in the Cape Cod region; and the glacial Genesee and other lakes of New York (Fairchild-I3). Additional examples are found in Scotland, Scandinavia, the north of Germany, etc. Ice-barrier lakes are as a rule very short-lived.

5. Organic barriers. The growth of vegetal material at the mouth of a river may serve directly to choke drainage and so transform the district into a lake, and indirectly it will serve this purpose by inviting deposition of fine detritus where the current is checked. The growth of coral reefs may also form a barrier across an indentation of the shore, which may then be transformed into a lake. According to Davis ( 7 ), the lakes of the Everglades in southern Florida are examples of this type.

6. Detrital barrier basins. These are perhaps the most common barrier basins, and to them by far the largest part of the barrier lakes now existing belong.

(a) Barricr beach basins. A barrier beach may cut off a valley or embayment from the ocean or from other lakes and so convert it into a separate lake basin. So long as the free connection with the parent body is maintained, so that water flows into the new basin from the sea or lake to which it belongs, it cannot be considered distinct, but only as an arm of the parent body. In some cases the opening remaining is so small as practically to prohibit the entrance of the water from the parent body. This seems to be largely the case in the Frische Haff and the Kurische Haff on the Prussian coast (2); and to a large extent also in the Black Sea. Occasionally the cut-off from the sea becomes brackish or fresh, as in the case of some ponds along the Massachusetts coast, and those of the coast of Pomerania, while in others excessive evaporation may cause the extinction of the lake, unless the barrier is broken, as in the salt lakes of Bessarabia on the northwest coast of the Black Sea.

(b) Fan delta basins. These are formed by the damming of a valley by the dry delta or fan of a tributary. Lake Pangkong in the Himalayas, back of Kashmir, represents this type. Its drainage is now entirely by seepage, the water being slightly brackish. Another example is Tulare Lake, a shallow sheet of water with indefinite marshy shores, situated along the San Joaquin River in the Valley of California. The upper tributaries of this stream have been ponded back by the alluvial fan of King River, which rises 
in the Sierra Nevada range. Lakes Brienz and Thun are divided by a delta or fan on which Interlaken stands, and other examples are found in the Alps, in the Mississippi region, and elsewhere. Marginal lakes also come into existence when the main stream aggrades its valley, thus damming the tributaries. The lakes along the Red River of Louisiana have been regarded as due to this process, but organic accumulations or "rafts" played an extensive part in the ponding of the tributaries. (Veatch-44.) These organic accumulations are to be regarded as detrital material, just as are the inorganic materials swept together.

(c) Moraine and drift-barrier basins. These are numerous in all glaciated regions, but are generally accompanied by some deepening of the basin through glacial scour. This is the condition of many of the Alpine lakes and it is also the condition of the Finger Lakes of New York. A typical example of a drift barrier lake now extinct is found in the Upper Genesee valley from Portageville southward. This was dammed by drift at Portageville, and the resulting lake overflowed southward for a time, until a gorge was cut through the rock to drain the waters northward. The drainage here was originally southward, but was inverted by depression of the land on the north. Slight glacial overdeepening also occurred. (Fairchild-13: Grabau-19.) Drift damming accompanied by warping is shown in the Great Lakes of North America. It must be clearly understood that only lakes formed in valleys dammed by drift or moraines belong to this class. Lakes formed in depressions in the drift itself, $i$. $c$., kettle lakes, are constructional, not obstructional. Morainal lakes are generally short-lived, although those blocked by great drift sheets may fairly be called permanent.

(d) Atmoclastic barriers are either land-slip barriers or dune sand barriers. (I) Land-slip barricrs originate when a landslide dams a mountain valley. They are mostly short-lived, for the drainage across the barrier will result in their rapid extinction. Lake St. Laurent, Io kilometers long, in the Oisans, western Alps, was created by a land slip in I $18 \mathrm{I}$. It existed about 40 years, during which period the farmers of the valley became fishermen, and it was destroyed by the breaking of the drift dam. (Reclus29:522.) In September, I 893, a great landslide, lasting three days and bringing down $800,000,000$ tons of rock, dammed the deep valley of one of the upper branches of the Ganges in the Himalayas, I 50 miles above the city of Hardwar, which lies at the mouth of the valley. The dam made was nearly $\mathrm{r}, 000$ feet deep and the 
lake behind it grew to a length of four miles before it overflowed, a year after the slide. "The flood occurred at midnight, August 26-27, I894. In four hours about 400,000,000 cubic yards of water were discharged, cutting down the dam nearly 400 feet, flooding the valley to a depth of from Ioo to i 70 feet, and rushing forward with a velocity of 20 miles an hour. . . . Every vestige of habitation was destroyed in villages along the Ganges above Hardwar. But so well was the notice of danger given that only one man lost his life, and that because he would not heed the warning." (DavisI I :I82, I83.) (2) Dune sand barriers may give rise to marshes and small ponds, and more rarely to lakes of some size. These will, however, rarely be deep, for seepage will keep down the level.

(e) Detrital dams built by organisms. Dams built by organisms of detritus are typically represented by beaver dams, and by the artificial dams built by man. Neither of these requires more than a passing notice.

\section{Classification of Lakes as a Whole.}

From a bionomic and stratigraphic point of view, lakes must be classified irrespective of the origin of the basin in which they are held. The most natural division from such a viewpoint should be based on the character of the water, for, since this is the medium in which life exists or sediments are deposited, its composition exercises a more or less controlling influence. Waters may be classed as fresh, salt or alkaline. Fresh waters do not on the average carry much over 0.2 part per thousand of dissolved mineral matter, of which only about 2 per cent. is sodium chloride. (See tables in Chapter IV.) With an increase in the percentage of sodium chloride, the water becomes brackish and then salt. Alkaline waters contain a large percentage of alkali carbonates. Lakes may next be divided into deep lakes, $i$. e., those in which an abyssal as well as a littoral region is distinguishable, and shallow lakes, those in which the abyssal district is wanting. The shallow lakes include permanent and temporary ones, the latter sometimes being extremely shallow, as in the case of playa lakes, which may not exceed six inches in depth. The presence or absence of an outlet or effluent is also of significance, and its permanent or intermittent character, when marked, must be considered. These features may be tabulated as follows: 
Classification of Continental Seas or Lakes.

A. Saline (without effluent).

I. Deep, with pelagic, littoral, and abyssal zones. (Caspian, Dead Sea.)

2. Shallow, with pelagic and littoral zones. (Aral, Great Salt Lake.)

B. Alkaline (without effluent).

I. Deep.

2. Shallow, with pelagic and littoral zones. (Albert and

C. Fresh.

Summer Lakes, Oregon; Mono Lake, California, etc.)

I. Without effluent or with only temporary one.

a. Deep, with pelagic, littoral, and abyssal zones. (Tanganyika.)

b. Shallow, with pelagic and littoral zones. (Eifeler Maare; Silver Lake, Oregon; Eagle Lake,

2. With effluent. California ; many ponds.)

a. Deep, with pelagic, littoral, and abyssal zones. (Lake Superior, Lake Nyassa, Lake Geneva, Lake Baikal.)

b. Shallow, with pelagic and littoral zones. (Lake Erie; most of the fresh water lakes of the world.)

\section{RIVERS.}

In the genetic classification of rivers we must recognize at the outset that we are dealing with two distinct things, the rivers themselves and their drainage basins. Either may be simple or complicated. A simple type of river may be conceived of as existing in a complicated drainage basin (see antecedent, superimposed consequents, and consequents on a peneplain surface); or the reverse may be conceived of, a complicated (polygene) river existing in a drainage basin of simple structure, as on a coastal plain. Consilering rivers alone, we may class them with reference to their development as simple or monogene and complicated or polygene; and with reference to their relation to the structure of the region as antecedent, or existing before the structure, and postcedent, coming into existence after the structure. Most rivers belong to the latter class. Rivers generally, by growth, capture and the acci- 
dents brought about by outside agencies, become polygenetic, $i$. $e$, become a union of originally separate rivers, but all of them begin as simple types.

\section{Simple or Monogene Rivers.}

Five simple or monogene types can be recognized. I. Consequent streams, II. Insequent streams, III. Overflow streams, IV. Glacial streams, V. Subterranean streams.

I. Consequent Streans. These are the streams which come into existence upon a new land surface. Such a land surface may be young or rejuvenated, but so far as the river is concerned, it is a new land. The mode of origin may be A. by origination (de novo), B. by extension, and C. by inheritance. In all cases the consequent is distinguished from the insequent type by the fact that it starts upon a sloping land surface and cuts primarily downward rather than headward, although this latter also occurs. From the other types it is distinguished by not having primarily a stored supply at its head, as in the overflow river from a lake, or in the stream supplied by the melting of a glacier. Its supply of water is derived from the run-off and the ground water.

A: Nezely originated consequents may be classed as principal and as tributary, the former entering the sea or receiving basin direct, the others being tributary to other consequents, which may or may not be principal ones. Calling the principal type the consequent of the first order, its consequent branches would be those of the second order, their consequent branches would represent the third order, and so forth. These streams may next be divided according to the type of land they come into existence on, the three types being: I. Constructional surface consequents, 2. Destructional surface consequents, and 3. Deformational surface consequents. The consequents arising on constructional surfaces may be divided into (a) coastal plain consequents, or those originating on a newly emerged coastal plain, elevated by purely epeirogenic movements of the land or by negative eustatic movements of the sea, or by the drainage of an elevated water basin; (b) fan delta consequents, or those originating on dry deltas of other streams or on landslides; (c) moraine and till surface consequents, or those coming into existence on a sloping surface of deposition of glacial detritus; and (d) lava and volcanic cone consequents, or those originating on the slopes of volcanoes or on lava flows. Consequents arising on a surface of destruction, upon simple elevation, are almost wholly represented by pcneplain consequents, $i . e$., those developing 
on an uplifted, slightly tilted peneplain or plain of subaërial denudation. Streams originating on a newly ice-scoured surface may be noted as of this class, but of minor importance. If surfaces of purely marine denulation are of sufficient extent to have streams originate on them on elevation, these would also be classed here. Finally, consequents arising on a surface of deformation include several types: those formed on a simple dome, those formed on a series of anticlines and synclines, and those formed on tilted fault blocks. In the first case we have radial consequents of the $\mathrm{n}^{t h}+\mathrm{I}$ order tributary to another consequent of the $n^{\text {th }}$ order which may be the first (principal consequent) or any higher order. In rare cases domes of deformation rise directly out of the sea, when the radial consequents are of the first order, $\mathrm{n}$ being zero. In the anticlinal and synclinal folds we have transverse consequents flowing down the limbs of the anticline, and longitudinal consequents flowing in the synclines. The first belong to the $\mathrm{n}^{\text {th }}+\mathrm{I}$ order, the second to the $\mathrm{n}^{\text {th }}$. In exceptional cases a transverse consequent may flow into the sea, the shore of which may be formed by an anticline, or the syncline may be filled by an arm of the sea or by a lake. Consequents flowing down the back slopes of inclined fault blocks are in all essentials like those flowing down the limbs of anticlines.

B. Extended consequents are streams of an older type which become extended across the newly emerged coastal plain. These streams do not differ from those originating on the coastal plain, except in their greater volume of water and hence greater erosive power. They will, therefore, cut deeper than the others, becoming the master streams of their respective regions, and directing to a large extent the further development of their drainage system. Streams extended across a dry delta may also be classed here, as are those extended across a plain of glacial deposition. In so far as the older part of the stream is concerned it may be simple or complex, monogene or polygene.

C. Inherited consequents. These are consequents which are superimposed upon a complex terrane by learning to flow upon a coastal plain which once covered the complex rocks, and which directed the course of the river, though long since removed by erosion. Superimposed consequents are believed to be illustrated by the lower courses of the Housatonic and Connecticut rivers in southern New England. The coastal plain strata which apparently once extended over this area have been entirely removed by erosion. (Dodge-12.) The coastal plain strata may be replaced by layers of volcanic ash (Gunnison River), by drift, by river, or eolian deposits, or, in exceptional cases, by glacial ice. 
II. Insequent Streams. These are essentially distinct from the preceding type in that they originate upon the side of a preexisting valley of erosion or dislocation, and in that their chief mode of development is by headward gnawing instead of downward cutting. Nevertheless, there are times when it might be difficult to distinguish this type from a consequent originating on an erosion surface, or one flowing down the back-slope of a fault block. For the question would arise, when is the erosion slope steep enough to support insequents instead of tributary consequents? In the case of the fault block, we may consider that the streams on the back slope are consequents and those on the fault scarps are insequents. Of course this merely emphasizes the fact that in any natural classification of inorganic, as well as of organic things, sharp lines do not exist, but the classes are connected by gradations.

Most insequent streams are classifiable into $a$. erosion-bluff and b. fault-scarp insequents. The former comprise ( I) wave-cut cliffs (marine and lacustrine), (2) river-cut cliffs, (3) ice-cut cliffs, (4) wind-cut cliffs, and (5) artificially-cut cliffs, while the second includes scarps due to faulting and to local subsidences, such as kettle-holes in moraines, etc., sink-holes over caverns and others. A third but rare type $c$. forms on the margins of pit or explosion craters, while a fourth type $d$. is seen in embankment insequents, where cliffs of construction or artificial embankments are gullied. This type approaches the consequent type developed on dry river deltas or alluvial fans, since it develops on a constructional surface.

Simple subsequent streams. Insequent streams, near the head of a coastal plain, may open out a lowland parallel to the strike of the strata on an underlying softer substratum. Such enlarged insequents have been termed subsequents, and in a young region these may be of simple type. In most cases, however, subsequents become compound through capture. Axial subsequents open up longitudinal valleys on the crests or axes of anticlines, and by sliding downward occupy the monoclinal valleys. (See chapter XXI.)

Obsequent streams. These are insequents peculiar on account of their location on the inface of a cuesta, as a result of which their course is in an opposite direction from that of the consequents. Rivers on the fault face of tilted blocks would also come under this category.

III. Overflow Streams. These are the spillways from standing water bodies and as such include all effluents of lakes. Such effluents may be terminal, carrying the waters of the lake directly to the sea or into a trunk stream which flows into the sea without 
further laking; or interlacustrine, spilling over from one lake into another. The St. Lawrence River is a good example of the former type, and the Niagara of the latter. Overflow streams are characterized by little or no sediment, this being all left behind in the lake. They may, however, pick up sediment on the way from their bed and banks, or from tributaries, and so obtain tools for erosion. Niagara is a good example of such a stream, free from sediment in its upper part and accomplishing its erosion work by undermining at the cataract and drilling on the floor.

IV. Glacial Streams. These have their water supplied by the melting ice mass, which also furnishes detrital material. Hence these streams are distinct from all others. Streams originating on the ice, $i$. e., superglacial streams, have the consequent habit, and might be classed as an extreme type of that group. But subglacial streams are unlike all others. Their peculiar position under the ice cover and subject to hydrostatic pressure, often forces them to flow across obstacles no normal river could surmount, or actually to flow for a part of their course uphill. Such abnormal courses of ancient subglacial streams are indicated by the position of the eskers which they have built. In many characters, subglacial streams approach subterranean streams.

V. Subterranean Streams. These are often of great extent and diversity, following enlarged joints in limestone strata, and forming caverns along their paths, which are subsequently more or less filled up again by stalactic deposits. Underground drainage may develop to the complete absorption of surface drainage, giving the peculiar Karst type of landscape so characteristic of the west side of the Balkan peninsula, and also seen in the Barren lands of Kentucky and Tennessee, in the plateau of the Cévennes in southern France, in the German Jura, and in many other regions. (Cvijic-5; Neumayr-27:500-510.)

\section{Polygene Rivers.}

Under this heading may be grouped the three types denominated by Davis: 1. compound rivers, 2. composite rie'ers, and 3 . complex rivers. (Davis-8:I83; 9:102.) Davis defines a compound river as one "which is of different ages in its different parts," and cites as examples "certain rivers of North Carolina which have old headwaters rising in the mountains and young lower courses traversing the coastal plain." These are the extended consequents of our classification. The term should be made to cover streams which by capture have enlarged their drainage basin at the expense 
of other streams Extended consequents, by reason of their greater water supply, are apt to become compound or at least their principal branches will be affected in this manner. This is especially the case with the subsequent type of stream. The present Moselle of western Europe is an example of a compound river, having acquired by capture some of the headwaters of the Meuse. (Davis, I0:229-230.) (Figs. 22, 23.)

A composite stream is defined by Davis as one including in its basin, drainage areas of different structure. In so far as the differ-

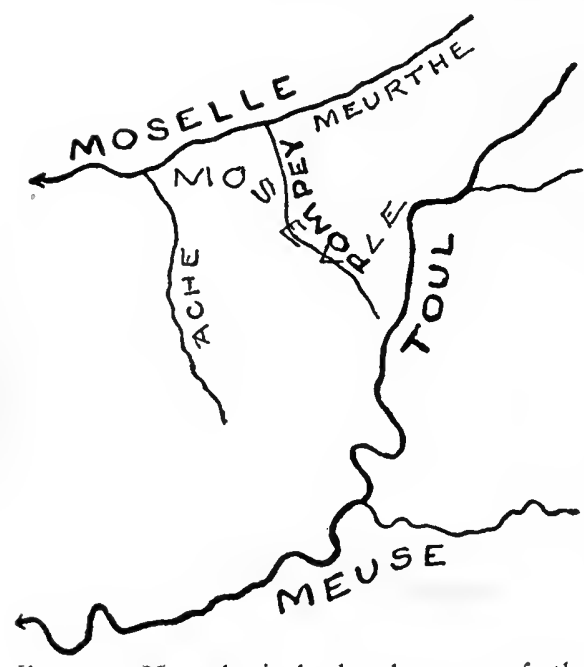

IiIg. 22. Hypothetical sketch map of the Meuse and Moselle rivers, France, before capture. (After Davis.)

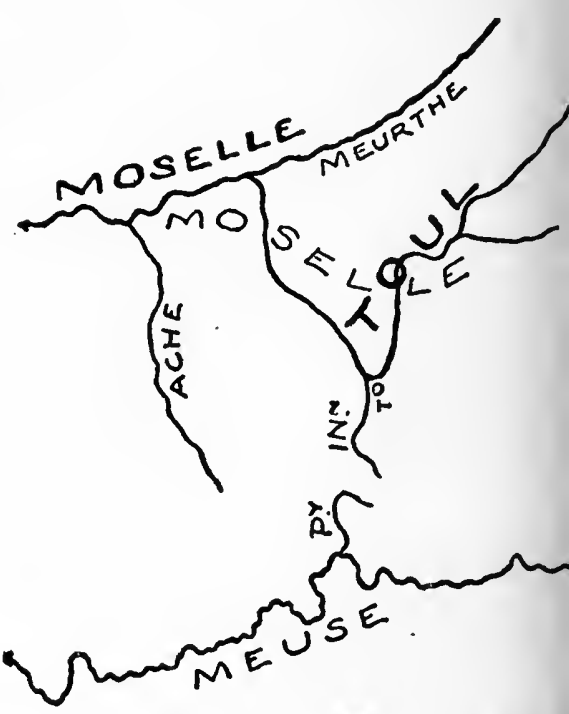

Fig. 23. Map of the Meuse and the $A$ selle after capture. (Davis.

ence in structure affects the stream, causing it to modify its course, this definition may stand. We must, however, bear in mind that we are dealing with two distinct things, the river and the drainage basin. A simple consequent on a destructional surface (peneplain) or a superimposed consequent on a much folded older terrane may flow across regions of different structure in different parts, $i$. e., have a composite drainage basin and yet be of simple character.

The third type of polygene river is the complex. This is defined by Davis as a river which "has entered a second or later cycle of development." Rivers inherited by an uplifted peneplain from the previous cycle are typical examples of this class. They will differ from simple consequents upon a peneplain in that they have ac- 
quired a meandering course, while the peneplain was low, and this will be in a large measure retained, so that the inherited strean will be characterized by deeply incised meanders, whereas the new consequent will generally be straight. A more pronounced complexity is produced when by warping, partial damming and division a river enters locally on a new cycle, while other parts remain comparatively unchanged. An example of such a river is the Genesee, which at present occupies the valleys of two formerly distinct streams of diverse origin. This is really the case with the St. Lawrence drainage system as a whole, the affluents of the lakes, which belong to this system, having a varied history, as already noted in the case of the Genesee.

Relative Ages of Rivers and River Systems. In discussing the relative ages of rivers and river systems, we must distinguish between the age of the river or river system and the age of the district it inhabits. Thus a young stream may exist in a young counitry, as in the case of new streams on a young coastal plain, or it may exist in a mature or old country. The age of the land must be considered distinct from the age of the river. (Johnson-2I.) Only the latter will be considered here. Streams are classed as young, mature and old, according to the degree of their development. No conception of actual time is involved, for of two rivers born at the same time one may reach maturity while the other is still very youthful. Young rivers are characterized by rapids and falls, and by steep-sided, narrow gorges. Lakes may further interrupt the course of the drainage. A river is mature when it has destroyed its lakes and falls, and reduced its valley sides to graded slopes, and broadened its floor so that it may swing upon it in great meanders. A mature river is able to carry away all the load that it receives, but generally has no power to do further erosion. A river system is mature when all the branches have become mature, but generally youthful branches are found long after the trunk stream las become mature. Old rivers are those which move sluggishly along across a flat, much-encumbered valley bottom. Their grade is so low that they cannot carry away the rock waste, and so they aggrade their beds, or stagger about in them by avoidance of the débris. In a river system the main stream may grow old, while its branches are still mature or even youth ful.

Aging of Rivers by Accident. Rivers may grow old rapidly through various accidents. Among these are mutilation, sudden overloading, and drowning. The first of these produces permanent senescence, and may be compared to the permanent aging of an animal body through a severe illness or accident. The second is 
only temporary, for as soon as the supply ceases the river will revive and begin active cutting again. This may be compared to a temporary depression or weakening from overwork, which produces temporarily a weariness akin to that of old age, but from which recovery is usually certain, on cessation of the excess of work. The third may be of long duration with ultimate revival, or it may lead to extinction. It may be compared with a serious illness, from which recovery is doubtful.

I. Mutilation. When a river has its headwaters or branches cut off by capture or diversion, it quickly begins to age. From a youthful, cutting or degrading stream it changes to a mature one, where graded conditions are maintained. By further reduction, old age is reached, when the river begins to aggrade its valley, by dropping what débris is brought to it. The river Bar, an affluent of the Meuse, is such an old river, aged by mutilation, which resulted in the loss of its headwaters. It now staggers through a débrisclogged valley, which is out of proportion to its present size. The Meuse itself may be considered at least a submature river, just able to maintain its course, which in this case means cutting through the rising ground, which is equivalent to carrying away all the débris brought to it without cutting, in a stationary region.

2. Sudden overloading of a mature or submarine river may also produce the phenomena of old age, by causing the river to aggrade its floor. This may occur while the river valley is still a long way from entering upon the state of old age. The gravel terraces of the Allegheny, Monongahela and other Pennsylvania rivers, which rise about 200 feet above the present stream channel, have been explained as remnants of high flood-plains due to aggrading of the valleys by the overloaded Allegheny in early glacial time. The débris was largely supplied to the river by the melting ice. Even the tributary streams were forced to aggrade their valleys from the mouth upward. Since then the rivers have cut down again through this old flood plain, leaving the terraces on either side to mark its former elevation. (Shaw, 35.) Similar examples are found in New England rivers.

3. Drozening of rivers also brings on the phenomena of old age. This drowning may be due to overflow of a lake to which the river is affluent, or to subsidence of the coast or to other causes. Examples of drowned coastal rivers are the Hudson, the lower St. Lawrence, and numerous other rivers of the North Atlantic coast. No erosion is accomplished by these rivers; they have no appreciable current of their own, the movements of the water being regu- 
lated by the tides, and they deposit all the débris furnished to them. They are justly called old rivers, though their old age is premature, and they may be situated in young valleys. Partial drowning results when, through damming by drift, a portion of a river valley is converted into a lake, as was the case in the upper Genesee River. (Fairchild-13.)

Revizal and Rejuvenation of Rivers. Rivers which have become prematurely old, or which have grown old in the normal cycle of development, may be revived or rejuvenated by an uplift of the land or by a removal of the cause of senescence. The overloaded stream is most easily revived by the removal of the cause of senescence, $i$. $e$., the excessive supply of material. This is better spoken of as a recovery. Drowned coastal rivers may be revived by elevation until they have again reached the condition prior to drowning. If further elevation occurs they will become rejuvenated and enter upon a new cycle of erosion as youthful streams. Partly or wholly drowned rivers, through damming by drift or otherwise, may be revived by removal of the dam, or, what is more of ten the case, by the cutting of a new outlet. This will result in a complex stream, in which the outlet portion is youthful, while the rest is mature or older. The narrow gorges with rapids and waterfalls connecting the present upper and lower Genesee valleys are examples of young connecting portions interpolated between revived mature portions.

Rivers which in the course of their normal develojment have reached a state of old age, may be rejuvenated by a favorable change of the environment, through an uplift of the land, or a lowering of the base-level of erosion, $i$. $e$., the local level to which erosion proceeds; or by an infusion of new life, in the case of certain rivers, through a change in climatic conditions, which will greatly increase the amount of water, and hence the power of work of the stream. The Great Falls of the Missouri in castern Montana occur in a rejuvenated valley, $i . e$., a valley now in its second or later cycle $\left(n^{\text {th }}+\right.$ I cycle, where $n$ may be the first or any later cycle). (Davis.) The rivers of the Piedmont district of Virginia, and all rivers which incised themselves into uplifted peneplains which they had helped to make, are examples of rejuvenated rivers, now in their $n^{\text {th }}+$ I cycle. These rivers are generally characterized by well-entrenched meanders, which differ strikingly from the crooked curves of young streams. Such meanders are shown by the Seine in the Normandy upland, the Moselle and the Rhine in the old Rhine uplands of western Germany, the Susquehanna in the old Appalachian upland, and by many other streams. 


\section{Underground Water (Ground Water).}

Ground water is that part of the hydrosphere enclosed within the pores of the rock of the earth's crust, and either circulating by slow movements within the crust, or remaining stagnant within its pores.

\section{Classification of Ground Waters.}

According to the mode of origin, ground water may be divided into three types.

A. Meteoric or Pluvial Waters, or those derived from rain or snow and penetrating into the crust from above. These form the vadose circulation.

B. Connate Waters, or those buried originally with the sediments in which they occur, and varying according to their derivation from fresh to marine waters. This is the fossil water, and to be conserved must remain stagnant within the pores of the rock.

C. Magmatic or Juvenile Waters, or those given off by cooling magmas and in a sense generated anew by the combining of gases from the igneous mass.

Some observers, notably Van Hise and his followers, would regard all ground water as of meteoric origin, and consider the high temperature and mineral content of such waters, originally cool and nearly pure, as due to a descent into regions of high temperature within the depths of the earth, or their coming in contact with heated igneous masses, and the consequent impartation of heat and thermal solvent power, so that both their temperature and mineral content are acquired properties. Other workers in this field, notably Eduard Suess and J. F. Kemp, have insisted on the magnatic origin of many if not most of the heated and mineral-laden waters, the temperature and mineral content of which are, therefore, primary or a part of their original character. It is this class of waters which is believed to be responsible for most of the ore deposits within the older rocks, and to such an origin may perhaps also be traced most of the lot and mineral springs of the present day. Recent experiments at Kilauea have resulted in the actual condensation of water from gases given off by the lavas.

The term connate waters was proposed by Lane (24:502), who calls attention to a class of waters which has been much neglected. Walther, more than any other writer, has insisted on the significance of fossil sea waters as an important source of salts concentrated from them by surface agencies under arid climatic conditions. 
The amount of such water preserved in the rocks depends, of course, on the volume of the pore space (see below, p. 140), which may be as high as $60 \%$ of the volume of the sediment, though of course it is much less in the majority of clastic deposits.

Lane has called attention to the role played by connate waters in preventing the downward passage of the meteoric waters, which will tend in a measure to dilute some of these stagnant waters. While the meteoric waters circulate freely in the upper zone of the earth's crust (the belt of weathering), the zone of permanent ground water is one of more or less stagnation, and one in which deposition of the mineral matter of these waters in the pores of the rock will take place. We have, therefore, beneath the zone of weathering and free circulation, one of cementation, and thus a barrier to the further downward progress of the meteoric waters is formed. This at the same time forms a barrier against the escape of the imprisoned connate waters, which will thus be conserved until erosion of the rocks sets them free once more. Lane was led by such considerations, and by the study of the composition of the deep-seated waters, to conclude that a large part of the ground water attributed by Van Hise and others to a meteoric origin was in reality connate, $i$. $e$., the imprisoned water of former oceans.

\section{General Course of Meteoric Waters.}

Rain falling upon the land is disposed of in several ways. A part of it runs off down the slopes (the run-off), a part sinks into the ground (the absorp), and a part evaporates, returning to the air (the evaporate). The part that sinks into the ground becomes the ground water, while the run-off starts the development of surface drainage. The quantitative relation between run-off, evaporate and absorp depends upon (I) the character of the surface, $i$. e., its topography or slope, porosity of material, state of saturation, amount of vegetable covering, etc., (2) the rate of rainfall or melting of snow, and (3) the subsequent dryness of the atmosphere. and perhaps other local features. Very porous soil holding little water will greedily absorb the rain if it falls not too heavily. In this latter case much will run off, as the rate of absorption cannot keep pace with the rate of supply. In a very dry atmosphere much will evaporate before it has time to sink in, while much more will be evaporated from the upper layers of the soil before it has descended far, or will be taken up by vegetation to be ultimately returned to the air. 


\section{Porosity of Rocks.}

The porosity of a rock or soil mass is determined by the fractional part of the mass occupied by open spaces or voids. (Slichter$37: I 6$.$) If a cubic foot of sandstone holds, on saturation, one-$ quarter of a cubic foot of water, the porosity of the sandstone is $\mathbf{2 5}$ per cent. The following table of tests made by Dr. E. R. Buckley, State Geologist of Wisconsin, shows the variation in the porosity of various building stones of that state:

\begin{tabular}{|c|c|}
\hline Kind of rock, and locality & $\begin{array}{l}\text { Average porosity } \\
\text { of two specimens } \\
\text { per cent. }\end{array}$ \\
\hline 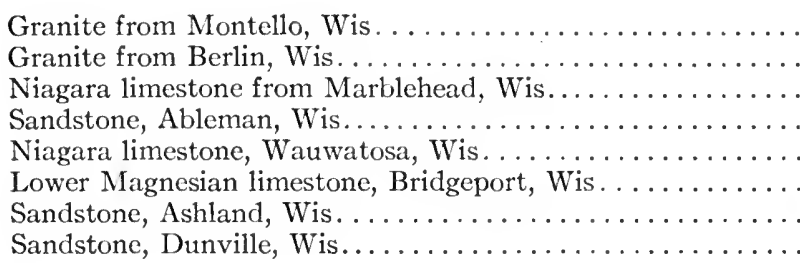 & $\begin{array}{r}0.237 \\
0.384 \\
0.770 \\
5.600 \\
6.400 \\
13.190 \\
20.700 \\
28.260\end{array}$ \\
\hline
\end{tabular}

The porosity of quartz sand usually varies between 30 and 40 per cent., and that of clay loams between 40 and 50 per cent., depending on the variety of size of grains in the mixture, and on the manner of packing the particles. (Slichter, 34, p. 17.) The pore space of fresh, strong granite varies from 0.2 to 0.5 per cent., the absorption of water being 0.08 to 0.20 per cent. by weight. Ordinary compact limestone varies from 2.5 to 12.5 per cent. (absorption I to 5 per cent. by weight of water), although the more porous limestone can absorb to per cent. by weight of water, corresponding to a pore space of 25.0 per cent. The more compact types of limestones, however, fall as low as 0.55 per cent. of pore space. Sandstones generally have a pore space ranging from 5 to 28 per cent. Chalk has been credited with the ability to absorb 20 per cent. by weight of water corresponding to a pore space of about $4 \mathrm{I}$ per cent. (Van Hise-43: 125 .) The pore space of an organic limestone from the Gulf of Naples was over 35 per cent. (Walther), while recent sediments of the Mississippi delta contained, according to Hilgard, a pore space ranging from 23 to $6 \mathrm{I}$ per cent. The actual size of the grains is of less importance in influencing the porosity of the mass than the variation in size within the same mass, or the arrangement 
or mode, of packing. Thus, if a quantity of shot be poured into a glass, and the quantity of water required to fill the pores be measured, it will be found that the porosity varies greatly if different methods be used in filling the glass, each producing a different arrangement. but that the same values may be obtained with small shot as with large. (Slichter-37:2I.) Slichter has determined that the minimum porosity of a mass of spheres, packed in the most compact manner, is 25.95 per cent. of the whole space occupied by the spheres, while the maximum porosity is 47.64 per cent. of the whole mass. (Slichter-38:295.)

The pores between the grains are both larger in diameter and shorter in length for a packing of spheres having a large porosity than they are for a packing of low porosity. As already noted, slight variations in the shape of the grains make little difference in the porosity of the mass, but variations in size within the mass make a great difference. Thus a mass of sand of uniform-sized grains will have a greater porosity than one in which the grains vary greatly. Many rocks of originally great porosity have suffered a considerable reduction in this respect by the filling of the pores by secondarily introduced mineral matter.

\section{The Water Table.}

The level beneath which the soil is completely saturated is called the level of groundwater, or the water table or water plane. This is also the summit plane of the true groundwater, that between it and the surface of the lithosphere constituting the subsurface water. This latter plays an important part in the influence it has on the soil and on plant growth.

The depth of the water table varies greatly both regionally and seasonally. Where the rainfall is heavy it usually lies only a few feet below the surface, but in arid regions its depth may be several hundred feet. In general the surface of the water table corresponds to the surface of the land, but the irregularities are less pronounced (Fig. 24.) Where the water table lies deep, it can be reached only by deep wells, and springs are wanting. Where it coincides with the surface of the ground, the region is a swamp or marsh.

\section{Depth and Quantity of Ground Water.}

According to Van Hise $(42: 593 ; 43: 189)$, at a depth of about 6 miles (about 10,000 meters) below the surface, the rock pressure 
is so enormous as to close effectively all cavities and pores. This is the limit of the zone of rock fracture, the zone below it being that of rock flowage. This is, then, the depth to which ground water can penetrate, though by far the largest quantity exists considerably above this. More recently the experiments of Adams and King have shown that pore spaces may exist at greater depths, even down to eleven miles. (Kemp-22.)

Slichter, assuming that the geologic limit of the existence of ground water is at an average depth of six miles below the surface of the land, and five miles below the floor of the sea, estimates the entire amount of ground water to be about 565,000 million million cubic yards, or about 430,000 million million cubic meters. This is nearly one-third the amount of the water of the sea as a whole. Ac-

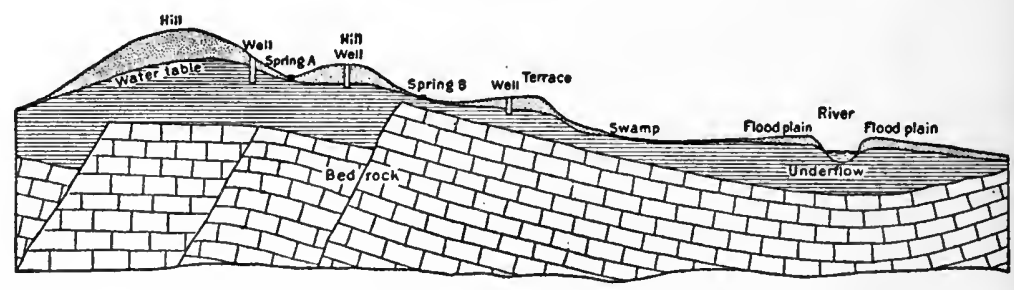

FIG. 24. Diagrammatic section illustrating the position of the water table. (After Slichter.)

cording to these estimates the total amount of ground water is sufficient to cover the entire surface of the earth to a uniform depth of from 3,000 to 3,500 feet. (Slichter-37.) These estimates are based on the selection of an average pore space for all rocks of Io per cent., which Slichter himself regards as too large rather than too small.

It has, however, been shown by Kemp that, according to the experience in deep mines, ground water of meteoric origin is limited to the upper I,000 feet of the earth's crust. This makes the total amount of ground water much less than that given by the estimates above cited. Kemp concludes that this ground water is sufficient to cover the earth's surface with a layer of water from only 50 to Ioo feet deep. Fuller subsequently made more close calculations, concluding therefrom that the layer of water would be 96 feet deep. (Fuller-14:59-72.) See the preliminary discussion on pp. 4 and 5 and further under thermal springs, their possible relation to magmatic waters, etc. (pp. 200-203). Finally movements of ground water, pp. 257-261. 


\section{BIBLIOGRAPHY III.}

\section{(See also references under Chapters II and IV.)}

I. AGASSIZ, LOUIS. 1876. The Parallel Roads of Glen Roy. Geological Sketches. 2nd series, pp. 32-76.

2. BERENDT, G. I869. Geologie des kurischen Haffes, Erläuterung zu Section 2, 3, 4, der geologischen Karte von Preussen, Königsberg.

3. CLAPP, F. C. 1902. Geological History of the Charles River in Massachusetts. Ameriean Geologist, Vol. XXIX, pp. 218-233.

4. CROSBY, WILLIAM OTIS. I899. Geological History of the Nashua Valley during the Tertiary and Quaternary Periods. Technology Quarterly, Vol. XII, No. 4, pp. 288-324, 4 plates.

5. CVIJIC, J. I893. Das Kartsphänomen. Geographische Abhandlungen, Vol. III, Wien.

6. DANA, JAMES D. I872. Corals and Coral Islands.

7. DAVIS, WILLIAM MORRIS. I882. On the Classification of Lake Basins. Proceedings of the Boston Society of Natural History, Vol. XXI, pp. 315-38I.

8. DAVIS, W. M. I889. The Rivers and Valleys of Pennsylvania. National Geographic Magazine, Washington, Vol. I, pp. I83-253.

9. DAVIS, W. M. I890. The Rivers of Northern New Jersey with Notes on the Classification of Rivers in General. Ibid., Vol. II, pp. 8I-IIo.

I0. DAVIS, W. M. I 896 . The Seine, the Meuse, and the Moselle. Ibid., Vol. VII, pp. I89-238.

II. DAVIS, W. M. I899. Physical Geography. Boston, Ginn and Company.

12. DODGE, R. E., and others. 1902. Physiography. United States Geological Survey, New York City Folio. No. 83.

I3. FAIRCHILD, H. L. I899. Glacial Genesee Lakes. Bulletin of the Geological Society of America, Vol. X, pp. 27-68.

14. FULLER, MYRON L. I906. Total Amount of Free Water in the Earth's Crust. Water Supply and Irrigation Paper, No. I60. United States Geological Survey.

I5. GILBERT, G. K. I890. Lake Bonneville. United States Geological Survey Monograph, Vol. I.

16. GRABAU, AMADEUS WILLIAM. I900. Lake Bouvé, an Extinet Glacial Lake in the Boston Basin. Occasional Papers of the Boston Society of Natural History, Vol. IV, Pt. III, pp. 564-60o, map.

17. GRABAU, A. W. I90I. Geology and Palæontology of Niagara Falls and Vicinity. Bulletin of the New York State Museum of Natural History, No. 45 , Vol. IX.

I8. GRABAU, A. W. I907. The Geographical Classification of Marine Life Districts. Science, N. S. Vol. XXV, No. 63I, p. I85. Feb. I, 1907.

I9. GRABAU, A. W. I908. Preglacial Drainage in Central Western New York. Science, N. S., Vol. XXVIII, No. 720, pp. 527-534.

20. HAGUE, ARNOLD. 1912. Origin of Thermal Waters of Yellowstone. Bulletin of the Geological Society of America, Vol. XXII, No. I, pp. IO2-I 22.

21. JOHNSON, DOUGLAS W. I905. Youth, Maturity and Old Age of Topographic Forms. American Geographical Society, Bulletin XXXVII, pp. $648-653 ; 3$ figs. 
22. KEMP, JAMES F. I9I3. The Ground Waters. Transactions of the American Institute of Mining Engineers, pp. 603-624.

23. KRÜMMEL, OTTO. I907. Handbuch der Ozeanographie, Band I.

24. LANE, ALFRED C. I909. Mine Waters and Their Field Assay. Bulletin of the Geological Society of America, Vol. XIX, pp. 50I-5I2.

25. LINCOLN, F. C. I907. Magmatic Emanations. Economic Geology. Vol. II, pp. 258-274.

26. MOORE, J. E. S. I903. The Tanganyika Problem. London.

27. NEUMAYR, MELCHIOR. I895. Erdgeschichte, Vol. I. Leipzig und Wien.

28. PENCK, ALBRECHT. I 894. Morphologie der Erdoberfläche. Vol. I.

29. RECLUS, JEAN JACQUES ÉLISÉE. I 867. La Terre, Vol. I.

30. RUSSELL, ISRAEL COOK. 1885. Geological History of Lake Lahontan. United States Geological Survey Monograph, Vol. XI.

31. RUSSELL, I. C. I890. Notes on the Surface Geology of Alaska. Bulletin of the Geological Society of America, Vol. I, pp. 99-I62.

32. RUSSELL, I. C. I898. Rivers of North America. New York, Putnam.

33. SALISBURY, ROLLIN D. I907. Physiography. New York, Henry Holt and Company.

34. SALISBURY, R. D., and others. 1902. The Glacial Geology of New Jersey. Geological Survey of New Jersey, Final Report, Vol. V.

35. SHAW, E. W. I9II. High Terraces and Abandened Valleys in Western Pennsylvania. Journal of Geology, Vol. XIX, pp. 140-156.

36. SLICHTER, C. S. I 899. Theoretical Investigations of the Motion of Ground Waters. 19th Annual Report of the United States Geological Survey, Pt. II, pp. 295-384, pl. xvii, figs. 54-89.

37. SLICHTER, C. S. IgO2. The Motions of Underground Waters. Water Supply and Irrigation Papers, No. 67.

38. SUPAN, ALEXIS. I 899. Die Bodenformen des Weltmeeres. Petermanns, Mittheilungen, Vol. XLV, pp. 177-188, with map I2.

39. SUPAN, A. I903. Terminologie der wichtigsten unterseeischen Bodenformen. Ibid., Vol. XLIX, pp. I5I-I52.

40. UPHAM, WARREN. I895. The Glacial Lake Agassiz. United States Geological Survey Monograph XXV.

41. UNITED STATES GEOLOGICAL SURVEY, Norfolk Folio, No. 80.

42. VAN HISE, CHARLES R. 1896. Principles of North American Precambrian Geology. I6th Annual Report of the United States Geological Survey, Pt. I, pp. 58I-872.

43. VAN HISE, C. R. I904. A Treatise on Metamorphism. United States Geological Survey Monographs, Vol. XLVII.

44. VEATCH, A. C. I906. Geology and Underground Water Resources of Northern Louisiana and Southern Arkansas. United States Geological Survey, Professional Paper No. 46.

45. WALTHER, JOHANNES. I9 Io. Lehrbuch der Geologie von Deutschland. Leipzig.

46. WILSON, J. HOWARD. I906. The Glacial History of Nantucket and Cape Cod. Columbia University Geological Series, Vol. I. 


\section{CHAPTER IV.}

\section{COMPOSITION AND PHYSICAL CHARACTERS OF THE HYDRO- SPHERE.}

\section{COMPOSITION OF THE HYDROSPHERE.}

The hydrosphere is never pure $\mathrm{H}_{2} \mathrm{O}$, but always includes dissolved salts and gases. The former are most abundant in sea water and in the waters of salt lakes, the latter in some underground waters. The composition of the larger divisions of the hydrosphere, the oceans and the intracontinental seas, the lakes, rivers and ground water, will be considered in turn. The totality of dissolved salts constitutes the salinity of the water, though in the open sea less than 80 per cent. of this is common salt $(\mathrm{NaCl})$. The totality of mineral matter is determined in parts (by weight) per 1,000 parts of water, or the number of grams in I, o0o grams (I liter) of water. This amount is expressed as so many permille $(\%)$ of salts. Thus a salinity of 35 permille exists when each I,000 grams (or approximately each liter) of sea water contain 35 grams of salts, as in average ocean water. (For details and corrections of method see Krümmel-20:22I-222.)

\section{Salinity of the Sea.}

The salinity of the sea as a whole has been calculated at 34.49 permille, but that of individual divisions varies greatly. The following table adapted from Krümmel gives the mean surface salinity for the principal divisions, to which is added the mean salinity of the entire volume. (Krümmel-20:333, 36I.)

The seven important elements which form most of the salts contained in solution in the sea water are: Chlorine $(\mathrm{Cl})$, Bromine $(\mathrm{Br})$, Sulphur (S), Potassium (K), Sodium ( $\mathrm{Na}$ ), Calcium ( $\mathrm{Ca})$, and Magnesium (Mg). 
Table Showing the Salinity of the Sea.

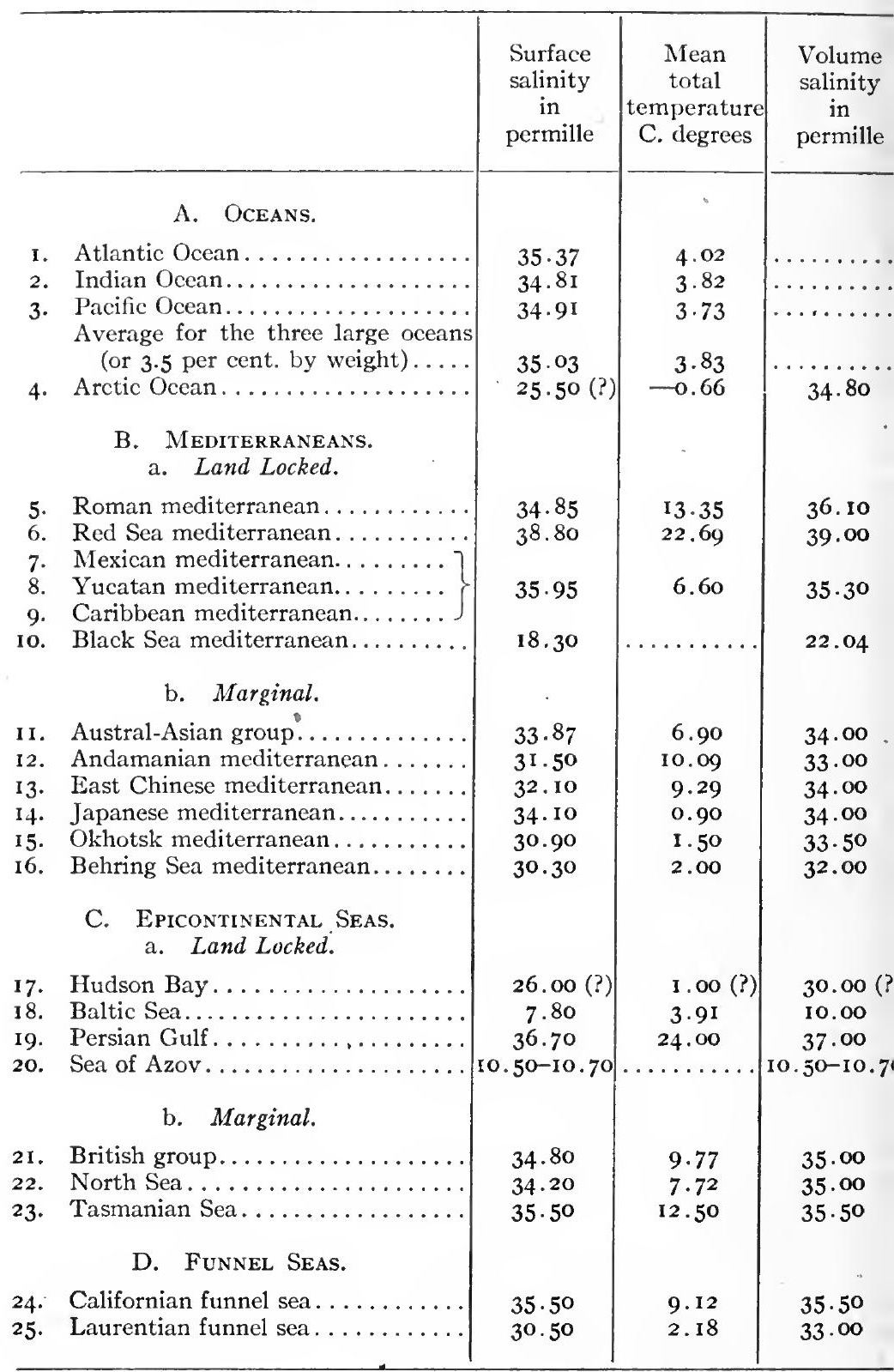


From a total of 77 very complete analyses of samples of ocean water obtained by the Challenger Expedition, Dittmar (2: 189, 204: Krümmel-20:219) has calculated the following average composition of the salt content of the sea. The calculations are in percentages of the total solids, in grams per thousand grams of sea water (permille) and in British tons per cubic mile of sea water. The total of the solids is taken at 35 permille, or 3.5 per cent. by weight of the sea water. The earliest calculations of Forchliammer ( 7$)$,

\begin{tabular}{|c|c|c|c|c|c|}
\hline & 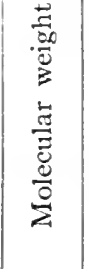 & 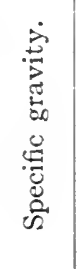 & 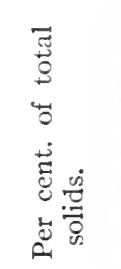 & 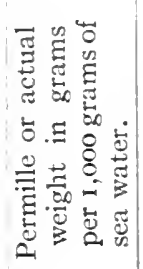 & 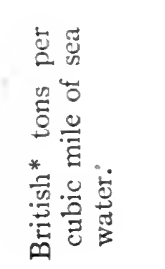 \\
\hline 1. Sodium chloride $(\mathrm{NaCl}) \ldots$. & $5^{8} \cdot 5$ & 2.17 & $77 \cdot 758$ & 27.213 & $117,434,000$ \\
\hline 2. Magnesium chloride $\left(\mathrm{MgCl}_{2}\right)$. & $95 \cdot 3$ & 2. I 8 & 10.878 & 3.807 & $16,+28,000$ \\
\hline 3. Magnesium sulphate (MgSO) & 120.4 & 2.65 & $4 \cdot 737$ & I. $65^{8}$ & $7,154,000$ \\
\hline 4. Calcium sulphate $\left(\mathrm{CaSO}_{4}\right) \ldots$ & $136 . I$ & 2.97 & 3.600 & I. 260 & $5,437,000$ \\
\hline 5. Potassium sulphate $\left(\mathrm{K}_{2} \mathrm{SO}_{4}\right)$. & $17+.1$ & $\cdots \cdots$ & 2.465 & 0.863 & $3,723,000$ \\
\hline 6. Calcium carbonate $\left(\mathrm{CaCO}_{3}^{4}\right) \dagger$. & $100: 0$ & 2.72 & 0.345 & 0.123 & 521,000 \\
\hline 7. Magnesium bromide $\left(\mathrm{MgBr}_{2}\right)$. & $184 \cdot 3$ & $\cdots$ & 0.217 & 0.076 & 328,000 \\
\hline Total. & & & 100.000 & 35.000 & $15 \mathrm{I}, 025,000$ \\
\hline
\end{tabular}

based on more than $\mathrm{I} 5 \mathrm{O}$ analyses of sea water, gave: $\mathrm{NaCl} 78.32 \%$ of the total solids, or a salinity of 26.862 permille: $\mathrm{MgCl}_{2}, 9.44 \%$, or 3.239 permille; $\mathrm{MgSO}_{4}, 6.40 \%$, or 2.196 permille; $\mathrm{CaSO}_{4}, 3.94 \%$, or 1.350 permille. The $\mathrm{K}$ is calculated as $\mathrm{KCl}, 1.69 \%$ of the total solids, or a salinity of 0.582 permille, no $\mathrm{K}_{2} \mathrm{SO}_{4}, \mathrm{MgBr}_{2}$ or $\mathrm{CaCO}_{3}$ being given. A residue of $0.2 \mathrm{I} \%$ or 0.070 permille is left, making a total of $100 \%$ solids, or a salinity of 34.299 permille.

Calculated in percentages of ions, we have (Tolman-39):

* One British ton equals 2,240 pounds avoirdupois; one metric ton equals $\mathbf{1}, 000$ kilograms, or $2,204.6$ pounds avoirdupois. One cubic mile of sea water (density I.026) weighs 4,3 I 5,000,000 tons.

$\dagger$ Including all traces of other salts. 


\begin{tabular}{|c|c|c|}
\hline $\mathrm{Cl} \ldots \ldots \ldots \ldots \ldots \ldots \ldots \ldots \ldots$ & $\begin{array}{l}\text { Per cent. } \\
55.292\end{array}$ & $\begin{array}{c}\text { Grams per liter. }{ }^{*} \\
19.68\end{array}$ \\
\hline $\mathrm{Br} \ldots \ldots \ldots \ldots \ldots \ldots \ldots \ldots \ldots \ldots \ldots$ & o. 188 & 0.07 \\
\hline $\mathrm{SO}_{4} \ldots \ldots \ldots \ldots \ldots \ldots \ldots \ldots \ldots \ldots$ & 7.692 & 2.74 \\
\hline $\mathrm{CO}_{3} \ldots \ldots \ldots \ldots \ldots \ldots \ldots \ldots \ldots \ldots \ldots \ldots$ & 0.207 & 0.08 \\
\hline 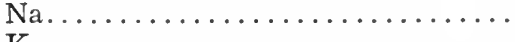 & 30.593 & I0.89 \\
\hline $\mathrm{K} \ldots \ldots \ldots \ldots \ldots \ldots \ldots \ldots \ldots \ldots \ldots \ldots \ldots \ldots \ldots$ & I. 105 & 0.40 \\
\hline $\mathrm{Mg} \ldots \ldots \ldots \ldots \ldots \ldots \ldots \ldots \ldots \ldots \ldots \ldots$ & $3 \cdot 725$ & 1.33 \\
\hline \multirow[t]{2}{*}{$\mathrm{Ca} \ldots \ldots \ldots \ldots \ldots \ldots \ldots \ldots \ldots \ldots$} & I. 197 & 0.43 \\
\hline & 99.999 & 35.62 \\
\hline
\end{tabular}

Besides the predominating seven elements in the sea, there are traces of numerous others, the quantity of which, precipitated as salts in the evaporation, are figured in the above table of Dittmar with the calcium carbonate. The following additional elements have been detected (for details see Krümmel-20:2I6, 2I8): Aluminium (A1), Arsenic (As), Barium (Ba), Boron (B), Cæsium (Ce), Cobalt $(\mathrm{Co})$, Copper $(\mathrm{Cu})$, Fluorine $(\mathrm{F})$, Gold $(\mathrm{Au})$, Iodine (I), Iron $(\mathrm{Fe})$, Lead $(\mathrm{Pb})$, Lithium (Li), Manganese $(\mathrm{Mn})$, Nickel (Ni), Phosphorus (P), Rubidium (R), Silicon (Si), Silver (Ag), Strontitum ( $\mathrm{Sr}$ ), Zinc ( $\mathrm{Zn})$, together with dissolved Oxygen (O), Nitrogen $(\mathrm{N})$, and Carbon dioxide $\left(\mathrm{CO}_{2}\right)$, the latter estimated at I 8 times the amount contained in the atmosphere. (Chamberlin and Salisbury-3:325).

The weight of the sea water, as a whole, being taken at $138 \times{ }_{10}{ }^{16}$ metric tons (Chapter I, p. 3), and the average percentage of salts by weight as 3.5, we obtain for the total amount of salt in the sea the product of $4.84 \times 1 \mathrm{IO}^{16}$ metric tons. The volume of salt, resulting from a complete evaporation of the oceans, would depend on the average specific gravity of the salt, which may be taken at 2.22. This would give $\mathrm{us} \frac{4.84}{2.22} \times \mathrm{IO}^{16}$ or $2.18 \times \mathrm{IO}^{16} \mathrm{cubic}$ meters, or 21.8 million cubic kilometers, a quantity sufficient, if spread over a level sea bottom of 361 million square kilometers, to make a layer more than 60 meters thick. Of this 47.5 meters would represent sodium chloride or common salt, 5.8 meters magnesium chloride, 3.9 meters would represent magnesium sulphate, 2.2 meters calcium sulphate, and 0.6 meter the remaining salts. The total quantity of salts forms a mass three times as great as the continent of Europe, or a little more than half the volume of land in Asia, which has $4 \mathrm{I} .6$ million cubic kilometers.

* With the average salinity taken as 35.6 permille. 
Variation in the Distribution of the Salt Content of the Occans and Intracontinental Seas.

The distribution of salts in the surface layers of the oceans varies with the degrees of latitude. Thus, for the Atlantic it is 32.80 permille between $70^{\circ}$ and $65^{\circ} \mathrm{N}$. lat. (Schott-36:21 $/$ ). It increases to 37.00 permille between $30^{\circ}$ and $20^{\circ} \mathrm{N}$ : lat., and decreases to 35.07 permille at the equator. Then it increases again to 36.52 permille between $20^{\circ}$ and $25^{\circ} \mathrm{S}$. lat., after which it decreases to 33 permille at $70^{\circ} \mathrm{S}$. lat. There are thus two maxima in the Atlantic. In the Pacific we have a salinity of 31.72 permille at $60^{\circ}$ $\mathrm{N}$. lat., increasing to 35.42 permille between $30^{\circ}$ and $25^{\circ} \mathrm{N}$. lat., and decreasing again to 34.36 permille at $10^{\circ}$ north of the equator. Then it increases to its second maximum of 36.18 permille between $15^{\circ}$ and $20^{\circ} \mathrm{S}$. lat., after which it decreases again to 33.00 permille at $70^{\circ} \mathrm{S}$. lat. In the Indian Ocean the first maximum of 35.37 permille lies near the equator, and the second between $25^{\circ}$ and $30^{\circ} \mathrm{S}$. lat. ( 35.88 permille). The mininum of 34.55 permille between these two lies about $10^{\circ}$ south of the equator. Southward the decrease is similar to that in the other oceans, to 33 permille at $70^{\circ} \mathrm{S}$. lat.; but northward from the equator the change is oscillatory. (Krïmmel-20:334.) The causes of this variation are to be sought chiefly in the varying rate of evaporation from the surface of the ocean, and the consequent increase in salinity. Evaporation is a function of the temperature, wind velocity and relative humidity. (Schott-36:2I8.) Opposing factors are the amount of precipitation, and the addition of fresh water by streams. melting icebergs, etc. Displacement of waters of a certain salinity through currents also must be considered. The following table gives the results of Marzelles' experiments in this direction (Schott-36:2I8):

I. Average evaporation in 24 hours with varying temperatures without considering wind velocity or humidity.

At $\mathrm{r}^{\circ} \mathrm{C} \ldots \ldots \ldots .80 \mathrm{~mm}$. At $19^{\circ} \mathrm{C} \ldots \ldots \ldots \ldots .52 \mathrm{~mm}$. At $\mathrm{II}^{\circ} \mathrm{C} \ldots \ldots \ldots \ldots .97 \mathrm{~mm}$. At $27^{\circ} \mathrm{C} \ldots \ldots \ldots \ldots 2.96 \mathrm{~mm}$.

II. Evaporation in 24 hours with the temperature of the air about $20^{\circ} \mathrm{C}$. and varying wind velocity.

With velocity of 0.3 meter per second............. I I mm.

With velocity of 4.2 meters per second ........... $1.90 \mathrm{~mm}$.

With velocity of 7.5 meters per second ............ $2.97 \mathrm{~mm}$.

With velocity of 10.3 meters per second............ $4 \mathrm{~mm}$. 
III. Evaporation in 24 hours with varying humidity and a temperature of the air of $20^{\circ} \mathrm{C}$.

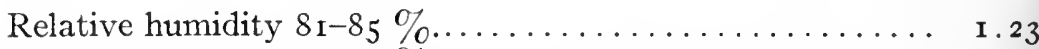

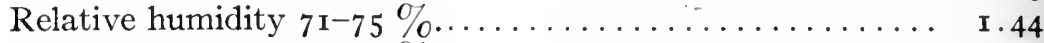

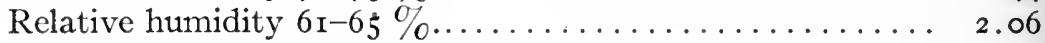

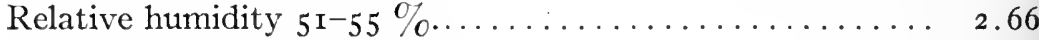

Relative humidity $4 \mathbf{r}-45 \% \ldots \ldots \ldots \ldots \ldots \ldots \ldots \ldots \ldots \ldots$

Experiments by Schott have given the following results in concentration of normal sea water through evaporation at a temperature of the air ranging around $25^{\circ} \mathrm{C}$. and an average velocity of the wind of 7.5 meters per second. The measurements were made on the Atlantic from the $5^{\text {th }}$ to the 8 th of September, I892, at $80^{\circ}$ clock each morning, on Io liters of sea water, in a vessel giving 600 square centimeters surface, and fully exposed to the wind.

\section{Date (8 A. M.)}

Sept. $5 \ldots \ldots \ldots \ldots$

Sept. 6.........

Sept. $7 \ldots . . \ldots \ldots$

Sept. 8........
Salinity permille 36.3 $38 \cdot 5$ 40.3 42 . I
Height of water column in $\mathrm{cm}$. Volume c. c.

$$
\begin{aligned}
& \text { I6. } 5 \\
& \text { I6.2 } \\
& \text { I } 5.9 \\
& \text { I } 5.6
\end{aligned}
$$

Thus in three days the decrease in volume was about 6 per cent., while the increase in salinity was nearly 6 permille.

Bathymetric Variation. Besides the regional variation, there is a bathymetric variation in the different water bodies. In rare cases is the salinity uniform throughout (homaline); it is commonly variable (heterohaline). A decreasing salinity downward constitutes an anohaline arrangement $(a h)$; an increasing one is a katohaline $(k h)$ condition. A decreasing followed by an increasing salinity downward constitutes a dichohaline $(d h)$ condition, while the reverse, an increasing followed by a decreasing salinity downward,

\begin{tabular}{|c|c|c|}
\hline & $\begin{array}{l}\text { Decreasing } \\
\text { salinity }\end{array}$ & $\begin{array}{c}\text { Increasing } \\
\text { salinity }\end{array}$ \\
\hline Homohaline & $\ldots \ldots \ldots \ldots \ldots \ldots \ldots \ldots \ldots, \downarrow$ & \\
\hline Heterohaline & $\left\{\begin{array}{l}\text { Anohaline } \ldots \ldots \ldots \ldots \ldots \\
\text { Katohatine } \ldots \ldots \ldots \ldots \ldots \\
\text { Dichohaline } \ldots \ldots \ldots \ldots \ldots \\
\text { Mesohaline } \ldots \ldots \ldots \ldots\end{array}\right.$ & \\
\hline
\end{tabular}
constitutes a mesohaline condition $(m h)$, the most saline layers being in the middle. (Krïmmel, $20: 334$.) These relations may be summarized graphically as follows: 
The following table copied from Krümmel shows the variation in salinity with depth, and the seasonal variations in the Bay of Danzig on the southern border of the Baltic. (20:353.)

Variation in Salinity, Bay of Daniig, I90z-1906.

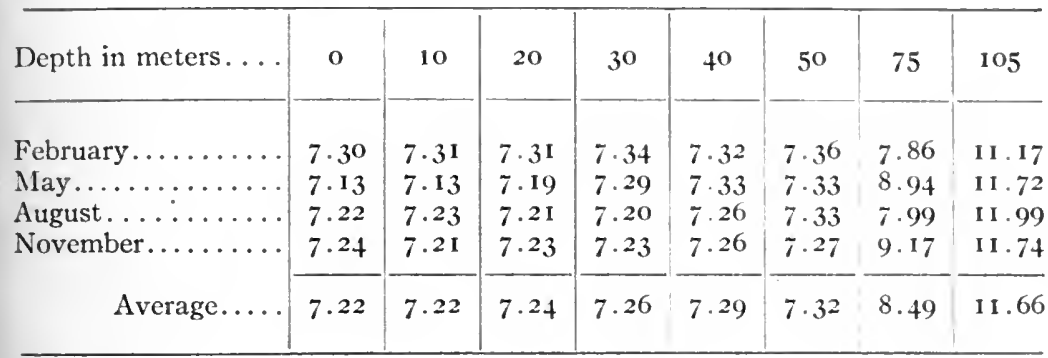

In the Arctic Ocean the variation in the salt content has been found by the Fram to average as follows (Krümmel-20:347):

Depth in meters:

Parts per 1,000 by weight

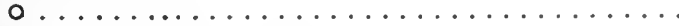
21.00
40
33.26

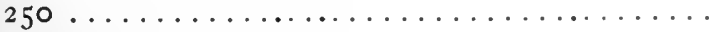
$34 \cdot 97$
$45^{\circ}$
35.02

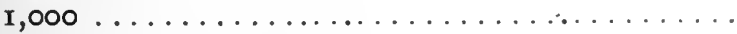
35.07
2,000
35.08
3,000
35.12

The increase is rapid at first owing to the fact that the surface strata are diluted by river waters and melting ice. A slight irregularify is shown by the fact that at one locality the salt content was 35.19 at 2,500 meters' depth. In the East Greenland Mediterranean Sea, between Spitzbergen and the Faroe Islands, the bottom layers, below 800 or 1,000 meters in depth, have a homohaline character, the salinity being $34.9 \mathrm{I}$ permille. A homothermal character of $-\mathrm{I} .2^{\circ} \mathrm{C}$. also prevails. Along the Norwegian coast the upper layers, of 200 to 300 meters, have a uniform salinity of something over 35.2 permille, south of $70^{\circ}$ north latitude, while north of that it decreases.

The following table gives some of the variations in salinity in the Atlantic Ocean (Krïmmel-20:338-34I): 
Table Showing Bathymetric Variations of Salinity in the Sea.

\begin{tabular}{|c|c|c|c|c|c|c|}
\hline \multirow[b]{2}{*}{$\begin{array}{l}\text { Depth in } \\
\text { meters }\end{array}$} & \multicolumn{6}{|c|}{ Parts by weight in 1,000 parts of sea water (permille) } \\
\hline & $\begin{array}{l}\text { Bay of } \\
\text { Biscay }\end{array}$ & $\begin{array}{l}43^{\circ} 7^{\prime} \\
\text { N. Lat. } \\
\text { I9 } 9^{\circ} 43^{\prime} \\
\text { W. Long. }\end{array}$ & Azores & $\begin{array}{l}\text { S. W. } \\
\text { Cape } \\
\text { Verde } \\
\text { Islands }\end{array}$ & $\begin{array}{c}\text { South } \\
\text { Atlantic } \\
23^{\circ} 33^{\prime} \\
\text { S. Lat. } \\
20^{\circ} 5^{\prime} \\
\text { W. Long. }\end{array}$ & $\begin{array}{c}\text { Off Cape } \\
\text { of } \\
\text { Good } \\
\text { Hope } \\
35^{\circ} 2^{\prime} \\
\text { S. Lat. } \\
13^{\circ} 8^{\prime} \\
\text { E. Long. }\end{array}$ \\
\hline o & $35 \cdot 78$ & 35.90 & 35.90 & 36.40 & 36.77 & 35.50 \\
\hline 100 & $\ldots \ldots \ldots$ & $\ldots . .$. & $\ldots \ldots \ldots$ & $35 \cdot 70$ & 36.60 & $\ldots \ldots \ldots$ \\
\hline 200 & 35.72 & - & $35 \cdot 75$ & $\ldots \ldots \ldots$ & 35.43 & $\ldots \ldots \ldots$ \\
\hline 500 & 35.60 & $\ldots \ldots$ & $\therefore \ldots \ldots$ & $\ldots \ldots \ldots$ & $34 \cdot 55$ & $34 \cdot 5^{\circ}$ \\
\hline 600 & $\ldots \ldots \ldots$ & $35 \cdot 45$ & $35 \cdot 40$ & $\ldots \ldots \ldots$ & $\ldots \ldots \ldots$ & $\ldots \ldots \ldots$ \\
\hline 692 & $\ldots \ldots \ldots$ & $\ldots \ldots$ & $\ldots \ldots \ldots$ & 35.10 & $\ldots \ldots \ldots$ & \\
\hline 800 & 35.60 & $\ldots \ldots$ & $\ldots \ldots \ldots$ & $\ldots \ldots$ & $\ldots \ldots$ & $\ldots \ldots \ldots$ \\
\hline 900 & $\ldots \ldots \ldots$ & $\ldots \ldots \ldots$ & $\ldots \ldots \ldots$ & $\ldots \ldots \ldots$ & $34 \cdot 33$ & $34 \cdot 36$ \\
\hline 1,000 & $35 \cdot 53$ & 35.65 & $35 \cdot 4^{\circ}$ & $\ldots \ldots$ & $34 \cdot 43$ & $\ldots \ldots$ \\
\hline 1,200 & $\ldots \ldots \ldots$ & $\ldots \ldots \ldots$ & $\ldots \ldots$ & $\ldots \ldots \ldots$ & $\ldots \ldots \ldots$ & $34 \cdot 5^{8}$ \\
\hline 1,500 & $35 \cdot 5^{1}$ & $35 \cdot 34$ & $\ldots \ldots \ldots$ & $\ldots \ldots \ldots$ & $34 \cdot 73$ & 34.60 \\
\hline 2,000 & $\ldots \ldots \ldots$ & 35.08 & $35 \cdot 10$ & $\ldots \ldots \ldots$ & $\ldots \ldots$ & $\ldots \ldots$ \\
\hline 3,000 & $\because 35.12$ & $\ldots \ldots \ldots$ & 35.00 & 35.00 & & $\ldots \ldots$ \\
\hline 4,000 & $\left\{\begin{array}{c}\text { to } \\
35.69\end{array}\right.$ & & & & & \\
\hline 4,777 & $\ldots \ldots \ldots$ & & $34 \cdot 77$ & & $\ldots \ldots \ldots$ & $\ldots \ldots \ldots$ \\
\hline 4,957 & & $\cdots \cdots$ & $\ldots \ldots \ldots$ & & $\ldots \ldots \ldots$ & $34 \cdot 72$ \\
\hline 5,045 & $\ldots \ldots \ldots$ & $\ldots \ldots \ldots$ & $\ldots \ldots$ & $\ldots \ldots \ldots$ & 34.67 & $\ldots \ldots \ldots$ \\
\hline 5,900 & $\ldots \ldots$ & $34 \cdot 90$ & $\ldots \ldots$ & $\ldots \ldots$ & $\ldots \ldots$ & $\ldots \ldots \ldots$ \\
\hline 6,035 & & $\ldots \ldots$ & & $35.8 \mathrm{I}$ & $\ldots \ldots \ldots$ & 舟 \\
\hline
\end{tabular}

In the Indian Ocean ( $35^{\circ} \mathrm{S}$. lat., $74^{\circ} \mathrm{E}$. long.) the salinity decreases from 35.3 at the surface to $34.3^{8}$ at 900 meters, increasing again to 34.45 at 1,500 meters and 34.65 at the bottom. It is thus a strictly dichohaline arrangement. A similar condition exists in the South Pacific, where a minimum of 34.2 to 34.3 is found at a depth of 730 meters.

The salinity of the Roman Mediterranean may be taken as an example of the conditions in the nearly landlocked types. In this the increase in salinity of the surface waters is from the west eastward. At the Straits of Gibraltar, where the Atlantic water enters, the salinity is 36.35 permille; at Cape Gata, Spain, it is 37.83 per- 
mille; between Greece and Barca (Africa) 38.46 permille, and about halfway between the islands of Rhodes and Cyprus (long. $30^{\circ} 18^{\prime}$ E., lat. $35^{\circ} 49^{\prime} \mathrm{N}$.) it is 39.40 permille. The salinity varies strongly with depth. Thus at the Straits of Gibraltar the following changes occur :

Surface......36.35 permille

$25 \mathrm{~m} \ldots \ldots .36 .56$ permille

$50 \mathrm{~m} . . . .37 .00$ permille

roo m.......38.07 permille

$200 \mathrm{~m}$........38.30 permille

$400 \mathrm{~m} \ldots . . .38 .46$ permille
The denser water flows out as an undercurrent and affects the salinity of the deeper strata of the Gulf of Cadiz for a long distance out. The density of 38.46 found at 400 meters depth in the Gibraltar Straits is found between Malta and Pantel-

leria at a depth of 200 meters and south of Greece at the surface. In the eastern region (Cyprus district) the surface salinity was found in the summer to be from 0.2 to 0.4 permille greater than at the bottom (2,000 to 2,950 meters). This change occurs in the upper 100 meters, and is believed to be due to the rapid evaporation on the surface. The seasonal change in the salinity of surface waters, due to the influx of fresh water through the streams, is well shown in the Adriatic, where in the spring the salinity sinks to 18 or even 16 permille in the neighborhood of the land, while in the winter the salinity is 38 permille even at the mouths of streams. This freshening of the surface waters extends, however, to the depth of only about one meter. Throughout the year salt water ascends the streams along their bottoms; in the Natissa River at the head of the Adriatic, it ascends as far as Aquileja, Io kilometers from the coast. (Krümmel-20:355.)

The Sea of Marmora, between the Black and Roman mediterraneans, has a surface layer, of I I meters or more, of low salinity (22 to 25 permille), followed by a rapid increase to a depth of 25 meters where the salinity is 28.5 permille. Beyond this follows a slow increase to a depth of 200 to 300 meters, where the salinity is 38.1 permille, increasing later to 38.4 permille, after which it remains constant to the bottom $(1,400$ meters).

The surface stratum of low salinity is again seen in the Black Sea, where, according to Wrangell and Spindler, the upper fo or 45 meters have a homolaline character of 18.3 permille. Downward this slowly increases to 19.7 at $90 \mathrm{~m}$., to 21.4 at $180 \mathrm{~m}$., 22.0 at $350 \mathrm{~m}$., and 22.4 to 22.5 from $900 \mathrm{~m}$. to 2,000 m. The Sea of Azov is an epicontinental sea, being very shallow, and, as a result, it is usually homohaline, with I0.5 to 10.7 (more rarely I I.0) permille. In the 
northeast, where fresh-water streams enter the basin, the salinity may be as low as 7 permille. In the Straits of Kertch, connecting the Azov and Black seas, the upper 5 meters of Io permille salinity flow outward, while the remainder ( 2 to 3 meters) represents the inflowing water from the Black Sea, with 16 to 17 permille, the isohaline surfaces lying higher in the east than in the west. In the Red Sea the salinity decreases on the surface from 40.43 in the north to 37.77 in the south. In the northern section the salinity increases downward from 40.43 to 40.55 permille at the bottom ( 547 meters), and in the southern, from 37.77 to $40.4 \mathrm{I}$ permille at the bottom ( 1,120 meters). In the greatest depth (2,160 meters) near the middle, the salinity is 40.68 permille.

\section{Composition of Lake Waters.}

The composition of the waters of enclosed basins varies greatly, as does also the absolute salinity, which is much greater than that of the ocean in many cases, and less in still more numerous cases.

The following table (Russell-29, table C; Clarke-4) gives the salinity of the surface layers of a number of enclosed waters in permillages.* For comparison it should be remembered that the permillage of average ocean water is 35 .

\section{Table of Salinity of Various Lakes.}

A. Saline and Alkaline.

Permille.

I. Tinetz Lake, a residue lake of the Caspian................ 289.000

2. Karaboghas (Karabugas) Gulf ................... 285.000

3. Elton Lake, Russia†......................... 270.627

4. Indevsk Lake.......................... 261.530

5. Bogdo Lake, Russia...................... $256.75^{\circ}$

6. Illyés Lake, Hungary..................... 233.747

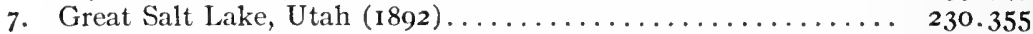

8. Owen's Lake, Cal., I 905 (triple alkali).............. 213.700

9. Urmiah Lake, Persia........................ 205.500

I0. Black Lake, Hungary ...................... I95.300

II. Dead Sea (maximum) ........................ I92. I53

12. Great Salt Lake, Utah (1889).................. 167.160

3. Lake Domoshakovo, Siberia. .................. 145.500

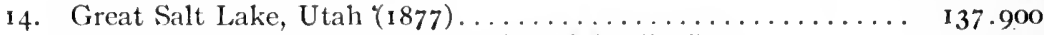

15. Soda Lake, near Ragtown, Nevada (triple alkali).......... II3.644

I6. Goodenough Lake, British Col. (alkali carbonate)......... I03.470

17. Sevier Lake, Utah......................... 86.403

18. Borax Lake, Cal. (alkali, carbonate-chloride)............ 76.560

* Equivalent to grams per liter of water.

$\dagger$ Average of 3 analyses. 


\section{Table of Salinity of Various Lakes-Continued.}

A. Saline and Alkaline.-Continued

19. Owen's Lake, Cal. I876 (sp. gr. 1.05I). . . . . . . . . . . .

Permille.

60.507

20. Mono Lake, Cal. (triple alkali).....................

49.630

21. Albert Lake, Oregon, 1890 (alkali) ..................

39.172

22. Albert Lake, Oregon, 1883 (sp. gr. I.02317) ............

$27 \cdot 357$

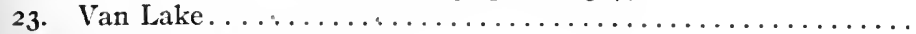

22.600

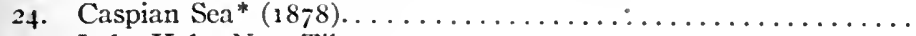

12.940

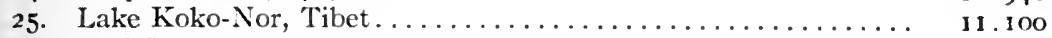

26. Aral Sea.............................. 10.842

27. Lake Biljo, Siberia....................... 8.800

28. Chichen Kanab (Little Sea), Yucatan.................. 4.446

29. Natron Lake, near Thebes, Egypt (alkali, carbonate-chloride)... $\quad 4.407$

30. Winnemucca Lake, Nevada (alkali, carbonate-chloride)...... $\quad 3.603$

31. Issyk-Kul, Siberia. . . . . . . . . . . . . . . . . . . 3.574

32. Pyramid Lake, Nevada (alkali, carbonate-chloride). . . . . . . . . 3.486

33. Walker Lake, Nevada (triple alkali) .................. $2.5 \mathrm{5}_{2}$

34. Palic Lake, Hungary .......................... 2.215

35. Humboldt Lake, $\dagger$ Nevada (alkali, carbonate-chloride)........ 0.929

36. Laacher See, Germany (alkaline sodium carbonate) . . . . . . . . 0.218

B. Fresh Water Lakes.

37. Lake Erie at Buffalot. . . . . . . . . . . . . . . . . .

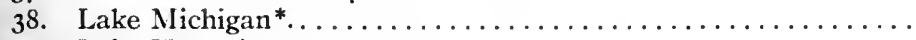

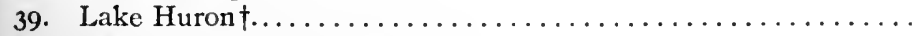

0. 105

40. Croton Reservoir, New York ...................

0.084

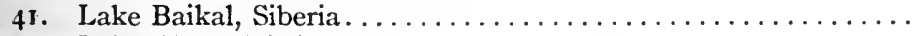

0.069

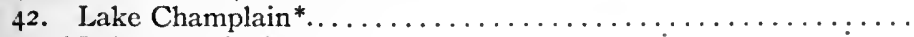

0.067

43. 'Lake Superior*.

0.058

As will be seen by a comparison inter se of the analyses made in I 876 and 1905 of the waters of Owen's Lake, California, a lake of triple alkaline waters, and those of the Great Salt Lake, Utah, made in 1877,1889 and 1892 , a difference of salinity, amounting in the case of Owen's Lake to 153.2 permille, and in that of Great Salt Lake to I 16.7 permille, obtained between the extreme dates. This shows the variation in concentration of the smaller salt lakes. In both cases it is seen that the concentration has been a progressive one in time. For Great Salt Lake. successive analyses show the following concentration, which, with the exception of the first, shows a regular progression.

* Average of 5 analyses.

t Average of 4 analyses.

$\ddagger$ Average of 6 analyses. 


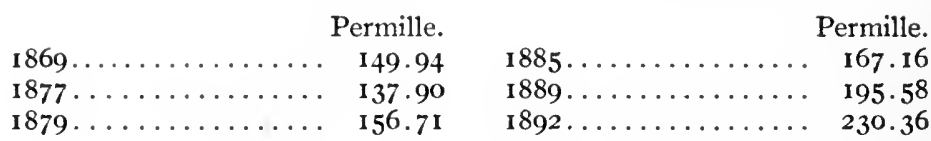

Elton Lake, Russia, gave in April a salinity of 255.6 permille; in August 264.980 permille, and in October 291.300 permille, the specific gravity in the last case being 1.273 .

The vertical range in salinity is well shown by a number of analyses of the waters of the Dead Sea, which are here tabulated. (Terreild, in Clarke, 4.)

Table Showing Vertical Range in Salinity in the Dead Sea.

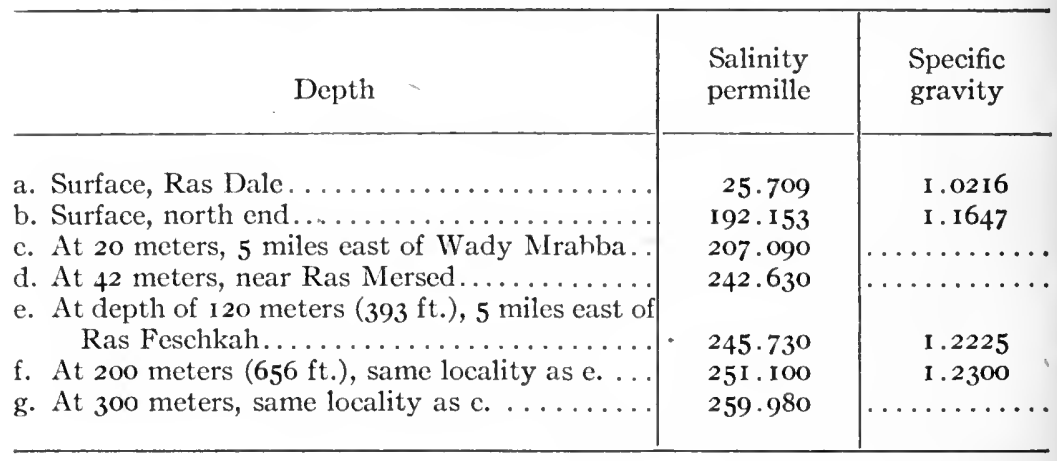

The salinity of the River Jordan, flowing into the Dead Sea, is only r.6r permille. Its carbonates and gypsum are precipitated when it enters the lake, and its contribution consists almost entirely of chlorides, derived from the Cretacic salt- and gypsum-bearing strata of the region. Soda Lake, Nevada, at one foot below the surface, where the specific gravity was I.Ior, gave a salinity of II 3.644 permille, a large part being carbonate and sulphate of sodium. At a depth of 100 feet the salinity was I 13.65 I permille.

The waters of salt and alkaline lakes may be divided into several fairly well-defined groups (Clarke-4:I34-I38). Among the salt lakes we have first a group of normal chloride waters, characterized mainly by sodium chloride, and having a close resemblance to oceanic water. They may represent remnants of the ocean water, or the salts may be due to leaching of ancient marine deposits carrying oceanic salt. The analyses of the waters of Great Salt Lake $\left(A_{1}\right)$ and of Illyés Lake. Hungary $\left(A_{2}\right)$ may be taken as examples. The second group is that of Natural Bitterns derived from the pre- 
ceding, but having its magnesium salts concentrated from prolonged evaporation, sodium chloride having crystallized out. The Dead Sea $\left(B_{1}\right)$ and Elton Lake, Russia $\left(B_{2}\right)$, are examples. The third group is characterized by sulphate waters, there being, however, no distinct line of demarcation between this and the last group. Sevier Lake, Utah $\left(\mathrm{C}_{1}\right)$, and Lake Domoshakovo, Siberia $\left(\mathrm{C}_{2}\right)$, show extremes. A somewhat different group comprises the sulphatechloride waters of the Caspian and the Aral Sea $\left(D_{1}\right)$, which show a falling off of the alkaline metals and an increase in calcium and magnesium, while the sulphates approach the chlorides. The bitterns of this type differ from the natural or normal bitterns $\left(\mathrm{B}_{1}, \mathrm{~B}_{2}\right)$ in the proportion of sulphates. This is shown in the analyses of the waters of the Karabugas Gulf $\left(D_{2}\right)$ and of Issyk-Kul Lake $\left(\mathrm{D}_{3}\right)$, Siberia. An extreme case representing a subgroup is shown in Lake Chichen-Kanab, Yucatan $\left(\mathrm{B}_{4}\right)$.

The alkaline lakes comprise, first, a group in which the carbonates are largely in excess of all other salts, constituting the typical carbon waters. Goodenough Lake, British Columbia $\left(\mathrm{E}_{1}\right)$, and Palic Lake, Banat, Hungary $\left(\mathrm{E}_{2}\right)$, are examples. A second group of alkaline waters is the carbonate-chloride group, these two salts predominating, while sulphates are present in subordinate quantity. Humboldt Lake, Nevada $\left(\mathrm{F}_{1}\right)$, Albert Lake, Oregon $\left(\mathrm{F}_{2}\right)$, and Pyramid Lake, Nevada $\left(\mathrm{F}_{3}\right)$, are examples of this type. "Triple" waters, in which chlorides, sulphates and carbonates are present in notable quantities, constitute the next group. Owens Lake, Cal. $\left(G_{1}\right)$, and Soda Lake, Nevada $\left(G_{2}\right)$, are examples of this type. Finally, the waters of two sulphate-chloride lakes of a moderate alkaline character, Lake Biljo $\left(\mathrm{H}_{1}\right)$ and Lake lioko-Nor $\left(\mathrm{H}_{2}\right)$, are included, and the corresponding constituents of the sea are also given (I). (Clarke-4:II8-I38.)

\section{Analyses of Types of Lake Water.}

I. Saline Lakes.

$A_{1}$ Great Salt Lake ( 1877 ) normal chloride waters.

$\mathrm{A}_{2}$ Illeyés Lake, Hungary, normal chloride waters.

$\mathrm{B}_{1}$ Dead Sea, natural bittern.

$\mathrm{B}_{2}$ Elton Lake, Russia, natural bittern.

$\mathrm{C}_{1}$ Sevier Lake, Utah, sulphate waters.

$\mathrm{C}_{2}$ Lake Domoshakovo, Siberia, sulphate waters.

$D_{1}$ Aral Sea, sulphate-chloride waters.

$\mathrm{D}_{2}$ Karabugas Gulf, sulphate-chloride bittern.

$\mathrm{D}_{3}$ Issyk-Kul Lake, Siberia, sulphate-chloride bittern.

$\mathrm{D}_{4}$ Lake Chichen Kanab, Yucatan, sulphate-chloride bittern. 


\section{Analyses of Types of Lake Water-Continued.}

2. Alkaline Lakes.

$\mathrm{E}_{1}$ Goodenough Lake, British Columbia, carbonate waters.

$\mathrm{E}_{2}$ Palic Lake, Hungary, carbonate waters.

$F_{1}$ Humboldt Lake, Nevada, carbonate-chloride waters.

$\mathrm{F}_{2}$ Albert Lake, Oregon, carbonate-chloride waters.

$\mathrm{F}_{3}$ Pyramid Lake, Nevada (mean of four concordant analyses), carbonate-chloride waters.

$\mathrm{F}_{4}$ Borax Lake, Lake Co., California, carbonate-chloride waters.

$\mathrm{G}_{1}$ Owen's Lake, California, "Triple" waters (I 905).

$\mathrm{G}_{2}$ Soda Lake, Nevada, "Triple" waters.

$\mathrm{H}_{1}$ Lake Biljo, Siberia, alkaline sulphate-chloride waters.

$\mathrm{H}_{2}$ Lake Koko-Nor, Tibet, alkaline sulphate-chloride waters.

\section{For Comparison}

I Ocean water.

TABLE, IN PERCENTAGES, OF TOTAL SOLIDS, OF

\begin{tabular}{|c|c|c|c|c|c|c|c|c|c|c|}
\hline & \multicolumn{2}{|c|}{$\begin{array}{l}\text { Normal } \\
\text { chloride }\end{array}$} & \multicolumn{2}{|c|}{$\begin{array}{l}\text { Natural } \\
\text { bittern }\end{array}$} & \multicolumn{2}{|c|}{$\begin{array}{l}\text { Sulphate } \\
\text { waters }\end{array}$} & \multicolumn{4}{|c|}{$\begin{array}{c}\text { Sulphate chloride } \\
\text { waters }\end{array}$} \\
\hline & $\mathrm{A}_{1}$ & $\mathrm{~A}_{2}$ & $B_{1}$ & $\mathrm{~B}_{2}$ & $\mathrm{C}_{\mathrm{I}}$ & $\mathrm{C}_{2}$ & $D_{1}$ & $\mathrm{D}_{2}$ & $\mathrm{D}_{3}$ & D. \\
\hline & $56.2 \mathrm{I}$ & 60.18 & $65.8 \mathrm{I}$ & 64.22 & 52.66 & 3.71 & 35.40 & 53.32 & 15.64 & 8.14 \\
\hline & & & 2.37 & & & & & & & \\
\hline & 6.89 & 0.44 & 0.31 & 6.82 & 10.88 & 63.62 & 30.98 & 17.39 & 55.94 & 58.64 \\
\hline & 0.07 & 0.04 & tr. & 0.04 & $\ldots \ldots$ & 0.08 & 0.85 & ....... & I. 26 & $\ldots \ldots$ \\
\hline & $\ldots \ldots$ & $\ldots \ldots$ & ........ & ....... & $\ldots \ldots \ldots$ & 0.07 & & & & \\
\hline & $\ldots \ldots$ & $\ldots \ldots$ & $\ldots \ldots$ & $\ldots \ldots$ & $\ldots \ldots$ & $\ldots \ldots$ & 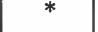 & $\ldots \ldots$ & 0.02 & \\
\hline & $\because$ & & $\cdots \cdots$ & $\cdots \cdots$ & $\cdots \cdots$ & $\cdots \cdots$ & $\cdots \cdots$ & $\cdots \cdots$ & ........ & $\cdots \cdots$ \\
\hline & 33.45 & 39.02 & II. 65 & II.27 & 33.33 & 30.61 & 22.62 & II.5I & & \\
\hline & $?^{43}$ & & I. 85 & & & 0.59 & & I.8 & $\begin{array}{r}11.70 \\
1.85\end{array}$ & $\begin{array}{r}11.99 \\
0.43\end{array}$ \\
\hline & & & & & & & & 0.06 & & \\
\hline & 0.2 & & 4.73 & o. I0 & 0.1 & 0.58 & & & & \\
\hline & 3.18 & 0.03 & 13.28 & I 7.55 & $3.0 \mathrm{I}$ & 0.74 & 5.50 & I 5.83 & 12.50 & 7.31 \\
\hline & $\ldots \ldots$ & 0.04 & tr. & $\ldots \ldots$ & $\cdots \cdots$ & tr. & $0.04+$ & $\ldots \ldots$ & $\ldots \ldots$ & $\ldots \ldots$ \\
\hline & & $\cdots \cdots$ & $\cdots$ & & $\cdots \cdots$ & tr. & $\cdots \cdots_{*}, \cdots$ & & & $\cdots \cdots$ \\
\hline & & tr. & & & …… & …..... & & & tr. & . \\
\hline & & . & & & $\ldots \ldots$ & & . & $\ldots \ldots$ & 0.6 & $\cdots \cdots$ \\
\hline & $\ldots \ldots$ & $\ldots$ & . & $\ldots$ & $\ldots$ & $\ldots \ldots$ & $\ldots \ldots$ & $\ldots \ldots$ & $\ldots \ldots \ldots$ & $\ldots \ldots$ \\
\hline Total \%... & 100.00 & 100.00 & 100.00 & 100.00 & 100.00 & 100.00 & 100.00 & 100.00 & 100.00 & 100.00 \\
\hline $\begin{array}{r}\text { Salinit } y \\
\text { permille. }\end{array}$ & 137.90 & 233.747 & 192.15 & 265.00 & 86.40 & 145.50 & I0. 84 & 285.00 & 3.574 & $4 \cdot 446$ \\
\hline
\end{tabular}

The composition of saline lakes in percentage of total solids is given in the following partial analyses of the waters of Great Salt Lake, a normal chloride water; of the Dead Sea, a natural bittern; and of the Caspian Sea, a sulphate-chloride water. The composi- 
Composition of Saline (and Alkaline Saline) Lakes, in Percentage of Total Solids.

\begin{tabular}{|c|c|c|c|c|}
\hline & Koko-Nor & Caspian & Dead & Great Salt \\
\hline $\begin{array}{l}\text { Sodium chloride }(\mathrm{NaCl}) \ldots \ldots \\
\text { Magnesium chloride }\left(\mathrm{MgCl}_{2}\right) \ldots \\
\text { Magnesium sulphate }\left(\mathrm{MgSO}_{4}\right) \ldots \\
\text { Calcium sulphate }\left(\mathrm{CaSO}_{4}\right) \ldots \ldots \\
\text { Potassitum sulphate }\left(\mathrm{K}_{2} \mathrm{SO}_{4}\right) \ldots \\
\text { Sodium sulphate }\left(\mathrm{Na}_{2} \mathrm{SO}_{4}\right) \ldots \ldots \\
\text { Calcium carbonate }\left(\mathrm{CaCO}_{3}\right) \ldots \ldots \\
\text { Magnesium carbonate }\left(\mathrm{MgCO}_{3}\right) \\
\text { Calcium chloride }\left(\mathrm{CaCl}_{2}\right) \ldots \ldots\end{array}$ & \begin{tabular}{|c}
64.4 \\
$\ldots \ldots \ldots$ \\
8.7 \\
$\cdots \cdots$ \\
$\cdots \cdots$ \\
16.1 \\
$4 \cdot 4$ \\
4.0 \\
$\cdots \cdots$
\end{tabular} & $\begin{array}{r}63.93 \\
\ldots \\
23.29 \\
3.99 \\
\cdots \\
\quad \ldots \\
2.66 \\
1.46 \\
4.65\end{array}$ & $\begin{array}{r}29.00 \\
65.00 \\
\cdots \cdots \\
\quad \cdots .40 \\
\cdots \cdots \\
\cdots \cdots \\
\cdots \cdots \\
\cdots \cdots \\
\cdots \cdots\end{array}$ & 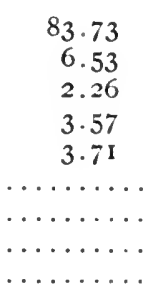 \\
\hline
\end{tabular}

tion, in like manner, of a moderately alkaline sulphate-clıloride water is given in the analysis of the waters of Lake Koko-Nor, Tibet.

COMPOSITION OF VARIOUS NATURAL WATERS.

\begin{tabular}{|c|c|c|c|c|c|c|c|c|c|c|}
\hline \multicolumn{2}{|c|}{$\begin{array}{l}\text { Carbonate } \\
\text { waters }\end{array}$} & \multicolumn{4}{|c|}{$\begin{array}{c}\text { Carbonate chloride } \\
\text { waters }\end{array}$} & \multicolumn{2}{|c|}{$\begin{array}{l}\text { Triple } \\
\text { waters }\end{array}$} & \multicolumn{2}{|c|}{$\begin{array}{l}\text { Sulphate chlo- } \\
\text { ride waters }\end{array}$} & \multirow{2}{*}{ Ocean } \\
\hline$E_{\mathrm{I}}$ & $\mathrm{E}_{2}$ & $F_{1}$ & $\mathrm{~F}_{2}$ & $\mathrm{~F}_{3}$ & $F_{4}$ & $\mathrm{G}_{1}$ & $\mathrm{G}_{2}$ & $\mathrm{H}_{1}$ & $\mathrm{H}_{2}$ & \\
\hline 7.64 & 15.68 & 31.82 & 36.04 & 41.04 & 32.27 & 24.82 & 36.51 & $9.9 \mathrm{I}$ & 40.05 & 55.29 \\
\hline$\cdots \cdots$ & $\ldots \ldots$ & $\ldots \ldots$ & $\ldots \ldots$ & $\ldots .$. & 0.04 & $\ldots \ldots$ & $\ldots \ldots$ & $\ldots \ldots$ & 0.04 & 0.19 \\
\hline 7.08 & 2.92 & 3.27 & I. 90 & 5.25 & 0.13 & 9.93 & 10.36 & $52 \cdot 33$ & 17.84 & 7.69 \\
\hline 41.41 & 41.02 & 21.57 & 20.67 & 14.28 & 22.47 & $24 \cdot 55$ & 13.78 & 6.22 & 5.55 & 0.21 \\
\hline$\cdots \cdots \cdots$ & $\ldots \ldots$ & $\ldots \ldots$ & $\ldots \ldots$ & $\ldots \ldots$ & $\ldots \ldots$ & 0.45 & $\ldots \ldots$ & I. .07 & $\ldots \ldots$ & $\ldots \ldots \ldots$ \\
\hline 0.62 & $\ldots \ldots$ & 0.07 & $\ldots \ldots$ & $\ldots \ldots$ & 0.02 & o. II & $\ldots \ldots$ & $\ldots \ldots$ & 0.02 & $\ldots \ldots \ldots$ \\
\hline$\cdots \cdots \cdots$ & $\ldots \ldots$ & $\ldots \ldots$ & $\ldots \ldots$ & $\ldots \ldots$ & $\cdots \cdots$ & 0.03 & $\cdots \cdots$ & $\ldots \ldots$ & $\ldots \ldots$ & $\ldots \ldots \ldots$ \\
\hline tr. & $\cdots \cdots \cdots$ & $\ldots \ldots$ & $\ldots \ldots$ & $\cdots \cdots$ & 5.05 & 0.14 & 0.25 & $\cdots \ddot{m}$ & $\cdots \cdots$ & $\cdots \cdots \cdots$ \\
\hline 36.17 & 35.75 & 29.97 & $39 \cdot 33$ & 33.84 & 38.10 & 38.09 & 36.63 & 21.83 & 30.60 & 30.59 \\
\hline 6.65 & $\ldots \ldots$ & 6.54 & I. .44 & 2.11 & I. 52 & I. 62 & 2.01 & 0.87 & I. 08 & 1.11 \\
\hline$\ddot{0.02}$ & $\cdots \ddot{0}, \ddot{6} 6$ & $\cdots \cdots$ & $\cdots \cdots$ & $\cdots \cdots$ & $y_{03}$ & tr. & $\ldots \ldots$ & $\cdots \cdots$ & 0.04 & $\cdots \cdots \cdots$ \\
\hline 0.04 & $\begin{array}{l}0.00 \\
3.35\end{array}$ & $\begin{array}{l}1.35 \\
\text { I. } 88\end{array}$ & $\begin{array}{l}\cdots \\
\cdots\end{array}$ & $\begin{array}{l}0.25 \\
2.28\end{array}$ & $\begin{array}{l}0.03 \\
0.35\end{array}$ & $\begin{array}{l}0.02 \\
0.01\end{array}$ & $\begin{array}{l}\cdots \\
0.22\end{array}$ & $\begin{array}{l}0.43 \\
7.28\end{array}$ & $\begin{array}{l}1.77 \\
2.90\end{array}$ & $\begin{array}{l}1.20 \\
3.72\end{array}$ \\
\hline 0.04 & 0.27 & 3.53 & 0.62 & 0.95 & 0.01 & 0.14 & 0.24 & 0.03 & 0.09 & $\ldots \ldots \ldots$ \\
\hline 0.33 & $\ldots \ldots$ & $\ldots \ldots$ & $\ldots \ldots$ & $\ldots \ldots$ & & 0.04 & $\ldots \ldots$ & 0.03 & $\ldots \ldots$ & $\ldots \ldots \ldots$ \\
\hline$\cdots \cdots$ & 0.35 & $\ldots \ldots$ & $\ldots \ldots$ & $\ldots \ldots$ & 0.01 & 0. & $\ldots \ldots$ & $\ldots \ldots$ & 0.02 & $\ldots \ldots \ldots$ \\
\hline$\cdots \ldots$ & $\ldots \ldots$ & $\cdots \cdots \cdots$ & $\ldots \ldots$ & $\ldots \ldots$ & & $\ldots \ldots$ & $\ldots \ldots$ & $\ldots \ldots \ldots$ & $\ldots \ldots$ & $\ldots \ldots \ldots$ \\
\hline$\cdots \cdots$ & $\ldots \ldots \ldots$ & $\ldots \ldots$ & $\cdots \cdots$ & $\ldots \ldots$ & $\ldots \ldots$ & $\ldots \ldots$ & $\cdots \cdots$ & $\ldots \ldots$ & $\ldots \ldots$ & $\ldots \ldots \ldots$ \\
\hline$\cdots \cdots \cdots$ & $\cdots \cdots \cdots$ & $\ldots \ldots$ & $\cdots \cdots$ & $\cdots \ldots$ & $\ldots \ldots$ & 0.05 & $\cdots \cdots$ & $\cdots \cdots \cdots$ & $\cdots \cdots$ & $\ldots \ldots \ldots$ \\
\hline 100.00 & 100.00 & 100.00 & 100.00 & 100.00 & 100.00 & 100.00 & 100.00 & 100.00 & 100.00 & 100.00 \\
\hline 103.470 & 2.215 & 0.929 & $39.1 \% 2$ & $3 \cdot 486$ & 76.560 & 213.70 & 113.70 & 8.80 & II. 10 & 35.00 \\
\hline
\end{tabular}

* Included with $\mathrm{SiO}_{2}$. † Including $\mathrm{PO}_{4}$ and $\mathrm{Fe}_{2} \mathrm{O}_{3}$.

The quantitative composition of a typical alkaline lake is shown by the following analysis made in 1883 by F. W. Taylor of the water of Albert Lake, Oregon, a carbonate water (sp. gr. I.023I7). (Russell-29:454.) 
Silica in solution $\left(\mathrm{SiO}_{2}\right)$.

Grams per liter

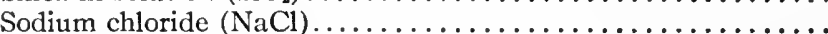

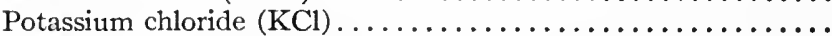

Potassium sulphate $\left(\mathrm{K}_{2} \mathrm{SO}_{4}\right) \ldots \ldots \ldots \ldots \ldots \ldots \ldots \ldots \ldots$

Potassium carbonate $\left(\mathrm{K}_{2} \mathrm{CO}_{3}\right) \ldots \ldots \ldots \ldots \ldots \ldots \ldots \ldots \ldots \ldots$

Magnesium carbonate $\left(\mathrm{MgCO}_{3}\right)$.

of the water

0.065

7.219

8.455

0.921

10.691

0.006

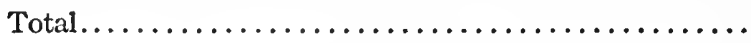

$27 \cdot 357$

The following analyses of the waters of Pyramid Lake, another carbonate-chloride lake, show variation vertically as well as horizontally. (Russèll-30:57, 58.)

\begin{tabular}{|c|c|c|c|c|}
\hline \multirow{3}{*}{ : } & \multicolumn{4}{|c|}{ Probable combination in grams per liter } \\
\hline & \multicolumn{2}{|c|}{ South of Anaho Isl. } & \multicolumn{2}{|c|}{ North of Anaho Isl. } \\
\hline & $\begin{array}{c}\text { I foot } \\
\text { below } \\
\text { surface* }\end{array}$ & $\begin{array}{c}200 \text { feet } \\
\text { below } \\
\text { surface }\end{array}$ & $\begin{array}{c}\text { I foot } \\
\text { below } \\
\text { surface } f\end{array}$ & $\begin{array}{c}350 \text { feet } \\
\text { below } \\
\text { surfacef }\end{array}$ \\
\hline Silica $\left(\mathrm{SiO}_{2}\right) \ldots \ldots \ldots \ldots \ldots$ & 0.0425 & 0.0300 & 0.4212 & 0.0200 \\
\hline Magnesium carbonate $\left(\mathrm{MgCO}_{3}\right)$ & $0.263^{2}$ & 0.2912 & 0.2800 & 0.2818 \\
\hline Calcium carbonate $\left(\mathrm{CaCO}_{3}\right) \ldots$ & $\ldots \ldots \ldots$ & $\ldots \ldots \ldots$ & 0.0447 & 0.0447 \\
\hline Potassium chloride $(\mathrm{KCl}) \ldots . .$. & 0.1374 & 0.1387 & 0.1474 & 0.1381 \\
\hline Sodium chloride $(\mathrm{NaCl}) \ldots$ & 2.2466 & 2.2428 & $2.24 \mathrm{II}$ & $2.255^{\circ}$ \\
\hline Sodium sulphate $\left(\mathrm{Na}_{2} \mathrm{SO}_{4}\right) \ldots \ldots$ & 0.2621 & 0.2757 & 0.2667 & 0.2737 \\
\hline Sodium carbonate $\left(\mathrm{Na}_{2} \mathrm{CO}_{3}\right) \ldots$ & $0.494^{\circ}$ & 0.4834 & 0.4738 & 0.4756 \\
\hline Total.... & $3 \cdot 445^{8}$ & $3 \cdot 4618$ & $3 \cdot 4949$ & $3 \cdot 4889$ \\
\hline
\end{tabular}

Nearly all the fresh water entering Pyramid Lake, which is without outlet, is delivered at the southern end by Truckee River, near the mouth of which the water is fresh enough for camp purposes. At the northern end of the lake the water is unfit for human consumption, but animals may drink it without injury.

3. Fresh-water Lakes. Water absolutely free from mineral mat-

* 99.23 per cent. of total solids accounted for.

** 99.19 per cent. of total solids accounted for.

$\dagger 99.94$ per cent. of total solids accounted for.

$\ddagger$ Error of 0.15 per cent. in excess. 
ter does not exist in nature. That of lakes and rivers suitable for drinking purposes (by man) always contains in the neighborhood of o.I permille of mineral matter, especially calcium carbonate. Water above 0.I 5 or 0.2 permille cannot be considered potable, especially if the percentage of sodium chloride is high. (Bibliography $\mathrm{V}$-44.) The average composition of fresh-water lakes is shown by the following analyses of the waters of Lake Baikal, the American Great Lakes and Lake Champlain. (Clarke-4:6I, 8I.)

Table of Average Composition of Lake Waters.

\begin{tabular}{|c|c|c|c|c|c|c|}
\hline & $\begin{array}{l}\text { Lake } \\
\text { Baikal }\end{array}$ & $\begin{array}{l}\text { Lake } \\
\text { Superior }\end{array}$ & $\begin{array}{c}\text { Lake } \\
\text { Michigan }\end{array}$ & $\begin{array}{l}\text { Lake } \\
\text { Huron }\end{array}$ & $\begin{array}{l}\text { Lake } \\
\text { Erie }\end{array}$ & $\begin{array}{l}\text { Lake } \\
\text { Cham- } \\
\text { plain }\end{array}$ \\
\hline $\mathrm{CO}_{3}$. & 49.85 & 45.26 & 48.82 & +8.99 & 45.64 & $45.8 I$ \\
\hline $\mathrm{SO}_{4} .$. & 6.93 & 4.33 & 5.67 & 5.64 & $9 .+8$ & II .03 \\
\hline $\mathrm{Cl} \ldots$ & 2.44 & I. 69 & 2.01 & 2. 19 & $5 \cdot 4^{\circ}$ & I. 78 \\
\hline $\mathrm{NO}_{3}$. & $0.2 \mathrm{I}$ & $0.5^{6}$ & 0.22 & $0.3^{\circ}$ & 0.12 & $\ldots \ldots$ \\
\hline $\mathrm{PO}_{4} \ldots$ & 0.72 & …..... & $\ldots \ldots$ & …... & $\ldots \ldots$ & $\ldots \ldots$ \\
\hline $\mathrm{Ca} \ldots$ & $23 \cdot 42$ & $25 \cdot 78$ & $23 \cdot+2$ & 23 . II & $23 \cdot 79$ & 21.19 \\
\hline Mg... & $3 \cdot 57$ & 4.96 & 6.94 & 6.35 & $5 \cdot 51$ & 4.21 \\
\hline $\begin{array}{l}\mathrm{Na} . . \\
\mathrm{K} . . .\end{array}$ & $\begin{array}{l}5.85 \\
3.44\end{array}$ & 4.96 & 3.65 & 3.21 & 4.84 & 8.80 \\
\hline $\mathrm{NH}_{4}$. & 0.08 & & 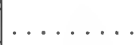 & & & \\
\hline $\mathrm{SiO}_{2} \ldots$ & 2.03 & 12.33 & 9.22 & 10.14 & 5.14 & $5 \cdot 5^{8}$ \\
\hline $\begin{array}{l}\mathrm{Fe}_{2} \mathrm{O}_{3} \ldots \\
\mathrm{Al}_{2} \mathrm{O}_{3} \ldots\end{array}$ & I. 46 & o. I3 & 0.05 & 0.07 & $\begin{array}{r}0.08 \\
\ldots .\end{array}$ & I. 60 \\
\hline Total. & 100.00 & 100.00 & 100.00 & 100.00 & 100.00 & 100.00 \\
\hline
\end{tabular}

III. Composition of River Water.

The composition of river water varies in accordance with the character of the rock, over or in which the river flows, and the nature of the supply. Though different rivers show varying amounts in the totality of solids, this is never very high, while at the same time the relative preponderance of the salts does not change greatly. The following table gives the totality of solids in a number of rivers, together with the predominant element or compounds in each. (Russell-3o, Table A ; Clarke-4:60-82.) 
Table Showing the Amounts in Permille of the Principal

\begin{tabular}{|c|c|c|c|c|}
\hline & & Total & $\begin{array}{l}\text { Cal- } \\
\text { cium } \\
\mathrm{Ca}\end{array}$ & $\begin{array}{c}\text { Mag- } \\
\text { nesium } \\
\mathrm{Mg}\end{array}$ \\
\hline I. & Rio de los Papagayos, Argentina $\ldots \ldots \ldots \ldots \ldots \ldots \ldots$ & 9.18500 & 0.73572 & 0.03307 \\
\hline & San Lorenzo River, California. . . . . . . . . . . . . . & 4.68500 & 0.23472 & 0.11609 \\
\hline & Pecos River, New Mexico; average of 6 analyses... & 2.83400 & 0.40999 & 0.10259 \\
\hline & 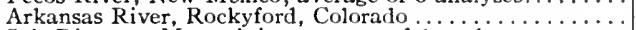 & 2.13400 & 0.27273 & 0.08024 \\
\hline & Salt River, at Mesa, Arizona; aver, of 6 anal. . . . . . . & 1.23400 & 0.09193 & 0.03319 \\
\hline 6. & Brazos River, Waco, Texas............. & 1.06600 & 0.10170 & 0.02175 \\
\hline & Mono Creek, California; aver. of 3 anal. & I. 00400 & 0.14889 & 0.05432 \\
\hline & Arkansas River, Little Rock. . . . . . . . & 0.79400 & 0.06034 & 0.01326 \\
\hline & Red River of the North below Assiniboine. & 0.55100 & 0.07102 & 0.04402 \\
\hline I0. & Red River of the North at Fargo, N. Dakota. & 0.39800 & 0.07375 & \\
\hline II. & Humboldt at Battle Mt., Nevada......... & 0.36150 & 0.04890 & 0.01240 \\
\hline I 2. & Jordan, Utah Lake, Utah............. & 0.30600 & 0.05580 & 0.01860 \\
\hline I3. & Los Angeles, Los Angeles (hydrant)...... & 0.24475 & 0.01750 & 0.02097 \\
\hline I4. & Rhine at Strassburg . . . . . . . & 0.23200 & 0.05869 & 0.00142 \\
\hline & Genesee at Rochester, New York. & 0.19526 & 0.04170 & 0.00896 \\
\hline I6. & Rhine at Cologne............ & 0.17800 & 0.04870 & 0.00991 \\
\hline I7. & Bear River at Evanstor, Wyoming. .. & 0.18450 & 0.04320 & 0.01250 \\
\hline 18. & Walker, Mason Valley, Nevada... & 0.18000 & 0.02280 & 0.00380 \\
\hline I9. & Mississippi at New Orleans. . . . . . & 0.16990 & 0.03720 & \\
\hline 20. & Lower Nile; average of I 2 monthly samples. & 0.16800 & 0.03377 & 0.00674 \\
\hline $2 \mathrm{I}$. & St. Lawrence, Pt. de Cascades, S. side....... & 0.16055 & 0.03233 & 0.00585 \\
\hline 22. & Rio Grande del Norte, Fort Craig, New Mexico. & 0.15760 & 0.01633 & 0.00123 \\
\hline 23. & 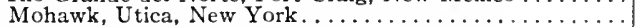 & 0.15250 & 0.03180 & 0.00690 \\
\hline 24. & Hudson, Hudson, New York. .. & 0.14238 & 0.02220 & 0.00465 \\
\hline 25. & Cumberland, Nashville, Tennessee........ & 0.13786 & 0.02987 & 0.00280 \\
\hline 26. & Passaic, 4 miles above Newark, New Jersey. & 0.13267 & 0.01459 & 0.00404 \\
\hline 27. & Sacramento, Sacramento, California......... & 0.11484 & 0.01279 & 0.00121 \\
\hline 28. & Maumee, Ohio. & $0.1097 \mathrm{I}$ & 0.02645 & \\
\hline 29. & Croton, New York City. & 0.08433 & 0.00905 & 0.00336 \\
\hline 30. & Moldau, above Prague $\ldots \ldots$ & 0.07400 & $0.0100 \mathrm{I}$ & 0.00361 \\
\hline & Truckee, Lake Tahoc, Nevada. & 0.07300 & 0.00930 & 0.00300 \\
\hline & James, Richmond, Virginia. . . & 0.07246 & 0.01284 & 0.00377 \\
\hline 33. & Delaware, Trenton, New Jersey & 0.06795 & 0.01104 & 0.00435 \\
\hline 34 . & 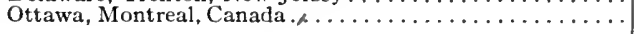 & 0.06116 & 0.00992 & 0.00161 \\
\hline
\end{tabular}

The following table gives the total salinity of a number of additional rivers, as quoted by Penck (26:309) and Clarke (4).

\section{Table Showing Total Salinity of Other Rivers.}

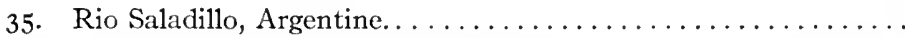

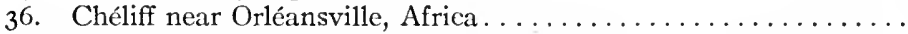

Permille.

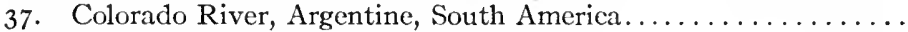

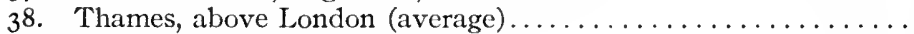

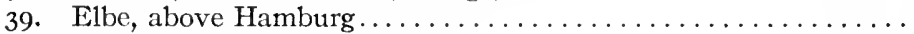

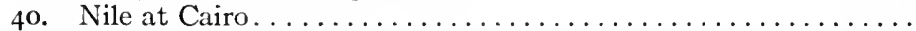

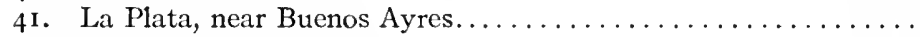

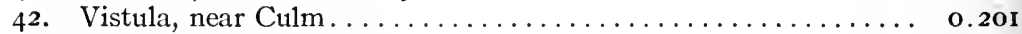

43. Dwina, Russia............................ o. 187

44. Danube at Budapest (average) .................. o.187

45. Rhone at Lyons (average) ...................... o.145

46. Rio Negro, above Mercedes, South America............. o.132

47. Parana, 5 miles above its entry into La Plata............. 0.098

48. La Plata, 5 miles above Buenos Ayres................ $0.09 \mathrm{I}$ 
Elements and Compounds Occurring in Various River Waters

\begin{tabular}{|c|c|c|c|c|c|}
\hline $\begin{array}{l}\text { Potas- } \\
\text { sium } \\
\mathbf{K}\end{array}$ & $\underset{\mathrm{Na}}{\text { Sodium }}$ & $\begin{array}{c}\text { Carbonic } \\
\text { acid } \\
\mathrm{CO}_{3}\end{array}$ & $\begin{array}{c}\text { Sulphuric } \\
\text { acid } \\
\mathrm{SO}_{4}\end{array}$ & $\underset{\mathrm{Cl}}{\text { Chlorine }}$ & Other substances present \\
\hline 0.04501 & 2.43219 & 0.00551 & 2.92535 & 2.99707 & $\mathrm{~S}$ \\
\hline 0.06044 & 1.07204 & 0.14477 & 2.20710 & 0.77209 & \\
\hline 0.02182 & 0.14226 & 0.04364 & I. 239 I I & 0.63835 & $\mathrm{SiO}_{2}, \mathrm{Al}_{2} \mathrm{O}_{3}, \mathrm{Fe}_{2} \mathrm{O}_{3}$ \\
\hline 0.00597 & 0.30943 & 0.56650 & I. 295 I2 & o. 10435 & $\mathrm{SiO}_{2}$ \\
\hline I. 70292 & 0.32553 & 0.11858 & 0.01430 & 0.51305 & $\mathrm{SiO}_{2}, \mathrm{Al}_{2} \mathrm{O}_{3}, \mathrm{Fe}_{2} \mathrm{O}_{3}$ \\
\hline \multicolumn{2}{|c|}{$\begin{array}{c}1.70292 \\
0.24806\end{array}$} & 0.24806 & 0.22109 & 0.35935 & $\mathrm{SiO}_{2}, \mathrm{Fe}_{2} \mathrm{O}_{3}$ \\
\hline trace & 0.10893 & 0.18875 & 0.45863 & 0.03614 & $\mathrm{SiO}_{2}, \mathrm{Al}_{2} \mathrm{O}_{3}, \mathrm{Fe}_{2} \mathrm{O}_{3}$ \\
\hline 0.00588 & 0.20580 & 0.08575 & 0.10012 & 0.30609 & $\mathrm{SiO}_{2}, \mathrm{Al}_{2} \mathrm{O}_{3}, \mathrm{Fe}_{2} \mathrm{O}$. \\
\hline 0.00650 & 0.05328 & 0.17340 & 0.12155 & 0.04838 & $\mathrm{SiO}_{3},(\mathrm{AlF})=\mathrm{O}_{3}$ \\
\hline \multicolumn{2}{|c|}{0.01485} & $0.2234^{8}$ & 0.00346 & 0.00394 & $(\mathrm{AlFe})_{2} \mathrm{O}_{3}$ \\
\hline 0.01000 & 0.04670 & $0.1544^{\circ}$ & $0.0477^{\circ}$ & 0.00750 & $\mathrm{SiO}_{2}, \mathrm{Al}_{2} \mathrm{O}_{3}$ \\
\hline$\ldots \ldots$. & 0.01780 & 0.06080 & 0.13060 & $0.0124^{\circ}$ & $\mathrm{SiO}_{2}$ \\
\hline$\cdots$ & 0.02968 & 0.05635 & 0.05724 & 0.01044 & 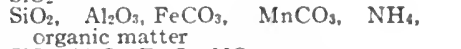 \\
\hline 0.00153 & 0.00503 & 0.08373 & 0.01888 & 0.00120 & $\mathrm{SiO}_{2}, \mathrm{Al}_{2} \mathrm{O}_{3}, \mathrm{Fe}_{2} \mathrm{O}_{3}, \mathrm{NO}_{3}$ \\
\hline 0.00230 & 0.00440 & 0.06460 & 0.04310 & 0.00240 & $\mathrm{SiO}_{2}, \mathrm{Al}_{2} \mathrm{O}_{3}, \mathrm{Fe}_{2} \mathrm{O}_{3}$, organic matter \\
\hline$\ldots \ldots$ & 0.00479 & 0.08377 & 0.02244 & 0.00742 & $\mathrm{SiO}_{3}, \mathrm{Al}_{2} \mathrm{O}_{3}, \mathrm{Fe}_{2} \mathrm{O}_{3}, \mathrm{PO}_{4}$ \\
\hline$\ldots \ldots$ & 0.00820 & 0.09820 & 0.01050 & 0.00490 & $\mathrm{SiO}_{2}$ \\
\hline trace & 0.03180 & 0.05760 & 0.02840 & 0.01310 & $\mathrm{SiO}_{2}$ \\
\hline$\ldots \ldots .$. & 0.03100 & 0.03830 & $\ldots \ldots$ & $\ldots \ldots$ & Carbonates and sulphates of $\mathrm{K}, \mathrm{Na}, \mathrm{Mg}$ \\
\hline 0.01329 & 0.005 I I & 0.00613 & 0.02929 & 0.0075 & $\mathrm{SiO}_{2}, \mathrm{Fe}_{2} \mathrm{O}_{3}$ \\
\hline 0.00115 & $0.005 \mathrm{I} 3$ & 0.06836 & 0.00831 & 0.00242 & $\mathrm{SiO}_{2}$ \\
\hline 0.00063 & 0.03220 & 0.01025 & 0.04700 & 0.03604 & Organic matter, traces of other minerals \\
\hline 0.00090 & 0.00360 & 0.05690 & 0.01870 & 0.00230 & $\mathrm{SiO}_{2}, \mathrm{Al}_{2} \mathrm{O}_{3}, \mathrm{Fe}_{2} \mathrm{O}_{3}$, organic matter \\
\hline 0.00058 & 0.00243 & 0.07278 & 0.01257 & $0.0058 \mathrm{I}$ & $\mathrm{SiO}_{2}, \mathrm{Fe}_{2} \mathrm{O}_{3}, \mathrm{Al}_{2} \mathrm{O}_{3}, \mathrm{H}$, organic matter \\
\hline 0.00050 & 0.01032 & 0.05727 & 0.00563 & 0.00299 & $\mathrm{SiO}_{2}, \mathrm{HNO}_{3}, \mathrm{Fe}_{2} \mathrm{O}_{3}, \mathrm{Al}_{2} \mathrm{O}_{2}$, organic matter \\
\hline 0.00163 & 0.02357 & 0.02634 & 0.01716 & 0.03192 & $\mathrm{SiO}_{2}, \mathrm{Al}_{2} \mathrm{O}_{3}, \mathrm{Fe}_{2} \mathrm{O}_{3}$ \\
\hline$\ldots \ldots$ & 0.00200 & 0.00887 & 0.00397 & $\cdots \cdots$ & $\begin{array}{l}\mathrm{H}_{3} \mathrm{PO}_{4}, \mathrm{SiO}_{2}, \mathrm{Al}_{2} \mathrm{O}_{3}, \mathrm{FeCO}_{3}, \mathrm{MnCO}_{3}, \mathrm{NaCl} \text {, } \\
\mathrm{Na}_{2} \mathrm{SO}_{4}\end{array}$ \\
\hline 0.00309 & 0.00162 & 0.04438 & 0.01401 & 0.00250 & $\mathrm{SiO}_{2}, \mathrm{Fe}_{2} \mathrm{O}_{3}$, organic matter \\
\hline 0.00154 & 0.00298 & 0.02248 & 0.00441 & 0.00213 & $\mathrm{SiO}_{2}, \mathrm{Fe}_{2} \mathrm{O}_{3}, \mathrm{Al}_{2} \mathrm{O}_{3}$, organic matter \\
\hline 0.00384 & 0.00756 & 0.00243 & 0.00843 & 0.00793 & $\mathrm{SiO}_{2},(\mathrm{AlFe})_{2}, \mathrm{O}_{3}, \mathrm{PO}_{4}$ \\
\hline 0.00330 & 0.00730 & 0.02870 & 0.00540 & 0.00230 & $\mathrm{SiO}_{2}$ \\
\hline 0.00251 & 0.00234 & 0.02954 & 0.00363 & 0.00105 & $\begin{array}{l}\mathrm{HNO}_{3}, \mathrm{SiO}_{2}, \mathrm{Al}_{2} \mathrm{O}_{3}, \mathrm{Fe}_{2} \mathrm{O}_{3} \mathrm{Mn}_{2} \mathrm{O}_{3}, \mathrm{NH}_{4} \text {, or- } \\
\text { ganic matter }\end{array}$ \\
\hline 0.00178 & 0.00072 & 0.02552 & 0.00175 & 0.00121 & 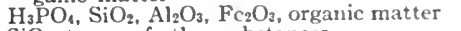 \\
\hline 0.00139 & 0.00239 & 0.02255 & 0.00194 & 0.00076 & $\mathrm{SiO}_{2} ;$ traces of other substances \\
\hline
\end{tabular}

\section{Table Showing Total Salinity of Other Rivers.-Continued.}

Permille.

49. Uruguay, above Fray Bentos. . . . . . . . . . . . . . . . o. 066

50. Amazon, between the Narrows and Santarem............. 0. 059

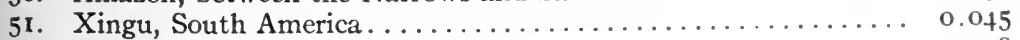

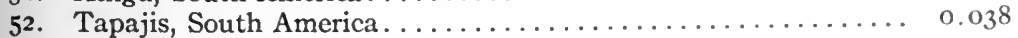

53. Amazon at Obidos........................ 0.037

In most of the rivers calcium is in excess, probably in the form of the bicarbonate. In some cases, however, as in the Jordan River, Utah, the calcium is chiefly in the form of the sulphate.

From the analyses of the waters of twenty American rivers (United States and Canada), it has been found that the average total amount of solids carried in solution is 0.15044 permille, of which 0.056416 permille is calcium carbonate (Russell-33:78). Forty-eight analyses of the waters of European rivers tabulated by Bischof give the average total solids in solution as 0.2127 permille with an average of O.II 39 permille of $\mathrm{CaCO}_{3}$, while forty analyses 
gave Rotl an average total of 0.2033 permille and of calcium carbonate 0.009598 permille (Russell-33:79). For both American and European rivers the above data give an average of total solids in solution of 0.1888 permille, of which 0.088765 permille, or 47 per cent. of the total solids, represents calcium carbonate.

The annual total transport of mineral matter in solution was compiled for a number of rivers by Russell (3I:79), and is given in the following rearranged and supplemented

\section{Table of Total Solids Carried in Solution, in Tons per Year.*}

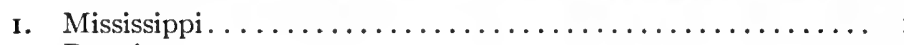

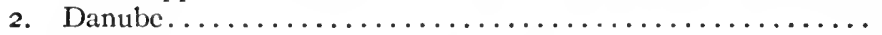

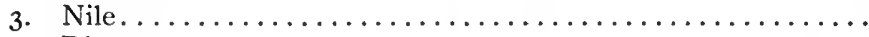

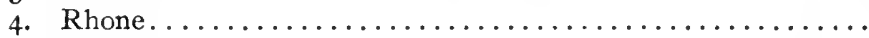

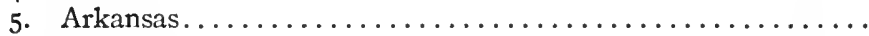

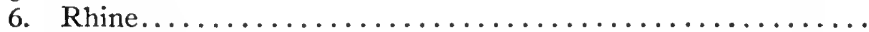

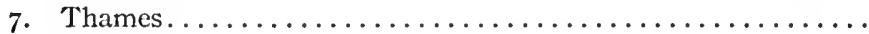

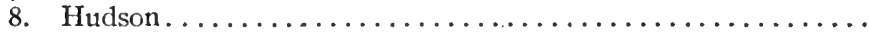

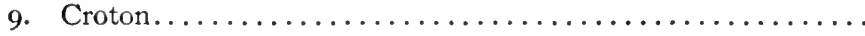

Total for nine rivers.

$112,832,170$

$22,521,430$

I6,950,00I

$8,290,464$

$6,828,350$

$5,816,804$

613,930

438,005

66,795

Sir John Murray $(22: 76)$ has computed the number of tons of different salts carried in solution in a cubic mile of river water; the average of which for nineteen of the principal rivers of the world is given in the following table (Russell-33:80) : $\dagger$

Table Showing the Amounts of the Different Salts Carried in Solution in One Cubic Mile of Average River Water.

Constituents.

Calcium carbonate $\left(\mathrm{CaCO}_{3}\right)$

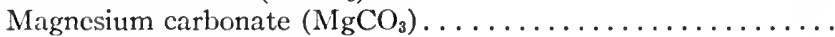

Calcium phosphate $\left(\mathrm{Ca}_{3} \mathrm{P}_{2} \mathrm{O}_{8}\right) \ldots \ldots \ldots \ldots \ldots \ldots \ldots \ldots \ldots \ldots \ldots \ldots$

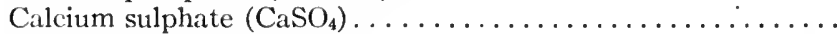

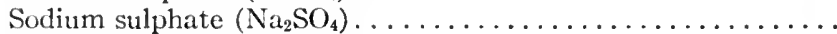

Potassium sulphate $\left(\mathrm{K}_{2} \mathrm{SO}_{4}\right) \ldots \ldots \ldots \ldots \ldots \ldots \ldots \ldots \ldots$

Sodium nitrate $\left(\mathrm{NaNO}_{3}\right) \ldots \ldots \ldots \ldots \ldots \ldots \ldots \ldots \ldots \ldots \ldots \ldots \ldots$

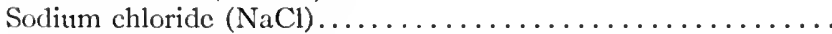

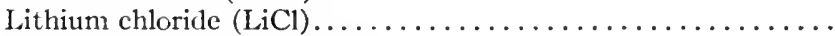

$\Lambda$ mmonium chloride $\left(\mathrm{NH}_{4} \mathrm{Cl}\right) \ldots \ldots \ldots \ldots \ldots \ldots \ldots \ldots \ldots \ldots$

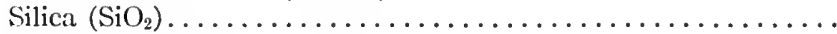

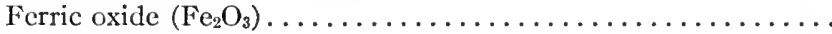

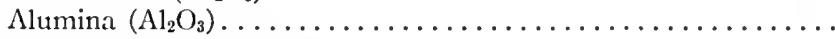

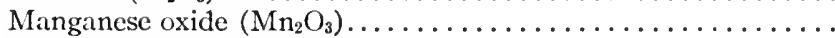

Organic matter.

Total dissolved matter.

* See other tables cited by Clarke- $4: 80$.

$\dagger$ Acids and bases combined according to the principles indicated by Bunsen.

$\ddagger$ One cubic mile of fresh water weighs about $4,205,650,000$ British tons of 2,240 pounds each.
British tons in one cubic mile. $\ddagger$ 326,710 I 12,870

2,913

$34,36 \mathrm{I}$

31,805

20,358

26,800

16,657

2,462

1,030

74,577

13,006

14,315

5,703

79,020

762,587 
Murray has further computed that the volume of water flowing into the sea in one year, for all the land areas of the earth, totals about 6,524 cubic miles, which, with the average composition given above, results in the grand total of $4,975,117,588$ British tons of mineral matter carried in solution into the sea annually. Large as the amount is, when compared with the total mineral matter in the sea, it dwindles in proportion. Of calcium carbonate alone 2,131 ,455,940 tons are carried into the sea annually, of magnesium carbonate $736,363,880$ tons, or a total of carbonates of $2,867,819,820$ tons, or, in round numbers, 2,868 million British tons, or 2,823 million metric tons.* (Krümmel figures out only 2,460 million metric tons of carbonates, using Penck's estimate [26:3Io] of 4,100 million metric tons of mineral matter carried into the sea annually, or $1 / 6000$ of the total amount of the water flowing into the sea. The percentage of carbonates dissolved in river water is taken as 60.) Although the percentage of carbonates in the sea may be as low as 0.2 , the absolute quantity is $99.4 \times 10^{12}$ metric tons, or 39,000 times as much as the yearly supply by streams, according to Krümmel's estimate. On these same estimates it appears that of sulphates there is 9 million times the amount by weight, while of chlorides there is I 7 million times the amount by weight brought into the sea annually by all the rivers of the world. (Krümmel-20:228.)

\section{Composition of Spring Water.}

Rain water is not absolutely pure $\mathrm{H}_{2} \mathrm{O}$, but always contains impurities gathered in its passage through the lower strata of the atmosphere. An analysis of rain water collected near London, England, gave the following composition:

\section{Table of Composition of Rain Water near London.}

Permille.

\begin{tabular}{|c|c|}
\hline Organic carbon. ......... & 0.00099 \\
\hline Organic nitrogen........ & 0.00022 \\
\hline 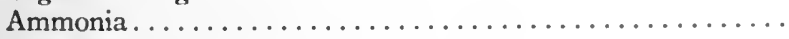 & 0.00050 \\
\hline 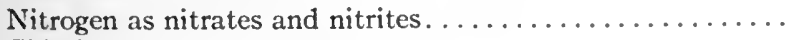 & 0.00007 \\
\hline 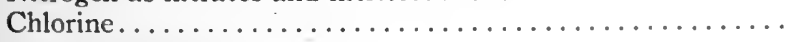 & $0.0063^{\circ}$ \\
\hline Other impurities $\ldots \ldots \ldots \ldots \ldots \ldots \ldots \ldots \ldots$ & 0.03142 \\
\hline
\end{tabular}

Total.............................. 0.03950

* One metric ton equals I,ooo kilograms, equals 2,204.6 pounds avoirdupois; I British ton equals 2,2 40 pounds avoirdupois. 
This is 39.50 grams in one thousand liters of rain water. At Troy, New York, the mean chlorine content of the rain water for one year was found to be 0.00164 permille, or 1.64 grams per I,000 liters.

At Lincoln, New Zealand, the impurities of the rain water were found by Gray to average during two years as follows:

Impurities of Rain Water.

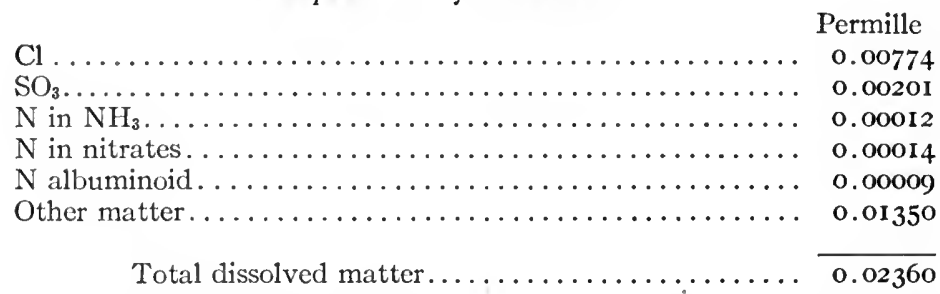

The following solids, in pounds per acre per annum, have been determined as brought by the rain in various localities. (Clarke$4: 46-47$.)

Solids in Rain Water. (Pounds per acre per year.)

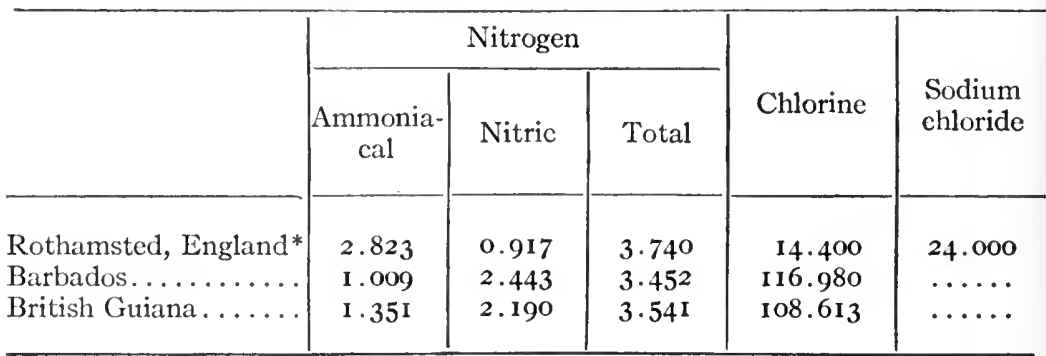

From the soil the rain water takes $\mathrm{CO}_{2}$ and humus acids derived from both living and decaying vegetation, and these, with the acids derived from the atmosphere, will exercise a solvent power upon the rocks through which the water passes. Several of them are good solvents of silica, and the streams passing through bogs are generally rich in this constituent. Thus the Ottawa drains a region occupied chiefly by crystalline rocks, covered by extensive forests and marshes, and its percentage of silica is 33.7 of the total inorganic solids. $\dagger$

*Average of five years.

† For a full discussion of the Geological action of the Humus Acids see Julien (17). For a correlation between eompositions of river water and source of the water see Hanamann (12). 
The ordinary spring or vadose water will thus have a certain type of composition, though varying greatly within that type. The leading acid ions in its mineral content are $\mathrm{CO}_{2}$ and $\mathrm{SO}_{3}$, and lime and magnesia are the leading bases, except in granitic countries or in arid regions. Lane thinks that the salinity is not commonly over I permille, that saturation with bicarbonates $(0.238$ permille of $\left.\mathrm{CaCO}_{3}\right)$ seems to be a very common goal, and that the specific gravity of such waters is not greater than I. Analysis A on page I7o may be taken as a type of such waters.

Waters regarded by Lane as showing large proportions of buried sea water were obtained from Sheboygan, Wisconsin. These have a salinity of 589.2536 grains per U. S. gallon ( 8.782 grams per liter, or 8.782 permille), of which $52.1 \%$ is $\mathrm{NaCl}$. Others have been obtained from Bowling Green, Ohio, which had a salinity of 3,297.93 grains per U. S. gallon (49.1 54 grams per liter, or 49.154 permille), of which $72.3 \%$ is $\mathrm{NaCl}$.

Magmatic waters obviously have the greatest range of variability in composition. Still it would not be proper to hold that all waters varying beyond the limits ordinarily set for meteoric waters or for connate waters are to be regarded as of magmatic origin. Such an assumption would disregard the evident ability of meteoric waters to take up mineral matter in their passage through the rocks. Since magmatic waters are essentially thermal, they will be more fully discussed under the section dealing with the temperature of the water. (See page 20I.) Analyses of spring waters from the Algerian Sahara gave the following extremes of composition (Rolland quoted by Walther-43:57):

Composition of Spring Water from the Sahara.

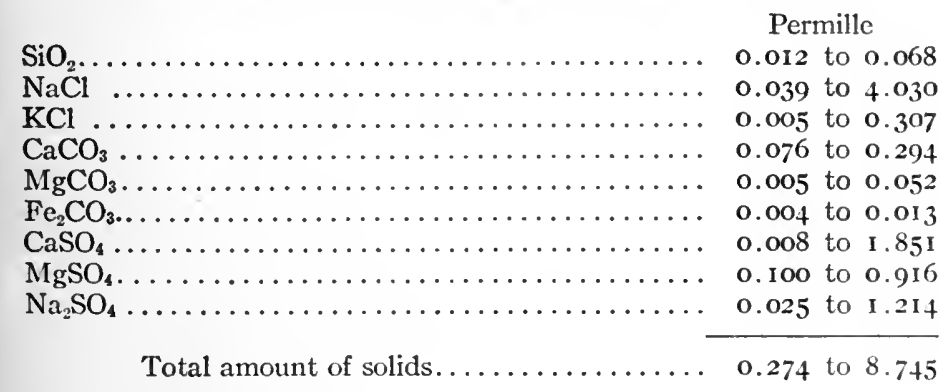

In the table on pp. I70-I7I a number of analyses of the waters of springs and wells are given to show their variations and general 
character. For a more extensive tabulation the student is referred to Clarke's Data of Geochemistry. As with the waters of lakes, so here a number of divisions are made, but no hard-and-fast line can be drawn between end members of adjoining groups. The following springs are given:

A. Spring near Magnet Cove, Arkansas-ordinary (Carbonate) spring water.

B. Spring near Mount Mica, Paris, Maine-ordinary (sulphate) spring water.

C. Artesian well, Cincinnati-chloride waters.

D. Upper Blue Lick Springs, Kentucky-chloride waters.

E. Utah hot springs, 8 miles north of Ogden, Utah-chloride waters.

F. The Kochbrunnen, Wiesbaden-chloride waters.

G.* Well, 2,667 feet deep at Conneautsville, Pa.-chloride waters.

H.* Boiling spring, Savu-Savu, Fiji-chloride waters.

I. $\dagger$ Congress Spring, Saratoga-chloride waters.

J. $\dagger$ Steamboat Springs, Nevada-chloride waters.

K. Bitter Spring Laa, Austria-sulphate waters.

L. Cruzy, Hérault, France-sulphate waters.

M. Pine Creek Valley Spring, near Atlin, British Columbiacarbonate waters.

N. Orange Spring, Yellowstone National Park-mixed waters.

O. The Sprudel, Carlsbad, Bohemia-mixed waters.

P. Chalybeate waters, Mittagong, New South Wales-mixed waters.

Q. Old Faithful Geyser, Upper Geyser Basin-siliceous waters.

R. Excelsior Geyser, Midway Basin-siliceous waters.

S. Great Geyser, Iceland-siliceous waters.

T. Hot Spring, Sulphur Bank, Clear Lake, Cal.-borate water.

U. Viry, Seine-et-Oise, France-phosphate water.

V. Holy Well, Zem Zem, Mecca-nitrate water.

W. Tuscarora Sour Spring, 9 miles south of Brantford, Canada-acid water.

X. Solfatara at Pozzuoli, Italy (volcanic) - acid water.

Y. Hot Lake, White Island, Bay of Plenty, New Zealand (a $10 \%$ solution of $\mathrm{HCl}$ ) - acid water.

* With much calcium. $†$ Notable quantities of other acid radicles present. 
Classification of Natural Waters.

Clarke $(4: 157)$ has summarized the characters of natural waters in the following classification:

I. Cliloride waters. Principal negative ion $\mathrm{Cl}$.

A. Principal positive ion sodium.

B. Principal positive ion calcium.

C. Waters rich in magnesium.

II. Sulphate waters. Principal negative ion $\mathrm{SO}_{4}$.

A. Principal positive ion sodium.

B. Principal positive ion calcium.

C. Principal positive ion magnesium.

D. Waters rich in iron or aluminum.

E. Waters containing heavy metals such as zinc.

III. Sulphato-chloride waters, with $\mathrm{SO}_{4}$ and $\mathrm{Cl}$ both abundant.

IV. Carbonate waters. Principal negative ion $\mathrm{CO}_{3}$ or $\mathrm{HCO}_{3}$.

A. Principal positive ion sodium.

B. Principal positive ion calcium.

C. Chalybeate waters.

V. Sulphato-carbonate waters $\mathrm{SO}_{4}$ and $\mathrm{CO}_{3}$ both abundant.

VI. Chloro-carbonate waters $\mathrm{Cl}$ and $\mathrm{CO}_{3}$ both abundant.

VII. Triple waters, containing chlorides, sulphates and carbonates in equally notable amounts.

VIII. Siliceous waters. Rich in $\mathrm{SiO}_{2}$.

IX. Borate waters. Principal negative radicle $\mathrm{B}_{4} \mathrm{O}_{7}$.

X. Nitrate waters. Principal negative ion $\mathrm{NO}_{3}$.

XI. Phosphate waters. Principal negative ion $\mathrm{PO}_{4}$.

XII. Acid waters. Contain free acids.

A. Acid chiefly sulphuric.

B. Acid chiefly hydrochloric.

While this emphasizes the essential types, it must be borne in mind that many waters are intermediate in character between these types, and their classification with one or the other may be a matter of opinion.

\section{Gases and Organic Matter in Natural Waters.}

Besides the dissolved mineral matter found in the natural waters of the world, there exist various dissolved gases and a varying proportion of organic matter. The relative quantity of different gases varies according to the temperature, as shown in the following table prepared by $R$. W. Bunsen and quoted by Clarke $(4: 45)$ : 
Table of Analayses of

\begin{tabular}{|c|c|c|c|c|c|c|c|c|c|c|c|c|}
\hline & A & B & $\mathrm{C}$ & D & E & $\mathrm{F}$ & G & H & I & $\mathrm{J}$ & K & $\mathbf{L}$ \\
\hline${ }_{B} 1 \ldots \ldots$ & 1.35 & trace & 55.83 & 53.08 & 58.79 & 56.58 & 62.31 & 57.91 & 42.00 & 35.00 & 0.57 & 3.73 \\
\hline $\begin{array}{l}\mathrm{Br}, \mathrm{I}, \mathrm{F} \ldots \\
\mathrm{so}_{4} \ldots\end{array}$ & 3.40 & 6097 & $\begin{array}{l}0.07 \\
3.12\end{array}$ & $\begin{array}{l}0.53 \\
6.03\end{array}$ & $\begin{array}{c}\text { traee } \\
0.94\end{array}$ & $\begin{array}{l}0.04 \\
0.78\end{array}$ & $\begin{array}{l}0.54 \\
0.03\end{array}$ & 338 & 1.15 & 45 & 6087 & 71 if \\
\hline $\mathrm{CO}_{3} \ldots \ldots \ldots$ & $\begin{array}{r}3.40 \\
53.59\end{array}$ & $\begin{array}{r}6.22 \\
6.22\end{array}$ & 2.63 & $\begin{array}{l}0.00 \\
2.34\end{array}$ & 0.61 & 3.13 & $\begin{array}{l}0.00 \\
0.27\end{array}$ & $\begin{array}{l}0.00 \\
\text { trace }\end{array}$ & 18.59 & 5.08 & $\begin{array}{r}0.75 \\
4.75\end{array}$ & $\begin{array}{r}14.10 \\
0.03\end{array}$ \\
\hline $\mathrm{PO}_{4} \ldots \ldots \ldots$ & $\ldots$ & $\ldots$. & $\ldots$ & $\ldots$. & $\ldots$. & trace & $\ldots \ldots$ & trace & trace & 0.03 & $\ldots$. & ..... \\
\hline $\mathrm{NO}_{3} \ldots \ldots$ & $\ldots \ldots$ & $\ldots \ldots$ & $\ldots$ & $\ldots \ldots$ & $\ldots \ldots$ & $\ldots \ldots$ & $\ldots \ldots$ & $\ldots$ & & & $\ldots \ldots$ & $\ldots \ldots$ \\
\hline $\mathrm{B}_{4} \mathrm{O}_{7} \ldots \ldots$ & $\cdots \cdots$ & $\cdots \cdots$ & $\ldots \ldots$ & $\ldots \ldots$ & .... & $\cdots \cdots$ & $\cdots \cdots$ & $\cdots \cdots$ & trace & 8.88 & $\cdots \cdots$ & $\ldots \ldots$ \\
\hline $\mathrm{H}_{2} \mathrm{SO}_{4}$ free. & .... & $\ldots \ldots$ & .... & ..... & .... & .... & $\ldots \ldots$ & .... & .... & .... & .... & $\cdots \cdots$ \\
\hline $\begin{array}{l}\mathrm{HNO}_{3} \text { free. } \\
\mathrm{HCl} \text { free. }\end{array}$ & $\cdots \cdots$ & $\cdots \cdots$ & $\cdots$ & & $\cdots \cdots$ & $\cdots \cdots$ & $\cdots \cdots$ & $\cdots \cdots$ & $\cdots \cdots$ & $\cdots \cdots$ & $\cdots \cdot$ & $\cdots \cdot$ \\
\hline $\mathrm{AsO}_{4} \ldots . .$. & $\cdots$ & …... & $\cdots$ & & … & trace & …. & $\ldots$ & …. & …. & …. & $\cdots \cdots$ \\
\hline $\mathrm{BO}_{2 .}$. & & & & & & 0.01 & & & & & & \\
\hline $\mathrm{Ka}$. & $\begin{array}{l}1.08 \\
0.63\end{array}$ & $\begin{array}{l}4.32 \\
0.21\end{array}$ & $\begin{array}{r}33.09 \\
0.27\end{array}$ & $\begin{array}{r}31.47 \\
0.96\end{array}$ & $\begin{array}{r}30.38 \\
3.76\end{array}$ & $\begin{array}{r}32.60 \\
1.16\end{array}$ & $\begin{array}{r}18.35 \\
1.55\end{array}$ & $\begin{array}{r}16.65 \\
0.93\end{array}$ & $\begin{array}{r}27.62 \\
0.78\end{array}$ & $\begin{array}{r}30.35 \\
3.79\end{array}$ & $\begin{array}{l}2.99 \\
0.35\end{array}$ & $\begin{array}{l}4.50 \\
0.03\end{array}$ \\
\hline Li. & $\begin{array}{l}0.03 \\
\ldots . .\end{array}$ & $\begin{array}{l}0.21 \\
\ldots . .\end{array}$ & $\begin{array}{r}0.28 \\
\ldots \ldots\end{array}$ & $\begin{array}{r}0.90 \\
\ldots \ldots\end{array}$ & $\begin{array}{l}3.60 \\
\text { traee }\end{array}$ & $\begin{array}{l}1.16 \\
0.04\end{array}$ & $\begin{array}{l}1.55 \\
0.04\end{array}$ & 0.93 & $\begin{array}{l}0.78 \\
0.08\end{array}$ & $\begin{array}{l}3.19 \\
0.27\end{array}$ & & 0.05 \\
\hline $\mathrm{NH}_{4}$. & & & & & & 0.07 & 0.23 & & & & 0.22 & . \\
\hline $\mathrm{Ca}$. & 30.95 & 22.37 & 3.72 & 3.56 & 4.90 & 4.05 & 13.86 & 18.34 & 6.03 & 0.25 & 7.63 & 0.02 \\
\hline Sr. . & ... & $\ldots \ldots$ & $\ldots \ldots$ & $\ldots \ldots$ & $\ldots \ldots$ & 0.12 & $\ldots$ & $\ldots$ & trace & ..... & $\ldots \ldots$ & $\ldots \ldots$ \\
\hline $\mathrm{Ba}$. & 3,45 & 2.62 & 1.13 & 1.57 & 0.40 & $\begin{array}{l}0.01 \\
0.61\end{array}$ & 253 & 0.04 & $\begin{array}{l}0.09 \\
3.41\end{array}$ & 000 & 1318 & 17.45 \\
\hline Mn... & 3. & 2.02 & 1.10 & 1.08 & 0.70 & 0.01 & 2.00 & $0.0 t$ & 3.41 & 0.01 & 13.18 & 17.45 \\
\hline $\mathrm{Fe}^{\prime \prime}$ & ..... & $\ldots .$. & ...... & $\ldots \ldots$ & ….. & 0.04 & …. & ….. & …. & … & …. & $\cdots \cdots$ \\
\hline $\mathrm{Fe}^{\prime \prime \prime} \ldots \ldots$ & $\therefore \ldots$ & $\ldots \ldots$ & $\ldots \ldots$ & $\ldots \ldots$ & $\ldots \ldots$ & .... & & $\ldots \ldots$ & $\ldots \ldots$ & . & $\ldots \ldots$ & $\ldots \ldots$ \\
\hline $\mathrm{Fe} \ldots$ & $\cdots$ & $\dddot{0}$ & $\ddot{0}$ & $\ldots \ldots$ & $\ldots \ldots$ & $\ldots \ldots$ & 0.25 & & 003 & trace & $\cdots \cdots$ & 001 \\
\hline $\begin{array}{l}\mathrm{Fe}_{2} \mathrm{O}_{3} \text {. } \\
\mathrm{Al}_{2} \mathrm{O}_{2} \text {. }\end{array}$ & $\ldots \ldots$ & $\begin{array}{r}0.49 \\
\ldots .\end{array}$ & 0.06 & … & 0.02 & $\ldots \ldots$ & $\cdots \cdots$ & $\begin{array}{r}\text { trace } \\
0.54\end{array}$ & $\begin{array}{l}0.03 \\
\text { trace }\end{array}$ & $\ddot{0} 01$ & 0.02 & 0.01 \\
\hline & & & & & & & 0.02 & 0.43 & . & & & \\
\hline $\mathrm{SiO}_{2} \ldots \ldots$ & 5.55 & 2.80 & 0.08 & 0.16 & 0.20 & 0.76 & 0.02 & 1.78 & ..... & 11.41 & 0.42 & 0.07 \\
\hline $\mathrm{Cd}, \mathrm{Zn}, \mathrm{Cu}$ & $\cdots \cdots$ & $\ldots \ldots$ & $\ldots \ldots$ & $\cdots \cdots$ & $\because \cdots$ & $\ldots \ldots$ & … & $\cdots \cdot$ & ..... & 034 & $\cdots \cdots$ & $\cdots \cdot$ \\
\hline $\mathrm{S}, \mathrm{As}, \mathrm{Sb}, \mathbf{H g}$ & $\cdots \cdots$ & $\cdots \cdots$ & $\cdots \cdots$ & … & ..... & $\cdots \cdots$ & $\cdots \cdots$ & $\cdots \cdots$ & $\cdots \cdots$ & 0.54 & $\cdots \cdots$ & $\cdots \cdots$ \\
\hline Total solid. & 100.00 & 100.00 & 100.00 & 100.00 & 100.00 & 100.00 & 100.00 & 100.00 & 100.00 & 100.00 & 100.00 & 100.00 \\
\hline $\begin{array}{l}\text { Permille } \\
\text { of total }\end{array}$ & 0.224 & 0.606 & 10.589 & 11.068 & 23.309 & 8.241 & $|309.175|$ & 7.813 & 12.022 & 2.850 & 62.371 & 101.000 \\
\hline
\end{tabular}

The $\mathrm{HNO}_{3}$ is found in some waters not included in this table. It is listed here on account of its interest as

Composition (in Percentages of Total Gases) of Dissolved Air in Rain Water at Different Temperatures.

\begin{tabular}{|c|c|c|c|c|c|}
\hline & $0^{\circ}$ & $5^{\circ}$ & $10^{\circ}$ & $15^{\circ}$ & $20^{\circ}$ \\
\hline Nitrogen $\left(\mathrm{N}_{2}\right) \ldots$ & 63.20 & $63 \cdot 35$ & 63.49 & 63.62 & 63.69 \\
\hline Oxygen $\left(\mathrm{O}_{2}\right) \ldots \ldots \ldots$ & 33.88 & 33.97 & 34.05 & $34 \cdot 12$ & 34.17 \\
\hline \multirow[t]{2}{*}{ Carbon dioxide $\left(\mathrm{CO}_{2}\right) \ldots$} & 2.92 & 2.68 & 2.46 & 2.26 & 2. 14 \\
\hline & 100.00 & 100.00 & 100.00 & 100.00 & 100.00 \\
\hline
\end{tabular}

The absolute amounts of the different gases vary more markedly with different temperatures. Thus a liter of pure surface water, under a normal barometric pressure of $760 \mathrm{~mm}$., contains the following absolute and percental amounts of dissolved gases in c. c. (Krümmel-20:293; Forel-8:95 gives somewhat different values.)*

* See also Cyrus F. Tolman (39). 
Spring and Well Waters

\begin{tabular}{|c|c|c|c|c|c|c|c|c|c|c|c|c|}
\hline M & $N$ & 0 & P & Q & R & $\mathrm{s}$ & $\mathrm{T}$ & U & V & W & $\mathbf{X}$ & $\mathbf{Y}$ \\
\hline 0.03 & $\begin{array}{c}10.07 \\
\text { trace }\end{array}$ & $\begin{array}{r}11.52 \\
0.03\end{array}$ & $\begin{array}{l}27.34 \\
\ldots \ldots\end{array}$ & $\begin{array}{r}31.64 \\
0.25\end{array}$ & $\underset{\text { tracé }}{20.91}$ & 13.52 & $\begin{array}{r}16.49 \\
0.03\end{array}$ & 5.11 & 16.44 & $\cdots$ & 0.34 & $\begin{array}{l}11.69 \\
\ldots \ldots\end{array}$ \\
\hline 1.31 & 32.80 & 31.19 & & 1.30 & 1.31 & 9.01 & trace & 7.74 & 14.04 & 22.11 & 55.08 & 10.64 \\
\hline 67.56 & 20.76 & 19.15 & 30.58 & 8.78 & 25.01 & 10.16 & 21.96 & 19.46 & 12.78 & & & \\
\hline trace & .... & 0.01 & $\ldots \ldots$ & $\ldots$ & trace & $\ldots \ldots$ & $\ldots$ & $\begin{array}{r}22.41 \\
6.33\end{array}$ & & trace & $\cdots \cdots$ & 1.91 \\
\hline trace & …. & …... & $\cdots$ & 1.19 & 1.34 & $\ldots$ & 25.61 & $\begin{array}{r}0.33 \\
\ldots . .\end{array}$ & $\begin{array}{l}24.62 \\
\ldots \ldots\end{array}$ & & & trace \\
\hline ..... & $\cdots \cdots$ & $\ldots$. & $\ldots \ldots$ & $\ldots$. & ..... & $\cdots$ & $\ldots$ & ..... & ..... & 69.62 & 16.62 & ..... \\
\hline ..... & .... & $\cdots \cdots$ & … & … & … & $\cdots$ & $\cdots \cdots$ & $\ldots \ldots$ & $\ldots \ldots$ & $\ldots \ldots$ & $\ldots$ & $\ldots$ \\
\hline & …. & … & …. & $\ddot{0} .24$ & 0.29 & $\ldots$ & …. & … & … & $\ldots \ldots$ & … & $\begin{array}{l}65+2 \\
\ldots \ldots\end{array}$ \\
\hline 1.13 & 7.65 & 32.49 & 7.13 & 2642 & $3 i 34$ & 19.71 & 24.99 & 3.32 & 12.66 & 0.26 & ce & 75 \\
\hline $\begin{array}{l}0.26 \\
0.20\end{array}$ & 3.78 & 1.35 & 8.96 & 1.93 & 2.43 & 1.88 & trace & $\begin{array}{l}0.32 \\
\text { trace }\end{array}$ & $\begin{array}{r}12.00 \\
6.67\end{array}$ & 0.44 & $\begin{array}{r}\text { race } \\
0.57\end{array}$ & 0.59 \\
\hline ..... & 0.10 & $\ldots$ & $\cdots$ & 0.40 & 0.15 & 0.98 & 788 & trace & $\cdots$ & ..... & & ..... \\
\hline 2.54 & 17.50 & 2.23 & 4.25 & 0.11 & 0.17 & $\begin{array}{l}0.20 \\
\ldots . . .\end{array}$ & trace & 30.38 & 8.70 & 3.70 & $\begin{array}{l}2.90 \\
2.91\end{array}$ & 2.30 \\
\hline ..... & $\cdots \cdot$ & 0.01 & $\ldots$. & ..... & ..... & $\ldots \ldots$ & $\ldots \ldots$ & $\ldots$ & .... & ..... & $\ldots$. & ..... \\
\hline 25.03 & 4.09 & 0.65 & 5.89 & 0.04 & 0.17 & 0.08 & trace & 1.21 & 2.70 & 0.50 & 0.55 & 0.34 \\
\hline ..... & ..... & 0.01 & ...... & trace & trace & ..... & ...... & $\ldots .$. & $\ldots .$. & & tra & trace \\
\hline ..... & $\ldots$. & .... & ..... & $\ldots \ldots$ & ..... & $\ldots \ldots$ & $\ldots \ldots$ & $\ldots \ldots$ & $\ldots \ldots$ & 2.17 & 3.47 & $\pi$ \\
\hline ..... & $\cdots$ & 002 & 158 & trace & 013 & & .... & $\cdots \cdots$ & $\cdots$ & ..... & $\cdots$ & 3.98 \\
\hline 0.21 & & & 10.04 & & 0.10 & & $\cdots$ & $\cdots$ & $\cdots$ & $\cdots \cdot$ & … & $\cdots \cdots$ \\
\hline 0.14 & 0.13 & & $\cdots$ & 0.12 & 0.17 & $\ldots$ & 0.40 & …. & …... & & & $\cdots$ \\
\hline 1.79 & $3 i 2$ & trace & ..... & 2758 & 16.58 & 4504 & ? 64 & & & 1.20 & 7.16 & 0.35 \\
\hline 1.19 & 0.12 & 1.04 & ...... & 27.08 & 10.30 & 9.5 .07 & 2.04 & 4.04 & 1.39 & $\ldots \ldots$ & & \\
\hline & $\cdots$ & $\cdots \cdots$ & $\cdots \cdot$ & $\cdots \cdot$ & $\cdots \cdots$ & So 32 & $\cdots \cdots$ & $\cdots$ & $\cdots$ & $\cdots \cdots$ & $\begin{array}{l}12.12 \\
\text { trace }\end{array}$ & 0.06 \\
\hline 100.00 & 100.00 & 100.00 & 10000 & 1000 & 10000 & 10000 & 10000 & 10000 & 1000 & 10000 & 10000 & 100.00 \\
\hline 7.829 & 1.612 & 5.431 & 0.225 & 1.388 & 1.336 & 1.131 & 5.343 & 0.490 & 3.455 & 6.161 & 2.47 & 158.051 \\
\hline
\end{tabular}

another free acid in natural waters.

Gases in a Liter of Pure Water.

\begin{tabular}{|c|c|c|c|c|c|c|}
\hline \multirow{3}{*}{$\begin{array}{l}\text { Absolute amounts } \\
\text { in c. c. per liter }\end{array}$} & $\begin{array}{l}\text { Tem- } \\
\text { pera- } \\
\text { ture }\end{array}$ & $\begin{array}{l}\text { Nitro- } \\
\text { gen }\end{array}$ & $\begin{array}{l}\text { Oxy- } \\
\text { gen }\end{array}$ & Argon & $\begin{array}{c}\text { Carbon } \\
\text { dioxide } \\
\left(\mathrm{CO}_{2}\right)\end{array}$ & Total \\
\hline & $0^{\circ}$ & $18.3^{2}$ & 10. 26 & 0.54 & $0.5 \mathrm{I}$ & 29.63 \\
\hline & $30^{\circ}$ & 10.46 & $5 \cdot 47$ & $0.3 \mathrm{I}$ & 0.20 & 16.44 \\
\hline \multirow{2}{*}{$\begin{array}{c}\text { Percentage of total } \\
\text { absorbed gases } \dagger\end{array}$} & $0^{\circ}$ & 61.8 & 34.6 & 1.8 & I. 7 & 100.00 \\
\hline & $30^{\circ}$ & 63.6 & $33 \cdot 3$ & 1.9 & 1.2 & 100.00 \\
\hline
\end{tabular}

* Compare with table of absorbed gascs in rain water, p. 170. 
The amount of dissolved gases depends directly on the pressure on the water. Thus a lake lying in lowlands contains more dissolved gases than a mountain lake, where the pressure is less. With rising barometer and sinking temperature the upper strata of water of a lake will absorb more gases, while with falling pressure and rising temperature gases will be given off. Change in temperature is, however, more important than change in pressure. With a rise from $0^{\circ}$ to $25^{\circ} \mathrm{C}$. the power of water for absorption of gases decreases from 30 to $40 \%$, while the extremes of pressure bring about a change in absorption of only about $6 \%$. The surface waters of lakes are generally saturated with atmospheric gases, though the presence of living animals and plants and the decay of organic matter tend to disturb the normal balance. In the deeper strata of the waters of lakes the power to absorb gases is much greater, owing to the increased pressure, but as a matter of fact the actual amounts correspond more nearly to those obtained in surface waters during periods of low temperature. This is due to the fact that the deeper waters depend for their atmospheric gases upon the amount furnished them by the upper layers, when supersaturated, this amount being greatest in the cold period; or upon the amount carried down to the deeper strata by surface waters acting as convection currents, when the temperature of the surface has sunk to that of the deeper strata. In the deeper strata of lake waters a deficit in oxygen and an increase in $\mathrm{CO}_{2}$ may further develop through the physiological activities of bottom organisms or the decay of organic matter. This change is less marked in surface waters, owing to the balancing effect of chlorophyll-bearing plants, which are absent in the deeper waters. (See Chapter XI.)

From the tables above given it is clear that the proportion of oxygen to nitrogen is much higher in the absorbed air of water than in the normal atmosphere. The latter has $2 \mathrm{I}$ parts of oxygen to 78 parts of nitrogen, the proportion being in round numbers as $1: 4$. In the absorbed air of pure fresh water the proportion of $\mathrm{O}$ to $\mathrm{N}$ at $\mathrm{O}^{\circ}$ is as $34.6: 6 \mathrm{r} .8$, and at $30^{\circ}$ as $33.3: 63.6$, or, in round numbers, in either case as $\mathrm{I}: 2$. In applying this fact, however, to the available oxygen for aqueous plant and animal life, it must be borne in mind that, though the proportion of oxygen to nitrogen is greater in water than in air, the absolute amount of oxygen per liter of the medium in which the organism breathes is vastly greater in air than in water, being $210 \mathrm{c}$. c. for each liter of air, and only Io c. c. for each liter of water.

Organic Matter. This is present in solution in many waters, especially those of rivers and lakes. Calculated in percentages of 
total solids, we find that it rises in some of the tropical streams to more than fifty per cent. The variation is shown in the following table $($ Clarke $-4: 83)$ :

Table of Organic Matter in Various Streams in Percentages of the Total Solids.

\begin{tabular}{|c|c|c|}
\hline Dant:be............ & 3.25 & Amazon... \\
\hline James............. & $4 \cdot 14$ & Mohawk. \\
\hline & $4 \cdot 55$ & e.......... \\
\hline & 10.36 & Neagh, Ireland.... 16.40 \\
\hline & I 1.42 & a............. 20.63 \\
\hline & I I 93 & .. 24.16 \\
\hline Cur & 12.08 & ... 49.59 \\
\hline Than & 12.10 & $\ldots .53 .89$ \\
\hline Genesee............. & 12.80 & Uruguay.......... 59.90 \\
\hline
\end{tabular}

In the tropical streams at the end of the list the high perceniage is due to the contributions formed by tropical swamps through which they flow. Lough Neagh, Ireland, derives its organic matter in part from peat bogs.

Among the vegetable acids present are Humic acid $\left(\mathrm{C}_{20} \mathrm{H}_{10} \mathrm{O}_{6}\right)$, Geic acid $\left(\mathrm{C}_{20} \mathrm{H}_{12} \mathrm{O}_{7}\right)$,* and Ulmic acid $\left(\mathrm{C}_{20} \mathrm{H}_{14} \mathrm{O}_{6}\right)$,* derived from peat or soil richly charged with decaying vegetation. They form various compounds or salts, such as ammonium humate, sodium and potassium humates, calcium humate, magnesium humate, ferric humate, etc. The alkaline salts are easily soluble in water, but those of the alkaline earths and metallic oxides are not soluble or only with great difficulty, but these are soluble in aqueous alkalies, especially ammonia and its carbonate. Humic acid itself dissolves in 8,333 parts of water at $6^{\circ} \mathrm{C}$. and in 625 parts at $100^{\circ} \mathrm{C}$. It is insoluble in water free from nitrogen or air. Among the products of higher oxidation of these acids are the more soluble crenic acid $\left(\mathrm{C}_{24} \mathrm{H}_{30} \mathrm{O}_{19}\right.$ Wurtz $)$, or Quellsäure, and apocrenic acid $\left(\mathrm{C}_{24} \mathrm{H}_{14} \mathrm{O}_{13}\right.$ Wurtz), or Quellsalzsäure. The former occurs in the waters of probably all springs, rivers, lakes, etc., and in rain water, rotten wood, peat, and tilled soil, and in bog ore, ochre, etc. It is easily soluble in water; its alkali salts (ammonium crenate, etc.) are, however, soluble to a less degree. Some of the salts of the alkalinc earths (calcium crenate) require much water, while others (magnesium crenate) are easily soluble. The salts of metals are insoluble (aluminium crenate, ferric crenate) or slightly soluble (ferrous crenate, manganese crenate). Apocrenic acid also occurs in the

* Formulas according to Mulder, others give different formulas. (See Julien17, 310.) 
waters of springs and rivers, and in tilled soil, peat, decaying wood, and bog ores; it easily dissolves in water. The salts of the alkalies and alkaline earths are soluble, the latter to a less degree. Some of the apocrenates of the metals are soluble, others insoluble.

The solvent action of these acids on siliceous rocks is of considerable importance. Humic acid is said to decompose silicates. The various humous acids absorb nitrogen from the air and form azohumic acids, which, in the presence of alkaline carbonates, are capable of dissolving silica, especially when it is in the amorphous state, though even quartz is corroded. From this it follows that a stream well supplied with these organic acids may acquire a high percentage of silica in solution, unless the solvent power is neutralized in some way. Since tropical streams carry the highest per cent. of organic matter they are likely to be rich in dissolved silica. Thus the Uruguay River, with $59.9 \%$ of the total solids as organic matter contains $46.22 \%$ of the remainder, or $18.53 \%$ of the whole, of $\mathrm{SiO}_{2}$, though the total salinity (inorganic) is only 0.04 permille. In the St. Lawrence, along the borders of which "the granite of the main and islands is almost everywhere covered with peat, full of stagnant ponds of dark bog water" (Hunt), $\mathrm{SiO}_{2}$ forms $23 \%$ of its total dissolved inorganic matter, while the Ottawa, which "drains a region occupied chiefly by crystalline rocks, covered by extensive forests and marshes" (Hunt-I6: I26; Julien-I 7:333), has 33.7\% of its total dissolved inorganic matter as $\mathrm{SiO}_{2}$.

\section{Chemical Work of the Natural Waters.}

The chemical work of the natural waters is chiefly that of the ground water, and is primarily confined to that zone or belt within the earth's crust which is permanently occupied by this water, i.e., that zone extending from the level of the ground water or the water table to the greatest depth to which such water extends. This belt, for which Van Hise estimates the great depth of 10,000 or 12,000 meters, but which others believe to be much less (see ante), constitutes the belt of cementation, in contradistinction to the belt of weathering, which forms the upper zone of the lithosphere above the level of the ground water. In this latter belt the activities are largely those of the atmosphere, but the ground water in passing through it also performs a considerable amount of both chemical and mechanical work, of which solution is the most pronounced.

The chief chemical processes going on in the belt of cementation are solution and redeposition, hydration, carbonation and oxida- 
tion. Reduction or deoxidation may also go on at times, and so may decarbonation and silication. Solution is less characteristic than in the belt of weathering, while deposition becomes of the greatest significance. Hydration and carbonation are important reactions, but oxidation is confined to the upper layers.

Solution. This is most active in the belt of weathering. Limestone, gypsum, and salt beds are dissolved by the underground water, with the production of caverns sometimes of very limited duration. The rate of solution may be estimated from the amount of dissolved matter discharged by the springs of a given region, and some data are available for this determination. Thus the warm springs of Bath, England (mean temperature of $120^{\circ} \mathrm{F}$.), discharge annually a quantity of dissolved sulphates of calcium and sodium, and chlorides of sodium and magnesium, sufficient to make a square column of mineral matter 9 feet in diameter and 140 feet high (Ramsay, quoted by Geikie-10:477). The St. Lawrence spring at Louèche, Switzerland, discharges every year I,620 cubic meters $(2,127$ cubic yards $)$ of dissolved sulphate of lime, which is equivalent to lowering a bed of gypsum one square kilometer (0.386I square miles) in extent, more than 16 decimeters (upward of 5 feet) in a century (Reclus; Geikie-10: 477). It is estimated that the Solnhofen limestone is reduced $\mathrm{I}$ meter in thickness in 72,000 years (Pfaff), and that of the Nittany Valley 1 meter in 30 ,ooo years (Ewing-6:31). T. Mellard Reade has calculated that throughout the entire globe there is removed annually in solution 96 tons (about 86 metric tons or tonneaux) of material per square mile, divided as follows: Calcium carbonate, 50 tons (45 tonneaux) ; calcium sulphate, 20 tons ( 8 tonneaux); sodium chloride, 8 tons ( 7.2 tonneaux) ; silica, 7 tons ( 6.3 tonneaux) ; alkaline carbonates, and sulphates, 6 tons ( 5.4 tonneaux); magnesium carbonate, 4 tons ( 3.6 tonneaux) ; oxide of iron, $I$ ton ( 0.9 tonneaux) (quoted by Van Hise-4I : 486).

The rate of solution is strongly influenced by the temperature of the solvent. "At temperatures above $100^{\circ} \mathrm{C}$., and especially above $185^{\circ} \mathrm{C}$., the activity of water may increase to an amazing degree." (Van Hise-4I : 79.) It thus follows that solvent action of water is greater at the equator than in the arctic regions, where it is practically at a standstill when the temperature is below $0^{\circ} \mathrm{C}$. Solution at any temperature goes on until saturation is reached, which is much sooner at high than at low temperatures.

Through continued solution extensive underground channels and grottos are produced within the upper zone of the earth's crust in limestone regions. The presence of these is marked on the surface 
by sink-holes, and sometimes by depressions filled intermittently with water. That all large caverns are the result of solution of solid limestone masses has been seriously questioned. Walther ( $42: 560$ ) has called attention to the fact that large dome-like chambers are commonly found in reef-like masses of limestone and that these are covered with stalactic deposits, showing that deposition and not solution has been active here for a long period of time. He suggests that many of these may be original hollows in the reef masses, such as are known to occur in structures of this type.

No minerals are wholly insoluble in the ground water solutions, even quartz, the most resistant, being at times attacked by moisturecarrying solvents. (Hayes-I4.)

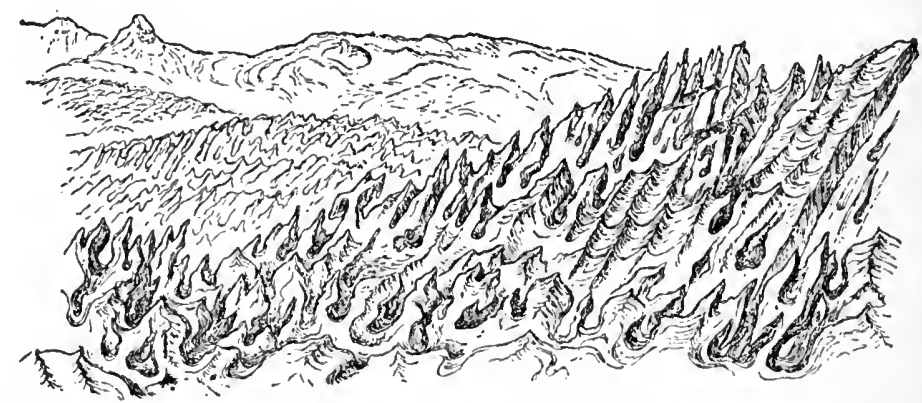

Fig. 25. Karren or lapiaz (rascles) topography of the Sentis formed by solution by surface streams on a limestone plateau. (After Heim.)

While solution is most characteristic of the belt of weathering, it is, nevertheless, not confined to it. Active solution goes on in the belt of permanent ground water, but it is here balanced by equally active deposition. Streams and rain water form a rough solution topography on limestone plateaus. These are illustrated by the Karren or lapiaz of the Sentis. (Fig. 25.)

Cementation. This is of equal importance with solution in the belt of cementation, forming one of the characteristic processes of this belt. It is practically unknown in the belt of weathering. The material deposited is largely derived from the belt of weathering, and the result of such deposition is the partial closing of the pore spaces in the rock below the level of ground water. The expansion of the minerals on hydration further tends to close up these pores. The ultimate result of these processes will be the induration 
or lithification of the rock masses. (See the section on diagenesis of rock masses, Chapter XIX.)

Not only are the pores in the rock masses filled, but fissures are closed up by the formation of mineral veins. Large cavities, either originally due to some disturbance, or solution-caves, brought into the belt of cementation by a rise of the ground water level, will be slowly filled by crystallized mineral matter. In the lead and zinc district of Missouri such caverns were slowly filling with crystals of calcite before the last change in ground-water level. These crystals have the form of huge scalenohedrons, some of them half a meter or more in length, and they project from the walls in the manner of crystals from the walls of a geode. The ordinary deposits of caverns, stalactites and stalagmites, characteristic of the zone of weathering, are wholly absent from these caverns, which were but recently exposed, by the lowering, through pumping, of the ground-water level, from a few meters to a depth of 45 to 60 meters (Van Hise$41: 565)$.

The temperature of the water within the belt of cementation may be greatly raised by the presence of masses of hot igneous rock, the time of cooling for which is much greater than that required at the surface. The juvenile waters given off by such lava sheets are likewise in a highly heated state, and so accomplish much solution.

Hydration. This is the chief reaction in the belt of cementation, and is second in importance only to deposition or cementation. Since water is everywhere present, the minerals are constantly exposed to it, and hydration as well as solution must result. It is in this belt that the great group of hydrous silicates and oxides, such as the hydromicas, chlorites, zeolites, serpentine, epidote, limonite, and gibbsite form most abundantly. Kaolin and talc also form here, though they are more characteristic of the belt of weathering. Gypsum is altered to anhydrite, in the belt of weathering, whereas hydration may change anhydrite to gypsum. The change in the process of hydration involves an increase in volume of from 30 to $5^{\circ}$ per cent.

Oxidstion. Water entering the soil commonly carries oxygen in solution, the amount varying with the porosity of the soil, lack of vegetation, atmospheric pressure, etc. Oxidation goes on throughout the belt of weathering, but affects only the upper layers of the permanently saturated belt, for the supply of oxygen is quickly exhausted, and its replenishing is a slow process. Normally the depth below ground-water level to which oxidation is restricted is not more than a few meters, but in exceptional cases this may go much far- 
ther. Thus in the Lake Superior mining region it has gone to a depth of Ioo meters on an extended scale, while in a few exceptional cases the depth affected has been 500 to 700 meters. In the San Juan district of Colorado it is marked at a depth of 600 meters, and occasionally is noted at $\mathrm{I}, \mathrm{OOO}$ meters. In the Missouri-Kansas lead and zinc district, on the other hand, oxidation scarcely extends beneath the level of ground water.

In the belt of weathering, and to some extent in that of cementation, hematite and limonite are the common products of oxidation of iron compounds. Throughout the remainder of the belt where oxidation occurs, magnetite is the common product of oxidation of iron, since this requires a smaller amount of oxygen in its production. Oxidation of the sulphur of pyrite and marcasite produces a ferrous sulphate of ferric oxide, and sulphuric acid, in the belts where oxygen is abundant. In the major part of the belt of cementation, where oxygen is not abundant, magnetite and sulphurous acid are more likely to be formed.

The oxidation of organic matter produces carbon dioxide and water, which join the circulating ground-water, producing carbonates in the belt of cementation. When the oxygen is all exhausted, organic and other compounds may be taken into solution, and so give the waters a reducing quality. Waters which have made long underground journeys are especially likely to be in this state. Oxidation of carbonates, and the liberation of $\mathrm{CO}_{2}$, may cause a considerable decrease in volume, amounting in some instances to 50 per cent. This may counterbalance the increase from oxidation of inorganic compounds, which, in some cases, is as much as 64 per cent. (Van Hise-4I : 608.)

Carbonation. Carbon dioxide is produced in abundance in regions of luxuriant vegetation, through the oxidation of the carbon, and hence the waters entering the soil here will be rich in $\mathrm{CO}_{2}$, but poor in oxygen. Conversely, in regions of little vegetation carbon dioxide will be lacking, but oxygen may be carried in considerable quantity by the water sinking into the ground. If this water encounters buried carbon in the form of coal beds or of other types, the oxygen will be used up and carbon dioxide produced. The same result is caused by the decomposition of carbonates in the zone of cementation. Carbon dioxide is also produced in enormous quantities in the zone beneath the ground water (the zone of anamorphism, see Chapter XIX) by silication or the union of silicic acid with the bases of the carbonate rocks, and the simultaneous liberation of the $\mathrm{CO}_{2}$ (Van Hise-4I).

The process of carbonation, or the union of $\mathrm{CO}_{2}$ with bases, 
within the belt of cementation is a slow one, and much of the $\mathrm{CO}_{2}$ therefore remains unused and issues again on the surface. The mineral springs of the Auvergne district of France alone furnish an amount of $\mathrm{CO}_{2}$, estimated by Lecoq at 7,000,000,000 cubic meters per year, and these represent only a small fraction of the carbonated waters of the world. Carbonation, or the production of carbonates, is, on the whole, one of the most important chemical reactions within the zone permanently occupied by the ground water.

\section{DENSITY AND SPECIFIC GRAVITY OF THE HYDROSPHERE.}

Pure water (distilled) has its greatest density at a temperature of $4^{\circ} \mathrm{C}$., and this is taken as the unit of measurement, or I. (Its salinity is $\circ$, and this may be expressed by $\mathrm{S}^{\prime}$, while that of any other water is expressed by S.) The addition of dissolved substances increases the density of the water, which in the case of normal sea water of 35 permille salinity ( $35 \mathrm{gr}$. of salts in $1000 \mathrm{gr}$. of sea water) at $0^{\circ} \mathrm{C}$. becomes $\mathrm{r} .02812$. This is expressed by the following formula: $\frac{\mathrm{S} 0^{\circ}}{\mathrm{S}^{\prime} 4^{\circ}}=\frac{\mathrm{I} .028 \mathrm{I} 2}{\mathrm{I}}=\mathrm{I} .028 \mathrm{I} 2$, where $\mathrm{S} 0^{\circ}$ represents the density of the water in question at $0^{\circ} \mathrm{C}$. and $\mathrm{S}^{\prime} 4^{\circ}$ that of pure water at $4^{\circ} \mathrm{C}$. For convenience sake we may transform the above formula into: $1000\left(\frac{\mathrm{S}^{\circ}}{\mathrm{S}^{\prime} 4^{\circ}}-\mathrm{I}\right)$, and express the result by the symbol $\sigma_{0}$. Thus for normal sea water of 35 permille salinity $\sigma_{0}=28$. I 2 , while, if the salt were $\mathrm{NaCl}$ only, $\sigma_{0}$ would be 26.67 . If wholly $\mathrm{MgSO}_{4}, \sigma_{0}$ would equal 36.94 . The general formula is $\sigma_{\mathrm{t}}=1000\left(\frac{\mathrm{S} \mathrm{t}^{\circ}}{\mathrm{S}^{\prime} 4^{\circ}}-\mathrm{I}\right)$ where $\mathrm{t}=$ the temperature at which the density of the water in question is taken. For sea water where $\sigma_{0}=28^{*}, \sigma_{4}=27.68, \sigma_{15}=$ $25.87, \sigma_{15.5}=25.76$ (approx.), $\sigma_{25}=23.24 .15^{\circ}$ is the temperature for which the hydrometers used in foreign laboratories are usually graduated, while those of English and American use are graduated for $60^{\circ} \mathrm{F}$. $\left(15.56^{\circ} \mathrm{C}\right.$.). Many of the newer instruments are arranged for the more usual temperature of laboratories, which is $25^{\circ} \mathrm{C}$. or $77^{\circ} \mathrm{F}$. For the same temperatures, distilled water has the following densities: $0^{\circ}$ C. $\left(32^{\circ} \mathrm{F}\right.$. $) 0.99987,4^{\circ} \mathrm{C}$. $\left(39.20^{\circ} \mathrm{F}\right.$. $)$ r. $00000,15^{\circ} \mathrm{C}$. $\left(59.00^{\circ}\right.$ F.) $0.99913,25^{\circ}$ C. $\left(77^{\circ}\right.$ F.) 0.99707 . (See the table given in Krümmel-20, $23^{2-233}$.) When the salinity is known $\sigma_{0}$ may be

${ }^{*} 28$ instead of 28.12 is used, since the tables of Knudsen given by Krümme ${ }^{1}$ are not calculated for decimal values of $\sigma_{0}$. 
calculated from the following formula devised by Martin Knudsen (Krümmel-20, 237), where $\mathrm{S}$ represents the salinity in permille. $\sigma_{\mathrm{o}}=-0.093+0.8149 \mathrm{~S}-0.000482 \mathrm{~S}^{2}+0.0000068 \mathrm{~S}^{3}$

According to this formula the density of the waters of the Karabugas Gulf, which has a salinity of 285 permille, should be $\mathrm{x} .353329$ at $0^{\circ} \mathrm{C}$. or $\sigma_{0}=353.329$, though since the salts are not those of normal sea water this figure is not wholly correct. While the maximum density of distilled water ( $\mathrm{I}$ ) is at $+4^{\circ} \mathrm{C} .\left(+3.947^{\circ} \mathrm{C}\right.$.), i. e., a density when $\sigma_{\theta}=0.00$, that of sea water of different concentration varies greatly.

The temperature at which any given water is at its greatest density may be designated $\theta^{\circ}$. Substituting this in the general formula we have $\sigma_{\theta}=1000\left(\frac{S_{\theta}-I}{S^{\prime} 40}\right)$. When the salinity is 35 permille, $\theta^{\circ}$ equals $-3.524^{\circ} \mathrm{C}$, , and $\sigma_{\theta}=28.22$ as compared with $\sigma_{0}=28 . \mathrm{I} 2$.

\section{Variation in Osmotic Pressure in Sea Water.}

By osmotic pressure is meant that pressure which causes diffusion between the solution of a substance and its solute, or between solutions differing in concentration. It varies directly with the concentration of the solution, and increases with the temperature. Thus for Baltic water with a salinity of $7.5 \%$, at a temperature of $18^{\circ} \mathrm{C}$. the osmotic pressure is 4.9 atmospheres; in water of the Red Sea, with $40 \%$ salinity and a temperature of $30^{\circ} \mathrm{C}$, it is 26.7 atmospheres. Normal sea water with a salinity of $35 \%$ has an osmotic pressure of 23.12 atmospheres at $0^{\circ} \mathrm{C}$. For water of $\mathrm{I} \%$ salinity at $0^{\circ} \mathrm{C}$. the osmotic pressure is 0.66 atmosphere (Krümmel= 20 , table, p. 24I). In general for each increase of one permille of salinity there is an increase of $2 / 3$ atmosphere in osmotic pressure, equivalent to the pressure of a mercury column $500 \mathrm{~mm}$. long.

Osmosis may be considered either as Exosmosis, or that tendency of the fluid within a submerged body to pass into the surrounding fluid, and Endosmosis, the tendency for the outer fluid to pass into the space occupied by the inner; or that action of the fluid which passes with greater rapidity into the other. The effect on organisms of the different osmotic pressures is very marked. Thus a frog placed into sea water loses, by exosmosis, which commences at once, a considerable quantity of water, and in a short time its weight is diminished by one-fifth. On the other hand, a salt-water fish placed suddenly into fresh water suffers through rapid increase by endosmosis of the water in its body, which results in swelling and death. 
(Regnard-28:437.) A direct passage of organisms from the fresh waters to the sea or the reverse is thus attended with great dangers to the organisms, and can be safely accomplished only through the intracontinental waters of intermediate salinity.

\section{TEMPERATURE OF THE HYDROSPHERE.}

\section{Freezing Point of Water.}

The freezing point of pure water is $0^{\circ} \mathrm{C}$. or $32^{\circ} \mathrm{F}$. With addition of salts the freezing point is lowered as shown in the following table, condensed from Krümmel (20:24I).

Salinity I permille, freezing point............. $-0.055^{\circ} \mathrm{C}$.

Salinity 5 permille, freezing point......................

Salinity 10 permille, freezing point............... $534^{\circ} \mathrm{C}$.

Salinity 15 permille, freezing point............

Salinity 20 permille, freezing point .............

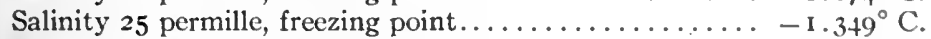

Salinity 30 permille, freezing point..............

Salinity 35 permille, freezing point..............

Salinity to permille, freezing point.............

Ordinary sea water of 35 permille salinity will therefore freeze at a temperature of $-\mathbf{r} .9^{\circ} \mathrm{C}$. or $+28.58^{\circ} \mathrm{F}$. when its density $\left(\sigma_{t}\right)$ is 28.2I. According to the formula given by Krümmel, the surface water of the Black Sea, with a salinity of 18.5 permille, will freeze at a temperature of $-0.99^{\circ} \mathrm{C} .\left(+30.2^{\circ} \mathrm{F}.\right)$, that of Behring Sea (3o permille) at $-\mathrm{r} .6^{\circ} \mathrm{C}$. $\left(+29.12^{\circ} \mathrm{F}\right.$.), while the water of the Baltic ( 7.8 permille) would freeze at about $-0.4^{\circ} \mathrm{C} .\left(+3 \mathrm{I} .28^{\circ} \mathrm{F}\right.$.) If $\sigma_{\circ}$ is known (see formula p. 180) then the freezing point $\tau$ of water may be calculated according to the following empirical formula devised by $\mathrm{H}$. J. Hansen of Copenhagen (Krümmel-20:240).

$$
\tau=-0.0086-0.064633 \sigma_{\circ}-0.0001055 \sigma_{0}{ }^{2}{ }^{*}
$$

According to this formula the waters of the Karabugas Gulf where $\sigma_{0}=353.329$ would freeze at a temperature of $-36.016^{\circ} \mathrm{C}$ or $-32.836^{\circ} \mathrm{F}$. if it were of the composition of normal sea water.

\section{Heat Capacity of Water.}

The heat required to raise a gram of pure water from $14.5^{\circ}$ to $\mathrm{r} 5.5^{\circ} \mathrm{C}$. is the unit of measurement of the heat capacity or specific heat of water, and is called the small calorie or gram-calorie. Saline waters have a smaller heat capacity than pure water, i. e., it takes less heat to raise a gram one degree. The following table is given

* The formula as printed in Krümmel is incorrect, the second term of the right-hand member is there given as $0.0064633 \sigma_{0}$. 
by Krümmel for the heat capacity of waters of different salinity at $17.5^{\circ} \mathrm{C} .(20: 279)$ :

\begin{tabular}{r|r|r|r|r|r|r|r|r|r}
\hline Salinity in permille.... & o & 5 & 10 & 15 & 20 & 25 & 30 & 35 & 40 \\
\hline Heat capacity........ & 1 . 000 & 0.982 & 0.968 & 0.958 & 0.95 & 0.945 & 0.939 & 0.932 & 0.926 \\
\hline
\end{tabular}

Warming of the Water Body. The heat conductivity of water is very low. It has been calculated that a mass of water 5,000 meters deep, and of a uniform temperature of $0^{\circ} \mathrm{C}$., would, if in contact with a heat source of $30^{\circ} \mathrm{C}$. at the surface, experience the following rate of warming. providing no other factor, such as convection currents, etc., entered in: In Ioo years no appreciable increase in temperature would be found at a depth of 100 meters; in 1,000 years not one per cent. of the surface warmth is to be found at a depth of $300 \mathrm{~m}$., while it takes 10,000 years to carry this fraction of the surface warmth to a depth of $\mathrm{I}, 000 \mathrm{~m}$., and one million years to carry it to a depth of $4.900 \mathrm{~m}$. After I,000 years the temperature at a depth of $100 \mathrm{~m}$. will be $7.3^{\circ} \mathrm{C}$., while at $200 \mathrm{~m}$. it will be only $0.6^{\circ} \mathrm{C}$. The temperature of $15^{\circ} \mathrm{C}$. descends in a half year I.3 meters, in a year $1.85 \mathrm{~m}$., in io years $5.8 \mathrm{~m}$. Thus daily or yearly variation of temperature is of little significance for great depths so far as conductivity of water is concerned.

Warming of the water is, however, produced by the absorption of the sun's rays, which penetrate to a certain depth, and through vertical convection currents. The latter are in part due to the evaporation on the surface and the consequent increase in density, which brings about a readjustment between the denser surface and the lighter, deeper waters. In the tropical waters of the Indian Ocean the average evaporation during the day is $1 / 4$ to $T / 3 \mathrm{~mm}$. per hour, which, for a surface layer of $\mathrm{I} \mathrm{mm}$., with a temperature of $26^{\circ} \mathrm{C}$. and a salinity of 35 permille at the beginning, would result in an increase of 13 to 16 permille at the end of the hour, or an increase in density from 1.023 to 1.033 , or 1.037 , which would cause this water to sink, carrying with it its temperature of $26^{\circ}$. Of course, the water begins to sink long before it has reached that density, in fact, as soon as it becomes slightly heavier through increased salinity.

Average Surface Temperature. The average temperature of the surface of the oceans varies from $-1.7^{\circ} \mathrm{C}$. at the poles to $27.4^{\circ} \mathrm{C}$. at $5^{\circ} \mathrm{N}$. latitude, the latitude of maximal surface temperature. It varies in the different oceans, where the maximum is $26.83^{\circ} \mathrm{C}$. in the Atlantic, $27.88^{\circ} \mathrm{C}$. in the Indian, $27.20^{\circ} \mathrm{C}$. in the Pacific. In all 
cases there is an abrupt increase between $45^{\circ}$ and $35^{\circ}$ both north and south latitude, where the temperature is sometimes nearly doubled in going toward the equator. Of course, the surface temperature is not divisible into a series of regular zonal belts, but is in reality quite irregularly distributed owing to the influence of currents, etc. Considering arerage surface temperatures as a whole, it appears that the Pacific is the warmest of the four oceans, its mean being $19 . \mathrm{I}^{\circ} \mathrm{C}$., whereas the mean of the Atlantic is only I6.9 ${ }^{\circ} \mathrm{C}$. The mean of the Indian Ocean is only $\mathrm{I} 7^{\circ} \mathrm{C}$. in spite of its high maximum of $27.88^{\circ}$. The Pacific is the great tropical ocean, so far as surface temperatures are concerned. owing to its great expanse in the equatorial region, where the Atlantic experiences its greatest contraction. Of the total surface of the Pacific 59.5 per cent., or about $3 / 5$, lies between $30^{\circ} \mathrm{N}$. and $30^{\circ} \mathrm{S}$. latitucle. This is well brought out by the wide distribution of coral reefs in the Pacific as compared with their occurrence in the Atlantic Ocean ; these reefbuilding coral polyps being confined to relatively shallow waters. A similar difference is shown in the temperature of the air over the two oceans, as noted by von Tillo, who found the temperature of the air over the Atlantic $2.6^{\circ}$ lower than that over the Pacific. As will be noted later, the waters of the Atlantic, taken as a whole, are warmer than those of the other oceans.

Vertical Variation of Temperature. As has been noted above, the heat conductivity of water is very low, and were it not for the absorption of the sun's rays by the deeper strata of water, and the existence of vertical convection currents, there would be little change in the temperature of the deeper waters. Krïmmel has introduced terms to designate the downward changes in temperature, for all heterothermal water bodies, $i . e$., those in which the temperature is not uniform throughout, or homothermal. When the temperature of the water decreases downward we have the anothermal arrangement which normally prevails in the open ocean and in some intracontinental seas of low latitudes; when, on the other hand, it increases downward, we have the katothermal arrangement. which is generally associated with a katohaline state. This condition exists in the intracontinental seas of higher latitudes during winter. A dichothermal arrangement, with a colder stratum between warmer upper and lower strata, is characteristic of such scas during the summer months, while the reverse, a mesothermal arrangement. with warmer strata enclosed between upper and lower coller layers. is found in polar waters, and may even extend into the other oceans.

In the anothermal arrangement of the ocean waters the decrease is, in general, comparatively rapid and uniform for the first $5^{\circ 0}$ 
fathoms ( 915 meters) or more, after which the rate of decrease becomes a slower one. Thus the Challenger Expedition found at one of its stations in the South Atlantic ( $35^{\circ} 59^{\prime}$ S., $1^{\circ} 34^{\prime}$ E.) a drop from $13.4^{\circ}$ to $\mathrm{I} 3.0^{\circ}$ in the first 100 fathoms, $i$. e., a decrease of only $0.4^{\circ}$ then a rapid drop to about $4.5^{\circ} \mathrm{C}$. at 400 fathoms, or a decrease of about $8.5^{\circ}$ in 300 fathoms, after which the decrease was a slow one again to nearly $2^{\circ}$ at 1.500 fathoms, or $6.5^{\circ}$ in 1,100 fathoms (Fig. 26). In general, the temperature of the deeper

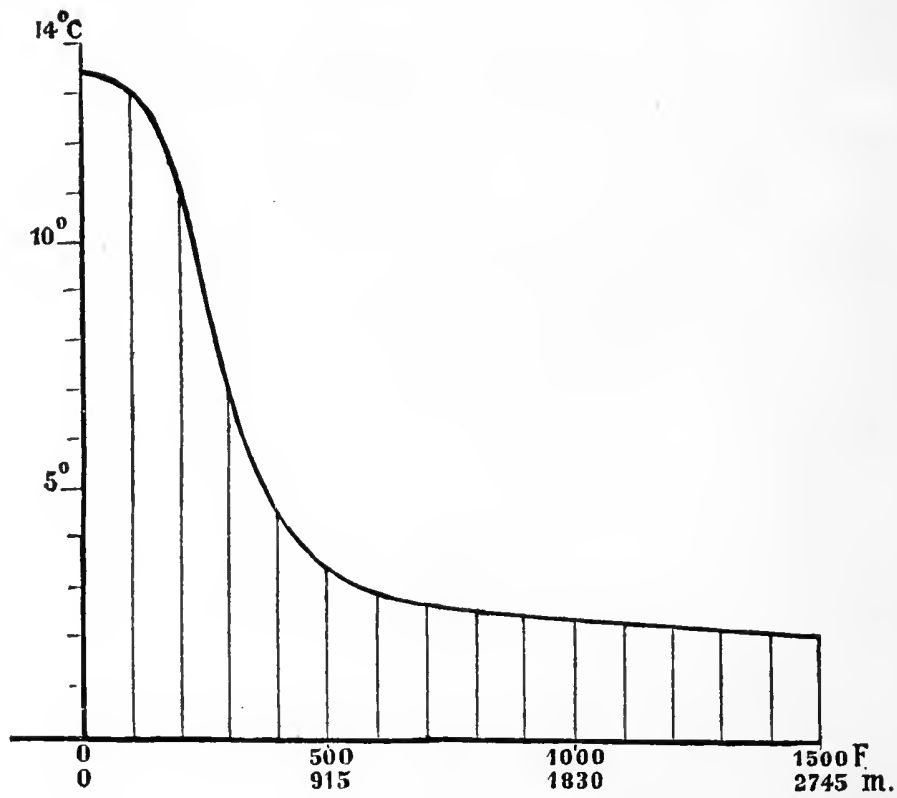

Fig. 26. Diagram illustrating the rate of decrease of temperature from the surface to 1,500 fathoms. Challenger station, South Atlantic, $35^{\circ} 58^{\prime}$ S. I ${ }^{\circ} 34^{\prime}$ E. (After Krümmel.)

parts of the oceans becomes relatively uniform below I,O0O meters, so that where the average depth is $4,000 \mathrm{~m}$. only the upper $1 / 4$ is affected. The other $3 / 4$ of the ocean are generally below $3^{\circ} \mathrm{C}$., and near the bottom the temperature, even in many parts of the tropics, is but little above $\mathrm{o}^{\circ} \mathrm{C}$.

\section{Temperature of the Sea.}

Horizontal and Vertical Distribution of the Temperature in the Three Great Oceans. Leaving the Arctic Ocean for sep- 
arate consideration, we must first note the principal sources of the hot and cold waters of the three great oceans, and then note their distribution. It need scarcely be repeated that the chief source of warm waters is the sinking warm surface water of the tropical regions of the ocean. The chief source of the cold waters, especially in the deeper parts, must be sought in the antarctic extensions of the three great oceans, though the cold waters of the Arctic Ocean to a considerable extent modify the surface layers of the North Atlantic and North Pacific.

The cooling of the surface waters of the antarctic extensions and the formation of ice, with the corresponding extrusion of the salts, greatly increase the density of the water, which will sink and carry the low surface temperatures with it. The following temperatures have been recorded for the antarctic extensions of the three great oceans, showing in each case a mesothermal arrangement. In the Atlantic at $61^{\circ} \mathrm{S}$. latitude off the coast of South America $\left(63^{\circ} \mathrm{W}\right.$. long.) the Belgica found surface temperatures of $+3.2^{\circ} \mathrm{C}$, which at 75 meters depth had fallen to $-\mathrm{I}^{\circ} .0$ and at $\mathrm{I} 25$ meters to the coolest, $-\mathrm{r} .4^{\circ} \mathrm{C}$. Rising beyond this the temperature reached $+0.4^{\circ} \mathrm{C}$. at 175 meters, $+1.9^{\circ}$ between 500 and $\mathrm{I}, 000$ meters, and then fell again to $+0.6^{\circ} \mathrm{C}$. at the bottom, 3.690 meters. At the other side of the Atlantic, in $70^{\circ} 30^{\prime}$ south latitude, off the South African coast $\left(94^{\circ} \mathrm{W}\right.$. long.), the same vessel found surface temperatures of $-1.8^{\circ} \mathrm{C}$., which increased downward more or less regularly to $+0.3^{\circ}$ at 175 meters, and to $+1.7^{\circ} \mathrm{C}$. at 400 meters, after which it decreased to the bottom ( 1,750 meters), where it was $+0.8^{\circ} \mathrm{C}$. In the antarctic extension of the Indian Ocean the Gauss found at $6512^{\circ}$ S. lat., $851^{1}{ }^{\circ}$ E. long. surface temperatures of $-1.80^{\circ} \mathrm{C}$., increasing to $-1.75^{\circ} \mathrm{C}$. at 75 meters, and then decreasing again to $-1.90^{\circ}$ C. between 175 and 200 meters. This is followed by an increase to $+0.35^{\circ}$ at $\mathrm{r}, 000$ meters, and a decrease to $-0.20^{\circ}$ at the bottom of 2,821 meters. At $62^{\circ} \mathrm{S}$. lat. and $56^{\circ} \mathrm{E}$. long. the Valdivia found surface temperatures of $-1.0^{\circ}$ decreasing to $-1.6^{\circ}$ at 75 meters depth, and rising again more or less regularly to $+\mathrm{I} .7^{\circ}$ C. at $300 \mathrm{~m}$. After this a decrease with some irregularity to $-0.4^{\circ}$ C. at 4,636 meters occurs. For the Pacific. the Belgica found at $6 \mathrm{I}^{\circ} \mathrm{S}$. lat. and $63^{\circ} \mathrm{W}$. long. surface temperatures of $-1.8^{\circ} \mathrm{C}$., increasing downward, though witl some irregularity, to $+1.7^{\circ} \mathrm{C}$. at 400 meters, after which a slow decrease followed to $+0.8^{\circ} \mathrm{C}$. at the bottom, of I,750 meters.

Turning, now, to the intercontinental portion of the three great oceans, we find that the temperature distribution in the upper IOo meters is largely affected by the seasonal variations, which for the 
surface are shown by the isobars of February and August on temperature maps. At a depth of 100 meters the surface influence is still visible to some extent. The Indian and West Pacific are strongly contrasted with the Atlantic. The zone of temperatures exceeding $25^{\circ} \mathrm{C}$. comprises the West Pacific, west of $125^{\circ} \mathrm{W}$. long. and between $18^{\circ} \mathrm{N}$. and $\mathrm{S}$. lat., and continues through the Banda and Flores seas into the Indian, extending northwestward to Ceylon, and westward beyond the Maldives (to $65^{\circ} \mathrm{E}$. long). In the Atlantic, on the other hand, only a small area in the Brazilian current reaches this mean temperature. Along the whole western border of tropical America, as well as tropical Africa, the temperature of the water does not rise above $20^{\circ} \mathrm{C}$. at a depth of Ioo meters, though higher temperatures exist at the surface. No temperatures of $0^{\circ}$ are known at a depth of Ioo meters in the North Atlantic or North Pacific, except at the south end of Greenland and in Denmark and Davis Straits and close to the southeast coast of Kamtchatka, where the cold currents enter from the Arctic. In Davis Straits, near the Arctic circle, the surface temperature varies from $+1.15^{\circ} \mathrm{C}$. to $+2.6^{\circ} \mathrm{C}$., whereas in Denmark Straits the surface temperature as well as that at 100 meters is $-0.7^{\circ} \mathrm{C}$, but at $5^{\mathrm{O}}$ meters it is $-1.5^{\circ} \mathrm{C}$, , rising to $+1.5^{\circ} \mathrm{C}$. at 150 $\mathrm{m}$. and to $+3 \cdot \mathrm{I}^{\circ} \mathrm{C}$. at $200 \mathrm{~m}$. At a depth of 200 meters the temperature distribution becomes greatly modified, the chief feature being the distribution of the warmer portions of this stratum in the three great oceans, which, instead of lying in the equatorial region, are now pushed to the north and south of the same, an arrangement which becomes still more pronounced at a depth of 400 meters. At this depth the zone of highest temperature, over $18^{\circ} \mathrm{C}$., lies in the West Atlantic below the Florida stream, at about $30^{\circ} \mathrm{N}$. lat. Between $22^{\circ}$ and $40^{\circ} \mathrm{N}$. lat. the temperature at this depth is everywhere above $17^{\circ} \mathrm{C}$. in the western half of the North Atlantic. In the South Pacific a temperature of $16^{\circ}$ was found only near the Fiji Islands at this depth, $14^{\circ}$ or even $12^{\circ}$ being the more usual maximum temperature. At a depth of 600 meters the area of maximum temperatures in the North Atlantic spreads eastward (between $20^{\circ}$ and $40^{\circ} \mathrm{N}$. lat.) and shows a height of over $10^{\circ}$, increasing in some cases to $16.8^{\circ}$ (northwest of the Bermudas), while under the equator the temperatures are only $5^{\circ}$ or $5.5^{\circ}$. Maximum temperatures of over $10^{\circ} \mathrm{C}$. are found besides in the South $\mathrm{Pa}$ cific in scattered areas, and in the Indian Ocean at this depth. At $\mathrm{I}, \mathrm{OOO}$ meters the mid North Atlantic is bounded by the $7^{\circ}$ isotherm, which is deflected northward to the North British coast. Temperatures of $8^{\circ}$ occur in two areas, between $30^{\circ}$ and $40^{\circ} \mathrm{N}$. lat. and $40^{\circ}$ 
and $80^{\circ} \mathrm{W}$. long., and in an eastward broadening area in the Spanish Sea, which nearer the land becomes $9^{\circ}$ or more and in the Gulf of Cadiz $\mathrm{II}^{\circ}$, thus showing the influence of the undercurrent of warmer Mediterranean waters. At 2,000 meters in the southwestern part of the South Atlantic, the southern part of the Indian, and the whole Pacific, the temperature lies between $2^{\circ}$ and $3^{\circ} \mathrm{C}$. It rises to something over $3^{\circ}$ in the other parts of the Atlantic, except in the southwest part of the Sargasso Sea region and in the Spanish Sea between the tropic of Cancer and Cape Finisterre on the north coast of Spain, where it is something over $4^{\circ} \mathrm{C}$. Temperatures above $3^{\circ} \mathrm{C}$. are also found at this depth in the two northern extensions of the Indian Occan-the Bay of Bengal and the Arabian Sea, the latter having temperatures as high as $5^{\circ}$ or $6^{\circ} \mathrm{C}$.

At $3,000 \mathrm{~m}$. the Pacific has a uniform temperature of $1.6^{\circ}$ to $2.2^{\circ}$ C., except where depressions surrounded by higher rims occur, as in the $\mathrm{Fiji}^{*}$ basin and the Coral basin, where the temperatures rise from $2^{\circ}$ to $2.7^{\circ} \mathrm{C}$. In the Indian Ocean at this depth great uniformity of $1.3^{\circ}$ to $1.9^{\circ} \mathrm{C}$. occurs with but few exceptions, notably beneath the Arabian and Bengal gulfs, where it rises sometimes to $2.9^{\circ} \mathrm{C}$. In the Atlantic the temperatures are somewhat higher, falling nowhere below $2^{\circ} \mathrm{C}$. north of $40^{\circ} \mathrm{S}$. lat., and rising more often to $2.2^{\circ}$ or even $2.9^{\circ} \mathrm{C}$. Only below the eastern part of the Guinea current, and the Sargasso Sea, are the temperatures more than $3^{\circ} \mathrm{C}$., reaching a maximum of $3.7^{\circ} \mathrm{C}$.

At 4,000 meters and lower the temperature of the North Pacific is nearly uniform at $1.6^{\circ}$ to $1.7^{\circ} \mathrm{C}$., even in depths of 6,000 meters. The same temperature occurs in the various depressions southwest of the Hawaiian Islands, except in the deeps, like the Tonga and Kermadec deeps, where temperatures as low as I.I $^{\circ} \mathrm{C}$. have been obtained. Near the border of the Antarctic continent the Belgica found temperatures of about $0.6^{\circ} \mathrm{C}$., while in the AtlanticIndian Polar basin, which descends below 5,000 meters, a temperature of $0^{\circ}$ to $-0.5^{\circ}$ obtains. This cold bottom water flows northward in the west Atlantic trough, for in the basins composing it bottom temperatures of $0.1^{\circ}$ to $0.4^{\circ}$ are found. The mid-Atlantic and the Whale swells, or rises, however, cut off the east Atlantic or South African trough from these cold waters to the south, for, although this descends to depths of 5.000 to 5.600 meters, the lowest bottom temperatures found are $+2.2^{\circ}$ to $+2.6^{\circ} \mathrm{C}$.

In the Cape trough to the south of the Whale ridge the temperature at $4,800 \mathrm{~m}$. is $0.9^{\circ} \mathrm{C}$. This shows that the Whale ridge can-

* Some lower temperatures occur in this basin also, suggesting that it is not completely closed. 
not fall below $3,000 \mathrm{~m}$., for the temperature of $2.4^{\circ} \mathrm{C}$. is that of the $2,950 \mathrm{~m}$. depth (Fig. 27). The mid-Atlantic rise is broken in the equatorial region just west of the great Romanche deep by cross channels descending to $5,000 \mathrm{~m}$. Through these channels the cold waters of the Brazil basin (derived from the Antarctic) find access

Sea Level

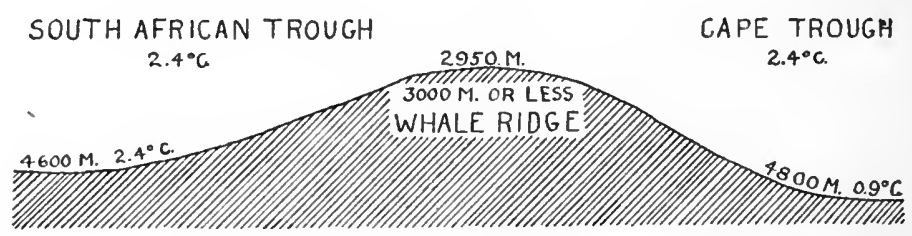

Fig. 27. Diagrammatic section of the Whale Ridge in the South Atlantic, showing the differences of temperature on opposite sides.

to the North African basin, but this trans-passage is a mild one, owing, probably, to the narrow character of the cross channel, for its effects are no longer noticeable beyond $2^{\circ}$ or $3^{\circ} \mathrm{N}$. lat., where the normal bottom temperatures of $2.2^{\circ}$ to $2.6^{\circ}$ characteristic of the North African basin are found.

S.o.

N.E.

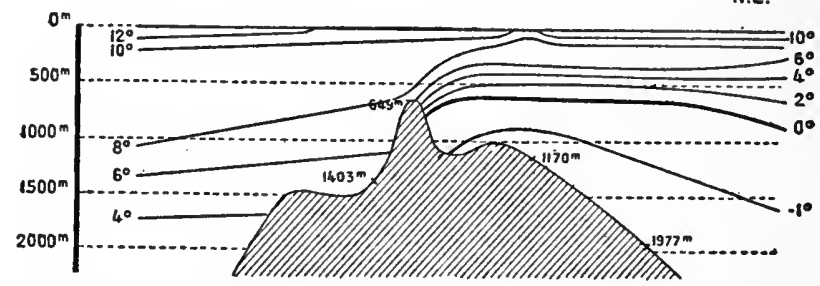

FIG. 28. Diagrammatic transverse section of the Wyville-Thomson Ridge in the North Atlantic, showing its effect as a thermal barrier. (After Prouvot and Haug.)

In the North Atlantic the bottom temperatures of $2.0^{\circ}$ to $2.6^{\circ}$ are preserved through the barring of the cold waters of the Arctic Ocean by the Wyville-Thonson and Faroë-Iceland and Denmark Straits ridges, which completely divide the two oceans below a depth of 550 to 580 meters. To the north of these ridges the temperature sinks as low as $-1.2^{\circ} \mathrm{C}$. in 2,222 meters (Fig. 28 ). 
Temperatures of the Mediterraneans and Epicontinental Seas Dependent on the Large Oceans. As a general chracteristic of mediterraneans may be noted the deep homothermal bottom layer, which, as a rule, has a somewhat higher temperature than that of the neighboring ocean at the same depth. Thus the Roman mediterranean has a temperature of $12.8^{\circ}$ between $200 \mathrm{~m}$. and 2,600 $\mathrm{m}$., while the layers above this show a gradual increase to $25.0^{\circ}$ at the surface. The temperature of the Atlantic in the Bay of Cadiz at 1,000 meters depth is normally not over $8^{\circ}$, though the outflow of the warm mediterranean bottom water raises it to $\mathrm{II}^{\circ}$, whereas in depths of $2,000 \mathrm{~m}$. the temperature of this part of the Atlantic is only a little over $4^{\circ} \mathrm{C}$. The Sea of Narmora below a depth of 220 to $350 \mathrm{~m}$. to the bottom of $\mathrm{I}, 403 \mathrm{~m}$. has a homothermal temperature of $14.2^{\circ}$, which is the approximate winter temperature of the surface water of the Ægean Sea. While thus the Marmora Sea has a higher bottom temperature than the Mediterranean, the Black Sea shows a much lower. Here, in summer, we have a typical dichothermic stratification, the minimum temperature of $6.3^{\circ}$ in the northern part lying at $75 \mathrm{~m}$., while the bottom at $131 \mathrm{~m}$. has a temperature of $8.3^{\circ} \mathrm{C}$. In the central area the minimum temperature is $7.3^{\circ}$ and lies only $45 \mathrm{~m}$. below the surface, while between IOO and 2,0 2 $\mathrm{m}$. the bottom temperature rises from $8.5^{\circ}$ to $9.1^{\circ} \mathrm{C}$. In the southern part the minimum temperature of $6.2^{\circ}$ lies at $65 \mathrm{~m}$, the bottom temperature at $366 \mathrm{~m}$. having risen to $8.9^{\circ}$. The South China Sea shows a fall of $10^{\circ}$ at $200 \mathrm{~m}$. from the surface temperature of $24^{\circ}$ characteristic of the upper $50 \mathrm{~m}$. At $\mathrm{r}, 000 \mathrm{~m}$. the temperature is $3.9^{\circ}$, at $\mathrm{I}, 500 \mathrm{~m} .2 .6^{\circ}$, but below $\mathrm{I}, 600 \mathrm{~m}$. to the bottom $(3,480 \mathrm{~m}$. $)$ a homothermal temperature of $2.5^{\circ}$ obtains, which is the average temperature of the Pacific at 1,500 meters. That the deeper strata of the China Sea are uninfluenced by the correspondingly colder waters of the Pacific, which sink to $1.6^{\circ}$ at $3,000 \mathrm{~m}$., indicates that the submarine barrier of this sea is nowhere below $\mathrm{I}, 600 \mathrm{~m}$. Similar conditions are found in the Celebes Sea, where a homothermal state exists below I,500 $\mathrm{m}$., with a temperature of $3.67^{\circ} \mathrm{C}$. In the Philippine waters, on the other hand, a homothermal condition with $10.9^{\circ}$ exists from $500 \mathrm{~m}$. to the bottom ( $\mathrm{I}, 28 \mathrm{O}$ meters), and in the neighboring Sulu Sea a temperature of $10.3^{\circ}$ characterizes the water from $730 \mathrm{~m}$. to the bottom at 4,070 m. Here, then, a greater separation from the Pacific is shown. The Red Sea offers some striking features owing to its situation in the tropical belt. It has the highest botton temperatures of all mediterraneans. this being, according to $\mathrm{J}$. Luksch, uniformly at $21.5^{\circ}$ from $700 \mathrm{~m}$. to its greatest depth at $2,200 \mathrm{~m}$. This is associated with a salinity of 
from 40.5 permille to 40.7 permille. The elevation of the marginal rim in the Straits of Bab-el-Mandeb, which rises to within $185 \mathrm{~m}$. of the surface, prevents the cooler and less saline waters of the Indian Ocean from entering. These waters in the Arabian Sea and Gulf of Aden have a temperature, at $800 \mathrm{~m}$., of $\mathrm{II}^{\circ}$ to $\mathrm{I} 3^{\circ}$. This is $4^{\circ}$ above the normal and is due to the outflow of the warm waters of the Red Sea. At 2,000 m. the temperature of the Arabian Sea is $5^{\circ}$ to $6^{\circ}$, whereas that of the Red Sea at this depth remains at $21.5^{\circ}$ (Fig. 29).

The three Central American mediterraneans, the Mexican, Yucatan, and Caribbean, show homothermal conditions below I,700 m., from which depth the temperature of $4.2^{\circ} \mathrm{C}$. continues to the greatest depth at $6,269 \mathrm{~m}$. In the corresponding depths of the Atlantic the temperature ranges from $4^{\circ}$ to $2^{\circ}$.

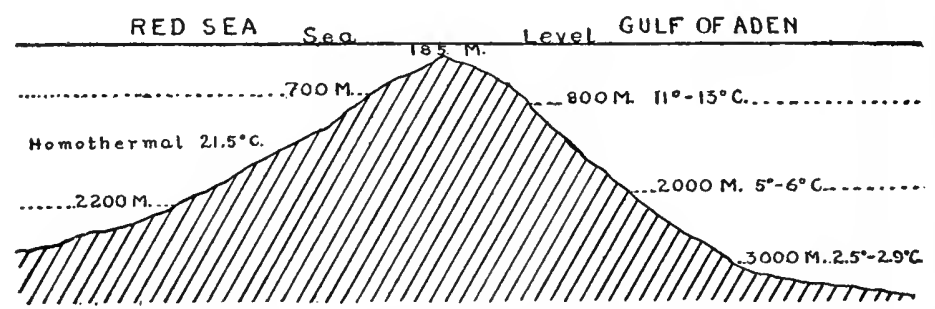

FIG. 29. Diagrammatic cross-section of the ridge dividing the Red Sea and the Gulf of Aden, to show temperature differences.

Among the epicontinental seas the Baltic may serve as an example of a special type of low salinity. The surface temperature varies, of course, greatly with the season, the minimal temperature ranging in the Danzig Bay region from $1.6^{\circ}$ to $2.8^{\circ} \mathrm{C}$, according to the rigor of the winter. This temperature extends through the upper 40 to $60 \mathrm{~m}$., which are also homohaline. The maximum density of water of the salinity of the Baltic $(71 / 2$ permille) is reached at $2.4^{\circ} \mathrm{C}$. Hence cooler waters will remain at the surface. The freezing point of this water is, moreover, at $-0.4^{\circ} \mathrm{C}$. Downward the temperature increases, so that at the bottom of the Danzig Bay temperatures of $5.68^{\circ}$ and $5.88^{\circ} \mathrm{C}$. have been found in February, while those of August range from $3.82^{\circ}$ to $4.90^{\circ}$. In the Alands deep, near the mouth of the Bothnian Gulf, surface temperatures of $-0.2^{\circ} \mathrm{C}$. extending to a depth of 20 meters were found in February, I903, and below this an increase to $3.07^{\circ}$ at 273 meters. In the summer months the temperature of the upper layers, varying in different years from 20 to $45 \mathrm{~m}$., ranges from $15^{\circ}$ to $18^{\circ}$ or over 
on the surface and from $14^{\circ}$ to nearly $16^{\circ}$ at the bottom. Below this surface layer a sudden drop occurs, a feature characteristic of fresh-water lakes. Thus east of Bornholm observations by F. L. Ekman in July, 1877, showed a surface temperature of $15.7^{\circ} \mathrm{C}$. slowly decreasing to $14^{\circ}$ at IS meters depth, followed by a sudden drop to $8^{\circ}$ at 20 meters, decreasing regularly to $5^{\circ}$ at 25 meters. The salinity here was 7.5 permille down to 30 meters, where it rose to 7.6 permille. Such abrupt changes are found only in water bodies of slight wave and current activities.

So far as measurements have been made in Hudson Bay, a nearly homothermal condition seems to be indicated, with temperatures between $-0.3^{\circ}$ and $-1.7^{\circ}$, to a depth of $365 \mathrm{~m}$. The North Sea is a typical and well-studied example of a marginal epicontinental sea. Southwest of the Dogger bank the strong wave activity and tides produce a homothermal arrangement which in winter has a temperature of $5^{\circ}$ to $6^{\circ}$. Northward and eastward this decreases to $4^{\circ}$ or even $3^{\circ}$. After a period of quiet days a surface layer of less salinity may form from the influx of fresh waters, and with this a low temperature occurs. Thus, while the salinity of the surface at the German station 15 (lat. $55^{\circ} 2^{\prime} \mathrm{N}$., long. $7^{\circ} 30^{\prime} \mathrm{E}$.) fell to 32.5 permille on February 24,1906 , the temperature fell to $2.89^{\circ}$; both salinity and temperature increased downward, being at 24 meters 32.18 permille and $3.20^{\circ}$, respectively. A typical kathothermal condition for February is shown by measurements off the mouth of the Moray Firth (Scottish station 25, lat. $58^{\circ}$ i I' N., long. $0^{\circ} 32^{\prime} \mathrm{IV}$.) on February 18, 1904, when the temperature rose from $6.63^{\circ}$ at the surface to $6.77^{\circ}$ at I Io m., and the salinity from 35.10 permille to 35.14 permille at the same depths. In the summer the reverse is true, the surface temperature $\left(18^{\circ}\right)$ being slightly higher than the bottom, $7.6^{\circ}$, at $35 \mathrm{~m}$., except where after storms a homothermal and homohaline condition prevails. A sharply defined stratification may occur even here, as shown by observations in the open North Sea in August, 1905 (lat. $55^{\circ} 22^{\prime}$ N., long. $4^{\circ} 18^{\prime}$ E.), when it was found that the temperature decreased slowly from $15.74^{\circ}$ on the surface to $15.67^{\circ}$ at 20 meters, then fell to II. $38^{\circ}$ at 25 meters, and to $8.26^{\circ}$ at 30 meters, and $8.25^{\circ}$ at 43 meters. On the west side of the Great Fisher bank the observations for 1903 show a sudden drop from $12.24^{\circ}$ at $30 \mathrm{~m}$. to $6.52^{\circ}$ at $40 \mathrm{~m}$., with but little decrease below this. Such a condition is general north of the Dogger bank.

Temperatures of Dependent Seas. In the Funnel seas with closed head the conditions of the ocean to which they are dependent prevail, and this is true of the Biscayan as well as of the California type. Where the head is open, leading into a mediterranean, the 
generally warmer bottom waters of this sea will influence the temperatures of the adjoining funnel sea. This is shown in the abnormally high temperatures of the Gulf of Cadiz and that of Aden.

Temperatures of the Arctic Ocean and Its Dependencies. Through the entrance over the Wyville-Thomson ridge of the warm waters of the guif stream, the eastern part of the Greenland Sea has a surface temperature of $+6^{\circ}$ to $+7^{\circ}$ in summer and something over $+7^{\circ}$ in winter. On reaching the latitude of Spitzbergen the main branch, much cooled, sinks beneath the cold but less dense icebearing East Greenland stream and turning southwestward produces the mesothermal stratification of this part of the waters as far as the ridge in Denmark Straits, across which the warm water still is able to pass. Midway between Spitzbergen and Greenland ( $78^{\circ}$ I $3^{\prime} \mathrm{N}$. lat., $2^{\circ} 5^{8^{\prime}} \mathrm{W}$. long.) the temperature is still $3 . \mathrm{I}^{\circ}$ and decreases more or less regularly to $-\mathrm{I} \cdot 3^{\circ} \mathrm{C}$. at the bottom $(2,690$ m.). Seven degrees farther south, near the center of the East Greenland Sea ( $7 \mathrm{I}^{\circ} \mathrm{N}$. lat., $5^{\circ} 9^{\prime} \mathrm{W}$. long.), a thin surface layer of warmer water has a temperature decreasing from $+4.6^{\circ}$ at the surface to $+2.0^{\circ}$ at 25 meters, below which lies arctic water from $-1.6^{\circ}$ at $50 \mathrm{~m}$. to $-\mathrm{I} .9^{\circ}$ at $75 \mathrm{~m}$., and decreasing to $-\mathrm{I} .3^{\circ}$ at I, $5^{16} 6$ meters. On the east coast of Greenland $\left(74^{\circ} 38^{\prime} \mathrm{N}\right.$. lat., $15^{\circ}$ $3^{\prime}$ W. long.), in the cold East Greenland stream, the surface temperature of $-0.95^{\circ}$ decreases to $-1.53^{\circ}$ at $50 \mathrm{~m}$. depth, and then increases again at the bottom $\left(277 \mathrm{~m}\right.$.) to $+0.70^{\circ}$, showing the in fluence of the warm submerged Gulf Stream drift from $180 \mathrm{~m}$. downward. In Denmark Straits west of Iceland and a little below the Arctic circle $\left(66^{\circ} 25^{\prime} \mathrm{N}\right.$. lat., $25^{\circ} 50^{\prime} \mathrm{W}$. long.) the surface temperature of $+1.7^{\circ}$ sinks to $-1.4^{\circ}$ at $20 \mathrm{~m}$., to $-1.6^{\circ}$ at $30 \mathrm{~m}$., and rises again to $-0.8^{\circ}$ at $40 \mathrm{~m}$., these temperatures representing the East Greenland stream. Then at 50 meters the temperature suddenly rises to $+5.3^{\circ}$, increases to $+6.3^{\circ}$ between 75 and roo $\mathrm{m}$., and then sinks again to $+5.0^{\circ}$ at $300 \mathrm{~m}$., then more rapidly to $-0.5^{\circ}$ at $600 \mathrm{~m}$., and to $-\mathrm{I}_{\mathrm{I}} \mathrm{I}^{\circ}$ at $650 \mathrm{~m}$., the bottom. Where the water is strongly and normally influenced by the Gulf Stream drift only an anothermal arrangement occurs, as north of the Faroe Islands $\left(63^{\circ}\right.$ $22^{\prime}$ N. lat., $5^{\circ} 29^{\prime} \mathrm{W}$. long.), where the temperature sinks from $+10.0^{\circ} \mathrm{C}$. at the surface to $-1.2^{\circ}$ at 2,222 fathoms. The measurements above given were made in the summer; for the winter months the temperature in the upper roo meters is much lower, the difference amounting at the surface, between July and April, to six degrees.

In general the temperature of the East Greenland Sea below $600 \mathrm{~m}$. is down to $0^{\circ}$, while from 800 or $1,000 \mathrm{~m}$. to $3,800 \mathrm{~m}$. homo- 
thermal conditions at $-\mathrm{I} .2^{\circ}$ to $-\mathrm{I} .3^{\circ} \mathrm{C}$. exist. In the Central Polar Sea, the temperatures of the upper strata (themselves of a dichothermic arrangement) are mostly below $-\mathrm{I}^{\circ} \mathrm{C}$. and range from $\mathrm{I} 60 \mathrm{~m}$. to $200 \mathrm{~m}$. in depth, where the temperatures sometimes are as high as $-0.2^{\circ}$. A second stratum of mesothermal character ranges from $+0.2^{\circ}$ to $+1.2^{\circ}$ and lies between 200 and 800 meters in depth, while a third deeper, nearly homothermal, one of $-0.7^{\circ}$ to $-0.8^{\circ}$ extends to depths of 3,000 and 3,800 meters, though the actual temperature of $-0.7^{\circ}$ is not reached above 1,400 to 2,000 meters depth. Of the other dependencies of the Arctic Ocean the shallow White Sea has winter temperatures of $-1.9^{\circ}$ to $-\mathrm{I} .6^{\circ}$, which range throughout and are associated with a salinity of 34.85 permille and 30.08 permille, respectively. In the summer months the temperature rises to over $+\mathrm{I} 3^{\circ}$ on the surface, but below $30 \mathrm{~m}$. the temperature is under $0^{\circ}$, while below $120 \mathrm{~m}$. it is $-1.6^{\circ}$, as in winter. This does not hold for the very shallow bays, however, where temperatures of $8^{\circ}$ to $9^{\circ}$ and over are still found at the bottom of 30 to 35 meters.

Mean Temperatures of the Oceans and Intracontinental SEas. The mean temperatures of the four oceans have been determined to be as follows (Krümmel-20:495), see, ante, p. 146: Arctic, $-0.66^{\circ}$; Pacific, $+3.73^{\circ}$; Indian, $+3.82^{\circ}$; Atlantic, $+4.02^{\circ}$; mean of three larger oceans, $+3.86^{\circ}$. This shows that, taken as a whole, the Atlantic is warmer than the other oceans, this being due to the comparatively high bottom temperatures. As already noted, when surface temperatures alone are considered those of the Pacific are higher than those of the other oceans. Of the mediterraneans, the Red Sea has the highest $\left(22.69^{\circ}\right)$ and the Japanese the lowest $\left(0.90^{\circ}\right)$ mean temperature. In the latter only the surface waters down to 100 or $150 \mathrm{~m}$. are warm, the western side being cooler owing to the cold southward-flowing current. The deeper waters of the central basin have a temperature of $0.7^{\circ}$ to $0.3^{\circ}$. Among the epicontinental seas the Persian Gulf has, as might be expected from its location, the highest mean temperature $\left(24^{\circ}\right)$, while Hudson Bay has the lowest $\left(1 \cdot 0^{\circ}\right)$.

Eutectic Temperatures. This term is applied to the temperature at which salts are separated from cooling waters holding them in solution by the simultaneous crystallization of the salt and water. This temperature is always lower than the temperature of freezing water, and differs for the different salts in the following order, as shown by Pettersson (27:30I, see also Krümmel-20:503); $\mathrm{Na}_{2} \mathrm{SO}_{4}$ $\left(-0.7^{\circ}\right) ; \mathrm{KCl}\left(-\mathrm{II}_{1} \mathrm{I}^{\circ}\right) ; \mathrm{NaCl}\left(-2 \mathrm{I} .9^{\circ}\right) ; \mathrm{MgCl}_{2}\left(-33.6^{\circ}\right) ; \mathrm{CaCl}_{2}$ $\left(-55^{\circ}\right)$. With progressive cooling the salts would thus be sep- 
arated out in the above order, sodium sulphate first and calcium chloride last. Owing to the presence of the other salts in sea water, however, $\mathrm{Na}_{2} \mathrm{SO}_{4}$ does not separate out at its eutectic temperature of $-0.7^{\circ}$, but only at $-8.2^{\circ}$. When the entire mass is frozen, a mixture of ice and salt crystals results, the so-called cryohydrate, which may be compared with graphic granite (pegmatite), the best known eutectic among rocks. The following table shows the results of Ringer's experiment in freezing $\mathrm{I}, 000$ grams of sea water of 35.05 permille salinity (Krümmel-20:504):

\begin{tabular}{|c|c|c|c|c|c|}
\hline 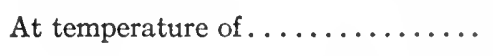 & $-5^{\circ}$ & $-8.2^{\circ}$ & $-10^{\circ}$ & $-15^{\circ}$ & $-23^{\circ}$ \\
\hline Liquid remains, grams.......... & $429 \cdot 5$ & $281 \cdot 5$ & $234 \cdot 0$ & I 86.1 & $134 \cdot 9$ \\
\hline Solid occurs, mostly ice, in grams... & 570.5 & 718.5 & 766.0 & 813.9 & 865.1 \\
\hline Solid $\mathrm{Na}_{2} \mathrm{SO}_{4}$ in grams in above solid . & 0.0 & 0.0 & I. 84 & 3.09 & 3.68 \\
\hline
\end{tabular}

Temperatures lower than $-8.2^{\circ} \mathrm{C}$. exist in the drift ice itself near the surface (at depth of $40 \mathrm{~cm}$.) from October to May inclusive, falling close to $-24^{\circ}$ in January. At a greater depth the temperature is invariably higher in the cold months and lower in the warm. Thus at $200 \mathrm{~cm}$. depth the January temperature, which at 40 $\mathrm{cm}$. was $-23.9^{\circ}$, was $-10.6^{\circ}$, while the July temperature, which at $40 \mathrm{~cm}$. was $-0.5^{\circ}$, was at $200 \mathrm{~cm} .-1.4^{\circ} \mathrm{C}$. In all cases the ice in winter is warmer than the air above it. The water, however; retains a nearly constant temperature of $-\mathrm{I} .5^{\circ}$ to $-\mathrm{I} .7^{\circ} \mathrm{C}$. From the above considerations it appears that sea ice is likely to be richer in sulphuric acid $\left(\mathrm{SO}_{3}+\mathrm{H}_{2} \mathrm{O}\right)$ than normal sea water, while sea water coming in contact with ice at a temperature below $-8.2^{\circ} \mathrm{C}$. will have its $\mathrm{SO}_{3}$ extracted and so become poorer in this substance. On the other hand, portions of the ocean where the sea ice melts will be richer in $\mathrm{SO}_{3}$ than normal sea water. The normal, according to Dittmar, is II .576 parts of $\mathrm{SO}_{3}$ to $\mathrm{IOO} \mathrm{Cl}$; according to Forchhammer, it is II.88; and, according to Schmelck, it is II.46. Pack ice melted by Irvine gave 10.84, I I.97, and I I.93 for different samples, two of them higher than the highest figure for normal sea water. One piece of ice melted by Hamburg gave a proportion of $\mathrm{SO}_{3}$ of 57.4 or 5 times as much as normal sea water. This, however, had only 0.05 permille of chlorine.

Range of Temperature of tile Oceans. The annual range of temperature of the waters is of greater bionomic significance than the absolute temperature itself. Sir John Murray has mapped these 
for the oceans (23) and from his maps the following general facts may be taken: For tropical waters, the range is small (less than $10^{\circ} \mathrm{F}$. or $5.55^{\circ} \mathrm{C}$.) in the Pacific between the tropics of Cancer and Capricorn, except off the west coast of South America, where the range increases to $15^{\circ}$ or even $20^{\circ} \mathrm{F}$. ( $\left(\mathrm{II}_{\mathrm{II}} \mathrm{I}^{\circ} \mathrm{C}\right.$.). In the Atlantic this small range of less than $10^{\circ} \mathrm{F}$. occupies about the same position, except off the North African coast and the Gulf of Guinea. A similar low range occurs in the Indian and Australian waters between $20^{\circ} \mathrm{N}$. and S. lat., except in the Madagascar region, where a greater range exists. Similar small ranges, but for low temperatures, exist in the Arctic Ocean, except where the Gulf Stream carries warmth to Iceland, and in the southern parts of the other oceans below $50^{\circ}$ or $60^{\circ} \mathrm{S}$. lat. Ranges of $20^{\circ}$ or over exist in the North Pacific north of $40^{\circ} \mathrm{N}$. lat. and in the North Atlantic between $30^{\circ}$ and $55^{\circ}$ $\mathrm{N}$. lat., likewise in the South Atlantic and Indian between $30^{\circ}$ and $50^{\circ}$ S. lat., from South America to New Zealand. The greatest ranges of temperature, more than $50^{\circ} \mathrm{F}$., or $27.78^{\circ} \mathrm{C}$., are found in the west Atlantic, eastward from the New England coast, and in the western part of the Philippine Sea. Ranges from $30^{\circ}$ to $40^{\circ} \cdot \mathrm{F}$. $\left(16.66^{\circ}\right.$ to $22.22^{\circ}$ C.) are found off the Rio de la Plata, and in the Roman Mediterranean, the Black, Caspian, and Baltic seas and in part of the North Sea, and in the northern ends of the Red Sea and Arabian Gulf, as well as the western North Atlantic and the western or Asiatic Pacific.

Shifting of the areas of great range of temperature may be brought about by storms or by change in currents or otherwise, and such a shifting may be lateral or vertical. This results generally in the wholesale destruction of animal life adapted to a smaller range, as illustrated by the enormous destruction of Tile fish off the New England coast in 1882, which exceeded in estimation the number of one billion, and covered the floor of the ocean in this region to a depth estimated at six feet with the bodies of dead Tile fish. The influence of the changes in temperature on the destruction of life will be more fully discussed in a subsequent chapter.

\section{Temperatures of the Terrestrial Waters.}

Temperatures of Lakes; Etc. Since lakes are mostly shallow the seasonal variations in temperature are more pronounced throughout than in the oceans or mediterraneans. The chief source of heat is the sun, whose rays are absorbed to a greater or less extent. Reflection from the surface, however, greatly reduces the amount 
which would otherwise go to heat the water, this reflection being in some instances with the sun near the horizon as high as $68 \%$ of the total radiation received (Dufour-5). The heat taken up by the water is chiefly absorbed by the upper layers; and absorption is greatest in water containing much sediment in suspense. Contact with warm air further warms the upper layers of the water. Transportation of the superficial heated layers to cooler depths occurs by convection as well as by wind or by currents. Loss of heat from the upper layers occurs through radiation, and through conduction or contact of the surface with cold air. Fresh water has its maximum density at $+4^{\circ} \mathrm{C}$. $\left(+39.2^{\circ} \mathrm{F}\right.$. $)$ and this may serve as a dividing line between warm and cold fresh water, the former being above, the latter below this temperature (Forel-8: 105). The densest layers sink, of course, to the bottom, and so warn water will show an arrangement of strata progressively cooler downward, $i$. e., an anothermal arrangement. This has been called direct stratification. Cold water, on the other hand, $i$. e., that below $4^{\circ} \mathrm{C}$., will have a reversed stratification, the warmer but denser layers, $i$. e., those at or near $4^{\circ} \mathrm{C}$., lying at the bottom, and the colder above. The temperature arrangement will be katothermal. For saline lakes, the temperature corresponding to their maximum density must be chosen as the dividing point.

Classification of Lakes According to Temperature. From the viewpoint of temperature three types of lakes may be recognized: a. tropical, where the water is always above the maximum density temperature $\left(4^{\circ} \mathrm{C}\right.$. for fresh water $)$; b. temperate, where it alternately rises above and falls below this temperature; and, c. polar, where it is always below the maximum density temperature. These lakes are, however, not restricted to the corresponding geographic zones of the earth. Tropical lakes always have a direct thermal stratification, or an anothermal arrangement. In spring and summer the stratification becomes increasingly marked, while in fall and winter it decreases until homothermic conditions are approached in winter. Examples of such lakes are the great lakes of upper Italy, i. e., Lake Geneva (Germ. Genfer. See, Fr. Lac Léman), etc.

Polar lakes always have a reversed thermal stratification, or katothermal arrangement, the warmest water (not above $4^{\circ} \mathrm{C}$., however) lying at the bottom. Here the stratification becomes most pronounced in fall and winter, decreasing in the spring and approaching homothermal conditions in summer. Such lakes occur in the polar regions and in the mountains of the temperate regions.

Temperate lakes assume a tropical habitus in summer and autumn, the stratification being pronounced in the former and tending 
to disappear in the latter. only to appear in reversed order as winter approaches, when the polar type of reversed stratification is pronounced. This will disappear again in spring and give place to the tropical type. The minimum and maximum surface temperatures of fresh-water lakes are: for tropical lakes $+4^{\circ} \mathrm{C}$. and $+25^{\circ}$ C. to $+30^{\circ} \mathrm{C}$; ; for polar lakes $0^{\circ}$ and $+4^{\circ} \mathrm{C}$.; and for temperate lakes below $+4^{\circ}$ in winter, and above $+4^{\circ}$ in summer, seldom rising, in the deeper lakes of the temperate zone, above $25^{\circ}$ C. In all cases the temperature of the surface waters is lower than that of the air immediately above it in summer, and higher in winter. The depth to which the seasonal variation penetrates is about 100 meters.

Differences of temperature also exist between the littoral and open lake or pelagic district, the former being warmer in summer and colder in winter than the latter. As has already been indicated, the bottom temperatures of tropical lakes are generally above $4^{\circ} \mathrm{C}$., though those of subtemperate ones may be at times as low as $4^{\circ} \mathrm{C}$. Temperate lakes, even those inclining toward either extreme, i. e., subtropical and subpolar, have a normal bottom temperature of $4^{\circ}$, though the former may at times be greater than $4^{\circ}$ and the latter less. Polar lakes have a normal bottom temperature lower than $4^{\circ} \mathrm{C}$., though the subtemperate ones may occasionally have as high a bottom temperature as $4^{\circ}$. Lake Geneva, having a depth of 309 $\mathrm{m}$. (surface elevation $375 \mathrm{~m}$.), is beyond the influence of seasonal variation $(100 \mathrm{~m}$.$) , nevertheless a difference of from 0.1^{\circ}$ to $0.3^{\circ}$ between seasons has been observed in the deepest layers. This is regarded as chiefly due to the sinking down of sediment-bearing waters of higher temperature. The actual temperatures at the bottom of this lake are from $+4^{\circ}$ to $+5^{\circ} \mathrm{C}$., while the temperature of the littoral belt varies from $+15^{\circ}$ to $+25^{\circ} \mathrm{C}$. in summer, that of the inflowing Rhone being $+10^{\circ}$ to $+15^{\circ}$. In winter the temperature of the littoral region sinks to $+4.5^{\circ}$ or to $+5.5^{\circ}$ in different years; only near the shore, in the shallow littoral region, does the temperature fall below $4^{\circ}$ and may fall to $0^{\circ}$ with the formation of ice. This results in the formation of a reversed thermal stratification, whereas that of the littoral region is normal or direct, as shown in the accompanying diagram (Fig. 30), copied from Forel. The line along which the densest water of $4^{\circ}$ temperature reaches the surface has been called the thermal barrier.

Freezing of Lakes. Where reversed thermal stratification exists the temperature on the surface may sink to $0^{\circ}$, and ice will be formed. This is normal in polar lakes, usual during the colder months in temperate lakes, and may occur in the shallow littoral belt 
of tropical lakes. where a thermal barrier separates this from the littoral zone, as in the above illustration from Lake Geneva. In quiet lakes, where the surface water has reached $0^{\circ}$, a slight lowering of the temperature, as during a still, clear night, will cause the formation of a uniform, continuous, though thin sheet of ice over the entire surface, which, if not.melted during the succeeding day, will thicken the following night by addition of ice on its under side, until a thick crust is formed. The increase in thickness is, however, at a diminishing rate, owing to the low conductivity of ice.

In disturbed waters ice floes are formed, a method of ice formation characterizing the sea and rivers as well. These pancake masses (Fr. glaçons-gâteaux, Ger. Kuchschollen) result from the union of the ice needles tossed about by the waves, these needles often forming suddenly in the super-cooled mass, through agita-

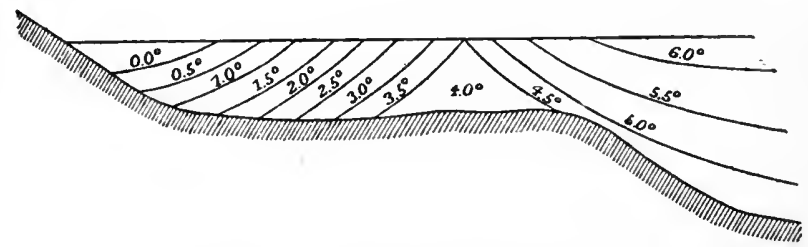

FIG. 30. Diagram representing thermal barrier of $4^{\circ}$ between the littoral and pelagic districts of Lake Geneva in winter. The barrier is in reality a vertical sheet. (After Forel-8.)

tion, or through the dropping in of snowflakes, analogous to the formation of crystals in a supersaturated solution on agitation or on dropping in of a crystal. The round form of the pancake floes is due to the constant friction they undergo. The density of ice is about 0.92 , while that of pure water at $0^{\circ}$ is 0.9998676 and that of normal sea water is 1.028 . (Pure water at $4^{\circ}$ [or better $3.947^{\circ}$ ], its maximum density, is taken as $I$.) It is, therefore, evident that ice will float on fresh as well as on salt water of the temperature permitting its formation. Owing to the addition of ice fragments and crystals on the margins of the cakes where they are thrown by the waves, the weight of the mass will increase until it sinks sufficiently to be covered by a thin stratum of water, which will cause further addition to the ice mass on its surface, while at the same time it grows marginally as well as on its under side. The ice mass eventually acquires the form of a plano-convex lens, with the convex side downward and a thickness of a meter or more. The ice floes will freeze together when heaped up by waves or currents or when coming in contact after the water has quieted down. 
As the temperature of ice sinks below zero, especially at night, further contraction takes place, and thus cracks are formed in the ice sheet, which may extend for hundreds if not thousands of meters in length and cross each other at various angles. Water rising in these fissures freezes, and so prevents the closing of the old fissures on the expansion of the ice during the day. A powerful lateral pressure is thus inaugurated which, if the whole lake is frozen, will cause the ice to move up on the shore, carrying materials with it and building a shore wall of ice-shoved boulders. while at the same time it may scratch the underlying rock layers and produce the effect of glaciation. Such boulder walls and ridges may also be built by the ice floes resulting from the breaking up of the ice in spring. These floes are driven onto the shelving shores by wind and carry stones up with them. This action is pronounced in northern lakes like those of Labrador. Tyrrell (40:64 B.) has described such ridges around Lake Winnipegasie, and Russell inentions their occurrence on other Canadian and northern United States lakes, where they are found " 40 or 50 feet from the water"s edge, are 20 feet high, and broad enough to furnish convenient roadways." (Russell-3I:52.) The same lateral pressure through expansion of the ice causes the buckling of the ice masses in the center of the lake. Only in very shallow water bodies will the ice extend to the bottom. Owing to the greater density of water at $4^{\circ} \mathrm{C}$., this will sink to and remain at the bottom, and the slow conductivity of both water and ice will prevent the reduction of the bottom temperature during the cold season. It is in this way that organisms can survive under the frozen surface of a lake.

Normal and Excessive Temperatures of Streams and of Ground WATER. The temperature of streams in a given area varies according to the season, but also with the volume of water and with its source, the length of the stream, the character of its bottom and banks, etc., so that different streams within the same region and at the same time may have different temperatures. Thus streams resulting from melting glaciers will always be cold, although, as they proceed in their course, the waters may be warmed to a certain extent by contact with the warm air. If much sediment is carried in suspension by a stream, its temperature will be proportionally higher. A stream flowing through a lake will, after leaving the lake, have in general the temperature of the surface waters of that body, which alone are carried out. Underground efluents in like manner have the temperature of the layers of water in which they originate.

Spring waters vary less in temperature, for their sources are 
generally below the influence of the seasonal variation, which in temperate regions may extend to a depth of $5^{\circ}$ feet. The normal temperature of spring water lies in general between $47^{\circ}$ and $5 \mathrm{I}^{\circ} \mathrm{F}$.

Freesing of Rivers. Rivers of comparatively gentle current will freeze over after the manner of lakes, but rivers of strong current will freeze over only under exceptional circumstances. In all cases the current continues under the ice.

Frecsing of Ground Water. The ground water will sometimes freeze to an astonishing depth. Thas in the Tundras of Alaska and Siberia the permanently frozen soil often extends to a great depth, that of Yakutsk, Siberia, having been given as $3^{82}$ feet. (K. E. von Baer, quoted by Russell-3I :I3O.) Sands saturated with glacial waters may freeze throughout and then behave like solid rock. In this manner faulting, crumpling, and other structures normal only to solid rock have been formed in the otherwise unconsolidated glacial sands and clays of the glacial period. (Berkey \& Hyde-I : 22323I.)

Mechanical work of freesing ground water. (Salisbury-34: 208.) The upper layers of the lithosphere in high latitudes are subject to periodic refrigeration below the freezing point of the ground water. This is especially true of the soil layer, which may be affected to a depth varying considerably with the latitude, the intensity, and above all the duration of the period of cold. When the soil is frozen, erosion is retarded, and where the subsoil is permanently frozen, as in the northern regions of the larger continents, the arboreal type of vegetation is absent as already noted. The freczing of the soil also disturbs the solid particles in it. Thus stones and boulders work their way up through the soil to the surface, producing constantly recurring stony surfaces, leading sometimes to the belief that stones "grow." Foundation walls of buildings which do not extend below the zone of freezing are likewise disturbed in this manner.

Moisture rising from the soil through capillary attraction may freeze as it reaches the surface and so form ice crystals which push upward by addition from below. These may be two or three inches in length, and they will raise leaves, sticks and stones.

Where the soil is thin the water may freeze in the crevices of the rock beneath the soil cover, and so shatter the rocks. This is especially effective where moisture is abundant, and where there is a frequent change of temperature from above to below the freezing point. (On the depth of frost in the Arctic regions see Woodward-45.)

Thermal Springs. Heated waters reaching the surface in the 
form of hot springs either represent the meteoric waters, which, as ground water, descended to sufficient depth to be heated to a high temperature, or which by contact with unexposed igneous masses became heated; or it is juvenile or magmatic water newly formed and liberated from the molten rock. The temperatures of the hot springs and geysers of Yellowstone National Park and of Iceland have been regarded as due to the contact with igneous masses, though Suess holds that they are due to the gaseous emanations of lava masses lying at moderate depths below the surface, cooling to a certain degree reducing them to the liquid state. Surface or vadose waters may find access to these newly formed or juvenile (magmatic) waters and so form a mixed product.

In non-volcanic countries the water probably comes from great depths. This is believed to be the case with the Bakewell Buxton, warm springs of England, which range in temperature from $60^{\circ}$ to $82^{\circ} \mathrm{F}$., and the three hot springs of Bath, which have a temperature varying from $104^{\circ}$ to $120^{\circ}$, and yield an estimated quantity of about half a million gallons daily. Prestwich estimates that the water rises from a depth of about 3,500 feet. The Mountain Home hot springs of Idaho have temperatures ranging from $103^{\circ}$ to $167^{\circ} \mathrm{F}$., and Russell estimates that the depth at which this temperature would be found in that region is about 5,000 feet below the surface. The Hot Springs of Arkansas have a temperature ranging from $95^{\circ}$ upward, and, if not magmatic, probably owe their temperature to contact with young igneous rocks still hot.

In the Yellowstone Park there are more than 3,000 hot springs and about 100 geysers. The geysers are intermittently eruptive hot springs, throwing their waters into the air at intervals, sometimes to a height of 200 feet or more. The eruption is believed, by those who hold to the vadose origin of the waters, to be due to the superheating of a long column of water in a tube with hot walls. If this results in the formation of steam in the lower part of the tube this may lift the column, causing an overflow of the water at the top and a corresponding relief of pressure. This permits a sudden expansion of the superheated waters into steam on the relief of pressure, and a consequent eruption of the entire mass. In the change of the water to steam it expands about 1,700 times. (See Hague-II.) (Fig. 3I.)

Magmatic or Juvenile Waters. The steam clouds accompanying volcanic eruptions, and formerly regarded as due to infiltration of surface or vadose waters into the volcanic regions, are now held by many geologists to be the result of gaseous emanations from the lava itself and their cooling and condensation into steam and 


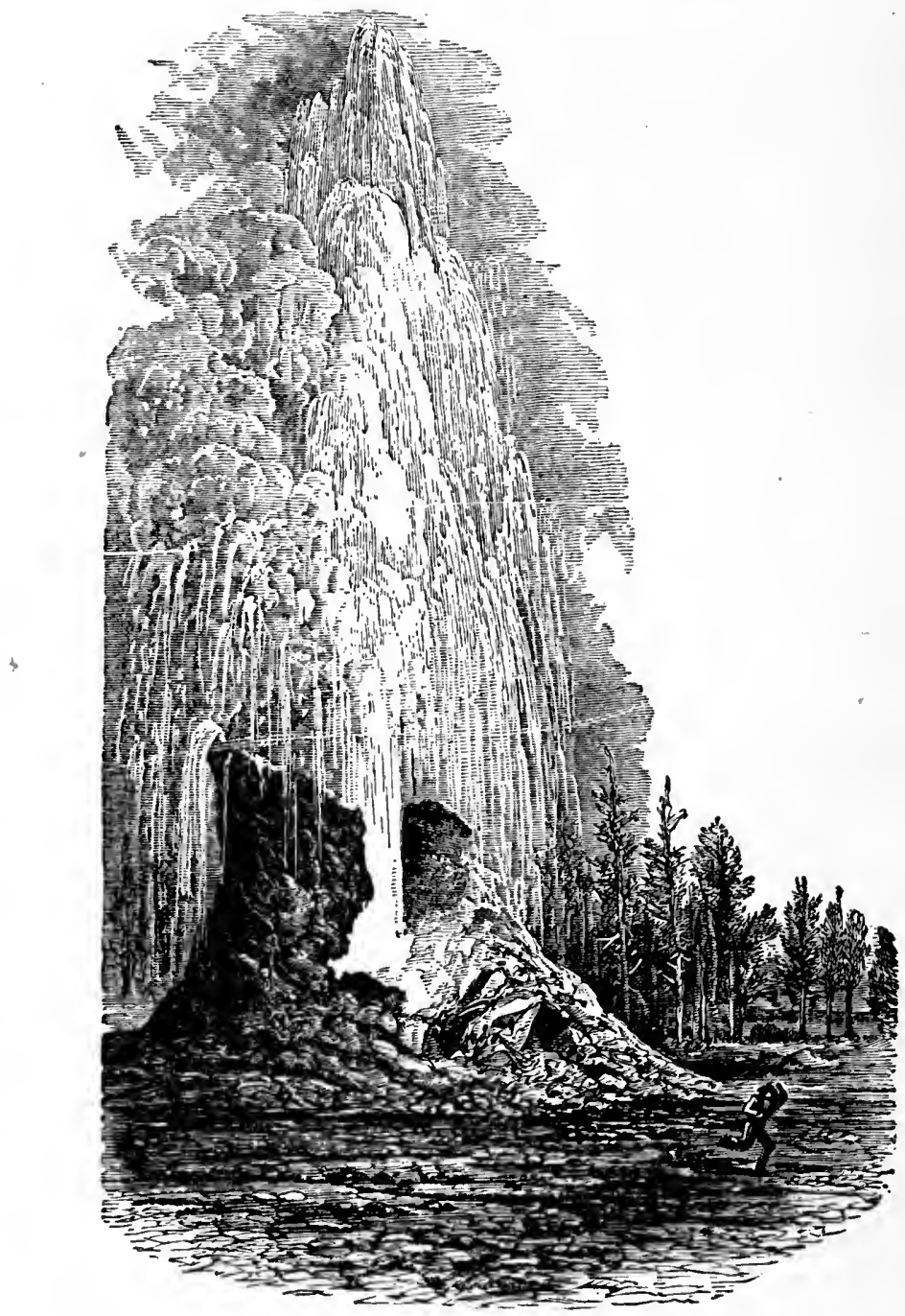

FIG. 3I. The Giant Geyser of the Yellowstone. (After Hayden.)

later water. Such waters are designated as juvenile or magmatic waters. Suess holds that, instead of volcanoes being fed by infiltrations from the sea (directly or indirectly), the sea receives additions through each eruption. (38.) He believes that the oceans and the whole body of vadose water were separated from the cooling litho- 
sphere, in the form of emanations. Tschermak, Reyer, de Lapparent, Kemp and others have actively supported the view of the importance of such magmatic waters, especially as causes in ore deposition, a view advocated by likie de Beaumont before i850. (Kemp-19:610-618; Lincoln-21 :258-274.) Armand Gautier (9) has shown that when powdered igneous rocks (granites, porphyries, trachytes, gneisses, gabbros, etc.) are raised to a red heat in a vacuum they give off water and gases among which hydrogen and carbon dioxide predominate. This is not water taken in by the rock, but water of constitution. The quantity of water lost at red heat varies from 7 grams per kilogram in granite to nearly 17 grams per kilogram in lherzolite. With the water is driven off from 3 to 18 times its volume of gases which are only in small part included gases, being produced mainly by the action of the ferrous salts in the rock upon vapor of water at a red heat. These gases are similar to volcanic gases, being rich in free hydrogen and $\mathrm{CO}_{2}$. The great eruption of Etna in I865 supplied I I,000 metric tons of water a day for 200 days, or a total of over $2,000,000$ tons for this critical period. A cubic kilometer of granite would furnish at red heat, from 25 to 30 million tons of water, one-fourth of which would be sufficient to supply a volume like that given out by Etna during the whole eruption of I 865 . "De Laumy estimates that the principal thermal springs of France discharge a total of 700,000 hecto-

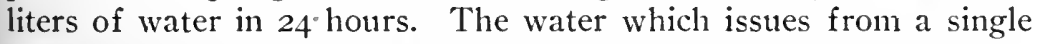
cubic kilometer of granite raised to a temperature of $600^{\circ}$ or $700^{\circ}$ C. would suffice to keep all these springs running for a year with a flow of 48,500 liters a minute." (Gautier-9:692.) Suess regards the springs of Carlsbad, Bohemia, as having their source in magmatic emanations, and he also places the hot waters of Iceland and the Yellowstone under this category. In fact, if we accept the conclusions of Kemp and others that the meteoric water is limited to the upper 2,000 feet or less of the earth's crust, we are forced to regard most thermal springs as newly originated or magmatic waters emanating from a not too deeply buried igneous mass which has not yet wholly expired. "Thermal springs," says Armand Gautier, "may be explained as a kind of gentle distillation of crystalline rocks in a region so hot that water of constitution tends to escape upon a slight increase in temperature." (9:693.) The view is also held to some extent by geologists that mineral veins owe their origin to just such emanations, the magmatic waters carrying with them in solution the mineral matter to be deposited in the fissures penetrated by these waters. (See Kemp-rg for summary of most recent opinions; also Schneider-35 and Hague-1 I.) 


\section{OPTICS OF THE. WATER.}

Of the greatest importance to organisms living in the sea or in fresh water is the depth to which sunlight penetrates. It is to this depth only that chlorophyll-generating plant life occurs, which in turn determines the depth to which animal life subsisting on it may penetrate. Thus the Characea exist in Lake Geneva to depths of $25 \mathrm{~m}$., while Hypnum lehmanie has been found as deep as $60 \mathrm{~m}$. (a single case.) Diatoms extend in summer to a depth of $20 \mathrm{~m}$., in winter to $80 \mathrm{~m}$.

The transparency of water varies greatly. Thus in tropical seas the animal and plant life can easily be seen at a depth of 20 meters or more, while 45 meters has been recorded near the Philippine Islands as a depth at which corals were still visible. A white plate submerged by von Kotzebu in tropical waters of the North Pacific was still visible at 50 meters, while Wilkes found that the depth at which such an object became invisible varied in the same region from 3 I to 59 meters. Observations on the Gazelle showed that the visibility depth of other colors was less than that of white, the depth at which yellow disappeared being $88 \%$ of that at which white disappeared, while for red it was $77 \%$ and for green $67 \%$. Experiments with submerged lights gave for the Lake of Geneva the following results :

Depth visible.

I. Moderator lamp with vegetable oil (July I8, I884) .4I.3 m.

2. Edison lamp, 7 candle power (March I 5, I886) ...50.9 m.

3. Arc light (August 8, 1885).............8. m.

A small electric lamp of 8 candle power was submerged in the Black Sea, where the depth was over 2,ooo meters. The depth at which the point of light disappeared varied from $3.7 \mathrm{~m}$. to $40 \mathrm{~m}$. that at which the light disappeared entirely varied from 43 to $77 \mathrm{~m}$., according to the locality. Measurements made by exposing photographic plates at various depths showed that the influence of the light still extended to 500 or $550 \mathrm{~m}$. depth. From various measurements it appears, however, that in the sea only the upper 300 meters receive light throughout the day, while at 350 meters depth light is present for only 8 hours.

In fresh water the depths beyond which photographic plates are no longer affected appear to be much less. Thus in Lake Geneva F. A. Forel found that silver chloride plates were affected in sum- 
mer to depths of $45 \mathrm{~m}$. only after exposure for a full day, while in winter the depth increased to I Io meters. Lake Constance (Bodensee) gave a depth for the same phenomena of $30 \mathrm{~m}$. in summer and less than $50 \mathrm{~m}$. in winter. Sensitive plates coated with silver bromide and exposed for a whole day in the Lake of Zurich were affected to a depth of 100 meters in August, I88I, and in the Walensee to a depth of $140 \mathrm{~m}$. in October, 1891. In the Lake of Geneva after Io minutes' exposure Fol and Sarasin found in August that the plates were faintly affected at II $3 \mathrm{~m}$. and not at all at 237 $\mathrm{m}$. In September very faint results were shown at $\mathrm{I}$ \%o $\mathrm{m}$. and in March, 1885 , at $192 \mathrm{~m}$., while at $235 \mathrm{~m}$. no effect was obtained. In the next year, however (March, I886), slight results were obtained at $240 \mathrm{~m}$. From these facts Forel concludes that the limit of light effect for silver bromide is between 200 and 240 meters, varying with the season and the water body, while at the same time the depth varies for different substances sensitive to light. $(8: 134$.

The recent work in the North Atlantic by the Michael Sars has brought out some very interesting results. A series of measurements of the intensity of the light at various depths was made, by a photometer carrying panchromatic plates and gelatine color filters. Near the Azores the light strongly affected the plates at 100 meters' depth, the red rays being weakest and the blue and violet strongest. At 500 meters the blue and violet rays still made distinct impressions, the violet and ultra violet still affecting the plate at $\mathrm{I}, 000$ meters. At I,700 meters, however, not the faintest trace of light effect occurred after 2 hours' exposure. Observations in several latitudes showed equal intensity of light as follows:

In $33^{\circ} \mathrm{N}$. lat. at about 800 meters depth.

In $50^{\circ} \mathrm{N}$. lat. at about 500 meters depth. In $67^{\circ} \mathrm{N}$. lat. at about 200 meters depth.

These depths correspond to those which were found to be the upper limit of the red pelagic crustaceans (Acanthephyra), as well as that of certain black pelagic fish (Gastrostomus, Cyema) in the same latitudes, so that these organisms are found only where during the daytime the chemically effective rays from the violet portion of the spectrum are alone active, or at depths where the red forms are as invisible as the black ones. It is only at night that they rise into the upper strata of the sea. (Hjort-I5; Murray and Hjort-24:557.) 


\section{BIBLIOGRAPHY IV}

See Also References Under Chapters III and V.

I. BERKEY, CHARLES P., and HYDE, JESSE E. I9II. Original Ice Structures Preserved in Unconsolidated Rocks. Journal of Geology, Vol. XIX, No. 3, pp. 223-23I.

2. CHALLENGER REPORTS, PHYSICS AND CHEMISTRY, Vol. I.

3. CHAMBERLIN, THOMAS C., and SALISBURY, ROLLIN D. 1906. Geology, Vol. I.

4. CLARKE, FRANK W. I908. Data of Geochemistry. United States Geological Survey Bulletin, No.330, Second Edition, Bulletin 49I, I9II.

5. DUFOUR, LOUIS. I873. Bulletin de la Société Vaudoise. Sciences Naturelles, XII, I. Lausanne.

6. EWING, A. L. I885. An Attempt to Determine the Amount of Chemical Erosion, etc., in the Limestone Valley of Centre County, Pennsylvania. American Journal of Science, 3rd series, Vol. XXIX, pp. 29-3I.

7. FORCHHAMMER, GEORG. 1865. On the Composition of Sea-Water in the Different Parts of the Ocean. Royal Society of London, Philosophical Transactions, Vol. CLV, No. 4, pp. 203-262.

8. FOREL, F. A. I90r. Handbuch der Seenkunde. Stuttgart.

9. GAUTIER, ARMAND. 1906. The Genesis of Thermal Waters and Their Connection with Vulcanism. English Abstract by F. L. Ransome, Economic Geology, Vol. I, No. 7. July-August.

10. GEIKIE, ARCHIBALD. I903. Text Book of Geology, Fourth Edition, Vol. I.

I1. HAGUE, ARNOLD. I912. Origin of Thermal Waters of Yellowstone. Bulletin of the Geological Society of America, Vol. XXII, No. I, pp. I02-122.

12. HANAMANN, J. I894. Archiv der Naturwissenschaftlichen Landesdurchforschung von Böhmen, Prague. Vol. IX, No. 4; 1898, Vol. X, No. 5 .

I3. HARRISON, J. B., and WILLIAMS, JOHN. I897. The Proportions of Chlorine and of Nitrogen as Nitric Acid and as Ammonia in Certain Tropical Rainwaters. Journal of the American Chemical Society, Vol. XIX, pp. I-9.

14. HAYES, C. W. I879. Solution of Silica under Atmospheric Conditions. Bulletin of the Geological Society of America, Vol. VII, pp. 2I4-2 I 7 .

I5. HJORT, JOHN. I9II. The Michael Sars North Atlantic Deep-Sea Expedition, 1910. Geographical Journal (London) April and May.

16. HUNT, T. STERRY, 1878. Chemical and Geological Essays. Second Edition.

17. JULIEN, ALEXIS A. I880. On the Geological Action of the Humus Acids. Proceedings of the American Association for the Advancement of Science, Vol. XXVIII, pp. 3 I I-4IO.

I8. KEMP, JAMES F. I908. Waters Meteoric and Magmatic. Mining and Scientific Proceedings, May 23, 1908.

19. KEMP, J. F. I9I3. The Gound Waters. Transactions of the American Institute of Mining Engineers. New York Meeting, Feb., 1913, pp. 603-624.

20. KRÜMMEL, OTTO. 1907. Handbuch der Ozeanographie. Band I. 
21. LINCOLN, F. C. 1907. Nagmatic Emanations. Economic Geology, Vol. II, No. 3, pp. $25^{8-274}$.

22. MURRAY, SIR JOHN. I887. On the Total Annual Rainfall on the Land of the Globe, and the Relation of Rainfall to the Annual Discharge of Rivers. Scottish Geographical Magazine, Vol. III, pp. 65-77.

23. MURRAY, SIR JOHN. 1899. On the Temperature of the Floor of the Ocean and of the Surface Waters of the Ocean. Geographical Journal, Vol. XIV, pp. 34-5I, 3 maps.

24. MURRAY, SIR JOHN, and HJORT, JOHAN. I9I2. The Depths of the Occan. Macmillan.

25. PALMER, CHASE. 19II. The Geochemical Interpretation of Water Analyses. Bulletin 479 U. S. Geological Survey, I9I I, 3 I pp.

26. PENCK, ALBRECHT. I 894. Morphologie der Erdoberfläche. Band I.

27. PETTERSSON, SVEN OTTO. I883. On the Properties of Water and Ice. Vega Expeditionens Vetenskapliga Iakttagelser, Band II, Stockholm, pp. 247-323.

28. REGNARD, PAUL. I89 I Physique biologique: Recherches experimentales sur les conditions physiques de la vie dans les caux. Paris.

29. RUSSELI, ISRAEL COOK. 1882-83. A Geological Reconnaissance in Southern Oregon. Fourth Annual Report of the United States Geological Survey.

30. RUSSELL, I. C. I 885. Geological History of Lake Lahontan, a Quaternary Lake of Northwestern Nevada. Monograph United States Geological Survey, No. XI.

31. RUSSELL, I. C. I890. Notes on the Surface Geology of Alaska, Bulletin of the Geological Society of America, Vol. I, pp. 99-162, pl. 2.

32. RUSSELL, I. C. 1895. Lakes of North America. Boston, Ginn and Company.

33. RUSSELL, I. C. I898. Rivers of North America. New York, Putnam.

34. SALISBURY, ROLLIN D. 1907. Physiography. Henry Holt.

35. SCHNEIDER, KARL. 1913. Beiträge zur Theoric der heissen Quellen. Geologische Rundschau. Zeitschrift für allgemeine Geologie, Band IV, Heft 2, pp. 65-IO2.

36. SCHOTT, GERHARD. 1902. Dic Verteilung des Salzgehalts im Oberflächenwasser der Ozeane. Petermanns' Mittheilungen., Vol. XLVIII, pp. $217-218$.

37. SCHOTT, GERHARD. I912. Geographie des atlantischen Ozeans. Hamburg, C. Boyson.

38. SUESS, EDUARD. 1902. Ueber heisse Quellen, Verhandlungen der Gesellschaft Deutscher Naturforscher und Aerzte, allgemeiner Theil.

39. TOLMAN, CYRUS F. 1890-9I. Carbon Dioxide of the Ocean and its Relation to the Carbon Dioxide of the Atmosphere. Journal of Geology, Vol. VII, pp. 585-620.

40. TYRRELL, J. BURR. I893. Report on Northwestern Manitoba, with portions of the adjacent districts of Assiniboia and Saskatchewan. Geology and Natural History Survey of Canada, Annual Report, Vol. V, new series, part i, Report E, 23 I pp.

41. VAN HISE, CHARLES R. 1904. A Treatise on Metamorphism. United States Geological Survey Monograph XLVII.

42. WALTHER, JOHANNES. 1893. Einleitung in die Geologie als historische Wissenschaft. Jena. 
43. WALTHER, JOHANNES. 1900. Das Gesetz der Wüstenbildung, First Edition. Jena.

44. WALTHER, JOHANNES. I912. Ibid. Second Edition. Leipzig.

45. WOODWARD, R. S. I890. Communication on the Depth of Frost in the Arctic. In Russell, Bulletin of the Geological Society of America, Vol. I, pp. 130-132. 


\section{CHAPTER V.}

MOVEMENTS OF THE HYDROSPHERE AND THEIR GEOLOGICAL EFFECTS.

The movements of the hydrosphere are manifested in the waves, the tides and seiches, the ocean and river currents, and the movements of ground waters. The effects of these movements upon the lithosphere are seen in mechanical erosion and the transportation of eroded material, and to a less degree in chemical solution and decomposition of the rock. Diminution or cessation of motion is followed by the deposition of the material in suspension. Deposition of material in solution at a distance from the source of origin is a further result of the movements of water. The effect of the motion upon the biosphere is shown by the increase in the supply of oxygen in the water and the transportation of food. The distribution of organisms is also affected to a considerable degree by the currents.

\section{WAVES.}

These are the undulatory motions of water produced by wind blowing over its surface. In the open sea, the motion of the water is an orbital one; the particles move in curves, and only the wave form advances. The top of the wave is its crest, the bottom the trough, the lines of both lying at right angles to the direction of the wind. The distance from crest to crest is the rave length, which in stormy weather in the open ocean varies between 60 and I 50 meters (200 and 500 feet). Swells may in some cases reach nearly twice this length, however. The rapidity with which wave crests travel is the velocity of the wave, which varies from Io to 15 meters per second (22 to 33.5 miles per hour, and may be as high as 60 miles per hour). The time taken by a crest to travel a wave length is the period of the wave, which in storm waves varies from 6 to io seconds or over. The vertical distance between the top of the crest and the bottom of the trough is the height of the wave, and its magnitude depends on the strength of the wind. In the open sea the average height of the waves varies between $2 \mathrm{~m} .(6 \mathrm{r} / 2 \mathrm{feet})$ and 5 
meters (nearly $16 \mathrm{I} / 2$ feet), while storm waves may have a height of 30 feet or over (IO-II.5 meters), reaching 50 feet ( $15+$ meters) in exceptional cases. On the shore the breaking wave or the surf may be as high as Ioo feet, or even higher. In mediterraneans the waves are as a rule smaller than in the open ocean. In the Roman mediterranean the maximum height is probably not over 5 meters (I6.38 feet). A height of 4 meters is regarded as the usual maximum for storm waves in the North Sea, though a maximum height of 6 meters, a length of 45 meters, and a period of 9 seconds have been reported.

The orbits in which the water particles of a given wave move have a diameter corresponding to the height of the wave, while the time required for the completion of the circuit by the water
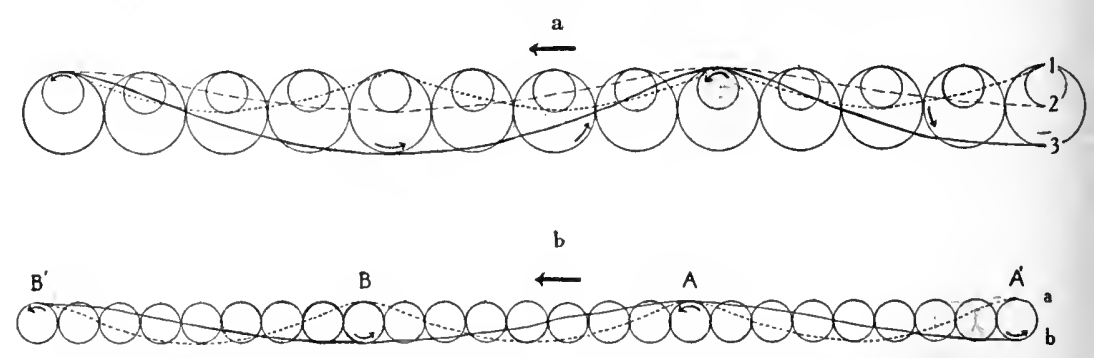

FIG. 32. Diagrams to illustrate wave form, and its change with change in size of orbit, strength of wind, etc. The heavy arrows indicate the wind direction and the direction of wave-form advance. The smaller (curved) arrows indicate the movements of the water particles. (Original.)

particle corresponds to the period of the wave. Thus when a particle has moved from the top of the orbit, where it forms a part of the crest of the wave, to the bottom, a trough has replaced the crest, the crest has moved half a wave length forward, or half the wave period has been completed, corresponding to half the revolution of the particle in its orbit. By the time the entire orbit has been completed the wave crest has traversed the entire wave length; the period is completed. The length of a wave period varies ordinarily for ocean waves from 5.8 to 9.5 seconds, corresponding to an orbital velocity of I.I to $2.3 \mathrm{~m}$. per second, and may sometimes exceed $4 \mathrm{~m}$. per second. The orbital velocity $(\mathrm{v})$ is obtained from the formula, $\mathrm{v}=\frac{h \pi}{\tau}$, where $h$ is the height of the wave (or the diameter of the orbit) and $\tau$ the wave period. ( $\pi=$ 3.I4I $59265359+$; 3.I 4 I6 approximately.) 
The preceding diagrams represent these movements and the resultant waves. (Fig. 32.) They show clearly the relation between the wave height and amplitude of the orbits, and that, with the same wave length, the increase in the size of the orbit brings about a corresponding increase in the height of the wave. At the same time it will be noted that the crest becomes sharper, the slopes being steeper and the angle more acute. If the velocity of the moving particle remains the same with an increase in the size of the orbit, the period must lengthen, because the particles have a longer path to travel before they return to their starting point. If, on the other hand, the period remains the same, or is shortened, giving the same or greater velocity for the wave progress, the orbital velocity of the particles must increase. This is also true when the wave increases in height by an increase in the size of the orbit, as is the case near shore. With the same size of orbit an increase in the wave length brings about a reduction in the sharpness of the crest. The change in wave length is brought about by a relative change in the spacing of particles whose position in the orbit differs by a uniform degree. Thus if, as in Fig. $32 \mathrm{~b}$, we have particles selected from the wave surface revolving in immediately adjoining orbits, of the size indicated and spaced so that they are just $45^{\circ}$ apart, we have the wave length $A B$, and the form given in the lotted line. This means that the velocity of the wind is such that it not only produces the orbit shown, but also reaches and sets in motion the second particle at the moment the first particle has completed $1 / 8$ of its revolution. If, now, the velocity of the wind increases, so that, when it reaches the next particle, the first one has completed only I/I 6 of its revolution, the wave length with the same size orbit would become twice as great and correspondingly flatter. But increased velocity of wind means an increase in the size of the orbit, which in turn means an increase in the height of the wave, and a sharpening of the crest. As the wave length increases the period would lengthen correspondingly, since the distance to travel increases, unless the wave velocity also increases, which means a great augmentation of the orbital velocity of the moving particles. The period does increase in length, but not in proportion to the increase in wave length. (See formula 1 , page 212.) Thus a wave with a length of 500 feet may have a period of Io seconds, which corresponds to a wave velocity of about 34 miles per hour. On increasing to 1,500 feet, the period will increase to between $I 7$ and 18 seconds, corresponding to a wave velocity of about 56 miles per hour. If the wave velocity had remained the same, the period would have been 30 seconds. The disproportional 
increase in the length of the period, therefore, means an increase in the orbital velocity, which, if the wave height also increases, must increase still further.*

Wave velocity (Davis-17:123) does not depend so much on the orbital velocity as on the rate at which the crest position is assumed by successive parts of the water, and this rate depends chiefly on the depth to which orbital oscillations are felt in the water body, so that the progress of the wave increases with the increase in the depth affected.

* The following formulæ copied from Krümmel $(42: 9)$ serve to show the relationship which exists between height and length of wave, its period, orbital and translatory velocity in deep water. In all these:

$\mathrm{r}=$ radius of orbit of water particles.

$\mathrm{h}=$ half the wave height, $i$. e., its height above mean surface.

$\mathrm{H}=$ entire wave height (bottom of trough to top of crest).

$\mathrm{v}=$ orbital velocity of water particles in meters per second

$\mathrm{Z}=$ depth of water (in meters) from mean surface.

$\lambda=$ wave length in meters.

$\mathrm{c}=$ translatory velocity or wave velocity (meters per second)

$r=$ wave period in seconds.

$\pi=3.1416$.

$\mathrm{g}=$ velocity of a free falling body at the end of the first second $(9.8 \mathrm{I} \mathrm{m}$.).

I The relation between the period of the wave $r$ and the wave length $\lambda$

$$
\text { is } \tau=\sqrt{\frac{2 \pi}{g} \lambda}
$$

II The relation between the wave velocity c and the period $r$ is

$$
r=\frac{2 \pi}{\mathrm{g}} \mathrm{c}
$$

III The relation between wave velocity $c$ and wave length $\lambda$ is

$$
c=\sqrt{\frac{g}{2 \pi} \lambda}
$$

IV The relation between wave velocity and size (radius) of the orbit $r$ is

$$
\mathrm{c}=\sqrt{\mathrm{gr}}
$$

$\mathrm{V}$ The relation between wave period $\tau$ and the radius of the orbit $r$ is

$$
\tau=2 \pi \sqrt{\frac{\mathrm{r}}{\mathrm{g}}}
$$

VI The relation between velocity $\mathrm{c}$ and period $\tau$ is

$$
\mathrm{c}=\frac{\mathrm{g}}{2 \pi} \tau
$$

VII Given velocity or period the wave length is therefore

$$
\lambda=\frac{2 \pi}{\mathrm{g}} \mathrm{c}^{2} \text { or } \frac{\mathrm{g}}{2 \pi} \tau^{2}
$$

VIII The orbital velocity $\mathrm{v}$ is found according to the formula

$$
\mathrm{v}=\mathrm{c} \frac{\mathrm{h}}{\mathrm{r}}
$$


The height of the waves increases until the resistance awakened by the orbital motion throughout the mass of water affected, balances the wind work on the surface. As increase in length depends on the increase in the spacing of particles, $i$. $e$., the increase in rapidity with which adjoining particles are affected, it is seen that the wave length may increase even after the height no longer increases. Thus while the height of hurricane waves or great "seas" is seldom over thirty or forty feet and their length perhaps 500 feet, the latter may increase to I, 500 feet, or three times, while the height does not, or but rarely, reach 50 feet. The velocity of such waves varies from 20 to 60 miles an hour, and their period from ro to 20 seconds.

The height of the waves depends not only on the strength of the wind causing them, but also on the size of the water body, especially the diameter of the surface along the path of the wind. Wind velocity is greater over the open sea than along the coast or inland, and this, together with their smaller size, makes the waves of inland lakes less pronounced than those of the sea, and hence lake shores suffer less erosion than the sea-coast. In a small water body the wave height is proportional to the square root of its diameter (Stevenson, Th.-68:358). As soon as the wave height exceeds $0.8 \mathrm{~m}$., it may be determined according to the following formula (modified from Stevenson), when $\mathrm{H}$ is the wave height in meters, $\mathrm{d}$ the diameter of the water body in kilometers (Penck$52: 466)$ :

$$
H=\frac{1}{3} \sqrt{d}+0.8-\frac{1}{4} \sqrt[4]{d}
$$

In the ocean the waves rise quickly to a height of 5 meters, but also decrease rapidly, as soon as the wind producing them ceases. The maximum height of waves in the open ocean, with a given wind velocity, is shown in the following approximate table, abstracted from Krümmel $(42: 75)$.

Table showing relationships between wind velocities and a'ave height.

\begin{tabular}{l|c|c|c|c|c|c|c|c|c|c|c}
\hline $\begin{array}{l}\text { Wind velocity in } \\
\text { meters per second } \\
(\mathrm{w}) .\end{array}$ & 1 & 2 & 3 & 4 & 5 & 10 & 15 & 20 & 25 & 30 & 40 \\
\hline $\begin{array}{l}\text { Maximum height } \\
\text { of waves in me- } \\
\text { ters (Hm). }\end{array}$ & 0.1 & 0.3 & 0.5 & 0.8 & 1.0 & 3.5 & 6.7 & 10.9 & 13.3 & 15.0 & 17.0 \\
\hline
\end{tabular}


With increase in the strength of the wind, the length of the waves increases more rapidly than their height; the former may increase threefold before the latter is doubled. Lieutenant Pâris noted, east of the Cape of Good Hope, that during strong westerly storms, extending over four days with remarkable uniformity, the height of the waves rose only from 6 to 7 meters, while the length increase threefold before the latter is doubled. Lieutenant Pâris i. e., $\frac{\lambda}{\mathrm{H}}$ changed from $\mathrm{I} 8.84$ to 33.57 . This increase in length means an increase in the velocity of the wave, which may rise to exceed that of the wind itself. The following table shows the mean velocity of the waves compared with that of the wind in the several oceanic bodies (Krümmel-42:80) :

Table showing relationships between mean wave and wind velocities.

Mean
velocity of
wind in
meters per
second

Atlantic Trade Wind.......... 5.9

South Atlantic West Wind....... I0.9

Indian Ocean West Wind........ I 2.5

Indian Ocean Trade Wind...... 7.0

Chinese Sea................ I I.3

West Pacific Region.......... 8.2
Mean

velocity of waves in meters per second

II.2

14.0

15.0

12.6

II. 4

12.4

Relation between Length and Height of Wave. This may be expressed by the formula $\frac{\lambda}{\mathrm{H}}$ and varies greatly according to the age of the waves. In young waves it may be ro or less, $i . e$, if the height of the waves is I meter its length would be ro meters or less. As the wave grows the quotient $\frac{\lambda}{H}$ increases until it is 50 or over. The following classification of waves was made by Pâris (Krümmel-42:83) :

Classification of waves.

\begin{tabular}{c|c|c|c|c|c|c}
\hline $\begin{array}{c}\text { Type of } \\
\text { Waves }\end{array}$ & $\begin{array}{c}\text { Very } \\
\text { High Sea }\end{array}$ & $\begin{array}{c}\text { High } \\
\text { Sea }\end{array}$ & $\begin{array}{c}\text { Rough } \\
\text { Sea }\end{array}$ & $\begin{array}{c}\text { Moder- } \\
\text { ate Sea }\end{array}$ & $\begin{array}{c}\text { High } \\
\text { Swell }\end{array}$ & $\begin{array}{c}\text { Ordinary } \\
\text { Swell }\end{array}$ \\
\hline$\vec{\lambda}$ Mean.......... & 19.1 & 21.0 & 21.6 & 38.7 & 29.3 & 32.5 \\
“ Maximum....... & 22.5 & 23.0 & 30.0 & 80.0 & 48.6 & 63.3 \\
"Minimum........ & 15.4 & 15.0 & 13.3 & 21.6 & 18.4 & 15.3 \\
\hline
\end{tabular}


We have seen that the higher the wave with a given length, the sharper the crest, or, what amounts to the same thing, the increase of length without or with but moderate increase of height flattens the crest, and this flattening lessens the destructiveness of the waves in the open sea. In sharp-crested waves the crest water "tends to roll forward faster than the front is built up, and this tendency is increased by the forward brushing of the wind. Sharp waves of moderate height break in 'white caps'; great seas gain curling or combing crests, which capsize small boats and break with dangerous force on the decks of large vessels." (Davis17: 124 .)

The Swell or Ground Swell. "Waves spread rapidly from the gales in which they are formed. As they advance they decrease in height, but retain length, velocity and period unchanged. Their long, flat undulation is called 'swell.' [German, Dïnung; French, houle.] It may swing for thousands of miles across the ocean, fading as it goes. The glassy water of calm weather in the equatorial 'doldrums' is always slowly heaving and sinking with passing swells." (Davis-17: I24-5.) The swell or ground swell of great hurricanes may break with destructive force on a coast a thousand miles or more distant. Davis states that "landing in the harbor of St. Helena is sometimes impossible on account of surf from swell that originates in winter gales in the North Atlantic, thousands of miles away." (I 26.$)$

Swells are much longer than true waves. The longest were measured by the French Admiral Mottez in the Atlantic, just north of the equator, and had a length of 824 meters (2,703.5 feet), a period of 23 seconds, or a velocity of $35.8 \mathrm{~m}$. (I 7.5 feet per second).

On the coast of Ascension Island, Buchanan (6:23t) observed in March, I886, a rhythmic breaking of the swell at intervals of 16 seconds, this being the period $(\tau)$ of the swell wave. These great "rollers" represented waves originating south of Newfoundland, and their length after traveling this great distance is determined from their period to be 400 meters. At Bournemouth, on the south coast of England, Dr. Cornish (IO) found the mean period of continuous series of I 39 breakers to be 19.35 seconds, corresponding to a wave length of 585 meters. Breakers with periods of 15 to 17 seconds are common at certain seasons of the year on the Channel and the Atlantic coast of England and Ireland, where they are known as "Death Waves" and regarded as indications of coming storms. The origin of these waves is in the Gulf Stream 
region, where their period is probably not over 8 to I I seconds, and their length from Ioo to 200 meters.

Depth of Wave Activity. The orbital radius of wave particles in the open sea decreases downward in geometrical progression, so that for each descent in depth equal to I/9 of the wave length the diameter of the orbit decreases by one-half. (Krümmel-42:6.) Thus :

For depths equal to the following fractions of the wave length, $\lambda \ldots . . . .$.

The diameter of the orbit $(2 \rho)$ is equal to the following fraction of the wave height $(2 h) \ldots .$.

\begin{tabular}{|l|r|r|r|r|r|r|r}
\hline & & & & & & \\
\hline & $\mathrm{I} / 9$ & $2 / 9$ & $3 / 9$ & $4 / 9$ & $5 / 9$ & $8 / 9$ & $9 / 9$ \\
\hline & & & & & & \\
$\mathrm{I}$ & $\mathrm{I} / 2$ & $\mathrm{I} / 4$ & $\mathrm{I} / 8$ & $\mathrm{I} / \mathrm{I} 6$ & $\mathrm{I} / 32$ & $\mathrm{I} / 256$ & $\mathrm{I} / 5 \mathrm{I} 2$ \\
\hline
\end{tabular}

At twice the depth of the wave length the orbital diameter will be $\frac{I}{262, I 44}$ part of the wave height at the surface. A wave of 90 meters in length and $3 \mathrm{~m}$. high (a not uncommon size in the open ocean, during strong winds) will show the following decrease of the orbits in which the particles move.

\begin{tabular}{c|c|c|c|c|c|c}
\hline Depth & 0. & $10 \mathrm{~m}$. & $20 \mathrm{~m}$. & $50 \mathrm{~m}$. & I00 m. & $200 \mathrm{~m}$. \\
\hline $\begin{array}{r}\text { Approximate size of } \\
\text { orbit }(2 \rho) \ldots\end{array}$ & $3 \mathrm{~m}$. & $1.5 \mathrm{~m}$. & $0.75 \mathrm{~m}$. & $91.5 \mathrm{~mm}$. & $2.79 \mathrm{~mm}$. & $.002725 \mathrm{~mm}$. \\
\hline
\end{tabular}

Thus with a wave length of I,500 ft. and a height of $50 \mathrm{ft}$. the orbital motion, which at the surface is $50 \mathrm{ft}$., will at a depth of $\mathrm{I}_{500 \mathrm{ft}}$. be $50 / 5 \mathrm{I} 2 \mathrm{ft}$. or I.I 7 inches, while at a depth of 3,000 ft. (500 fathoms) it is $50 / 262, \mathrm{I} 44 \mathrm{ft}$. or 0.0023 of an inch, or 0.058 millimeter or practically nothing. At roo fathoms, a wave 600 feet in length on the surface and with a height of $30 \mathrm{ft}$. (i.e. an orbital diameter $(2 \rho)$ of $30 \mathrm{ft}$.) will be represented by orbital movements of 0.7 inch in diameter. 
The radius of the orbit $\rho$ may be calculated according to the following formula of Bertin (quoted by Krümmel-42:6)

$$
\rho=\text { he }^{-2 \pi \frac{z}{\lambda}} \text { or } \log \frac{\rho}{h}=-2 \pi \mathrm{m} \frac{z}{\lambda}
$$

where $\mathrm{h}$ is the half height of the waves (radius of orbit on surface); $\mathrm{e}$ the basis of the natural logarithms $(2.7 \mathrm{I} 8) ; z$ the depth of water in meters from the mean surface, $\lambda$ the wave length and $m$ the modulus of the common system of logarithms (0.4342944819), while $\pi=3 . \mathrm{I} 4 \mathrm{I} 6$.

Waves in Shallow Water. "When waves run into shoaling water their period remains unchanged, their height increases, and their velocity and length decrease. The height increases because the wave energy at any given point is spent upon a lessening depth of water. The velocity decreases because the forward propagation

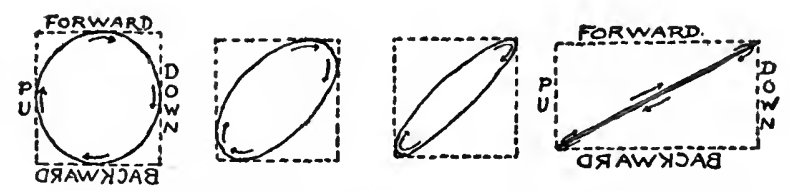

FIG. 33. Diagrams showing the change in the orbit described by the moving particles of the waves as they approach the shore, and their direction of movement. (After Davis.)

of wave disturbance is slower in shallow than in deep water. The wave length decreases because the forward waves are more retarded than the following waves. The period is unchanged because, at any given point, one wave is as much delayed in arrival as another.

"On a steep-sloping beach the waves may wash up and down without breaking; then the orbit is a narrow ellipse, much inclined forward; directly on the beach the orbit is practically a line coincident with the slope of the beach; and here the water rises as it advances and falls as it recedes. This relation of rise and fall to forward and backward motion is not found where the orbit is an oval. If the orbit is a vertical ellipse, rise goes with the last half of recession and the first half of advance; fall goes with the last half of advance and the first half of recession." This is illustrated by the "square frames" fitted to different forms of orbit in the above diagrams (Fig. 33) given by Davis.

"On a gradually shoaling bottom, swell changes to surf or breakers close to shore. The height of the wave increases, its front 
becomes steeper than its back, its crest curls forward and at last plunges into the trough ahead of it, splashing and surging up the beach. Just at the time of breaking, the water may be seen ascending in the concave front of the wave and curling forward at the crest. Breaking is therefore the result of normal orbital movement at a place where the water is so shallow that there is not enough of it to build up the front of the wave." Davis thinks that this is a more effective cause than the "drag" of the waves on the bottom in shallow water, and their consequent retardation.

In general the critical point at which breaking of waves occurs is found where the depth is equal to the height of the wave, or the diameter of the orbit in which the water particles move. This is, however, complicated by the ground swell over submerged banks, such as the Dogger bank, the Newfoundland banks, the Agulhas banks, etc., where the shoaling of the water results in the breaking of waves over water several times deeper than the height of the visible waves. Thus waves have been known to break in water 25 to 30 meters deep, on the north coast of Spain, in 48 meters near Terceira, in the Azores; 46-57 meters off Punta Robanal, North Spain, and at 84 meters on the Syrian coast. During heavy tidal runs at Faira Island, north of the Orkneys, heavy surf was found, according to Stevenson, in water 70 meters deep, and Airy mentions surf on the outer margin of the "Grounds" at the mouth of the English Channel where the water was I80 to 200 meters deep ( 100 fathoms). Again heavier and shorter seas have been observed over the Wyville Thomson ridge between Faroe and Scotland than on either side of it, although the ridge culminates at a depth of 300 to 500 meters below the surface of the ocean.

On the Banks of Newfoundland the water is often stirred to the bottom, although the depth is 50 meters and over. Heavy waves breaking on the decks of the vessels in water 20 to 25 meters deep often leave there sand stirred up from the bottom. The stirring up of the bottom is also shown by the fact that the remains of $M y a$ truncata, which lives buried at a depth of 20 to $25 \mathrm{~cm}$. in the sandy bottom, are found in the stomachs of bottom-feeding fish, which could have obtained them only after they were dug up by the waves.

The sand and mud of the bottom of the North Sea is kept in constant motion by the waves and the tides, so that no seaweeds can become attaclied, except on the rocky cliffs of the coast. Measurements made in Lake Ontario showed that stirring of the sand at the bottom by storm waves does not extend down to 20 feet. Four empty boxes were anchored in the sloping sand bed of the 
lake bottom "at equal distances over a length of 650 yards, in depths of 6 feet, 12 feet, 18 feet and 20 feet. After storms it was found that the first box in the shallow water became filled with sand; the box in 12 feet of water half-full; in the one at 18 feet there was very little sand; and at 20 feet there was no sand in the box." (Wheeler-73:I0.)

In the open Atlantic ripple marks have been found at a depth of 200 meters, but in the English Channel they occur only down to depths of 40 meters, and to depths of 50 meters in the Roman mediterranean. Off the Florida coast, too, Agassiz has noted disturbances to a depth of 200 meters.

Destructive wave work, however, does not extend to such depths, especially in the more protected water bodies. Thus submarine constructions in the Mediterranean scarcely suffer damage from storms at a depth of 5 meters, and the coarse sand at the bottom of the Bay of Biscay in less than 10 fathoms of water is scarcely disturbed. (Delesse-21.) A great oceanic swell may, on reaching a coast, break more than once. The first surf line will occur at about the point where the shoaling water becomes equal in depth to the wave height. If this is far from shore the water mass, after breaking, will roll forward as a wave of diminished height, and this will break again where the further shoaling demands it, and this may be repeated several times. The resultant piling up of the waters on the coast will induce a strong seaward-tending bottom current or undertow, which will carry the less heavy substances out along the bottom.

The height to which a breaking wave may be thrown, or the height of the surf, is sometimes surprising. Lighthouses and even rock cliffs have been destroyed at a height of IOO feet above sealevel. The lighthouse of Unst, the northernmost of the Shetland Islands, which stands nearly 60 meters above sea-level, repeatedly has had its windows broken by the high-dashing surf. "During northeasterly gales the windows of the Dunnet Head lighthouse [on the north coast of Caithness in Scotland], at a height of upwards of 300 feet above high-water mark, are said to be sometimes broken by stones swept up the cliffs by sheets of sea water, which then deluge the building." (Geikie-26:56r.)

The surf from the ground swell alone will, "even when no wind is blowing, often cover the cliffs of North Scotland with sheets of water and foam up to heights of 100 or even nearly 200 feet." (Geikie-26:56I.)

As the waves advance on the shore, they tend to become more and more nearly parallel to the shore line, mainly as a result of the 
differential decrease in velocity. Where the shore projects into headlands or points, the energy from a considerable crest line is concentrated, resulting in intensive destructional work. In bays, on the other hand, the energy of a small portion of the crest line is stretched, as it were, over a broad area, and hence becomes relatively weak. This is shown in Fig. 34, copied from Davis, where the energy of the crest line $\mathrm{DF}$ is concentrated on $\mathrm{df}$, whereas at $\mathrm{AC}$ only the energy of the short portion of the crest lying between a $\mathrm{c}$ is felt. The bay head thus becomes a place of relative safety for vessels and a region of slight erosion.

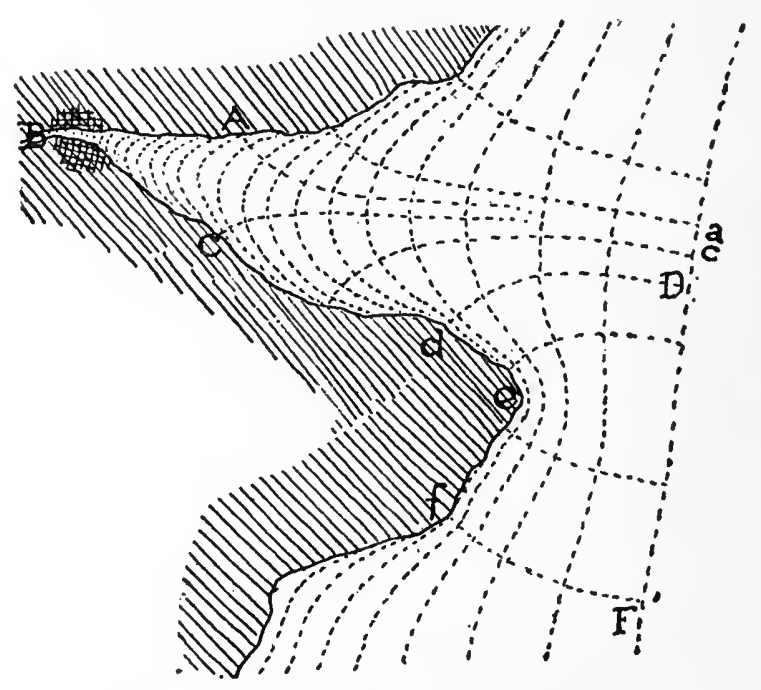

FIG. 34. Map showing concentration of energy from a considerable crest line upon a narrow headland and its diffusion in the bay or harbor. (After Davis.)

An on-shore wind produces a shoreward "drift" of the water aside from the movement due to waves. The "undertow" is the return current flowing outward at the bottom. This is, of course, greatly increased during strong wave action. When the wave strikes the shore obliquely, a movement parallel to the shore is inaugurated, and this is the longshore or littoral current, the chief agent in the transportation of material along the shore.

Destructive Work of the Waves. Wherever the waves beat upon a shore, erosional work of some kind is going on. If the shore is sandy, the waves may only stir up the sand, which will then be carried seaward by the undertow, or along the coast by the 
longshore currents. The actual impact of the waves upon a sandy or rocky shore produces comparatively little effect. By compressing the air in the caves or joint cracks, completely closed by the water, or by hydraulic pressure, the waves may succeed in ultimately shattering the rocks or loosening large masses. The most effective wave erosion work is, however, accomplished by hurling pebbles and even boulders or ice blocks against the cliffs, and so undermining them and by removing the pieces broken off by this process, by frost action or otherwise.

The force of the waves in great storms is often surprising. Measurements with a dynamometer made by Stevenson on the north coast of Scotland gave a force of impact equal to about $3,000 \mathrm{kgm}$. per square meter in summer (6I I lb. per square foot), and more than $10,000 \mathrm{kgm}$. per square meter in winter $(2,086 \mathrm{lb}$. per square foot), while in exceptional storms the force may exceed $30,000 \mathrm{kgm}$. per square meter. "The greatest result yet obtained at Skerryvore was during the heavy westerly gale of 29 th of March, 1845 , when a pressure of 6,083 lbs. per square foot was registered. The next highest is 5,323 lbs." (Stevenson-67:25.) At Cherbourg, on the coast of France, and at Algiers, on the north coast of Africa, similar measurements gave a force 3,000 to $3,500 \mathrm{kgm}$. to the square meter, while at Civitavecchia, on the west coast of Italy, a force of $\mathrm{I} 6,000 \mathrm{kgm}$. per square meter has been obtained.

Observations on the transporting powers of waves are also available. Rock masses weighing IOO tons have been known to be moved by the great waves of winter storms on the north British coast. Many times blocks weighing five tons or over have been torn from the ledges or from foundations and dragged many yards by the waves. At Plymouth, during a severe storm in November, 1824, granite blocks up to I4,000 pounds were broken from the harbor embankment, and pushed uphill in some cases for 60 yards.

"On more than one occasion at Plymouth during the construction of the breakwater large blocks of stone, some of them weighing 7 to 9 tons, were removed from the sea slope of the breakwater at the level of the low water, carried over the top a distance of ${ }_{13} 8$ feet, and piled up on the inside. In one night 200,000 tons [British] of stones were thus removed; and on another occasion 9,000 tons." (Wheeler-73:18.) At the Peterhead breakwater waves 30 feet in height and 500 to 600 feet long have on three occasions displaced blocks weighing over 40 tons eacl at levels from 17 to 36 feet below tide, and at Cherbourg over 200 blocks weighing eacl about 4 tons were lifted over the top of the breakwater, while blocks weighing over 12 tons were turned upside down. 
Murchison and Stevenson noted in the Bound Skerries, the eastern ramparts of the Shetland Islands, a gneiss block weighing $71 / 2$ tons at a height of about 7 meters above sea-level, which shortly before, during a southerly storm, had been dragged over a ragged surface from a position 22 meters nearer the sea, and at the same elevation, by the waves which broke over these cliffs. The path along which the boulder was dragged was clearly marked by the splinters left by the way, and the block itself showed the marks of the concussions during passage. Blocks from 6 to 13 tons in weight were elsewhere seen to have been transported inland at a height of $20 \mathrm{~m}$. above the sea. The most noteworthy case on record is, howevei, that of the dislocation of the breakwater in the harbor of Wick in North Scotland by an unusually heavy eastern storm in December, 1872 . The depth of water in the bay is more than Io meters, while just outside it is over 30 meters. The breakwater consisted, above the foundation, of three large blocks, weighing 80 to 100 tons each, across which a huge concrete monolith weighing over 800 tons was cast in situ, and firmly anchored to the blocks by iron anchors. The total mass weighed I,350 tons, and yet this mass was torn from the foundations by the successive wave impacts, and hurled into the inner harbor a distance of Io to 15 meters, the monolith and the three foundation stones remaining anchored together and being moved as a single mass.

Shingle has been thrown from the beach to the roadway, I 8 feet above high water, at Brighton, England, by southwest gales. Sir John Coode found that "on one occasion . . 3 3 $3 / 4$ million tons of shingle had been torn down from the Chesil Bank and carried seaward by the waves; and on another occasion $4^{\mathrm{T}} / 2$ million tons were scoured out, three-fourths of which was removed back after the gale ceased." (Wheeler-73:I7.) On this same bank a laden sloop of roo tons burden became stranded during a heavy gale in I824, and was cast to the top of the bank, where it was more than 30 feet above ordinary high water. "At Hove [England] it was calculated that 27,000 tons of shingle were removed from the beach in a heavy gale during one set of spring tides, and that Io,ooo tons were drifted along the beach in two tides on another occasion." Entire shingle banks may be removed in a single storm. "In the Solent, near I Furst Castle [England], a shingle bank two miles long and I2 feet high, consisting principally of flints resting on a clay base, was moved forward in a northeasterly direction 40 yards, during a storm in 1824." (Wheeler-73:17.)

Rock fragments weighing from Io to $\mathrm{I} 5 \mathrm{O}$ lbs. have been rolled along the shore of Barnstable Bay, England, between Hartland 
Point, a cliff of Carbonic rock, and Abbotsham, I2 miles distant; the boulders have been rolled "for a distance of from io to I 5 miles and piled up into banks of from 100 to 150 feet wide and 20 feet high, the top being from 6 to 9 feet above high water." $($ Wheeler $-73: I 7$.

The progress of wave erosion on a cliff of uniform exposure depends in a large measure upon the relative hardness or resistance of the rock in question. Unconsolidated material is readily removed, even in sheltered places. Berkey (4) has estimated from observations extending over a year that the cutting back of a cliff of glacial sand and fine gravel near Port Jefferson, at the head of a narrow enclosed bay on the north shore of Long Island, New York, proceeds at the rate of 10 feet per hundred years. On the exposed outer shore of Cape Cod, the unconsolidated glacial sands and older clays are cut back at a rapid rate, as shown by the necessity of repeated removal of the lighthouses at the three Nauset Lights.

The Island of Sylt, on the west coast of Schleswig-Holstein, furnishes an instructive example of rapid erosion. The sand dunes which protected this island from the sea began to move eastward, in the middle of the eighteenth century, and the sea followed. The church of the village of Rantum had to be taken down, and in thirty years the sand hills had passed the site, and the waves had swallowed the foundations of the church. Fifty years later the former site of the church was nearly 300 yards from the shore. (Andresen-2.)

Many striking examples of the advance of the sea on a low coast are recorded in the district of the Landes on the west coast of France. This region between the Gironde and the mouth of the Adour, is believed by many to be subsilling, while others hold the advance of the sea as due to wave and current erosion entirely. The retreat of the coast near the Garonne is estimated at not less than 2 meters per year; the lighthouse of Cordonan, formerly situated on the coast, is at present separated from the mainland by an inlet 7 kilometers in width. On many portions of the coast the dumes are washed away by the constant advance of the sea.

On the south coast of the North Sea subsidence with encroachment of the sea through erosion is abundantly illustrated. The Zuidersee, originally a marsh, then a coastal lake, finally became an arm of the sea, and is constantly increasing in depth, being navigable to-day by much larger vessels than in the former centuries. In many places the sea now covers sites of villages which flourished thirty years ago. A structure built by the Romans under Caligula, 
which sank into the sea anno 860, was discovered in the last century at a distance of 4,7 IO meters off the west coast of Katwijk, in south Holland, while the remains of another structure swallowed earlier by the sea now lie at a distance of a mile from the coast. The dunes at Gravenzande, north of the Meuse mouth, which in I 726 had a width of 640 meters, had been entirely removed by the sea near the end of that century, making an average retreat of the coast for this section of Io meters per year.

On the west coast of Denmark, erosion of the coast proceeds at a rapid rate, accompanied by subsidence. At Agger, near the western end of the Lümfjord, a strip of coast 14I meters in width disappeared between the years I8I5 and 1839, making an annual retreat of more than 5.6 meters. Even more extended was the loss between the years 1840 and 1857 , during which time the sea devoured a strip 157 meters broad, the coast thus retreating at a rate of more than 9.4 meters per year. In many places along the coast of the North Sea submarine forests are found, with many stems still erect, while numerous structures built in historic times are now beneath the water.

The cliffs of glacial sand, gravel and boulder clay which form the coast of Yorkshire, England, for 36 miles from Flamborough head to the mouth of the Humber furnish numerous examples of rapid erosion by the sea. The process is generally a removal of the loose material at the foot of the cliffs, by the waves, with a partial undermining of the cliff, followed by the slipping of a large mass into the sea. The cliff faces the opening of the Skagar Rack on the opposite shore of the North Sea, 400 miles away, and so is exposed to the full force of the waves of this turbulent epicontinental sea during northeast gales. The ordinary rise of the spring tides is 16 feet, the water reaching the foot of the cliff thronghout a great part of the length, in some places rising 2 to 3 feet above the foot. At low tide the beach is 150 to 300 yards wide. "The waste of the cliff has been estimated at 2 miles since the time of the Romans, a mile of which has gone since the Norman Conquest." (Wheeler-73:222.) Phillips (54) and others have estimated a loss of $2 \frac{1}{4}$ yards annually, equal to 30 acres a year over the 36 miles of coast, the average height being taken at 40 feet. On one part of the coast a recession of 215 feet occurred in the 37 years between 1852 and 1889 , according to the estimates of Captain Kenny, while Captain Salversen estimated the erosion on I 2 miles of the coast to be I 32 feet in 40 years, or a loss of 204 acres. From the record of old maps it appears that whole townships have been devoured by the sea, while others have lost churches, 
houses and the greater part of their land. "Kilnsea church fell in $1826-36$, and the village was removed. Nearly the whole of this parish has been washed away during the last century. Aldborough church is far out at sea and Thorpe parish has been reduced from 690 to 148 acres. Of Ravenser and Ravenserodd, once a seaport town at the mouth of the Humber, not a vestige is left." (Wheeler$73: 222$.) Wheeler has estimated that the total quantity of material falling from this cliff each year is $1,615,680$ cubic yards, of which 969,408 cubic yards is alluvial matter carried away in suspension. This occurs only for about two hours before and two hours after high water of spring tides, or about four hours 260 tides a year. Thus each tide would carry away about 3,728 cubic yards. (73: 225.)

The progress of erosion of steep rocky coasts is strikingly illus-

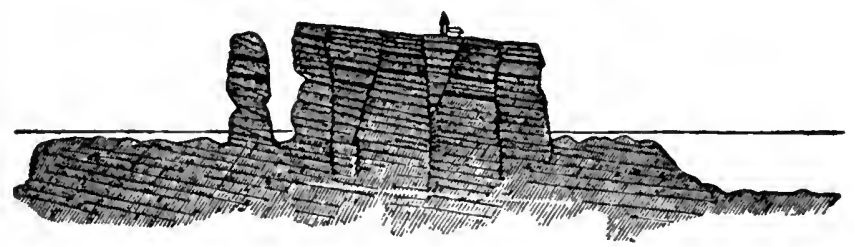

FIG. 35. Diagrammatic view of the Island of Helgoland (direction S. IV. by N. E.), showing the great erosion platform, especially in the southwest side, where the beds dip into the island. The rock is Bunter Sandstein) (Triassic) much faulted. (After Walther.)

trated by the numerous sea stacks found on nearly every coast, and so familiar from the illustrations in the basaltic cliffs of Nova Scotia, the chalk cliffs of Yorkshire and the Isle of Wight in England, the Old Red Sandstone cliffs of North Britain, the Zechstein cliffs of the Sunderland coast, the Buntsandstein of Helgoland, etc. On these coasts the erosion is seen to progress at an almost visible rate, changes in outline being perceptible often from year to year. Perhaps the most noted example is the island of Helgoland, the position of which, off the mouth of the Elbe, makes it such an important strategic possession for the German Empire that they obtained it in 1890 from England by relinquishing Zanzibar. In 1570 this island extended eastward across the present dune, where it formed the Wittecliff of Muschelkalk, which had the height of the present Helgoland. Destruction of these limestone banks by the Helgolanders made it possible for the great flood of I7I2 to separate the entire mąss of Muschelkalk and chalk from the main mass of Helgoland. In the nineteenth century the last remnant of this mass was a little island covered by dunes, which was threat- 
ened with complete destruction by the great storm flood of Cliristmas, I 894 , and is at present protected from the waves by artificial constructions. (Fig. 35.)

Rounding and Sorting of Detritus by Wave Action. Wave work on sand grains is limited to those of larger size. Shaler (63) has called attention to the fact that between the smaller grains of sand on the beach a cushion of water exists, due to capillary attraction, and that to this the wet beach sand owes its firmmess. It is this cushion of water which prevents the sand grains from rubbing against each other, and thus the finer grains remain angular. Experiments by Daubrée $(16: 256)$ showed that granules $0.1 \mathrm{~mm}$. in dianleter will float in fecbly agitated water, and that hence grains of this size and less could not be mechanically rounded by water. Destructible material, such as feldspar grains, is slowly eliminated in wave-churned sands. On the shores of eastern Moray the sands contained only ro per cent. of feldspar, whereas, at the river mouths which furnished the sands, 18 per cent. of feldspar grains is still found. The rounding, purity and assortment according to size is never as great as in the case of wind-blown sand, but probably in most cases better than river sands. (See the tables and discussion on p. 256.)

Pure sands, $i$. $e$., sands consisting of one mineral-generally quartz-are sometimes found on the seashore, though, as a rule, other minerals are present. An unusually pure beach sand is found at West Palm Beach, on the Atlantic coast of Florida, nearly everything but quartz being eliminated. The grains are, however, mostly subangular, though the material has been transported for many miles along shore from the Piedmont region to the north. Shaler $\left(6_{3}\right)$ calls attention to the fact that these sands, though somewhat rounded, are not much smaller than those in the region of that coast about Cape Hatteras, whence they come.

Large rock fragments, on the other hand, are rapidly rounded by the waves. At Cape Ann, cubes of granites of a kind which forms excellent blocks for paving city streets are worn by the surf in the course of a year to spheroidal forms, with an average loss of more than an inch from their peripheries (Shaler-63:208), while fragments of hard-burned bricks are reduced to half their size by a year of moderate beach-wearing.

\section{TIDES.}

Tides are the periodic rise and fall of the ocean waters, due to combined attraction of sun and moon, and occur twice in every 
24 hours and 52 minutes. At flood tide the water is high, at ebb tide, low. Twice each month, at new moon and at full moon, the tides are exceptionally high, owing to the relative position of sun and moon at these times, when they exert a combined influence of the same character upon the waters. Such tides are called Spring Tides. Twice a month also, at the period of first quarter and last quarter of the moon, the interval between high and low water is at its lowest, since at such times the moon and sun act in contrary direction upon the waters, each tending to neutralize the force of attraction of the other. This constitutes the Neap Tides.

In the open ocean the rise is estimated to be 2 or 3 feet, but along coasts this is generally greatly increased. This is especially the case where the water is crowded into narrowing bays, as illustrated by the Bay of Fundy, a funnel sea, with the highest known tides of the world. The mouth of this bay is 48 miles wide and its depth at this point from 70 to I IO fathoms. The bottom rises at the rate of 4 feet per mile for 145 miles, when the head of the bay is reached. Near the mouth the spring tides vary from 12 to I 8 feet, while at its head, in Cobequid Bay, the range is as high as 53 feet, that of the neap tide being $3 \mathrm{I}$ feet. The tide runs up the Petit-Codiac River from the head of the bay, presenting a more or less perpendicular wall. This is the tidal bore which is seen in a number of rivers, such as the Severn and the Wye of England, the Seine of France, the Hugli of India, and the Tsien-Tang of China, where it is sometimes 25 feet high and very destructive. According to the observations of Captain Moor, $11 / 4$ million tons of water rushed past a point in the river in a minute. Up river the tides are often felt for a considerable distance. Thus its influence is felt up the Hudson as far as Troy, New York, up the Delaware nearly to Trenton, and 70 miles up the St. John's River in New Brunswick, where it is felt at an elevation of 14 feet above mean sea-level. The salt water does not actually run up the rivers to the distances mentioned, the waters of the Hudson, for example, being fresh above Poughkeepsie. The tidal influence is felt rather in a backing up of the river water, which is of course accompanied by a checking of the current, a condition favoring the deposition of material held in suspension.

Where tides pass through narrow channels, tidal currents or races are produced, which are generally effective agents in scouring the channels or preventing deposition. Where bars or other obstructions retard the entrance of the tide into a narrow bay or estuary, it may not reach its full height before the setting in of ebb tide, and thus the rise and fall will be less than on the unprotected shore. 
The removal of such a bar would cause a greater rise and fall of the tide on the shores of the bay, and so produce the appearance of subsidence of the land. Johnson $(35 ; 37)$ has used this explanation to account for many apparent indications of recent subsidence along the Atlantic and other shores.

Comparison of Tides and Waves. Tides may be regarded as huge waves sweeping successively around the earth from east to west, their theoretical period being a little over 12 hours and 26 minutes. If lines were drawn connecting the points which have the same high tide at the same moment, these cotidal lines would mark the crests of the tide waves. Normally there would be two such cotidal crest lines on opposite sides of the earth, and between them would be the cotidal trough line. If the earth were covered by a universal ocean of uniform depth, the cotidal lines would be great circles, and the, period of the tide waves would be exactly 12 hours and 26 minutes. The velocity at the equator would be equal to that of the rotation of the earth, and is approached by the tides of the deep and open sea. The continents, however, greatly interfere with this movement of the tides, and this is especially the case in bays or funnel seas, where we have not only an increase in the height of the wave, but also a change in interval between high and low water, or between the crest and trough of the wave. As the bay narrows, low water occurs nearer the following than the preceding high tide, the rise being more rapid than the fall. In some estuaries the duration of rise is to the duration of fall as one is to ten or twenty. In such cases we have the production of the tidal bore already mentioned, the water rushing up the estuary as a visible wall of water with a speed of ten or more miles per hour.

The tidal currents (flood and ebb) likewise suffer a striking change. In the ocean "the flood begins three hours and six minutes before high water, attains its greatest velocity at high water, and ceases three hours and six minutes later." (Davis-17: 129.) Likewise, in the ebb tide, slack water occurs at mid-interval between high and low tides. This is illustrated by the tides in the center of the English Channel, where the current flows up the channel (toward Dover) for three hours before high tide, and down the channel for three hours after. This phenomenon is understood when we compare the movement of the waters of the tidal wave with that of the ordinary wave. Rise and fall of the tide is brought about by the vertical component of the orbital movement of the water, while the back and forward currents are due to the horizontal component. The change in the latter occurs at mid-tide, which is the period of slack water. 
The conformation of the coast line and the relation of the tidal wave to it modify this interrelation of current and tide. Thus at the mouth of the Elbe, at Cuxhaven, the reversal of the current occurs I hour and 30 minutes after low water, and I hour and 25 minutes after high water. Thus during the first hour and a half of falling tide a current still runs up the Elbe, and during the same interval of rising tide the current still runs down. On London Bridge one may observe that in the center of the Thames the current still runs up stream, even after the water has fallen 2 feet, while at the mouth of the Thames, at the Mouse lightship, the reversal of the current occurs 2 hours after high and low water.

At the heads of small bays, and on shores where the tide comes on broadside, slack water agrees with high and low tides; all the rising tide having a flood current, all the falling tide an ebb current. This is, however, not the case when the tide progresses obliquely along the shore.

Interference of Tides. In bays or channels open in two directions, remarkable interferences may occur by the meeting of high and low tides or by cross tides. "At New York high tide entering from the harbor reaches the rocky narrows of Hell Gate when a low tide arrives through Long Island Sound, and six hours later a low tide from the harbor meets a high tide from the Sound." (Davis-I 8:87.) This produces a rapid back and forth flowing current or tidal race, which made this passage a dangerous one to vessels until the channel was widened by blasting away the rocks.

Even more complicated interferences occur in the English Channel, especially near the Dover Straits, where the tides from the Atlantic and the North Sea meet, with the production of the familiar strong series of currents and waves. In the Irish Sea the meeting of two tides of equal height from opposite directions, and with a difference of phase of 12 hours, produces excessive tides ( 5 to 7 meters), but, owing to the direct opposition of movements of the two tidal streams, complete slack water results, as is the case at the Isle of Man. When, on the other hand, the phase difference is 6 hours, no rise or fall of the tide will occur, since a crest approaching, say, from the right, balances a trough approaching from the left. In both the movement is to the left, that of the crest being forward and that of the trough being backward, and so a current of double strength will alternately flow in the one and the other direction, slack water being halfway between high and low water time.

Where the waters are crowded in narrow channels, as between islands or headlands, the tidal stream likewise becomes greatly 
strengthened. Between the cliffs of the Pentland fjord the tidal stream known as the Roost has a velocity of Io to I I knots, and even steamers which have a speed of more than I I knots avoid steaming against this stream when the wind favors it. Between the Orkneys and the north coast of Scotland, tidal streams of 8 to Io knots are normal during spring tides. In such tidal races irregularities of the coast will produce whirlpools such as the one off Mosken and Värö, among the Lofoten Islands, famous for centuries as the "Maelstrom"; or the even more dangerous "Saltstrom" at the mouth of the Saltenfjord on the Norwegian mainland opposite. The whirlpool known since the days of Homer as the Charybdis, in the Straits of Messina, and the fainter but equally noted maelstroms at Scilla, on the Italian coast of the Straits, owe their peculiarities to the meeting in the narrow passage of the tides from the Tyrrhenian and Ionian seas, which have a phase difference of 6 hours, and thus high water approaches from one and low water from the other side, the differences being adjusted by the strong currents generated which change in direction every six hours. Owing to the conformation of the borders and bottom of the passage, strong whirls of water are produced, which bring the colder and more saline waters from the deeper parts and with it deep water organisms, such as the larval form of the eel, etc.

Tidal currents extend to much greater depth than that reached by wave motion. North of the Dogger bank, in water 73 meters deep, the maximum tidal current in the upper Io meters of water, measured at intervals of six hours, was I 5.9, 20.4 and $20.1 \mathrm{~cm}$. per second, and in 70 meters' depth or 3 meters above the bottom, the corresponding velocities were $8.9, \mathrm{I} 3.2$ and $10.2 \mathrm{~cm}$. per second. The tidal wave in this case was not over I meter high; deep water waves of this height would be imperceptible at a depth of 70 meters, while the tidal stream still retained 56,65 and $5^{\text {I }}$ per cent. respectively, of its surface velocity.

Tides and tidal streams are not as pronounced in the mediterraneans as in the open sea, and this difference becomes emphasized when the outlet of the mediterranean is narrow, as in the case of the Straits of Gibraltar. The Gulf of Mexico (Mexican mediterranean), with a wider opening, still illustrates this phenomenon, the range of the tide at Galveston, Texas, being less than I foot.

Tides independent of the Atlantic tides and more nearly comparable to the seiches in lake basins also occur. In still more enclosed basins, as in the Black Sea, tides are wanting altogether. In large lakes a periodic rise and fall of the water of slight extent has been observed and compared with the tides. These lake tides 
are very small, that of Lake Michigan, for example, having an interval of only 2 inches. More irregular oscillations of the entire water body of lakes are found in the sciches, which are due to some disturbance of the water as a whole, as in the case of sudden barometric changes, in storms, etc., and may be compared to the oscillation of the water in a basin which has been lifted on one side and suddenly dropped. Such oscillations will continue for some time after the cessation of the disturbing force.

Tidal Scour and Transportation. Wherever the tide passes through a narrow channel so as to produce a race, considerable scouring of the bottom results. Thus the tidal stream channels in salt marshes are kept open by this tidal scour, and not infrequently harbors are benefited by such scour. Transportation of sand and mud by tidal currents is often extensive. Sand grains I/roo inch (about $0.25 \mathrm{~mm}$.) will be moved in a state of semisuspension by tidal currents of 3 or 4 knots. The movement is, however, principally a forward, backward movement, the sands carried away by ebb tide being brought back during flood. This is illustrated by the case of a vessel which sank at the mouth of the Gironde, opposite Verdun, where she rested on her keel at the bottom of the channel in 6 fathoms of water at low tide. "At the end of the ebb tide the sand was so scoured as to leave a space under the keel at both ends, leaving the hull only supported in the middle; at the end of the flood tide the vessel was again completely buried in the sand, the sand bed extending Ioo yards fore and aft of the vessel and 50 yards from each side." (Partiot-50 and Wheeler-73:I6.)

\section{Marine CuRrents.*}

Currents of the Oceans. Ocean currents are due to a combination of causes, which may be classed either as primary or as secondary stream constituents. The primary causes are the active producers of the currents, and as such may be noted (I) internal or endogenetic causes, existing within the water itself, such as local differences in density, due to variation in temperature and salinity under the influence of varying sunshine, evaporation, rainfall, or melting of snow and ice; (2) external or exogenetic causes, such as variation in air pressure, and especially the winds. Among the secondary causes which act chiefly in modifying the current may be noted, I, friction, 2 , the rotation of the earth on its axis, $\rightarrow$ and

* In this section I have followed Krümmel closely.

† This operates to deflect all moving particles on the surface of the Northern Hemisphere to the right, and to the left in the Southern. 
3. the configuration of the basins. It is this latter, $i . e$, the presence of continental masses in the path of the currents, which causes a piling up of the waters on the coast against which it is driven by the primary causes, and a potential depression of the surface from which it flows away. In the one case, then, the heaped-up water must flow away, and in the other compensating streams originate, drawing the water into the space whence removal has taken place.

In a symmetrical ocean reaching from pole to pole and covering

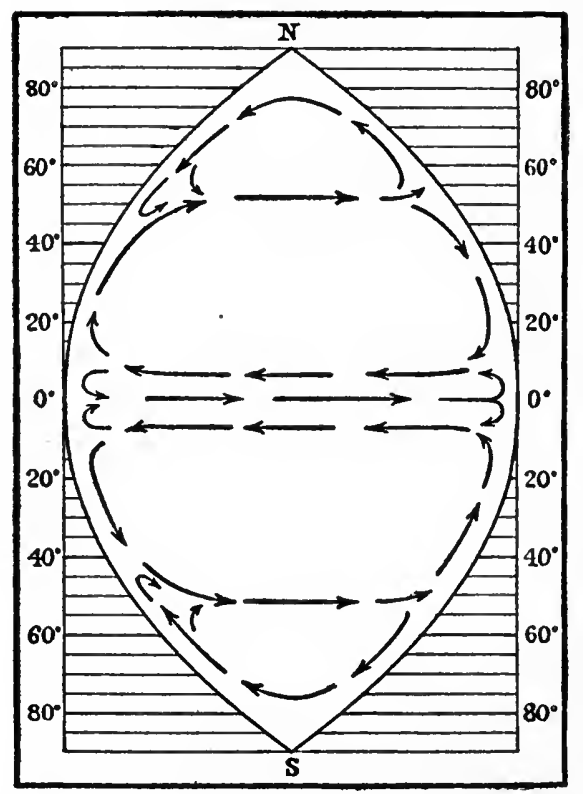

FIG. 36. Schematic representation of ocean currents in an ideal ocean. (After Krümmel.)

a meridional distance of $90^{\circ}$, we would have a symmetrical arrangement of currents as shown in the annexed diagram reproduced from Krümmel (Fig. 36). On both sides of the equator, at $10^{\circ}$ north and south latitudes, the equatorial streams would flow westward and on approaching the western shores, bending respectively northward and southward and crossing eastward again in $50^{\circ}$ north and south latitude, would approach the equator again along the eastern border of the sea, thus constituting the principal north and south circulation. Between the equatorial currents setting westward is an eastward-setting equatorial counter current, 
while two polar currents also exist, each flowing westward and forming a complete circulation with the eastward-flowing northern arm of the main circulation. The configurations of the lands are largely responsible for the course of the currents in the different oceans. Broadly outlined, the currents of the several oceans and its main dependencies are as follows:

The Atlantic Ocean. The North Equatorial current is somewhat variable in its position, its southern border ranging from $6^{\circ}$ north latitude in March to $12^{\circ}$ north latitude in September, and with an average velocity of 15 to 17 natitical miles per day, or from 32 to $36.5 \mathrm{~cm}$. per second, I.I5 to $1.3 \mathrm{~km}$. per hour,* the maximum rising to $2.4 \mathrm{~km}$. per hour or over. The direction of this current is west-southwest to west, east of longitude $35^{\circ}$, then turns due west and becomes west-northwest at the Lesser Antilles.

The South or principal Equatorial current is of a very constant character, and crosses the equator diagonally. Its southward extent is near $15^{\circ}$ south latitude, while its northern border is already $I^{\circ}$ north latitude in the meridian of Greenwich during the winter and spring months. Its average velocity in June, July and August is 20 to 24 nautical miles in 24 hours, or from $1.5^{8}$ to $1.85 \mathrm{~km}$. or more per hour, while velocities as high as 72 nautical miles per 24 hours ( 5.55 kilometers per hour) occur. The current divides at Cape St. Roque, the eastern point of South America, one arm passing southward to become the Brazil current and the other uniting with the North Equatorial current to produce the Guiana current, which later becomes the Gulf Stream. The velocity of this northern arm near Cape St. Roque is not infrequently from 30 to 60 nautical miles per 24 hours ( 2.3 to 4.6 kilometers per hour). The Guiana stream is continued as the Caribbean stream, with a velocity of 24 to 72 nautical miles per day (1.85 to 5.55 $\mathrm{km}$. per hour). It here becomes a veritable sea in motion rather than a single stream. In the Gulf of Mexico it bends eastward and leaves between Florida and Cuba as the warm Gulf Stream, flowing at first eastward, then turning northward between Florida and the Bahama banks, and then crosses the North Atlantic as the Gulf Stream or West-wind drift. At the Florida Straits the average annual velocity is 72 nautical miles per day $(5.55 \mathrm{~km}$. per hour $)$,

* The nautical or geographic mile (Seemeile) as defined by the United States Coast Survey is "equal to one-sixtieth part of the length of a degree on the great circle of a sphere whose surface is equal to the surface of the earth." This makes the value of a nautical mile $6,080.27 \mathrm{ft}$. or $1,853.248$ meters. The British admiralty knot is 6,080 ft. The German Seemeile, in terms of which the following measurements are given, is equal to $1.852016 \mathrm{~km}$. or $6079.55 \mathrm{ft}$. 
but rises to 100 or 120 nautical miles in the colder and warmer seasons, $i$. e., $\mathbf{I} .5$ to 2.5 meters per second, a velocity which compares favorably with that of many great rivers in their lower reaches during high water.

The western border of the Gulf Stream follows pretty closely the edge of the continental shelf and renkains more or less sharply defined. It is often abruptly outlined by the rising of a wall of cold water, the temperature of which in different seasons is from $10^{\circ}$ to $20^{\circ}$ lower than that of the Florida stream. This so-called "cold wall" is an effective barrier to migration, and its displacement by strong winds brings about anomalous bionomic results. Eastward the current widens from 30 nautical miles in the straits to twice that at Cape Canaveral, and becoming from 120 to $15^{3}$ nautical miles wide opposite Charleston. It constantly increases northward. Southeast of New York the average velocity has become reduced to from 30 to 48 nautical miles per day, though sometimes it rises to 72 nautical miles. The stream as such cannot be traced beyond the meridian of the eastern border of the Great Newfoundland banks, before reaching which it already begins to break up into a series of separate streams of varying temperature. The velocity of the West-wind drift becomes reduced to an average of I 2 or I 5 nautical miles in mid-ocean, though as much as 43 nautical miles per day has been observed. The well-known mild temperatures of the British Isles, especially Ireland, where flowers bloom in January, though the latitude is that of Labrador, are due to the impingement against the coast of a branch of this warm West-wind drift. Dividing on the British coast, both arms of this branch enter the North Sea, one by way of the English Channel and Dover Straits, and the other around the north coast, the Hebrides and Orkneys, while sending a third arm along the Norwegian coast. A large part of the West-wind drift or "Irish Stream," however, turns northward to Iceland, passing to the west of the Faroe Islands and turning westward and southwestward as the Irminger current, running parallel to the cold East Greenland current and sending a branch around Cape Farewell into Davis Straits. Throughout this course the velocity of the current is probably less than 2I cm. per second. From the west coast of Davis Straits the cold southward-flowing Labrador current runs past. the Newfoundland coast and the eastern border of the Grand Banks and disappears on reaching the Gulf Stream. This disappearance has been regarded as due to a "swallowing" of the cold water by the warm, or to a submergence of the cold beneath the warm, but is probably due rather to dispersal as suggested by Krümmel. Part 
of the cold water passes westward and southwestward into the St. Lawrence Gulf and Cabot Straits, and bathes the eastern coast of the United States to Cape Cod (Cabot current). It is probably recognizable in the "cold wall" bordering the Florida current. Another part turns eastward and even northeastward, occasionally carrying iceberg fragments to the North British coast.

The southern arm of the WVest-wind drift forms the Canary current, which flows southward between Madeira and the Cape Verde Islands, to join the North Equatorial current. Flowing from higher to lower latitudes, it is a relatively cool current, varying in velocity from 8 to 30 nautical miles per day (o.62 to $2.3 \mathrm{~km}$. per hour).

The Equatorial Counter current of the Atlantic is especially well developed off the African coast, where it is known as the Guinea current. Its position varies with the seasons, but it is always a warm current. It is not traceable over the entire mid-Atlantic, being formed by recurring branches of the two equatorial currents. In March its western end lies near $25^{\circ}$ west latitude, and in September near $40^{\circ}$ west latitude, and in other months it lies between these. It broadens westward, gaining an average velocity of perhaps 18 nautical miles per day, though velocities as high as 40 or $5^{\circ}$ may occur, while at Cape Palmas a velocity of 85 nautical miles per day has been recorded. Owing to the conformation of the West African coast, an arm of the Guinea current is deflected northward, though its main mass enters the Gulf of Guinea. This is especially the case in the summer months.

In the South Atlantic the principal warm stream is the Brazil current, which follows the South American coast to latitude $49^{\circ}$ or $50^{\circ}$, before reaching which it has turned eastward and united with the cold Cape Horn current, forming the South Atlantic connecting current, which varies in velocity between 6 and 33 nautical miles per 24 hours. The northern part of this connecting stream has a higher temperature than the southern, as is to be expected from the double origin of this current. An arm of the Cape Horn current turns northward along the Patagonian coast, forming the cold Falkland current, which is always at least $3^{\circ}$ to $4^{\circ}$ cooler than the neighboring Brazil current.

Where the cold West-wind drift of the South Atlantic meets the West African coast, it turns northward and becomes the cold Benguelan current, with a velocity of generally more than I2, but seldom more than 30 , nautical miles per day, a velocity sufficient to deflect the red-brown water of the Congo northward and cause the floating mangrove islands and tree trunks furnished by this 
stream to be carried northeastward, far out into the Atlantic. Of the two great current rings thus formed in the Atlantic, that of the North Atlantic turns clockwise, that of the South Atlantic counter clockwise. The areas enclosed by them are relatively free from currents, both air and water, and mark a region of high air pressure. The northern is filled with the floating seaweed forming the Sargasso Sea, while the southern is relatively free from accumulated drift material. Transportation of floating material (plankton) from one circle to the other occurs sometimes, but generally these circles remain distinct.

The Arctic Ocean. In this ocean the chief current is the continuation of the Gulf or Atlantic stream, which, after giving off a branch to the southeast into the North Sea around the North British coast, continues past the Shetland Islands along the Norwegian coast to beyond North Cape, where it splits into a number of minor streams, one of which, the North Cape current, turns east along the north coast into the Barent Sea, to the south coast of Nova Zembla, with a branch north to Franz Josef Land. Another arm continues northward to Spitzbergen, where it can be recognized beyond $80^{\circ}$ north latitude. All along its course, driftwood from tropical regions has been observed, the most noted example being the bean of the West Indian Entada gigalobium, one of the commonest drift materials of the Gulf Stream, which was found by Otto Torell in latitude $80^{\circ} 8^{\prime}$ north, longitude $17^{\circ} 40^{\prime}$ east, the western point of North East Land. The cold currents most pronounced are the East Greenland current already noted and its branch, the East Iceland current. This meeting with the warm water of the Gulf Stream extension produces a series of complicated whirls, which have a decided influence on the distribution of the temperature, the salinity, and, with these, the planktonic life. (See the maps given by Helland Hansen and F. Nansen-3o; Krümmel-42:652.) Various other cold streams have been charted, such as the cold Bear Island stream, issuing from the Barent Straits, another issuing from Kara Straits and passing along the south and west coast of Nova Zembla, one between Nova Zembla and Franz Josef Land, and one between the latter and Spitzbergen, flowing southward and westward. All these are branches of a general southward drift of the cold surface waters of relatively low salinity, which result from the inpouring and excessive precipitation of fresh waters, and give the arctic waters in general a higher.level than that of the neighboring oceans. On the Atlantic side the outlets are on the two sides of Spitzbergen, especially between Spitzbergen and Greenland. Another line of outflow is from the waters 
of the Parry Archipelago, eastward to Baffin Bay, and south to Davis Straits, where it becomes part of the Labrador current, which is further fed by recurving waters of the West Greenland current. (See maps, Krümmel-42:663.)

The Pacific Occan. The currents of this ocean conform more nearly to the typical arrangement sketched at the beginning than do those of any other terrestrial ocean. The North Equatorial stream, driven by the northeast trade winds, crosses the entire ocean from east to west $\left(\mathrm{S} .87^{\circ} \mathrm{W}\right.$.), a distance of 7,500 nautical miles, with an average velocity of 14.5 nautical miles in 24 hours, $31.08 \mathrm{~cm}$. per second or $1.12 \mathrm{~km}$. per hour, and with a high percentage of stability. The southern border of this stream lies $10^{\circ}$ north of the Equator in summer, and $5^{\circ}$ in winter. East of the Philippines, the current turns north, increasing its velocity to 30 or even 50 nautical miles per day. The main body goes north to form the Kuroshiwo or Japan current, which, skirting Japan, gives rise to the North Pacific West-wind drift and bends southward again on the West American coast as the California current. This replaces the waters carried westward in the North Equatorial current under the influence of the northeast trade wind, and corresponds to the Canaries current of the North Atlantic. A smaller part of the North Equatorial stream bends off through the Ballingtang channel north of the Philippines into the China Sea, where, especially in winter, during the period of the northeast monsoon, it adds a considerable amount to the cyclonal circulation of that mediterranean. Finally, large parts of the current become reversed, especially in summer, to form part of the Equatorial Counter current. The South Equatorial current is much stronger than the northern, velocities of 20 nautical miles per day being normal, velocities of 40 or 50 not uncommon in all seasons, while occasional velocities of 70,80 , or even more than roo nautical miles in 24 hours have been recorded. The greatest velocity is in its northern part, near or north of the Equator, especially in the eastern region, and here the rapid movement brings about a welling up of the colder, deeper waters as clearly indicated by the tongue-like drawing out of the isotherms west of the Galapagos Islands on the temperature chart of the Pacific. The length of this stream is about 8,500 nautical miles; its northern border may reach to $I^{\circ}$ or $2^{\circ}$ north of the Equator. Opposite the Molucca Straits the northern part of the stream bends northward and, recurving, produces its part of the Equatorial Counter current. The greater part, however, flows southward along the Australian coast, and constitutes the East Australian current. This in part disposes of the excess of water driven against this 
coast by the southeast trades, as the South Equatorial current, and in part becomes a compensating current to replace the eastwardflowing waters of the great South Pacific West-wind drift. This finally turns northward as the Peruvian current, with an average velocity of I 5 nautical miles per day, which velocity is greatly increased as it nears and finally joins the South Equatorial strean, which has the effect of an aspirator. Cold waters well up between the Peruvian current and the South American coast, and these were formerly regarded as Antarctic waters flowing northward.

The Equatorial Counter current crosses the entire Pacific from west to east, being especially strong during the northern summer, when it occupies the zone between $5^{\circ}$ and $10^{\circ}$ north latitude, though in winter it shrinks to a narrow band between $5^{\circ}$ and $7^{\circ}$. With the varying season the strength of the current fluctuates. Thus in winter it is from 5 to 8 nautical miles per day, while in summer it rises to 9 or 12 nautical miles.

The Indian Ocean. The currents of this ocean are subject to semiannual variation induced by the alternate dominance of the winter or summer monsoons. During the winter or northeast monsoons the currents correspond in a measure to those of the Atlantic and Pacific. Two westward-flowing currents separated by an eastward-flowing counter current occur. The South Equatorial is the most pronounced, its boundaries being between $10^{\circ}$ and $27^{\circ}$ south latitude, while the counter current lies between $2^{\circ}$ and $5^{\circ}$ south latitude. This latter has a strength of 20 to 60 nautical miles per day. During the northern summer, when the southwest monsoon prevails, the southern westward-flowing current is broadened to near $5^{\circ}$ south latitude, the counter current as such has disappeared, while the movement of the waters north of the equator is eastward.

Against Madagascar the impinging South Equatorial current divides, a large part passing southward as the Mozambique current, and later becoming the Agulhas stream, which bathes the coast of Cape Colony in South Africa outside of the continental shelf, where velocities ranging from 50 to 1 Io nautical miles per day have been noted. South of the Cape of Good Hope the Agulhas current meets the southern continuation of the cold West-wind drift of the South Atlantic, which causes it to splinter into numerous fingers, the spaces between which are taken by the cold fingers of the eastward-flowing stream. In addition to carrying off the waters of the South Equatorial current, the Agulhas stream further acts in a compensatory manner to supply the water carried eastward by the strong west winds of the southern latitudes. This south Indian 
West-wind drift is again continued in part in the northward-flowing West Australian current, the close analogue of the Benguelan current of the South Atlantic. The velocity of this current generally ranges from i8 to 36 nautical miles per day, though sometimes it is scarcely perceptible. The main part of the West-wind drift, however, continues eastward past Cape Leeuwin and along the South Australian coast past Tasmania to the Pacific, forming part of the great circumpolar current of the Antarctic region. That this great eastward drift around the antarctic continent is a reality has been shown by many tests with floating bottles, one of which, thrown overboard December I6, I900, off the Patagonian coast (long. $60^{\circ}$ W.), was picked up June 9, I904, on the north coast of New Zealand (long. $172^{\circ}$ ) having traveled in $1,27 \mathrm{I}$ days a distance of 10,700 nautical miles, or nearly $2 / 3$ the circumference of the earth, between latitude $40^{\circ}$ and $50^{\circ}$ south, a distance equal to that from pole to pole, or an average of $81 / 2$ nautical miles per day. (Mrp, Krümmel-42:677.)

A characteristic accompanying feature of the wind-drift currents is a vertical compensatory movement, the upwelling of the colder, deeper waters where the velocity of the surface stream is such that the lateral compensation is insufficient. An example of this has already been cited in the tongue of deep-green, colder water extending westward from the Galapagos into the blue warm water of the South Equatorial current of the Pacific. A similar phenomenon occurs along the west American coast, where the California current draws up the colder, deeper water on its landward side. This is likewise the case in the Canary and Benguelan streams, as well as along the west coast of South America. The upwelling follows the wind, while a compensating downward movement of the warmer water must occur before the wind. This explains the phenomenon that a persistent land breeze will cause the upwelling along the coast of the colder waters, the warmer being blown out to sea, while a sea breeze brings the warmer surface waters. Thus it is observed at the bathing beaches on the North German coast that the north winds cause a warming, but south winds a distinct cooling of the water.

Currents in Mediterraneans and Epicontinental Seas. The currents of intracontinental water bodies are generally mere branches of the main oceanic circulation, and sometimes indeed, as in the case of the Caribbean and Mexican seas, are an integral part of it. The circulation of the North Sea is a southward-bending branch from the Gulf Stream, and the main currents of the East Greenland mediterranean are also a part of this larger circulation. 
The currents of the Arabian Sea and the Bengal Bay are clearly a part of the circulation of the Indian Ocean, while the circulation of the China Sea is in part a branch of the North Equatorial current of the Pacific. In general, the circulation of the mediterraneans is a cyclonal one, and it becomes more individualized the more the water body is separated from the oceans adjoining.

The Roman Mediterranean, which is connected with the Atlantic only by the narrow Gibraltar Straits, nevertheless receives a small branch of the northern West-wind drift. This stream, though subject to modification by local winds, is recognizable throughout, and influences the migration of the sands of the bottoms and coasts. It passes eastward along the north coast of Algiers, through the narrows between Tunis and Sicily, with a velocity of 5 to 10.5 nautical miles per day, and south of Malta toward Barca (Africa), causing eddies in the Gulf of Sidra, turning northward on the Syrian coast, and westward on the south coast of Asia Minor, around Crete into the Ionian Sea, then north along the Dalmatian, and south along the east Italian coasts, making a counterclockwise circulation in the Adriatic. In the Tyrrhenian Sea it continues northwestward, then west in the Ligurian and southwest along the Spanish coast, thus completing the counter-clockwise circulation. This circulation takes place largely under the influence of the local winds, and is not always constant.

Both the Adriatic and Egean seas have practically independent circulations in a counter-clockwise direction, and a similar circulation exists in the Black Sea, though a part of the water moving along the west coast of this body passes out as a strong stream through the Bosphorus, the Sea of Marmora, and the Dardanelles into the Agean Sea. To compensate this outflow, a deeper lying current enters from the Egean and the Marmora Sea. At Constantinople the outflowing stream of the Bosphorus has a velocity of $123 \mathrm{~cm}$. per second at the surface, and rapidly decreases to nothing at 20 meters' depth. At 25 meters' depth the inflowing stream is at its maximum with a velocity of $73 \mathrm{~cm}$. per second with moderate diminution downward, its strength at $40 \mathrm{~m}$. depth being still $43 \mathrm{~cm}$. per second. Makaroff has estimated that the outflowing stream carries $10,530 \mathrm{cb} . \mathrm{m}$. per second, while the inflowing carries only 5,700 cb. m. per second: This makes a yearly deficit of $\mathrm{I}^{2} \mathrm{cb}$. km., the excess carried out over the inflow, and this has to be replaced by the annual precipitation and afflux of water from the drainage basin. A similar out-and influx take place through the Straits of Kertch between the Sea of Azov and the Black Sea. Just the reverse motion is seen at the mouth of the Roman Mediterranean and that of 
the Red Sea. Here the ocean waters are of less salinity than those of the mediterraneans, and they flow in on the surface, while the more saline waters from the mediterraneans escape below the surface to the oceans, influencing the salinity of the adjoining parts of the sea. In the Straits of Bab-el-Nandeb the surface waters enter the Red Sea with a velocity of 2 to $23 / 4$ natutical miles per hour, extending down with diminishing velocity to $\mathrm{I} 3 \mathrm{O}$ or I 40 meters, below which the outflowing stream ranges in velocity from $I$ to 3 nautical miles per hour.

An outflowing surface stream, the Baltic Stream, carries the weakly saline waters of the Baltic through the Ore Sound and continires along the Swedish coast of the Kattegat, where it is driven by the prevailing west wind and the rotation of the earth. Its velocity at a distance of 4 to 6 miles from shore is 24 to 48 nautical miles per day in calm weather. Turning westward along the Norwegian coast, it may reach a velocity of 80 to roo nautical miles in 24 hours. It normally flows against the prevailing wind, which must reach great strength before it is able to reverse the current even temporarily. This stream has its greatest strength in the spring and early summer months, when the influx of fresh water into the Baltic is at its maximum.

The currents of the Baltic and its branches are largely dependent on the wind and are further complicated by the tidal currents and the relative amount of influx and evaporation. In the spring 76 per cent. of all currents flows westward, owing to the strong influx of land waters and the pronounced east winds. In summer this drops to 60.5 per cent., when evaporation over the Baltic becomes strong and west winds prevail, while during autumn and winter $7 \mathrm{I}$ per cent. and 69 per cent. of all currents of the Baltic flows westward. The strength of the outflowing streams may reach 3 to 4 nautical miles per hour in the narrows of the western part, or Belt Sea. The Finnish Gulf, which is scarcely separated from the Baltic, and has therefore much the structure of a funnel sea, is characterized by a westward-flowing surface stream of fresher water and an eastward-flowing compensating stream of greater salinity at some depth below the surface. The Bothnian Gulf, on the other hand, has a more independent circulation in the counter-clockwise direction, and this corresponds to its greater distinctness from the Baltic. The current flows into the gulf east of the Aland Islands, and out on the west, except when interfered with by strong winds.

The circulation of other northern intracontinental seas, like Hudson Bay, St. Lawrence Gulf and Kara Sea, is a cyclonal one in the counter-clockwise direction. A similar circulation exists in the Red 
Sea, where the current sets north on the Arabian and south on the African coast. Here, however, the strong monsoons act as modifiers of this general circulation. Similar conditions exist in the Persian Gulf, but here, as in epicontinental seas generally, the circulation is strongly modified by winds and tidal streams. The marginal mediterraneans of the West Pacific coast show the cyclonic circulation in the counter-clockwise direction characteristic of the northern hemisphere, but more or less modified by the inflowing circulation of the North Pacific itself. The Japan Sea may be taken as typical. Here a branch of the warm and highly saline Kuroshiwo current enters through the Straits of Korea, and follows the west coast of Japan northeastward. It sends branches out to the Pacific through the several straits, and then turns into the Gulf of Tartary, where it unites with the counter current from the north, the low temperature and salinity of which strongly influence the Asiatic coast, which it follows to the east coast of Korea. The circulation within the sea of Okhotsk, and to a less extent in Behring Sea, follows the same plan, though in the latter the influence of the warm Kuroshiwo in summer causes marked modifications such as a northward flowing warm surface stream in the western half to Behring Straits.

The Australian group of mediterraneans is of especial interest, as it lies on both sickes of the equator and so partakes alternately of both systems of circulation. At the time of the northeast monsoon the counter-clockwise circulation normal for the northern hemisphere exists in the China Sea, the water running W. S. W. along the Chinese coast with a velocity of 20 to 40 nautical miles toward the coast of Anam, where it reaches velocities of 50 to 80 nautical miles per day, turns south and east, and then to the northeast, along the west coast of Borneo, Palawan Island and the Philippines, with velocities of 15 to 25 nautical miles per day. The currents of the Java, Flores and Banda seas flow prevailingly eastward with southward flowing branches through the straits between the small Sunda Islands and on both sides of Timor. The reverse direction is taken by the circulation in the time of the southwest monsoon. Along the coast of Cochin China, the stream flows northeastward, reaching a strength of 40 to 70 nautical miles at Cape Pedaran; along the Anam coast it flows north, and off the South Chinese coast in general eastward. Along the coast of Palawan and Borneo the movement is southwestward, the circle being closed by a northward stream from the Natuna to the Condore islands. In the Java, Flores and Banda seas the main direction of the flow is westward. It thus appears that the circulation in med- 
iterraneans and epicontinental seas of the northern hemisphere, when not a part of the main oceanic circulation, as in the American mediterraneans, is normally a singly cyclonic movement in counterclockwise direction, while the movement of the main oceanic circulation of this hemisphere is clockwise. Only in the case of the seas lying on the Equator does a reversal of conditions occur when the sun crosses to the north of the Equator during the northern summer or the period of southwest monsoons.

The type of currents found in funnel seas of the Californian type is illustrated by that water body. During the cooler months the prevailing northwest winds drive the surface waters southward, while in summer the monsoon-like southeast winds drive the surface waters into the gulf. At a depth of 50 meters the stream flows again southward.

Marine Currents in Relation to Migration and Dispersal, Past and Present. As will be more fully set forth in Chapter XXIX, ocean currents are among the important factors in influencing migration of organisms, and they are the chief cause of the dispersal of the plankton or floating matter, organic and inorganic, of the sea. The numerous records of the wide dispersal of floating matter, such as sealed bottles, purposely thrown into the sea, wrecks of known date, tree trunks brought by tropical rivers to the sea, and carried by the ocean currents to the arctic regions, and others have indeed been one of the chief sources of our knowledge of the direction of these currents. Taking our cue from these dispersals in the modern sea, we niay look for similar evidenze of currents in the past. In such determination the dispersal of the holoplanktonic organisms serves perhaps as the best guide. In the early Palæozoic, the graptolites seem to furnish reliable indications of the general course of the currents, and they have been so used in the construction of Palæogeographic charts. (Ruedemann-60:488; Grabau-29; Map figs. $I, 2,7,8$.) Sometimes the direction of the current can be found by the position which the rhabdosomes of the graptolites assumed in the strata, as in the case cited by Ruedemann from the Utica shales of Dolgeville, New York, where not only the rhabdosomes of the graptolites, but also the spicules of sponges, fragments of byozoans and shells of Endoceras proteiforme have a parallel arrangement, indicating an east-northeast by south-southwest direction of the currents. "That the flow came from N. $78^{\circ}$ E. and ran toward S. $78^{\circ} \mathrm{W}$., can be inferred from the appearance of the mud-flow structure, the drift ridges behind the fossils (Endoccras), the eastward pointing of the apices of the Endociras shells, and often also of the sicular ends of the graptolites. 
Gastropods have been noticed with transversally arranged fragments, which apparently were arrested by the immovable shell, on the east side, and with a drift ridge of longitudinally arranged fragments on the west side." (Ruedemann-59:380-38I.) Since the general direction of the great ocean currents seems to have been to the northeast, this indication of a southwestward flow establishes a secondary recurving current of the type common at the present time.

Depth of Current Action. The depth of current action can often be ascertained by the scouring which it accomplishes on the bottom, sweeping off all fine sediment, and leaving a "hard bottom." T. M. Reade has recorded such bottoms between Gran Canaria and Teneriffe in the Canary Islands in depths of 2,000 meters. (T. M. Reade-56.) This is, however, to be regarded as more properly the work of a tidal current. In the Florida straits, at depths of 160 to $55^{\circ}$ meters, the bottom is kept clean, the fine mud being swept beyond the edge of the Pourtales Plateau, which consists of recent organic material consolidated into a hard breccia. The bottom of the Straits of Gibraltar is swept clean and smooth through the outward flowing bottom current.

\section{Lake Currents.}

Lakes, owing to their usually small size, are not influenced in the same manner by the primary current-producing agents as are the larger water bodies. It is true that on the large lakes, like those of North America, longshore currents, due to prevailing winds, are of considerable significance, not only in navigation, but in the transportation of material along the beach, and the building of bars, sandspits, etc. In general, however, the movements of lake waters induced by wind partake of the nature of a vortical circulation. The wind blowing steadily across the surface of a lake forces the water to the opposite shore, where it sinks, while the compensatory streams behind the wind rise from below. This produces an under current flowing in the opposite direction from that on the surface, and at a depth depending on the temperature, density, etc., of the water and the configuration of the basin. (Forel-24:8I-83.)

\section{River Currents.}

Rivers are currents of water confined between banks of rock or soil, and they differ from currents in water bodies in that typically their movement is due to gravity alone. While the whole mass of 
water of the river is in motion, nevertheless there is to be found in each cross-section of a river a point of maximum motion. This is generally a short distance below the surface, and in a symmetrical section, near the center. This fast-moving portion of the river is especially designated the "current," and its course in a winding river is always more curving than that of the river itself. As a result, it impinges alternately upon the right and left bank of the river, which points become the centers of maximum erosion. The bank against which the current impinges will be kept vertical by undermining, and the river at the same time will be deepest at that point. The opposite side is shallow, the bank sloping, and deposition rather than erosion occurs.

Velocities of River Currents. The velocity of a river depends on a number of factors, first among which may be mentioned the slope of the river bed, and next the volume of water. The width of the channel is also an important factor, this varying from the indefinite width of the sheet floods of Arizona and Mexico (McGee-45) to the narrow canyons of a youthful topography. The slope may vary from nearly horizontal to vertical; in the one case, a nearly stagnant stream results; in the other, the extreme of a waterfall is produced. The most variable of these factors is the volume, and hence the velocity of a given current may change greatly between low and high water. Sudden changes in volume due to sudden precipitation of vast amounts of water, as in semiarid regions, may produce a marked change in the slope or width of the chamnel, and so affect the strength of the current in a more permanent manner. Within the same stream velocities vary according to slope, or width and depth of the channel. Thus the velocity of the Rhine, during medium height of water, has been found to be $3.42 \mathrm{~m}$. per second at the Bingerloch, $0.63 \mathrm{~m}$. at Werthausen and $1.5 \mathrm{~m}$. at Mannheim, while high water at Coblenz gave a velocity of $1.88 \mathrm{~m}$. per second. The Vistula (Weichsel) during high water has a velocity of $\mathrm{I} .2$ to $\mathrm{I} .9 \mathrm{~m}$. per second. The Neckar above Mannheim at medium water has a velocity of $0.9 \mathrm{~m}$., but at high water over $3 \mathrm{~m}$. The Danube at Vienna has a velocity of I.94 $\mathrm{m}$. per second during high water, while the maximum velocity of the Mississippi between the mouths of the Ohio and the Arkansas is $1.9 \mathrm{I} \mathrm{m}$. and between Bayou la Fourche and the forking is $1.76 \mathrm{~m}$. per second. (Krümmel-42:575, footnote.)

Perhaps the best example of local changes due to change in the bed of the river is furnished by Niagara. This river is placid and calm from its head near Lake Erie to within a half mile or more of the falls, the fall being $\mathrm{I}_{4}$ feet in something over 20 miles, and 
the current very slight. Then a sudden change in the slope of the river bed, causing a descent of 55 feet in less than half a mile, transforms the river into a rushing torrent-the rapids above the fallsculminating in a drop of 160 feet at the cataracts, over which 22,400,000 cubic feet of water fall per minute. Below the falls strong currents and eddies continue for a while, due to the disturbance of the water at the falls. Then, however, the river becomes relatively calm again with moderate current, easily navigable for about two miles. The channel is from 1,200 to 1,300 feet wide at the top, and the water from 160 to 190 feet deep. At Suspension Biridge the channel suddenly contracts to 700 or 750 feet at the top, while the water is not over 35 feet deep. In this narrow and shallow gorge the whirlpool rapids are situated, the great volume of water rushing through it with indescribable force, far exceeding that of the upper rapids. The descent at the same time is slightly more than 50 feet in a distance of about a mile, or about half the descent of the upper rapids. The curious eddy of the whirlpool is entirely due to the conformation of the channel, which here bends at right angles. A second narrowing at Fosters Flats again produces rapids, but below this the river becomes relatively quiet and placid again, and navigable for seven miles of its lower course.

Erosive Power of Rivers. The erosive power of a river, $i . e$., the ability to overcome cohesion, varies as the square of its velocity. Pure water does little or no actual erosion, this being accomplished by the transported material. The rock fragments carried by the stream corrode its bed, while at the same time they abrade each other. In the part of a stream bed unsupplied by new material from tributaries it is noticeable that there is a progressive diminution in size of the fragments downstream, the reduction being proportional to the weight of the rock in water and the distance traveled. The following measurements made on the river Mur show the progressive reduction in average size of the fragments in accordance with distance (Hochenburger-33:53, quoted by Penck$\left.5^{1}: 292\right)$ :

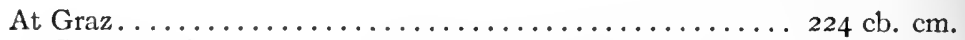

At Gössendorf....... ( $10 \mathrm{~km}$. below Graz) ........ $184 \mathrm{cb} . \mathrm{cm}$.

At Wildon........... ( $26 \mathrm{~km}$. below Graz) ........ $132 \mathrm{cb} . \mathrm{cm}$.

At Landscha......... ( $43 \mathrm{~km}$. below Graz) ........ I17 cb. cm.

At Unterschwarza..... ( $56 \mathrm{~km}$. below Graz) ........ $81 \mathrm{cb} . \mathrm{cm}$.

At Dippersdorf....... ( $71 \mathrm{~km}$. below Graz) .......... 60 cb. $\mathrm{cm}$.

At Leitersdorf ....... ( $83 \mathrm{~km}$. below Graz) ........ $50 \mathrm{cb} . \mathrm{cm}$.

At Mauth-Eichdorf.... (101 km. below Graz) ......... $33 \mathrm{cb} . \mathrm{cm}$.

At Wernsee......... (112 km. below Graz) ........ $37 \mathrm{cb} . \mathrm{cm}$.

At Unter-Mauthdorf... (120 km. below Graz) ........ $21 \mathrm{cb} . \mathrm{cm}$. 
The distance necessary for rock fragments to travel before they become completely destroyed varies with the character of the rock, as shown in the following table:

Rhætic sandstone ..... (Average weight, 40 grams)...... $15 \mathrm{~km}$.

Clay slate......... (Average weight, 24 grams) ....... $4^{2} \mathrm{~km}$.

Orthoceras limestone. . (Average weight, 61 grams)....... $64 \mathrm{~km}$.

Granular limestone... (Average weight, 40 grams)....... $85 \mathrm{~km}$.

Granite........... (Average weight, 36 grams)...... $278 \mathrm{~km}$.

Rate of crosion. From the known area of the hydrographic basin of a river, and the measured amount of transportation of the material in the river, it is possible to arrive at a reasonably accurate estimate of the rate of erosion of the river system in question. Thus the Mississippi system, with a hydrographic basin 1,244,000 square miles in area and an annual discharge of seliment of 7,47 I,4 I I,200 cubic feet of sediment, erodes at the rate of one foot in 4,640 years; while the Ganges system, with a hydrographic basin of only 400,000 square miles and an estimated annual discharge of sediment of $6,368,000,000$ cubic feet, erodes its basin one foot in I,75I years. Other estimates make it I meter in 7,78I years, or I foot in about 2,628 years. The greater efficiency of the Ganges is attributable in large part to heavy rainfall during six months of the year, and to the steeper slopes of the basin.

Le Conte $(43: I I)$, using the Mississippi basin as more typical than the Ganges for the earth's surface as a whole, concludes that the continent is probably lowered at the rate of one foot in 5,000 years.

Transporting Power of River Currents. Streams move solid material either by rolling it along the bottom or by carrying it in suspension. Suspension of fine material is favored by minor upward currents in the main current, while others carry it down again or against the side of the channel. Suspended material is repeatedly dropped and picked up again, the solid particles making their journey down the river with many interruptions. The total amount of material transported by rivers is often very great. Thus the Mississippi River carries more than $400,000,000$ tons of sediment each year to the Gulf of Mexico, or more than a million tons a day. The exact volume, according to the measurements of Humphreys and Abbot $(34: 178-150)$, is $7,47 \mathrm{I}, 4 \mathrm{II}, 200$ culbic feet, a mass sufficient to cover an area of one square mile to a depth of 268 feet. The amount carried to the sea by all the rivers of the earth has been estimated at perhaps 40 times this quantity. (Salisbury-62:I22.)

The following table (Kayser-39:345) gives the amounts of ma- 
terial carried in suspension or rolled along the bottom of some of the larger streams of the world, according to the investigations of Guppy and T. Mellard Reade.

Table showing the transportation of material by rivers.

\begin{tabular}{|c|c|c|}
\hline Stream & $\begin{array}{l}\text { Water in } \\
\text { cu. meters } \\
\text { per sec. }\end{array}$ & $\begin{array}{c}\text { Material } \\
\text { carried } \\
\text { in cu. meters } \\
\text { per year }\end{array}$ \\
\hline 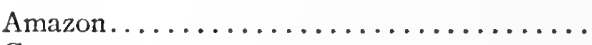 & 69,580 & $\because \cdots \cdots \cdots$ \\
\hline 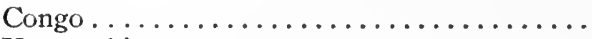 & 50,970 & $\therefore \ldots \ldots \ldots$ \\
\hline 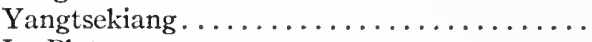 & $2 \mathrm{I}, 8 \mathrm{IO}$ & I $82,000,000$ \\
\hline 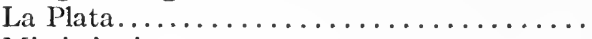 & 19,820 & $44,000,000$ \\
\hline Mississippi $\ldots \ldots \ldots \ldots \ldots \ldots \ldots \ldots \ldots \ldots$ & 17,500 & 2 I I $, 500,000$ \\
\hline 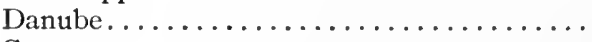 & 8,502 & $35,540,000$ \\
\hline 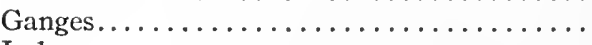 & 5,762 & $18,030,000$ \\
\hline Indus. . . . . . . . . . . . . . . . . . . . & 5,649 & $\ldots \ldots \ldots$ \\
\hline Nile. .................................... & 3,680 & $\ldots \ldots \ldots$ \\
\hline 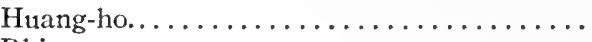 & 3,285 & $472,500,000$ \\
\hline 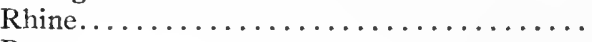 & I, 974 & $\ldots \ldots \ldots$ \\
\hline 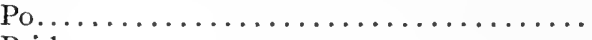 & I,735 & I I $, 480,000$ \\
\hline 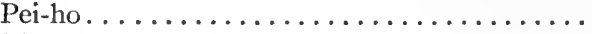 & 220 & $2,266,000$ \\
\hline Thames......................... & 65 & 528,300 \\
\hline
\end{tabular}

The ability of a current to transport material varies in general as the sixth power of its velocity. Thus, if the velocity is doubled, the carrying power is increased 64 times. A current having a velocity of 3 feet (or approximately I meter) per second (about 2 miles per hour) will move ordinary rock fragments of the size of a hen's egg and weighing about 3 ounces. From the law of variation it follows that a current of ten miles per hour will carry rocks weighing one and one-half tons, while a torrent of 20 miles per hour will carry rock masses Ioo tons in weight. Taking the varying specific gravities of different rocks into consideration, the table on page 249 has been constructed by T. E. Blackwell ( 5 ; cited by Beardmore- $3: 7$; Penck-5I:28I) to show the size of the various rock masses transported by currents of varying velocity.

According to the experiments of Forbes $(23: 474)$ made in a shallow trough, the following velocities were required to stir up various sediments from the bottom:

\section{Table of velocities required to stir up bottom material.}

Moist brick clay at a velocity of............. $0.077 \mathrm{~m}$. per sec. Fine fresh-water sand at a velocity of .......... $0.213 \mathrm{~m}$. per sec. Sea sand at a velocity of ............... $0.337 \mathrm{~m}$. per sec. Gravel, pea size, at a velocity of............. $0.6 \mathrm{ro} \mathrm{m}$. per sec. 


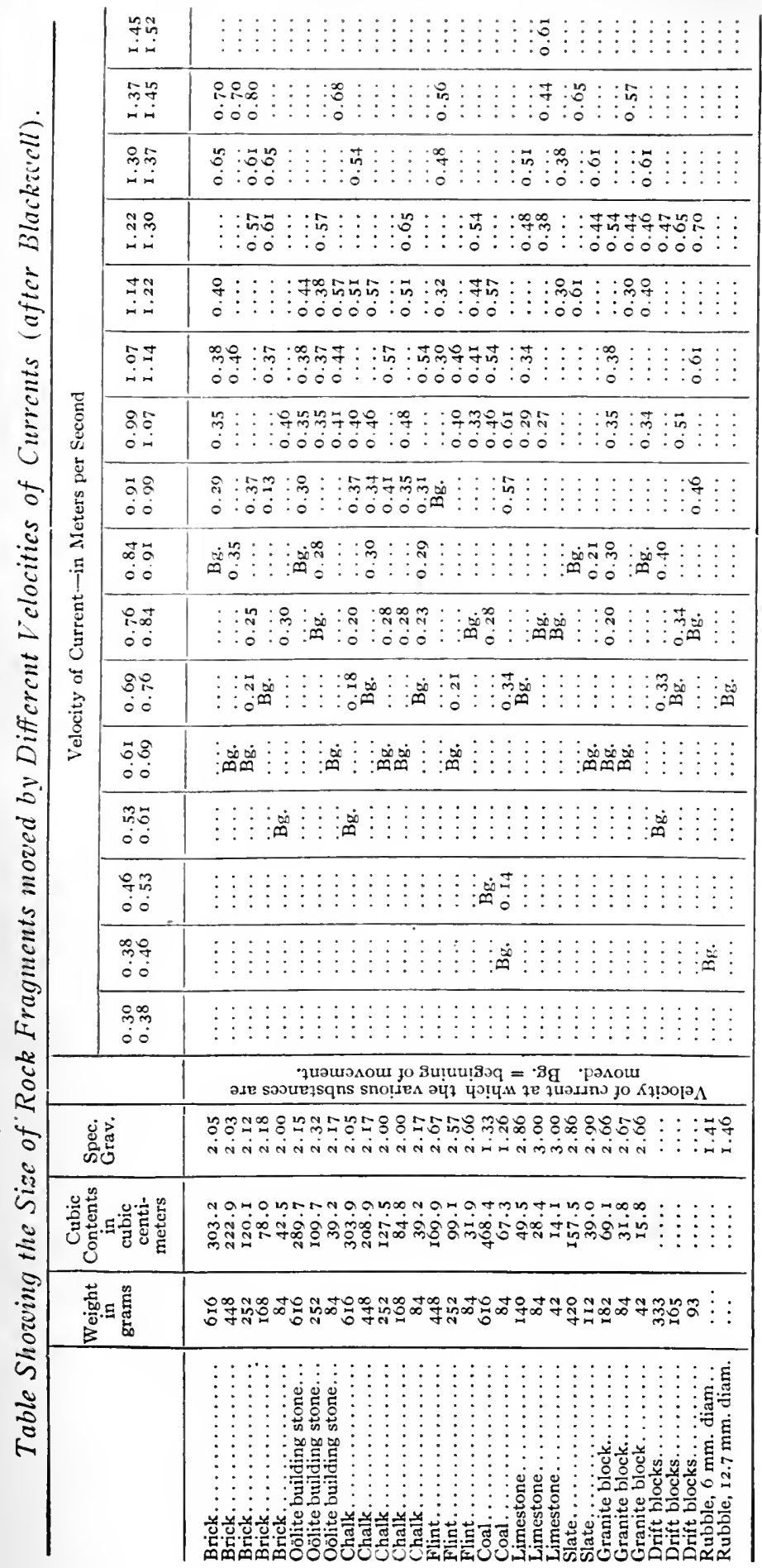


Recent experiments by Sorby $(66: I 80)$ indicate that a current of about 6 inches per second is sufficient to slowly drift along granules of common sand having a diameter of about a hundredth of an inch. No rippling of the sand was produced until the velocity was somewhat greater. In the bed of the River Rhine at Breisbach the following measurements were made by Suchier $(7 \mathrm{I}: 33 \mathrm{I} ;$ Penck-5I :283) to ascertain the velocity at which various sediments begin to move, (I) through the influence of the current alone, and (2) after the sediments on the bottom are stirred up :

A. With stream bed covered by fine sediment.

Under action of current alone, no movement found, with bottom velocity at. ..................... $0.694 \mathrm{~m}$. per sec.

After being stirred up, the movement of the sediment began for fragments of the size of beans, when bottom velocity reached..................... $0.897 \mathrm{~m}$. per sec.

Fragments of the size of hazelnuts, when bottom velocity reached.

Fragments of the size of walnuts, when bottom velocity reached. . . . . . . . . . . .

Fragments of the size of a pigeon egg, when bottom velocity reached.................... I.I 23 m. per sec.

B. With river bottom free from sediment, the smallest particles

are moved when the current velocity reaches at bottom........................ I. 80 m. per sec.

Pebbles of pea and hazelnut size move freely under a velocity of . . . . . . . . . . . . With noticeable noise at................ I.300 m. per sec.

Pebbles of walnut size are moved without stirring and such of 250 gr. weight after stirring up, with current at . . . . . . . . . .

Pebbles of $\mathrm{I}, \mathrm{ooo}$ gr. wt. rolled at................ $1.589 \mathrm{~m}$. per sec.

C. General movements of pebbles:

Up to the size of pigeon eggs, at. ........... 1.623 m. per sec.

Up to the size of hens' eggs, at.............. (including such of $\mathrm{I}, 500 \mathrm{gr}$.)

Pebbles of less than 2,500 gr. wt. are moved at....... I. $800 \mathrm{~m}$. per sec. All pebbles moved at..................... $2.063 \mathrm{~m}$. per sec.

It is evident that it requires a much greater velocity to start the movement than is required to keep it up. This is shown by the following comparison: 
Size of pebbles

Hazelnut size........... $0.923 \mathrm{~m}$. per sec.

Walnut size........... I.062 m. per sec.

Pigeon egg size.......... I.123 m. per sec.
Velocity required to start motion

I.35 m. per sec.

I.39 m. per sec.

$1.45 \mathrm{~m}$. per sec.

The transportation of the coarser detritus in streams is chiefly by rolling along the bottom, more rarely by pushing along. The entire river bed may be in motion, forming a waste stream saturated with water, which in the case of the Rhine at Ragaz and the Birsig at Basel has been found to possess a depth of more than three meters (Pestalozzi-53:vi) and of four meters in the Danube at Vienna. This phenomenon is, however, ordinarily restricted to mountain streams in flood.

The sands of the river bottoms generally assume the arrangement of a series of low banks, alternating in position on opposite sides of the stream. Opposite each low bank is a deep channel with steep sides, harboring the main current of the river. These banks, which in general have a triangular outline, their bases against the river banks, slowly wander downstream, through removal of the sand on the upstream side, its passage across the bank and deposition against the downstream side. On the middle Rhine such banks move at the rate of 200 to 400 meters per year downstream, this being increased to three times that amount in years of high water. In seven years a bank may thus reach the former position of the one next downstream on the same side. (Grebenau, cited by Penck$5 \mathrm{I}: 286$.) In the regulated reaches of the Danube at Vienna, the sand banks have wandered in seven years from 700 to 1.000 meters downstream. (Penck-5I:286.) In the Loire the sand banks migrate at the rate of 1.72 to 3.61 meters per day in summer and 2.37 to $18.65 \mathrm{~m}$. per day in winter, according to the varying angle of fall of the water, which is from 0.28 permille to 0.45 permille. This also shows the great difference between the transport in summer and winter, the latter being the season of floods and high water generally. In all cases the motion of the waste matter is much slower than that of the water, and the amount of water passing a given point may be a thousand times the amount of sediment carried past that point in the same period. Thus the Rhine above Germersheim carries nearly $7 \mathrm{cu}$. $\mathrm{cm}$. of waste for every cubic meter of water, while the Danube at Vienna carries on the average $\mathrm{I} 3 \mathrm{cu} . \mathrm{cm}$. in every cubic meter of water. That sands and pebbles can be transported in the course of time to great distances by river currents 
is shown in the great delta of the Huang-ho, which extends for 300 miles or more from the mountains which have furnished the sediment. The sands and round quartz pebble conglomerate at the base of the Carbonic of North America (Pottsville) have been spread over an area of more than 400 miles radius. With progressive transport a constant decrease in the size of the fragments occurs, owing to the grinding processes which they undergo. [See the table given above for the reduction of the sediments of the Mur River (p. 246).]

Sorting Power of Rivers. When sands and gravel consist of a variety of material, a gradual assorting and elimination of the more destructible matter will result by river transportation, as well as wave action. This sorting of sands by rivers and by the waves along the shore is, however, always much slower and generally less complete than when it is done by the wind. The gravels of the River Saale at Jena, derived from the Thüringer Wald, consist chiefly of fragments of the Culm and Cambric formations. The Siluric, Devonic, Zechstein and Buntsandstein formations of this region are scarcely represented in the Saale gravels on account of the preponderance of soft shales, sandstones, limestones and dolomites, which in the course of transportation are destroyed. (Keilhack-40: 15 .)

Analyses (Mackie-46: I49) of the sands of the River Spey derived from the fundamental gneiss of Scotland showed at Cromdale I 8 per cent. of feldspar and I per cent. of mica, while further down the river at Orton the percentage of feldspar was only I2. That of the River Findhorn above Dulsie bridge showed 42 per cent. of feldspar, while between Forres bridge and the sea the percentage was reduced to twenty-one. This shows the gradual washing out by rivers of the feldspar and mica. On the seashore, as already noted, further assorting takes place. Thus the average per cent. of feldspar in the sand furnished by the four principal rivers of Eastern Moray (Spey, Lossie, Findhorn, Nairn) was Io, whereas in the rivers themselves, near their mouths, the average per cent. was I8. Prolonged sorting by either waves or river currents may thus produce nearly pure quartz sand by the removal of the other destructible minerals. The distance traveled by river gravels is often very great. Pebbles from the hills bordering the Red Sea have been found in the Nile Delta, 400 miles away. (See Chapter XIV.) There are reasons for believing that the well-rounded quartz pebbles of the Sharon (Upper Pottsville) conglomerate of Ohio and western Pennsylvania and the Olean of southern New York have traveled over 400 miles from their original source. 
Rounding of Sand Grains. (Goodchild-27; Mackie-47:300.) The chief factors concerned in the rounding of sand grains by attrition are :

I. The size of the particles.

2. Their specific gravity.

3. Their hardness.

4. The distance over which they had traveled.

5. The agent by which they had been transported.

The amount of rounding of a particle varies directly as I, 2 and 4 , and indirectly as 3. Particles transported by wind are more rounded than those transported an equal distance by water.

A cube, with the side measuring $I$ inch, presents an area of 6 square inches, while a sphere of one inch diameter presents a surface of only 3.14I59+ square inches. Now, since the surface area of bodies of similar figure, but different in size, varies as the square of their linear dimensions, a doubling of the linear dimensions of the cube would increase its surface area to 24 square inches. If the diameter of the sphere is doubled, the surface area becomes $12.566+$ square inches. On the other hand, reducing the cube from a linear dimension of one inch to one of half an inch by the side, the area of its surface is reduced from 6 square inches to one and one-half square inches. In like manner the reduction of the diameter of the sphere to one-half inch reduces its surface area to 0.78539 square inch.

The volumes of bodies of similar figure, however, increase as the cube of their respective linear dimensions, or decrease as the cube root of those dimensions. Thus, while the sphere reduced from one inch to one-half inch diameter changes in area from 3.1416 square inches to 0.78539 square inch, its volume will change from 0.5236 cubic inch to 0.06545 cubic inch. That is, while the superficial area is decreased to one-fourth, the volume is decreased to one-eighth its original amount. Since the weight of an object depends on its volume, it follows that the decrease in weight is greater than the decrease in surficial area, and, since adhesion (surface tension or the adhesion between the object and the medium in which it is immersed) is dependent on the surficial area of the object, it follows that in the wearing down of a sand grain the decrease in weight is always greater than the decrease of surface tension. Thus, with the progressive wearing down of a sand grain, a stage will be reached when the surface tension will balance the gravitational force, and further wearing of the grain becomes impossible in that medium. So, with a given medium and strength 
of current, grains below a certain size will not be rounded. Since the buoyancy or surface tension (adhesion between water and sand) of salt water is greater than that of fresh water, the smallest rounded grain of the former should be somewhat larger than that of the latter, other things being equal. Again, since the surface tension of air is very much less than that of water, very much smaller grains will be rounded by wind than by water. In other words, wind-blown sands of even extremely small size will come in contact with each other and with stationary objects, and so become worn and rounded. The fact that all grains below a certain size show angularity, and that the transition from rounded to angular grains is not a gentle but an abrupt one, is readily noticeable in both modern sands and ancient sandstones. Moreover, grains of materials of different specific gravity, but of the same size, will show a greater rounding with higher specific gravity. (Mackie47:298.) Ziegler (75) noted from experiments that quartz particles less than I mm. in diameter showed repulsion due to the viscosity of the liquid. He concludes that it is impossible that grains less than $0.75 \mathrm{~mm}$. in diameter could be well rounded under water, but if rounded must be wind-worn.

Since mineral particles have less weight in water than in air, it follows that particles of the same size and material will suffer more erosion in air on this account also.

Hardness and the distance over which the material is transported are likewise factors in the rounding of grains, the amount of rounding varying indirectly as the former and directly as the latter. Mackie has reduced the variability of the rounding $(R)$ of particles to the following formula:

$$
\mathrm{R} \propto \frac{\text { size } \times \text { the specific gravity } \times \text { distance }}{\text { hardness }}
$$

Distance (d) traveled may be expressed by the number of times the body turns on its axis. This number of times for a cube with side measuring $x$ will be $\frac{d}{4 x}$ and since the weight of such a cube is expressed by $\mathrm{x}^{3} \times \operatorname{sp}$. gr. (i.e. the size or volume $\mathrm{x}$ multiplied by its sp. gr.) we have

$$
R \propto \frac{x^{3} \text { spg. } \frac{d}{4 x}}{h}=\frac{x^{2} \text { spg.d }}{4 h} \text { or generally } \frac{x^{2} \text { spg.d }}{m h}
$$

where $m$ varies with the outline of the figure, being 4 in a cube, and $3.14 \mathrm{I} 6$ in a sphere, with proportional values for other forms. Since 
sand grains weigh less in water than in air, a corresponding correction must be made (47), the formula being according to Mackie for water:

$$
\mathrm{R} \propto \frac{\mathrm{x}^{2}(\text { spg. }-1) \mathrm{d}}{\mathrm{mh}}
$$

On making a comparison (Mackie-47:310) of the relative efficiency of wind and water as rounding agents, we have from the formulas

$$
\text { for wind } \mathrm{R} \propto \frac{\mathrm{x}^{2} \text { spg.d }}{\mathrm{mh}} \text { and for water } \mathrm{R} \propto \frac{\left.\mathrm{x}^{2} \text { (spg. }-1\right) \mathrm{d}}{\mathrm{mh}}
$$

the following relationships:

$$
\frac{\text { wind agency }}{\text { water agency }}=\frac{\text { spg. }}{\text { spg. }-1} \text { which for quartz }=\frac{2.65}{1.65}
$$

or wind $=\mathrm{I} .6$ times water, but since average wind velocities are always greater than average water velocities, it follows that the result attained by wind will be much greater than that given. Markie has calculated that with a wind velocity of 8 miles an hour, and a water velocity of 2 miles an hour, the ability of the wind to round a given quartz particle (sp. 2.65) is nearly 29 times as great as that of water. Mackie concludes that "under the conditions stated, particles less than one-fifth the diameter of those rounded by water will be rounded to an equal degree by wind" $(47: 310)$. Mackie has calculated the values of the coefficient of roundability or psephicity for various minerals a few of which are given (Mackie-47:302).

Table showing coefficient of psephicity of minerals in air and w'ater.

In air

$\begin{array}{lcl}\text { Quartz } & \text { spg. } & =0.38 \\ \text { Orthoclase } & \text { " } & =0.40 \\ \text { Tourmaline } & \text { " } & =0.43 \\ \text { Garnct } & " & =0.53 \\ \text { Hornblende } & \text { " } & =0.57 \\ \text { Zircon } & \text { " } & =0.59 \\ \text { Biotite } & \text { " } & =1.05 \\ \text { Chlorite } & =1.20 \\ \text { Muscovite } & =1.30\end{array}$

In water

$$
\begin{aligned}
\text { spg. - I } & =0.23 \\
\text { h } & =0.29 \\
\text { " } & =0.30 \\
\text { " } & =0.39 \\
\text { " } & =0.39 \\
\text { " } & =0.45 \\
\text { " } & =0.70 \\
\text { " } & =0.76
\end{aligned}
$$

Examination of a sample of sand from the River Spey at Craigellachie, Scotland, at a point where it could not be contaminated by admixture of particles derived from the sandstones showed, according to Mackie $(47: 306)$, no appreciable rounding of the quartz grains, "though they certainly did not all of them present the marked angularity of the quartz grains in most boulder clays." The feldspars also were angular, though some of them, be- 
ing kaolinized in a high degree, exhibited considerable blunting of their angles. The chlorite flakes were generally rounded, though with frayed, irregular edges, the muscovite and biotite were somewhat rounded on their prominent angles, but generally of irregular outline. The hornblende and garnets were angular, as was also the zircon, though showing occasionally ground-glass surfaces. Mackie concludes that these sands had traveled not less than 70 miles.

A specimen of sand from the seashore, midway between Lossiemouth and Covesea on the south coast of the Moray Firth, gave Mackie the following results :

Table showing rounding of sands of Moray Firth.

\begin{tabular}{|c|c|c|c|c|c|}
\hline Mineral Particles & $\begin{array}{c}\text { No. } \\
\text { ob- } \\
\text { served }\end{array}$ & Rounded & $\begin{array}{l}\text { Sub- } \\
\text { angu- } \\
\text { lar }\end{array}$ & Angular & $\begin{array}{l}\text { Average } \\
\text { round- } \\
\text { ing* }\end{array}$ \\
\hline Hornblende $\ldots \ldots \ldots \ldots \ldots$ & IO & . & 5 & 5 & I. 5 \\
\hline Kyanite.............. & 2 & . & I & I & I. 5 \\
\hline Biotite . . . . . . . . & I6 & 3 & 7 & 6 & I. 8 \\
\hline Opaque iron ore $\ldots \ldots \ldots \ldots \ldots$ & 3 & I & $\mathbf{I}$ & I & 2.0 \\
\hline Chlorite................. & 4 & I & 2 & $\mathbf{I}$ & 2.0 \\
\hline Muscovite........... & 20 & 7 & 9 & 4 & 2.2 \\
\hline Quartz ${ }^{* *} \ldots \ldots \ldots \ldots$ & 38 & 6 & 13 & 19 & I.7 \\
\hline Feldspar** ............ & 26 & 8 & 13 & 5 & $2 . I$ \\
\hline
\end{tabular}

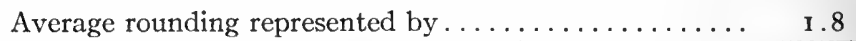

A sample from the sand dunes of Culbin, in the same region, gave the following:

Table showing rounding of sands of Culbin dunes.

\begin{tabular}{|c|c|c|c|c|c|}
\hline Mineral Particles & $\begin{array}{c}\text { No. } \\
\text { ob- } \\
\text { served }\end{array}$ & Rounded & $\begin{array}{l}\text { Sub- } \\
\text { angu- } \\
\text { lar }\end{array}$ & Angular & $\begin{array}{l}\text { Average } \\
\text { round- } \\
\text { ing }\end{array}$ \\
\hline Staurolite $\ldots \ldots \ldots \ldots \ldots \ldots \ldots$ & 2 & . & $\cdots$ & 2 & I. 0 \\
\hline 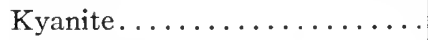 & 2 & . & $\mathbf{I}$ & I & I. 5 \\
\hline Garnet.................. & 45 & I 3 & I 4 & I 8 & I.9 \\
\hline Hornblende............... & 5 & 3 & I & I & 2.4 \\
\hline Tourmaline $\ldots \ldots \ldots \ldots \ldots \ldots$ & I3 & 8 & 4 & I & 2.5 \\
\hline Opaque iron ore $\ldots \ldots \ldots$ & Io & 7 & 3 & . & 2.7 \\
\hline Sphene.............. & 9 & 8 & . & $\mathbf{I}$ & 2.8 \\
\hline Zircon................ & 7 & 7 & . & . & 3.0 \\
\hline Feldspar............... & I6 & Io & 5 & I & 2.6 \\
\hline Quartz................ & 16 & 6 & 9 & I & 2.3 \\
\hline
\end{tabular}

Average rounding represented by ........... 2.27

* Obtained by counting 3 for a round, 2 for a subangular, and I for an angular particle and dividing the sum by the number of particles in each group.

** A proportion of these evidently derived from the sandstones of the coast. 
Comparing this with the sea sands, it is at once apparent that the rounding is much more pronounced, though the sands were carried only a few miles. These sands have a common origin and are of about the same degree of fineness.

\section{Movement of Underground Waters.}

The movement of underground water depends on the nature of the material through which it flows and the space available for this flow. Underground channels or tumnels may allow the water to flow as readily as it does upon the surface. If the channel is filled completely, the water is under hydrostatic pressure, and it may be forced up a rising slope. Such a stream may act as an aspirator, drawing water or air through fissures past which it flows, and causing currents to flow toward it by suction, and even causing water to rise from a lower to a higher level. This has been regarded by Penck and others as the cause of the currents flowing from the ocean into the land at the island of Cephalonia, Greece, the water replacing that which is drawn up by suction of a strong underground stream, which completely fills its channel. For these currents, which formerly drove the "sea mills of Cephalonia," Crosby and Crosby (I4) and Fuller (25) have offered other explanations. Underground streams of this kind are further illustrated by some subglacial streams, which, being confined in a tumnel-like tube, often flow uphill, as shown by the eskers which mark their former course. (Grabau-28.)

Water flowing through a porous soil has of course a vastly lower rate of motion under the same gravitational influence on account of friction. The rate of movement of water through such a porous medium depends on the following factors:

I. Size of pores in the water-bearing medium.

2. Porosity of material, $i . e$., the relative abundance of pores.

3. Pressure gradient, or change in pressure or head, per unit of length, measured in the direction of the motion.

4. Temperature of water.

In general the rate of flow varies with the variation in all of these factors, the law governing this rate of flow or velocity $(v)$ being expressed by the formula of Darcy, $v=k \frac{p}{h}$, where $p$ is the difference in pressure at the ends of the column of soil (measured by height of water column), $h$ the length of the column and $k$ a constant depending upon the deterninable characters of the soil, 
especially the size of the grains. The following formula of Allen Hazen $\left(32: 5 f^{I}\right)$ takes more factors into consideration and serves for experimental purposes, $v=c d^{2} \frac{h}{l}(0.70+0.03 t), v$ being the velocity of the water in meters per day in a solid column of the same area as that of the sand, $c$ a constant factor found empirically to approximate $\mathrm{I}, 000 ; d$ is the "effective size" * of sand grains in mm., which is such that Io per cent. of the material is of smaller grains and 90 per cent. of larger grains than the size given; $h$ is the loss of head; $l$ is the thickness of sand through which water passes, and $t$ is the temperature on the centigrade scale. The loss of head is measured from points just inside the ends of the column of sand or soil. (See, further, King-4I :59; and Slichter-64:322, $329 ; 65: 19,22$.

The quantity of water transmitted by a column of sand depends upon the length of the column and the head of water, and furthermore varies with the effective size of the soil grain, the temperature of the water and with the porosity of the soil. The flow varies as the square of the size of the soil grain, and doubling the size of the grain will quadruple the flow of water. Thus the flow through a soil whose effective size of grain is I $\mathrm{mm}$. is 10,000 times the flow through a soil whose effective size of grain is o.or $\mathrm{mm}$. The flow at $70^{\circ} \mathrm{F}$. is about double that at $32^{\circ} \mathrm{F}$.

The Underflow. This is the moving sheet of water beneath the bed and banks of a stream through the porous medium. This may be so concentrated as to produce a subterranean stream, scores of feet in depth and miles in breadth. It naturally follows a line of depression in the surface of the sustaining impervious layer-the Thalweg-and the rapidity of flow will depend in a very large measure upon the texture of the material forming the river bed. Where this is fine the water will be stored, but a considerable underflow is impossible. Where the material is coarse sand and gravel, however, as near the mountains, the water will readily flow through it. In arid regions, the lower reaches of the surface streams often disappear altogether, by sinking into the ground. They are then continued by the underflow, and only occasionally after a heavy storm are the "dry washes" filled again by a rushing surface torrent. In general, the underflow follows the trend indicated by the surface branches, which may extend as dry washes

* Determined by experiment to be the mean diameter of the grains, or the one which, if all the grains corresponded to that size, would give the soil the porosity it actually has. 
across the alluvial fan built up by the dropping of the stream-transported material.

Rate of Flow of Underground Water. The following table adapted from Slichter $(65: 27)$ shows the theoretical rate of flow and amount of transmission determined by experiment for various kinds of soil, with a porosity of 32 per cent., and at the temperature of $50^{\circ} \mathrm{F}$. and with pressure gradients of $1: 1$, and 100 feet to $\mathrm{I}$ mile.*

Table showing permeability of various soils.

\begin{tabular}{|c|c|c|c|c|}
\hline \multirow{2}{*}{ Kind of soil } & \multirow{2}{*}{$\begin{array}{l}\text { Diam- } \\
\text { eter of } \\
\text { grains }\end{array}$} & \multicolumn{2}{|c|}{$\begin{array}{l}\text { Velocities in miles } \\
\text { per year }\end{array}$} & \multirow{2}{*}{$\begin{array}{l}\text { Maximum } \\
\text { flow in } \\
\text { cubic feet } \\
\text { per n.in. }\end{array}$} \\
\hline & & $\begin{array}{c}\text { Pressure } \\
\text { gradient } \\
\mathbf{I}: \mathbf{I}\end{array}$ & $\begin{array}{l}\text { Pressure } \\
\text { gradient Ioo } \\
\text { ft. to I mile }\end{array}$ & \\
\hline Silt............. & $\left\{\begin{array}{l}0.01 \\
0.04\end{array}\right.$ & $\begin{array}{l}0.0113 \\
0.1807\end{array}$ & $\begin{array}{l}0.00026 \\
0.00408\end{array}$ & $\begin{array}{l}0.000036 \\
0.000577\end{array}$ \\
\hline Very fine sand......... & $\left\{\begin{array}{l}0.05 \\
0.09\end{array}\right.$ & $\begin{array}{l}0.2823 \\
0.9147\end{array}$ & $\begin{array}{l}0.00638 \\
0.02066\end{array}$ & $\begin{array}{l}0.000901 \\
0.002920\end{array}$ \\
\hline Fine sand........ & $\left\{\begin{array}{l}0.10 \\
0.20\end{array}\right.$ & $\begin{array}{l}1.1290 \\
4 \cdot 5180\end{array}$ & $\begin{array}{l}0.0255 \mathrm{I} \\
0.10210\end{array}$ & $\begin{array}{l}0.003605 \\
0.0144^{20}\end{array}$ \\
\hline Medium sand.... & $\left\{\begin{array}{l}0.25 \\
0.45\end{array}\right.$ & $\begin{array}{r}7.0580 \\
22.8700\end{array}$ & $\begin{array}{l}0.15940 \\
0.51650\end{array}$ & $\begin{array}{l}0.022530 \\
0.073000\end{array}$ \\
\hline Coarse sand. . & $\left\{\begin{array}{l}0.50 \\
0.95\end{array}\right.$ & $\begin{array}{r}28.2300 \\
101.9000\end{array}$ & $\begin{array}{l}0.63770 \\
2.30200\end{array}$ & $\begin{array}{l}0.090120 \\
0.325300\end{array}$ \\
\hline $\begin{array}{l}\text { Very coarse sand } \ldots \ldots \ldots \\
\text { or }\end{array}$ & 1.00 & 112.9000 & 2.55100 & 0.360500 \\
\hline Very fine gravel......... & 2.00 & 45 I. 8000 & 10.21000 & I. 442000 \\
\hline Fine gravel.... & $\left\{\begin{array}{l}3.00 \\
5.00\end{array}\right.$ & $\begin{array}{l}1016.0000 \\
2823.0000\end{array}$ & $\begin{array}{l}22 \cdot 96000 \\
63 \cdot 77000\end{array}$ & $\begin{array}{l}3.244000 \\
9.012000\end{array}$ \\
\hline
\end{tabular}

Note.-The last figures (o) in the higher numbers are approximate.

Direct observations on the underflow of water to the Loup River, Nebraska, have indicated a rate of one-third of a mile per

* The number in italics gives the value just before the upper limit of each grade is reached. Compare table, p. 287, Chapter VI. 
day, a rate so high ( $120+$ miles per year, compare column 4 of table) that the observations are probably erroneous. Observations on seepage of water from canals, ctc. (Slichter-65:42), have given rates of $0.2074,0.2500,0.3000$, and 1.0369 miles per year, values closely in accord with those received by experiment.

Pervious and Impervious Strata. Strata which, from their porosity, permit a flow of water through them are called pervious, while those not so constituted are impervious. Quartz sandstones, especially those of uniform grain, are usually the most pervious, and shales the most impervious of stratified rocks. Limestones are generally impervious, owing to the filling of their pores by secondary deposit, a change much less characteristic of quartz sandstones, though also found here. Some limestones are, however, porous enough to be good water bearers, such as chalk and partly consoli-

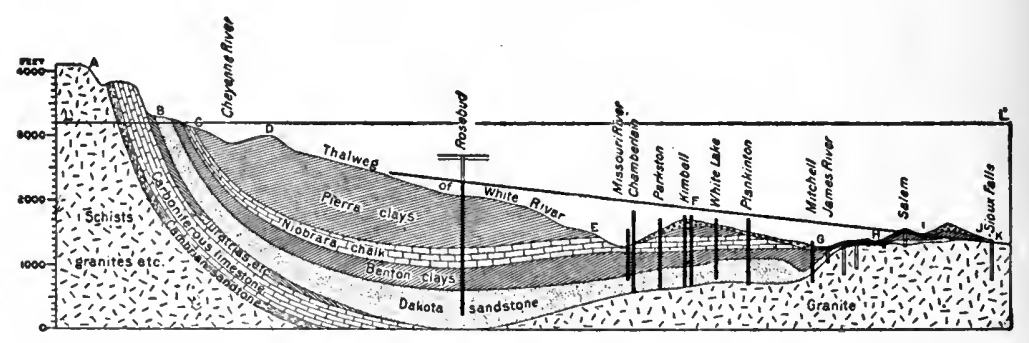

FIG. 37. Cross-section through South Dakota artesian basin. Elevations above sea-level. Vertical scale much exaggerated over the horizontal. (After Slichter.)

dated shelly limestone (coquina, etc.); limestones rendered porous in the belt of weathering by solution; and limestones rendered porous by dolomitization through replacement of some of their calcite by magnesium carbonate.

The Deeper Zones of Flow. Pervious strata confined between impervious ones may, from their position, carry surface waters to great depths and constitute a deeper zone of flow. In thus being confined between impervious layers it differs from the surface zone, which is bounded below by an impervious layer, but above is not confined, but formed merely by the upper limit of ground water. Whereas the subsurface flow follows the slope of the region, that of the deeper zone depends on geologic structure. The deeper zone also draws its supply from great distances and is independent of the local drainage level, while that of the subsurface zone is local. An example of such a pervious bed is the Dakota sandstone of the Front Range and the Great Plains, which is capped by the impervi- 
ous Benton clay of the Cretacic. The water enters along the outcrop of this formation more than 3,000 feet above sea-level. Over parts of the Great Plains the Dakota has descended near to or even below sea-level. while perhaps 2,000 feet of other strata are piled above it. When tapped by artesian wells the water will rise to within 2,400 to I,500 feet above sea-level, according to the distance from the mountains. As the surface over most of the country is lower than this, the restilt is the formation of actively flowing artesian wells (see Fig. 37).

\section{Springs.}

Springs are the escape of ground water at the surface of the lithosphere. By surface of the lithosphere is here meant any point where the lithosphere is in contact with a mass of water or air; thus we have sublacustrine springs and springs formed in subterranean channels, in wells, etc.

Springs commonly issue where the contact between a pervious and an impervious lower layer is exposed in section. In the Helderberg Mountains the spring line is at the base of Siluric or Devonic limestones, where they rest upon impervious clays (Brayman), or unconformably upon the Hudson River beds. Along the line of contact between the Devonic Onondaga limestone, a porous rock, and the Siluric Monroe limestone, a compact, impervious one in western New York, Canada, and Michigan, occurs a line of copious springs. The contact line here is a disconformity, and the water sometimes gushes out in great volume. The contact between the Lockport dolomite and Rochester shales along Niagara gorge and the whole front of the Niagara escarpment constitutes another such spring line, and so does the upper surface of the Black Shale throughout the southern Appalachians. Where the section is made only into the pervious layer, as in a well, a general seeping or "welling" of the ground water takes place: where the surface is depressed to the ground-water level, or below it, a similar "welling" of the ground water takes place. Swamps are formed in this way, which may be regarded as natural wells on a large scale.

\section{Water in the Solid Form.}

Snow and ice may, on the one hand, be considered as water in the solid state, and so referred to the hydrosphere; or, on the other hand, as a rock, solid only at low temperatures. In the latter case it belongs either to the igneous or pyrogenic rocks when due to 
solidification of water, or to the atmogenic when precipitated as snow and snow ice. Ice is thus a substance intimately uniting the hydrosphere and lithosphere, just as water in the form of vapor unites the hydrosphere and atmosphere. The freezing. of water has been dealt with to some extent under the heading of temperature influence on the hydrosphere. As a rock it will be dealt with in Chapter VI and its larger structural features will be taken up in Chapter VIII. Glacial deposits naturally fall under the heading of autoclastic rocks and are discussed in Chapter XII, while deformation due to glacial motion is considered in Chapter XX. Finally, the results of glacial sculpture are treated under the head of glyptogenesis, or the land forms produced by the sculpturing agents. In the present chapter a brief preliminary summary of the movement of water in the solid form and its geological effects will be given.

Kinds of Movement of Solid Water. Water in the solid state may become translocated either (I) passively by transportation, or, (2) actively by movements due to its own gravitative and internal readjustments. Transportation may be either by wind, as in the case of snowflakes and ice crystals, or by water, as icefloes or icebergs. Wind-transported snowflakes and ice crystals may accomplish a certain amount of geological work by corrasion, as noted in Chapter II, and they may be heaped up in dunes or deposited in strata, which may be temporary, or may endure for a long time, with gradual metamorphosis into crystalline ice. One result of windtransported snow is a special distribution, and consequently the placing of sources of water supply in positions which might probably not be accessible to them in any other way. Water-transported ice blocks often act as powerful agents in erosion and destruction, and they may be responsible for groovings and markings on rock surfaces not otherwise explainable. Extensive deposits of transported material frozen into the ice block or resting on its back are also sometimes formed, as in the case of the Grand Banks of Newfoundland, where the débris brought by the icebergs from the north is dropped upon their melting and so embedded in and made part of contemporaneous marine sediments, boulder conglomerates here accunlulating beneath the zone of wave activity. The anomalous occurrence of erratics or strayed rock masses in marine formations is also accounted for by floating icebergs. Such ice-rafted erratics have been found in the Caney shale of Oklahoma (Carbonic) (Woodworth-74).

Ice masses, moving over the surface of the land constitute the glaciers, which may be either glacial streams or glacial sheets. Their motion is due to a variety of causes, among which partial 
melting and refreezing of the ice crystals constituting the mass are at least important ones. (See the discussion by Chamberlin and Salisbury-9:313-323.) Observations on glaciers flowing in valleys have shown that motion is faster at the center than at the sides, and near the top than at the bottom. A current analogous to that found in water streams is thus produced, which also meanders more strongly than does the ice stream as a whole. In broad glaciers, formed by the union of a number of branches, several lines of rapid motion may exist, with lines of weaker movement between. Upward currents within the ice also exist, which bring débris from the bottom to the surface at the sides. In this manner lateral moraines of rock and soil are formed on the surface of the valley glacier. This morainal material, augmented by that falling from the cliffs between which the glacier flows, is left at the foot of the ice with much that is carried along the bottom, there to constitute the terminal moraine.

Rate of Movement. Movement of glaciers is, as a rule, gieater in summer than in winter. Some of the glaciers of Greenland move 50,60 , or even more feet per day in summer time, while a case of Ioo feet per day has been noted (Chamberlin \& Salisbury-9). In this case the movement in April was only $3+$ feet. Such rapid movements occur only where the ice of large inland areas crowds down into comparatively narrow fjords. In Switzerland the rate of motion ranges from I or 2 inches to four feet or more per day, while the Muir glacier of Alaska has been found to move 7 feet or more per day (Reid). The causes affecting rate of movement of the ice are: I, thickness and volume of the ice sheet; 2 , slope of the land surface; 3 , slope or gradient of upper surface of the ice; 4 , character and relief of the rock bed ; 5 , temperature; 6 , quantity of water falling on or reaching the glacier.

Wasting of the Glaciers. Glaciers waste away by melting at their surface, front and sides, and to some extent at the bottom, where heat is generated through friction and compression as well as by the rise of the earth's heat through conduction under cover of a thick ice sheet. Glaciers also waste away by evaporation, the ice changing directly to the form of vapor. The wasting of glaciers on the surface is generally spoken of as ablation.

Erosive Work of Icc. The erosive work of ice may be twofold: denudation, or the removal of material formed through decomposition and disintegration of the rock surface, and the active removal of fresh rock material by scraping, plucking, etc., or glacial corrasion. The general process of erosion by ice has been termed cxaration by Walther (from arare, to flow). This word might be re- 
stricted to glacial denudation, $i$. $e$, the removal and transport of weathered material. (See ante, Chapter I.)

The first step in glacial erosion is generally ablation, or the taking up of the weathered material on the surface of the land. When ice accumulates through a long period of gradual refrigeration, punctuated by intervals of partial melting, the waterlogged soil, the product of pre-glacial weathering, is incorporated as an integral part into the base of the glacier or ice sheet and carried away with it when movement begins. Through shearing and through formation of ascending ice currents this material may be carried upward, and, from being subglacial, becomes successively englacial and then superglacial. The part remaining in the bottom of the ice is used as a tool for the corrasion of the rock surface, which soon is worn down to the undecomposed layers and becomes smoothed, polished, and marked by parallel striæ, the direction of which indicate the direction of ice movement. The material held in the base of the ice sheet (the product of denudation plus material which may have descended from the surface) is likewise polished and striated, this in the flatter fragments of rock usually being confined to two faces.

The heat generated by friction over the rock surfaces, augmented by the rising heat of the earth, owing to the ice blanketing, may result in melting the basal portion of the ice sheet, or glacier, whereupon a layer of basally transported material or till is deposited on the previously eroded surface, protecting it from further erosion. If the direction of motion of the ice is subsequently changed, it may not again remove this material, but leave it to protect the striæ made during the early period of movement (Crosby). That ice is able to move over unconsolidated material without actively eroding it is shown by many observations (Fairchild-22). Glacial grooves of exceptional size are sometimes formed, the best known being those of Kelley's Island in Lake Erie. The most effective work of corrasion by glaciers seems to occur somewhere above the lower end of the glacier, so that deepening of the valley above its mouth results. Both glaciers and ice sheets effect little or no erosion at their front or margins. At the head of the glacier, $i$. e., at the Bergschrund, plucking or pulling out of loose blocks occurs, resulting in the formation of cirques. Plucking also occurs on the lee side of projecting rock masses which on their stoss side are eroded by corrasion, the result being a rock mass with smooth upper surface, gradually rising in the direction of ice movement, and terminating in a rough cliff downstream. These structures are known as roches mou- 
tonnées. Combined erosion by glaciers and subglacial streams is called fluvioglacial erosion.

Transportation by Ice. As already noted, much material may be transported by floating icebergs or floes and so become incorporated in marine sediments. Land ice transports rock débris on its surface as superglacial drift, within its mass as englacial drift, and at its bottom as subglacial drift. In form the superglacial material generally constitutes lateral and median moraines. (See postea Chapter XII.) The englacial is likely to be scattered, and the subglacial is often in the form of a more or less continuous sheet. Changes from one position to another are constantly effected, the subglacial rising by shearing and upward currents to become englacial or superglacial, the englacial becoming subglacial by basal melting of the ice or superglacial by surface ablation, and the superglacial material becoming englacial or subglacial through the action of descending currents or by falling through fissures or crevasses. By melting on reaching the sea this material may be incorporated with marine sediments, or by advancing over forests and swamps it may be deposited on organic accumulations (future coal beds), and finally, by taking up material from the bottom of the shallow sea over which it passes, the ice may incorporate remains of marine organisms in continental sediments, as in the case of the fossils of Tertiary or younger age included in the drumlins of Boston Harbor and the moraine of Cape Cod. (Crosby and Ballard-13, Crosby-1 I.)

\section{BIBLIOGRAPHY $\mathrm{V}$.}

1. AIRY, G. B. Tides and Waves. Encyclopedia Metropolitana.

2. ANDRESEN, C. C. I86I. Om Klitformationen og Klittens Behandling og Bestyrelse Kjobenhavn.

3. BEARDMORE. 1872. Manual of Hydrology. London.

4. BERKEY, C. P. 1913. Private Communication.

5. BLACKWELL, J. E. Report on the Referees' Report upon the main drainage of the Metropolis (cited by Beardmore).

6. BUCHANAN, J. Y. I888. The Exploration of the Gulf of Guinea. Scottish Geographic Magazine, Vol. IV, pp. I77-200; 232-25I.

7. CARNEY, FRANK. 1910. Glacial erosion on Kelley's Island. Bulletin of the Geological Society of America, Vol. XX, pp. 640-645, pls. Io8-I Io.

8. CHAMBERLIN, T. C. I884. The Requisite and Qualifying Conditions of Artesian Wells. U. S. Geological Survey, 5th Annual Report, pp. I 3 I-I 80, I 883-84.

9. CHAMBERLiN, T. C., and SAlisbURY, R. 1906. Geology, Vol. I. New York, Henry Holt \& Co.

I0. CORNISH, VAUGHAN. I9I0. Waves of the Sea and Other Waves. London.

I I. CROSBY, W. O. 1879. Fossiliferous Boulders in the Drift of Truro. Proceedings of the Boston Society of Natural History, Vol. XX, pp. 136-140. 
12. CROSBY, W. O. 1902. A Study of Hardpacked Sand and Gravel. Technology Quarterly, Vol. XV, pp. 260-264.

13. CROSBY, W. O., and BALLARD, H. O. 1894. Distribution and Probable Age of the Fossil Shells in the Drumlins of the Boston Basin. American Journal of Science, 3d series, Vol. XLVIII, pp. 486-496.

14. CROSBY, W. O., and CROSBY, F. 1896. The Sea Mills of Cephalonia. Technology Quarterly, Vol. IX, No. I, pp. 6-23.

15. COODE, SIR JOHN. 1853. Description of the Chesil Bank. Minutes of the Proceedings of Civil Engineers. Vol. XII. Abstracted in Wheeler (73), pp. I44-1 48 .

16. DAUBRÉE, A. 1879. Études Synthétiques de Géologie Expérimentale Paris.

17. DAVIS, W. M. 1898. Waves and Tides. The Journal of Geography, Vol. II, pp. 122-1 32 .

18. DAVIS, W. M. 1899. Physical Geography. Boston, Ginn \& Co.

19. DAVIS, W. M. 1905. Illustrations of Tides by Waves. The Journal of Geography, Vol. IV, pp. 290-294.

20. DELESSE, A. 1872. Lithogie du Fond des Mers.

21. DELESSE, A. 1877. Lithogie des Mers de la France. Paris.

22. FAIRCHILD, H. L. 1905. Ice Erosion Theory a Fallacy. Bulletin of the Geological Society of America, Vol. XVI, pp. 13-74, pls. 12-23.

23. FORBES, EDWARD. I856-57. Abrading power of water at different velocities. Proceedings Royal Society of Edinburgh, Vol. III, pp. 474477 .

24. FOREL, F. A. Igor. Handbuch der Scenkunde. Stuttgart.

25. FULLER, M. L. 1907. Conditions of the Circulation of the Sea Mills of Cephalonia. Bulletin of the Geological Society of America, Vol. XIX, pp. $22 \mathrm{I}-232$.

26. GEIKIE, A. I893. Textbook of Geology, 3rd ed. Macmillan.

27. . GOODCHILD, J. G. 1897. Desert Conditions in Britain. Transactions of the Edinburgh Geological Society, Vol. VII, pp. 203-222.

28. GRABAU, A. W. I900. Lake Bouvé. An extinct Glacial Lake in the Boston Basin. Occasional Papers of the Boston Society of Natural History, Vol. IV, pt. III, pp. 564-600.

29. GRABAU, A. W. 1910. Physical and Faunal Evolution of North America during Ordovicic, Siluric and early Devonic time, Chapter IV of Outlines of Geologic History, Chicago.

30. HANSEN, HELLAND, and NANSEN, FRIDTJOF. 1907. Report on the Norwegian Fishery and Marine Investigations, 1907. Bd. II. Christiana. Summary in Internationale Revue der gesammten Hydrobiologie und Hydroegraphie, Bd. II, Sept. 3, p. 338. Revue by W. Bremeche. Annales de Hydrologie, 1900, p. 353.

31. HANSEN, HELLAND, and NANSEN, FR. 1913. Remarks on the Oceanographical Investigations carried out by the "Fram" in the North Atlantic in 1910, and in the South Atlantic in I91. "The South Pole" by Roald Amundsen, Vol. II.

32. HAZEN, ALLEN. I892. Some Physical Properties of Sands and Gravels. Report of the Massachusetts State Board of Health, I892, p. 541.

33. HOCHENBURGER. I886. Ueber Geschiebsbewegung und Eintiefung fliessender Gewässer. Leipzig. 
34. HUMPHREYS, A. G., and ABBOTT, H. L. I861. Report upon the Physies and Hydraulies of the Mississippi River, upon the protection of the alluvial region against overflow, and upon the decpening of the mouths. Philadelphia, I 86I, Washington, I867.

35. JOHNSON, D. W. I9ro. The Supposed Recent Subsidence of the Massachusetts and New Jersey Coasts, Science, N. S., Vol. XXXII, pp. $721-723$.

36. JOHNSON, D. W. I9II. Botanical Evidence of Coastal Subsidence. Science, New Ser., Vol. XXXIII, pp. 300-302.

37. JOHNSON, D. W. I912. Fixité de la cote Atlantique de l'Amérique du Nord. Annales de Geographie, tome XXI, pp. 193-2I2.

38. JOHNSON, D. W. I9I3. The Shoreline of Cascumpeque Harbor, Prince Edward Island. Geographical. Journal, London. August, pp. I52-I64.

39. KAYSER, E. 1905. Allgemeine Geologie, 2nd ed. 4th ed. I9I2 Stuttgart.

40. KEILHACK, K. 1908. Lehrbuch der praktischen Geologie, 2nd edition. Stuttgart.

41. KING, F. H. I899. Principles and conditions of the movements of Ground Water. Nineteenth Annual Report, U. S. Geological Survey, pt. II, pp. 59-94.

42. KRUMMEL, O. I9I I. Handbuch der Ozeanographie. Bd. II. Stuttgart.

43. LE CONTE, JOSEPH. 1893. Elements of Geology, 3rd edition.

44. McGEE, W. J. I 893. Potable Waters of Eastern United States. Fourteenth Annual Report, U. S. Geological Survey, pt. II, pp. I-47.

45. McGEE, W. J. I 897. Sheet flood erosion. Bulletin of the Geological Society of America, Vol. VIII, pp. 87-II2.

46. MACKIE, WILLIAM. I897. The sands and sandstones of Eastern Moray. Transactions of the Edinburgh Geological Society, Vol. VII, pp. $148-172$.

47. MACKIE, WILLIAM. I897. On the Laws That Govern the Rounding of Particles of Sand. Transactions of the Edinburgh Geological Society, Vol. VII, pp. 298-31I.

48. NANSEN, FRIDJOF. 1902. Oceanography of the North Polar Basin. Kristiana.

49. OCHSENIUS, CARL. 1893. Ueber unterirdische Wasseransammlungen. Zeitschrift f. praktische Geologie, Bd. I, pp. 36-4o.

50. PARTIOT. I 892 . Études sur les Rivières à Marie. Paris.

51. PENCK, A. I 894. Morphologie der Erdoberfläche. Vol. I, Stuttgart.

52. PENCK, A. I 894. Ibid., Vol. II.

53. PESTALOZZI. I878-79. Die Geschiebe-bewegung und das Natürliche Gefälle der Gebirgsflüsse, Progr. der eidgenossischen. Polytechnischen Schule, $1875^{-79}$, Zurich.

54. PHILIIPS, JOHN. I835. Illustrations of the Geology of Yorkshire. Part I. The Yorkshire Coast.

55. POUILLON-BOBLAGE. 183I. An account of the tidal and other zones observed on the surface of the limestone rocks on the shores of Greece. The Edinburgh New Philosophical Journal, 183I, p. 333 et seq. Also, Journal de Geologie, 1831 .

56. READE, T. MELLARD. I 888 . Tidal action as an agent of Geological change. Philosophical Magazine, Vol. XXV, pp. 338-343.

57. REID, HARRY FIELDING. 1895-1913. Variation of Glacicrs. Journal of Geology, Vol. III-XXI.

58. REUSCH, HANS. 1879. Einiges ueber die Wirkungen des Meeres auf die West Küste Norwegens. Neues Jahrbuch f. Mineralogie und Geologie, 1879, pp. 244 et seq. 
59. RUEDEMANN, R. 1897. Evidence of current action in the Ordovician of New York. American Geologist, Vol. XIX, pp. 368-39I.

6o. RUEDEMANN, R. 1904. Graptolites of New York, Pt. I. Memoirs of the New York State Museum of Natural History, Vol. 7, pt. I.

61. RUSSELL, I. C. I 895. The Influence of Débris on the Flow of Glaciers. Journal of Geology, Vol. III, pp. 823-832.

62. SALISBURY, R. D. 1907. Physiography. New York, Henry Holt.

63. SHALER, N. S. 1894. Phenomena of beach and dune sands. Geological Society of America Bulletin, Vol. V, pp. 207-2 I2.

64. SLICHTER, C. S. I 899 . Theoretical investigation of the motion of ground waters. Nineteenth Annual Report of the U. S. Geological Survey, pt. II, pp. 295-384.

65. SLICHTER, C. S. I902. The motion of underground waters. U.S. Geological Survey, Water Supply and Irrigation Papers. No. 67.

66. SORBEY, HENRY C. 1908. Application of Quantitative Methods to the Study of the Structure and History of Rocks. Quarterly Journal of the Geological Society of London, Vol. LXIV, pp. 171-233.

67. STEVENSON, TH. I850. Account of experiments upon the force of the waves of the Atlantic and German Oceans. Transactions of the Royal Society of Edinburgh. Vol. XVI, pp. 23-32.

68. STEVENSON, TH. 1852. Observations on the relation between the height of the waves and their distance from the windward shore. New Edinburgh Philosophical Journal, Vol. LIII.

69. STEVENSON, TH. I $856-1858$. On the destructive effects of the waves on the northeast shores of Shetland. Proceedings of the Royal Society of Edinburgh, Vol. IV, pp. 200-20I.

7o. STEVENSON, Th. I886. The design and construction of Harbours. 3rd edition. Edinburgh. A. \& C. Black.

71. SUCHIER. I883. Die Bewegung der Geschiebe des Oberrhein. Deutsche Bauzeitung, No. 56, p. 33 I, cited by Penck, I, 283.

72. THOULET, J. 1904. L'Ocean. Ses Lois et ses Problèmes. Paris. Hachette et Cie.

73. WHEELER, W. H. I902. The Sea Coast. Longmans, Green \& Co., London.

74. WOODWORTH, J. B. 19I2. Boulder beds of the Caney shales at Talihina, Oklahoma. Bulletin of the Geological Society of America, Vol. XXIII, pp. $457-462$, pls. $23-24$.

75. ZIEGLER, VICTOR. I9II. Factors influencing the rounding of sand grains. Journal of Geology, Vol. XIX, pp. 645-654. 


\title{
C. THE LITHOSPHERE
}

\author{
CHAPTER VI.
}

\section{CLASSIFICATION OF THE ROCKS OF THE EARTH'S CRUST.}

As has been outlined in the introductory chapter, the stratigrapher deals with the genesis of the rocks of the earth's crust and considers their structure and composition, or the petrographical characters of rocks, chiefly from the point of view of their bearing on lithogenesis. The dynamic forces active in the production of rocks are likewise considered by him in their bearing upon this subject. Naturally, those rocks which bear the most satisfactory evidence of chronological succession, $i$. e., the stratified rocks, receive most attention, for it is the business of the stratigrapher to establish the events in the history of the earth in the order of their occurrence.

\section{SUBDIVISION OF ROCKS.}

Numerous subdivisions of rocks have been proposed, most of them being largely or entirely artificial in character. The most familiar divisions are: igneous, aqueous, colian, and organic. The last three are commonly classed together as stratified or sedimentary, as opposed to the unstratified or igneous rocks. Metamorphic rocks are generally grouped by themselves, though in the beginning they were grouped with the stratified (6). The chief objection to this classification lies in the fact that, under the aqueous as well as under the organic groups, rocks of chemical and of mechanical origin are included. Nor are all of the rocks so classed truly sedimentary or stratified. One of the earliest attempts at a rational classification based on origin was that of Carl Friedrich Naumann, who, in the second edition of his Lehrbuch der Geognosie, I858 (2I), recognized two classes in which all rocks are included. These are: I, The Protogenous, or original; and II, the Deuterogenous, or derived, terms corresponding essentially to the endogenetic and 
exogenetic divisions used in this book. Naumann's terms have been adopted in the latest of French text-books by Haug (I4), but in a more restricted meaning. He, first of all, divides all rocks into roches exogènes, or those formed on the outside of the earth, $i . e$., the sedimentary rocks; and into the roches endogines, or those having their origin from within the lithosphere, $i$. e., the volcanic rocks. The exogene rocks are then divided into roches protogènes, comprising (a) the chemical and (b) the organic deposits, and roches deutogènes, or the clastics. The old notion of a primary distinction between igneous and sedimentary rocks still prevails in this classification, but Haug recognizes the important distinction between clastics and nonclastic sediments. Zirkel (3I), too, used similar subdivisions of primary rank when he divided rocks into: A, Original crystalline. and B, Clastic rocks; terms used by Naumann in the first edition of his Lehrbuch, 1850. The term for the first group was not well chosen, since it included rocks which were not crystalline, $i . e$., obsidian, etc. For this reason Zirkel substituted the term non-clastic in 1873 . Both Naumann and Zirkel included metamorphic rocks in their class of Protogene or non-clastic (crystalline) rocks. $H$. Rosenbusch (24), in 1877, on the other hand, included metamorphic rocks in his class of stratified rocks (Geschichtete Gesteine), which, with the class of massive rocks (Massige Gesteine)-the igneous rocks of our present classifications-constituted the two major divisions of rocks. In 1898 (25), however, he made the three following classes: I, Eruptive rocks (Eruptivgesteine). These are the igneous rocks of other authors and they are divided into: a, deep-seated rocks, or Tiefengesteine (Plutonic rocks of other classifications) ; b, dike rocks, or Ganggesteine; and, c, effusive rocks, or Ergussgesteine, $i$. e., volcanic rocks of later classifications. II, Stratified rocks (Schichtige Gesteine). These include clastic sediments and chemical precipitates from water; rocks of organic origin and the porphyroid rocks. The latter, though bedded, are clearly out of place in this division, as the author himself recognizes, since they never were sediments nor are such now, but are metamorphic derivatives of igneous rocks. Siliceous rocks of organic (biogenic) and those of aqueous (hydrogenic) origin are grouped together by Rosenbusch in this classification, and the same is true for calcareous rocks. Coals and other combustibles are placed in a separate subdivision or appendix. Under argillaceous rocks are included the phyllites and other more or less altered or metamorphosed clay rocks; under sandstones he includes quartzites, and under calcareous rocks he places marbles, but other metamorphic rocks are placed in the third main division. Altogether the grouping 
within this class is as illogical and unsatisfactory as it well could be. III, Crystalline slates (Krystalline Schiefer). This includes the gneisses, mica schists, talc sclists, chlorite schists, amphibole and pyroxene rocks, serpentines, the metamorphic calcareous, magnesian, and iron rocks, and emery. These, then, include metamorphic sedimentaries as well as metamorphic igneous rocks, and this grouping can be excused only on the ground of convenience. Rosenbusch, indeed, tries to separate these metamorphics of diverse origin by proposing the prefix ortho for those derived from igneous, and para for those derived from sedimentary rocks. To the above three groups is added a fourth, that of the original crust of the earth, Erste Erstarrungs Kruste. We owe to Johannes Walther (30) the first comprehensive attempt at a truly genetic classification of all rocks. One of the essential features of this system is the recognition of the fact that metamorphic rocks belong with the rocks from which they are derived. He proposed four main divisions, namely: I, mechanical or clastic; II, chemical precipitates and sublimates; JII, organic; and, IV, volcanic rocks, or consolidated lavas.

This is essentially the classification adopted in this book, except that a stronger distinction is made between the first group, the Exogenctic, or clastic, and the others which are classed as Endogenetic (Grabau-9). The Endogenetic are those formed by agents acting from within, $i . e$., by agents intimately associated with the rock mass forming; they produce rocks by solidification, precipitation or extraction of the mineral matter from the states of igneous fusion, aqueous solution or vaporization. The Exogenetic rocks, on the other hand, are those formed by agents acting from without upon already existing rock matter, reducing it to a finer condition either by mechanical or by chemical means, while still leaving it in a solid state. They are, in fact, the clastic rocks of earlier writers, while the Endogenetic rocks are the non-clastic.

\section{The Endogenetic Rocks.}

These are best understood when we approach them through a consideration of the material of the earth as a whole, and the conditions under which it appears to us. Aside from the solid state, three general conditions may be conceived of under which the material of the earth's crust may exist. These are: I, the molten condition, or state of igneous fusion and solution; 2 , the state of solution in water; and. 3 , the state of vapor or incorporation in the air. A molten magma is not merely produced by a change of condition 
from the solid to the liquid state through a rise in temperature (i. e., snow or ice to water), though this is undoubtedly to be regarded as the simplest state of fusion. A much more complex state, however, exists in the fusion of compound materials such as the rock magmas consist of. These are to be regarded as solutions of the silicates one in another or several in one, under a condition of high temperature. Solutions of salts in water are not actually different in kind from these "igneous solutions," though they take place at a lower temperature. Since, however, such a large part of the earth's surface consists of water in the liquid state, it is convenient to consider solution in water as distinct from igneous solutions. This conception makes it possible to identify the three states of the material from which the lithosphere is to be formed, respectively, with the pyrosphere, hydrosphere, and atmosphere. By a direct crystallizing out from the three states (or precipitation in the amorphous state), we have three groups of endogenetic rocks composing the lithosphere, namely: I, the pyrogenic, or igneous; 2 , the atmogenic, or atmospheric; and, 3, the hydrogenic, or aqueous (in a restricted sense). By the physiological activities of the organisms which constitute the biosphere, the biogenic or truly organic rocks are formed and these may be divided into zoogenic, or animalformed, and phytogenic, or plant-formed. These four types of endogenetic rocks may then be tabulated as follows:

I. Pyrogenic, or igneous, rocks-Pyroliths.

2. Atmogenic, or atmospheric, rocks-Atmoliths.

3. Hydrogenic, or aqueous, rocks (in a restricted sense)Hydroliths.

4. Biogenic, or organic, rocks (in a restricted sense)-Bioliths.

The origin and interrelations of these types are shown in the following diagram (Fig. 38).

The first of these groups comprises the Igneous rocks of most current classifications, the other three are commonly included with the clastic rocks as sedimentaries. Metamorphic rocks, though generally considered independently for convenience sake, belong strictly with the unaltered rocks from which they are derived, and of which they constitute modifications. The chief practical difficulty in placing them with their unaltered prototypes in a scheme is found in the impossibility of determining the precise types from which they have been derived (see further below).

The further subdivisions of the Endogenetic rocks are primarily based on chemical composition, and secondarily on texture. As a rule, composition is most readily expressed in terms of the minerals composing the rock if they can be ascertained, and this is 
a simple matter in all but the pyrogenic rocks. In refined work the chemical composition of the latter is by some subjected to a recalculation into the minerals which satisfy the composition (Cross, Iddings, Pirsson, etc.-4), though this at best seems an artificial procedure.

Texture and structure have been used with rather indefinite limitations. In general, texture is the fine structure or microstructure, concerned especially with minute arrangement of the compo-

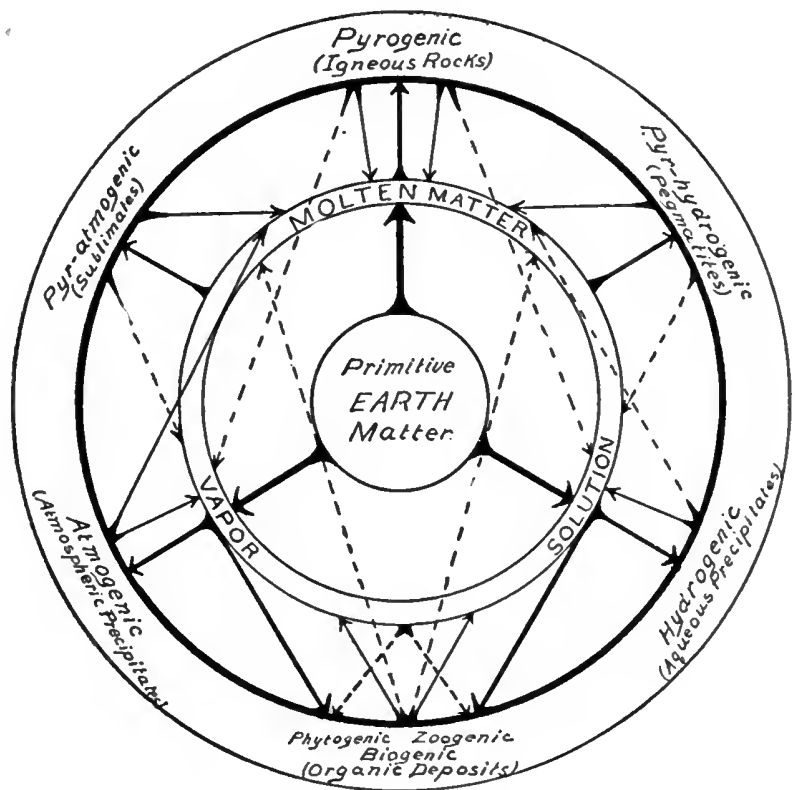

FIG. 38. Interrelations of the Endogenetic Rocks.

"The material of the earth may be in three states before solidification, i.e., that of fusion, of solution in water, and that of vapor. From these states by direct deposition (endogenetically) we get the three types of fundamental rocks-the Igneous, or Pyrogenic; the Aqueous, or Hydrogenic; and the Atmospheric, or Atmogenic (snow and snow-ice). By the physiological activities of organisms we have formed the Organic, or Biogenic, rocks, the material of which is derived either from the atmosphere (chiefly through plants-Phytogenic, though also in a minor degree through animals, as indicated by the heavy dotted line); or from the water (chiefly through animals-Zoogenic, though also in a minor degree through plants). The lighter arrows show to which states the rocks finally return, the dotted lines indicating the less likely change. Biogenic rocks are either vaporized or dissolved, hence the return arrows rise from the center. Pyro-atmogenic rocks, half way between Pyro- and Atmogenic are illustrated by sublimates, and Pyro-hydrogenic rocks, half way between Pyro- and Hydrogenic, by pegmatites." (Grabau-9:232.) 
nent particles, while structure is the coarser arrangement. It might be serviceable to retain structure as a general term, and to speak of the finer structure of rocks, $i$. $e$., that which can be seen in a hand specimen, as texture, while the coarser structural features, generally, visible only in the field, come under the heading of geotectonics, or earth architecture.

The texture of Endogenetic rocks is either crystalline or amorphous, each of these having a number of subordinate phases, peculiar to one or other of the classes of endogenetic rocks. A type of texture or aggregation of a higher order approaching structure may also be observed at times in the endogenetic rocks, which give them a resemblance to rocks of clastic origin. The three types of these aggregates, spherites, granulites, and pulverites, will be discussed at the end of the section on endogenetic rocks. A brief description of each class follows:

I. The Pyrogenic or Igneous Rocks (Pyroliths). These rocks result from the cooling of a molten magma, and are crystalline or glassy, or of intermediate character. The following groups, based on the composition of the magma, are most generally met with:

\section{Composition Groups.}

I. Granite group, where the composition is that of granite, which when fully crystallized out would result in the formation of quartz and orthoclase with hornblende and biotite or muscovite generally present.

II. Syenitic group, where the composition is that of syenite, resulting on crystallization in the formation of orthoclase and hornblende, with other accessory minerals generally present.

III. Dioritic group, where the composition is that of diorite, i.e., resulting in the crystallizing out of plagioclase and hornblende, frequently with some orthoclase, biotite, and other minerals, and sometimes with sufficient silica to form free quartz.

IV. Gabbroitic group, with the composition of gabbro, which on crystallization will yield pyroxene and plagioclase, with or without basic minerals, as olivine, etc.

V. Ultra Basic group, the component minerals being ferromagnesian silicates, without feldspar, and in the more basic with olivine.

The first of these constitutes the acid group with the percentage of silica $\left(\mathrm{SiO}_{2}\right) 68$ or over, the second and third constitute the in- 
termediate group with the percentage of silica $\left(\mathrm{SiO}_{2}\right)$ between $5^{*}$ and 68; while the fourth and fifth constitute the basic group, with the percentage of $\mathrm{SiO}_{2}$ below 50 . That this classification is only approximate appears from the fact that some gabbros have a percentage of $\mathrm{SiO}_{2}$ approaching 55, while some granites fall as low as 62 per cent. Each of these groups may be subdivided according to texture as follows:

\section{Textural Groups.}

I. Crystalline Division.

A. Holocrystalline, or Granitic. Also called phaneritic, with the minerals all crystallized out, and the leading minerals visible magascopically, as in granite. They may occasionally exhibit a rude porphyritic structure. The crystals may be in part idiomorphic (automorphic), each having its own form, or allotriomorphic (xenomorphic), having their outline determined by the surrounding crystals, or both. In basic igneous rocks, of either holo- or cryptocrystalline texture, an ophitic structure may occur, in which the crystals of pyroxene have the character of large plates, separated and penetrated by fine needles and crystals of feldspar. The pyroxene has crystallized around the feldspar, as shown by the fact that the pyroxene is in optical continuity on both sides of the obstruction. Orbicular structure may also occur in basic igneous rocks, and consists of an abundance of spheroidal aggregates ranging in size up to that of a walnut or over, and composed of silicates with radial or concentric arrangements. In the well known napoleonite from Corsica they consist of concentric shells with a radial structure and composed of hornblende and feldspar alternately. The Finnish granite, known as Rapakiwi, belongs here. (Harris-I3.)

B. Cryptocrystalline, also called aphanitic, with a considerable proportion of the mineral constituents not visible magascopically. When larger crystals (phenocrysts) are scattered through the main mass (ground mass) the rock is said to be porphyritic or porphyry.

* 55 , according to some. 
When the ground mass predominates, the phenocrysts being few, the rock is spoken of as porphyritic rhyolite, trachyte, etc. But if the phenocrysts abound then the rock is called a rhyolite porphyry, trachyte porphyry, andesite porphyry, etc.

Porphyries (Cross, etc.-4) may, in a general way, be divided into light-colored, or leucophyres, and dark-colored, or melaphyres, and, according to the character of the phenocrysts, into Quartz-leucophyres, Feldspar-leucophyres, Quartz-melaphyres, Feldspar-melaphyres, etc. When intermediate as to color the names quartz-porphyry or quartzophyres, feldspar-porphyry or feldsparphyres, hornblende porphyries, or hormblendophyres, etc., are useful.

Cryptocrystalline texture may be original or secondary through a process of devitrification of lavas originally glassy or acrystalline. They may be divided as follows:

B-I. With Trachytic texture, the ground mass consisting of an aggregate of little rods of feldspar in parallel arrangement. This is sometimes visible to the unaided eye.

B-2. With Felsitic texture (lithoidal), when the ground mass is so dense as to appear acrystalline except under the microscope, where it is seen to consist of minute quartz and feldspar grains with some glass.

B-3. Vesicular and Amygdaloidal, with a cryptocrystalline ground mass, but with numerous vesicles or steam holes which may be filled with mineral matter (amygdaloidal texture).

II. Amorphous Division.

C. Acrystalline, or glassy, the greater part of the mass being an amorphous glass, without crystalline character even under the microscope. It may be divided into:

C-I. Vitreous, or obsidianic, when a uniform glass as in obsidian.

C-2. Perlitic with spheroidal structure due to concentric cracks from contraction in cooling. Ex. Perlite. 
C-3. Vesicular, or pumiceous and scoriaccous. When rendered light and cellular by the abundance of steam holes due to expansion of the steam during solidification. The commoner, rougher type constitutes the scoriaceous texture. These vesicles may characterize the entire mass or be limited to layers or streaks. In the basic rocks the scattered vesicles may become filled by mineral matter either during or subsequent to the volcanic period, and so produce an amygdaloidal structure.

C-4. Spherulitic, microspherulitic, variolitic, etc. Containing globes or spherules made up of extremely delicate fibers of feldspar, arranged radially and emberlded in a mass consisting chiefly of aggregates of tridymite or quartz. In size these spherulites may range to several inches. Microspherulitcs. are very minute spherulitic bodies, often occurring in great numbers in bands or affecting the entire ground mass. The large spherulites of older acid lavas are often partly or totally replaced by flint or quartz. In basic rocks a similar structure is known as variolitic. Lithophysc are spherulitic structures varying up to a foot or more in diameter, and consisting of concentric shells separated by interspaces. (For illustrations, see Iddings-1 5 ; pls. xtli and rliii.)

Cryptocrystalline and Acrystalline rocks may also exhibit a banded texture, i. $c$., flow structure on a small scale (see beyond). From the combination of any member of the composition group with members of the texture group we get the common types of pyrogenic rocks, as follows*:

* For a more detailed discussion of the pyrogenic rocks the student is referred to the Hand Book of Rocks, by J. F. Kemp, and to the work of Cross, Iddings, Pirsson and Washington, on Quantitative Classification of Igneous Rocks, cited in the Bibliography. Sce also Harker, A Natural History of the Igneous Rocks, and for a brief treatise, his Pctrology for Students, Cambridge. 
I. The Granite magma, when holocrystalline constitutes granite, when cryptocrystalline, rluyolite, quartz felsite (petrosilex) or quartz porphyry; when glassy, (I) rhyolite obsidian, (2) perlite, or (3) rlyolite pumice.

II. The Sycnitic magma when becoming holocrystalline constitutes syenite; when cryptocrystalline, trachyte felsite, or trachyte porphyry; when glassy, (1) syenite obsidian, (2) perlite, or (3) syenite pumice.

III. The Dioritic magma when becoming holocrystalline constitutes diorite or quarts diorite (free quartz present); when cryptocrystalline, andesite, andesite felsite, or andesite porphyry and dacite, dacite fclsite, or dacite porphyry; when glassy, (1) andesite obsidian, or (2) andesite pumice.

IV. The Gabbroitic magma when holocrystalline constitutes gabbro and olivine gabbro; when cryptocrystalline, augite andesite or augite andesite prophyry, and basalt or basalt porphyry; when glassy, (1) basalt obsidian, or (2) scoria.

$\mathrm{V}$. The Ultra basic (non-feldspathic) magmas, when holocrystalline constitute pyroxenite, and peridotites (with olivine); when cryptocrystalline, augitite and limburgite (with corresponding porphyrys); and, when glassy, basic obsidians and scorias.

The following may further be noted:

Dolcrite, a field name to be used for a holocrystalline rock, either a diorite or a gabbro, in which the ferromagnesian minerals cannot be determined at sight. (Chamberlin and Salisbury-2: 452.)

Trap, a field name for a cryptocrystalline, non-porphyritic, dark rock, of either dioritic or gabbroitic composition.

Diabase, a holocrystalline rock of gabbroitic composition, but with a cliabasic (ophitic) texture, the plagioclase feldspar crystals being lath-shaped and fully crystallized (idiomorphic), while the augite between them is allotriomorphic. It occurs chiefly as a dike rock or in sills.

Hornblendite, a holocrystalline rock composed of hornblende without feldspar.

Water and Ice as Igncous Rocks.

Water solidifying into ice by a lowering of temperature must be referred to the igneous rocks. Its texture may be holocrystalline, but is more conmonly cryptocrystalline, or glassy. It must be 
placed at the ultra basic end of the scale, being entirely free from $\mathrm{SiO}_{2}$ when pure. (See Kemp-17.)

\section{Metanorphic Derizatives of Igneous Rocks.}

These comprise: (I) Gneisses, which include granite gneiss, syenitic gneiss, dioritic gneiss, gabbroitic gneiss, pyroxenitic gneiss, peridotitic gneiss, according to the nature of the pyrogenic rock from which they have been derived. (2) Schists, including some mica schists due to crushing and shearing of acid igneous rocks, hornblende schists derived from basic igneous rocks: chlorite and perhaps talc schists. (3) Serpentines and some soapstones derived from basic igneous rocks. The weathering products of igneous rocks will be discussed at some length in a later chapter.

2. The Atmogenic or Atmospheric Rocks (Atmoliths). This group is represented by snow and snow ice, ${ }^{*}$ which are precipitates from the atmosphere, as rock salt and gypsum are precipitates from the water. It forms a surface rock of considerable extent at the present time in the Polar regions, while at various periods in the earth's history it has extended widely over regions now for the most part freed from it. The importance of snow ice in stratigraphy is emphasized by the preservation in it of animals in an almost unaltered condition and by the glacial deposits to which it has given rise in various geologic periods. In composition ice is simple, consisting throughout of a single mineral mass, and in texture it is granular crystalline, though appearing compact with conchoidal fracture. The types here comprised are: I., Snow; II., Firn; and, III., Glacier Ice.

I. Snow. This is a loose aggregate of needles and flakes of crystalline form and structure, precipitated in this state from the atmosphere in which the material was held as water vapor. The crystalline form is soon lost through partial nelting and evaporation, a fine granular powder resulting. This is the first step in metamorphism (diagenism).

II. Firn, or Névé. This is an aggregate of snow grains, either loosely held together or united by ice cement. These aggregates are full of air bubbles. Firn is formed below the snow line and represents a further step in metamorphism of the snow.

III. Snow ice, or Glacier Ice. This is a granular crystalline mass in which the individual crystalline ice grains range from the

* Water ice which is to be considered an igneous rock resulting from the cooling of a magma is of little stratigraphic importance. (See above, p. 278.) 
size of a pea near the firn border to that of a hen's egg. The crystals are intimately united, so that in fresh ice they cannot be distinguished.

3. The Hydrogenic Rocks (Hydroliths). These are the only true aqueous rocks and they are wholly of chemical origin. Though often forming beds of considerable extent, they do not generally enclose evidence of their age, though in some cases organic remains are found. As a rule, however, the age of a bed of rock salt or gypsum can be determined only by the age of the enclosing rocks. Chemically formed, or hydrogenic limestones, on the other hand, may include organic remains, as is the case in calcareous tufa and cave deposits. Many great limestone beds which are sparingly fossiliferous have frequently been considered of chemical (hydrogenic) origin, but it is not improbable that many, if not most, of these will prove to be of clastic origin. Among hydrogenic rocks of less stratigraphic importance are siliceous sinters and their alteration products and the various ferrites or iron ore deposits, which owe their precipitation from water to inorganic reactions.

4. The Biogenic Rocks (Bioliths). These are the only true organic rocks, $i$. e., those due directly to the physiological activities of organisms. They are among the most important rocks with which the stratigrapher has to deal, for they are the rocks richest in organic remains. As examples may be mentioned the organic limestones, such as coral and shell rock; and the organic oozes, whether calcareous or siliceous. Here also belong the deposits of coals and vegetable materials in all stages of carbonization, from peat to anthracite.

Bioliths may be divided into Zoöliths, or those of animal origin, and Phytoliths, or those of vegetal origin. The latter include two important types, those formed by the direct accumulation of vegetal matter, such as peat, coals, etc., which, from their burnable nature, have been called caustobioliths* (Potonié, see Chapters $\mathrm{x}$ and $\mathrm{xi}$ ), or better caustophytoliths; and those forming pure accumulations of mineral matter, either silicia (diatoms) or lime (nullipores, etc.). These are the acaustophytoliths. Caustobioliths may also be of zoögenic origin (caustozoöliths), but these are rare (some oils, etc.). Finally, caustoliths of non-organic origin are also known, such as chemically formed petroleum, asphalt, graphite, and sulphur. Caustobioliths have been divided into three groups, according to their mode of origin. These are:

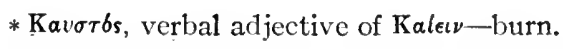




\section{Caustobioliths.}

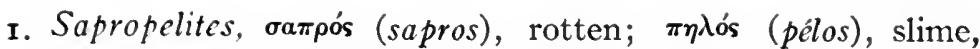
mud; $\iota \tau \eta s$ (ites), derived from. These are derived from the decaying organic matter of water organisms, both animal and plant, algæ, etc.* (sapropel, Faulschlamm, decay ooze, putrid slime). When formed into rock they constitute sapropeliths or sapropelites. $\dot{\dagger}$ They differ from the humus rocks in their greater content of fat and protein.

2. Humus and Humulith. These are deposits derived from decaying land plants, including those of swamps and marshes. Carbohydrates are an important product of the decay of the higher plants. All peat and coal deposits belong here. Lithified, they form humus rock or chamaeliths ( $\chi$ ara on the ground, Greek equivalent of humus; the Latin would be humulith).

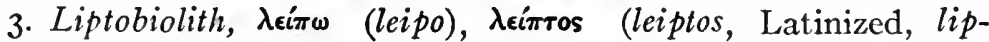
tos, left behind, residual and biolith). These comprise the resins and gums, amber, copal, etc., which, from their greater resistance to decay remain behind after the destruction of the plants contaning them.

Subdivision of Hydrogenic and Biogenic Rocks. In both hydrogenic and biogenic rocks the chemical division is most readily made on the basic elements of the salts. In texture hydrogenic rocks are both crystalline and amorphous while in biogenic rocks the amorphous texture predominates.

Textures of Amorphous Hydrogenics. Among the amorphous hydrogenics the following subtextures are most marked:

(a) Botryoidal, with grape-like, rounded surfaces.

(b) Pisolitic, of large spherules.

(c) Oölitic, of small spherules, also characteristic of the biogenic rocks.

(d) Banded, as in stalactic deposits (stalactites and stalagmites).

(e) Laminated, or scaly.

(f) Fibrous.

(g) Concretionary.

(h) Tufaceous, as in calcareous and siliceous. tufa or sinter.

Textures of Biogcnic Rocks. Among the biogenic rocks we note the following subtextures:

* Mineral structures, such as shells and skeletons, are of course excluded.

$\dagger$ The termination pelite should be restricted to oozes or slimes of endogenetic origin, leaving the termination lutyte for oozes of exogenetic or clastic origin. 
(a) Granular, the texture of the fine organic oozes.

(b) Oölitic, consisting of minute spherules or oölite grains.

(c) Earthy texture.

(d) Compact conchoidal, as in coal, etc.

The following table gives some of the principal hydrogenic and biogenic rocks (Grabau-9) :

Table of the principal types of hydrogenic and biogenic rocks.

\begin{tabular}{|c|c|c|c|c|c|}
\hline Class & \multicolumn{5}{|c|}{ Composition } \\
\hline & $\begin{array}{l}\text { (a) } \\
\text { Alkali- } \\
\text { ous }\end{array}$ & $\begin{array}{c}\text { (b) } \\
\text { Calcare- } \\
\text { ous }\end{array}$ & $\begin{array}{c}\text { (c) } \\
\text { Siliceous }\end{array}$ & $\begin{array}{c}\text { (d) } \\
\text { Ferru- } \\
\text { ginous }\end{array}$ & $\begin{array}{l}\text { (e) } \\
\text { Carbona- } \\
\text { ceous }\end{array}$ \\
\hline $\begin{array}{c}\text { Hydroliths } \\
\text { Original }\end{array}$ & $\begin{array}{l}\text { Rock Salt, } \\
\text { Etc. } \\
\text { Natural } \\
\text { Soda }\end{array}$ & $\begin{array}{l}\text { Chemical } \\
\text { Limestone, } \\
\text { Stalactic } \\
\text { Deposits, } \\
\text { Calcareous } \\
\text { Tufa, Gyp- } \\
\text { sum, An- } \\
\text { hydrite, } \\
\text { etc. }\end{array}$ & \begin{tabular}{|l} 
Siliceous \\
Sinter, \\
Vcin \\
Quartz, \\
Flint, \\
Chert
\end{tabular} & $\begin{array}{l}\text { Bog Ore, } \\
\text { Limonites, } \\
\text { Siderites, } \\
\text { etc. }\end{array}$ & \\
\hline Metamorphic & & $\begin{array}{l}\text { Marble, } \\
\text { Alabaster }\end{array}$ & $\begin{array}{l}\text { Quartz } \\
\text { Rocks }\end{array}$ & $\begin{array}{l}\text { Specular } \\
\text { Hematites, } \\
\text { Magnet- } \\
\text { ites, etc. }\end{array}$ & \\
\hline $\begin{array}{l}\text { Biolitis } \\
\text { Original }\end{array}$ & $\begin{array}{l}\text { Phosphate } \\
\text { Rocks }\end{array}$ & $\begin{array}{l}\text { Organic } \\
\text { Limestoncs } \\
\text { Coral Rock } \\
\text { Shell beds, } \\
\text { (organic } \\
\text { oozes, etc.) }\end{array}$ & $\begin{array}{l}\text { Siliccous } \\
\text { Organic } \\
\text { Oozes, } \\
\text { Diatoma- } \\
\text { ccous } \\
\text { Earth } \\
\text { Tripolite, } \\
\text { etc. }\end{array}$ & $\begin{array}{r}\text { Limonites } \\
\text { (organic) }\end{array}$ & $\begin{array}{l}\text { Peat, Lig- } \\
\text { nite, Bitu- } \\
\text { minous } \\
\text { coal, some } \\
\text { Anthracites } \\
\text { etc. (Caus- } \\
\text { tobioliths) }\end{array}$ \\
\hline Metamorphic & & Marble & $\begin{array}{l}\text { Quartz } \\
\text { Rock } \\
\text { or } \\
\text { Quartzites }\end{array}$ & $\begin{array}{l}\text { Specular } \\
\text { hematites } \\
\text { spathic } \\
\text { and mag- } \\
\text { netic } \\
\text { iron ores }\end{array}$ & $\begin{array}{l}\text { Certain an- } \\
\text { thracites, } \\
\text { Native } \\
\text { coke, Bitu- } \\
\text { mens, etc. } \\
\text { Graphite } \\
\text { in part }\end{array}$ \\
\hline
\end{tabular}


Spherytes, Granulytes, and Pulverites (pelytes). These names have been suggested (Grabau-ı) for rocks composed of aggregates of constructional origin simulating in texture destructional or clastic rocks and having many features in common with them, such as stratification, etc. The textures which characterize these rocks are spherytic, granulytic, and pulierytic, corresponding to the textures rulaceous, arenaceous, and lutaceous among the clastic rocks. Thus a rock formed of volcanic bombs would be a spheryte, one formed of lapilli or oolitic grains a granulyte, and one formed of diatom frustules, or minute radiolaria or foraminifera, a pulieryte. The last three types would be of biogenic origin, and therefore would constitute biopulierytes, two of them being biosilicipulverytes, the material being silica, the third a biocalcipulveryte, the material being calcite. A pulverytic rock of hydrogenic origin would be a hyllopulveryte. As suggested above. the term pelyte (from the Greek $\pi \eta \lambda$ os, slime) might well be restricted to muds and slimes of endlogenetic origin, and so be used instead of the word pulveryte. Thus, instead of pyro-, atmo-, hydro-, and biopulverytes, we may use the terms, pyropelytes, atmopelytes, hydropelytes, and biopelytes.

Chemically formed oolites are liydrocalcigranulytes, or. if of silica, hydrosilicigranulytes. The oolitic iron ores of Wisconsin (Siluric) are probably hydroferrogranulytes. Organically formed oolites are biocalcigranulytes; granular snow (firn) is an atmogranulyte, and volcanic lapilli form a pyrogranulyte. A bed of volcanic bombs is a pyrospheryte, and one of unworn coral or Girvanella heads a biospheryte (biocalcispheryte). All of these rocks are of endogenetic or nonclastic origin.

Ooliths, Pisolithis, Rogensteine, etc. Rocks composed of spherical grains of either hydrogenic or biogenic origin are called Oolites or Ooliths when the grains are small, and Pisolites or Pisoliths (Pea grits) when they have the size of a pea or over. Rogensteine are ooliths or pisoliths in which the grains (ooids) are held together by a more or less argillaceous cement. In typical ooliths, so named from their resemblance to fish-roe, each grain consists of successive concentric shells of carbonate of lime, and has, moreover, commonly an internal radiating fibrous structure, which gives a black cross between crossed nicols. The lime is often deposited around some foreign body, but also often without such a body, forming a sphere hollow at the center. The granules consist sometimes of aragonite, sometimes of calcite, or they are formed by an intermediate substance, litypeit. Great variation in size occurs. 
The giant pisoliths * of Zepce, Bosnia, range from 2 to 13.5 centimeters in diameter, but ordinary ooliths do not range much above I.5 $\mathrm{mm}$. In the Bosnian examples the kernal is magnesite and the surrounding shells dolomite. Both concentric and radial structure is shown in these and they are believed to have been formed in hot springs, similar to the pisoliths of the Carlsbad Sprudel.

True ooliths and pisoliths are precipitations (hydrogenic or biogenic) and their spherical form is an original structure. Rocks of clastic or worn calcite grains or fragments of shells, etc., may resemble ooliths, and are indeed often mistaken for them. To such Bornemann has applied the term pseudo-ooliths, and they belong to the category of exogenetic rocks, unless, indeed, they are subsequently enlarged by deposition of lime about them. Concretions nay also assume the form of ooliths or pisoliths, but they are secondlary or diagenetic structures. Three modes of origin have been most widely discussed by geologists and one or the other has frequently been regarded as the sole mode. These are: I. Chemical, or hydrogenic; 2. animal, or zoogenic; and, 3. plant, or phytogenic. Each of these will be discussed under its appropriate heading in succeeding chapters.

\section{The Exogenetic, or Clastic Rocks}

In discussing next the clastic rocks, the agent active in the production of their present characteristics will be considered as of primary importance in making the larger divisions. It is not always possible to determine what was the cause of the clastic condition of a given rock, since other agents subsequently active have produced those features which give the rock its most characteristic aspects. Thus a sand mass may owe its origin in part to atmospheric disintegration and in part to the mechanical activity of the water. Its final form, however, may be given by æolian action, the mass becoming finally by diagenism a consolidated sand-dune. It will, however, be observed that the agent last active, and therefore the one whose characteristics were most strongly impressed upon the mass, $i . e$, the wind, is not only responsible for the form and structure which the deposit eventually takes on, but also, in part at least, modifies the original form of the component grains. Thus without overlooking the claims of the other agents those of the wind may be considered as greatest and the rock is therefore placed under the division of wind-formed clastics, or anemoclastics.

* These should be classed as hydrospherytes. 
The relative clains of the various agents active in the production of a given clastic rock once determined-provided there is more than one agent-it will be found that most rocks fall under one of five groups, though some rocks may fall so precisely half way between two groups that it becomes a matter of individual opinion where it should be placed. The five principal groups are:

I. Pyroclastic rocks, or pyroclasts.

2. Autoclastic rocks, or autoclasts.

3. Atmoclastic rocks, or atmoclasts.

4. Anemoclastic rocks, or anemoclasts.

5. Hydroclastic rocks, or hydroclasts.

6. Bioclastic rocks, or bioclasts.

The interrelations of these rocks are shown in the following diagram (Fig. 39), on page 286.

\section{Textural Groups.}

In these divisions the grain of the rock or its texture is of greater importance than the composition, for, although the latter is often the prime cause of selective destruction of rocks, yet this is generally only on a minor scale, and the destruction of the different rocks by the same agent, especially when mechanical, goes on without much reference to the composition. On the other hand, the size of the grain is generally directly proportional to the intensity of action of the agent (aided of course by the composition and structure of the original rock), and so naturally takes a higher classificatory rank. These types of texture or grain of clastic rocks are recogniized :

I. Rudaceous* texture, or that of the rubble rocks, in which the grain is larger than that of a sand grain. Consolidated rocks of this texture are Rudytes (psephytes of many authors).

2. Arenaceous $\dagger$ texture or that of sand rocks, irrespective of composition, in which the size of the grain varies from being barely visible to that of a grain of rice. Consolidated rocks of this texture are Arenytes (Psammytes of some authors).

3. Lutaceous $\ddagger$ texture or that of impalpable powder or rock flour. Consolidated rocks of this type are Lutytes (i. e.. mud rocks). (Pelytes in part of some authors.)

* From rudus, Lat. for rubble.

† From arena, Lat for sand.

$\ddagger$ From lutum, Lat. for mud. 
Size of Grain. In recent years attempts have been made to establish a more precise mode of designation of the various types based on size of grain. The following is the standard adopted by the New York City aqueduct commission and may well be adopted as a general standard with the emendations given beyond.

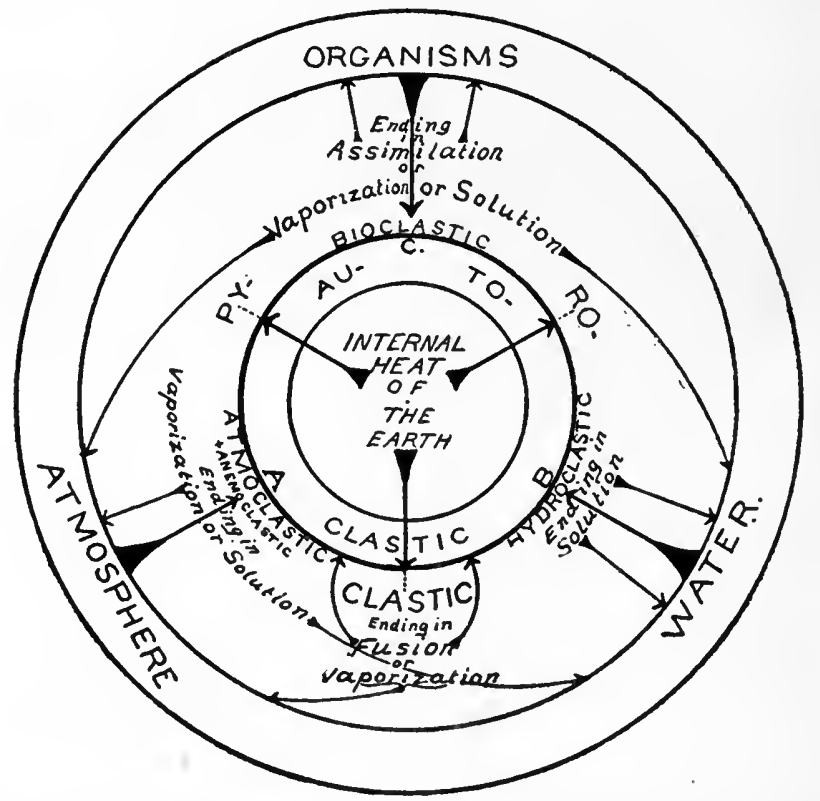

Fig. 39. Diagram showing the interrelations of the exogenetic rocks. A B C represent the crust of the earth or lithosphere. From within this shell, but still external so far as the crust is concerned, the volcanic explosions produce the pyroclastic rocks on the surface of the earth. Within the crust itself are formed the autoclastic rocks. From without the shell the attack by atmosphere, hydrosphere and biosphere produce, respectively, atmoclastic (and anemoclastic), hydroclastic and bioclastic rocks. The final result of the destructive activities of the various agents is the return of the material either to the air as vapor or to the water in solution, or more rarely to assimilation by the biosphere (salt, etc.). Fusion may transfer some of the material to the realm of the pyrosphere. The cycle of change is thus complete and redeposition will be as endogenetic rocks.

I, Coarse gravel above 5. mm.; 2, fine gravel 5 to $\mathrm{I} \mathrm{mm}$.; 3 , coarse sand I to $0.5 \mathrm{~mm}$. ; 4, medium sand 0.50 to $0.25 \mathrm{~mm}$. ; 5 , fine sand 0.25 to $0.10 \mathrm{~mm}$; 6 , superfine sand 0.10 to $0.05 \mathrm{~mm}$.; 7 , rock flour (silt, Merrill) 0.05 to $0.01 \mathrm{~mm}$. ; 8, superfine flour (fine silt, Merrill) 0.010 to $0.005 \mathrm{~mm}$.; 9 , clay size 0.005 to $0.0001 \mathrm{~mm}$. 
Eventually this classification was published by Merrill in 1898 $(20: 380)$, the only difference being that he gives the range of fine gravel as betiveen 2 and 1 millimeter, and classes everything above $2 \mathrm{~mm}$. as gravel. Crosby $(3: 205)$ has given a somewhat different valuation for some of the types as follows:

Fine sand: $0.45 \mathrm{~mm}$.; superfine sand: $0.28 \mathrm{~mm}$.; quartz flour: $0.16 \mathrm{~mm}$.; superfine quartz flour : $0.08 \mathrm{~mm}$.

Keilhack $(16: 527,528)$ gives the following classification, according to size of grain: $I$, grains above $2 \mathrm{~mm}$. diameter: gravel: 2 , grains from 2 to $1 \mathrm{~mm}$. diameter : very coarse sand; 3, grains from I to $0.5 \mathrm{~mm}$. diameter: coarse sand; 4 , grains from 0.5 to $0.2 \mathrm{~mm}$. diameter: medium sand; 5, grains from 0.2 to $0.1 \mathrm{~mm}$. diameter: fine sand; 6, grains from 0.1 to $0.05 \mathrm{~mm}$. diameter: superfine sand; 7 , grains from 0.05 to 0.01 diameter: dıst; 8 , grains smaller than o.oI mm. diameter: finest dust. Nos. 2 to 6 inclusive were classed merely as sands; the varietal names are here added.

It will be seen that the subdivisions of the sands here given correspond very closely to those selected by the New York engineers, who, however, place the grains above $1 \mathrm{~mm}$. in diameter into the category of gravel. No. 7, rock flour of the engineer's table, also corresponds to No. 7, dust of Keilhack's table.

From these analyses, we may construct the following table, which may serve as a standard for comparison:

Table of standard sizes of rock fragments.

1. Boulders.......... above $\quad 150.0000 \mathrm{~mm}$.

2. Cobbles......... I $5^{0.000}$ to $50.0000 \mathrm{~mm}$.

3. Very coarse gravel... 50.000 to $25.0000 \mathrm{~mm}$.

4. Coarse gravel...... 25.000 to $5.0000 \mathrm{~mm}$.

5. Fine gravel...... 5.000 to $2.5000 \mathrm{~mm}$.

6. Very coarse sand (or very fine gravel)...

7. Coarse sand........

8. Medium sand.......

9. Fine sand..........

10. Superfine sand.....

I I. Rock flour .........

12. Superfine flour......

13. Clay size.........

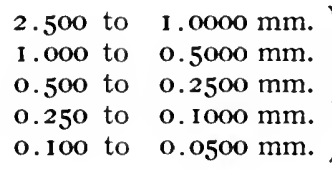

0.050 to $0.0100 \mathrm{~mm}$. Texture lutaceous; on 0.010 to $0.0050 \mathrm{~mm}$. consolidation forming 0.005 to $0.0001 \mathrm{~mm}$. lutytes.
Texture rudaceous; on consolidation forming rudytes.

Texture arenaceous; on consolidation forming arenytes.

Orth (22), Laufer (18) and Wahnschaffe (29) are in essential agreement with Keilhack, and so is E. Wollny. Orth calls material from $\mathrm{r} \mathrm{mm}$. to $3 \mathrm{~mm}$. very coarse sand and fragments, above $3 \mathrm{~mm}$. 
pebbles. Laufer and Wahnschaffe call grade 4 of Keilhack's scale fine sand and both 5 and 6 very fine sand. Wollny makes his medium sand from 0.5 to 0.25 and his fine sand 0.25 to o.r. From 0.1 to 0.05 he calls coarse silt, from 0.05 to 0.025 medium silt, from the last to $0.005 \mathrm{~mm}$. fine silt, and below that to $0.00 \mathrm{I} \mathrm{mm}$. colloidal clay. Orth, Laufer, etc., call 0.05 to $0.01 \mathrm{~mm}$. dust, and everything below that finest dust. Wollny calls fragments from 5 to $2 \mathrm{~mm}$. medium gravel, from to to 5 coarse gravel and above $10 \mathrm{~mm}$. stones.

Thoulet has given these dimensions, gravel: coarse, $9.0 \mathrm{~mm}$; medium $4.5 \mathrm{~mm}$.; fine $3.0 \mathrm{~mm}$.; sand: coarse (a) $1.32 \mathrm{~mm}$., (b) 0.89 ; medium (a) 0.67 , (b) 0.54 , (c) 0.45 ; fine (a) 0.39 , (b) 0.34 , (c) 0.30 , (d) $0.26 \mathrm{~mm}$; very fine $0.04 \mathrm{~mm}$. Silt below $0.04 \mathrm{~mm}$.*

It will be seen that Crosby and Thoulet differ most from the others, and also from each other. Their definite sizes are less satisfactory than the ranges given by the others. $f$

\section{Types of Sands Based on Origin.}

Sherzer (26) has recently proposed to subdivide sands according to their mode of origin into 7 groups, each with a number of subgroups. They are herewith given, separated into clastic and nonclastic sands, and each is referred to its proper place in the classification adopted in this book. Three additional types are added to make the series complete (Grabau-IO: I006).

\section{A. Clastic sands (Exogenetic).}

r. Glacial sand type $ł \ldots \ldots \ldots \ldots \ldots$ Autoclastic $=$ autoarenyte

2. Volcanic sand type............. Pyroclastic $=$ pyroarenyte

3. Residual sand type............. Atmoclastic $=$ atmoarenyte

4. Aqueous sand type............. Hydroclastic $=$ hydroarenyte

5. Eolian sand type .............. Anemoclastic $=$ anemoarenyte

6. Artificial sands (added)........... Bioclastic $=$ bioarenyte

\section{B. Non-clastic sands (endogenetic, see page 283).}

7. Organic sand type............. Biogenic sand (biogranulyte)

8. Concentration sand type........... Hydrogenic sand (hydrogranulyte)

9. Snow and firn sand (added)........... Atmogenic sand (atmogranulyte)

ro. Lapilli or igneous sand (added)......... Pyrogenic sand (pyrogranulyte)

* These grades are numbered I, 2, etc., by Thoulet.

$\dagger$ For further analyses see the table given under wind transportation, p. 59.

$\ddagger$ In this he includes the material resulting in the manufacture of talus in avalanches, rock slides, rock and mud flows, and earth movements along joint planes. All except the first, which is atmoclastic, belong under the autoclastic group with the glacial sand type. 
Sherzer designates as subtypes sands of one type modified by another agency and calls them by a compound term. Thus an aqueo-residual sand (hydro-atmoclastic sand) is one in which the granules have been produced by the various residual agencies, and are subsequently more or less modified by water action. Again a residuo-aqueous sand (atmo-hydroclastic) is one in which waterrounded grains have been subjected to the agencies of weathering, and give more or less evidence of such action. The principal subtypes or intermediate types may be grouped as follows:

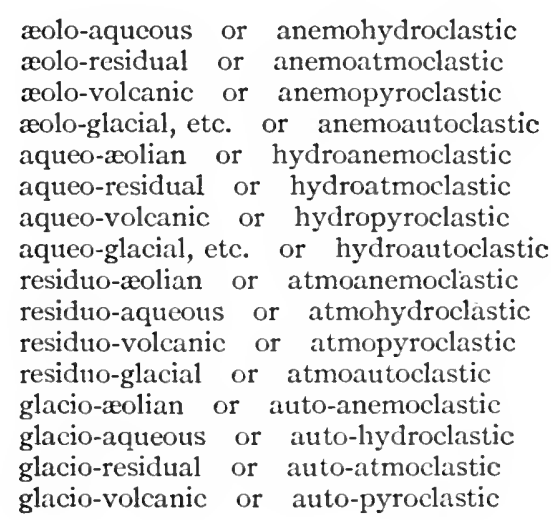

In all cases the agent last modifying the type is placed first, the agent producing the original type last. The organic clastics or bioclastics are of such recent origin that reworking by other agents has not occurred on an extensive scale. When it occurs, the coupling of the respective prefix with bioclastic will designate it. Reworking of other sands by volcanic agencies is of so rare an occurrence that such types may be neglected, although in a complete classification they must be included.

The organic (biogenic) and concentration or chemical (hydrogenic) sand types may also be reworked, producing æoloörganic and æolo-concentration types, aqueo-organic and aqueo-concentration types, etc.-i. $e$., the wind- or water-worn and the weathered biogenic and hydrogenic sands. The characters of the undisturbed endogenetic sands will be more fully dealt with in later chapters. The principles of classification applied to sands may equally be applied to the coarser or rudaceous material and the finer or lutaceous matter. 


\section{Composition of Clastic Rocks.}

In composition clastic rocks may be pure or impure, simple or complex. If one mineral type predominates, such as line or quartz, this fact may be combined with the corresponding textural term into a compound word expressive of both. Thus, if the material of the clastic rock is pure lime, the rock becomes a calcirudyte, a calcarenyte or a calcilutyte, according to the texture. If quartz, the rock becomes a silicirudyte, a silicarenyte, or a silicilutyte, according to the texture. If the rock is impure it will still be possible to designate it, keeping in mind that the dominant mineral constituent furnishes the name. Thus we may have siliceous calcirudytes, calcarenytes, calcilutytes or calcareous silicirudytes, silicarenytes, silicilutytes. Or the impurities may be iron, carbon, clay, etc., in which case we use the prefixes ferruginous, carbonaceous, argillaceous, ẻtc.

Lutytes are most generally formed among the argillaceous or clay rocks, but pure argillutytes are not very common. Generally they are siliccous, calcareous or carbonaceous argillutytes, all of which are more familiarly known by the structural terms shales or slates, which terms, however, express nothing definite in regard to the composition.

Clastic rocks of complex composition, as, for example, those formed from the reconsoliclation of disintegrated granites (arkoses), can be spoken of simply as rudytes, arenytes, or lutytes, without attempt at defining their composition.

Examples of clastics under each group are as follows:

I. The Pyroclastics. In composition these are seldom simple, being mostly complex siliceous rocks shattered by volcanic explosions. The more or less indefinite terms tuff, volcanic breccia and agglomerate are commonly used. The essential types are:

Pyrorudytes: coarse, chiefly angular volcanic blocks and bombs, loose or recemented by finer material-volcanic breccias and agglomerates.

Pyrarenytes: coarse tuffs where the grain is not above the size of the ordinary sand grain $(2 \mathrm{~mm}$.). They generally show rude stratification and may contain organic remains. (Vide, the buried cities and human remains in the tuffs of Vesuvius and other volcanoes.)

Pyrolutytes: fine tuffs composed of volcanic dust and ashes. Stratified, and enclose remains, as in the case of pyrarenytes. 
Volcanic sand is characterized by irregular and sharply angular outline, giving no evidence of erosion except in the case of the larger particles, where partial rounding from mutual attrition during suspension occurs. The sands are comparatively well sorted, according to size, the finest material being often carried far away. More or less well defined crystals are generally visible under the microscope, but as a rule much of the material is amorphous, showing flow structure or vesicular character. (26:629, with references.) Subsequent modification and rounding by water or air gives us hydropyroclastics and anemopyroclastics, while weathering produces atmopyroclastics. When water laid, remains of marine or fresh-water organisms may be enclosed in these strata, or drifted land organisms may be entombed, as in the case of the Tertiary "Lake beds" of Florissant, Colorado.

2. The Autoclastics. This group comprises all rocks shattered or crushed within the earth either by pressure of one mass upon the other, or by movement of rocks over each other. Fault-breccias and the material of the "crush zones" must be classed here, as well as fragments produced by avalanches. Earthquake-shattered rocks may also be included, though they may likewise be considered transitional to the pyroclastics. By far the most important autoclastic products, however, are those resulting from glacial erosion. Ice, including all the material frozen in it, is a part of the earth's crust while it exists, and hence any material ground up between the ice and the rock on which it moves is of the type of the material crushed between other moving rock masses (ex. fault breccia). Furthermore, since all ice-transported material has received its most characteristic features from that agent, we may with propriety include such material in this group, even though it was originally broken by atmospheric agencies. Such rocks, if determinable, would come under the compound heading, auto-atmoclastic.

Fault breccias or autorudytes partake of the composition of the rocks from which they were formed, with probably slight changes due to secondary modifications. In limestones there may thus occur pure autocalcirudytes, while among pure quartz rocks autosilicirudytes may occur. In general, however, the composition of autoclastic rocks is quite impure, and this is particularly the case in the autorudytes and other types which result from the consolidation of glacial deposits. The latter are of the most importance to the stratigrapher, for there can be little doubt that they are represented 
in many of the geologic periods of the earth's history. Autorudytes of glacial orişrin, when unaffected by other agents, are characterized by the polished and striated surfaces of the boulders, larger pebbles and cobbles. Flat blocks generally have only two sides striated, while the margins may remain angular. The characteristic striation is soon lost through subsequent wear by streams from the ice, the material thus becoming hydroclastic (potamoclastic). The characteristics of glacial sands, whether derived from the crushing of igneous or of clastic rocks, lie chiefly in their angularity and freshness of grain, unless subsequent weathering has attacked these. If the material is derived through crushing of igneous or other crystalline rocks, it will show a variety of mineral grains. The quartz grains will be sharp-edged and pointed, with strongly vitreous and concloidal surfaces, while the cleavable minerals will show fresh cleavage faces as well as sharp outlines. (Sherzer-26:623.) When pure clastic rocks such as sandstones are crushed by ice the resulting material will be pure, with sharply angular grains, which may or may not be derived from originally rounded grains.

Glacial boulders and sands are frequently reworked by the glacial streams and so become hydroautoclastic or aqueo-glacial (Sherzer). The finer rock flour, etc., may be reworked by wind and so become anemo-autoclastic or rolo-glacial (ex. loess). See further, Chapters XII and XIII.

3. The Atmoclastics. These comprise rocks broken in situ, either by chemical or mechanical means; and recemented without further rearrangement by wind or water. Most of the rocks of this type are of complex composition, and there is a characteristic angularity in the coarser material which shows the absence of water. Stratification also is coarse or absent altogether. Characteristic examples are found in talus breccias, which when consolidated form typical atmorudytes; in the extensive subaerial accumulations of waste along slopes of most mountains, and in many of the Tertiary and earlier subaerial deposits, which were neither windlaid nor deposited in water bodies. Remains of land plants and animals are often characteristic of these rocks. The kaolinite and laterite, i. e., decomposition products which mantle the rock in unglaciated regions, when consolidated, also form typical examples of atmoclastic rocks.

The composition of atmoclastic rocks varies, of course, greatly, according to the nature of the rock from which they are derived, and the complication of the atmospheric processes involved. Under 
arid climatic conditions mechanical disintegration will predominate, especially in the case of crystalline rocks. Through differential expansion and contraction under heat and cold the minerals of the rock will become separated and a mixed sand results, in which the minerals have sharp outlines, owing to splintering along cleavage planes. Reconsolidation of such a sand produces arkoses, which, as in the case of the Torridon sandstone of Scotland, may have all the appearance of an igneous rock. In moist climates chemical alteration or decomposition of the feldspars (Mackie-19:444) and other decomposable minerals will set in, resulting eventually in the production of clay, etc., in which quartz and mica abound. The chief processes in this chemical destruction or decomposition of rock minerals consist of oxidation (and deoxidation), hydration (and dehydration), and carbonation; silication and desilication may also occur and solution of minerals also belongs here. (Van Hise$28: 46 r$.) Under rainy or pluvial conditions the clay and mica will be removed, the latter suffering mechanical destruction, while the quartz will become mechanically concentrated. When not modified by subsequent water or wind activities, the quartz and other resistant mineral grains will be found fresh and angular, without evidence of subsequent rounding, while complete crystals of idiomorphic minerals of the crystalline rock are among the resulting constituents. When modified by subsequent agents, various subtypes are produced, namely, hydro-atmoclastic, anemo-atmoclastic, etc.

4. The Anemoclastics. These are the wind-laid deposits which are often of great extent, and are of great importance to the stratigrapher. Ancmorudytes are probably unknown, but anemoarenytes and anemolutytes are widely distributed. Some familiar examples are anemosilicarenytes represented by solidified sand dunes of quartz sand; anemocalcarenytes, such as the consolidated wind-blown or reolian rocks of Bermuda in which the sand grains are wholly calcium carbonate; and the complex ancmolutytes forming extensive deposits of rolian dust, chiefly of volcanic matter, in the Tertiary strata of North and South America, and in which some of the best preserved remains of mammals have been found. These deposits approach and grade into the pyrolutytes which form in volcanic regions, and in fact it becomes a matter of opinion where the line between the two is to be drawn. The wind-laid loess is also a good example of an impure anemolutyte. 
In form, anemoclastic sand grains are apt to be more thoroughly rounded and worn than similar grains worn by water. In general, rounding of superfine sand, $i$. $c$., grains below $0.1 \mathrm{~mm}$., is not accomplished by water (Chamberlin and Salisbury-I :246; Daubrée-5:256), but such grains may readily be rounded in air. As shown by Mackie (see Chapter V), particies of quartz sand, less than one-fifth the diameter of those rounded by water, will be rounded to an equal extent by wind. Pitting and frosting of the surface is another characteristic result of æolian activity, as is also assortment according to size of grain and specific gravity of mineral, so that in a typical æolian sand the grains are of approximately uniform size, and of the same mineral throughout, generally quartz.

Most æolian sand and dust is derived from some other type of sand, such as residual material (anemoatmoclastic), glacial sand (anemoautoclastic), river or beach sand (anemohydroclastic), or volcanic sand (anemopyroclastic). Extensive deposits of anemobioclastic sands may accumulate around quarries, etc., especially where stone is crushed for road material. Where the reworking by wind has been extensive, the evidence of the original character may be destroyed. Eolian sand in a state of rest may have its grains coated with iron oxide, as in the case of the red sand of the Arabian desert. (Philipps-23:I IO.)

5. Tine Hydroclastics. These comprise by far the larger number of clastic rocks. They are the water-laid deposits and include the following common types:

a. Hydrorudytes, or conglomerates of variable composition.

b. Hydrosilicirudytes, or pure quartz conglomerates, and various varietics due to admixture of simple mineral matter.

c. Hydrocalcirudytes, or pure lime conglomerates and the varieties due to iron, silica or other simple impurities in the paste.

d. Hydrarenytes, or water-laid sandstones of variable composition.

e. Hydrosilicarenytes, or pure quartz sandstones with varieties due to simple admixtures in the paste.

f. Hydrocalcarenytes, or pure lime sandstones with varietics as above.

g. Hydrolutytes, or water-laid mud beds of variable composition. 
h. Hydrargillutytes, or pure clay beds and varieties due to the presence in small amounts of silica, lime, iron, or carbon.

i. Hydrosilicilutytes, or pure quartz-mud rocks, with their varieties due to a slight admixture of argillaceous, calcareous, carbonaceous, glauconitic, or ferruginous matter.

j. Hydrocalcilutytes, or pure lime-mud rocks, with their varieties due to a slight admixture of argillaceous, siliceous, carbonaceous or ferruginous matter.

The prefix "hydro" in all these cases is omitted when it is understood that the rocks are water-laid deposits. This is the class of rocks with which the stratigrapher has most to deal, for they comprise by far the largest portion of the sedimentary rocks, and they most commonly contain organic remains in greater or less abundance. In general, hydrorudytes have their pebbles rounded. the degree of rounding depending on the length of time that the pebbles have been subject to water wear, the character of the material, the intensity of the abrading force, etc. Extensive and prolonged wave or current action will further result in eliminating much if not all of the perishable mineral matter, so that a muchworked-over conglomerate will consist largely or wholly of quartz pebbles. The same is true of the arenytes, although the sorting here is not so pronounced as that by the wind. Pure hydroclastic quartz sands do occur, however, as at Escambia, on the Gulf coast of Florida, in which scarcely a fragment of mineral other than quartz is found. The granules of this sand range in size from o.I to $1.0 \mathrm{~mm}$. (fine to coarse sand, averaging 0.25 to $0.50 \mathrm{~mm}$. (medium sand). At West Palm Beach, on the Atlantic coast of Florida, a similar pure sand occurs which apparently has been transported along the shore from the Piedmont region to the north. In both of these cases the grains are subangular. The finest sand and the rock flour and clays will retain their angular outlines unimpaired, for, as Daubrée has shown, quartz and other mineral particles of $0.1 \mathrm{~mm}$. or less diameter will float in faintly agitated water.

In the broader considerations of hydroclastic rocks it is important that current or river-worn clastics be distinguished from marine or other wave-formed clastics. The former may be spoken of as fluvio-clastic (potamoclastic*) deposits, and the latter as kymoclastic. $\dagger$ So far as grain is concerned, no marked distinction exists

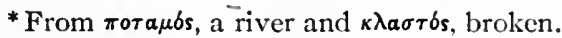

†From $\kappa \hat{\imath} \mu \alpha$, a wave and $\kappa \lambda a \sigma \tau \delta$ s, broken. 
in the lutaceous and arenaceous types, but the rudaceous sediments of fluvio-clastic origin may often be distinguished from those of wave-laid origin by minor characters of the component material. Thus exceedingly well-rounded boulders of moderate size are more characteristic of river than of wave work. The remarkable percussion or shatter marks (Schlagnarben) found on fine-grained boulders transported by torrents are further to be noted. They consist of semicircular or crescent-shaped slits, appearing as if made by a thumb nail, and crossing each other or interlocking in an indeterminate manner. They are due to a sudden blow upon the smooth surface from a rounded pebble or boulder of equally hard rock.

6. The Bioclastics. These are the clastic rocks which owe their essential character to organisms. The only class of great importance is that for which man is responsible. Thus bricks (as material), plaster, concrete, cement, etc., are no mean portion of the material composing the uppermost layers of the earth's crust, and are all to be included with the bioclastic division of rocks.

\section{Summary of "Sedimentary Rocks."}

The following table shows the more familiar types of "sedimentary" rocks, with the more important species included under each :

\section{Conglomerates Puddingstones. $\}$}

2. Breccias.

3. Sandstones. $\left\{\begin{array}{l}\text { Hydrorudytes } \\ \text { Hydrosilicirudytes } \\ \text { Hydrocalcirudytes }\end{array}\right.$

$\left\{\begin{array}{l}\text { Pyrorudytes (agglomerates) } \\ \text { Autorudytes } \\ \text { Autosilicirudytes } \\ \text { Autocalcirudytes } \\ \text { Atmorudytes } \\ \text { Atmosilicirudytes } \\ \text { Atmocalcirudytes } \\ \text { Biorudytes (artificial rubble rock) }\end{array}\right.$
$\left\{\begin{array}{l}\text { Autoarenytes } \\ \text { Autosilicarenytes } \\ \text { Atmosilicarenytes } \\ \text { Anemosilicarenytes } \\ \text { Hydrarenytes } \\ \text { Hydrosilicarenytes } \\ \text { Bioarenytes (artificial sandstones) }\end{array}\right.$


4. Slates.

$\left.\begin{array}{l}\text { Shates. } \\ \text { Muales. } \\ \text { and rocks } \\ \text { Clay stones } \\ \text { (argillytes) }\end{array}\right\}$

5. Tuffs.

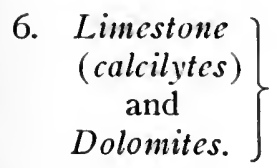

Autolutytes (argillaceous)

Autosilicilutytes (argillaceous)

Autoargillutytes (pure, siliceous, calcareous or carbonaceous)

Atmolutytes (argillaceous)

Atmoargillutytes (pure, siliceous, calcareous, or carbonaceous)

Anemolutytes (argiilaceous)

Anemoargillutytes (pure, siliceous, calcareous, or carbonaceous)

Anemosilicilutytes (argillaceous)

Hydrolutytes (argillaceous)

Hydrargillutytes (pure, siliceous, calcareous, or carbonaceous)

Pyrarenytes

Pyrolutytes

(Hydrogenic calc-rocks (Hydrocalcilytes) (chemical limestones)

Biogenic calc-rocks (Biocalcilytes) (coral rock, shell rock, oozes, etc.)

Autocalcirudytes, calcarenytes, and calcilutytes

Atmocalcirudytes, calcarenytes, and calcilutytes

Anemocalcarenytes and calcilutytes

Hydrocalcirudytes, calcarenytes, and calcilutytes

The Cosmoclastic Rocks.

This term has been proposed by Prof. H. L. Fairchild for the original rocks of the earth, which, according to the Planetesimal hypothesis of earth origin, were formed through accretion of fragments derived from space. (Fairchild-8; Chamberlin and Salisbury-2, ii, Chapter I.)

Special Rock Terms.

Rock Terms Emphasizing Composition. It is often necessary or desirable to emphasize the composition of a rock rather than its 
texture or origin. This is already done in the familiar terms limestone, claystone, ironstone, etc. While these terms are good and useful, more euphonious technical terms might be found preferable in some cases. Such terms should end in ith, or yte, to signify that they refer to rock masses rather than minerals. Thus rocks composed chiefly of the mineral calcite, or whatever origin, $i$. $\mathcal{c}$., limestones, may be termed calciliths or calcilytes.

Thus we may have:

quartz rocks or siliciliths or silicilytes

limestones or calciliths or calcilytes

dolomite rock or dolomiths (dolomiliths) or dolomytes (dolomilytes)

gypsum rock or gypsolith or gypsolytes

claystones or rocks or argilliths or argillytes

iron stones or ferriliths or ferrilytes

carbon rocks (coals, peats, etc.) or carbonoliths or carbonolytes

rock salt or haliliths or halilytes

Autochthonous* and Allochthonous $\dagger$ Deposits. These terms were first introduced by Gümbel in 1883 to designate: the first, deposits (especially coal) formed in situ, and the second, deposits made from transported material. The first comprises all hydrogenic and many biogenic deposits, although deep-sea oozes are allochthonous. Coal formed from vegetation in situ is autochthonous, while transported vegetal matter forms allochthonous coal. Clastic deposits are typically allochthonous.

\section{BIBLIOGRAPHY VI.}

I. CHAMBERLIN, T. C., and SALISBURY, R. Preliminary paper on the driftless area of the Upper Mississippi Valley. Sixth annual report, U. S. Geological Survey, pp. I99-322.

2. CHAMBERLIN, T. C., and SALISBURY, R. I906. Geology, Vols. I and II.

3. CROSBY, W. O. I908. Report of the State Water Supply Commission. Progress Report for 1907, p. 205.

4. CROSS, WHITMAN; IDDINGS, JOSEPH P.; PIRSSON, LOUIS, V., and WASHINGTON, HENRY S. I903. Quantitative Classification of igneous rocks based on chemical and mineral characters, with a systematic nomenclature.

5. DAUBRÉ, A. I879. Études Synthétiques de Géologie Expérimentale. Paris. earth.

* aútos (autos), self; $\chi^{\theta \dot{\omega} \nu v}$ (chthon), the earth; i.c., belonging to the same

$\dagger 2 \lambda \lambda$ os (allos), another; $\chi^{\theta \dot{\omega} \nu v}$ (chthon), the earth, i.e., from another region. 
6. DE LA BECHE, HENRY T. I833. Geological Manual, 3rd edition.

7. DILLER, JOSEPH S. I 898. The Educational Series of Rock Specimens. U. S. Geological Survey, Bulletin I 50.

8. FAIRCHILD, H. L. I904. Geology under the Planetesimal Hypothesis of Earth Origin. Bulletin of the Geological Society of America, Vol. XV, pp. 243-266.

9. GRABAU, A. W. 1904. On the Classification of Sedimentary Rocks. American Geologist, Vol. XXXIII, pp. 228-247.

10. GRABAU, A. W. I9II. On the Classification of Sand Grains. Science, N. S., Vol. XXXVII, pp. I005-I007.

I I. HARKER, ALFRED. 1902. Petrology for Students. 3d edition, Cambridge Natural Science Manuals.

12. HARKER, ALFRED. I909. The Natural History of the Igneous Rocks. New York, Macmillan Co.

13. HARRIS, G. F. I898. Narrative of a Geological Journey through Russia (Rapakiwi described.) Geological Magazine, Vol. XXXV, pp. I1-I3.

14. HAUG, EMILE. 1907. Traité de Geologie. I. Les Phenoménes géologiques. Paris, Armand Colin.

15. IDDINGS, J. P., and Others. I 899. Descriptive Geology, Petrography, etc., of the Yellowstone National Park. U. S. Geological Survey, Monograph XXXII, pt. II.

16. KEILHACK, KONRAD. 1908. Lehrbuch der praktischen Geologie, 2te Auflage. Stuttgart, Ferdinand Enke.

17. KEMP, JAMES F. I900. A Handbook of Rocks, without the Microscope. New York, D. Van Nostrand \& Co. Second edition. I9I I, $5^{\text {th }}$ ed.

18. LAUFER, E., und WAHNSCHAFFE, F. 1879. (Classification of Sands:) Abhandlungen zur geologischen Special Karte von Preussen. Bd. III, I, p. 24.

I9. MACKIE, WILLIAM. I897. The feldspars present in sedimentary rocks as indicators of the conditions of contemporaneous climate. Transactions of the Edinburgh Geological Society, Vol. VII, pp. 443-468.

20. MERRILL, GEORGE P. I898. Mechanical analysis of residual sand of diabase and of washed kaolin. Bulletin' r 5o, U. S. Geological Survey, pp. 380 and 383 .

21. NAUMANN, CARL FRIEDRICH. I850. Lehrbuch der Geognosie. Second edition 1858 .

22. ORTH. I875. Bczeichnung des Sandes nach der Grösse des Kornes. Neues Jahrbuch für Mineralogie, Volume for I 875 , p. 55I.

23. PHILIPPS, J. ARTHUR. I882. The sands of the Arabian Desert. Quarterly Journal of the Geological Society of London, Vol. XXXVIII, pp. IIO-II3.

24. ROSENBUSCH, H. I877. Mikroskopische Physiographie der Massigen Gesteine. Stuttgart. Schweizerbart'sche Verlagshandlung. 4th edition in 1908 .

25. ROSENBUSCH, H. I898. Elemente der Gesteinslehre. Stuttgart. Schweizerbart'sche Verlagshandlung.

26. SHERZER, W. H. I9Io. Criteria for the recognition of the various types of sand grains. Bulletin Geological Society of America, Vol. XXI, pp. 628-662, pls. $43-47$.

27. THOULET, J. I88I. Etude minéralogique d'au sable de Sahara. Bulletin de la Société Mineralogique de France, T. IV, pp. 262-268.

28. VAN HISE, C. R. I904. A treatise on metamorphism. Monograph U. S. Geological Survey, No. XLVII. 
29. WAHNSCHAFFE, F. I903. Anleitung zur Wissenschaftlichen Bodenuntersuchung. Berlin. With literature. $2^{\text {te }}$ Auflage.

30. WALTHER, JOHANNES. I897. Versuch einer classification der Gesteine auf Grund der Vergleichenden Lithogenie. Congrès Géologique International. Compte Rendu de la VII ${ }^{\text {me }}$ session, St. Petersburg, I897, $3^{\text {me }}$ partie. pp. 9-25.

31. ZIRKEL, FERDINAND VON. I866. Lehrbuch der Petrographie. 2nd cd. I 893, Leipzig.

\section{Supplementary.}

32. FINLAY, GEORGE I. I913. Introduction to the Study of Igneous Rocks. McGraw Hill Book Co., New York. 


\section{CHAPTER VII.}

STRUCTURAL OR TECTONIC FEATURES OF ROCK MASSES. ORIGINAL STRUCTURES AND LITHOGENESIS OF THE PYROGENIC ROCKS.

When rock masses are considered on a large scale, certain structural features are seen which furnish a clue to the geological history of the region. These can generally be observed only in the field. Two classes of such structural or tectonic features are recognized: (I) original structures and (2) secondary or later structures. To the first belong all those accompanying the phenomena of rock formation, features of essential significance in the study of the origin of the formation which they characterize. To the second belong all structures due to subsequent disturbances such as faults, folds, cleavage, and the like, as well as metamorphisn, or the alteration of rocks. While all these need to be carefully considered in working out the stratigraphy of any region, they have not the importance possessed by the original structures, which alone furnish clues to the method of formation of the rock possessing them. In this and the next eleven chapters the Original Structures of rocks will be discussed; the secondary ones will be taken up in Chapters XIX and XX. Since each class of endogenetic rocks has its own mode of origin, the original structures of each must be of corresponding individuality.

\section{THE PYROGENIC ROCKS.}

Pyrogenic or igneous rock masses naturally fall into two great divisions, (a) the intrusive and (b) the effusive. The former solidify within the crust of the earth, appearing as a part of the surface only through subsequent erosion of the overlying masses, while the latter reach the surface in a molten condition, and on solidifying form the uppermost crust of the earth at that point. In otherwise undisturbed regions intrusive igneous masses are always younger than the enclosing rocks, while effusive igneous 
masses are younger than the subjacent, but older than the superjacent strata.

\section{IntRusive, IGNEOUS Bolmes.}

The classification of intrusive igneous bodies as structural features must be based primarily on their origin, form, and relation to enclosing rock masses, while size and attitude with reference to horizontal plane are criteria of minor significance. (Daly-7:505.)

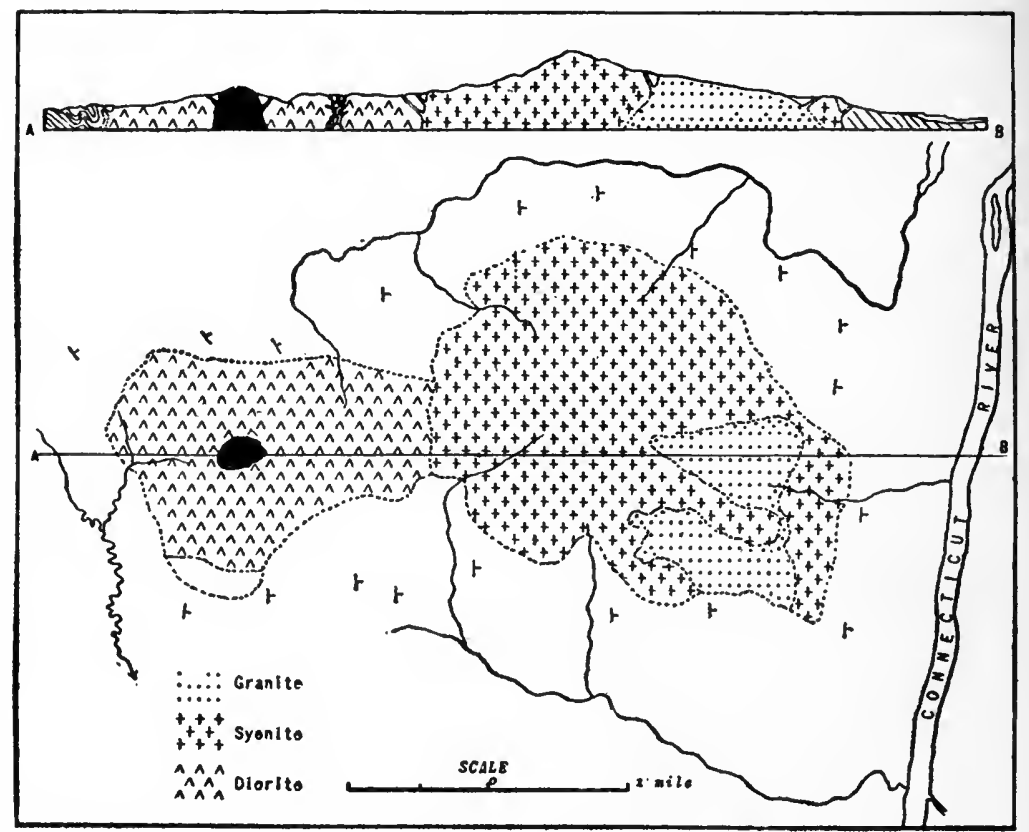

Fig. 40. Diagrammatic map and section of Ascutney Mountain, Vermont, illustrating a composite stock of successive intrusions, in stock or boss form, of diorite, syenite, and granite. A small boss of syenite (shown in black) cuts the diorite. These bodies cut crystalline schists, the attitude of which is shown by the dip-strike symbols. (After Daly.)

From the point of view of origin, or method of intrusion, two great divisions of igneous intrusive masses may be recognized, (a) the abyssal, deep-seated, or plutonic (Ticfengesteine), the method of intrusion of which may be either a process of eating into the enclosing rocks (einfressen), or a pushing aside of the surrounding rocks, and (b) the injected masses, the Ganggesteine of Rosenbusch, the Hypabyssal division of Brögger. The abyssal division 
includes two types, I. The Batholith and 2. the Stock and Boss. The distinction between these two groups is largely one of size. Batholiths are large intruded masses of granitic or other holocrystalline pyrogenics, such as form the central granite core of mountain masses. Suess holds that these masses are intruded through the adjacent formations as a result of fusion, constituting thus a transfusion mass or Durchschmclaungsmasse. A boss (Fig. 40) is a subterranean intrusive mass of moderate size with a circular or subcircular ground plan. The term has been used for such masses up to several miles in diameter, but is best restricted to the smaller

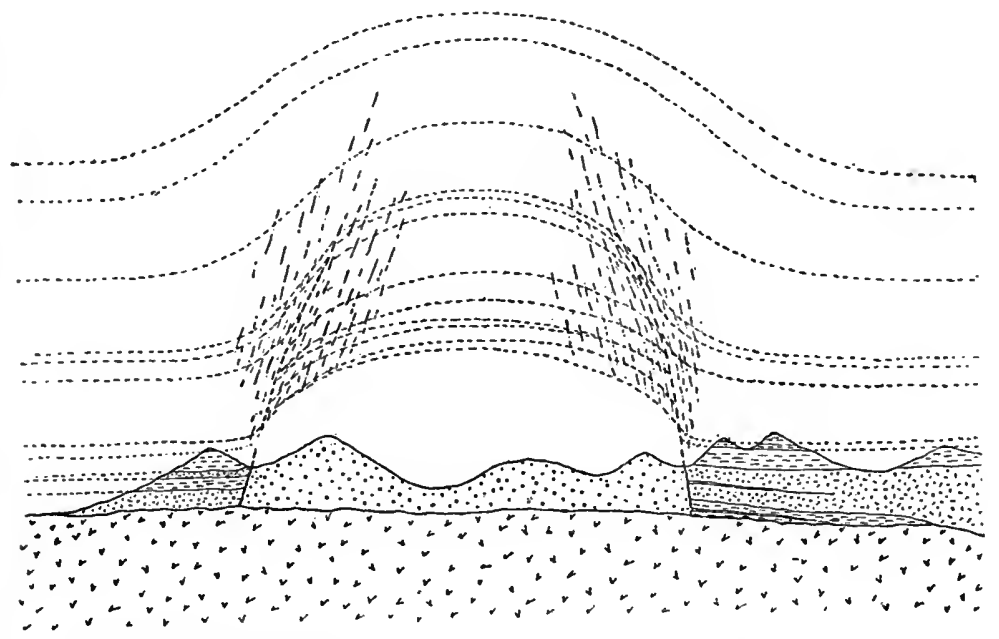

FIG. 4I. Ideal section of the Holmes Bysmalith (after Iddings).

masses of this type. A stock, on the other hand, is characterized by irregularity of shape, and often by smaller size than that of the boss.

The Hypabyssal intrusives may be divided into:

I. The transwerse or those injected across the planes of stratification of the invaded formation, and

II. The parallel or those injected along the planes of stratification of the invaded formation. (Daly-7:507.)

The first of these groups includes, I. Dikes, 2. Eruptive veins, 3. Apophyses or tongues, 4. Bysmaliths, 5. Necks, and 6. Chonoliths. A dike (Fig. 44) is characterized by nearly or quite parallel walls, relatively close together, and may cut the planes of strati- 
fication at any angle except parallelism. Dikes may be simple or complex. In the latter case, they are multiple when sucressive intrusions of the same material occur in the same fissure; and composite when showing successive injections of different material in the same fissure. Eruptive veins are injections into irregular branching cracks, while apophyses are tongues of igneous matter projecting irregularly into the rock from a larger intrusive mass. A bysmalith (Iddings-17:708) (Fig. 4I) is an injected mass of

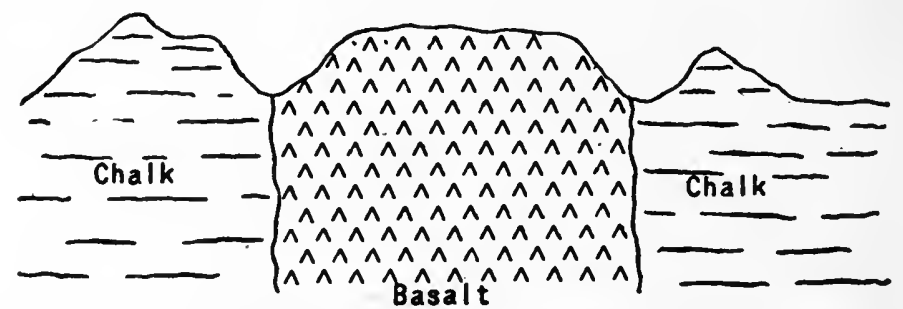

F1G. 42. Section of a typical volcanic neck. (After Geikie, Ancient Volcanoes of Great Britain, Vol. II.)

igneous rock filling a more or less circular cone or cylinder in strata, and having the form of a plug. This plug may reach the surface or may end against a domed roof of strata, simulating a laccolith in appearance. It differs from other masses of this type in that the enclosing strata have been displaced by faulting, a solid block of nearly horizontal strata being lifted at one time by the force of the intrusions. The Holmes bysmalith of the Yellowstone is a typical example. With laccoliths this type agrees in having a more or less well-defined floor of other rock on which it rests. Necks (Fig. 42) are the solid plugs of lava filling old volcanic vents. They are generally regular in outline and section. Chonoliths (Daly-7:498) (Fig. 43) are the intrusive masses injected into actual or potential cavities formed by dislocation of rock formations such as is brought about during mountain building, and not classifiable as dikes, sills, or laccoliths, bysmaliths, or necks. They are of irregular form, and show a complex relation to the invaded formation. In the process of injection they may crowd aside and mash the country rock, intruding irregularly into all the fissures thus formed. Of the intruded igneous masses this is perhaps the commonest kind.

The second group or that of the parallel hypabyssal igneous masses comprises, I. Intrusive sheets, II. Laccoliths, and III. Phacoliths. The first of these includes (a) sills, and (b) interfor- 
mational sheets. Sills are sheets intruded between parallel strata. They have essentially the characters of dikes, except that they are

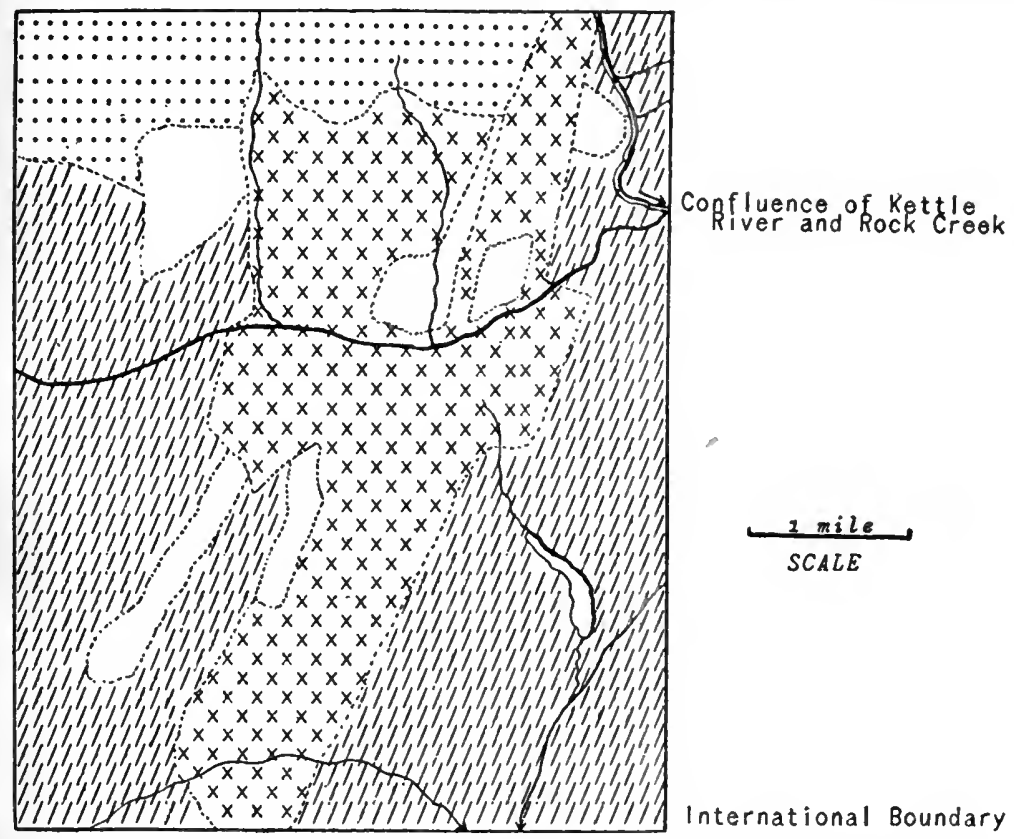

FIG. 43. Diagrammatic map of a Tertiary "chonolith" of thombenporphyry (crosses), cutting intensely folded Palreozoic sediments (broken lines) and Tertiary sandstones and conglomerates (white) Kettle River, British Columbia. (After Daly.) Late 'Tertiary lava caps (dots) cover the porphyry in the north. The Tertiary sediments are tilted and fanlted, the intrusions occurring at the same time or immediately after.

bounded by parallel strata. Like dikes, they may be simple, multiple or composite. (Figs. 44.45.) Interformational sheets differ from sills in that they are intruded along a line of unconformity,

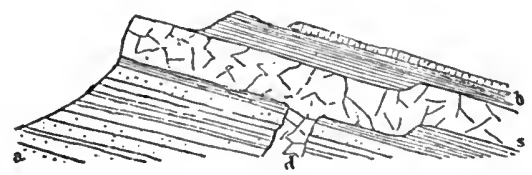

FIG. 44. Section of an intrusive sheet or sill (s) and connecting dike (d). and that therefore the subjacent strata are not parallel to it, though the superjacent ones are. 
Laccoliths differ from sheets in being lens-like in mass, thick in the center and dying away laterally. In the process of intrusion

W. by $N$,

C. by S.

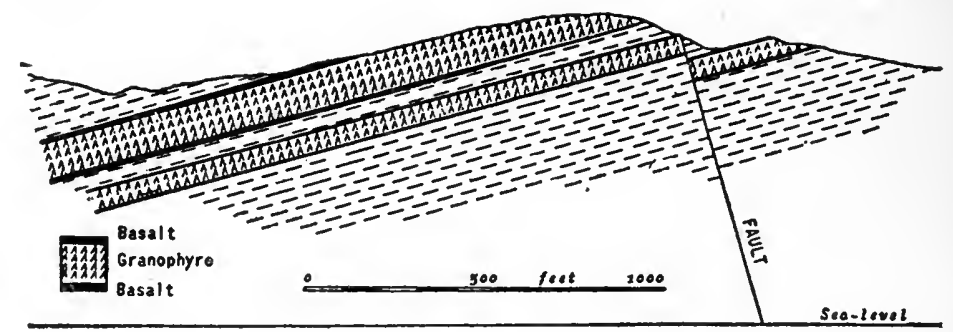

FIG. 45. Section of a composite sill, Island of Skye (after Harker). The stratified Lias was cut by the sill of basalt; a later sill, of granophyre, was intruded along the middle plane of the basic sill-the latter itself may have been double.

the overlying strata are arched. Laccoliths may be simple or compound, when divided by strong beds of the invaded formation. (Judith Mountains.) They may be multiple or composite (Fig. 46),

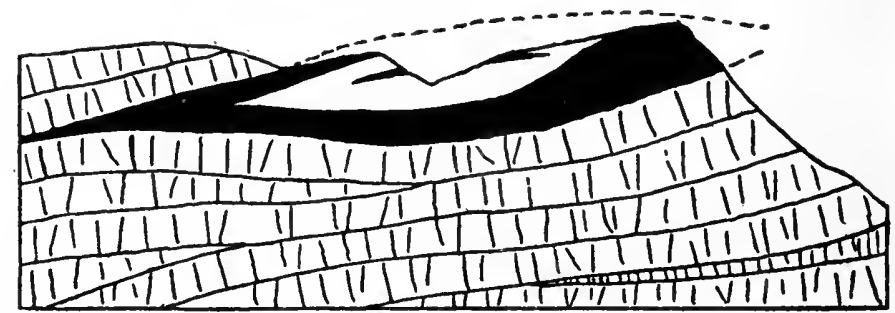

Frg. 46. Section of a composite laccolith. (After Weed and Pirsson.) The laccolith cuts heavy-bedded lava flows. Its maximum thickness is I50 feet. Black: basalt; white: granophyre.

as in dikes and sills. Like sills, they may also be interformational. (Fig. 47.) In form they may be symmetric or asymmetric. These variations are illustrated in Fig. $5 \mathrm{I}$.

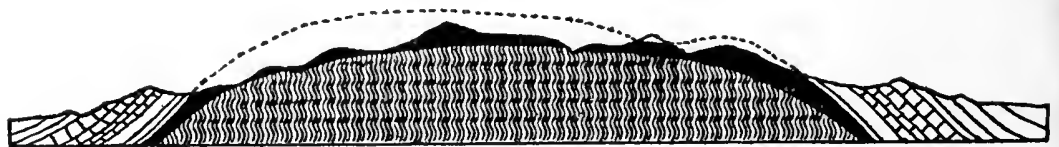

Fig. 47. Section of an interformational laccolith. (After Weed and Pirsson.) The floor of the porphyry laccolith (in black) is composed of preCambric crystalline schists; the cover, of Palæozoic sediments. The length of the section represented is about ten miles. 
Phacoliths (Harker-15:76) are intrusions of igneous rocks between strata which have been folded and occupying the points of

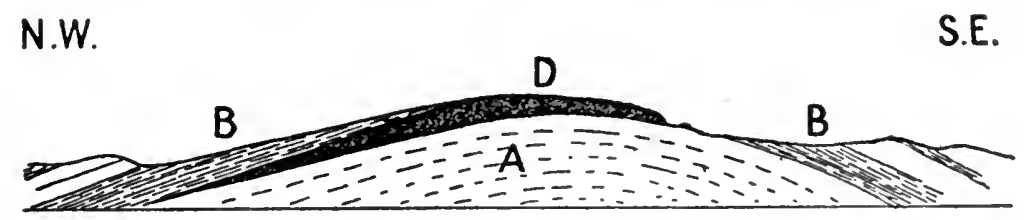

Fig. 48. Lenticular intrusion (phacolith) in anticline of Ordovicic strata, Corndon, Shropshire, England. (After Lapworth and Watts.) A. Flags and shales; B. ashes and andesite; D. dolerite.

greatest pressure relief, as in the crests and troughs of a simply folded series of strata. (Figs. 48, 49.) As Harker points out, they

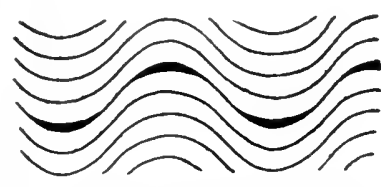

Fig. 49. Diagram to illustrate phacolith intruded in connection with folding. (A f ter Harker.)

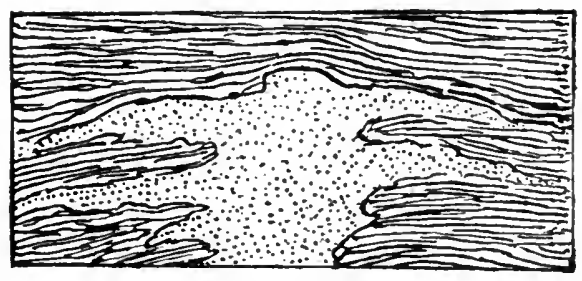

FIG. 50a. Hypothetical development of a folded laccolith. Ist stage. (After Baltzer.)

differ from laccoliths, in that they are a consequence of folding, instead of the cause of the uplift as in laccoliths. Their distinction from the Chonoliths of Daly lies in their parallelism to the strata

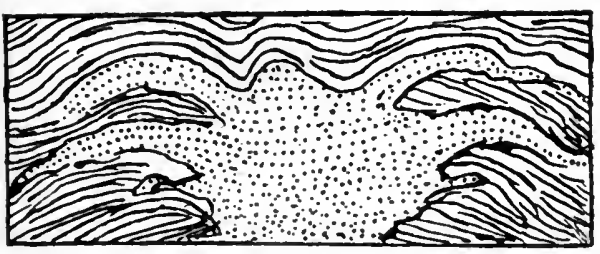

FIg. 5ob. The same as Fig. 50a, in the second stage (Baltzer).

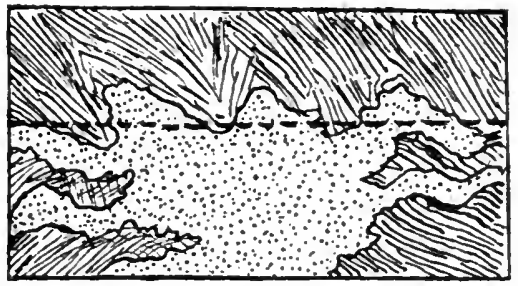

FIG. 50c. The same, in the third stage (Baltzer).

between which they are intruded, while chonoliths are irregular, commonly, in part at least, transverse. A typical example of a phacolith is seen in the accompanying section from Corndon, Shrop- 
shire. (Lapworth and Watts-20:342.) A remarkable modification of such intrusions through later folding is described by Baltzer ( 1 ) from the Aarmassive, in the Alps. In the Aletschhorn (4,198 meters high) he finds that the schists which form the summit of the mountain rest discordantly upon the surface of the granite,

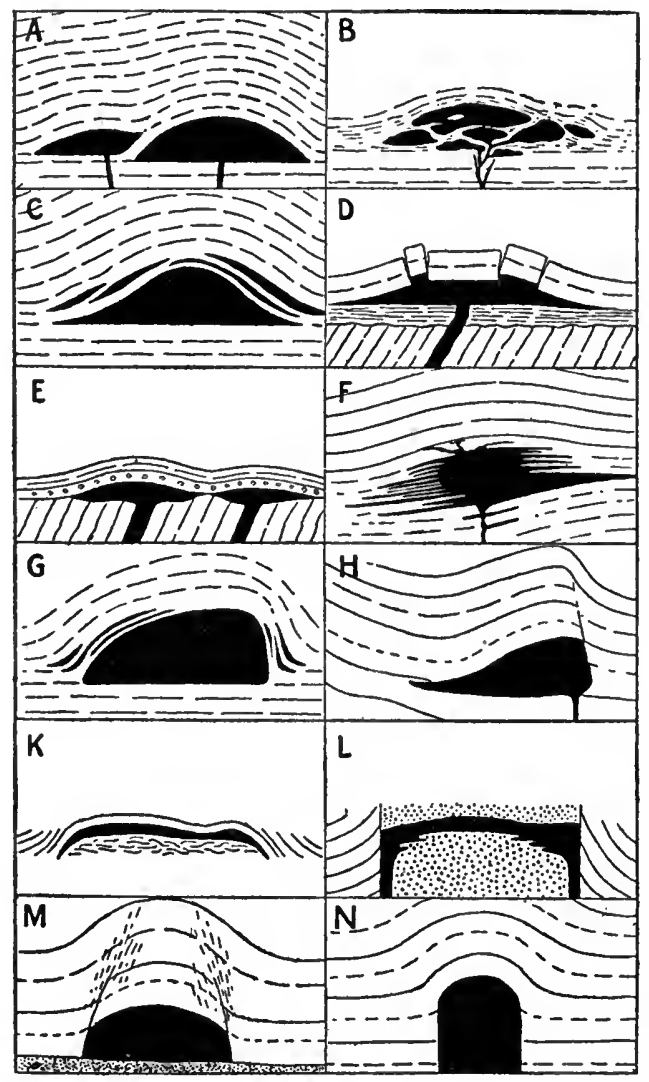

FIG. 5I. Diagrams illustrating intrusive masses. A. Laccolith (Mt. Holmes, Henry Mts., Utah). B. Compound laccolith (El Late Mountains, Colorado). C. Laccolith with subsidiary sheets (Judith Mts. type, Montana). D. Laccolith with broken cover (Ragged Top Mt., Black Hills, S. Dakota). E. Interformational laccolith (Deadwood Gulch, Black Hills). F. Compound laccolith-cedartree type (La Plata Mts., Colorado). G. Abruptly protuberant laccolith (Mt. Hillers, Henry Mts.). H. Asymmetric laccolith (Mt. Marcellina, West Elk Mts., Colorado). K. Intrusion in Little Rocky Mts. (Montana). L. Intrusion in volcanic vents (Island Skye). M. Bysmalith (Mt. Holmes). N. Plutonic plug (Ideal). (After Harker.) 
$i . e$, the relation is like an inverted unconformity. This relation is believed to be due to subsequent folding of the cntire mass. The process is illustrated in the three diagrams on page 307. (Figs. 5Oa-5oc.)

The end result is an intrusive mass which appears to cut across folded strata and so is indistinguishable from the Chonoliths of Daly.

Igneous versus Sedimentary Contact. It is of the greatest importance that the nature of the contact between igneous and nonigneous formations be determined. Three types of contacts may be recognized, I. Fault contacts, 2. Igneous contacts, and 3. Sedimentary contacts. Fault contacts are secondary contacts and will be considered in a subsequent section, as they have no direct bearing on the history of the igneous mass. Igneous and sedimentary contacts, on the other hand, are primary and intimately connected with the origin of one or the other of the formations in contact. The igneous contact stamps the igneous mass as the younger, while the sedimentary contact shows the sedimentary formation to be the younger of the two. As a rule, when exposures are sufficiently good, the nature of the contact is not difficult to determine unless both igneous and sedimentary mass have subsequently become metamorphosed. Sometimes the subsequent intrusion of igneous material along the contact of an older igneous with a sedimentary formation obscures the nature of the original contact.

The chief criteria for use in determining relative ages of igneous intrusive bodies in contact with sediments are the following:

Contacts of subterrancan or abyssal masses.

(I) If the granitoid boss, stock or batholith is in contact with sediments of known age, and these sediments have been metamorphosed or partly remelted by the igneous rock, which may even enclose fragments of the sediment, then the igneous rock is of younger age than the sediments, which were there before the molten magma ate its way into them.

(2) If sediments of a known age rest unconformably upon a granitoid mass (granite, syenite, diorite, gabbro, etc.), worn fragments of which are included in the sediments next adjoining the igneous mass, the age of the igneous mass is very much greater than that of the adjacent strata, for the igneous mass was exposed by erosion before the sediments now resting upon it were laid down. In such case the igneous mass has not metamorphosed the sedi- 
ments. Such contacts may be sharp, where the surface of the igneous mass has been swept clean before the deposition of the sediments, as in the case of the pre-Cambric granite floor of the Manitou region in Colorado (Crosby-6), upon which abruptly appear the clean-washed sands of the basal Palæozoic of that region (Fig. 52), or it may be a transition contact where the old igneous mass has been much decomposed, while the subsequent sediment is made up of the partly reworked upper layers of the old regolith. An example of this is found in the contact of the Lake Superior sandstone of the Marquette region with the altered peridotites of pre-Cambric age, where it is often impossible to

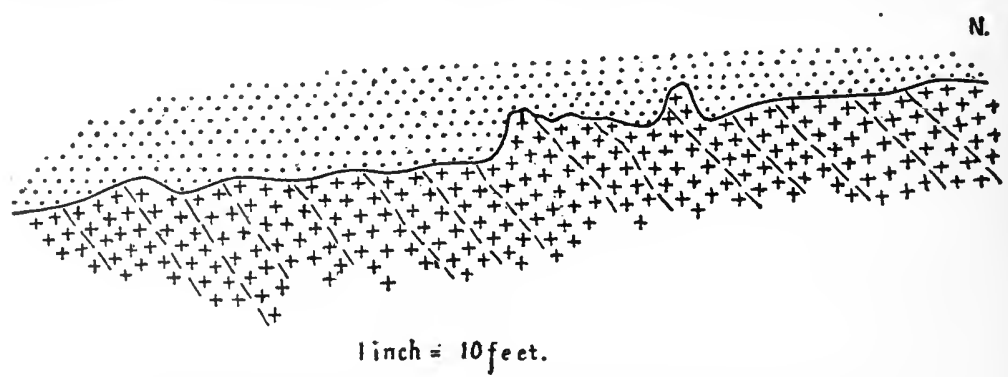

FIG. 52. Irregularities in sedimentary contact, of basal Palxozoic sandstones on pre-Cambric granite in Williams Canyon, Colorado. The general character of the contact is a sharp and, for the most part, very smooth one. (After Crosby.) The granite mass is part of an abyssolith.

determine the precise line of contact. Great difference in age may exist between these two.

For such an ancient igneous mass, which has been uncovered by erosion, and subsequently covered by sediments, with which it is in sedimentary contact, the name Abyssolyth is proposed. Such an abyssolyth is seen in the granite mass of Pikes Peak, the contact of which, with the Palæozoics, is a sedimentary one. (Fig. 52.)

\section{Contacts of hypabyssal or injected masses.}

Dikes, sills, laccoliths, etc., are younger than the strata which they cut, or which they have metamorphosed. Their proximal age limit is, however, not determined by the strata in which they occur, unless some of these strata should contain erosion fragments of the intrusives, when the latter must be considered as very much older than the strata containing such fragments, and which are in seclimentary contact with the igneous masses. 
In general terms: Strata underlying igneous masses, parallel with them, are always older than those masses, but strata lying directly upon such igneous rocks must be considered older only if they have been altered or in any way affected by the igneous mass while the latter was still hot, but younger if they are not affected and especially if they contain worn fragments of the igneous rock. An exception must, however, be made in the case of strata deposited upon a hot laval stream, the heat of which later affects the strata of younger age. In such a case evidence within the strata or the igneous mass will generally furnish the clue to the respective ages of each. Misinterpretation of the contact between adjoining formations may result in grave errors regarding the relative ages of these formations. Thus up to within very recent times the great granitic and gneissic masses of the Canadian shield known as the Laurentian were believed to represent the oldest known rocks of the earth's crust, the metamorphosed rocks now called the Keewatin series being regarded as the next younger, and representing ancient sediments resting unconformably upon the Laurentian. It is now known, however, that in many instances at least the contact between the Laurentian and the Keewatin is an igneous contact, the former being intruded into the latter, and hence younger than it.

\section{Effusive IGneous Masses}

Effusive masses, $i$. e., volcanic flows or sheets are always younger than the strata on which they rest and older than the strata which overlie them. Volcanic sheets are distinguished from sills, which are younger than both the enclosing strata, by the fact that only the stratum underlying the flow is metamorphosed, while the overlying one generally contains fragments of the flow. Furthermore, the upper portion of the flow shows generally a more or less vesicular structure which indicates the exposed surface of the old lava sheet.

Features of the Basal Contact of Lava Sheets. The basal contact of lava sheets may furnish important evidence of the physical condition of a region prior to its invasion by the lava flow. Thus a land area, bare or covered by soil either dry or with a comparatively small content of water, will give a relatively smooth and uniform contact line with the overflowing lava sheet. A saturated soil, or one covered by water, will give a very different kind of contact. The conversion of the water into steam will cause a violent ebullition along the line of contact, accompanied by an inter-kneading 
of the igneous and non-igneous rocks, and not infrequently a transformation of the basal part of the flow. Such features have been described from the base of the Newark trap sheets of the Paterson region of New Jersey by Fenner (II). He finds that in places "along the contact for a width of ten feet or more the trap and mud show evidence of having experienced the most violent agitation"- the two being mixed and kneaded together in a surprising manner. "The mud has boiled through and through the seething

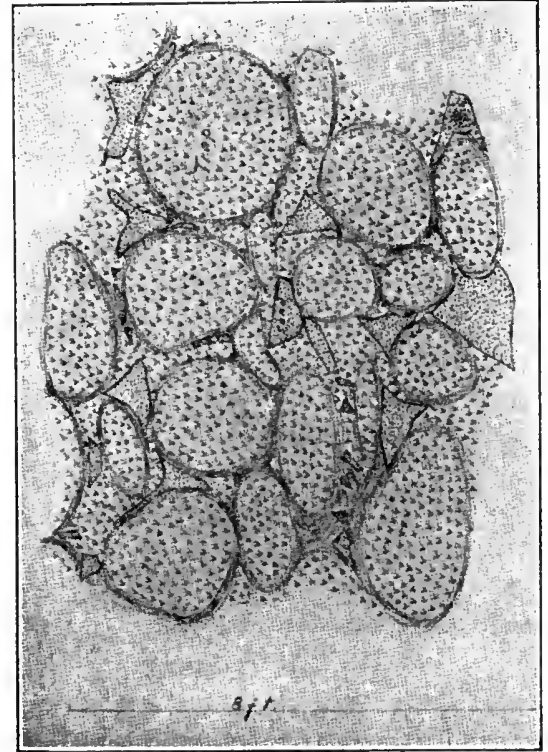

FIG. 53. Bouldery structure, with included sand masses brought from below. Trap sheet near Paterson, N. J. (After Fenner.)

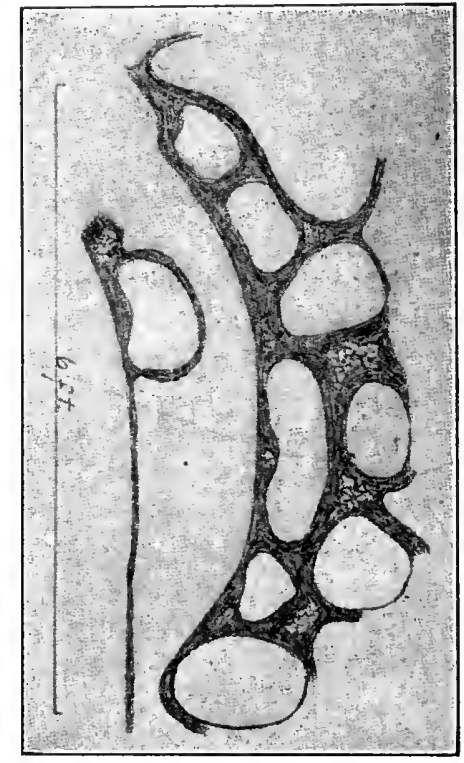

FIG. 54. Bouldery structure in lower part of extruded trap sheet, near Paterson, N. J. (After Fenner.)

body of lava until particles of mud of every size from minute specks to large masses have become incorporated in the pasty flow. Both lava and mud are full of blowholes, steam vents, and other forms of irregular pipes and cavities which attest the violent escape of gases." (II:3I3.) The amount of injected mud decreases upward and the vesicular character gradually gives way to purer igneous rock. In structure this is still very peculiar, showing the effect of escaping gases through the mass. A boulder-like structure is produced, the "boulders" being of dense trap with crusts of dark 
glass. (Figs. 53, 54.) Between these "boulders" lie vugs of minerals especially rich in zeolites.

Emerson (IO:6I) has described inclusion of "mud drops" or mud anygdules in the upper part of the Triassic trap of the Holyoke region in the Connecticut Valley, where occur also the gray laminated shales confusedly mingled in the trap, and appearing under the microscope as an intimate mixture or "complete emulsion of the two non-mixing fluids," the lava and the mud. He finds that the base of the sheet has similar pronounced mud inclosures in one place, while at another, a hundred rods north, "along the base of the same sheet the black compact aphanitic trap rests on the same coarse sandstone, and contains only a few long steam holes." Emerson regards the basal layer as the underolled top layer.

The Carbonic lava flows of the coast of Fife, Scotland, show in their bases a series of pipes or funnels which were evidently formed by the steam generated when the lava flowed over the wet sands. These pipes extend vertically into the lava and generally are filled with zeolites or with calcite.

The rhyolitic flows of the Yellowstone National Park rest in places upon a deposit of well-laminated rhyolite dust, while the basal part of the flow itself along the contact is marked by a thin layer of perlitic glass. (Iddings-18:358.) In the Grand Canyon of the Yellowstone the bottom contact of a younger flow of rlyolite on a thick mass of basalt shows a tuffaceous character passing upward into denser material which in turn passes up into porphyritic glass, and this into lithoidal lava. (18:390.) Another small sheet of rhyolite on Saddle Mountain has its basal contact on basaltic breccia, marked by white rhyolitic tuff, followed by fissile light gray lithoidal rhyolite with small phenocrysts, passing up into darkcolored spherulitic and glassy rhyolite with lithophyse and small phenocrysts. (I $8: 392$.

Features of the Upper Surfaces of Lava Flow's. The upper surfaces of lava streams vary with the nature of the lava itself and the conditions under which it is extravasated.

I. Basic lavas. These are well illustrated in the character of the extravasations of the Hawaiian Islands. The kinds of surfaces represented by these lavas may be classified as (a) ropy, (b) the pillow'y or pahoehoe and the rough or aa.

The ropy lava, the least common, lias the aspect of irregular coarse pieces of rope, generally intertwined in an extreme manner, the strands moreover being longitudinally ridged. The rock is moderately vesicular. The pillowy or pahoehoe (pr. pah-hoy-hoyliterally, with satiny surface) has been compared with the pitch 
dumped from a large number of enormous caldrons and allowed partly to run out, some masses running together and some advancing over preceding masses. (Fig. 55.) (Duton-9; Dana-8:9; Hitchcock-16:280.) These hummecks form a rolling surface, with fine wrinklings which produce the satin aspect. The pillowy masses have sometimes a glassy exterior half an inch or less thick, forming tachylite, in which a variolitic texture may sometimes be found. The rough or aa lava presents a striking contrast with the pahoehoe. "It consists mainly of clinkers, sometimes detached, sometimes partially agglutinated together, with a bristly array of sharp, jagged,

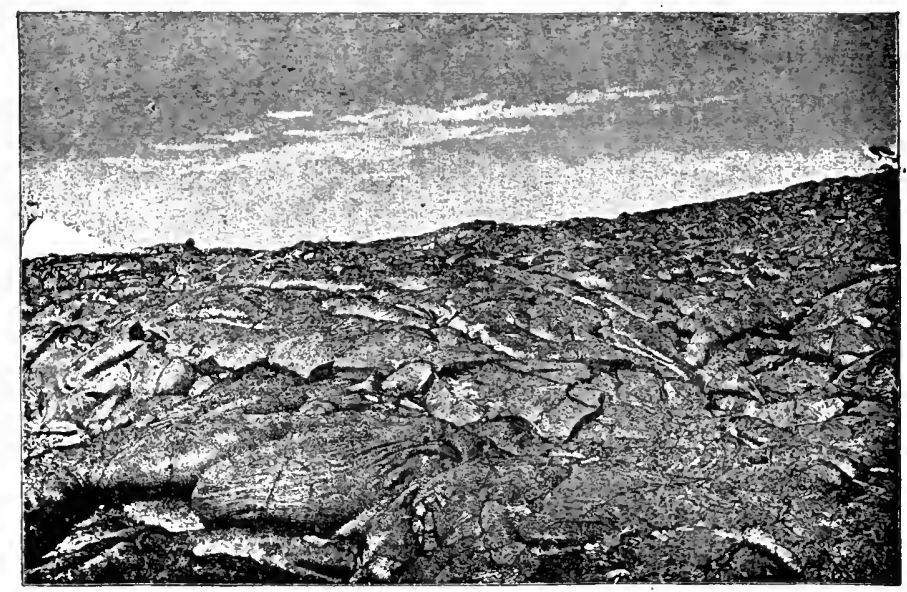

FIG. 55. Pahoehoe lava of Mauna Loa, Hawaiian Islands. (After Dutton.)

angular fragments of a compact character projecting up through them." (9:95.) The breaking up of the lava occurs during the flow. The masses are sometimes piled together in confused heaps to a height of 25 to 40 feet above the general surface. The individual fragments vary in size from an inch to ten feet, or even much more. In texture the lava is usually less vesiculated than the pahoehoe, not scoreaceous, but cavernous exteriorly. Large projecting masses of jagged lava occur, some having been noted on southern Hawaii, of slablike form and very compact- "twenty feet or more long, eight feet high and three to ten inches thick, standing vertically together, with a curving over at the top somewhat like gigantic shavings." (8:IO.) Associated with aa lava are lava balls or pseudobombs of concentric structure, sometimes wrongly taken for bombs. "These lava balls are smoothish exteriorly, more 
or less rounded and boulder-like, and vary in size from an inch or less to tell fect or more." (Dana-8: Io.)

Peach and Horne have described and figured the lava surfaces of the Ordovicic rocks of the south of Scotland. (2I.) One of their striking characteristics is the pillow-shaped or sack-like form which they present. "On a weathered face they sometimes look like a pile of partially filled sacks heaped on each other, the prominences of one projecting into corresponding hollows of the other." (Geikie-13:193.) The rocks are finely amygdaloidal, the vesicles being grouped in lines parallel to the outer surface of the pillow-like block in which they occur.

The spaces between the subspheroidal masses are sometimes filled with fine sediment, sometimes with fossiliferous limestone, and again with radiolarian chert, these being deposited upon the surface flow after cooling or sometimes before: Some of the radiolarian cherts, however, appear to be deposited contemporaneously with the lava, for they are intercalated with it. These lavas are believed to represent submarine eruptions, at successive periods, while between these periods, normal sedimentation took place. Structures of this kind have been found in the lower Ordovicic (Arenig) lavas of Cader Idris, Merionethshire, North England.

A similar structure occurs in the post-Carbonic (Tertiary) variolitic diabase of the Mont Genèvre district in the French-Italian border. (Cole and Gregory-3.) The structure of this lava is spheroidal on a large scale, most conmmonly "resembling pillows or soft cushions pressed upon and against one another." As shown in the cliffs, they appear as swelling surfaces with curving lines of junction. (Fig. 56.) Small vesicles occur in the rude spheroids, especially toward the margin, while in some places the whole rock becomes vesicular and slaggy. The surfaces of these masses are covered by a crust of variolite, from $\mathrm{I}$ to 7 or 8 centimeters thick, the variolites being grouped or drawn out in bands parallel to the surface and varying from almost microscopic to a diameter of $5 \mathrm{~cm}$.

Ransome finds a structure of this character in the basic lava of Point Bonita, Marin County, California, and comes to the conclusion that it is essentially a flow structure and that hence the rock in question is an extravasated lava. (23.) He regards the structure as indicating a lava of intermediate viscosity between that producing the pahoehoe and that resulting in the aa surface.

Crosby has described structures of this type from the Carbonic lavas of the Nantasket region of eastern Massachusetts. (5.) While the careful study of these structures in the cases cited has 
led the observers to the conclusion that such features are reliable as indications of surface flows, yet there are cases in which these surfaces have such an intimate relation with marine sediments as to suggest the possibility of intrusion. An example of this kind is described by Fox and Teall ( $12: 2 I I$ ) from the Greenstone of the Lizard and Mullion Island, where intimate association with radiolarian cherts suggested that the lava was intruded between the sheets of chert near the surface of the sea bed upon which they were being deposited. This intimate association with radiolarian cherts also found in the Arenig lavas of Great Britain seems at

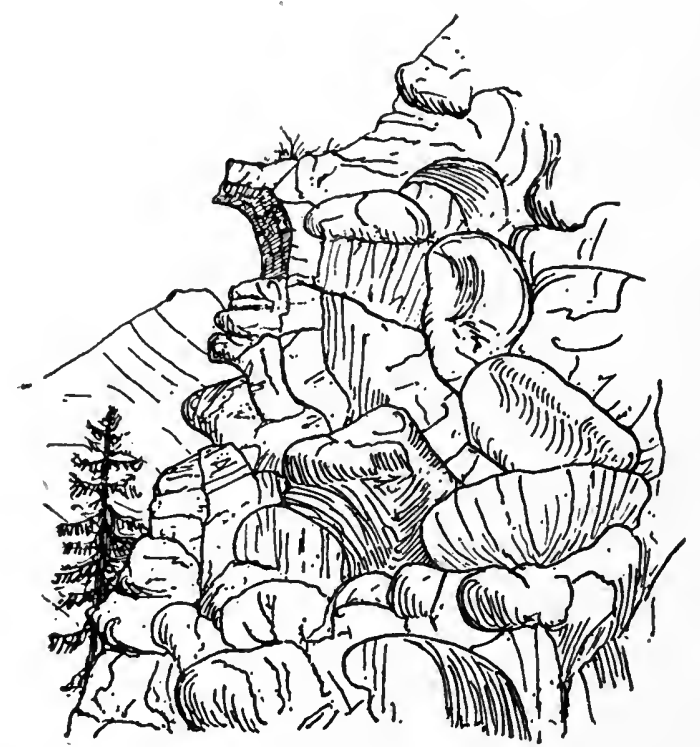

FIG. 56. Spheroidal or pillow lava with variolitic selvages. North end of Le Chenaillet Ridge, above the Durance Mont Genèvre region, France. (After Cole and Gregory.)

present the only good indication of the probable submarine origin of the lava. So far as the pahoehoe type of surface is concerned, it appears to be equally characteristic of subaqueous and subaerial extravasations. . That constant and reliable minor differences exist between subacrial and subaqueous lava surfaces is scarcely to be doubted, but at present such differences appear to be unrecognized.

The aa type of lava has also been recognized in older formations. In the pre-Cambric rocks of the Vermilion iron-bearing district of Minnesota occur bunches of igneous rocks having a concentric 
structure. They have been referred to the pseudo bombs of the aa. (Clements-2.) Some of the Triassic extrusives near Greenfield, Nassachusetts, have been referred to this type by Hitchcock. (16:283.)

2. Acid lavas. These are as a rule very viscous and slow moving, and may solidify before they spread far. The surface is generally rough or ropy, the former being a feature of some acid lava flows of Vulcano in the Lipari group (obsidian), the other being illustrated by lavas of Vesuvius. As shown in the Vesuvian stream of 1858 , which was very viscous and slow moving, the surface has been wrinkled and folded in quite a remarkable manner, some of the folds closely resembling coils of rope. 'This is the surface feature seen in artificial slags, flowing from a furnace. The cause of this appears to be the wrinkling of the chilled surface crust through the continued onward movement of the liquid mass below. Sometimes the breaking of the lava crust produces a heap of large and small fragments or blocks, so that the lava stream looks like a huge mass of broken fragments confusedly piled together. (Block lava, Schollenlaz'a.) Sometimes lavas of the more acid type are very liquid and flow rapidly. In such cases a rough and ragged cindery surface is produced suggestive of aa lava. The surface suggests the solidification of a boiling, squirting mass (spratige Lav'a). Such a surface is seen in the lava stream of I 872 on Vesuvius. In rapidly cooling lavas the surface of the stream may be covered with a crust of hard slaggy material which, breaking and rolling under at the front of the moving lava stream, forms a slaggy floor on which the more compact lava comes to rest. This crust of slag is responsible for the relatively little effect which the lava of a submarine volcano produces on coming in contact with the water, or for the phenomenon of a lava stream flowing across a snowfield without completely melting it. (Credner $-4: I_{50}$.)

\section{Minor Structural Characters of Volcanic Rocks.}

Flow Structure. A banding of igneous rocks is often noted, this banding sometimes simulating stratification, for which it has at various times been mistaken. It is produced by the disposition of the crystals, vesicles or other recognizable structures in more or less parallel lines, which, however, are constantly interrupted by obstacles around which the lines curve in such a manner as to show that it was due to the flowing of the viscous mass around the obstacle. Flow structure is not confined to surface flows, but also 
occurs in injected masses such as dikes, sills, etc., where it is often very well developed. It is more marked in acid than in basic rocks, especially in obsidians, rhyolites and felsites, etc. The flow structure of basic rocks is more generally seen on a large scale in the orientation of porphyritic crystals or the arrangement of vesicles into line.

Stratification of Flozes. A succession of surface flows in a given region will produce true stratification of the lavas in which

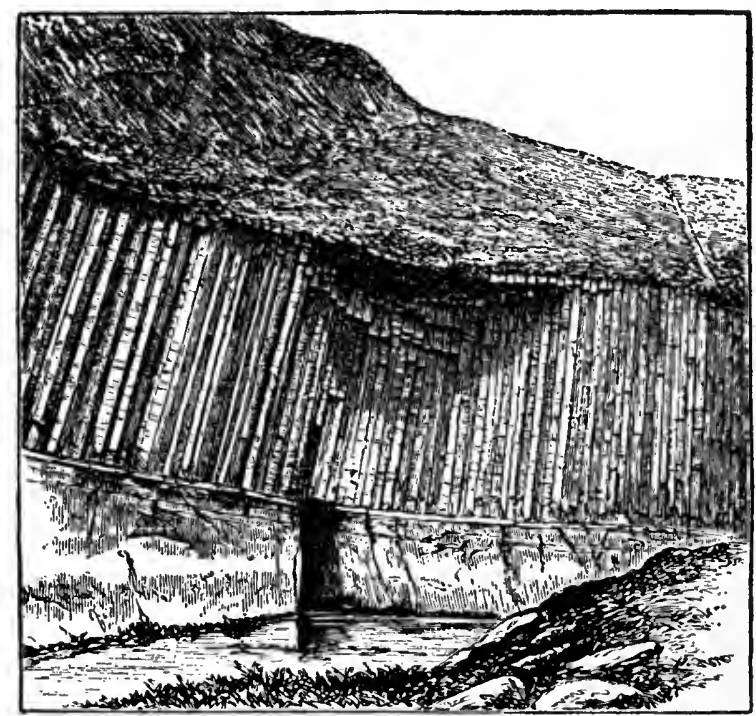

Fig. 57. Columnar structure in basalt near Fingal's Cave, Island of Staffa, W. Scotland.

each layer becomes in turn the top of the lithosphere at that point. (See p. 697.) Such volcanic strata may be distinguished by differences in texture if not composition.

Columnar Structure. This is a contraction phenomenon in which prismatic columns commonly with six uniform faces form on the cooling of the magma. In general the prisms form at right angles to the enclosing walls. In dikes the prisms thus are horizontal or nearly so, while in flows and intruded sheets the columns stand upright. (Ex., Fingal's Cave [Fig. 57] ; Giants' Causeway, etc.) Sometimes they are curved, as in Clamshell Cave, Staffa. Often the columns or prisms are non-persistent through the bed, but die out one into the other, with a wavy, irregular shape. (Geikie- 
I3:25.) Though most common in basic rocks, this structure is also found in the acid types, as is well shown by the columnar obsidian and other rhyolites of the Yellowstone National Park. (Iddings-I8.) (Fig. 58.)

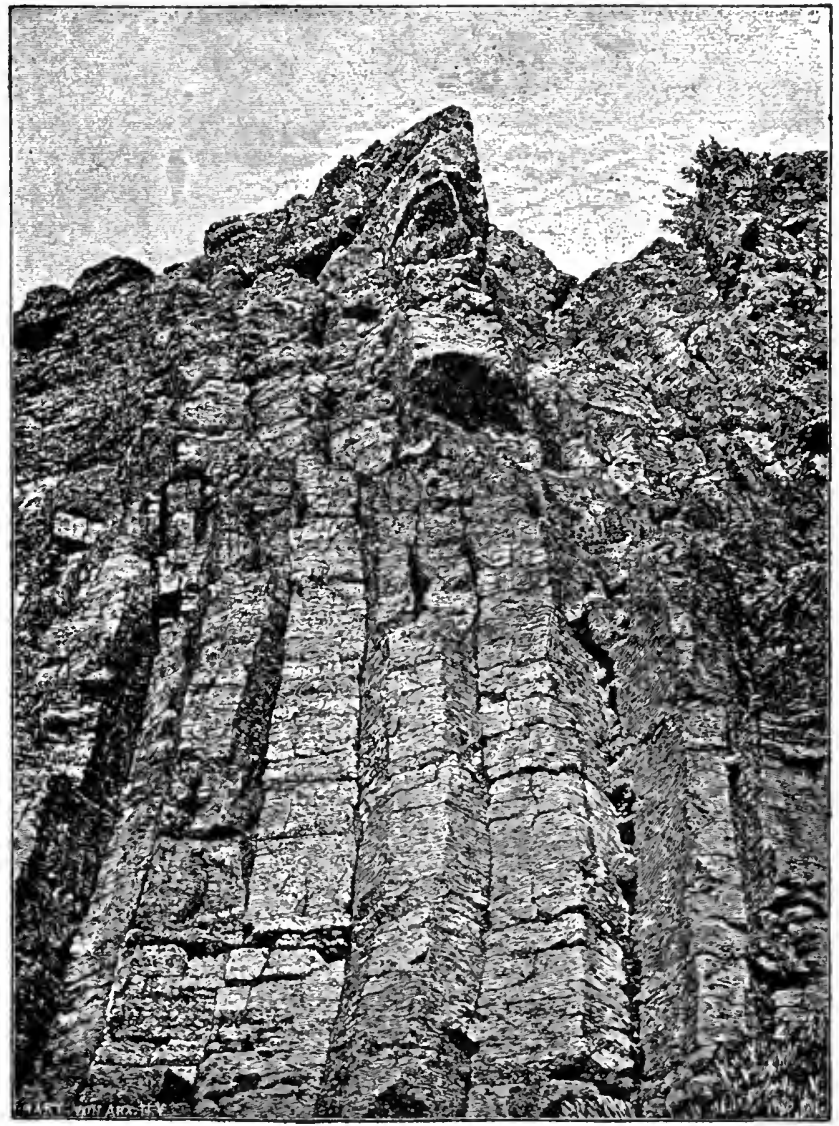

Fig. 58. Columnar structure in obsidian. Obsidian cliff, Yellowstone National Park. (After Iddings.)

Variation in Grain. In both effusive and intrusive masses a variation in the coarseness of texture or size of grain is observable between the outer faces of the mass and its interior. In general there is a regular increase in coarseness toward the center, due to less rapid chilling of the inner portion of the mass. Queneau (22) has been able to establish a table for determining distance from 
wall by size of grain in such rocks as the trap of the Palisades. (Lane-19. See also the various minor structures of pyrogenic rocks referred to in Chapter VI.)

\section{BIBLIOGRAPHY VII.}

I. BALTZER, A. 1903. Die granitischen Intrusions-massive des Aarmassives. Neues Jahrbuch für Mineralogie. Beilage Band XVI, pp. 292325 .

2. CLEMENT, J. MORGAN. I903. Vermilion Iron-bearing District of Minnesota. Monograph XL, U. S. Geological Survey, I890.

3. COLE, G. A. J., and GREGORY, J. W. I890. The Variolitic Rocks of Mt. Genèvre. Quarterly Journal of the Geological Society, London. Vol. XLVI, pp. 295-332.

4. CREDNER, HERMANN. I897. Elemente der Geologie. 8te Auflage. Leipzig. Wilhelm Engelmann.

5. CROSBY, W. O. I 893 . Geology of the Boston Basin, Nantucket and Cohasset. Occasional Papers of the Boston Society of Natural History, IV, Vol. I, pt. I.

6. CROSBY, W. O. I 899. The Archæan Cambrian Contact near Manitou, Colorado. Bulletin of the Geological Society of America, Vol. X, pp. I $41-164$.

7. DALY, REGINALD R. A. I905. Classification of Igneous Intrusive Bodies. Journal of Geology, Vol. XIII, 485-508.

8. DANA, JAMES D. I $89 \mathrm{I}$. Characteristics of Volcanoes. New York, Dodd, Mead \& Co.

9. DUTTON, C. E. I884. Hawaiian Volcanoes. 4th Ann. Rept., U. S. Geological Survey, pp. 8I-2I9.

10. EMERSON, B. K. I 897. Diabase pitchstone and sand inclosures of the Triassic trap of New England. Geological Society of America, Bulletin, Vol. VIII, pp. 59-86, pls. 3-9.

II. FENNER, C. N. 1908. Features indicative of physiographic conditions prevailing at the time of the trap extrusions in New Jersey. Journal of Geology, Vol. XVI, pp. 299-327.

12. FOX, HOWARD and TEALL, J. J. I 893. On a Radiolarian chert from Mullion Island. Quarterly Journal Geology Society, London, Vol. XLIX, pp. 2 I I-220, pl. IV.

13. GEIKIE, A. I897. Ancient Volcanoes of Great Britain, Vol. I. London, Macmillan \& Co.

14. GEIKIE, A. Ibid. Vol. II.

15. HARKER, ALFRED. 1909. The Natural History of Igneous Rocks. New York, Macmillan Co.

16. HITCHCOCK, CHARLES H. 1909. Hawaii and its Volcanoes. Hawaiian Gazette Co.

I7. IDDINGS, J. P. Bismalith. Journal of Geology, Vol. VI, 1898, pp. 704710.

I8. IDDINGS, J. P., and Others. I899. Geology of the Yellowstone National Park. Monograph U. S. Geological Survey, XXXII, pt. II.

19. LANE, ALFRED C. 1905. The Coarseness of Igneous Rocks and its Meanings. American Geologist, Vol. XXXV, pp. 65-72. 
20. LAPWORTH CH. and WATTS. 1894. Proceedings of the Geologists' Association, Vol. XIII.

21. PEACH, BENJAMIN N., and HORNE, J. I899. The Silurian Rocks of Great Britain. Memoirs of the Geological Survey of the United Kingdom. Vol. I, Scotland.

22. QUENEAU, A. L. I902. Size of grain in igneous rocks in relation to the distance from the cooling wall. Columbia School of Mines Quarterly, Vol. XXIII, pp. I8I-195, 6 plates.

23. RANSOME, F. LESLEY. I 893. The Eruptive Rocks of Point Bonita. Bulletin of the Department of Geology of the University of California. Vol. I, pp. 7I-II4, plates 6 and 7 . 


\section{CHAPTER VIII.}

STRUCTURE AND LITHOGENESIS OF THE ATMOGENIC ROCKS

\section{SNOW}

Snow is a direct condensation of the moisture of the air, when the temperature falls below $32^{\circ} \mathrm{F}$. $\left(0^{\circ} \mathrm{C}\right.$. $)$. This occurs in high latitudes throughout much of the year, but in low latitudes, during the summer season, only in high altitudes. It is in these regions of more or less continuous precipitation of snow that it remains as a permanent cover of the surface throughout the year, constituting the permanent snow ficlds. The lower limit of the permanent snow fields constitutes the snow-linc. The snow-line may be considered under two aspects: (a) Its dependence primarily on climatic conditions, giving the climatic snow-line, and (b) its dependence primarily on orographic features, giving the orographic snow-line. The climatic snow-line depends in the first place upon the course of the mean summer isotherm of $\mathrm{o}^{\circ} \mathrm{C} .\left(32^{\circ} \mathrm{F}\right.$.), but there are other climatic factors which modify this, as, for example, the amount of precipitation of snow during the winter months, exposure to the sun, and warm and dry winds from the land; the steepness of the mountain sides, and their altitude, etc. The orographic snow-line is the lower limit of both snow fields and separate neve patches, which owe their permanent preservation mainly to favorable orographic surroundings. They may thus occur in ravines and gullies far below the true snow-line.

Height of Snozu-line. The snow-line is always higher than the lower limit of snowfall, and it is of course much higher in the equatorial than in northern regions. Thus in the Bolivian Andes, near the equator, it is 5,500 meters ( 18,500 feet) on the west side and 4,876 meters ( 16,000 feet) on the east side, while in latitude $70^{\circ} \mathrm{N}$. (Lapland) it is about 915 meters (3,000 feet), and in Greenland $\left(60^{\circ}-70^{\circ}\right.$ N. lat. ) about 670 meters $(2,200$ feet $)$. From numerous observations Humboldt obtained the following table of 
relationship) between latitude, the lower linit of snowfall, and the snow-line. (Hann- $4: 3$ I3.)

$\begin{array}{crcr}\text { Altitude of Snowfall and of Snow-line } & \text { (Metcrs). } \\ \text { Latitude } & \begin{array}{c}\text { Lower } \\ \text { limit of } \\ \text { snowfall }\end{array} & \begin{array}{c}\text { Lower limit } \\ \text { of eternal } \\ \text { snow }\end{array} & \text { Differences } \\ & & & \\ 0^{\circ} & 4,000 & 4,800 & 800 \\ 20^{\circ} & 3,000 & 4,600 & 1,600 \\ 40^{\circ} & 0 & 3,000 & 3,000\end{array}$

These figures are approximate and represent average conditions. Many temporary and local variations from these averages occur.

The equatorial limits of regular snowfall (at sea-level) are as follows, the figures in parentheses giving the range of occasional snowfall: On the west coast of America, $45^{\circ}\left(34^{\circ}\right) \mathrm{N}$. to $45^{\circ}$ $\left(34^{\circ}\right) \mathrm{S}$.; east coast, $35^{\circ}\left(29^{\circ}\right) \mathrm{N}$. to $44^{\circ}\left(23^{\circ}\right.$ ?) S. Interior, $30^{\circ}$ $\left(19^{\circ}\right)$ N. to near tropics in South America. For the Old World, on the west coast of Europe, $45^{\circ}\left(33^{\circ}\right)$ N., on the east coast of Asia, $30^{\circ}\left(22.5^{\circ}\right) \mathrm{N}$.; on east and south coast of Australia, $34^{\circ} \mathrm{S}$. (occasional). For the interior of Asia snow falls to $24^{\circ}\left(22^{\circ}\right) \mathrm{N}$. latitude; on the Mediterranean to $37^{\circ}\left(29^{\circ}\right) \mathrm{N}$. latitude, while in the interior of South Africa it falls occasionally at $24^{\circ}$ S. latitude. (Hann-4:3I4.) That the distribution of snow and ice resulting from it was different in former geologic periods is shown by the extent of former glaciation.

Conversion of Snow into Ice. The deeper portions of the snowfield are gradually converted into snow ice through the intermediate state of firn or nevć. The process of transformation of snow into ice involves the partial melting and regelation of the granules and the cementation of the remainder by the reconsolidated snow water. This is a process of diagenetic metamorphism or diagenesis.

\section{GLACIERS.}

When the mass of ice resulting from the consolidation of snow begins to spread, creeping or flowing away from the center of accumulation, it gives rise to glaciers. From their mode of occurrence, glaciers may be divided into, A. true glaciers or glacier streams, and B. icc caps, or glacier sheets. True glaciers are com- 
parable to streams, and, like them, are confined in more or less definite channels. Their length may be ten miles or more. The most typical form is that of the valley glacier or alpine glacier, extending from the mountain flanks or from a plateau through a well-defined valley. They may be simple throughout or multiple in the upper reaches, where several streams unite to form one master stream of ice. At the foot of the valley they may spread

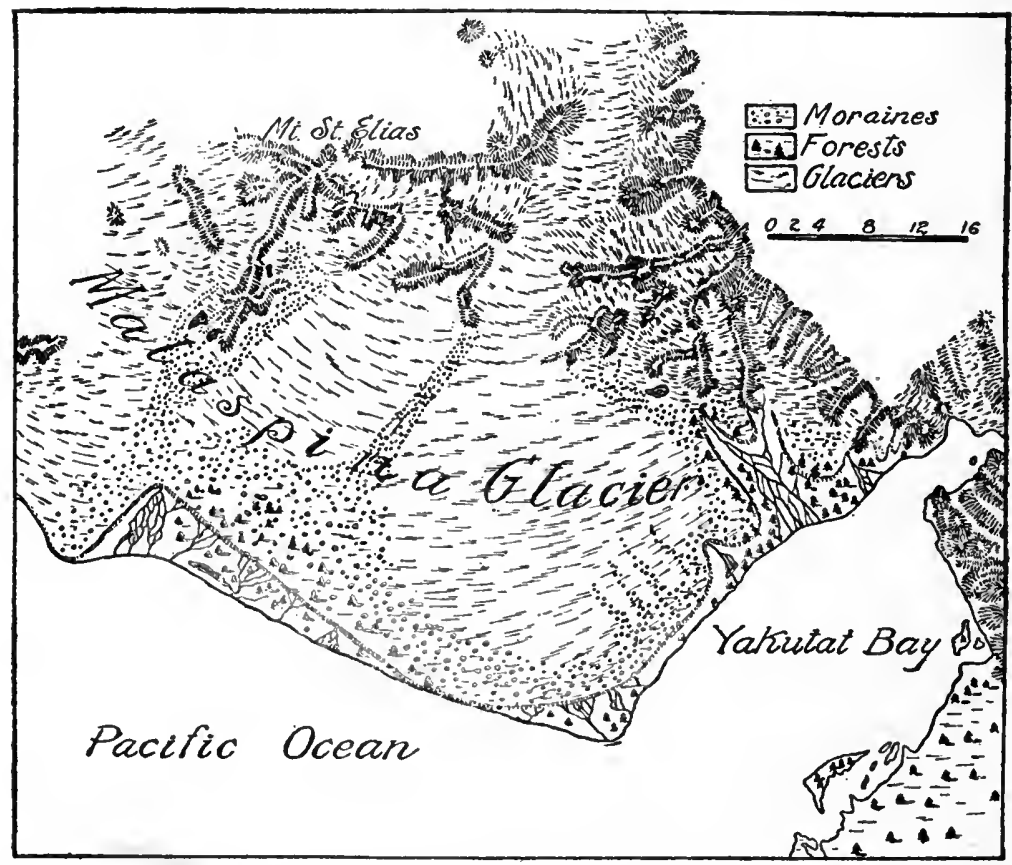

FIG. 59. Map of the Malaspina Glacier and of Yakutat Bay, Alaska; the type of a piedmont glacier. (After Russell.)

out into glacier fans or piedmont glaciers, which may be simple, $i$. e., resulting from a single glacier, or compound, when formed by the confluence of two or more glaciers from adjoining valleys. (Example, Malaspina glacier, generally regarded as a typical piedmont glacier. Fig. 59.) Of secondary rank among true glaciers are cliff glacicrs (Gchängegletscher), resting in the depressions at the foot of cliffs on the mountain flanks, and never descending to a valley; cirque glaciers (Kargletscher) in deep mountain hollows or cirques surrounded by high peaks, and ravine glaciers (Schluchtgletscher), resting in deep gorges with precipitous walls. 
Ice caps, or glacial shects, are expansions of ice, covering and concealing the underlying topography, to which their surfaces do not correspond. They may be compared to a flood, not confined within banks, but spreading over and uniformly submerging hills and valleys alike. The smaller glaciers of this type are the plateau glaciers, such as are found in Iceland, parts of Scandinavia, etc., while the larger constitute the continental glaciers or ice sheets.

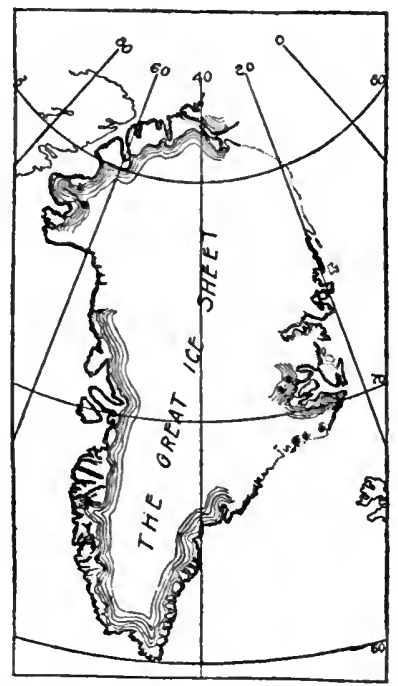

FIG. 6o. Map of Greenland, showing the ice cap and the ice-free borders. (After Stieler, from Chamberlin and Salisbury.)

Of these the great ice cap of Greenland, with an area of nearly 2,000,000 square kilometers, is a well-kinown example. (Fig. 6o.) Another example of a little explored ice sheet is the continental ice sheet of Antarctica, which ends seaward in ice cliffs 50 meters or more in height. (I.) In Pleistocenic time several huge ice caps covered the northern part of North America. (Fig. 6r.) They were contiguous along their margins, where they interfered the one with the others in respect to freedom of movement, interferences now expressed in the distribution of their transported material and frequently by the absence of erosion along the line of contact. From the margins of the ice caps of the present day numerous glaciers descend, many of them into the sea, where their ends may break off and become icebergs. In continental glaciers no bounding rock walls hem in the ice, though occasionally in the thinner mar- 
ginal portion one of the higher peaks may project through the ice as a nunatack.*

Stratification of $I c e$. Since the ice of the snow fields and of

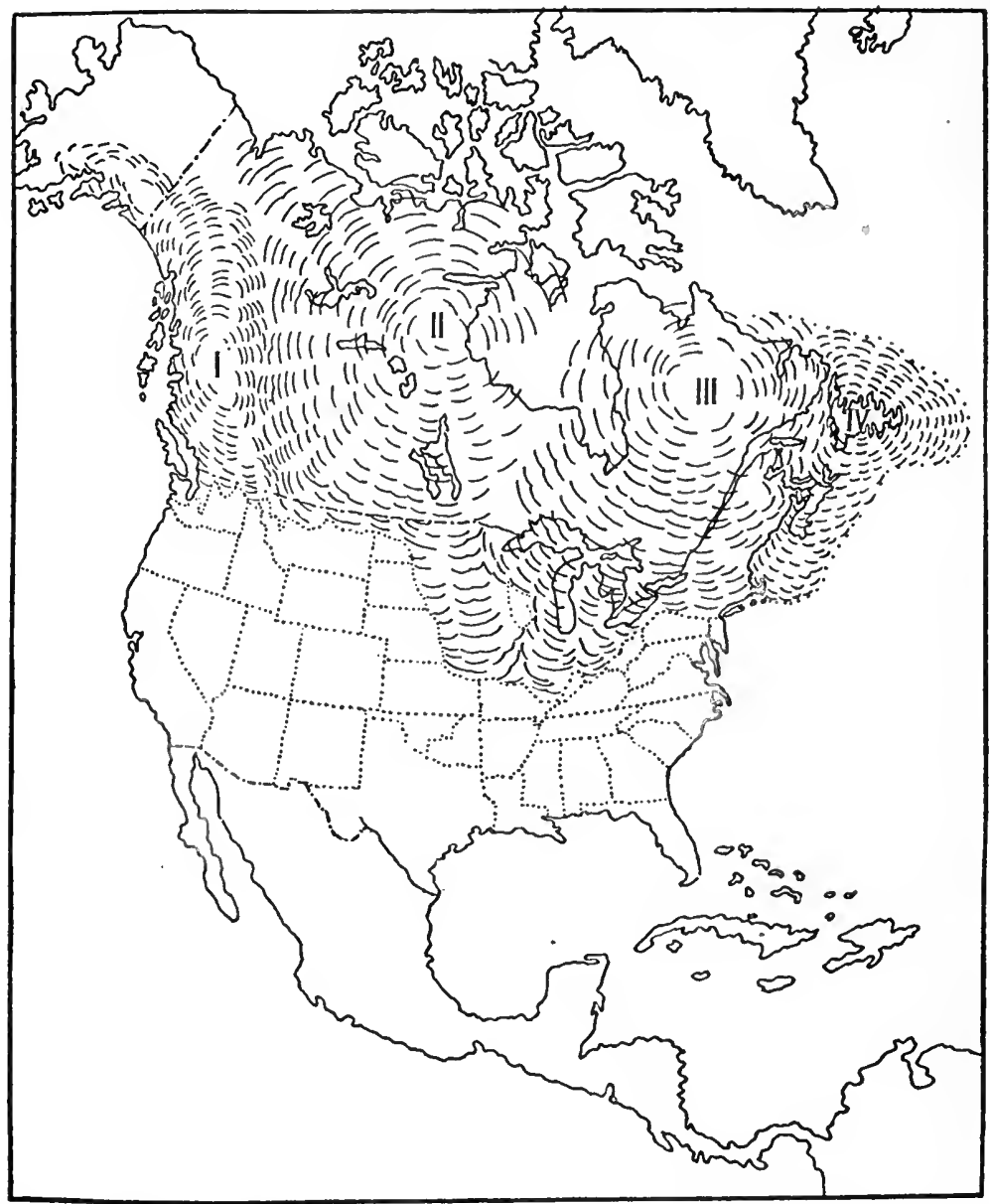

FIG. 6I. Map of North America in Pleistocenic time, showing four centers of dispersion of the ice. I., Cordilleran; II., Keewatin; III., Labradoran; IV., Newfoundland. - (After Wilson.)

glaciers is the product of successive deposits of snow in more or less continuous sheets, each of which at the time forms the surface layer of the earth at that point, it follows that snow ice has a

*For types of glacial deposits see Chapter XII. 
stratified structure. This may not always be visible, but, on the other hand, it may be very proninent. It is especially well marked where layers of wind-blown dust or sand were spread over the older layer before the deposition of the new one.

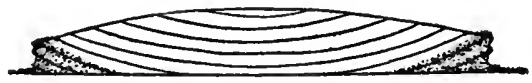

FIG. 62. Diagram illustrating lateral upturning of ice layers in a glacier. the bottom line is sea level. (Chamberlin and Salisbury.)

Shear Zones and Flow S.tructure. Instead of moving uniformly as a mass, lines of more rapid movement within the ice may develop, as the result of which a shear structure will come into existence. This may simulate stratification, especially when, as is commonly the case, débris from the bottom is carried up into the ice along the shear zones. Though a secondary structure, it may be mentioned here for purposes of comparison.

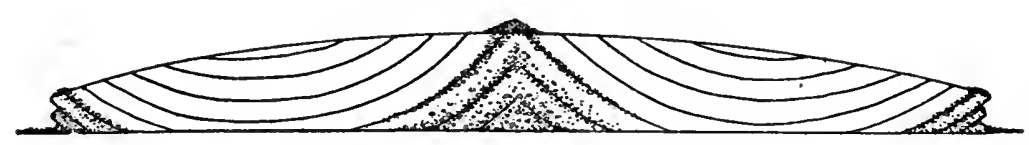

FIG. 63. Diagram illustrating compound or double glacier, with débris-laden layers rising laterally and medially, forming corresponding moraines. The bottom line is sea-level. (Chamberlin and Salisbury.)

Flow structure is developed within many glaciers. This is most pronounced near the front of the ice and along its sides. The layers near the front turn up and the débris within the ice thus gradually reaches the surface. Along the sides the movement is also from below upward, and where two valley glaciers have joined into a single trunk glacier, the current of each still remains distinct, and we have upward moving currents from both sides in the centęr as well as on each side. (Figs. 62, 63.)

\section{BIBLIOGRAPHY VIII.}

I. AMUNDSEN, ROALD. I913. The South Pole. 2 volumes. London' John Murray. New York, Lee Keedick.

2. CHAMBERLIN, T. C. I885-1886. The Rock Scouring of the Great Ice Invasion. Seventh Annual Report of the Director of the U. S. Geological Survey, pp. $155^{-254}$.

3. CHAMBERLIN and SALISBURY. 1909. Geology, Vol. I. 2nd edition, pp. 32I-22. Extended bibliography on glacier motion, with summary. 
4. HANN, JULIUS. 1903. Handbook of Climatology. Translated by R. de Courcy Ward. New York, Macmillan Co.

5. HOBBS, WILLIAM H. I9II. Characteristics of existing Glaciers. New York, The Macmillan Company.

6. PENCK, ALBRECHT, and BRÜCKNER, EDUARD. I90I-1909. Die Alpen im Eiszeit-alter. 3 Bände. Leipzig.

7. REID, HARRY FIELDING. I895-1913. The Variation of Glaciers. I-XVIII. Journal of Geology, Vols. III-XXI.

8. REID, H. F. I896. The Mechanics of Glaciers. I. Journal of Geology, Vol. IV, pp. 912-928.

9. REID, H. F. I90I. De la progression des glaciers, leur stratification et leurs veines bleues. Congrès Géologique International, Compte Rendu, VIII ${ }^{\text {me }}$ Session, pp. 749-755.

Io. REID, H. F. I905. The flow of Glaciers and their Stratification. Appalachia, Vol. II, pp. I-6, 2 pls., I fig.

I I. REID, H. F. I907. Ibid. Johns Hopkins University Circular, new series, No. 7, pp. 24-26 [6I2-614], I fig.

I2. REID, H. F. 1908. On the Internal and Basal Melting of the Ice of Glaciers. Zeitschrift für Gletscherkunde, Bd. III, H. I, pp. 68-70.

13. REID, H. F. 1909. The Relation of the Blue Veins of Glaciers to the Stratification, etc. Congrès Géologique International, IX ${ }^{\text {me Session, }}$ pp. 703-706.

I4. RUSSELL, I. C. I883-I884. Existing glaciers of the United States, 5th Annual Report of U. S. Geological Survey, pp. 309-362.

15. RUSSELL, I. C. I897. Glaciers of North America. Boston and London, Ginn \& Co. 
CHAPTER IX.

\section{ORIGINAL STRUCTURES AND LITHOGENESIS OF THE TRUE AQUEOUS OR HYDROGENIC ROCKS.}

True aqueous or hydrogenic deposits, i. $\varepsilon$., precipitates from solution in water, may be grouped under a number of divisions, according to the mode of origin. The principal groups are :

I. Marine, or oceanic (halmyrogenic, halogenic,* or thälassogenic $\dagger$ ).

2. Lacustrine (limnogenic $\ddagger$ ), including those of lakes, ponds, marshes, salinas, and playa lakes.

3. Fluvial (potamogenic §).

4. Terrestrial, including those of springs, both cold and hot, of geysers, the deposits in caverns, mineral veins, etc. They comprise deposits of both vadose and magmatic waters. Under this head must also be placed the salitrales of Patagonia and other regions.

Chemical deposits of the open sea when not alteration products are practically limited to carbonates of lime and of magnesia, though these are rare in the modern ocean. In enclosed mediterraneans or other cut-offs from the ocean, deposits of calcium carbonate are formed, while gypsum and salt may be precipitated on evaporation of the water. Complete evaporation may result in the deposition of the rarer salts, especially those of potash.

In lakes chemical deposits are chiefly confined to the carbonates of lime, which may be extremely abundant. Complete evaporation, however, may result in the deposition of a variety of salts, including chlorides, nitrates, borates, sulphates, carbonates, etc. Chemical deposits of fluvial origin are chiefly limited to the carbonates of lime, though deposits of iron oxides and carbonates may also be formed. Finally, the terrestrial deposits of this type include carbonate of lime and silica, as well as a large variety of additional mineral

$* \dot{a} \lambda s=$ salt.

$\dagger \theta \alpha \lambda \alpha \sigma \sigma \alpha=$ the sea.

$\ddagger \lambda \iota \mu \nu \eta=$ a marsh, lake, pond.

$\S \pi$ or $\alpha \mu b s=$ river. 
substances which fill up fissures and other cavities, forming veins and other types of deposits. Chief attention will here be given to the deposits of carbonate of lime and magnesia, to gypsum and anhydrite, and to chloride of sodium and some other common salts.

\section{OCEANIC PRECIPITATES.}

Chemical Deposits of the Deep Sea. Purely hydrogenic rocks, $i$. $\mathcal{c}$., precipitates, are practically unknown in the open ocean, but chemical deposits, in part alteration products, are found. Here belong the manganese concretions, which are found widely distributed over the floor of the abyssal portion of the Pacific Ocean and elsewhere. They generally enclose foreign objects, pieces of pumice, the teeth of sharks-often of extinct Tertiary species - the ear-bones of whales, etc., or even fragments of siliceous or calcareous sponges. The encrusting material is disposed in concentric layers and consists of manganese oxide up to 63 per cent. and iron oxide up to 45 per cent., the iron in some cases even exceeding the manganese. Clay and silica make up the remainder, one or the other having been found to approach 50 per cent. of the mass. Copper, nickel, lead, cobalt, molybdenum, and traces of zinc, lithium and thallium have also been found in these concretions. The source of the manganese has been thought to be the sea water, in which it occurs as the bicarbonate, which, when coming in contact with the oxygen of the air, is precipitated as the peroxide. The small quantity of this salt found in the sea water has, however, cast doubt on this explanation, and others have sought for the source of the manganese in the decomposition products of basic volcanic rocks in the sea, or in submarine volcanic eruptions or in mineral springs. (See summary by Potonié-46:166.) Another alteration product is found in the crystals of Phillipsite, a hydrous silicate of aluminium, calcium and potassium, found abundantly in the deeper portions of the Pacific and Indian oceans. They not infrequently occur in the form of crossed twins. These are also regarded as due to precipitation of decomposition products of submarine volcanic rocks, taken into solution in the water of the deep sea.

Glauconite, too, may be mentioned here. It accumulates in the shallower portions of the sea, being more largely confined to the littoral district, $i$. e., the continental shelf. Since this mineral is, however, more properly to be regarded as an alteration product of the finer marine sediments, its discussion is best deferred until these sediments have been considered. (See Chapter XV.) 


\section{CHEMICAL LIME AND MAGNESIA DEPOSITS.}

Chemical Precipitation of Carbonate of Lime and MagNESIA In THE OCEAN. In the modern oceans the chemical precipitation of lime and magnesia as limestones and dolomites is almost unknown. It is true that crystals of dolomite grow in vugs and cavernous openings of coral reefs (Skeats-5o), and calcite and aragonite crystals were found abundantly in the cavities between the organic fragments composing the coral rock in the deeper portions of the Funafuti core, but those deposits belong rather to the category of diagenetic modifications. This general absence in the modern sea of such deposits is not a safe argument for the similar freedom of the ancient sea from these deposits. Indeed, there are many horizons where limestones and dolomites accur, which, from the absence of organic remains, are difficult to explain as of other than chemical origin. This is especially the case with the preCambric limestones, for which Daly (12:I63) advocates a chemical history. He suggests that the lime of the pre-Cambric ocean was precipitated on the ocean floor by the agencies of decaying organic matter. This accumulated in quantity owing to the absence of the bottom scavengers which had not then come into existence, and which now keep the sea bottom free from organic matter to a large extent. Furthermore, the low temperatures of our sea bottoms permit only a very slow putrefaction of the organic matter which does remain. In earlier seas, however, temperatures may haye been much higher, permitting such putrefaction on a large scale.

During putrefaction ammonium carbonate is given off in large volumes. This converts the chloride and sulphate of calcium into carbonate, which is then precipitated, the reactions being:

$$
\begin{aligned}
& \mathrm{CaSO}_{4}+\left(\mathrm{NH}_{4}\right)_{2} \mathrm{CO}_{3}=\mathrm{CaCO}_{3}+\left(\mathrm{NH}_{4}\right)_{2} \mathrm{SO}_{4} \\
& \mathrm{CaCl}_{2}+\left(\mathrm{NH}_{4}\right)_{2} \mathrm{CO}_{3}=\mathrm{CaCO}_{3}+2 \mathrm{NH}_{4} \mathrm{Cl} .
\end{aligned}
$$

Experiments (Irvine and Woodhead-30:79. Quoted by DalyII : IOI) have shown that sea water is readily modified by putrefying organic matter or effete substances derived from living animals. Four small crabs, weighing 90.72 grams, were placed in sea water absolutely free from carbonate of lime. After twelve months they produced an alkalinity in the water equal to the production of 45.36 grams of calcium carbonate. This was due to the decomposition of calcium sulphate by the uric acid and other effete matter. In a second experiment, with temperatures ranging from 
60 to 80 degrees Fahrenheit, the decomposition of urine mixed with sea water precipitated practically all the sulphate of lime present in seventeen days. The complete putrefaction after death of nine small crabs in 2 liters of sea water, at temperatures varying from $70^{\circ}$ to $80^{\circ} \mathrm{F}$., resulted in the precipitation of all the lime salts in the form of carbonates.

One objection that has been raised against this theory of lime deposition is that in the decay of organic matter carbon dioxide is likewise generated, and that this would tend to keep the lime in solution. This is indeed the accepted explanation for the absence of calcareous deposits in the deep sea, where only red clay is deposited (see beyond, Chapter XV). Natterer emphasizes the importance of the abundant ammonia resulting from the decay of the organic matter on the sea bottom, and holds that this must be capable of precipitating lime and magnesia from the sea as carbonates, but only when there is no free $\mathrm{CO}_{2}$ present. The reaction of ammonium carbonate and sodium carbonate resulting from organic decay (Steinmann-5I:I99) with the calcium sulphate results in the precipitation of calcium carbonate, which, according to Linck $(33: 500)$ is aragonite and not calcite. Magnesium carbonates and dolomites, however, are not directly separated from sea water through the reactions with ammonium and sodium carbonates (Philippi-45:432), but will separate after an interval of time, especially if the calcium salts are first removed. Murray and Irvine ( $36: 104)$ found that a mixture of sea water and urine after standing several days furnished the precipitate under $A$ of the following table, the urine decomposing and furnishing the alkaline carbonate. After filtering out this precipitate and permitting the liquid to stand ten days longer the precipitate given under $\mathrm{B}$ was obtained.

A

B

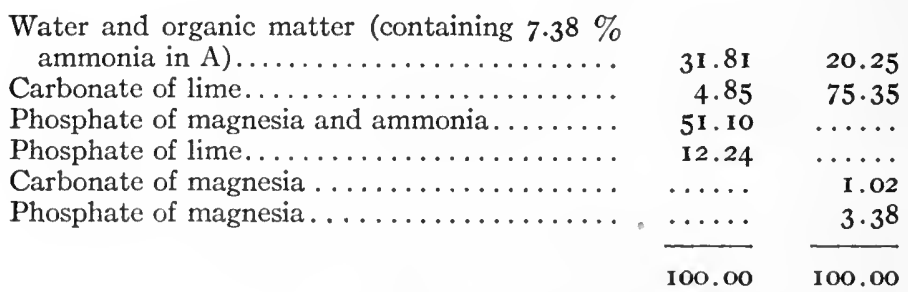

The carbonate of magnesia was precipitated only after much, and perhaps nearly all, of the calcium was precipitated as carbonate A considerable amount of the precipitating alkali, $i$. e., the am- 
monia, was removed from the mixture in the first precipitate. From the experiments cited, it appears that hydrous carbonate of magnesium can be precipitated by ammonium carbonate emitted from decaying animal remains, the precipitation being much slower than in the case of calcium carbonate, and being retarded by the presence of calcium salts in the solution. If the pre-Cambric ocean was nearly limeless, as argued by Daly, the proportion of precipitated magnesium carbonate would be high, even possibly approaching the ratio of true dolomite. The general proportion of dolomites to limestones in the various formations of the earth's crust is shown in the following table. (Daly-I2:165.)

Table showing proportion of dolomites to limestones in the geological series.

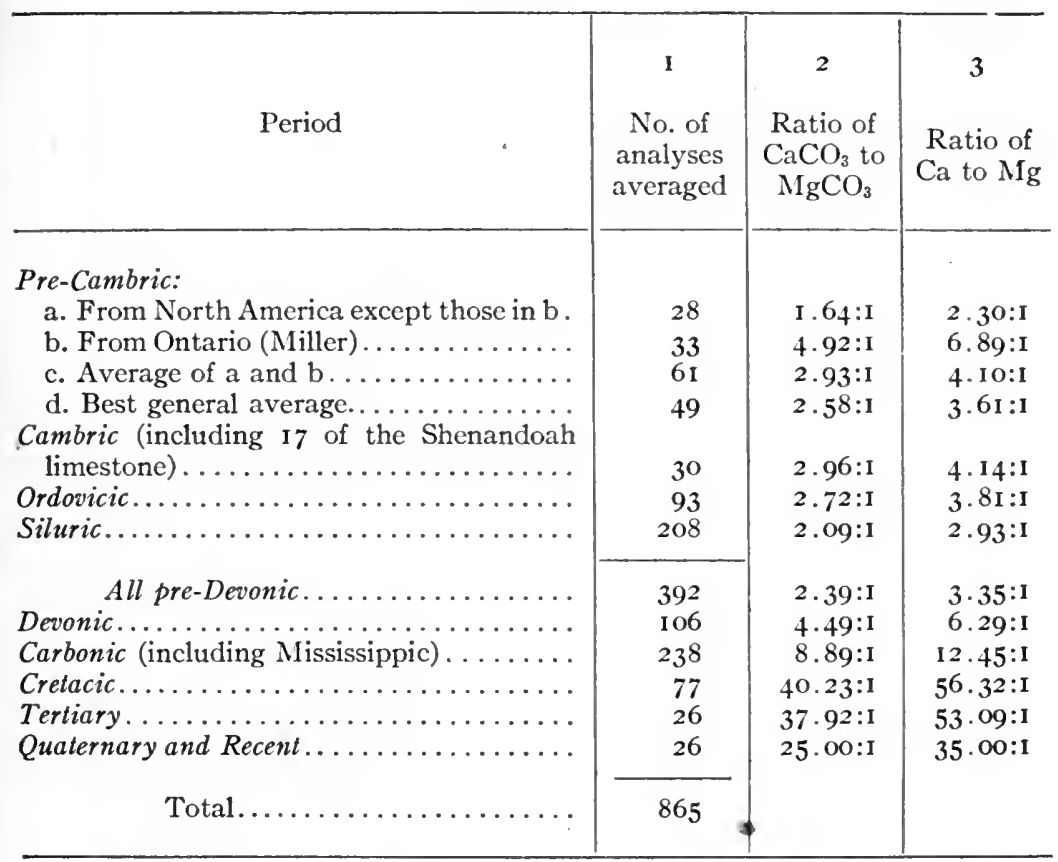

This table shows that the ratio of calcium to magnesium is fairly constant for all pre-Devonic rocks (shown by 392 analyses chiefly from North America), the average being 3.35:I. In the Devonic the ratio rises abruptly and increases rapidly in the Carbonic. The Cretacic shows an apparent maximum, but might be 
exceeded by Tertiary and later formations if more analyses were available. Daly points out that the ratio of calcium to magnesium in all pre-Devonic formations is significantly close to the same ratio in the rivers now draining pre-Cambric terranes, as shown by the Ottawa River, where the average ratio is $3.69: \mathrm{I}$. From this he suggests that during pre-Devonic time the river-borne magnesium and calcium were wholly precipitated, after diffusing, to the sea bottom. Daly holds that the study of the grain of unmetamorphosed Cambric and pre-Cambric carbonate rocks convincingly shows that they are not of clastic origin nor of direct organic origin through accumulation of shells or skeletons. Microscopic examinations of typical specimens from a mass more than 7,000 feet thick seem to indicate that neither horizon nor distance from the old shore lines affects the singularly monotonous grain of the rocks. "The constituent particles are either idiomorphic and roughly rhombohedral, or anhedral and faintly interlocking. The former are everywhere of nearly uniform average diameter, ranging from $0.01 \mathrm{~mm}$. to $0.03 \mathrm{~mm}$., with an average of about $0.02 \mathrm{~mm}$. The anhedral grains range from $0.005 \mathrm{~mm}$. to $0.03 \mathrm{~mm}$., averaging about $0.015 \mathrm{~mm}$. in diameter." (Daly-12:I68.) A similar uniformity of grain was found in the Archæan dolomites of Idaho, in the magnesian limestones and dolomites of the Belt terrane with Beltina danai, in the Clarke range, and in the Siyeh and Sheppard siliceous limestones of northwestern Montana (Middle Cambric). Similar fine-grained dolomites have been found by Vogt in Norway, and are believed to be chemical precipitates. (Vogt-55, quoted by Daly-12:I68.) An apparently good case of lime deposition in the sea by chemical separation, through the influence of decaying organic matter, is found in the fine calcareous and magnesian mud at the bottom of the Bay of Naples. (Walther and Schirlitz-67:336.) This mud is relatively poor in organic remains, and seems to have been separated from the lower strata of water, which are poorer in lime and magnesia than the upper. Stony crusts consisting chiefly of calcium carbonate, of ferruginous clay, of double silicates of sodium and potassium holding manganese, of silica, and of carbonate of magnesia are found at the bottom of several mediterraneans, as, for example, the Roman Mediterranean between Crete and Africa on the one hand, and Crete and Asia Minor on the other. Also between Crete and Greece and in parts of the Agean Sea, as well as in the Red Sea, where they are common, and the bottom waters are rich in ammonia (Phillipi-45: 429.) Calcareous concretions were dredged by the Challenger from a blue clay in 2r6-255 m. depth west of New Guinea, and these are 
regarded as of purely chemical origin. The rapid cementation of lime sands in the deeper sea by the deposition of lime or magnesium carbonate is a further illustration of this phenomenon, as is also the rapid cementation of reef limestones and the sands and rubble on the borders of the reef. Darwin found that the breccias of coral fragments on the outer margins of the reefs were so firmly cemented that it was difficult to chop off a fragment, even with a chisel. The Pourtales plateau, south of Florida, is a hard limestone surface of recent origin. . All loose material not cemented by lime deposits is swept off the plateau by the Gulf Stream. Similar submarine banks are found between the Canaries and the South African coast (the Seine-Dacia and Josephine banks), the Campeche banks of Yucatan, the Mosquito bank of the east coast of Nicaragua and elsewhere.

What is true of modern coral reefs and banks is equally applicable to older deposits of this character. The cementation of the organic (biogenic) limestone of the reefs of the various geological periods is undoubtedly due to precipitation of lime from the sea water. This, however, is always of minor importance, and the reef deposits must be classed with biogenic rocks. A rapid cementation of detrital lime sands and muds seems to be indicated in many limestone banks. It has been especially described for the Muschelkalk (Philippi-45: +38 ), and is suggested by certain features in a number of linestone beds, and is to be explained as due to rapid chemical deposition of lime between the grains of the calcareous clastic material.

Among the indications of rapid hardening of such banks is the attachment of crinoids by flat, disk-like expansions, which is possible only on a hard bottom; by the attachment of molluscs and other hard-bottom-loving organisms, and by channelings and borings which may be filled by the immediately succeeding materials. Such rapid hardening makes possible the formation of conglomerate or of brecciated layers which contain fragments of the underlying limestone layer. Such intraformational conglomerates have been described by Walcott from Lower Cambric limestones of eastern New York and Pennsylvania and from Virginia and Tennessee (57; $58: 34$ ), and by Wagner from the Muschelkalk of the vicinity of Jena $(56 ;$ Fig. 3). Here the lower bed represents a worn surface and many fissures which are filled by the material of the succeeding layer. This upper layer is also characterized by a basal conglomerate with pebbles of the lower rock. That the upper layer was also rapilly cemented is shown by the occurrence of a large Encrinus root and a rich molluscan fauna over its surface. Much care, 
however, is needed to distinguish such conglomerates from the basal conglomerates marking a disconformity between the two layers. The Cretacic chalk of western Europe has also been regarded as in part made up of chemical precipitates. This refers especially to the cement which unites the shells of foraminifera, etc. The chemical part of the cement consists of microscopic calcite rhombohedrons and less regular calcite grains, a large part of these originating from the recrystallization of organic aragonite (Cayeux-9). Walther regards the cementing material of the fine calcilutytes of the Solnhofen region as due to chemical precipitation (64:212).

Oölites and Pisolites of Chemical or Purely Hydrogenic Origin. These have been described from a number of localities, occurring both in recent formations and in older geological deposits. The familiar pisolite of the Carlsbad Springs in Bohemia is a typical example, formed by the encrustation of minute particles of quartz or feldspar, held in suspension by the rising waters, and turned in all directions, so as to produce uniform encrustations. Gas and air bubbles likewise may form the nuclei of such encrustations, which in that case have a hollow center. The usual composition is $\mathrm{CaCO}_{3}$, with a small quantity of $\mathrm{FeCO}_{3}$ (Zirkel-70:488; Hochstetter$24: 83$ ), but the mineral is neither calcite nor aragonite, but a third modification "Ktypeit," convertible by heat into calcite. On the shores of seas, the water of which holds much lime, particles of broken shells, grains of igneous rocks, etc., are encrusted by $\mathrm{CaCO}_{3}$. forming a rock of typical oölitic appearance. On the shores of the Island of Gran Canaria in the Canary Islands, between Las Palmas and Isleta, encrustations of carbonate of lime are found, according to $\mathrm{L}$. von Buch, around fragments of broken molluscs, and small sand grains of trachyte and basalt. This sand becomes consolidated into a porous rock, which is quarried at low tide. The water of the waves throughout the greater part of the year has a temperature of more than $20^{\circ} \mathrm{C}$., and seems to be abundantly able to dissolve lime and redeposit it around the grains of sand, forming a "Rogenstein." In the Mexican lagoons oölites are formed, according to Virlet d'Ooust, by the encrustation with lime of insect eggs, and these oölites closely resemble those from the Jurassic.

On the coast of Ascension Island recent oölites are formed, according to Darwin, by the encrustation of rounded fragments of fossils. Similarly, fragments of shells and grains of coral sand on the north coast of Tahiti are coated with lime, according to Dana $(13: 372)$, and transformed into oölites. Other examples are cited from the coast of the Sinai peninsula at Wadi Deheese, and in the Reede of Suez (Walther-59:884). These last two examples 
are, however, regarded by Rothpletz as of algous origin (see beyond). Linck $(33: 498)$ has obtained for these recent oölites an aragonite reaction, while the fossil oölites are by him referred to calcite.

Linck $(33: 506)$ has experimented with the chemical precipitation of lime from artificial sea water with results leading to the following conclusions :

The maximum solubility of calcium carbonate in sea water is about $0.0191 \% \mathrm{CaCO}_{3}$. If this maximum is exceeded deposition of $\mathrm{CaCO}_{3}$ occurs, in the form of calcite in temperate climates and of aragonite in tropical climes, but without the formation of spheruliths. The same thing is true of solutions of calcium carbonate otherwise free from salts. If the calcium sulphate of the water is precipitated as carbonate by sodium or ammonium carbonate, it is always aragonite and of sphærulithic form. These reagents will precipitate calcite from solutions of calcium sulphate otherwise free from salts, both at $40^{\circ} \mathrm{C}$. and at $18^{\circ} \mathrm{C}$. The solubility of aragonite is thus shown to be greater in solutions which are poor in or free from other salts than in those rich in such salts, and that it is greater in colder than in warmer solutions. For calcite just the reverse holds true, and hence, at a given temperature, sea water will hold in solution more calcium carbonate than fresh water, but there may be circumstances under which aragonite and calcite are soluble in equal degree, and so may be formed simultaneously. Both calcium carbonate and calcium sulphate are more readily soluble in sea water than in fresh water. Applying his results to the elucidation of the question of the origin of marine oölites. Linck finds that the under saturation of sea water precludes deposition of lime without the intervention of a precipitating reagent, and this he finds in the sodium and ammonium carbonate resulting from the decay of organic matter. The precipitated material is usually in the form of sphæruliths or concretions of aragonite with or without an inner grain. The latter is found in the neighborhood of coasts, where the lime is deposited around fragments of shells or coral, grains of quartz or other sand, foraminifera, etc., while in the open sea they are without central kernel. Linck considers that all oölites and pisolites are of inorganic or chemical origin, and that, whenever organic remains occur in the mass, these are mechanically enclosed, or, in the case of unicellular algæ, the oölite grains serve as a basis for attachment. In the open sea the spheruliths sink to the bottom in time, while near the shore they are piled up into sand dunes and assorted, according to size, with more or less mechanical wear. In the course of time the 
aragonite spheres are converted into ealcite, with often complete retention of structure. The opinion of Rothpletz, who regards most of these oölites as of organic (phytogenic) origin, will be given later (Chapter XI).

Deposits in Enclosed or Nenrly Enclosed Basins. The Black Sea (Andrussow-4) is characterized by relatively slight vertical currents, owing to the superficial layer of water of less salin-. ity. This layer, I25 fathoms deep, is alone furnished with oxygen from the surface, while below that the water is poisoned by the gases resulting from the putrefaction of the dead animal bodies which have sunk to the bottom from the surface layers, and which, in the absence of scavengers, were left to decompose in the relatively high bottom temperatures. Only anaërobic bacteria, especially $\mathrm{Bac}$ terium hydrosulfuricum ponticum, live in the lower strata of these waters. At a depth of about Ioo fathoms begins the separation of $\mathrm{H}_{2} \mathrm{~S}$ by these bacteria, the quantity being 33 c.c. to Ioo liters of water, and rapidly increasing until at 500 fathoms it is 570 c.c. to Ioo liters of water. Further down the increase is less rapid. Ammonium carbonate is also produced in large quantities. The black mud between 300 and 717 fathoms is charged with an abundant separation of iron sulphide ( $\mathrm{FeS}$ ), according to the following reactions (Murray and Irvine-36:93, modified by Daly-I I: 103):

$$
\begin{aligned}
& \mathrm{RSO}_{4}+2 \mathrm{C}=2 \mathrm{CO}_{2}+\mathrm{RS} \\
& \mathrm{RS}+2 \mathrm{CO}_{2}+\mathrm{H}_{2} \mathrm{O}=\mathrm{H}_{2} \mathrm{~S}+\mathrm{RCO}_{3} \mathrm{CO}_{2} \\
& \mathrm{RS}+\mathrm{RCO}_{3} \mathrm{CO}_{2}+\mathrm{H}_{2} \mathrm{O}=2 \mathrm{RCO}_{3}+\mathrm{H}_{2} \mathrm{~S} \\
& \mathrm{Fe}_{2} \mathrm{O}_{3}+3 \mathrm{H}_{2} \mathrm{~S}=2 \mathrm{FeS}+\mathrm{S}+3 \mathrm{H}_{2} \mathrm{O}
\end{aligned}
$$

With the iron sulphide and free sulphur there is also formed a powdery precipitate of $\mathrm{CaCO}_{3}$, which at a distance from shore, where mechanical detritus is less abundant, forms layers and thin banks of fine-grained limestone, whereas nearer the shore the powdery lime is mixed with fine detritus. Shells of the planktonic young of pelecypods and the frustules of pelagic diatoms are likewise abundant in these deposits (Andrussow-4).

Chemical Limestone Deposits of Lakes in Arid Regions. While chemical precipitation of lime is found in the sea only under exceptional conditions, and is of merely local significance, tle e chemical precipitation of lime from drying lakes in arid or semiarid regions becomes a matter of greater import. The site of the former Lake Lahontan in the Great Basin region (western Nevada) was characterized by calcareous deposits of great extent, as was also Lake Bonneville, the predecessor of Great Salt Lake. Three types 
of hydrogenic lime are recognized by Russell $(47: 2 I I ; 48)$ in the basin of Lake Lahontan, where they covered the surfaces of nearly all the rocks, on the shores and bottom of the old lake. The oldest deposit is the Lithoid tufa. It is compact, gray, sometimes forming a cement for the ancient gravels, and not infrequently contain-

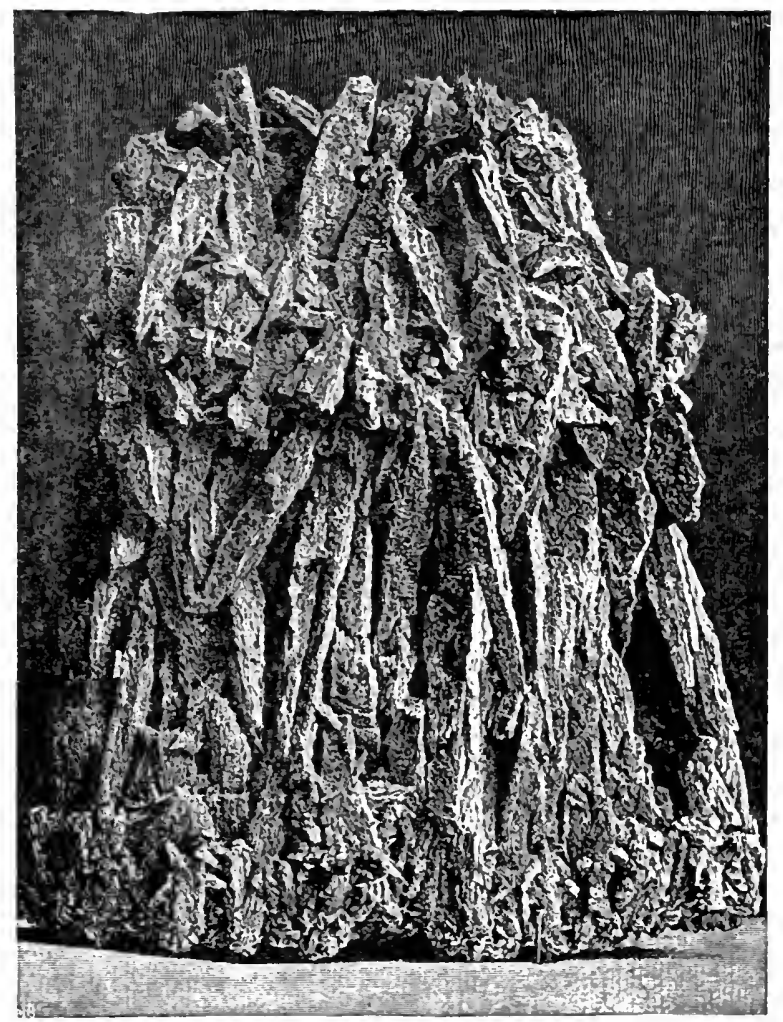

Fig. 64. A group of crystals of thinolite, or thinolithic tufa. Lake Lahontan basin, Nevada. (After Russell.)

ing the shells of fresh-water gastropods. After an interval of exposure the second type, or Thinolithic tufa, was deposited over the first. It consists of orthorhombic prisms 6 to 8 inches in length and almost half an inch thick (Fig. 64). These have a peculiar internal structure, and were at first considered pseudomorphs after gaylussite, but thcir structure does not agree with that of any known mineral. The entire layer is from 6 to 8 feet thick where 
best developed. Similar crystals are found in the deposit of the extinct lake of Mono Valley, California. The last deposit is the Dendritic tufa, and it is also the most abundant. Its greatest depth is more than twenty feet, and may be as much as fifty. (Fig. 65.) Between Wadsworth and Pyramid lakes, the old floor of Lake Lahontan is completely covered over an area of several square miles by dome-shaped masses of this tufa, commonly spreading in mush-

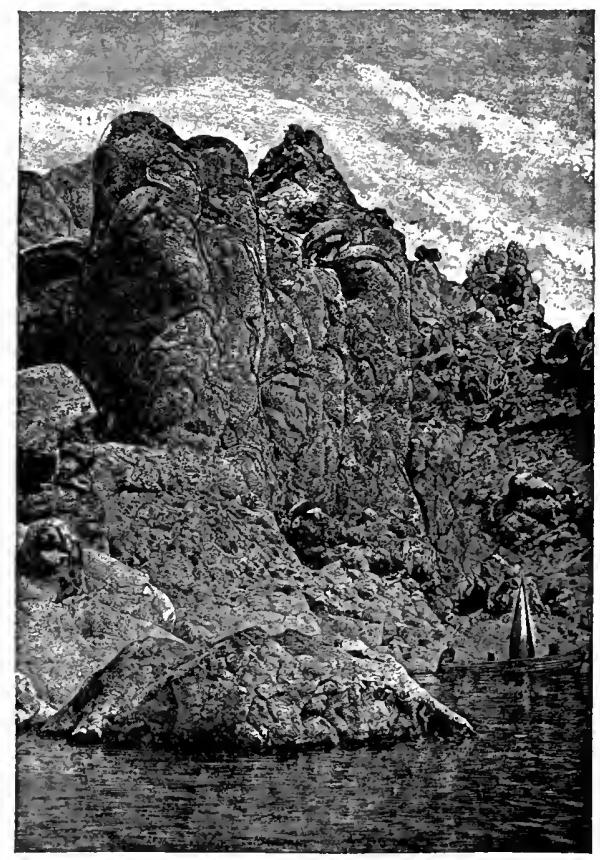

FIG. 65. Tufa domes, shore of Pyramid Lake, Nevada. A remnant of Lake Lahontan. The deposit is of dendritic tufa. (After Russell.)

room fashion, and up to 5 or 6 feet in diameter. (Fig. 66.) Interference with one another's growth produces polygonal outlines. This is the case on Carson River, where they sometimes form a pavement of hexagonal blocks, each about 2 feet in diameter. The dendritic character of this tufa is seen on weathered surfaces. Where embedded in the gravel or silt deposits of the lake or the interpolated river sediments, these tufa deposits form definite limestone horizons, with or without fossils, these limestones horizons being indicative of desert conditions, under which they were chemically precipitated. 
Older Deposits of This Type. What appears to be a deposit closely related to the last type is found in the upper Permic Magnesian Limestone series of Durham, Englant. Here many of the beds are composed of more or less spherical masses of dolomite having a radiating structure and varying greatly in size and form; pisolitic, botryoidlal, reniform and large globular masses being common.

Limestone Deposits from Rivers. Throughout the limestone region of torrid America, especially on the margins of the bolson plains of Mexico, a deposit of limestone is forming as a white superficial crust, sometimes comparatively free from foreign material, at others forming the cement of conglomerates. This con-

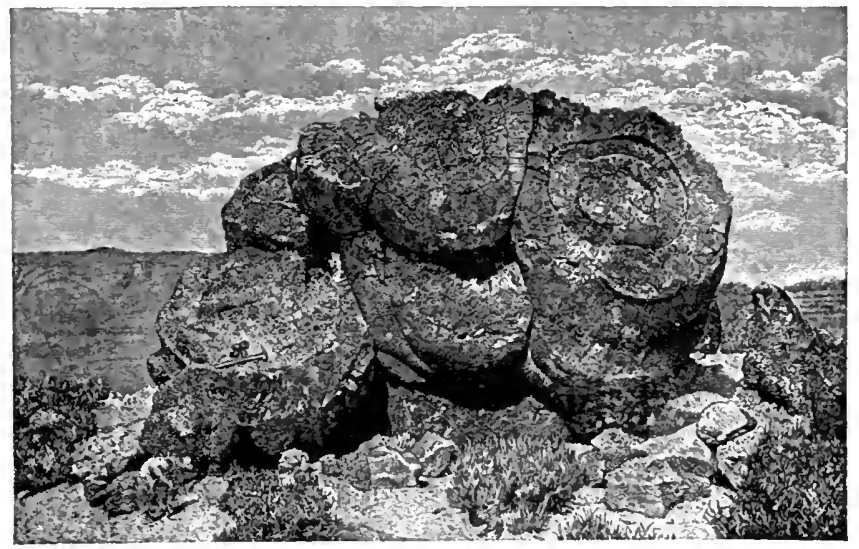

FIG. 66. Spheroids of dendritic tufa. Basin of Lake Lahontan. (After Russell.)

centrate of lime is called tepetate, and consists of material dissolved from the limestone surfaces, and transported in solution by the torrential rivers.

The Catinga limestone of Bahia, Brazil (Branner-6:193), is a good example of a river-deposited limestone. The material is derived from the older Salitre (Jurassic) or other limestones, and the deposition probably began as far back as the Tertiary, and still continues. The attitude of the beds is generally horizontal, and their thickness ranges up to nearly Ioo fect.

The deposition of this rock is due to the partial evaporation of the lime-saturated strean waters as they leave the limestone regions, and to the liberation of the carbon dioxide during the warming under the semitropic sun. The deposition of lime usually begins at 
falls or cataracts, and proceeds both upstream and downstream, filling the shallow parts first, because of the greater exposure of the water at those places. "Any downstream slope of the stream bed that causes a rippling of the water exposes it to the air, liberates more carbon dioxide, and thus causes an increased deposition of lime on the downstream side." Barriers are thus built up in time. Embankments formed in this way vary in height from half a meter to four meters. The rock is hard at the upper surface, more or less overhanging and cavernous on the downstream side. Where streams spread out to form arms or embayments, the floors of these are covered with soft, marly limestone. The same is true over the flat portions of the limestone valleys. In the low grounds water often remains stagnant in broad, shallow pools, especially in some of the sink-hole depressions. The deposit here formed is always soft and marly when fresh, but becomes as hard as a normal limestone on ageing. "At many places these lime deposits, both the newer and older ones, contain plant impressions and enclose the remains of land shells." Sometimes the shells are cemented together into a hard-shell limestone, the species being those still existing in the region. Angular as well as water-worn fragments of all kinds of rock are not infrequently found embedded in this limestone.

"When a broad, gentle and rather even slope carries the limecharged waters in shallow sheets toward a channel, the lime is precipitated more rapidly along the edge of the plain, where, on account of a change to a steeper grade, the water breaks into ripples or spray. This causes the bluff to encroach steadily on the low ground, and the process must eventually lead to the low ground being entirely filled up." The bluffs thus formed curve over at the top, and are full of caverns due to the irregularity of the deposit. The roofs of the caverns are hung with stalactites. "Often the travertine is deposited in masses of such shape that they break from their own weight and form a talus slope at the base of the bluff, and this, too, in time is covered over by later deposits, and is incorporated in the great limestone sheet." Some of these bluffs are from 25 to 30 meters high, which is, therefore, the thickness of the great limestone thus forming on dry land. The process is one of chemical aggradation.

Deposits of Lime by Springs. Calcareous tufa is a common deposit by springs emerging from limestone formations. The deposit of lime here is due largely to the relief of pressure and the escape of $\mathrm{CO}_{2}$, which held the lime in solution (see postea). Organic bodies, such as leaves, sticks, etc., are commonly encrusted by this lime, which at first is a fine slime, but soon hardens on ex- 
posure to the air. Much lime is also precipitated upon certain living mosses (Hypnum, etc.) by what appears to be the physiological activity of the plant itself (see p. 475). The calcium carbonate deposits of the hot springs of the Yellowstone, etc., are probably due to organic activities. Nevertheless a considerable part of the calcareous tufa or travertine is a purely hydrogenic deposit. (Fig. 67.)

At the Baths of San Vignone in Tuscany the travertine is deposited at the rate of six inches a year, while at San Filippo, Sicily,

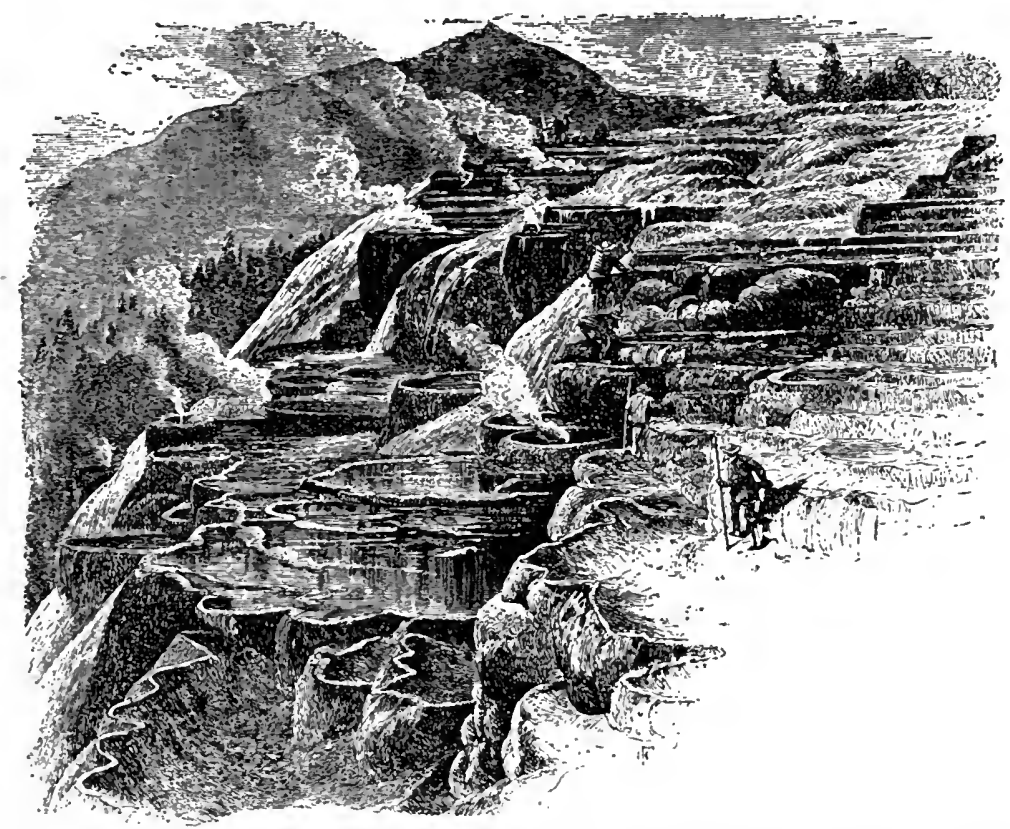

FIG. 67. The Mammoth Hot Springs of the Yellowstone National Park, showing the formation of calcareous deposits by hot springs. (After Hayden.)

it is one foot in four months, the deposit having grown to a height of at least 250 feet, and forming a hill a mile and a quarter long and a third of a mile broad. (Lyell-34:402.) The deposits at Narni, Italy, increase proportionally to the rate of flow, little lime being deposited in stagnant water. The amount also increases with distance from source and consequent length of exposure to the air, and with decrease in temperature. Percolating ground water often deposits lime in the pores of clastic strata and so cements them. This is shown by the lime-sand dunes of the Bermuclas, which are 
consolidated in this manner and by the formation of conglomerates with a limestone matrix or cement within deposits of the Pleistocenic ice sheet, the lime in this case being commonly derived from the solution of limestone fragments included in the deposit.

The Onyx Marble. A remarkable type of spring deposit is the so-called onyx marble or Mexican onyx so extensively used for decoration and other purposes. (Merrill-35.) This is a compact, highly crystalline and commonly beautifully variegated deposit of calcium carbonate, which occurs interbedded with breccias, or with ordinary porous tufas in many localities. In Yavapai County, Arizona, these have been found on the side of ravines in crystalline schists which stand on edge and are penetrated by basic dikes. The deposit occurs interbedded with breccias made of the country rock, and forms irregular, somewhat concentric layers, from a fraction of an inch to two or more feet in thickness, and lying essentially horizontal. The massive layers are separated from one another by porous cellular ones. At Cave Creek, Arizona, large blocks of the onyx up to 4 feet or more in diameter are embedded in tufaceous material. In Mexico, whence the original supply came, this rock is found in masses up to ten feet or more in diameter in a tough, reddish or dark-brown clay, overlying a closely cemented conglomerate. In one instance (at Antigua Salines) it is found in a hard, flint-like country rock, and appears to be a regular vein formation. Similar onyx deposits are found in western Utah.

In Lower California this onyx marble occurs in the desert region near the Gulf coast. It is found here in layers, slabs and blocks 20 inches to 3 or more feet thick, interstratified with tufaceous beds and ancient lake bed material, and shows a most surprising variety of delicate colors and tints. Elsewhere in lower California on the steep slopes of Tule Arroyo, a deep canyon in dark mica schist and blue-gray silicified limestones and quartzites standing on end, similar deposits of these onyx marbles were made by former springs. At first a cellular travertine was formed cementing the angular fragments of the older rocks, with which the slopes were strewn, into a coarse breccia. After several feet of such deposits, the compact onyx marble succeeded, probably through a change in the constitution of the spring or the conditions of deposition. "In time the onyx-forming action ceased-and for a period no calcareous deposition whatever took place, the slopes becoming once more covered with angular particles of the older rocks from higher up, these in their turn becoming cemented into breccias when the springs resumed their work. In this way were built up the alternating layers of breccia, tufa and onyx, until finally all deposition practically 
ceased, and spasmodic but fiercely rushing streams cut the arroyo to its present depth, exposing in either wall the irregularly alternating beds described." (Merrill-35:548.) Two highly carbonated springs still occur in the bottom of the canyon, building small beds of tufaceous material.

Considering the nature of the country rock in this and the Arizona localities, and the highly carbonated character of the springs still remaining, one is led to regard the water as magmatic or juvenile, bringing its burden of lime from greater depth.

In Algeria, North Africa, province of Oran, deposits of this type occur, covering an estimated area of about 12 acres. The formation consists of strata varying from 6 inches to 4 feet in thickness and separated by beds of compact travertine. The deposits are of Quaternary age, resting unconformably upon Middle Miocenic limestones and sandstones. Similar deposits are also found in Persia.

A significant fact bearing on the mode of deposition of these formations is that these deposits occur in regions of comparatively recent volcanic activity, and it is highly probable that the onyx marbles were deposited in heated waters and possibly under the surface of a pool or shallow lake, which would prevent too rapid loss of $\mathrm{CO}_{2}$, resulting in ordinary porous travertine. Such travertine was formed after the periodic draining of the lakes.

Underground Deposits of Lime. Caverns are especially noted for the extent and variety of their deposits of calcium carbonate. In certain Missouri caverns once submerged by a rising of the ground water, $i$. $e$., caverns formerly situated within the belt of cementation, lime was deposited as crystals of calcite, lining the walls, as in huge geodes (ante, p. 177). Caverns within the belt of weathering and hence not filled by the ground water are characterized by the deposition of stalactites and stalagmites normal to such caverns. These are formed by the water percolating through the limestone of the roof of the cavern and becoming suspended in drops. Partial evaporation of the water in the dry air, or the escape of the $\mathrm{CO}_{2}$ which held the lime in solution, results in the formation of a ring of lime for each drop, from the base of each of which a second drop becomes suspended, with the subsequent addition of a second calcareous ring at the bottom of the first one. By this process a hollow tube is formed, which grows by addition below, and increases in thickness by successive layers added by the water flowing on the outside of the tube. After a time the external deposits increase to such an extent that they will cover the opening of the tube, or this may become closed by deposits within it. The 
stalactite then grows after the manner of an icicle by external additions, and may become of great size. By the confluence of a series of stalactites, banded sheets of lime are formed, which hang from the roof of the cavern, a curtain of stone screening nooks and chambers. Stalagmites are formed on the floor of the caverns from the lime still contained within the water after it drops from the stalactite. They may be sheet-like, forming a solid floor for the cavern, or they may grow up into mounds. In the latter case they are often in the form of successive caps, one above the other, their edges frequently fringed with stalactites, which give the surface of the stalagmite mound a fluted appearance.

Cavern deposits may sometimes form on such a scale that the cavern is filled again by crystallized marble, which is often beautiful enough to be sought for commercial purposes. In the Southern Appalachians, and in Missouri and Arkansas, broken-down caverns have made possible the quarrying of the stalagmitic deposits for onyx marble. There are similar deposits in clefts and caverns in the Eocenic limestones of the Nile valley in Egypt. These have been extensively used for architectural and other purposes. In Italy, too, at many localities such cavern deposits occur, and have been worked since ancient times.

\section{Method of Deposition of Lime from Solution.}

According to Fresenius, carbonate of lime is soluble in pure water, in the proportion of I part in I0,800 of cold, and I part in 8,875 parts of boiling water, while others have placed the proportion at much less. "In carbonated waters the neutral carbonate of lime unites with the carbonic acid to form the bicarbonate of lime, which is readily dissolved in water to the extent of 0.88 gram per liter in water saturated with carbonic acid gas at the ordinary atmospheric pressure and a temperature of Io degrees centigrade." (Weed-68:637.) With increased pressure the solubility increases, with corresponding increase in the amount of $\mathrm{CO}_{2}$ absorbed, until the maximum is reached, which is about 3 grams per liter. When the waters are free from carbonic acid, but contain alkaline and earthy salts, the formation of unstable supersaturated solutions of carbonate of lime is favored. From this the lime is gradually precipitated, the precipitation being more rapid when the salts in solution are the chlorides of the alkalies and alkaline earths than when they are the sulphates of these same bases. Magnesium sulphate and sodium sulphate form solutions with a certain amount of sta- 
bility; but, according to T. Sterry Hunt, the lime is all precipitated in eight to ten days.

When the water is saturated with carbonic acid, the chlorides of the alkalies and alkali earths will form unstable supersaturated solutions, from which the lime crystallizes out at low temperature as the hydrous carbonate. The solution then retains only 0.8 gram of carbonate of lime per liter. corresponding to that dissolved by the $\mathrm{CO}_{2}$. If, however, sodium and magnesium sulphates are present in the solution in carbonated waters, the capacity of these waters for carbonate of lime is nearly doubled. Thus carbonated water holding either of these sulphates in solution in the proportion of $\mathrm{I}$ to IOO or less will take into permanent solution, under ordinary temperature and pressure, a quantity of pure carbonate of lime equal to 1.56 to 2 grams in a liter. Thus only when free $\mathrm{CO}_{2}$ is present in pure or mineral waters will $\mathrm{CaCO}_{3}$ be held in permanent solution. The precipitation of this lime may be brought about by an abstraction of the carbonic acid necessary to hold it in permanent solution. The abstraction may be caused by (Weed$68: 670)$ :

I. Relief of pressure.

2. Diffusion of the $\mathrm{CO}_{2}$ by exposure to the atmosphere.

3. Evaporation.

4. Heating.

5. Influence of plant and animal life.

The first of these is mainly active in nature where springs issue on the surface, while the second occurs on a more extended scale, as in the formation of stalactites and stalagmites and in the encrustations formed in petrifying springs. Here diffusion of the $\mathrm{CO}_{2}$ is facilitated by increase of surface of exposure, and in such cases evaporation generally accompanies diffusion. The deposition of lime through evaporation is illustrated by the tufa deposits of Lake Lahontan. Deposition through heat, illustrated by the encrustation in boilers, is of little significance in nature. Precipitation through the influence of plant and animal life belongs under the head of deposits of Biogenic type, and will be more fully discussed later.

\section{Deposits of Marine Gýpsum and Salt.}

Gypsum and Salt of Marine Origin. Gypsum and salt are as a rule the products of similar plysical conditions of precipitation, though they do not by any means always occur together. 
Both are notably absent from the open ocean and the ordinary type of mediterranean. In the marginal portions of the more enclosed mediterraneans in the arid belts of the earth such deposits often abound. Examples of these are found on the borders of the Black Sea, to a moderate extent on the borders of the Red Sea, and in the Rann of Cutch on the west coast of India.

Experiments of Usiglio. The precipitation of salt on the evaporation of sea water was studied by Usiglio at Cette $(52)$ on the Mediterranean. He began with 5 liters of water, which at $12.5^{\circ} \mathrm{C}$. had a density of $1.025^{8}$ and a salinity of 38.45 permille, and by evaporation in the air obtained the results given in the accompanying table, reduced to grams per liter of volume. No salt was deposited until the water had been reduced by evaporation to nearly one-half its volume (53.3 per cent.) and a density of $1.0506,{ }^{*}$ when slight deposits consisting chiefly of $\mathrm{CaCO}_{3}$ and ferric oxide were made. When, on further evaporation, the density had increased to I.I304, hydrated calcium sulphate (gypsum) began to deposit, this continuing tuntil a density of 1.2627 was reached. During the change in the density from I.I3 to I.208, 84.34 per cent. of all the $\mathrm{CaSO}_{4}$ was precipitated as gypsum. After this $\mathrm{NaCl}$ was deposited mixed with a little magnesium chloride and sulphate, and this continued until the density was 1.2627 , when all the sulphate of lime had been deposited together with 78.23 per cent. of the total quantity of $\mathrm{NaCl}$. After this $12.3^{8}$ per cent. of the total $\mathrm{NaCl}$ was precipitated without any gypsum. At a density of 1.2444 a little sodium bromide had begun to deposit. Thus between densities 1.0506 and 1.208, only 0.1583 per cent. of the total solids had been deposited, and this chiefly as lime sulphate and carbonate and as iron, but between densities I.22I and I.3I8 the following mixture was precipitated:

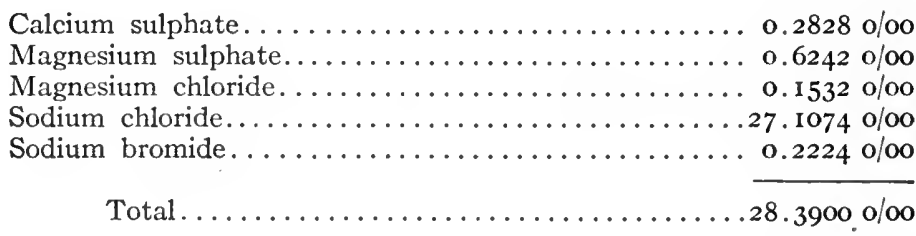

Of this 28.3900 permille of total solids, 27.1074 permille, or about 95 per cent., was sodium chloride. The volume had now been reduced to 1.62 per cent. of the original volume of 5 liters

* The values here given are taken from the table. Slightly different values for intermediate densities are often given. (See the article on Salt in Encyclopedia Britannica, also Clarke--Io.) 


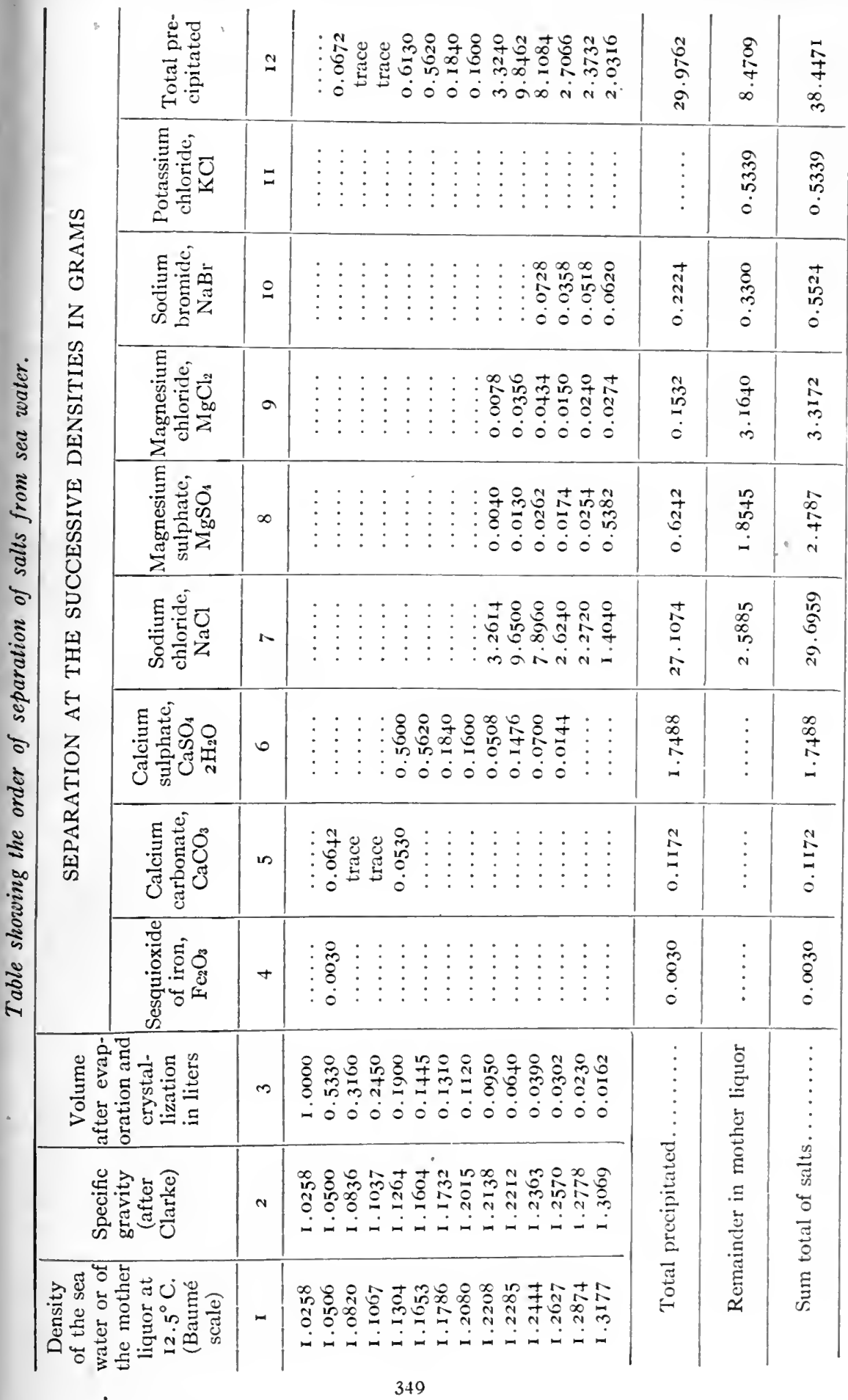


(o.08I liter), and this, the mother liquor, still contained the following quantities of salts:

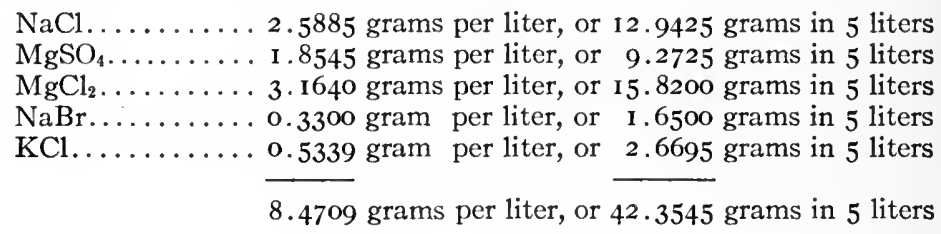

Up to this point the separation of the salt had been fairly regular, but now the difference of temperature between night and day became an influencing factor. At night nearly pure magnesium sulphate was deposited ; by day this was mixed with sodium and potassium chloride. With the mother liquor at a specific gravity of I.3082 to 1.2965 , there was formed a very mixed deposit of magnesium bromide and chloride, potassium chloride and magnesium sulphate, with the double magnesium and potassium sulphate, corresponding to the kainite of Stassfurt, Germany. A double chloride of magnesium and potassium similar to the carnallite of Stassfurt was also deposited. The mother liquor, which had again risen to specific gravity of $\mathrm{I} .3374$, contained only pure magnesium chloride.

The Bar Theory of Ochsenius. In 1877 Carl Ochsenius (37), following a previous suggestion of G. Bischof, sought to explain the formation of extensive salt deposits of great thickness by assuming that they were formed in a nearly enclosed lagoon or bay cut off from the main water body by a barrier beach or bar, across which the water was just able to pass. Concentration of the water within the lagoon and over the bar proceeds by evaporation, and as the water over the bar becomes denser and heavier it sinks and flows down the bar and into the lagoon. If the surface evaporation over the lagoon equals the inflow of salt-bearing waters, it is evident that precipitation of salt must result from the constant increase in salinity, and the depth of the salt deposit will depend on the original depth of the lagoon and on the length of time that these conditions obtain. The constant addition of salts to the water of the lagoon, brought about by the.influx of sea water and its evaporation from the surface of the lagoon, would result in the same concentration that is produced by evaporation of a given quantity of sea water, as in Usiglio's experiments. The same result would be obtained. In Usiglio's experiments, $\mathrm{NaCl}$ began to deposit when one liter of the water was evaporated to 0.095 , or about one-tenth 
of its original volume. At that time there were $38.45^{-1.58}$ or 36.87 grams of salts in 0.095 liters of water, which corresponds to 388 grams in I liter, or a salinity of 388 permille. The most saline body of water given in the list of salt lakes on p. I 54, i. $\mathcal{c}$., Tinetz Lake, has a salinity of only 289 permille, while the next body, the Karabugas Gulf, has a salinity of only 285 permille. It is evident that neither of these waters is saline enough to deposit salts, and this is known to be the case (Andrussow-3). On the other hand, 38.38 grams in 0.190 liter, or a salinity of 202 permille, marks the point at which calcium sulphate will be deposited. It is evident that such precipitation can take place in both the above water bodies, and that it may indeed take place in all of the nine lakes cited first in the list on page I $54_{4}$. That it does not so take place is in all probability due to the variation in composition of these bodies from normal sea water. Many of these lakes deposit magnesium or other sulphates, and some of them have deposited sodium chloride at a former time of greater salinity.

Calcium sulphate is a usual accompaniment of salt deposits occurring as gypsum or anhydrite, and forming alternating layers with the salt, as in the so-called annual rings (Jahresringe) of the Stassfurt and other salts, or as mixtures recognizable only on analysis. Only in rare cases is gypsum or anhydrite absent, as in the great deposits of Miocenic age at Vieliczka, where the salt is absolutely pure. As seen from the table of Usiglio, pure calcium sulphate is deposited first, and then sodium chloride with small admixtures of calcium and magnesium sulphate and some magnesium chlorides. If now, after a period of salt precipitation, the salinity of the water should become reduced by an unusual influx of sea water, salt deposition will cease, and after a while gypsum or anhydrite will form to be again succeeded by salt deposits. If, however, the bar remains closed for. a period after the precipitation of all the calcium sulphate, only pure salt will be deposited, and this will continue until the mother liquor is nearly depleted of sodium chloride (see the table). After this no more deposition is possible except through renewal of the water across the bar, and so it is evident that the deposition of pure salt is limited in thickness. It is apparent that very thick deposits of pure salt cannot be explained in this manner.

The influx of much water across the bar may bring with it silt, and this will be deposited first, the succession becoming. from below up, silt, gypsum and salt. With the silt the organisnis of the adjoining sea may enter the bay, but, owing to the rapid increase in 
density of the water, they will soon die, and their remains become embedded within the layer of silt.

The Bitter Lakes of Suez an example. A characteristic exam. ple of this type of deposit was formed in the Bitter Lakes on the Isthmus of Suez, and which before 600 B. C. formed the Heroöpolite Gulf, a continuation of the present Gulf of Suez and the Red Sea. After the gulf became separated by silting up to such an extent that the supply of water from the Red Sea just balanced the evaporation from the surface of the gulf, and the salinity was of corresponding magnitude, salt began to deposit, and continued until some time after complete separation from the Gulf of Suez, and transformation into the Bitter Lakes, when only the intensely saline mother liquor remained. When in I86I-1863 the present canal was cut through these lakes, a mass of salt $13 \mathrm{~km}$. long, $6 \mathrm{~km}$. broad and averaging $8 \mathrm{~m}$. in thickness, was found. In the center of Great Bitter Lake, this salt mass was estimated at 20 meters in thickness. The salt was of course quickly dissolved by the fresher waters of the canal which pass through these lakes, but until I869 the salt beds were still covered by a layer of mother liquor.

When discovered (Bader-4), the salt mass consisted of parallel layers of varying thickness separated by thin layers of earthy matter and gypsum. Soundings to a depth of $2.46 \mathrm{~m}$. showed 42 layers of similar composition and varying from 3 to $18 \mathrm{~cm}$. in thickness, while the earthy layers between them were only a few millimeters in thickness. At a depth of $1.47 \mathrm{~m}$. from the surface were found a bed of mixed powdery gypsum and clay o.I $12 \mathrm{~m}$. thick and a bed of pure powdery gypsum 0.07 meter thick. The clay layers were as a rule richly fossiliferous, containing the shells of numerous genera and species of molluscs now living in the Red Sea.

There is here illustrated a long succession of flooding and partial drying up of these Bitter Lakes. On the influx of the waters from the Red Sea, mud was deposited, followed quickly by deposition of gypsum. After this the salt crystallized out, with an admixture of magnesium sulphate. As the waters became concentrated, the animals perished and their shells sank to the bottom, where they became embedded in the growing deposit.

The amount of bittern salts in the mother liquor which covered the salt beds of these lakes until I869 was insufficient for the quantity of salt found deposited in these lakes. It must therefore be assumed that on the successive inundations from the Red Sea the mother liquor then present was partly carried out in diluted form, and that the quantity last found represented only the residue since the last flooding of the lakes and the closing of the bar. The 
amount of evaporation since that time was sufficient to lower the surface of the Bitter Lakes appreciably below that of the Red Sea

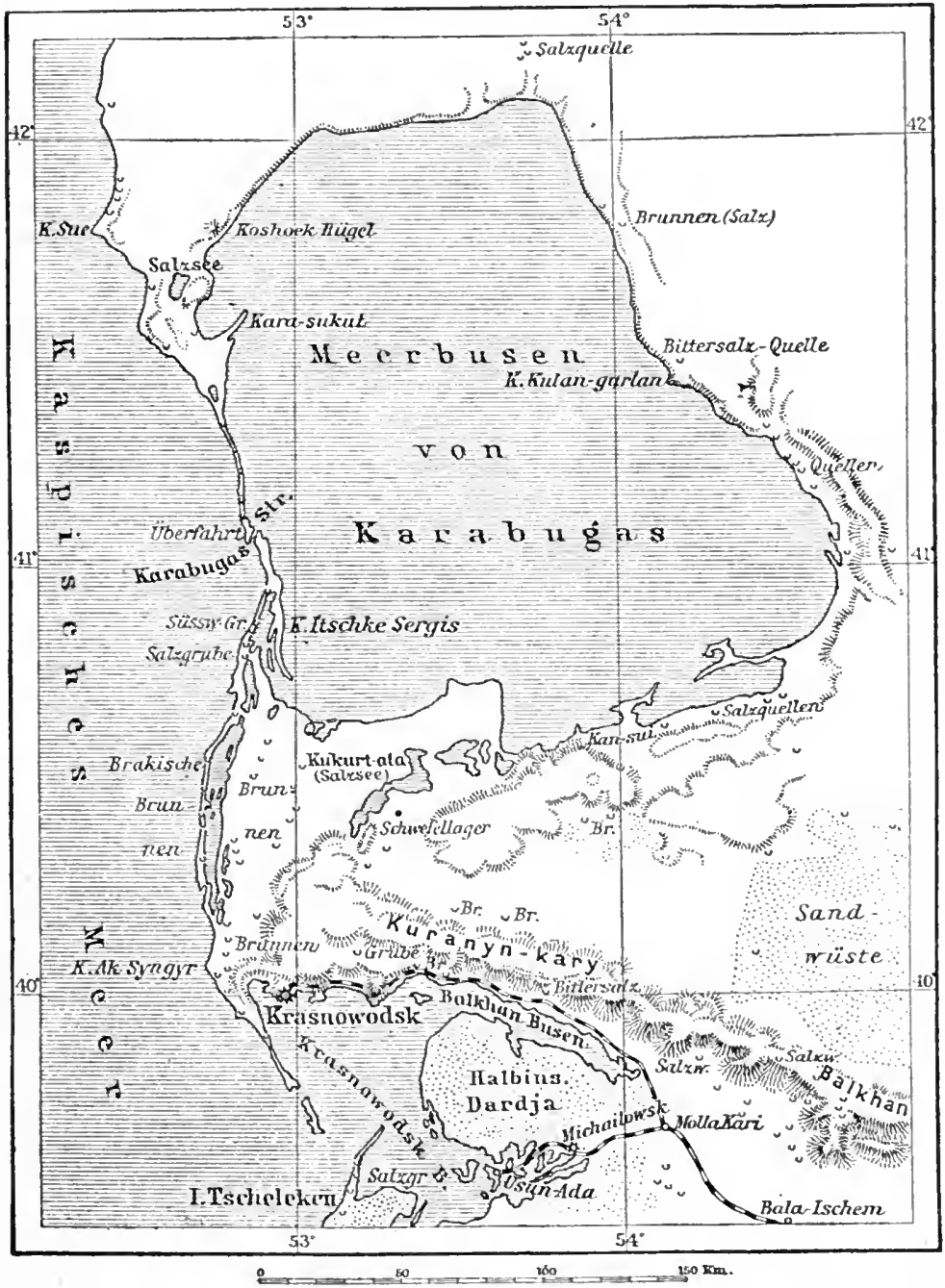

FIG. 68. Map of the Karabugas Gulf. (After von Seidlitz, Globus, I899.)

(high water), two thousand million cubic meters of water being ne:essary to raise the surface to the level of the canal. (Ochsenius$38: 164$. 
The Karabugas Gulf. The Karabugas Gulf on the eastern border of the Caspian Sea is frequently cited as a typical example of the salt lagoon, cut off from the main body of the Caspian Sea by a long, partly submerged bar. Ochsenius himself used it as an illustration. As we have seen, the salinity of this body of water, while sufficient for the deposition of gypsum, is not great enough for the deposition of salt. As will be seen by a reference to the analysis of the water of the Karabugas (p. I 58 ), which is an example of a sulphate chloride bittern, magnesium entirely replaces the calcium. This is also shown in the deposits at the bottom of this basin, where over an area of 1,300 square miles a deposit of Epsom salts (sulphate of magnesia) is formed, 7 feet thick and amounting to an estimated total of $\mathrm{I}, 000,000,000$ tons. (Fig. 68.)

This gulf further illustrates the enormous destruction of organisms due to the intense salinity, a destruction which would render all salt deposits of such a gulf highly fossiliferous. Andrussow calls attention to the large number of fish which are carried across the bar into the Karabugas, where they perish. "Their carcasses float about as long as the water flowing into the gulf moves them, after which they either sink to the bottom, or are driven onto the shore. The carcasses of Clupea, Atherina, Cyprinus, Lucioperca, Acipenser and Sygnathus piled upon the shores are partly eaten by the native birds, and the quantities of dead fish which lie upon these shores in March can be measured by the fact that the gulls at this season of the year feed only on the eyes of the fish, and do not even take the trouble to turn over the fish to get at the other eye." (Andrussow$3: 29$; and Walther-62:95.)

Among other organisms killed in the saline waters of this gulf, Cardium edule should be mentioned. This euryhaline organism abounded in the gulf before it reached the stage at which sulphates were deposited. The shells of this species occur in enormous number on the shores of the Karabugas. (Andrussow-3:33.)

It is a significant fact that all deposits of salt along the borders of the present seas, as well as inland, are found in regions of relative aridity; that, in other words, salt deposition demands a suffciently dry climate to allow an excess of evaporation over precipitation or influx. Thus salt deposits of all ages and occurrence are indicative of dryness of climate.

\section{Natural Salt Pans.}

Of the natural salt pans in the vicinity of the seashore, the Rann of Cutch on the northwestern coast of India is perhaps the 
best known. (Walther-6I:789.) This is a low-lying coastal area, flooded during the southwest monsoon period in some parts to the depth of I meter. The Rann is the true salt plane; it covers an area $300 \mathrm{~km}$. long and $100 \mathrm{~km}$. broad. It merges into flat planes free from vegetation, the so-called Put, and is surrounded and diversified by the sand-dune region, the so-called Thurr. Here the dunes are 25 to 130 meters high, with flat areas often carrying lakes up to 20 meters in depth, and this region is inhabited chiefly by foxes, jackals, wolves, rats, snakes, etc. In the region of the Rann proper animal life, as well as plant life, is exceedingly scarce. The smooth, flat surface of the Rann is composed of sandy clay, which is constantly kcpt moist by the included salt. The shallow pools scattered about on its surface are covered in winter by crusts of pure salt, generally only about $10 \mathrm{~cm}$., but occasionally over a meter in thickness.

The Nile delta, too, is characterized by a large number of salinas or natural salt pans. These extend along the coast from Abu Sir to Sheik Zayed, and owe their salt to the flooding from the Mediterranean and the rapid evaporation due to the desert climate of the coast. The salt is often covered by wandering sand dunes, which when they reach a great thickness become filled through efflorescence with crystals of gypsum 3-5 cm. long. These unite into heads I to 4 meters broad and from 0.5 to 1 meter in thickness.

On the borders of the Red Sea are a number of salinas. One, west of Amfila (Hanfela) Bay on the Abyssinian border, lies below sea-level, and is surrounded by a wall of gypsum. The streams flowing from the East Abyssinian Mountains into this depression evaporate, adding their contribution to the saline deposits. At Allolebod, on the southern coast of the Red Sea, the deposits in the natural pans show regular interstratification by layers of gypsum, similar to the annual rings of the Stassfurt salt. These layers mark the periodic inundation of the salt pans. Though extensive, these salt deposits can in no wise be compared with those of past geologic periods. (Grabau-19.)

\section{Evaporation of Cut-offs from the Sea.}

When, in an arid region a portion of an indentation of the sea is cut off, by tectonic movements, by delta deposits, or otherwise, the waters thus separated may evaporate, leaving a salt sea or salina in which the salt of the original water body becomes concentrated. The Salton-sink region in the Lower Colorado Pasin of California is an example of such a cut-off. The delta built by the Colorado 
River into the former upper end of the Gulf of California, cut off the head of this water body from the remainder of the Gulf, converting it into a separate lake. This was at first converted into a fresh or brackish water lake by the continued influx of the river water, with a corresponding rise of the level as indicated by the traces of old shore-lines 40 feet or so above the present sea-level, the deposit of calcium carbonate and the presence of numerous shells of fresh or brackish water molluscs. The Colorado repeatedly changed its mouth, discharging at intervals into the Gulf of California. Whenever this occurred the lake began to shrink, the waters evaporating under the drying influence of the Westerlies descending from the high coastal ranges. The Salton-sink represents the present concen-

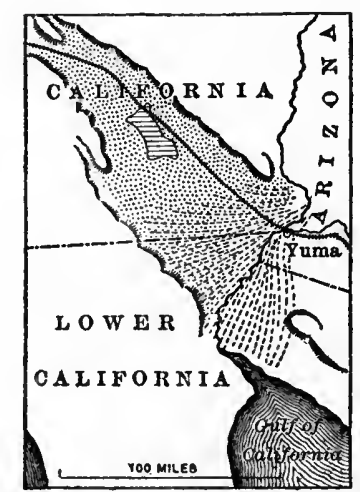

Fig. 69. Sketch map of the Salton Sink Region. (After Davis.)

tration of these waters, the bottom of this lake being 273.5 feet below mean sea-level (Freeman and Bolster--17:46-5I). Before the recent overflows of the Colorado (I891, I905, I906-07) the waters of the Salton Lake were intensely saline and its shores were fringed with broad belts covered with white crusts of salt. The author $(19: 3,4)$ has estimated that the salt resulting from the complete evaporation of the sea waters originally cut off from the head of the Gulf of California would form a bed $12.5 \mathrm{~m}$. thick over the area of the present Salton Lake. (Fig. 69.)

\section{NON-CALCAREOUS TERRESTRIAL PRECIPITATES.}

\section{Salt Lakes and Salinas.}

Salt lakes and salinas are characteristic features of the arid regions of the earth, and they occur in nearly every country. Those of the drainless basin of the Caspian have long been well known. 
Of these, Elton Lake, a natural Bittern witl a salinity of 27 I permille, furnishes a good example. It lies in the flat clayey steppe, has clay banks, a length of $18 \mathrm{~km}$. and a wilth of $14 \mathrm{~km}$. As shown by the analyses in the table (p. ${ }_{5} 8, \mathrm{~B}_{2}$ ), it contains only o.I per cent. of $\mathrm{Ca}$, but 17.55 per cent. of $\mathrm{Mg}$, while the sodium is only I1.27 per cent. This is due to the fact that a part of the sodium has crystallized out as $\mathrm{NaCl}$, from a liquor formerly of much higher salinity. Two layers of salt are found at the bottom of the lake, the lower $2.5 \mathrm{~cm}$., the upper 4 to $5 \mathrm{~cm}$. thick. Analyses of these salts gave the following:

Upper Bed Lower Bed

\begin{tabular}{|c|c|c|}
\hline $\mathrm{NaCl} \ldots . . .$. & 87.08 & 90.50 \\
\hline $\mathrm{MgCl}_{2} \ldots \ldots \ldots \ldots \ldots \ldots \ldots \ldots \ldots \ldots$ & 3.25 & 2.17 \\
\hline $\mathrm{MgSO}_{4} \ldots \ldots \ldots \ldots \ldots \ldots \ldots \ldots \ldots \ldots$ & 0.53 & 0.47 \\
\hline $\mathrm{CaSO}_{4} \ldots \ldots \ldots \ldots \ldots \ldots \ldots \ldots \ldots \ldots \ldots \ldots \ldots$ & I. 13 & I. 49 \\
\hline \multirow[t]{2}{*}{ 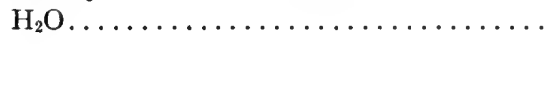 } & 6.85 & $3 \cdot 51$ \\
\hline & 99.84 & 98.14 \\
\hline
\end{tabular}

Into this lake flows a small stream, the Chara Zacha, which annually carries enough salt into the lake to make a crust $4 \mathrm{~cm}$. in thickness.

Baskunchak Lake (Walther-6I:787), also in the Astrakhan district of Russia, north of the present Caspian, is another example. It lies on the eastern border of the Volga and has a length of $16 \mathrm{~km}$. and a breadth of $9 \mathrm{~km}$. Analysis by Goebel (I) and Nikitinsky (2) gave the following composition of the brine:

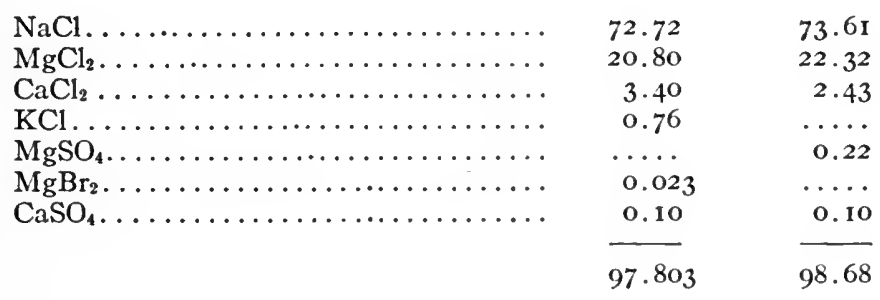

In the center of the lake was found a salt bed averaging $160 \mathrm{~cm}$. in thickness, the thickness at 500 meters from shore being considerably over 2 meters. Eight distinct layers are recognizable, separated by layers of clay. The upper layer contained 91 per cent. $\mathrm{NaCl}$, the second 95.4 per cent. $\mathrm{NaCl}$, the fourth 97.2 per cent., the eighth 
97.82 per cent., and below this lies a coarsely crystalline salt $1.5 \mathrm{~m}$. thick and of perfect transparency containing 98.7 per cent. $\mathrm{NaCl}$. The upper layers consist of small crystals which are dissolved during the spring rains. The larger crystals of the deeper layers remain undissolved and further increase in size during the summer, and thus the deeper layers are constantly becoming poorer in magnesium chloride and as the salt becomes purer it also increases in density.

This region is characterized by more than a hundred lakes of varying salinity, many of which deposit very pure rock salt. Many of these are covered by drifted sands which have dried up the lakes and drawn away the bitterns, so that the salt under the sand is perfectly dry and very pure. Some of these lakes of the Astrakhan district deposit magnesium chloride, others magnesium or sodium sulphate, and others still, gypsum.

South of the Caspian, in Persia, is an extensive desert nearly 800 miles in length and in places over 200 miles in width, covered with salinas and dry salt, and dune sand areas. Of the salinas, that of Darya in Namak may be noted. For $2 \mathrm{~km}$. from the margin of the salina the ground is muddy and contains the skeletons of animals which probably died of thirst ; beyond this a zone of earthy salt follows, with the appearance of a frozen swamp during a thaw. Six to eight kilometers from the border begins the pure salt, in the form of irregular polygonal masses 20 to $90 \mathrm{~cm}$. in length. The crust of salt beyond this extends for $40 \mathrm{~km}$. and is from 2 to 3 meters thick, and very hard.

The Great Salt Plain of Lop, in Eastern Turkestan, is described by Huntington (28) as resembling "the choppiest sort of sea with whitecaps a foot or two high ; and frozen solid." He says: "When we camped in what we hoped was a soft spot and tried to drive in the iron tent-pegs, most of them bent doublc. We had to use an axe to hew down hummocks of rock salt a foot high before we could get places smooth enough for sleeping" (p. 25I). The roughness of this salt plain is explained as follows: "During the longcontinued process of drying up the ancient lake of Lop deposited an unknown thickness of almost pure rock salt. When the salt finally became dry it split into pentagons from five to twelve feet in diameter, the process being similar to that which gives rise to mud-cracks. The wind, or some other agency, apparently deposited dust in the cracks; when rain or snow fell, the moisture brought up new salt from below; and thus the cracks were solidly filled. When next the plains became dry the pentagons appeared again. This time the amount of material was larger and the penta- 
gons buckled up on the edges and became saucer-shaped. By countless repetitions of this process, or of something analogous to it, the entire lake-bed became a mass of pentagons- with ragged, blistered edges." (Huntington-28:252-3.) In the salt of this plain Huntington found "a half-buried plover, dead for centuries-ever since the time when the bottom of the lake was still soft." Aside from this, and from a few deeply buried roots of some reeds, Huntington found no signs of life for nearly a hundred miles of his journey in this region.

In the African deserts salinas are equally characteristic. Those of the Bilma and Kalala oases in the Sahara supply much of Central Africa with salt. A new crust of salt several inches thick forms over these lakes in a few days after the harvesting of the preceding salt crop.

Salt deposited by Katwee Lake north of Albert Edward Nyanza Lake in Central Africa contains 81.7\% NaCl, 5.32\% $\mathrm{Na}_{2} \mathrm{SO}_{4}$, $8.43 \% \quad \mathrm{~K}_{2} \mathrm{SO}_{4}, 2.46 \% \quad \mathrm{Na}_{2} \mathrm{CO}_{3}$, 0.15\% $\mathrm{Fe}_{2} \mathrm{O}_{3}$, and $0.82 \% \mathrm{H}_{2} \mathrm{O}$. In the Kalahari, salinas are a characteristic feature. (Passarge-43.)

Calcium sulphate in the form of gypsum or anhydrite is, as we have seen, a frequent accompaniment of the deposits of sodium chloride in the cut-off lagoons of the sea and in normal salt lakes. Gypsum of undoubted marine origin has been found on some small coral islands in the Pacific, where it constitutes a residue formed by the evaporation. of lagoons, and may reach a thickness of 2 feet. Gypsum may also be deposited by concentrated lake water, as in the case of Lake Chichen-Kanab in Yucatan. Gypsum likewise forms on an extensive scale in the playas or sebchas of desert regions. At Fillmore, Utah, such a deposit covers an area of 2 square miles and has been opened to a deptin of 6 feet without reaching bottom. (Russell-48:84.) In general it accumulates in the center of the basin in the form of gypsum, rendering the bottom and sides of the basin impervious and so forming a foundation on which the salt may accumulate, above which, in turn, is formed the impervious cover of anhydrite. Such deposits in desert regions are often of considerable thickness. The great depression of the Ued Rir, which merges from the south into the Schott Mel Rir, carries a flooring of gypsum which extends at least to a depth of 50 meters, and beneath which is often a great accumulation of water under strong hydrostatic pressure. Piercing of one of these gypsum floors in South Tunis in 1885 , at a depth of $90 \mathrm{~m}$., discovered a well of water which rushed up with such force as to hurl blocks weighing $12 \mathrm{kgm}$. into the air. (Ochsenius $-4 \mathrm{I}: 38$.)

In many sections the salinity is not sufficient to produce solid 
salt beds whereupon crystals of salt form in the clayey deposits left on drying of the water bodies. Salt crystals or the molds they occupied are common in many ancient deposits, for which a similar origin may be assumed.

Salt is deposited in the shallow marginal portions of the great Salt Lake of Utah in spite of the fact that the salinity of the lake as a whole is only 230.4 permille. Greater concentration exists, of course, in the shallow marginal pools. In South America salinas are extensively developed in Patagonia and elsewhere. Darwin ( $14: 76$ ) describes one of these as consisting in winter "of a shallow lake of brine, which in summer is converted into a field of snow-white salt. The layer near the margin is from four to five inches thick, but toward the center its thickness increases. This lake was two and a half miles long and one broad. Others occur in the neighborhood many times larger, and with a floor of salt, two and three feet in thickness, even when under water during the winter." Analysis of this salt gave only 0.26 per cent. of gypsum and 0.22 per cent. of earthy matter. The borders of these salinas are formed of mud in which crystals of gypsum up to three inches in length occur. Crystals of sulphate of soda lie scattered about on the surface, and among these the mud was thrown up by numbers of some kind of worm, upon which the flamingos, which frequent these salinas, seem to feed. As already noted, this salt is extensively deposited on the floor of the Karabugas Gulf, where a layer seven feet thick covers an area of I,300 square miles. Shunett Lake of Siberia also deposits this salt.

The "Salitrales" of Patagonia. These should be mentioned in this connection. They are most abundant near Bahia Blanca. "The salt here, and in other parts of Patagonia, consists chiefly of sulphate of soda with some common salts. As long as the ground remains moist in the salitrales (as the Spaniards improperly call them, mistaking this substance for saltpetre), nothing is to be seen but an extensive plain composed of a black, muddy soil, supporting scattered tufts of succulent plants. On returning through one of these tracts, after a week's hot weather, one is surprised to see square miles of the plain white, as if from a slight fall of snow, here and there heaped up by the wind into little drifts. This latter appearance is chiefly caused by the salts being drawn up, during slow evaporation of the moisture, round blades of dead grass, stumps of wood, and pieces of broken earth, instead of being crystallized at the bottoms of the puddles of water. The salitrales occur either on level tracts elevated only a few feet above the level of the sea, or on alluvial land bordering rivers." (Darwin-I4, Chapter IV.) At a distance of some 
miles from the sea the incrustations on the plain consist chiefly of sulphate of soda, with only seven per cent. of common salt. while nearer to the coast the common salt increased to 37 parts in a hundred.

\section{Deposits of Sodium Sulphate and Carbonate.}

In the Great Basin region of North America soda lakes are not uncommon. In Wyoming lakes of this type form deposits on their floors which contain 40 to 45 per cent. sodium sulphate, alternating with clay layers. The Donney lakes contain a bed of soda 2 to 3 meters thick. At Wilmington a bed of natural soda more than four meters thick was found at the bottom of the lake. Similar sediments are found in Mono Lake, California; Albert Lake, Oregon; and Owens Lake, California. Sevier Lake, Utah, was covered in January, I 880 , by a crust of salt ro to $\mathrm{I} 2 \mathrm{~cm}$. thick, beneath which the following sediments occurred in descending order:

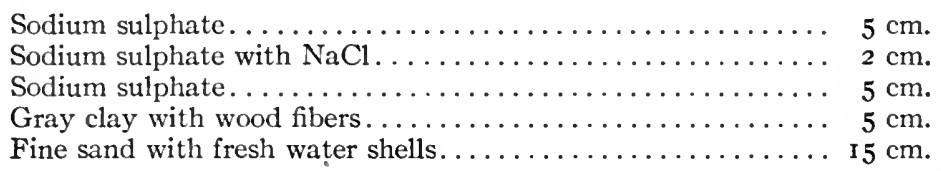

This lake is at times entirely dry. Other lakes depositing sodium sulphate are Altai Beisk, Domoshakovo, Kisil-Kull, and Schunett lakes in Siberia. Great Salt Lake likewise deposits sodium sulphate during the winter, even casting it up in heaps upon the shore (Gilbert-I8). Lakes depositing alkaline carbonates are also common. They occur in Hungary, Egypt, Armenia, Venezuela, and in Utah, California, and Nevada, especially in the playas of the last named state. Those of the Soda Lakes near Ragtown, Nevada, may be taken as typical, they having been worked for commercial purposes. The sodium carbonate of these lakes is but slightly contaminated by sodium sulphate and chloride. These soda lakes gave the following analyses, the first from Big, the others from Little Soda Lake, the last being market soda (Clarke-IO:I9I; 226):

(I)

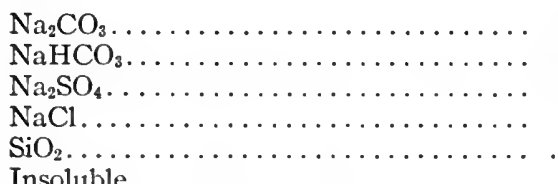

45.05

$3+.66$

1.29

I. 6 I 80

$$
\frac{16.19}{99.60}
$$

(2) 44.25 34.90

0.99

I. IO

...

2.81

I5.95

100.00
(3) 52.20 25.05 5 . 10 $3 \cdot 3 \mathrm{I}$ 0.27 14.16 
These soda lakes also deposit crystals of gaylussite $\left(\mathrm{CaCO}_{3} \cdot \mathrm{Na}_{2} \mathrm{CO}_{3}\right.$ $5 \mathrm{H}_{2} \mathrm{O}$ ), although the analysis of the water shows no calcium, the minute quantities of this element brought in by springs, etc., probably combining at once to form this mineral (Clarke-IO:I9I; 227). The carbonates deposited by these lakes are probably three in number: thermonatrite $\left(\mathrm{Na}_{2} \mathrm{CO}_{3} \cdot \mathrm{H}_{2} \mathrm{O}\right)$, natron $\left(\mathrm{Na}_{2} \mathrm{CO}_{3} \cdot 1 \mathrm{IOH}{ }_{2} \mathrm{O}\right)$, and trona or urao $\left(\mathrm{Na}_{2} \mathrm{CO}_{3} \cdot \mathrm{NaHCO}_{3} \cdot 2 \mathrm{H}_{2} \mathrm{O}\right)$. The proportion of these varies, but the third is the most important. This is the first salt crystallizing out on fractional crystallization of the waters of Owens Lake, Inyo County, California, where sodium carbonate is manufactured on a commercial scale. The following analysis shows the composition of the salts of successive crystallizations which took place during the experiments (Chatard, quoted by Clarke-I0:192; 228):

Table showing successize crystallization, resulting from the evaporation of the waters of Owens Lake.

\begin{tabular}{|c|c|c|c|c|c|c|}
\hline Stage of Crystallization & $\begin{array}{l}\text { Nat'l } \\
\text { Waters }\end{array}$ & $\begin{array}{l}\text { First } \\
\text { Crop }\end{array}$ & $\begin{array}{l}\text { Second } \\
\text { Crop }\end{array}$ & $\begin{array}{l}\text { Third } \\
\text { Crop }\end{array}$ & $\begin{array}{c}\text { Fourth } \\
\text { Crop }\end{array}$ & $\begin{array}{l}\text { Fifth } \\
\text { Crop }\end{array}$ \\
\hline \multicolumn{7}{|l|}{$\begin{array}{l}\text { Specific gravity of water or } \\
\text { mother liquor .......... }\end{array}$} \\
\hline At temperature (C).......... & $25^{\circ}$ & $27.9^{\circ}$ & $25^{\circ}$ & $26.25^{\circ}$ & $35.75^{\circ}$ & $\begin{array}{r}\mathrm{I} .30 \\
\mathrm{I} 3.9\end{array}$ \\
\hline Salin & 77.098 & $385 \cdot 49$ & & $\cdots \cdots$ & & \\
\hline Volume..... & I . 00 & 0.20 & . & $\cdots \cdots$ & $\cdots$ & . \\
\hline \multicolumn{7}{|l|}{ Composition: } \\
\hline $\mathrm{H}_{2} \mathrm{O} \ldots \ldots$ & $\cdots \cdots$ & $14 \cdot 51$ & $4 \cdot 33$ & $3 \cdot 43$ & 2.24 & I I.03 \\
\hline$\ldots \ldots$ & $34 \cdot 95$ & $43 \cdot 75$ & 22.84 & 18.19 & $\mathrm{I} 2.5 \mathrm{I}$ & $55 \cdot 0$ \\
\hline $\mathrm{NaHCO}_{3}$ & $7 \cdot 40$ & 30.12 & 10.53 & 4.06 & 3.88 & 4.09 \\
\hline$\ldots \ldots \ldots$ & $14 \cdot 3^{8}$ & 3. I 8 & 25.44 & 26.70 & I9.0I & $5 \cdot 70$ \\
\hline$\ldots \ldots \ldots$ & 38.16 & $7 \cdot 44$ & 35.06 & $45 \cdot 59$ & 60.99 & I9. I6 \\
\hline$\ldots \ldots \ldots$ & 0.63 & 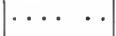 & $\cdots$ & ( & $\ldots \ldots$ & \\
\hline$\ldots \ldots$ & $\ldots \ldots$ & $\cdots \cdots$ & $\cdots \cdots$ & $\cdots$ & $\ldots \ldots$ & $2 . c$ \\
\hline $\mathrm{KCl} \ldots$. & 4.07 & I. .07 & I. I 2 & I. 14 & I . 2 I & 2.93 \\
\hline$(\mathrm{CaMg}) \mathrm{CO}_{3} \ldots$ & 0.08 & 0.14 & & & & \\
\hline$(\mathrm{AlFe})_{2} \mathrm{O}_{3} \ldots \ldots \ldots \ldots \ldots$ & 0.05 & 0.01 & & & $0.0 \mathrm{I}$ & 0.02 \\
\hline $\mathrm{SiO}_{2} \ldots \ldots \ldots \ldots \ldots \ldots$ & 0.28 & 0.055 & 0.09 & 0.06 & 0.05 & o. 16 \\
\hline & $\ldots \ldots \ldots$ & 0.032 & & & & \\
\hline Insoluble....... & o & 0.078 & & & & \\
\hline Total. & 100.00 & I $00.3^{85}$ & $99.4 \mathrm{I}$ & 99.17 & 99.90 & IOO.I. I \\
\hline
\end{tabular}

In Egypt there are 9 soda lakes, the largest io $\mathrm{km}$. long, $3 \mathrm{~km}$. broad, and 6 meters deep (Walther-6r:790). The salt forming on 
the bottom of these lakes consists of a lower bed 5 meters thick with much sodium carbonate in its composition and an upper layer also 5 meters thick composed largely of sodium chloride. The smaller lakes generally dry up, only salt encrustations remaining, while the sand of the surrounding desert is underlain by a dark gray clay containing gypsum and sodium salts.

\section{Borax AND Borates.}

Borates are deposited by some lakes of which Borax Lake, Lake County, California, is a typical example. The analysis of the water is given on $\mathrm{P} . \mathrm{I} 59, \mathrm{~F}_{4}$, the mineral contents of the water being chiefly sodium carbonate and sodium chloride, with borax (Sodium biborate, $\mathrm{Na}_{2} \mathrm{~B}_{4} \mathrm{O}_{7}$ ) next in importance. The bed of the lake is occupied by a large mass of crystallized borax of great purity. A neighboring smaller lake, Hachinchama, furnished a larger supply of borax, which probably came from neighboring hot springs.

Deposits of borates are forming in a number of "marshes" or playa lakes of Nevada and California. Rhodes' marsh, Esmeralda County, Nevada, has a central area of common salt surrounded by a deposit of sodium sulphate, outside of which borax and ulexite $\left(\mathrm{NaCaB}_{5} \mathrm{O}_{2} \cdot 8 \mathrm{H}_{9} \mathrm{O}\right)$ occur. According to M. R. Campbell $(8: 40 \mathrm{I})$ these salts of similar lakes in California are leached from beds of Tertiary sediments. Searles's marsh or borax lake, in San Bernadino County, California, has furnished the following succession through borings (De Groot-15 :535; Clarke-10: 199; 235):

\section{Surface}

I. Salt and thenardite $\left(\mathrm{Na}_{2} \mathrm{SO}_{4}\right) \ldots \ldots \ldots \ldots \ldots \ldots \ldots, 2$ feet

2. Clay and volcanic sand, with some hanksite: $\mathrm{Na}_{22} \mathrm{~K}\left(\mathrm{SO}_{4}\right)_{9}$

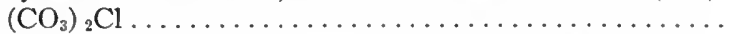

3. Volcanic sand and black clay, with bunches of trona $\mathrm{Na}_{3} \mathrm{H}$ $\left(\mathrm{CO}_{3}\right)_{2} .{ }_{2} \mathrm{H}_{2} \mathrm{O} \ldots \ldots \ldots \ldots \ldots \ldots \ldots \ldots \ldots \ldots \ldots \ldots \ldots \ldots$

4. Volcanic sand, containing glauberite $\mathrm{Na}_{2} \mathrm{Ca}\left(\mathrm{SO}_{4}\right)_{2}$; thenardite, and a few crystals of hanksite..............

5. Solid trona overlain by a thin layer of very hard material

6. Mud, smelling of hydrogen sulphide and containing laycrs of glauberite, soda, and hanksitc.................

7. Clay, mixed with volcanic sand and permeated with hydrogen sulphide............................ $230+$ feet

Borax is chiefly found in the top crust or crystallized in the water which sometimes accumulates in the depressions of the bed (Clarke10). The layer is reproduced by slow degrees, through capillary action, which brings up the soluble salts from below. Some 20 dis- 
tinct mineral species have so far been obtained from the deposits (see Clarke-10:199-200; 235), mostly sulphates, borates, and carbonates, with some chlorides, soda niter $\left(\mathrm{NaNO}_{3}\right)$, and ammonium salts. In the southern part of San Bernardino County, California, near Daggett, occurs a solid bed of colemanite $\left(\mathrm{Ca}_{2} \mathrm{~B}_{6} \mathrm{O}_{11} \cdot 5 \mathrm{H}_{2} \mathrm{O}\right)$ from 5 to $3 \mathrm{O}$ feet in thickness, highly crystalline, and interstratified with lake sediments. At one end it is much mixed with sand, gypsum, and clay, suggesting that it had been laid down at the edge of an evaporating sheet of water. Colemanite was originally obtained from Death Valley Desert, California. The Mohave Desert, on the borders of California and Nevada, and the Atacama desert of South America have in recent times been the chief sources of boron compounds, the boron in these deposits having probably been supplied by hot springs and solfataras of volcanic origin. In the South American region, the principal mineral is ulexite $\left(\mathrm{NaCaB}_{5} \mathrm{O}_{9}\right.$. $\left.8 \mathrm{H}_{2} \mathrm{O}\right)$.

In Tuscany deposits of borates are formed on an extensive scale from emanations of fumaroles or jets of steam issuing from the ground. The deposits concentrate in lagoons, forming orthoboric acid or sassolite $\left(\mathrm{H}_{3} \mathrm{BO}_{3}\right)$, ammonium borate or larderellite $\left(\left(\mathrm{NH}_{4}\right)_{2} \mathrm{~B}_{8} \mathrm{O}_{13} \cdot 4 \mathrm{H}_{2} \mathrm{O}\right)$; borocalcite or bechilite $\left(\mathrm{CaB}_{4} \mathrm{O}_{7} \cdot 4 \mathrm{H}_{2} \mathrm{O}\right)$, the hydrous ferric borate; lagonite $\left(\mathrm{Fe}^{\prime \prime \prime}{ }_{2} \mathrm{~B}_{6} \mathrm{O}_{12} \cdot 3 \mathrm{H}_{2} \mathrm{O}\right)$, and the ammonium compound boussingaultite $\left(\left(\mathrm{NH}_{4}\right)_{2} \mathrm{Mg}\left(\mathrm{SO}_{4}\right)_{2} \cdot 6 \mathrm{H}_{2} \mathrm{O}\right)$. In the most concentrated of the lagoons the orthoboric acid $\left(\mathrm{H}_{3} \mathrm{BO}_{3}\right)$ amounted to 19.3 grams per liter.

From Tibet borax deposits have been known since very early time. In the lake plain of Pugha, in Ladakh, the deposits occur at an elevation of 15,000 feet above the sea. The deposit covers an area of about 2 square miles and has an average depth of 3 feet. It is formed by hot springs which issue at this elevation with a temperature ranging from $54^{\circ}$ to $58^{\circ} \mathrm{C}$. The deposit is impure, other minerals, including gypsum, occurring with it.

\section{Deposits of Nitrates.}

Soda niter, or Chili saltpeter $\left(\mathrm{NaNO}_{3}\right)$, is found in the deposits of Searles's Marsh and in various other parts of southern California, especially around Death Valley, and along the boundary between Inyo and San Bernardino counties, forming beds associated with the later Eocenic clays. In Searles's Marsh it is associated with the borates, and the same holds true for the occurrences in the Atacama and Tarapaca deserts, northern Chile. Here are found the largest known deposits of nitrates in the world, the amount being officially 
estimated at 2.316 millions of metric quintals $(254,760,000$ short tons). The niter fields lie between 50 and 100 miles from the coast, and at elevations exceeding 2,000 feet. The crude sodium nitrate or "caliche" occurs in deposits scattered over a large area and is associated with salt and ulexite. A section of one of the "calichera" or niter deposits in the Atacama Desert, 50 miles west of Taltal, shows (Clarke-I0:207; 242):
1. Sand and gravel..................
oft. $1 / 2$ inch
2. "Chusca," a porous, earthy gypsum........ o ft.
6 inches
4. "Costra," a low grade caliche, containing much sodium chloride, feldspar and earthy matter .................... I to $3 \mathrm{ft}$.
5. "Caliche"................... I to $3 \mathrm{ft}$.
6. "Coba," a clay................. +3 inches

The caliche varies in its percentage of $\mathrm{NaNO}_{3}$ from 31.9 to 56.25 . Sometimes it contains up to $7 \% \mathrm{CaSO}_{4}$, at others up to $10 \%$ or over $\mathrm{MgSO}_{4}$, and again up to $34.6 \% \mathrm{Na}_{2} \mathrm{SO}_{4}$. Insoluble impurities may range as high as $45 \%$ or over. No potassium salts appear in these deposits, but anhydrite, gypsum, epsomite, halite and other minerals are associated with the nitrates.

In the Tarapaca desert the bed of "caliche" is from 4 to 12 feet thick. Other localities are known in South America, but they are of much less importance. Potassium nitrate, or saltpeter, is found as an immense deposit near Cochabamba, Bolivia, associated with borax. It contains $60.7 \% \mathrm{KNO}_{3}, 30.7 \% \quad \mathrm{Na}_{2} \mathrm{~B}_{4} \mathrm{O}_{7}$, and traces of $\mathrm{NaCl}, \mathrm{N}_{2} \mathrm{O}$ and some organic matter.

\section{Other Minerals Deposited Under Desert Climates.}

Among the minerals known to be found under conditions of inadequate rainfall is carnotite, a more or less impure hydrated vanadate of uranium and potash. It is found as a yellow crystalline powder or in loosely coherent masses, and contains radium. It occurs somewhat abundantly in Montrose County and elsewhere in Colorado, and has been found in the Mauch Chunk red shale of Pennsylvania-a formation formed under comparatively arid conditions. (Wherry-69.)

\section{ORIGIN OF THE SALINE DEPOSITS.}

The source of the various saline deposits is a subject of considerable importance, since it promises to throw light on the condition 
of accumulation of ancient deposits of this type, and hence to furnish a clue to the physiographic characters of the region at the time of such deposition. In general, we may divide the deposits of salts into those abstracted from the hydrosphere, either directly deposited from the water or secondarily redeposited after leaching, and those of chemical origin, $i$. $e$., formed by reactions of salts with each other.

\section{Sources of Sodium Chloride.}

Marine. Practically all deposits of sodium chloride may be tracel back to the ocean water as their original source. Direct deposition by evaporation and concentration of sea water is, however, not the only mode of origin of such salts, although many atthors, following Ochsenius, have so regarded it. The bar theory has already been discussed, and its application to the origin of many saline deposits has been indicated. It has been shown that such deposition can take place only in arid regions. where evaporation concentrates the sea water within a nearly cut-off basin, to the extent required for the deposition of the salts, and holds it at such a state by removing a quantity of water equal to that brought by the feeding current from the sea. In order that such a feeding may be accomplished, it is necessary that the saltdepositing bay be in the vicinity of a constant source of supply, $i$. $c$., the ocean or an inland saline sea of vast dimensions, like the Caspian. In such an ocean or inland sea, deposits of clastic and organic character would accumulate, so that for every great salt deposit formed in the neighborhood of the sea by concentration of sea water, there should be a corresponding fossiliferous series of normal marine type of sediments. Furthermore, as shown by the deposits in the Bitter Lakes of Suez, and the Karabugas Gulf, the deposits formed within the natural salt pan will be highly fossiliferous, full of the remains of the organisms of the contemporaneous sea from which the supply of salt water was derived. These two criteria are the most significant, and when they fail, as in the case of the salt deposits of the Mid-Siluric (Salinan) of North America, these deposits cannot be regarded as the results of direct evaporation of sea water. (Grabau-I9.)

Leaching of Salt from Older Formations and Its Segregation. Extensive salt deposits may form by the leaching of the salt of an older saliferous formation and its redeposition within a drainless basin by concentration through evaporation. That such salt deposits are now going on is believed to be the case in a number of regions. 
A large part of the salt of the Dead Sea is said to be derived through leaching of an older salt bed.

A far more important, because more universal, source of salt is found in the imprisoned or connate waters of the older marine sediments. When sediments carrying such water are exposed by erosion, their saline contents will be drawn to the surface by capillarity and the evaporation of the water. It is obvious that this can proceed on an extended scale only in arid districts, where meteoric waters play but a minor part. The salt from the fossil sea water will form an efflorescence on the surface of the rocks, where it will remain until removed by the wind or rain. If the region is a drainless basin the salt redissolved by the rain will be carried to the center of a neighboring depression, where it will accumulate on evaporation of the water. Salt carried by wind may be deposited anywhere within or without the basin.

The quantity of salt which is furnished by various ancie:nt marine sediments depends to a large degree upon the pore space of the rock. As we have seen (page 140), this is sometimes as high as $60 \%$ or over, but more generally falls below 40 . If we take $35 \%$ as an average measure, and take the salinity of the former ocean as equal to that of to-day, $i . e ., 35$ permille, we can readily see that marine sediments include about $\mathrm{I} \%$ of sea salt, which is threefourths $\mathrm{NaCl}$. A marine formation, which has a thickness of $\mathrm{I}, 000$ meters, as in the case of the Jura of Europe, could furnish a bed of salt approximately io meters thick and extending over the entire area covered by such a formation. If such salt becomes concentrated into a smaller area, the deposit will, of course, be of a proportionally greater thickness.

Analyses of modern marine sediments have shown an even greater salt content, due to electrolytic separation of the salt from sea water. Thus the deep-sea red clay contained from 6.8 to $8 \%$ of salt. Diatomaceous ooze contained $5.4 \%$; Antarctic glacial clay, I.9 to $3.7 \%$; Globigerina ooze, I.o to $3.4 \%$. These differences in amount are due to differences in absorption power of the various sediments. (Andrée-2 :355.)

The leaching of the connate salts from old sediments furnishes the rivers with their load of salt in solution; as an example may be quoted the high percentage of chlorine which rises to $32.63 \%$ in the Rio de los Papagayos of Argentina. In this same river the water carries $26.48 \%$ of sodium,* its total salinity being 9.185 permille. This water runs into the ocean, but if sinilar water runs into

* This percentage is of the total solids, corresponding to 2.997 and 2.432 permille, respectively. See table pp. 162-3. 
a drainless basin it is evident that the salt will be deposited on evaporation of the water, and that such deposits are limited in thickness only by the depth of the basin and the continuation of erosion of the tributary area. Salts deposited in this manner will, of course, be free from marine organic remains, though terrestrial organisms or brine animals may be enclosed. The area tributary to this basin will show extensive erosion during the period of formation of the salt deposits, while the salt beds themselves rest on the formation elsewhere eroded, and will be covered by a formation which elsewhere rests on the eroded surface of the formation below the salts, or on an earlier one.

Besides the segregation of the salts in desert regions through streams, due credit must be given to the wind. Where rock surfaces are covered with an efflorescence of salt, the dry wind may sweep it away and redeposit the salt particles mixed with clay or dust. In rare cases large particles of salt may be picked up by the wind and dropped elsewhere, as in the case of the remarkable salt hail which fell near the Lucendro bridge of the Gotthard road on August 30, 1870, at II A. M. (Kengott, quoted by Walther-6o.) Saline clays may be deposited at any altitude by the wind, while playa surfaces may be dusted over with a layer of salt particles, which adhere to the surface rendered damp by the presence in the clay of hygroscopic salts.

Shallow salt lakes or playas may be dried by a covering of desert sands, which will sponge up the mother liquor and so leave only the pure salt behind. On reaching the surface of the covering sand dunes through capillary action, the efflorescing salts may be scattered far and wide by the winds. Desert salts are probably, as a rule, free from the potash salts.

These mother liquor salts crystallize, as a rule, only at very high or very low temperatures. Thus kieserite $\left(\mathrm{MgSO}_{4} \cdot \mathrm{H}_{2} \mathrm{O}\right)$ crystallizes out in the laboratory only on evaporation of the solution at temperatures above $100^{\circ} \mathrm{C}$., while a solution of carnallite $\left(\mathrm{KMgCl}_{3} \cdot 6 \mathrm{H}_{2} \mathrm{O}\right)$ first loses its water at a temperature of $120^{\circ} \mathrm{C}$. This same substance, however, has been found to crystallize out at a low winter temperature, such as can readily be produced in continental areas, or where snow is mixed with the brine.

\section{Sources of Calcium Sulphate.}

Gypsum, like salt, is deposited from sea water direct, or from concentrated lake waters or in playas. It may be said to have the 
same source as the sodium chloride, being one of the constituents of the sea water whether recent or fossil. Gypsum forms as an efflorescence or incrustation in caves, and it is also produced extensively by the alteration of other rocks. Oxidation of pyrite in calcareous rock often results in the formation of this mineral and so does the double decomposition between other metallic sulphates and calcium carbonate.

\section{Sources of Alkaline Carbonates.}

The crigin of the alkaline carbonates deposited by many waters has been attributed to the leaching of volcanic rocks. Near Owens Lake some of the seepage waters percolate through beds of volcanic ash, and contain even a higher proportion of alkaline carbonates than the lake itself. The rocks from which these salts were originally derived seem to have been mainly rhyolites, andesites, and others rich in alkalies and relatively poor in lime. (Clarke-1o, 2d ed. :220.)

Other sources of alkaline carbonates in natural waters and soils are found in the double decomposition between calcium bicarbonate and alkaline sulphates (T. Sterry Hunt) or alkaline chlorides (E. von Kvassay) and in the reduction of alkaline sulphates by organic matter and the subsequent absorption of $\mathrm{CO}_{2}$ from the air (E. Sickenberger). Finally, Ochsenius suggested that alkaline carbonates are formed by the action of $\mathrm{CO}_{2}$, commonly of volcanic origin, on the mother liquor salts. In Egypt, Chile, and Bolivia he finds also a lack of association of lime and sodium carbonate, but he notes the occurrence of eruptive rocks as sources of $\mathrm{CO}_{2}$ exhalations. In Utah and in the Sahara he finds an association of lime with the mother liquor salts, but no sodium carbonate, because eruptive rocks. the sources of $\mathrm{CO}_{2}$, are alssent. Finally, in Nevada he finds the mother liquor salts associated with eruptive rocks and much soda. He concludes, therefore, that an association of lime with the mother liquor salts alone produces no alkaline carbonates, but that $\mathrm{CO}_{2}$ emanations from volcanic sources (with or without the presence of lime reaction on these salts) will produce the alkaline carbonates. The widespread occurrence of sodium carbonate in the soils of aricl regions is attributed by Hilgard (23) to the reaction between alkaline salts and calcium bicarbonate. When by excessive irrigation these salts are dissolved they rise to the surface by capillary attraction to form the crusts of "alkali." 


\section{Sources of Boric Acid and Borates and of Nitrates.}

Boric acid and saline borates are commonly formed by volcanic activities, as in the case of the Tuscan fumaroles, where ammonium salts also occur, an association found in undoubted volcanic vents. Leaching of rocks containing borosilicates (tourmaline, axinite, datolite, etc.), as in the case of granites, mica schists, etc., also probably accounts for some of the deposits of borates, and more rarely such deposits originate from sea water, though Ochsenius and some other writers attempt to refer all such deposits to a marine origin. When the origin is undoubtedly a marine one, magnesium borates are the result, while lake deposits, like those of California and Chile, contain calcium borates, with nitrates near by. Volcanic waters and fumaroles, on the other hand, yield ammonium compounds along with the borates. The sodium nitrate deposits of Chile and other regions and the extensive potassium nitrate beds of Bolivia are likewise regarded by Ochsenius, Penrose, and others as of marine origin, either directly or indirectly. Ochsenius derives the Chilean nitrates from the mother liquors of salts deposited in the Andes, which, flowing downward to the plains, have their chlorides partly converted to carbonates by $\mathrm{CO}_{2}$ of volcanic origin. The nitrogen is brought as ammoniacal dust from guano beds upon or near the sea coast, the heavier phosphatic particles being left behind. The sufficiency of the amount of ammoniacal dust thus carried has been questioned, and it has been pointed out that carbonates are comparatively rare in the nitrate regions.

Penrose $(44: I 6)$ regards the nitrate fields as a former ocean bottom and likewise derives his nitrogen from guano, the iodine from decomposing sea weeds or from mineral springs and the accompanying borates from the decomposition of rocks, containing boron-bearing minerals. A volcanic origin has also been suggested for the nitrogen (Clarke-Io, 2d ed.:246).

\section{Sum Mary.}

To sum up, it is apparent that salt deposits of to-day, when not referable to a volcanic source, are only to a slight extent due to direct evaporation of the water on the sea coast, but that by far the more prominent mode of formation is a secondary one, the salt being derived from the enclosed connate waters of marine sediments or from the products of alteration. In all cases a relatively arid climate is necessary to permit extensive evaporation, so that salt 
deposits may legitimately be considered as indices of dry climates during the period of their formation. Since most modern salt deposits are of continental origin, a similar origin may have obtained for the deposit of past geologic periods.

\section{ANCIENT SALT DEPOSITS.}

Salt deposits are found in most geological formations from the Cambric (?*) to the Present, and in all cases they are associated with other evidence of continental expansion. Until recently the salt range of India was supposed to hold the oldest salt deposits, these underlying marine strata of Lower Cambric age. It is now held, however, that these salt deposits are of much later age, perliaps even as late as Tertiary time, and that the Cambric strata owe their present position above the salt beds to an overthrust. The thickness of many of the ancient salt deposits is very great, individual beds Ioo feet thick having been found in the Siluric deposits of Michigan. Deposits of much greater thickness are known, but these are either complicated by intercalated anhydrite or polyhalite layers, or they are in the form of salt domes, a formation of limited extent, and of secondary origin.

The Stassfurt Salts. The extensive salt beds of Upper Permic (Zechstein) age in North Germany in the Stassfurt, or more properly the Magdeburg-Halberstadt region, may be taken as an example of a complex deposit in which the strata have, on the whole, suffered little alteration or rearrangement. The order of succession is as follows, in descending order (Walther-65):

I. Lower Buntsandstein (capping rock)

2. Red clay with concretions of anhydrite and salt cavities........................ abt. $20 \mathrm{~m}$.

3. Anhydrite layer (Anhydrite IV) .......... abt. $4 \mathrm{~m}$.

4. Rock Salt........................... abt. to m.

5. Anhydrite III (Pegmatitanhydrit).......... abt. $5 \mathrm{~m}$.

6. Red clay ......................... abt. Io $\mathrm{m}$.

7. Younger Rock Salt, with about 400 annual rings of Polyhalitc............................. $80 \mathrm{~m}$.

8. Main anhydrite (Hauptanhydrit) Anhydrite II varying..................... from 30 to $80 \mathrm{~m}$.

9. Salt clay, averaging............... from 5 to $10 \mathrm{~m}$.

10. Carnallite zone.................... from 15 to $40 \mathrm{~m}$.

This is sometimes overlain by a layer of rock salt, at others by a kainite layer followed by one of "sylvinite" or "hartsalz" and that by one of schoenite before reaching the salt clay.

*The Indian salt deposits are the only ones of significance which have been referred to the Cambric. 
I I. Kieserite zone averaging............ $18 \mathrm{~m}$.

12. Polyhalite zone averaging............

13. Older Rock Salt with about 3,000 "annual" rings

of anhydrite averaging.............. $245 \mathrm{~m}$.

Nos. II, I2, and 13 have a combined thickness ranging from 150 to perhaps 1,000 meters.* The "annual" rings of anhydrite form layers averaging 7 millimeters thick, separating the salt into sheets of 8 or 9 millimeters.

14. Older anhydrite and gypsum (Anhydrite I) averaging....................

15. Zechstein limestone or dolomite

16. Kupferschiefer

17. Zechstein conglomerate

18. Upper Rothliegende (base of section)

The lower members, beginning with Anhydrite I and ending with the carnallite zone (and sometimes the kainite, sylvinite and schoenite zones), form one depositional series, the last being the salts from the mother liquor. This is followed by a protecting layer of clay. Apparently a second depositional series began with the second or main anhydrite and the Younger Rock Salt, but lacks the mother liquor salts.

Altogether more than thirty saline minerals are found in the Stassfurt deposit. Of these some of the more prominent besides the halite and anhydrite are:

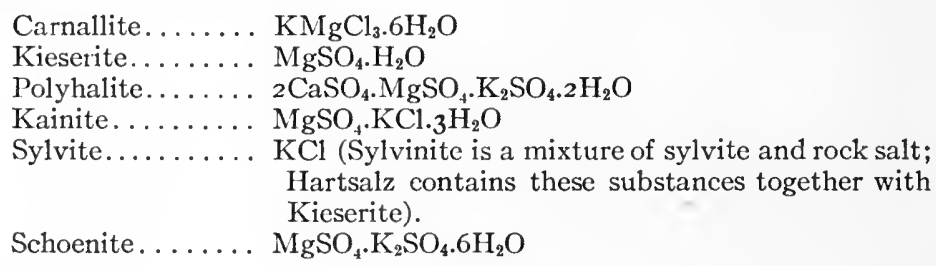

Borates, especially boracite $\left(\mathrm{Mg}_{7} \mathrm{Cl}_{2} \mathrm{~B}_{16} \mathrm{O}_{30}\right)$, occur with the carnallite and in the overlying zone. A noteworthy fact is that these deposits are absolutely unfossiliferous, in spite of the fact that organic remains would here have a chance for perfect preservation.

These deposits have been commonly regarded as illustrations of the Bar Theory, but against this interpretation strong objections have been urged, especially by Walther $(62: 63)$ and by Erdmann (I6). Walther uses as his main arguments against such an origin the absolute want of organic remains in these deposits, and the fur-

* This is probably the result of thickening through subsequent diagenetic processes, the average of the salt deposits in undisturbed regions being about $35^{\circ}$ meters. 
ther fact that anhydrite is the first deposit and not gypsum, as would be the case for evaporating sea water. The second series of leposits above the mother liquor salts again begins with anhydrite instead of gypsum. Walther $(65)$ regards these deposits as due to evaporation of a shallow late Permic or Zechstein sea, entirely cut off from the ocean, and surrounded by a country changing gradually from pluvial to desert conditions. This old sea extended from the Urals in Russia, on the east, over North Germany, and the region of the North Sea to the center of England. On the south its boundary was partly formed by the Bohemian mass, and the old Vindelician and Armorican Mountain chains, the former in the region of the present Danube plain, the latter extending through France, Belgium, South England, and Ireland. In the north, and on the southeast, the separation was caused by the development of extensive broad marsh lands. During the gradual evaporation of this sea, the salt deposits accumulated in the deeper areas of the basin, where to-day they cover scarcely the fiftieth part of the original area of the salt sea. As partial areas were laid bare the salt deposited there was again dissolved by the streams and carried to the pools which still existed, and thus the concentration became more and more pronounced. Under the influence of changing temperature and moisture with the change of seasons, the nature of the precipitate varied, and thus the salt beds are separated at regular intervals by layers of anhydrite or polyhalite, forming the annual rings. Their number suggests that the deposition of the Stassfurt salt occupied a period of about I0,000 years. Erdmann (16) holds that the amount of anhydrite in the deposits is too great to be derived solely from the drying up of this sea, and he therefore supposes that additional amounts of calcium sulphate were brought into it by the streams from the surrounding regions.

According to Van't Hoff and Weigert (54:I I4O) anhydrite forms from gypsum in sodium chloride solutions at $30^{\circ} \mathrm{C} .\left(+86^{\circ} \mathrm{F}.\right)$, while in the sea water this transformation takes place at $25^{\circ} \mathrm{C}$. $\left(+77^{\circ} \mathrm{F}\right.$.). At ordinary temperatures, according to Vater, calcium sulphate crystallizes from a saturated solution of salt in the form of gypsum. Such high temperatures are not to be found in water of bays still in connection with the sea, especially in the present latitude of the Stassfurt salt deposit, unless indeed the temperature of the whole earth was higher. The Red Sea, which to-day has the highest temperature of any mediterranean, has a bottom temperature of $21.5^{\circ} \mathrm{C}$., its mean temperature being $22.69^{\circ} \mathrm{C}$. The Persian Gulf, on the other hand, has a mean temperature of $24^{\circ}$, owing to its greater shallowness (see Chapter IV). Where influx of cooler 
ocean water is prevented, however, the temperature of the entire body may easily rise to the required degree. When the deeper layers had become a concentrated brine the successive influxes of calcium sulphate, probably during the rainy period when the streams brought this mineral in solution from the surrounding country, were, on passing through these layers of brine, deposited directly as anhydrite, in alternate layers with the salt deposits. That these influxes of calcium sulphate were not due to successive ingressions of the open sea is shown by the utter lack of marine organic remains in these strata. In this manner were formed the 3,000 or more layers of anhydrite which divide the older rock salt. With the progress of concentration, the supernatant solution became a bittern rich in magnesium salts, whereupon the calcium sulphate united with these salts, forming polyhalite $\left(2 \mathrm{CaSO}_{4} \cdot \mathrm{MgSO} \mathrm{SO}_{2} \cdot \mathrm{SO}_{4} \cdot 2 \mathrm{H}_{2} \mathrm{O}\right)$. The polyhalite stratum of Stassfurt is essentially a bed of rock salt, containing, with other impurities, from 6 to 7 per cent. of polyhalite. With further concentration of the mother liquor, kieserite $\left(\mathrm{MgSO}_{4} \cdot \mathrm{H}_{2} \mathrm{O}\right)$ was deposited, this requiring a temperature above $72^{\circ} \mathrm{C}$. for its deposition. The zone named after it contains about $17 \%$ of this mineral, together with I3 of carnallite, 3 of bischofite, 2 of anhydrite, and 65 of rock salt. At this stage polyhalite was no longer deposited.

The final step in the concentration of the mother liquor produced the carnallite zone. The average composition of this zone is 55 per cent. of carnallite, 25 of rock salt, I6 of kieserite, and 4 of various other minerals. The carnallite $\left(\mathrm{KMgCl}_{3} \cdot 6 \mathrm{H}_{2} \mathrm{O}\right)$ was formed from the chlorides which had hitherto remained in solution, and it represents the more or less complete drying up of the bittern lake. The protecting layer of clay must have been formed by winds, for water would have caused a resolution of the carnallite.

The reëstablishment of the conditions of deposition, first for anhydrite and later for rock salt, which produced the "younger succession," suggests a renewed invasion of the sea. This is negatived, however, by the absence of organic remains either in the salt clay or in the succeeding anhydrite. This younger series may, therefore, be wholly of continental origin, the anhydrite and salt being both derived from connate waters.

The change to a dry climate over the region of North Germany is understood when we take into consideration the fact that at the beginning of Permic time the Armorican Mountain chain began to rise, extending from the region of what is now central France northwestward to the present Irish Isle. This placed a barrier directly across the path of the prevailing Westerlies, which then were ap- 
parently much as they are to-day. As a result, rainy conditions prevailed on the windward side of these mountains, where the old mediterranean or Thetis Sea of that day was situated, but arid conditions were produced over the region beyond these mountains by these winds, which on crossing the mountains became aridifiers. As a result of this change in climate the region of North Germany, Belgium, etc., previousiy one of much moisture and characterized by the formation of luxurious coal swamps, became the theatre of deposition of the red sands of the lower Permic or Rothliegende. The lower division of this deposit forms a transition from the coalbearing formations preceding and contains at first some coal and plant remains. Extensive forests of calamites, ferns, and conifers covered the rising lands, for at first the barrier was not sufficient to keep the moist winds out. The progressive development of the mountain system finally involved some of the earlier Rothliegende deposits, so that the later division, mostly free from plant remains, rests unconformably, in part on the folded and eroded lower division. There is thus indicated a progressive aridification of the region, due no doubt to the continued growth of the Armorican Mountain system which became more and more effective as a barrier for the moisture-laden southwest winds.

The Rothliegende desert was invaded by the Zechstein Sea from the North Russia region, marked at first by invading channels with a marine fauna, while elsewhere sand-dunes, now forming the Weissliegende, covered the lowlands. Then followed the peculiar conditions producing the Kupferschicfer, which were probably due to a separation of the early waters from the ocean to the north, to form a shallow, brackish lake into which streams from the surrounding old land, the Harz, Frankenwald, Erzgebirge, and rheinische Schiefergebirge, carried mineral matter in solution. The abundant fish fauna of this lake eventually succumbed to the gradual fouling of these stagnant waters and the carcasses were buried in the black muds, which also enclosed the metallic precipitates. 'The renewed invasion of this area by the Russian Sea then led to the formation of the marine Zeclistein with its Bryozoa reefs and rich fauna, and for a long time the conditions of an open sea existed over North Europe. That the winds from the southwest still maintained their drying characteristic is shown by the deposits of western England. which remained of the arid type, and extended down to. and perhaps partly into, the Zechstein (Magnesian limestone) Sea. The marine fauna of the Zechstein found conditions of existence more favorable where the old Kupferschiefer muds were absent, as around the margins of the old lands and the projecting islands of 
older rock. Here the fauna is richest, and the rcefs often rest directly upon the eroded old land. Over the floor of the sea, however, underlain by the black muds, conditions of existence were less favorable, probably because the gases resulting from the decay of the vast number of fishes in these muds were constantly rising, and so the fauna is much poorer as well as more or less dwarfed in species and in individuals.

With the persistence of the aridifying winds it required only a second closing of the inlet of the North Russian waters to convert the Zechstein Sea into a salt pan, through the gradual evaporation of the water. It is probable that the connection with the sea was temporarily reëstablished at least once during this period, this being indicated by the formation of the upper salt series. With the progressive drying up of this sea, the red continental sands encroached, and eventually covered the entire region of the former Zechstein Sea, forming the Bunter Sandstein, the base of the Trias. Thus actual desert conditions were established over Northwest Europe and continued until the invasion of the Muschelkalk Sea.

The Siluric Salts of North America. These present a rather different type of deposit. In southern Michigan this formation reaches a thickness of nearly a thousand feet. It includes nine separate salt beds, several of them 100 feet thick, while the lowest one is $\mathrm{I} 60$ feet thick (Lane-32:pl. $\mathrm{xl}$ ). The annual rings characteristic of the Stassfurt salt seem to be wholly wanting here, and the same is true for the potash salts. The various beds of salt are separated by layers recorded in the wells as shale or limestone, some of which, however, are most probably gypsum or anhydrite. In central New York the following succession is shown in descending order:

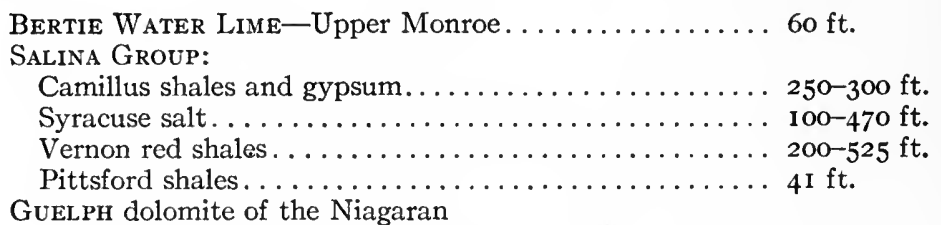

The salt series (Syracuse) is thinner than in Michigan. In the well sunk at Ithaca, New York, it has a thickness of only 470 feet and includes seven salt beds ranging in thickness from 17 to 54 feet, with shale partings ranging from 6 to 82 feet in thickness. Where actually exposed, as in the Livonia and other salt shafts, something akin to the annual rings of Stassfurt is seen, in thin intercalated layers of gypsum and shaly material. These are, however, discon- 
tinuous and only locally developed. The beds are all horizontal and in rare cases are any of the layers distorted as is so commonly the case in the North German salt deposits. Pieces of rock, either shale or limestone, are not uncommonly embedded in the salt; sometimes these pieces are large, and seem to represent a broken-up cover of clay or lime, which subsequently sank into the upper salt layers, or was buried by the new formed strata.

The Pittsford shale at the base of the series represents a change from the preceding Niagaran (Guelph) sea to the continental conditions under which the salt was deposited. The shale alternates with dolomitic layers which contain the last survivors of the Guelph fauna. Near the middle of the mass occur a few black shale layers crowded with fragments and molts of entire individuals of six species of Eurypterida, including the genera Eurypterus, Pterigotus, and Hughmilleria, and several species of Phyllocarida, and at least one Synxiphosuran (Pseudoniscus roosevelti). Followed eastward for two hundred miles, this fauna is found in black shale layers in the Shawangunk conglomerate of eastern New York and Pennsylvania, which is interpreted as a great continental fan formed along the rising Appalachians during the same period, and forming part of the upward movement of the North American continent of that time, which resulted in the complete withdrawal of the Niagaran sea of that period. (Grabau-20.)

The close of the Pittsford shale epoch marks the period of destruction of the animal life of the Siluric sea in North America, the red Vernon shales, a distinct continental type of deposit 400 feet or more in thickness, succeeding in central New York. These can likewise be traced eastward, where they swell enormously, forming the Longwood shales of New Jersey some 2,00o feet thick, and throughout of continental origin. While the red Vernon shales of central New York were depositing, salt formed in the deeper basin of southern Michigan. Some of this may have resulted from the final evaporation of the waters of the Niagaran sea, for the salt there lies frequently directly upon the limestone. No gypsum or anhydrite has been recorded, but, as before noted, it is not improbable that some of the limestone beds recorded in the well sections are in reality anhydrite. The salt of central New York was probably derived altogether from connate waters enclosed in the recently formed marine Niagaran and earlier strata which underlay and surrounded the salt basins and which suffered extensive erosion during this period. While these salt deposits were forming, red sedimentation was still going on in eastern New York, New Jersey, and Pennsylvania. The central New York salt basin exterds from the Oatka 
valley in Wyoming county to Morrisville in Madison county and southward for an undetermined distance. Western New York is free from salt, which was either not deposited, or was removed by erosion during Upper Siluric time.

Immediately above the red Vernon shales the salt is coarsely crystallized, the crystals being commonly embelded in the mud. Limestone, shale and gypsum occur as fragments mixed with the clear salt crystals, the whole forming a brecciated mass. Sometimes in the basal salt beds there is an abundance of layers and irregular masses of shale and limestone, while in other localities the salt is almost pure. At Livonia this basal layer is succeeded by 8 feet of stratified marlyte grading upward into impure magnesian limestones, both shales and limestones being full of seams and veins of salt, often with columnar structure in the larger veins. Overlying the limestone is the main salt bed. It is often very pure and well stratified. Shaly matter and gypsum occur in thin streaks, but, on the whole, the impurities are not more than two or three per cent. of the entire bed. Non-continuous layers of limestone or shale several inches thick sometimes occur. The crystals of salt are much smaller than those of the mixed salt, and vary considerably in size in the different layers. The salt is again capped by a layer of mixed salt like that found below. Gypsous shales are common here, these containing more or less disseminated salt. Irregular and more persistent layers of dark magnesian limestone also occur in the upper part of the salt bed. They are up to two or three feet in thickness and full of salt seams and grains, and have the appearance of having been formed above the salt and of having settled down into it. The roof of the salt bed likewise consists of large and small blocks of gypsous shale, the spaces between the blocks, sometimes several inches in width, being filled with salt. These salt veins sometimes extend upward into the overlying rock for 200 feet, though, as a rule, they are much shorter.

The total thickness of the salt beds of central New York, including the shale layers, ranges from Ioo to Igo feet, but southward it thickens to 470 feet, in the Ithaca well. The limestone layers in this formation show evidence of exposure to the air during their formation, by the abundance of mudcracks which are filled by salt, gypsum or black mul. They are entirely unfossiliferous, as is this whole series of deposits.

The Camillus shales overlying the salt are gray, often containing beds of magnesian limestone and great masses of gypsum, together with some anhydrite. This gypsum has been regarded as an alteration product, being formed from impure limestones of the water lime 
type. Numerous hopper-shaped cavities formerly occupied by salt crystals occur in the shalier beds.

When we consiler the former extent of the Niagaran strata, from central New York to the Rocky Mountains and from the Ohio or southward to Hudson Bay, and its thickness, which in Wisconsin is still over 800 feet, and realize that much of this was worn away during Salina time by the streams flowing into the Salina basins of New York. Michigan, and Canada West, we can understand that the connate sea water held in these strata was quite sufficient to
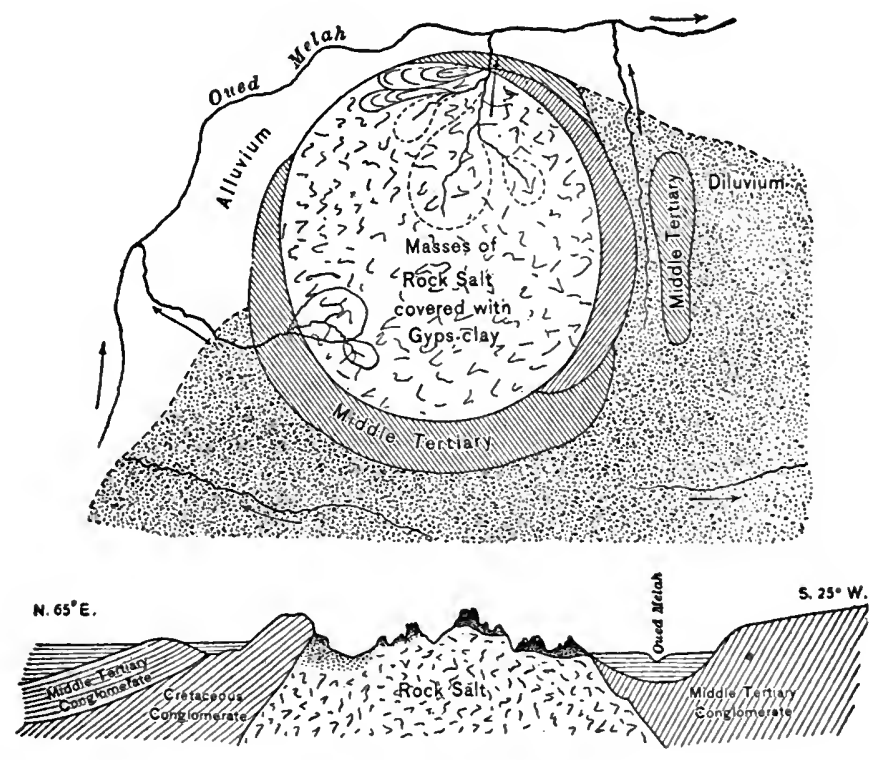

FIG. 7o. Map and cross-section of Rhang-el-Melah, a salt dome in Algeria. (After M. Ville.)

furnish all the salt of the Salina deposits. The intercalated limestone and shale layers likewise had their origin in the erosion products obtained from these Niagaran formations. The fact that all around the Salina area the Lpper Siluric strata rest on Niagaran except where the continental deposits of Salina time intervene, and the further fact that no undoubted marine equivalents of the Salinan are known in North America, greatly strengthen the argument for the wholly continental origin of these salt deposits.

The Salt Domes. These should be briefly mentioned here, as accumulations of salt in circumscribed areas, often to a thickness of 
several thousand feet. They are of all ages and owe their form to rearrangement of the salt mass through the force of crystal growth inherent in the salt, and in this process they have often seriously disturbed the enclosing strata. (Hahn-2I ; Harris-22; see further under diagenesis, Chapter XX.) (Fig. 7o.).

\section{BIBLIOGRAPHY IX.}

I. ANDERSON, W. S. I89o. The Solubility of Carbonate of Lime in Fresh and Salt Water. Proceedings of the Royal Society of Edinburgh, Vol. XVI, pp. 319-324.

2. ANDREE, KARL. I9I2. Ueber Sedimentbildung am Meeresboden, I ter Teil. Geologische Rundschau, Bd. III, Heft 5-6, pp. 324-360.

3. ANDRUSSOW, N. I 897. Der Adschi-darja, oder Karabugas-Busen. Petermanns Mittheilungen, Bd. XLIII, pp. 25-34.

4. ANDRUSSOW, N. I 897. La Mer Noire, Guide des Excursions du VII me. Congrès Géologique International, No. 29.

5. BADER, H. 1869. Ueber die Bitterseen des Suezkanals. Verhandlungen der kaiserlich-königlichen geologischen Reichsanstalt, pp. 287-289, 3 I I .

6. BRANNER, J. C. I9II. Aggraded Limestone Plains of the Interior of Bahia and the Climatic Changes'Suggested by Them. Bulletin Geological Society of America, Vol. XXII, No. 2, pp. I87-206.

7. CAMPBELL, M. R. 1902. Reconnaissance of the borax deposits of Death Valley and Mohave Desert [California]. Bulletin U. S. Geological Survey, No. 200.

8. CAMPBELL, M. R. 1903. Borax Deposits of Eastern California, Bulletin U. S. Geological Survey, No. 21 3, pp. 40I-405.

9. CAYEUX, L. 1897. Contribution à l'Etude de micrographie des terrains sedimentaires. Lille.

Io. CLARKE, F. W. I908-I9II. The Data of Geochemistry. Ist edition. Bulletin 330, U. S. Geological Survey, 2nd cdition Bulletin 49I. (Unless otherwise stated the pages of both editions are given.)

II. DALY, REGINALD A. 1907. The Limeless Ocean of Pre-Cambrian Time. American Journal of Science. 4th series. Vol. XXIII, pp. 93-I I5.

12. DALY, R. A. 1909. First Calcareous Fossils and the Evolution of the Limestones. Geological Society of America, Bulletin XX, pp. 153-I7o.

13. DANA, JAMES D. I872. Corals and Coral Islands. New York, Dodd \& Mead.

I4. DARWIN, CHARLES. 1841. Voyage of the Beagle.

15. DE GROO'T, HENRY. I890. The Searles Borax Marsh. Ioth Report, California State Mineralogist, pp. 534-539.

16. ERDMANN, E. 1908-09. Die Entstehung der Kalisalzlagerstätten Zeitschrift für Angewandte Chemie, Vol. XXI, pp. I685, I702, also Demonstration von Salzmineralien, Ibid., Vol. XXII, pp. 238-239. 1909.

17. FREEMAN, W. B., and BOLSTER, R. H. 1910. Surface Water Supply of the United States, 1907-08. Colorado River Basin, U. S. Geological Survey Water Supply Paper, No. 249, pt. 9.

I8. GILBERT, G. K. I890. Lake Bonnevilie. Monograph U. S. Geological Survey, Vol. I.

19. GRABAU, A. W. I9I2. The Origin of Salt Deposits with Special Reference to the Siluric Salt Deposits of North America. Bulletin No. 57, Mining and Metallurgical Society of America. 
20. GRABAU, A. W. I913. Early Palæozoic Delta Deposits of North America. Bulletin of the Geological Society of America, Vol. XXIV, pp. 399-528.

21. HAHN, F. F. I9I2. The Form of Salt Deposits. Economic Geology, Vol. VII, pp. I20-135.

22. HARRIS, G. D. 1909. The Geological Occurrence of Rock Salt in Louisiana and East Texas. Economic Geology, Vol. IV, pp. 12-34.

23. HILGARD, E. W. I896. The Geologic Effieacy of Alkali Carbonate Solutions. American Journal of Science, 4th ser., Vol. II, pp. 100-107.

24. HOCHSTETTER, F. V. 1856. Karlsbad, seine Geognostische Verhältnisse und seine Qucllen, Karlsbad.

25. HUBBARD, LUCIUS L. I893. Origin of Salt, Gypsum and Petroleum. Geological Survey of Michigan, Vol. V, pt. II, Introduction, pp. i-xxiv.

26. HUNT, T. STERRY. I859. On some Reactions of the Salts of Lime and Magnesia and on the formation of Gypsum and Magnesian rocks. American Journal of Science, 2nd ser., Vol. XXVIII, pp. I 70-I 87, 365-383.

27. HUNT, T. S. I866. Further Contributions to the History of Lime and Magnesium Salts. American Journal of Science, 2nd ser., Vol. XLII, pp. 49-67.

28. HUNTINGTON, ELLSWORTH. 1907. The Pulse of Asia. Houghton Mifflin \& Co.

29. IRVINE, ROBERT, and YOUNG, GEORGE. I889. On the Solubility of Carbonate of Lime under Different Forms in Sea-water. Procecdings of the Royal Society of Edinburgh, Vol. XV, pp. 3I6-320.

30. IRVINE, ROBERT, and WOODHEAD, G. SIMS. 1889-90. On the Secretion of Carbonate of Lime by Animals. Proceedings of the Royal Society of Edinburgh, Vol. XV, pp. 308-316, Vol. XVI, pp. 324-354, Vol. XVII, pp. 79-108.

31. KNOP, A. I874. Ueber Kieselsäureabscheidungen und Oōlithbildung. Neues Jahrbuch für Mineralogie, etc., I 874, pp. 28I-288.

32. LANE, ALFRED C. I 893. The Geology of Lower Michigan with Reference to Deep Borings. Michigan Geological Survey, Vol. V, pt. II.

33. LINCK, G. 1903. Die Bildung der Oölithe und Rogensteine. Neucs Jahrbuch für Mineralogie, Beilage Band XVI, pp. 495-5I3.

34. LYELL, CHARLES. 1875. The Prineiples of Geology, I th edition, Vol. I. Lcndon, John Murray.

35. MERRILL, GEORGE P. I895. The Onyx Marbles: Their Origin, Composition and Uses, Both Ancient and Modern. Smithsonian Institution, U. S. National Museum. Report for I 893, pp. 54I-585.

36. MURRAY, JOHN, and IRVINE, R'BERT. I89I. On Coral Reefs and Other Carbonate of Lime Formations in Modern Seas. Proceedings of the Royal Society of Edinburgh, Vol. XVII, pp. 79-IO9.

37. OCHSENIUS, KARL. I877. Die Bildung der Steinsalzlager und ihrer Mutterlaugensalze. Halle.

38. OCHSENIUS, KARL. I878. Beiträge zur Erklärung der Bildung von Steinsalzlagern und ihrer Mutterlaugensalzc. Nova Acta der kaiserlichLeopoldish-Carolinischen deutschen Akademie der Naturforscher, Bd. XL, No. 4 , pp. I 2 I-I 66.

39. OCHSENIUS, KARL. I888. On the formation of rock salt beds and mother liquor salts. Philadelphia Academy of Sciences, Proceedings, I 888 , pt. 2, pp. I $81-187$.

40. OCHSENIUS, KARL. I 893. Bedeutung des orographischen Elementes "Barre" in Hinsicht auf Bildungen und Veränderungen von Lagerstäten und Gesteinen. Zeitsehrift für Praktische Geologie, Bd. I, May, June. 
41. OCHSENIUS, K. I893. Ueber unterirdische Wasseransammlungen, Zeitschrift f. Praktische Geologie, I, pp. 36-40.

42. OCHSENIUS, K. I902. Review das Gesetz der Wüstenbildung von Johannes Walther, Centralblatt für Mineralogie, Geologie u. Palæontologie, pp. 55I-590, 620-633.

43. PASSARGE, SIEGFRIED. 1904. Die Kalahari. Versuch einer physisch-geographischen Darstellung der Sandfelder der südafrikanischen Becken. Berlin, Dietrich Reimer.

44. PENROSE, R.A.F., Jr. I9 Io. The Nitrate Deposits of Chile. Journal of Geology, Vol. XVIII, pp. I-32.

45. PHILIPPI, E. 1907. Ueber Dolomitbildung und Chemische Abscheidung von Kalk an heutigen Meeren. Neues Jahrbuch f. Mineralogic, etc. Festband, pp. 397-445.

46. POTONIE, H. I906. Naturwissenschaftliche Wochenschrift, Bd. V.

47. RUSSELL, ISRAEL C. $\mathbf{1} 88 \mathrm{I}-82$. Sketch of the geological history of Lake Lahontan. A Quaternary lake of northwestern Nevada. 3rd Annual Report, U. S. Geological Survey, pp. I 89-235.

48. RUSSELL, I. C. I 885. Geological history of Lake Lahontan, a Quaternary lake of northwestern Nevada. Monograph, U. S. Geological Survey, $\mathrm{XI}$.

49. SEIDLITZ, N. VON. I 899. Der Karabugas-Mcerbusen des Kaspischen Meers. Globus, Vol. LXXVI, pp. I3-17.

50. SKEATS, E. W. I903. The Chemical Composition of Limestones from upraised coral islands, with notes on their microscopical structure. Bull. Mus. Comp. Zool., XLII, pp. 53-I26.

5I. STEINMANN, GUSTAV. I889. Ueber Schalen und Kalksteinbildung. Bericht der Naturwissenschaftlichen Gesellschaft. Freiburg.

52. USIGLIO, J. I849. Analyse de l'eau de la Méditerranée sur les cotes de France. Annales chem. phys., 3rd ser., Vol. XXVII, pp. 92-107; 172-191.

53. VAN'T HOFF, J.H. 1905. Zur Bildung der Ozeanischen Saltzablagerungen, I. Braunschweig.

54. VAN'T HOFF and WEIGERT, F. I9or. Untersuchungen über die Bildungsverhältnisse der Ozeanischen Salzablagerungen, insbesondere des stassfurter Salzlagers. Sitzungsberichte der königlich-preussischen Akademie der Wissenschaften zu Berlin, pp. I I 40-1 I48.

55. VOGT, J. H. L. I 898 . Der Marmor im Bezug auf seine Geologische Struktur und seine Mechanischen Eigenschaften. Zeit. f. Prakt. Geol. January, February, Vol. VI, pp. 4-16; 43-52.

56. WAGNER, R. Abhandlungen der königlich-preussischen Geologischen Landesanstalt, N. F. Heft 27.

57. WALCOTT, C. D. 1894. Palæozoic Intraformational Conglomerates. Geological Socicty of America, Vol. V, pp. 191-I98. Plates I, 5-7.

58. WALCOTT, C. D. I896. The Cambrian Rocks of Pennsylvania. Bull. U. S. Geological Survey, No. I34.

59. WALTHER, JOHANNES. I888. Die Korallenriffe der Sinaihalbinsel. Abhandlungen der königlich-sächsischen Gesellschaft der Wissenschaften. (Mathematisch-Physische Klasse.) Leipzig, Bd. XIV, pp. 437-505.

6o. WALTHER, J. I89I. Die Denudation in der Wüste und ihre Geologische Bedeutung. Ibid., Vol. XVI, pp. 347-569.

6I. WALTHER, J. I893-4. Einleitung in die Geologie als historische Wissenschaft. Jena, Gustav Fischer.

62. WALTHER, J. 1900. Das Gesetz der Wüstenbildung in Gegenwart und Vorzeit. Ite Auflage. Dietrich Reimer, Berlin. 
63. WALTHER, J. I903. Die Entstehung von Salz und Gyps durch topographische oder klimatische Ursachen. Centralblatt f. Min. Geol. Pal. pp. $211-217$.

64. WALTHER, J. I904. Die Solnhofener Plattenkalke Bionomisch betrachtet. Festschrift zum zoten Geburtstage von Ernst Haeckel. Jena, Gustav Fischer.

65. WALTHER, J. I9ro. Lehrbuch der Geologie von Deutschland. Quelle $\&$ Meyer, Leipzig.

66. WALTHER, J. I9I2. Das Gesetz der Wüstenbildung in Gegenwart und Vorzeit. Neu bearbeitet 2 te Auflage. Quelle \& Meyer, Leipzig.

67. WALTHER, J., and SCHIRLITZ, R. I886. Studien zur Geologie des Golfes von Neapel. Zeitschrift der deutschen geologischen Gesellschaft, Bd. XXXVIII, pp. 295-34I.

68. WEED, WALTER HARVEY. I889. Formation of Travertine and Siliceous Sinter by the Vegetation of Hot Springs. 9th Annual Report, U. S. Geological Survey, pp. 613-676, pls. $78-87$.

69. WHERRY, E. T. I908. Communication on the occurrence of Carnotite in Pennsylvania. American Association for the Advancement of Science. Proceedings of the Baltimore Meeting.

70. ZIRKEL, FERDINAND von. I866. Lehrbuch der Petrographie, Bd. I. Lemberg. Zweite 'gänzlich neu verfasste Auflage. Leipzig. Wilhelm Engelmann, 1893. 
CHAPTER $\mathrm{X}$.

MORPHOLOGY AND LITHOGENESIS OF THE TRUE ORGANIC OR BIOGENIC ROCKS. ZOÖGENIC DEPOSITS.

Biogenic rocks, or Bioliths as Chr. G. Ehrenberg has termed them, are deposits of organic material, or material formed through the physiological activities of the organisms. In general, Bioliths may be divided into those in which the organic matter is preserved in the form of carbon or compounds of carbon, and those in which only the inorganic mineral matter, abstracted from the food or the medium in which the organism lives (air, water, or soil), is preserved. The former are almost wholly restricted to plantformed (phytogenic) deposits, or phytoliths, and the latter are best represented by animal-formed (zoögenic) deposits or zoöliths. As the organic carbon deposits, whether plant or animal, all have the property of combustibility, they have been designated caustobioliths, * while the non-combustible organic deposits of purely mineral character are designated acaustobioliths.

The following classification of the types of biogenic deposits, or Bioliths (Biolites), may be made:

A. Zoögenic Deposits or Zoöliths.

I. Coral reefs.

2. Sponge reefs.

3. Bryozoa reefs.

4. Shell colonies.

5. Shell limestones.

6. Crinoidal limestones.

7. Calcareous oozes.

a. Foraminiferal oozes.

b. Pteropod oozes.

c. Cyprid oozes.

* From $\kappa a v \sigma \tau \iota k \delta s=$ capable of burning, Bios, life, $\lambda i \theta o s$, stone. Caustoliths of inorganic origin also exist: e.g., sulphur deposits. 
8. Siliceous oozes.

a. Radiolarian oozes.

b. Sponge spicule oozes.

9. Phosphate (guano) deposits.

B. Phytogenic Deposits or Phytoliths.

I. Nullipore reefs and limestones.

2. Algous travertine.

3. Phytogenic oölites.

4. Chara marls and limestones.

5. Diatomaceous oozes.

6. Caustophytoliths.

a. Sapropeliths.

b. Peat.

c. Lignites, brown coal, etc.

d. Coals.

e. Deep sea vegetal deposits.

In the present chapter only the zoögenic deposits will be discussed, the phytogenic being referred to the next chapter.

\section{CORAL AND OTHER REEFS.}

Coral reefs have been formed in all geologicai periods, from the Cambric to the present, and recent investigations seem to indicate the existence of archæocyathid corals in reef-like association during the pre-Cambric (Animikie) in the Canadian region. Reefs are complex structures, and corals often play only a minor part in their construction. Calcareous algæ, or Nullipores, are commonly among the most important reef organisms (Marshall Howe-50), while Hydrocorallines are equally abundant. In fossil reefs Sponges and Bryozoa are often the most important reef organisms. The term coral will be used here in its more general or comprehensive sense, so as to include the hydrocorallines, both the recent millepores and their fossil representatives, the Stromatoporoids. Among the corals proper two classes are represented: Madrcporaria, or stone corals, and the Alcyonaria. The latter, however, furnish only a small contribution to the reef. Many other lime-secreting organisms occur besides corals and nullipores. They are, however, of secondary significance, and, on the whole, contribute only a fraction of its mineral matter to the reef.

The general characteristics of modern coral reefs will first be discussed, and this will be followed by a review of reefs of the past. 


\section{Characters and Development of Modern Coral Reefs.}

Types of Modern Coral Reefs.-Three types of coral reefs are recognized in the modern seas: the fringing reef, barrier reef, and atoll. The Fringing Reef, or shore reef (Figs. 7I-2), is a platform of coral rock closely bordering a continent or island of earlier origin and extending some distance from the shore. Seaward the platform of coral rock is often somewhat higher than the inner end, rising into low ridges or mounds of living or dead coral and coral sand often awash at low tide. It is intersected by channels and a pronounced but shallow channel extends between it and the shore. Its seaward side is often rather steep, but it descends into comparatively shallow water. This is the zone of active coral growth as well as destruction, for here wave activity is most marked. Within the outer rim conditions of life are less favorable, since

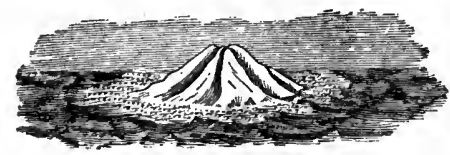

FIG. 7I. Island with fringing reef, and submarine platform over which the surf breaks. (After Le Conte.)

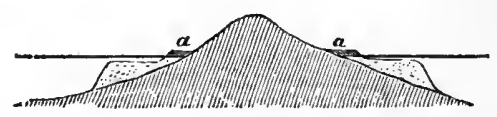

FIG. 72. Diagrammatic cross-section of the island and reef shown in preceding figure. $a, a$, Dead coral material added to island. (After Le Conte.)

here the water is more stagnant, and the channels are scoured out by the tidal currents and the solvent action of the water. The influx of fresh water and clastic sediment from the land also hinders coral growth to a considerable extent within the outer rim of the fringe. Typical examples of fringing reefs are found on the borders of the Sandwich, Solomon, Friendly, and Navigator islands, the New Hebrides and Mariana islands and many others, all in the Pacific, also in the Seychelles and Nicobar islands and in Mauritius, as well as parts of the coast of Madagascar and Mozambique in the Indian Ocean. In the Red Sea they occur on both the Arabian and African shores, and in the Atlantic on the coast of Florida and around nearly the whole of the islands of the West Indies.

The Barrier Reef (Figs. 73-4) is situated further from shore and consequently has a greater depth of water both between it and the land and on the seaward side. It may be formed from the fringing type by the subsidence of the land and the simultaneous upward growth of the corals on the outer border of the reef (Darwin); 
by the seaward growth of the front of the reef and the enlargement by solution of the channel betiveen the reef and the land without subsidence (Nurray, Agassiz), and, finally, by the independent upward growth of the corals into reefs on a suitable platform at a distance from the shore. The Great Barrier Reef on the northeast coast of Australia extends for 1,250 miles from Torres Strait in $9.5^{\circ} \mathrm{S}$. lat. to Lady Elliott Island in $24^{\circ} \mathrm{S}$. lat. At Cape York the sea-

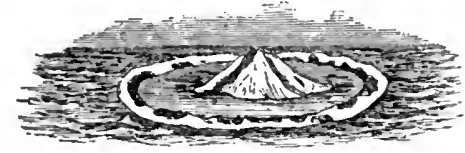

FIG. 73. Barrier reef around central island. The surf (white) shows the location of the reef. which is dotted with small coral islands. (After Le Conte.)

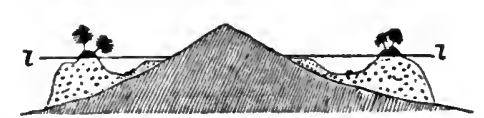

FIG. 74. Diagrammatic section of the island shown in the preceding figure, showing location of recfs (dotted). (After Le Conte.)

ward edge of this reef is nearly 90 miles distant from the coast and it descends to a depth often exceeding 1,800 feet. It represents "a great submarine wall or terrace, fronting the whole northeast coast of Australia, resting at each end in shallow water, but rising from very great depths about the center. Its úpper surface forms a plateau, covered by io to 30 fathoms of water, but studded all over with steep-sided block-like masses which rise up to low water level." : (Jukes-Browne-53; 54.) These individual reefs are espe-

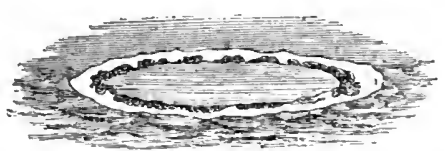

Fig. 75. An atoll formed of disconnected coral islands arising from a submerged recf which is outlined by surf (white). (After Le Conte.)

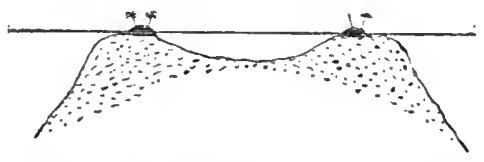

FIG. 76. Diagrammatic section of an atoll, showing depth of central lagoon, and relation of the islands to the reef. (After Le Conte.)

cially numerous along the edge of the bank and protect the comparatively shallow water over the reef, as well as the numerous inner reefs scattered over the surface, from the effects of the waves of the open ocean. In most barrier reefs, the outer edge is in places often awash at low tide and islands and bars of dead coral and sand are formed. These may coalesce and in time become covered with vegetation. Thus a strip of land is formed, lying some hundred yards or less from the extreme outer edge of the reef. 
Where the barrier reef is not far from land, gaps always occur in it opposite the mouths of rivers.

Other examples of barrier reefs occur in the Pacific, where they encircle some of the Society Islands, including Tahiti, the Fiji Islands, and New Caledonia. The last is 400 miles long and about ten miles distant from shore. The Pelew Islands and the Comoro Isles in the Mozambique Channel are surrounded by barrier reefs and other examples occur in the middle of the Red Sea.

The Atoll is an elliptical, oval or roundish ring of coral, its continuity broken here and there by channels which lead into the central lake-like expanse of water, the lagoon. The outside water is commonly very deep, while the water of the atoll is shallow. Thus, off the Cocos-Keeling atoll, the depth sounded at a distance

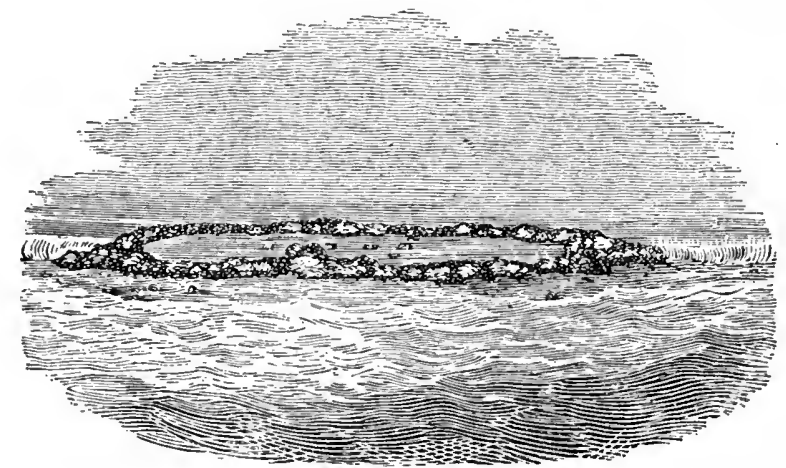

FIG. 77. The atoll of Whitsunday Island. (From Le Conte.)

of 2,200 yards from the reef's edge was I,200 fathoms, while the depth of the lagoon is only from two to seven fathoms (3.5 to I3 meters). In the atolls of the Low Archipelago the depth varies from 35 to 70 meters ( 20 to 38 fathoms), in the Marshall group from 50 to 60 meters (30-35 fathoms), and in the Maldive group up to 90 meters ( 45 to 49 fathoms). (Figs. 75-77.)

The openings in the reefs are always on the leeward side, and so the water within the lagoon is seldom much disturbed. In it live swarms of organisms of all kinds, including fishes and, preëminently, sharks. The calcareous alga Halimeda grows abundantly over the floor of the lagoon of Funafuti in the Ellis group, and of many other atolls in the Pacific, and it has been collected in quantity in the lagoon of Diego Garcia in the Chagos group in the Indian Ocean and elsewhere.

Atolls are especially abundant in the Pacific and the Indian 
oceans. Of the Pacific atolls the largest group forms the Low Archipelago in the center of the Pacific, south of the equator, and next the Caroline Archipelago in the western part of the Pacific, north of the equator. The Marshall group, the Gilbert Islands, the Ellis Island group with Funafuti, and a number of scattered atolls, lie between the two first mentioned archipelagoes. In the Indian Ocean the Laccadives, the Maldives, the Chagos, and the Sava de Nalha groups form the largest of the associations of atolls. The Cocos-Keeling islands may also be mentioned as isolated but typical atolls in the eastern part of the Indian Ocean (lat. $12^{\circ} \mathrm{S}$., long. $96^{\circ}$ E.).

From the geological point of view, a classification based on the relationship of the reef to the continental block is perhaps of even more fundamental significance. On such a basis reefs may be divided into oceanic, those encircling oceanic islands or resting on oceanic platforms, and epicontinental or neritic, those growing upon or on the border of the continental shelf and around the islands pertaining thereto. Each group may be represented by fringing and barrier reefs, as well as by atolls, though the latter are more commonly confined to the oceanic type.

In general only the epicontinental type is represented in the older deposits of the known earth's crust, though some of these may well have had deep, marginal depressions similar to those found off many of the western Pacific reefs. The dolomite reefs of the Tyrol have, however, been regarded as atolls. Of existing examples of epicontinental reefs the Great Barrier Reef of Australia may be considered the best representative. In their composition and internal structure and in the factors influencing their distribution, all reefs are more or less alike.

Factors Limiting the Distrinution of Modern Coral Reefs. The geographic distribution of modern coral reefs falls within that portion of the oceans lying approximately between $28^{\circ}$ north and south latitudes, in those depths in which the mean annual temperature does not fall below $+68^{\circ} \mathrm{F}$. $\left(+20^{\circ} \mathrm{C}\right.$. $)$, nor rise very much above that point. Nost of the existing coral reefs are found in the Pacific Ocean, whose average surface temperature is the highest of the four oceans (19. ${ }^{\circ} \mathrm{C}$., $66.38^{\circ} \mathrm{F}$., maximum $27.60^{\circ}$ C., $80.69^{\circ}$ F.). (See Chapter IV.) The Indian Ocean comes next with a mean annual temperature of $17^{\circ} \mathrm{C} ., 62.6^{\circ} \mathrm{F}$. $\left(27.88^{\circ} \mathrm{C}\right.$, $82.18^{\circ} \mathrm{F}$. maximum), and it is next in importance with reference to the distribution of coral reefs. The Atlantic (mean annual temperature $16.9^{\circ} \mathrm{C} ., 62.42^{\circ} \mathrm{F}$., maximum $26.83^{\circ} \mathrm{C}$., $80.38^{\circ} \mathrm{F}$.), finally, is surprisingly poor in coral reefs, though numerous fringing reefs occur 
in the West Indies, off the coast of Florida and on the coast of Brazil. This is clearly due to the fact that the tropical belt is most contracted in the Atlantic. The Bermuda Islands are a remarkable exception to the general law of distribution of coral reefs, for they are found in the latitude $32^{\circ} \mathrm{N}$., and are therefore the farthest removed from the equator of any modern coral reefs. Their occurrence in such a position is favored by the Gulf Stream, which brings the warm waters of the tropics. No coral reefs are known in the eastern part of the Atlantic.

The eastern part of the Pacific is likewise free from reefs, and this is to be correlated with the fact that the cooler ocean currents from north and south converge here, as in the east Atlantic, to form the equatorial currents. The coral reef area of the Pacific lies west of the 120 th meridian (E.), the greatest area lying between $130^{\circ} \mathrm{E}$. and $145^{\circ} \mathrm{W}$. longitude and between $15^{\circ} \mathrm{N}$. and $25^{\circ} \mathrm{S}$. latitude. The most extensive eastern group is that of the Low Archipelago with Ducie Island, its eastern outpost. The largest western group is that of the Caroline Archipelago, but many scattered atolls and fringing reefs occur to the west of this, notably in the China Sea, where the Paracelle group forms an extensive cluster of atolls in lat. $112^{\circ} \mathrm{W}$., long. $17^{\circ} \mathrm{N}$. The fringing reefs of the Sandwich Islands form a large single and isolated group in the mid-Pacific north of the equator.

The coast of the mainland and the islands of the western Pacific within the coral zone are generally bordered by reefs either fringing or barrier, beginning with the Great Barrier Reef on the south, and extending to the fringing reefs of the Loo Choo group.

The Indian Ocean is generally lined by fringing reefs, which extend with interruptions from Madagascar north along both sides of the Red Sea, in the Persian Gulf around Ceylon and the Nicobar Islands and south along the coast of Sumatra and Java to Australia. In the western half lies the great group of atolls, the Maldives and Laccadives, extending from the equator north to lat. $I 3^{\circ}$ and the Chagos and Sava de Malha groups. The fringing reefs of the Seychelles and of Mauritius also fall in this half of the Indian Ocean. The eastern half contains only the Cocos-Keeling group and some atolls off the northwest coast of Australia.

In general, then, reefs of various kinds occur in the three larger oceans, but are mainly confined to the western half of these oceans. The Indian Ocean alone has representatives in the eastern half, but they are far less abundant than in the western. The Atlantic has no typical atolls, though the Bermudas come near to representing them. 
Depth of Water. The greatest depth at which reef-building corals flourish is 20 to 25 fathoms, though occasionally reef-building species may extend down to 40 or 45 fathoms. At this depth Madrepora has been found growing on the Macclesfield and Tizard banks of the China Sea. These corals were, however, as a rule, of much slighter build than those found in shallow water. The depth here given is of course not the downward limit of corals as a whole, for some species are known to extend to great depths (sec Chapter XXVIII). Reef corals, however, flourish best in shallow water, their most luxuriant growth being above $\mathrm{I}_{5}$ or $\mathrm{Io}_{\mathrm{o}}$ fathoms and to just below low-tide level. Indeed many coral reefs luxuriate in spite of the fact that they are exposed at exceptionally low tides, as shown in Great Barrier Reef of Australia (Saville-Kent-77). The alcyonarian Heliopora and the hydrocoralline Millepora, however, are active reef builders at 35 and 40 fathoms, and nullipores extend to a depth of 35 fathoms.

Intensity of Light. That the range in depth is in part to be correlated with the intensity of the sunlight is shown by the fact that species of reef corals placed in a light-proof life car die after the light has been excluded for several weeks. At Fort Jefferson in the Tortugas, reef corals grow on the peripheral piles of the government wharf, but are absent from the permanently shaded portions. (Vaughan-87:240.)

Now, as has been shown by the investigations of the optics of sea water (see ante, p. 204), the visible deptl in the open ocean in $33^{\circ}$ north latitude is roughly 50 meters $\left(27^{\mathrm{T}} / 3\right.$ fathoms), and in $50^{\circ}$ north latitude it is 40 meters (22 fathoms). In the tropics the depth is even greater, and it thus appears that the reef-building species flourish within the zone of visibility and therefore of greatest intensity of the sunlight.

Temperature. As long ago shown by Dana, the minimum annual temperature of the water must be $68^{\circ} \mathrm{F} .\left(20^{\circ} \mathrm{C}\right.$.), or the mean annual temperature must be above $70^{\circ} \mathrm{F} .\left(21.2^{\circ} \mathrm{C}\right.$.). (Murray-68: 25-27.) All the principal coral-reef regions lie within the equatorial belt where the range of temperature is not over $10^{\circ}$ Fahrenheit $\left(5.5^{\circ}\right.$ C. $)$, and recent observations and experiments have shown that the precipitation of carbonate of lime both by organisms and by inorganic agencies is most active at high temperatures. SavilleKent $(77: 98)$, indeed, insists that reef building is influenced by temperature much more than by the species of corals, for he finds that the same species which build the reefs in tropical waters are not reef-building in extratropical regions. He further holds that it is only in the shallower water where precipitation of lime is caused 
by evaporation that coral conglomerates and limestones occur. Corals as such are, however, by no means restricted to the tropics. Astrangea dance grows on the southern shore of Massachusetts at Woods Holl, and Lophohelia prolifera and Dendrophyilia ramea form dense beds at a depth of from 100 to 200 fathoms off the coasts of Norway, Scotland and Portugal.

Other Physical Conditions. For the successful growth of reef corals it is further necessary that the water should be generally in a state of agitation, the stagnation of the inner marginal waters of the reefs or the lagoons being for the most part unfavorable to the growth of coral. This is chiefly due to the fact that still water permits fine sediment to be deposited, and this quickly kills the polyps. On the other hand, very powerful surf is equally deleterious to the coral polyps, for it will throw the shingles against the soft polyps and so destroy them. Moreover, the heavy breakers will tear off the branching madrepores, and loosen even the massive mrandrinas, owing to the fact that the dead base of the colony is often so much riddled by boring organisms that it easily succumbs to the onslaught of the waves. When such a great mass of coral is loosened, it will be rolled along the reef, rounding and grinding the other corals in its course. (Bourne-14:440.)

A strong current likewise seems to be unfavorable to the growth of corals, if it sets directly against them. Thus at Diego Garcia, and especially at the east end of East Islet in the Chagos group, strong direct currents strike the reef, which is barren here and suffering rapid erosion, where the whole force of the current falls directly upon them. "As the current parts and flows round the obstacle one meets with a reef covered with débris, but barren of live coral; further on, as the current moderates in force, one finds a few growing heads of coral; and finally, at the further end of the reef, where the current has abated its force considerably, there is a luxuriant bed of living corals and Alcyonaria." (Bourne-I4.) The same facts have been observed at Celebes, and the conclusion seems to be supported by many observations "that direct and strong currents are unfavorable to coral growth, that moderate tangential currents are extremely favorable, and sluggish or still water again unfavorable." A hard rock bottom is furthermore a necessity for good coral growth, these organisms finding it impossible to become attached to muddy or silty bottoms.

A normal composition of sea water is required, and the normal salinity of 35 permille seems to be most favorable, as in the open oceans, but a surface salinity decreased to 32.1 permille, as in the China Sea (volume salinity 34 permille), or even 31.5 permille, as 
in the Andamanian marginal mediterranean (volume salinity 33 permille) does not prevent their growth. On the other hand, a surface salinity of 38.8 permille, that of the Red Sea (39 permille volume salinity), is not too high for their development.

Composition and Structure of tiie ReeF. Our knowledge of the composition and structure of the deeper parts of a modern coral reef has been obtained from examination of the accessible parts of reefs and from a deep boring made on the atoll of Funafuti in the Ellis Island group, for the purpose of ascertaining these facts. Three attempts were made, beginning in 1896 , and the depth finally reached was I,I I4 feet ( 185 fathoms). (David-22.) This boring passed only through pure limestone of organic origin to the depth reached, without trace of any other rock. The organic remains found were chiefly corals, calcareous algæe and Foraminifera, besides other types. A boring made from the deck of a ship into the floor of the lagoon, where the water was i 7 fathoms deep, showed a deposit consisting of the calcareous alga Halimeda opuntia, with an abundant admixture of Foraminifera, and having a thickness of over roo feet. At a depth of 245 feet, Madrepora, Porites and Heliopora were encountered, forming a solid mass of coral rock. As these corals are shallow-water types, it is evident that subsidence has taken place and that the lagoon of Funafuti has been filled up to a depth of at least 245 feet (nearly $4 \mathrm{I}$ fathoms).

\section{Materials Composing the Reef.}

The most important of the reef corals of modern reefs are the branching Madrepores, Pocilloporas and Porites and the heads of Astreans and Mreandrinas. Among the hydrozoans Millepora is very abundant, the common species being $M$. complanata and $M$. alcicornis. In addition to the corals a number of species of nullipores occur on the reefs, and often become as important as, if not more so than, the corals themselves. This is the case with the reefs of Christmas Island, of Fiji and Funafuti, where, besides, a prominent part is taken by Foraminifera, Echinodermata, Bryozoa, Pelecypoda and other organisms.

Within the lagoon of some atolls corals flourish in abundance. At Diego Garcia in the Chagos group the more delicate branching species of the Madreporaria flourish in considerable numbers, and true reef-building species of Porites, Mæandrina, Pocillopora and others are also found. "Many of the species growing in the lagoon at a distance of five miles and upward from its outlet are identical 
with those growing on the outer reef. In addition to them are numerous species such as Seriatopora stricta, Mussa corymbosa, Favia lobata, Fungia dentata, and many others that are not found on the outside." This is due to the fact that these corals are either free (Fungia) or attached by such slender stems that they could not maintain themselves in the strong surf and currents of the open ocean.

Within the lagoon these species grow close together and form knolls and patches, which, together with the clastic débris washed into the lagoon, tends to fill it up compietely. The distribution of the organisms in the atoll of Funafuti in the Ellis Island group (long. I $79^{\circ}$ E. and lat. $8^{\circ} 30^{\prime} \mathrm{S}$.) may be taken as representative (Finckh$3 \mathrm{I})$. "On the ocean side up to as far in as the wash of the waves reaches at low-water spring tide, the reef platform is densely covered with vigorously growing organisms." A thinly branching Lithothamnion is the most abundant, appearing in small, isolated shrub-like clusters, from $I$ to 5 inches in diameter and varying similarly in height. Between these grow small Madrepora loripes, Brook. On the outer edge of the platform lichenous and knobby Lithothamnia occur, but no Porites nor Heliopora carulea. None of these species forms patches of great size, owing to the intense intraspecific struggle for existence which takes place here, though eventually Lithothamnion seems to be the victor over the corals and hydrocorallines. This vigorous growth extends for only 2 or 3 feet downward at the edge of the reef below the level of low-water spring tide, below which the reef becomes comparatively destitute of organisms.

The Lithothamnion zone is dissected by a large number of narrow cross channels, which give it a fringed appearance. The edge is generally somewhat raised and rough on account of the Lithothamnion growth, and the encrustation of the surface by Foraminifera, like Carpenteria and Polytrema. This feature is less marked or wholly absent on the lagoon side of the coral reef platform. Different species of Lithothamnion characterize this fringe in different parts of the atoll. Thus in the eastern or windward portion a lichenous form abounds, while in the western or leeward portion of the lagoon rim a thinly branching species and another lichenous form with stony knobs entirely replace the first species.

Next to the Lithothamnion, the branching nullipore Halimeda abounds on the reef, both on the lagoon and ocean slopes. It lives to the $45^{-}$fathom level, while the Lithothamnion has been found alive at 200 fathoms' depth. The hydrocorallines are chiefly represented by the branching Millepora alcicornis and the more massive 
M. complanata. The first is restricted to the lagoon side, the second also occurs on the ocean side. Among the corals Heliopora carulea is by far the most important, but is scarcely found on the outer rim of the atoll. It occurs on the lagoon side, where it often forms the chief lime contributor next to the algx. The yellow Porites limosa and a purple species of Forites also occur on the lagoon side, but seem to be rare or absent on the ocean side. Large blocks of rock made of dead Porites abound in some sections, showing this coral to have been formerly of great importance. Besides these species, the branching Madrepora loriceps abounds on the western rim of the atoll, but is rare elsewhere. Pocillopora of several species also occurs. Astrean corals seem of far less importance at Funafuti than at other coral reefs. The reef platform has a width of 1,300 yards where it supports the islet of Fualopa, but it is mostly much narrower. It consists of a smooth, barren surface formed on dead Lithothamnion coral sand, and coral fragments, generally overlying a basal stratum of dead Helipora carulea, Porites or both. In many cases this old Helipora reef still forms the surface of the platform within the Lithothamnion fringe, the islet being built upon it by the accumulation of coral and Lithothamnion sand and breccia. A dense growth of sea weed is characteristic of the submerged portion of the platform.

In general, the ocean rim of the leeward portion of the atoll is characterized by the enormous quantity of branching Lithothamnion with its vivid coloration, the great abundance of Madrepora loriceps, the general small size of all the species and the absence of Heliopora corulca and Millepora alcicomis. The platform is smooth and not divided into zones, while the transverse channels are short and shallow.

On the windward side, the branching and knobby forms of Lithothamnion are wholly absent, while the lichenous form present has a dark color. Corals are scarce, Madrepora loriceps, Heliopora carulca and Millepora alcicornis being wholly wanting, while Pocillopora grandis, though rare, is the predominant type. No large masses of coral are, however, found. The platform is divided into erosion, corrosion, seaweed and Lithothamnion zones, while transverse channels are numerous, deep and long.

From the platform surface rise the islands built by the calcareous débris derived from the destruction of the corals and nullipores and the old reef rock. As might be expected, the islets are most abundant on the windward side of the atoll, where by far the greatest part of the rim is covered by them, while on the leeward side they are few and much smaller. The leeward islets consist of 
the débris of the reef organisms with plentiful Halimeda sands, but the windward islets are largely composed of the material torn from the reef platform, and sand is scarce.

In places where the islets are absent, the leeward rim passes gradually from an area covered by living organisms nearest the ocean into a central portion of perfectly bare and smooth Lithothamnion rock. Thence to the edge next to the lagoon the conditions of the ocean face of the reef repeat themselves, but on a smaller scale.

On the lagoonward slopes sands abound, consisting either wholly of Halimeda fragments or of these mixed with Foraminifera and shell fragments. On the seaward side the platform generally ends in a cliff or vertical wall, one or two fathoms deep, beyond which the general submarine slope of the atoll begins.

\section{Structure of Coral Reefs.}

In most modern coral reefs it is found that the lens-shaped clusters of growing corals or reef mounds are scattered over the foundation platform "like tufts of vegetation in a sandy plain" (Dana$20: I 74)$, and that they are surrounded and connected by coral sand resulting from the destruction of the reefs by the waves and by organisms. The individual reef mound generally rises as an isolated lens-like mass above the sea bottom to near the surface of the water, and is composed of coral heads and branching forms, between which coral sand and shells and shell fragments of molluscs, echinoderms and other organisms accumulate. The form varies from a shallow lens, which is almost a layer, to that with lateral slopes as high as 45 degrees or over. A peculiar variety known as "chapeiros" were described by Professor Hartt (46:19I, 199-200) from the coast of Brazil. These grow in small, scattered patches, "and, without spreading much, often rise to the height of forty to fifty feet or more, like towers, and sometimes attain the level of low water . . . at the top they are usually very irregular, and sometimes spread like mushrooms or . . umbrellas. Some of these chapeiros are only a few feet in diameter." They grow thickly scattered over considerable areas in those waters. According to Dana, "the rock of these submerged coral heads is but a loose aggregation of coral in the position of growth, except possibly in their lower portion, where the open spaces may be filled with sand and fragments cemented together."

Except where reefs rise from great oceanic depths, their sub- 
merged slopes are generally low, frequently falling much below io degrees. This is particularly the case in the Bermudas, where the slopes are very gentle. The following are given for Hamilton Island in this group. (Dietrich, quoted by Walther-90:903.) Westward the shallow reef extends for 19.4 kilometers, then for the next 8.9 kilometers the slope averages 2 I degrees 50 minutes, carrying the depth to 3,566 meters. Then for the next I I kilometers it rises again at an average angle of one degree 20 mintites to a depth of 3.310 meters, falling again for the next 36 kilometers at an average angle of 2 degrees 27 minutes to 4,846 meters in depth. On the same island the slope to the south-southwest, after passing the reef which extends for 4.3 kilometers, averages 3 degrees 22 min-

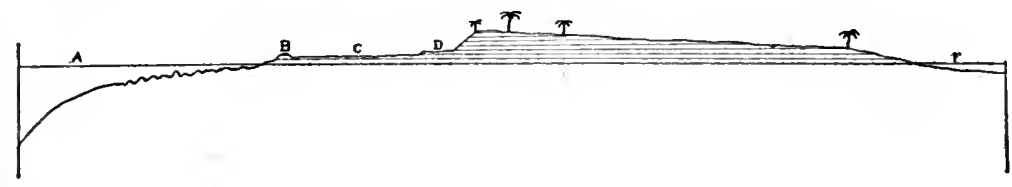

150 Yards

FIG. 78. Section of Keeling atoll, drawn from the outer coast at low water, across one of the smail islands to the lagoon. A-Level of the sea at low water. At $A$ the depth is 25 fathoms, and the distance rather more than 150 yards from the edge of the reef. B-Outer edge of flat part of reef, which dries at low water; the edge either consists of a convex mound, as represented, or of rugged points, like those a little farther seaward, beneath the water. C-A flat coral rock covered at high tide. D-A low projecting ledge of brecciated coral rock washed by the waves at high water. E-A slope of loose fragments, reached by the sea only during gales; the upper part, which is from six to twelve feet high, is clothed with vegetation. The surface of the islet gently slopes to the lagoon. F-Level of the lagoon at low water. (After Darwin.)

utes for a distance of 20.5 kilometers, carrying the depth to I,234 meters. Then it rises again at an angle of $3^{\circ} 8^{\prime}$ for the next 5.5 kilometers until the depth is only $933 \mathrm{~m}$. Following this a slope of $3^{\circ} 55^{\prime}$ for $8 \mathrm{~km}$. carries the depth again to $\mathrm{I}, 48 \mathrm{I}$ meters, beyond which for the next $26.7 \mathrm{~km}$. the average angle increases to $4^{\circ} 9^{\prime}$, carrying the depth to 3,420 meters. Southward after passing the reef $(2-9 \mathrm{~km}$. from shore), the margin of the reef falls at an angle of $8^{\circ}{ }_{11}^{\prime}$ to a depth of 3.328 meters, which is reached $23.1 \mathrm{~km}$. from the edge of the reef. On the north side of David Island the reef extends for $15.35 \mathrm{~km}$., then falls at an angle of $10^{\circ} 8^{\prime}$ to a depth of 2.798 meters, reached at a distance of $15.65 \mathrm{~km}$. from the edge of the reef. On the Bermulas the angle of slope of the edge of the reef varies from $3^{\circ} 22^{\prime}$ toward the S.S.W. to $8^{\circ}$ i $I^{\prime}$ toward the S., $10^{\circ} 8^{\prime}$ to the north and $21^{\circ} 50^{\prime}$ to the west. 
Of $4 \mathrm{I}$ slopes determined on the Bahama Islands the lowest is $0^{\circ}$ and the highest $28^{\circ} \mathrm{I} 8^{\prime}$. Seventy-five per cent. of the slopes are below $10^{\circ}$, while one-third of the entire number of determined slopes falls below $5^{\circ}$.

On Keeling Island, on the other hand, only a few slopes fall below $10^{\circ}$. Nearly half the number of slopes recorded by Dietrich lie between 30 and 43 degrees, one being as high as $63^{\circ} 21^{\prime}$.

A section made by Darwin on this reef showed that "the water deepens for a space between one and two hundred yards wide, very gradually to 25 fathoms ( 45.72 meters), beyond which the sides, plunge into the unfathomable ocean at an angle of $45^{\circ}$. To the depth of ten or twelve fathoms ( $18-22$ meters) the bottom is exceedingly rugged, and seems formed of great masses of living coral similar to those on the margin." (Darwin-2I :22.) The corals and Hydrozoa growing here were Millcpora alcicornis, Madrepora cf. corymbosa, Porites and Astreans. The madrepore was not found in the shallow part of the reef nor in the lagoon, and this and the Astraeans seem to be restricted to the outer slope. Below 12 fathoms and especially at a depth greater than 20 fathoms, the bottom was covered with coral sand, while at 200 to 300 fathoms, and even at 360 fathoms, the floor consisted of finely triturated fragments of stony zoöphytes, particles of the lamelliform genera not being recognized, while shell fragments were rare. (Fig. 78.)

At a distance of 2,200 yards from the breakers, no bottom was found with a line 7,200 feet in length, hence the submarine slope of this coral island is steeper than that of any volcanic cone. (Darwin.) Submarine cliffs are also indicated.

In the shallow part of the reef Porites in places forms nearly the entire floor in great, irregular, rounded masses from four to eight feet broad and little less in thickness. These mounds are separated from each other by narrow, crooked channels about six feet deep, generally intersecting the reef at right angles. On the upper surface of these masses the polyps were often dead, but growth occurred around the margin. This was due to the exposure of these corals at lowest tides, the upward limit of growth having been reached. Further seaward the entire mass was alive. The same is true of the Millepora. Closely within the line marked by these partly dead polyps, and thus above the zone of coral growth, flourish three species of nullipores, one thin like a lichen, one with stony knobs as thick as a man's finger, and one moss-like, with thin, rigid branches. These also require the breakers, for they do not exist in any abundance in the protected hollows in the back part of the reef. They thus form only a fringe about 20 yards in width, but located 
where they form an effective protection against the breakers. They form an artificial breakwater rising about 3 feet higher than the rest of the reef. This is a very common occurrence in modern reefs. Steep slopes are found around many modern atolls, and it appears that where the currents run with greatest force near the reef the slopes are steeper. In the Maldive and Chagos atolls such steep slopes are common. At Heawandoo Pholo 50 and 60 fathoms were found close to the edge of the reef, and at 300 yards' distance no bottom was obtained with a 300-yard line. On Egmont Island a slope of $45^{\circ}$ was found, while the slopes on the Cardoo atoll were so great that no bottom was obtained with a line 200 fathoms long at only sixty yards from the reef.

The general character of the slopes on the Low Archipelago closely corresponds to that found on the Keeling atoll, the slope a short distance beyond the edge of the reef being $45^{\circ}$. In some cases, however, the slope is that of a vertical cliff. Perpendicular or even overhanging cliffs are, however, also found in the quiet water of the lagoon, while in other cases, where the water is generally tranquil, though not always so, as on the leeward side of Mauritius, the slope is a very gentle one.

The shores of the lagoons within the atolls also vary greatly. At Keeling atoll (Fig. 78) they shelve gradually where the bottom is of sediment, and irregularly or abruptly where there are coral reefs. In the Marshall group, on the other hand, the slope is often abrupt so that we pass directly "from a depth of two or three fathoms to twenty or twenty-four, and you may pursue a line in which on one side of the boat you may see bottom, and on the other the azure blue deep water." (Chamisso, quoted by Darwin-21.) In the Matilda atoll of the Low Archipelago the surface of the great exterior reef slopes gently toward and beneath the surface of the lagoon, and then ends abruptly in a little cliff 3 fathoms deep. At its foot a ledge forty yards wide extends, shelving gently inward like the surface reef, and is terminated by a second little cliff 5 fathoms deep, beyond which the bottom of the lagoon slopes off to twenty fathoms, its average central depth. The ledges appear to be formed of coral rock, often porous, so that the sounding lead descends several fathoms through holes in them. Some lagoons, on the other hand, have gentle slopes to the center.

Sections made by Captain Maclear, R. N., of the small island of Masamarlu in the Red Sea show not only the nature of the slopes of a coral island, but also give indisputable proof of subsidence since the commencement of the growth. "In each case the surface of the fringing reef, after shelving very gently downward 
to a depth of about three or four fathoms, is bounded by a submarine cliff. This in one section (No. I) contintes almost unbroken to a depth of about 500 feet, except that a kind of edge or terrace is clearly indicated at a depth of rather less than IoO feet. In the other section the foot of the great submarine cliff is found at about 500 feet, but . . . the cliff is distinctly divided into two precipices by a shelving bank of coral and sand, which begins at a depth of about I 40 feet and reaches the brow of the lower precipice at about 260 feet. This bank is covered by 'sand and coral.' At

No. I.

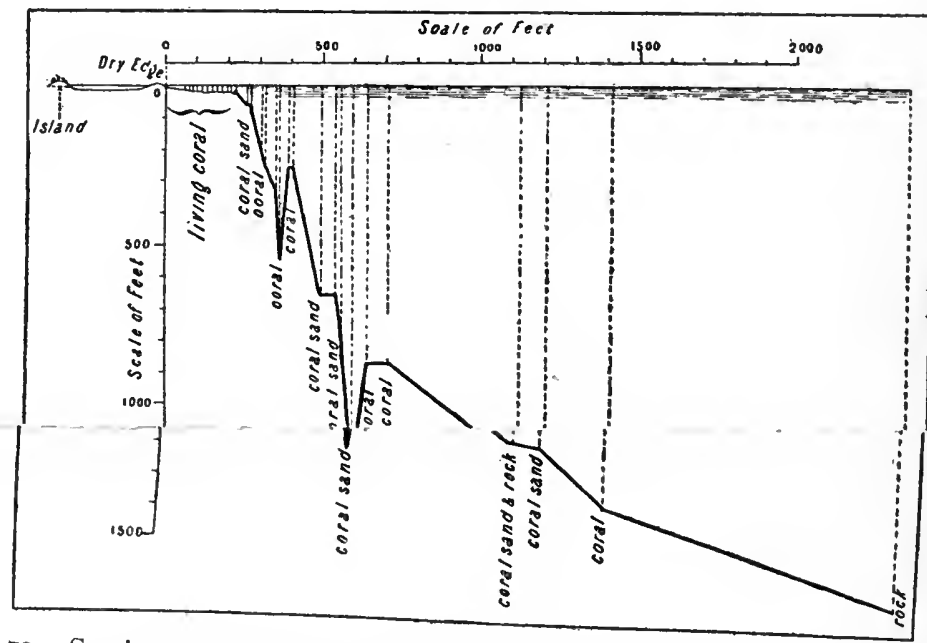

Fig. 79. Section I of Masamarhu Island in the Red Sea, showing the characters of the slopes according to Captain Maclear. (After Saville-
Kent.)

this depth in each section the island is, as it were, defended by a deep and narrow ditch, the edge of its steep glacis being formed by a sharp arète of coral which in one case rises into soundings of falls to a second ditch, the bottom of whis the first section rapidly below sea-level, while its counters which is more than $I, 200$ feet Beyond this, after a level counterscarp rises more than 300 feet. degrees. The second ditch is wanting in the descends at about 30 and sand are found in the bottong in the second section. Coral arètes are formed by coral apparently the ditches, and the two 
indicate subsidence from about 25 fathoms to the present depth of these points. (Figs, 79, 80.)

Cavernous character of reefs. Observation on modern reef knolls shows that the mass as a whole is often cavernous, large, empty spaces remaining where branching corals reach across to form a solid canopy. These caverns are the favorite haunts of the echinoderms, Mollusca and Crustacea which inhabit the reefs, and through the openings by which they communicate with the open sea the pelagic fish of the reefs find constant in- and egress. Such

No. II.

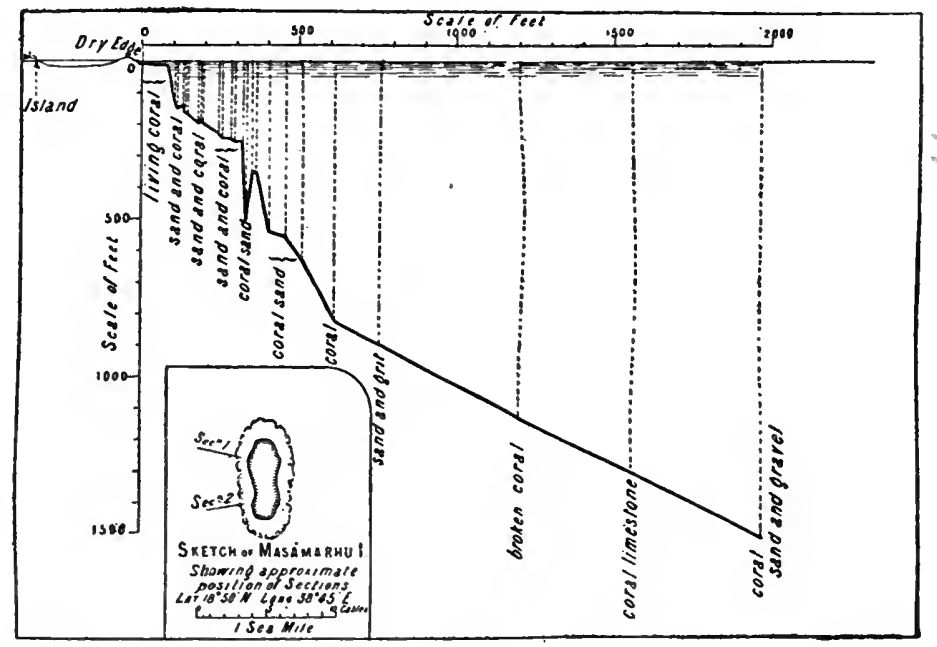

FiG. 8o. Section 2 of Masamarhu Island in the Red Sea. The small map shows the location of the sections. (After Saville-Kent.)

caverns may be preserved after the coral rock is uplifted into dry land, and Walther (90:912) has argued for such an initial origin of many limestone caverns in earlier geological formations.

- In general the structure and form of barrier reefs around oceanic islands differ in no essential from those of the atolls, so that the designation of such a barrier as an atoll with high land rising within the lagoon (Balbi) is quite applicable. Such are the reefs of Tahiti and others in the Society Archipelago, of Vanikoro and of others. The distance from shore of the reef is from one to one and a half, and occasionally even more than three miles, in the Society Archipelago (Ellis). In the few cases where encircled highlands exist in the Caroline Archipelago greater distances are ob- 
served. Thus on the south side of Hogoleu this is no less than 20 miles, 6 miles on the east and 14 miles on the south.

The central mountains in the Society and other groups are generally bordered by a fringe of flat and often marshy, alluvial land, from one to four miles in width, and consisting of coral sand and detritus thrown up from the lagoon channel, and of soil washed down from the hills. These island hills vary greatly in height and character. At Tahiti the height is 7,00o feet, though the maximum diameter of the reef is only thirty-six miles. At Maurua the central peak is about 800 feet high, and the maximum diameter only a little more than two miles. In other cases it is much lower; at Manouai only 50 feet. In most cases the rock is that of an old volcano, while in some cases it is old crystalline rock and in others raised coral reef rock. The number of peaks varies from one to nearly a dozen (Hogoleu).

What has been said of barrier reefs around oceanic islands also applies to the fringing reefs of such islands. These differ from the encircling barriers only in the narrowness of the dividing water channel or moat. Thus on the western side of Mauritius the reef generally lies at a distance of about half a mile from the shore, though in some parts it is distant from one to two and even three miles. In general, the fringing reef rests on the gently sloping submerged portion of the island mass, which in most cases does not descend, within the limits of the reef, to depths greater than those at which coral polyps flourish. Where such a greater depth exists it is to be accounted for either by progressive subsidence and upbuilding of the reef, or by outward growth upon a basis of coral detritus, which forms a talus in front of the growing reef. Fringing reefs are breached by passages in front of every river and streamlet which descends from the enclosed land. Such breaches are found in barrier reefs only in front of the larger streams where the width of the lagoon channel is not too great. The width of the reef varies with the inclination of the substratum.

Characters of Epicontinental Reefs. Reefs resting for the main part upon the continental shelf or its margin are found to-day in the western portions of the three oceans covering the tropical belt, namely, the Pacific, Indian and Atlantic. The largest and most characteristic are those of the western Pacific, the Great Barrier Reef of Australia occupying the first place among these. This, as already noted, extends with a few interruptions for about a thousand miles; its average distance from the land is between twenty and thirty miles, while in some parts this distance increases to between fifty. and seventy miles. It encloses a great lagoon strip which varies in 
depth from ten to twenty-five fathoms, and has a sandy bottom. Southward, where the reef increases in distance from the shore, the depth of the lagoon increases to forty and in some places more than sixty fathoms. Just outside of the reef the water descends to profound depths.

The surface of the reef consists of a hard, white agglomerate of many kinds of corals with numerous projecting points. The outer rim is highest, and is traversed by narrow gullies, and is breached at rare intervals by ship canals.

In form the Great Barrier Reef is a triangular wedge, widening gradually from the shore outward for a distance of from 30 to 90 miles. Just outside of the reef the descent to abyssal depths is abrupt, the outer face of the reef forming a great wall in some cases exceeding 1,800 feet in height, and fronting the whole northeast coast of Australia. Along the outer edge of the platform produced by the reefs is the true barrier, a linear series of reefs bieached by narrow passages. Inside the barrier is a clear and broad channel generally from 15 to 20 fathoms deep, with its bottom covered by unconsolidated lime sand or by a sand" largely composed of the foraminiferan Orbitolites, these remains in some cases also making up the whole sand of the beach either of the coral islets or the neighboring shores.. Outside, in the deep sea, the dredge obtained only a fine-grained, impalpable, pale, olive-green mud, which was wholly soluble in dilute hydrochloric acid, and when dried had the character and consistency of chalk.

Great masses of Porites and Mreandrina flourish on the outer border of the reef, and these when detached from their anchorage are rolled about by the waves and worn, while at the same time grinding down the rock mass bencath until the whole coral head is reduced to fine sand or mud. Such rounded detached masses of Mæandrina 6 or 8 feet in diameter are common among the loose blocks rolled up from the outer slope onto the reef. They may be seen just inside the surf at low water, extending for some miles, and are known as "Turks' heads." Madrepora, Millepora and other genera also characterize the outer reef together with numerous species of astræans. Inside the channel mentioned lie the "inner reefs" separated from each other by narrow waterways through which the tide rushes with great force. Sometimes these tidal currents continue in the same direction even for two or three days, especially after great storms have driven large volumes of water into the reef area. Between the inner reefs and the mainland of old rock lies a shallow channel, mostly free from coral growth.

Among the inner reefs are many, which are to a large extent 
composed of one type of coral. Thus on the Organ Pipe Reef of Thursday Island Tubipora musica predominates, while another reef of this island is largely composed of the blue Heliopora corulea. Other important contributors to the Great Barrier Reef material are Euphyllia, Galaxea, Mussa, Trachyphyllia, Symphyllia, Goniastræa, Prionastræa, Favia, Fungia, etc.; none of these are, however, as important as are the various species of Porites and Madrepora. The hydrocorallines, Millepora and the red Distichopora also add materially to the lime of the great series of reefs.

The reefs on the eastern coast of Africa are of the fringing type, extending for a distance of nearly forty miles, from lat. $I^{\circ}$ $I 5^{\prime}$ to $I^{\circ} 45^{\prime} \mathrm{S}$., and with an average distance from shore of somewhat more than a mile. The depth of the lagoon is very slight, and this continues for some distance outside of the reef, where it is only from 8 to 14 fathoms at a distance of a mile and a half from the reef. The external margin of the reef is formed of projecting points, within which there is a space from 6 to 12 feet deep with patches of living coral on jt. At Mombas (lat. $4^{\circ}$ S.) a reef fringes the coast for thirty-six miles, at a distance of from half a mile to one mile and a quarter from the shore. The channel within this reef, ranging in depth from 6 to 15 feet, is navigable for canoes and small craft. Outside of the reef the depth is about 30 fathoms at a distance of nearly half a mile. Part of this reef is very symmetrical, with a uniform breadth of 200 yards (Darwin-2I).

The reefs of the Florida coast form an interesting example of the fringing type on a shallow continental platform. The southern coast of Florida rises from 12 to ${ }_{5} 5$ feet above the sea-level, in the form of a curving ridge, which encloses an extensive fresh-water swamp, the Everglades. The surface of this lies only two or three feet above sea-level, and is dotted over with small islands, the socalled hummocks. Some distance outside of the southern border of the land lies a row of small islands or "keys" of dead coral rock and sand, ranging from 5 to 30 miles distant from shore and continued westward in a curved line far beyond the western coast of the peninsula. The islands are low and of limited extent, that of Key West near the western end of the line being less than 4 miles long, while the longest of the islands is only 15 miles in length. The keys slope toward their northern shore, and present a steep face to the south, where they are separated from the living reefs by an open channel. Between the keys and the southern coast of the mainland the water is very shallow and navigable only to the smallest boats. This lagoon is, moreover, dotted with small, low mangrove islands. The mangrove trees growing here extend their 
aërial roots in all directions, forming a tangle, which becomes efficient in checking sediment-laden currents and causes them to de-

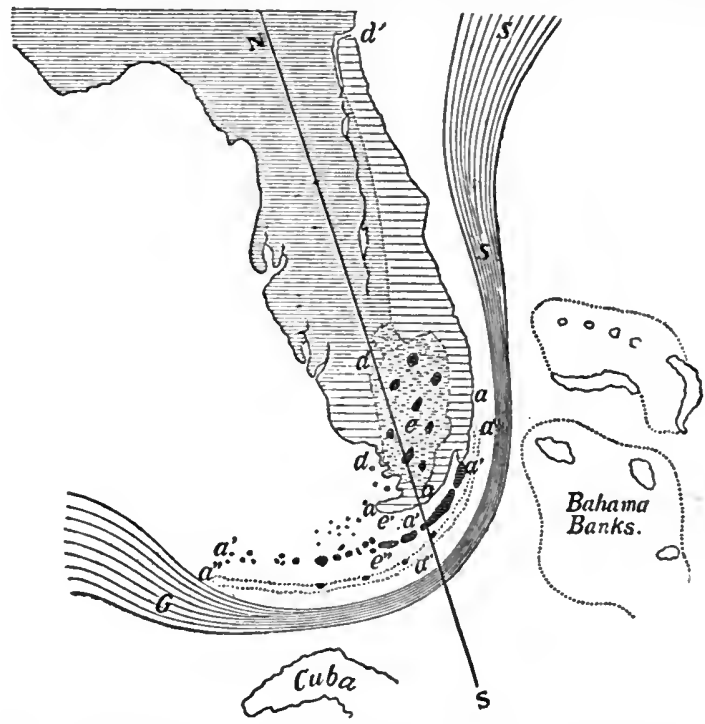

FIg. 8I. Map of Florida, showing the keys and reefs. (After Le Conte.) $a-$ Southern coast ; $a^{\prime}$-keys; $a^{\prime \prime}$-living reef; $d-d^{\prime}$-older coral rock $e$-everglades; $e^{\prime}$-shoal water; $e^{\prime \prime}$-ship channel; GSS-Gulf Stream.

posit their load. Hence the inner lagoon will gradually silt up, and this has already progressed so far that a considerable portion of the area forms mud flats at low tide. (Figs. 8I, 82.) Here, then, a

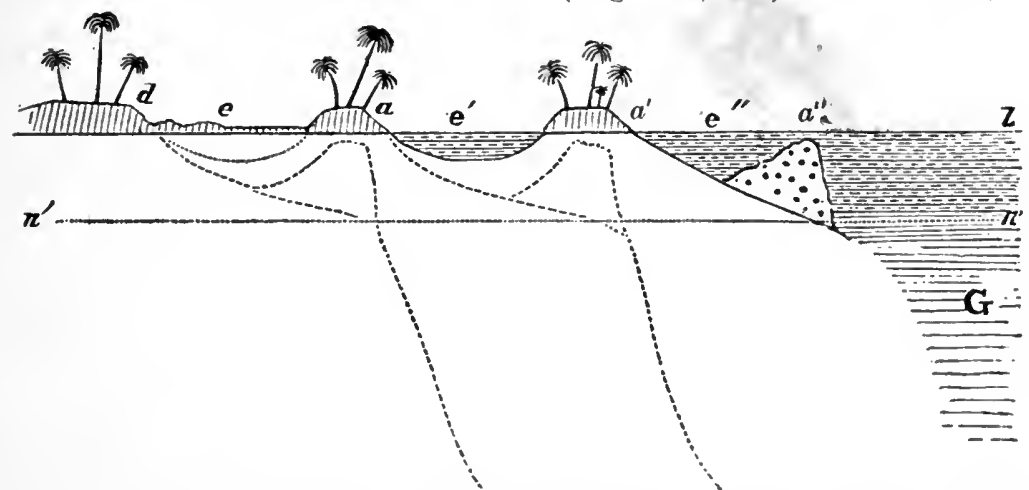

FIG. 82. Diagrammatic section of Florida along the line N.S. in the preceding figure, showing the relative position of the various parts, lettering the same. The dotted lines indicate hypothetical former conditions. (After Le Conte.) 
clastic mud sediment rich in organic matter rests directly upon the ancient coral reef now represented by the keys, a relationship expressed in the rocks of the older geological periods by the superposition of a black carbonaceous shale above an earlier coral limestone.

Outside of the line of keys and from 3 to 15 miles distant from it is a line of living coral reefs, consisting of mounds made up of branching madrepores, Porites, etc., besides many smaller genera such as Manicina, Agaricia, etc. Corallina and Lithothamnion also add a large percentage of calcareous material to the reef.

These reefs are for the most part submerged, rising only here and there to the surface. Between them and the keys lies the outer lagoon, a long, narrow channel five to six fathoms deep and navigable for small vessels. Here the sedimentation consists of coral sand and of the shells of marine organisms, thus producing a normal marine limestone, which is either in the form of a coral breccia or a more or less oölitic calcarenyte. Outside the living reef, the bottom rapidly descends to the abyssal depths of the Florida Straits (2,916 feet).

While nullipores, or the stony algx, luxuriate in the outer zone of the reef, where they form a distinct Nullipore zone in the face of the strong surf, the more delicate branching and brittle corallines are confined to the channels and lagoons within the reef, where they often form thick carpets in the quiet water. Thus the shallow parts of the bottom of the ship channel between the living Florida reefs and the old reefs or keys are covered with the so-called "country grass," one of these calcareous algæ. This is especially noticeable between Fowey Rocks, Triumph Reef and Long Reef on the one side, and Soldier Key and Ragged Keys on the inside (Agassiz$2: 126,127)$. The floor of Hawk Channel, which has a depth of from 6 to 7 fathoms, is covered with disintegrated corals and corallines (Pourtales; Dana-20:2II), while some of the keys in the Dry Tortugas and Marquesas are wholly composed of fragments of corallines bound together into a solid mass. Among these corallines a large species of Opuntia is especially noticeable.

It has been shown by Agassiz that the keys, the southern rim of the mainland, and a strip including the north shore of the Everglades and extending as far north on the eastern shore as St. Augustine, are of coral-reef origin. When this last strip was the living reef, the platform in front was being built out into the sea by the accumulations of the shells of organisms which lived in abundance in the genial waters of the Gulf Stream border. When the platform was sufficiently extended a new line of reefs came into existence, 
forming a barrier reef at a listance from shore where now lies the outer rim of the Florida mainland. The lagoon behind this new reef was of the character of the present outer lagoon, and received normal marine sediments, until with progressive upbuilding the outer reef was converted into a series of dead keys and a new line of reefs came into existence upon the meanwhile extended submarine platform. This new line was subsequently converted into the present line of keys, the preceding row became the southern coastal rim, and the old lagoon behind it was converted by successive steps into the present Everglades. The present inner lagoon channel between the mainland and the keys is gradually approaching the same fate, and it and the line of keys will in turn be added to the mainland, while the present living reef will gradually emerge as a line of islands and the lagoon behind it suffer filling up. It is not likely that a new line of reefs will form outside of the present one, as the force of the Gulf Stream will prevent further extension on the Pourtales Plateau of the submarine platform which serves as the foundation of the reef. (Le Conte-59;60.)

It is to be noted that as the building of the new reef progresses, leading to the extinction of the preceding inner reef, a new type of sedimentation-the mud-flat type-will come into existence behind the older reef, while contemporary calcareous deposits will accumulate in the outer lagoon and on the reef. Thus the top of the limestone series formed by these shell accumulations and reefs will rise progressively seaward, while mud-flat and later continental conditions will progressively replace the marine conditions from the landward side outward. Precisely such conditions existed in the Onondaga (Middle Devonic) period of New York and Pennsylvania, where the coral-forming conditions progressed toward the northwest, while the black Marcellus muds replaced them on the south and east.

Theories of Origin of Types of Coral Reefs. Of all the reef types, the fringing reef alone requires no special explanation of origin, since here the corals grow in shallow water under normal conditions of habitat. All continental or island shores in the tropics, in which the submarine slope is a moderate one, are suitable for coral reef development, provided mechanical detritus is absent or of negligible amount and the other necessary conditions, clearness and saltiness of the sea, absence of large streams, sufficient wave activities, absence of cooling currents, sufficiency of food supply, etc., concur. Corals will grow under such conditions out to the zone of depth limit (20-25 fathoms). Where the stbmerged platform on which the corals grow is increased in extent seaward by the accumm- 
lation of organic or other débris, as in the case of the Florida region, coral reefs may progressively develop seaward in what was originally water of too great a depth for normal coral growth.

Oceanic barrier reefs and atolls, on the other hand, rise from depths greater than those at which reef corals flourish, and so these types need further explanation. Two principal theories have been proposed for their explanation: the subsidence theory of Darwin, elaborated and strengthened by Dana, and the spreading ring theory proposed by Murray and elaborated by Alexander Agassiz.

Subsidence Theory of Darwin. Fringing reefs surrounding oceanic islands may be progressively converted into barrier reefs and finally into atolls by a constant subsidence sufficiently slow to permit the reef corals to grow upward and maintain themselves in a relatively uniform depth within the normal limit. By such a subsidence the older dead coral masses are carried constantly to lower depths, while the top of the reef flourishing on this foundation of dead coral constantly keeps near to the surface of the sea. The channel between the reef and the rock island will become wider as more of this island is submerged, while at the same time it becomes filled by the coral sand, and broken coral masses thrown over the reef and the land-derived detritus supplied by the streams from within. Growing nullipores and other organisms will likewise help in filling the constantly widening lagoon. When subsidence has progressed so far that the central land mass has become entirely submerged, the barrier reef has changed to the atoll and the ring lagoon to the open lake-like body of water within the ring of coral reefs and islets.

This explanation readily accounts for the observed gradation between the fringing reefs and atolls noted in the islands of the $\mathrm{Pa}-$ cific, where every stage seems to be represented. It accounts for the steep slopes and the occasional cliffs of the outside of the reef which descend to abysmal depths, as well as the occurrence of dead reef corals at depths where they cannot live-corals which have been carried by subsidence of their foundation beyond their normal depth and drowned. This theory áccounts also in a satisfactory way for the remarkable distribution of the various kinds of reefs in the Pacific, as shown by Dana. In the middle of the atoll area of the Pacific there is an extensive area 2,000 miles long by 1,000 miles wide free from islands. This is roughly surrounded by a belt of small atolls, outside of which occurs the region of large or grouped atolls, then a belt in which the reefs are mostly barriers and finally the belt of fringing reefs. This distribution is of course to be traced only in a general way. Outside of the last belt there is even 
some evidence of elevation. The subsidence theory accounts for this distribution by assuming that the central area has gone down so fast that the corals could not gain a foothold or were drowned out completely. The small atolls show a rapid and great submergence, but not sufficient to prevent coral growth entirely, the upward growth barely keeping pace with the subsidence, and with no opportunity for spreading. The successive belts show the decrease in the amount of subsidence, so that we pass progressively from large atolls to barrier reefs and finally to fringing reefs, where the zone of no stbsidence is reached, beyond which the movement seems to have been in the opposite direction and dead, fringing reefs cling to the sides of high islands often, at a considerable elevation above the present sea-level.

Evidence of subsidence. The most convincing proof of the correctness of this theory for the explanation of at least some of the coral reefs of the Pacific is furnished by the deep boring on the atoll of Funafuti, which showed organic limestone consisting of corals, Foraminifera, calcareous algæ and other organisms to a depth of I,II4 feet, the extent of the boring. The boring made in the lagoon showed the existence of solid masses of shallow-water corals (Porites, Madrepora, Heliopora) at a depth of 245 feet under a layer of calcareous algx (Halimeda opuntia) and Foraminifera, more than a hundred feet thick. Other evidence of subsidence is furnished by sacred structures erected by the natives on certain coral islands. These now stand in the water, and the paths worn by the feet of the devotees are at present passages for canoes. (Dana-20.)

Davis has recently shown (23) that Dana furnished convincing proof of the theory of subsidence in the region of some coral atolls. This lies in the fjord-like bays which indent much eroded mountain islands, around which coral reefs grow. If no subsidence has taken place, these valleys would be more or less filled by alluvial deposits, since clastic material is constantly brought into the sea by the wash from the mountain. Where, however, the valleys are unobstructed embayments, and continue as such under the water, the evidence of progressive subsidence with corresponding en. croachment of the sea up the valleys seems clear. As Dana says: "The very features of the land, the deep indentations, are sufficient evidence of subsidence to one who has studied the character of the Pacific islands." And, again: "When ... we find the several valleys continued on beneath the sea, and their enclosing ridges standing out in long, narrow points, there is reason to expect that the land has subsided after the formation of the valleys. For such an island 
as Tahiti could not subside even a few scores of feet without changing the even outline into one of deep coves or bays, the ridges projecting out to sea on every side. . . The absence of such coves, on the contrary, is evidence that any subsidence which has taken place has been comparatively small in amount." (Davis-23: 183 .) The following diagram (Fig. 83 ), illustrating this principle, is copied from Davis.

The Spreading Ring Theory of Murray. Sir John Murray's theory of coral reef formation is an elaboration of the early explanation of the forms of coral reefs propounded by the poet-natu-

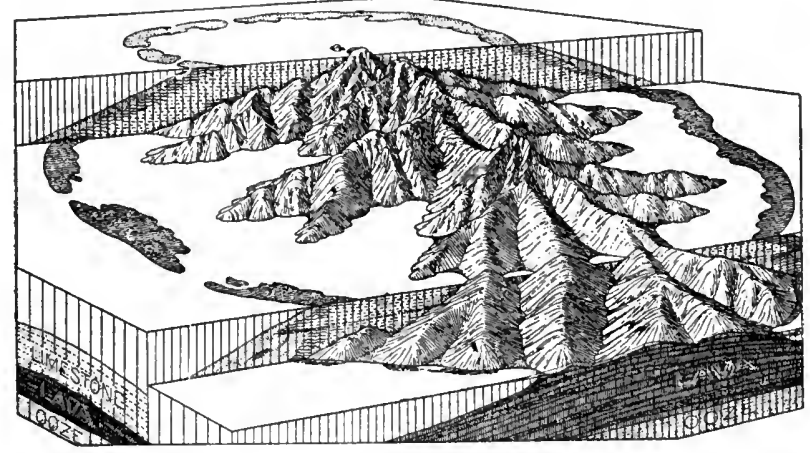

FIG. 83. Block diagram illustrating the effects of subsidence of a much dissected island around the borders of which grow coral reefs. The effect of subsidence is produced by adding to the surface of each successive block an amount equal to the postulated subsidence. The deep embayments in the middle block, from which terrigenous sediment is absent, can be produced only by subsidence. (After Davis.)

ralist Adalbert von Chamisso. It is based on the existence of submarine banks of volcanic or other origin, rising to within a moderate depth beneath the surface of the sea. The existence of such banks has been abundantly shown by soundings of the Challenger and other exploring expeditions. Such submerged surfaces afford a habitat for lime-secreting organisms, such as deep-sea corals, echinoderms, molluses, crustaceans, etc., and their shells and skeletons will gradually raise the surface of the submerged bank until it comes within the zone of reef-coral growth. As pointed out by Chamisso, the corals on the outer side of a growing mass are situated most favorably with regard to wave activity, food supply, etc., and so the reef will rise to the surface as an atoll. The nearer it approaches the surface, the more unfavorable will become the atoll for the 
growth of corals, and these eventually die out on the interior, while they continue to flourish vigorously on the exterior of the atoll. By the accumulation of coral débris on the outer slope of the reef a foundation is formed for the spreading of the coral ring, as in the case of the Florida reefs, and so the diameter of the atoll increases, while at the same time the solvent action of the water in the lagoon and the scouring action of the tide will enlarge the area of the enclosed water body. It may, however, be questioned if the great depth of some lagoons, 40 to 50 fathoms, can be accounted for in this way, especially as in many cases the tendency is to fill up the lagoon by nullipore growth and accumulation of débris.

That such an origin must be accepted for certain atoll reefs is shown by the observations of Guppy (4I) on certain uplifted islands of the Solomon group. On Ugi, Santa Anna, Treasury and Stirling islands, he found unmistakable evidence of a nucleus of volcanic rock, which was covered by an earthy, stratified deposit of mixed foraminiferal and volcanic material similar to the deep-sea muds, several hundred feet thick, and highly fossiliferous, containing the remains of pteropods, pelecypods and echinoderms. On the flanks of these elevated beds are found deposits of coralline limestone varying from 16 to too feet in thickness, and representing the reef deposits now elevated above the sea-level. Santa Anna has the form of an uplifted lagoon, the coral rock 80 feet in thickness and resting on a friable, somewhat argillaceous rock resembling a deepsea deposit. Here we have, then, a clear example of reefs growing on a platform, built up of foreign material, and similar features are shown on the Fiji Islands and the Great Barrier Reef, and on the reefs of the Bahamas, Florida and the Bermudas in the West Atlantic. All of these areas show either stationary conditions or actual evidence of recent elevation.

Multiple Origin of Reefs. On the whole, the subsidence theory seems to be applicable to many, though far from all, oceanic reefs, where at the same time spreading of the coral ring by outward growth may have coöperated. Epicontinental reefs, on the other hand, or those forming on the margins of the continents and around continental islands, are probably in all cases to be explained by growth on suitable foundations, without subsidence, the reef expanding as the platform on which it grows expands. Such an origin is almost certain for the Great Barrier Reef of Australia, and for the Florida reefs, and such an origin is to be postulated for most of the older reefs, which all or nearly all belong to the epicontinental type.

Rate of Growtil of Reef Organisms. Comparatively little is 
known regarding the rate of growth of the organisms forming the reefs. Experiments and observations on Funafuti reef organisms showed that the lichenous forms of Lithothamnion grow very slowly, no appreciable increase in size occurring in five months. When, however, the alga was killed by too long exposure to the sun at low tide, turning white as a restilt, a resubmergence caused the pink color to reappear in a few days by the spreading from a center where some cells still remained alive. Halimeda, however, the alga producing the greatest amount of calcareous débris, grows more rapidly, a cluster 3 inches in height and of equal thickness, and weighing 14.38 grains after it was dried, growing in a period of six weeks.

The rate of increase of Millepora on Funafuti was found to be I6.5 per cent. per annum for the massive $M$. complanata, while the branching $M$. alcicornis showed an average increase in size of $\mathrm{I}$ inch in 34.7 weeks. The latter species also covers objects entangled in its mass, and fragments of Halimeda and other corallines may thus be enclosed. Of the corals, Porites limosa was found to increase in weight at the regular rate of 47.27 per cent. per annum. The encrusting coral Hydnophora microcona was found to spread at the rate of one inch in 39 months. Astrcopora ocellata, though forming new calices between the old ones, showed no measurable increase in size during the period of observation. Pocillopora grandis increased in all directions at a rate of one inch in 13.5 weeks; while small pieces of $P$. vorrucosa were found to increase in weight at the startling rate of $\mathrm{I} 5 \mathrm{O}$ per cent. per annum. This, however, was partly due to the expansion of the living matter over the broken surface, and the formation of new calices there, a feature not normal under natural conditions. A similar large increase was found for $P$. paucistellata. The mushroom coral Montipora incognita showed a rate of growth in one direction of half an inch in three months, and an average increase in three directions measured one inch in 35.7 weeks.

An extensive growth of the coral Orbicella anmularis took place upon a bell olive jar and decanter recovered in 1857 from the wreck of a vessel supposed to be the British frigate Severn, lost off Turk's Island in the West Indies in 1793 . These specimens are now preserved in the Museum of the Boston Society of Natural History. (Crosby, 18:209; Verrill-88.) During the 64 years of submergence Orbicella annularis attached to the bell spread out on all sides. The thickness at the center is about 8 inches and the breadth 15 . The olive jar and glass decanter are cemented together by a similar mass of the same species. The wreck lay in from three to ten 
fathoms of water, and it was covered astern of the middle by thickbranching Madrepora, the branches of which were twelve inches in diameter and sixteen feet in height. This makes a rate of growth for this coral of three inches per year.

Darwin cites some experiments made on the east coast of Madagascar in December, I83o, by Dr. Allan, of Forres. Twenty corals were weighed and placed apart on a sand bank in water 3 feet deep at low tide, each of them reaching in the following July nearly to the surface and being quite immovable, while some had grown over the others. A block of concrete taken at Fort Jefferson, Tortugas, and which had been in the water only twenty years, had a specimen of Mcandrina labyrinthica growing on it, which measured a foot in diameter and four inches thick in the most convex part. (Dana20: I24.) At Key West, a Mrandrina had grown to a radius of six inches in twelye years. An Oculina diffusa planted as a germ in this same region grew in 14 years to a height of four inches and a breadth of 8 inches, while a Mcandrina clivosa in the same time reached a height of two and a quarter inches and a breadth of seven and a half inches.

The rate of growth of coral reefs is, however, much slower than the rate of growth of the corals and other organisms composing them, since these grow only in isolated patches. Estimates on the rate of increase in height of reefs allow two hundred years for every foot of increase.

Compacting Agents of Coral Reefs. The isolated coral heads of the reefs do not of themselves produce the solid limestone masses characteristic of these structures, unless they are bound together either by chemical precipitation of lime in the interstices or by organic agencies. On Funafuti $(74: 147)$ it is the lichenous Lithothamnion which performs this office most effectively, cementing the coral masses to each other and to the reef as a whole. This nullipore will attack both living and dead corals and will cause every interstice as well as every space between the branches, if present, to be transformed into one,solid mass. Thus the coral mass will be permanently added to the reef, enlarging it by the amount of its bulk when taken possession of by the Lithothamnion. Observations show that a coral once attacked by the nullipore will remain stunted, and thus the amount of addition to the reef depends on the period of growth reached by the coral when attacked by the Lithothamnion.

On the Great Barricr Reef it was found that reef forming was less a function of the species of coral than of the temperature, for the same species forming solid reefs in the warmer portions of the 
reef-area remained unconsoliclated in the southern part, where the temperature was lower.

A characteristic feature of the closing stages of reef formation at any locality seems to be the production of coarse oölitic sands. Dana $\left(20: I_{5} 6\right)$ points out that such oölitic beds "appear to be confined to the superficial formation of a reef, that is, to the beach and wind-drift accumulations." The same thing was shown by Agassiz.

\section{Destruction of the Coral Reef.}

Formation of Coral and Other Organic Lime Sand and Mud. The agents at work destroying the reef rock are both inorganic and organic. (74:140.) The most effective inorganic agent is the surf which constantly beats against the outer edge of the reef. Alone, however, it is of little effect, unless it succeeds in breaking off branches of the corals, which may then be hurled up onto the reef, or over it into the lagoon. Coral polyps seem to flourish best

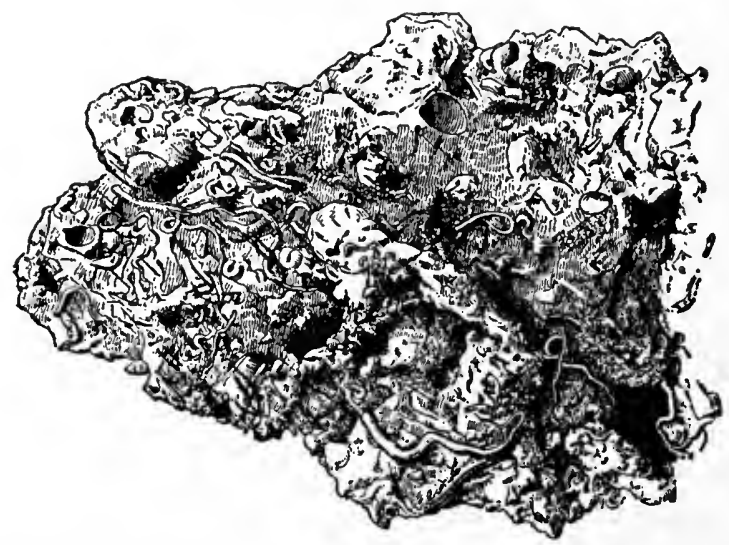

FIG. 84. Organic limestone of corals, corallines, serpula tubes, echinoderm fragments, ctc. Pourtales platcau. (After A. Agassiz.)

where the surf is strongest, so that we have the anomaly of a rock mass growing into the very teeth of one of the most powerful agents of rock destruction. Wherever the surf encounters loose blocks of stone, such as volcanic bombs, or coral heads torn from their foundations, it at once assumes all of its force as an agent of destruction, for it will roll about these rock masses and so grind the coral rock beneath them to powder. On the Florida reefs boulders 
of coral occur formed from the heads of large meandrinas and astreans torn by the waves from their anchorage and rolled about, grinding down the rock beneath them and also being worn themselves.

Perhaps by far the largest contribution of coral sand and mud is made by the activities of organisms. Darwin found that two species of the Parrot fish (Scarus), "one inhabiting the surf outside the reef and the other the lagoon, subsist entirely . . . by browsing on the living polypifers." (2I.) On opening several of these fish, he found their intestines distended by small pieces of coral and finely ground calcareous matter, which must pass daily from them as the finest sediment. On Funafuti, on the other hand, no evidence of such destruction of coral rock by fish was found, though they apparently fed to some extent on the Lithothamnion. In like manner the reported destruction of coral masses by holothurians found no confirmation on Funafuti, where these echinoderms live wholly on the organic matter of the sand and mud. Worms, molluscs and crustaceans, however, appear to be active destroyers of coral rock, though at Funafuti the molluses were found to live among the coral masses without interfering with them. On these reefs, however, the Lithothamnion rock was found riddled by Gephyrean worms and an Aspidosiphon "from two to three inches in length, but very thin, and possessing a long retractile proboscis, by which it is seen at low tide to feed off the Lithothamnion-covered rock immediately surrounding its abode. . . . A small piece of reef rock, a few inches in diameter, when broken off, will show as many as Io or I $_{5}$ of these animals." Echinoderms also dwell in cavities which they have hollowed out of the reef rock, and which, except for the recuperative growth of the Lithothamnion, they would rapidly destroy. Among the most efficient coral destroyers are probably the Crustacea, and they are generally credited with the production of much of the coral sand. Not only the corals themselves, but the shells of molluscs and the tests of echinoderms are ground up by these voracious feeders, the resultant being a mixture of lime sand and flour, which by the sorting action of the waves is distributed in beds around the reef.

Much coral sand will become lodged in the interstices of the reefs between the growing coral masses, thus binding the whole into a solid mound. One of the marked features of this mound of coral rock is the absence of stratification, and when solidified the mound will be an irregular, structureless, often lens-shaped mass of lime rock embeclded in stratified calcarenytes and calcilutytes. Along the margin of the reef the clastic lime rocks will be deposited, 
generally with a steep inclination dependent on the slope of the reef itself, but it will form nearly horizontal beds at a distance from the reef. Close to the reef the clastic material is often a rudyte, consisting of worn fragments of coral embedded in the sand. Calcarenytes are, howcver, the most characteristic clastic sediments around the reef, while calcilutytes or lime-mud rocks are deposited at a distance, where the fine lime mud settles in deeper and more quiet water. Around modern coral reefs the water after a storm is milky for great distances, owing to the presence in suspension of the lime-rock flour. Agassiz has noticed this fine sediment in suspension at a distance of $\mathrm{I} 2$ to 20 kilometers from the reef. After a prolonged storm 4 to 5 centimeters of coral mud were laid down between two tides. (Agassiz-2.)

In the lagoon of Keeling atoll the fine lime débris resulting from the erosion of the reef appears like chalk, but when dry is seen to be very fine sand. Finer grained, purely calcareous lime mud forms large soft banks from the southeast shore of the lagoon, covered with a thick growth of Fucus. Similar material is obtained from the Bermuda reefs and has often been mistaken for true chalk. Dunes of these sands are not infrequently heaped up on the higher parts of the reef, and the steep, submerged slopes are covered with them, even where the angle of the slope is as high as $55^{\circ}$. Similar white lime sands and muds are deposited along the Brazilian coast for a space of I,300 miles, from the Abrolhos Islands to Maranlão.

The sand and rolled coral heads soon become cemented into a hard platform of coral rock more or less structureless in character, this being accompanied in many cases by the growth of Lithothamnion. In Keeling atoll this flat submerged platform "varies in width from 100 to 200 , or even 300 , yards, and is strewed with a few large fragments of coral torn up during gales." (Darwin-2I.) This platform is uncovered only at low water, and Darwin found the rock so well cemented that he could break off a piece only with the aid of a chisel. Calcarenytes composed of the rounded particles of shells, corals, spines of echini, and other calcareous structures occur with the rocks of pure coral mud. These sands are found even where the slopes are as high as $50^{\circ}$. The reef rock itself is often so altered in its older portion that no organic structure can be ascertained in it.

Close to the reef there is often an interlocking of organic and clastic lime rock, for at intervals the reef organisms will extend outward over the region previously covered by the coral sand, after which this sand may again overwhelm the fringe of the reef. 
Fossil Coral and Stromatopora Reefs.

CAMIRIIC ANd PRE-CAMbric. The oldest reef-forming organisms, the Archcocyathida, were originally referred to the sponges, and more recently to the primitive perforate madreporarian corals, of which group they probably form a distinct order. They have been reported from a number of localities in the Cambric, including both Western United States (California, Nevada) and the eastern part of North America (Newfoundland, Labrador), Sardinia, Spain, Northern Siberia and Australia. In a number of these localities they have been found to constitute layers or strata of which they formed the principal portion, but they did not build massive reefs comparable to those of the present day. Since they were all simple corals, and of a very porous character of skeleton, they were not especially adapted to the formation of reefs. Nevertheless, they constituted an important limestone builder of this period, forming in the straits of Belle Isle, Labrador, beds of coral limestone varying in thickness from 25 to 50 feet. In many cases evidence of shallow water, such as conglomerates, ripple marks, trails, etc., are found in association with the beds of Archæocyathidæ. In Sardinia (Bornemann) and in Australia similar extensive reefs of these corals are found, in some cases extending up into the Ordovicic.

The recent finding of archæocyathid fossils forming limestone masses in the Animikie of Canada makes this one of the oldest if not the oldest reef-building coral. The probabilities are that these corals lived in shallow and comparatively warm waters.

The Hydrocoralline, Cryptozoön, formed an important reef builder in the upper Cambric and lower Ordovicic of North America. It always occurs in layers which often have a considerable extent. The individual heads are spherical, from $\mathrm{I}$ to 2 feet in diameter, or plate-like, with a thickness of one or two feet, and from 5 to Ioo feet in horizontal extent. These are not reefs as we apply the term to such structures in the modern sea, though superficially they must have had the appearance of a platform of coral heads not dissimilar to some parts of the broader portion of the Great Barrier Reef of Australia. They may perhaps be referred to as "bedded reefs," and their distribution is probably synchronous with that of the stromatoporoid and other hydrocoralline genera.

These types apparently also formed similar bedded reefs in the pre-Cambric sediments of North America. Walcott has figured a "reef" of Cryptozoön (?) frequens (?=C. occidentale, Dawson) from the Algonkian linestone (Belt terrane) of northwestern Montana, where it forms beds from 6 inches to 3 feet or more in thick- 
ness. (Walcott-89, p1. I1.) It also occurs in similar beds in Alberta and British Columbia, and in Arizona.

ORDovicrc. Reefs of the bedded type have been reported from the Lower Ordovicic, Cryptozoön minnesotensis forming the chief reef builder. Little is known about the detail of occurrence, thickness, and extent of these reef masses, which have been found in many localities in the eastern United States and Canada. In the Middle Ordovicic (Chazyan) the genera Stromatocerium and Stylarca form similar developments in New York, Tennessee, Kentucky and Oklahoma. In the Black River horizon Stromatocerium is reënforced by Columnaria and Tetradium, in Tennessee and Kentucky, and these genera also form reef-like associations in the Cincinnatian of these states. These same genera, together with Beatricia, Labechia, Calapœecia, etc., form reef-like associations in the Richmond of North America from Baffin Land and Anticosti to the Mississippi Valley and also in Colorado, Nevada, Wyoming and Alaska. (Vaughan-87:244.) None of these is to be regarded as a typical reef, these structures being rather of the type of plate-like expansions or bedded reefs, often of not more than a single layer of hydrocorallines. They were undoubtedly an important source of the lime sands and lime muds of the formations in which they occur, though in many cases they seem to lie in undisturbed position as of growth. It is not improbable, however, that the corals and hydrocorallines of one section were ground up to form the sand which covers undisturbed layers of the same horizon.

Siluric. Coral reefs are well developed in the Siluric, where typical Palaeozoic reef builders-Favosites, Heliolites, Halysites, Syringopora, etc--among the corals, and stromatoporoids among the hydorcorallines abound. They have been especially described from Wisconsin and from the Island of Gotland in the Baltic Sea. Others occur in the Upper Siluric of western Ontario and Michigan, in the Louisville limestone of the Falls of the Ohio, the Lewistown limestone of Pennsylvania, and in the Wenlock of England and in Bohemia.

Niagaran Reefs of Wisconsin. The Siluric strata of southeastern Wisconsin are characterized by typical coral reefs which form mounds almost entirely composed of coral and Stromatopora masses, and separated from.each other by interspaces of some extent, in which the coral sand and mud were deposited in stratified layers. (Chamberlin-15:364; Grabau-40.) These mounds stand out in relief, owing to the peculiar resistance of the structureless reef rock to erosion, while the bedded strata of calcarenyte and calcilutyte between them more easily suffered denudation. In the 
older days quarries were opened in these recfs, but, owing to the absence of stratification planes or seams, the operations were more difficult and costly, and the old quarries were abandoned when the bedded strata were discovered.

The exposed face of the old quarry is generally thoroughly weathered, and it shows an all but structureless surface, the chief characteristic of which is the total absence of stratification. The reefs consist largely of stromatoporoids, among which the genus Clathrodictyon seems to abound. The reefs as exposed are generally several hundred feet in diameter, with a height of perhaps 50 feet. They thus constitute a series of independent reef mounds rising from a platform which is sometimes composed of organic accumulations and at others of clastic material. On the borders of the reef mounds the material consists of coral sand, consolidated into calcarenyte, and this dips away from the reef in all-directions. This dip is not due to any tectonic deformations, but is the original dip of the clastic material on the flanks of the reef. The dips observed in the Shoonmaker quarry near Wauwatosa range as high as 54 degrees close to the reef, while dips of 28 to 34 degrees are more common, and others as low as 18 degrees occur. Further away the strata become practically horizontal. (Grabau-40.) At the Distillery quarry in Milwaukee (foot of Twenty-ninth Street) dips of 40 degrees toward the east and west and of 20 degrees and more to the south have been observed. The two reefs mentioned and a third in the grounds of the National Military Asylum form a triangle, in the center of which quarries have been opened to a great depth in evenly bedded, rather fine-grained calcarenyte, this being the coral and crinoid sand derived from the reef and swept together in even-bedded strata in the inter-reef spaces. These limestones are sparingly fossiliferous, the roving orthoceratitic cephalopods alone occurring in abundance. The strongest possible contrast existed between the reef mounds, on the one hand, on the borders of which flourished a rich fauna of corals, bryozoans, brachiopods, molluscs, trilobites, and crinoids, and the nearly barren sandy bottoms of the comparatively shallow sea on the other; desert areas surrounding luxuriant oases of animal and plant life.

A typical reef mound exposed by quarrying operations near Cedarburg, 20 miles north of Milwaukee (Grabau-40), shows a thickness of about 30 or 40 feet of coral rock, though the full measure is not exposed. The dianieter of the old reef mound was perhaps 300 feet from north to south. Much of the reef rock has become dolomitized, and in many of the bedded strata the corals have been dissolved out. The central part of the reef consists of 
stromatoporoids, with perhaps a moderate development of Favosites and other corals. On the flanks of the reef numerous smaller corals are found, together with an abundance of crinoids, brachiopods, molluscs, and some trilobites. The peripheral dips of the bedded strata are of the usual character, and here, as in the other reefs, a repeated interfingering of the reef rock and the bordering clastic strata is marked. Several miles from Groth's quarry, just described, is Anschütz quarry, on the road to Grafton. Here the bedded strata on the flanks of the reef are well shown, their character being that of a typical calcarenyte locally known as sandstone. The general arrangement of the Siluric reef mounds of Wisconsin is in more or less linear series parallel to the old shore of the period, but probably at a considerable distance from that shore. (Chamberlin-I 5.) The arrangement appears to have been that of a barrier reef, the eastward extent of which can be traced through northern Michigan, where an abundant coral fauna, probably in reef association, is found on Drummond Island and elsewhere. Its eastern extent appears to have been in the vicinity of Lockport, New York, but neither there nor in Michigan have actual reef structures been observed. Farther south occurred independent reefs, remains of which are now found at Louisville, Kentucky, at the Falls of Ohio. Probably many other reefs of this age exist in the Hudson Bay region, where strata of this age still await detailed exploration.

Siluric Reefs of Gotland. One of the finest exhibitions of Palæozoic coral reefs is found on the western coast of the Island of Gotland in the Baltic Sea. (Wiman-93; Hedstrom-47; Munthe65.) Here the erosion by the waves both at the present altitude and during a former period of higher water has exposed a series of wonderful sections through the ancient reefs such as are probably not to be found anywhere else in the world, though equally fine sections of Mesozoic and later reefs are well known. There appear to be two main horizons in which the reefs occur, separated by a disconformity, one series being best exposed in the northern and the other in the southern part of the island.

In general aspect the "reefs" are lenticular mounds locally known as "klintar." They stand out as bold cliffs on the shore, their massive, structureless character offering great resistance to both wave and atmospheric erosion, whereas the bedded enclosing strata are more rapidly reduced by both agencies, and so produce indentations and reëntrants in the coast line. (Fig. 85.)

Unlike the Siluric reefs of Wisconsin, those of Gotland are practically unaltered by subsequent dolomitization, and hence their 
structural character and composition can be readily ascertained. The materials of which they consist are partly corals, among which are Halysites and Favosites, both massive and branching forms, Striatopora, Pachypora and Syringopora, which latter is especially adapted by its loose method of growth to retain the coral sand produced by the erosion of the reef. Stromatopora heads are likewise common in these reefs, and often of large size, and with them occur calcareous algæ (Sphærocodium) and Spongiostroma, which sometimes constitute as much as 50 per cent. of the reef-building types, though when occurring alone they form beds instead of reefs.

On the borders of the Gotland reefs characteristic interfingering of the organic and detrital limestone is often well shown, as for instance at the cliff of Hoburgen in the sonthern part of the island. Often masses of stratified sand appear to be included in the reef mass, a phenomenon also observed in the reefs of $\mathrm{W}$ isconsin. The

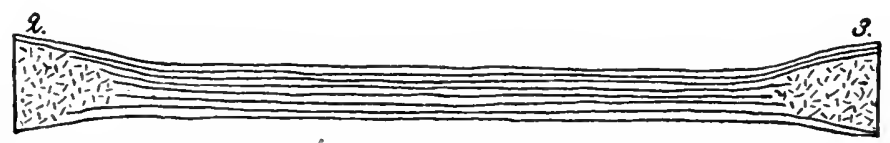

Fig. 85. Diagram of the reef structure at Gotland, and the relation of the reefs to the bedded formations. (After Wiman.)

detrital lime sand is thickest on the border of the reef, and it is often well stratified, dipping away from the reef as in the Wisconsin examples. Overturned coral heads are common on the border of the reef, these being torn from their original anchorage and rolled about by the waves of the Siluric sea, which used them as millstones. to grind the coral and other organic rock into sand and mud, which was either deposited within the interstices of the reef or swept outward to form bedded strata of limestone. The detrital lime sand is in part the result of such destruction of the corals and the brachiopod and molluscan shells, but to a large extent it is derived from the dismemberment of crinoids, the stems and calices of which yield an abundance of discs and plates through the natural dissociation of these components on the maceration of the dead organism. Much of this crinoidal detritus is alreadly of sufficiently small grain to be directly included among the stratified sediments forming outside the reef. Crinoidal conglomerates, formed of the discs of the larger crinoid stems, as well as coral conglomerates, are of common occurrence on the borders and summits of the reefs. 
The Gotland reefs often rest on marly clay beds or on oölitic sands. When the latter is the case, it appears that these oölitic sands immediately succeed a shallow-water, if not terrestrial quartz sandstone, and are themselves of very shallow-water origin, showing an abundance of wave activities. The reefs were thus evidently built in water of no considerable depth, as is further shown by the structure of the reef borders themselves. Where the reef rests on the marl shales, the latter show evidence of relative plasticity at the time of reef formation, for the reefs, with growing size and weight, sank into the marly muds to some extent, forcing the mud away in either direction or causing the layers to bend down under the reef.

The reefs of this section apparently formed a barrier parallel to the old Scandinavian land, in part of which graptolite-bearing shales seem to have been deposited at the same time. The earlier reef series shows its proximity to the land by the fact that, in the lagoons between the reef mounds, terrestrial or semiterrestrial organisms, the eurypterid Pterygotus and the scorpion Palreophonus, were found together with marine organisms. It is highly probable that the reef was dotted with islets, and that perhaps even freshwater lagoons existed, and this would serve to explain the existence of these continental organisms. It is noteworthy that the Pterygotus beds occur at the lower boundary of a distinct hiatus, which marks a period of land condition for the entire island, and was probably of much greater extent.

Upper Siluric Reefs of North Amcrica. Reef structures are known from the Upper Siluric (Monroan) formation of western Ontario and Michigan and the equivalent Lewistown limestone of Pennsylvania. They probably occur in formations of similar age in northwest Canada. The best example of these reefs occurs in the Anderdon limestone quarry, about a mile northeast of Amherstburg, Ontario. (Sherzer and Grabau-80:43.) Its thickness is only from 6 to 8 feet, but its horizontal extent is unknown. It is probably of the nature of a series of lenses of organic limestone, surrounded by and passing into the finest lime mud strata (calcilutytes) derived from the destruction of the reef. The organisms of the reef are mainly stromatoporoids, Stromatopora galtense and Clathrodictyon ostiolatum predominating. With these occurs the small branching stromatoporoid, Idiostroma nattressi, which was especially adapted to capture the coral sand and mud produced by the grinding action of rolled Stromatopora heads. Corals of the genera Favosites, Diplophyllum and Cladopora, all well adapted to capture coral sand, on account of their loosely branching habit, and simple 
corals of less importance as reef builders also occur. Brachiopods and molluses appear to be rare. however. A remarkable feature of this reef is the enclosing rock, which is a calcilutyte and wholly unfossiliferous so' far as exposed, except in the upper layers. Organisms seem to have been confined entirely to the reef, while the surrounding area was the site of the deposition of the finest lime mud. It is highly probable that the fineness of this mud explains the absence of macroscopic forms of life, because few animals can exist in muddy water such as this must have been.

Elsewhere in this horizon reef structures of similar type are developed. They are well shown in the Lewistown limestone of central Pennsylvania, where, near Tyrone, they consist almost wholly of stromatoporoids of the same species as at Anderdon, together with the Favosites, Cladopora and Diplophyllum found there. In the Manlius limestone of New York State similar Stromatopora reefs are found. These are more especially of the bedded type, consisting of one or more layers of Stromatopora heads of various sizes and belonging to a number of genera and species. Other organisms are rare, and the enclosing strata are mostly calcilutytes.

It is a common fact that such bedded Stromatopora reefs are enclosed in calcilutytes, and this seems to be due in part to the absence of other organisms which could furnish lime sand. The mutual attrition of the massive Stromatopora heads seems to have resulted chiefly in the formation of lime nuud. If so, the progress of sedimentation here must have been an exceedingly slow one.

Devonic Coral Reers. The Devonic formations abound in coral reefs both in North America and Europe. They occur in the lower Devonic of Konjepruss, Bohemia, in the Onondaga of New York, and the Falls of Ohio, the Traverse group of Michigan, the Devonic of Canada, of Belgium, the Eifel and elsewhere. The details of the reef structure of only a few of these have been investigated, and these will be discussed at some length.

Lower Devonic Recfs of Konjepruss, Bohemia. As exposed in the quarries near Konjepruss, the lower Devonic limestone of Bohemia $\left(F_{2}\right.$ of Barrande) shows a massive, structureless reef facies, in which the zoögenic limestone is largely composed of massive Favosites and stromatoporoids, while brachiopods, molluses, trilobites and small corals also abound, especially on the margin of the reef. Laterally this reef limestone merges into a stratified, coralline limestone (see Kayser and Holzapfel-55). The reefs are underlain by the Upper Siluric platey limestones and black graptolite shales, but whether they rest directly on these deposits or are preceded by shell layers has not been ascertained. 
The Onondaga Recfs of New York. The Onondaga limestone of the State of New York is a good example of an ancient formation resulting from the growth of numerous coral reefs and the accumulation of their attendant deposit of clastic lime sands. (Grabau-40.) The formation varies in thickness from about 50 feet in the eastern part of the state to about 200 feet in the western, and is in part continued westward into Ohio and Michigan by the Columbus and Dundee limestones, the age of which, however, appears to be somewhat younger. Throughout this extent the formation rests upon an old land surface, or the deposits of continental origin formed during that period, and partly reworked by the transgressing sea. At first more or less siliceous limestones containing shells of molluscs and brachiopods were formed (Schoharie grit, Decewville beds), and on this foundation the corals began to grow. It appeais that the corals formed a series of barrier reefs roughly parallel to the old coast line, which passed through New Jersey, southeastern Pennsylvania, central Maryland and West Virginia. Close to the shore in the northern part clastic deposits, chiefly grits, were forming, but the southern section is marked by the accumulation of black muds (Romney shale) with a depauperate fauna of few species. The conditions were much the same as we find now in Florida, where the inner lagoon is a region of black mud deposits with a mingling of marine and fresh-water organisms. In Pennsylvania and in New York a succession of reefs was apparently formed parallel to this southeastern shore, each series progressively farther removed to the north and west from this coast. The gradual advance of the inner lagoon conditions toward the northwest is shown by the progressive creeping out of the black mud deposits over the old dead reefs, the Onondaga limestone being progressively covered by the black Marcellus muds, which are to a large extent the lagoon equivalents of the reef limestone farther seaward. In most localities the deposits formed immediately over the dead reefs continue to be of lime sands derived, no doubt, from the still-living reefs farther out to sea. These lime sands were, however, abundantly charged with silica, probably in the form of sponge spicules and diatoms, and these gave rise to the layers of chert found in these upper rocks in such abundance in some localities, and on which account this rock early received the name of Corniferous limestone. These corniferous deposits swell between the reefs, where most probably the lagoons were situated, and they are buried in turn by the encroaching black mud deposits which represent conditions of deposition unlike those found in the open sea. That the deposits of black mud were pro- 
gressively replacing the deposits of limestone is shown by the fact that the highest layer of these rocks in western New York, the Agoniatite limestone, extended eastward during a temporary eastward transgression of the sea, and rests on 50 feet of these black muds in eastern New York, where the Onondaga is only 50 feet thick, and on 175 feet of black muds in Maryland, where the Onondaga limestone is absent. In western New York, where the Onondaga is about 200 feet thick, it consists of reefs in the lower part, followed by shell limestones and cherty beds in the upper. This in turn is followed by over 50 feet of black shale practically barren of fossils except in a few localities, and there sometimes including the remains of eurypterids and other arthropods adapted to brackish or fresh waters and rarely found except in the deposits of shallow coastal lagoons, protected embayments or fresh-water lakes or rivers. In Ohio and southern Michigan the deposits of limestones of the Onondaga type began much later, and also continued much

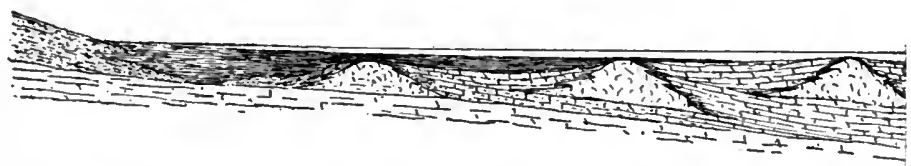

FIG. 86. Diagram showing successive advances of the coral reefs and accompanying clastic lime sands and the covering muds of the inner lagoons.

later, so that the overwhelming black muds reached that part of the sea only toward the close of the deposition of black Marcellus muds in western New York. (Fig. 86.)

Few of the actual reefs have been located and described, this being due more to lack of attention directed toward their structure than to their non-exposure. It is also important to bear in mind that modern quarrying operations are carried on in the bedded strata of inter-reef origin, and that the structureless reefs, so difficult to operate in, are avoided. This is strikingly shown by the quarries opened in these limestones in western New York (Williamsville), two of which are found on opposite flanks of a reef several hundred feet in diameter; the reef itself being untouched. (Grabau-40:340.) In the quarries the various dips away from the reef are shown, these, however, not often exceeding $10^{\circ}$. (Fig. 87.) On one side the sloping floor of the quarry is formed by the upper surface of the reef, and here the composition of the reef can be ascertained. Enormous heads of branching Syringoporas, 
Eridophyllum, Synaptophyllum and Diplophyllum occur here, their interstices filled in with coral sands. Favosites likewise abound, the heads being often of enormous size. Large Cystiphyllums and Cyathophyllums also occur, and crinoid stems are equally abundant. In the bedded limestones near the reef, fragments of Favosites abound, and sometimes heads of great size occur, but they are partly worn, and very commonly overturned. Here we have the coral breccia formed of the dead coral heads on the borders of the reef, enclosed in the coral sand derived from the reef by the grinding action of the waves which rolled about these fragments of coral and used them as tools for their destructive work. Brachiopods, bryozoans, molluses and other lime-secreting organisms are also plentiful on the borders of the reef, while the remains of giant placoderm fishes found in these deposits further" complete the

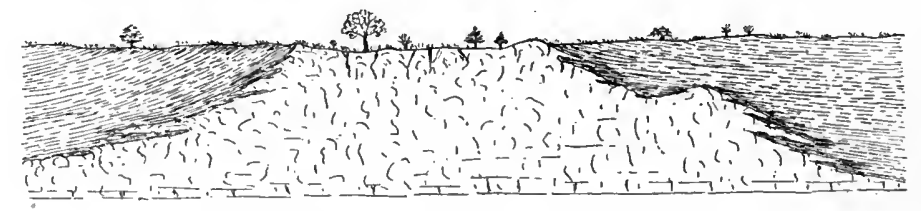

FIG. 87. Section of a reef in the Onondaga limestone of Williamsville, N. Y. Two quarries have been opened in this section, one on either side of the reef. The left-hand (eastern) quarry does not quite touch the reef, but the floor of the right-hand (western) quarry rests partly upon the reef and exposes the low secondary reef-mound.

faunal list and show us some of the organic agents influential in the destruction of the coral reef and the production of the coral sand. These fishes are especially abundant in the later deposits of this series in Ohio and Michigan, from which I9 species have been obtained as against 8 species from the Onondaga of New York.

In some portions of the Ohio limestones small globular bodies, Calcisphara robusta, abound, sometimes making up the limestone. These resemble the spore capsules of the fresh-water lime-secreting alga, Chara, and may be part of a plant, or more probably a foraminiferan, of the kind living abundantly to-day in the quiet waters of the lagoons within the coral recfs. (See description of Funafuti.)

Reefs of this age are likewise found in southern Indiana and adjacent portions of Kentucky (Jeffersonville limestone of the Falls of the Ohio).

Middle Devonic Reefs of Michigan. In the Hamilton or Traverse group of Michigan reefs are well developed, and almost every 
characteristic of the structure of I'alacozoic recfs is shown. The best examples are found in the eastern area of the northern part of the Southern Peninsula in the vicinity of Alpena. Here their occurrence is marked in the topography by low mounds or swellings which rise above the general level of the country, a feature observed in Siluric coral reefs as well, as, for example, in the neighborhood of Visby, on the Island of Gotland, where such knolls form a marked feature of the topography, many of them being surmounted by windmills.

The Alpena reefs (Grabau-40) are mostly well exposed in the quarries which are extensively opened up in this rock, the purity of which makes it desirable for chemical and other purposes. Analyses of the reef rock have given over $99 \%$ of calcium carbonate. The

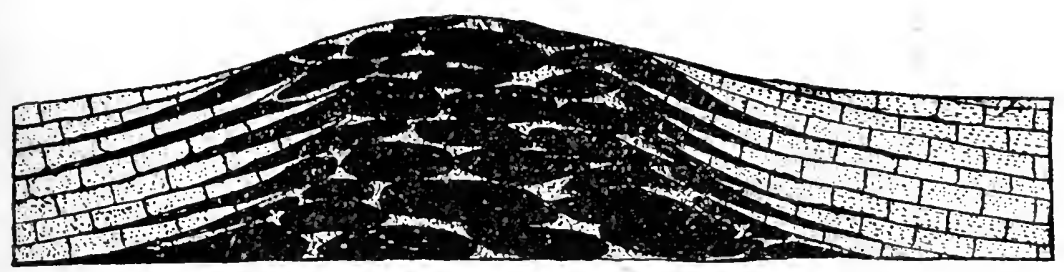

Fig. 88. Diagram of the reef structure in the Traverse (Middle Devonic) limestones of Alpena, Mich. The black masses represent corals (Favosites, Acervularia, etc.) and stromatoporoids. The dip of the calcarenytes and calcilutytes on the margin of the reefs and the interfingering of the reef and clastic formations are shown.

reef mounds are of the usual lens shape, the height averaging 35 feet, while their diameter at the base is several hundred feet. The chief reef-builders are large heads of Favosites, Acervularia, and stromatoporoids, many of them three or four fect in diameter, while occasional stromatoporoids up to ro feet in diameter also occur. Branching species of Favosites are common, and bryozoans, crinoids and brachiopods help to swell the organic content of the reef. Between these organisms the coral sand abounds, binding the whole into a solid, structureless mass, in which lines of stratification are entirely wanting. Even where the coral sand fills extensive cavities in the reef mass, no stratification is shown. In stuch cases the coral heads may be found wholly enclosed in the sand, and often overturned. For the most part, however, the coral heads lie in their normal position of growth, successive heads growing on a foundation of older corals embedded in crystalline sand. (Fig. 88.)

On the borders of the reef-mounds the clastic lime sand forms beds which are often steeply inclined. Close to one of the mounds, 
for example, the dip was $28^{\circ}$, then rapidly changed to $14^{\circ}$, and then more gradually to $2^{\circ}$. The sand here is finer than that filling the cavities in the reef, but it often includes fragments and partly worn heads of Favosites, Stromatopora, etc., lying in all positions. Occasionally the material is a coral breccia, but for the most part it is a calcarenyte. Farther away from the reef-mound it frequently becomes a calcilutyte or rock made up of the finest lime flour. Throughout the marginal zone there is an interlocking of organically formed and fragmental lime rock, indicating a periodic spreading outward of the reef and a subsequent overwhelming of each expanded rim by fragmental deposits. These spreading fringes of the reef consist mainly of the smaller branching corals and of bryozoans, which at times extend far out on the foundation of coral sand. These expanded rims, formed when erosion temporarily ceased, extend outward to form the dividing planes between the successive strata of the bedded limestones, where they are often replaced by films of silty or even clayey material. These periodic cessations of erosive activity on the reef and the spreading of the reef fauna over the surrounding beds of unfossiliferous coral sand must be due to the local protection of the reef mass from the waves. This may be brought about by the becoming effective of some outer barrier formed by the slow growth of an outer reef which has become of sufficient height to break the force of the waves, or by the building of a temporary sand or shell bar. At such times the various minor organisms of the reef fauna find it possible to spread in all directions in the relatively quiet water, and so form a layer of fossiliferous material between the thicker layers of coral sand limestone. It is on these dividing planes, as every collector knows, that the largest number of specimens is found, the limestones themselves only rarely carrying unworn fossils.

In some cases, however, the dividing planes close to the reef mark a period of especial destructiveness, when the smaller corals and other organisms torn from the reef are rolled outward and come to rest in more or less worn conditions as a bed of organic conglomerate upon the uniformly grained clastic limestones. In some cases the spreading organic rims are marked by the death of the corals, especially the simple types, and by their partial solution. The cyathophylloid corals often have their epithecas dissolved away. On such a partly corroded surface Bryozoa and other attached organisms grow, showing that conditions unfavorable to the true corals did not affect some of the other organisms. These conditions are well shown in the upper part of the reefs near Alpena. 
On the western side of the State of Michigan, in the Petoskey and Traverse Bay regions, at present only the marginal portions of the reefs are shown in the outcrops and cuttings: here the rock is made up of fragments of Acervularia davidsoni, Favosites and stromatoporoids embedded in the crystalline sand, these often forming a veritable coral conglomerate, such as is found on the flanks of modern coral reefs. Farther away from the reef the coral fragments cease, once the rock becomes a well-stratified calcarenyte or calcilutyte. That the waters in which these beds were deposited were shallow is shown by the occasional cross-bedding and the ripple marks found in these strata, as well as by the repeated phenomenon of contemporaneous erosion and deposition, and the wedging out of certain strata and the thickening of others. Not infrequently seams of carbonaceous material separate some of the layers of the limestone, and in these layers plant remains are not uncommon.

The sections exposed below the city of Petoskey in the Traverse Bay region are very instructive in this connection. As stated, they represent the marginal portions of the reefs and show a succession of erosion planes dividing the entire mass into strata from a few feet to 10 or 20 feet in thickness. These strata show successive accumulations of coral sand with worn pebbles of corals or stromatoporoids, generally of the size of a man's fist or larger, and arranged in strata which in some cases are horizontal, in others dip in various directions at low angles. There is a certain succession of remains in the various strata, those of the higher beds being distinct from those of the lower. In the upper beds the branching stromatoporoid Idiostroma caspitosum is the chief organism, and this is often found in the position of growth, its finger-like branches spreading to capture the coral aand. Most of this coral sand has since been dolomitized with the result that the mass is rendered porous. The coral pebble strata are often traceable for miles without apparent change in character.

These successive erosion planes suggest that periodic subsidence was going on here during the growth of the reef, each stratum being eroded when its growth had brought it to within the level of wave activity. The change in fauna with the change in the growth of the reef is analogous to the changes in fauna found at successive steps in the building of modern reefs. A striking feature of the clastic strata of this region is the frequent intercalation of calcilutytes made from the finest lime flour. These and the equally pure beds of calcarenyte are in some cases separated by layers of carbonaceous shales indicating a period of plant growth, and probably even local terrestrial conditions in the form of vege- 
tation-covered islets, such as are characteristic of coral reefs to-day. -Devonic Reefs of the Attawapishkat River, Canada. In the southern part of the Province of Keewatin, in Canada, reef structures occur in the Devonic limestones. (Bell-12:27G, 28G.) These have been exposed in natural sections by the Attawapishkat River, an affluent of James Bay. These reefs have the character of great spongy and cavernous limestone masses often occupying the full height of the cliffs, which is about 40 feet. They are structureless masses of rudely lens-like character and "largely made up of fossils, although the number of species does not appear to be great." The principal forms are brachiopods (Meristella, Stropheodonta), a trilobite and corals. Stromatoporoids are probably also among the abundant reef-builders. The thinly bedded limestones which enclose the reefs dip away from them at various angles, and are sparingly fossiliferous. These beds are more easily removed by

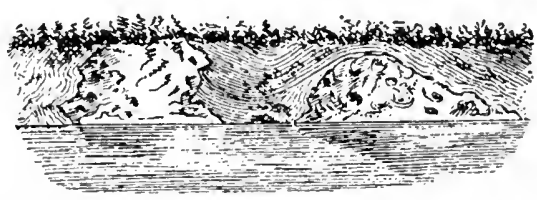

FIG. 89. Reef mounds enclosed in bedded formations of Devonic age. Attawapishkat River, Canada. (After Bell.)

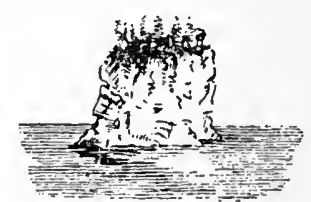

FIG. 90. A single reef mass left by erosion of the bedded rocks. Attawapishkat River, Canada. (After Bell.)

erosion, with the result that the reef masses stand out in bold relief like the Klintar of Gotland. The numerous islets in the Attawapishkat River "appear to consist of single masses," each of these reef-cores being left in relief by the removal of the surrounding strata. They are locally known as zigruams by the native Indians. (Figs. 89, 90.)

Middle Devonic Reefs of the Eifel and Belgium. The Middle Devonic Stringocephalus beds of the Eifel show in many sections a typical reef structure similar to that already described for the Devonic of North America. As in other cases, the reef masses stand out in relief, forming high cliffs of structureless limestone often dolomitized. The structure and topography are in many cases modified by the eruption through these limestones of Tertiary volcanic rocks. The chief reef-building organisms in these deposits are Favosites, Cyathophyllum, Endophyllum, Stromatopora and Actinostroma. Brachiopods, gastropods, pelecypods and cephalopods are also characteristic and sometimes abundant. The usual 
inclined marginal strata have been noted in a number of sections in the Eifel, and the character of the reefs is not unlike that of the more massive American reefs, such as that of the Niagaran of Wisconsin. The reef masses rest upon a foundation of crinoidal limestone.

The corresponding Middle Devonic Calcaire de Givet (Givétien) of Belgium has the reef structure well developed. (Dupont-27.) The reefs have at first impression the appearance of amorphous limestone, passing into more or less saccharoidal rock. On weathered surfaces a somewhat brecciated structure appears, together with numerous outlines of corals or sponges, slightly left in relief by the solution of the enclosing limestone. Stromatoporoids make up a large part of the reef, but they have been profoundly altered, so that it is difficult now to separate the stromatoporoids along their lamine or structure planes even with a hammer. It is only on weathered surfaces that the true composition of the reef is shown, the fresh surfaces showing only a compact rock often with conchoidal fracture, full of cavities, but without trace of the stromatoporoids or other organic content. As in other cases, the reef is structureless, no stratification being visible. The reef-formers beside the stromatoporoids (Stromatactis and Pachystroma), include Favosites, Alveolites and more rarely cyathophylloids. Cyathophyllum cospitosum occurs on the margin of some of the reefs in crowded heads from $\mathrm{I} .5$ to 2 meters in diameter. The flanking beds of clastic limestone show well-marked stratification, and between the reef knolls these clastic limestones often contain beds of crinoidal fragments, and others largely composed of shells.

Dupont deduces from the arrangement of the reef masses that they constituted fringing reefs to the land of that period, and he has found indications of a breach in the reef line in the Frasnien reef north of the Couvin, which is analogous to the interruptions in the reef opposite the mouths of streams coming from the fringed land. Reef structures of similar character are found in the Devonic of the Karnic Alps on the Austro-Italian border. (Frech-34; 35.) The reefs are chiefly in the Middle Devonic, and composed of Alveolites, Heliolites, Stromatoporas, etc., while Stringocephalus and other brachiopods are among the other characteristic organisms of the reefs. The reefs themselves rest on bedded Lower Devonic (Konjeprussian) limestones composed of an abundance of brachiopods and crinoids, of corals and of other organisms.

Mississipric ReErs. These are less abundant and are not so widespread as the Devonic reefs. None have as yet been described from America, though they are known to exist in some sections. 
Mississippic Reefs of Belgium. In the Mississippic (Tournasien and Viséen) of Belgium occurs a distinct reef facies known as "Calcaire de Waulsort" and belonging in part to both of the above subdivisions. This limestone is a massive, structureless agglomeration of the stromatoporoids Stromatocus bulbaceus Dupont and Ptylostroma fibrosa Dupont. To the surfaces of these hydrocorallines adhere numerous fronds of the bryozoan Fenestella. Corals play only a small part in these reefs, including Amplexus coralloides and a few other rare types. The reefs are in the form of small massive heaps or islets scattered through the bedded limestones which surround them and are marginally entangled with them. These limestones are of diverse character, and chiefly marked by the clearness of their stratification. Two varieties of this limestone may be distinguished, the amorphous and the crinoidal. The latter, formed from the dissociated joints of crinoid columns, commonly fill the channels in the reef mass proper. As in the case of the Devonic reefs, these also are disposed in the form of fringing reefs parallel to the old shore, and separated from it by a lagoon canal of greater or less width. In one case the reef has been followed for a distance of 60 kilometers.

- Mississippic Reefs of Great Britain. In the Mountain limestone of Great Britain certain structures occur which have been interpreted by Tiddeman $(84 ; 85)$ as reefs, but this interpretation was challenged by Marr (62). The structures in question occur in the Craven district of Yorkshire, on the south side of the Craven fault system, in the Pendleside and Clitheroe limestones. "The form and the system of arrangement of the white limestones [of the knolls] are peculiar. The stratification of the deposits is usually somewhat obscure, and the masses rise in the form of conical or ovoid eminences up to a height of 300 or 400 feet. The change of thickness occurs in a very limited horizontal extent. These eminences ordinarily present upon their sides strata which dip away from the mass in all directions; but when the rocks of the eminences have been quarried, or denuded by atmospheric agents, one sees that the stratification, rough as it is, preserves its horizontality or agrees with the direction of inclination of the surrounding country. ..." (Tiddeman-85:32I; Marr's translation-62.)

"At the foot of these mounds, or reef knolls, as I would call them, we have in many places a breccia formed of fragments of the limestone, which, I take it, have been broken off the reef above between wind and water, and have subsequently been covered up by the mud of the Bowland shales and compacted into a breccia. 
Fragments of limestone similarly consolidated occur, though more rarely, on the sides of these knolls themselves. I would call these reef-breccias." (Tiddeman-84:602.) The knolls are crammed with brachiopods, pelecypods, crinoids, corals, etc., many fairly perfect. This, however, is true only in a general sense, for in places the limestone is apparently entirely devoid of fossils, though this, as in the case of many of the other reefs cited, may be due to obliteration of the organic structure.

Marr (62) has pointed out the abundant evidence of folding and thrusting in the rocks of this region, and he would explain these knolls as due wholly to tectonic movements, the thickening of the limestone being due to folding and thrusting. That the region has been much disturbed is clearly evident from the facts given by Marr, but that the knolls are wholly due to tectonic causes seems doubtful. The original reefs of the limestones would serve as centers of resistance in which the cumulative effects of the thrusts would be most strongly marked.

\section{Fossil Reefs of Bryozoa and Other Organisms.}

Bryozon Reefs of tile German Zeciistein. In the Zechstein of the southeastern district of Thuringia in Germany reef structure is well developed. The reef-forming organisms here are, however, no longer corals but Bryozoa. These bryozoan reefs form large block-like masses of structureless dolonite which lies scattered within the normal bedded Zechstein strata. When erosion has carved away the enclosing bedded strata, the reef mass stands out in relief, forming frequently isolated bastion-like mounds, not uncommonly surmounted by a castle or an ancient burg. The reefforming organisms are chiefly closely crowded masses of Acanthocladia anceps, Fencstclla retiformis, Phyllopora and other Bryozoa. Corals are wholly absent, but brachiopods are well represented by Productus horridus, Strophalosia goldfussi, Terebratula clongata, and Spiriferina cristata, while the pelecypods are represented by Pseudomonotis speluncaria and Prospondylus liebcamus. The most abundant organism, however, is a lime-secreting sponge or hydrocoralline, Evinospongia, which covered the cliffs up to the level of the sea. These reefs grew upon the cliffs of older rocks which projected as islands and as lines of crags above the floor of the early Zechstein sea. They extended along the southern border of the Harz old land and the East Thuringian peninsula, from Köstritz past Pössneck, where they are especially well developed, 
past Saalfeld to Eisenach and southward around the peninsula to Liebenstein. The floor of the Zechstein sea had previously been covered with the black Kupferschiefer mud rich in decaying organic matter, chiefly the carcasses of dead fish and decomposing algæe, and in which the copper now obtained from it was precipitated. These deposits did not cover the ledges upon which the reefs subsequently grew when normal marine conditions were established. These reefs grew to the height of 40 to IOO meters, with steep sides which, however, often show the interfingering with the clastic limestone which surrounds their flanks. This limestone is often almost devoid of organic remains, forming a dark "Stinkstein" or a blue compact

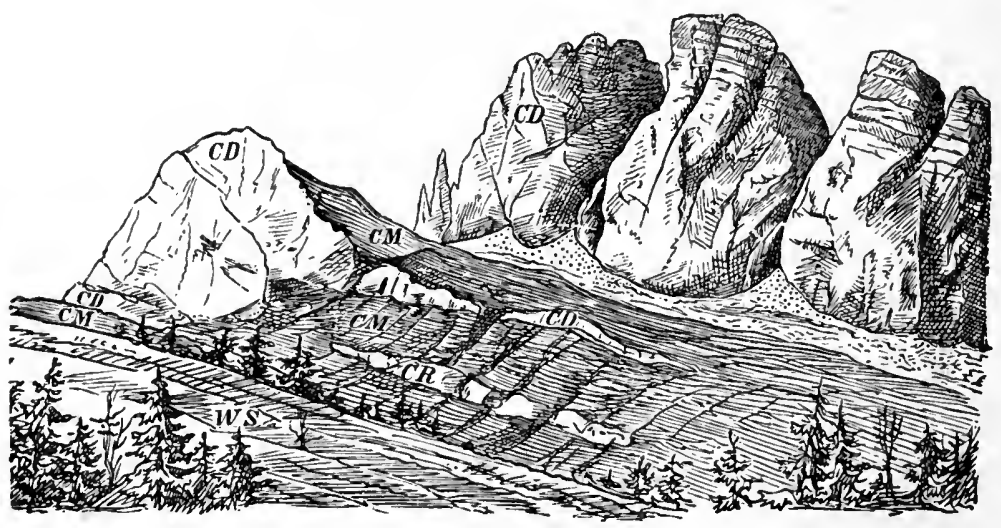

FIG. 9I. Dolomite reefs of South Tyrol. Richthofen reef on left with tonguelike extensions into the contemporaneous marls. Sett Sass on right. C D-Structureless Schlern-dolomite. (Kayser.)

lime, both well stratified, and succeeded by a porous dolomitic "Rauchwacke." The growth of the reefs came to an end with the closing of the outlet from the open ocean to this epicontinental sea, and the beginning of gypsum and salt deposition (referred to in the preceding chapter), the reefs being eventually buried under hydrogenic or clastic deposits.

The Triassic Reefs of the Tyrol. The dolomites of the southern Tyrol are regarded by many geologists as examples of fossil reefs on a gigantic scale. They consist of huge, structureless and more or less circumscribed masses of limestone or dolomite representing a distinct facies of the mid-Triassic, which is elsewhere represented by the bedded and often highly fossiliferous Cassian, and underlying Wengen and Buchensteiner divisions of the 
Ladinian. The masses are often of great thickness, that of the Schlern-dolomite reaching over 3,000 feet (1,000 meters), and they are commonly of limited horizontal extent. Tongue-like offshoots of the "reef rock" extend into the surrounding bedded strata as is the case with modern coral reefs. The reef character of these masses was first pointed out by von Richthofen (72), and they were subsequently more fully described by Mojsisovics (64). This author calls attention to the fact that the position which these isopic masses occupy with reference to the heteropic strata enclosing them is that of a reef mass growing upon a basis of volcanic or other origin, but rising above the level of the sea floor on which the heteropic deposits were forming. The latter, therefore, have their bases at a lower level than the reef masses, which always project above the synchronous bedded deposits surrounding them.

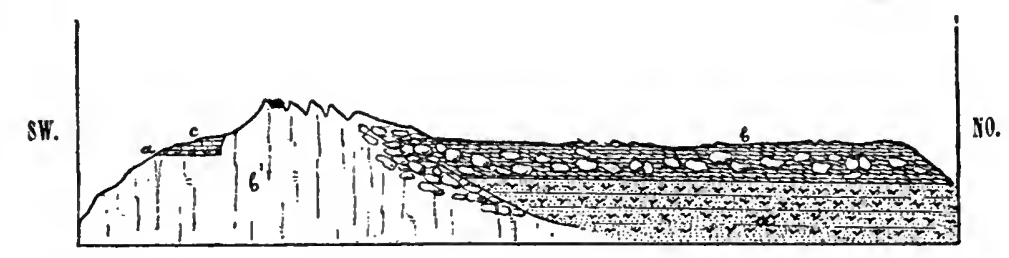

FIG. 92. Section of the Schlern-massif, showing the relationship of the dolomite "reef rock" to the bedded formations, South Tyrol. (After Mojsisovics.)

The chief structural characters pointing to the reef origin of these masses are: the resemblance of the isolated dolomite masses to upraised reefs; the great concentration of the dolomite masses thousands of feet thick tailing off laterally into marly deposits of much less thickness, but formed during the same interval of geologic time and often showing inclined bedding near the reef; the absence of bedding in the "reef masses"; and the occurrence of interfingering masses and of blocks of the dolomite material on the slopes of the "reefs" and apparently intercalated among the surrounding sedimentary deposits. (Figs. 91, 92.) On the other hand, many observers (Ogilvie-7o, Diener and Artharber-24 and others) hold that the structural features are due to faulting and that the dolomite masses are fragments of once continuous deposits of marine origin. They do not deny, however, that they constitute distinct facies of the Cassian, Wengen and Buchenstein or even earlier berls.

Corals are very rare in the dolomite, calcareous alga and echinoderms constituting the chief organic remains. This has forced the 
advocates of the reef theory to regard these deposits as more strictly nullipore reefs, in which corals played only a secondary part. The organisms of these massive dolomites have for the most part been destroyed during the alteration of the deposit, but it has been possible to ascertain that the chief lime contributors were a coral, Thecosmilia subdichotoma, and a coralline alga, Diplopora annulata. The abundance of this and other calcareous algæ is the cause for the frequent interpretation of this mass as a nullipore reef. Brachiopods (Koninckina leonhardi, Rhynchonella faucensis), pelecypods (Daonella parthanensis) and cephalopods (Ptychites acutus, Gymnites palmai, Japonites ganghoferi, Hungarites bavaricus, etc.) occur at a few points, as for example, in the massif of the Zugspitze, but are as a rule very rare. Large gastropods (Chemnitzia) occur at many localities in the reef masses. The bordering heteropic limestones sometimes consist largely of Diplopora fragments, and as a rule are very rich in organic remains, especially close to the reef.

Recently the problem has been attacked by Professor Skeats (82) from the chemical and petrographical side. He started with the ascertained facts that in modern coral islands remote from land areas and volcanic rocks the amount of insoluble residue in the reef rock is negligible. The same is true also of many coral rocks associated with volcanic rocks, though those in the proximity of the volcanic masses were found to contain a considerable quantity of insoluble material, amounting in some cases to 4 per cent. or over. With this as a basis, he made numerous analyses of the dolomites, which showed the prevailing purity of the rock, the percentage of insoluble residue being in the majority of cases less than one per cent., and frequently almost zero. Where residue is present, it can generally be attributed to association with contemporaneous volcanic rocks, as is the case in the raised coral reefs of Fiji.

Taking the purity of the rock, the absence of structure and its occurrence as enormously thick masses in the surrounding clastic strata into consideration, there appears to be no other mode of origin than that due to the growth of corals, with an abundance of calcareous alga, foraminifera and echinoderms, such as are found in some modern coral reefs. These Triassic reefs formed a barrier reef to the land mass lying to the north, whose main axis consisted of the crystalline rocks now forming the central chain of the Alps. In the beginning of Triassic time continental sediments spread north from these highlands, forming the Bunter Sandstein deposits of Germany. In mid-Triassic time, however, a marine invasion from the north caused the deposition of the Muschelkalk, only to be fol- 
lowed again by non-marine sedimentation in later Middle and Upper Triassic time. While the period during which reefs were forming corresponds largely to that during which the Wellenkalk and Muschelkalk were forming north of the Alps, it probably continued to some extent into the time when the continental sedimentation began in the north.

In view of this relationship of the reef to the old coast line, the development of certain accessory features becomes of interest. Thus the interfingering, the cross-bedding and the irregular overlapping structure characteristic of the more or less inclined beds on the flanks of the reef (Uebergussschichtung) with their irregular swelling and the union and separation of layers, are confined to the parts of the reefs farthest away from the old shore, $i$. e., the southern or outer side of the reef, where it was exposed to the wave destruction and where it rose steeply from the sea. The lagoon side, on the other hand, is characterized by the abundance of Diplopora related to the modern Cymopolia, delicate, branching corallines, which abound only in the protected waters of the lagoons, and do not occur on the outer side of the reef, where the stony nullipores find a congenial habitat.

In the upper bedded strata of the Cassian formation, coarse oölites are common in the eastern part of the reefs, a feature associated with the closing stages of reef formation at the present day. The Raibler beds overlying the reefs also are oölitic, and contain many layers of calcarenytes. A remarkable feature of these dolomite reefs is the accompanying eruptive series of augite porphyry lavas, which began after the reef had already assumed massive proportions. The reef masses thus appear to have set a limit to the extent of these lava flows in one direction, and they spread over the submerged flanks on which the clastic sediments, formed by the destruction of the reef, had accumulated. The result was the formation of a remarkable limestone tuff breccia, which is commonly found at the base of these flows.

The Jurassic Reefs of Solnhofen. In the Jurassic beds of the Solnhofen district in Bavaria, famous for its lithographic stones and the beautifully preserved fossils found in it, reef structures are well developed and have recently been fully described by Walther (9I). The thin-bedded lithographic layers (calcilutytes) are found to rest in shallow basins in a coarse, unstratified or rudely stratified limestone with which they interfinger at the margin of the basins, and which even rises above the level of the youngest of the lithographic stones (Figs. 93-95). These coarse, unstratified limestones are reefs on a large scale, composed chiefly of sponges, corals and 
bivalve molluses, among which large and coarse types, such as oysters, Pecten, Hinnites, Lima and especially the curiously twisted Disceras predominate. The last is so abundant in some places, $e . g$., Kelheim, that the beds have become known as the "Disceras limestones." These molluses flourished on the margin of the reefs, where the wave activities were strong, and food plentiful. Large and coarse gastropods were also plentiful, including Nerinea, Cerithium, Turbo, Pleurotomaria and others. With these also occur large brachiopods (Terebratula and Waldheimia), which occupied the cavities in the reefs, and sea urchins, which had heavy skeletal parts and crawled about on the reefs. All these are now incorporated in the coarse reef rock which constitutes a large portion of this formation. These organisms are best preserved on the margins of the reefs, the main portion having more commonly the appearances of a structureless limestone or dolomite (Franken dolomite,

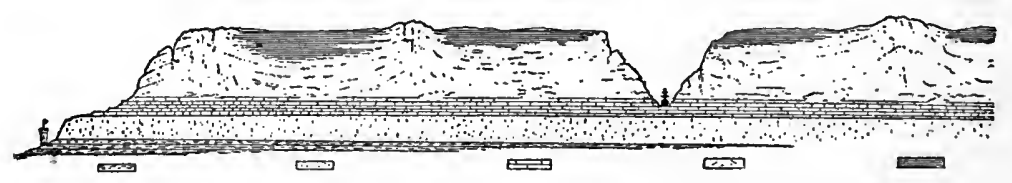

FIG. 93. Section through the reef region (Jurassic) of the Altmühl, in the Pappenheim-Eichstädt region (near Solnhofen) in Bavaria. The reef rock is structureless, the thin bedded "Plattenkalke" or lithographic beds are shown in the lagoon-like depressions in the reef. (After Walther.)

Kelheim limestone). This rock is well shown in the gorge of the Danube at Kelheim, and in numerous other natural and artificial exposures in Franken. As a rule, the reef masses stand out in relief in the present topography, while the inter-reef portion, occupied by the thin-bedded calcilutytes (Plattenkalke), is often worn out into a hollow or depression. The individual knolls seem to have had an arrangement suggestive of atolls, though on the whole this series of reefs is more properly to be regarded as forming a barrier reef to the old Jurassic land. (Fig. 93.)

The reef-rocks of the Swabian Alb have recently been studied by Dr. Fritz Berckhemer,* who finds that the Hydrozoan Ellipsactinia is one of the principal reef-builders, holding the place of the stromatoporoids of the Palæozoic, and of the milleporoids of later time. These, together with nullipores and the lime-sand derived from

* Fritz Berckhemer. Eine vorläufige Mitteilung über den Auıbau des Weissen Jura $\epsilon$ (Quenstedt) in Schwaben. Jahreshefte d. Vereins f. Vaterl. Naturkunde in Würtemberg, 69 Jahrgang, I9I3 pp. 1xxvi-1xxii. 
the destruction of the reef, make up the "reef masses" which surround the basins in which the platy limestones (Plattenkalke) were deposited. In many cases, these Hydrozoa reefs rest upon or over the sponge reefs of a lower horizon.

The presence of islands on these reefs is shown by the eolian more or less oölitic limestones with pronounced eolian cross-bedding, shown in the quarries of Schnaitheim and Zandt. These have precisely the structure of the eolian rocks of Bermuda. Walther suggests that the organisms of the reefs near Nattheim were abruptly killed and preserved by the mud spread over them, and so they escaped the usual fate of the coral reef organisms, which are destroyed by boring organisms, and changed to structureless dolomite. Subsequent silicification has resulted in the wonderful preservation of this coral fauna, for which this region has become famous.

The basins containing the fine and thin-bedded lithographic rock form the strongest possible contrast to the enclosing reef mass. In

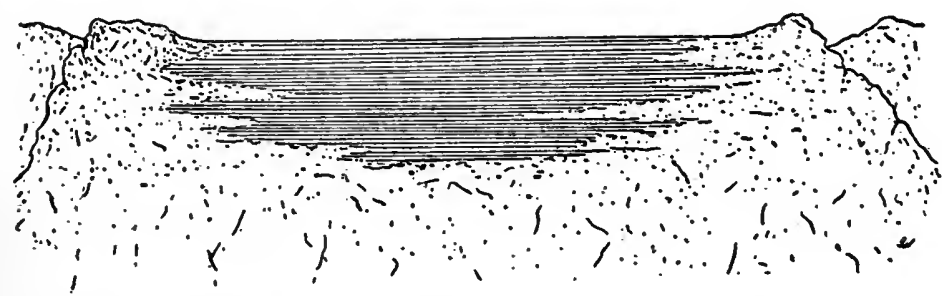

FIG. 94. Diagrammatic section of a lagoon in reef-rock, with lithographic limestone layers of extreme thinness (Plattenkalke) occupying the depressions. (After Walther.)

these sediments of impalpable lime mud the most delicate organisms were preserved with a marvelous perfection. The feathers of the ancient bird, Archæopteryx; the wing membrane of the flying saurians, the dragon-flies and other insects, with the veining of their wings perfectly retained, are wonderfully well preserved, and even the delicate jellyfish left its impressions in marvelous perfection. Sometimes secondary reefs occur in the midst of the basin, indicating a temporary encroachment of the reef builders, which later on were again overwhelmed by the fine mud which produced the lithographic calcilutytes. The strata are often very thin, and very uniformly bedded. The heavier bedded ones are used for lithographic purposes, the thin ones for roofing and flagging purposes. At intervals argillaceous layers occur, and some of the beds retain a mudcrack structure. The evidence adduced by Walther goes to show 
that the clayey beds are due to deposition of terrigenous dust, and in them the terrestrial insect fauna was buried.

It appears, then, that these lagoon-like depressions or basins in the coral reefs of the Jurassic sea of that region were slowly filled by the fine lime mud. derived from the destruction of the reefs, by terrestrial dust brought by the strong winds from the distant land and by chemical precipitation of lime. Thus were formed the finegrained lime deposits, which reach in places a thickness approaching a hundred feet. In the more clayey beds and between the layers were preserved the insects and plants blown from the mainland or the marine types brought there during the flooding of the lagoons. Walther has shown from the position of these remains that with

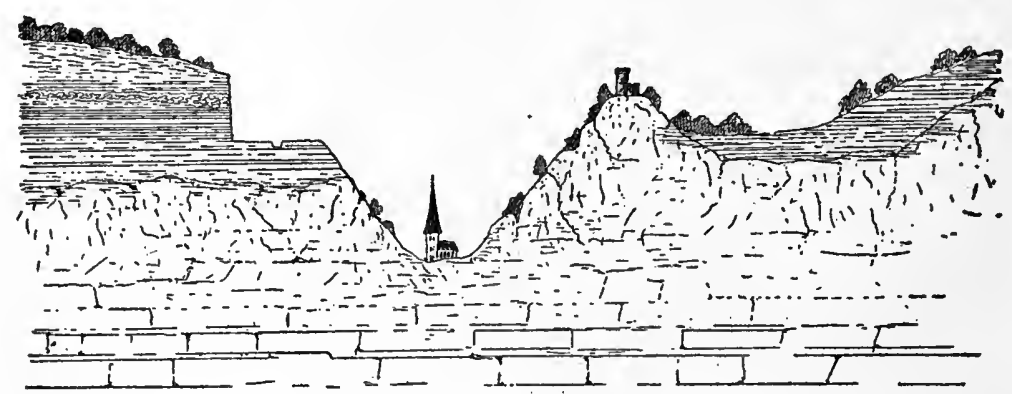

FIG. 95. Section of the reef rock (Franken dolomite, Jurassic) of Kelheim, Bavaria. The thin bedded "Plattenkalke" are shown by horizontal lining. Those in the upper left-hand portion show distortion through gliding. ("Krumme Laage," see page 781.) (After Walther.)

few exceptions they were brought there dead, and left as stranded carcasses on the ooze of the lagoon bottom, which was mostly covered by little water if not altogether exposed. The repeated evidence of shallow water, and even complete exposure of the lagoons to the air, suggests that these deposits were accumulating during a slow subsidence of the region and that the filling of the lagoons in general kept pace with the sinking of the reefs. The absolute uniformity of the entire series of thin-bedded limestones further shows that the physical conditions remained uniform during their deposition. Walther assumes that the old shore of the Vindelician land was some $20 \mathrm{~km}$. to the south, but no clastic mud was carried by the currents to these reefs. Instead, the terrigenous dust incorporated in the thin sediments represents wind-blown material. It is in these dust-bearing layers that most of the fossils are found, especially the insects, of which there are 72 genera and 103 species, 35 per cent. 
of these being dragon-flies. The peculiar character of the fauna, and the indications which it furnishes of having been stranded on surfaces of calcareous mud, suggest that the lagoon was nearly dry and flooded only during exceptionally high tides or during storms, after which the water soon ran off again. (Walther-9r.) (Fig. 96.) Some such conditions are represented to-day by the lagoons of Lil and Mejt, in the Marquesas Archipelago, where the water is brackish. and poor in organisms, while at Jabor and Jaluit the lagoons have become fresh. (Agassiz-8:3I, 273, 284.) Where abundant rain

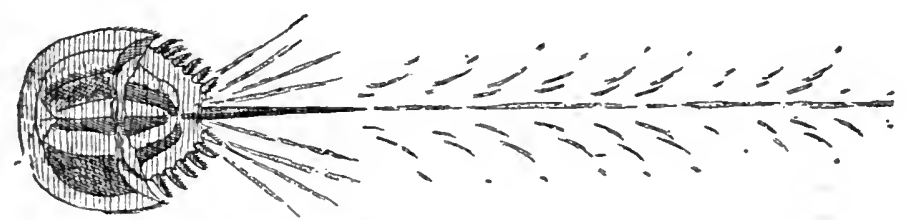

Fig. 96. A horseshoe crab (Limulus) and the marks of its death struggles, showing that it was left stranded on the mud forming the lagoon deposits. (After Walther.)

water dissolves some of the limestones, the eolian sand is soon solidified by the redeposition of this lime in the interstices, as in the case of the Bermuda sands. Moreover, some of this dissolved lime may be reprecipitated in the lagoon, a process believed by Walther to have taken place in the lagoons of the Solnhofen region. As a result of these and other chemical activities in the lagoons of these reefs, we have not only the rapid and complete encasement of the dead organisms and their perfect preservation in consequence, but also the remarkable preservation of the muscle fibers of reptiles, fishes, etc., which have been transformed into a rock containing $70 \%$ of $\mathrm{Ca}_{3} \mathrm{P}_{2} \mathrm{O}_{3}, \mathrm{I} 2 \%$ of $\mathrm{CaCO}_{3}, 3.5 \%$ of $\mathrm{CaSO}_{4}, 6.5 \%$ of $\mathrm{CaFl}_{2}$, $3 \%$ of $\mathrm{Na}_{3} \mathrm{PO}_{4}$ and $0.5 \%$ each of $\operatorname{Mg}_{3} \mathrm{P}_{2} \mathrm{O}_{8}$ and $\mathrm{K}_{3} \mathrm{PO}_{4}$, together with small quantities of water-and organic substances.

The lagoon in which the Plattenkalke were formed was thus apparently a great lifeless surface, on which the carcasses of land and sea animals, cast there during storms or brought by the wind, or, as in the case of the flying reptiles and the early bird, Archreopteryx, dropped there on the death of the animal, were so quickly enclosed by the fine, chemically precipitated lime ooze that the usual forces of destruction, scavengers, bacteria, etc., did not succeed in destroying them or dissociating their parts. They were entombed in a hermetic and antiseptic mud case, and thus preserved in all their perfection of form and delicacy of structure which, until the re- 
cent discoveries of the wonderfully preserved Cambric fauna of British Columbia, had not its equal the world over.

Conditions like those which existed in the Solnhofen region during Jurassic time are unknown in any modern coral reef; neither were they repeated in any of the numerous reefs known from the Palæozoic, Mesozoic or Cenozoic periods of the earth's history. They remain an example of a unique type of reef resulting through a remarkable concatenation of topographic, climatic, lithologic and faunistic conditions not met before, nor since attained.

The Sponge Reefs of the Sivabinn Jura. In the Upper or White Jura of Swabia, massive, structureless limestones and dolomites are found, which prove to be reefs built largely of lime-secret-

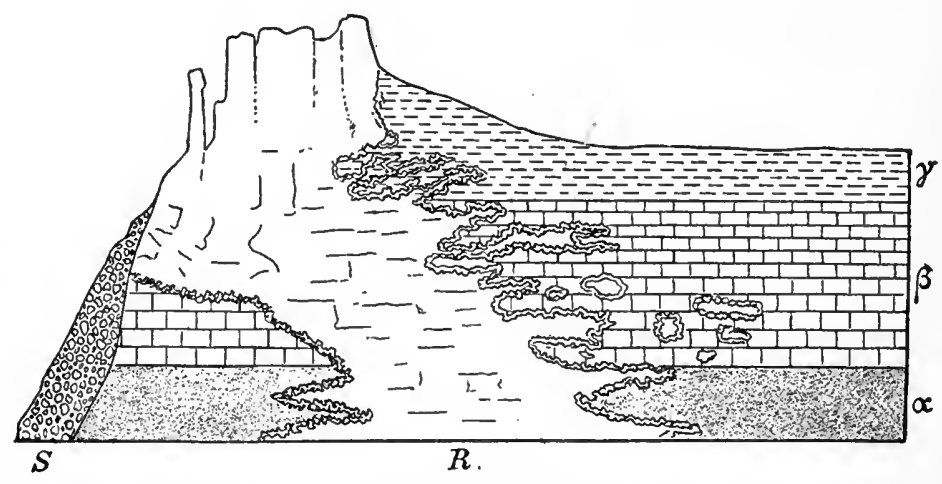

FIG. 97. "Sponge Reef" of the lower White Jura of Swabia. (E. Fraas.) $\mathrm{R}$-Structureless reef limestone. $\boldsymbol{\alpha}, \boldsymbol{\beta}, \boldsymbol{\gamma}$, associated bedded Jurassic limestones, marls, etc. S. Talus. (From Kayser.)

ing sponges. These reefs from their massive character stand out in relief through the erosion of the softer enclosing rock, and so form pinnacles, buttresses or even isolated outliers of the Swabian Alb, which since the earliest days have formed the favorite site of castles and other strongholds. These sponge reefs sometimes extend through several subdivisions of the Upper (White) Jura, as shown in the accompanying figure (Fig. 97), after E. Fraas, where the reef is surrounded by bedded sediments of the stages $\alpha, \beta$ and $\gamma$. The reef contains many other well-preserved organisms besides sponges, among which latter the genus Cnemidiastrum predominates. On the flanks of the reef a breccia of reef rock is found with some clay, and this passes into the normal bedded strata of clastic limestones.

Miocenic Reers of the Austro-Russian Border. The low 
ranges of hills known as "M jodoboren" in Galicia (Austria), and as "Toltry" in Podolia across the border in Russia, and which extend northward into Volhynia and southward into Bessarabia, have commonly been explained as representing Bryozoa reefs (Hieber-48; Teisseyre-83) of Upper Miocenic (Sarmatian) age. In reality they represent reefs of earlicr Miocenic age (Mediterranstufe) covered by bryozoan layers of Sarmatian age (Michalski). The Toltry reefs consist chiefly of corals and Vermetus masses, and form a structureless limestone, which eastward and westward passes into stratified clastic limestones and nullipore beds. These are on the whole horizontal, but in the neighborhood of the reefs have an irregular and often inclined position, similar to the overlap and interlap structure on the borders of modern reefs. The reef limestone, called Vermetus limestone, rises above the level of the enclosing bedded limestones and constituted a barrier reef parailel to the Miocenic shore which existed several kilometers to the east. Upon these mid-Miocenic reefs settled in later Miocenic (Sarmatian) time the Bryozoa Leprailia terebrata Sinz, and the worm tubes Serpula gregalis Eichw., which formed structureless limestone masses covering the older reefs. Over the clastic limestones enclosing the older reefs and in the depressions in the Vermetus limestones were formed oölitic and conglomeratic limestones containing Ervilia podolica, Cardium obsoletum, Trochus, etc.

Pliocenic Bryozoa Reefs of Kertch. The peninsula of Kertch, which partly separates the Black Sea and the Sea of Azov, has been famous for more than a century for its remarkable reef limestones, first described as composed of Bryozoa by Pallas in I 803 . They form picturesque hillocks and stacks along both the Azov and Black Sea coasts, many of them dissociated by erosion from the mainland and rising as partly submerged towers and stacks from the shallow waters. They are developed in a less degree on the opposite peninsula of Taman, where the same formations are represented by more clastic and argillaceous deposits. These reefs have been described and illustrated in great detail in a monograph devoted to them by Andrussow (i I). They form knolls or tower-like masses of unstratified limestone, consisting almost wholly of the Bryozoan Membranipora (Pleuropora) lapidosa (Pallas), and are embedded in stratified clastic limestones and argillaceous beds belonging to the Mäotic stage of the Pliocenic. Many of these beds are largely composed of molluscan shells, chiefly Modiola volhynica Eichw. var. minor Andrussow, while others are fragmental layers in which the material is largely broken shells, mingled with Bryozoa and Serpula fragments. Where these layers meet the reef 
knolls, they are commonly inclined, and an interlapping of the clastic layers with layers composed of Membranipora and Serpula masses is common.

The reef itself consists of a cavernous limestone composed of knolls of Membranipora with the intervening areas largely filled by a small Spirorbis shell. The surface is commonly marked by winding channels and irregular depressions, in which Mäotic mollusc shells abound. Especially numerous is the shell Sphenia cimmeria Andrus. which makes up masses of shell limestone, sometimes in cavities within the reef itself. The sides of the reef masses are commonly very steep, often vertical and at times overhanging, and the surface of the reef at all stages of growth possessed a higher hypsometric* niveat than did the surrounding bedded material. The height of the reef masses ranges up to 30 meters. Sometimes they are embedded in argillaceous layers, derived probably from the neighboring land.

\section{Bedded ReEFs.}

A type of reef differing from the lenticular one described is found in a number of Palacozoic rocks, where stromatoporoids are the chief or only reef organism. Instead of forming local aggregations built up into lens-like mounds, the heads of the stromatoporoids are evenly distributed in beds of slight thickness, but of wide horizontal extent. They grew apparently on a shallow sea bottom, at a considerable distance from the shore, as shown by the frequent worn character or overturned position of the heads, and by the scarcity or absence of siliceous sediment. Sometimes the reef consists of a single layer of "heads," which may measure up to 5 or 6 feet in diameter; at other times it consists of superimposed heads or fragments of heads, forming beds twenty or more feet in thickness and traceable for several thousand feet or even, with some interruptions, for miles. Sometimes this sheet reef contains only a small number of heads more or less worn, and embedded in calcarenyte derived from the wear of the stromatoporoids, and sometimes it is entirely replaced, for a short distance, by the coral sand. Channels, filled with the coral sand, are characteristic features, and these and the larger interruptions of the continuity of the reef pro-

* Andrussow has proposed the term Palreohypsometric to express the relative position which the deposits had at the time of formation, while folding and dislocation may have entirely changed this relationship, the present hypsometric position of such deposits not being the same as that which they possessed at the time of their formation. 
duce a varied aspect in the sections where they are exposed. Characteristic examples of sheet reefs of this type are found in the uppermost Siluric beds (Manlius) of central and eastern New York and in the mid-Devonic limestones (Transverse group) of western Michigan.

Loss of Structure Through Alteration of Reef Limestones.

In many of the foregoing examples of fossil reefs the organic structure of the limestone has been wholly or almost completely destroyed through subsequent alteration of the rock. In the Niagara reefs of Wisconsin the stromatoporoid structure is scarcely recognizable, except in a few cases on weathered surfaces. The same is true of the Devonic and Carbonic reefs of Belgium, and especially of the dolomites of the Tyrol. In all these cases dolomitization is one of the chief factors in the destruction of the organic structure, while recrystallization of the undolomitized limestones has had a similar effect. Such changes are not uncommonly observed in modern coral limestones, where the hard parts, composed of aragonite, as in reef-forming corals (Madreporaria), gastropoda and some calcareous algæ are rendered unrecognizable by recrystallization as calcite, and where dolomitization obliterates the structure of even the more stable calcite organisms. Sections of modern coral limestones have shown that three types of mineral structure may be recognized, due to different degrees of alteration of the rock. (Skeats-81 : 105; 82:128; Cullis-19: 40\%.)

I. Limestones consisting largely of calcite, but containing also organisms with hard parts of aragonite, while not infrequently secondary aragonite has been deposited in crystallographic continuity with the aragonite of the organism.

2. Limestones produced from gradual alteration and recrystallization of the first type of limestone, thus resulting in a rock in which organic remains and matrix alike consist entirely of calcite.

3. Limestones produced from either the first or second type by the replacement of some of the calcium carbonate by magnesium carbonate, resulting in the occurrence in the rock of generally idiomorphic crystals of dolomite; continued replacement will result in the complete change of the limestone to dolomite. When the rock is completely dolomitized, it becomes usually quite structureless, the crystals of dolomite being almost entirely allotriomorphic.*

* See, further, dolomitization in Chapter XIX. 


\section{Ballstone ReEfs.}

In the Siluric (Clinton and Lockport) horizons of western New York and the Wenlock of western England, reef-like accumulations of an impure argillaceous calcilutyte occur, of a lens-like or balllike form, and embedded in shales or fragmental limestones, which arch more or less around them. They vary from two to fifty feet in diameter, though one in the Lockport has a length of I Io feet. When not spherical, they range in thickness from one to fifteen feet. In England these have long been known as Ball Stones, but their origin has not heretofore been described. While in large part composed of fine, calcareous mud, the structural groundwork of these lenses is formed by branching and fan-like types of Bryozoa or other organisms which grew upon the sea bottom in colonies, and which captured the fine sediment from the water and formed a suitable medium for its retention. On these reefs, as rich feeding grounds, lived a multitude of brachiopods, molluscs, trilobites and other organisms, whose remains are now found in or around these lenses, while many of them are comparatively rare or unknown in the adjoining strata. In western New York (Grabau--39:99; Sarle-76) these ball reefs are found in the upper Clinton limestone (Irondequoit limestone), and are either entirely embedded in this otherwise clastic lime rock (calcarenyte) or lie in its upper portion, partly enclosed in the overlying Rochester shales. More rarely are reefs of this type found in the higher Lockport dolomite. They are generally in the form of flattened lenses due to the cessation of growth before they had reached their full size. These reefs are often closely crowded, so that it has been possible to step from one reef knoll to the others in places where erosion has exposed their upper surfaces. The bryozoans forming the foundation of these structures are several species of fistuliporoids, these sometimes being the only organic material found in the reefs. Trilobites, especially the cephala and pygidia of Illænus, abound near the margin, and brachiopods are also common, most abundant among them being Whitficldella nitida. The silt captured by these organisms was exceedingly fine, so that the rock is a typical argillaceous calcilutyte, and breaks with a conchoidal fracture. On fresh surfaces the bryozoans are not visible, except when their epithecal surface is exposed, but weathering generally brings out their structure.

The Wenlock Ballstones are generally more spherical than those of New York, in which the lens form prevails. They are found at various levels in the thin-bedded limestones of Wenlock Edge in 
Shropshire, and, according to the observations of the author of this volume, are in all essentials similar to those of the New York Siluric. They form a marked contrast to the surrounding rock, which is generally a well-bedded calcarenyte, not only by their structureless form, but by the compactness and fineness of the material composing them. The foundation of those balls appears to be formed by a branching coral, while other organisms seem to be rare.

\section{STRUCTURES FORMED BY THE GROWTH OF SHELL COLONIES.}

Tepee Buttes. Gilbert and Gulliver have described a series of buttes or erosion hills of conical outline carved from the Cretacic Pierre shales along the Arkansas River and some of its tribataries in Colorado. (Gilbert and Gulliver-38.) From their resemblance

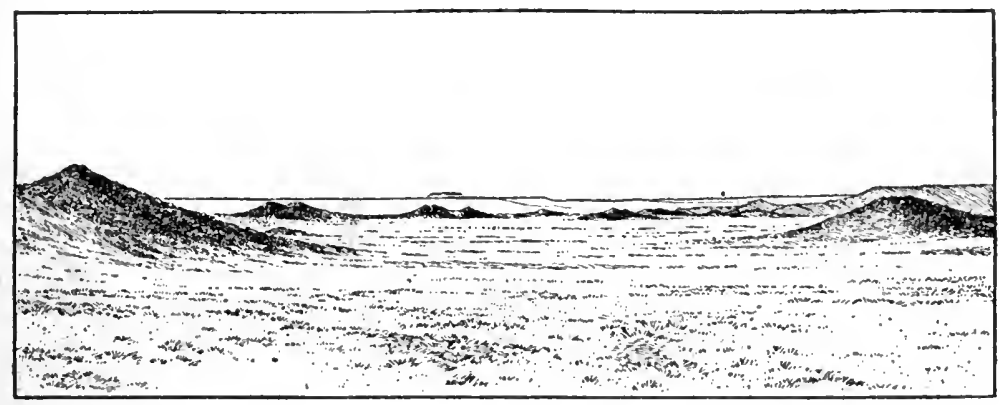

Fig. 98. View of a group of Tepee-Buttes near Canyon City, Colorado. (After Gilbert and Gulliver.)

to the Indian "tepee" or conical hut, they have applied the name of tepee buttes to them. (Figs. 98, 99.) The buttes have an irregularly cylindrical core of limestone, varying from 2 to 24 feet in diameter in different examples. The average diameter is, however, Io to I5 feet, while the height is unknown. (Fig. IOo.) This limestone core consists of an aggregation of shells, "embedded in a matrix which is composed of fragments of shell, water-worn grains of calcite, foraminifera and clay." The shells are mostly those of Lucina occidentalis var. ventricosa, which makes up by far the larger part of the core. With these occur other characteristic marine Cretacic species. The core is enclosed in the Pierre shales, the passage from the limestone to the shale being abrupt. There is, however, a certain 
amount of interpenetration of the limestone and shale. "Processes of the limestone embrace portions of the shale, and the contiguous shale contains outlying lumps of the limestone." The best exposed cores have a stratified appearance, with beds from one to three feet in thickness, and separated by more or less continuous horizontal

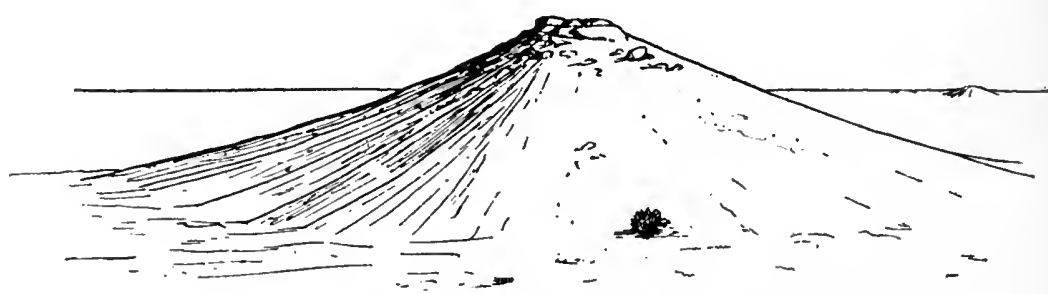

FIG. 99. A single tepee-butte, showing the top of the limestone core. (After Gilbert and Gulliver.)

partings of shale. The presence of these shale partings indicates that the core was not built any faster than the surrounding deposits of mud.

Various explanations have been offered by the authors cited for the origin of these cores. The best of these, and the one favored by the authors, regards these accumulations of shells as colonies,

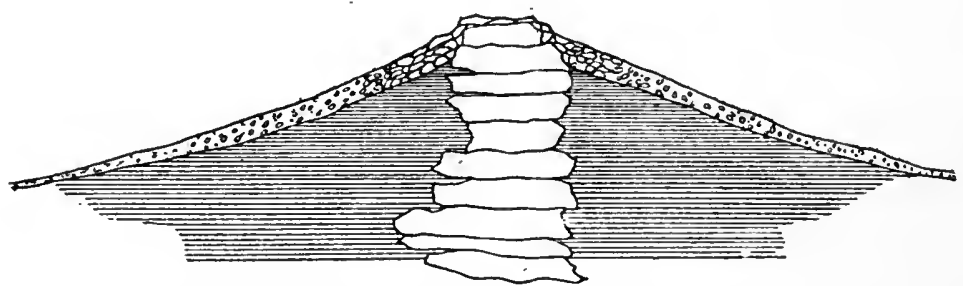

FIG. 100. Ideal section of a tepee-butte, showing the core of organic limestone, the enclosing bedded shales, and the cover of talus. (After Gilbert and Gulliver.)

which, having begun in a given place, continued there through a long period of deposition, the later organisms living on the shell heaps of their dead predecessors without migrating much outward onto the surrounding muddy ocean bottom. Professor Shaler has suggested that Lucina may have had a byssus, by means of which it would attach itself to the dead shells of earlier generations, which would readily explain the localization of these deposits. On these shell heaps would be the best feeding ground for other 
animals, whose remains would thus become incorporated with the Lucina.

Other Examples. On the modern coast we sometimes find colonies of Mytilus edulis growing in isolated spots, surrounded by black mud deposits. As the colony increases the young individuals will attach themselves to the older shells, remaining chiefly within the circumscribed area occupied by the original colony, since any transgression outside this area would be checked by the soft mud, which offers no means of attachment. In this manner, on a slowly subsiding bottom, a core of shell limestone may be formed, surrounded by mud, in which only occasional shells are found.

Some of the "Reef Knolls" described by Tiddeman (85) from the Carbonic limestones of the Clitheroe district, England, appear to be due to colonies of shell-building animals, more than to the growth of reef corals. Their structure, however, is more like the coral reefs than the tepee butte cores.

\section{BEDDED ZOÖGENIC DEPOSITS.}

Crinoidal Limestones. Among the limestones of all geologic formations, beds composed largely or wholly of crinoid remains are common. These remains are generally the stem joints, and they vary greatly in size, from that of a pin head or smaller to those over one inch or more in diameter. Generally the fragments of each bed are more or less uniform in size, this latter depending on the species of crinoid which has flourished in that region. Crinoids are admirably adapted to the formation of limestone beds, because, on the death of the animal, the long stems, as well as the calices and arms, readily separate into their component ossicles, and thus with little rearrangement furnish the material in proper size of grain for a limestone bed. Kirk (56) has recently brought forward much evidence to show that many crinoids separate from their anchorage and become more or less planktonic in later life. Thus schools of floating crinoids may be washed into shallow water, there to accumulate as crinoidal limestones. The crinoidal character of an ancient limestone is not always noticeable on the fresh surface, but on weathering this structure is brought out. When accumulations occur within the zone of wave activity, cross-bedding and other shallow water structures may result.

Shell Limestones. Beds of unbroken shells or coquina are likewise found in different geologic horizons. Often great beds of limestone occur, in which one species of shell predominates to the 
practical exclusion of others. Such are the great beds of Pentamerus oblongus extending widely through the Siluric of Gotland and New York; the beds of Anoplotheca in the Clinton of the Rochester region, and those composed of Exogyra or other shells in the Cretacic of Texas; the limestones entirely made up of Turritella mortoni in the Eocenic of Virginia, and numerous other examples. Rocks of this type generally form thin beds among the clastic sediments. From the nature of the material, these beds can be only rudely stratified, and irregularities in thickness may be expected where wave action has not been strong.

Calcareous and Siliceous Oozes. These often form beds of considerable thickness, as in the case of the chalk. These accumulations when pure always indicate either a remoteness of the shore, with perhaps deep-iwater conditions, or a very low relief of the land, which has been peneplaned to such an extent that no clastic sediments are derived from it. The oozes formed in the modern ocean include the following types:

I. Calcareous: a, Foraminiferal; b, Pteropod; c, Entomostracan ; d, Coccolith, and e, Rhabdolith ooze.

2. Siliceous: a, Ralliolarian; b, Diatom.

\section{r. The Calcareous Oozes.}

Recent Foraminiferal Oozes. These are represented in the modern sea by the Globigerina ooze (Fig. I05), so named from the preponderance of the shells of Globigerina, which is represented by ten

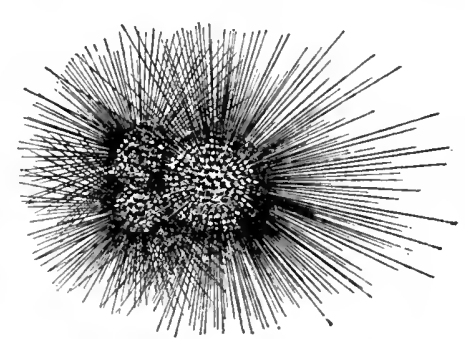

FIG. ror. Globigerina bulloides. x 40. (After Wyville Thomson.)

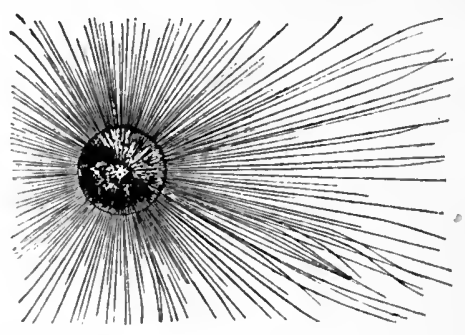

FIg. 102. Orbulina universa. $\mathrm{x} 40$. (After Wyville Thomson.)

species, while Pulvinulina is represented by five species. The total number of species of foraminifera making up this ooze is only $2 \mathrm{I}$, distributed in 9 genera, but only four species are of great importance in the making of this ooze. These are Globigerina bulloides 
(Fig. Ior), in the northern hemisphere and most of the tropical seas; Globigcrina dutertrei, for the higher southern latitudes; and, further, Orbulina universa (Fig. I02) and Hastigerina pelagica. The foraminifera of this ooze all inhabit the upper 200 meters of the ocean, leading a planktonic existence (Chapter XXVIII). It is only on the death of these organisms that their shells sink to the bottom and become incorporated in contemporaneous sediments of other origin, or, if this is rare or absent, to accumulate as extensive, more or less pure deposits of shells. The ooze is never absolutely composed of foraminiferal shells, for the shells of other planktonic organisms also enter into the composition. Among these are the shells of pelagic molluses, such as the pteropods and heteroporls, both often of considerable size; ostracods (Crithe producta, Cy-there dictyon); minute planktonic algæ. Coccolithophores or coc-

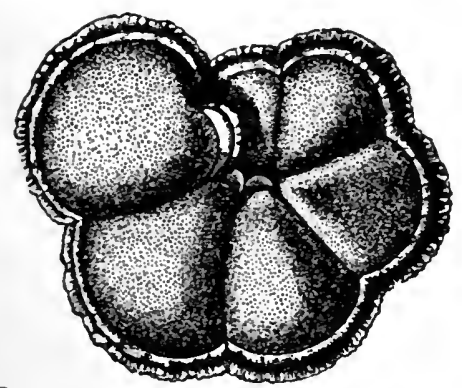

FIg. 103. Pulvinulina. A multichambered foraminiferal shell (after Murray) much enlarged.

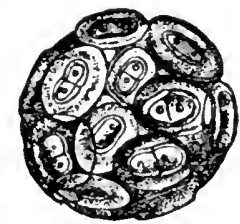

FIG. 104. Coccolithophora. (After A. Agassiz.) $\times 600$.

coliths (Fig. 104) and rhabdoliths. These pelagic admixtures are further supplemented by those of sea-bottom or benthonic origin, among which bottom-living Foraminifera may constitute as high as 3 per cent. of the mass. Furthermore there are clastic lime and other fragments; spines of echinoderms, shells of molluscs; worm tubes; deep-sea corals: Bryozoa, etc. In all, these never make up more than $25 \%$ of the mass, and, according to Murray and Renard, on the average only $9 \%$. From the amount of pelagic calcareous organisms in these deposits, Murray and Renard have calculated that there are at least sixteen tons of floating carbonate of lime in one square mile of water surface, distributed through the upper 100 fathoms of the sea. The clastic material is often less than $1 \%$ and averages $3.3 \%$ in the II 8 samples obtained by the Challenger expedition. In depth the Globigerina ooze is most abundant between 2,500 and 4,500 meters, its mean depth being 3,660 
meters. The I 8 samples obtained by the Challenger expedition were distributed as follows:

\begin{tabular}{|c|c|c|c|}
\hline & & & $\begin{array}{l}\text { Percent- } \\
\text { age of } \\
\mathrm{CaCO}_{3}\end{array}$ \\
\hline Less than & $\mathbf{I}, 000$ fathoms...... (I,830 m.) & 5 & \\
\hline Between $\mathbf{I}, 000$ and & $\mathrm{I}, 500$ fathoms. . . . (I,830-2,750 m.) & I3 & $60-70 \%$ \\
\hline Between $\mathbf{I}, 500$ and & 2,000 fathoms. . . . $(2,750-3,660 \mathrm{~m})$. & 35 & \\
\hline Between 2,000 and & 2,500 fathoms..... (3,660-4,570 m.) & 49 & $62 \%$ \\
\hline Below & 2,500 fathoms.....(4,570 m.) & 16 & $50 \%$ \\
\hline
\end{tabular}

It will be observed that the percentage of $\mathrm{CaCO}_{3}$ in the oozes decreases with depth, being only $50 \%$ in the samples from the greater depths. The average of the in 8 samples gave $64.5 \%$ of $\mathrm{CaCO}_{3}, 30.6 \%$ of non-calcareous silt, $3.3 \%$ mineral particles, and r.6\% siliceous organisms. The lime was distributed as follows:

Remains of pelagic organisms................ $53.1 \%$

Remains of benthonic organisms................ $2.1 \%$

Remains of other organisms..................... $9.3 \%$

$$
.64 .5 \%
$$

Among the mineral matter other than lime associated with the Globigerina oozes may be mentioned glauconite, and phosphate and manganese concretions.

Sir John Murray concluded from experiments made that it takes the dead foraminiferal shells from three to six days to sink to a depth of 4,500 meters, the rate being slowest in the deeper water. Solution of the lime of the shells by the sea water increases rapidly with depth, owing to the increase in pressure. Thoulet found that the rate varied greatly with the size of the shells and particles, those averaging $0.75 \mathrm{~mm}$. in diameter taking $\mathrm{I} .09$ days to reach a depth of 4,500 meters, while those having a diameter of only 0.I2 $\mathrm{mm}$. required 7.47 days for the same distance.

Not infrequently fragments and blocks of terrestrial rocks are found in the Globigerina deposits, as, for example, fossiliferous Palæozoic rocks marked by glacial scratches, and found by the French expedition northeast of the Azores, $1,100 \mathrm{~km}$. from the European coast, carried there by drift ice probably during the last glacial period; and the coarse fragments of crystalline rock found in the South Atlantic between Tristan da Cunha and Kapstadt, in $35^{\circ}$ to $36^{\circ} \mathrm{S}$. lat., and others from the Indian Ocean.

The areal distribution of the Globigerina ooze is a considerable 
one, being in round numbers $10_{5}$ million square kilometers or $\mathbf{2 9 . 2}$ per cent. of the entire oceanic surface (Krümmel-57:188). Its principal distribution is, however, in the Atlantic Ocean, where it occupies more than 44 million square kilometers, overshadowing all the other deep-sea sediments. In the Indian Ocean 3 I million square kilometers of bottom are covered by this deposit, but in the Pacific it covers only 30 million square kilometers, a comparatively small percentage of the bottom of that ocean.

Fossil Foraminiferal Oozes. Typical foraminiferal oozes are found in fossil form mainly in the chalk of the west of Europe and

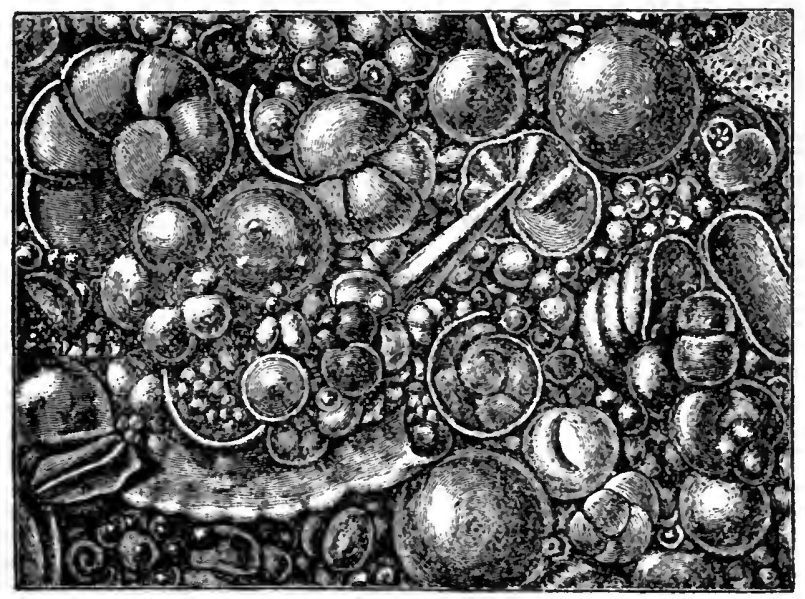

FIG. 105. Globigerina ooze. $\mathrm{x}$ 20. (After Murray and Renard.)

elsewhere. Deposits of foraminiferal shells, of large benthonic types, are, however, developed in other horizons. Such are the Fusulina limestones of the Carbonic and Permic, and the Nummulite and Orbitoidal limestones of the Tertiary. These are best classed as shell rocks. Chalk, on the other hand, is a distinct foraminiferal ooze, a calcipulverite, but, unlike the Globigerina rock, it is not formed of pelagic, but of benthonic or bottom types. (Fig. Io6.) Among these the biserial Textularia holds the same position that Globigerina does in the modern deposit, while another benthonic form, Rotalia, is also common. Pelagic forms, however, are not wholly absent, nor should we expect them to be. Nineteen species have been recognized as found both in the modern Globigerina ooze and the Cretacic chalk, but this identification of species is largely due to the lack of distinctive characteristics. Coccoliths also are 
common in the chalk, and diatoms, Radiolaria and sponge spicules probably were as plentiful in the chalk as in the modern deposits, but these siliceous structures have since been dissolved, and the silica redeposited as flint. Among the clastic admixtures quartz is also common, indicating the neighborhood of land.

The principal species of the chalk is Textularia globulosa (Fig. I06, $a$ ), which lives to-day in the estuary of the Dee near Chester, but of course forms no extensive foraminiferal deposits there. (Murray-67:477.)

In the island of Malta, Oligocenic limestones (Aquitanien) occur which are made up largely of pelagic Globigerina, and nearly

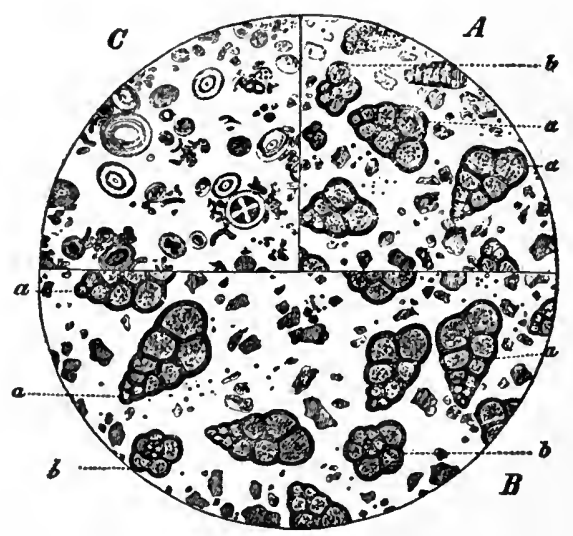

FIG. 106. Preparation of white chalk, showing the foraminifera, ctc. (After Zittel.) A-Chalk from Sussex, Eng. B-Chalk from Farafrah, Libyan desert. Both $\mathrm{x} 60$. a-Tertularia globulosa; $b$-Rotaiia (Discorbina) marginata. C--dried residuc of milky chalk water with coccoliths. x 700 .

40 per cent. of the species of this rock still live in the neighboring Mediterranean. These beds further contain phosphate concretions and green sands such as characterize the modern sea bottom in depths from 500 to 2,000 meters, and also sharks' teeth similar to those found by the Challenger in the greater oceanic depths. The percentage of lime in the Globigerina deposits of Malta ranges from 95 to 98.6 . These deposits appear to have been formed in the greater depths of a mediterranean rather than in the open sea. Sinilar foraminiferal deposits have been obtained from the Pliocenic of Sicily and Calabria.

In this connection it must be noted that foraminiferal limestones are not necessarily deep-sea or even submarine deposits, for the 
shells of littoral species may be washed up onto the shore, where they form an extensive foraminiferal sand, as in the case of the Orbiculina shells of the Bahamas. These shells may then be blown inland to form beds of foraminiferal limestone often of great purity, at a distance from the shore on the dry land. Such is the case with the limestone of Junagarh on the Kathiawar peninsula, IVest India (see Chapter XIII), and the foraminiferal limestones of Jamaica may have a similar history.

Zoögenic oölites. Among the numerous theories advanced to explain the origin of the oölites is that of their zoögenic origin, the rôle of oölite-former being commonly assigned to Foraminifera. Thus Ehrenberg regarded the oölites of the Jura of many localities as formed by the more or less recrystallized shells of Melonites

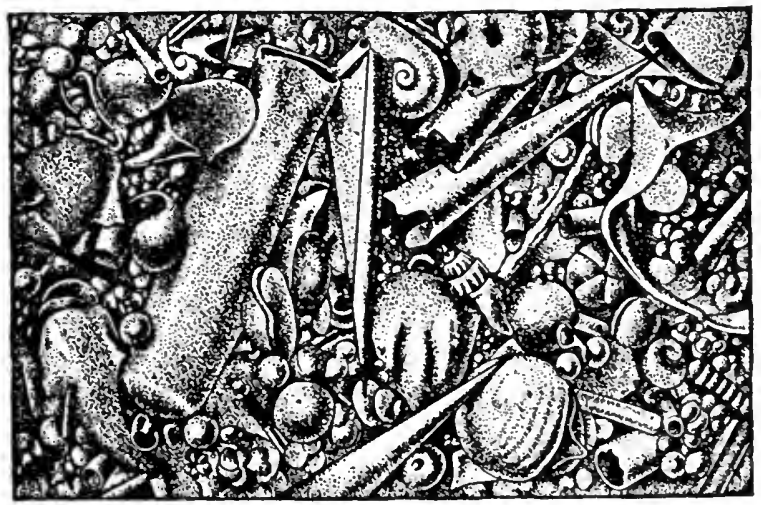

Fig. 107. Pteropod ooze. $x$ ro. (After Murray and Renard.)

(Mikrogeologie). The oölite-forming organism described by Bornemann as Siphonema incrustans and referred to algre was relegated by Nicholson to the Foraminifera on account of its resemblance to the recent foraniniferan Syringamnina fragilissima Brady, while Sorby and Withered also regard it as a foraminiferan, the former finding its resemblance closest to Hyprammina vayans Brady. This organism forms oölites in the Siluric and Devonic. The oölites of the Muschelkalk regarded by Bornemann as due to algous growths are referred by Frantzen to zoögenic origin, as lime separated by acid of the animal organisms. By others these same oölites have been regarded as of purely hydrogenic origin.

Recent Ptcropod Ooze. (Fig. 107.) This is fomm in only a few tropical and subtropical regions resting like the foraminiferal oozes upon the swells and submarine ridges. In all there are known 6 
genera and 35 species of planktonic pteropods in this ooze, but only three genera, Limacina, Clio and Cavolinia, are abundantly represented. With these occur the heteropods Carinaria, Atlanta and Oxygyrus. These shells make up from one-quarter to one-half the entire mass, the remainder being chiefly Foraminifera. The depth at which these delicate shells occur is between I,000 and 2,700 meters; below this they give way to purer Globigerina ooze. In the Atlantic these deposits occur especially around the Azores, on the outside of the Antilles, west of the Canary Islands, and on the South Atlantic rise between Ascension and Tristan da Cunha. In the Indian Ocean they occur off the African coast from the equator to Sokotora, and to the west of Cape Comorin near the Nicobar and Mentawie Islands. In the Pacific they surround the Fiji Islands, occur east of the Great Barrier Reef, around the Kermadec and Hawaiian Islands, and especially in the region of the Paumota or Low Archipelago. The total area covered by these deposits does not exceed one and a half million square kilometers.

Fossil Pteropod Oozes. These are known from various horizons; in the Upper Devonic of New York State occurs a limestone composed almost entirely of Styliolina fissurella, embedded in dark shales, which are sparingly or not at all fossiliferous. The limestone varies in thickness from 6 inches to a few feet, and has been traced from the Genesee Valley to Lake Erie, a distance of over sixty miles. Clarke has estimated that 40,000 individuals occur on the average in a cubic inch of the rock ( $16: 15)$. In the Cambric, beds of limestones, largely composed of Hyolithes and Orthotheca, occur, and some Upper Siluric horizons carry layers formed of Tentaculite shells (Manlius limestone of New York, etc.).

Entomostracan Oozes. These are seldom of great purity as oceanic deposits. The Ostracoda, Crithe and Cythere are abundant among the plankton of the ocean, and their shells are found mingled with Foraminifera and pteropods. No pure marine ostracod ooze has been obtained from the deep sea. These organisms also occur in salt pools (Cypris salina, etc.), in the estuaries of rivers (Cypris, Potamocypris, Pontocypris, Cythere, etc.) and in fresh-water lakes and pools. At the Ayin Musa Springs near Suez, calcareous deposits are formed by the abundant accumulation of the shells of Cypris delecta (Fraas-32:I82). Limestones of Cypris shells have also been found in the fresh-water Tertiary deposits of western America. Eolian deposits of this type are also known.

Coccolith and Rhabdolith Oozes. Coccoliths are the minute oval plates of lime which cover the planktonic Coccolithophora, small algæ of the order Calcocytea, while rhabdoliths are slender 
rods, radially arranged in the Rhabdosphæra. Both are members of the family Coccolithophoridæ, of the order Chrysomondaceæ, minute organisms referred by some to the algæ, and by others to the Flagellata among the Protozoa. (See Chapter XXIV.) They make up an important part of the Globigerina ooze of the present day, and their remains also abound in older deposits. In the North Atlantic certain dredgings in $4,004 \mathrm{~m}$. brought up ooze in which coccoliths formed 68 per cent. of the sediment. Certain chalks have also been found to consist almost wholly of coccoliths and rhabdoliths. The size of the individual coccolith plates ranges from $0.00 \mathrm{I}$ to $0.003 \mathrm{~mm}$. in diameter, and Huxley has divided them into two groups: discoliths, disk-shaped, convex on one side and concave on the other, and cyatholiths, of a form somewhat resembling that of a shirt stud. Minute calcareous disks of this kind are separated out of a solution of lime sulphate or lime chloride by the action of ammonia generated by the decomposition of organic matter, and from this it has been inferred that coccoliths are of inorganic origin.

\section{The Siliceous Oozes.}

These comprise the radiolarian and diatonaceous oozes, the first animal and the second plant structures.

Radiolarian Oozes. (Fig. 108.) These are typically abyssal deposits; the shells, owing to the resistance which they offer to solution, can sink into depths below those at which foraminiferal shells dissolve, and so they are typically found associated with the deepsea red mud. Indeed, the deposit is seldom if ever free from the red mud, which forms a sort of medium in which the radiolarian shells are embedded. When more than 20 per cent. of the sediment is made up of Radiolaria, it is called a Radiolarian ooze. The most abundantly represented and best preserved of these planktonic Radiolaria are the Nessellaria and Spumellaria, while the Phæodaria are more sparingly and the Acantharia not at all represented in the deposits, though abundant in the plankton. This is due to the fact that the skeletons of the last group are not siliceous, but consist of acanthin, which, like chitin, is readily destroyed after the death of the organism.

The Challenger found this ooze in its deepest soundings in the western Marian deep in 8,184 meters. It contained 54.4 per cent. of Radiolaria and other siliceous organisms, 3.1 per cent. of pelagic and 0.1 per cent. of benthonic Foraminifera, 0.8 per cent. of other 
lime-secreting organisms, I.7 per cent. mineral matter and 40 per cent. of the fine red mud.

The geographic distribution of this deposit is much less than that of the Foraminifera, the total area covered by it being only something over 12 million square kilometers, or 3.4 per cent. of the total ocean bottom. It seems to be entirely wanting in the Atlantic, and restricted to the region around the Cocos and Christmas islands in the Indian Ocean. In the Pacific it finds its greatest distribution between $5^{\circ}$ and $15^{\circ}$ north latitude, and between Central America and $165^{\circ}$ west longitude. A few other isolated patches in the Pacific contain this deposit.

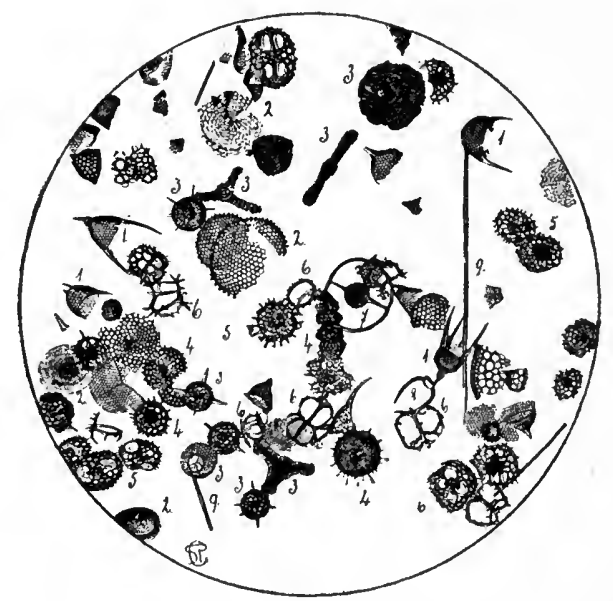

FIG. I08. Radiolarian ooze from the Indian Ocean. x 40. (After Krïmmel.) I. Tricyrtida; 2. Dicyrtida; 3. Discoidea; 4. Prunoidea; 5. Larcoidea; 6. Coronida; 7. Sphæroida; 8. Chætoceras (Diatom ) ; 9. Sponge-spicules.

Fossil radiolarian oozes also occur, but in most cases it may be questioned whether they are really deep-sea deposits. An example is the radiolarian rock described by Rüst $(75: I 8 I)$, which has been regarded as of deep-sea origin, but Walther has insisted that the high content of Carbonaccous material and the quantity of littoral sediments oppose this view. The island of Barbados also furnishes a colored clay which contains an abundance of radiolaria (Barbados earth), and this has been regarded as a deep-sea deposit similar to that found in the Pacific at 5,000 m. and now brought to the surface by a local elevation. Limestones similar to the modern Globigerina ooze also occur on this island. 
Radiolaria have been found in cherts of various ages from the Ordovicic on, and some of these cherts are believed to be due to the segregation of silica furnished by the Radiolaria and other silicasecreting organisms.

The Jurassic Radiolarite of the Alps. In certain portions of the Austrian Alps, a remarkable deposit of radiolarian mud is found in the upper Jura. (Hahn-43, I:389.) This radiolarite, as it is called, consists of intensely blood-red, more rarely greenish, jaspery layers, alternating with dense, brown-red or greenish gray quartzose and argillaceous marls, the total having a thickness varying from Io to $25 \mathrm{~m}$., the increase being due to increase in the marly layers. Under the microscope it appears as an extremely fine-grained, almost homogeneous mud rock, filled with minute spherical crystal bodies, referable to Radiolaria. The original ornamentation of these bodies is seldom preserved in the argillaceous layers, but the jasper contains Spumellarians in a wonderful state of preservation. This rock thus appears to be of the type of radiolarites which represent the deep-sea radiolarian oozes, and are found to-day in depths of from 3,000 to 7,000 meters.

These radiolarites rest on Upper Lias, or on variegated ammonite limestone or breccias of Middle Liassic age. Some indications point to a disconformable relation with the underlying rock, there being apparently an absence of Dogger and part of the Malm. This would suggest land conditions with erosion prior to submergence, the sinking being a rapid one down to the depths at which such ooze will accumulate.

Upward the radiolarite passes into gray calcilutytes with Aptychus of Tithonic age. This indicates a gradual shoaling of the water, which culminated in land conditions in the next succeeding period.

Similar deposits of Radiolarite have been described from the Lower Carbonic beds of the Rhine district (Wilckens-92:354) and from various parts of Great Britain. These examples of older radiolarites are believed to be of shallow-water origin. Such cherts are well shown in the Carboniferous (Mississippic) limestone series of Gower in western England (Dixon and Vaughan-25:52I). They are finely and sharply laminated, many of the lamina being lenticular or wedge-shaped. They are also found in the lower Culm of Devon (Codden Hill beds), from which they were first described by Hinde and Fox, who, however, regarded them as deep-sea deposits. From the nature of the deposits themselves, as well as from the character of the including rocks, others have come to the con- 
clusion that these rocks are of shallow-water or lagoon origin. (Dixon and Vaughan-25:522.)

The Onondaga coral reefs of western New York are succeeded and sometimes replaced by very cherty limestones, and it is not impossible that the chert layers in the so-called Corniferous limestone represent shallow-water radiolarites accumulated in the lagoon behind the coral reefs.

Recent Diatomaceous Ooze. (Fig. I09.) This is a phytogenic deposit, but is best considered in this connection. It is most abundant in the ocean in the higher latitudes of both hemispheres, and originates from the phytoplankton of the colder and less saline waters of the polar regions. The diatom frustules of the ooze obtained in the southern hemisphere belong to a number of genera (Navicula, Coscinodiscus, Fragillaria, Synedra, Asteromphalus, Rhizosolenia,

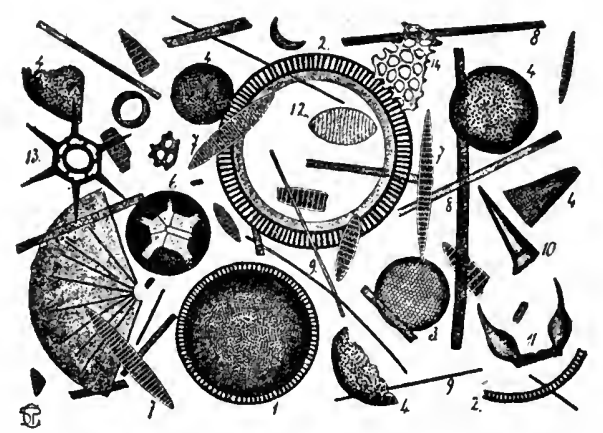

FIG. 109. Diatom ooze. $x$ 200. (After C. Chun.) I-5. Coscinodiscus; 6 Asteromphalus; 7. Fragilaria antarctica; 8, 9. Synedra; 10. Rhizosolenia; I1. Chætoceras; 12. Navicula (?); 13, 14. Dictyochi and Radiolaria.

etc.), and associated with them are fragmentary frustules, Radiolaria, sponge spicules, lime particles, etc.

These sediments form a circumpolar belt in the southern hemisphere, and likewise form a band across the northern Pacific. The southern area comprises nearly 22 million square kilometers. In the tropical regions diatomaceous sediments also occur. They have been found to constitute a veritable tripolite or infusorial earth at depths from 2,700 to 5,200 meters under the Peru stream between Callao and Galapagos. Between the Marian and Philippine Islands the floor of the Pacific is covered in patches by the frustules of Coscinodiscus rex, one of the largest known forms, with a diameter of $0.8 \mathrm{~mm}$. This occurs in depths ranging from 4,500 to 6 ,000 meters. Altogether about 23 million square kilometers of the ocean bottom, 
or about 6.4 per cent. of the entire sea floor, are covered with this deposit.

Diatoms likexvise live in fresh water and deposits of diatomaceous ooze may form under such conditions.

Fossil Diatomaceous Earths of Both Fresh and Salt Water Origin. These are widely distributed over the world, especially in Tertiary deposits. They ordinarily go under the name of Infusorial earth or Tripolite, so named from the deposits at Tripoli in North Africa. The most extensive is that found at Richmond, Virginia, which extends for many miles, and is in some places at least 40 feet in thickness. Other deposits are found in the Great Basin in Nevada, Oregon, and California, where they form beds of great thickness usually interstratified with volcanic material.

\section{Phosphate Deposits.}

Guano. A subordinate type of zoögenetic rock is the guano, formed from the droppings of innumerable birds which inhabit isolated islands and promontories on the sea coast. Near Iquique, Province of Tarapaca, Chile, such a deposit with a thickness of Io meters is known, and it is estimated that it may have formed in I,IOO years. The deeper strata of these formations are generally darker in color and more crystalline. Deposits of the excrements of seals sometimes alternate with those of birds in certain places on the coast of Tarapaca. Here these deposits contain numerous smooth fragments of porphyry from 3 to $\mathrm{Io} \mathrm{cm}$. in length, derived from the stomach content of these seals. (Tschudi in Walther-90:853.)

A number of distinct phosphate minerals are found in guano.

\section{BIBLIOGRAPHY $\mathrm{X}$.}

(See also Bibliography XI.)

r. AGASSIZ, ALEXANDER. 1883. The Tortugas and Florida Reefs. American Academy of Arts and Sciences, Memoirs, Vol. XI, pp. 107-I34 (Abstract, American Naturalist, Vol. XVII, pp. 1267-r 268, 1883).

2. AGASSIZ, A. 1888. Three Cruises of the Blake. Vol. I. Bulletin of the Museum of Comparative Zoölogy, Harvard College, Vol. XIV.

3. AGASSIZ, A. 1889. The Coral Reefs of the Hawaiian Islands. Bulletin of the Museum of Comparative Zoölogy, Cambridge, Vol. XVII, pp. $121-170$.

4. AGASSIZ, A. 1893. A Reconnaissance of the Bahamas and of the Elevated Reefs of Cuba, etc. Bulletin of the Museum of Comparative Zoology, Vol. XXVI, pp. 1-203, with plates and maps. 
5. AGASSIZ, A. I 894. Notes from the Bermudas. American Journal of Science, 3rd series, Vol. XLVII, pp. 4I I-4I6, Figs. I-7.

6. AGASSIZ, A. 1895. A Visit to the Bermudas in March, 1894. Bulletin of the Museum of Comparative Zoölogy, Vol. XXVI, pp. 205-28I.

7. AGASSIZ, A. I896. The Florida Elevated Reef. With notes on the geology of Southern Florida, by Leon S. Griswold. Bulletin of the Museum of Comparative Zoölogy, Vol. XXVIII, No. 2, pp. 29-62; 26 plates.

8. AGASSIZ, A. 1903. The Coral Reefs of the Tropical Pacific. Memoirs Museum of Comparative Zoölogy Harvard College, Vol. XXVIII, text and plates.

9. AGASSIZ, LOUIS. I852. Florida Reefs, Keys and Coast. Annual Report of the Superintendent of the Coast Survey for 1851 , pp. I45-I6o.

I0. AGASSIZ, L. I869. Florida Reefs, Keys and Coast. Ibid., for I866, pp. I20-130.

I. ANDRUSSOW, N. I910-12. Die Fossilen Bryozoenriffe der Halbinseln Kertsch und Taman. Lieferungen I-3, Kief.

12. BELL, R. I886. Reef Structures on Attawapishkat River. Geology and Natural History Survey, Canada, Annual Report, Vol. II, pp. 27G, $28 \mathrm{G}$ and plate.

13. BONNEY, T. C. 1889. In Darwin's Coral Reefs. Appendix to 3rd edition. (Smith, Elder \& Co.)

i4. BOURNE, G. C. 1888. Chagos Group. Proceedings of the Royal Society of London, Vol. XLIII, p. 440.

I5. CHAMBERLIN, T. C. I877. Geology of Wisconsin, Vol. II.

I6. CLARKE, JOHN M. I885. On the Higher Devonian Faunas of Ontario County, N. Y. Bulletin, U. S. Geological Survey, No. I6.

r7. CROSBY, W. O. I884. On the Elevated Coral Reefs of Cuba. Boston Society Natural History Proceedings, Vol. XXII, pp. 124-I30.

18. CROSBY, W. O. I892. Guide to the Geological Collection, Boston Society of Natural History.

19. CULLIS, GILBER'T. I904. The Mineralogical Changes observed in the Cores of the Funafuti borings. Report on the Atoll of Funafuti, pp. $392-420$.

20. DANA, J. D. I89o. Corals and Coral Islands, 3rd edition.

21. DARWIN, CHARLES. I889. The Structure and Distribution of Coral Reefs, 3rd edition.

22. DAVID, EDGEWORTH. 1904. Narrative of the Second and Third Expeditions, section IV of Funafuti Report, pp. 40-60.

23. DAVIS, W. M. I9I3. Dana's Confirmation of Darwin's Theory of Coral Reefs. American Journal of Science, 4th series, Vol. XXXV, pp. I73-I 88.

24. DIENER, C., and ARTHABER, G. 1903. Handbook of the International Geological Congress.

25. DIXON, E. E. L., and VAUGHAN, A. I9II. The Carboniferous Succession in Gower, etc. Quarterly Journal of the Geological Society of London, Vol. LXVII, pp. 477-57I.

26. DRASCHE, R. VON. I878. Fragmente zu einer Geologie der Insel Luzon. Wien.

27. DUPONT, E. I88I. Sur l'origine des calcaires dévoniens de la Belgique. Bulletin de l'Academie Royale de Belgique, ser. 3, T. II, pp. 264-28o.

28. DUPONT, E. I883. Sur les Origines du Calcaire Carbonifère de la Belgique, ibid., ser. 3 T. V, pp. 2 I I-229. 
29. DUPONT, F. I888. Les Iles Coralliennes de Roly et de Philippeville. Bulletin de la Musée Royale Histoire Naturelle de Belgique, T. I, pp. 8-9 et seq.

30. ENDELL, K. Ueber die Chemische und Mineralogische Veränderung Basische Eruptivgesteine bei der Zersetzung unter Mooren. Neues Jahrbuch für Mineralogie. Beilage Band $3 \mathrm{I}$, Heft I, pp. I-54, bibliography.

31. FINCKH, ALFRED E. 1904. Biology of the Reef-forming Organisms at Funafuti Atoll. Funafuti Report, Section VI, pp. 125-150.

32. FRAAS, O. Aus dem Orient.

33. FRECH, FRITZ. I887. Ueber das Devon der Ostalpen, I. Ibid., III, 1894. Zeitschrift der deutschen geologischen Gesellschaft, Bd. XXXIX, pp. 659-738; Bd. XLVI, pp. 446-500.

34. FRECH, F. I894. Die Karnischen Alpen. Halle.

35. FRECH, F. 1897. Ueber Korallenriffe und ihrem Anteil an dem Aufbau des Erdrinde, "Himmel und Erde," Bd. IX, pp. 97 et seq.

36. FUCHS, THEODOR. I 883 . Welche Ablagerungen haben wir als Tiefsee Bildungen zu betrachten? Neues Jahrbuch für Mineralogie, Geologie und Palæontologie. Beilage Band II, pp. 487-584.

37. GARDINER, J. STANLEY. The Fauna and Geography of the Maldive and Laccadive Archipelagoes. Vols. I and II.

38. GILBER'T, G. K., and GULLIVER, F. P. I895. Tepee Buttes. Bulletin of the Geological Society of America, Vol. VI, pp. 333-342.

39. GRABAU, A. W. I90I. Geology and Palæontology of Niagara Falls and Vicinity. Bulletin 45, N. Y. State Museum of Natural History.

40. GRABAU, A. W. I903. Palæozoic Coral Reefs. Bulletin of the Geological Society of America, Vol. XIV, pp. 337-352.

4I. GUPPY, H. B. I887. Observations on the Recent Calcareous Formations of the Solomon Group made during I882-84. Transactions of the Royal Society of Edinburgh, Vol. XXXII, part III, pp. 545-58I.

42. HAECKER, V. 1905. Ueber Tiefsee-Radiolarien. Monatsberichte der deutschen geologischen Gesellschaft, pp. $3+1-3+4$.

43. HAHN, F. F. I910. Geologie der Kammerken Sontagshorngruppe, I. Jahrbuch der kaiserlich-königlichen geologischen Reichsanstalt. Bd. LX, Heft 2, pp. 389-90; 3II-420; II, Heft 4, pp. 637-7I2. Sections, Map, etc.

44. HALligaN, G. H. 1904. Report of Lagoon Borings, Funafuti Report, Section VIII, pp. I60-164.

45. HARRISON, J. B., and JUKES-BROWNE, A. J. I895. Notes on the Chemical Composition of Some Oceanic Deposits. Quarterly Journal of the Geological Society of London, Vol. LI, pp. 313-328.

46. HARTT,.CHARLES F. 1870. Geology of Brazil.

47. HEDSTROM, H. I9IO. The Silurian Stratigraphy in the Neighborhood of Visby. Guide 2o, to the excursions, International Geological Congress, XIth session, Stockholm.

48. HIEBER, VINCENS. 1882. Geologische Studien in den ostgalizischen Miocän-Gebieten. Jahrbuch der kaiserlich-königlichen geologischen Reichsanstalt, Bd. XXXII, pp. 193-329.

49. HILL, W., and JUKES-BROWN, A. J. 1895. On the Occurrence of Radiolaria in Chalk. Quarterly Journal of the Geological Society of London, Vol. LI, pp. 600-608, pl. XXII.

50. HOWE, MARSHALL A. I912. The Building of Coral Reefs. Science N. S., Vol. XXXV, pp. $837-842$. 


\section{4 PRINCIPLES OF STRATIGRAPHY}

51. IRVINE, ROBERT, and WOODHEAD, G. SIMS. I889, I890. On the Secretion of Carbonate of Lime by Animals. Proceedings of the Royal Society of Edinburgh, Vol. XV, pp. 308-316, Vol. XVI, pp. 324-354.

52. JAHN, JAROSLAV J. 1903. Geologische Exkursionen im AelterenPalæozoikum Mittelböhmens. Internationaler Geologen Kongress, IX Session, Vienna, Führer für Exkursionen.

53. JUKES-BROWNE, A. J. Voyage of H. M. S. Fly, Vol. I, Chapter XIII. 54. JUKES-BROWNE, A. J. Manual of Geology.

55. KAYSER, E., and HOLZAPFEL, E. 1894. Ueber die Stratigraphischen Beziehungen der böhmischen Stufen, F. G. H. Barrandes, zum rheinischen Devon. Jahrbuch der kaiserlich-königlichen geologischen Reichsanstalt, Vol. XLIV, pp. 479-5I4, 5 figs.

56. KIRK, EDWIN. I9II. The Structure and Relationship of Certain Eleutherozoic Pelmatozoa. U. S. National Museum, Proceedings, Vol. XII, pp. I-1 37 .

57. KRÜMMELL, O. 1907. Handbuch der Ozeanographie, Vol. I.

58. LANGENBECK, R. I897. Die Neueren Forschungen über die Korallenriffe. Hettner Geographische Zeitschrift, III.

59. LE CONTE, JOSEPH. 1857. On the agency of the Gulf Stream in the formation of the Peninsula of Florida. American Journal of Science, second series, Vol. XXIII, pp. 46-60.

6o. LE CONTE, JOSEPH. 1902. Elements of Geology, 4th edition. New York, D. Appleton \& Co.

61. LINCK, G. 1903. Die Bildung der Oölithe und Rogensteine. Neues Jahrbuch f. Mineralogie, etc. Beilage Band XVI, pp. 495-5I3.

62. MARR, J. E. I 899 . On Limestone-knolls in the Craven District of Yorkshire and Elsewhere. Quarterly Journal of the Geological Society of London, Vol. LV, pp. 327-358.

63. MICHALSKI. I 895. Sur la nature géologique de la chaine de collines de Podolie nomimées "toltry." Bulletin de la Comité Géologique, tome XIV, No. 4, p. I 8 et seq.

64. MOJSISOVICS, E. VON. I879. Die Dolomit-Riffe von Süd-Tiro: und Venetien. Vienna.

65. MUNTHE, H. 1910. The Sequence of Strata in Southern Gotland. Guide to the Excursions of the International Geological Congress, II session, Stockholm.

66. MURRAY, SIR JOHN. 1879-80. On the structure and origin of coral reefs and islands. Proceedings of the Royal Society of Edinburgh, Vol. X, pp. 505-518.

67. MURRAY, J. I890. The Maltese Islands, with Special Reference to their Geological Structure. Scottish Geographic Magazine, Vol. VI, pp. $45^{\circ}-488$.

68. MURRAY, J. 1897. On the Distribution of the Pelagic Foraminifera at the Surface and on the Floor of the Ocean. Natural Science, Vol. XI, pp. $17-27$.

69. MURRAY, J., and IRVINE, R. I889. On Coral Reefs and Other Carbonate of Lime Formations in Modern Seas. Proceedings of the Royal Society of Edinburgh, Vol. XVII, pp. 79-I09.

70. OGILVIE-GORDON, M. I 893. Contributions to the Geology of the Wengen and St. Cassian strata in Southern Tyrol. Quarterly Journal of the Geological Society of London, Vol. XLIX, pp. I-78.

7I. POURTALES, L. F I87I. Illustrated Catalogue of the Museum of Comparative Zoölogy at Harvard, No. IV. Deep-Sea Corals. 
72. RICHTHOFEN, F. VON. I860. Geognostische Beschreibung der Umgebung von Predazzo, St. Cassian und der Seisser Alpe in Süd Tyrol. Gotha, I 860.

72a. RICHTHOFEN, F. VON. I874. Ueber Mendola-Dolomit und SchlernDolomite. Zeitschrift der deutschen geologischen Gesellschaft, pp. $225-238$.

73. ROTHPLETZ, AUGUST. 1909. Ueber die Einbettung der Ammoniten in die Solnhofener Schichten. Abhandlungen der kaiserlichen Bayerischen Akademie der Wissenschaften. II Klasse. XXIV Bd., II Abt., pp. 3I 3337 .

74. ROYAL SOCIETY OF LONDON. Igo4 The Atoll of Funafuti. Borings into a Coral Reef and the results. Report of Coral Reef Committee, London, 1904 .

75. RÚST. I888. Beiträge zur Kenntniss der Fossilen Radiolarien aus Gesteinen der Kreide. Palæontographica, Vol. XXXIV, pp. 18I-2I4.

76. SARLE, CLIFTON J. I90I. Reef Structure in Clinton and Niagara Strata of Western New York. American Geologist, Vol. XXVIII, pp. 282-299, pls. 27-3I.

77. SAVILLE-KENT, W. I893. The Great Barrier Reef of Australia. London, W. H. Allen \& Co.

78. SEMPER, KARL. I88I. Animal Life as affected by the Natural Conditions of its Existence. International Scientific Series, Vol. XXXI.

79. SHERLOCK, R. L. I903. The Foraminifera and Other Organisms in the Raised Reefs of Fiji. Bulletin of the Museum of Comparative Zoology, Vol. XXVIII, pp. 349 et seq.

8o. SHERZER, W. H., and GRABAU, A. W. Igio. The Monroe Formation of Michigan. Michigan Geological and Natural History Survey, Publication, Vol. I.

81. SKEATS, ERNST W. rgo3. The Chemical Composition of Limestones from Upraised Coral Islands with notes on their microscopical structure. Bulletin of the Museum of Comparative Zoölogy, Vol. XLII, pp. 53-I26.

82. SKEATS, ERNST W. I905. On the Chemical and Mineralogical Evidence as to the Origin of the Dolomites of Southern Tyrol. Quarterly Journal of the Geological Society of London, Vol. LXI, pp. 97-I4I, Feb., I905.

83. TEISSEYRE, L. 1884. Der podolische Hügelzug der Mjodoboren als ein Sarmatischer Bryozoenriff. Jahrbuch der kaiserlich-königlichen geologischen Reichsanstalt, Vol. XXXIV, p. 299.

84. TIDDEMAN, R. H. I889. On the Concurrent Faulting and Deposit in Carboniferous times in Craven, Yorkshire, with a note on Carboniferous Reefs. Report British Association. (Newcastle-on-Tyne), pp. 600-603.

85. TIDDEMAN, R. H. I891. Ibid. Congrès Géologique International Compte Rendu, 4ème sess., I 888, pp. 319-329.

86. VAUGHAN, THOMAS WAYLAND. I9I0. A Contribution to the Geological History of the Florida Plateau, Carnegie Institute of Washington, Publication I33.

87. VAUGHAN, T. W. I9I. Physical conditions under which Palæozoic Coral Reefs were formed. Bulletin of the Geological Society of America, Vol. XXII, pp. 238-252.

88. VERRILL, A. E. I867. Boston Society of Natural History. Report on Collections.

89. WALCOT'T, C. D. 1906. Algonkian Formations of Northwestern Montana. Bulletin of the Geological Society of America, Vol. XVII, pp. I-28. 
90. WALTHER, JOHANNES. 1894. Einleitung in die Geologie, part III, Lithogenesis der Gegenwart.

91. WALTHER, JOHANNES. I904. Die Fauna der Solnhofener Plattenkalke Bionomisch Betrachtet, Festschrift zum Siebzigsten Geburtstage von Ernst Haeckel, Jena, I904.

92. WILCKENS, O. I908. Radiolarit im Kulm der Ottendorn-ElsperDoppel-Mulde. Zeitschrift der deutschen Geologischen Gesellschaft, Monatsblatt, 1908, p. 354 .

93. WIMAN, KARL. I897. Ueber Silurische Korallenriffe. Bulletin of the Geological Institute of Upsala, Vol. III, pp. 3I I-325, pls. 8-Io. 


\section{CHAPTER XI.}

\section{CHARACTER AND LITHOGENESIS OF ORGANIC OR BIOGENIC ROCKS-(CONTINUED). PHYTOGENIC DEPOSITS.}

Phytoliths, or rocks formed from the remains of plants, may be classed with reference to their material as acaustophytoliths and caustophytoliths. The latter comprise the peats, coals, bitumens, etc., while the former include calcareous or siliceous mineral matter secreted by the growing organism. With reference to their source of origin, phytoliths may be classed as autochthonous, or such as are deposited where they grew, or allochthonous, those brought from other localities and so deposited in foreign soil.

Autochthonous acaustophytoliths have been mentioned in the preceding chapter, in the growth of nullipores on coral reefs, and allochthonous acaustophytoliths have been described in the diatomacecus oozes. In this chapter we shall discuss more fully the two classes of phytoliths, beginning with those depositing mineral matter other than carbon.

\section{ACAUSTOPHYTOLITHS.}

Deposits Formed by Lime-secreting Alge. Among the plants belonging to the comparatively low division of algae are a number which secrete carbonate of lime or silica and deposit it either as a coating on the exterior or within their tissues.

Modern Marine Forms. Among the lime- and silica-secreting alga of the modern ocean the following may be especially mentioned.

Order Cyanophycea, or Blue-Green Alga.

This order contains several lime-secreting members, some of which become important as rock builders.

Phytogenic Oölites. On the shores of Great Salt Lake, Utah, 
Rothpletz (36) has noted that the genera Glœocapsa and Glœothece, which are rich lime-secreters, form snow-white oölite grains which are scattered among the sand and pebbles of the low shores, and blown landward into dunes ranging up to 6 feet in height. "The cells of the Glœocapsa are $2 \mu^{*}$ in diameter and spherical, those of the Glœothece 2 to $3 \mu$ thick and 4 to $5 \mu$ long. The lime is enclosed in the alga-body in the form of rounded tubercles, which often mass themselves together into larger irregular tubercular bodies. It is a fine-grained aggregate of calcite which always encloses numerous dead alga cells that have already lost their greenish coloring." Three forms were recognized: Ist, irregular tubercular bodies, several millimeters in diameter; 2nd, spherical or oval forms, about one-third millimeter in diameter; and, 3 rd, thin rods, about half a millimeter long and one-tenth millimeter broad. These oölites are forming day by day through the secretion of lime by these algæ.

Since analysis of the water of Great Salt Lake (see Chapter IV) shows only a small quantity of calcium chloride or sulphate and no carbonate, no lime would be precipitated from the lake itself, except for the activities of these minute plants. When it is considered, however, that the streams tributary to this lake bring in quantities of carbonate of lime, all of which is precipitated as oölite grains, it becomes a question whether the algous growth is so active as to use up all this lime or whether "the strong brine of the lake seems to be incapable of holding calcium carbonate in solution" (Clarke-8:146) and it is therefore precipitated chemically. $\dagger$

Similar oölites are forming on the shores of the Red Sea, where they are widely distributed along the west coast of the Sinai peninsula. Here they are drifted inland often for many kilometers, or even days' marches distant from the shore, and constitute white dune sands of oölitic material, a continental formation built of material of marine origin. These grains generally contain vermiform and often branching canals, more or less filled with calcite.

${ }^{*}$ I $\mu=0.00$ I mm., called a micron.

$\dagger$ Of the rivers tributary to Great Salt Lake, the following may be noted with their percentage of $\mathrm{CO}_{3}$ and $\mathrm{Ca}$ (Clarke-8:I45):

A. Bear River at Evanston, Wyoming........ $\mathrm{CO}_{3}$

$\mathrm{Ca}$

B. Bear River at Corrine, Utah............ 2I .53

23.69

C. Jordan River at intake of Utah and Salt Lake

Canal....................... 2.67

D. Jordan River near Salt Lake City......... trace

10. 12

E. City Creek, Utah.............. 52.57

F. Ogden River at Ogden, Utah............. 33.68

G. Weber River at mouth of Canyon........ 40.00 
These are believed to be due to the presence of thread-like algæ living symbiotically on the lime-secreting species and being encased by the deposits of lime.

In the low coastal tract in the further environs of Suez, Quaternary oölites of this type are found, built up subaërially into beds and dunes and frequently consolidated into hard oölitic limestones (Bauermann). These oölites, however, generally contain a foreign sand grain, but the lime surrounding them has the structure of the oolites of Great Salt Lake and on solution leaves the organic residuum found in these.

Some observers contend that the oölites of the Red Sea region have a radial structure, but this is denied by others. Linck, moreover, holds that this radial structure, when it occurs, does not indicate organic growth. He interprets the rods as minute crystals of aragonite deposited in a purely hydrogenic manner.

Oölites regarded as due to the growth of algæ have been described from the salt lakes of the Kalahari desert of Africa. (Kalkowsky-26.) From his studies Rothpletz concludes that the "majority of the marine calcareous oölites with regular zonal and radial structure are of plant origin; the product of microscopically small algæ of very low rank, capable of secreting lime." (Rothpletz-Cragin-36:279.) On the other hand, Linck, who approached the subject from the experimental point of view, is equally positive that these oölites are wholly of chemical origin, deposited either freely or upon a foreign nucleus, under the influence of chemical reaction, as aragonite (really ktypeit) and that when organic remains, such as algæ, etc., were enclosed they lived upon the growing shells of inorganic origin or were mechanically enclosed by the chemical deposit. The algous rods (Algenstäbchen) of Rothpletz he regards as minute crystals of aragonite. The aragonite oölites are subsequently altered to calcite, which is the condition of most fossil oölites. (See further under fossil oölites, postea, p. 47r, and oölites of chemical origin, antc, p. 336, Chapter IX.)

\section{Order Chlorophycea, or Green Alga.}

In this division the chief lime-secreting algæ of the modern sea are the genera Halimeda and Udolea of the group Siphonales. These grow in the shallower portion of the coral reefs connecting dead coral masses. (Agassiz-I :82.) Halimeda opuntia and H. tridens form masses of lime on the shores of St. Thomas. (Challenger Narrative-7:I27.) It is a jointed plant and readily broken up into small lime rods. An analysis of Halimeda gave $\mathrm{CaCO}_{3}, 90.16 \%$, 
$\mathrm{MgCO}_{3}, 5.5 \% ; \mathrm{CaSO}_{4}$ and $\mathrm{SiO}_{2}, 0.5 \%$; organic matter $3.8 \%$. This alga forms extensive limestone deposits within the lagoons of coral atolls, as in the case of Funafuti, and in the Red. Sea.

\section{Order Phaphycea or Brozen Alga.}

This division, which contains the great algæ (Laminaria, Macrocystis), the floating Sargassum, and the attached rock weed or Fucus, has no important lime-secreting members, but the diatoms, important on account of their siliceous frustules, belong here. Their general character and importance have already been discussed in the preceding chapter.

\section{Order Rhodophycece or Floridea-Red Algce.}

This division contains several very important types which act in part as rock-builders. These include the genera Corallina, Jania, Melobesia, Lithothamnion, and Lithophyllum and they are distributed from the equator to the arctic regions. The living plant often contains as much as $85 \% \mathrm{CaCO}_{3}$ and many of the more massive ones (Lithothamnion, etc.) build heavy barriers on the outer zone of coral reefs, where wave activity is most pronounced. Lithothamnion fasciatum occurs in the Arctic Sea on the coast of Norway at a depth of $70 \mathrm{~m}$., on the Russo-Lapland coast from ro to 55 meters, at Spitzbergen, $18-36 \mathrm{~m}$., and at Nova Zembla in 45 meters. L. polymorphum and Corallina officinalis are found on the Great Banks in $22 \mathrm{~m}$. (Walther). L. racemus forms masses of the size of a fist in the Gulf of Naples on the Secca di Gajola in 25 meters depth, while the smaller $L$. ramolosum abounds in 45 to 60 meters on the Secca di Benda Palummo, or pigeon bank. (Walther-50:220; $52: 41$.)

In the Caribbean Sea nullipores occur down to depths of $284 \mathrm{~m}$. (Agassiz-2:I $f I$ ) and in the Gulf of Naples Lithothamnion, Corallina and Lithophyllum occur at depths of 30 to $65 \mathrm{~m}$. (Walther-50:220.) The name "Nullipore" is generally applied to all these lime-secreting algx. It is derived from the old Lamarckian genus Nullipora, which included four species of calcareous organisms, all probably belonging to the family Corallinacex of the red algæ.

The name Lithothamnion was generally applied to the unsegmented coralline alga, but has more recently been restricted, while other generic groups-Lithophyllum, Goniolithon, Phymatolithon, etc.-have been separated from the original group. 
The nullipores are often the most important lime-contributors to the coral reefs, far more important than the corals themselves. This las been found to be the case in Funafuti reef (Finckh), the Fiji reefs (Gardiner), the Chagos group (Gardiner), etc. In all these, animal, especially coral life is relatively unimportant, while plant life (nullipores) flourishes luxuriantly. (See the photograph of a Lithothamnion reef in Nature, Vol. LXXII, pp. 57 I, 572.)

In Bermuda, too, corals play a subordinate part in the reef formation, Lithothamnion taking its place among the principal reef builders (Agassiz-3). Nullipores also grow on the Challenger Bank, raising the surface from considerable depths to within the zones of coral growth. (Howe-24.)

Lime-Secreting Alg.e of Fresh Water. These are chiefly represented by Chlorophycex of the family of the Stoneworts or Characea, and they are widely distributed in the fresh-water lakes of the temperate regions, and form extensive deposits of marl. Analyses of Chara from the fresh-water lakes of Michigan showed that something over $0.6 \mathrm{I}$ gram of soluble mineral matter occurs in an average plant. This mineral matter is nearly $94 \% \mathrm{CaCO}_{3}$ and is deposited as an encrustation on the outside of the plant. This encrustation renders the stems and branches of the alga almost white, and very brittle. On the average from 50 to 80 plants were found on a square decimeter of lake bottom. Extensive beds of marl or bog lime have in this manner accumulated at the bottoms of ponds and small lakes. (Davis-14.) Marl beds composed chiefly of the remains of Chara hispida have been found in various parts of Scotland and elsewhere. Extensive deposits of "Characerlime" have been formed in the lakes of Denmark by the growth of Chara. (Wesenberg-Lund-56:555-156.) Such deposits are also known among the older rocks. The organs of fructification of the Characex sometimes accumulate in such quantities as to form parts of extensive beds of limestones in both recent and earlier formations.

In the Devonic of Ohio, and in other formations, occur linestones often to a large extent composed of small spherical and fluted bodies described under the name of Calcisphora robusta Williams. These have also been regarded as the organs of fructification of one of the Characex.

\section{Fossil Phytolithe of Algots Origin.}

Fossıl Oölıtes. These occur in all gcological horizons either as autochthonous or ats allochthonous deposits. The latter generally 
show evidence of wind transportation, as in the case of modern oölite dunes of the Floricla coast, the shores of the Great Salt Lake of Utah, and the coast of the Arabian Sea. Such transported material generally shows eolian cross-bedding, a feature very commonly associated with fossil oölites. This is well shown in the Siluric oölites of Gotland and better still in the Jurassic oölites of England, where remarkably fine examples of wind bedding are seen.

The oolites of the Upper Siluric (Monroan) of Michigan have been referred by Sherzer (43) to an origin similar to that of the Great Salt Lake oölites. Rothpletz regards those from the Lias and the Triassic Wetterstein Kalk of the northern Alps as due to algous growths. From the Carbonic of England, oölites have been described and referred to algous origin. The same is true of the well-known oölites of the Jurassic of England which have given many of the formations their local names (Superior oölite, Great oölite, etc.) These oölites show, according to Wethered $(58 ; 59)$, organic structures similar to those described by Nicholson and Etheridge as Girvanella problematica from the upper Siluric of the Girvan district of Ayrshire. Both oölites and pisolites of these horizons show often a concentric encrustation of organic fragments by. organisms forming flexuous or contorted tubules. Several species have been distinguished by Wethered (58), among them Girvanella pisolithica, which forms the Peagrit of the Inferior oölite and coralline oölite.

Rogensteine of the Bunter Sandstein. The remarkable oöliths of the Bunt Sandstein of North Germany known as Rogensteine have been described in great detail by Kalkowsky (27). This author restricts the name oölith to the rock having an oölitic structure, and proposes the term "ooid" for the individual grains. The diameter of the ooids never falls below $0.1 \mathrm{~mm}$., though smaller grains occur (0.I-0.5 mm.), which he regards as ooids in the making-"embryonic ooids." The maximum size is $7 \mathrm{~mm}$., only one case exceeding that having been known. He finds in all cases foreign bodies forming the nuclei of the ooids, these bodies being commonly small crystals of calcite, or again scales and rods of a fine-grained clay slate. Kalkowsky finds the following structures represented:

I. Concentric structure, layers of clear calcite of varying width, alternating with more or less opaque calcite layers carrying impurities of clay.

2. Fine radial structure, produced by radial arrangement of fine threads of $\mathrm{CaCO}_{3}$. 
3. Spindle structure, the concentric layers are traversed by elongated spindles which become pointed toward the periphery and the center of the ooid, the structure of the spindles being an irregular mass of calcite grains.

4. Cone shaped, conical bodies traverse the concentric layers, their points at the center of the ooid. These cones are built up of concentric layers of a radius often somewhat smaller than that of the ooid itself, and separated by interradii containing clay and sand and having a somewhat radial structure.

By a combination of these structural groups, eight or nine different ooid types were produced. Special types among these are the roller form, the hemiooids, the polyooids, and the cystiform ooids. These ooids are held together by a cement of $\mathrm{CaCO}_{3}$. Kalkowsky regards these structures as due to secretion of lime by minute algæ of low organization, all traces of which are destroyed by reciystallization.

Walther $(53: 80)$ suggests that the Rogensteine of the Bunt Sandstein of North Germany may have been formed in salt seas in the desert, similar to those now forming through algous growth in the Great Salt Lake of Utah, and in the Salt Lakes of the Kalahari desert.

The stromatoliths of Kalkowsky are large masses of calcareous material having a stratified as well as fibrous structure. He regards them as structures similar to the ooids, only vastly larger and growing chiefly in one direction, $i$. e., upward. In size they are found up to one meter in diameter, and they often form beds of considerable extent.

Alteration of Oölites. Linck (Chapter IX) finds that recent oölites consist or have consisted of aragonite, and that fossil oölites, so far as investigated, are calcite, from which he concludes that alteration to calcite is a change which all oölites undergo with lapse of time. It may also be briefly noted that oölites of chenical as well as organic (phytogenic) origin may be altered by replacement by other minerals. Thus siliceous as well as iron oölites are known, both probably due to replacement of calcareous oölites. Of the former a good example is found in silicified oölites of the salt seas of the Kalahari desert in Africa (Kalkowsky-26), and in the Ordovicic limestones of central Pennsylvania (Ziegler-6I). Of the latter a typical example occurs in the basal iron ores of the Siluric in Wisconsin where the grains are regular pellets of uniform character, probably of phytogenic origin. Linck holds that original oölites (chemically formed) of aragonite are saturated with iron solutions, 
so that the aragonite is changed to iron carbonate which subsequently alters to iron oxide as outlined by Sorby and others.

Spherocodium and Girvanella Deposits. In the Palæozoic and later limestones of many countries are found rounded masses of lime ranging in size up to several centimeters and referred to the genera Sphærocodium and Girvanella. These often occur in sufficient abundance to constitute a large part of the rock mass, as in the case of the Sphærocodium beds of the Siluric of Gotland. Sphærocodium forms rounded masses generally coating foreign bodies and consists of a simple network of unicellular threads, which result in the formation of successive shells of calcareous tissue. The genus has been found abundantly represented in the Siluric of Sweden and in the Triassic of the Alpine region.

Girvanella consists of irregularly twisted, tubes and forms irregular knobby or rod-like masses, also, as a rule, adhering to foreign bodies. It has been found in the Ordovicic of England and America and in the Carbonic limestone (Mississippic), the Superior oölite and the Coralline oölite of England.

Other algous types of the Palæozoic, with similar mode of growth, are Siphonema, found in the Ordovicic, and Zonotrichites from the Rhætic. (Rothpletz-35; 37.) Algæe have also been described from the Trenton limestone of New York. (Ruede- mann-38.)

Fossil Nullipores. The fossil nullipores are well represented in older geological formations. As already noted, the Triassic reefs of the Tyrol are regarded by many as chiefly of nullipore origin. The leading alga is a coralline, Diplopora, which occurs largely as. dissociated joints of the branches. These algæ are closely related to the living Cymapolia, which, like Halimeda, is a jointed siphonaceous member of the Chlorophyceæ or green algæ. The red algæ (Rhodophyceæ) are also well represented from the Jura to the Pliocenic, some fifteen or more species being known in a fossil state. Sometimes they formed extensive encrustations on the shores and islands of ancient seas, as in the case of the Miocenic Leythakalk of the Vienna basin, formed chiefly by Lithothamnion ramossinum Reuss. This nullipore forms bundles and mats of numerous short, wart-like or club-shaped branches from 2 to $5 \mathrm{~mm}$. in diameter. As the lime is in the form of calcite, it is commonly well preserved together with other calcite structures, while associated fossils of aragonite are for the most part dissolved away and the lime redeposited as calcite among the algous masses. (See Mojsisovics29:498.)

Fossil Chara. Fossil stems and fruits of Chara are responsible 
for many fresh-water limestones, as long ago pointed out by Lyell. Such a fresh-water limestone was described by him from a comparatively recent deposit in Forfarshire. In the Eocenic of the Paris Basin, Chara lyelli is rock-forming. Chara-like bodies have also been discovered in abundance in Devonic limestones of Ohio, as above noted.

\section{Travertine and Siliceous Sinter Formed by Alge in Hot Springs.}

In the waters of hot springs, the world over, algre of various types have been observed to grow, in temperatures ranging from below $100^{\circ}$ to $200^{\circ} \mathrm{F}$. (55). In the hot springs of the Yellowstone National Park they occur in waters between the temperature of $90^{\circ}$ and $185^{\circ} \mathrm{F}$., more having been found in warmer waters; but in California they have been found in waters of a temperature of $200^{\circ} \mathrm{F}$. These algæe through their physiological activities separate lime or silica from the waters of these hot springs, producing extensive deposits of travertine, or of siliceous sinter, according to the nature of the spring and its water. Not all the deposits of travertine or siliceous sinter are due to this cause; many are of purely hydrogenic origin, being precipitated from the water by loss of pressure, by diffusion or by abstraction of the solvent gases, by evaporation, or by chemical reaction. In widely separated regions, however, plants have been found active in the separation of these mineral matters from the water-examples being the travertine deposits of the Carlsbad Sprudel in Bohemia, and the hot springs of Yellowstone National Park, in the United States, and the geyserite or siliceous sinter deposits of the latter region. The extensive sinter deposits of Iceland and New Zealand are probably also in large part due to algous growth.

\section{Method of Line Deposition by Plants.}

We have seen above that lime carbonate is held in solution by the excess of $\mathrm{CO}_{2}$ in the water and that any agent which causes the abstraction of the $\mathrm{CO}_{2}$ also causes the precipitation of much of the calcium carbonate. Plants obtain the carbon of which their tissues are built by decomposing the carbon dioxide derived either from the air or from the water, according to the mode of life of the plant. It is thus obvious that where aquatic life is abundant, much $\mathrm{CO}_{2}$ will be abstracted from the water, and thus deposition 
of the lime carbonate is brought about. Algæ are most effective in this respect, different algæ accomplishing the separation in different ways. According to Dr. Coln (IO), who studied in detail the algous limestones of the Carlsbad Sprudel, the lime is deposited first in minute crystals in the slime between the vegetable threads and upon their surface. At first these crystals are separate, but continued growth in numbers produces star-like clusters which by enlargement grow into grains of calcareous sand. Further growth results in the union of the grains into a solid mass of travertine.

"The exact relation of the crystals and grains of carbonate of lime varies in the different species of alga. In the Oscillaria of Carlsbad, and allied species, the crystals form in the slimy intercellular tissue; in Halimeda, the carbonate of lime forms a sieve-like cover about the tips of the algæ filaments; and, in Acetularia it occurs as a tube about the stalk of the plant. In the Charæ the lime is separated and deposited in the cells and cell walls of the back alone, while in the Corallines [Corallina, Lithothamnion, etc.] it is found only within the cells." (Weed-55:643.) In the last mentioned types, especially in Lithothamnion and allied forms, the surface layer alone is living, the lime occupying the successive strata of dead cells beneath. In this manner thick masses of limestone are built up. Solution of the lime in acid sets free the dead cell walls which will either remain behind as a tangled mass of filaments, or float as pellicles on the surface of the solution. Rothpletz found this to be the case in the green fission-alga secreting the lime of the oölites as well as in the red algæ, which form extensive limestone deposits.

Where calcium carbonate is absent, as in the Great Salt Lake, or occurs only in small quantities, as in sea water, the lime-secreting plants decompose the calcium chloride, phosphate or sulphate and deposit it within their tissues as carbonate. The same is believed to be true of many animals, which take the lime from the sea water in the form of the sulphate, but deposit it in their shells and skeletons as carbonate. The reaction is brought about through the formation of ammonium carbonate as a decomposition product, which in turn, precipitates the calcium in the form of carbonate from the solution within the dead cells.

Separation of Siliceous Sinter by Plants.

The silica is at first deposited in and upon the plants in the form of a gelatinous substance, often quite brilliantly colored, in 
golden-yellow, orange, or red, and in the hottest waters pale fleshpink or even white. "These algæ are often so thickly encrusted by silica that the plant structure is not recognizable even under the microscope, and their presence is often only to be distinguished by the color." (Weed-55:657.) The color varies with the temperature, so that in the differently heated portions different colors obtain. The order of color from progressive cooling is white, pale flesh-pink, bright orange, yellowish-green, emerald. The most luxuriant growth exists in the pools into which the waters flow, where leathery sheets of tough gelatinous material with coralloid and vase-shaped form abound. In some cases, the algæ twelve to fifteen inches long unite their tops into a solid roof, which may become the floor of a second story of algous growth in a new basin. "The exact manner in which the alga of these waters eliminate the silica from solution is not known, but the process appears to be due to the vital growth of the plant, for both the algæ filaments and their slimy envelope are formed of gelatinous silica. Upon the death of the alga which have separated this jelly from the spring waters there is a loss of a large part of its water and a change to a soft, cheesy, but more permanent form. This dehydration is carried still farther if the silica be removed from the water and dried, but if allowed to remain in the cold water pools there is a further separation of silica, possibly due to organic acids, formed by the decaying vegetation reacting upon the silica salts of the water. This hardens the existing structures, in certain cases, and generally covers the pillars with a frost-like coating of silica." (Weed-55:664.)

It is in the inner dead layers of the algous mass that the gelatine hardens first into silica, the outer layer continuing alive. Fibrous varieties of sinter are formed in many of the Yellowstone and New Zealand hot springs by the growth of the algæ Calothrix, Mastigonema, and Leptothrix, the first two producing a "furry" sinter in strata from a sixteenth of an inch to half an inch thick, the last forms fibrous, straw-like masses.

Mosses and diatoms have also been found active in separating out the silica of the hot springs of the Yellowstone. The moss (Hypnum aduncum var. grasilescens, Br. \& Sch.) grows on the lower parts of the slopes where the water is cooled to blood heat, and has lost much of its lime and part of its silica. The silica is abstracted from the water by the physiological activities of the plant and, in turn, encloses and buries the moss. Diatoms are especially active in the tepid marshes, Denticula c'alida being the predominant type, though a number of other species occur. Extensive beds of diatomaceous earth are formed by their siliceous skeletons. 


\section{VEGETAL DEPOSITS. (CAUSTOPHYTOLITHS.)}

The actual accumulations of vegetal matter in the strata of the earth's crust are perhaps of even greater significance than the lime and silica deposits caused by plants. There are few horizons which have not some kind of plant deposit in the form of carbonaceous material. They occur even in the Algonkian, where a bed of anthracite two meters thick is found in the upper part of the middle Algonkian or Jatulian formation north of Lake Onega in Finland.

As already noted, Caustophyloliths have been divided into those formed from plants living where their remains are found to-day, autochthonous caustophytoliths, and those transported to their present place of occurrence, or allochthonous. Autochthonous caustophytoliths may be terrestrial or aquatic, according to the condition of life of the plants, i. e., whether land or aquatic plants. Allochthonous caustophytoliths are primarily allochthonous, when the material of which they were made was transported in the living, or at least undecomposed, condition to the place where it is now found, and secondarily allochthonous, when transportation occurred after the plant had become a caustophytolith.

Modern autochthonous deposits of vegetal matter are found in the sea, especially in enclosed bodies of sea water, in marine marshes, fresh water swamps, and in bogs and wet woods. Allochthonous deposits may be found èmbedded in marine, lacustrine, fluviatile or even æolian deposits.

PETROGRAPHICAL TYPES OF VEGETAL DEPOSITS. As noted in Chapter I, vegetal deposits may occur in one or another of the following types: I, Sapropeliths; 2, Humuliths; and, 3, Liptobioliths. Each of these groups will be considered at some length.

\section{SAPROPELITHS.}

These are accumulations of the decaying organic tissues of aquatic animals and plants at the bottom of the sea, or in fresh water lakes and ponds. In the unconsolidated state it is a foul organic slime (Faulschlamm), or slime of decomposing organic matter derived from the water. In so far as plants contribute to this slime, it is of algous origin, since any deposit formed by higher plants normally belongs to the next type, the humuliths. The chief chemical difference between such sapropelitic material and that formed by land and swamp plants is the higher fat and protein content of the former. Sapropeliths accumulate only in relatively 
quiet waters, since strong agitation of the water results in the inclusion of much oxygen and the consequent complete oxidation of the organic matter-a feature observed in strongly agitated lakes.

The decaying vegetal matter rarely accumulates in any great quantity as an absolutely pure caustobiolith. Most commonly inorganic or organic mineral impurities are present in greater or less quantity. Among them clay or mud is often a very important constituent, forming argillaceous sapropeliths (if the clay is of small amount) or more commonly sapropelargilliths or in general sapropellutytes. Lime of clastic or organic origin may form the admixture producing sapropelcalc rocks (sapropelitic calcilutytes, sapropelitic calcipulverytes, etc.), while silica, especially that of diatoms, produces a siliceous or diatom sapropelith. Marine sapropelargillites are common on many shallow sea coasts, especially in protected areas, where they constitute deposits of black muld. These mud flats exposed at low tide are extensive generators of hydrogen sulphide, which leads to the precipitation of sulphides, especially those of iron. In this way the foundations are laid for the formation of highly carbonaceous lutytes or black shales rich in iron pyrites and with the remains of a more or less depauperate fauna. Such deposits are forming in the estuaries along the Atlantic coast, and in a fossil state these seem to be represented in part at least by the Devonic Genesee shale of New York State. They are further forming in the lagoons behind the coral reefs of Florida, and in a fossil state these are represented by the Middle Devonic Marcellus shale of New York, and perhaps to a certain extent by the Utica shales of eastern North America. Again they are forming to-day in the depths of the Black Sea, and this type appears to be represented by the Permic Kupferschiefer of Thuringia, and possibly the oil shales of the Calciferous series (Lower Carbonic) of Scotland. The Posidonia shales of the Jurassic of Europe, and some of the Upper Devonic (Portage) shales of New York have also been interpreted on this basis. (Pompeckj-3I and Clarke-9.) This interpretation is, however, questionable. The black shales of southern United States, $i$. $e$, , the Chattanooga, are probably more nearly referable to the class of argillaceous humuliths. The various fossil sapropellutytes furnish oil on distillation and may in part be the source of the petroleum in the underlying rocks.

Purer sapropeliths from the Tertiary are known as Dysodil (Greek $\delta v \sigma \omega ́ \delta \eta^{s}=$ ill-smelling), on account of their bad odor on burning. Carbonic sapropeliths are represented by Cannel coal, a characteristic of which is that it burns with a bright flame. Both Dysodil and Cannel coal are, however, commonly impure, the im- 
purity or "ash" being primary, i.e., due to the non-burnable mineral matter originally a part of the plants, or secondary, due to the admixture of foreign material, either mechanical sediment or chemical precipitate. Though rare, absolutely pure sapropelitic deposits occur. According to the stage of consolidation and age, these have received distinct names, as shown in the first columns of the subjoined table after Potonié ( $32: 53)$.

\begin{tabular}{|c|c|c|c|}
\hline $\begin{array}{c}\text { Pure } \\
\text { Sapropeliths }\end{array}$ & $\begin{array}{l}\text { With admixture of organic } \\
\text { lime or silica }\end{array}$ & $\begin{array}{l}\text { With admixture of clastic } \\
\text { material, clay or sand }\end{array}$ & \\
\hline $\begin{array}{l}\text { Sapropelite } \\
\text { (unconsolidated) } \\
(\text { sapro+pel) }\end{array}$ & \begin{tabular}{|l|l|} 
Calcareous sapro- & Diatom- \\
pelite & pelite \\
Sapropelitic cal- & \\
ciliths &
\end{tabular} & \multirow[t]{2}{*}{$\begin{array}{l}\text { Argillaceous (and arena- } \\
\text { ceous) sapropelite and } \\
\text { sapropelitic argillyte } \\
\text { or microarenyte }\end{array}$} & \multirow{2}{*}{ 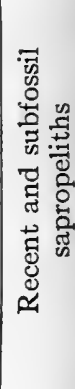 } \\
\hline $\begin{array}{l}\text { Saprocollyte } \\
\text { (hardened sapro- } \\
\text { lite) } \\
\text { (sapro+colla, glue) }\end{array}$ & $\begin{array}{l}\text { Diatomaceous-calc sapro- } \\
\text { pelite and Diatomaceous } \\
\text { sapropelcalcilith (often } \\
\text { also containing clayey } \\
\text { sediment, etc.) }\end{array}$ & & \\
\hline $\begin{array}{l}\text { Saprodillyte } \\
\text { (pure Dysodil) } \\
\left(\begin{array}{l}\text { sapro }+ \text { odemeis, } \\
\text { odor) }\end{array}\right.\end{array}$ & $\begin{array}{l}\text { Bituminous marl, shales, } \\
\text { etc. }\end{array}$ & $\begin{array}{l}\text { Most bituminous argillites } \\
\text { and argillaceous lutytes } \\
\text { (ex. Jurassic Posidonia, } \\
\text { shales) }\end{array}$ & 苞 \\
\hline $\begin{array}{l}\text { Sapanthraconyte } \\
\text { (sapro + anthrax, } \\
\text { coal = sapropelite } \\
\text { coal, i.e., purest } \\
\text { cannel coal }\end{array}$ & Most bituminous calcilytes & $\begin{array}{l}\text { Zechstein Marl shales } \\
\text { (Kupferschiefer) }\end{array}$ & $\begin{array}{l}\infty \\
\cdots \\
0 \\
0 \\
0 \\
0\end{array}$ \\
\hline \multicolumn{2}{|c|}{$\begin{array}{l}\text { In the purest state largely or almost entirely } \\
\text { biogenic and therefore aquatic-autochtho- } \\
\text { nous formations, } i \text {.e., produced through } \\
\text { autochthonous sedimentation. }\end{array}$} & \multicolumn{2}{|l|}{$\begin{array}{l}\text { Allochthonous, with ref- } \\
\text { erence to the lutaceous } \\
\text { or finely arenaceous con- } \\
\text { stituents, but autoch- } \\
\text { thonous, with reference } \\
\text { to the organic constitu- } \\
\text { ents, therefore produced } \\
\text { by allochthonous and } \\
\text { autochthonous sedimen- } \\
\text { tation. }\end{array}$} \\
\hline
\end{tabular}

Petroleum. Among the fossil sapropelytic substances petroleum takes the first rank. It is, however, to be regarded as a diagenetic 
product from sapropelytes, the result of distillation. Both animal and plant remains, especially alga, are now generally regarded as the material from which petroleum is distilled, and the rocks rich in such deposits, namely, the sapropelytic rocks, must therefore form the mother rock of petroleum of organic origin.

Sapanthraconyte or Cannel Coal. This has an amorphous structure and a dull luster of a greasy or silky character, quite distinct from the luster of true coal. The contrast is well shown by the carbonized remains of the rhizomes of plants preserved in the fossil slimes of ancient marsh bottoms. Thus stigmaria embedded in cannel coal will show the bright luster of true coal in contrast with the duller cannel coal. The vertebraria or rhizomes of Glossopteris occurring in the Petroleum shales of the Southern Permic show a similar contrast. Cannel coal is found in America in the Carbonic of Ohio, Indiana, and especially eastern Kenticky, where Breckenridge is a noted locality. It is especially valuable for the manufacture of gas on account of its abundance of volatile hydrocarbons. Remains of fishes, crustaceans (Cypris), merostomes (eurypterids), etc., and more rarely amphibians, are found in some localities, these in most cases being fresh-water species. At Linton, Ohio, more than 50 species of fishes and amphibians were found in the cannel coal. Analyses of cannel coal gave the following results. (Dana-1 I :662.)

(For comparison analyses of anthracite and of bituminous coal are given) :

$$
\begin{array}{llllllll}
\text { Locality } & \mathrm{C} & \mathrm{H} & \mathrm{O} & \mathrm{N} & \mathrm{S} & \text { Ash }
\end{array}
$$

Cannel coal from Brecken-

$\begin{array}{llllll}\text { ridge, Hancock Co., Ky. . } 68.13 & \cdot 6.49 & 5.83 & 2.27 & 2.48 & 12.30\end{array}$

$\begin{array}{lllllr}\text { Cannel coal from Wigan... } 80.07 & 5.53 & 8.10 & 2.12 & 1.50 & 2.70\end{array}$

Cannel coal or "Torbanite"

from Scotland $\ldots \ldots \ldots \ldots 64.02 \quad 8.90 \quad 5.66 \quad 0.55 \quad 0.50 \quad 20.32$

Anthracite coal from Penn$\begin{array}{lllllll}\text { sylvania.............. } & 92.59 & 2.63 & 1.61 & 0.92 & \ldots & 2.25\end{array}$

Bituminous "non - caking",

coal from Brier Hill, Ohio. $78.94 \quad 5.92 \quad$ I1.50 $\quad 1.58 \quad 0.56 \quad 1.45$

Microscopic algæ are often well preserved in cannel coals. Pollen of Cordaites spores, wood and numerous alga were found, together with fish remains, Crustacea and coprolites in the "Boghead" or Permic cannel coai of Autun (Bertrand-4). Cannel coal and ordinary (humus) coal are often associated, the sapropelites forming the foundation for the growth of land or swamp plants. Thus a layer of cannel coal will often underlie one of bituminous or of 
anthracite coal, and, ninoreover, the two may become interstratified, the one or the other predominating, according to the length of time during which the conditions responsible for either existed. Where the beds are relatively thin the coal is spoken of as banded cannel or bituminous coal, as the case may be. A section from Recklinghausen in Westphalia illustrates a complex relationship. In descending order we find:

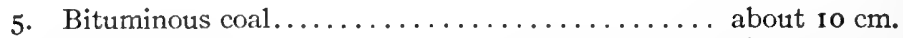

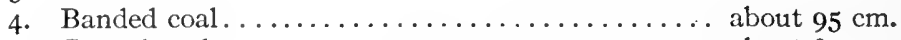

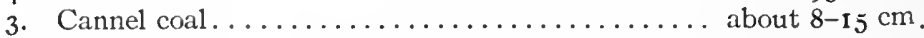

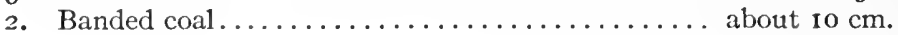

I. Cannel coal......................... about I.3 m.

This section shows, first, a water body in which algæ and other truly aqueous plants lived and accumulated as decomposition slime, followed by marshy conditions with growth of higher plants, but with repeated inundations to furnish the decomposition slime from which the bands of cannel coal were formed. This is followed by a second period of complete submergence, with the formation of cannel coal. Then the alternating conditions were repeated, with the result that more banded coals were formed, and the area was finally converted into a marsh or moor with the formation of pure bituminous or gas coal.

The algous origin of cannel coals has, however, been seriously questioned by Jeffrey (25). He finds, on the basis of numerous well-prepared microscopic sections from widely separated regions, that the organisms found in abundance in boghead coals are not of the nature of colonial gelatinous algæ, as has been asserted by Renault, Bertrand and Potonié, but are spores of vascular cryptogams. This, Jeffrey holds, also overthrows the algal hypothesis of the origin of petroleum and similar substances, these instead having been mainly derived from the waxy and resinous spores of vascular cryptogams laid down on the bottoms of shallow lakes during the coal period. "These lacustrine layers, either as cannels, bogheads, or bituminous shales, according to the sporal composition and the admixture of earthy matter, are the mother substance of petroleum. Pressure and temperature either separately or combined, in the presence of permeable strata, have brought about the distillation of petroleum from such deposits." (Jeffrey$25: 290$.)

Jet (Ger. Gagat, Fr. jais, and jayet). This mineral, for which Gümbel suggested the name gagatite, is a sapropelith obtained in black sapropelargillytes of Mesozoic and younger formations. What 
are perhaps the most important deposits are found in the Liassic rocks (zone of Ammonites serpentinus) of Yorkshire, England, being especially obtained near Whitby, where it is mined and wrought into all sorts of ornaments and toys, and, together with the famous ammonites of the same formation, sold as native curiosities. The jet here occurs in thin lenticular masses between. the layers of the hard bituminous shale (sapropelargillyte) and occasionally shows under the microscope the structure of coniferous wood, referred to araucarians. Scales of fish and other organisms of jet rock are frequently impregnated with this bituminous matter, which may replace the original tissues. Drops of liquid bitumen are also found in the cavities of some of the fossils. Petroleum and inflammable gases are likewise associated with jet deposits and iron pyrite occurs, often replacing the fossils. The Lias of IVürttemberg in Germany also furnishes jet, especially the Posidonia shale, which is of the age of the Whitby beds. Of the same age is the shale furnishing the original deposits on the river Gagas in ancient Lycia, Asia Minor. Jet has also been obtained from Tertiary deposits.

Jet is characterized by its hardness, which is greater than that of asphalt, its conchoidal fracture, and by the fact that it is less brittle than anthracite, and is susceptible of a high polish. Its common association with driftwood leads to the supposition that its chief source is carbonized wood enriched by secondary impregnation with bituminous matter obtained from sapropelite. Analysis of the jet from Holy naden, Württemberg, gave $\mathrm{C} 7 \mathrm{1.0} \%, \mathrm{H} 7.7 \%, \mathrm{O}$ $23.3 \%, \mathrm{~N}$ trace, $\mathrm{S}$ trace, Ash 0.9-2.9\%.

\section{Black Shales.}

Many black or blackish blue shales of various horizons show characters which stamp them as sapropelargillites. The best known of these is the Posidonia shale of the IVest European Upper Lias (Lias $\epsilon$ ). This shale, so named from the abundance of the pelecypod Posidonia bronni, Voltz, is typically developed in Württemberg, where especially the locality of Holzmaden near Stuttgart has become famous on account of the wonderful preservation of the great marine saurians found in these shales. Other localities are Whitby and Lyme Regis in England. The wide distribution of this formation, as well as its organic contents, proves it to be of marine origin, though from the nature of the occurrence of the fauna, as 
well as the character of the rock, it must be assumed that the regions were not open sea, but a coast lagoon or perhaps a marginal epicontinental sea, laid bare to some extent at low tide with the formation of extensive mud flats on which were stranded animals and plants drifted in from the sea, and washed from the land. The fact that the lower side of the fossils is generally better preserved than the upper shows that the organisms were partly embedded and corroded on the exposed surfaces by the acids generated on the mud flats from the decaying organic matter. Had the water been deep, the carcasses of the Ichthyosaurians, etc., could not have been stranded in the mud, but would probably have continued to float until they were cast on the shore or until decay had brought about the dissociation of the skcletal elements, which would then become scattered on the bottom. Instead of this, not only are they intact, but the skin of the Icluthyosaurians has been found as a carbonaceous film surrounding the skeleton in its normal relationship. Besides these saurians numerous well preserved Pentacrini are found which were carried into those water bodies attached to driftwood. Gastropods, worms, cephalopods, and crustaceans also occur, and fish are likewise common and well preserved. Land plants, conifers, and cycads abound, and land animals, especially insects and pterosaurs, also occur. The driftwood is commonly transformed into jet, by the secondary enrichment of the decaying wood by bituminous matter from the mud. Besides these macroscopic remains, the shale abounds in microscopic fossils of sponges (?) (Phymatoderma), Foraminifera, coccoliths, and diatoms (?). Other black shales of a similar origin are probably found in the Devonic Ohio black shale with its rich fish fauna, and the Upper Devonic black shales of New York. The Marcellus shale of New York has already been referred to as a similar sapropelargillyte, but formed in the lagoons behind the Onondaga coral reef. The oil shales of Australia, with the rhizomes of Glossopteris, the so-called "vertebraria" often replaced by or transformed into jet, also belong here. Finally, it must be emphasized that black shales also are formed by the decay of land and swamp plants and that these, therefore, belong more truly with the true coals and other humuliths. (See page $5^{\mathrm{I}} 3$.)

Sapropeicalcilyths, Sapropelsilicilyths, and Sapropelferrilyths.

Bituminous or asphaltic limestones are formed when lime sands or muds or organic calcipelytes are deposited along with much 
organic matter, either animal or plant. Fusulina limestones often contain asphaltic material in abundance, and the same is true to a certain extent of Stromatopora limestones, where the organic matter may be represented by concentric films of asphaltum or other bituminous matter. Nummulitic as well as nullipore limestones may, in like manner, have a bituminous constituency. The finest calcilutytes are often impregnated with bituminous matter, especially if, as in the Upper Cambric of Sweden, they are intercalated in bituminous shales (sapropelargyllites). Such rocks when struck with a hammer give out a fetid odor which causes them to be classed as fetid limestones, or "stinkkalk." Metamorphism of limestones of this type would result in the production of graphitic marbles. Sapropelites in which silica forms the leading accessory constituent are represented by diatomaceous oozes in which the decay of the organic matter has produced the bitumen. The Eocenic Menilite shales of the Paris basin and the Oligocenic Menilite shales of Galicia are typical examples. The latter might perhaps be regarded as the source of the petroleum of that region. Sapropelferrilytes are bituminous iron carbonates such as are deposited under certain conditions in some bogs.

\section{Recent Humuliths.}

These are formed by the growth in situ of plants, either such as grow on the land or those living in marshes and swamps (autochthonous) or formed from material rafted or drifted together (allochthonous). Marshes, swamps, and bogs are the chief sites of accumulation of such deposits at the present time, and a consid eration of these must precede the discussion of the older deposits of humuliths, i. $e$., the coals.

In general we may adopt the word moor for all the surfaces of land, whether high or low, which, with more or less wetness, are covered by successive growths of vegetation, the remains of which accumulate to form beds of peat. Three kinds of moor may be distinguished: the marine low moor, or marsh; the fresh water low moor, or swamp: and the upland moor, or bog. The restriction of the terms here given, and in part at least advocated by Shaler many years ago, will prove useful and make for precision. Shaler $(42: 264)$ has given us a useful classification of modern moorlands which, with some slight changes, chiefly rearrangements, is as follows (Parsons-30) : 


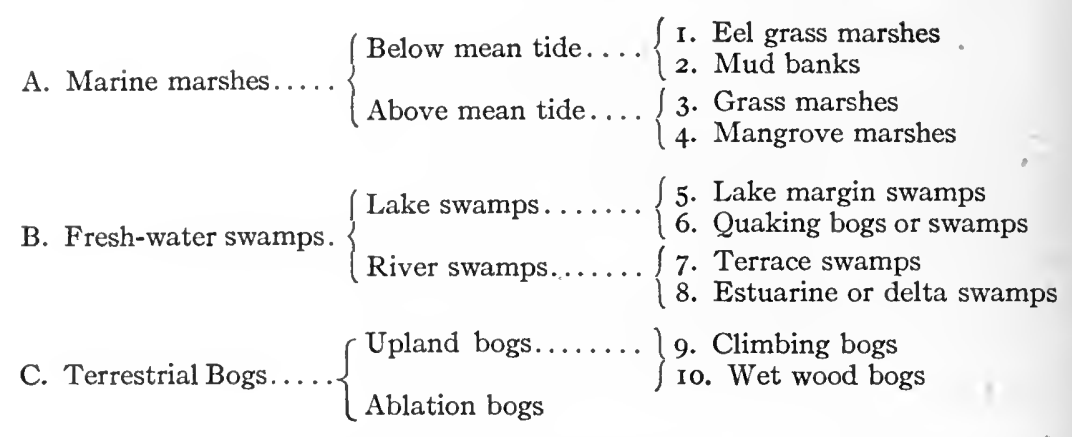

A more recent classification of peat moors, adopted by the students of the West European peat deposits, has reference to the succession of plant types found in the moors. It applies to the fresh-water swamps and terrestrial bogs only. Three types are recognized: a, Low moor, or flat moor (Flachmoor, Verlandungsmoor) ; b, Intermediate or Transition moor (Zwischenmoor, Uebergangsmoor) ; and, c, High moor or Upland moor (Hochmoor).

The transition moors are less well characterized than the low and high moors, and the tendency of some authors is to eliminate them altogether. A further group, however, the forest moor, or dry peat moor, is separated by most modern authors. For purposes of mapping, the following divisions of modern fresh-water or terrestrial deposits of caustobioliths have been recognized in Germany (Ramann-33:I35):

I. Slime deposits (fresh-water sapropelytes).

II. Flat or low moor deposits-Terrigenic moor deposits ( $V$ erlandungsmoorablagerungen) comprising:

A. Peat: formed by

I. Reed association or a Phragmitetum * (Phragmites, America; Arundo, Europe).

2. Sedge association or Cyperacetum or Caricetum (Cyperus, Carex, etc.), including:

a. Magnocaricetum or tall sedge plantation.

b. Parvocaricetum or low sedge plantation.

3. Moss association or Hypnetum (Hypnum and certain

B. Mold. species of Sphagnum, etc.).

III. Forest peat (dry peat).

IV. Highmoor peat.

* The ending etum designates a plantation, grove or association in which the plant to whose name it is suffixed forms the principal type. 
The reed association or phragmitetum is not wholly restricted to the low moors, but also occurs, though more sparingly, on the high moors. The same may be said of certain sedge associations or cyperacetes. Among the mosses certain species of Hypnum (as, for example, $H$. fluitans, giganteum, and trifarium, in Europe, and certain Sphagnums) occur with the reed associations, partly forming floating mats or growing among the reeds. The sphagnums are most characteristic of the high moors.

The following classification comprises the important subdivisions of the areas of deposition of modern caustobioliths:

A. Marshes-Marine.

I. Sapropelite region-submerged.

a. Eel grass marsh.

b. Mud flat region.

2. Humulite region-emerged.

a. Grass or Spartina marsh.

b. Mangrove marsh.

B. Szamps-Fresh Water.

I. Sapropelite region.

2. Humulite region.

a. Moss or Hypnetum zone.

b. Sedge or Cyperacetum zone.

c. Reed or Phragmitetum zone.

d. Tree or arboretum zone.

(I) Alder or Alnetum zone.

(2) Cypress or Taxodetum zone.

(3) Tupelo or Nyssetum zone.

C. Bogs-Terrestrial.

I. Forest moors.

2. Upland bogs (High Moors).

\section{Marine Marshes.}

The development of marine marshes proceeds in the following manner (Shaler-4I:359; Davis, W. M.-16): An off-shore sand bar is built by the waves on the gently sloping sandy sea-bottom. or a barrier beach is built between two projecting headlands. The scouring action of the tides will keep open a channel through this beach so that a connection between the sea and the lagoon is always maintained. Bars may be built in water from 20 to 30 feet in depth. and are due to the breaking of the large waves off shore, which then pile up in front of them the detritus which they have dug up 
from the sea-bottom. The bar grows until at last it rises above the level of ordinary tides, and thus becomes a barrier beach. Meanwhile, at low tide, the sun dries out the upper portion of the sand, which then becomes mobile, and is piled up into shoreward advancing sand-dunes. Thus a barrier-beach of some breadth may be formed. While this is going on, deposition of sediments within the lagoon behind the beach takes place, for here the water is mostly quiet, while sediment is carried in both by streanis from the land and by the tide. As soon as an accumulation of mud or fine sand over the bottom has begun, it is taken possession of by eel grasses (Zostera marina, etc.), which soon cover the bottom with a dense growth. These plants, belonging to the pond-lily family, have become adapted to a marine habitat, and cannot live outside of the salt water. Wherever these plants grow sufficiently near the surface they form at low tide a tangle, passage through which is accomplished only with difficulty by the swimmer or the oarsman. "A tidal current of two miles an hour, swift enough to carry much sediment, is almost entirely deadened in this tangle of plants." (Shaler-4I.) As a result, the sediment will sink down between the leaves of the plant and there will rapidly accumulate a bottom deposit of mud, which encloses the vertical stems of the plants. With the fine sediment, fronds of sea-weed are carried by the current, and these with pebbles or shells attached to their bases will settle to the bottom and become buried in the mud. The presence of decaying vegetal and animal matter gives a characteristic color and odor to these deposits which may readily be observed wherever the mud flats are exposed at low tide. Where the mud is calcareous, extensive beds of calcilutytes may be formed in this manner, which may even retain the vertical impressions of the plants or other organisms which have "combed" out the nud from the sea water. What appears to be a good example of this kind is found in the Ordovicic (Lowville) limestone of the Black River valley, etc., in New York, where the remains of the vertical stems form a characteristic feature-of the rock, the appearance on cross-section having given rise to the term "Bird's Eye," by which the rock is commonly known.

Where the mud has accumulated to such an extent that at low water the flat is uncovered the eel grass will die, and its place is gradually taken by the marsh grasses. For a time mussels will occupy patches of the mud flat surface, and a mussel bed of some thickness may be formed on the substratum of black mud. Microscopic examination of the mud will show that it consists of illassorted and generally angular grains. The marsh grasses com- 
monly push their growth from the shore outward. Their roots and stems, partly submerged at each tide, readily entangle sediment and so the level of the deposits is rapidly raised to where it will be covered only at the highest tide. At this stage portions of the marsh are sometimes inhabited by enormous numbers of the fiddfer crab (Gelasimus). At this point the process is generally arrested except for the decay of the older vegetation and the growth of new crops. The appearance of the marsh and its structure are shown in the following map and section, copied from Shaler (Figs. IIo, I IOa.) In cases where much sand is carried into the lagoon by the tidal currents, the eel-grass-mud-flat stage may be entirely omitted, the marsh-grass stage following directly upon the sandy filling of the lagoon.

The salt marsh vegetation consists chiefly of grasses and sedges.

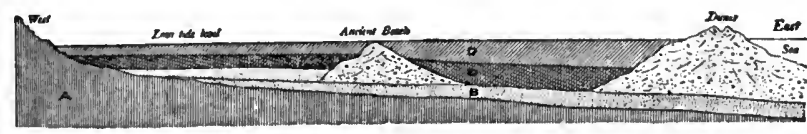

A. Bed rock. B. Sanl and gravel. $\quad$ C. Eel grasa layer. D. Upper marah.

FIG. 110. Ideal section of a salt marsh formed behind barrier beaches. (After Shaler.)

Among the former the genus Spartina leads with seven species. not all of which are, however, of marine habitat. Some species are of world-wide distribution, while others occupy a restricted area. In vertical range the species also vary. In the lowest zone occupied by those plants, $i$. $e$., the zone limited downward very nearly by half tide and upward by ordinary high tide, the tall, coarse, rank-smelling salt thatch, Spartina glabra Mull., var. altomiflora Loisel and Merr, is the sole representative of these grasses, except for occasional stragglers from the zone above. This plant has large, hollow, jointed stems, broad, yellowish-green leaves, and grows from two to four or even six feet high. It produces numerous seeds, and sends strong, thick and very characteristic underground stems in all directions into the substratum on which it grows. From these, at nodal intervals, spring the long, fibrous, much branched roots. The underground stems, and those parts of the aerrial branches buried in the mud are the most frequently preserved, and these are readily distinguished from other plants by their size and straw color, which is retained for a long time. The aerial parts of the plant, i.e., the leaves and stems, become very brittle at the end of the growing season and are broken off by 
the waves and shore ice. They often accumulate along the highwater line or are carried out to sea.

This plant, which is thus submerged for about half the time, is especially abundant in the banks of the tidal creeks. The deposits which it forms are rich in mineral matter, they themselves rarely forming accumulations approximating in purity those due to the species growing at a higher level. Above the salt thatch zone is the peat zone proper, which is submerged by salt water only from I to 4 hours each day. Many species grow here, sedges (Carex) as well as grasses, but only two are common on the northern coast, Spartina patens Muhl. and Distichlis spicata (L.) Greene. These salt marsh grasses are both short, from 6 to I2 or I4 inches tall, with rather slender, tough, wiry stems, and dull grayish-green, slender, involute leaves. Their root stocks are slender, tough and numerous, their roots long, fibrous, and branching. The peat formed by these plants cannot be mistaken for that of any other form of vegetable deposit with which it is likely to be associated. "It differs from the turf formed by sedges in the persistence with which the underground stems retain their form and individuality instead of collapsing and flattening, in the lack of the remains of leaves and aërial branches, in color, in the absence of definite lamination, in the amount of silt generally contained, and, more than all else, in the presence of the white or light-colored finely branching roots, which penetrate the mass in every direction and make up the great bulk of the material." (Davis-I $5: 632$.)

The leaves and stems of these two salt marsh grasses are more persistent than those of the salt thatch, but they also are largely removed during the winter by ice, wind, and tides. A fresh water species, $S$. cynosuroides Willd. with a culm 2 to 6 feet high and narrow leaves 2 to 4 feet long and a half inch or less in width below and tapering to a slender point, inhabits the banks of rivers and lakes, or occurs in rich soil from the Atlantic to the Pacific.

Sedges, Carex salina and Carex maritima, are also characteristic of the salt marshes, and often add a considerable part to the peat formed.

The tidal marshes are dissected by meandering channels through which the salt water ebbs and flows twice a day. These channels are generally narrow and deep, the width being determined by various factors, chief among which is the scouring force of the tidal current, and the resisting force and growing power of the marsh vegetation.

During the slow conversion of the lagoon into a marsh the sand dunes from the beach commonly advance over the growing 
mass, while at the same time the waves may cut back the beach line. Thus it may happen that a section of a marsh is exposed along the shore, below the cover of dune sand. Examples of such old marshes showing on the coast may be seen at Cape Cod, near the Nausett Lights, on the coast of Nantucket, along the western coast of Long Island (near Bath Beach), and elsewhere.

The sequence of events thus outlined would lead to the formation of the following succession of deposits (Davis. C. A.$15: 626-7)$ : At the bottom the section should show sand, silt. or mud up to about twelve feet below low-water mark; between this level and that of low water should occur silt surrounding the easily recognizable remains of the eel grass and mingled with it should

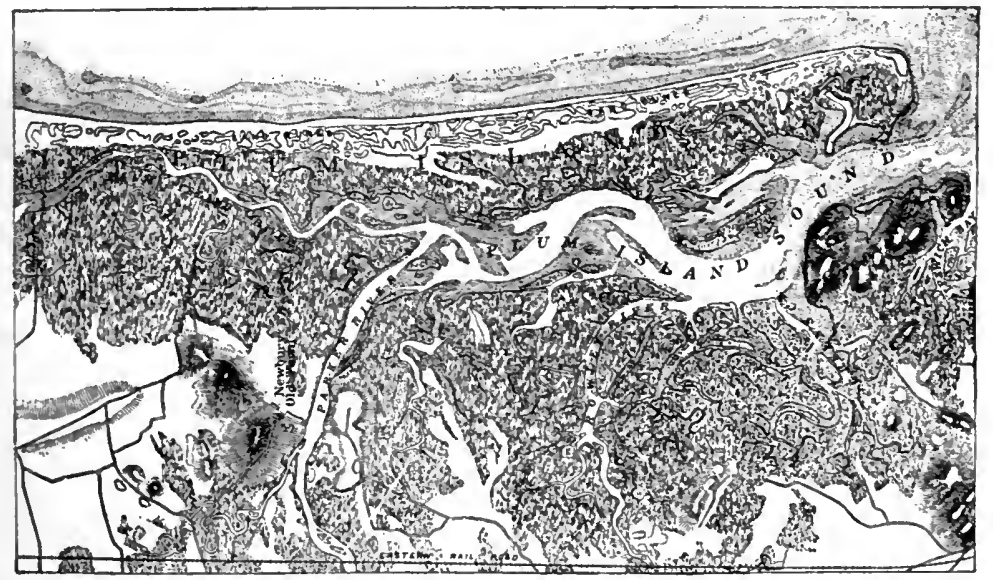

FIG. IIoa. Map of the Plum Island (Massachusetts) marshes, dissected by meandering tidal streams. (After Shaler.)

be the shells of molluses and the remains of other marine organisms. Above this should occur another layer of silty mud up to the level above which the salt water grasses grow. The next higher stratum should contain the remains of these plants in constantly increasing numbers, until they form the bulk of the stratum. This would result from the observed fact that there is a level above the low-tide mark below which these plants do not go, while, at the greatest depth at which they do grow, the number of individuals is small compared with that found higher up, where these grasses find their most favorable conditions for growth. "At the top of the section should be a distinct turf, formed of the characteristic plants growing on the surface, which, because of the very definite fixed habits of these species, would be, relatively, very thin." (Davis-I 5.) 
Considerable variation from this normal section is to be expected, for salt marsh building may be interrupted at any stage by blowing sands, and the whole may be greatly complicated by subsidence or elevation of the coast. In some cases studied, as on the Massachusetts coast, the structure of the marsh does not conform to this succession in some of its major features, showing that the history here has been quite different from that outlined. "In many cases.. . . the deposits below the surface, instead of containing eel grass and salt thatch remains, was entirely composed of the very different and definitely recognizable sort of vegetation that never grows where salt water reaches, $i$. $e$., the deposits were largely of fresh water origin." These deposits often show considerable accumulation of woody material, including stumps of large pine trees, near the surface and for a few feet below. "The structure of these marshes also often showed salt water intrusion in varying degree in different parts of the same area, the deposit of the salt marsh material being progressively thicker as the ocean was approached." (Davis-I5.) In the case of these marshes, the salt water deposits were made up of the species of plants which grow at or near high-tide level, while eel grasses and species which can stand partial submergence were rare or absent. Even where no fresh water peat was found underlying the salt peats the species making up the latter were those growing at present at high tide level or above, although the peat formed by these was often below present low-water level. This, if not due to compacting, indicates subsidence of the coast during or since the formation of the peaty deposits. Oscillation of the coast, or at any rate of the tidal range, is indicated by the intercalation in some cases of fresh water peat between layers of salt marsh peat. Salt marshes of this type must be interpreted as follows: On a flat coastal plain, above the reach of tide, owing to the moist climatic conditions and probably to the growth of trees preventing free drainage, are formed swampy areas in which an accumulation of fresh water peat goes on to an indefinite extent. By a slight but constant progressive subsidence of this coast the sea enters in, kills the fresh water peat, and begins to cover more or less permanently a part of the coastal strip of this plain. Since the growth of marsh grasses on the open exposed coast is ordinarily an impossibility, owing to the violent wave work, it follows that the first step in the conversion of the fresh to the salt marsh is the building of the barrier beach. If the barrier beach is built far enough from the shore, owing to the gradual shoaling of the water, a broad lagoon of salt water will be left between it and the shore, and in this the salt peat may gradually form, 
as outlined above in Shaler's hypothesis. Such marsh deposits are now forming on the Long Island and New Jersey coasts. As the coast slowly subsides the marsh grasses will encroach upon the dead fresh water swamps, and since the subsidence is a slow one only the plants growing at high water level or above will enter into the constitution of this deposit. Among these on the Massachusetts coast, the grass Spartina patens Muhl. is the chief type, which will form successive layers if the subsidence is slow, and so a progressive overlap of the Spartina patens layer over the fresh water peat will take place, with the result that this peat thickens seaward because in that direction deposition began earlier. During all this time the lagoon beyond the area of the fresh water peat deposit may be slowly filling up and the ordinary salt peat would form, beginning with the more euryhaline species of salt grasses, such as Spartina glabra, and followed by the more stenohaline species, such as S. patens. Progressive erosion and landward migration of the outer bar would eventually result in the entire removal of the purely marine peat series, so that, as in the case of the Massachusetts marshes, the only part remaining behind the bar is the compound peat mass, commonly of fresh water peat at the bottom and salt water peat on top.

In such cases as these the bar has successively migrated shoreward until it has reached if not transgressed the original shore which existed at the time that the fresh water peat was forming on the coastal plain.

If the subsidence is more rapid than the upbuilding of the Spartina patens peat, the more frequent submergence of the surface will kill that species and its place is taken by the more euryhaline $S$. glabra, which, in turn, may be succeeded by a mussel bed or mud flat.

Conversion of salt peat into coal. The burial of a salt peat marsh under silts of marine or terrestrial origin would tend to its preservation and ultimate conversion into coal. Such coal will, however, be very high in ash, for the high tides, especially during stormy periods, will spread much silt over them, while wind-blown sand from:the shore may also add a quantity of mineral matter. Hydrogen sulphide is generated in great abundance in peat beds to which salt water has access. This is apparently due to the action of certain bacteria on the sulphates contained in the water. By reaction with iron compounds of the silt and other mineral matter iron sulphides are formed, which are deposited as iron pyrite. This mineral is abundant in the inorganic constituent of the salt marsh peat. Such formation of hydrogen sulphide does not occur 
in fresh water peats, unless these are subsequently submerged by marine waters.

\section{Mangrove Marshes.}

These occur in the tropics and take the place of the salt grass marshes of temperate climes. The mangroves comprise some twenty species, characterized by numerous slender trunks varying from five to sixty feet in height. These rise to just above the level of high tide, and are crowned with heavy foliage, which, when the tide is full, appears to float upon the water. From the crown, stolonal processes are sent off and these, in turn, give rise to descending roots, which, after reaching the sea-floor, become fixed and serve to support the trees against the effects of the tides and waves. Shaler believes that the mangrove thickets may advance over the sea-floor at the rate of twenty or thirty feet in a century. Their seaward extent is limited by the deepening of the water and the force of the waves, and by fish which feed upon the growing extremities of the roots. The densely interwoven stems and roots of the mangrove form an effective barrier for the retention of silt. The flow of water from the land is checked, and sediment deposited, until the roots and stems are completely buried, when the plants die and give way to other types of vegetation. Commingled with these buried trunks and roots we find a considerable littoral fauna, a part of which was directly attached to the bases of the mangrove or crawled about on them, and another part which lived on or in the mud which accumulated between the stems. (See further, Chapter XXVIII.)

\section{Fresh Water Swamps.}

The sapropelite region of swamps is largely confined to the deeper parts of the lakes where planktonic fresh water algæ sink to the bottom upon their death and where Characex grow and produce a layer of sapropelcalcilite or marl. The formation of sapropelite is, probably, far less extensive than in marine waters, for terrestrial vegetation will take root in all shallow waters or push out as floating mats from the shore, the deposits resulting being, therefore, chiefly humuliths. Floating algæ are rare in all except the smaller, more stagnant, lakes or pools, and thus the chief deposits of this type on the deeper lake bottoms are the Chara marls. Fresh water swamps may be subdivided into lake swamps, river swamps, and estuarine swamps, which merge into the marine marshes. 
Lake Swamps. Around the margins of lakes and fresh water ponds a variety of plants are found more or less submerged. The number of species of flowering plants having such a habitat is comparatively small, the endogenous plants predominating, with the water lily family, especially Potamogeton, as the leading class. Of the flowerless plants Hypnum and Sphagnum, two mosses, and the alga Chara are the most significant. The depth at which seed plants will grow ranges from 15 to 25 feet, very few, such as the water lilies, being able to establish themselves in depths greater than io feet. As the 25 -foot limit is approached the number of species rapidly diminishes, this being apparently due to the decrease in light and heat available. Of the plants growing in deeper water, the algae, especially the species of Chara, should be mentioned as

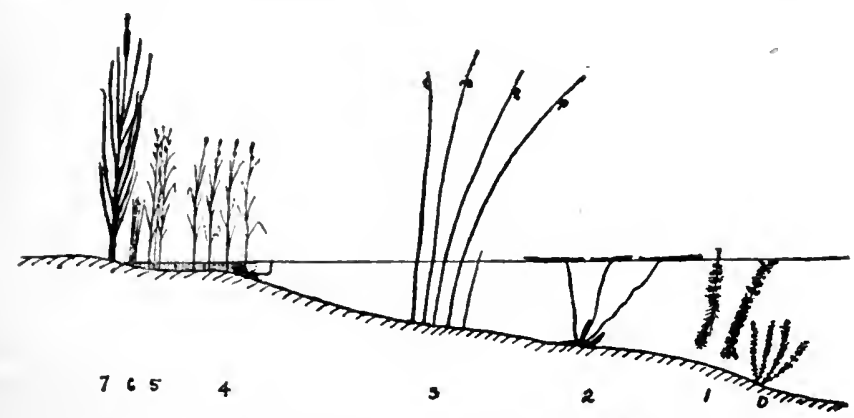

FIG. III. Diagram of plant zones in small lake near Merryman's Lake, Michigan. (After Davis.) o, Chara; I, floating bladderworts; 2, yellow pond lily; 3, lake bulrush; 4, Sartwell's sedge; 5, bottle sedge; 6 , spike rush; 7 , cat-tails.

significant. These are instrumental in raising the bed of the lake or pond by the formation of marl (ante, p. 471). Floating or planktonic plants also abound in most fresh water ponds and lakes, especially in the stagnant portions. The most important of these are the Bladderworts (Utricularia), of which there is a number of species, and Myriophyllum which may cover whole surfaces of the ponds.

The most important species of peat-forming plants in lakes do not grow in water over two feet in depth. These comprise, among others, the cat-tail flags (Typha), the Bur reeds (Sparganium), the Water Plantain (Alisma), the Arrow-heads (Sagittaria), some grasses (Zizania), the wild or Indian rice (Phragmites), Reed grass, and several sedges, in addition to the pond lilies. Hypnum and Sphagnum grow near the surface.

In lakes more than 25 feet in depth, filling by the formation of 
marl or sapropelite from floating plants has to occur to bring the bottom to the required level where the higher plants can gain a foothold. These will slowly build up the floor of the lake by partly decayed vegetal matter, the rate increasing with progressive shoaling, owing to the increase in the number of plant species and their greater luxuriance. The succession of types is shown in the preceding diagram (Fig. IrI), copied from Davis.

In the filling of lakes by vegetal growth a prominent part is taken by the plants which build floating mats from the shore outward. Chief among these in our temperate climes is the sedge Carex filiformis L., which forms a mat of felted and interwoven stems and roots, making a buoyant structure capable of supporting considerable weight. This sedge may grow with its rhizomes submerged a foot or more below the surface of the water and its roots extending nuch farther downward. These mats may be from a few inches to two feet in thickness near their lakeward end, while toward the shore they become more and more solid and eventually no longer float. The solid portion gradually extends lakeward, partly by the accumulation of more or less decayed vegetal matter beneath the mat, and the pond thus becomes filled. The sedge is sometimes largely replaced by the cat-tail Typha latifolia, which likewise aids in the building of the mat. As the surface of the mat approaches the level of the water, dense growths of the moss Hypnum will occur; other plants follow, including ferns and the Sphagnum moss, and, finally, the tamaracks and spruces will begin to migrate outward, and the pond passes from the quaking bog stage to the more or less wooded tamarack swamp (see Fig. II2). As the forest advances the sedges begin to die, being unalle to flourish in the shade. The ground becomes covered by a heavy growth of Sphagnum moss, which may grow to some extent in the water, but more commonly forms a surface growth which may reach a thickness of several feet. The stumps and trunks of dead and fallen trees are gradually embedded in this growing mass of vegetal material, becoming an integral part of the accumulating peat deposit. As the Sphagnum forms the most conspicuous part of the surface of the swamp and is a vigorously growing plant, it has commonly been credited with being the chief agent in the production of swamp peat, the plant itself being known as the peat moss. It appears, however, that this moss must be regarded as only a contributor so far as swamp peat is concerned.

In a consideration of lake swamps we must not neglect the fact that lake basins come into existence in a great variety of ways (see ante, p. II6), and that in some cases these basins may from the 
outset be so shallow as to quickly assume the character of a swamp or bog, without passing through all the stages described. Furthermore, it has been shown that lakes may actually be produced by the growth of vegetation, as in an upland moor, this forming either a barrier or an enclosing rim. In such a case the bog precedes the lake, which may subsequently be filled by the development and encroachment of the swamp vegetation.

River and Estuarine Sacumps. These are produced where the borders of the rivers with broad flood plains are raised through the building of natural levees by the overflowing stream. The vegetation growing on the borders of a river will tend to arrest the sediment carried by the rising water in times of flood, when the flood plains on either side are inundated. These higher marginal ridges will therefore separate the lower flood plain from the river, and thus the waters resulting from the overflow of the river will find

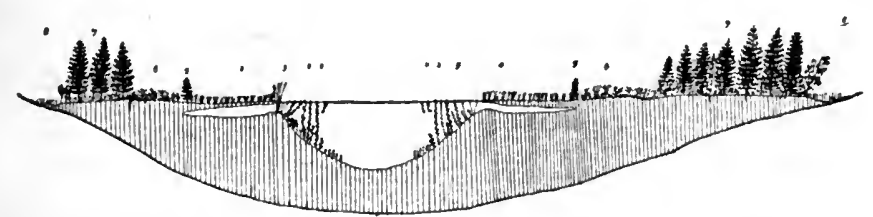

Fic. II2. Diagram showing how plants fill depressions from the sides and top. (I) zone of Chara and floating aquatics; (2) zone of pondweeds or potamogetons; (3) zone of water-lilies; (4) floating sedge mass; (5) advance plants of conifers and shrubs; (6) shrul and sphagnum zone; (7) zone of tamarack and spruce; (8) marginal fosse. (After Davis.)

it impossible to return to the river on its subsidence. Thus extensive swampy lands are formed over the inundated parts of the flood plain, which may also enclose an extensive series of shallow lakes. The back Swamps of the Mississippi are examples of this sort of occurrence.

Delta surfaces may be covered with swamps in the same manner that lakes are formed on deltas, through irregular deposition and obstruction of drainage. At the heads of estuaries, fresh-water swamps may likewise form which further out may merge into or pass beneath grass marshes due to encroachment of the sea.

From a consideration of the succession of plant associations during the gradual filling of a lake, it must be apparent that in the resulting deposits there will be noticeatle a stratification, due to the superposition of successive types of $\therefore$ ad vegetal matter. In general, these may be grouped according to their decreasing hygrophylous characters into the following divisions: I, limnic; 2 , tel- 
matic; 3 , semiterrestric, and, 4, terrestric. The needs of the plant associations in mineral food also vary with the development of the swamp or bog, the earliest plants deriving their food from the water or the bottom on which they grow, while the succeeding groups must depend more and more upon the older plant deposits for their mineral nourishment, and this becomes less and less in amount. We have thus a series with decreasing demand on the substratum for food, and these are classed in descending order, as cu-, meso- and oligotraphent types, and they may be found among various hygrophylous types. From the deposition of these types of vegetation we get en-, meso- and oligotrophic types of peat deposits,

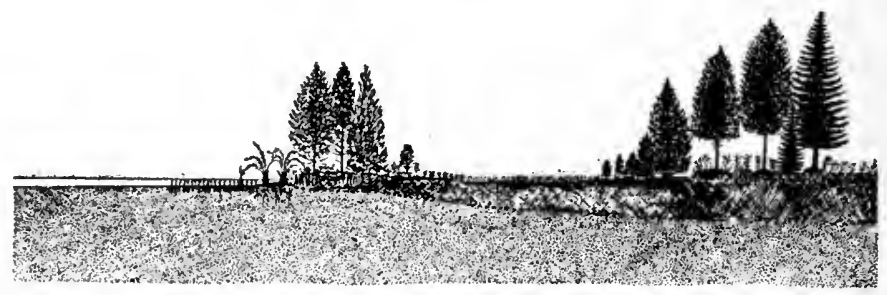

FIG. II3. Ideal section, showing the approximate relation (I) of the different types of peat, and (2) the plant societies at Algal Lake, northern Michigan. (After C. A. Davis.) The succession of plant associations from without inward is: (I) Tamarack-spruce-cedar swamp, with young tamarack at the inner border; (2) open sedge marsh, with islands of tamarack wood; (3) swamp loosestrife (Decodon verticillatum) gradually advancing lakeward, and forming "stools" on which grow mosses, ferns, sedges and shrubs, finally killing the loosestrife; (4) cat-tail flags; (5) potamogeton. The peat formed by these plants thickens away from the lake, and is humus peat. Below this, and forming the lake bottom, is a mass of sapropelitic peat, composed of green algx, with diatoms, and an abundance of pollen-grains of conifers, forming a structureless mass.

the last of which normally occurs in the upper part of the stratified series.

It is, however, apparent that in the gradual closing of a lake by vegetal deposits, those formed near the shore will have the largest supply of mineral food, especially where affluents bearing such food enter, and that the waters within the growing rivers of eutrophic vegetation will become poorer and poorer in foodstuff, so that the inward succession of plant associations will take on successively a meso- and an oligotraphent character, and the deposits of peat in such a basin, when completely filled, will be eutrophic peat around the margin, mesotrophic next within, while in the center it will be oligotrophic, and thus of a distinct character. Thus within the same 
horizontal section there will be a marked clange in the peats filling a single basin. Such differences are frequently observed in single basins, and also between adjoining basins, where slight differences in the physical characters may bring about marked variation in the result. The range of variation is enormously increased under the influence of fluctuating climatic conditions such as nearly every country experiences sooner or later.

An inverted order of superposition may result from a raising of the water level, of ten due to the growth of a retaining rim of peat,

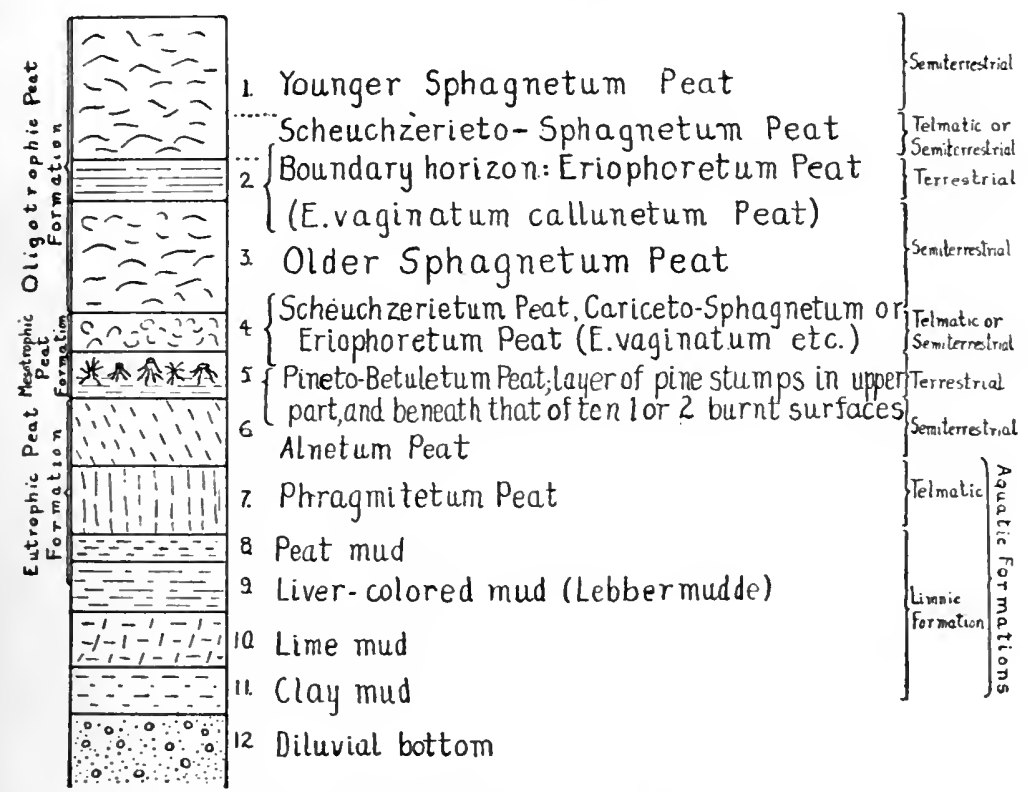

Fig. II4. Section through a North German peat bog, showing the succession of strata. (After Ramann.)

or through sinking of a floating mat. A floating mat is composed of interlacing roots and stolons of hygrophytes, above which form semiterrestrial or even oligotrophic peats. When the weight becomes too great, the floating mat sinks with its load, and the mesotrophic and eutrophic deposits will again form. Thus a layer of oligotrophic peats may occur interpolated between layers of eutrophic peat deposits.

A section seven meters deep through a North German peat series in which the peat-forming processes had come to an end gave the succession shown in the above diagram (Fig. I14). 
In general, the three principal zones given on p. 486 (the reed or Phragmitetum, the sedge or Cyperacetum and the moss or Hypnetum zones) may be recognized as those which tend to succeed each other in the process of filling the lake or pond, though one or another of them may at times be absent. Toward the last the waterloving trees begin to migrate into the swamp, among which in our northern climes are the alders (Alnus incana, A. serrulata, A. maritima near the coast, and $A$. glutinosa in western Europe), forming the Alnetum zone. Elsewhere in the United States the tamarack (Larix americana) takes the place of the alders, forning the Laretum. In the southern states the Cypress (Taxodium distichum) or the Tupelo (Nyssa uniflora) occupies this zone, forming, respectively, a Taxodetum and a Nyssetum. Under and among these trees a rich herbaceous flora flourishes, including ferns, sedges, the Equisetum fluviatile, the pitcher plant, Saracenia, violets, Galium, Impatiens and a host of others. Sphagnum, however, is absent. In the cypress swamps of Florita (Stevenson-46:I44, etc.) and the Gulf Coast, logs and woody roots are common. At New Orleans the cypress and other trees were found superimposed one upon the other, in an upright position, with their roots as they grew. A cypress swamp dissected in cutting a canal from Lake Pontchartrain showed three tiers of stumps in the 9 feet excavated, these ranging one above the other. The earlier trees apparently rotted away at the level of the ground before the later ones grew over the same site. The peat in the cypress swamp is formed by an accumulation of the forest litter, the swamps themselves being due for the most part to impeded drainage on an almost level surface. The depth of the material has been reported as in some cases more than iso feet. Among the largest swamps on our coastal plain are: Okefenoke Swamp in southern Georgia, and the smaller Dismal Swamp of Virginia and North Carolina, which covers about 500 square miles.

In Okefenoke Swamp, which lies 50 miles from the ocean and II 5 feet above the mean tide, the peat is about ro feet thick, and cypress stumps abound. The wetter portions are often free from trees and show a luxuriant growth of cane, pickerel weed and water lilies, but little or no Sphagnum. (Harper-23.)

The Dismal Swamp (49) is only a few feet above sea-level, and has a peaty deposit at least fifteen feet deep (C. A. Davis); resting on Pliocenic sands. Lake Drummond lies on its western border (see ante, p. 120). Sphagnum plays only a small part in the peat formation of this swamp, the canes, a grape, the bald cypress (Taxodium distichum) and the junipers (Juniperus viryiniana) being the chief peat-forming plants. Of these the junipers 
occupy the drier spots, but the others generally grow in the water. The projecting knees of cypress and the arched roots of Nyssa are much in evidence. The knees are formed only where the cypress grows in water, and serve as a sort of breathing organ or pneumatophore. They are excrescences from the roots, rising above the water, of a subcylindrical form, and crowned by a cabbage-shaped expansion of bark, rough without and often hollow within. When through a rise of water these knees are submerged the trees will die.

Extensive cedar ŝwamps (Chanccyparis thyoides) occur on the Atlantic coastal plain of the Lnited States north of Florida. The peat increases in thickness inward from the shore to perhaps $I_{5}$ feet, and is full of tree trunks buried at all depths, these having either rotted away or become uprooted. The peat is very pure, containing only 3.35 per cent. of ash. The trees on the surfaces of these marshes have broad, spreading roots, which do not penetrate very far into the ground, but rely upon the great horizontal extent of their shoots, which penetrate very deeply.

\section{Terrestrial Bogs.}

These include the forest bogs or moors and the high moors. They may be the regular successors of the lake and river swamps. but more of ten they develop independently upon a rocky or sandy substratum. Such are the familiar upland moors, covering the hillsides in Great Britain and Scandinavia, as well as large parts of northern Germany, and broad areas of northern Asia, and of Canada and the northern United States.

Forest Moors. Beeches, pines and spruces succeed the taniarack and alders, and form the transition to the high moors. Here the ground is dry, and a wood flora appears, often characterized by orchids. In these woods dry peat or forest peat results from the falling and partial decay of the trunks, branches and leaves of the trees. The character of the resulting peat varies with the type of vegetation, especially with the predominant arboreal types. Decay is partly accomplished through the influence of microörganisms. The destruction of the dry peat and its conversion into earthy mold or its entire decay are furthered by the growth of a number of grasses, especially the common latir-grass, Deschampsia fleruosa Trin. The growth of peat mosses among the trees in the transition of the bogs to the high moor type will result in killing these trees through increasing moisture. Decay at the point of exposure above 
the moss will result in the breaking off of the trunk at that point, and the subsequent complete embedding of the stumps in the peat. Such old pine and other stumps are common features of the upland bogs.

Upland Bogs, or High Moors. These are built up by the re-

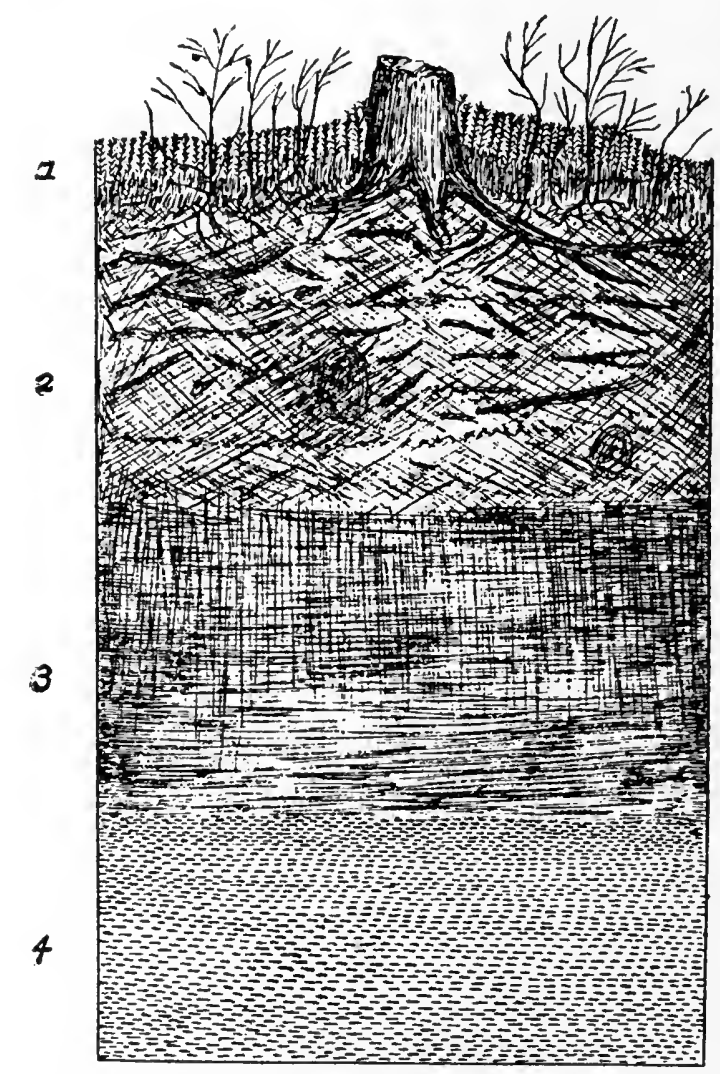

FIG. II5. Section through a mature peat deposit near Hermansville, Menominee Co., Michigan. (After Davis.) I. Surface vegetation; 2, layer containing roots and coarse vegetable débris; 3 , fully decomposed dark peat; 4, light-colored structureless peat.

mains of peat mosses, especially the Sphagnum mosses and related types. These form the bulk of the peat in the upland bogs, though in some cases they are largely replaced by one or more members of the pondweed family, especially Scheuchscria palustris, or of the sedge family, notably the cotton grass, Eriophorum vaginatum L., 
and the bulrush, Scirpus caspitosus, L., and other species. Thus in the upland bogs of Great Britain, Splagnum is of little importance as a peat-maker, its place being taken by Scirpus cospitosus and Eriophorum a'aginatum. Other types, such as the heather, Calluna zulgaris and Erica tctralix, are among those dominant in some localities. The Scandinavian and north German moors, on the other hand, are chiefly made up of species of Sphagnum. Where, however, the Sphagnum is exposed during the winter for lack of snow covering, as along the coast of Norway, it disappears, and its place is taken by the bulrush, Scirpus cospitosus. Heather peat, formed by Calluna vulgaris, is also found in the high moors of North Germany, as is also Molinia peat, formed by Molinia corulca. Both Sphagnum peat and peat formed by the Schenchzeria, the cotton grass and by Scirpus caspitosus are found in Canada and the northern United States. The place of the heather is taken by Vaccinium (blue berries, cranberries, etc.), Andromeda and other members of the Heath family.

In northern Germany (Ramann-34:139) the high moors generally consist of an older, strongly decayed Sphagnum peat and a newer, little decomposed, more porous Sphagnum peat, the two being separated by a dividing layer of peat formed by Eriophorum i'aginatum and Calluna vulgaris (Eriophoretum and Callunctum, see the section, Fig. II4). Overlying these is a peat layer formed of the most recent growths, the heaths, lichens, etc. The double character of the Sphagnum peat is explained by the gradual diminution of the water raised in the peat bog by capillarity, so that, as the bog rises by continuous growth, a time will come when the amount of water is too small for further Sphagnum growth. Then other plants take the place of the moss, until by decomposition the latter has been reduced again in volume, and as a result become less permeable to surface waters. Moist conditions will then return, and a new growth of Sphagnum begins. Owing to the fact that the old Roman roads were built upon the dividing layer of terrestrial peat, it becomes possible to measure the rate of growth of the upper peat layer, which must have accumulated during the past two thousand years.

The external form of the high moor is domed, and permits the run-off of the rain water, which produces moist margins, where hygrophytes of various kinds will grow.

The upland peat bogs of Great Britain generally occur on undulating and sloping ground. When the slopes of the surface do not exceed $10^{\circ}$, the peat generally grows to considerable thickness, but where these slopes are greater the peat is also much thinner. 
Marshes ("flows") seldom occur, since lakes and pools were rare in the original surface. The peat rests either directly on the rock surfaces or on the surface of glacial deposits, the contact being a sharp one. In the Pennines the peats cover elevations like the Cross Fell, which rises to 879 meters. It here sometimes has a thickness of 4.5 meters. The peat is largely formed from the common reed, Phragmites communis. Sphagnum is scarce in this peat, as already noted for the whole of Great Britain. In places the peat contains an old forest bed, sharply marked off from the other deposits and at an altitude not exceeding $780 \mathrm{~m}$. A section of a peat bog in this district gave (Samuelson-40:200):

c. Scirpus caspitosus peat, yellow brown in color, very rich in humus, not moldered, containing remains of dwarf shrubs. Washing gave only numerous small specimens of Cenococcum geophilum ........................ $125 \mathrm{~cm}$.

b. Phragmites-Carex peat, containing numerous large stools, stems, twigs, and roots of birch. The finer material consists to a great extent of wood detritus. No coal found. Nutlets of Ajuga reptans and seeds of Viola sp. were washed out from a peat sample. Pollen grains of elm, hazcl and pine, spores of ferns and leaves of Sphagnum

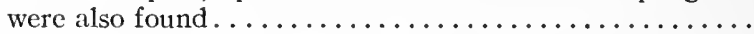

a. Boulder clay.

$75 \mathrm{~cm}$.

This peat, as that of other regions of northern Europe, especially Fennoscandia, shows the occurrence of an Alpine vegetation during the period of formation of the early peat. In the Cross Fell the remains of these are not found in situ, however. Then followed a period when the region was an extensive reed swamp, and this was succeeded by wet birch. forests, which in turn were replaced by the wet moorland.

A section of a peat moor in the southern Uplands of Scotland gave the following succession in descending order, the altitude being about 300 meters above sea-level (Samuelson-40:201) :

6. Scirpus ccespitosus peat, mixed with Eriophorum vaginatum, and also containing solitary Calluna stems. Pollen grains of alder, birch, grasses, hazel, pine, Typha latifolia, etc. and spores of Polypodium vulgare and Sphagnum occur... $100 \mathrm{~cm}$.

5. A sharply marked layer of pine "stools" with individuals sometimes exceeding $50 \mathrm{~cm}$. in diameter; rarely burntsurrounding peat highly moldered and contains numerous stems of Calluna and birch twigs; a hazelnut also found. .

4. Eriophorum vaginatum peat, rich in humus, containing some birch fragments-very likely the roots penetrating from above-washing gave Cenococcum geophilum, some Calluna shoots, stones of Empetrum nigrum - pollen grains of birch,

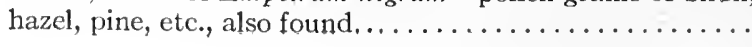

$30 \mathrm{~cm}$.

$45 \mathrm{~cm}$. 
3. Eriophorum vaginatum peat very little moldered, Sphagnum rare, Empetrum stems numerous-few small birch twigs. Stones of Empetrum, numerous achenes of Potentilla comarum, etc., also pollen of birch, pine, etc., and spores and leaves of Sphagnum and brown fungus hyphæ........

2. Forest peat, rather rich in humus, hard and firm. Fine material consists chiefly of wood detritus. In the peat are numcrous trunks and twigs of birch-no coal-washing gave achenes of Potentilla comarum, seeds of Viola and numerous fruits of different Carex species. No determinable microörganisms.................... $45 \mathrm{~cm}$.

Total peat........................ $240 \mathrm{~cm}$.

I. Moraine with large stones

$20 \mathrm{~cm}$.

The two forest beds ( 2 and 5 ) appear to be of wide extent over the Scottish uplands, the peat layers between varying in thickness and to some extent in composition. The lowest bed always consists of the remains of a birch forest. The dividing peat generally contains arctic plants.

In the Grampians, Carex peat ( $150 \mathrm{~cm}$.) rests directly upon the boulder clay, or sometimes has a stratum of Sphagnum peat at the base. Scirpus caspitosus peat or Eriophorum i'aginatum peat follows this.

In the northwest Highlands of Scotland similar successions are met with. In Coire Bog, in Easter Ross, the following section occurs (Lewis quoted by Samuelson-40) :

Dominant Plant

I. Scirpus-Sphagnum.... $3 \mathrm{ft}$.

2. Pinus sylvesiris L.......

3. Sphagnum.......... I-3 ft.

4. Pinus sylvestris L........

5. Eriophorum........ $5 \mathrm{ft}$.

6. Betula alba $\mathrm{L} . \ldots \ldots \ldots .2-3 \mathrm{ft}$.

7. Empetrum nigrum $\mathrm{L} \ldots \ldots$.. $1 \frac{1}{2} \mathrm{ft}$.

8. Salix arbuscula L .......

9. Sand

Total peat...$\quad$ I3-16 ft.
Accompanying Plant

Calluna (abundant in upper layers) Menyanthes trifoliata $\mathrm{L}$.

Eriophorum vaginatum $L$.

Eriophorum, Polytrichum

Betiila nana L. (abundant in upper layers). Dryas octopetala L. Potentilla comarum, Nestl. (abundant in the lower layers).

10. Closely packed stones

While most Swedish and many German authors refer the stratification of the peat to successive changes in the level of ground water as outlined above, other authors follow James Geikie, who refers this alternation of regetation to changes in climatic conditions 
accompanying changes in physical outline of Great Britain. His succession of late glacial and interglacial stages in Scotland is as follows :

5. Upper Turbarian or Sixth Glacial Stage.

High-level corrie glaciers, with snow line at 3,500 feet; peat overlying Upper Forest; raised beaches at 25 to 30 feet; somewhat cold and wet climate.

4. Upper Forestian or Fifth Interglacial Stage.

Upper Forest overlying lower peat; relatively dry and genial climate; land area somewhat more extensive than now.

3. Lower Turbarian or Fifth Glacial Stage.

Valley-glaciers, with average snow-line at $\mathbf{2 , 4 0 0}$ to $\mathbf{2 , 5 0 0}$ feet; Lower Peat overlying Lower Forest; raised beaches at 45 to 50 feet; cold and wet climate.

2. Lower Forestian or Fourth Interglacial Stage.

Lower Forest overlying morainic accumulations of Fourth Glacial stage; genial climate; land area of greater extent than now.

I. Mecklenburgian or Fourth Glacial Stage.

District ice-sheets and large valley glaciers of Highlands and Southern Uplands; raised beaches at $\mathbf{I} 00$ to $\mathbf{I} 35$ feet; Arctic climate, with snowline ranging from $\mathbf{I}, 000$ feet in west and northwest to $\mathbf{I}, 500$ feet or thereabout in Central Scotland.

The typical succession of strata of the Scottish peat bogs agrees with this series of changes, this being as follows:

\begin{tabular}{|c|c|c|}
\hline Peat Deposits & Blytt's Climatic Period & Geikie's Climatic Period \\
\hline 5. Upper Peat Deposits & $\begin{array}{l}\text { The Subatlantic Period } \\
\text { (moist and cold) }\end{array}$ & Upper Turbarian \\
\hline $\begin{array}{l}\text { 4. Upper Forest Bed } \\
\text { pine or birch - re- } \\
\text { placed in the Shet- } \\
\text { lands by a Calluna } \\
\text { layer }\end{array}$ & $\begin{array}{l}\text { The Subboreal Period } \\
\text { (warm and dry) }\end{array}$ & Upper Forestian \\
\hline $\begin{array}{l}\text { 3. Middle Peat Deposit } \\
\text { commonly with a } \\
\text { thin layer near the } \\
\text { middle containing } \\
\text { arctic plants(second } \\
\text { arctic bed) }\end{array}$ & $\begin{array}{l}\text { The Atlantic Period } \\
\text { (warm and moist) }\end{array}$ & Lower Turbarian \\
\hline $\begin{array}{l}\text { 2. Lower Forest Bed } \\
\text { chiefly of birch re- } \\
\text { mains }\end{array}$ & $\begin{array}{l}\text { The Boreal Period } \\
\text { (warm and dry) }\end{array}$ & Lower Forestian \\
\hline $\begin{array}{l}\text { I. Lower Peat Deposit } \\
\text { containing the re- } \\
\text { mains of the first } \\
\text { arctic flora (first } \\
\text { arctic bed) }\end{array}$ & $\begin{array}{l}\text { The Subarctic and Arctic } \\
\text { Periods }\end{array}$ & $\begin{array}{l}\text { Arctic Tundra time, at } \\
\text { close of Mecklenburg- } \\
\text { ian ice age }\end{array}$ \\
\hline
\end{tabular}


The Arctic Tundras. The permanently frozen areas of northern Europe, Asia and America are covered for the most part by a growth of peat which rises in the form of rounded hills or banks of approximately uniform height. Frozen solid in winter, they are thawed out on the surface during the summer months. Throughout northern Europe the old peat vegetation, which consisted largely of Sphagnum, has perished, only on the borders of the natural drainage channels are cotton grass and Sphagnum still found growing. The causes of this widespread destruction of the peat moss and of the consequent cessation of peat formation are the rising of the permanently frozen ground-level beneath the moss, and the overgrowing of the moss by lichens, especially Lecanora tartarca, which covers both living and dead organisms with a uniform mantle. The peat protects the ice beneath it from melting, so that in Lapland ice exists the year round under peat only. Melting of the peat bogs proceeds down to a depth of 30 to $40 \mathrm{~cm}$. With the increase in thickness of the peat, the ice is more protected and its surface rises, the result being that the plants are less and less supplied with moisture. This eventually leads to their destruction. The tundra of Alaska covers the whole surface, except the faces of steep cliffs, along the borders of Behring Sea and the Arctic Ocean. It is typically "a swampy, moderately level country, covered with mosses, lichens and a great number of small but exceedingly beautiful flowering plants, together with a few ferns. The soil beneath the luxuriant carpet of dense vegetation is a dark humus, and at a depth exceeding about a foot is always frozen." (Russell-39: I25.) Lakelets and ponds abound in the level parts, and they occur even on the hillsides, where, except for the spongy retaining vegetation, no such accumulation would be possible. The dense vegetation extends up the mountainsides wherever conditions are favorable and covers even steep crags. "On the steep slopes, as in the swamps, the vegetation is always water-soaked, owing to the extreme humidity of the climate in which it thrives." Mosses and lichens characterize the flora with a notable absence of trees. "Cryptogamic plants make more than nine-tenths of its mass. On their power to grow above as they die and decay below depends the existence of the tundra." Two species of Equisetum flourish with rank luxuriance over great areas along the Yukon. Excavations show "that the fresh luxuriant vegetation at the surface changed by insensible gradations to dead and decaying matter a few inches below and finally became a black, peaty humus, retaining but few indications of its vegetable origin." (Russell-39:126.) The depth of the humus layer at St. Michaels is about two feet. A mile east of the 
village it is about twelve feet. "In the delta of the Yukon a depth of over fifteen feet was seen at one locality. A depth of 150 to 300 feet has been assigned by several observers to the tundra, where it is exposed in a sea cliff on Eschscholtz Bay, at the head of Kotzebue Sound." Here the surface layer of humus is rich in mammalian remains. It is evident that the conditions here differ from those found in North Europe, where the rising ground ice eventually puts a stop to further peat formation. Russell thinks that in Alaska "there is apparently no reason why this process [of growth above, decay below, and conservation of the partly decayed vegetation by freezing] might not continue indefinitely, so as to store up vegetable matter. in a way that is only paralleled in the most extensive coal fields." (39: 127.)

"On the flood plains of the larger rivers, and generally throughout all the lowlands of Alaska, peaty deposits are forming in the same manner as on the tundra, modified, however, by the growth of arborescent vegetation and by the intrusion of sand and clay in places that are flooded during the high-water stage of the rivers.

"At many localities along the Yukon, sections of peaty deposits are exposed often eight or ten feet thick and several long. The bluffs ... are from fifteen to twenty feet high ... . and nearly always frozen solid.... Some of the vegetable layers are interstratified with sand and clay; others at the surface are still increasing in thickness and have a dense forest growing on them. Not infrequently there is a stratum of clear ice interbedded with the layers of peat, sand and clay.". (Russell-39.)

The moist, cool climate prevailing over eastern Canada has also been conducive to the extensive growth of peat bogs, which cover all the area around the St. Lawrence and the Ottawa, as well as on Newfoundland and on the smaller islands off the coast. On Anticosti Island in the Gulf of St. Lawrence there are peat beds covering in some cases areas from one hundred to more than a thousand acres in extent, with a thickness of ten feet or over. (Twenhofel-48:66.) The peat rests on sands and gravels, sometimes with Mya arenaria, and at other times it rests directly upon the croded limestone surface of early Palrozoic age. The lower peat deposits often contain tests of sea urchins (Strongylocentrotus dröbachiensis), fragments of lobsters and crabs, gastropods, etc., which are brought there by birds, chiefly crows, or which have been washed up by unusually high waves and tides. These marine organic remains are often very abundant. In the wooded areas, where trees have only a slight foothold owing to the shallowness of 
the soil, fallen trees abound and are entombed in the growing and only partially decaying vegetation.

The temperature of Anticosti ranged, during the six years from 1897 to I902, from $+26^{\circ} \mathrm{C}$, which occurred once, to $-39^{\circ} \mathrm{C}$, which occurred twice. The average temperature for June, July and August is about $+\mathrm{I} 2.5^{\circ} \mathrm{C}$., that of the winter months about $-10^{\circ}$ C., or an annual average of about $+2^{\circ} \mathrm{C}$. Precipitation during the three months of the growing season varies from 23 to 28 centimeters, the mean annual rainfall lying between 50 and $100 \mathrm{~cm}$., but nearer the latter. Cloudiness and fogginess often prevail. (Twenhofel-48.) In southern latitudes peat is more rarely formed from mosses. In the Chonos Archipelago (S. L. $44^{\circ}$ to $46^{\circ}$ ) every piece of level ground is covered with Astilia pumata and Donatia magellanica, which by their joint decay compose a thick bed of elastic peat. (Darwin-1 $2: 2.7-26$.)

Astilia is the chief peat former of Tierra del Fuego. Fresh leares appear constantly around the growing stem, while the lower ones decay. (Stevenson-46:563 $(I 6 I)$.) Every plant in the Falkland Islands becomes converted into peat, but the most important plants are a variety of "crowberry" also common on Scottish Hills (Empetrum rubrum), a creeping myrtle (Myrtus nummularia), a dwarf species of water marigold (Caltha appendiculata) and some sedges and sedge-like plants. "The roots, preserved almost unaltered, may be traced downward in the peat for several feet, but finally all structure is obliterated and the whole is reduced to an amorphous structureless mass." (Stevenson-46:564 (I67).)

\section{Peat in the Tropics.}

Sphagnum does not occur south of N. L. $29^{\circ}$, but peat is formed by a variety of plants south of this line. The cypress swamps of Florida contain thick deposits of peat, with cypresses, grasses, ferns and myrtle making up the bulk of the vegetation. On Bermuda a thickness of at least 50 feet is assigned to the peat in one of the two great peat swamps. "The climate is such that plants of Carboniferous type could grow well, for the banana thrives, while palms and Indian rubber trees attain great size." (Stevenson-46:567 (I65).) Extensive peat bogs are found in the Amazon region and in the interior of Africa. In the region between the Gulf of Guinea and the sources of the Niger, extensive peat deposits are formed by the sedge Eriospora pilosa Benth. On the Island of Sumatra occurs a large swamp, $90 \mathrm{~km}$. from the coast, on the left bank of the river 
Kampar. It has a width of 12 kilometers and an area of more than 80,000 hectares, and is covered by trees rising mostly to a height of $30 \mathrm{~m}$. It contains a peat deposit which has been sounded to a depth of 9 meters. This peat consists largely of decayed woody tissue. The larger roots of trees, with their upward pointing pneumatophores, form a solid basis in this swamp, which makes traversing possible. The numerous varieties of trees have mostly slender stems, bearing only a small crown of leaves, but with broad, buttressed roots rising three to four meters above the ground, and with remarkable aërial roots projecting in bundles for a meter or a meter and a half from the trunk. Gymnosperms and monocotyledons are wholly wanting among the taller trees of this swamp, these being chiefly composed of dicotyledons. Among the smaller trees and bushes monocotyledons occur, though sparingly. Tree palms are rare, but bushes of this family abound, especially several species of a small Calamus. A small tree fern (Alsophila?) was also found scatteringly. The herbaceous vegetation is sparingly represented both in species and individuals. Grasses and sedges are practically wanting, the ground between the trees, where not occupied by the aërial roots or "knees," being strewn with decaying leaves. Sphagnum is wholly wanting, and other mosses, liverworts, lichens and herbaceous Pterydophytes are rare. Epiphytes occur only in the leafy crown of the trees on account of the smooth character of their trunks. Phanerogamous water plants appear to be rare, but thread-like algæ were found to be numerous where the forest was lightened through uprooting of trees by the winds. Toward the margin of this tropical swamp the vegetation gradually changes, merging into that of the surrounding drier land. (Potonié32.)

\title{
Fossil Humuliths.
}

The Humuliths of former geological periods are represented by the following types:

\author{
Lignite, \\ Brown Coal, \\ Bituminous Coal, \\ Anthracite, \\ Graphite.
}

Lignite is wood, especially that of coniferous trees, which is in its early stages of alteration, but still shows the woody characters in unmistakable manner. Lignites are found in Mesozoic deposits 
and are especially abundant in and characteristic of the Tertiary, where they are often associated with brown coal.

Broan Coal is a compact or earthy, altered peat deposit, especially characteristic of the Tertiary rocks. It represents one of the intermediate stages from peat to mineral coal, and still often shows evidence of its organic origin. It varies from pale brown or yellow to deep brown or black, though some shade of brown is the prevailing color. It contains from 55 to 75 per cent. of carbon, has a specific gravity of 0.5 to $\mathrm{I} .5$ and burns easily with a sooty flame and strong odor, leaving a light ash. The most extensive deposits are in the Oligocenic of North Germany, but peat beds altered to Brown coal have also been observed in post-Tertiary deposits.

Bituminous Coal. This coal, also called soft coal, is found in the Mesozoic and the Carbonic. It is black, compact, usually brittle, with cubical or conchoidal cleavage, and has a shiny luster. It contains from 75 to 90 per cent. of carbon and generally some sulphur. Its specific gravity ranges from I.2 to 1.35 , and it burns with a bright, clear flame. Some varieties cake on burning, others are consumed to ashes. Generally no trace of organic matter is recognizable, except under the microscope.

Anthracite, or hard coal, is the most highly mineralized form of coal, with a black color, strong, metalloid or vitreous luster and conchoidal fracture. Its specific gravity ranges from I.35 to I.7, and it contains over 90 per cent. of carbon. It kindles with difficulty, but burns in a strong draught with great heat and without smoke, caking or odor. It occurs in disturbed regions where the volatile matter has been driven off through heat and metamorphism. Some anthracites also originate through extensive loss of the volatile gases before entombment.

Graphite, or pure carbon, is found chiefly in ancient crystalline rocks, such as gneisses, mica schists, metamorphic limestones, etc. When originating from organic matter it is the product of extreme metamorphism, but it may also be formed in purely inorganic manner.

\section{Ancient Moors.}

Among the moors of past geological time, those of the Anthracolithic or Carbonic period deserve especial attention, for they have not only furnished a large part of the coal supply of the world, but their wonderful luxuriance of growth and strangeness of type invest them with peculiar interest, and make the restoration of these ancient swamps and forests and their subsequent burial a problem full of fascination. 
Comparison with modern moors leads to the conclusion that those of Carbonic time were of the flat or low moor variety, or that type in which arboreal vegetation plays a more significant part than it does in our upland bogs. While the seashore or marsh type was not unrepresented, it is apparent from the cliaracter of the vegetation that the prevailing moor type of that period, now represented by our coal beds, was of the fresh-water swanı or morass type. The character of the vegetation itself points to this, since the tissues of the Carbonic trees are of coarse-cell type like those of the rapid-growing trees of our swamps, instead of the closecelled type characteristic of upland bogs and due to slower growtl. Of all the known modern swamps that of Sumatra, above described, comes nearest to representing the conditions of the Carbonic moors, for the character of the vegetation seems to point unmistakably to a moist, tropical climate for at least part of our Carbonic coal deposits.

The place of the modern bulrushes and other reeds was taken in Carbonic time by the gigantic reed-like relatives of the modern Equisetum, i. e., the Calamites. The usual occurrence of these plants in sandstones preceling coal beds indicates that they performed much the same land-forming office in those days that the reeds do to-day. They have in common with them the characteristic power of sectional repetition of parts which enables the plant to continue growth and putting forth of roots, even though it is progressively buried by the accumulating silt.

The tree types succeeding the calamites, the Lepidophytes, including Lepidodendra and Sigillaria, were true swamp. plants with horizontally spreading roots, the Stigmaria. These fossil roots have a remarkable similarity to the spreading roots of Pinus and other moor trees of the present day, and, like these; were adapted for growth on wet ground, where firmness of foundation was secured by great horizontal spreading, and where it was not necessary to penetrate into the soil for moisture, as in regions of low-lying ground-water level. A basal enlargement of the trunks of trees, such as characterizes $N$ yssa uniflora and others of our swamp trees, is also often seen in these Carbonic types. This feature likewise tends to keep the tree erect, owing to the greater weight of the basal portion. Structures suggestive of the cypress knees or pneumatophores of our subtropical swamps have also been found associated with the Sigillaria, while structures suggestive of the breathing pores or lenticels, so characteristic of the basal portions of the trunks of trees in the tropical swamps, occur in the Carbonic Lepidophytes, where they form the Syringodendron surface. 
The characters of the Ferns and the Sphenophyllacex of the Carbonic likewise point to moist tropical conditions during that period, and since the coal deposits resulting from the growth of these plants are so widely distributed in regions which to-day have a temperate climate, it is apparent that conditions now characteristic of the equatorial region of the world were during the Carbonic period more widely distributed. In Chapter II a possible cause for the increase in temperature was discussed, this being the greater supply of $\mathrm{CO}_{2}$ in the atmosphere which would retain the heat and so raise the temperature of the entire earth's surface. The removal of this atmospheric constituent and the storage of the carbon in the tissues of plants would bring about a progressive lowering of the temperature, and this refrigeration of the climate would bring on the glacial conditions known to have existed in Permic time. It is a notable fact that the coal-forming period was preceded by a period of wide and extensive submergence and the building of limestones in all parts of the world. This would result in setting free much $\mathrm{CO}_{2}$, and hence would supply the conditions favorable to the development of the tropical coal swamp on the emergence of the land.*

The coals formed during the Mesozoic periods have probably a history similar to that of the Carbonic coals, though seashore conditions and those of lagoons and estuaries may have been more common. The Tertiary coals, especially those of northern Europe, appear to have been formed in swamps closely similar to our modern cypress swamps of southern North America. Many of the species found in the brown-coal deposits of North Germany, such as the Magnolias, Liquidambar, Sassafras, Catalpa, Swamp Cypress, etc., are still living in these swamps, though they have become extinct in Europe. The remarkable depth of the brown-coal deposits of North Germany, reaching north of Cologne nearly Ioo meters, gives some indication of the length of time required to accumulate such a mass of vegetal material by successive periods of growth and decay. As in the case of the Carbonic deposits, the Tertiary coal period was preceded by extensive limestone deposits and succeeded by a period of gradual refrigeration which culminated in the Pleistocenic glaciation.

\section{Black Soil and Shales of Humulithic Origin.}

Long-continued growth of vegetation produces in some regions a thick accumulation of a dark loam, such as is seen in the black

* See also p. 9o, and the reference to Koken's work in Chapter XXIII. 
cotton soil (regur) of India and in the black earth (tchornozom) of Russia. Such deposits may subsequently harden into black, carbonaceous shales. Examples of such shales are probably to be found in the Chattanooga black shale of eastern Alabama, etc., of Lower Mississippic age. This in places includes thin layers of coal, and in other respects bears evidence of having been a former residual soil, the black color of which is due to the abundance of partially decayed land vegetation.

\section{Burial of Peat Deposits.}

Peats formed near the coast, even when of fresh-water or swamp origin, may be buried by a subsidence of the land and a consequent transgression of the sea. Such subsidence may be so slow that salt-water or marsh peat may transgress over the fresh-water peat, as in the case of the Massachusetts coast (see ante, p. 493). Where subsidence is more rapid, fresh-water peat may be covered by marine sands, as in the Bay of Morlaix, Brittany (Finistère), where, according to Cayeux, two layers of peat with Arundo phragmites are separated and again covered by marine sands. In the flat, maritime plain of Pas-de-Calais, a section now three meters above the sea-level shows:

Marine sand with Cardium edule, I meter.

Marine clay with Hydrobia ulva, I meter.

Peat.

Marine sand with Cardium edule.

In the mouth of the Shelde similar deposits of peat, I to I.5 meters thick, are enclosed between sediments with marine organisms. At Cotentin, in Normandy, 20 meters of peat are overlain by marine sands, and similar deposits are found in other parts of France, in Belgium, Holland and elsewhere. As shown, however, by the deposits of Anticosti, the presence of such marine organisms in the strata covering the peat need not always indicate subsidence after the formation of the peat.

The section made by the river Tay in the Carse lands of southeastern Scotland shows a peat bog now forming the river bed and covered by about I 7 feet of alluvial material, which near the top contains cockles, mussels and other marine forms. The peat of this region rests in part on alluvial sands and in part on marine clays, and is itself of terrestrial origin. It is "highly compressed and splits readily into lamina, on whose surfaces are small seeds and wing cases of insects. As a rule, but not always, it is marked 
off sharply from the overlying clay and silt." The upper layers of the peat represent transported material from farther up the stream, and consist of silt with twigs and branches and trunks of trees. Other examples are cited by Stevenson (46).

Glacial till is not an infrequent cover for peat deposits. Sir William Dawson $(17: 63)$ has described an early Quaternary bog in Nova Scotia, where the peat was covered by 20 feet of boulder clay and so compressed that it had almost the hardness of coal. In the New England States such peat buried under glacial drift is not uncommon, and it has been observed in widely separated districts in the glaciated area. In Montgomery County, Olio, a bed of peat, I 5 to 20 feet thick, and with its surface formed by Sphagnum grasses and sedges, underlies go feet of gravel and sand. The peat contains coniferous wood, bones of elephant, mastodon and teeth of giant beaver. In southwestern Indiania and part of Illinois an ancient soil, 2 to 20 feet thick, and containing peat, muck, rooted stumps, branches and leaves, lies at a depth of 60 to I20 feet below the surface.

Peat deposits on the flood plains and deltas of rivers are likely to be buried under the silt and mud when the river rises, and likewise, when through a change in climate or other cause a river begins to rapidly aggrade its flood plain. In such cases the peat deposits will be buried under regular strata of sand and clay of continental origin, and it would happen that the trees still standing are gradually buried in the silt and sand. "Even the slender canes of the Mississippi delta, killed by salt-water invasion, remain standing after they have been surrounded by several feet of silt." (Stevenson-46.) The filling of the hollow bark of still erect trees, in which the wood has decayed, by sand and mud and so ensuring their preservation in an erect form, is a familiar fact to students of the Coal Measures. The well-known section at South Joggins, Nova Scotia, shows erect Sigillaria and other trees in considerable number. The most important part of the section containing these trees is as follows (Dawson-18):

Sandstone with erect Calamites and Stigmaria roots...... $6 \mathrm{ft} .6 \mathrm{in}$. Argillaceous sandstone, Calamites, Stigmaria and Alethop-

teris cuchitica . ...................... I ft. 6 in.

Gray shale, with numerous fossil plants, and also Naiadites,

Carbonia and fish scales...................... $2 \mathrm{ft} .4$ in.

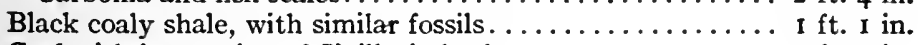

Coal with impression of Sigillaria bark............. o ft. 6 in.

"On the surface of the coal stand many erect Sigillariæ, penetrating the beds above, and some of them nearly three feet in 
diameter at the base and nine feet in height. In the lower part of many of these erect trees there is a deposit of earthy matter blackened with carbon and vegetable remains and richly stored with bones of small reptiles, land snails and millipedes." Dawson considers that "on decay of the woody axis and inner bark they must have constituted open cylindrical cavities, in which small animals shel-

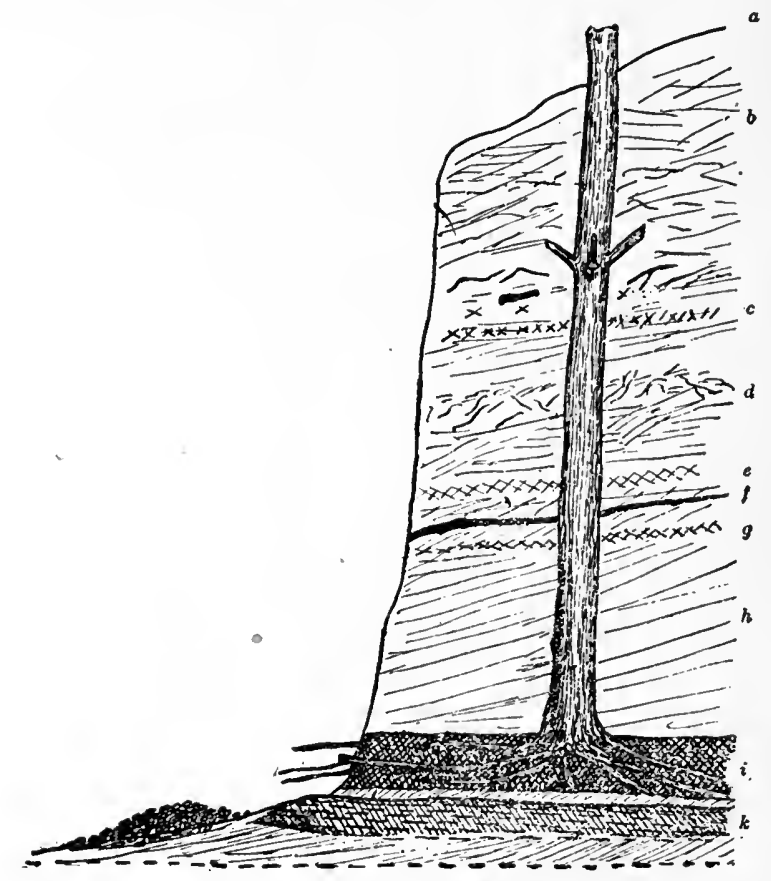

FIG. II6. Buried peat bed near Marquette, Michigan, with bog-iron stratum below and sand dune above. Exposure made by easterly storm. (After Davis.) $a$, stump of buried tree; $b$, sand stratum, with roots and other plant remains; $c, e$, and $g$, pine needles; $d$, sand with grass remains; $f$, iron sand; $h$, pure sand, crossbedded; $i$, peat stratum, with standing pine stump; $k$, bog iron. (Height of section about I $_{5}$ feet.)

tered themselves, or into which they fell and remained imprisoned. These natural traps must have remained open for some time on a subaërial surface." Fifteen out of twenty-five erect trees proved to have these contents, in one no less than twelve reptilian skeletons occurring. In a few instances portions of the cuticle, ornamented with horny scales and spines, had been preserved. In these deposits, it is evident that the trees after being buried up to a certain depth rotted away on the surface or were blown down, and that 
then the inner tissues decayed until only the bark, embedded in upright position in the mud, remained behind. The bark of fallen trees is generally pressed flat on the decay of the inner tissues by the weight of the superincumbent sediment. In Alaska the Yahtse River, "issuing as a swift current from beneath the glacier, has invaded a forest at the east, and has surrounded the trees with sand and gravel to a depth of many feet. Some of the dead trunks, still retaining their branches, project above the mass, but the greater part of them have been broken off and buried in the deposit. Other streams, east from the Yahtse, have invaded forests, as indicated by dead trees standing along their borders. Where the deposit is deepest the trees have already disappeared, and the forest has been replaced with sand flats. The decaying trunks are broken off by the wind, and are buried in prostrate position. This deposit consolidated would resemble closely a Coal Measure conglomerate." (Russell, cited by Stevenson-46.)

Modern tree trunks have been found on the coast with their interior decayed and filled with sand down into the roots. (Potonié32.) Sand dunes advancing over a peat bed will put an effective stop to further peat formation and serve as a factor in preserving the peat so formed. It is not improbable that many of the sandstones which succeed the coal beds of our Carbonic series owe their origin to such covering wind-blown sands.

In advancing over the peat the sand dunes will likewise advance over the forests associated with the peat and bury them. This can be seen in many regions where only the tops of large trees project above the sands, as on the shores of Lake Michigan, etc.

In rare cases peat deposits may be buried by landslides, by mud flows, etc. In all cases where the deposit, first spread over the swamp or bog, is a fine one, impressions of the last fallen leaves and branches may be preserved in great detail. In this manner are formed the roof shales with their wonderful wealth of plant inpressions, which makes it possible for us to-day to reconstruct the vanished flora of the Coal Period. The clay or soil in which the plants had their roots is in most cases preserved as a "fire clay." that is, a clay which can be used for pottery which has to withstand intense heat. It contains little iron, and is nearly free from lime and alkalies, of which the clay was deprived by the growth of the plants.

\section{LIPTOBIOLITHS.}

These may be dismissed with a few words. The exudations of resins, gums, wax, ctc., from resinous trecs.are characterized by 
relative stability of composition, and are not easily decomposed. They may thus form accumulations of greater or less extent, while the plant tissues which they enclose decay wholly. The subfossil Copal is a typical example, while from older rocks (Oligocenic) of North Germany comes the amber. Many minor types of liptobioliths occur in nature, but they are of more mineralogical than geological value.

\section{Allochthonous Vegetal Deposits.}

Vegetal material transported from other localities and deposited where it did not grow is found frequently at the present time, both upon the land and in the sea. It also occurred in the past. On the Missouri, Mississippi and other rivers, rafts and whole floating islands of vegetation are known, and logs are found scattered widely through deposits to which they are wholly foreign. "These drifted materials are everywhere distinguishable from plants buried in situ, for they have been deprived of all tender parts; of the harder woods in Carboniferous times there are few traces except decorticated stems, casts of the interior, indeterminate forms grouped under Knorria, Sternbergia and some other names.". (Stevenson-46:642.)

"In all extensive deposits of driftwood the trees are battered, stripped of leaves, bark and often of branches; they arc scattered on the strand or piled in irregular loose heaps, where, exposed to the air, they decay; or, if in more favorable conditions, the interstices become filled with sediment, the trees become merely logs in shale or sandstone, even their genus being unrecognizable except by microscopic study of the structure." (Stevenson-46:557.)

The coal deposits of the Commentry basin in France have long becn held to be a good example of a fossil allochthonous coal. It is now known, however, that this coal is formed in situ, after all. Stigmaria are found in place, while the trecs are arranged in all positions, upright, leaning and prostrate. The resemblance to a forest ravaged by a hurricane is very close.

Marine Vegetal Deposits. Marine plants, owing to the buoyancy which they possess on account of the numerous air spaces in their tissues, will float on the surface of the water until stranded on the shore or on a mud flat. Their presence in the deep sea deposits is not noted, because they will continue to float until decomposed. On the other hand, in the shallower portions of the littoral district marine plants may accumulate in abundancc. Spores of plants are not infrequently found in marine sediments. But by far the most 
noteworthy deposits of plants in marine sediments are the deepsea accumulations of leaves and driftwood of terrestrial origin. In the Caribbean, on the lee side of the West Indian Islands, the Blake dredged "masses of leaves, pieces of bamboo and of sugar cane, dead land shells, and other land débris" at a depth of over $\mathrm{I}, 000$ fathoms, and ten or fifteen miles from land. (Agassiz-I : 29I.) The Albatross in its dredging expedition on the west coast of Central America between the Galapagos Islands, the west coast of Mexico, and the Gulf of California, found nearly everywhere a muddy bottom or one composed of Globigerina ooze, and generally containing terrigenous matter. Scarcely a single haul of the trawl was made which did not bring up a "considerable amount of decayed vegetable matter, and frequently logs, branches, twigs, seeds, leaves, fruits," much as found by the Blake on the east coast, but in vastly greater quantities. Even at a depth of over 2,000 fathoms these remains were found. (Agassiz-2:II, I2.)

The Challenger also found twigs, woods, and seeds at a depth of 800 fathoms near Ki Island, and also within 20 fathoms off the coast of Amboina Island, both west of New Guinea. South of Mindanao, at a depth of 2,I 50 fathoms, palm fruits, and fragments of wood and bark were found, while about 50 miles off the coast of Luzon at a depth of 1,050 fathoms were dredged fragments of leaves, stems and wood, the latter overgrown with Serpula.

The distance from shore to which material is carried by flotation is often indicated by the state of preservation of the material. White says: "If the material is macerated, corroded, rolled, defoliated, skeletonized, incrusted, or bears other signs of having been for some time in the water it is liable to have been transported for some distance. . . . If long in sea water the fragments are likely to bear the marks of abundant marine organisms. particularly if in tropical sea water. On the other hand, the occurrence of clean, unbroken, smooth leaves, and particularly of large segments of fern fronds, with their full complement of carbonaceous residues, is prima facie evidence of minimum exposure to water and of the least subjection to the action of swift currents or waves." (White-6o.)

\section{BIBLIOGRAPHY XI.}

\section{(See also Bibliography X.)}

I. AGASSIZ, ALEXANDER. I888. . Three Cruises of the Blake. Vol. I.

2. AGASSIZ, A. 1892. General Sketch of the Experlition of the Albatross, from February to May, I89I. Harvard College, Museum Comparative Zoölogy, Vol. XXIII, pp. 1-89. 
3. AGASSIZ, A. I895. A visit to the Bermudas in March, 1894. Bulletin of the Museum of Comparative Zoölogy at Harvard College, Vol. XXVI, pp. 205-28I.

4. BERTRAND, C. E. 1892. Pila bibractensis et le Boghead d'Autun. Société Histoire Naturelle d'Autun, I892. (This also contains a "Communication faite sur le Boghead" by B. Rénault.)

5. BIGELOW, HENRY B. I905. The Shoal-water Deposits of the Bermuda Banks. Proceedings of the American Academy of Arts and Sciences, Vol. XL, No. I5, pp. 557-592 (with other literature references on Bermuda and other coral reefs).

6. BORNEMANN, J. G. I885. Beiträge zur Kenntniss des Muschelkalks, insbesondere der Schichtenfolge und der Gesteine des Unteren Muschelkalkes in Thüringen. Jahrbuch der königlich-preussischen geolog. ischen Landesanstalt und Bergakademie, pp. 267-320, pls. VII-XIV.

7. CHALLENGER EXPEDITION. Narrative, Vol. I.

8. CLARKE, F. W. I9I I. The Data of Geochemistry. 2nd edition. Bulletin U. S. Geological Survey, 49 I.

9. CLARKE, JOHN M. 1904. The Naples Fauna, II. Memoir N. Y. State Museum Natural History, Vol. VI.

I0. COHN, FERDINAND. 1862. Die Algen des Karlsbader Sprudels mit Rūcksicht auf die Bildung des Sprudels Sinters. Abhandlungen der Schlesischen Gesellschaft der Naturwissenschaften, Heft 2, pp. 35 et seq.

I1. DANA, JAMES D. I895. Manual of Geology. 4th edition. American Book Co.

12. DARWIN, CHARLES. I846. Journal of Researches, Vol II.

13. DAVIS, CHARLES A. 1903. Contribution to the Natural History of Marl. Geological Survey of Michigan, Vol. VIII, pt. II, Chapter V.

14. DAVIS, C. A. 1907. Peat: Essays on Its Origin, Uses and Distribution in Michigan. State Board of the Geological Survey of Michigan, Annual Report for 1906.

15. DAVIS, C. A. I910. Salt Marsh Formation near Boston and Its Geological Significance. Economic Geology, Vol. V, No. 7, pp. 623-639.

16. DAVIS, WILLIAM M. 1896. The Outline of Cape Cod. American Academy of Arts and Sciences, new series, Vol. XXXI, pp. 303-332.

17. DAWSON, SIR WILLIAM. I868. Acadian Geology. 2nd edition, London.

I8. DAWSON, SIR W. 1882. On the Results of Recent Explorations of Erect Trees, Containing Animal Remains in the Coal-formation of Nova Scotia. Proceedings of the Royal Society of London, Vol. XXXIII, pt. II, No. 218 , pp. 254-256.

19. FINCKH, ALFRED E. 1904. Biology of the Reef-forming Organisms at Funafuti Atoll. Funafuti Report, Section VI, pp. I25-I50.

20. FRANTZEN, W. I888. Untersuchungen ueber die Gliederung des unteren Muschelkalks in einem Theile von Thüringen und Hessen und ueber die Natur der Oolithkörner in diesen Gebirgsschichten. Jahrbuch der königlich-preussischen geologischen Landesanstalt und Bergakademie für I887, pp. I-93, Tafel I-3 (see section B-Untersuchungen ueber die Natur der Oolithischen Gesteine im unteren Muschelkalk, pp. 79-93).

2I. GARDINER, STANLEY J. I898. The Coral Reefs of Funafuti, Rotuma and Fiji, together with some Notes on the Structure and Formation of Coral Reefs in General. Proceedings of the Cambridge Philosophical Society, Vol. IX, pp. 4I7-503. 
22. GAUB, FRIEDRICH. 1910. Die Jurassischen Oolithe des schwäbischen Alb. Geologische und Palæontologische Abhandlungen (Koken), Bd. XIII, Heft I, pp. I-79, pls. I-X. (With many literature references.)

23. HARPER, R. M. 1909. Okefenoke Swamp. Popular Science Monthly, Vol. LXXIV, pp. 596-613.

24. HOWE, MARSHALL A. 1912. The Building of "Coral" Reefs. Science, N. S., Vol. XXXV, pp. $837-842$.

25. JEFFREY, EDWARD C. 1910. The Nature of Some Supposed Algal Coals. Proceedings of the American Academy of Arts and Sciences, Vol. XLVI, pp. 273-290, 5 plates.

26. KALKOWSKY, E. 1901. Die Verkieselung der Gesteine in der Nördlichen Kalahari. Isis.

27. KALKOWSKY, E. 1908. Oolith und Stromatolith im Norddeutschen Bundsandstein. Zeitschrift der deutschen geologischen Gesellschaft, pp. 68-125, pls. 4-II.

28. LYELL, CHARLES. 1829. On a Recent Formation of Fresh Water Limestone in Forfarshire. Transactions of the Geological Society, London, Vol. II, p. 24.

29. MOJSISOVICS, VON MOJSVAR, EDMUND. 1879. Die Dolomit Riffe von Südtirol und Venetien. Wien.

30. PARSONS, ARTHUR L. 1904. Peat; Its formation, Uses and Occurrence in New York. 23rd Annual Report of the State Geologist for 1903, Albany.

3r. POMPECKJ, J. F. 1901. Die Jura-Ablagerungen zwischen Regensburg und Regenstauf. Geognostische Jahreshefte, Jahrgang I4, pp. 43 et seq.

32. POTONIE, H. I9Io. Die Entstehung der Steinkohle und der Kaustobiolithe überhaupt. 5 th edition, Berlin.

33. RAMANN, E. 1910. Einteilung und Bau der Moore. Zeitschrift der deutschen geologischen Gesellschaft, Bd. LXII, pp. I29-135.

34. RAMANN, E. 1910. Beziehungen zwischen Klima und dem Aufbau der Moore. Ibid., pp. 136-142.

35. ROTHPLETZ, A. I89I. Fossile Kalkalgen aus den Familien der Codiaceen und der Corallineen. Zeitschrift der deutschen geologischen Gesellschaft, Bd. XLIII, pp. 295-322, pls. XV-XVII.

36. ROTHPLETZ, A. 1892. On the Formation of Oölite. (Botanisches Centralblatt No. 35, I892, pp. 265-268). English translation by F. W. Cragin, American Geologist, Vol. X, pp. 279-282, 1892.

37. ROTHPLETZ, A. 1908. Ueber Algen und Hydrozoen im Silur von Gotland und Oesel. Kgl. Svenska Vet. Akad. Handl., Vol. XLIHI, No. 5, 25 pp., 6 plates.

38. RUEDEMANN, R. I909. Some Marine Algæ from the Trenton Limestone of New York. New York State Museum Bulletin 133, pp. 194-2 I6, 3 pls., 5 figs.

39. RUSSELL, I. C. Notes on the Surface Geology of Alaska. Geological Society of America Bulletin, Vol. I, pp. 99-I62, pl. 2.

40. SAMUELSON, GUNNAR. 19io. Scottish Peat Mosses. Bulletin of the Geological Institution of the University of Upsala, Vol. X, pp. 197-260, with literature.

41. SHALER, N. S. 1885. Preliminary Report on Sea Coast Swamps of the Eastern United States. 6th Annual Report of the U. S. Geological Survey, pp. 353-398. 
42. SHALER, N. S. I890. General Account of the Fresh Water Morasses of the United States with description of the Dismal Swamp District of Virginia and North Carolina. Ioth Annual Report of the United States Geological Survey, pt. I, pp. 253-339.

43. SHERZER, W. H. I9oo. Geology of Monroe County, Michigan. Geological Survey of Michigan, Vol. VII, pt. I.

44. STEINMANN, G. I889. Ueber Schalen und Kalksteinbildung. Bericht der Naturforschenden Gesellschaft zu Freiburg i. B., Bd. IV, p. 288.

45. STEMME, H. I909. Das natürliche System der Brennbaren Organ. ogenen Gestaine (Kaustobiolithe). Zeitschr. für Praktische Geologie, 17. Jahrgangang, pp. 4-12.

46. STEVENSON, JOHN J. 1910-1913. The Formation of Coal-beds. 506 pages. Published in 4 parts: Part I. Proceedings of the American Philosophical Society, Vol L, pp. 1-116; Part II. ibid., pp. 519-643; Part III, ibid., Vol. LI, pp. 423-553; Part IV, ibid., vol. LII, pp. 31-162.

47. STOLLE, J. I9I0. Die Beziehungen der Nordwest-deutschen Moore zum Nacheiszeitlichen Klima. Zeitschrift der deutschen geologischen Gesellschaft, Bd. LXII, pp. 163-189.

48. TWENHOFEL, W. H. I9 Io. Geologic Bearing of the Peat Beds of Anticosti Island. American Journal of Science, Vol. XXX, pp. 65-7x.

49. UNITED STATES GEOLOGICAL SURVEY. I902. Geological Atlas of the United States, Folio No. 8o. Norfolk folio, Va.-North Carolina.

50. WALTHER, JOHANNES. 1885. Die Gesteinbildenden Kalkalgen des Golfes von Neapel und die Entstehung structurloser Kalke. Zeitschrift der deutschen geologischen Gesellschaft, Vol. XXXVII, Heft 2, pp. 329-357.

51. WALTHER, JOHANNES. 1893-4. Einleitung in die Geologie als historische Wissenschaft. Jena.

52. WALTHER, JOHANNES. I9Io. Die Sedimente der Taubenbank im Golfe von Neapel. Anhang zu den Abhandlungen der königlich-preussischen Akademie der Wissenschaften vom Jahre 19 Io.

53. WALTHER, JOHANNES. I9Io. Lehrbuch der Geologie von Deutschland. Leipzig, Quelle \& Meyer.

54. WEBER, C. A. I910. Was lehrt der Aufbau der Moore Norddeutschlands ueber den Wechsel des Klimas in post-glacialer Zeit? Zcitschrift der deutschen geologischen Gesellschaft, Bd. LXII, pp. I43-I62.

55. WEED, WALTER HARVEY. I 889. Formation of Travertine and Siliceous Sinter by the Vegctation of Hot Springs. U. S. Geological Survey, 9th annual report, pp. 613-676.

56. WESENBERG-LUND, C. I9or. Lake-lime, pea ore; lakegytje. Medd. fra. Danskgel. Forening u. Copenhagen, I90 I, p. 146.

57. WETHERED, EDWARD. I889. On the Microscopic Structure of the Jurassic Pisolite. Geological Magazine, New Series, decade III, Vol. VI, pp. 196-200, pl. VI, figs. 8-II.

58. WETHERED, EDWARD. I 890 . On the Occurrence of the Genus Girvanella in Oölitic Rocks, and Remarks on Oölitic Structure. Quarterly Journal of the Geological Society, Vol. XLVI, pp. 270-283.

59. WETHERED, EDWARD. I890. The Inferior Oölite of the Cotteswold Hills, with special reference to its microscopical structure. Quarterly Journal of the Geological Society, London, Vol. XLVII, pp. 550-579, pl. 20. 
60. WHITE, DAVID. I9II. Value of Floral Evidence in Marine Strata as indication of Nearness of shores. Bulletin of the Geological Society of America, Vol. XXII, pp. 22 I-227.

61. ZIEGLER, VICTOR. I912. The Siliceous Oölites of Central Pennsylvania. American Journal of Science, $4^{\text {th }}$ series, Vol. XXXIV, pp. I13-127. 


\section{CHAPTER XII.}

\section{ORIGINAL CHARACTERS AND LITHOGENESIS OF THE EXOGENETIC ROCKS. THE PYROCLASTICS AND THE AUTOCLASTICS.}

The original structures of Exogenetic or clastic rocks are mainly those formed during their deposition. Therefore the structures of each division of these rocks will show individual peculiarities, and hence each division will be considered by itself.

\section{PYROCLASTIC ROCKS.}

Modern Pyroclastics. Tuffs and volcanic breccias (pyrolutytes, pyrarenytes, and pyrorudytes) are typically formed about the volcanic vents which have furnished the material. (Their essential lithic characteristics have been described in Chapter VI.) Ordinarily the distance from the volcano at which the deposit will form will be dependent on the fineness of grain. Thus pyrorudytes will be formed close to the volcano, while the pyrolutytes will often form at great distances from the vent. These latter are often carried very far by the winds, and finally deposited as æolian or windblown volcanic ash (anemopyrolutyte). In such cases the structure of the deposit partakes of that of other anemoclastic rocks. Many tuffs are deposited in water, and so become closely allied to typical hydroclastic rocks and partake of their structure. The finer waterlaid volcanic tuffs (Hydropyrolutytes) often show a perfect stratification, and they sometimes are rich in organic remains. An example of finely bedded pyrolutytes is found in the fine paper shales of volcanic ashes of Florissant, Colorado, where a wealth of beautifully preserved insects, leaves, and silicified trees testifies to the adaptability of these deposits to the preservation of fossils. These deposits are commonly referred to a Tertiary lake caused by the damming of a valley by a lava flow. The possibility that the deposits are those of a river flood plain or playa lake must not be overlooked. The great abundance of insects, spiders, and leaves, the erect tree trunks, and the scarcity of aquatic animals point this 
way. The aquatic forms found comprise a thin-shelled Planorbis, always occurring in a crushed condition, a Physa and a single specimen of a bivalve, and eight species of fishes. Birds' feathers and bones and the skeletons and feathers of entire birds have also been found. Strongly sun-cracked layers point to repeated desiccation of the shallow lake, and this condition, first recognized by Lesquereux, is not excluded by the character of the fish, the water plants, water insects or molluscs. (Scudder-22; 23.)

Volcanic débris falling on the surface of the land will show little regularity of deposition. The coarser material will exhibit no bedding lines or only the very rudest ones, while volcanic sand or ashes may not infrequently show a moderate stratification, which will generally be more marked in the finer material. Where the ashes come to rest on a slope these stratification planes will be inclined.

Organic Remains of Modern Pyroclastics. Organic remains are not infrequent in pyroclastic rocks. They are best preserved in the finer grained deposits. Of these the remains of man and his works are often the most abundant in the modern tuffs, whole cities and their inhabitants having not infrequently been buried. At Herculaneum and Pompeii human bodies were completely encased in the fine mud from Vesuvius, which on hardening formed a perfect mold of the body, so that plaster casts could afterward be made from them.

Older Pyroclastic Deposits. From South America and from portions of the Great Plains of western North America, Tertiary xolian tuffs (Anemopyrolutytes) rich in the bones of mammals, have been described. In the Eocenic deposits of the Wind River Basin in Wyoming, a white tuff bed $\mathrm{I}_{3}$ feet in thickness lies interbedded with the Wind River sands and clays. (Sinclair and Granger-28:93 et seq.) It rests on a heavy brown sandstone containing rolled pebbles of tuff and is succeeded by greenish shales. In the upper 4 or 5 feet of tuff occurs much pumice; snow white grains from the size of bird-shot to small peas are found enclosed in a fine-grained gray matrix. The most abundant macroscopic mineral enclosed in the white pumice is biotite, while small fragments of feldspar are occasionally found. Under the microscope the fine felt-like mass of volcanic glass of the pumice encloses in the order of relative abundance: (I) orthoclase, often zonal, sometimes twinned, either with recognizable crystallographic boundaries, more or less broken, or in small laths; (2) plagioclase; (3) olive green biotite; (4) hornblende; and, (5.) black opaque grains, probably iron oxide. 
The lower part of the tuff consists of a finer grained mass, in which the round mass of felt-like glass fibers and wisps contains angular fragments of feldspar, quartz, biotite, and hornblende in greater abundance than in the upper part. Balls of hard green shale occur in the tuff and these and channel-filling of contemporaneous origin point to a fluviatile deposition of the material.

In the Bridger of the same region occurs a white tuff ranging in thickness from 25 to 75 feet which carries frequent lignitic beds varying in thickness from six inches to a foot. No clay, sand or gravel occurs as in tuffs of fluviatile origin, and it is believed that this bed is a lacustrine deposit. In regions where the tuff bed is absent it is replaced by arkose beds with clay pellets and apparently wind-blown pyroclastics, the whole traversed by tubules suggestive of root canals, and representing the terrestrial part of the accumulation.

In the Oligocenic of this region pyroclastic material is more pronounced. In the erosion troughs formed at the close of the Eocenic volcanic mud flows accumulated, beginning with a finegrained buff-colored tuffaceous shale, in which was found a skull of Titanotherium heloceras. This was followed by mud flows carrying large angular or rounded blocks of hornblende andesite, up to 3 or 4 feet in diameter and consisting of ash, pumice, lapilli and pebbles and cobbles of pre-Tertiary quartz, granite, and gneiss, forming an agglomerate 46 feet in thickness near Wagon-bed spring. Its distribution was controlled by the preëxisting valleys and so it is absent in many localities. Repeated flows seem to be indicated by what appear like channels of erosion in some of the older flows, filled with andesite cobbles embedded in gray ash. The volcanic eruption seems to have continued throughout the lower Oligocenic, showering the surrounding country with ash and dust. This in some localities accumulated to a thickness of over 500 feet. Locally this ash is quite unconsolidated, but, as a rule, it shows calcareous cementation and it may pass upward into a tuffaceous limestone. Angular fragments of more or less devitrified pumice, and sharp splinters of isotropic glass, make up more than fifty per cent. of the soft ash. The rest consists of angular fragments of plagioclase, orthoclase resembling microcline, hornblende, biotite and some quartz besides some other minerals. The quartz and microcline are believed to have been intermingled wind-blown material, from the gneiss débris which forms alluvial fans elsewhere in this region. Tuffs of volcanoes near or in the sea will contmonly enclose remains of marine organisms. Examples of these have 
been described from the Cambric of North America, and from other deposits. (See further, Chapter XXII.)

\section{AUTOCLASTIC ROCKS.}

We may define an autoclastic rock as made of the fragmental material resulting from the movement of one rock mass over another, both contributing from their substance to the clastic material, though, owing to different degrees of hardness, that furnished by one of the masses may be most prominent, while that contributed by the other may be almost if not wholly destroyed during the movements.

Classification of Autoclastic Rocks. According to the type of movements in the formation of an autoclastic rock we may classify the products as follows:

I. Exogenous, or those due to external forces, including:

a. Those due to compressive strains, $i$. e., thrust-fault breccias.

b. Those due to gravitational strains, comprising:

(I) Breccias, etc., formed by ordinary gravity or normal faulting subsequent to the formation of the strata, a secondary structure, and

(2) Breccias and brecciated structures formed by slipping or gliding of material during the process of accumulation under the influence of gravity, and resulting in the production of intraformational breccias, or, when the brecciation is incomplete, contorted stratification. Glacial deposits are best placed here.

2. Endogenous or endolithic structures, or those due to internal forces, including:

c. Those due to movements resulting from solution and recrystallization, as in ice, salt, etc.

d. Those due to increase or decrease in volume from hydration, carbonation, oxidation, etc., or the reverse, as in change of anhydrite to gypsum, or the removal of certain elements, as in dolomitization of limestones. The distortion of salt layers, of gypsum beds, and limestones producing the contorted structure which, from its resemblance to the coiled intestine, has been called enterolithic structure (German, Gekröse), may be cited as illustrations.

The more important types may be described in detail. 


\section{Fault Breccias.}

So far as understood, fault breccias due to thrusting and those due to gravitational readjustment are not essentially different in character, except that the former may frequently be parallel to the bedding planes of stratified rocks in which such thrusting has taken place, while the latter are likely to cross these planes at an angle. Both are, however, secondary features formed within the rock mass, after its deposition if not its consolidation. In these dynamic movements, autorudytes, autoarenytes, and autolutytes result, and they are often accompanied by the formation of slipping surfaces or slickensides. The coarser rocks of this type often simulate hydroclastics, owing to the fact that during the movement of the rock masses past each other the angles of the fragments were worn off and have become rounded by mutual friction. (Van Hise-30:679.) In this condition the bed may readily be mistaken for a hydroclastic conglomerate (hydrorudyte). Such beds have been termed pseudoconglomerates. Typical autorudytes or dynamic breccias consist generally of more or less angular fragments embedded in a matrix of crushed material. In all cases the autorudytes are composed of the material of the enclosing rock with the fragments derived from the most brittle of the beds from which it was formed. Thus an autorudyte formed from interstratified layers of limestone and quartzite will have its fragments mainly composed of the quartzite.

Since autorudytes so often simulate normal conglomerates, it becomes important to determine the criteria by which the two may be distinguished. For it is obvious that, if the former is mistaken for the latter, it will lead to an entirely erroneous interpretation of the history of that region. This is particularly the case where the autorudyte may be mistaken for a basal conglomerate. Alternating beds of shales or pure lutytes, and fine lutaceous arenytes or graywackes, may by deformation be broken up in such a manner that the arenytes yield pebbles, more or less rounded by mutual friction, while the shale flows and fills the spaces between the fragments. (Van Hise-30.)

The pseudo-conglomerate thus produced will have "a slate matrix and pebbles of graywacke [argillaceous silicarenyte] which, so far as its own characters are concerned, could not be discriminated by any one from a true conglomerate." (Van Hise-3o.) Autoclastic limestone pebbles of a rounded character are common in the Cambro-Ordovicic rocks of the Taconic region, and in other disturbed Palæozoics in many portions of the world. They are extremely characteristic of pre-Cambric rocks. 
The following criteria are given by Van Hise as aids in discriminating between autorudytes and true conglomerates (hydrorudytes):

I. "An autoclastic rock must derive its material mainly from the adjacent formation . . . from the superior formation as well as from the inferior. . . . In true basal conglomerates, on the other hand, while the material is very frequently derived in large measure from the immediately subjacent formations, they also usually contain a small proportion of material from various foreign sources, and . . . not . . . from the overlying formations, as may the autoclastic rocks."

2. "In an autoclastic rock, . . . the pebbles . . . will in many cases be found to be less rounded than in a true basal conglomerate. If . . . followed for some distance a considerable variation will frequently be found-fragments being here well rounded and there very imperfectly rounded. The well-rounded fragments are concentrated, as are also the angular fragments. A basal conglomerate, on the other hand, has a considerable uniformity in the degree of the rounding of its pebbles in passing along the same horizon, but at the same place the large fragments may be angular and the small ones well rounded . . ."

3. "In many cases the interstices of an autoclastic rock are filled with material of a vein-like character, whereas in a basal conglomerate the filling material is largely fine detritus. But sonetimes . . . the filling material of an autoclastic rock may be water-worn grains of sand, which have been separated by dynamic action, and are therefore indistinguishable from the ordinary matrix of a true conglomerate."

4. "In most instances a bed of autoclastic rock, if followed, may be traced into on ordinary brecciated or partly brecciated form. A basal conglomerate, on the other hand, if followed along the strike and dip, may change its character, but it will be a gradual change into the ordinary mechanical sediments, whereas an autoclastic rock is likely to have very sudden variations in character." (Van Hise-30:680-8I.)

\section{INTRAFORMATIONAL BRECCIAS.}

These are contemporaneous phenomena, formed as one of the sequential divisions of a single rock series. They are almost wholly confined to calcareous rocks, and seem to be most typical of calcilutytes or fine calcarenytes. Such rocks, composed largely of the 
finest lime-mut, accumulate in shallow water or in part even above the normal level of the sea. In form they probably constitute a sort of mud flat delta, the nuud being brought and spread out in part at least by streams, which must have derived it from the erosion of earlier limestones. Mud cracks or desiccation fissures testify to the shallow water in which these sediments were accumulating. On exposure partial hardening permits the formation of a supcrficial crust, which may subsequently break or become deformed by the sliding of the entire mass seaward. Such sliding has been observed in modern deposits as discussed more fully in Chapter XX.

Fracturing and Piling Up of Material. If the surface layers alone slide, a fracturing will result which produces a mass of angular or subrounded flat mud-cakes, which will be piled together, as the result of this sliding, in a confused mass, the fragments most frequently standing on end, but also inclined in all directions. They will be surrounded by the fine still fluid mud which wells up around them and in which these fragments become embedded. Thus is formed an "edgewise conglomerate," as these accumulations have come to be known, a contemporaneous feature abounding in the finer calcilutytes and calcarenytes of all horizons. Both the cakes and the enclosing matrix may contain organic remains; the former would carry such fine organic fragnents as sponge spicules, plant fibers, etc., which may be washed in with the mud or may exist in the water in which it is deposited, while the matrix becomes normally fossil-bearing since it is a part of the submerged deposits. Professor Seeley (24) (Brown-1) has considered the cakes, as a whole, due to organic growth, and described them under several species of the new genus Wingia. The intraformational conglomerates described by Walcott (3I), though mostly of a much coarser character, probably in part represent such gliding conglomerates. Examples where such cakes of lime-mud carrying fossils were formed through fracturing on drying have been described by Hyde (I6) from the Coal Measure limestones of Ohio. In these cases, however, no sliding seems to have occurred, the fragments being embedded where formed. These "desiccation conglomerates" will be referred to again in Chapter XX.

Distortion of Layers in Gliding. If a large mass of rock slides there will be less of fracturing and more of distortion of the layers along the gliding zone and this will be pronounced in proportion to the weight and compactness of the beds overlying the gliding plane. Good examples of such distortion are found in the Trenton limestone of New York (Hahn-12) as exposed in the gorge at Trenton 
Falls, where several such layers are visible. It is also well shown in the fine calcilutytes of the Solnhofen beds (Jurassic) of Bavaria, a formation shown by many characters to be of shallow water origin. (See further, Chapter XX.)

\section{Gracial Deposits.}

If we consider ice as water in the solid form, glacial deposits must be classed under the hydroclastic division of rocks. It is manifest, however, that the essential features of glacial deposits are those which most strongly differentiate them from ordinary hydroclastics, be they fluvial, lacustrine, or marine. In some characters they may resemble atmoclastic and in others autoclastic deposits, but their most marked characteristics are not shared with any other type. Nevertheless, the method of formation of the most typical glacial clastics is closely analogous to that of autoclastic fault breccias. Both are produced by the movement of one rock mass over another, for ice in this relation has the essential characters of a solid rock, and both furnish material for the resulting rudyte or finer rock, though that furnished by the ice is readily destroyed. It is true that material not produced by mutual attrition of the two rock masses, the basal rock and the ice rock, may be, and commonly is, incorporated in the subglacial material, but this merely points the essential peculiarities of this autoclastic rock. It is also true that the movement of glaciers cannot be directly compared with that of rock masses involved in faulting, in so far as it is a gliding partly due to internal forces as well as to gravity. Still the essential fact remains, that clastic material is produced by the movement of one rock mass over another and that both rock masses contribute from their substance to the production of this material. In this respect, then, glacial débris may be compared, on the one hand, with that formed by gravity faulting, and, on the other, with that formed by gliding masses resulting in the production of intraformational breccias. Since the ice also moves by constant internal readjustments from recrystallization, the products of such motion may to a certain extent be compared with enterolithic deformations.

Characters of Modern and Pleistocenic Glacial Deposits. The material resulting from the plucking and abrasive action of the ice varies in grain from the finest rock flour to boulders of almost unlimited size. Except where disintegration of the rock surface previous to glaciation has occurred, the fine material will all be rock flour with clay notably absent. The arenaceous material also shows in its angularity and sharpness of grain that it has been 
produced by mechanical crushing of fresh rocks. Such sand, from the Mer-de-Glace, Switzerland, shows sharp, fresh, angular fragments with the barest traces of weathering, and very little wear. The composition is varied, and the assortment very poor. The quartz grains of glacial sands show the characteristic conchoidal fracture, sharp edges and keen points. Cleavable minerals show fresh, clean surfaces and little, if any, trace of internal decomposition. In composition the variation is very great, dependent, of course, upon the original character of the rock ground up by the ice. The assortment according to size is also very marked.

Till or boulder clay is an intimate mixture of rock flour and glacial sand, together with a varying per cent. of clay derived from rocks decomposed prior to glaciation. Crosby holds that very little of the original residuary soil is incorporated in the till covering New England, for the color of this till is bluish and shows no traces of oxidized material below a certain level, where recent oxidation has been active. "Experiments show that an admixture of a very small proportion of highly oxidized residuary clay, like that of the south, with a typical till, is readily detected in the change of color." (Crosby-7:232.) In the most typical till, i. e., that due wholly to glacial erosion of a country from which all decomposed material is absent, the amount of kaolinite is extremely slight, all the finer material being rock flour due to mechanical crushing. An analysis of till from drumlins of the Boston Basin, from Somerville to Nantasket, gave Crosby the following results expressed in percentages of the total material exclusive of the boulders and other stones over 2 inches in diameter (Crosby-6) :

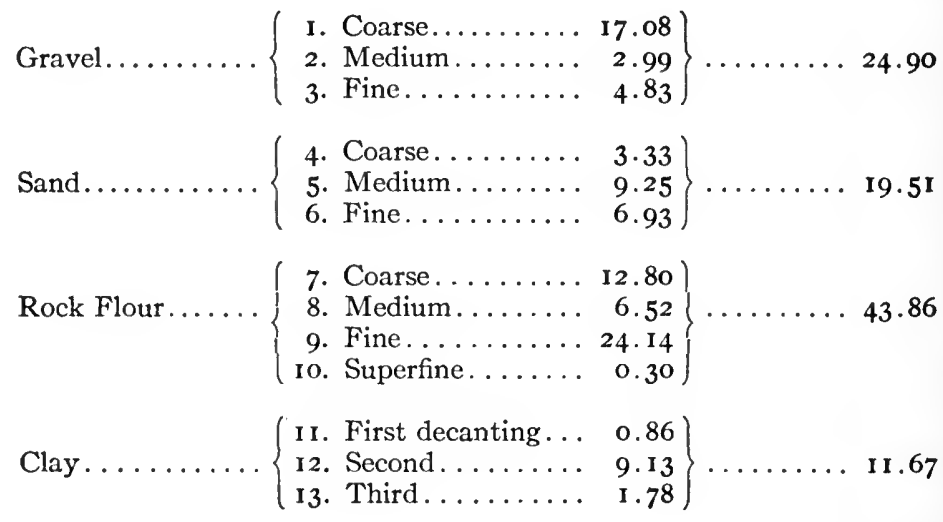


Thus, after exclusion of the larger stones the till consists of about $25 \%$ of gravel, $20 \%$ of sand, 40 to $45 \%$ of extremely fine sand or rock flour and only about $\mathrm{I} 2 \%$ of clay. (See also Ries-I9.)

The intimate admixture of coarse and fine material in the unmodified glacial drift or till renders its pore space of the slightest and so makes it an admirable impervious layer, through which ground water cannot penetrate. This is well shown in the unoxidized character of much of the till, its color when freshly excavated being of a bluish slate. Only the surface layers, or some included layers of modified sand or gravel, may show such oxidation. Modified till differs mainly in the somewhat worn character of the granules, the progress of weathering in the decomposable minerals and the better assortment of the material according to size. With this comes increased pore space and consequently penetration of ground water accompanied by oxidation, and a change to ochery or brown colors. All gradations may be observed, from the slightly modified drift barely moved by the waters from the melting ice sheet, to the much worn and fairly well-assorted material of the glacial streams, which quickly assumes all the characteristics of water-laid deposits and must be classed with the hydroclastics.

The pebbles and boulders of the glacial drift also show distinctive peculiarities. One essential is their imperfectly worn character. Most commonly they are in the form of flattened masses highly polished and striated on the flat faces, but angular or but slightly worn on the other sides. Rounded boulders are the exception. In size they vary enormously, and this is often true for the lithologic character as well. Crosby has found that much of the coarse material of some New England deposits was of comparatively local origin, these deposits, moreover, having been subject to a certain amount of transportation by water. Of some tons of material coarse enough for ready identification about 5o per cent. came from a belt of rock extending for 13 miles north of the deposit, and 40 per cent. from the next 8 to Io miles, while only Io per cent. came from distances greater than 23 miles $(7: 23 I-2)$.

Transportation of the coarser material by glacial streams results in more or less perfect rounding of the boulders, and the effacement of the striations on the surface. Moreover, the attendant assorting of the material according to size will result in the greater concentration of such bouldery deposits, whereas in the true till the boulders are scattered and embedded in the finer material.

Boulders of ice as well as ice sand derived from the gliding ice, 
mass are apt to be incorporated in the forming deposit, but such boulders are by virtue of their composition subject to speedy destruction. As a result a depression will be formed in the glacial deposit, due to the caving-in of the overlying material into the hollow left by the vanishing ice boulder. Such kettle holes are common in both modified and unmodified glacial deposits and serve to identify them as such.

\section{Ancient Glacial Deposits.}

Boulder clays and modified glacial deposits are found at a number of geological horizons from the pre-Cambric onward. The rock formed by the consolidation of such deposits is known as tillite and its essential character is found in the heterogeneous mixture of the material, the absence of stratification and the striation of the larger blocks, and the fragments of dense texture. Several of the more prominent cases may be discussed in some detail.

The Pre-Cambric Tillite of Canada. In the Lower Huronian of the Cobalt region in Canada an extensive boulder bed and tillite have been found, indicating glacial origin. (Coleman-2, 3, 4, 5.) The tillite is a consolidated boulder clay or till and the boulders are angular or subangular, and not infrequently striated, but no striation of the underlying rock has yet been observed. The boulders are often 2 or 3 feet or more in diameter and distant a couple of miles from the exposures of the rocks. Some of the boulders of this conglomerate are tons in weight, and the areal extent of the mass has been traced over I,O0O miles east and west and 750 miles north and south, while the thickness at Cobalt is about five hundred feet. The boulder clay of this horizon and that of the Permo-Carbonic and other regions is almost indistinguishable in hand specimens or in thin sections under the microscope. Some stratified slaty beds have been found at Cobalt in the great mass of unstratified conglomerate suggesting a possible interglacial period. The glacial origin of these has been questioned by Knight (I7) and others.

Cambric Glacial Deposits. These have been recorded from northern Norway, where in the Varanger fjord an unstratified tillite with striated boulders rests upon a striated rock surface of the preCambric Gaisa series and is succeeded by beds of Cambric age. (Strahan-29.) From the Yantzi Canyon in China, lat. $3 \mathrm{I}^{\circ}$, Bailey Willis (33) has obtained striated boulders occurring in tillite perhaps I 50 feet thick and overlain by Middle Cambric marine deposits. Still more striking and better known are the Cambric tillites of South 
Australia (lat. $30^{\circ}$ to $43^{\circ}$ S.). (Howchin-14, I5; David-8, 9.) They extend for 460 miles from north to south and 250 miles from east to west, and have a thickness of I,500 feet. Numerous boulders and pebbles showing glacial stria have been obtained (see the figures given by Howchin-15), the character of these boulders indicating a southward movement. Intercalated with the tillite are beds of linestone and radiolarian beds. No striations have been found on the underlying rocks. (David-8, 9.)

In South Africa (lat. $29^{\circ} \mathrm{S}$.) tillite of late pre-Cambric or early Cambric age forms a part of the Griquatown series of Cape Colony, occurring over alnost 1,000 square miles. It contains typical scratched boulders.

The Permic Glacial Deposits. These have been observed in India, Australia, South Africa (Davis-Io; Schwartz-2I), and South America (White-32). The South African deposit constitutes the Dwyka conglomerate, the lowest member of the Karoo formation (Davis-10:700). It varies in thickness up to 1,000 feet or more and extends from the Indian Ocean between $29^{\circ}$ and $33^{1} \%^{\circ}$ south latitude northward approximately to Belfast, westward to the Vaal River and thence in latitude $29^{\circ}$ to within less than a hundred miles of the Atlantic, and southward to within about 150 miles of Capetown. Its former extent was apparently much greater. "It rests for the most part unconformably on a grooved and striated surface of older rocks, but along its southern border it follows conformably a series of sandstones and shales. It consists chiefly of an unstratified and consolidated clastic ground mass with subangular or rounded scraps, stones, and boulders of many kinds, the finer textured stones and boulders being usually well scratched. It is conformably overlaid by a coal-bearing series of shales and sandstones." (Davis-10:400.)

"The glacial origin of the Dwyka formation is as unquestionable as is that of the drift sheets of northeastern America or of northwestern Europe; but the Permian ice-sheet, by which the Dwyka was formed, moved in general southicard, from the region of the equator toward the region of the pole." (Davis-10: OI. $^{\text {) }}$ The indications are that the Dwyka ice "was a broad and continuous ice sheet which spread across about 600 miles of country, east and west, and which advanced at least 500 miles poleward from its apparent source. It moved across a region which bore subdued mountains here and there. but which was reduced to moderate relief by previous erosion over large areas." (Davis-10:4I.3.)

Along its southern margin in latitude $33^{\mathrm{I} / 2^{\circ}}$ south it invaded a water-covered area. A number of fluctuations are recorded, and 
upon the final recession a climate favoring a luxuriant growth of plant life succeeded, as testified to by the coals of the overlying Ecca formation. "Demonstrably marine deposits are nowhere associated with the Dwyka," not even where it "repeatedly reaches the shore of the Indian Ocean"; but marine Devonic fossils occur in the Bokkeveld series 2,500 feet or more below the basal member of the Dwyka in the Karoo district, while between them lies the conformable Witteberg series, forming the transition from marine to glacial continental. The structural evidence shows that mountains were absent at this time, though high lands existed which supplied the material of the Karoo formation.

Davis has presented the facts which show that neither great elevation nor changes in land area or land form were able to produce a glacial climate in subtropical South Africa, nor could any conceivable arrangement of ocean currents produce it. General refrigeration alone, either by a decrease of solar radiation or by a change in the constitution of our atmosphere, without shifting of wind belts, would have to be so extreme as to reduce the summer temperature of South Africa to such an extent that the summer rains would become summer snows, while the winters would still be dry, and extremely cold. Such a refrigeration would freeze up all the temperate lands of the globe and would hardly be in harmony with the rich marine and land life of the Permic deposits found in these regions, nor with the evidence of warm climate furnished by arid deposits of this period in other regions. A shifting of the pole, as elsewhere suggested, to such an extent that it would lie somewhere in the Indian Ocean would account satisfactorily not only for the Dwyka conglomerate, but also for the Talchir glacial formation of northwestern India, the movement of the glaciers forming this being, like those which formed the Dwyka, away from the equator, but in the opposite direction. It would also account for the Muree glacial formation of southeastern Australia.

Koken ( I $7 \mathrm{a})$ has discussed this question at length, with special reference to India, and he gives a map of the world showing the possible position of the poles at that time under the theory of polar displacement. He places the North Pole near Tultenango. Mexico (lat. $20^{\circ} \mathrm{N}$., long. $100^{\circ} \mathrm{W}$., of to-day), and the South Pole in the middle of the Indian Ocean (lat. $20^{\circ}$ S., long. $80^{\circ}$ E., of to-day).

\section{Endolithic Brecciation.}

Endolithic brecciation, or the shattering of the strata by forces at work within the rock mass itself, is best shown in formations 
containing anhydrite, which by hydration is changed to gypsum. This process involves an increase in volume, estimated by some (Credner, Fritsch, Bauer, Geikie) as low as 33 per cent., and by others (Naumann, Zirkel, J. D. Dana) as high as 60 per cent. J. Roth, indeed, has calculated that the increase in volume resulting when anhydrite takes up two molecules of water of crystallization to form gypsum is as high as 62.3 per cent.

It is probably true that calcium sulphate is largely deposited in the anhydrous state, especially when it originates under arid conditions (see ante, Chapter IX). Certain it is that anhydrite abounds in many of the older strata along with gypsum, and it is not improbable that in such cases the gypsum is the result of hydration of the anhydrite. In view of the great force exerted within the rock mass by the expansion due to this hydration, we would expect to find the results in a shattering and deformation of the enclosing strata. This expectation is commonly realized, for such endolithic brecciation is a frequent if not constant accompaniment of gypsumbearing strata, especially in the Palæozoic. Cases have been described from the Salina and Monroe beds of New York, Ohio, Michigan, and Canada. (Grabau and Sherzer-11:29; Kraus$18: 167-171$.) Brecciation of this type is not uncommon in salt deposits, where through recrystallization a pronounced pressure results, which may even affect the enclosing strata, deforming and disrupting them. This subject will be more fully discussed in the chapter on diagenism.

\section{BIBLIOGRAPHY XII.}

I. BROWN, THOMAS C. I9I3. Notes on the Origin of Certain Palæozoic Sediments, Illustrated by the Cambrian and Ordovician Rocks of Center County, Pennsylvania. Journal of Geology, Vol XXI, pp. 232-250.

2. COLEMAN, A. P. 1907. A Lower Huronian Ice Age. American Journal of Science, $4^{\text {th }}$ series, Vol. XXIII, pp. I87-192.

3. COLEMAN, A. P. I908. Ancient Ice Ages and Their Bearing on Astronomical Theories. Journal of the Astronomical Society of Canada, Vol. II, No. 3, pp. 132-I35.

4. COLEMAN, A. P. I908. The Lower Huronian Ice Age. Journal of Geology, Vol. XVI, pp. I49-I58.

5. COLEMAN, A. P. 1908. Glacial Periods and Their Bearing on Geological Theories. Bulletin of the Geological Society of America, Vol. XIX, pp. $347-366$.

6. CROSBY, WILLIAM OTIS. I89I. Composition of Till or Boulder Clay. Boston Society of Natural History Proceedings, Vol. XXV, pp. II 5-I 40.

7. CROSBY, W. O. 1896. Englacial Drift. American Geologist, Vol. XVII, pp. 203-234. 
8. DAVID, T. W. EDGEWORTH. 1903. Australasian Association for the Advancement of Science. Report of the Ninth Meeting, pp. 199-200.

9. DAVID, T. W. E. 1906. Glaciation in Lower Cambrian, Possibly in Pre-Cambrian Time. International Geological Congress. Compte Rendu, Mexico, pp. 27I-274; 275-298.

10. DAVIS, WILLIAM MORRIS. 1906. Observations in South Africa. Bulletin of the Geological Society of America, Vol. XVII, pp. 377-450.

I I. GRABAU, AMADEUS W., and SHERZER,WILLIAM H. 1910. Monroe Formation of Michigan. Michigan Geological and Biological Survey, Publication 2.

12. HAHN, F. FELIX 1912. Untermeerische Gleitungen bei Trenton Falls (Nord Amerika), und ihr Verhältniss zu Ähnlichen Störungsbildern. Neues Jahrbuch für Mineralogie, Geologie und Palæontologie, Beilage Band XXXVI, pp. I-4I, pls. I-III.

13. HATCHER, J. B. I900. Sedimentary Rocks of South Patagonia. American Journal of Science, $4^{\text {th }}$ Series, Vol. IX, pp. 85-108.

14. HOWCHIN, WALTER. I903. Report of South Australian Glacial Investigation Committee. Australasian Association for the Advancement of Science. Report of the Ninth Meeting; Hobart, Tasmania, 1902, pp. 194-r99.

14a. HOWCHIN, WALTER. 1906. The Geology of the Mount Lofty Ranges, Part II. Transactions and Proceedings and Report of the Royal Society of South Australia, Vol. XXX, pp. 227-262 (especially pp. 228-234).

15. HOWCHIN, W. 1908. Glacial Beds of Cambrian Age in South Australia. Quarterly Journal of the Geological Society of London, Vol. LXIV, pp. 234-263, pls. XIX-XXVI.

16. HYDE, JESSE E. 1908. Desiccation Conglomerate in the Coal Measure Limestones of Ohio. American Journal of Science, 4th series. Vol. XXV, pp. $400-408$.

17. KNIGHT, CYRIL W. 1909. On the Lower Huronian Ice Age. Canadian Mining Journal, Vol. XXX, pp. 727-728.

I7a. KOKEN, E. 1907. Indisches Perm und die Permische Eiszeit. Neues Jahrbuch für Mineralogie, etc. Festband, pp. 446-546. Map.

18. KRAUS, EDWARD H. 1905. On the Origin of the Caves of Put-inBay Island, Lake Erie. American Geologist, Vol. XXXV, pp. I67-I 7 r.

19. RIES, HEINRICH. 1906. Clays, Their Occurrence, Properties and Uses. John Wylie and Son.

20. ROGERS, A. W. r9o5. An Introduction to the Geology of Cape Colony. London.

21. SCHWARTZ, ERNEST H. L. 1906. The Three Palæozoic Ice Ages of South Africa. Journal of Geology, Vol. XIV, No. 8, pp. 683-69r.

22. SCUDDER, SAMUEL H. r882. The Tertiary Lake Basin of Florissant, Colorado, between South and Hayden Parks. United States Geological and Geographical Survey of the Territories, Vol. VI, pp. 279-300.

23. SCUDDER, S. H. I 883. Ibid., I2th Annual Report, pp. 27 I-293.

24. SEELEY, A. r 906 . Geology of Vermont. Report of the State Geologist for 1906, pp. 174-78.

25. SHERZER, W. H. I9Io. Criteria for the Recognition of Sand Grains. Bulletin of the Geological Society of America, Vol. XXI, pp. 625-662.

26. SINCLAIR, WILLIAM J. 1906. Volcanic Ash in the Bridger Beds of Wyoming. Bulletin of the American Museum of Natural History, Vol. XXII, pp. 273-280. 
27. SINCLAIR, W. J. 1909. The Washakie, a Volcanic Ash Formation Ibid., Vol. XXVI, pp. 25-27.

28. SINCLAIR, W. J., and GRANGER, WALTER. I9II. Eocene and Oligocene of the Wind River and Big Horn Basins. American Museum of Natural History Bulletin, Vol. XXX, pp. 83-I I7.

29. STRAHAN, AUBREY. I897. The Glacial Phenomena of Palæozoic Age in the Varanger Fjord. Quarterly Journal of the Geological Society of London, Vol. LIII, pp. 137-I 46, pls. 8-10.

30. VAN HISE, CHARLES R. I 896. Principles of North American PreCambrian Geology. I6th Annual Report of the United States Geological Survey, part I, pp. 58I-872.

31. WALCOTT, CHARLES D. I 894. Intraformational Conglomerates. Bulletin of the Geological Society of America, Vol. V, pp. I9I-I98.

32. WHITE, DAVID. 1907. Permo-Carboniferous Climatic Changes in South America. Journal of Geology, Vol. XV, pp. 6I 5-633.

33. WILLIS, BAILEY. 1907. Researches in China, Vol. I, part 1. Carnegie Institute of Washington Publications. 


\section{CHAPTER XIII.}

\section{ORIGINAL STRUCTURE AND LITHOGENESIS OF THE ATMOCLASTIC}

AND ANEMOCLASTIC ROCKS

\section{A. ATMOCLASTIC ROCKS.}

Typical atmoclastic rocks owe their origin entirely to disintegration or disruption of older rocks, while the accumulation and arrangement of this material are brought abont by atmospheric agencies under the influence of gravity. The most typical atmoclastic rocks are those produced in situ by subaërial decay and not subsequently disturbed. Here belong the laterite and kaolinite, the formation of which was described in Chapter II, pp. 37, 39. Taken by itself, such rock may show a complete absence of stratification and a gradation in texture from coarse blocks next to the unaltered rock to fine soil and humus at the surface where disintegration and decomposition affect rocks of uniform grain such as granites or other holocrystallines. A downward gradation into the older rock may be pronounced which, if the upper layers are reworked by water or other agencies, forms an apparent transition bed between widely distinct formations. The products of atnıospheric disintegration may become rearranged by flowing, sliding or gliding under the influence of gravity. The talus at the foot of a cliff is an example of such rearrangement. The surface gradient of such an accumulation is generally ligh, varying from 60 degrees or over in the coarsest series to 23 degrees or even less in the fine-grained series.

Stagnant atmoclastic material is the exception; in general movement to lower levels occurs. When more or less saturated with water, the angle of slope is correspondingly lowered, and the talus approaches more and more the character of an alluvial fan. The atmoclastic sediments then grade into the hydroclastic or aqueous type. If, on the other hand, the wind is a factor in rearrangement and deposition of the material, this becomes an anemoclastic rock and has to be treated as such.

The waste of the land is on the march to the sea. Everywhere 
the loose rock débris is streaming toward the ultimate repository, the sea, or to the rock-rimmed desert basins of the earth, from which in many cases there is no escape. This great w'aste stream, as it has been aptly termed, covers much of the surface of the land, and may consist wholly of débris, or of débris and water in varying proportions. As the amount of water increases the fluidity of the mass rises, and the rate of its motion is increased, while the angle at which graded conditions prevail is decreased. Thus where the material is pure waste the angle will commonly be more than 20 degrees, and steeper in proportion as the material is coarser. Furthermore, the material of the talus heap is constantly undergoing disintegration, and, as it becomes finer, the potential angle of slope is lowered. The actual lowering will be accomplished by a process of "creep," which is often greatly aided by frost action and by temporary saturation with water, which may become instrumental in suddenly lowering the angle through landslides.

The totality of the deposits formed by subaërial agencies on the plains in front of the mountains is classed as piedmont waste deposits. They may be formed wholly by "dry creep" from the mountains, or, as is most generally the case, by combined creep and the wash of mountain streams. Alluvial fans or dry deltas thus form the connecting link between the atmoclastic and the hydroclastic types of deposits, for, though strictly belonging to the fluviatile division of the latter, they partake of many of the characteristics of the former, and are indeed partly produced by subaërial creep. (Walther-52; Penck-37:25; Barrell-2.)

\section{Characteristics and Occurrence of Modern Atmoclastic Formations.}

Extensive recent formations of atmoclastic origin are found only in the comparatively arid regions of the world, and as these are the last which have come under the detailed observation of the geologist, though they cover about a fifth of the land surface of the earth, their significance with reference to the former history of the earth has been largely overlooked. It is only within recent years that the desert regions of the world have been studied in detail and their phenomena applied toward the interpretation of the genesis of older formations of the earth's crust. So long as the destructive powers of the atmosphere and streams were regarded as their chief attributes, while the sea was held to be the chief receptacle of the product of this destructive activity, it was natural that the marine 
origin of all formations should be considered axiomatic, except where fossils indicated fresh water, in which case fresh-water lakes or inland seas of any desired magnitude were postulated as the medium in which these formations were deposited. Now, however, that we have the extensive observations on the subaërial origin of formations of great thicknesses, embodied in the epoch-making works of Walther and others, there is no longer any excuse for accepting the time-worn marine or fresh-water lake origin of all the sedimentary formations. It becomes more and more apparent that, where formerly marine conditions were regarded as the only possible ones for the deposition of certain formations, desert conditions are often the more probable explanation, while formations generally referred to a lacustrine origin prove in many cases to be subaërial deltas and flood-plain deposits of streams or the accumulation of wind-transported material upon a relatively dry land surface. It is no longer one of the axioms of the stratigrapher that all stratified deposits were laid down under water; in fact, we must be prepared to question the subaqueous origin of all formations that do not show by the occurrence of either marine or fresh-water fossils throughout that they were formed under water. The possibility of the existence of unfossiliferous subaqueous formations is not excluded, and the subsequent destruction of the organic contents of the formation must be considered. At the same time the possibility of a subaërial origin of all unfossiliferous clastic formations, or of those containing marine or fresh-water fossils only at great intervals, must be borne in mind, while the occurrence of remains of terrestrial organisms should be considered as prima facie evidence of subaërial origin of the formations containing them until their subaqueous origin is positively established.

Texture of Atmoclastic Rocks. Among the characters of atmoclastic rocks should first be mentioned their coarseness of grain, especially near the mountains from which the material has been obtained. In the talus region the material will not only be coarse, but the blocks will for the most part be angular. Often the structure is suggestive of morainal accumulations. (Walther-52: 103.) Large and small, round and angular blocks abound in the sandy ground mass with a total absence of sorting, the result of the indiscriminate piling together of the material by the tremendous flood rains of the desert. The evidence of violent impact is further shown by the abundance of concussion marks and the total absence of the woody vegetation which is ground to fragments and washed away by the floods. Portions of the delta built by less violent floods show interbedded, well-stratified, sandy layers, and these become 
more characteristic at a distance from the mountains, where they also are finer grained and frequently clayey. On the surface of the dry delta the coarse blocks gradually give way to finer, rounded, flat or irregularly worn pebbles, with streams of coarser material between the finer gravel, and with at intervals flat surfaces of lutaceous material (playas or takyrs) beautifully marked by polygonal sun cracks.

Mojement of Atmoclastic Material. The movement of atmoclastic material is twofold. There is, first, the quiet, more or less continuous creep and flowage of the material under the influence of gravity, and conditioned by the change from coarse to finer material under the disintegrating atmospheric influences. Secondly, there is the sudden movement, exemplified by landslides or rock avalanches. These are very generally conditioned by a saturation of the rock débris on a mountainside by water, which thus renders the mass more fluid and lowers the potential angle of stability. A third type of movement may be considered as combining the claracteristics of both of the preceding types, and thus representing a compound of gliding and creeping movements. Sliding of rock and soil as the result of earthquakes may also be considered here.

\section{Slow Movements of Rock and Soil.}

Rock and Soil Creep. The creep of soil is always a slow process. It scarcely affects the surface, which is covered by a blanket of vegetation, beneath which the maximum movement takes place. Götzinger (18) holds that creep is largely due to the work of saturating waters which increase the volume of the mantle rock and set it in motion by forcing the particles upward and outward, this motion being translated into a maximum one down the slope of the surface on which the soil rests. Frost is, of course, an important agent in causing the downhill movement of the soil cover. If such creep takes place over inclined or vertical beds of rock, the upper ends of these beds will suffer overturning or bending in the direction of the creep.

Solefluction or Rock Flow. To the more rapid movement of the rock débris saturated with large quantities of water, the name solefluction has been applied (Anderson-I). This was first described from Bear Island in the North Atlantic (lat. $741^{1 / 2}$ $\mathrm{N}$.), where on account of the hard winters much rock débris is produced by mechanical weathering. The melting of extensive snow masses in spring produces a large quantity of water, which trans- 
forms the surface material into a pasty mass, and this under the influence of gravity will move slowly down even gentle slopes, the movement being a flowage at a rate much exceeding that of the slow, subaërial creep. Along the valleys mud streams or mud glaciers are formed, the movement of which may be prolonged during a considerable period of time. Such mud streams consist of material of all sizes from the finest grains to huge, angular blocks. The rapidity of movement of the mud streams of Bear Island is shown by the fact that vegetation rarely gets a foothold on these masses of débris. The width of the mud streams of Bear Island ranges up to 35 meters and the depth to about 2 meters.

The "stone rivers" of the Falkland Islands form other examples of such atmoclastic accumulations. (Darwin-II.) Valleys here are filled by gray masses of rock débris, with a width of several hundred meters to several kilometers, and having from a distance a glacier-like aspect. Beginning in the uplands, they descend to the low country, several streams uniting, until finally the entire mass debouches into the sea. The streams include vast accumulations of quartzite blocks of irregular form, though parallelepipedal forms predominate. In length they vary from $1 / 2$ to 7 meters, the width being half as great, while their thickness depends on that of the original beds of the parent rock from which they are derived. These blocks are angular and are piled one above another in an irregular manner. It has been held that these streams, which are now mostly covered by vegetation, came into existence when the Falkland Islands were experiencing a rougher climate, comparable to some extent to that of Bear Island to-day. The original arrangement of the strata into hard quartzite beds enclosed in soft layers is considered as having a fundamental influence on the formation of these rock streams, this arrangement being the usual one where such streams are well developed.

Stone glaciers, a modification of the rock stream phenomenon, have been described from Alaska (Capps-7). They vary in length from one to five kilometers, and in width from 100 to 500 meters. The angle of surface slope varies from 9 to 18 degrees, and the size of the rock fragments averages $20 \mathrm{~cm}$. for porphyry, but more for diorite and limestones and less for slates. Blocks several feet in diameter also occur. In form these stone glaciers resemble true glaciers, being thickest in the center, where they also show evidence of more rapid motion. Frontally these glaciers end in a face up to 30 meters in height and having a slope generally of $35^{\circ}$, the maximum slope of material of such coarseness. The whole aspect of the mass suggests motion. 
The interstices between the blocks are occupied by ice at a short distance beneath the surface, and the freezing and rethawing are in large part responsible for the present movement.

The original accumulation of these rock glaciers was believed to be due to a large extent to transportation of the rock masses by true glaciers and their deposition along the path of the glacier, rather than at the front in a moraine. Some modern ice glaciers of this region pass downward into rock glaciers, and furnish a suggestion of the mode of origin of those accumulations. Rock streams thought to owe their origin in part to ice glaciers were described by Howe (24) from the San Juan Mountains in Colorado, while others observed in Veta Peak, Colorado, were found to be wholly independent of ice work. In the San Juan Mountains these streams are found in the valleys in the higher peaks, and they are tongue-like, having a length ranging up to one kilometer and a wilth up to 600 meters, while the thickness ranges from 20 to 40 meters. The inaterial is a mixture of large and small angular blocks, the largest having a diameter of 5 meters. A sharp demarcation exists between the stone streams and the talus of the rock walls, from the foot of which the stream starts. The rock stream of Veta Peak is remarkable in that it consists of fragments of a whitish porphyry derived from the summit of the mountain, and, although the rock stream passes down between banks of red shale and sandstone for a distance of 1,700 feet or more, not one particle of any other kind of rock than porphyry is to be seen. The porphyry fragments are of approximately uniform size, fine material being for the most part wanting. Only a few large fragments occur, the average size being from $I$ to 2 feet in diameter, only one over 6 feet having been noted. The length of the stream is something over a mile, while the drop of the surface from the head to the foot of the stream in that distance is about 2,200 feet. The width in the lower part of the stream is 500 feet, but its two feeding branches are each about $\mathrm{I}, 000$ feet wide above the junction. The depth is estimated at from I3o to 300 feet.

\section{Rock Slides and Falls.}

These are common in nearly all mountain regions. They may occur in the surface soil and débris which cover the slope, and in the decomposed rock masses of the mountainside, or they may occur in fresh rock. In the former case, saturation by water is commonly a preliminary occurrence, the slide occurring when the inertia and friction of the rock masses are overcome. Such slides leave con- 
cave scars in the mountainsicle and accumulate in convex masses in the valley bottoms.

Such a rock fall in one of the upper Ganges branches in the Himalayas brought down $800,000,000$ tons of rock in three days, filling the narrow valley to a depth of a thousand feet with débris. (See ante, p. 127.) The rock fall here was facilitated by the loosening and undermining of the sloping strata of rock.

A remarkable case of rock fall occurred in the little town of Frank, Alberta, Canada, in 1903, where the Cretacic sandstones and shale of Turtle Mountain suddenly gave way and fell into the valley below, forming a huge heap of débris, which spread out in the valley bottom. The cause of the slide was the loosening of the mass through coal-mining operations.

In I88I a great rock fall occurred in the village of Elm in Switzerland. Loosened by undermining in a slate quarry, a huge mass of rock broke away on the mountainside and fell onto the platean in which the quarry was situated. Striking this surface, the mass broke, and numerous large fragments were hurled by the impact through the air, and fell into the valley below, where they formed a rock stream which in all essentials resembles that of the Alaskan region above described. (Heim-20.)

In both of the above-mentioned cases of rock falls or slides the fragments showed percussion marks, while chips were sometimes split off as with a hammer. The recent extensive rock slides of the Panama Canal are other examples of such phenomena.

Rock and Soil Slides Started by Earthquakes. Slides are not infrequently started by earthquakes, especially where slopes are steep and the material more or less water-soaked. As a result of the earthquake of November I6, I9I I, a portion of the shores of the Lake of Constance (Bodensee) sank into the sea. The lake border (Seehalde) was deformed for a total length of about $16 \mathrm{~km}$; on the left for a distance of $10 \mathrm{~km}$. to the extent of $\mathrm{x} / 2 \mathrm{~km}$., and on the right shore for a distance of $6 \mathrm{~km}$. length to the amount of about $I I / 2 \mathrm{~km}$. The edge of the sublacustrine shelf was locally translated 2.4 to $18 \mathrm{~m}$. lakeward, the point of abrupt descent (Absturztiefe) was moved between $\mathrm{I} .4$ to $8 \mathrm{~m}$., the elevations on the border of the break rose from 0.2 to $2 \mathrm{~m}$. In the expansion about 9,000 cubic meters of rock and soil material were moved.

\section{Ancient Examples of Rock Streams and Slides.}

Many brecciated rock masses occurring in older geological formations, of which the explanation is in doubt, may here find an 
interpretation. Known examples of this type are the Siluro-Devonic breccias of Mackinac and vicinity in Michigan, the limestone breccias of Gibraltar, the rubble drift of south England and the rock streams of the Ural in the vicinity of the mines of Bakalsk.

Tine Mackinac Limestone Breccia. (Grabau-r 8.) This is a remarkable example of a breccia made up of large and small angu-

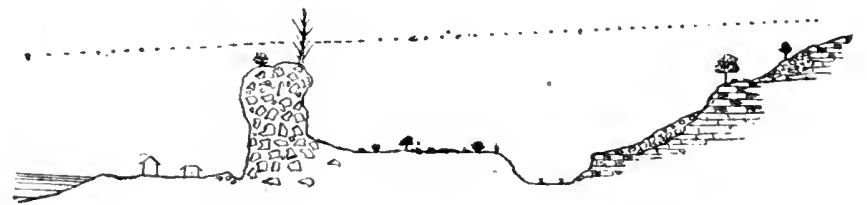

FIG. 117. Diagram illustrating the relation of the brecciated limestone to the bedded rocks at St. Ignace, Michigan. The stack is shown again in Fig. 118. The dotted line represents the hypothetical former extent of the brecciated material.

lar fragments of finely bedded upper Siluric (Monroan) limestones and dolomites, derived from a still intact cliff of this limestone near St. Ignace in the Upper Peninsula. The deposit is best seen in the cliffs of Mackinac Island, nearly the entire mass of which seems to be composed of this rock, which must here have a thickness of between 200 and 300 feet or more. The fragments are of all sizes

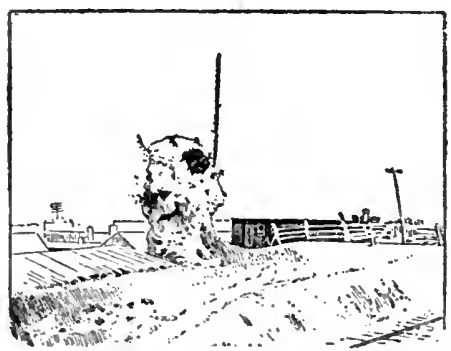

FIG. 118. View of the ancient stack of brecciated limestone at Point St. Ignace. The cliff of bedded strata is to the right of the railroad (lower right-hand corner). (After Holbbs.)

from that of a pinhead to blocks ten feet or more in diameter, and their position in the breccia is such that the stratification lines of the individual blocks dip in all directions. The distance to which these blocks have been carried from the parent ledges is many miles, and the width of this ancient stream is unknown. At St. Ignace the high ground behind the beach consists of the stratified 
Monroe dolomites in undisturbed horizontal position, but in front of these at a level represented in the cliffs by bedded strata are erosion stacks of the brecciated rock, carved from the cliff during a period of higher level of the lakes. The position is such as to indicate that these stacks are evidently a part of the rock stream, while the cliffs behind the stacks are a part of the original cliff. In one part of Mackinac Island the breccia is found to be underlain by shales and thin limestones of Monroan (or Salinan?) age. (Figs. II 7, II 8 .)

That the rock stream represented a subaërial flow of the rocks is shown by its character. Fine, rounded quartz grains, blown from a distance, are incorporated in the mass. The age of this stream is Lower Devonic, the Middle Devonic Onondaga strata enveloping and enclosing it and partly incorporating it as a somewhat reworked product.

\section{Residual SoIls.}

The product of rock decay in situ, whether of the nature of laterite or kaolinite, pure or impure, not only furnishes material for other agents to rework, but may also be recomposed in situ without much or any disturbance. The same is true of crystalline sand resulting from disintegration through insolation of granitic and other coarse-grained crystalline rocks. If the upper layers are reworked by a transgressing sea or by wind or rivers, a perfect graclation from the unaltered crystalline to the overlying stratified rocks may be produced. Such a gradation is seen in the basal arkose of the Lake Superior sandstone, where it rests on the preCambric peridotites. The indistinctness of the contact has led some olsservers to regard it as of the igneous type. Residual soils of limestone regions would have a sharper contact with the underlying parent rock from which they are derived by solution. They consist of the residual clay left after the removal of the lime in solution. Such clay is rendered carbonaceous, if the old land surface presents obstructed drainage, and swampy conditions prevail as on a peneplain. In extreme cases layers of coal of the terrestrial (humulith) type may be formed. Eolian dust may be added, and the whole subsequently reworked by a transgressing sea and covered by marine deposits into which it will grade. Thus a complex deposit of dark clay shales will be produced, the age of which ranges from the period of exposure of the region to subaërial solution to the period of resubmergence by the sea. Some of the mid-Palæozoic black 
shales of North America, notably the Chattanooga shale of Tennessee, seem to have been produced in this manner.

\section{B. ANEMOCLASTIC OR EOLIAN DEPOSITS. ANEMOLITHS.}

Deposits which owe their location and form to transportation and deposition by wind are commonly known as eolian deposits, and when consolidated become eolian rocks or anemoliths. At first regarded as of relatively little importance, they are being recognized in constantly increasing number among the clastic rocks of the geological column, and their thickness, great horizontal extent and often marked structural characters, as well as the evidence they furnish regarding the former physical geography of the region in which they are found, render them of special significance to the student of earth history.

Source of Material of Eolian Deposits. The ultimate origin of the material entering into eolian deposits is extremely diverse. Only a small part is directly due to the corrasive action of the wind, freighted with sand grains or other material, which act as the tool in the erosive work (see ante, Chapter II). A large part is derived from the products of atmospheric decay or is directly produced by insolation, and so is primarily of atmoclastic origin. But the mechanically produced sand and rock flour, whether due to stream or wave work, or derived through the grinding of the rock masses into sand and powder by glaciers, form no mean source of wind-transported material. Not unimportant in this connection is the dust produced by organisms, such as herds of animals pounding a rock mass to powder beneath their hoofs, and, above all, the activities of man in breaking up rocks by mechanical means, and grinding to powder the surface of the country under the wheels of his vehicles. The annual amount of dust produced by heavy or rapicl traffic over an ordinary road is probably far in excess of the niechanically formed detritus produced by erosive action of an ordinary stream in a bed of similar width. The dust produced in quarrying and mining operations forms no mean addition to the material furnished for eolian transport, while coal dust, the product of incomplete combustion, sometimes constitutes an important mineral impurity of the air (see antc, Chapter II). Where rocks are ground. as in cement mills or in stone crushers, the air for considerable distances all around is murky with suspended dust. This settles on and around the vegetation of the neighborhood, but may also be 
transported for a considerable distance. In the course of long periods of time, deposits of considerable extent and thickness may accumulate, though at present no data are available by which their extent can be measured.

An important contribution of clastic material available for eolian work is due to the explosive activities of volcanoes. The finer grades of pyroclastics are spread far and wide, and furnish one of the most significant of eolian deposits. As has been shown in an earlier chapter, some of this material is held suspended in the air for a long period of time, and settles far from the place of its production. The dust from Krakatoa encircled the globe several times before settling. Material which has thus been carried to a distance from the source of production, although in point of origin belonging strictly to the pyroclastics, must, in view of its assortment and transportation by wind, be regarded as atmoclastic, since the mode of deposition, more than the mode of production (clastation*), gives the resulting rock mass its chief structural characteristics.

It should finally be noted that material for eolation is also supplied by endogenetic processes. Thus certain pyrogenics, the finer grained lapilli, may be subject to wind transportation and assortation, and on deposition may acquire a typical eolian structure. They would commonly be admixed with and not separable from ordinary eolian pyroclastics. The most typical of atmogenic deposits, snow, is also most commonly exposed to colian modification, snow dunes or snow drifts being among the common forms assumed by this deposit. Besides the form, this deposit also shows the other common characters of wind-drifted material, such as uniform size of grains and dune bedding structure, though the latter is brought out only when dust layers alternate with the layers of snow. The ability of the wind-driven snow crystals to act as agents of erosion has been noted in an earlier chapter (p. 52).

Hydrogenic and biogenic deposits may also be found among the material subject to eolation. Thus salt crystals and gypsum flakes separated from lakes or marginal lagoons may be blown away by the wind. The dune-forming oölites of Great Salt Lake, believed to be of phytogenic origin, and the wind-blown deposits of foraminiferal shells in many regions, are examples of the biogenic anemoliths. Finally, accumulations of wind-blown organic fragments, such as seeds, leaves or whole plants, whether microscopic or macroscopic, must be classed among the biogenic anemoliths. These are probably never of great significance. 
The various types of wind-deposited rock material or anemoliths may, then, be grouped as follows:

\section{Endogenetic \\ (non clastic) \\ Anemoliths}

I. Pyrogenic

2. Atmogenic

3. Hydrogenic

4. Biogenic

\author{
Exogenetic \\ (clastic) \\ Anemoliths
}

1. Pyroclastic

2. Autoclastic

3. Atmoclastic

4. Anemoclastic

5. Hydroclastic

6. Bioclastic

The term anemolith in this case refers to deposition by wind, while the origin of the material is indicated by the qualifying term. The immediate sources of the material for sand dunes are the beach sands of sea and lake, the flood plains and terraces of rivers, glacial deposits and disintegrating rocks of the region. The dunes of our coast are largely fed by the beach sands. River terraces and flood plains furnish much of the material for the dunes of river valleys, while glacial sands sometimes directly furnish material for dunes, as on the uplands of Cape Cod, and in the North German lowlands. Desert dunes may be derived from disintegrating sandstones, as in the case of the Libyan and Nebraskan dunes, or from the flood plains of rivers, as in the case of the Kizil Kum and Kara Kum of the Transcaspian deserts. Dry lake bottoms may also form a temporary source of eolian material.

\section{Textural Types of Anemoliths.}

Two textural types of anemoliths may be recognized, anemolutytes or dust deposits and anemoarenytes or eolian sand-dune deposits. Anemolutytes will, as a rule, show no, or but little, discernible bedding structure, and this may also be true of the fine grades of anemoarenytes. The loess may be taken as a typical example of this kind of deposit. Eolian sands (anemoarenytes), especially the coarse types, commonly accumulate in the form of sand dunes, and these will show a typical dune-bedding structure. This is also true of biogenic and atmogenic anemoliths.

\section{General Characteristics of Modern Eolian Deposits.}

The chief claracters of eolian deposits are their thorough sorting, according to size of grain and mineral material, the round- 
ing and pitting of the individual grains, and the kind and character of stratification and cross-bedding. The form of the deposits is of less significance, since that form may be altered or destroyed subsequently.

Sorting of Material According to Size and Specific Gravity. A series of experiments was made by J. A. Udden (5I) with a cylinder suspended ninety feet above the ground on a bluff overlooking the Mississippi River, and arranged so as to catch the dust carried by winds of different velocities ranging from I4 miles to 29 miles per hour. From these experiments Udden concluded that "the different grades of materials are so far separated from each other in the direction of the wind movement that, even with considerable changes in velocity, the principal area of the deposition of sediments of one grade will not far encroach upon that of the deposition of material much coarser or much finer." "Thus, fine gravel or sand will never be carried to the region of the main dust deposits, and wind-formed sediments will be quite uniform in composition for any given area. A similar conclusion was reached by von Zittel in reference to the sands of the Libyan desert. (Zittel56.)

It may thus be stated as the first important character of eolian deposits that they are well sorted, according to size and specific gravity of the material, and this means that the deposits of a given locality will consist, to a very large extent, of one mineral type. Thus, an original mixture of grains of various kinds may by prolonged eolian action be sorted into nearly pure accumulations of the grains of the different minerals. As will be more fully shown beyond, calcareous particles are thus separated from others and segregated into eolian limestones, while clay and other dust particles are removed from the sands which result from the decomposition of igneous rocks, leaving only pure quartz behind. The clay itself accumulates to form deposits of loess. In the Sinai desert, where the quartz is derived from the decomposition of dark-red granite, it represents approximately one-fourth the volume of the original rock. (Walther-52:133.) The formation of a dune 10 meters high and 20 meters broad results in the accompanying liberation of perhaps 5,000 cubic meters of finest particles of feldspar and hornblende, which are carried away by the wind. As most of the quartz sand is probably derived from granites, it is apparent that the amount of fine material produced must be enormous. Much of this is carried as dust by the wind.

Size of grains in eolian deposits. The size of the grains in eolian deposits varies greatly. According to Sokolow, no undoubted 
eolian deposits are known in which the diameter of the grains exceeds 4 or $5 \mathrm{~mm}$. (48); more usually it is less than $\mathrm{I} \mathrm{mm}$. The sands of the Libyan desert range from $0.5 \mathrm{~mm}$. to $2.0 \mathrm{~mm}$. in diameter with the grains of a given sample of nearly uniform size. Grains of the Sylvania sandstone of Michigan and Ohio, a fossil eolian deposit, vary in average size in different samples from 0.18 to $0.3 \mathrm{~mm}$., though an occasional grain $0.5 \mathrm{~mm}$. or more in diameter occurs. Dune sands from Michigan City, Indiana, have an average diameter of grain of nearly $0.3 \mathrm{~mm}$., while various samples from Albuquerque, New Mexico, averaged from this size to 0.13 $\mathrm{mm}$. in diameter (Sherzer and Grabau-45: The Sylvania Sanclstone-77). Eolian dust deposits range, of course, downward to the finest particles, which will settle out of the atmosphere, or which may be washed out of it by rains or captured by hygroscopic saltcovered surfaces.

Rounding of Sand Grains. The process of rounding of sand grains has been discussed at length in Chapter V, p. 253, where it was also pointed out that wind-blown sands are more perfectly rounded, especially the finer grades, than grains of similar size subjected only to water wear. Besides the wearing off of the corners and the general dulling of the surface from prolonged wear, pitting of the grains also results from the violent impact of grain on grain to which they are all subjected.

In general it may be stated that sand grains of eolian origin are more or less perfectly rounded, and this together with their well-assorted character makes valuable criteria by which such eolian sands may be recognized. In general, the greater the amount of transportation and the more frequent the rehandling of the sand by the wind, the more perfect will be the rounding, as well as the assortment. Sands of parts of the Libyan desert, derived from an older sandstone, the Nubian, and carried in some cases a distance of a hundred miles or more, show a pronounced rounding of grain, as well as perfection of assortment, while sands from the desert near Albuquerque, New Mexico, derived from the not very distant crystallines are poorly assorted, and many of the smaller grains are still angular. Sands of shore dunes such as those derived from the glacial sands of Lake Michigan show only moderate rounding, the transportation and wearing having been of comparatively slight extent. Similar conditions occur in dune sands from the Pacific coast, while a like subangular form also persists in sands from IVest Palm Beach, Florida. Eolian sands along the Nile valley, derived primarily from the disintegration of the crystallines, are not only very poorly assorted, but they also are mostly angular with only 
the larger grains rounded. Others, however, carried in from the desert, are well rounded and assorted.

Stratification and Cross-bedding of Eolian Deposits. Eolian deposits may or may not be well stratified. Deposits of dust of a loess-like character often show an entire absence of bedding planes, the material being homogeneous throughout. Walther found in the deserts of Turkestan near Askabad layers of loess-like material a meter or more in thickness without apparent bedding, interpolated between layers of stratified sand and gravel. In the steppes surrounding the desert, the coarse and rigid stems of the steppe plants check the wind current, which then drops much of its load of dust. Rain will wash the dust from the air and from the leaves of the plants on which it has settled. This accumulates around the plants through which it is protected from further removal by the wind. The same office is performed by the coarse blades of the Buffalo grass (Buchloë dactyloides, Bouteloua oligostachya) and other plants which abound in the semiarid Great Plains east of the Rocky Mountains in North America. As the dust accumulates the mantle of vegetation will rise to a higher level. The roots of the dead plants, however, will continue to penetrate the deposit until their decay leaves a series of vertical tubes, or a series of carbonaceous streaks penetrating the structureless mass. The tubes may subsequently be filled by mineral matter, as in the case of many loess deposits, where the filling of the tubes is by calcite, and where their presence is believed to be in part the cause of the remarkable vertical cleavage of these deposits. Older fossil examples of this type are also known, one of the best being the well-known Portage sandstone of Devonic age, which is exposed in the banks of the Genesee gorge at Portage, New York. The fine, uniform, structureless texture of this rock makes it an excellent building stone, though the presence of the vertical tubes, described originally as fucoids (Fucoides verticalis), often mars this quality for certain purposes. The loess-like origin of this rock seems undoubted, though the accumulation was near the coast, rather than inland.

Dust carried by wind to regions of more extensive rainfall will be washed from the air by the rain and accumulate as a more or less stratified loess. In like manner dust carried across surfaces rendered hygroscopic by the presence of salts will adhere to these surfaces and so, as a rule, become finely stratified.

On the whole, it must, however, be emphasized that regular stratification is not characteristic of eolian deposits. Where strata show fine or uniform bedding water always has played more or less of an active part in its deposition, though the idea of standing wa- 
ter bodies, passive influence, or receptive waters is not necessarily involved in this concept. Irregular stratification and cross-bedding of a complex type may, however, be regarded as one of the most characteristic structural features of the coarser eolian deposits.

Eolian cross-bedding is especially characterized by discontinuity. The successive cross-bedded layers or wedges are limited above and below by erosion planes, which are of contemporaneous origin. While deposition goes on in one section of the deposit, erosion of a previously formed one in part supplies the material, or alternate deposition and erosion may characterize any portion of the series. Furthermore, as will be more fully discussed in the summary chapter on these structural features, the varying currents will result in the inclination of the cross-bedding in different directions in the successive sections. Horizontal beds will be rare or wanting, a feature readily distinguishing this type from the diagonal bedding due to torrential action. Finally, as Huntington (25) has insisted, the tangency of the inclined beds with reference to the erosion surface below, or their gradual bending toward parallelism with this plane as they approach it, is one of the most reliable criteria by which eolian deposits can be recognized.

\section{Sand Dunes, Their Origin and Form.}

Wherever along the beach the sun has dried out the sands, they have lost the coherency which they possessed when saturated with water, and are then readily blown about by the winds. As a result, sand dunes are formed along most coasts, these dunes gradually traveling inland, and burying forests, fertile lands and buildings unless their landward march is checked by a barrier. either natural or artificial. The distance to which wind-blown material is carried depends chiefly on the fineness of the material, its specific gravity and the strength of the wind. Examples of such transportation have been given in Chapter II.

The sand particles move under the direct influence of the wind, and their rate of movement depends on their size and the strength of the wind. According to Sokolow (48: $\left.1_{5}\right)$, when the wind velocity is $4.5 \mathrm{~m}$. per second, quartz sand grains of $0.25 \mathrm{~mm}$. diameter will glide only along the surface of the ground without rising freely above it. With a wind velocity of is meters per second, however, sand grains of $1 \mathrm{~mm}$. diameter will be raised some distance into the air. With the wind of no great strength and the sand not very fine, movement of the grains is along the surface of the 
ground, or only a few centimeters above it. Since the sand grains of the shore dunes have in large part an irregular, more or. less flattened form, their movement is not a rolling, but a gliding one. The larger grains move only by jerks, and only under the influence of strong gusts of wind. A greater force is needed to start the movement of a grain, which then will continue its progress even under a diminished wind force.

While a steady and continuous wind will cause a uniform and constant onward movement of sand grains, with the result that eventually all the finer particles are removed by the wind, a more or less interrupted series of wind gusts or variable winds will result in the irregular movement of the particles and their temporary arrangement into wave-like forms. On a small scale these constitute wind ripples, while the larger ones are the dunes.

Wind ripples are common on sandy surfaces where the irregular motion of the wind creates eddies and cross currents. (See Chapter XVII for formation of ripples.) With a given wind they vary in height and distance apart, according to the size of the sand grains composing them. Sokolow gives the following table of such relationship :

\begin{tabular}{|c|c|c|}
\hline Size of grain & $\begin{array}{l}\text { Height of } \\
\text { ripple }\end{array}$ & $\begin{array}{c}\text { Distance } \\
\text { between ripples }\end{array}$ \\
\hline $\begin{array}{r}0.2 \mathrm{~mm} \\
1.0 \mathrm{~mm} \\
2 \text { to } 3.0 \mathrm{~mm} \text {. }\end{array}$ & $\begin{array}{l}10 \mathrm{~mm} \text {. } \\
25 \text { to } 40 \mathrm{~mm} \text {. } \\
70 \text { to } 100 \mathrm{~mm} \text {. }\end{array}$ & $\begin{array}{l}8 \text { to } 10 \mathrm{~cm} \text {. } \\
25 \text { to } 35 \mathrm{~cm} \text {. } \\
60 \text { to } 120 \mathrm{~cm} \text {. }\end{array}$ \\
\hline
\end{tabular}

The form of the ripples is synmetrical, with a gentler windward and a steeper leeward side. Up the windward side the sand grains are rolled or pushed until they reach the crest and roll down the leeward side. In this ninnner the ripples advance in the direction of wind motion, this advance being at a variable rate dependent on the size of the grain and the strength of the wind. Helman $(21: 384)$ obtained the following average rates of advance for sand ripples on continental dunes or barchans in the sandy desert of the Khanat of Chiwa in Turkestan:

Strength of Wind

(metcrs per second)

6

4

3
Average advance of ripples in millimeters
9.0
$5 \cdot 2$
$3 \cdot 3$

Similar results have been obtained by Sokolow on shore dunes. 


\section{Types of Sand Dunes.}

Three types of sand dunes are recognized, their characters being largely determined by their location. These are: ist, shore dunes, or those formed from the sands left to dry on the retreat of the water; 2nd, river-bed dunes, and, 3 rd, inland or desert dunes. While all of these have fundamental features in common, they, nevertheless, show individual characteristics due to the topographic diversity and structural peculiarities of the respective regions in which they occur.

(I) Strand Dunes. These are a common feature of the coasts, being found on the shores of the sea and of the larger lakes. Typical and well-known examples of seashore dunes are found in the Provincetown region of Cape Cod, Massachusetts, and from there southward along Long Island coast and the sandy coast from New Jersey to Florida. They are further found on the shores of the Baltic, especially on the narrow sand bars which separate off the Kurische and Frische Haff on the east Prussian coast, and on the west coast of Kurland and the Gulf of Riga in Russia. (Berendt4.) Extensive dune areas are also found on the east and south coast of the North Sea, especially in Denmark, and the coast of the Netherlands and Flanders from the mouth of the Elbe to Pas-deCalais, while the French coast of the Bay of Biscay bears the most extensive dune accumulations of all. Finally, extensive shore dunes are developed on the eastern and southern coast of Lake Michigan, and to a lesser extent on the shores of the other Great Lakes of North America. Shore dunes are most typically developed where a broad flat zone of sand fronts a low country, as in the examples cited, but they may also occur where such a sand zone lies at the foot. of rocky cliffs. In. such cases the dunes will accumulate on the summit of the cliff, as on the Normandy coast of France, the west coast of Jutland and the West Schleswig-Holstein coast, farther south, where the height of the cliff in one case (Island of Sylt among the north Friesian islands) was 34 meters and that of the dunes upon it reached a height of 28 meters. They are, however, never found where rocky coasts descend directly into the waters, as on the northern New England coast and the rocky coast of the maritime provinces of Canada, the rocky coasts of Great Britain and of Scandinavia and Finland. The best development of coastal dunes seems to be on a sinking coast, over $90 \%$ of the coast dunes of Europe being thus located, according to Sokolow.

The most important coastal dunes of Europe (Sokolow), if not of the world, are found on the French coast of the Gulf of Bis- 
cay, extending without interruption from the mouth of the Adour to that of the Garonne, a distance of over $240 \mathrm{~km}$. They are arranged in parallel rows, ten being the maximum number, covering a strip of coast from 4 to 8 and in some places even $10 \mathrm{~km}$. wide, and approximating an area of 120,000 hectares (296,520 acres). Their height ranges up to 90 meters, making them the highest known coastal dunes. It is true that there are dunes with a height of from 120 to 180 meters on the west coast of Africa between Cape Bojador and Cape Verde, but these appear to be desert dunes which have reached the coast from the Sahara under the influence of prevailing northeast winds.

The country bounded seaward by the great dune belt of the Biscayan dunes is a low, marshy tract known as the Landes, which by many geographers is believed to be subsiding, and the shore of which is retreating at a rapid rate. Near Houtin, in the northern part, the sea advances at a rate estimated at not less than 2 meters per year, while great difficulty is experienced by St. Jean-de-Luz, south of Biarritz, at the southern end of the dune region, from the encroachments of the sea.

On the south coast of the North Sea along the entire coast of Belgium (Flanders) and the Netherlands, to the mouth of the Elbe, extends a nearly uninterrupted dune belt, which altogether forms a length far exceeding that of the coast of the Landes. These dunes are not as high as those of the Biscayan coast, averaging 15 to 20 meters, with the highest, near Petten, attaining only 35 meters. The coast here is known to subside at a rate where measured of I.I meters per century, and as further indicated by the gradual deepening of the Zuidersee, formerly a swamp, but now an embayment of the sea.

The dunes of the Danish coast of the North Sea are of especial interest on account of their rapid inland advance. This section, together with the coast of Schleswig-Holstein, forms the second largest dune region of Europe, covering an area of 67,000 hectares ( 165,557 acres), many of the dunes reaching a height of 30 meters. The retreat of this coast has been discussed in an earlier chapter, but an example may be repeated here to show the rate of dune advance. In I757 it was found necessary to tear down the church of the village of Rantum on the Island of Sylt on the west coast of Schleswig-Holstein, because it was reached by the advancing dunes. In 1791 or 1792 the entire dune chain had passed over the church ruins, these then lying on the shore which had advanced to this point. Sixty years later the site of the church was 700 feet from shore, the depth there being 12 feet. The second church has 
since been buried by the advancing dunes. (Forchhammer-16:27.) A similar case is shown in the changes produced by migrating dunes on the Kurische Nehrung, in East Prussia, where a church was buried and again resurrected by the advancing dunes between the years 1809 and 1869 .

On the south coast of the Baltic exists another important dune area of Europe, its strongest expression being found on the $\mathrm{Ku}-$ rische and Frische Nehrung, two very long narrow sandbars separating off shallow lagoons on the coast of East Prussia. The height of the dunes here reaches 60 meters and more, and hence these are, next to those of the Gascony coast, the most important coastal dunes of Europe.

- Dunes of great size and covering an extended area occur on the North African coast of the Mediterranean, especially on the Great Syrt. Elsewhere on the Mediterranean coast they are of little importance.

The dunes of the east coast of North America have been studied to a much less extent than those of the European coast. Perhaps the best-known region is that of the extreme tip of Cape Cod at Provincetown, where the dunes reach a height not exceeding 30 or 40 meters. This entire section is a region of sandbars and beaches built by the waves and shore currents from material washed from the Truro and Wellfleet coast, a region exposing high cliffs of glacial and earlier sands to the open Atlantic. The dunes built at Provincetown slowly advance southward and westward, burying forests and hamlets in their path, though their march has to some extent been arrested in the Provincetown region by artificial means, at an expenditure of $\$ 28,000$ between the years 1826 and 1838 .

On the Long Island coast the dunes are moderate, but on the New Jersey coast and on that of the Carolinas they reach a considerable height and extent, and in their inland march bury forests and even buildings.

(2) Lake Shore Dunes. These are well illustrated by the dunes so extensively developed on the eastern shore of Lake Michigan from the Straits of Mackinac to the Chicago area. Here extensive glacial sands in part forming beach lines of a subsequent lake stage of greater extent than the present are heaped into sand dunes by the prevailing westerly winds. Some of these sand dunes on the northwest coast of Michigan are grassed over and wooded, but others are still in an active state of movement, advancing upon and burying the forests. In height these dunes range to a hundred feet or more, especially in the southern area, as in Dune Park, Indiana. Near Muskegon, Michigan, occurs one of the largest dunes 
in the world. It is several hundred feet high, and from its advance has become known as "Creeping Joe."

(3) River Flood-Plain and River-Bottom Dunes. Rivers flowing through broad, open valleys, especially in semiarid regions, are often accompanied by an extensive development of border dunes, while those rivers flowing through narrow canons are essentially free from such accumulations. In a humid climate dunes are seldom formed on river-bottoms, even though these may be broad and supplied with an abundance of sand. In illustration of this it may be noted that river border dunes are not common in western Europe, except in the sunny and somewhat drier regions of southern France and Spain. Thus, while in the North German plains and in England the few dunes which have been formed in the past are low and soon covered with vegetation, the valley of the Gardon in Langtuedoc shows dunes io meters high, while dunes rising to a height of 25 meters are found in the sandy desert region on the right bank of the Guadalquivir in Andalusia in southern Spain. In eastern Europe, on the other hand, river dunes are much more extensively developed. Thus even the smaller streams of the northern half of the Russian regions have dunes rising to a height of 5 meters, while southern Russia, with its dry continental climate, shows them extensively developed. A nearly continuous dune belt, reaching sometimes a width of $12 \mathrm{~km}$., and with dunes averaging 10 or $12 \mathrm{~m}$. in height, extends along the middle course of the Dnieper below Kief, while the lower course of this stream shows a still more extensive dune area, especially in the government of Taurida. The sands here are found on the left bank of the Dnieper, and extend over an area more than $150 \mathrm{~km}$. long, with a maximum width of $30 \mathrm{~km}$. In the midst of this area, however, are often spots free from sand, while in some parts a broad area of meadow and wooded land separates the sand area and the river. The height of the dunes is mainly from 5 to $7 \mathrm{~m}$., but exceptional cases, where the height rises to II.2 m., have been noted. The sand is almost exclusively quartz rock, with only a very slight admixture of feldspar and dark grains, probably of iron oxide. The grains are well rounded, often spherical, angular grains being wholly wanting. The color of the dunes as a whole is a light golden yellow. The sands of the middle Dnieper are somewhat coarser, but they do not exceed on the average the diameter of $0.4 \mathrm{~mm}$. In roundness, purity and color the sands of the two areas are much alike. A still greater development of river border dunes is found in the valleys of the Don and the Donetz. In the Don valley the dune zone has a width 
ranging from 8 to $18 \mathrm{~km}$., the average being $\mathrm{I} 2$ or $\mathrm{I} 3 \mathrm{~km}$., while the height of the dunes may reach 30 meters. In the Donetz valley the width of the zone is sometimes $10 \mathrm{~km}$., but the height of the dunes does not as a rule exceed 5 or $7 \mathrm{~m}$. The shores of the Volga in the Kazan district also furnish extensive dunes, which wander far into the steppes. Still more extensive dune development is found in the river valleys of central Asia, as, for example. along the River Oxus, or Amudaria, and the Jaxartes or Syrdaria, both of which are tributary to the Aral Sea. (Walther-52:IIO.) These streams bring vast quantities of sand and mud from the Tian-Shan, Great Pamir, and Hindu Kush mountains, in which they rise, and spread them over the low ground of their flood plains, which range in width up to $10 \mathrm{~km}$. The thickness of the deposit made by the Oxus was found to be $23 \mathrm{mt}$. at Tschardschui. The rivers rise 3 meters from March to July and overflow the flood plains, depositing the sandy sediment. As the water of the Jaxartes falls, the hot northern winds soon dry the deposit, and carry away all the finer dust particles, leaving only the pure quartz sand, which is heaped into dunes. These wander southward across the Kizil Kum desert, sometimes at a rate of 20 meters during a stormy day, but generally the sand masses move at an average rate of 6 miles per year. Reaching the Oxus, these sands are incorporated in its sediment, and the operations of sorting the deposits on the flood plain of this river are repeated and the sands again heaped into dunes, which wander southward across the Transcaspian or Kara Kum desert, until they reach the borders of the Caspian Sea. The activities of the streams are unceasing, and the supply of material in the mountains in which they rise is practically inexhaustible. Thus there is a constant succession of sand dunes wandering southward across these deserts, and layer upon layer of sand accumulates, each showing the characteristic eolian structures, and helping to build up a deposit of pure, unfossiliferous sand of almost unlimited thickness.

In North America dunes are rare and insignificant in the river valleys of the eastern and central region, but are more frequently found in the drier climates of the west. Perlaps the most extensive river dune area on this continent is that of the Columbia and Snake rivers in Oregon and Washington between Dallas and Riparia, the sand being derived from the flood plains of the rivers, which are widely exposed during the dry season.

(4) Inland or Desert Dunes. The largest areas of shifting sands are the deserts. Their occurrence is even more dependent on 
aridity of climate than is the case with river dunes, for moisture will permit the growth of regetation and so check the movements of the sands. Where, however, the cover of vegetation is destroyed by man or other agencies, dunes may occur even in moist climates, as is the case in northern France. Belgium and the North German lowlands.

The height of continental dunes may range up to I50 or even 200 meters, and the area covered by them is often very large. In Hungary the total dune area covers some I3,200 sq. km., with single dunes rising $52 \mathrm{~m}$. in height. Large areas also occur in European Russia, but the greatest dune districts are in the deserts of Asia, Africa and Australia. In the Sahara dunes cover only one-ninth of the total area $(Z$ ittel-56), but even so this aggregates a total of 18,000 geographical square miles. Arabia is largely a land of drifting sands. Almost the whole southern area is occupied by the terribie Desert of Roba-el-Khali or the desert Dehnā, which is wholly covered by colian sands and is without the relief of oases. Its length is 150 geographic miles, its width 80 . Sands form nearly one-third of the entire surface of Arabia, or not less than 15,000 geographic square miles. (Palgrave-35:9I.) In the northern part of the peninsula is the Nefud desert of red sands, while other sandy deserts of Asia are found in Syria, Iran, Baluchistan, northern India, eastern Turkestan and Mongolia, where continuous sandy desert areas extend for hundreds of kilometers (Przhevalsky-39). In North America extensive sand dune areas of the continental type are found between the Rockies and the Sierra Nevada, in the Colorado and Mohave deserts of southern California and in the Sand Hill region of Nebraska and the adjoining area. In Nebraska this region covers an area of more than 18 ,000 square miles, or almost one-fourth of the total area of the state. The sand is largely derived from the disintegration of the Tertiary sandstone, and to this is due in part its purity. The size of the grains varies considerably, but the average centers around 0.25 to $0.1 \mathrm{~mm}$., the maximum scarcely rising above $1.0 \mathrm{~mm}$.

The sand hills of Nebraska enclose numerous valleys, ranging in size from mere basins to valleys a mile in width and many miles long. Numerous lakelets generally arranged in groups occur in these valleys, the individual lakes ranging from small ponds a hundred yards across to bodies of water a mile or more wide and four or five miles long. In Cherry county fifty or more such lakes form a single group. These lakes exist because the climate is now moist, for which reason also much of the sand-hill region is covered with vegetation, though many bare areas of drifting sand still occur. 
The chief agent in holding the dunes and making the spread of vegetation possible is the bunch grass (Andropogon scoparius), though the sand grass (Calamorilfa longifolia) and the needle or silk grass (Stipa comata) are also important as binders. The most characteristic plant next to the bunch grass is the dagger weed (Yucca glauca), which often occurs in great abundance. At the present time hollows or "blow-outs" are more characteristic of these sand hills than new dunes. These blow-outs begin where. from overgrazing or fires, the vegetation is destroyed, and will increase in size until they are from 300 to goo feet in circumference with sides of bare sand sloping inward at an angle of about 30 degrees to the bottom, which may be from 20 to 75 fect or more beneath the rim. (Pool-38.) In South America continental dunes are best developed in the great Atacama desert of Chile, west of the Andean chain. Finally many of the deserts of Central and West Australia are characterized by dunes of great extent.

\section{The Forms of Dunes.}

Three main dune forms may be recognized, of which all others constitute more or less divergent modifications. These are: Ist. the conical hill; 2nd, the long ridge, generally occurring in parallel groups, and, 3 rd, the crescent-shaped dune or barchan. The crescent or barchan type is most characteristic of the inland desert regions. It presents a gently convex surface to the wind, while the lee side is steep and abrupt. The horns of the crescent mark the lateral advance of the sands. Its wide distribution and all but universal presence in the sandy deserts of all continents make this type the normal one for sand hills formed on an open area. Indeed, it is probable that in very many cases the linear ridges are mere modifications of this type, formed by the lateral confluence of many simple barchans. This is often shown in the wavy form of the crest line, as in the case of the dunes of the Transcaspian desert.

On the coast, barchans, though present, are less characteristic. Here we find the linear series more commonly developed, because a nearly constant and uniform supply of sand is furnished by the parallel coast, and because the sloping ccast itself exerts a directing force. Coastal dunes never have a symmetrical cross section, the windward side generally having a gentle slope of from $10^{\circ}$ to $20^{\circ}$, which may in places be somewhat convex, while the leeward slope is generally much steeper, being often as high as $30^{\circ}$. 
Origin of Intercalated Dust and Clay Layers, and of Clay Balls in Sand Dunes.

The depressions between the sand dunes when not occupied by standing water, as in the moist sand-hill region of Nebraska, often represent a flat playa or takyr surface, the dried mud bed of a temporary lake, which evaporated soon after its formation under the influence of a dry climate. Such surfaces are common in most desert regions, and they are not infrequently characterized by mud cracks, footprints and trails of various animals. When the sand dunes advance over sucli a surface a horizontal bed of clay will separate the diagonally bedded eolian sands. This clay bed will of course be of limited extent only, wedging out around the margin of the playa. If the clay layer of the playa surface is very thin ( I to $2 \mathrm{~cm}$.), the pieces into which it splits on drying will curl up like shavings, and in such a condition they may be blown by the wind into the dune. Here, on becoming moistened by the winter rains, they will be compressed into flat lenticles of clay and form the "clay galls" so common in modern as well as ancient eolian deposits.

Clay and dust accumulations are not confined, however, to the depressions between the dunes. A light wind, active for a period of time, may dust over the dune with a coating of argillaceous particles, which then become incorporated in the sand mass as oblique partition layers. Such occurrences are not uncommon in the Transcaspian (Kara Kum) and other deserts. They appear as steeply inclined slieets of clay penetrating the dunes, and are not infrequently found in the form of parallel "clay dikes," Io to 15 meters in length, in the interdune areas, where they may rise a centimeter above the flat surface, representing the residual base of a crossbedded dune, the top of which has moved onward.

\section{Peat and Lignite Deposits in Sand Dunes.}

Shore dunes often transgress across peat deposits formed in swamps or marshes behind the dunes. Such peat deposits, sometimes with old tree stumps, are found on the shores of Nantucket, and are sometimes buried under deep masses of dune sand, as at the Nauset lights on Cape Cod. They are characteristic of other regions as well. Forests buried by advancing dunes are killed, and the wood, if buried long enough, is converted into lignite. The 
same thing is true of coatings of vegetation which are buried by the readvancing sands. In the sand dunes of Cape Cod many such examples are found, and the same is true for the sand hills of $\mathrm{Ne}$ braska. Indeed, this may be seen in almost all coastal dunes where vegetation has gained a temporary foothold. Such sands would thus become lignitic, and the fragments of lignitized and broken wood may be scattered and incorporated in the sands over a wide area. The lignitic sands of the Raritan formation of New Jersey apparently had such a history.

\section{Transgressive Relation of Dune Sands to Subjacent Formations.}

The southward transgressing dunes of the Kara Kum or Transcaspian desert spread layers of sand over the older fluvial or marine deposits. The pure quartz sands of the Libyan desert, derived from the disintegration of the Nubian sandstone a hundred miles away, transgress across the floor of Cretacic and Tertiary limestones, and the weathered-out fossils of these formations are enclosed in the basal part of the sands.

In the profile of the earth's crust many cases of such transgressive relation of unfossiliferous sandstones upon fossiliferous marine deposits are found. Examples are the St. Peter on the Beekmantown limestone, the Sylvania on the Monroe dolomites, the Bunter Sandstein upon the marine Zechstein, the Keuper upon the Muschelkalk and many others. Such deposits point strongly to an origin comparable to that of modern desert sands which overlie marine sediments of an earlier age.

\section{Examples of Older Eolian Deposits.}

The Loess as an Example of a Dust Deposit. The loess is a continental deposit of loosely arranged, angular grains of calcareous silt loam, typically intermediate in fineness between sand and clay and of remarkably uniform mechanical composition. Normally it is without stratification, and breaks off in vertical slabs, with the result that perpendicular cliffs are formed. Loess was first described from the valley of the Khine, but is also known from southeastern Europe, from North Anerica, and especially from China, where it was fully described by von Richthofen (42). Here the loess sometimes has a thickness of a thousand feet or over, and is believed to be primarily the disintegrated rock material bronght by 
the winds from the Desert of Gobi in central Mongolia. Evidence of fluvial action is, however, not wanting, many gravel beds of great extent and great distance from their source pointing to river activities. It has been thought (Wright-54) that the distribution indicates a vast body of standing water which temporarily occupied the loess-covered area in late Tertiary or Quaternary time, but this interpretation does not sufficiently account for the absence of fossils in the loess, nor does it do justice to the ability of rivers and wind to distribute fine sediments in broad level plains. For the whole of Asia the loess-covered area comprises about $1,324,000$ square kilometers (5II,I5O square miles) (v. Tillo), which, with an average estimated thickness of 30 meters, gives a total of nearly 40,000 cubic kilometers of loess material. All this material has of course been removed from the rock surfaces of the country where it originated. (Walther-5I:50.) The loess is characteristically penetrated by vertical tubes, the calcite-filled hollows left by the decay of grasses and roots. These help to produce a vertical splitting of the mass, which otherwise shows no planes of separation, since stratification is for the most part absent. As a result, the walls of loess left on the dissection of the loess area by the Yellow River and its tributaries form vertical bluffs of great height. "Millions of Chinese live on the valley floors of dissected basins of this kind, for the loess is extremely fertile where well watered. Great numbers of the people inhabit cave-like dwellings excavated in loess bluffs; in a thickly populated district not a house may be seen. The yellowish color of loess prevails everywhere. It gives color and name to the great river of the region and to the sea into which the river flows." (Davis-13:3I7, 3IS.) The loess of the Mississippi Valley region and of the plains generally, is also commonly interpreted as a deposit of wind-blown material, though indications of aqueous activities are not wanting. The principal evidence for the eolian origin of this "Prairie loess" (Shimek-46) is found (I) in the absence in the deposit of shells belonging to distinctively water species; (2) the presence of land shells of species that live on the shores of ponds; (3) the difficulty of imagining a submergence of the loess-covered area of such character as to account for its peculiarities; for in a permanently standing body of water the uniformity of distribution of material of the given degree of fineness characteristic of the loess could not be secured; (4) the reasonable influence of vegetation in arresting wind-blown dust. Professor Wright $(55: 205)$ gives some facts which seem to oppose the eolian origin of the Mississippi valley loess: ( I) The distribution of the loess in about equal proportions upon both sides of the Missouri 
River, as well as the presence of the loess where the prevailing winds are least likely to pile it up. (2) The exclusive dependence upon wind for the distribution of the loess leaves out of consideration the difficulty of accounting on this basis for the extensive leveltopped terraces which frequently occur. (3) The agency of water in the distribution of loess is favored by, or at any rate consistent with, the fact that the loess is quite uniformly found to be thickest on the margin of the streams flowing out of the glaciated region, and that it is of somewhat coarser texture nearer the streams, thinning out at a distance from them, and merging gradually into a more clayey deposit. The stratification of the loess is also considered as indicating deposition by water. Boulders and granitic pebbles have been found in the loess on the Osage River, which can be accounted for only on the supposition that they were carried there by floating ice. The source of the material of the Mississippi Valley loess seems to be in close connection with the deposits of the last glacial period. This is sliown not only by the distribution, but also by the not infrequent interstratification of loess and marginal glacial drift and till. The close relationship of the Asiatic and European loess to the ice border has also been suggested, but for Asia this is at least somewhat doubtful. Indeed, the source of a part even of the American loess is traceable to the nonglaciated arid regions of the west.

Our present knowledge of the character of the deposits designated loess leads to the conclusion that the source of the material is various, being in part the dust blown from the deposits in front of the ice sheet, in part the dust derived from deserts and steppes, and in part the silt of river flood plains or other sources. The glacial origin fits best the American and European, and the desert origin the Asiatic deposits, but none are probably of simple character throughout. Though a marine origin has been advocated for the loess by some writers, the consensus of opinion is that the loess is a continental deposit. The evidence, further, points to the wind as the chief agent in distribution, distribution by rivers being of secondary importance. Deposition was for the most part upon dry land, vegetation playing no doubt an important part in the separa tion of the dust from the air, though rain also must be credited to a certain extent with this function. It is, however, essentially a steppe deposit. All such loess is practically without stratification. Some loessic material was no doubt deposited in standing water and more perhaps on river flood plains, but the totality of this was far below that of purely eolian origin. Secondary reworking and redistribution by wind, rivers and waves also occurred, and is going on at the present time. To a certain extent this is also true of the 
primary distribution and deposition of loess, for loess is forming today in China and Central Asia, and in many other regions of the world.*

Fossils and concretions in the loess. The fossils of the loess are few and found only at intervals. They are for the most part shells of land snails (Helix, Pupa, Succinea) and of pond and stagnant water types (Planorbis, Paludina, etc.). Bones of land vertebrates are, however, not uncommon in many loessial deposits, while stems and roots of grasses and other plants, more or less replaced or mineralized, are characteristic features in certain regions, especially in China. Curiously formed calcareous concretions known as Loessmännchen, Loesspïppchen, or Loesskindel are also found in many deposits of loess. These often occur in horizontal tiers, giving a semblance of stratification to the deposit. They are, however, of secondary origin, and the arrangement is not necessarily indicative of original stratification, but may represent successive levels of ground water. An analysis of the concretions of the German loess gave $($ Blanck-5):
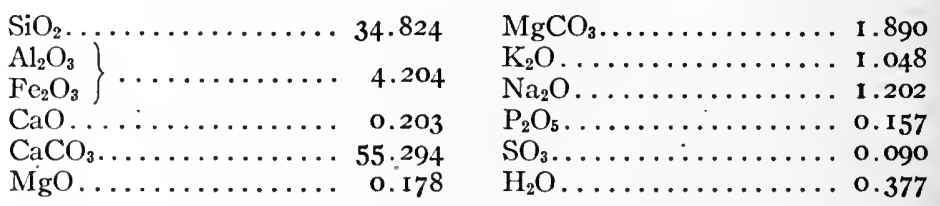

Cenozoic and Mesozoic Loess-like Deposits. Deposits of this type are probably more widespread than is realized at present. The White River clays of Oligocenic age in western North America have been regarded by W. D. Matthew (3I) as probably of this type, though the included sandstones are in part at least fluviatile and in part perhaps dune sands. The chief characters stamping these deposits as eolian loess are the fineness of their texture, the lack of stratification and the absence of plants, fish or aquatic reptiles or invertebrates, as well as the larger numberr of land mammals. All of these characters are incompatible with the theory of a lacustrine origin of these deposits commonly held for them. A loesslike origin has also been suggested for the Harrison beds of Nebraska, a Miocenic formation. (Loomis-30:I7.) Anemolutytes comparable to the modern loess seem to be represented by the Keuper marls of western Europe. These have been regarded as the loessic deposits formed around the borders of the Triassic desert,

* For a comprehensive bibliography of the loess see Stuntz and Free (50) pp. I24-140, 
in which the New Red sandstone of Britain was accumulating, partly at least as a sand-dune formation. (Lomas-29.)

Palcozoic Loess-like Deposits. Unstratified deposits of fine and uniform-grained rocks, free from organic remains and having a general loess-like character, are not uncommon in Palæozoic and later formations. As already noted, the Nunda or Portage sandstone of central New York, a formation of Lpper Devonic age, has the characteristics of a consolidated loess. This is especially seen in the Genesee Valley near the type locality, where the rock for considerable thicknesses shows a lack of stratification and a fineness and uniformity of grain strongly suggestive of these characters in Pleistocenic loess. There is a notable absence of fossils, except vertical tubes (Fucoides verticalis), similar in many respects to those found in more recent loess. The rock, furthermore, splits with a decided vertical tendency, forming slabs of varying thickness. This deposit was probably not formed far from the sea, and was succeeded by normal marine sediments.

Certain portions of the St. Peter sandstone also appear to be of this character, as shown by the fineness and uniformity of grain, absence of stratification and splitting into vertical slabs. Much of this sandstone appears, however, to be of dune origin, subsequently in part reworked by a transgressing sea.

Many other Palæozoic formations will probably prove on further study to have a loess-like origin. This appears to be especially so in the case of those fine-grained, nonstratified deposits which are associated with continental formations of another type, such as fluviatile beds, dune deposits, salt and gypsum beds, etc. Often such loess-like deposits are of a red color, owing to the presence of iron in the ferric oxide stage. The red Vernon shale of eastern New York apparently furnishes a good example of this type of deposit. This formation is of mid-Siluric age, and marks in the opinion of many the beginning of a period of widespread continental sedimentation under arid climatic conditions. This red shale in the Syracuse area is followed by the salt deposits of Salina age.

The red color of this formation is due to the presence of dehydrated ferric oxide, of which 2.25 per cent. occurs in the entire mass. Ferrous oxide of iron is present in small quantities (0.75 per cent.) (Miller-34:I5I). The iron is distributed in small quantities, but with great uniformity throughout the mass. It is not impossible that, as Miller argues, the color was not originally red, but yellowish, the iron being in the form of the hydrate. Subsequent dehydration would produce the red color. In this connection it is interesting to know that the ordinary yellow loess commonly con- 
tains a higher percentage of ferric oxide than that found in these red lutytes. Thus of seven analyses of North American loess, the lowest gave $\mathrm{Fe}_{2} \mathrm{O}_{3} 2.52 \%$ and $\mathrm{FeO} 0.31 \%$ and the highest $\mathrm{Fe}_{2} \mathrm{O}_{3}$ $5.22 \%$ and $\mathrm{FeO} 0.35 \%$. Another had $\mathrm{Fe}_{2} \mathrm{O}_{3} \cdot 3.74 \%$ and $\mathrm{FeO}$ $\mathrm{I} .02 \%$. The average of the seven is $3.35 \% \quad \mathrm{Fe}_{2} \mathrm{O}_{3}$ and $0.56 \% \mathrm{FeO}$. (Clarke-Io:486.) It is thus seen that so far as the red color of the Vernon shale is concerned it is due only to the anhydrous condition of the ferric oxide, and not to the greater abundance of this mineral.

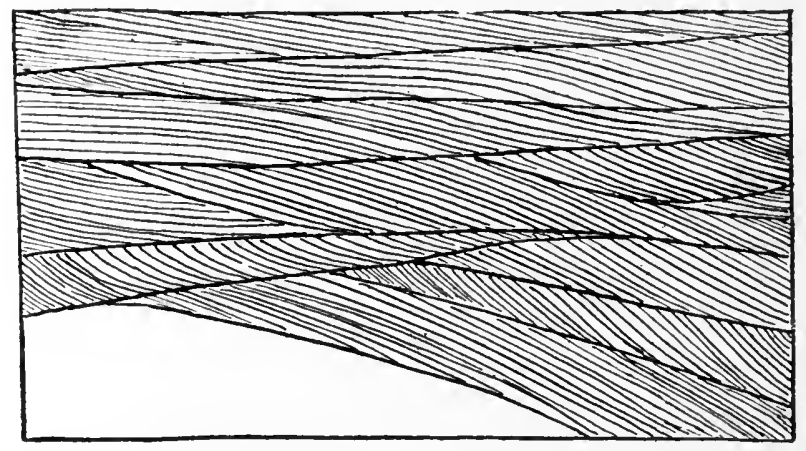

FIG. I19. Cross-bedding in Sylvania Sandstone (Siluric). (After Sherzer and Grabau). Scale $I: 60$.

Older Deposits of Dune Type.

Consolidated deposits showing the characters and structures of dune sands have been obtained from many of the geological horizons of the past, and closer attention to the structural details of rock masses will probably reveal their presence in still other formations. Among Tertiary sandstones which have been regarded as of this origin or show evidence pointing that way may be mentioned the Monument Creek beds of Colorado, while an example of Cretacic sandstones of this type is found in the Nubian sandstone of Egypt, though this is probably not of this character throughout. Certain parts of the Dakota sandstone of the western United States and of the Raritan formation of the east also must be mentioned. Other examples will undoubtedly be found on closer study. In the Jurassic of western North America occurs a sandstone of great thickness and wide areal extent, which shows in a wonderful manner the peculiar type of cross-bedding formed by migrating sand 
dunes. This is the White Cliff sandstone of southern Utah, the origin of which as a subaërial dune sand deposit can hardly be questioned.

The Triassic shows many examples of dune sands, commonly much iron-stained, though these are generally associated with fluviatile and sometimes lacustrine deposits. They have been recognized in both America and Europe. In the Triassic strata of England and the Elgin sandstone of Scotland this eolian origin seems to be well indicated.

In the Palreozoic occur many deposits which bear the earmarks of an colian or dune origin. Among those that may be cited in this comnection are the white dume sands beneath the Nagnesian limestone of England and the similar beds of "Weissliegende" in Germany; the Kanab and Colob formations (probably Permic) of southwestern Utah and northwestern Arizona; parts of the Old Ped sandstone of Britain; and the Sylvania and St. Peter sandstones of Siluric and Ordovicic age, respectively, in the United States. The Sylvania sandstone may be taken as a typical example of this kind

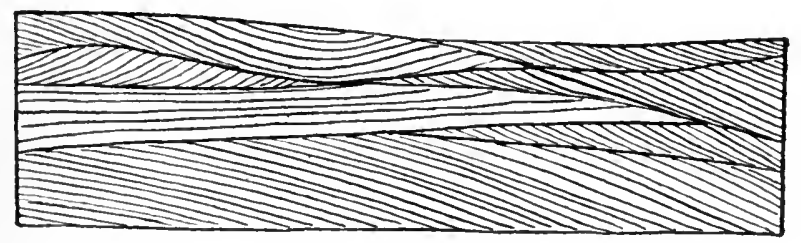

F1G. I20. Cross-bedding in Sylvania Sandstone (Siluric). (After Sherzer and Grabau.) Scale $\mathrm{I}: 80$.

of deposit (Sherzer and Grabau-45:72). This rock consists of well-rounded grains of quartz, of nearly uniform size, and seldom carrying over 3 per cent. impurities, these being mainly calcium and magnesium carbonates. In fineness, uniformity of size, roundness of grain and purity of composition it outrivals the most typical modern desert sands, such as are found in various parts of the Libyan and Sahara deserts. Cross-bedding of the eolian type is well developed, as shown by some of the accompanying sketches (Figs. I19, I20). Altogether this deposit ranges in thickness up to 300 feet, and is distributed over an area of more than six degrees east and west longitude and four degrees north and south latitude. It may be regarded as one of the best examples of a ralieozoic dune sand deposit known to us. 


\section{Volcanic Dust Deposits.}

As lias been shown in an earlier chapter (II), the fine dust resulting from explosive eruptions of volcanoes is carried far and wide over the surface of the earth and becomes a part of many widespread contemporaneous deposits. Of the 18 cubic kilometers ( 4.3 cubic miles) of volcanic dust and cinders thrown into the air on the explosion of Krakatoa in 1883 , one-third fell at a distance of more than I 5 kilometers or 9.4 miles from the seat of disturbance. At a distance of 1,000 miles from the volcano ashes still fell inches deep. Shaler has estimated that not less than 300 cubic miles of fine dust have been discharged by the Javanese and Malayan volcanoes since 1770 , and more than an equal quantity of such dust has been thrown into the air by other volcanoes of the earth during the same period. The settling of this material all over the surface of the earth forms an important addition to the eolian rocks of the crust.

In character this volcanic dust consists of minute angular grains of vitreous or glassy material, often showing by their curved form that they are parts of the walls of glass bubbles. This material has been recognized in deposits of various ages among the stratified series of the earth's crust. Extensive deposits of anemopyrolutytes and pyrarenytes have been found in the Tertiary of South America, especially in Patagonia, where the remains of mammals are found in it. Sinclair (47) has found that the Bridger (Eocenic) beds of Wyoming are largely composed of such material, though crossbedded fluviatile deposits of sanidine and other sands are likewise characteristic. The fine pyrolutyte of the Florissant basin is an example of deposition of volcanic dust under playa lake or river flood plain conditions with the entombment of many remains of terrestrial organisms. Pyrolutytes and pyrarenytes are common in many regions of the earth, but the conditions of their deposition are not fully understood in most cases.*

\section{Special Indicators of Eolation.}

Rocks of terrestrial origin are not infrequently characterized by the presence in their mass of wind-carved pebbles or glyptoliths. $\dagger$ These are commonly dreikanter, and they indicate that for a time at least the region containing them was above sea-level and subject

\footnotetext{
* See further under pyroclastic rocks, Chapter XII. † Woodworth, 53a.
} 
to the sweep of the prevailing winds. These dreikanter may then be buried in deposits of eolian, fluviatile and even marine origin, but only in the first case are they likely to be left in an undisturbed position.

Besides being found in abundance in desert and semidesert areas of to-day (see ante, Chapter II), they are also known from a number of older deposits. They have been described by Walther from the pre-Cambric Torridon sandstone of Scotland, and they are not uncommon in the basal Cambric Eophyton sandstone of Sweden. At the other end of the scale they are found in Pleistocenic deposits of Germany and North America, where in some cases, as at Cape Cod, Massachusetts, they are buried by subsequent fluviatile and eolian deposits in the position in which they were formed. (Davis.) They have also been found in the Triassic beds of England, where wind-corraded and polished surfaces, and surfaces showing insolational flaking also occur.

Accumulations of pebble beds, especially where the pebbles are covered with desert varnish, may in some cases also be traced to extensive eolation, which removed all the finer material and subsequently buried the residual pebble beds under new accumulations of eolian sands and dust. What seem to be pebbles of this kind buried by dunes of oölites, which have since been changed to iron appear at the base of the Siluric section in Wisconsin.

\section{Calcareous and Other Nonsiliceous Eolian Sands.}

Recent and Tertiary Examples. On Bermuda, where siliceous material is wanting, the dunes are composed entirely of calcareous material. This consists in part of fragments of shells and in part of coral sand, while foraminiferal shells (Orbiculina, etc.) frequently make up a considerable portion of the deposit. The older dune sand of the islands has been consolidated into a hard rock (anemocalcarenyte, Bermudaite), which is locally known as "sandstone," though nearly pure calcium carbonate. Shells of Helix and Livona are enclosed in this calcarenyte, the former a land shell, the latter marine. These shells of Livona in some cases were carried into the dune sand by the wind, but in others they were buried, together with Arca, Chama and Tellina, by the dunes which advanced over the site on which they grew. Below the beds of calcarenyte are finer layers, some of them calcilutytes, and, like the calcarenytes, they generally show wind-drift structure and fine lamination. Eolian limestones composed almost wholly of oölite grains are now 
forming on the shores of Great Salt Lake in Utah, where oölites are constantly developing through the activities of unicellular algæ. Eolian limestones in which the grains are Foraminifera and particles of shells may also be deposited by the wind many miles inland and often high above the level of the sea. These deposits are stratified and cross-bedded and probably more common than generally assumed, since they are usually taken for marine deposits. The absence of marine organic remains larger than those transportable by wind, however, indicates their eolian origin, while the presence of land animals is an additional piece of evidence. Limestones of this type have been described from the coast of the Arabian Sea (Evans-14:578-580), where they constitute the Miliolitic formation, so called on account of the abundance of the foraminifer Miliola. The Junagarh limestone overlying the Deccan trap in the Kathiawar Peninsula of western India is a typical example of this kind of rock. It underlies the city from which it takes its name, at a distance of about 30 miles from the sea, and has a thickness probably exceeding 200 feet. It is mainly formed of calcareous particles derived from shallow-water organisms of recent types, each particle being ordinarily surrounded by an envelope of deposited carbonate of lime, the whole being bound together by a later cement of the same material. Interspersed with the calcareous grains are minute mineral fragments derived from the igneous rocks of the neighborhood, but they constitute only from 6.5 to 12.5 per cent. of the whole. The limestone is divided by horizontal planes into tiers 3 to 4 feet thick, the division planes marking decided breaks in deposition. Between the planes the lamination is very oblique and cut off abruptly, both above and below, by the major division planes. Usually the inclination is different on either side of the plane, the direction, which is generally to the east, remaining constant, or varying even to reversal. The angle of inclination with the horizontal may be anything up to $30^{\circ}$, and may vary from point to point of the same division of the rock, though on the whole it is rather regular.

In other parts of the Kathiawar Peninsula similar conditions exist, and it has been found that the rock is purer in proportion to its distance from the sea, along the border of which it is not infrequently mixed with much siliceous sand. (Fedden-15.) Sometimes, as on the south coast of the peninsula, the beds are rubbly and earthy, and in them have been found two specimens of Bulimus, two of Helix and one of Cyclotus. On the coast, at Veráwal, the Miliolite limestone passes laterally into an open, porous, sandy rock, made up very largely of organic fragments and minute organisms, 
resembling a raised beach in the vicinity. In the interior the "miliolite" is stated to occur "capriciously in the gorges of the hills or as patches on their sides like remnants of a snowdrift," while on Chotila Hill it forms a fringe around the truncated top at a height of $I, 173$ feet above sea-level. Other more siliceous deposits of this type are known from Cutch, where they form a "concrete" on low ground and at the foot of the hills bordering the Rann, with strong. oblique bedding and with shells of the land snail Buliminus.

Limestones of the Junagarh type are also well developed on the southeastern seaboard of Arabia, overlying the nummulitic limestone or sometimes resting directly on the granite. These form white-domed hills of calcarenyte of unknown thickness and from 100 to 200 feet above the level of the sea, extending inland as far as the eye can reach. On the sea border they show scarps up to a hundred feet in height. The rock contains hardly a fossil laiger than the size of the grains composing it, though in some localities large shells of Hippopus and Ostrea, as well as corals, are abundant in this rock up to 40 feet above sea-level, indicating former submergence to that extent. A small quantity of hyaline quartz and dark specks, probably hornblende, also occur. The calcareous particles are largely remains of minute Foraminifera. (Carter-8:33, 34.) The age of all of these limestones is not older than late Pliocenic; indeed,. some of them are forming now near the coast. The Junagarh limestone is believed to have been formed from the material blown inland from the coast, but Evans doubts if it has been carried from the present coast 30 miles away. He holds rather that at the time of the formation of this rock the peninsula stood some I 50 feet lower than at the present day, and had the character of an island or group of islands.

Microscopic examination of the foraminferal shells of the Junagarh limestone by Dr. Frederick Chapman shows that they are in most instances worn and polished apparently by eolian action. At 30 miles from the sea the common or frequent forms are Miliolina trigonula (Lam), M. cf. oblonga (Montagu), Pulvinulina repanda (F. and M.), Nonionina communis (d'Orb), Polystomella striatopunctata, Amphistegina lessonii (d'Orb). Other rarer genera are Discorbina, Truncatulina, Rotalia and (?) Operculina. Some Ostracoda were also present, much worn and polished.

The Montpelier limestones of Jamaica (Hill-23:137) may also belong to this type. They have a thickness of 500 feet, and are almost entirely composed of foraminiferal remains, especially Orbitoides, Nummulinæ, and Miliolidæ, all shallow-water forms. There is, however, a total absence of macroscopic fossils, which, if the 
deposit is marine rather than eolian, is at least a surprising fact.

Extensive false-bedded limestones composed almost entirely of comminuted marine shells and containing bones of land animals in places occur near Cape Town in South Africa, and belong probably to this type of deposit. (Rogers and Schwartz-43.) Windblown calcareous deposits of almost pure foraminiferal shells, and consisting of subglobular Miliolinæ and inflated Truncatulina lobatula, have been found on the Isthmus of Earawalla, between Dog's Bay and Gorteen Bay, on the southwestern coast of Galway, Ireland. They form low dunes covering an area 1,000 yards from northeast to southwest, and about 350 yards from bay to bay. Land shells occur at intervals, but very few if any marine shells, except such as appear to be derived from kitchen middens in the vicinity,

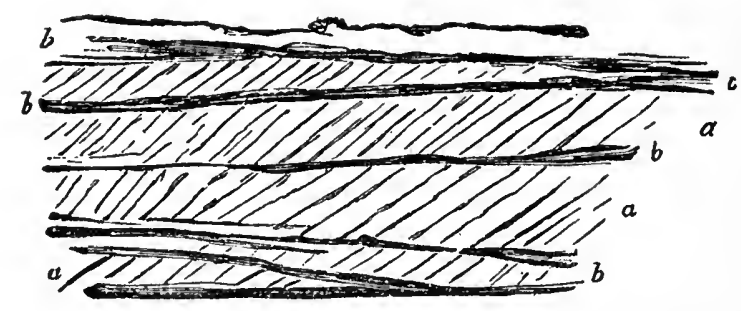

F1G. I2I. Cross-bedding in Jurrasic oölites of Somersetshire, England. (After De la Bèche.) a, $a, a$, diagonal layers of broken shells, fish-teeth, pieces of wood, and oölite grains, lying in plane of diagonal bedding. $b, b, b, b$, mud layers.

or have been carried up by birds for food. The surface drift in the North Atlantic, together with local currents, carries an abundance of Foraminifera into Dog's Bay, where every high tide spreads them over the gently sloping strand, together with small Gastropoda. They dry rapidly and are carried landward by the wind, the whole surface sometimes being in a state of rolling motion. Foraminifera, Ostracoda, fragments of shells, etc., thus travel across the isthmus, sometimes into the bay on the opposite side. These organisms are not surrounded by an extra coating of lime, as in the case of the Indian examples, probably because such chemical deposition of lime is less characteristic of cooler climates.

Wind-carried Foraminifera have been found in the eastern desert of Egypt, in the sands obtained near the foot of a gully in the hills, about a mile west of the Gulf of Jemsa, on the western side of the Red Sea. On the islands in the Red Sea no siliceous sand is to be found, as a rule. The sands are calcareous, and are chiefly formed-from comminuted fragments of corals and shells, as 
on Gaysum Island, or of Foraminifera, as on the southern side of Gaysum Island, where Orbitolites complanata is the predominant form.

Older Examples. Some of the Jurassic oölites of Great Britain appear also to belong in the category of wind-drifted calcareous sands. De la Bèche (3) figures a pronounced cross-bedding structure of the Forest marble (oölite) of Somersetshire, here reproduced. (Fig. I2I.). The diagonal layers are "composed of broken shells, fish teeth, pieces of wood and oölitic grains, sometimes mere rounded pieces of shells, the various substances lying in the planes of the diagonal layers, and presenting every appearance of having been shoved or pushed over the more horizontal surfaces formed
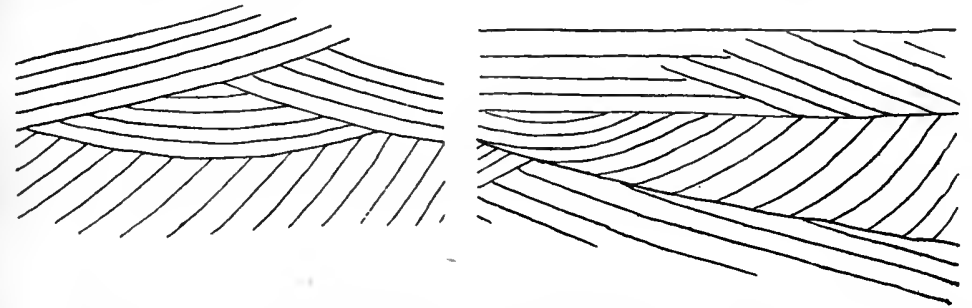

FIgs. 122a and b. Cross-bedding of uniform-grained St. Louis limestone (calcarenyte), south of St. Louis, Mo. Scale $1: 25$.

during the intervals between the mud deposits." The cross-bedding is rather more regular than that of wind deposits generally, and suggests the torrential type. De la Bèche states that the Bath oölite of Somersetshire is likewise of this type, the rounded fragments being drifted together with the true oollite grains. According to Evans ( $14: 580$ ), the grains of the Great Oölite often show a worn character, suggesting abrasion by the wind, and he holds that the false-bedded oolites which succeed the Stonesfield slates are not improbably of eolian origin. Personal examination of a number of these British oölites has convinced the author of their remarkable resemblance to wind-drifted sands. The cross-bedding figured above (Fig. I22), from the Mississippic calcarenytes of Missouri, also suggests an anemoclastic origin for at least a portion of this rock.

Possible application to othe chalk beds. The remarkable composition and the structural characters of the White Chalk of western Europe have commonly arrested attention and given rise to speculation regarding its origin and mode of deposition. At first it was thought that the deep-sea Globigerina ooze forms a modern analogue of this deposit, but when it was found that the foraminiferal shells composing the chalk were very largely of shallow-water 
benthonic forms this hypothesis had to be given up. Nor would the character of the adjacent deposits bear out such an interpretation. The absence of stratification in some parts and the fineness, homogeneity, and uniform character of the deposit give it a loesslike aspect. The fossil echinoderms and other macroscopic organisms, which are found at intervals, suggest proximity to the sea, with occasional inundations, though dead echini tests might readily be blown inland as well.

The layers of flints in the chalk have a similar rude horizontality to that assumed by the Loessmännchen in Pleistocenic structureless loess, and like these are of secondary origin, and not necessarily evidence of stratification. Such an arrangement may express rather the periodic stand of the ground water as suggested by Potonié. Where regular stratification and an abundance of macroscopic organisms are found, a submarine origin no doubt must be maintained.

Dunes of Gypsum. A remarkable type of dune sand has been described from New Mexico. This is the white sand of Otero county which forms a tract of dunes of nearly pure granular gypsum covering an area of about 350 square miles. The gypsum sand is derived from the "ribs" of gypsum which rise above the salt flats in successive ridges. These gypsum beds belong to the Red bed series of Permic age. The action of the elements soon breaks up the exposed gypsum crystals into small grains, which are carried away by the wind and piled up into dunes. The salt and alkaline salts forming on the surfaces of the salinas are also driven with the gypsum, but on account of their solubility do not remain in the dunes. (Herrick-22.)

\section{BIBLIOGRAPHY XIII.}

r. ANDERSON, J. G. I906. Solifluction, a Component of Subaërial Denudation. Journal of Geology, Vol. XIV, No. 2, pp. 9I-I 12.

2. BARRELL, JOSEPH. I906. Relative Geologic Importance of Continental, Littoral, and Marine Sedimentation. Journal of Geology, Vol. XIV, pp. 3 I $6-356 ; 430-457$.

3. BECHE, SIR HENRY T. DE LA. I85I. The Geological Observer.

4. BERENDT, G. I 869 . Geologie des Kugischen Haffẻs und seiner Umgebung. Königsberg.

5. BLANCK, EDWIN. 1907. Ueber Kalkkonkretionen Landw. Vers., Vol. LXV, pp. $47 \mathrm{I}-479$.

6. CALL, RICHARD E. 188r. Fossils of the Iowa Loess. American Naturalist, Vol. XV, pp. 585-586.

7. CAPPS, STEPHAN R. I910. Rock Glaciers in Alaska. Journal of Geology, Vol. XVIII, No. 4, pp. 359-375. 
8. CARTER, J. H. I852. Journal of the Bombay British Royal Asiatic Society, Vol. IV, pp. 33-34.

9. CHAMBERLIN, T. C., and SALISBURY, R. D. 1885. The Driftless Area of the Upper Mississippi. 6th Annual Report of the United States Geological Survey, part I, pp. 205-322, pls. XXIII-XXIX (American Loess).

I0. CLARKE, F. IV. I9II. The Data of Geochemistry. Bulletin of the United States Geological Survey, No. 49I.

I1. DARWIN, CHARLES. I84I. Voyage of the Beagle.

12. DARWIN, GEORGE. I 884 . On the Formation of Ripple Mark in Sand. Proceedings of the Royal Society of London, Vol. XXXVI, pp. I8-43.

13. DAVIS, WILliAM M. I 899. Physical Geography. Ginn \& Company, Boston.

I4. EVANS, JOHN W. 1900. Mechanically-formed Limestones from Junagarh (Kathiawar) and Other Localities. Quarterly Journal of the Geological Society of London, Vol. LVI, pp. 559-583; 588-589.

15. FEDDEN, F. I885. Memoirs of the Geological Survey of India, Vol. XXI, pp. 126-I 28.

I6. FORCHHAMMER, G. 184I. Geognostische Studien am Meeresufer. Neues Jahrbuch für Mineralogie, Geologie und Palæontologie, pp. I-38.

17. FREE, E. E. I9I. The Movement of Soil Material by the Wind. United States Department of Agriculture, Bureau of Soils, Bulletin 68.

18. GÖTZINGER, G. I907. Beiträge zur Entstehung der Bergrückenformen. Geographische Abhandlungen, Band IX, Heft I.

19. GRABAU, A. W. I907. Subaerrial erosion cliffs and talus in the lower Devonic of Michigan, Science, N. S., Vol. XXV, pp. 295-296.

20. HEIM, ALBERT. I 882. Der Bergsturz von Elm. Zeitschrift der deutschen geologischen Gesellschaft, Vol. XXXIV, No. 4, pp. 74-II5.

21. HELMAN, C. H. I89I. Beobachtungen über die Bewegung des Flugsandes im Khanate von Chiwa. "Izwestija," d. kais.-russ. geogr. Gesellschaft, Vol. XXVII, pp. 384 (in Russian).

22. HERRICK, C. L. Igoo. The Geology of the White Sands of New Mexico. Journal of Geology, Vol. VIII, pp. I I 2-I 28.

23. HILL, R. T. I899. The Geology and Physical Geography of Jamaica. Bulletin of the Museum of Comparative Zoology at Harvard College in Cambridge, Vol. XXXIV, pp. I-226. Appendix by T. Wayland Vaughan on Some Cretaceous and Eocene Corals from Jamaica, pp. 227-256.

24. HOWE, ERNEST. 1907. Landslides in the San Juan Mountains, Colorado, including a consideration of their causes and their classification. United States Geological Survey, Professional Paper 67.

25. HUNTINGTON, ELLSWORTH. I907. Some Characteristics of the LGlacial Period in Non-Glaciated Regions. Geological Society of America Bulletin, Vol. XVIII, pp. 35I-388, pls. 3I-39.

26. KEYES, CHARLES R. 1908. Geologic Processes and Geographic Products of the Arid Region. Geological Society of America Bulletin, Vol. XIX, pp. $570-575$, pls. $38-4$ I.

27. LEVERETT, FRANK. I 899. The Illinois Glacial Lobe. United States Geological Survey, Monograph XXXVIII, pp. 167-I77 (American loess).

28. LOMAS, JOSEPH. I906. On the Origin of the Trias. Proceedings of the Yorkshire Geological Society, N. S., Vol. XVI, pp. 15-20.

29. LOMAS, J. 1907. Desert Conditions and the Origin of the British Trias. Geological Magazine (V), Vol. IV, pp. 5II-5I4; 554-563. 
30. LOOMIS, F. B: 1909. Turtles from the Upper Harrison Beds. Nebraska Miocenic. American Journal of Science, 4th series,Vol. XXVIII, pp. 17-26.

31. MATTHEW, W. D. I899. Is the White River Tertiary an Eolian Formation? American Naturalist, Vol. XXXIII, pp. 403-409.

32. McCONNELL, R. G. I903. Report on the Great Landslide at Frank, Alberta, 1903. Annual Report of the Geological Survey of Canada, Vol. XV, p. 34aa.

33. McGEE, W. J. I89I. The Pleistocene History of North Eastern Iowa. Annual Report of the United States Geological Survey, Vol. XI, part I, pp. 19I-257.

34. MILLER, W. J. I9I0. Origin of the Color in the Vernon Shales. Bulletin of the New York State Museum of Natural History, 140. 6th Report of Director for 1909, pp. 150-156.

35. PALGRAVE, W. G. I 865 . Narrative of a Year's Journey through Central and Eastern Arabia, Vol. I.

36. PASSARGE, S. I904. Die Kalahari. Berlin.

37. PENCK, ALBRECHT. I894. Morphologie der Erdoberfläche, Vol. II., Stuttgart.

38. POOL, RAYMOND J. I9I3. Glimpses of the Great American Desert. Popular Science Monthly, Vol. LXXX, pp. 209-235.

39. PRZHEVALSKY, N. M. (Prjevalsky). 1883. Dritte Reise durch central Asien.

40. PUMPELLY, RAPHAEL W. I879. Relation of Secular Rock Disintegration to Loess, and Glacial Drift and Rock Basins. American Journal of Science, 3rd series, Vol. XVII, pp. I33-I44.

41. PUMPELLY, R. W. 1908. The Physiography of Central Asian Deserts and Oases. Carnegie Institute, Publication 73, Vol. II, pp. 243-387. Washington.

42. RICHTHOFEN, FERDINAND VON. 1877. China, Vol. I.

43. ROGERS, A.W., and SCHWARTZ, E. H. L. I 898 . Transactions of the South African Philosophical Society, Vol. X, pp. 427-436, pl. X.

44. RUETSCHI, G. I9I I. Vorlängige Mittheilungen über die Veränderungen des Unterseebeckens (Bodensee) durch das Erdbeben von 16 November, I9II. Jahresberichten und Mittheilungen des oberrheinischen geologischen Vereins, N. F., Bd. II, Heft I, pp. Io8-I I 8.

45. SHERZER, W. H., and GRABAU, A. W. 1909. The Sylvania Sandstone, Its Distribution, Nature and Origin, Michigan Geological and Biological Survey, Geological Series I, pp. 6I-86, pls. II-VII, and text figures.

46. SHIMEK, B. I904. Loess Papers. The Loess of Natchez, Miss. The Loess and the Lansing Man. The Lansing Deposit Not Loess. Loess and the Iowan Drift. Evidences (?) of Water-Deposition of Loess. Bulletin from the Laboratories of Natural History of the State University of Iowa, Vol. V, No. 4, pp. 298-38I.

47. SINCLAIR, W. J. I906. Volcanic Ash in the Bridger Beds of Wyoming. Bulletin of the American Museum of Natural History, Vol. XXII, pp. $273^{-280}$.

48. SOKOLOW, N. A. I 894 . Die Dünen, Bildung, Entwickelung und Innerer Bau. Deutsche vom Verfasser Ergänzte Ausgabe von Andreas Arzreni. Berlin.

49. STAMM, K. I9II. Schuttbewegungen. Geologische Rundschau, Bd. II, pp. $167-177$.

50. STUNTZ, S. C., and FREE, E. E. 19II. Bibliography of Eolian Geology. United States Department of Agriculture, Bureau of Soils, Bulletin 68. 
51. UDDEN, JOHAN A. I898. The Mechanical Composition of Wind Deposits. Augustana Library Publications, No. I.

52. WALTHER, JOHANNES. I89I. Die Denudation in der Wüste und ihre geologische Bedeutung. Abhandlungen der königlich sächsischen Gesellschaft der Naturwissenschaften. Bd. XVI, pp. 347-569.

53. WALTHER, J. I90o. Das Gesetz der Wüstenbildung in Gegenwart und Vorzeit, Berlin. 2nd edition, I912, Leipzig.

53a. WOODWORTH, J. B. 1894. Post-Glacial Eolian Action in Southern New England. American Journal of Science, 3rd ser. Vol. XIVIII, pp. 63-7I.

54. WRIGHT, G. FREDERICK. I902. Origin and Distribution of the Loess in Northern China and Central Asia. Bulletin of the Geological Society of America, Vol. XIII, pp. I27-I38.

55. WRIGHT, G. F. I904. Evidence of the Agency of Water in the Distribution of the Loess in the Missouri Valley. American Geologist, Vol. XXXIII, pp. $205^{-222}$.

56. ZITTEL, KARL A. VON. 1883. Beiträge zur Geologie und Palæontologie der Libyschen Wüste. Palæontographica, XXX. 


\section{CHAPTER XIV.}

\section{ORIGINAL STRUCTURE AND LITHOGENESIS OF THE CONTI- NENTAL HYDROCLASTICS.}

A very large, perhaps the largest, portion of the stratified clastics of the earth's crust consists of water-laid deposits, or hydroclastics. By this is not meant that they were deposited in standing water, though this is true of a large portion of them, but that water was influential in the making of the deposit. They therefore include river-laid clastics as well as those formed in the sea or in lakes.

Hydroclastic rocks may be divided into the following groups:

I. Stream or river-laid clastics (potamoclastics).

2. Lake or lacustrine clastics (limnoclastics).

3. The Delta-a transitional deposit.

4. Marine clastics (haloclastics).

Each of these will admit of a number of subdivisions. The potamoclastics and limnoclastics, together with the atmoclastics, anemoclastics, pyroclastics, and autoclastics belong to the continental or terrestrial type of clastics, as opposed to the marine or haloclastics. Seacoast deltas form the transition from the one to the other. The continental hydroclastics, together with the delta deposits, will be considered in this chapter; the marine hydroclastics being reserved for the next.

\section{RIVER-LAID CLASTICS, OR POTAMOCLASTICS.}

All along the river course, from near the head to the mouth, clastic deposits may be forming, their character and amount varying with the character of the stream and its environment. Under the latter, the kind of rock material and climate must be mentioned as all-important controlling factors. The amount of weathered rock material available for transport and final deposition is also of the greatest importance. We may consider the clastic river deposits under the following headings: 
a. Alluvial fans.

b. Flood plains.

c. The playa-a temporary expanse of certain rivers.

Considering the classes of streams mentioned in Chapter III (p. 129), it may be noted that the deposits of consequents and insequents are essentially alike, those of overflow streams may be neglected as insignificant, but deposits of glacial streams, from their abundant supply, are of the greatest importance. Only the residual clays of subterranean streams need to be considered.

a. Alluvial Fans. Wherever the débris-laden stream leaves its steep mountain bed and debouches upon the piedmont belt, or the floor of a large valley, it changes from a degrading stream, or one just at grade, to an aggrading stream, since the change in the angle of the river bed brings with it decreasing velocity of the current. In its steeper development the alluvial fan grades directly into the talus and other atmoclastic deposits with which, indeed, it forms a continuing sedimentary series, the river portion often being difficult to separate from the purely atmoclastic type.

Form and Extent of Modern Alluvial Fans. In extent alluvial fans vary from an area of only a few square feet to one covering thousands of square miles. Small alluvial fans are best described as semi-cones with a surface slope which may be as high as $20^{\circ}$ or even $30^{\circ}$. As the fan increases in size its surface angle is lowered, until, in the very large deposits of this type, the surface seems almost to be horizontal. Small cones are seen to rise regularly toward the notch in the hills through which the river debouches, but in the very large alluvial fans there may result a confluence of many adjoining deposits, which will obliterate the effects of regularity. On all large fans, whether simple or confluent, erosion channels abound, for the streams building the deposits divide near the head of each fan into numerous distributaries, each of which, when not depositing, will be eroding. Thus a succession of contemporaneous erosion surfaces will result, and later beds will be deposited on the eroded surfaces of the older. In this manner the effect of a disconformity may be repeatedly produced within the depositional unit, and such apparent disconformities might lead to grave misinterpretations of the age and relationships of the adjoining beds. Should y by subsidence, the sea cover such an alluvial fan of great extent, a decided break would appear between the nonmarine and marine strata, the latter gradually encroaching by overlap upon the eroded surface of the old subaërial fan.

Among the large alluvial fans or dry deltas of modern times 
may be mentioned that of the Merced in California. of the Garonne at the northern base of the Pyrenees, the delta of the Cooper River in the Lake district of South Australia, the great flood plain delta of the Huang-ho or Yellow River of China, and the similar but compound Indo-Gangetic delta plain of northern India.

The Merced River of California rises in the Sierra Nevadas and carries much waste down their steep western slopes. Reaching the broad open valley of California, which lies between the Sierra and the Coast range, it has built a fan which at present has a radius of about 40 miles. This consists of gravel near the mountain, and of fine silt at a distance. On account of the gentle slope of the surface, the water is turned readily from one channel into the other at the head of the fan.

"The many rivers issuing from the valleys of the Sierra Nevada and the Coast range upon the 'Valley of California' have formed an extensive plain, of which the Merced fan, . . . is only a part. The successive fans are so broad and flat that their slightly convex form can hardly be recognized without the aid of surveying instruments. Nearly all the streams run in shallow channels, but little beneath the gently sloping surface of the fans. The fans from the east and west meet in a broad, flat-floored trough." (Davis-18:29I.)

River-made plains of this type are formed on both sides of the Alps. Those on the south have begun to cut valleys into the old deposits, while those on the north have cut to a depth of $\mathrm{I}, \mathrm{OoO}$ feet, leaving the former plain as a series of ridges. The river Po flows eastward between the broad plain built by the rivers from the high Alps on the north, and the narrower one built by the streams from the lower Apennines. Where it enters the Adriatic Sea the Po builds a normal delta.

While the material of this river plain is typically a subaërial deposit, intercalated marine beds are not wanting. They have been reported from the Venetian region where they represent periodic encroachment of the sea. (Penck-4I.)

One of the most extensive of modern dry deltas is that of Cooper Creek in the Lake district of South Australia. Its area is more than twice that of the Nile delta, its length being nearly i 85 miles and its width over Izo miles. The water in the river, however, is abundant only after strong rains, the various distributaries being changeable canals on the surface of the delta. (Petermann-43.)

Even larger than the Cooper Creek alluvial fan is that of the Huang-ho or Yellow River of China. Its head is about 300 miles 
from the present shore, and has an elevation of only 400 feet above sea-level. It has thus an average fall of $\mathrm{I} 1 / 3$ feet per mile, a slope so gentle that it is imperceptible. Along the coast the fan extends from near Pekin southward for about 400 miles to where it joins the great plains of the Yang-tse-kiang, being interrupted, however, by the mountainous province of Shantung.

Owing to the very gentle slope of the fan the overflow at its head and the corresponding diversion of a distributary will result in the inundation of vast areas. The mouth of the river has been shifted more than 200 miles north or south, such shiftings having been numerous during Chinese history. "The flood of 1887 covered an area estimated at 50,000 square miles, immensely fertile and swarming with villages. The number of people drowned was at least a million and a greater loss followed from famine and disease caused by the flood." (Davis-18:290.) Flood plain fans of this type thus furnish excellent examples of the manner of destruction and burial by river silts of terrestrial organisms, and they further illustrate how peat deposits in swamps may be buried to be converted in the course of time into coals. The material carried by the Yellow River is mostly fine silt derived from the loess in the interior, which from its color gives the name to the river. The fineness of the material accounts in part at least for its very gentle slope, for it can be carried to great distances before it settles out.

Growing steadily but slowly seaward it is, of course, inevitable that marginal marine deposits should be enclosed in the growing fan. Very slight depression of the land would cause a partial flooding by the sea, with accompanying marine deposits. In its seaward growth the great delta has annexed the former rocky island, which is now the Province of Shantung.

The Indo-Gangetic alluvial plain is an example of a river plain formed of many confluent dry deltas and carried forward by the two great rivers of northern India-the Indus on the west and the Ganges, with the tributary Brahmaputra, on the east. Numerous small streams feed these rivers from the south slope of the Himalayas, carrying an abundance of coarse and fine débris. (Oldham-40.) The great alluvial plain extends over an area of about 300,000 square miles, and comprises the richest and most populous portion of India. It varies in width from 90 to nearly 300 miles, and entirely separates the lower peninsula of India from the Himalayas to the north. It rises 924 feet above the sea in its highest portion, and the deepest boring has located these deposits at a depth of nearly a thousand feet below the present sea-level. This is at 
Lucknow, which lies approximately midway between the Indus and the Ganges headwaters and about 370 feet above sea-level. It abounds in gravels and conglomerates near the sloping borders, but lutaceous or clayey deposits, more or less arenaceous, prevail over much of the plain, especially near the center, with only subordinate deposits of sand, gravel, and conglomerates. Beds of blown sand of great thickness are found in some regions. Pebbles are scarce at a distance of more than twenty or thirty miles from the enclosing hills. Shells of river and marsh molluses are occasionally found, and calcareous concretions and nodules of irregular shape, locally known as kankar, are frequent. "The more massive forms are a variety of calcareous tufa, which sometimes forms thick beds in the alluvium and frequently fills cracks in the alluvial deposits, or in older rocks." (Oldham-40:437.) Calcareous tufas also form conglomerates in the stream beds by cementing pebbles derived from the hills. In the clays along the borders and in the shoals of the Jumna River a great variety of vertebrate remains has been found, including elephant, hippopotamus, ox, horse, antelope, crocodile, and various fish. Borings in other regions revealed the presence of peat, forming extensive beds to a depth of 20 to 30 feet below the surface, while a layer of stiff blue clay I $_{5}$ feet in thickness was found io feet below the surface at Calcutta. Clay and variegated sand with calcareous concretions, mica and small pebbles alternated to a depth of 120 feet, below which a quicksand was found. At I 52 feet this became dark and coarse of grain and intermixed with red water-worn nodules of hydrated iron. At 159 feet a stiff clay was found which, at 163 feet, became friable and contained much vegetable and ferruginous matter. Lower still fine and coarse sands alternating with clays occur, while at 340 feet a ruminant bone was found, and pieces of tortoise shell at still greater depth. Three hundred and ninety-two feet below the surface pieces of coal, such as are found in the mountain streams, and fragments of decayed wood were found in the sand, while below 400 feet sand and shingle of fragments of primary rocks abounded. The borings also showed wood, remains of terrestrial mammals, fluviatile reptiles, and fresh-water molluscs. No traces of marine fossils have been found. The presence of earthy limestones in these deposits is of especial interest, because it shows that limestones do not necessarily indicate lacustrine or marine conditions. As already noted, in northern Mexico and other tropical regions of America, a superficial crust of white lime, often free from foreign material, is formed. This material, called tepetate, has been dissolved from the limestones of the surrounding region, transported in solution by 
the streams, and then redeposited by evaporation. (Hill and Vaughan-30:2.56.)

Basins Filled by River-IVashed Waste. There are many examples of great basins surrounded by mountains and filled to a certain extent by the waste washed from the mountains. The larger of these basins are generally formed by tectonic movements, the process being a downwarping. An example of such a valley holding a "waste lake" is the upper Arkansas valley, back of the Front Range of the Rocky Mountains. As the basin was forming by warping, the rivers deposited their load on its floor, while at the same time the outlet of the Royal Gorge was being cut through the Front Range. The plains of waste within the basin slope forward from the mountainsides, but they have been only slightly dissected so far. Another excellent example is found in the Vale of Kashmir, enclosed by the front and middle ranges of the Himalayas in northwest India. In area this vale equals that of the Connecticut, being elliptical in form, a hundred miles long from southeast to northwest, and forty or fifty miles broad. It is formed by a downwarping between two lofty mountain ranges, which, for the most part, have very steep sides. The floor of the valley is deeply filled with river-laid waste, coarse near the mountains, but free from pebbles at the center. Its depth is measured probably by thousands of feet, while its surface elevation is more than 5.000 feet above sea-level. Across this plain meanders the Jhelam River, which escapes by a deep gorge through the enclosing mountains. Southern Europe furnishes another good example of a wastefloored basin in the oval plain of Hungary, which has a diameter of about 200 miles. Gravelly, sandy and loamy materials brought by the rivers from the enclosing mountains have formed this plain. which rises slightly toward the mountains, where it is formed of gravels, while the level center is a fine silt plain, resembling an abandoned lake bottom. The Danube and its tributaries meander through it and escape by the leep gorge of the Iron Gate cut through the Transylvanian Alps.

A somewhat similar basin lies in southwestern Wyoming, within the embrace of a series of mountain ranges, the Wasatch on the west, the Uinta on the sonth, and the Wind River Ranges on the north and east. The Green River flows through this basin and escapes by a deep canyon through the Uinta Monntains. The original deep filling of waste material has now been extensively trenched by the rivers and converted into a dissected upland, with valleys cut into the old waste deposit, in some cases a thousand feet 
deep. Other waste basins of this kind are found in Spain, Italy, and clsewhere.

In arid regions the basins often have an inward drainage and are filled by the combined atmoclastic creep and the river wash. Fans with their heads rising 500 feet or more above their bases and extending ro or 15 miles outward characterize such basins. The water of the stream evaporates or sinks into the ground before the center of the basin is reached. When such fans become confluent they form huge waste plains of relatively steep grade, filling the valleys and partly burying the mountain slopes. In Utah, Nevada, and Arizona depressions of great depth have thus been wholly filled, while the waste mantle backs up 2,000 or 3,000 feet on the mountain flanks.

"A great part of Persia consists of large basins enclosed by mountains and without outlet to the sea. Long waste slopes stretch forward 5 or 10 miles with a descent of 1,000 or 2,000 feet, stony near the mountain flanks, and graduaily becoming finer-textured and more nearly level. The central depressions a re absolute deserts of drifting sands, with occasional saline lakes or marshes.

"Central Asia repeats the same conditions on a still larger scale. The basin of eastern Turkestan includes many half buried ranges in its central part. It is quite possible that some ranges are completely covered with waste. Many rivers flowing from the mountain rim wither on their way toward the chief central depression; only the largest river (Tarim) reaches it, there spreading out in Lob (Lake) Nor. The chicf settlements are near the border of the basin, where the larger rivers come out from the mountains." (Davis-I8:3II.)

The deposits of these regions must be considered as in part at least of purely atmoclastic and anemoclastic origin.

River Flood Plains. River flood plains vary enormously in extent as well as in the character of the material. Streams with relatively steeply sloping beds may have stony flood plains, if they are abundantly supplied with coarse detritus from the head and sides. The flood plain of the Saco in the Intervale is covered with rounded cobbles and boulders, these often forming a regular cobblestone pavement. The stream is a rushing one, and in flood carries away all the finer material. A large part of the boulders and cobbles is formed of the granite of which this part of the White Mountain region is composed, but a part of the material at least is derived by the rehandling of flood-plain deposits formed during the preceding flooded stage period controlled by the melting ice of the glacial period. 
Flood plains of streams of less velocity are made up of fine materials left by the river when it overflows its banks. As most of the deposit is formed near the river the banks on either side are higher than the surface of the plain away from it, there being thus a gentle slope away from the river. In this way the natural levees of the Mississippi are built, which rise considerably above the level of the "back swamps" on either side. Here the slope away from the river east or west is 5 or Io feet to the mile, while the general southward slope of the entire flood plain is under half a foot to the mile.

A striking example of a flood plain is afforded by that of the Nile, which flows from a well-watered region through a desert country without receiving a tributary for a thousand miles, except a few small wet weather streams. Entrenched beneath the desert uplands this flood plain holds its own for a length of 500 miles, and maintains a width of from 5 to 15 miles, broadening on the delta to over 100 miles. The annual inundation of the flood plain is caused by the northward movement of the belt of equatorial rains in summer. The flood begins in June and usually rises 25 feet or more at Cairo in the late summer or early autumn. The annual addition of the river silt causes a slow rising of the entire flood plain estimated to amount to $4 \frac{1}{2}$ inches a century.

This region furnishes an instructive example of widely varying contemporaneous deposits within the same general area. On the one hand occur the drifting, cross-bedded, well rounded and pure quartz sands of the desert, and, on the other, the extremely fine. well-stratified muds of the river flood plain. Both enclose the remains of organisms or of structures built by man, but there is an essential difference between the remains found in each deposit. Aside from ruins of human habitations and other works of man, only occasional remains of animals which were adapted to a dry climate are preserved in the desert sands. These, on the whole, will be rare because burial is often a slow process, and the bones of the dead creatures will crumble unless quickly covered. On the flood plain, on the other hand, aquatic organisms abound, giving a totally different faunal as well as floral association. According to the rash doctrine of the persistence of lithologic units, recently advocated by some geologists, such contemporaneous deposits would be interpreted as of different ages.

From the nature of deposits on river flood plains, perfect and often very fine stratification is to be expected. This may be considered as characteristic of typical flood plains. "The plains of the Po and of the Ganges and the great fan of the Huang-ho are very 
largely composed of fine sediments; the proportion of fine to coarse materials in the extensive deposits of these rivers seems to be greater than it is in many of the so-called lake beds of the west [of North America]." (Davis-19:36I-362.)

River flood plains consisting of fine material are especially adapted for receiving the transit impression of organisms as well as sun-cracks, rain-drop impressions, etc. Indeed, almost the only known modern examples of such structures commonly referred to seashore origin are found on river flood plains or on the surfaces of the playas.

Another feature characterizing many river flood plains is the levelness of their surfaces, which argues well for the close approximation to horizontality of their strata. Many minor irregularities

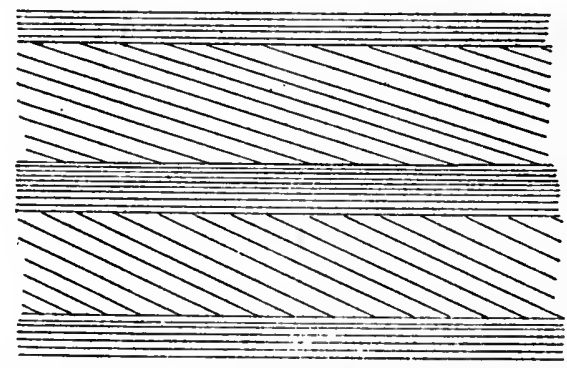

FIG. 123. Torrential iype of cross-bedding; seen in modern torrential deposits. (After Hobbs.)

will, of course, be found, such as shallow channels, filled by later deposits and other evidence of contemporaneous erosion.

Cross-Bedding of Torrential Sediments. Whenever sands and gravels are spread by torrential floods, diagonal or cross-bedding on a large scale will result. Between the nearly horizontal layers of finer sands or gravels occur beds inclined at a nearly uniform and relatively large angle with the enclosing layers. Successive crossbedded strata will have their beds slope in the same direction, which is that of the stream producing them. Such a type of crossbedding is wholly inconsistent with the theory of wave formation or of currents in a body of water. It has been observed in modern torrential deposits (Hobbs-3I:29I), and is a characteristic feature of many ancient sandstones and conglomerates, the torrential origin of which it indicates (Fig. I23). It is not an infrequent structure in the torrential deposits of the terminal moraine on Long Island. (See further, Chapter XVII.)

Thickness and Composition of River Deposits. The thickness 
of river deposits is practically unlimited, and depends on the source of supply of material and the depth of the valley in which it is deposited. Where downwarping of a piednont belt occurs, so as to form a geosyncline, the thickness of the formation may become enormous. Torrential deposits in Calabria. Italy, have been found I,500 feet or more in thickness and including boulders of many petrographic types, often exceeding a foot in diameter. The Alhambra formation of Spain is at least $\mathrm{I}, 000$ feet thick and consists mainly of river deposited pebbles distinctly water worn and varying in size from a fraction of an inch to six inches or more in length. Some of the partly dissected, but still unconsolidated torrential deposits fringing the Front Range of the Rocky Mountain region contain boulders many feet in diameter. Some torrential deposits may be entircly composed of rounded boulders with only enough sand and fine gravel to fill the interstices. Portions of the Old Red sandstone of Scotland furnish splendid examples of fossil boulcier beds of this kind.

The Siwalik formation of India furnishes an excellent example of a sub-recent fluviatile deposit of great thickness. It skirts the southern border of the Himalayas, forming the Siwalik Hills. The strata have been uplifted by the latest movement in this region and exposed by erosion. The thickness of the formation is upward of I5,000 feet, and, except at the base, where it is characterized by passage beds from the underlying marine Sirmur group, it is of non-marine origin throughout. In age it is said to range from Miocenic to Quaternary, though most of it belongs to the Pliocenic. In this formation. "sandstone immensely predominates and is of a very persistent type from end to end of the region and from top to bottom of the series. Its commonest form is indistinguishable from the rock of corresponding age known as Molasse in the Alps, and is of a clear pepper and salt gray, sharp and fine in grain, generally soft, and in very massive beds. The whole Middle and Lower Siwaliks are formed of this rock, with occasional thick beds of red clay and very rare thin, discontinuous bands and nodules of earthy limestone, the sandstone itself being sometimes calcareous and thus cemented into hard nodular masses.

In the Upper Siwaliks conglomerates prevail largely: they are often made up of coarsest shingle, precisely like that in the beds of the great Himalayan torrents. Brown clays occur oftcn with the conglomerate, and somctimes almost entirely replace it. This clay, even when tilted to the vertical, is indistinguishable in hand specimens from that of the recent plains deposit; and no doubt it was formed in a similar manner, as alluvium. The sandstone, too, of 
this zone is exactly like the sand forming the banks of the great rivers, but in a more or less consolidated condition." (Medlicott and Blanford-38:524.) The fossils of this formation are of fresh water or of terrestrial types exclusively, and they, as well as the nature of the deposit, point the continental origin of this formation. "The mountain torrents are now in many cases engaged in laying down great banks of shingle at the margin of the plains, just like the Siwalik conglomerates; and the thick sandstones and sandy clays of the Tertiary series are of just the same type of form and composition as the actual deposits of the great rivers." (Medlicott and Blanford.)

In the Salt Range of the Punjab these alternating gray and greenish sandstones and the red and light brownish orange clays "are from seventy to a hundred and twenty feet in thickness, being very frequently about a hundred feet each, but some zones are much thicker." (Wynne-62:I08.)

Depth of Compound Continental Deposits. The great amount of material which may accumulate in deserts as the product of combined creep, torrential and eolian deposit is seen from a well boring near Ashkabad, Turkestan (Walther-57:I05), which penetrated sands, clays and gravels to a depth of 666 meters without finding rock bottom. No organic remains were found, and the character of the material is similar to that of the surface deposits of the Transcaspian desert, from which it is inferred that this entire mass of over 2,000 feet of sediment accumulated under climatic and topographic conditions similar to those now prevailing.

Chatter or Percussion Marks. A characteristic feature of many boulder or cobblestone deposits of modern time as well as of former periods is the presence of numerous crescentic chatter or percussion marks on the finer grained and well-rounded pebbles, especially porphyries, quartzites, and the like. These have much the form and size of impressions made by the end of a finger nail in soft clay, and are due to the violent impact of one rounded pebble or boulder upon another. Such marks are plentifully produced by the impact, one upon another of the hard, fine-grained pebbles used for grinding in the revolving cylinders of cement mills and other works.

Organic Remains in Torrential Deposits. On the whole, organic remains will be few or absent in coarse torrential deposits. Even tough masses of wood will be shattered and completely annihilated. As a result, such deposits will be free from organic remains, though, of course, with increasing fineness of the sediment the possibility of the preservation of such remains increases. Since 
in semi-arid regions violent floods arise abruptly, sweeping down the previously almost dry river beds, and converting them in a few minutes into raging torrents, it is apparent that organisms may be surprised and suddenly overwhelmed and their remains entombed in the resulting deposits of the flood. We need only recall such disasters as that which recently befell a transcontinental railroad where the sudden flooding of a previously dry wadi swept away a trestle and its load of cars, these with their luckless passengers being buried in the sand and silt of the lower course of the stream. The many unrecorded entombments of cattle and other creatures by just such sudden floods would, if known, form adequate illustrations of the origin of many fossiliferous sandstones of the past.

One of the chief causes of the destruction of animal life on plains of subaërial deposition is found in the periodic droughts affecting these regions. The geologic effects of such droughts have been noted in many tropical countries, especially along the west coast of Africa, in India, and in South America. Darwin (17) has described the "gran seco" or great drought which occurred between the years 1827 and 1830 , when, in the northern part of the province of Buenos Ayres (South America) and the southern part of St. Fé, vast numbers of birds and animals perished, the vegetation withered and died, and the brooks became dry, until finally the whole country was turned into a dusty, waterless waste. Darwin writes: "A man told me that the deer used to come into his courtyard to the well, which he had been obliged to dig to supply his own family with water; and that the partridges had hardly strength to fly away when pursued. The lowest estimation of the loss of cattle in the province of Buenos Ayres alone was taken at one million head. A proprietor at San Pedro had previously to these years 20,000 cattle, at the end not one remained.

"I was informed by an eye-witness that the cattle in herds of thousands rushed into the Parana, and being exhausted by hunger they were unable to crawl up the muddy banks and thus were drowned. . . . Without doubt several hundred thousand animals thus perished in the river: their bodies when putrid were seen floating down the stream; and many in all probability were deposited in the estuary of the Plata. All the small rivers became highly saline, and this caused the death of vast numbers in particular spots; for when an animal drinks of such water it does not recover. . . Subsequently to the drought of 1827 to '32 a very rainy season followed which caused great floods. Hence it is almost certain that some thousands of the skeletons were buried by the deposits of the very next year." Darwin adds very pertinently, 
"What would be the opinion of a geologist, viewing such an enormous collection of bones, of all kinds of animals and of all ages, thus embedded in one thick earthy mass? Would he not attribute it to a flood having swept over the surface of the land, rather than to the common order of things?" (Darwin-I7, Chapter viii.) These droughts are of frequent occurrence and seem to show an approximate periodicity of about fifteen years.

Distances to Which Material May Be Carried by Rivers. Wade (55), in his study of the distribution of the gravels derived from the hills of igneous rock facing the western border of the Red Sea, comes to some interesting conclusions regarding the distance to which pebbles may be transported by subaërial agencies. On the eastern side of these ranges the fragments have traveled only a short distance, lying still in the plains at the foot of the hills. On the western side of the Red Sea ranges the gravels appear to have been carried along the main wadis and old lines of drainage often to great distances. "The pebbles have traveled in more or less westerly directions down the wadis, into the important north-and-south wadi which continues the line of the Nile north from Quena. They are abundant for some distance north and south of Quena. Thence they have been carried northward down the Nile Valley.

The most interesting occurrences of the rocks, which the Survey geologists say 'could only come from the Red Sea' are at Heluan, a few miles south of Cairo . . . and in the Delta itself, where they were found in the Royal Society's boring at Zagazig. Thus these rocks have been river-borne for at least 400 miles." (Wade55 :244.) The age of these gravels is Pleistocenic.

Extensive deposits of apparently river-borne pebbles are found in many older formations. In the Trias of England they have been found 300 miles from their source. The Pottsville conglomerate series of eastern North America extends northwestward for a distance of 400 miles or more, the pebbles of the series throughout being derived from the Appalachians on the southeast.

Purity and Rounding of Fluriatile Dcposits. On the whole, the material of a subaërial fan is very heterogeneous, but by prolonged reworking and the sorting action of running water a considerable assortment into kinds as well as sizes of grain may be effected. In dry climates the disintegration of granitic rocks is not accompanied by extensive decomposition. Fresh feldspar crystals will remain, and these may be rounded by wind attrition. (Wade-55.) In moister climates, on the other hand, feldspar will decay, forming kaolin or laterite, and by deflation or by flotation these products of finer grain will be swept away. 
Form of River Pebbles. Rudolf Hoernes (32) has recently insisted upon the distinctive characters possessed by the pebbles subject to prolonged river and wave transport. According to him, river-borne pebbles are always flat, and more or less wedge-shaped, owing to the fact that the current merely shoves the coarser material along its bottom. Marine and lacustrine pebbles, on the other hand, are rounded or roller-shaped, because the waves tend to roll the material.

Eduard Suess in $\mathbf{1 8 6 2}$, in describing the fluviatile Belvedere gravels of the Vienna district, says, in effect $(53: 64,65)$ : "A comparison of a considerable quantity of such pebbles shows that they conform more or iess to a single typical form, being almost without exception sharpened to a wedge-shaped form on one side. This form distinguishes shoved pebbles from rolled pebbles; it is produced by the pushing along, over the bottom, of the rock fragments by the current of the strean. Rolled pebbles, such as are moved to and fro by the surf on the shore, never have the wedgeshaped form, but a uniformly oval or cylindrical ground form." According to J. Lorenz von Liburnau $(37: 95,96)$ the flat river pebbles suffer chiefly a horizontal rotation, so that the top and bottom of the pebbles are rubbed against the overlying and underlying ones, while at the same time the edges are worn off, the result being a mass of flat, worn cakes with smooth, rounded edges.

In contradistinction to these observations and deductions, Penck emphatically insists upon the rolling of pebbles on the stream-bed as the chief method of river transport. Such rolling may affect scattered pebbles or the entire mass, in which case the entire sediment on the river bottom is in motion, the individual pebbles rolling and striking against one another, with the result that rounded pebbles are produced. In portions of the Rhine bed, such a mass three meters in depth is thus moved along. (Penck-4I :284.)

It is extremely doubtful if the distinctions made by Suess and Hoernes can be considered of more than local applicability. The character of the rock which has furnished the material is probably of much greater significance, as pointed out by Walther. Thus, on the shores of Lake Michigan, where the bed rock is a uniform grained limestone, the pebbles are chiefly of a rounded or rollershaped character, while on Lake Erie, where the cliffs are of shale, flat gravel predominates, except where glacial deposits have formed a local source of supply. Again, on a relatively steep shore, where wave-work is pronounced, as on the northern Massachusetts coast, the pebbles are well rounded through rolling, while on a shallow coast, where the wash of the waves rushes up and down the beach 
as a sheet flood, the pebbles are more often merely moved backward and forward without much overturning, or, again, the pebbles are scarcely moved, but polished and worn by the sand carried back and forth across them.

Pebbles of glacial stream deposits are always rounded, since in such deposits only the more massive rocks escape destruction. The pebbles and coarser rocks of the White Mountain streams are all well rounded, this being especially well shown in the flood plain of the Saco River at Intervale. Destruction of all the weaker type of rocks by prolonged river transport is also imminent, and this is especially the case on large river flood plains or deltas. Prolonged exposure of granitic or other coarse-grained igneous rocks results in their disintegration, and thus by a process of assorting, the pebbles may be reduced to a few fundamental lithologic types, such as quartz, porphyry, etc. There are many older quartz conglomerates with well-rounded pebbles, but free from fossils, which appear to represent extreme cases of concentration. The Millstone grit, the Pottsville conglomerate, and the Shawangunk and other conglomerates are almost wholly composed of quartz pebbles. In many cases these quartz pebbles are derived from vein quartz, but in other cases they are probably a highly indurated quartzite in which the individual grains have become obliterated.

It is difficult to understand how extensive conglomerates, sometimes many hundreds or even a thousand feet in thickness, and composed almost entirely of quartz pebbles embedded in quartz sand, can have originated. If the material of the pebbles is vein quartz, an enormous destruction of rock is indicated, since veins form only a small portion of the rock mass carrying them. If the material of the pebbles is an older quartzite, the problem is less difficult. Again, in some cases the pure quartz pebble conglomerates may be formed of the reworked gravels derived from the destruction of older conglomerates. Thus the pebbles of the "yellow gravel" of the coastal plain may be the product of the destruction of the formerly much more extensive Pottsville conglomerate. In this connection it is interesting to record that some of these pebbles are fossiliferous, carrying corals of Siluric age. This may represent a silicified limestone, the silica thus being of secondary origin. Whether any such origin may be postulated for a considerable portion of the quartz pebbles is doubtful.

From our present knowledge of the subject, it seens that no constant differences can be ascertained between river and shore pebbles, both may be round or flat, and both may be well worn or subangular, and form part of a mass of a very uniform lithic char- 
acter, or one composed of a heterogeneous aggregate. On the whole, destruction of all but the resistant quartz seems more assured on the flood plain of large rivers than on the seashore; and certainly the wide transport of such material is more readily effected by streams.

The sorting action of streams on sands has already been discussed. (Chapter V, p. 252.)

Overlap Relations of River Deposits. In a growing subaërial river delta, the later formed portions will progressively overlap the earlier formed parts, coming to rest upon the basement beds, beyond the margin of the older beds of the delta. Since, however, this can be recognized only as an overlap of formations of definite chronologic value, and not an overlap of continuous beds, this subject is better discussed after the simpler type of marine overlap has been described. The general theoretical relationship is expressed by the following diagram (Fig. I24), from which it will be seen that the principal overlap is away from the source of supply. There may, of course, be a slight headward overlap due to aggrada-

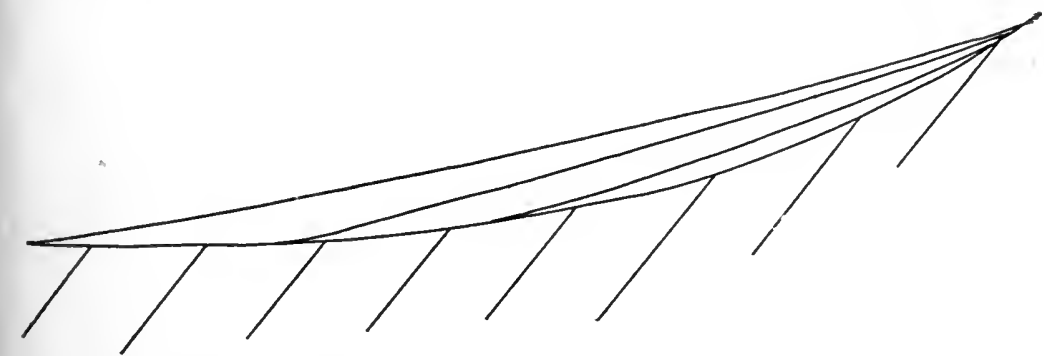

FIG. 124. Diagram showing normal non-marine progressive overlap, each later stratum resting upon the old land surface beyond the edge of the preceding one. A slight headward overlap is also indicated.

tion of the upper part of the river channels as the grade is lowered. This, as a rule, will be slight and local as compared with the overlap at the other end, though it is not to be denied that at times such a headward overlap may be considerable.

Flood Plains of Glacial Streams. These are of exceptional character owing to the abundant supply of detritus as well as water from the melting ice. As already pointed out in Chapter III, p. I36, such streams when overloaded will form extensive deposits in their valleys, aggrading these to a considerable depth. Subsequent change in the character of the stream, either from diminution of supply, 
from increase in the amount of water by sudden melting, or from a general uplift of the region, will cause the rivers to entrench themselves in the old flood plains, leaving the remnants as terraces on either side of the valley. Nearly all the streams coming from the glaciated region have such terraces, which mark the greater deposition in periods preceding the present one. Examples of deposits of this type now forming are seen in the valleys of the streams coming from the Alaskan and other glaciers.

River and Flood Plain Deposits from Continental Ice-Sheets. Several types of such deposits are recognized and are noteworthy on account of their peculiarity; among these are: I. the torrential moraine, or kame; 2 . the frontal, or apron plain; 3. the esker; and, 4. the glacial sand plain, or temporary lake delta. The essential characters of each are as follows:

I. Torrential moraine or kame deposits. These are irregular hills of semi-stratified sands and gravels, all of the pebbles being water worn. The material was derived from the ice and was dumped by the rivers in front of the ice-sheet. These deposits are commonly of irregular shape, being more or less confluent cones of débris, and often complicated by the formation of kettle holes from the melting of included ice blocks, as in normal moraines. The topography of such a deposit, when extensive, is often a series of knobs and basins.

2. The frontal or apron plain. This is also a subaërial deposit and consists of the material carried forward from the glacial moraine by streams, and spread as a veneer or mantle over the older formations in front of the ice. Where it is spread over a coastal plain, it is generally of uniform thickness, this decreasing from the source outward. The material also becomes finer away from the source of supply. Kettle holes may occur, but they are less frequent than in the kame moraine. Cross channels made by the streams from the ice are not uncommon features. Typical examples of such apron plains are found south of the moraine on Cape Cod, and in similar relations to the moraines on Nantucket, Martha's Vineyard, and Long Island. In the Cape Cod sections of this apron plain facetted pebbles or dreikanter have been found in place, indicating wind activity and further proving the subaerrial origin of this deposit. Such wind work may locally modify the deposit, substituting wind cross-bedding for the horizontal bedding given to them by the water.

Marine fossils may be locally embedded in such deposits if they are formed near the shore, and when a partial subsidence is succeeded by further deposition by streams from the ice. A fine 
example is shown by the fossiliferous layers of Sankaty Head on Nantucket, which, however, lie really within the kame-moraine area rather than in the present apron plain. It is probable, however, that the fossiliferous beds themselves belong to an earlier apron plain, for it is known that the Wisconsin ice sheet advanced over this deposit and built its moraine and apron plain further south. (Wilson-60:13.)

3. The esker. (Swedish os, pl. osars.) This term is applied to long, narrow ridges of sand and gravel with steeply sloping sides and often a sinuous outline. The summit of the esker is generally a narrow, flat space between the sloping sides, the cross-section being very nearly a triangular one. The eskers of the last glacial period run in general parallel with the direction of the ice movement and while occurring largely perhaps in the north and south valleys, along which the main drainage lines from the ice discharged, they are not confined to these, but of ten pass indifferently over hills and through valleys. In height they rarely exceed roo feet, but in length they may be followed for tens or in rare cases even hundreds of miles. Their best development in this country is in New England, while Scandinavia and Finland furnish some of the best illustrations in the Old World.

Eskers may be formed in various ways, such as by filling of gorges in the ice, by accumulation of débris in englacial tunnels and by aggradation of their bed by sub-glacial streams. (Grabau-23.) This last is the most characteristic method of formation. Streams originating under the ice are enclosed in a tunnel and, being under an enormous hydrostatic pressure, will fill this tunnel after the manner of the water in a city main. It may thus be forced upward and will discharge at a level much above that of its upper courses, if it is located in a valley sloping against the ice mass, as is so often the case.

Flowing uphill, such a stream will tend to erode the roof of its tunnel, and simultaneously to aggrade its bottom in the higher (upstream) parts. As the stream rises in the ice by roof erosion, the floor is more and more aggraded until this filling all along the line has reached the level of the outlet, or risen slightly above it. Melting removes the supporting walls on either side of this aggraded river-bed, when the sides will slump, giving the characteristic lateral slopes and the triangular cross-section to the esker. At points where the original deposit is narrow, so much material will be involved in the slumping to give the proper angle of repose that the surface of the esker will be actually lowered. Thus irregularities in height in the esker are readily accounted for. (Woodworth-6r.) 
4. Glacial sand plains. Whenever the ice holds up a temporary body of water between its front or sides and the margins of the valley or basin in which it lies, opportunity for the formation of glacial deltas or sand plains is given. These may be formed around the margins of the lake by streams coming from the land, when they partake of the true delta to be described beyond. Such deltas have been recorded from glacial lakes in New Jersey and elsewhere. The marginal sand plains of the Upper Hudson-Valley were deposited in lakes bordering the ice sheet which occupied the center of that valley. Sand plains formed at the front of the ice of material carried by streams from the ice abound in New England, especially in eastern Massachusetts, where they have been fully described.* A characteristic feature of these sand plains is their correspondence in height to the elevation of the outlet, which determined the level of the temporary lake. Not infrequently a number of successive sand plains is formed corresponding to a succession of lake levels determined by progressive uncovering of lower outlets. In New England these plains are generally highest in the southern portions of the old northward sloping valleys and become progressively lower toward the north. In Lake Bouvé, an extinct glacial lake in the Boston Basin, eight series of such sand plains are known, each series lower than the preceding one on the south. (Grabau-23:580.) A special example of rather striking character is seen in the sand plains of Wellfleet, Eastham, and Truro on Cape Cod, which were deposited in a lake held in an embayment in the eastern ice lobe, and dammed in part by the terminal moraine of that ice lobe, across which the discharge of the waters occurred. In this case the highest series of plains lies between the two lower series. By the melting of the ice these plains were left without any immediately surrounding land barrier, as isolated sand masses running northward into the ocean from the eastern end of the terminal moraine. (Grabau-24; Wilson-60:52-66, pls. 34, 36, 37, 38.) In form the isolated sand plain, revealed on the melting of the ice and the drainage of the temporary lake, consists of a surface slope which is gently forward from the center of origin; a steeper frontal or delta slope, joining the surface slope abruptly, and having a lobate or scalloped outline, and a still steeper back slope often with concavities between sharp cusps. This latter surface is due to slumping after the supporting ice front against which the delta was built had melted away. Its slope, therefore, represents the angle of repose of the material under the conditions of formation. The gentle surface slope represents the subaërial part of the delta, while

* See papers by Crosby, Grabau, Clapp, etc., cited in Chapter III. 
the lobate front is the slope of the front of the original delta where the oblique frontal layers or fore-set beds were added. The lobation is due to the division of the stream into a number of spreading fingers or distributaries, each of which builds its own portion of the delta forward. In section it will be seen that the greatest part of the sand plain is composed of the sloping fore-set beds, which are inclined at an angle of 20 or more degrees. The upper ends of the fore-set beds are abruptly truncated, and on these truncated edges rest the coarser, nearly horizontal, top-set beds which constitute the subaërial part of the delta. The foot of the fore-set beds generally rests upon a thin series of bottom-set beds of finest material, of ten of clay or rock flour. All the beds are well stratified and the pebbles are, as a rule, well rounded.

Consolidated Sand Plains. Sand plains of Pleistocenic age have, in some cases, become consolidated so as to form a rock mass of more or less induration. This is especially the case where many of the pebbles are of limestone, when partial solution and redeposition of the lime in the interstices will occur. A typical example of such a consolidated deposit is seen on the banks of the lower Niagara River, near the railroad station at Lewiston, New York. Here steep fore-set beds are seen dipping at an average angle of I5-20 degrees toward the south. The beds are sufficiently well cemented to form a vertical wall, though the material can be broken into its component pebbles by blows of a hammer. The deposit, which is perhaps 30 or 40 feet thick, appears to have formed in a body of water held up against the front of the Niagara escarpment by an ice lobe lying a short distance to the north. Streams from this ice lobe supplied the pebbles and sand which built up the delta.

This deposit is sufficiently consolidated to resist ordinary erosion, and river, lacustrine, or even marine sediments could be formed over it without disturbing it. Indeed, since the formation of this deposit this region is believed to have been invaded by the sea by way of the Hudson, Lake Champlain, and the St. Lawrence, but this was not of sufficient duration to permit the formation of extensive marine deposits. It is easy to see, however, that these steeply inclined delta beds of coarse material, followed by marine sediments, such as would have been formed had the sea stood here longer, and this in turn by lacustrine deposits, such as would be formed if the present lake should expand, would give a complex succession of formations, the history of which would be decipherable only with considerable difficulty.

The Nagelfuh of Salsburg. (Crammer-13:325-334.) The city of Salzburg in the Austrian province of the same name and close 
to the Bavarian border furnishes a remarkable example of a consolidated conglomerate or pebble rock of the type described. This goes by the name of Nagelfluh, from the fact that where the relatively small pebbles have fallen out of the matrix a depression like that made by the head of a nail is seen. This rock appears in several large erosion remnants within the city; one of them, the Mönchsberg, rises with perpendicular walls (partly artificial) and is pierced by a tunnel through which one of the city streets is carried. Other remnants are the neighboring Rainberg, and the more distant hill of Hellbrunn. All of these are evidently part of a once continuous conglomerate bed, which has since been dismembered by erosion. The cohesion of the material is such that old crypts hollowed in this rock and used in the third century as places of secret worship are still in a practically unchanged condition.

The walls show inclined bedding which indicates the delta character of these deposits (Penck-42:I6I-I66). According to the opinion of Penck, Crammer, and others, the sand and pebbles were washed into a lake which occupied the Salzburg basin during post-glacial time. The fact that the Nagelfluh rests upon a glacial moraine, as determined by excavations and observations on natural and artificial exposures, seems to indicate that this deposit is of post-glacial age, though other observers have held that the age of the deposit might be greater, perhaps late Tertiazy.

Nagelfluh of similar character, but probably of greater age, is found in a number of localities in South Germany and elsewhere. In some cases, as in Munich, it is used extensively for building purposes. It is, of course, not necessarily true that all conglomerates of this type are of non-marine origin, though most of them probably are river deposits.

Playas or Takyrs and Salinas. In the low, flat-bottomed depressions of undrained desert basins the rivers at times of flood will spread out into extensive shallow lakes of temporary existence. In the Great Basin region of western North America one such temporary lake reaches a length of about Ioo miles by a breadth of I 2 to 15 miles, but with the water scarcely more than a few inches deep. Here the fine silt of the river is deposited, gradually subsiding as the shallow lake evaporates. After complete evaporation a smooth, hard-baked surface remains, marked by sun-cracks and the tracks of animals which visited the spot before complete hardening of the mud had occurred. Raindrop inpressions likewise remain on such a surface. In structure the material is beautifully and finely stratified, as may be seen on the sides of the sun-crack rifts. This constitutes the playa of the American deserts (Mexico 
and the southern United States), the takyr or schala of Asia, or the sebcha of Africa. Russell has described a number of such temporary playa lakes from the western United States (49:50). He finds them a characteristic feature of the greater part of the valleys of Nevada, the largest being in the Black Rock Desert in the northwestern part of the state. It forms during the winter months and reaches an area of from 450 to 500 square miles, but is seldom over a few inches in depth. Often after storms it is a vast sheet of liquid mud, a characteristic of many playa lakes. In a few hours or a few days the water of the lake may all evaporate, leaving a hard, dry and absolutely barren surface, cracked in all directions as the surface contracts in drying. "The lake beds then have a striking resemblance to tesselated pavements of cream-colored marble, and soon become so hard that they ring beneath the hoof-beats of a galloping horse, but retain scarcely a trace of his foot-prints." Around the margin of the lakes is a belt of plain with desert vegetation, the transition to which is formed by a marshy tract which in summer is marked by an abundant efflorescence of salts.

Mechanical analysis has shown that the material of the playa may be Ioo per cent. clay, and that laterally it will gradually pass through the addition of sands into the surrounding eolian deposits. In limestone regions where siliceous rocks are wanting the material of the playa will be largely lime mud, and this may be the origin of some of the finely bedded, sun-cracked calcilutytes of the American Siluric, where the percentage of lime and magnesium carbonates is seventy or less.

If the playa lake exists for some time it may become stocked with certain forms of organisms, especially types whose eggs or larvæ can be transported by wind or by birds. The small crustaceans Estheria, Daphnia, and Cypris are characteristic of desert lakes, the first having been found in ponds which are dry for eleven successive months. (Fischer, quoted by Walther-57:94.) When, as is frequently the case, salts are present in the sediment, these effloresce on the surface, and from their hygroscopic character keep the surface of the playa sufficiently moist to prevent the removal by the wind of the accumulated material, and further to catch all dust particles carried across the surface by the winds. Thus the surface of the playa becomes dusted over with a fine coating of sand or dust, this process being repeated as the salts rise to the surface of the newly added layer. Where salt is present in great abundance a moist, slippery surface with incrustations of salt results, thus forming salinas. When wet, their surface is impassable, but when dry a crust of hard salt of dazzling whiteness characterizes 
the salina. As already noted, the thickness which such a salt deposit may reach is practically limited only by the depth of the basin and the supply of the salt.

The deeply cleft surface of the dry playa is not infrequently buried by the wandering sands of the desert, while the rifts between the polygonal blocks are filled with wind-blown material, or the mud of the next succeeding inundation, and so preserved. This is made possible by the rapidity with which the playa surface becomes flooded, a case being on record where a lake io to is kilometers wide and of immeasurable length, though only from an inch and a half to a foot in depth, came into existence in twenty minutes. (Obrutschew, quoted by Walther-57:IIO.) It must, however, be noted that the dried surface of the playa is not infrequently softened on being wetted, and that from swelling and flowage of the mud the cracks may be closed again before they are filled. In this manner many mud-cracked surfaces are again obliterated. From preliminary experiments, Barrell concludes $(2: 53 I-532)$ that "a mud-cracked loam or silty clay, even when the sand particles are imperceptible to the fingers, is an unfavorable material for the preservation of its detailed surface features, . . . Upon being wet by rain the rapid swelling and disintegration of the surface stratum would turn the surface of such a deposit into a creamy mud. . . " On the other hand, "a pure clay, slowly subsiding from quiet waters, and wet sufficiently long to become compact upon drying, would retain its mud cracks upon rewetting, either by rain previous to flooding or by the flood waters themselves." When the newly deposited layer is a very thin one it will curl up like shavings on drying and these clay shavings will be blown into the sand dunes, where, upon subsequent softening, they will be compressed into clay lentils or pebbles, and so become a constituent part of an otherwise pure sandstone.

Preservation of Footprints, Etc., in Subaërial Deposits. Of the greatest significance is the relative ease with which tracks of animals are preserved in desert deposits. The scarcity of rain permits their almost indefinite retention on suitable surfaces without being buried. In the Sahara desert tracks of camels made in I 877 were still perfectly recognizable in I892 (Foureau-2I:I75), the interval of fifteen years having altered them but little. Whereever (Walther-57:88) a temporary accumulation of water after a desert rain attracts the varied desert fauna, or allows animals living on the border of the desert to make extended excursions into the flooded regions, their footprints will be left upon the impressionable surface of mud, remaining after such an inundation. These 
will in time be covered by the shifting sands of the desert and a relief mold will be produced by the covering sands. Such a relief impression will be more readily preserved than the original impression, which may be destroyed by the softening of the clay surface of the playa. A single extensive inundation by heavy rains of a desert surface may permit a wide horizontal migration across this surface of animals which never before and never after entered this region. Thus their tracks may be widely preserved in a single horizon in a desert formation, like those of Cheirotherium in the Upper Buntsandstein (Walther-57:88), even though the animal lived during a much longer time period. Repeated floodings, annually or at intervals of many years, will permit the formation of successive track-bearing layers, by animals living on the border of the desert. This mode of preservation certainly accords best with the characters of the tracks found in such formations as the Ne:vark sandstone of the eastern United States, whereas the frequent assumption that the successive track-bearing beds were made between tides and buried by the sediment brought in by the returning tide does not allow for the obliterating effect of the tide, an argument equally applicable to stream-laid deposits upon the fresh tracks. (Voigt-54:I66.)

The conditions favoring the preservation of footprints in desert regions militate against the preservation of the animals themselves. For, unless the body is buried at once, it is sure to fall a prey to the desert carnivora, while sun and wind will complete the destruction of what remains. This explains the scarcity of remains of the animals in the strata which contain their footprints.

Other Structural Characters. Ripple marks and rill marks, though usually regarded as typical only of marine formations, are equally, if not more, characteristic of the non-marine deposits. Their discussion is, however, deferred until hydroclastic sediments have been more fully discussed.

\section{NORMAL PALUDAL AND LACUSTRINE CLASTIC DEPOSITS.}

Clastic deposits in swamps (paludal clastics) are of relatively little importance except when associated with vegetal deposits. These latter are by far the most important, the clastics being subordinate and confined to the sediments carried in by wet weather streams and rains, or the dust settling out of the air.

Deposits in ponds and lakes, on the other hand, $i . e$., in water 
bodies free or nearly so from growing vegetation, are of more significance, since they add a decided individualistic note to the terrestrial hydroclastic series with which they are commonly associated. It is true that many of their most pronounced characteristics are due to peculiarities in the composition of their waters which will give rise to deposits of special chemical character, such as have been discussed in preceding chapters. In other respects, again, the nature of the sediment is not very different from that of the ocean, except in so far as the absence of the tides, the difference in composition and specific gravity of the water and the difference in size of the water body influence such deposition. The last falls practically out of consideration in lakes of great size, such as the American Great Lakes.

The clastic sediment of lakes is chiefly derived from two sources, that resulting from the erosion of its shores by waves, and that brought in by the tributary streams. Erosion is very marked, especially in the larger lakes, such as Erie, Ontario, Huron, etc., and the product is distributed along the shore as shingle, or heaped up into storm terraces, as on Lake Michigan. Coarse material is seldom carried far out into the lake, but accumulates along the shores, where it is subject to constant wave attack. The finer sand and mud, however, resulting from such wave attack are carried out from shore and slowly settle all over the lake bottom and sides. This also happens to some of the fine slime brought in by streams, but this tends for the most part to sink to the lake bottom. The coarsest of the river-borne sediments will build up a delta at the shore, but the finer mud, which is held in intimate suspension in the stream water, is carried beyond this point. Its presence in the stream water renders that water heavier, and it will, therefore, not mingle with the lighter warm water of the surface of the lake, but will sink to the deeper, cooler and denser strata. Thus a mud-laden stream passing into a lake will become submerged, often passing along the lake bottom, and occasionally forming a channel there, bounded by submerged mud banks on either side. The force of the current will finally be dissipated in the deeper waters of the lake and the sediment will slowly sink to the bottom, forming horizontal and well-stratified layers of mudrock, free from irregularity of bedding and of uniformly fine grain. Mingled with sediments of this type are the muds which were held suspended for a time in the upper waters and which settled all over the lake bottom.

With the seasonal variation in the strength of the streams there must be a corresponding variation in the grain of the sediment. 
Thus when the current is powerful and surcharged with sediment slightly coarser material may be carried to the lake bottom than is the case during the period of lessened river activity. A series of annual layers is thus formed which in any given case may serve to measure the length of time required for the formation of the deposit. This method has been applied by Berkey (8) for the determination of the time required for the deposition of finely bedded clays.

\section{DELTAS.}

Deltas are the terminal deposits of rivers, and, as such, have an intimate association with the continental clastics. It is true, of course, that a part of the delta of the seacoast is of submarine origin, and its discussion therefore falls more essentially under the heading of marine clastics. Still, deltas are peculiar features of relatively limited distribution, and in no way represent normal marine conditions. Indeed, a part of the delta is always typically non-marine, and the place of the delta is therefore intermediate between true continental and marine clastics. Moreover, deltas are common in-lakes, these belonging, of course, entirely to the continental division of the hydroclastics.

A typical delta may be taken as one that is built into a body of standing water, the level of which is essentially a permanent one. Subsequent drainage of the water body may expose the delta as we have seen, but all such changes bring the delta-building process to an end. On the whole, deltas are more abundant on lakes than on the seashore, partly because lakes are not subject to tidal currents and fluctuation of level, but partly also because wave activity on the sea coast is greater. Fluctuation in level due to tides does not necessarily militate against delta building, as is shown by the Indus delta, which is built where the tidal range is Io feet, while that of the Ganges is built into a sea having a tidal range of 16 feet. Where wave action is strong, however, and especially where long shore transport of material is pronounced, delta building is restricted. Deltas are thus the triumph of river deposition over wave and current destruction, and their location and extent will be determined by the relative importance of the opposing processes. As examples of typical existing deltas on the sea coast may be named that of the Nile, on the Mediterranean; of the Po, on the Adriatic; the confluent deltas of the Rhine and Meuse; and that of the Ems, on the North Sea; the deltas of the Lena and of the Mackenzie, on the open Arctic Ocean; those of the Ganges, Brah- 
maputra and the Indus, on the Indian Ocean; of the Niger and the Orinoco, on the Atlantic Ocean; and the Mississippi delta on the Gulf of Mexico. Of the numerous deltas on the protected waters of Europe and Asia may be mentioned that of the Danube on the Black Sea, the Volga on the Caspian, and those of the Oxus (Amudarja) and the Jaxartes (Syr-darja) on the Aral Sea.

Form and Rate of Grozeth of Deltas. The form of the deltas varies greatly from the typical triangular outline resembling the Greek letter delta $(\Delta)$ characteristic of the Nile delta (the type of deltas; Fig. 125) to the long, narrow estuarine filling of the Mackenzie mouth, on the one hand, and the very broad, but short, cuspate delta of the Tiber, or the still narrower strip-like or stunted delta formed by the Cavonne on the Gulf of Taranto, southern Italy,

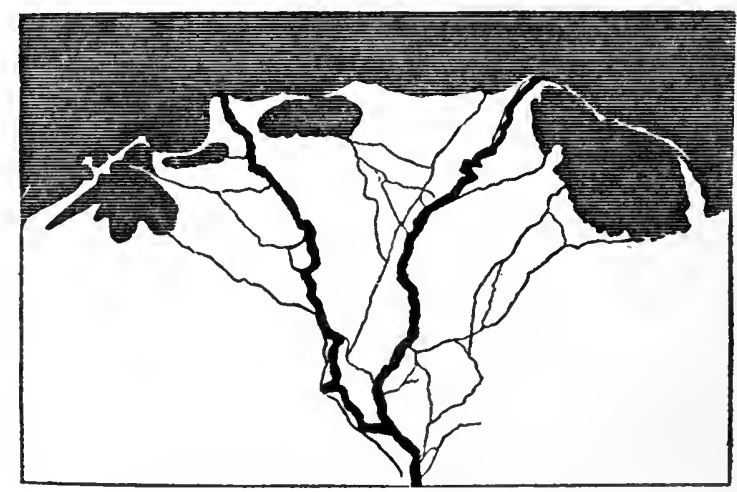

FIG. I25. The Nile Delta.

on the other. The mouth of the delta-building river may advance singly (unilobate) without dividing into distributaries, as is nearly the case with the Ebro on the northeast coast of Spain, or it may be multilobate with the distributaries pushing each its own narrow lobe forward, which may even become a finger-like extension, as in the remarkable Mississippi delta. It the distributaries are numerous, they may form a network of streams, as on the Nile delta, which advances by a continuous, more or less scalloped front.

In size the deltas of the present day vary from an insignificant deposit at the mouth of a small stream to areas covering many thousands of square miles, as in the deltas of the Nile, the Lena, and the Mississippi. Confluent deltas of several streams occur, making irregular deposits with many lagoons, as in the RhineMeuse-Ems delta; while deltas building on a coast with many 
islands may gradually annex these to the land by enclosing them in the growing delta. The hilly province of Shantung has thus been enclosed in the great delta of the Huang-ho, and a number of small islands have been included in the delta of the Aspropotamos in western Greece.

The rate of growth of deltas varies greatly and is often considerable. Thus the Jaxartes increased by $13 \frac{3}{4}$ square miles between I847 and 1900. (Andrussow-I :49.) The delta of the Rhone is said to have lengthened more than 26 kilometers since $400 \mathrm{~B}$. C. The southwest pass of the Mississippi delta grew, according to Captain Talcot, I04 meters in length in 1838 , the south pass 85 meters, the northeast and southeast passes each 40 meters, and the pass à l'Outre 92 meters, giving an average of 80 meters per year for each pass. While this holds for the year in question, it is not possible to consider that such an increase occurs in all years. Indeed, often one year destroys what is built in the preceding year. The Po delta has increased between the years I 200-1600 at an average rate of 25 meters per year, but from 1600 to 1804 its rate of increase was 70 meters per annum. One of the most rapidly growing deltas is that of the Terek, on the Caspian. Within a period of 30 years the water has been pushed back I5 kilometers by the growth of the delta, which increased thus at the rate of half a kilometer per year. The other extreme is shown by the delta of the Danube, which at one of its mouths is not over 4 meters per year, though somewhat more rapid at another. The average increase of the Nile is about 4 meters per year, while the delta of the Tiber is estimated to increase at the low rate of I meter per year. According to Pumpelly, the Huang-ho has increased on the average at a rate of 30 meters per year between B. C. 220 and A. D. I730.

Thickness or Depth of Deltas. (Credner-I4.) The depth of delta deposits on modern sea coasts varies greatly, but is, on the whole, comparatively slight. Thus the mud of the Nile delta is not over Io or 15 meters thick. It rests on loose sea sand. The delta deposits of the Rhine have a thickness of 60 meters, those of the Rhone over Ioa meters. In the Po the depth averages I22 meters, though near Venice I72.5 meters were penetrated without reaching bottom. The delta deposits of the Ganges and Brahmaputra rest on older sediments and average only 20 meters in thickness. The actual delta deposits of the Mississippi range from 9.5 to I6 meters near New Orleans, increasing to 30 meters at the head of the passes, beyond which the thickness rapidly increases. They rest throughout on a stiff blue clay of earlier age. The Rhone 
delta in Lake Geneva has a thickness of 180 to 275 meters and a length of nearly two English miles.

Delta Slopes. The surface of the delta has always a gentle slope, this being steeper in the smaller deltas than in the larger ones, and steeper also in the deltas of coarse material than in those of fine silts. The frontal slope of the delta is, as a rule, much steeper, being sometimes as high as $25^{\circ}$ or $30^{\circ}$, or in some cases even $35^{\circ}$ in the small deltas of Pleistocenic and modern lakes. In the larger deltas, especially those on the sea coast, the frontal slope is much gentler. The strata of the Rhone delta in Lake Geneva are so slightly inclined that they almost take on a horizontal attitude. The total thickness of this delta, I8o to 275 meters, is distributed over nearly 2 miles. The frontal slope is $\mathrm{I}$ to 18 . A much gentler slope is seen in the delta of the same stream in the Mediterranean, where the rate is 1 in 160 , the depth increasing from 4 to 40 fathoms in the distance of 6 or 7 miles from the mouth of the stream.

Deltas of small lakes often show a steeper inclination for the older coarser beds than for the finer younger ones. Thus the delta of the Aar in the Lake of Brienz shows near the shore an inclination of the beds amounting to 30 degrees. About 300 meters from the shore the grade has decreased to 20 degrees, while at the extreme margin of the present delta, I, IOO to $\mathrm{I}, 200$ meters from the shore, the beds are nearly horizontal. The delta of the Dundelbach in the southwest angle of the little Lake of Lungern in Switzerland shows coarse beds near the margin, sloping at an angle of 35 degrees, while the younger layers have a very gentle slope only.

The Bird-foot Delta of the Mississippi. The lower part of the Mississippi delta has a remarkable form, distinguishing it from all other modern deltas. From Forts Jackson and St. Philip onward for a distance of nearly 25 miles the river is confined in a narrow channel or "neck" which finally divides at the "Head of the Passes" into three divergent channels, or passes, each bordered by low banks of stiff clay and forming a structure resembling a bird's foot. One of these passes, the Pass à l'Outre, divides again into the North Pass and the Northeast Pass. The other two, the South Pass and the Southwest Pass, continue, as single narrow fingers, the latter for nearly 20 miles. Some distance above the head of the passes a similar channel, the Main Pass, extends northward, and still farther up a group of small channels diverges from the neck. The material composing the banks of the neck and the passes is wholly unlike ordinary river silt, though in general a thin superficial layer of this occurs. Primarily, however, the banks 
consist of a stiff blue clay not unlike the stiff "Port Hudson clays" . (Hilgard-29) which underlie the whole delta. Such mud is brought to the surface in a series of mud volcanoes or mud-lumps which, from time to time, arise on the delta surface. These are believed by Hilgard to be formed of the fine mud brought down by the river and precipitated outside of the delta by flocculation. Over this liquid mud are spread the river sediments, the weight of which and that of the growing marshes and their pressure upon the mud

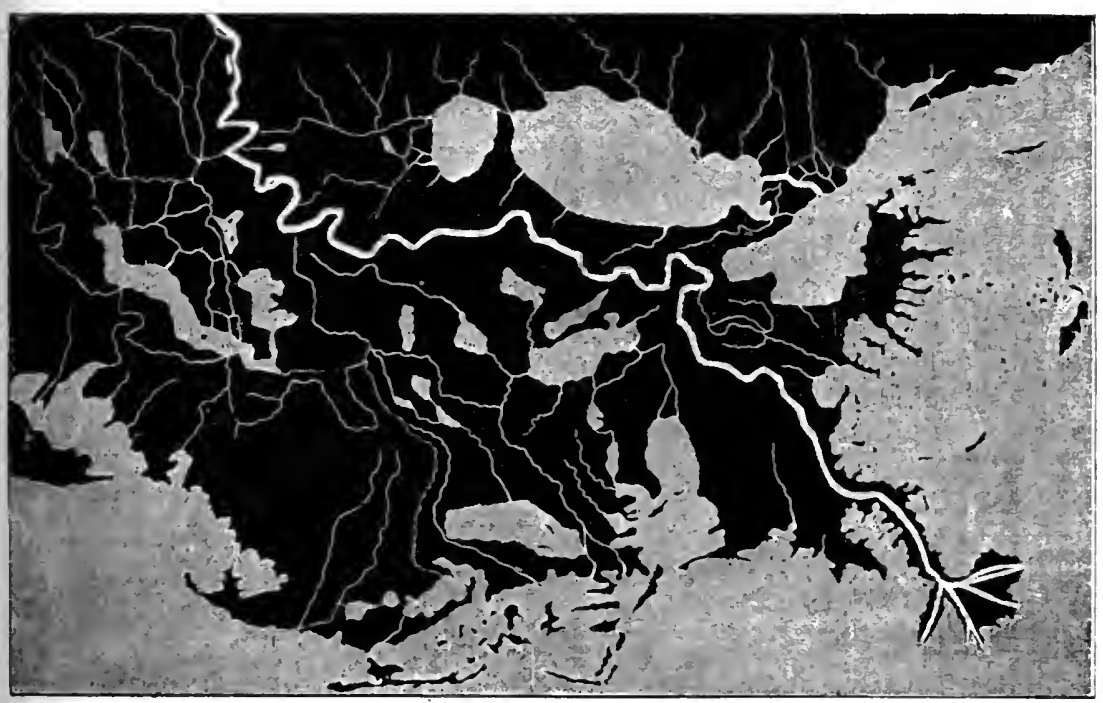

Fig. 126. The Mississippi Delta. At the "bird foot" the passes are from right to left: North Pass, Northeast Pass (these two unite to form the Pass à l'Outre). South Pass, Southwest Pass. The Northeast Pass has a small southern brancl, the Southeast Pass (not shown). while another group of channels, diverges from the "neck" about five miles above the "head of the passes."

layers result in local upheavals and formation of mud lumps or craters, as long ago suggested by Lyell. Rod soundings in such a crater have reached a depth of 24 feet, but no solid bottom. The mud flow from these craters varies with the stages of the river. becoming much more lively in times of flood, when great masses of water, or of silt brought down by the river. press upon the layer of liquid mud. Hilgard believes that the banks of the neck and the passes are formed of the disintegrated and redeposited mud from stuch mud lumps, and that when a mud lump arises in the channel. as has recently occurred, a division is likely to take place. Hilgard 
testifies to the tough, resistant character of this clay, which when wet is almost inerodable by pure water. (29.)

Structure and Composition of the Delta. Theoretically the delta consists of bottom-set, fore-set, and top-set beds. These are all well developed in the small deltas formed in Pleistocenic time in temporary ice-dammed lakes and now open to examination after the draining of these lakes. In the deltas on the sea coast, however, one or the other of these beds is often absent, or two may merge, this being most frequently the case with the fore-set and bottomset beds.

The fore-set beds of small or young deltas are generally steeply inclined, as already noted. This is especially the case when the supply of detritus is large. As the delta increases in size the later fore-set beds become more flattened and bend over at the bottom into the horizontal bottom-set beds. The upper ends of the foreset beds, on the other hand, show more or less of erosion and across their truncated edges are deposited the top-set beds. There may, of course, be at times a bending over of the top-set beds into the fore-set, but in the young delta the contact is more or.less sharp. In the larger deltas of fine material, on the other hand, the top-set beds may be more or less continuous with the fore-set, and, indeed, the two may imperceptibly grade into each other, without even a change in angle.

The top-set beds of small deltas consist of the coarser material laid down in nearly horizontal beds. If we assume that the normal delta begins as a subaqueous detrital cone or semi-cone growing in circumference, it is apparent that fore-set and bottom-set beds alone exist during the earlier stages. As the radius of the cone increases, its summit is invariably truncated by the waves and by the stream itself, which carries the detritus out to the front of the cone. Thus a level plane is formed partly by non-deposition and partly by contemporaneous erosion truncating the fore-set beds. Its surface will be to some extent below water level, the depth depending on the strength of the wave activity. Upon this plane will be deposited the top-set series which the current can no longer carry to the edge of the growing delta. The top-set series will continue to grow in thickness and extent as the delta grows, and its landward part will begin to emerge and become subaërial. The extent to which this subaërial part of the top-set series will grow is determined by the strength of the river and the slope which it can control. In smaller deltas the frontal angle of the delta is also the junction between top-set and fore-set beds and marks the extent of submergence of the delta. In larger deltas the top-set beds go deeper. 
Examination of deltas permanently or temporarily laid dry shows that the structure is by no means a uniform or simple one throughout. Thus the delta of the Dundelbach, lail open to observation by the partial drying of the Lake of Lungern into which it was built, showed striking variation. Near its head it consists of beds of coarse and fine gravel, sloping at an angle of about 35 degrees. Large, flat rock fragments rest with their surfaces on the inclined gravel layers, and a bed of compressed bituminous woods and leaves, six inches in thickness, is interbedded with these gravels in one part of the section. In general, the successive inclined layers are only a few inches thick; and this thickness does not increase toward the lower end in the coarser layers. In the fine mud layers, however, there is an increase in thickness downward before the layers bend over horizontally at the bottom. These finer textured layers rest gently against the steeper, coarser ones, filling especially the angle between the steeper layers and the flat lake bottom.

The numerous (20 or more) well borings made into the confluent deltas of the Po, Etch, and Brenta, in the region about Venice, have revealed the fact that the structure of the delta is an extremely heterogeneous one. While the beds are, in general, horizontal, with only minor undulations, the succession is scarcely the same in any two of the bore holes. This proves that the beds of the delta form a succession of lenticular masses, of very limited extent. Only two sandy layers, carrying water, have proved in any way constant; all other layers quickly wedge out laterally. (See the combination of profiles given by CrednerI4: pl. I, Fig. 9.) The successive layers comprise brown clays alternating with yellowish sands with lignites and occasionally layers containing marine organisms. The series includes several beds with molluscan remains. Marine molluses, especially Cardiacea, abound in the higher fossiliferous layers, while in the deeper beds only occurs the intermingling with these of fresh-water types. In some wells lignites with associated land snails, such as Succinea, Pupa, Helix, etc., were found. Vegetable material occurs at four successive horizons in the Po delta down to a depth of 100 meters. The material is the same as that now forming marshlands on the coast of the Adriatic. This and the occurrence of the land snails in the lower beds would suggest subsidence since delta-building began here. The borings near Venice show that about one-third of the material making up the upper sixty meters of the delta ground consists of lignite and peat.

Quite a different picture from this is presented by the mud 
deposits of the Nile. At low water these are visible in the steep banks which then rise 8 to to meters above water level. The hardened Nile mud forms a series of horizontal beds varying in thickness from a fẻw inches to several feet, and looks more like an ancient stratified series than like a modern deposit. The material of the Nile mud is a more or less uniformly fine-grained one, the size of the grains varying from $\mathrm{I} / \mathrm{I} 3$ to $\mathrm{I} / \mathrm{I}$ oO mm., rarely reaching $\mathrm{I} / \mathrm{Io} \mathrm{mm}$. in size. It is a unique deposit probably not paralleled by any other modern one on the face of the earth. An analysis of the mud (Clarke-12:48I) gave:

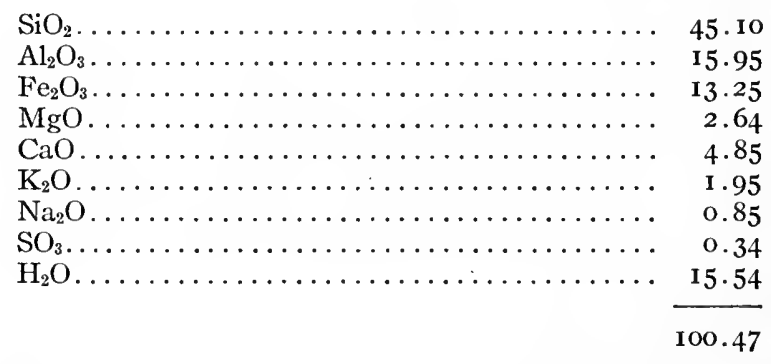

The remarkable fact about this mud is its high iron and low organic content, though some analysts have found the finely divided organic matter as high as 5.53 per cent. or even 7.9 per cent. Some analyses show an admixture of barium carbonate over wide areas.

In other deltas the organic material is pronounced. The abundant admixture of leaves and more or less lignitized wood in some deltas has already been noted. In the Po delta it occurs in four successive horizons. In the Ganges delta such deposits are found between 9 and 15 meters in depth, together with carbonized trunks of trees characteristic of the region, such as Heritiera littoralis, which abounds in the lower part of Bengal. In the lower Mississippi delta driftwood is common, the logs being at times united into floating rafts. Not infrequently erect trunks are found among these, with their roots spreading in all directions, as if while growing there they were submerged by a subsidence. The Mackenzie River delta likewise contains an abundance of carbonized driftwood, and this is true of many other deltas.

More striking, however, in some ways is the abundance of finely divided vegetable matter in some deltas. Thus the mud of the Vistula (Weichsel) loses, according to G. Bischof (9) 23.3 per cent. on ignition, most of this being organic material. The clay of the Vistula delta in the Bay of Dantzig is so rich in organic material that it has a deep black color, and is locally known 
as pitch, "pech." The bearing of this fact on the origin of some black shales will be considered later.

Organisms of the Delta. Narine organisms are not uncommon in sea-coast deltas, but they are, as a rule,' distributed in certain layers only. Lyell has explained the occurrence's of marine molluscs in extensive beds between the fresh water layers of the delta as due to wave work, which casts masses of shells upon the growing delta surface. In some parts of the Rhone delta marine and fresh water shells alternate in the deposit. This is explained by Lyell as probably due to the alternating occupancy of lagoons and channels on the growing delta by salt or by fresh water, according as the prevailing wind or other causes may ordain. As already noted, the delta of the Po also contains fresh water organisms associated with marine shells, but only in the lower beds, while upward the shell deposits become purely marine. Foraminiferal shells often abound in modern deltas. Thus the Mississippi mud was found to contain an abundance of marine Polygastrica and Phytolitharia as well as fresh water Polythalamia. Phytolitharia also abound in the mud of the Nile. Indeed, the range of foraminiferal shell material in the Nile mud is from 4.6 to Io per cent., while the Ganges carries as high as 12.4 or even 25 per cent. of foraminiferal material.

Other animal remains have been found, but are less abundant. Remains of arthropods occur in the Po delta sometimes in close association with the lignites. Remains of river animals also abound in modern deltas, as shown by the presence of turtles and crocodile remains in the delta deposits of the Ganges and the Zambesi. Terrestrial vertebrate remains have likewise been found in these deltas, among them bones of recent antelope, buffalo, lion, hippopotamus, and other mammals.

Gaseous Emanations of Deltas. The gradual decomposition of the organisms in the delta deposits gives rise to gaseous emanations which either escape through artificial borings in the delta or find natural passageways through the mud, building up craters as in the mud-lumps of the Mississippi delta. The numerous borings in the delta of the Po have furnished an abundance of inflammable gas, the use of which for illuminating purposes has actually been attempted. Sulphuretted hydrogen is also developed, especially where sea water comes in contact with the decaying vegetable matter, as noted in the case of marine marshes (see ante, page 493). In the mud-lumps of the Mississippi delta, the volume of gas emitted is between $\mathrm{I} / 2 \mathrm{O}$ and $\mathrm{I} / 3 \mathrm{O}$ that of the mud flow from these craters. The gas is probably not instrumental in these mud eruptions, but merely an accompaniment of the same. 
Cementation of Delta Deposits. The delta deposits may be compacted merely by pressure, or the component particles may be bound together by the introduction of a cement. The Rhone delta contains much sandstone, the grains of quartz being bound by a calcareous cement, due to the abundance of lime in the stream. The presence of numerous limestone pebbles in glacial deltas also becomes a source of lime which is redeposited among the pebbles and cements them. Such an example is found in the partly consoliclated gravels of the Pleistocenic delta in the Ontario basin near L.ewiston, and a still more extensive one in the Nagelfuh delta of the Salzburg region already referred to. Cementation by infiltrated iron oxides also occurs.

Deposits of lime are especially abundant in deltas of arid regions, such as the Volga, the Indus, the Nile, and the Colorado. Extensive deposits of massive travertine and caliche have been formed in Arizona and New Mexico. Such deposits are, however, also found where the river water is high in lime content, as in the Rhine delta and in the Rhone delta already mentioned. In the latter case the approach to a semi-arid climate over the delta in the mediterranean is a further factor aiding deposition of lime. The silt of the Rhine delta in the Lake of Constance contains $30.76 \%$ of $\mathrm{CaCO}_{3}, \mathrm{I} .24 \% \mathrm{MgCO}_{3}$, and $5.20 \% \mathrm{FeCO}_{3}$. The other principal constituents are $\mathrm{SiO}_{2}$ 5. $14 \%, \mathrm{Al}_{2} \mathrm{O}_{3} 4.77 \%, \mathrm{Fe}_{2} \mathrm{O}_{3} 2.69 \%$. and small quantities of the oxides of manganese, magnesium, calcium, potassium, and sodium.

Modification of the Delta Surfaces. The chief modifications suffered by the delta are wave and wind erosion, and the formation of deposits over the surface of the delta. Wind erosion affects the surface of the delta, while wave erosion oceurs around the margin of the delta when the force of the river no longer is able to continue construction. It is common on a sinking coast, as is shown by the encroachment of the sea on the deltas bordering the North Sea. Wave erosion may also become effective when deltabuilding has practically come to an end owing to the decrease of supply incident to development of low relief with old age. In such a case the sea may gradually encroach on the delta and plane away the upper layers, until the remaining remnant of the delta is wholly submerged, when normal marine sediments may succeed. In all such cases there is commonly found a fringing belt of dunes at the outer margin of the delta, as in the case of the Rhine delta. Such dunes may also be formed where building is still in progress, as in the Rhone delta, where dunes are formed between the two principal mouths of the stream. Other eolian deposits may form 
on the delta, such as dust brought from a distance and windarranged material from the surface of the delta itself. Additional river deposits in the form of natural levees may be built by the overflowing river, which leaves much of its material near the bank, which is thus raised above the surface of the delta on either side. The floor of the channel may also be raised by aggradation, and the river thus flows at a level much higher than that of the surrounding country. Where the levees are artificially raised the river bed may come to occupy a position far above the normal level of the delta or flood plain. Thus the channel of the Po has been elevated in this manner to such an extent that it is said to rise above the tops of the houses in the town of Ferrara (Le Conte$36: 26)$. Where the sea temporarily floods part of the delta, deposits of salt may occur, as in the Rann of Cutch and other lowlying delta districts. The Nile delta is likewise characterized by saline deposits along the coast, due to evaporation of the sea water which at intervals floods the surface. Over these salt beds sand dunes are seen to wander. Deposits of vegetal material in swamps further characterize many delta surfaces. Such deposits may be marine marsh deposits or fresh water swamp deposits, or both. Salt and gypsum deposits are not uncommon on the lower part of the deltas in arid climates.

Relation of Delta Building to Crustal Movements. From the known relations of rivers to delta building it would appear that periods of strong river activities are also, as a rule, periods of pronounced delta formation, while, conversely, periods of diminished river work will be, on the whole, periods of slow and comparatively limited delta building. In general, youthful ungraded conditions of a land with corresponding ligh relief favor delta building, while mature or graded conditions characteristic of regions of low relief are correspondingly unfavorable to delta building. There are, however, modifying circumstances which may, to a certain extent, reverse these results, but as a general working proposition they may be confidently accepted. Furthermore, conditions of youth and high relief with active river work are productive of an abundance of coarse waste, which will result in the outward and upward building of deltas with strongly contrasted slopes in fore-set and top-set beds, while the finer waste supplied in lesser quantities by a region of relative maturity will tend to build outward deltas of gently inclined layers and, on the whole, of uniformity of slopes or confluence of top-set, fore-set, and bottom-set beds. In youthful regions of much waste supply the subaërial part of the delta will become a prominent feature, while the reverse will 
be true in regions past maturity and of slight supply of waste. It is thus readily conceivable that periods of intensive and extensive delta building may alternate in the earth's history with periods during which deltas are of relatively insignificant extent and the size and number of deltas in one period afford no criterion by which those of another may be measured.

Effect of subsidence. While the effect of stationary sea-level will be the rapid outward building of the delta, with pronounced development of the fore-set beds, slow subsidence will result in the extensive development of top-set beds and a restriction in the building of the fore-set beds. If the subsidence is periodic and interrupted, the sea will temporarily encroach on the delta, and the terrestrial top-set beds will be covered by a layer of marine sediments. Continued deposition by the rivers will, however, crowd back the sea, and renewed building of top-set beds will occur. In this manner intercalated marine layers will be formed between the terrestrial deposits. Such layers are found in modern deltas as already noted, and they are also common in older delta deposits, where they are generally taken as indicating the marine origin of the entire formation. That they have no such value is clearly shown by their relation to the continental beds in modern delta deposits. If subsidence were slow and more or less regular, continued deposition by rivers would tend to keep the sea out altogether, and a thick deposit of top-set beds of terrestrial origin would result. Such deposits of considerable thickness are found to characterize the larger modern deltas, which thus appear to occupy sites of continued subsidence. Similar conditions prevailed over the sites of delta deposits of Mesozoic and Palæozoic time, resulting in the formation of continental deposits of great thickness.

Subsidence of such a rate as to be in excess of the building power of the streams will put an end to the process of building the deltas and result in their final submergence. This has been brought about in a number of cases where former deltas and parts of deltas are now below sea-level. In earlier geologic periods such complete submergence has resulted in the burial of the delta deposit beneath a marine series of greater or less thickness. Credner (14) and others have, indeed, held that any subsidence is detrimental to the process of delta building, and that such stuctures are found only on rising or at least stationary coasts. That subsidence has, however, played a part in the formation of modern deltas is shown by the presence in most of them of terrestrial remains and peat layers, etc., which now lie at a considerable depth beneath sea-level (Fig. I27). 
Effect of clevation. Slight elevation of the delta area results in the destruction by erosion of the top-set series in the upper parts of the delta, and the carrying forward of the material to be added to the subaqucous fore-set series. The zone over which continental deposition takes place will also advance seaward, and thus terrestrial sediments will come to rest on marine deposits. Where the inclination of the fore-set beds is very gentle these terrestrial beds may come to rest upon them with practically no change in dip. Cessation of elevation or reversal of movement and the resumption of normal delta building will result in the deposition of a new terrestrial series on top of the erosion plane, and a new marine series on top of the terrestrial series nearer the sea. A hiatus and disconformable relationship will thus appear between the two nembers of the terrestrial part of the delta, and this disconformity will be re-

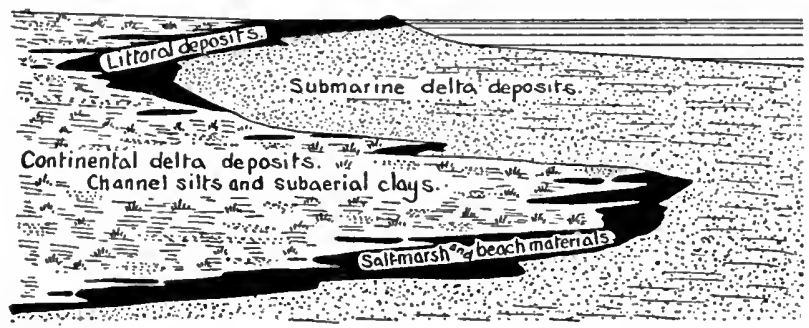

FIG. 127. Diagrammatic section of a seashore delta, showing the relation of continental and submarine deposits in a region of fluctuating sea-level. (After Barrell.)

placed seaward by a terrestrial layer interpolated between two marine series. If the delta front is comparatively steep it may, of course, happen that the uplift carries the erosion to the top of the delta front, beyond which deposition will be submarine. In a very large delta slow rising will result in the slow seaward migration of the zones of erosion and the zone of terrestrial deposition, the lowering of the upper part of the delta by erosion progressing steadily, while at the same time the zone of terrestrial deposition extends farther and farther outward. (Barrell-6.)

Deltas Merging into Desert Deposits. A remarkable combination of a river delta with desert deposits, on the one hand, and marine deposits, on the other, is shown by the Colorado on the Arizona-California and Lower California boundary. This delta was originally built into the Gulf of California, the head of which was by it completely severed from the main part of this funnel sea. The cut-off portion dried out completely under the influence of 
the drying westerlies, leaving the arid Coahuila basin north of the delta, the central portion of which is 300 feet below sea-level; while southward the delta enters the present head of the California Gulf. Occasionally a northwest distributary of the Colorado, the New River, carries water into the basin, which in the past has filled to overflowing, a fresh water lake being thus formed. The drying up of this left saline deposits upon the lacustrine beds, and these, together with the eolian and occasional river deposits, form a complicated series of sediments succeeding the former marine deposits of the region, all of these changes being brought about without any change in the sea-level. A moderate subsidence or a partial destruction of the delta would let the sea in again, and thus marine deposits would once more succeed the complicated terrestrial series. The area thus affected is somewhere in the neighborhood of 5,000 square miles. (Fig. 69, Chapter IX.)

\section{COLORS OF CONTINENTAL CLASTICS.}

The color of clastic rocks depends to a very large degree upon the states of oxidation of its iron content, and the absence or abundance of carbon. A low state of oxidation gives colors ranging from green to blue, while the higher states of oxidation are marked by yellow, orange, brown, or red colors. According to the carbon content, the color may vary from white, when no carbon is present, through various shades of gray to black. Abundant carbon in the strata will prevent oxidation of the iron and will reduce the higher oxides to the lower. Lack of carbon favors high oxidation.

Sediments deposited on land or in very shallow waters are especially subject to oxidation, unless there is an abundance of organic matter present to prevent such oxidation. In moist or pluvial climates with a moderate amount of vegetation, the soil is apt to be bluish from the prevention of a high degree of oxidation by the vegetation. This is especially true where the vegetation is intimately associated with the soil. The manner in which this is accomplished on the western side of Nicaragua has already been referred to (p. 36). Where black soils are formed, as on swampy surfaces, especially on low alluvial plains or peneplains, oxidation is likewise prevented. The same thing is true of delta deposits rich in carbon. Where, however, vegetation is extremely luxuriant it may prevent the saturation of the soil with moisture through transpiration and likewise prevent a satisfactory commin- 
gling of the regetation with the soil. In such cases oxidation may proceed without hindrance, as in the case of the eastern slopes of Nicaragua, where red soil from 3 to Io meters deep underlies the dense vegetation.

In seasons of dryness, when the amount of vegetation is small, the iron of the sediments of deltas and alluvial fans may become thoroughly oxidized. Where dryness prevails for most of the year, and where vegetation is as a result scanty, such oxidation may be especially favored. Thus semiarid or even desert regions would furnish the best conditions for such oxidation. On river flood plains there is always sufficient moisture to result in the formation of hydroxides of iron, and hence the colors of such deposits will range from yellows to ocher and brown. It is only under conditions of intense heat that dehydration will result with a consequent change in color toward the reds. Such change of color may, however, take place as the result of aging of the deposit, as pointed out by Crosby. In such a case dehydration is virtually spontaneous, and " . . . the color of the deposit, so far as it is due to ferric oxide, is, other things being equal, a function of its geological age." "In other words," says Crosby further, "the color naturally tends with the lapse of time to change from yellow to red; and, although this tendency exists independently of the temperature, it is undoubtedly greatly favored by a warm climate." (I5.)

Barrell (4:288) holds that "a still more potent cause exists . . . in the dehydration effected by the great increase in pressure and moderate rise in temperature which takes place upon the burial of the material to some thotisands of feet beneath later accumulations." Under such pressure the tendency would be for the oxide to give up its water with corresponding reduction in volume (see ante, p. I 77 ), just as shales are formed by the giving off of about one-half the combined water by the silicate of alumina, and this at temperatures probably often far below boiling point.

It is, of course, necessary that organic matter should be absent from such a deposit, for its presence would prevent oxidation in the first place. It is not necessary that the absolute amount of iron should be very large to affect the color of the deposit. The brilliant red Vernon shales of the eastern New York Siluric carry only 2.25 per cent. of ferric iron and 0.75 per cent. of ferrous iron (Miller-39). The chief desideratum is that the iron should be in an extremely fine state of subdivision and intimately disseminated or diffused through the mud or dust deposits. This fine division and diffusion of the iron have been noted by Dawson for the red 
Mississippic beds of Nova Scotia, where the iron has "the aspect of a chemical precipitate rather than of a substance triturated mechanically" (20:25). The same thing has been noted by Hilgard with regard to the red tropical soils, where the percentage of ferric oxide is by no means markedly high, but where the oxide is very finely diffused throughout the mass.

Finely diffused oxide of iron, but in the state of ferric hydrate, is the coloring agent of the yellow loess of China. The total amount of ferric oxide in American loess ranges from 2.50 per cent to 3.74 per cent., and in one case to 5.22 per cent., while a limited amount of $\mathrm{FeO}$ (from $0 . \mathrm{I} 2$ to $\mathrm{I.02} \%$ ) is also present, but organic carbon is very slight, ranging from 0.09 to 0.19 per cent. Dehydration of the iron with age, especially after burial, would result in the formation of fine-grained red deposits, in every respect similar to the Vernon red shales.

The red Vernon shales, like red shales and sandstones frequently, are associated with salt and gypsum deposits. This is an indication of arid conditions during the deposition of the muds from which these shales are formed. Salt and gypsum deposits of the present time are associated with gray and bluish-gray muds and it is only by sulssequent oxidation and dehydration that the red color is produced.

One of the essentials in the production of red rocks by sucil subsequent oxidation and dehydration appears to be the virtual absence of organic matter which would prevent oxidation. Where the ground water level is high organic matter will accumulate and oxidation is prevented. But where the sands and muds are exposed to circulating air in dry seasons, with a low ground water level, more or less complete oxidation of the iron will take place. Such a condition is found in delta deposits of arid regions, as, for example, the Nile delta, in which organic matter seems to be of very small amount, while the iron content is comparatively high. It is probable that the Nile mud on aging would take on a red color.

There is, however, another factor which may affect the change in color, and that is the lime carbonate content of the deposit. This is high in many delta deposits of arid regions and its presence may prevent the production of a red color by the formation of complex silicates of lime, iron, and alumina. According to Ries ( $47: 6, I I$ ) a buff or cream color is produced if clay containing three times as much lime as iron or more is burned into bricks. Magnesia has the same coloring effect on the burned ware as lime, while alkalies tend to turn the iron red into a brown. As the Rhine delta in the Lake of Constance has nearly 12 times as much lime carbonate as 
iron oxide, it would not produce red bricks, and it is not improbable that the lime would have the same effect in preventing the formation of a red color with age.

Alternation of Red Beds aith Those of Other Colors. This is a feature often found in older formations and has also been observed in modern continental hydroclastics. Huntington $(34: 364)$ has described such deposits of pinkish or reddish sandy clays and sands alternating with whitish or greenish clays from the uplifted and dissected Pleistocenic deposits of the basin of Seyistan in eastern Persia. These layers are well shown in cliffs from 400 to 600 feet high, exposed by recent erosion. The red beds are continuous and, while preserving their general aspect for many miles, they vary greatly in detail. Wedging out layers of sand or even gravel occur, slight erosion disconformities, occasional ripple marks, worm-casts and rain-drops are not uncommon, and the uniform oxidation of these beds indicates long exposure to the air under conditions of aridity. This is further shown by the condition of the modern delta deposits of the region, of which the subaërial part is well drained and aërated and everywhere of a light brown color. On the shores of the modern Lake of Seyistan, where the clayey beds are saturated with water and subject to successive floodings, the brown colors are replaced by light colored soils with black bands. The margin of the present lake supports a dense growth of reeds and the clay deposits on its bottom are greenish and white. The greenish and whitish beds of the dissected older deposits correspond to these lake sediments. They represent subaqueous deposits formed during the greater extent of the lake, and in continuity and uniformity, as well as color, they contrast strongly with the pink and red beds formed during the contraction of the lake as subaërial sediments.

Alternating red and white layers of this type are characteristic of the Moencopie formation of northern Arizona and southern Utah, a deposit of Permic age. The absence of fossils and the general close correspondence between these beds and the series exposed in the dissected basin of Seyistan have led Huntington to the conclusion that both have a similar origin.

Alternations of gray and green sandstones with red clays are well shown in the Middle Siwalik group, a late Tertiary deposit exposed in the foothills of the Himalayas. As previously noted. this formation represents a fluviatile deposit, of the type now forming over the Indo-Gangetic plain. A corresponding Deronic cxample is seen in the Catskill formation of eastern New York and Pennsylvania, where, through a thickness of perhaps 5,000 feet, 
there is a constant alternation of red shales and greenish sandstones. The physical characteristics of the deposit and the absence of marine and presence of land and fresh water organisms show that this series was formed under fluviatile conditions similar to those of the Siwalik.

Lateral variation in color is also a frequent feature of older deposits and can be explained by the contemporaneous beds now forming in the Seyistan basin, where the oxidized subaërial deposits merge laterally into the unoxidized subaqueous or lacustrine ones. The fossiliferous Permic limestones and shales of Kansas may be traced southward into red sandstone and shales of the same age in Oklahoma, the latter being practically unfossiliferous. These red clays may be in part the residual clays from dissolved limestones (Beede-7) and in part of clastic origin. Their high state of oxidation suggests widespread subaërial deposition under sufficiently arid conditions to permit the free influence of the atmosphere. Lateral variation of a more irregular character is shown in some Mesozoic clays, such as the Potomac group of the Atlantic coast, and the Cretacic Atlantosaurus or Como beds of Wyoming, and in the Tertiary beds of the Wind River and Bighorn basins and elsewhere. In the Wasatch and Wind River clays analyses have shown the iron content to be as follows 7 Sinclair and Granger-52:115):

\begin{tabular}{|c|c|c|c|c|}
\hline \multirow{2}{*}{ Horizon } & \multirow[b]{2}{*}{ Phase } & \multirow{2}{*}{$\begin{array}{c}\text { Total Iron } \\
\text { calculated as } \\
\mathrm{Fe}_{2} \mathrm{O}_{3} \\
\%\end{array}$} & \multicolumn{2}{|c|}{ Total Iron } \\
\hline & & & $\mathrm{FeO}$ & $\begin{array}{c}\mathrm{Fe}_{2} \mathrm{O}_{3} \\
\%\end{array}$ \\
\hline $\begin{array}{l}\text { I. Mottled (red and blue) clay, } \\
\text { Wind River.............. }\end{array}$ & $\begin{array}{l}\text { red } \\
\text { blue }\end{array}$ & $\begin{array}{l}8.16 \\
6.67\end{array}$ & $\begin{array}{l}0.19 \\
0.38\end{array}$ & $\begin{array}{l}7.91 \\
6.24\end{array}$ \\
\hline 2. Blue clay, Wasatch........... & blue & $3 \cdot 34$ & $0.5^{2}$ & 2.77 \\
\hline 3. Red clay, Wasatch, same locality & red & 4.82 & 0.58 & $4 \cdot 18$ \\
\hline
\end{tabular}

Sinclair and Granger comment on these analyses as follows: "In all the samples examined, the total iron in the red clays is in excess of that present in the blue by 1.48 per cent. to I.49 per cent. The amount of ferrous iron in the blue Wasatch clay is less than that present in the red, while in the mottled Wind River clay it is 
slightly greater in the blue than in the red phase, but in neither case does it seem possible to ascribe the blue color to ferrous oxide, as this substance is far exceeded in amount by ferric iron, evidently occurring in the blue clay in some other form than ferric oxide (hematite), perhaps as a hydrous silicate. In the Wasatch clay the red contains $1.41 \%$ more $\mathrm{Fe}_{2} \mathrm{O}_{3}$ than the blue; in the Wind River clay $\mathrm{Fe}_{2} \mathrm{O}_{3}$ in the red phase is $\mathrm{I} .67 \%$ greater than in the blue. If this excess of iron is present in the form of hematite, as the red color seems to show, it is possible that the remaining iron in the red clay may be in the same form as in the blue (a hydrous silicate?) and that the blue color has been masked by the red pigment."

"The results of analysis seem to show that the blue color has not been derived from the red by reduction of the iron as ordinarily understood. The red color may have been derived from the blue by conversion of the hypothetical silicate into carbonate by meteoric waters, and the subsequent oxidation of these salts, or by the introduction of iron compounds in solution and their concentration and oxidation possibly under drier climatic conditions than existed during the deposition of the blue clays. We favor the latter alternative and regard the coloration of the clays as a phenomenon controlled by conditions active during the deposition of each individual stratum (red or blue, as the case may be), and not by subsequent or secondary changes. Under the arid conditions which exist at present over most of the Wind River and Bighorn basins, the blue clays show no tendency to weather red. The layer of weathered mud-cracked clay on the surface of bad land slopes cut in the blue clays is yellow from the hydrous oxide, limonite." ( $52: I_{15}$, II6.)

Original Red Color of Sediments. Whatever the case above mentioned shows, it must not be overlooked that some sediments when deposited already have a decidedly red color, or that this may be acquired before burial. Soils washed from regions of extensive laterite formation will be deposited as red sediments either on land or in the sea. Such sediments may be carried great distances from regions where they are formed to regions where their production is prohibited by the local climatic conditions. Russell held that the red sands of the Newark system were deposited with a coating of red iron oxide formed during decomposition. This conclusion may, however, be questioned.

Desert sands not infrequently have their grains coated with a thin deposit of iron oxide which often gives the sands a brilliant color, as in the case of the carmine sands of the Nefud desert of 
northern Arabia. The source $(57: 25)$ of the iron is believed to be in the sand itself, as shown by analysis, the coating having formed under the influence of the sun's heat, as the desert varnish forms on the larger pebbles and boulders. This latter, however, is subject to destruction owing to the size of the fragments, for Walther has observed that after a heavy rain this brown coating is quickly removed by the impact of the rock masses. In like manner a coating of iron oxide on sand grains subject to wind transport must be destroyed, and this probably accounts for the almost uniform white or golden color of desert sands. The absence of such a coating, then, on the pebbles of ancient desert gravels need not be surprising, and the yellow or white color of gravel and coarse sand beds intercalated between red deposits may not necessarily indicate great climatic differences, but may result rather from the destruction of the color coat in the coarser material.

\section{EXAMPLES OF OLDER CONTINENTAL HYDRO- CLASTICS.}

Examples of fluviatile and lacustrine deposits have been recognized in nearly all geological horizons, from the pre-Cambric to the present. Not all stratigraphers agree in regarding the formations enumerated below as of unequivocally non-marine origin, but the more obviously fluviatile and glacial formations are recognized as such by most recent students of the subject.

\section{Cenozoic or Tertiary Examples.}

Among the Tertiary deposits of the Great Plains regions of the western United States are many beds showing stratification, but composed in large part of alternate pebble and sand beds, with cross-bedding structure well marked. These have commonly been classed as "lake deposits," but, as Davis (19:345) has shown, these are more likely deposits made by running water, and represent outwash plains or alluvial fans, formed by the streams from the mountains. Some of these deposits, as in the case of the Vermillion Creek beds in Wyoming, consist near the mountains from which they have been derived of excessively coarse conglomerates between 3,000 and 4,000 feet thick, nearly structureless, lines of stratification being rarely perceived. "The blocks of which the conglomerate is chiefly formed range from the size of a pea to masses with a weight of several tons . . ." (King-35:369.) At some 
distance from the mountains the beds consist of coarse red sandstones interbedded with clays and arenaceous marls. In the Arapahoe and Denver formations of Colorado, basal conglomerates from 50 to 200 feet in thickness are succeeded by arenaceous clays, and these, in turn, are followed by 400 feet of ertuptive débris, above which are again conglomerates and sands derived from the mountains. Cross-bedding and wedging out of layers are common, showing a considerable current. In some of the beds "tree stumps in erect position with roots in mud layers and broken trunks in sand or gravel . . . occur (Cross-16:I68) and contemporaneous lava flows are interbedded with the sediments.

In these deposits the remains of terrestrial vertebrates are frequently abundant, while fresh water animals are found only where temporary bodies of water existed. Associated with typical atmoclastic are lacustrine deposits, often rich in remains of fish or other fresh water animals, and colian deposits (anemoclastics). Not infrequently the atmoclastics extend out covering either lacustrine or eolian deposits.

The Eocenic and Oligocenic deposits of the Wind River and Bighorn basins in Wyoming have already been referred to. These deposits consist of clays and sands often well banded and alternating red and bluish in color, of arkose sands, and of conglomerates and occasional fine tuffs or pyrolutytes. They contain land and river vertebrates, such as crocodiles, turtles, garpike, Eohippus, Heptodon, Lambdotherium, etc., and shells of Unio. Microscopic as well as macroscopic study of the deposits has shown that they are derived from the crystalline or other rocks of the enclosing mountains, and their character and mode of occurrence show that they were either wind or river transported. In the coarser sandstones and arkoses of the Wind River and Bridger (?) beds, Archæan granites and Palæozoic quartzites are readily recognizable. "The well-rounded gravels, found in some of the arkoses, point with equal certainty to running water as the transporting agent, while fluviatile deposition is shown by the frequent channels filled with coarse sandstone which cut irregularly across the finer clays, by the frequent interstratification of sandstone lenses with the clays and by the presence in the latter of fish, crocodiles, and turtles, and occasional beds of Unios. Local swamps are indicated by lignites in the blue clays and sandstones, but never in the red clays."

Sometimes change in climate or steepening of grade is indicated by coarsening of sediments . . . "for instance, the coarse, frequently cross-bedded arkose forming the lower member 
of the so-called Bridger of the Beaver Divide appears to represent a series of conjoined alluvial fans spreading out over the banded clays of the Wind River, but it is not possible to say whether the gravels and sands were transported by torrential streams under a dry climate or by streams whose carrying capacity had been increased by uplift." (Sinclair and Granger-52:II3.) The freshness of the feldspars indicates that they had not been leached by carbonated waters, such as might be expected to occur if they were deposited in a region of high humidity. This also suggests that they have not been derived from the parent rock by ordinary weathering processes, but rather by temperature changes, which shatter the minerals without affecting their freshness. Altogether, the deposits suggest dry, not necessarily arid, climate, with rapid changes of temperature and rapid transportation for short distances and burial beyond the reach of carbonated waters.

The clays of the Wasatch and Wind River deposits are commonly banded, altcrnating beds of red and blue-green clay or of red with mottled clay occurring. "The red clays are frequently streaked with blue-green color along joint cracks or are traversed by anastomosing green lines along what may have been the courses of roots. The beds are lenticular in shape, varying from a few inches in thickness, with little horizontal extent, to strata from 18 inches to 50 feet in thickness, traceable sometimes for several hundred yards to a mile or more. . . . Lignite is never found in the red clays, but may be present in the blue. . . ." The fossils found in the red beds are always fragmentary, "the more resistant parts, such as jaws and teeth, predominating. In the blue and mottled clays associated skeletons . . . of Coryphodon were found." (Sinclair and Granger-52:II4, II5.) The microscope has not revealed any essential difference between the variously colored clays.

Sinclair and Granger ascribe the color banding to the alternation of moist and dry climatic conditions, though no evidence of excessive aridity has been found; the fauna of the red and blue bands being the same. "The clays cannot owe their color to different sources of supply, for they are microscopically the same and the alternation of color bands is too regular and of too frequent recurrence to permit this inference. The red clay cannot represent upland oxidized wash, for waters swift enough to carry the bone fragments found in the clay would also transport rock fragments of some size, and these are not found." The blue clays of the Wasatch are sometimes lignitic and often afford associated skeletal remains, and this suggests that they were formed during cycles 
of more abundant rainfall, when the surface of the intermontane basin was prevented from drying out rapidly. The red clays, however, appear to have been formed "during the drier cycles, when the carbonaceous matter of decaying plants was completely oxidized, concentration and oxidation of iron compounds occurred, and animal bones exposed at the surface were weathered and broken before entombment." Conditions of this kind seem to have been widespread, as shown by similar color banding in the Wasatch in other localities.

In the Wasatch formation along the contacts of red and blue beds or in many of the red beds themselves great numbers of fragmentary jaws and scattered teeth of vertebrates have been found. The clays appear to represent the deposits on the dry basin floor over which the bones of these creatures were scattered and weathered before being buried. In the blue clays associated skeletons are common. These are the remains of animals which were either drowned and rapidly covered beneath fluviatile sediments or were mired in the soft clays. The teeth found in the WVind River area usually have the roots worn away and only the harder enamelcovered crowns are preserved. The Unio beds of the Wasatch are always of limited extent and seem to be confined to the blue clays. The lignite layers in these clays are usually mere dirt bands, but some in the Wind River basin have considerable thickness $(52: I I 7)$.

The Oligocenic beds of this region contain limestone deposits associated with wind-laid volcanic tuffs. These limestones, which are found near the top of the series, are a spring deposit forming sheets of tufaceous limestone, or layers of white nodular masses, calcareous without, but containing more or less silica within. Worn quartz, feldspar, and pink granite pebbles are sometimes found in the limestone, which is also partly replaced by silica in the form of opal or chalcedony. No fossils have been found in the limestone, which appears to have been formed under relatively dry climatic conditions.

These Tertiary deposits on the eastern slopes of the Rockies have thus all the characteristics of deposits formed under semiarid conditions. These conditions prevail to-day in this region under the influence of the westerly winds, which, on crossing the Coast Range, where they leave most of their moisture, become still drier on crossing the Rockies. Greater elevation of the mountain ranges would probably increase the aridity of the intermont basins in this region and so reëstablish the conditions of Tertiary time.

Hobbs (3I) has recently described a typical torrential formation of great thickness from southern Spain. This ranges in age 
from Miocenic to the present. Its material is derived from the crystallines of the Sierra Nevada, from the northern flanks of which it extends for twenty-five miles, and locally from the Triassic dolomite of the Sierra Haraña (Alhambra formation). The formation, approaching a thousand feet in thickness, is a conglomerate near the mountains with pebbles varying "from a fraction of an inch to six inches or more in length." Within the various stream vaileys local peculiarities of rock material exist, corresponding to the peculiarities of the rocks in the respective headwater branches of these streams. At a distance from the mountains fine material prevails, much of it of a loess-like character, indicating wind and playa-lake deposition. Floated plant material, such as roots and brushes, appear to be characteristic of some of the finer deposits. These torrential deposits seem to be intimately related to the semiarid conditions of the interior of Spain, caused by the monsoon winds. These winds blow northward from the Mediterranean in summer, crossing the Sierra Nevada and leaving much of their moisture on the southern slopes. Descending the northern slopes they are relatively drying winds and so permit the formation of these periodic torrential deposits.

Similar torrential deposits of great thickness and ranging in age from late Tertiary to the present are described from southern Italy (3I:290). A marked cross-bedding structure, already referred to (Fig. I23), so similar to what is commonly found in ancient sandstones, is characteristic of many of these deposits. The Siwalik formation of India has already been cited as a subaërial deposit of similar character and age. It is of great interest in that it reaches the enormous thickness of 15,000 feet. Here also belongs in part the Mollasse of the Alps. This is a complex series of light-colored sandstones and conglomerates with occasional limestones, found in the Alpine forelands, in the south of Germany and in Switzerland. The lower part of the Mollasse is of Oligocenic age and begins as a marine series. In southern Germany this reaches in places a thickness of 600 meters (Bavaria) and is followed by an immense series of fresh water sands and conglomerates approaching a thousand meters in thickness. This series shows in part brackish water and in part fluviatile and lacustrine conditions. The brackish water phase contains Cyrena, Cerithium, Cytherea, etc., and the fresh water Limnæus, etc. Numerous leaves and other remains of land plants (Cinnamomum, Juglans, Quercus, Betula, Rhamnus, etc.) are found locally, forming what is known as "Blättermollasse" and forming occasional beds of brown coal, which is extensively exploited in the Bavarian fore-Alps. Red sedi- 
ments forming the "red Mollasse" are frequent in the upper nonmarine part of the Oligocenic Mollasse, especially in Switzerland, but occur also in upper Swabia. The red beds are generally followed by conglomerates with pebbles ranging in size from that of an egg to that of a man's head and locally kown as Nagelfluh. These in places reach a great thickness. Away from the Alps the material becomes finer. The Miocenic Mollasse succeeding this often begins with calcareous beds to a large extent formed of the shells of the land snail, Helix rugulosa (Rugulosa limestones). This is followed by a series of loose sands, glauconitic sandstones and conglomerates (Nagelfluh) several hundred meters thick in the southern part of the region. The lower part of this series is again purely marine, but the upper part is once more brackish and nonmarine, beds containing Cardium sociale, Melanopsis, etc., marking the brackish portion; sands with Paludina, Unio, and Chara fruits, marking the lacustrine and fluviatile. These series constitute the Middle Mollasse. The highest beds finally forming the Upper Mollasse of Upper Miocenic age are again wholly non-marine. They consist of sands, clays, marls, occasional thin beds of brown coal, local volcanic tuffs and especially non-marine limestones. These so-called Sylvana limestones consist of the shells of the land snails Helix sylvana and H. inflexa, of those of the pond and river snails Planorbis, Limnæus, etc. Bones of the mastodon also occur. Other beds contain an abundance of the shells of the river and lake molluscs, Unio, Anodonta, Limnæus, Melania, Melanopsis, etc. Local deposits of thin marly limestones with plant (maple, poplar, etc.) and insect remains also occur, as in the celebrated deposit of Öningen on the Lake of Constance (Bodensee) and local deposits like those of the Steinheim basin with its sands filled with Planorbis, Helix, and land vertebrates. Remains of terrestrial vertebrates abound in all of these deposits.

Since the axis of the Alps is parallel to the direction of the rainbringing winds, both sides receive an abundant rainfall, though within the mountains are dry valleys. The extensive formation of the Mollasse, partly of subaërial origin on the northern side of the Alps, suggests a different condition during Tertiary times, so as to result in a more arid condition on the north, or, at any rate, in conditions which would favor the formation of extensive alluvial fans.

Mesozolc Examples of Continental Hydroclastics.

The Potomac Formation of the Atlantic coast of North America represents a series of delta and flood plain deposits comparable 
to those of the Huang-ho and the Indo-Gangetic plain. Extensive torrential deposits are absent here, the series being composed mainly of sands and clays. The series goes back to late Jurassic or early Comanchic time, and comprises four main divisions, the Patuxent, Arundel, Patapsco, and Raritan. The organic remains in these deposits are chiefly land plants, while the remains of a land fauna have also been found. No narine organisms are known except in the upper part of the series, the Magothy formation of New Jersey, which, however, also contains land plants. Above this series lie sands and clays with an Upper Cretacic marine fauna. These deposits were spread upon a broad coastal belt by rivers coming from the region of Palreozoic and older strata on the northwest, where peneplanation was in progress. The sea margin at this time must have been some distance farther to the east than the present coast. The rivers were numerous and more or less evenly spaced, so as to produce a continuous series of confluent deltas which extended from Massachusetts to the Gulf of Mexico. Landward the subdivisions of this series are separated by erosion disconformities, marking periodic upwarpings, but seaward they become thicker, and the disconformities probably disappear. Somewhere east of the present coast line these deposits probably pass into a continuous marine series, now submerged.

The fluviatile origin of these deposits is suggested by the discontinuity of the strata, beds and lenses of clay and gravel occurring in sand and vice versa. Many of the clays are strongly variegated in color, the state of oxidation of the iron varying both horizontally and vertically, while concentrated segregations of the iron also occur. Such variable conditions for oxidation exist on river flood plains, but not in lakes or on the sea bottom. The abundant plant remains, which by their character show little transportation, as well as the absence of marine, brackish or even lacustrine organisms, strongiy indicate fluviatile conditions, as do also the bones of dinosaurs, turtles, and crocodiles.

The Arundel formation appears to have been deposited within stream valleys eroded in the Patuxent, and in this formation gypsum has been found. This suggests greater aridity during the period of deposition of this formation than during the time the more widely spread sands and clays of the other divisions accumulated. In the Raritan formation feldspathic sands occur, further suggesting an increase in aridity, while lignitic quartz sands alternating with highly oxidized sands testify to a variety of conditions. Some of the quartz sands show the characteristics of dune deposits. Upward the occurrence of lignites with Teredo borings marks the 
beginning of marine invasion, the river building processes being overcome by the invading forces of the sea. (See further, Barrell-6.)

The Red Beds of North America. The Red Beds of the Rocky Mountain region and the similar red sandstones of the Newark formation of the eastern United States are now generally recognized as subaërial deposits, in part of fluviatile and in part of eolian origin, with subordinate lacustrine and rarely estuarine conditions. The source of the western red beds was the old Palæocordilleran chain of mountains formed at the end of the Palæozoic, and extending northwestward from Arizona to northern California. On the Pacific side of this chain marine T'riassic and Jurassic beds were forming, while east of the range a series of alluvial fans accumulated, these being now in part represented by the Red beds. Their highly oxidized character indicates that accumulation was under semi-arid climatic conditions, such as would prevail with a westerly wind sweeping over a mountain chain of sufficient height to deprive it of most of its moisture. That vegetation, nevertheless, existed in some parts of the mountain slopes is shown by the abundance of the petrified woods preserved in these deposits, into which they were probably carried by torrential streams. According to Williston and Case (59) the upper Red beds, from Lander, Wyoming, on the north to New Mexico, Kansas, and Texas, on the south, range from five hundred to possibly a thousand feet in thickness and are "barren or almost barren measures characterized by light colors of the sandstone, often of eolian origin, and more or less interspersed or capped with massive beds of gypsum." It may be added, however, that some authors still hold to the marine theory of origin of these beds. (See, especially, Henning-28.)

Vertebrate fossils of Triassic (Keuper) age are reported from all along the line of outcrop, chiefly comprising phytosaurs and labyrinthodonts, closely agreeing with species from the European Keuper. Some of the lower Red beds of the southern and western region are of Permic age, and indicate the earlier commencement of this type of sedimentation.

Triassic Red Beds of Eastern North America and of Europe. The Newark series is likewise best regarded as forming local remnants of a combination of widespread alluvial fans, river flood plain, and eolian deposits, derived from the Appalachians to the west and built out toward the east on the low coastal plain, or into depressions, and under conditions of semi-aridity which permitted pronounced oxidation of the sediments. The beds themselves abound in shrinkage cracks, raindrop impressions and animal foot- 
prints. Fish remains and shells of Estheria are found in intercalated black shales, and terrestrial plant remains are not uncommon in some sections. Much feldspar occurs and this together with the oxidation of the iron compounds indicates the relative aridity of the climate. Intrusive sheets and lava flows characterize the northern development, and coal beds the southern. Barrell and Kümmel have brought forward evidence in the sediments that a part of the material in Connecticut and in New Jersey was derived from the east as well as from the west. They therefore consider the deposits as formed in large basins bounded by faults, rather than accumulations on a coastal plain surface. Until recently the Triassic deposits of eastern North America were interpreted as estuarine accumulations (Russell-48; Chamberlin and Salisbury-II), but the detailed study of the physical characters of the rocks has developed the evidence which shows them to be continental deposits (Barrell-5). Similarly the corresponding Triassic deposits of northern and western Europe, the New Red sandstone of England and the Bunter Sandstein and Keuper of Germany had been regarded as estuarine, tidal, or lake deposits (Reade-46), but their subaërial origin, as sediments deposited by rivers chiefly from the mountains of that period on the south and west, is being more generally recognized. On the Continent the material was chiefly derived from the old Vindelician mountain range which existed where now is the valley of the Danube and separated the Alpine Triassic sea from the North German lowlands. According to Bräuhäuser (Fraas-22:5I3) the pebbles of the Lower Bunter sandstein of Schramberg are not worn by rolling, but the pebbles of the conglomerate forming the base of the Middle Bunter are well rounded and their size decreases from southeast to northwest. The material is derived from the crystallines and from the Rothliegende of the Permic. Wind-cut facetted pebbles also occur, but they have been more or less worn by subsequent reworking. Walther (58:79) speaks of middle and eastern Europe in Lower Triassic time as a huge desert area supplied with variable detritus by streams from the mountains on the south and west, and covered by endless dunes, interspersed with ponds, and once at least by a large relict sea. Clastic material accumulated to a depth of 400 to 600 meters, after which the sea invaded the region from the east and the marine Muschelkalk was deposited. An earlier temporary and partial invasion of the sea is suggested by fossiliferous horizons. The Keuper marks a return to continental sedimentation, which in Switzerland, France, and England was uninterrupted. At the beginning widespread sandstones (Schilfsandstein) were 
formed, these being interpreted as flood plain and delta deposits. (Fraas-22:5I6). The upper sandstone (Stubensandstein) has been interpreted as probably in part a fluviatile and in part an eolian formation, the sandstones representing an accumulation on a flat piedmont area at the foot of the actively eroded Vindelician mountain chain. The extensive variegated clays of the Keuper have been regarded by Lang and others as marine sediments, but Philippi (44:463), Fraas $(22: 5 I 7)$, and Walther (58) consider then rather as aërial sediments especially of eolian origin, representing a sort of loess-like accumulation. This interpretation is suggested by the manner of occurrence in these sediments of the skeletons of phytosaurians, aëtosaurians, land turtles, and labyrinthodonts, with occasional dinosaurs, all lacking evidence of transport or destruction by aquatic animals such as might be expected if the remains were carried into the sea. The prevailing color of these sediments is red except where they were subsequently reworked by water, and here a gray color predominates.

\section{Palfozoic Delta Deposits.}

These are numerous, especially in North America, where a whole series has been determined. Thus the entire Coal Measure series and Permic of eastern North America chiefly consist of river deposits with only occasional incursions of the sea. The Pottsville conglomerate at the base of the series is an especially good example. It was deposited from two centers, one in east central Pennsylvania, the other in southern Virginia. From these points outward the beds progressively overlap away from the source of supply, and apparently upon an old land surface, there being in these sections no marine equivalents. The Pocono sandstone is a similar deposit, and between it and the Pottsville lies the Mauch Chunk red shale, a deposit of river flood plain and eolian origin during a period of relative aridity (Barrell-3). Still earlier in the Devonic a similar deposit, the Catskill, was formed progressively replacing a marine formation (Chemung) westward (Grabau-25). The Oneonta (Portage) sandstone of New York and the upper Hamilton or Ashokan formation is interpreted as of the same character. Still earlier in the Devonic the Esopus grit represents the characters of a sea-level delta built westward by a stream debouching near northern Pennsylvania. The Gaspé sandstone of eastern Canada likewise represents a Devonic dry delta deposit. Still earlier in the Siluric and Ordovicic similar dry deltas were built 
to the northwest by streams from an old Appalachian continent, these deposits sometimes replacing marine sediments westward, at others building out upon a dry land or, in one case at least, a desert area. (Grabau-27).

A remarkable feature of these deposits is the repeated succession upon light colored pebble deposits, with evidence of torrential origin, of finer red sediments with characters suggesting flood plain and eolian origin. Such are in the Ordovicic the light Bald Eagle conglomerate followed by the red Juniata shales, in the Siluric the Shawangunk conglomerate followed by the red Longwood shales, in the Devonic the Hamilton and Oneonta sands followed by the Catskill red beds, in the Mississippic the Pocono conglomerate and sandstone followed by the red Mauch Chunk shale. This succession seems to indicate conditions which permitted easterly winds to sweep across a more or less elevated land mass (Appalachia), where they were deprived of much of their moisture, thus creating semi-arid conditions on the west of this land mass. Moderate aridity, with periodic torrential rainfalls and swollen streams

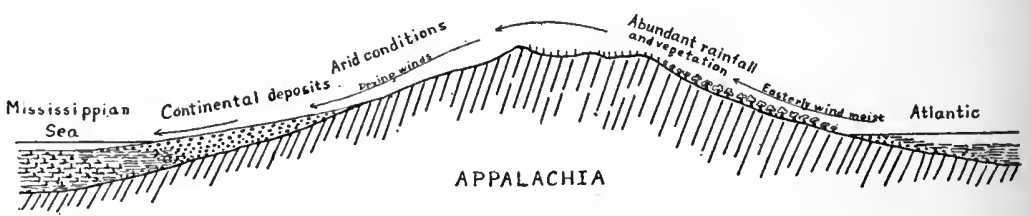

FIG. 128. Hypothetical section of Appalachia in Palæozoic time to show the possible arrangement of the winds, and the corresponding deposits.

forming alluvial fans of pebbles, seems to have existed repeatedly, but in each case was followed by drier conditions such as would be produced by a renewed elevation of the land, and the consequent deposition in the lee of the land mass of highly oxidized sands and dust as river flood plain and eolian formations, which are now seen in the red beds. The conditions favoring such deposition are illustrated in the preceding diagram (Fig. I28).

Deposits of a similar character are found in the Old Red sandstone of western Europe, and the Siluric deposits of the north of England and the south of Scotland also show much evidence of deltaic origin.

One of the most striking examples of a seashore delta of Upper Devonic age seems to be represented in the black shale of Ohio, Michigan, and western New York. To be sure this has also been interpreted as a deep sea deposit, but its peculiarities all point 
to a delta-like origin, represented to a certain degree by the modern deposits at the mouth of the Mississippi. The abundance of spores of rhizocarp-like plants, represented to-day by fresh water plants, the presence of tree trunks, and especially the thinning away eastward and southward, and their interpolation between normal shallow water marine sediments, all point to the delta origin of these shales.

Note:-For a full discussion of the Early Palæozoic delta deposits of Eastern North America, see Grabau, 27.

\section{BIBLIOGRAPHY XIV.}

I. ANDRUSSOW, N. I 893. Physical Exploration of the Black Sea. Geographical Journal, Vol. I, pp. 49-5I.

2. BARRELL, JOSEPH. Igo6. Relative Geological Importance ot Continental, Littoral and Marine Sedimentation, Journal of Geology, Vol. XIV, pp. 336-354; 430-457; 524-568.

3. BARRELL, JOSEPH. I907. Origin and Significance of the Mauch Chunk Shale. Bulletin of the Geological Society of America, Vol. XVIII, pp. $449-476$, pls. $49-52$.

4. BARRELL, J. I908. Relations between Climate and Terrestrial Deposits. Journal of Geology, Vol. XVI, pp. I 59-190; 255-295; 363-384.

5. BARRELL, J. I9I I. Central Connecticut in the Geologic Past. Proceedings and Collections of the Wyoming Historical and Geological Society, Vol. XII, pp. I-3o.

6. BARRELL, J. I912. Criteria for the Recognition of Ancient Delta Deposits. Bulletin of the Geological Society of America, Vol. XXIII, pp. $377-446$.

7. BEEDE, J. W. I912. Origin of the Sediments and Coloring Matter of the Red Beds of Oklahoma. Seience, N. S., Vol. XXXV, pp. $34^{8-350 .}$

8. BERKEY, C. P. I905. Laminated Interglacial Clays of Grantsburg, Wisconsin. With chronological deductions. Journal of Geology, Vol. XIII, pp. 35-44.

9. BISCHOFF, GUSTAV. I863. Lehrbuch der chemischen und physischen Geologie, 2nd edition, Vol. I. English: Elements of Chemical and Physical Geology, edited and in part translated by G. H. Paul, London, Cavendish Society, I859, 3 vols.

10. BLAKE, W. P. Igor. The Caliche of Southern Arizona. Abstract. Engineering and Mining Journal, Vol. LXXII, pp. 60I-602.

II. CHAMBERLIN, T. C., and SALISBURY, R. D. I906. Geology. Vol. III. New York, Henry Holt \& Co.

12. CLARKE, F. W. I9II. The Data of Geochemistry. 2nd edition. Bulletin United States Geological Survey, No. 491.

13. CRAMMER, HANS. 1903. Das Alter, die Entstehung und Zerstörung der Salzburger Nagelfluh. Neues Jahrbuch für Mineralogie, u. s. w., Beilage Band XVI, pp. 325-334.

14. CREDNER, GEORG RUDOLF. I878. Die Deltas, Ihre Norphologie, Geographische Verbreitung und Entstehungs Bedingungen. Petermann's Geographische Mittheilungen Ergänzungsheft, No. 56, pp. I-74, 3 Tafeln. 
15. CROSBY, W. O. I89I. On the Contrast in Color of the Soils of High and Low Latitudes. American Geologist, Vol. VIII, pp. 72-82.

I6. CROSS, WHITMAN. I 896. Geology of the Denver Basin in Colorado. Monograph U. S. Geological Survey, XXVII.

I7. DARWIN, CHARLES. I84I. The Voyage of the Beagle.

I8. DAVIS, W. M. I 898. Physical Geography. Ginn \& Co.

19. DAVIS, W. M. I900. The Fresh-water Tertiary Formations of the Rocky Mountain Region. Proceedings of the American Academy of Arts and Sciences, Vol. XXXV, pp. 345-373.

20. DAWSON, J. W. I848. On the Coloring Matter of Red Sandstone and of Grayish and White Beds Associated with Them. Quarterly Journal of the Geological Society of London, Vol. V, pp. 25-26.

21. FOUREAU, F. 1893. Au Sahara, Reviewed in Petermann's Geographische Mittheilungen, Bd. XLVII, Litteraturbericht, p. I75, I897.

22. FRAAS, E. I9II. Geologische und Palæontologische Beiträge aus dem Triasgebiet von Schwaben und Franken seit 1907. Geologische Rundschau, Band II, pp. 5I I-520 (with literature).

23. GRABAU, A. W. I894. Lake Bouvé, an Extinct Glacial Lake in the Boston Basin. Occasional Papers of the Boston Society of Natural History, Vol. IV, pt. 3, pp. 564-600.

24. GRABAU, A. W. 1897. The Sand Plains of Truro Wellfleet and Eastham, Cape Cod. Science, N. S., Vol. V, pp. 334-335, 36r.

25. GRABAU, A. W. I906. Types of Sedimentary Overlap. Bulletin of the Geological Society of America, Vol. XVII, pp. 567-636.

26. GRABAU, A. W. IgIo Continental Formations of the North American Palæozoic. Compte Rendu du XIme Congrès Géologique International, pp. 997-1003.

27. GRABAU, A. W. I9I3. Early Palæozoic Delta Deposits of North America. Bulletin of the Geological Society of America, Vol. XXIV, No. 3, pp. 399-528.

28. HENNING, KARL L. I9I3. Die Red Beds. Ein Beitrag zur Geschichte der bunten Sansteine. Geologische Rundschau, Bd. IV, Heft 4, pp. 228-244.

29. HILGARD, E. W. 1912. A New Development in the Mississippi Delta. Popular Science Monthly, Vol. LXXX, pp. 237-245, Map.

30. HILL, ROBERT T., and VAUGHAN, T. WAYLAND. I898. Geology of the Edwards Plateau and Rio Grande Plain Adjacent to Austin and San Antonio, Texas, with references to the occurrence of underground waters. I 8th Annual Report, United States Geological Survey, pt. II, pp. 194-322.

3I. HOBBS, W. H. I906. Guadix Formation of Granada, Spain. Bulletin of the Geological Society of America, Vol. XVII, pp. 285-294.

32. HOERNES, RUDOLF. I9II. Gerölle und Geschiebe. Verhandlungen der kaiserlich-königlichen geologischen Reichsanstalt, Bericht vom zoten Sept., I9I I, No. I2, pp. 42 et seq.

33. HUNTINGTON, ELLSWORTH. 1907. The Pulse of Asia. Houghton, Mifflin Co.

34. HUNTINGTON, E. 1907. Some Characters of the Glacial Period in Non-glaciated Regions. Bulletin of the Geological Society of America, Vol. XVIII, pp. $35 \mathrm{I}-388$, pls. 3I-39.

35. KING, CLARENCE. I878. Systematic Geology. United States Geological Exploration of the Fortieth Parallel. Vol. I. 
36. LE CONTE, JOSEPH. I 896. Elements of Geology, $4^{\text {th ed. D. Appleton }}$ $\&$ Co., New York

37. LIBURNAU, J. LORENZ VON. I888. Die geologisehen Verhältnisse von Grund und Boden.

38. MEDLICOTT, HENRY B., and BLANFORD, W. T. I879. Manual of the Geology of India, pt. II.

39. MILLER, W. J. I910. Origin of the Color in the Vernon Shale. New York State Museum Bulletin 140, pp. I50-156.

40. OLDHAM, R. D. I893. Manual of the Geology of India, 2nd edition, Calcutta.

4I. PENCK, ALBRECHT. 1894. Morphologie der Erdoberfläche, Vol. I.

42. PENCK, ALBRECHT, and BRÜCKNER, E. 1902. Die Alpen im Eiszeit-Alter.

43. PETERMANN, A. 1867. Ein Flussdelta im Inneren von Australien und die neuesten Entdeckungen von Warburton und den deutschen Missionären Walder, Kramer und Meissel, I 866 and I867. Petermann's Geographische Mittheilungen, pp. 437-447.

44. PHILIPPI, EMIL. I901. Ueber die Bildungsweise der Buntgefärbten klastischen Gesteine der continentalen Trias. Centralblatt für Mineralogie, Geologie und Palæontologie, pp. 463-469.

45. PHILIPPS, J. A. I $88 \mathrm{I}$. On the Constitution of Grits and Sandstones. Quarterly Journal of the Geological Society of London, Vol. XXXVII, pp. 6-27.

46. READE, T. MELLARD. 1889. The New Red Sandstone and the Physiography of the Triassic Period. The Naturalist, April, I 889, pp. Io8-i I I.

47. RIES, HEINRICH. 1910. Clays and Shales of Michigan. Geological Survey of Michigan, Vol. VIII, pt. I, pp. I-67.

48. RUSSELL, ISRAEL C. I 878. The Physical History of the Triassic Formation of New Jersey and the Connecticut Valley. Annals of the New York Academy of Sciences, Vol. I, No. 8, pp. 220-254.

49. RUSSELL, I. C. I 895. Present and Extinct Lakes of Nevada. National Geographic Monograph No. 4, American Book Co.

50. RUSSELL, I. C. 1897. Lakes of North America. Macmillan \& Co.

5I. RUSSELL, I. C. I899. Subaërial Decay of Rocks and Origin of the Red Color of Certain Formations. Bulletin 52, U. S. Geological Survey.

52. SINCLAIR, W. J., and GRANGER, WALTER. I9II. Eocene and Oligocene of the Wind River and Big Horn Basins. American Museum of Natural History, Bulletin, Vol. XXX, pp. 83-117, pls. IV-IX.

53. SUESS, E. I882. Der Boden der Stadt Wien.

54. VOIGT, F. S. I 836 . Weitere Nachrichten über die Hessberger Thierfährten. Neues Jahrbuch für Mineralogie, u.s.w. I 836, pp. I66-174.

55. WADE, ARTHUR. I9Ir. Observations on the Eastern Desert of Egypt. Quarterly Journal of the Geological Society of London, Vol. LXVII, pp. 238-262, pls. I $3-16$.

56. WALTHER, J. I 893-94. Einleitung in die Geologie als Historische Wissenschaft.

57. WALTHER, J. I900. Das Gesetz der Wüstenbildung in gegenwart und Vorzeit. Ed. I (Ed. II, I9I2).

58. WALTHER, J. I9ro. Die Bunte Sandwüste. Lehrbuch der Geologie von Deutschland. Kapitel I3, pp. 79-82. Die Keuperzeit-ibid., Kapitel I 5, pp. 87-9o. 
59. WILliston, SAMUEL W., and CASE, E. C. I912. The Permo-carboniferous of Northern New Mexico. Journal of Geology, Vol. XX, pp. 3-12.

60. WILSON, J. HOWARD. 1906. The Glacial History of Nantucket and Cape Cod, Chapter IV; Columbia University Press, Geological Series, Vol. I.

61. WOODWORTH, J. B. Some Typical Eskers of Southern New England. Boston Society of Natural History Proceedings, Vol. XXVI, pp. 197-220.

62. WYNNE, A. B. I878. The Geology of the Salt Range in Punjab. Memoirs Geological Survey of India, Vol. XIV, p. 608. 


\section{CHAPTER XV.}

\section{STRUCTURAL CHARACTERS AND LITHOGENESIS OF THE MARINE HYDROCLASTICS.}

Marine hydroclastics are accumulating in nearly every portion of the ocean to-day, and their fossil representatives are among the most widespread of the geological formations. They are most abundantly developed in the littoral portion of the seas, including the epicontinental seas, but also occur in the abyssal regions. In general, we may classify the material with reference to its source, either as terrigenous or land-derived, or as oceanic or derived from purely marine deposits. The latter group is - essentially limited to the regions around coral reefs or other organic deposits, and so has a marked uniformity of petrographic character. Viewed as a whole, marine clastics are nearly always well stratified, and they are as a rule fossiliferous. Indeed, it may be seriously questioned if marine clastics are ever wholly free from organic remains, though for considerable distances off certain shores organisms may be so rare as to escape detection. Thus Kindle (54) reports dredging off the coast of Alaska for a hundred miles or more along the shore, without finding any organic remains whatever. This of course does not prove their absence, but only indicates their scarcity, and indeed at another point of the same coast organisms were abundant. Moreover, such dredging affects only the surface layers of the sea floor, and does not prove the absence of remains in somewhat deeper layers.

It is perfectly well known that marine organisms migrate with the seasons, and that at a certain locality, where life was abundant during one season, it is almost entirely absent in another, the organisms having migrated into deeper water. What is true of seasons is also true of longer periods, some regions formerly well stocked with organisms being barren for years at a time, after which a return of the fauna takes place. Such migration up and down the ocean floor is often determined by factors difficult to as- 
certain. In the Alaskan case it may be due to the abundance of cold water carried in from the land by the melting of the glaciers, which, as shown by Tarr (92), has recently become very marked through changes which also caused an advance of the glaciers in certain localities. Portions of the glaciers hitherto protected by débris or otherwise have been suffering ablation during July and early August at a rate sufficient to lower the ice surface four inches a day.

While marine fossils are as a rule a reliable indication of the marine origin of a given series of clastics, this is the case only when the fossils are generally distributed throughout the mass, or when there is no other positive indication of a non-marine origin. As has already been shown, eolian limestones composed almost wholly of marine organisms are forming at the present time, and have formed in the past. Fossils weathering out from a marine series may be incorporated in the next overlying continental formation, as in the case of the Eocenic and other fossils of the rocks forming the floor of the Libyan desert, which are included in the overlying desert sands. Marine organic remains may be carried inland by winds, by birds or in some other manner, and thus become incorporated in terrestrial formations. Finally, deposits of terrestrial character may be at intervals submerged by a momentary encroachment of the sea, as in the case of the Po, the Rhine and other deltas, with the result that intercalated marine sediments are formed. Or, again; the sea may invade a large territory previously the theater of terrestrial deposition, and by reworking the upper layers of the continental deposits, or in some cases the entire mass, may impress upon it locally a marine character. This has been the case with the St. Peter sandstone, largely an eolian formation; with the upper part of the Sylvania sandstone of similar origin; with the Dakota and apparently also with the Potsdam sandstone, which, in many sections, still shows characters pointing to torrential or eolian origin of a considerable portion of the rock.

It should of course also be emphasized that the reverse is likely to hold, namely, that absence of marine fossils is not an absolute indication of the non-marine character of a formation, though absence over a very large area may probably be taken as a fairly certain guide. The physical characters of the rocks and their relationships must be taken into careful consideration. Among the negative characters of marine clastics are: the absence of mud cracks, rain prints, footprint impressions, rill marks, etc., though all of these may occur in the shore zone. 


\section{SUBDIVISIONS OF THE AREAS OF MARINE DEPOSI-} TION. TYPES OF MARINE DEPOSITS.

The following districts and zones or regions of deposition of clastic material may be recognized in the sea:

I. The Littoral District, or that ranging from the shore to the edge of the continental shelf, that portion of mediterraneans corresponding to this, and the whole of the bottoms of epicontinental seas. Deposits formed here are "littoral deposits," and they are among the most varied of their kind. The littoral district is divisible into the shore zone between tides and the permanently submerged shallow water or neritic zone* (Flachsee), extending to the isobath of 200 meters.

2. The Bathyal District (Renevier) is that district lying between the outer linit of the neritic zone, $i$. $e$., the 2oo-meter line, and approximately the isobath of 900 , or, in round numbers, $I, 000$ meters. It represents the steep slope from the edge of the continental shelf to the point of decreasing angle of slope. This comprises only the upper portion of Penck's aktic region, which extends to the mean sphere level of 2,400 meters below sea-level (see Chapter I). (Fig. I, p. 8.)

3. The Dcep Sea or Abyssal District. This, according to Penck and others, begins at the 2,400-meter line, but so far as deposition is concerned begins practically at the 1,ooo-meter isobath.

A general classification of oceanic sediments, including all types, was made by Murray and Renard $(62: 186)$, as follows:

\section{Murray and Renard's Classification of Marine Deposits.}

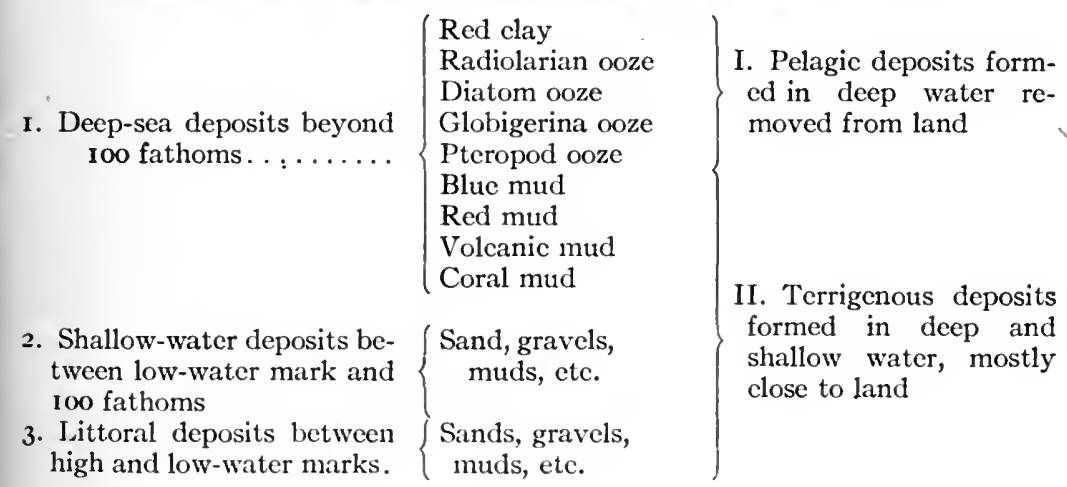

* Haug $(+3: 86)$ and others have shown a tendency to use neritic in the sense in which littoral is here used, restrieting that term to the shore zone or intercotidal region. The use here advocated seems the most serviceable. 
Otto Krümmel ( $55: 152)$ has made a threefold division of marine sediments, modifying the classification of Murray and Renard as follows :

\section{Krïmmel's Classification of Marine Deposits.}

\section{LITTORAL OR NEAR LAND DEPOSITS.}

I. Strand or shore deposits.

2. Shelf (shallow water) deposits:

Each comprises boulder, gravel, sand, and mud deposits, which according to their source are clastic, volcanic, biogenic, chemical (halmyrogenic) and glacial.

\section{HEMIPELAGIC OR DEEP SEA TERRIGENOUS DEPOSITS.}

I. Blue and red mud (including volcanic mud).

2. Greensand and green mud.

3. Lime sand and lime mud:

(Subdivisions as under littoral.)

\section{EUPELAGIC DEPOSITS DISTANT FROM LAND.}

A. Epilophic deposits (formed on the submarine ridges and swells).

(a) Calcareous deep sea ooze.

I. Globigerina ooze.

2. Pteropod ooze

(b) Siliceous deep sea ooze.

B. Abyssal deposits:

3. Diatomaceous ooze.

4. Deep sea red clay

5. Radiolarian ooze

Since diatomaceous oozes have been found at depths of $5,000-$ 6,000 meters, and Globigerina ooze is sometimes found in depths greater than that where red clay accumulates, the subdivisions of the Eupelagic deposits as given by Krümmel are hardly satisfactory (Philippi-69). Andrée (4) suggests dividing Krümmel's Group III into calcareous and noncalcareous (siliceous), the former comprising Globigerina ooze, with Pteropod ooze as a facies, the latter diatomaceous ooze and the deep-sea red clay with the radiolarian ooze as a facies of the latter. This entire class, with the exception of the red clay, has been discussed under organic deposits or biogenics (Chapter $\mathrm{X}$ ).

The distinction between areas of deposition and types of deposits must be clearly kept in mind. The former, as we have seen, comprise (I) the littoral district, with its two zones, (a) the shore and (b) the neritic zones; (2) the bathyal district and (3) the abyssal district. Oceanic deposits must be classified first as to their 
origin and next as to their mode of occurrence. Thus we may make the following classification, taking occanic deposits as a whole:

\section{A New Classification of Marine Deposits.}

I Marine hydrogenics (halmyrogenic deposits) or chemical precipitates from the sea water. (These have been fully discussed in Chapter IX.)

II MARINE BIOGENICS or organic deposits of marine origin

A Benthonic or living on sea bottom

I Littoral-originating in littoral district

a Shore zone

(I) autochthonous or growing in situ

(2) allochthonous or cast up from deeper water

b Neritic or shallow water zone

(I) autochthonous-growing in situ

2 Bathyal

(2) allochthonous-transported, usually from shore zone

(1) autochthonous

(2) allochthonous-transported, usually from littoral zone

\section{Abyssal}

(I) autochthonous

(2) allochthonous - transported from the littoral or bathyal regions

B Pelagic or living in the open ocean and its extension into the shore indentations, either as plankton or nekton. (See Chapter XXVII.) These may settle in the Littoral, Bathyal or Abyssal districts, remaining either in place, or more or less rearranged or worked over, especially in shallow water whence they may be cast on shore and even blown inland.

III MARINE CLAstics. Fragmental material worn off by or in the sea

A Hydroclastics - worn off or rearranged by the sea waves or currerits

I Terrigenous or land-derived

a from continent including continental islands

b from oceanic islands exclusive of coral reefs, and other organic deposits

2 Thalassigenous; or sea-derived

a organic lime sand and mud derived from coral reefs, from nullipore reefs, shell deposits, ctc.

b derived from halmyrogenic or chemical deposits. Clastic material derived by destruction by waves of chemical deposits formed by the sea (not known). Chemically formed marine oölites when worn by waves may come under this head

B Bioclastics: rock material broken up by marine organisms

Marine bioclastics. These may, according to the source from which the material was originally derived, be classed as

I Terrigenous, from continents and islands

2 Thalassigenous, from coral reefs, etc.

IV MARINe DERELICTS, or stragglers from other realms. These may be deposited in the Littoral, Bathyal or Abyssal districts

A Land-derived, either from continents or islands

I Terrestrial, derived from the land 
a Organic: land plants or animals floating out to sea or rafted seaward (as under b) and deposited in the Littoral, Bathyal or Abyssal districts. (Microörganisms blown out to sea with the dust would also be classed here.)

b Inorganic: rocks, sand, gravel, etc., rafted from land and deposited in the Littoral, Bathyal or Abyssal districts. According to the method of transport we have:

(1) plant rafted: rocks, etc., held by roots of floating trees etc.

(2) animal rafted: stones in stomachs of modern sharks, and seals, and of Jurassic Mystriosaurus and Plesiosaurus as well as in the stomachs of many land animals which may float out to sea

(3) ice rafted: by icebergs and floating ice cakes

(4) wind rafted: wind-blown dust or sand, and volcanic material brought from the land

(5) ship rafted: substances carried out by ships or man-made rafts and cast overboard or deposited on the foundering of the ship

(6) carried into the sea by slipping or gliding

2 Aquatic: derived from the rivers and estuaries. This would comprise chiefly river animals and plants which have been carried out to sea

3 Derived from adjacent higher zone by gliding or thrusting

B Atmospherically derived

Since the chief atmogenic solids, snow and hail, have only a temporary existence, deposits from this source may be neglected. Rare cases of organisms, such as seabirds, which spend most of their lives in the air, might perhaps be included here, but they may as well be classed with terrestrial derelicts

C Meteoric-of Extratelluric origin

Here belong the cosmic dust and the meteorites

D Of Subcrustal Origin

This includes volcanic eruptions beneath the sea and on the coast, so that both pyrogenics and pyroclastics flow or are projected into the sea. The direct pyroclastics merge of course into the wind-transported pyroclastics

\section{DISCUSSION OF THE MARINE CLASTICS.}

In the following pages the clastic deposits will be discussed with reference to the regions in which they are deposited. Lacustrine clastics will be repeatedly used for parallel illustrations.

\section{The Littoral District and Its Deposits.}

The term littoral zone is frequently restricted to the part between high and low-water mark, $i$. e., the shore, while the term neritic has recently come into use for that portion between low water and the edge of the continental shelf. The term littoral dis- 
trict is, however, best applied to all that part of the sea above the deep-sea portion, i.e., approximately above the hundred-fathom line. This is in conformity with usage of the term in bionomics (Ortmann-63:5), where the littoral fauna and flora are those occupying the sea bottom within the illuminated region. It is in this sense that the tern littoral will be used throughout this book, while the littoral zone or the zone between high and low water will be referred to as the shore.

Littoral deposits are found between the edge of the continental shelf and the high-water edge of the shore. In the shore zone they grade imperceptibly into continental deposits, through the zone of the strand, while at the outermost margin of the littoral district they grade into abyssal deposits. Around the margins of oceanic islands the littoral belt is of greater or less width, according to the slope of the submerged portion of the island.

It is within the littoral district as here defined that by far the largest proportion of clastic material is deposited. It is here also that the bulk of the hydrogenic and the biogenic deposits of the sea is formed.

\section{The Shore Zone (Inter Co-tidal Zone; Littoral Zone in Restricted Sense).}

The separation of the shore zone, or that portion between high and low-water mark, from the portion of the littoral district never uncovered, is of very little significance from the lithogenetic point of view, however much its import biologically. For, although this zone is the focus of the destructive activity of the waves, their work is not limited to this portion. It is known that wave work is very effective at a depth of thirty feet, while at sixty it has still an influence upon the bottom deposits. In fact on a gently sloping coast, the destructive work of the waves is found in the deeper water away from the shore, rather than in the shore zone: Neither has the shore a distinctive type of sediment; not even the pebbly sediment is confined to it, but occurs also at a distance from shore; nor are sands, muds or even organic deposits excluded from the shore, the sands and muds being often more characteristic than the pebbles. As for organisms, only stationary or attached types discriminate between the shore and the permanently submerged zone, and among these certain ones do not make an absolute distinction. The shore zone is, however, of significance in this respect, that characters typical of continental deposits, such as mud cracks, rain- 
prints, footprints, etc., can be impressed upon the exposed sediments, and preserved under favorable circumstances.

Since the magnitude of tides varies with the moon's phases, the exact limit of the shore zone is never fixed. During spring tides the zone encroaches upon the strand, that indefinite zone just above high water, while the ebb succeeding will lay bare portions of the zone generally submerged. On lakes the shore zone practically disappears (it would be wrong, however, to say that there is no littoral district on the lakes) unless the seiche is to be considered as equivalent to the tides.

Facies of the Shore Zone. The shore zone may represent one or more of a variety of facies, or types of material, none of which can be considered as strictly confined to it. The most typical facies of the shore zone are: I, the rocky cliff facies; 2 , the bouldery facies; 3 , the gravelly facies; 4 , the sand facies; 5 , the mud flat facies, and 6 , the organic facies. Each of these facies has its distinct physical and organic characters.

\section{Rocky cliff facies.}

This is most significant from the point of view of bionomics, as will be more fully discussed in a later chapter. Erosion is active here, and coarse fragments are broken from the cliff and accumulate as a submarine talus and boulder pavement. Where rock accumulation takes place, a rudaceous phase will be found next to the cliff, the material of the rock fragments being that of the cliff from which they are derived. Since in such cases the rock fragments broken from the cliff may fall into water sufficiently deep to prevent much attrition of the fragments, the resultant rudyte may be a breccia, the fragments being in the main angular. Examples of such cliff rudytes are found in the St. Croix formation of the Dalles region of the Wisconsin River, and in the Lake Superior sandstone of Marquette, Michigan. Some of these may of course be old, subaërial talus slopes reworked by the transgressing sea. This appears to be the case with the basal Mid-Devonic limestones (Dundee) of Michigan and western Ontario. (See Chapter XIII.)

\section{Bouldery facies.}

Where a rock cliff fronts the waves, the fragments broken from the cliff by the frost and by the sea are generally ground into 
pebbles, sand and mud, unless the water at the foot of the cliff is sufficiently deep to render the force of the waves ineffective. Thus boulders will seldon accumulate in such numbers as to make a bouider beach at the foot of a cliff, since the destruction of the cliff proceeds with sufficient slowness to allow the reduction of most of the fragments to pebbles or smaller particles. If, however, the sea eats into a morainal or other bouldery deposit, as is the case of many portions of the New England and Long Island coast of the North Atlantic, a heavy boulder beach arranged in the form of a pavement by the close approximation of the boulders through wave and shore-ice work will result. In like manner, when the sea encroaches upon an old subaërial talus heap, a boulder beach may be formed, the waves being able to round off and arrange the boulders, but not to destroy them. The boulders themselves become a natural barrier, against which the waves beat themselves to pieces without accomplishing much erosional work. Where the tides are exceptionally high, as in the Bay of Fundy, the boulders broken from the cliffs by the frost and insolation will be rolled and worn at high tide, but the power of the waves is too small, and the time during which the boulders are subject to their influence too short, to produce any other results. Here the accumulation of boulders is really to be compared with a subaërial talus, which is periodically, but for a short time only, exposed to wave activity. On the whole, boulder beaches other than those due to erosion of drift deposits are of comparatively rare occurrence, and the same thing may be said of ancient marine boulder beds. It is doubtful if many such existed, most of the boulder beds of former geologic epochs being probably of continental origin. That boulders of even moderate size may for a long time remain entirely unmoved by the waves is shown on the east coast of Scotland, where the boulders and ledges are covered by living Acmrea or by extensive growth of sea weeds. Even delicate sea ancmones are found attached to these boulders, often in such a position that a slight movement of the boulders would grind them to pieces. In other cases the boulders and pebbles are encrusted by a growth of Lithothamnion or Melobesia. It sometimes happens that in certain zones, or areas, the waves are able to move the boulders, with the result that there they are entirely bare of either vegetation or animal covering.

\section{Gravel facies.}

By far the greater part of the present shore lines of the world is sandy or gravelly, the former predominating. Gravelly beaches or 
beaches of cobbles or shingles are chiefly characteristic of steeply sloping and exposed rocky shores, where the finer product of erosion is carried by the undertow to deeper water, the coarser alone remaining. The character of the pebbles will of course partake of that of the cliff from which they are formed, those derived from the more easily shattered rock, as well as the most difficult to grind to powder, predominating. Thus on the north shore of Massachusetts felsite pebbles predominate, on Lake Michigan limestone pebbles, and on the shore of Lake Erie flat shale pebbles. These pebbles are often piled up into extensive terraces, especially after heavy storms. These terraces may show on section a rude and irregular bedding, but the regular cross-bedding (torrential type) found in many old conglomerates was not formed in this manner.

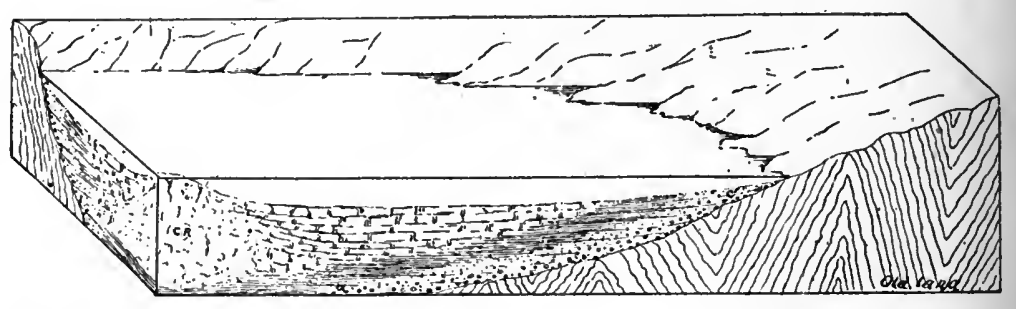

FIG. I29. Diagram illustrating the deposits in the littoral district of the sea. At the shore gravelly and sandy facies occur, these shading off seaward into lutaceous, and, finally, calcareous sediments. The latter are derived from the coral reef C. R., $i$. $e_{\text {. }}$, they are thalassigenous, while the others are terrigenous. The overlapping of the formations is also shown.

Organic remains in pebble beds. On the beach, where the pebbles undergo much movement, most organic remains, such as shells, bones, etc., are rapilly destroyed. Nevertheless, they are occasionally preserved, as is shown by the occurrence of worn shell fragments even in the high gravel terraces.

That organic remains are common in older boulder and pebble beds has been the experience of many geologists, though some of the so-called conglomerate beds are due to causes other than those active on sea beaches. A comparatively modern example of a pebble and sand beach now abandoned by a slight elevation of the coast is found in eastern Scotland. Near Goldspie on the Moray Firth, the lower of the elevated beach lines abounds in entire shells of Acmæa and other shore forms, as well as in worn fragments of this and other shells. Boulders up to the size of six inches or more, 
and well worn, are found in this beach. Other examples no doubt occur in other sections of this coast and elsewhere.

Boulder beds of Tertiary age are not uncommon. In the Miocenic of the Vienna Basin, some of the best preserved pelecypos and gastropod shells are found in a boulder bed with pebbles up to six inches or more in diameter, and well rounded. The Cretacic boulder beds of South Germany and of Sweden are other examples. In the former well-worn boulders up to several feet in diameter constitute the deposit, while anong them abound fragments and entire individuals of brachiopods, pelecypods and other organisms often in a remarkable state of preservation. In the Dresden region pothole-like hollows are found in the old porphyries with a depth of 20 feet or more, and these are filled with a coarse boulder conglomerate of Cretacic age, the individual boulders often a foot or more in diameter, and well worn. Among these boulders sponges, oysters and other organisms occur in abundance. In Scania and elsewhere an Upper Cretacic conglomerate of pebbles and boulders worn or angular contains Belemnites and other fossils of that period, many of them showing no wear. One of the most striking examples of such a conglomerate is found on the.present eastern coast of Sutherland, North Scotland, near the village of Helmsdale. The formation occurs as a coastal strip, largely eroded by the present sea, and forming a series of low-lying skerries exposed at low water. The age of the formation is Jurassic, but it is almost wholly composed of large and small fragments of Caithness flags (Lower Old Red sandstone), some of the fragments reaching the astonishing length of 20 feet or more. The larger fragments lie in irregular positions, their stratification planes dipping in all directions, and they resemble in every respect the fragments now found at the foot of the cliffs of these flags on the exposed Caithness coast. Among the fragments and firmly embedded in the conglomerate and breccia matrix are worn heads of coral (Isastrea), shells, Belemnites and other Jurassic organisms. Many of the smaller organisms have apparently escaped all wear.

\section{Sandy facies.}

Sand is by far the most typical material of the shore zone, on lakes as well as on the seashore. To a large extent the sand consists of quartz grains, since this is the least destructible constituent of rocks. In regions of purely calcareous sources of sand, as in the Bermudas, and on many coral reef islands, the sand is largely or 
wholly composed of grains of calcium carbonate, with or without magnesium.

As Shaler has pointed out, the sand of the seashore is compacted into a resistant mass by the films of water which separate the grains and which are held in position by capillary attraction. Whoever has walked on wet beach sand has noted the difference in firmness between the wet and dry sands, the former often constituting a hard, level floor. On such a surface the force of the waves is spent; the sands will retain their original angular character, since the dividing film of water acts as a cushion, which prevents the mutual attrition of the grains. Thus the grains of beach sand are normally angular and with fresh surfaces, and this type of sand should be looked for in normal marine sandstones. (Shaler88.) Shaler cites as an example of marine sands protected in this manner from wearing, the sand of northern Florida . . "which has traveled southward from the region beyond Cape Hatteras" ... and which "is not more rounded than much which is in the inner or landward dunes of the coast within sound of the ocean waves." $(88: I 5 I$.

When, through drying, the binding films of water are destroyed, the sands become loosened and are then readily shifted about by the wind, accompanied by mutual attrition of the grains. Here, then, no permanent structural features are formed. Both rill and ripple marks. left on the retreat of the tide are either obliterated by the wind or washed away by the returning tide, owing to the noncoherency of the material. An exception to this seems to be the wave mark on a very gently sloping sand beach, and the hollows excavated behind pebbles or shells by the return of the wave on such a beach. Examples of these are known from the Upper Medina sandstone in western New York, and in other formations. (Fairchild-32.)

Marine arkoses. Accumulation of feldspathic sands on the sea coast and their incorporation in marine strata are effected under a peculiar combination of circumstances such as exist to-day in the Gulf of California, as described by McGee (57). The granitoid rocks of this region are subject to disintegration under the arid climatic conditions, due to the interception of the Westerlies by the coast ranges. Decomposition is practically absent, the disintegrated material being transported by sheet floods. These result from exceptional thunderstorms, accompanied by sudden and extensive precipitation. Part of the material is carried into the Gulf and there assorted by the waves, the coarsest and cleanest material being deposited at the salients of the coast, while in the reëntrants much 
finely comminuted material is deposited with the coarse quartz and feldspar. Quartz-feldspar-mica sandstones are thus produced under conditions permitting the entombment of marine organisms.

Sorting of sands and gravels by z'az'es. The conditions under which waves accomplish sorting of sands and gravels according to size and material are given by Bailey Willis $(105: 481)$ as the following:

(a) Vigorous wave action, accompanied by strong undertow.

(b) Prolonged transportation in consequence of dcep water and continuous currents.

(c) Moderate volume of sediments.

On the other hand, the conditions under which sorting is not or but slightly accomplished are, according to Willis :

$\left(a^{\prime}\right)$ Feeble or diffused wave action.

(b') Concentrated deposition.

( $\left.c^{\prime}\right)$ Excessive volume of sediment.

In general, with a given amount of loose materials to work upon, the waves will accomplish sorting in proportion to their strength and the strength of the undertow. The finest material will be carried out farthest, while only the coarsest material will be left behind. Where the material is all of one kind, as, for example, quartz sand, the sorting will be entirely according to size, while variation in the mineralogical character of the material may lead to a sorting, according to the specific gravity as well. Thus quartz sands may be entirely washed free from mica and clay particles, while garnet and magnetite, two characteristic accompaniments of sands derived from many igneous or metamorphic rocks, will segregate through the washing out of all quartz grains.

This sorting according to size and specific gravity is best accomplished if, in addition to the strong wave movement which stirs up the sediment, strong currents exist which can transport the material for long distances. The smallest and lightest material may thus be carried much farther away from the point where the coarsest is dropped, the separation being thus most pronounced. In this respect the separation by currents will be analogous to the separation of sediments by wind. A water current of a given velocity is equaled in carrying power only by a wind current of 28 times that velocity (Udden-99:3I9), but wind currents exceeding average ocean currents in velocity by very much more than that are characteristic of many regions, especially in the upper atmosphere. Thus material projected or carried into the air stands a much better 
chance of sorting than does material in the sea. Moreover, material dropped by one air current may be picked up again by another while sands dropping in deeper water below the reach of the currents are more likely to be left undisturbed by them.

If the amount of supply of detritus is great, sorting will be impeded. Flocculation, or the gathering together of particles, will occur, the coarser carrying down with them the finer. Flocculation is less marked in wind-transported material, where the load is always much less per unit of bulk of the carrier than in most waters, and for this reason also the sorting by wind is more pronounced than that by water. Udden thinks that under ordinary circumstances this difference is nearer I to 100,000 than I to I,000. (99:32S.) The slope of the sea bottom (Willis-I05:484) is also a determining factor in the transportation of material by marine currents. Where the slope is a gentle one, sand may be carried for 200 miles or more, as on the Atlantic coast of the United States, where the continental plateau is covered with sands to its outer rim. The transporting current here is the undertow, assisted by tides. Since, however, the force of the undertow is largely determined by the strength of the waves, it follows that in circumscribed and very shallow seas no such extensive transportation is possible. Where the slope is a steep one, as on the west coast of South America, the force of the undertow is dissipated, though pebbles and sand will more readily move down the slope. As a rule, the distance to which sands are transported in such a case is limited.

Organic remains in marine and lacustrine sands. These are generally common, especially in the sea, though areas free from such remains are known, as in the case of the Alaskan coast, already cited. Such absence is, however, due to purely local causes. Even in the beach sands organic remains abound. Everywhere along our coasts shells in numbers, and crustacean and echinoderm tests to a lesser degree are buried in the sands of the beach, and in those just below the low-water line. In the neritic zone animal life of all kinds abounds on the sandy bottoms (see Chapter XXVIII). Abandoned shores of lakes and of the sea also are rich in organic remains. The higher beaches of the late Pleistocenic stages of the Great Lakes contain numerous shells of fresh-water mollusca, and so do the sands of the old shore lines of Niagara and other rivers. So abundant are shells and other organisns in the sands of the modern sea coast that their entire absence from older sandstones must be looked upon as indicative of conditions of deposition other than normal. It is begging the question to assume the subsequent removal of such remains either by solution or otherwise, for even 
though percolating waters should dissolve away the shells a mold or impression of the same will remain, which no agent short of metamorphism can obliterate, and that not always. The abundance of organic remains in sandstones of all kinds and colors and of all ages shows that there are no inherent characteristics in sand which prevent the preservation of such remains. In practically all cases when organic remains or their inpressions are wanting in sandstones, we have a right to assume that they were not present at the time of formation of the deposit. Such absence suggests a subaerial rather than subaqueous origin for the deposit, and as such it should be considered unless other unmistakable characteristics point to a subaqueous (marine or lacustrine) origin. (For application to basal beds see Pumpelly-75:217.)

\section{Muddy facies.}

This generally occurs in intimate association with an organic facies in the shore zone. Where sands accumulate in sheltered marginal lagoons, plants (eel grass) and animals commonly contribute their remains to enrich and color the mud. Salt marshes are the normal successors of the mud flat, the organic element here being in the ascendency. (See ante, Chapter XI.) The purely inorganic structures of such a mud flat are, in addition to stratification, the mud cracks, rain prints and rill marks, and the tracks and trails of animals frequenting the shore. During very high spring tides extensive portions of a very flat shore may be covered with a layer of mud, which on the retreat of the tide may become marked by mud cracks and footprint impressions. Since such areas will be uncovered for a fortnight, the clay may become sufficiently hardened to permit the pernianent preservation of the mud cracks. It must, however, be borne in mind that when the mud deposit made by one inundation is comparatively thin, as is apt to be the case, this layer will on drying curl up into shaving-like masses and be blown away by the wind. While under exceptional conditions the mud cracks, rill marks and tracks formed in the shore zone may be preserved, such preservation is far from being characteristic.

Flocculation and the conditions of mud deposits. "The formation of mud deposits at the mouths of great rivers emptying in the sea, as in the case of the Misșissippi, is favored by the presence of the salt in the sea water. Flocculation, or the drawing together of particles, takes place much more extensively in salt than in fresh water, and as a result such particles will sink more quickly in sea 
water than in lakes. Experiments (Brewer-11: 168 ) have shown that clay which had been in suspension in fresh water for thirty

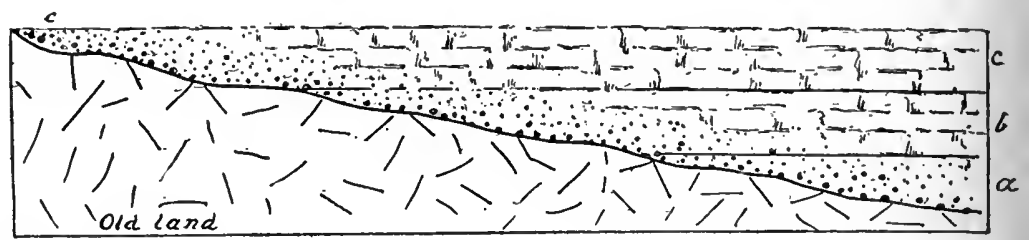

FIG. I30. Diagram showing the lateral shading off of the clastic sands and pebbles into calcareous deposits without intervening muddy phase. The successive formations $a, b$, and $c$ change shoreward into arenytes. An apparently continuous sand bed; $a-c$ is thus produced resting upon the old land surface.

months had not settled out as clearly as the same clay from a solution of common salt in less than thirty minutes. These results have, however, been questioned by Wheeler (ro3), who gives the accompanying table, showing the rate of settlement in the two media :

Table Showing Rate of Settlement of Solid Matter in Fresh and Salt Water.

\begin{tabular}{|c|c|c|c|c|c|c|c|c|c|c|c|c|}
\hline \multirow{3}{*}{ No. } & \multirow{3}{*}{$\begin{array}{l}\text { No. of } \\
\text { grains } \\
\text { to a } \\
\text { lineal } \\
\text { inch }\end{array}$} & \multirow{3}{*}{ Material } & \multicolumn{4}{|c|}{$\begin{array}{l}\text { Time taken } \\
\text { to settle }\end{array}$} & \multicolumn{4}{|c|}{$\begin{array}{l}\text { Water } \\
\text { clear }\end{array}$} & \multirow{3}{*}{$\begin{array}{l}\text { Ft. } \\
\text { pei } \\
\text { minute }\end{array}$} & \multirow{3}{*}{ Remarks } \\
\hline & & & \multicolumn{2}{|c|}{ Fresh } & \multicolumn{2}{|c|}{ Salt } & \multicolumn{2}{|c|}{ Fresh } & \multicolumn{2}{|c|}{ Salt } & & \\
\hline & & & m. & sec. & $\mathrm{m} . \mathrm{s}$ & sec. & h. t & $\mathrm{m}$. & h. & $\mathrm{m}$. & & \\
\hline $\mathbf{I}$ & 5 & Small pebbles.......... & o & I & $\cdots$ & $\cdots$ & $\cdots$ & & $\cdots$ & & 0.50 & $\begin{array}{l}\text { Water not } \\
\text { discolored }\end{array}$ \\
\hline & $\begin{array}{l}\text { I0 } \\
20\end{array}$ & $\begin{array}{l}\text { Small pebbles.......... } \\
\text { Coarse sand }\end{array}$ & 0 & $\mathbf{r}$ & & & & & $\cdots$ & & $\begin{array}{l}0.42 \\
0.21\end{array}$ & $\begin{array}{l}\text { discored } \\
\text { do } \\
\text { do }\end{array}$ \\
\hline & $20-60$ & 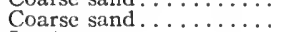 & 0 & $\begin{array}{c}2 \pi \\
4\end{array}$ & $\cdots$ & $\cdots$ & $\cdots$ & $\ldots$ & $\cdots$ & $\cdots$ & 0.13 & $\begin{array}{l}\text { do } \\
\text { do }\end{array}$ \\
\hline 2 & I 00 & Sand $\ldots \ldots \ldots \ldots \ldots$ & o & Io & $\ldots$. & $\ldots$ & $\ldots$. & $\ldots$ & $\ldots$ & $\ldots$ & 5.04 & do \\
\hline 3 & 200 & $\ldots \ldots \ldots$ & 0 & 25 & $\cdots$ & ... & $\ldots$. & $\cdots$ & $\cdots$ & $\ldots$ & 2.40 & do \\
\hline 4 & $\cdots \cdots$ & Whiting. .......... & I 2 & 0 & $\cdots$ & $\cdots$ & 0 & $3 c$ & $\cdots$ & $\cdots$ & $\cdots$ & \\
\hline 5 & $\cdots \cdots$ & Plaster of Paris. . . . . . & 5 & 0 & $\cdots$ & ... & of & Io & $\cdots$ & $\cdots$ & $\cdots$ & do \\
\hline 6 & 300 & Warp Trent. . . . . . . . & o & $4 i$ & o & 45 & o & $\mathrm{I}$ & 0 & $\mathrm{I}$ & I. 20 & $\begin{array}{l}\text { Water scarcely } \\
\text { discolored }\end{array}$ \\
\hline 7 & I, 400 & (Fine warp, Dutch river). & I 2 & o & I5 & o & 3 & 30 & 22 & 0 & 0.70 & Water turbid \\
\hline $\begin{array}{l}8 \\
9\end{array}$ & & $\mathrm{rsh} \ldots \ldots \ldots$ & 2 & 0 & 2 & o & o & 6 & of & 9 & 0.42 & do \\
\hline $\begin{array}{r}9 \\
\text { I0 }\end{array}$ & $\begin{array}{l}1,000 \\
2,000\end{array}$ & Warp marsh . ......... & 8 & o & 9 & o & I & 어 & of & 33 & & do \\
\hline I I & $\begin{array}{r}2,000 \\
600\end{array}$ & $\begin{array}{l}\text { (Alluvium, Boston Dock) } \\
\text { (Alluvium, River Parrctt) }\end{array}$ & 3.3 & 0 & 28 & o & 7 & 이 & $\begin{array}{l}1 \\
0\end{array}$ & 30 & 0. II & do \\
\hline I 2 & 1,500 & Tilbury Basin.......... & $\begin{array}{r}4 \\
18\end{array}$ & $\begin{array}{l}0 \\
0\end{array}$ & $\begin{array}{r}2 \\
18\end{array}$ & $\begin{array}{r}40 \\
0\end{array}$ & $\begin{array}{r}0 \\
10\end{array}$ & $\begin{array}{r}15 \\
0\end{array}$ & $\begin{array}{l}0 \\
9\end{array}$ & $\begin{array}{r}18 \\
0\end{array}$ & $\begin{array}{l}0.22 \\
0.46\end{array}$ & do \\
\hline I3 & 1,600 & Brick clay........ & 17 & 0 & 15 & o & I & 30 & $\mathrm{~J}$ & o & & do \\
\hline I4 4 & I. 1.40 & Boulder clay .......... & 24 & 0 & o & 22 & 0 & 43 & o & $3 c$ & 0.35 & do \\
\hline
\end{tabular}

The phenomena of flocculation lave been attributed to chemical reaction, but seem to find a better explanation in the forces of at- 
traction or tension existing among the fine particles of a solid in suspension. These forces are modified by the existence of the salt in the solution. (Whitney-IO4; Clarke-20.) According to the experiments of G. Bodländer (Io), the sodium chloride of the sea water is not so important in this respect, other salts, especially magnesium chloride, being more active. Carbon dioxide, which abounds in sea water, also rapidly clears it of suspended clay particles, but temperature changes seem to be of little significance in this respect. (Krümmel-55:152-21\%) Even in sea water, however, the finest particles do not settle out completely after several wecks of rest.

Terrigenous muds extend from the shore to abyssal depths. They will be more fully considered under the neritic zone.

\section{Organic facies.}

This consists of the eel grass and peat marsh areas of the sea coast and of the rush and swamp borders of lakes and ponds. The characteristics of these have been fully described in previous chapters, and need not be dwelt upon here at length. Extensive mussel beds such as are forming in many places on our sea coast may also be classed here, though these are as a rule intimately associated with the muddy facies of the flats. Shallow-water coral and Lithothamnion growths are other examples of this facies, which belongs with the lithogenic rather than the lithoclastic division.

\section{Subaqucous Solifluction.}

The movement or gliding of rock material when saturated with water, which under subaërial conditions is called solifluction (see Chapter XIII), also takes place under subaqueous conditions. Arnold Heim proposed to distinguish this mode of movement as subsolifluction $(47: I 4 I)$. Such movements have occurred in many regions of the world, both on lakes and on the seashore, but only a few cases have been fully investigated. Among these are the glidings which in 1875 and again in 1877 affected the village of Horgen on the Lake of Zurich (Switzerland), and the one which took place in the village of Zug on the Zuger See in the Canton of Zug (Zoug), north central Switzerland. Both of these were described by Professor Albert Hein and others in special publications, and summarized by Arnold Heim in 1908 (47:136). 
The village of Horgen is situated on the southern shore of the Lake of Zurich. The shore, which is here composed of the sandstones and marls of the Mollasse, was covered originally by sand, gravel and clay in the upper part, and this, near the shore, was underlain by soft muds, which extended lakeward, covering the rocks to the center of the lake. On the ground thus underlain with soft mud rests a part of the railroad, which skirts the southwestern shore of the lake (Zürichseebahn), the Horgen station being built close to the shore. A sea wall was built and the surface raised a slight amount ( 0.4 to 0.6 meter) by filling-in, but prior to this a number of buildings and a stone-cutting yard were removed, so that on the whole the excess of loading was slight. On February 9, I875, when the filling in was nearly complete, the new sea wall and the filled area suddenly sank for a length of I 35 meters, the lake along the line of the railroad reaching a depth of 7 meters. The examination showed that a part of the bottom layer of soft mud had slid lakeward; so that the more resistant overlying sand and gravel beds came to rest upon the rock surface. The gliding continued until the mud layers had completely bared the rock slopes for a distance of nearly 300 meters lakeward. The most pronounced of these glidings occurred on June 12 , I 875 , this, however, affecting mainly the sublacustrine mud layers. By filling in a part of the sunken area and carrying the railroad line farther inland, the construction was completed and the line opened for traffic September 20, I875. The following day was one of heavy rains, and on the morning of the 22nd fissures began to open in the made land, the new wall began to crack, and suddenly a part of the wall, 85 meters long, and the station lands and tracks to a width of 23 meters sank beneath the inrushing lake waters. Just before noon a second subsidence took place, a third one followed early in the afternoon, and others followed on the $23^{\mathrm{rd}}$ and $24^{\text {th }}$ of September. The total area which thus disappeared beneath the water of the lake had a length of 204 meters and a width of 48 meters, with an area of 6,560 square meters. Subsequent glidings occurred in October and November.

The gliding began on the steeper slopes at a distance from shore, and was then transferred shoreward. The first effect of the gliding of February 9 was the lowering of the outer slope from 3I per cent. to 27 per cent., but the gliding of June 12 caused the complete baring of the rock for a distance of I 50 meters or more, and a change of grade back to 30 per cent. or $3 \mathrm{I}$ per cent., and even a higher one farther lakeward. This became even more pronounced in the glidings of September and later. The total extent of the glidings was $45^{\circ}$ meters, and the material was carried out to 
a depth of 125 meters. The affected part of the coast extended from Horgen to Käpfnach, a distance of $1.5 \mathrm{~km}$. The material was spread over the lake bottom, raising it from I to 3 meters. In October, 1877, another small portion (the Sustplatz) subsided (Frankfurter Zeitung, Beilage zu No. 304, 1877), showing that movements are not ended. Nore recent glidings if they occurred have not come to our notice.

The village of Zug has a similar record. As early as 1435 , on March 4th, 26 houses on the "Niederen Gasse," in the old part of the village, slipped into the lake, 60 persons perishing at the time. In 1593 the level of the lake was lowered by drainage, and further subsidences occurred. On July 5, I887, three successive portions of the shore fell into the lake, submerging more than 20 houses. The material which slid into the sea consisted of sandy mud, a delta built by the Lorze when the lake stood at its higher level. A broad stream of mud flowed into the sea, 300 meters from the point of fracture, to a depth of 23 meters, under the lake level, and then continued outward to a distance of about I,O20 meters from shore and a depth of 45 meters below lake level as a broad mud flow i 50 to 250 meters wide and from I to 4 meters high. The gliding began in the lakeward region, and migrated landward, as in the case of headward-growing streams. The remarkable fact here is that the average grade of the surface along which the gliding has taken place from the break to the end of the mud stream, a distance of I,020 meters, was only 4.4 per cent. The earlier, smaller movement extended for only about 500 meters into the lake and over a grade of 6 per cent. The same rule thus seems to hold for the subaquatic as for the subaërial solifluction, namely, the larger the moving mass the smaller the average slope on which it moves.

Many similar though less instructive glidings have taken place on the Swiss lakes, among them those of Montreux-Veytaux on Lake Geneva (Schardt-85;86). Nathorst has also described similar subaquatic glidings in Sweden.

In 1895 or thereabouts movements of this type occurred at Odessa, where several buildings slid into the Black Sea. The distance to which this mass was carried is unknown, but it was on a much larger scale than that at Zug.

Submarine glidings of this type are probably common, but no measurements are made of them. Such glidings are often indicated on the steeper slopes by the breaking of the cables. In no case, however, have the magnitude and extent of the glidings been ascertained, though dislocations by faulting are known (see page 890 ).

It is of course evident that material thus sliding down a sub- 
marine surface must be piled up to some extent in the deeper areas where it comes to rest. As the result of such gliding the strata must suffer much deformation, especially if they are at all consolidated. Such deformations have all the characters of orogenic disturbances due to lateral pressure, and indeed it has been suggested that some extensive mountain folds and overthrusts may have originated in this manner. These deformations will be more fully discussed in Chapter XX.

Accessory Features of Subaqueous Gliding. Among the accessory features produced by subaqueous and especially submarine solifluctions, we may mention in addition to the deformations already noted, and to be more fully discussed in a later chapter, the following phenomena:

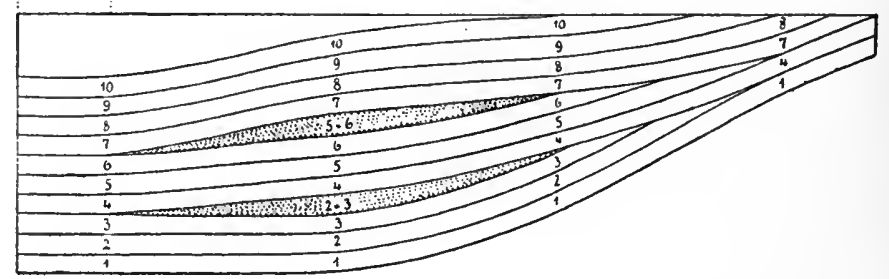

FIG. I3I. Diagram illustrating the changes in stratification due to subaquatic gliding. In the shore section strata are eliminated, while farther out duplication occurs. (After Heim.)

I. Increase of the strata in the lower regions where the shore material is carried by gliding, and where strata are thus repeated by the superposition of portions of the same strata upon one another. 2. Reduction of the number of strata in the zone affected by the gliding where the ends of the strata are thus removed, and on the deposition of subsequent beds a local disconformable relation is produced with hiatus signifying no appreciable time interval. 3. Superposition of older on younger beds. Thus at Zug, the mass which slid into the sea was more than 99 per cent. formed during the former high-water period of the lake, and came to rest by gliding upon the deposits formed since the present water level was established (Fig. 131). 4. Displacement of facies. Thus at Zug gravel and even coarse blocks were carried by gliding into the region where they would otherwise be absent. In submarine solifluction shore sediments may be carried out to the neritic belt, or the latter into abyssal regions. A shore breccia may thus come to lie among offshore marine sediments. 5. Destruction of life. The benthonic and to 
some extent also the pelagic life will be destroyed by such glidings and the distribution of the fauna will be altered. Such a case has been noted in connection with the rock slide at Elm. Such disturbance might result in the sudden destruction of the entire benthonic fauna, young and old alike, all stages being found together. Above the mass of material which caused this destruction may come a stratum carrying only remains of planktonic organisms without sedentary benthos, which would return only after a while. (Heim$47:$ : 57.$)$

The Permanently Submerged or Neritic Zone (Flachsee, Shallow Water or Thalassal Zone).

This zone extends from the low-water line of the shore zone, a somewhat variable line, to the edge of the continental shelf. Several provinces of more or less importance may be recognized, chief of which are:

I. The estuary.

2. The marginal lagoon.

3. Epicontinental seas and mediterraneans.

4. The ocean littoral.

I. The Estuary. This is the point of meeting place of the terrestrial and marine realms. It receives on the one hand the sediments and other material brought by the rivers from the land, and on the other it admits the waters of the sea, which for a time at least modify the character of the deposit. Alternately the waters of the land and of the sea predominate, as a result of which the deposits formed in the estuary will have characteristics typical of both. As a good example, we may consider the estuary of the La Plata in South America. This has a length of 125 miles, and receives the water of the Paraña and Uruguay rivers. The currents of these rivers thus come into periodic contention with the tides from the Atlantic. (Willis-105:49I.) Where the power of the tidal wave balances that of the rivers, no current exists, a condition which may continue for hours. (Revy-8I:29, 30.) Here at from Io to 20 miles above the mouth of the estuary, the material held in suspension is dropped, as a result of which submerged banks are forming, which eventually grow into islands. The current during both flood and ebb tide is swifter in the deep channels than in shallow portions of the estuary, hence deposits made during flood tide will be more copious over the shallows than in the deeper channels, 
which latter are also more subject to scour during the ebb tide. The shallows thus become tide flats, which later are raised rushgrown islands, thus restricting the water within narrow channels. The original length of the La Plata was 325 miles, but about twothirds of this has been filled up in the manner described. Where material of different sizes is brought by the rivers into the estuary the coarser will be dropped when the current is first checked by the rising tide, the finer following when the checking is complete. During the scouring of the bottom at ebb tide much of the fine material may be carried away again. (Willis-105:492.)

The floor of the Hudson has in many places been built up by mud deposits to such an extent that extensive mud flats are laid

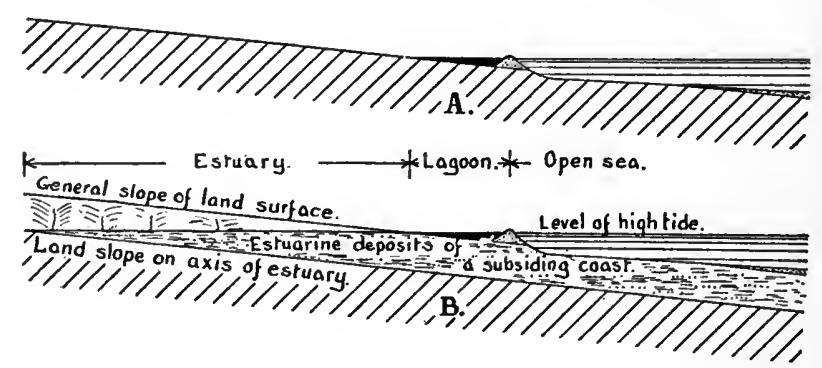

FIG. 132. Diagram illustrating the relationship between subsidence and the growth of estuarine deposits. A, bar and lagoon (barachois) on a young coast; $B$, estuarine deposits covered by transgressing sea on subsiding coast. The bar and lagoon rest on terrestrial deposits and not on the old crystalline base. (After Barrell.)

bare at low tide, a hundred or more miles above its mouth, while the channel over much of this distance is comparatively shallow. The rock bottom of the Hudson, on the other hand, is, in places, as in the Highlands, more than 600 feet below tide level. It is proper to note, however, that a part of the filling of this channel is probably glacial, only the upper hundred feet on the average being river silt.

The estuary of the Severn (Sollas-89) may serve as another example. The tidal channel of this river is notorious for its mud. "At ligh tide it is filled with a sea of turbid water, thick and opaque with tawny-colored sediment; as the tide ebbs a broad expanse of shining mud flats is revealed fringing the coast; but so like is the water to the mud that, seen from a distance, it is often hard to tell where the sea ends and the shore begins. It is the same with its tributaries, the Wye, the Usk, Ely and Rhymney on 
the Welsh side, the Avon, Yeo, Parrot and others on the English coast." (Sollas-89:6II.)

The origin of this mud has been a subject of much dispute. In part no doubt it is supplied by the rivers which have a catchment basin of 9,193 square miles (English), but much is also produced by the waves washing the shores of the estuary. The water in the tidal portion of the Severn Channel flows up and down twice daily at the rate of from 6 to 12 miles an hour, a velocity much greater than that required to move along large boulders of rocks. As a result scouring of the channel occurs in many places. The development of the currents has been described by Mr. W. R. Browne (I3): "In ordinary tidal channels such as the Avon below Bristol, the course of events during an ebb seems to be as follows. At first the slope of the surface is exceedingly small (in the Avon it was about $I \frac{1}{2}$ feet in $71 / 4$ miles), and, while the velocity at the surface is considerable, it diminishes rapidly from thence downward, and at some distance from the bottom becomes nil. This continues for about two-thirds of the ebb, the surface velocity increasing up to a certain point, and then becoming nearly constant. During all this time not only is no scour going on at the bottom, but, if the waters be muddy, an actual deposition of silt is taking place. At this time, after about two-thirds of the ebb, the water has fallen about threequarters of its total height, the slope of its surface has considerably increased, and the conditions approximate to those of an ordinary river. The bottom layers of the water then spring suddenly into motion, the surface velocity diminishes steadily as the tidal waters disappear, until it assumes the normal rate of the low-water flow. During this period a scour of the bottom is of course going on; but, as this velocity is not much higher than in the subsequent period of low-water flow, the rate of scour will not be much greater; and the actual scour will be insufficient to compensate for the amount of deposit from the tidal waters which has taken place, not only during the period of high water, but also during the first twothirds of the ebb. It must follow, therefore, that the scouring effect of the tide is little or nothing, and the observed incapacity of tidal flows to sweep away the silt they have deposited is amply and satisfactorily explained."

Sollas thinks that eventually much of the silt will find its way out to sea, owing to the constant outward pressure of the normal river current. As a part of the material is carried seaward from the constant mass moved back and forth, new material is supplied by the rivers.

The material of this estuarine mud consists of "a variable quan- 
tity of fine, argillaceous granules, small, angular fragments of colorless transparent quartz containing numerous minute included cavities, a few similar fragments of flint, siliceous fragments of a glauconite green color, minute crystals of quartz of the ordinary form, minute prisms of tourmaline highly dichroic and similar in form to macroscopic prisms of schorl, and minute rhombohedra of calcite." Materials of organic origin also occur, such as coccoliths and rarely coccospheres, both of the ordinary cyatholith type so common in adjacent seas and in the Atlantic ooze; further, Foraminifera, including Miliola, Textularia, several species, Nonionina crassula, Polystomella umbilicata, Rotalia sp., Spirillina sp., etc., more rarely spicules of Alcyonaria, fragments of echinoderm skeletons and minute spines; and triradiate spicules of calcisponges, probably Sycandra. "Most of the Foraminifera are quite empty, glassy and transparent; but some contain a brownish, soft granular material; and in one instance a small Rotaline form was observed partially replaced by pyrites." (90:6I4.) The siliceous organic remains comprise chiefly sponge spicules, very rarely Radilaria, and a variable quantity of diatoms. The remains of other organisms found in the mud are all of marine types, though they occur on the banks of rivers at a great distance from a truly marine area.

In the muds of the rivers above the limit of tidal influence, only spicules of fresh-water sponges and diatoms were found (Spongilla fluviatilis), foraminifera and other marine organisms being absent. Nor were any of these organisms derived from the Mesozoic strata through which these rivers flow. The organic remains of the modern, as well as the older, muds of the Severn estuary were apparently all derived from the Bristol Channel, which is the further enlargement of the Severn estuary and along the shores of which from Io to I 5 miles west of the Severn estuary marine life abounds. The older alluvial deposits of the Severn estuary have a maximum thickness of about 50 feet. These comprise in descending order:

Zone I. Upper clay $\begin{cases}\mathrm{a} & \text { More sandy zone } 5 \text { to } 7 \text { feet } \\ \mathrm{b} & \begin{array}{l}\text { More argillaceous zone, with disseminated } \\ \text { vegetable matter } 7 \text { to } 8 \text { feet } \pm\end{array}\end{cases}$ Upper peat, I to 2 feet 6 inches

Zone 2. Lower clay

Lower peat, I to 4 feet

Zone 3. Sands and mud

Gravel

Triassic sandstones 
The gravel contains glacial pebbles and rolled boulders up to a cubic foot in size. It is not always present. The mud is a marine or tidal deposit like the blue clay which replaces it elsewhere, and from which it differs chiefly in being nearly or quite free from clay. There seems to be a gradual transition from coarse at the bottom to fine at the top. Some of the sands contain fragments of a bryozoan, and many chips of pelecypod shells, including a small Avicula. Foraminifera, spines of echinoderms and sponge spicules also occur. In a section through Caldicot Marsh near Portskewet, fifty feet deep, a bed of marl was encountered Io feet above the base, which contained a mixture of fresh and brackish water shells, such as Limnæa, Planorbis, Scrobicularia piperata and Cardium edule. Diatoms are common in it, and also remains of Chara. A similar bed occurs near Cardiff, about ig miles farther south. It occurs at the same depth. Altogether the beds of zone 3 represent a normal estuarine deposit, with a fauna and flora both brackish and fresh.

The lower part of zone 2 has remains of forest trees associated with it. It is covered by blue clay with Foraminifera and other marine organic remains, indicating a subsidence. The upper Peat bed, sometimes the only one, "consists of various plant remains, including leaves and roots of yellow flags and spores and mycelia of fungi, while its upper surface is strewn with trunks and branches of trees, oak, fir, and birch being the chief. The fir still retains its bark, and the heartwood, when cut, is often found to have preserved its original color. Some of the wood has been bored by some kind of beetle." (90:621.) The peat is very pure, though containing occasional sand grains, Foraminifera or sponge spicules. It often contains an abundance of spherules of iron pyrites, and sometimes the vegetable cells are filled with it, these occupying the place of the departed protoplasm within the resistant cell walls. The origin of this pyrite is similar to that of coast marshes or swamps in general. When the salt water comes in contact with the decaying vegetable matter a series of reactions occurs, which will end in the formation of iron pyrites. The upper clay contains Foraminifera, sponge spicules and other marine organisms, besides disseminated vegetal material.

2. The Marginal Lagoon or Barachois. These names are applied to the water bodies cut off from the main portion of the sea by the formation of barrier beaches. So long as the lagoon is not filled in by silt and organic deposits, it belongs to the neritic zone of the littoral district. The process by which it is converted into 
tidal flats and marshes has already been sketched. (See Chapter XI.) It need only be noted here that the deposits accumulating in the lagoon are the finer sands and muds brought by the tidal currents, and the sands blown across from the beach. Though stratification may be well marked in these lagoon deposits, the evidence of agitation by waves or currents is slight. Cross-bedding structure is not characteristic of such deposits, but ripple marks, of the oscillation type, $i$. e., symmetrical, sharp crests with broad, rounded troughs, may be formed. A characteristic feature of these deposits is the presence of the eel grass leaves which penetrate the strata in a vertical direction, having been instrumental in the precipitation around them of the suspended material, through a checking of the velocity of the current. In the last-formed deposits of the lagoons organic matter will predominate and peat beds-the coal of the future-mark the transition through the shore zone to terrestrial conditions. Of older deposits of this type the Lowville limestone has already been cited. This is a formation of fine lime mud deposited around vertical stems or branches of a marine organism, probably not a plant, however. Thus the resulting calcilutyte is penetrated by numerous vertical tubules, now largely occupied by crystalline calcite, and producing on the bedding planes the so-called bird's-eye structure which gave the formation its original name.

3. Epicontinental Seas and Mediterraneans. Those portions of the littoral district which extend into the land as arms or partly enclosed embayments of no great depth, without being estuaries of great rivers, are of considerable importance to the stratigrapher, since epicontinental seas of this type were very characteristic of many geologic epochs. Their chief significance is, however, a faunal one, since sedimentation, except in special cases, does not differ much from that upon the continental shelf. Nearly landlocked epicontinental seas within pluvial districts, such as Hudson Bay or the Baltic Sea, do not differ appreciably from the littoral belt of the open ocean, but where such enclosed seas occur in arid climates the greater density and increased salinity of their waters will inftuence perceptibly not only the fauna and flora, but also the deposits. If the intracontinental sea of the arid or semiarid climate is a mediterranean, $i$. $e$., if its center extends to depths much greater than its outlet, the peculiarities of the deposits will be emphasized. The Black Sea forms an instructive example of the conditions found in an almost completely enclosed water body of great depth in a semiarid region. According to Andrussow $(5 ; 2 \mathrm{I}: 200)$, the superficial 
water layer, of about 125 fathoms, has a less salinity and density than the deeper water, being largely renewed by the fresh water of the drainage. The heavier lower water is derived from the Mediterranean by way of the richly saline Marmora and Egean seas, requiring about 1,700 years for its renewal. Vertical currents are slight on account of the greater density of the deeper water, and hence these lower waters have not sufficient oxygen to support animal life. Sulphuretted hydrogen is separated out, probably through the agency of sulphobacteria, in the deeper water; beginning at $\mathrm{IOO}$ fathoms, with 33 c.c. of $\mathrm{H}_{2} \mathrm{~S}$ per $\mathrm{I} O \mathrm{O}$ liters of water until, at 500 fathoms, 570 c.c. of $\mathrm{H}_{2} \mathrm{~S}$ per Ioo liters of the water are separated. Below this the increase is less rapid. As the $\mathrm{H}_{2} \mathrm{~S}$ increases, the sulphates of the water decrease, and carbonates and FeS are separated out.

The sediments of the Black Sea comprise sandy detritus to a depth of 20 fathoms, below which occurs gray, blue, sticky mud rich in Modiola phaseolina to the Ioo-fathom line. In the great depths occurs a very fine, sticky, black mud with rich separation of $\mathrm{FeS}$, abundant remains of planktonic diatoms, and shells of young pelecypods, which have descended to this depth on completion of their early pelagic existence (mero-planktonic stage). Besides the black is a dark-blue mud with less FeS, but a richer separation of $\mathrm{CaCO}_{3}$ in minute grains, this lime often constituting thin banks, while pelagic diatoms are likewise abundant. Clarke $(2 \mathrm{I}: 20 \mathrm{r})$ has suggested the possible origin of some of the Upper Devonic black shales of New York (Portage) under similar conditions, but this is a much mooted question. Pompeckj (7I : 43 et seq) has interpreted the black Posidonia bromi shales of the Jurassic of Regensburg, Bavaria, as deposits of this type. It is, however, difficult to understand how such a region can furnish conditions for the perfect preservation of the saurians of that period, so that in some cases even the skin of the animals is intact.

4. The Ocean Littoral, or the Neritic Zone. This is the most widely distributed littoral belt at the present time. Its deposits vary considerably, according to distance from shore, depth of water and relation to currents. In general a seaward gradation in the texture of the material from coarse to fine is observable, sands being found near shore (though often extending out for great distances), while muds are formed further offshore and in specially protected places. In the Arabian Sea muds are carried from 700 to 800 miles from land, owing to the nature of the ocean currents. Calcareous accumulations are typical of this region, especially those formed around coral reefs. These have been fully described above. 


\section{Deposits of the Bathyal District.}

On the whole the deposits of this region, which nominally lie between 200 and 900 meters or between IOO and 500 fathoms, are continuous with those of the neritic zone on the one hand, and with those of the abyssal on the other. The following deposits seem to be most characteristic of this district, though extending into both of the adjoining ones:

Table Showing Kinds and Distribution of Bathyal Deposits.

\begin{tabular}{|c|c|c|c|c|}
\hline & \multirow{2}{*}{ Clastic deposits } & \multicolumn{2}{|c|}{ Mean depth } & \multirow{2}{*}{$\begin{array}{l}\text { Area covered } \\
\text { in square miles }\end{array}$} \\
\hline & & in fathoms & in meters & \\
\hline I & Blue mud................ & I,4I I & 2,397 & $14,500,000$ \\
\hline 2 & Red mud................. & 623 & 1,140 & 100,000 \\
\hline 3 & Green mud................ & 513 & 920 & \\
\hline 4 & Green sand................ & 449 & $82 \mathrm{I}$ & 850,000 \\
\hline 5 & Volcanic mud.............. & I,033 & I, 889 & 600000 \\
\hline 6 & Volcanic sand............... & 243 & 444 & 600,000 \\
\hline 7 & Coral mud................ & 740 & 1,353 & 2556800 \\
\hline 8 & Coral sand................ & 176 & $322\}$ & $2,556,800$ \\
\hline
\end{tabular}

The table on page 669, taken from Clarke's Data of Geochemistry $(20 b: 489)$, gives the analysis of the terrigenous and volcanic muds and the green sands: I, Blue mud dried at $110^{\circ}$ (Brazier); 2 , red mud dried at $100^{\circ}$ (Hornung); 3, green mud dried at $110^{\circ}$ (Brazier) ; 4, green sand dried at $110^{\circ}$ (Brazier) ; 5, volcanic mud dried at $I I^{\circ}$ (Brazier).

Three types of land-derived muds are found in the modern sea away from the shore. These are the blue, the red and green muds.

The Blue or Slate-Colored Mud. This is the most widely distributed, extending, according to Murray and Renard, over an area of $14,500,000$ square miles. It covers the floors of the shallow sea to the edge of the continental shelf, as well as the floor of the entire polar sea. The greatest depth at which it was observed by the Challenger was 5, I20 meters. In the Gulf of Naples it begins at a depth of 15 meters, where in contact with the sea water it gen- 
Table of Analyses of Muds of Terrigenous and Volcanic Origin.

\begin{tabular}{|c|c|c|c|c|c|}
\hline & $\begin{array}{l}\text { (I) } \\
\text { Blue mud }\end{array}$ & $\begin{array}{l}(2) \\
\text { Red mud }\end{array}$ & $\begin{array}{c}(3) \\
\text { Green mud }\end{array}$ & $\begin{array}{c}\text { (4) } \\
\text { Green sand }\end{array}$ & $\begin{array}{c}(\mathbf{5}) \\
\text { Volcanic } \\
\text { mud }\end{array}$ \\
\hline 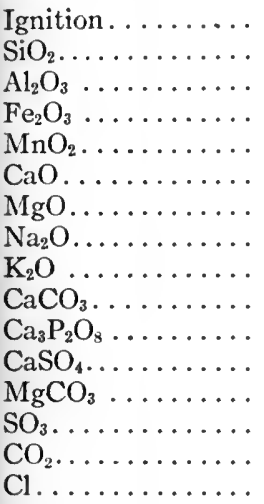 & $\begin{array}{r}5.60 \\
64.20 \\
13.55 \\
8.38 \\
\ldots \ldots \\
2.51 \\
0.25 \\
\ldots \ldots \\
\ldots \ldots \\
2.94 \\
1.39 \\
0.42 \\
0.76 \\
\ldots \ldots \\
\ldots \ldots \\
\ldots \ldots\end{array}$ & $\begin{array}{r}6.02 \\
31.66 \\
9.21 \\
4.52 \\
\ldots \ldots . \\
25.68 \\
2.07 \\
1.63 \\
1.33 \\
\ldots \ldots \\
\ldots \ldots \\
\ldots \ldots \\
\ldots \ldots \\
0.27 \\
17.13 \\
2.46\end{array}$ & $\begin{array}{r}3.30 \\
31.27 \\
4.08 \\
12.72 \\
\ldots \ldots \\
0.30 \\
0.12 \\
\ldots \ldots \\
\ldots \ldots \\
46.36 \\
0.70 \\
0.5^{8} \\
0.57 \\
\ldots \ldots \\
\ldots \ldots \\
\ldots \ldots\end{array}$ & $\begin{array}{r}9.10 \\
29.70 \\
3.25 \\
5.05 \\
\ldots \ldots \\
0.22 \\
0.13 \\
\ldots \ldots . \\
\ldots \ldots \\
49.46 \\
\text { trace } \\
\text { I.o7 } \\
2.02 \\
\ldots \ldots \\
\ldots \ldots \\
\ldots \ldots\end{array}$ & $\begin{array}{c}6.22 \\
34.12 \\
9.22 \\
15.46 \\
\text { trace } \\
1.44 \\
0.22 \\
\ldots \ldots \\
\ldots \ldots \\
32.22 \\
\text { trace } \\
0.27 \\
0.83 \\
\ldots \ldots \\
\ldots \ldots \\
\ldots \ldots\end{array}$ \\
\hline 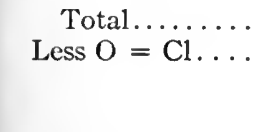 & 100.00 & $\begin{array}{r}101.98 \\
0.87 \\
101.11\end{array}$ & 100.00 & 100.00 & 100.00 \\
\hline
\end{tabular}

erally has a red or brown color, due to iron oxide or hydrate, and when dried its color is gray or brown from the oxidation of its contained iron sulphides. Pure clay often constitutes only a small proportion of this mud (though ranging from 16 to 97 per cent.), and the lime content may be as high as 35 per cent. Quartz is a characteristic constituent. This is the type of mud which has in the past given rise to most of the marine shales and slates.

The Red Mud. This is much more restricted in its distribution than either the blue or green. It is found opposite the mouths of tropical rivers, such as the Amazon and the Yang-tze-Kiang, and is derived from the red laterite or residual soil of the tropical countries. Its percentage of pure clay varies from 28 to 68 , and its lime content varies from 6 to 60 per cent.; glauconite is absent, but quartz is characteristic. The red mud closely resembles the red mud of the deep sea, which has, however, a different origin, being probably in large part the product of decay of volcanic material which has settled to this depth. Muds of this kind may easily preserve an 
abundance of shells and other remains of marine organisms. Since they are formed opposite the mouths of great rivers, which may sweep terrestrial organisms into the sea, such remains may also be expected in these deposits.

The Green Mud. This ranges in depth from 180 to 2,300 meters (99 to 1,250 - fathoms), and may contain as much as 56 per cent. of lime. In shallower depths this green mud passes into greensands. The percentage of clay in the green mud varies from 24 to 48 . Glauconite is one of the chief constituents of both the greensands and green muds.

Greensand. This is essentially the mineral glauconite, an impure hydrous silicate of iron and potassium. Clarke states that, "according to the best analyses, glauconite probably has when pure the composition represented by the formula $\mathrm{Fe}^{\prime \prime \prime} \mathrm{KSi}_{2} \mathrm{O}_{6}$ aq., in which some iron is replaced by aluminum, and other bases partly replace K." This is forming in the present ocean near the "mud line" around continental shores. It is never pure, but contaminated by alteration products and other substances, and hence its composition varies widely. In the present ocean it is chiefly formed on the interior of foraminiferal shells, and it is believed that the decomposing organic matter in these shells is responsible for its formation. According to Murray and Renard $(62: 383)$, the shell is partly filled with fine silt or mud, and upon this the organic matter will act. "Through intervention of the sulphates contained in the sea water, the iron of the mud is converted into sulphide, which oxidizes later to ferric hydroxide. At the same time alumina is removed from the sediments by solution, and colloidal silica is liberated. The latter reacts upon the ferric hydroxide in presence of potassium salts extracted from adjacent minerals, and so glauconite is produced." (Clarke-20b:402.) The constant association of the glauconite shells with the débris of rocks in which potassium-bearing minerals such as orthoclase and muscovite occur seems to sustain this view of Murray and Renard of the origin of glauconite.

Glauconite may, however, form under other conditions than those now obtaining in the glauconite region of the present oceans. L. Cayeux (15) has shown that in certain instances glauconite has formed subsequent to the consolidation of the rocks in which it. occurs. Cayeux shows that this mineral can also form without the intervention of organisms.

While glauconite of the present sea and in the sedimentary rocks is crystalline (monoclinic, La Croix), having a definite cleavage, though not crystal form, the mineral caladonite of nearly identical composition is earthy in texture and never granular. This is a de- 
composition product of augite in various basaltic rocks, and may be identical with glauconite (Clarke). Another mineral of similar appearance is greenalite, found in the iron-bearing rocks of the Mesabi range of Minnesota. It is free from potassium, the iron being practically all in the ferrous state (Leith-56:2fo), while in glauconite, where potassium is an essential constituent, the iron is mainly in the ferric state. Cayeux has also observed that glauconite is frequently present in arable soils, in all conditions from perfect freshness to complete alteration into limonite, to which Clarke remarks that the formation of the species is perhaps "one of the modes by which potassium is withdrawn from its solution in the ground water." (20b:49.4.) "Probably, in all their occurrences," says Clarke, "the final reaction is the same, namely, the absorption of potassium and soluble silica by colloidal ferric hydroxide. In the ocean these materials are prepared by the action of decaying animal matter upon ferruginous clays and fragments of potassium-bearing silicates. In the sedimentary rocks, where glauconite appears as a late product, the action of percolating waters upon the hydroxide would account for its formation. In igneous rocks the hydroxide is derived from augite, or perhaps from olivine, and percolating waters again come into play. Thus the various productions of glauconite and caladonite become the results of a single process, which is exactly equivalent to that in which potassium compounds are taken up by clays." (20b:494.)

Greensands are found in nearly all formations from the Cambric to the present, and often constitute a predominant element of the formation, as in the Cretacic Greensands of England and America. Analyses of the mineral from different horizons show on the whole a close correspondence in composition, there being, however, a steadily decreasing percentage of potash from the older to the more recent. In the table on page 672 , the average composition of various glauconites is given: (a) from the Lower Ordovicic of Minnesota, (b) from the Cretacic Greensands of Wooburn, Antrim, Ireland, (c) from the Cretacic Greensand marls of Hanover County, Virginia, (d) modern oceanic glauconite, mean of four analyses from Challenger dredgings (analyses b, c, d quoted from Clarke-2ob: 494).

The mechanical composition of typical greensand marls (Navesink) of the Cretacic of New Jersey has been determined by Prather $(73: 162: 74)$ to be as follows:

Fine clay (settling out of suspension in water in the course of from I to 24 hours), I4.4I per cent.; sand, almost wholly composed of pure glauconite, pyrite, shell fragments and Foraminifera (set- 
Table of Analyses of Glauconite from Various Horizons.

\begin{tabular}{|c|c|c|c|c|}
\hline & $\begin{array}{l}\text { (a) } \\
\text { Ordovi- } \\
\text { cic }\end{array}$ & $\begin{array}{l}\text { (b) } \\
\text { Cretacic } \\
\text { Ireland }\end{array}$ & $\begin{array}{l}\text { (c) } \\
\text { Cretacic } \\
\text { Virginia }\end{array}$ & $\begin{array}{c}\text { (d) } \\
\text { Modern } \\
\text { oceanic }\end{array}$ \\
\hline 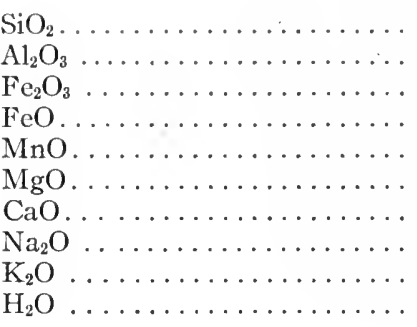 & $\begin{array}{r}48.18 \\
6.97 \\
\cdots \cdots \\
27.08 \\
\cdots \cdots \\
\cdots \cdots \\
\cdots \cdots \\
7.25 \\
7.40 \\
8.75\end{array}$ & $\begin{array}{r}40.00 \\
13.00 \\
16.81 \\
10.17 \\
\cdots \cdots \\
1.97 \\
1.97 \\
2.16 \\
8.21 \\
6.19\end{array}$ & $\begin{array}{r}51.56 \\
6.62 \\
15.16 \\
8.33 \\
\cdots \cdots \\
0.95 \\
0.62 \\
1.84 \\
4.15 \\
10.32\end{array}$ & $\begin{array}{r}53.6 \text { I } \\
9.56 \\
21.46 \\
1.58 \\
\text { trace } \\
2.87 \\
1.39 \\
0.42 \\
3.49 \\
5.96\end{array}$ \\
\hline 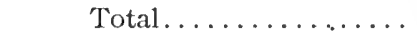 & 99.63 & 100.48 & $99 \cdot 55$ & 100.34 \\
\hline
\end{tabular}

tling out of suspension in water in five minutes or less), 85.59 per cent. A sample from a lower bed of the same formation (Navesink) gave clay as above 8.18 per cent.; sand, composed about equally of pure glauconite and of rounded grains of quartz, with some mica, 9I.82 per cent.

Many grains of glauconite represent internal molds of foraminiferal shells, though frequently further enlargement of these molds, after the solution of the shell, produces irregular glauconite nodules. W. B. Clark ( I $7: 238$; I8) believes that the New Jersey glauconites were formed in much the same manner as the modern glauconites of the ocean, but Prather $(74: 509)$ points out some objections to this interpretation, and cites evidence of shallow-water conditions during the accumulation of these glauconite sands. He finds that the casts of Foraminifera are the exception. The greensand grains of the Lower Ordovicic dolomites of Minnesota are regarded by Hall and Sardeson (42:I86) as having their origin "in the chemical conditions of the mingled mineral matters of the including rocks. ..." and not in the chemical changes within foraminiferal shells. (See Hunt-49:303; 50: 196, 309; 51 : 257.) Though modern glauconite deposits are chiefly confined to depths at or for some distance below the Ioo-fathom line, the frequent association of this mineral with typical littoral deposits, and in formations containing a littoral fauna, indicates that in the past it may have formed in 
shallower water sufficiently removed from the shore to prevent excessive detrital deposition.

The secondary origin, through erosion of older greensand deposits and redeposition of the material in shallow water, must also be considered. Such deposits are forming at the present time by the erosion of the Cretacic greensands of the Atlantic coastal plain. Andrée $(3: 38 r)$ holds that this may have been the origin of greensand lenses in the Neocomien sandstones of northwest Germany (Teutoburger Wald, especially the Oswing). The lower Cenomanien deposits of greensands (Essener Greensand) of northwestern Germany are other examples of such deposits formed near shore, passing laterally near Mons into a shore conglomerate with rich fauna.

Greensand is to-day found sporadically on the shallow ocean floor under the Gulf Stream in depths of only a few hundred meters. (Pourtales-72:397.)

The decomposition of glauconite produces, according to $\mathrm{L}$. Cayeux, ferric hydroxide and pyrite, but other alteration products may also result. Thus the bright-red "Redbank" sands of the New Jersey Cretacic seem to owe their color to the decomposition of the glauconite mingled with the quartz grains of the deposit. This decomposition may be due to the more porous character of these sands, but that it was not produced under present climatic conditions is shown by the bright-red tints which indicate a prolonged period of subjection to dehydrating agencies.

\section{Deposits on Lee Banks and on the Edge of the Continental Shelf.}

Where ocean currents carrying fine silt pass from shoals to deep. water, the checking of the current resulting causes a deposition of more or less of the silt. (Willis-105:497.) Thus on the lee of a submerged ridge a bank of silt will form, the structure of which is probably that of the delta, the successive additions being at a comparatively steep angle. The Gulf Stream crosses several shoals or submerged terraces, and deposits of the type mentioned are formed in the lee of these. "The steepest slope of the Gulf of Mexico from the Iooth to the 2,oooth-fathom line is in the position of a lee-bank northwest of the Yucatan plateau. ... The Blake plateau, over which the.Gulf Stream sweeps north of the Bahamas, is clean, hard limestone, but a lee-bank of mud and ooze is forming on its short, steep slope into deep water." (105:497.)

A similar type of deposit is forming on the edge of the conti- 
nental plateau off the Atlantic coast of North America. The plateau or shelf itself is covered with shore-derived arenaceous deposits. Dredgings from these were examined by Bailey Willis, who states that they "are indeed finer near the eastern edge, yet are distinctly granular and incoherent."

The black muds of the Ordovicic with their world-wide distribution of graptolites seem to offer an older illustration of this type of sedimentation. The graptolites are often arranged so as to indicate current action, and it appears that these muds (Deep Kill, Norman's Kill, Utica) were distributed by these currents and deposited on the ocean floor under their pathway.

\section{Abyssal Deposits.}

In the abyssal district of the ocean, beyond the one thousandmeter line, current-borne detrital material is relatively unimportant. Terrestrial material borne by currents is not unknown, however, as in the case of the deep-sea vegetal deposits already referred to. Even rock waste is carried by currents to realms of greater depths where these are not far from shore, while terrestrial material carried by floating icebergs or rocks held by the roots of floating trees or sea weeds may come to be deposited at any depth. Among other deposits of the littoral district which pass over into the abyssal, greensand has already been noted, as extending to a depth of 700 fathoms. The characteristic deposits of this district, exclusive of the marine derelicts, may be divided, according to their origin, into the pelagic and the terrigenous. To these must be added the meteoric or extra-terrestrial materials, and the subcrustal or volcanic.

\section{Abyssal Deposits of Pelagic Origin.}

Pelagic deposits are those which have descended to the bottom from the pelagic district of the ocean, $i$. $e$., the upper hundredfathom layer of water of the open ocean. They comprise chiefly the shells and skeletal parts of pelagic animals and plants, such as Foraminifera, radiolaria, pteropods, ostracods and diatoms, the shells and other hard parts of pelagic molluscs, and the skeletal parts of fish, especially the teeth of selachians, and, further, the ear bones of whales, and other hard parts of this as well as other pelagic vertebrates. The young stages of organisms, such as molluses, brachiopods and echinoderms, may also be included in these 
deposits. The former group may be termed the holopelagic group, since it comprises organisms permanently at home in the pelagic district, while the latter may be termed the meropelagic group, comprising types at home in the pelagic district during part of their lives only.

-Foraminifera, ostracods and pteropod shells are calcareous, and these form the chief source of the lime deposits of the deep sea. Foraminiferal oozes of the modern sea generally abound in the shells of Globigerina, hence the term Globigerina ooze is applied to them. It should be emphasized, however, that the Foraminifera of this ooze are pelagic species, $i$. $c$., types which float in the pelagic district of the open ocean. This point is often overlooked in interpreting former foraminiferal oozes as deep-sea deposits. Thus it has been shown repeatedly that the Foraminifera of the chalk are largely of littoral types with only such pelagic additions as might be expected from the fact that the pelagic district really overlaps the littoral. Nevertheless the chalk is commonly compared with the modern Globigerina ooze, and referred to abyssal deposits, whereas the Foraminifera composing it point rather to a littoral origin.

The great purity of deep-sea oozes of pelagic origin is due to the fact that the amount of terrigenous material settling here is relatively slight. Thus in tropical seas, in depths of 600 fathoms or less, pelagic shells of carbonate of lime often constitute 80 per cent. to 90 per cent. of the deposit. With increasing depth, however, the percentage of carbonate of lime decreases, though the surface conditions are the same. Thus at 2,000 fathoms the lime is less than 60 per cent., at 2,400 fathoms 30 per cent. and at 2,600 fathoms ro per cent. (Chamberlin and Salisbury-16:382), while below this lime is generally absent. The most rapid falling off of the percentage of lime carbonate is below 2,200 fathoms, while between 2,400 and 2,600 fathoms the floor of the ocean is covered with red clay. The explanation generally given for this decrease in the percentage of carbonate of lime is the greater power of solntion of the deeper waters, owing either to the great pressure under which it exists or to the abundance of $\mathrm{CO}_{2}$ in it derived from emanations from the sea floor, or to both causes. (For other factors influencing this, see Philippi-69.) The red clay of the deeps has been regarded as the insoluble residue left on solution of these shells, a not unlikely source for at least a part of this deposit.

Radiolaria and diatom shells are siliceous, and often constitute extensive deposits in the modern oceans. Diatoms are, however, not confined to salt water, but occur in fresh water as well. Ex- 
tensive beds of diatoms are known in various older deposits both marine and lacustrine. Characteristic examples are found in the coastal plain strata of eastern North America, where a single bed underlying the city of Richmond, Virginia, has a thickness of I8 feet. Beds of fossil Radiolaria of considerable thickness are also known from older deposits, the most famous being the "Barbadoes earth" and the "Tripolite," though this name is often applied to diatomaceous or other siliceous earths.

\section{Abyssal Deposits of Terrigenous Origin.}

Among these may first be noted the terrigenous matter carried to great distances by the currents, especially opposite the mouths of great rivers. Thus terrigenous deposits are carried out for a thousand miles opposite the mouth of the Amazon. The fine coral mud, found around oceanic coral islands, often making the water milky for miles, may settle to the more moderate depths of the abyssal region around these islands. Characteristic deep-sea deposits of continental origin are the blue, green and red clays already referred to, the greensand in the upper portion and the deposits of drift logs and leaves, such as were dredged by the Blake and the Albatross in the Caribbean and off the west coast of America. The most abundant deep-sea deposits of terrestrial origin are volcanic ejectamenta, especially the finer volcanic ashes which are spread far and wide by wind currents and eventually settle on sea and land alike. Even fragments of pumice, dropped on the surface of the ocean and floated until they become waterlogged, are characteristic of deep-sea deposits. Volcanic glass and lapilli are likewise found in the deep-sea deposits, some of these probably originating from submarine volcanoes. It is believed that much of the red clay which covers the deeper ocean floor is a result of the decomposition of such volcanic material. This floating volcanic débris is often classed as pelagic, but it is evident that it has nothing in common with the true pelagic material. It may for convenience be classed as pseudopelagic, in which class also may be included the leaves, tree trunks, etc., which have floated out from the land (pseudoplankton) and come to rest on the bottom of the deep sea. All of these are strictly terrestrial, only the holopelagic and meropelagic types being truly marine.

\section{The Red Clay.}

The red clay of the deep sea is distributed over an area aggregating $51,500,000$ square miles, and occurs in depths below 2,400 to 
2,600 fathoms. It contains much volcanic débris, besides the bones of mammals, zeolitic crystals and spherules of extra-terrestrial origin. As already noted, the solution of the pelagic shells in deeper water liberates a minute quantity of such red clay, but a consiclerable part also appears to be derived by decomposition of volcanic dust. The clay is generally rich in Radiolaria; indeed these have been regarded as forming merely a phase of the red clay deposit of the deep sea, they seldom if ever occurring quite pure.

\section{Analyses of Deep-Sea Deposits.}

The following analyses quoted from Clarke (20a-436) give (a) the composition of the red clay from 23 analyses. Others have given a carbonate of lime content as high as 60 per cent. Added to this are analyses of (b) radiolarian ooze, (c) diatom ooze, (d) Globigerina ooze, average of 2I analyses, (e) Globigerina ooze very high in carbonate, and (f) pteropod ooze. All samples dried at $110^{\circ}$. Soluble and insoluble portions in analyses $a, b$ and $d$ are not separated in the table.

Table of Analyses of Deep-Sea Deposits.

\begin{tabular}{|c|c|c|c|c|c|c|}
\hline - & $\begin{array}{c}\text { a } \\
\text { Red clay }\end{array}$ & $\begin{array}{c}\text { b } \\
\text { Radio- } \\
\text { larian } \\
\text { ooze }\end{array}$ & $\begin{array}{c}\mathrm{c} \\
\text { Diatom } \\
\text { ooze }\end{array}$ & $\begin{array}{l}\text { d } \\
\text { Globi- } \\
\text { gerina } \\
\text { ooze }\end{array}$ & $\begin{array}{c}\mathrm{e} \\
\text { Globi- } \\
\text { gerina } \\
\text { ooze }\end{array}$ & $\begin{array}{c}\mathrm{f} \\
\text { Ptero- } \\
\text { pod } \\
\text { ooze }\end{array}$ \\
\hline 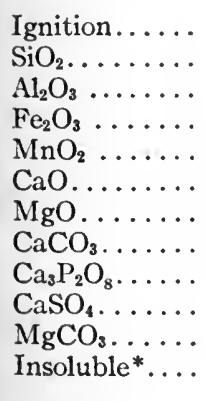 & $\begin{array}{r}4.50 \\
62.10 \\
16.06 \\
11.83 \\
0.55 \\
0.28 \\
0.50 \\
0.92 \\
0.19 \\
0.37 \\
2.70 \\
\ldots . \cdots\end{array}$ & $\begin{array}{r}7.41 \\
56.02 \\
10.52 \\
14.99 \\
3.23 \\
0.39 \\
0.25 \\
3.89 \\
1.39 \\
0.41 \\
1.50 \\
\ldots \ldots\end{array}$ & $\begin{array}{r}5.30 \\
67.92 \\
0.55 \\
0.39 \\
\ldots \ldots \\
\ldots \ldots \\
\ldots \ldots \\
19.29 \\
0.41 \\
0.29 \\
1.13 \\
4.72\end{array}$ & $\begin{array}{r}7.90 \\
31.71 \\
11.10 \\
7.03 \\
\text { trace } \\
0.41 \\
0.12 \\
37.51 \\
2.80 \\
0.29 \\
1.13 \\
\cdots \cdots\end{array}$ & $\begin{array}{l}1.40 \\
1.36 \\
0.65 \\
0.60 \\
\ldots \ldots \\
\cdots \cdots \\
\cdots \cdots \\
92.54 \\
0.90 \\
0.19 \\
0.87 \\
1.49\end{array}$ & $\begin{array}{l}2.00 \\
3.65 \\
0.80 \\
3.06 \\
\ldots \ldots \\
\ldots \ldots \\
\ldots \ldots \\
82.66 \\
2.44 \\
0.73 \\
0.76 \\
3.90\end{array}$ \\
\hline & 100.00 & 100.00 & 100.00 & 100.00 & 100.00 & 100.00 \\
\hline
\end{tabular}

* Contains silica, alumina, and ferric oxide not separated. 


\section{Older Deposits That Haz' Becn Considered of Deep-sea Origin.}

The question, Are there any deep-sea deposits among the sediments in the older geological series, has been variously answered in the past. Sir John Murray held that abyssal sediments were not represented among the known sediments, except perhaps in such instances as the radiolarian ooze of Barbados. Chalk has in the past frequently been cited as an example of a deep-sea deposit ${ }^{\circ}$ of Cretacic time, and this opinion is still defended by some. (Supan91 : 855.) There seems to be, however, a growing recognition of the fact that this formation is of comparatively shallow-water origin, the organisms composing it being benthonic rather than pelagic.

Many older radiolarian cherts or radiolarites have been referred to deep-sea origin. Their almost constant interpolation between beds of shallow-water origin has, however, thrown doubt upon this interpretation. Of comparatively deep-water origin are believed to have been the massive limestones of the Trias of the eastern Alps and of some of the Jurassic deposits of the Alpine region. This applies especially to the Aptychus beds of the Upper Jurassic, some of which seem to have no other remains than the opercula of ammonite shells, the so-called Aptychi. These opercula are believed to have sunk to the bottom on the death and clecay of the pelagic ammonite, while the shell continued to float and eventually was deposited in other sediments of generally shallower water origin.

Whether these deposits will eventually prove to have such an origin, or whether they, too, may not be of shallow-water origin, must for the present remain undecided.

In North America the black muds of the Upper Devonic have been regarded as of deep-water origin (Clarke-2I), but formed under conditions similar to those obtaining in the Black Sea. The same origin has been suggested by Pompeckj (7I) for the dark Liassic shales with saurian remains found in Württemberg and in England. In both cases, however, the deposits may with equal if not greater certainty be classed as of shallow-water origin.

\section{Concretions of the Deep Sea.}

Concretions are a characteristic feature of the deep sea. Though not clastic, they may be noted here for the sake of completeness. Foremost among these are manganese concretions, which are widely distributed on the abyssal ocean floor. Sometimes they occur in 
heaps of small grains or lumps. They range in depth to over 8,000 meters, being especially abundant in the Pacific. They are, however, also found in shallow water, as in the case of the deposits formed in Loch Fyne in Scotland. (Buchanan.) The mineral is generally the hydrous oxide, and, according to Murray, is a product of disintegration of the volcanic rocks found so abundantly in these deeper waters. The manganese and iron derived from the volcanics are at first in the form of carbonate, after which they become altered to the oxide. The concretions commonly contain fragments of pumice or lapilli or a bone or other organic structure as a nucleus. (See also Chapter IX.) Besides the manganese concretions there。 are concretions of other minerals, of which barium is one.

\section{Cosmic Deposits in the Deep Sea.}

Fine particles with a metallic interior often magnetic are found in the deeper water deposits. These have been interpreted as cosmic dust, the product of meteoric showers. Chamberlin and Salisbury $(16: 38 I-2)$ state that the number of meteorites which enter the atmosphere daily has been estimated at from i 5,000,000 to 20,$\infty 00,000$, and that if on the average each weighs Io grains (a high estimate), the total amount of extra-terrestrial matter reaching the earth yearly would be 5,000 to 7,000 tons, of which about threefourths on the average would fall into the sea. At this rate it would take some fifty billion years to cover the sea bottom with a layer one foot in thickness.

\section{Submarine Volcanic Deposits.}

Deposits formed on the floor of the ocean by submarine volcanic eruptions probably constitute an important part of the deep-sea deposits. Not all of the widely distributed volcanic material, however, found in the deep sea is the product of submarine volcanic eruptions; a large part of the pumice, lapilli and voleanic glass and dust is derived from terrestrial volcanoes, and is carried to the deep sea by flotation on the surface of the ocean, or as wind-borne dust, or as both. The Hawaiian Islands represent the restilt of prolonged submarine volcanic eruptions, and the accumulation of the material in the vicinity, until they rose to the present height of the sea-level. For the general subject of submarine eruptions, sec Thoulet (94). (See also Chapter XXII.) 


\section{Interruptions of Marine Sedimentation.}

It is generally assumed that deposition in the deep sea is relatively constant and not subject to interruptions of any but accidental character. Under this latter may be classed the appearance of submarine volcanoes, which will act in a twofold manner by disturbing the waters of the bottom of the sea and creating currents which will stir up and sweep away sediment previously accumulated, and, second, by forming a new. series of deposits, as well as creating new slopes and regions of deposition. Seismic disturbances likewise cause interruptions of sedimentation and rearrangement of sediments.

In the lesser depths of the ocean, however, the currents of the surface will to a certain extent also affect the bottom sediment. This is partly due to their ability to sweep away loose material even in considerable depths and partly to their influence in preventing sedimentation. As already noted in Chapter $V$ in narrow passages, the currents may be effective at considerable depths. Agassiz states "that the bottom of the Gulf Stream along the Blake plateau is swept clean of slime and ooze, and is nearly barren of animal life." ( $\mathrm{I}: 259$.$) This effect is felt to a depth of 1,28 \mathrm{I}$ meters. According to Verrill, the floor of the ocean beneath the Gulf Stream in depths of $\mathrm{I} 50$ to 600 meters, and at a distance of 100 to $200 \mathrm{~km}$. from land, is covered with fine sand, mostly quartz, some feldspar, mica and magnetite, fragments of shells, etc., coral and rhizopods. Fine mud is absent and is even scarce in depths of I,OOo meters, having apparently been carried away by the Gulf Stream. A current of more than $7 \mathrm{~mm}$. per second at the bottom can stir up and move shell particles of o.I $2 \mathrm{~mm}$. or less in diameter and be quite effective in transporting mud particles. Currents of $3 \mathrm{~mm}$. per second can carry along Globigerina ooze. Measurements on the Gulf Stream have shown a velocity of about $3 \mathrm{I} \mathrm{mm}$. per second at a depth of $910 \mathrm{~m}$. west of the Bermudas. In I,I00 m. depth, however, no measurable velocity was shown.

As already noted (Chapter V), the passages between the several islands of the Canary group have their bottoms kept clean by the tidal currents rushing through them. These currents are effective to a depth of 2,000 meters. On the submarine banks in the neighborhood of these islands the denuding effect of the tidal currents is felt to considerable depths. On the Seine bank only hard rock bottom was found in depths of less than 200 meters. In greater depths, down to 964 meters, only coarse sand was found. Only in the 
depths exceeding 1,500 and 2,000 meters is an accumulation of the fine Globigerina ooze possible.

In the passes between the islands of the Indian Archipelago, the Siboga expedition found mostly "hard bottom," the sounding instruments bringing up only broken-off rock fragments, or impressions of a rock bottom. In exceptional cases coarse sand was found. Since these depths extend to 1,500 meters, it is probable that we have here a prevention of sedimentation by the removal of the particles before they reach the bottom, rather than any effect of eroding work of the current at such depth. (Weber-IoI : 187.) Compensatory currents, such as those formed in the Roman Mediterranean by greater evaporation, also affect sedimentation. In the case mentioned the Gibraltar current flows in at the surface, while a deeper current passes out beneath, affecting the lower 30 meters of the water in the pass. Currents due to melting ice also affect sedimentation. The diatoms of the Antarctic region settle only north of the region of drift ice (Philippi). In addition to the oceanic and the tidal currents, the upward currents, which bring the colder water of the depths to the surface, are effective agents in modifying deposition. All such currents are further effective in determining the facies of the sediment, arid abrupt changes from one to another type of sediment may often be due to them.

It thus appears that sedimentation on the sea bottom is unequal in extent and that the surface of more elevated ridges, or areas subject to current scour, may remain free from sediment, while this is accumulating all around. Cases of interruption of the continuity of sediments referable to such causes are not unknown from the older rocks. A good example is found in the Upper Siluric beds of the Helderberg Mountains in eastern New York. Near the city of Kingston a submarine ridge of folded and eroded sandstones of Mid-Ordovicic age projected above the general bottom of the late Siluric sea, and was kept free from the deposits accumulating all around it. Thus the Rosendale waterlimes and the Wilbur limestone are wanting over the Kingston ridge, but present all around at a distance of a few miles. Only the upper part of the Cobbleskill limestone is deposited upon the ridge, which became buried in the deposits accumulating around it, to which, however, the ridge itself did not contribute any material. These deposits, however, accumulated in shallow water, as lime muds derived by the erosion of a not too distant limestone shore. The shallow water is indicated by the abundance of mud cracks at several levels. The absence of the Credneria beds and of the carinata-quader (sandstone) in the vicinity of Dresden (Plauenscher Grund) has also 
been referred to the existence of elevated ridges and cliffs in the Cretacic sea in that vicinity, on which coarse boulders formed the only loose material, while around were accumulating finer sediments. (Petrascheck-65:26 ct scq., Fig. 4.5.)

It further appears that interruption of sedimentation and even contemporaneous erosion are processes which may be active in the moderate depths of the ocean, especially between depths of 200 and 900 meters, $i$. e., in the bathyal zone of the sea. Such an interruption may give rise to a uistinct hiatus, as well as a variation in thickness of sediments. It is not improbable that some of the breaks in the geological series referred to subaërial erosions and the formation of disconformities may be due to the processes outlined above. That such is frequently the case may perhaps bc questioned, though much emphasis is laid upon it by some stratigraphers and students of Palæogeography. (Bailey Willis-106; I07.)

The numerous breaks in the Alpine Jurassic limestone series have been regarded by Neumayr and others as examples of discontinuous deposition without the occurrence of periods of dry land and erosion. Currents are believed to have been the disturbing agent. From the Rhretic upward irregularities in the distribution of the sediment are of increasing frequency and extent; these are partly due to variations in the sea-level, partly to tectonic movements of the suboceanic floor, and partly to the periodic want of material for sedimentation (Diener). In part these breaks may also be due to oceanic or tidal currents. (Andrée-3.)

Stratigraphic gaps are numerous in the geological formations of North America, but it remains still to be determined which of these, if any, are due to contemporaneous erosion, or to prevention of deposition by currents, etc. Some of the gaps in the Ordoricic limestones of the Appalachians may be explained in this manner. When the great limestone series of the Palæozoic of western North America are more fully investigated, evidences of such intraformational gaps may be found.

Persistence and Variation in Timickness of Marine Strata.

One of the familiar phenomena confronting the field geologist is the enormous variation in the thickness of strata when traced from point to point. For this variation several explanations are available. In the first place, it often happens that a given series of great thickness is in other regions represented by only a fraction of the formation, this being due to the occurrence of a constantly 
widening hiatus between the adjacent formations. Thus it appears that the Lower Ordovicic series of eastern North America is represented by some 2.500 feet of limestones in central Pennsylvania, while only about 400 feet are found in the Mohawk Valley of New York. This diminished series, however, represents only the lowest part of the Pennsylvania deposits, the entire middle and upper part being absent. Upon these beds rests a series of limestone 2,500 feet thick and representing the Middle Ordovicic, but this again is represented by less than 100 feet in the Mohawk Valley. This time, however, it is the upper part of the Middle Ordovicic which is present. Thus the gap in the Mohawk Valley cuts out all but the lowest of the Lower Ordovicic and all but the highest of the Middle Ordovicic. Southward the gap becomes less by the appearance of higher members of the subjacent and lower members of the superjacent series. This is perhaps the most frequently applicable explanation of the differences in thickness of marine formations of similar lithologic character. In the next place, there is variation in thickness due to variation in character of the sediment. Formations of different lithic composition may show great variation in thickness due to original difference in deposition. Thus a sandy series is likely to be much thicker than a shale series into which it passes and which was formed during the same period. Again, sediments of two kinds from separate sources may overlap, and so one may thin away as the other thickens. This is especially the case where continental sediments overlap a marine series of the same age or vice versa. The Catskill and Chemung series of the Upper Devonic of the eastern United States is a case in point. The Catskill continental beds are thick in the east, but die away westward, while beneath the thinning cover of this series the marine Chemung increases progressively from nothing in the east until it alone fills the interval in western New York. But even the marine series may overlap in this manner. Thus the Black shales of Portage time are thickest in Ohio, and wedge out eastward in New York and Pennsylvania. Their place is taken by the sandy Portage beds which have their source in the east and grow thinner toward the west.

The third cause of differences in thickness is local variation in the regions of sedimentation. A relatively shallow and stationary area of the sea bottom may experience little sedimentation, while a slowly subsiding area may receive a great supply of sediment of essentially similar character. The Moscow shale of the Middle Devonic of western New York is a good example of this. In the Genesee Valley region its thickness is about 250 feet, while on Lake 
Erie it is only 17 feet. Still further west in Canada the thickness increases again to over a hundred feet. The 17 feet of shales in the Lake Erie section apparently represent the 250 feet of the eastern section, but owing to lack of accumulation, probably because the water remained shallow and currents were active, the amount of deposit was slight. That this shallow area seems to have formed a barrier between the eastern and western faunas is indicated by their diversity.

In contradistinction to this marked variation is the persistence in thickness of the underlying Encrinal or Morse Creek* limestone. This bed is only about 2 feet thick, but it has been traced almost continuously from western Ontario. (Thedford) to the Genesee Valley, a distance of over 200 miles, and throughout the extent it retains its lithic character, thickness and uniformity of organic content. (Grabau-39.)

\section{Comprehensive Formations.}

Under this title may be grouped deposits which apparently without break continued over long periods of time. That such exist has frequently been observed, though many apparent lithic units have been found to consist of several members separated by disconformities. The Hunton limestone of Oklahoma was formerly believed to be a unit, extending without break from the Niagaran to the Oriskanian. It is now known to consist of at least four distinct and disconformable members separated by great time gaps (Reed-80). The Durness limestone of northern Scotland, believed to range from Lower Cambric to Ordovicic, is now known to consist of a basal member of Lower Cambric age, separated by a hiatus and disconformity from the Lower Ordovicic, the Middle and Upper Cambric being wanting. (Grabau-40.) That such comprehensive formations occur, nevertheless, is shown by the deposits on the floor of the modern deep sea, where teeth of Tertiary sharks (Carcharodon) occur side by side with remains of organisms now living. Here sedimentation is so slow that the time interval since the Tertiary, when these sharks died, has not been sufficient to completely bury their teeth.

So far, however, no such comprehensive sediments are known from the older geological formations, though a commingling of organisms of various geological horizons is not uncommon. This

* The "Encrinal Limestone" of western New York is not the same as the Tichenor of central New York. 
may be due to a weathering out of the fossils of an older formation and their incorporation in the deposits of a later one, as in the case of the Ordovicic fossils included in the base of the overlying Mississippic black shale in Tennessee, or again fossils of an older formation may be washed out along the shore and incorporated in the new deposit. Thus Miocenic oyster shells on the Atlantic coast serve as a basis for attachment of modern oysters, and are buried with these in the modern deposits.

\section{BIBLIOGRAPHY XV.}

1. AGASSIZ, ALEXANDER. 1888. Three Cruises of the Blake, Vol. I. Houghton, Mifflin \& Co.

2. ALLEN, H. S. IgoI. The Settlement of Solid Matter in Fresh and Salt Water. Nature, Vol. LXIV, pp. 279-28o. London.

3. ANDREE, KARL. I9OI. Ueber Stetige und Unterbrochene Meeressedimentation, ihre Ursachen, sowie ueber deren Bedeutung für dic Stratigraphie. Neues Jahrbuch für Mineralogic, etc. Beilage Bd. XXV, pp. 366-421.

4. ANDREE, K. 1912. Ueber Sedimentbildung am Meeresboden, Iter Teil. Geologische Rundschau, Bd. III, pp. 324-360 (with extended bibliography).

5. ANDRUSSOW, N. 1897. La Mer Noire. Guide des Excursions du VII ${ }^{\text {me }}$ Congrès Géologique International, No. 29.

6. BARUS, CARL. 1889. Subsidence of Fine Solid Particles in Liquids. American Journal of Seience, 3rd series, Vol. XXXVII, pp. I22-129.

7. BEHRENS, J. H. 1873. Ueber die Untersuchung der Grundproben (der Pommerania-Expedition $\mathbf{1} 87 \mathbf{I}$ in die Ostsee). I. Jahresberichte des Committee's für Wissenschaftliche Untersuchungen der deutschen Meere in Kiel, pp. 57-63. Berlin.

8. BIGELOW, H. B. 1905. The Shoal-water Deposits of the Bermuda Banks. Proceedings of the American Academy of Arts and Sciences, Vol. XL, pp. 559-592.

9. BLAKE, J. F. I903. On the Original Form of Sedimentary Deposits. Geological Magazine, N. S., Dec. IV, Vol. X, pp. 12-18, 78-80.

10. BODLÄNDER, G. I 893 . Versuche ueber Suspension. Neues Jahrbuch für Mineralogie, etc., .Vol. II, pp. I47-I68.

11. BREWER, W. H. I883. On the Subsidence of Particles in Liquids. Memoirs of the National Academy of Sciences, Vol. II, pp. I63-175.

12. BREWER, W. H. I885. On the Suspension and Sedimentation of Clays. American Journal of Sciences, 3rd series, Vol. XXIX, pp. I-5.

13. BROWNE, WALTER R. I88I. The Relative Value of Tidal and Upland Waters in Maintaining Rivers, Estuaries and Harbors. Proceedings of Institute of Civil Engineers, Vol. LXVI, pp. I-68 (including extended discussion).

14. BUCHANAN, J. Y. I89r. On the Composition of Some Deep-sea Deposits from the Mediterranean. Royal Society of Edinburgh, Proceedings, Vol. XVIII, pp. I3I-I38.

15. CAYEUX, L. 1897. Contributions à l'étude nicrographique des terrains sédimentaires. Mémoires Société géologique du Nord. 'Tome IV, part 2, pp. 163-1 84 . 
16. CHAMBERLIN, T. C., and SAlisBURY, R. D. 1906. Geology, Vol. I. Henry Holt, New York.

17. CLARK, WILLIAM B. 1893. A Preliminary Report on the Cretaceous and Tertiary Formations of New Jersey. Geological Survey of New Jersey, Annual Report, Vol. II, pp. I69-239, pls. IV-VI.

18. CLARK, W. B. I894. Origin and Classification of the Greensands of New Jersey. Journal of Geology, Vol. II, pp. I6I-I 77 .

19. CLARKE, F. W. 1907. The Composition of the Red Clay. Journal of Geology, Vol. XV, pp. 783-789.

20. ClARKE, F. W. I908-I9II. The Data of Geochemistry. U. S. Geological Survey (a), Bulletin 330, (b), 2nd edition, $49 \mathrm{I}$.

21. CLARKE, JOHN M. 1903. The Naples Fauna, part II. Memoir. N. Y. State Museum of Natural History, VI.

22. COLE, G. A. J., and CROOK, T. 1910. On Rock Specimens, Dredged from the Floor of the Atlantic off the Coast of Ireland, and Their Bearing on Submarine Geology. Memoirs of the Geological Survey of Ireland. 34 pp., 9 figs., I map.

23. COLLET, L. W. 1908. Les Depôts marins. Paris. $8^{\mathrm{vo}}, 325$ pages.

24. COlle'T, L. W., and LEE, G. W. I906. Sur la Composition chemique de la Glaticonie. Compte Rendu I42, pp. 999-IOoI.

25. COLLET, L. W.; and LEE, G. W. 1906. Recherehes sur la Glauconie. Proceedings of the Royal Society of Edinburgh, Vol. XXVI, pt. IV, pp. $238-278$.

26. CORNISH, VAUGHN. I898. Sea-beaches and Sandbanks. Geographical Journal, Vol. XI, pp. 528-5+3, 628-657.

27. CORNISH, V. I 898 . On the Distribution of Detritus by the Sea. Report of the 67th Meeting of the British Association held at Toronto, 1897, p. 716.

28. DAUBREE, A. I894. Deep-sea Deposits. A review of the Challenger Expedition. (Translated from "Journal des Savants," Dec., I 892, pp. 733-743, Jan., 1893, pp. 37-54.) Annual Report Smithsonian Institution for 1893 , pp. $545^{-5} 56$.

29. DELESSE, A. I871. Lithologie des Mers de France et des Mers principales du Globe. E. Lacroix, Paris.

3o. DURHAM, W. I878. Suspension of Clay in Water. Proceedings of the Royal Physical Society of Edinburgh, Vol. IV, pp. 46-50.

31. EHRENBERG, C. G. I872. Mikrogeologische Studien als Zusammenfassung seiner Beobachtungen des kleinsten Lebens der Meeres-Ticfgründe aller Zonen und dessen geologischer Einfluss. Monatsberichte der königlichen Akademie der Wissenschaften. Berlin, pp. 265-322.

32. FAIRCHILD, H. L. I90I. Beach Structure in the Medina Sandstone. American Geologist, Vol. XXXVIII, pp. 9-14, 3 pls.

33. FENNEMAN, N. M. 1902. Development of the Profile of Equilibrium of the Subaqueous Shore Terrace. Journal of Geology, Vol. X, pp. i-32.

34. FORBES, EDWARD. I844. On the Light Thrown on Geology by Submarine Researches. Edinburgh New Philosophical Journal, Vol. XXXVI, p. 318.

35. FORCHHAMMER, G. I841. Geognostische Studien am Meeresufer. Neues Jahrbuch für Mineralogie, u. s. w., pp. I-38, taf. III.

36. FUCHS, TH: 1883. Welche Ablagerungen haben wir als Tiefseebildungen zu betrachten? Neues Jahrbnch für Mineralogie, u.s.w. Beilage Bd. II, I 883 , pp. 487-584.

37. GEBBING, J. 1909. Chemische Untersuchungen von Meeresboden-, 
Meerwasser- und Luftproben der Deutschen Südpolarexpedition. "Deutsche Südpolarexpedition, I901-1903", VII, Heft II, pp. 77-234.

38. GLINKA, K. I 896 . Der Glauconit, seine Entstehung, sein chemischer Bestand und die Art und Weise seiner Verwitterung. Publication de l'Institut agronomique de novo-Alexandria. St. Petersburg.

39. GRABAU, A. W. I898. Faunas of the Hamilton Group of Eighteen Mile Creek and Vicinity. I6th Annual Report, N. Y. State Geologist, pp. 23I-239.

40. GRABAU, A. W. I9ro. Ueber die Einteilung des Nordamerikanischen Silurs. Compte Rendu du XIme Congrès Géologique International, pp. $97 \mathrm{I}-995$.

41. GUMBEL, C. W. VON. I888. Die Mineralogisch-Geologische Beschaffenheit der auf der Forschungsreise S. M. S. Gazelle gesammelten Meeresgrund-Ablagerungen. In "Die Forschungsreise S. M. S. Gazelle in den Jahren I 874 bis '76," II. Physik und Chemie, pp. 69-I I6. Berlin.

42. HALL, CHRISTOPHER W., and SARDESON, F. W. I895. The Magnesian Series of the Northwestern States. Geological Society of America Bulletin, Vol. VI, pp. I67-I98.

43. HAUG, EMILE. 1907. Traité de Géologie, Tome I.

44. HAZEN, ALLEN. I9O4. On Sedimentation. Transactions of the American Society of Civil Engineers, Vol. LXIII, pp. 45-88.

45. HEIM, ALBERT; CULMANN; GRÄNICHER, G.; HELLWAG, W.; LANG, FR., MOSER, R. I 876. Bericht und Expertengutachen ueber die im Februar und September, I875, in Horgen Vorgekammenen Rutschungen (mit 3 Tafeln). Zurich, 1876 . (A copy of this now rare publication is in the Geological Library of Columbia University.)

46. HEIM, ALBERT; MOSER, R.; BURKLI; ZIEGLER, and others, I888. Die Katastrophe von Zug, 5 Juli, I887 (mit 5 Tafeln). Gutachten der Experten, herausgegeben auf Veranlassung der Behörden von Zug. Verlag von Hofer und Burger, Zurich, I 888.

47. HEIM, ARNOLD. I908. Ueber Rezente und Fossile Subaquatische Rutschungen und deren Lithologische Bedeutung. Neues Jahrbuch für Mineralogie, etc., I908, II, pp. 136-1 57, 2 figs., pl. I3.

48. HEIM, F. 19II. In W. Brennecke. Ozeanographische Arbeiten der deutschen Antarktischen Expeditionen. Annalen der Hydrographie, etc., Vol. XXXIX, pp. 350-353, 464-47I, taf. 25, pp. 642-647.

49. HUNT, T. STERRY. I878. Chemical and Geological Essays.

50. HUNT, T. S. 189I. Mineral Physiology and Physiography.

5I. HUNT, T. S. 1892. Systematic Mineralogy.

52. JOLY, J. 1900. The Inner Mechanism of Sedimentation. Report of the British Association for the Advancement of Science, p. 732.

53. JOLY, J. I 1902. Ibid. Proc. R. Dublin Soc., N. S., Vol. IX, pp. 325-332.

54. KINDLE, E. M. 19I I. Cross-bedding and Absence of Fossils Considered as Criteria of Continental Deposits. American Journal of Science, Vol. XXXII, pp. 225-230.

55. KRÜMMEL, OTTO. 1907. Handbuch der Ozeanographie, Bd. I, 2nd ed. 56. LEITH, C. K. 1903. The Mesabi Iron-bearing District of Minnesota. Monograph U. S. Geological Survey, XLIII, 3 I 6 pp., 33 plates.

57. McGEE, W. J. I 896 . The Formation of Arkose. Science, N. S., Vol. IV, pp. $962-963$.

58. MURRAY, JOHN. I900. Description of Marine Deposits on the Cable Route between Bermuda, Turk's Island and Jamaica. Proceedings of the Royal Society of Edinburgh, Vol. XXII, pp. 409-429. 
59. MURRAY, JOHN. 1909. On the Depth and Marine Deposits of the Indian Ocean, with Descriptions of the Deposit-Samples, Collected by J. Stanley Gardiner in 1905. (The Percy Sladen Trust Expedition to the Indian Ocean in 1905.) Transactions of the Linnæan Society, Vol. XIII, 3, pp. 355-396, pls. 22-24. London.

6o. MURRAY, JOHN, and LEE, G. V. 1909. The Depth and Marine Deposits of the Pacific. Memoirs of the Museum of Comparative Zoology at Harvard College, Vol. XXXVIII, I69 pp.

6I. MURRAY, JOHN, and PHILIPPI, E. I908: Die Grundproben der "Deutschen Tiefsee-Expedition," Bd. X der Wissenschaftlichen Ergebnisseder "Deutschen Tiefsee-Expedition I 898-I899" auf dem Dampfer Valdivia, pp. 67-206, taf. XVI-XXII, 2 maps. Jena.

62. MURRAY, JOHN and RENARD, A.' F. I89I. Deep Sea Deposits. In "Report on the Scientific Results of the Voyage of H. M. S. Challenger during the years $1873-1876 . "$ London. (Reviewed in extenso by K. Futterer in Neues Jahrbuch für Mineralogie, u.s. w., I 893, Bd. II, pp. 28I-320.)

63. ORTMANN, ARNOLD E. I894. Anmerkung über Littoral Jenaische Denkschrift, Vol. VIII, p. 5. Anmerkung.

64. OWENS, J. S. I9II. Experiments on the Settlement of Solids in Water. Geographical Journal, Vol. XXVII, pp. 59-79.

65. PETRASHECK. I 894. Studien über Facienbildung 'im Gebiete der sächsischen Kreideformation. Leipziger Inaugural Dissertation.

66. PHILIPPI, E. I908. Ueber das Problem der Schichtung und ueber Schichtbildung am Boden der heutigen Meere. Zeitschrift der deutschen geologischen Gesellschaft, Vol. LXI, pp. 346-377.

67. PHILIPPI, E. I908. Zwei Proben vom antarktischen Eisrand. Centralblatt für Mineralogie, pp. 356-357.

68. PHILIPPI, E. I909. Ueber Schichtbildung am Boden der heutigen und vorweltlichen Meere. Internationale Revue der gesammten Hydrobiologie und Hydrographie, Vol. II, p. 9.

69. PHILIPPI, E. I9IO. Die Grundproben der deutschen Südpolar-Expedition I90I-I903. "Deutsche Südpolar Expedition," Vol. II, Heft 6, pp. 4 II -416.

70. PHILIPPI, E. I9 Io. Ueber Sandablagerungen am Boden, der kūsten-

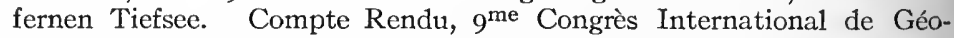
graphie, Genève I908, t. II, pp. 426-432.

7I. POMPECKJ, JOSEF F. I90I. Die Jura Ablagerungen zwischen Regensburg und Regenstauf. Geognostische Jahreshefte, Bd. XIV, pp. 43 et seq.

72. POURTALĖS, L. F. VON. I87o. Der Boden des Golfstroms und der atlantischen Küste Nordamerikas. Petermann's Geographische Mittheilungen, Bd. XVI, pp. 393-398.

73. PRATHER, JOHN K. I905. The Atlantic Highlands Section of the New Jersey Cretacic. American Geologist, Vol. XXXVI, pp. I62-178, 3 pls.

74. PRATHER, J. K. 1905. Glauconite. Journal of Geology, Vol. XIII, pp. 509-5I3.

75. PUMPELLY, R. I89I. The Relation of Secular Rock Disintegration to Certain Transitional Crystalline Schists. Bulletin of the Geological Society of America, Vol. II, pp. 209-224.

76. QUINCKE, G. 1901. The Clearing of Turbid Solutions. Report of the British Association for the Advancement of Science. Glasgow. 
77. QUINCKE, G. 1904. Ueber die Klärung trüber Lösungen. Verhandlungen des Naturhistorisch-Medizinischen Vereins. Heidelberg, N. F., Bd. VII, pp. 97-104.

78. RAMANN, E. I906. Einteilung und Benennung der Schlammablagerungen. Zeitsehrift der deutschen geologischen Gesellschaft, Bd. LVIII, Monatsberichte, pp. 174-183.

79. RAMSAY, W. 1876 . On the Influence of Various Substances in Accelerating the Precipitation of Clay Suspended in Water. Quarterly Journal of the Geological Society of London, Vol. XXXII, pp. I29-I33.

8o. REED, CHESTER A. I9II. The Hunton Formation of Oklahoma. American Journal of Science, $4^{\text {th }}$ series, Vol. XXXII, pp. 250-268.

8I. REVY, J. J. Hydraulics of Great Rivers.

82. ROBERTSON, D. I 874 . Note on the Precipitation of Clay in Fresh and Salt Water. Transactions of the Glasgow Geological Society, Vol. IV, pp. 257-259.

83. ROBSON, H. 1904. Abysmal Deposits. Nature, Vol. LXIX, p. 297.

84. RUTOT, A. I883. Les Phénomènes de la Sédimentation Marine étudiés dans leurs rapports avec la Stratigraphic Régionale. Bulletin du Míuséc royal d'Histoire naturelle de Belgique, Vol. II, pp. 4I-83.

85. SCHARDT, H. I892. Notice sur l'effondrement du Quai du Trait du Baye, etc. Bulletin de la Société Vaudoise des Sciences Naturelles. 28, No. 109.

86. SCHARDT, H. I 893. L'effondrement du Quai du Trait de Baye à Montreux survenu le I9 Mai, I89I. Bulletin de la Société Vaudoise des ingénieurs et.des architects.

87. SCHUCHT, F. 1904. Das Wasser und scine Sedimente im Flutgebiete der Elbe. Jahrbuch der kōniglich-preussischen geologischen Landesanstalt, XXV, pp. $431-465$.

88. SHALER, NATHANIEL S. I895. Beaches and Tidal Marshes of the Atlantic Coast, National Geographic Monographs, No. 5, pp. 137-168. American Book Company.

89. SOLLAS, W. J. I883. The Estuaries of the Severn and Its Tributaries: an Inquiry into the Nature and Origin of Their Tidal Sediment and Alluvial Flats. Quarterly Journal of the Geological Society of London, Vol. XXXIX, pp. 6II-626.

89a. SORBY, HENRY C. 1908. On the Application of Quantitative Methods to the Study of the Structure and History of Rocks. Quarterly Journal of the Geological Society of London, Vol. LXIV, pp. I7I233, pls. xiv-xviii.

90. SPRING, W. 1900. La Floculation des Mileux Troublés. Recueil des travaux chimiques des Pays-Bas, Vol. XIX, pp. 222-294.

91. SUPAN, ALEXANDER. I9I I. Grundzüge der physischen Erdkunde. $5^{\text {te }}$ Auflage, Leipzig, Veit \& Co.

92. TARR, RALPH S. 1907. Recent Advance of Glaciers in Yakutat Bay Region, Alaska. Bulletin of the Geological Society of America, Vol. XVIII, pp. 257-286.

93. THOULET, J. I900. Fixation des argiles en suspension dans l'eau par les corps poreux. Comptes Rendus, des Séances de l'Académie des Sciences, Paris. I30, p. I639.

94. THOULET, J. I903. Les volcans sous-marins. Revue des Deux Mondes. 73 année, $5^{\text {ème }}$ période, t. XIII, livre 3, I, II, pp. 61 I-624. 
95. THOULET, J. 1906. Le calcaire et l'argile dans les fonds marins. Comptes Rendus, des Séances de l'Académie des Sciences, Paris. 142, pp. $738-739$.

96. THOULET, J. 1908. Etude comparée des fonds marins anciens et actuels. Annales des Mines, Io series, t. XIII, p. 236.

97. THOULET, J. I910. Instructions pratiques pour l'établissement d'une carte bathymétrique-lithologique sous-marine. Bulletin de l'Institut Océanographique de Monaco, Nr. 169.

97a. THOULET, J. I9I I. Carte bathy-lithologique de la côte du Golfe du Lion entre l'embonchure de la. Têt et Gruissan. Comptes Rendus des Séances de 1'Académie des Sciences, Paris: 152, pp. I037-1038.

98. TORNQUIST, AL. 1909. Ueber die Wanderung von Blöcken und Sand am ost-preussischen Ostseestrand. Schriften der physisch-ōkonomischen Gesellschaft, pp. 79-88, taf. I, II.

99. UDDEN, J. A. 1894. Erosion, Transportation and Sedimentation Performed by the Atmosphere. Journal of Geology, Vol. II, pp. 3I8-33I.

Ioo. VERNON-HARCOURT, L. F. 1900. Experimental Investigations on the Action of Seawater in Accelerating the Deposit of River-silt and the Formation of Deltas. Minutes of the Proceedings of the Institute of Civil Engineers, Vol. CXLII, pp. 272-287. London.

ıor. WEBER, M. I900. Die niederländische "Siboga" Expedition zur Untersuchung der Marinen Fauna und Flora des Indischen Archipels. Petermann's Geographische Mittheilungen, Vol. XLVI, p. I87.

102. WEULE, K. I896. Zum Problem der Sedimentbildung. Annalen der Hydrographie, Bd. XXIV, pp. 402-4I3.

103. WHEELER, W. H. 1902. The Sea Coast. New York, Longmans, Green \& Co.

104. WHITNEY, MILTON. I892. Some Physical Properties of Soils. United States Department of Agriculture, Bulletin No. 4.

105. WILLIS, BAILEY. 1893. Conditions of Sedimentary Deposition. Journal of Geology, Vol. I, pp. 476-520.

106. WILLIS, B. 1910. Principles of Palæogeography. Science N. S., Vol. XXXIII, Feb. 18, 1910, pp. 246-251.

107. WILLIS, B. r911. The Influence of Marine Currents on Deposition in Continental Seas. Abstract, Science, N. S., Vol. XXXIII, pp. 313-314.

I08. WORTH, R. H. I899. The Bottom-deposits of the English Channel from the Eddystone to Start Point, near the Thirty-fathom Line. Transactions of the Devonshire Association for the Advancement of Science, Vol. XXXI, pp. 356-375. 


\section{CHAPTER XVI}

\section{CHARACTERS AND LITHOGENESIS OF THE BIOCLASTIC ROCKS.}

Bioclastic rocks consist of fragments of older rocks which have been broken by the mechanical activities of organisms. Among these man is the most active, and he is undoubtedly the greatest producer of bioclastic rocks. To distinguish this type the name of artificial clastics is applied to it, and as examples concrete and other artificial stone may be mentioned. These need not be more fully discussed, though their variety is great and their characters manifold.

There are also other organisms which in a more or less effective way render rocks clastic and so furnish the material from which new rocks nay be formed. Chief among these are the great herds of vertebrates of the plains and steppes and the even larger animals of former geological periods.

Pechuel-Loesche $(7: 823)$ describes the destruction of the land surface through the immense herds of cattle which he had witnessed in Herero land, German Southwest Africa. He says in effect: "In extensive manner these animals aid in the leveling of many land areas. As the dryness increases, the herds of grazing cattle become more numerous around the last of the sparsely distributed water bodies. Thousands and tens of thousands of the large and the small animals overrun for miles the surrounding country for days, weeks and months. Through countless hoofbeats the ground is loosened, and so furnishes enormous masses of dust, while at the same time all inequalities are trampled down and destroyed. The inclined surfaces would be furrowed by numerous rain-water gullies, if these were not constantly destroyed by the hoofs of the roaming animals, and if it were not for the fact that the rain water is constantly guided along the paths formed by the animals going to and from the water in long lines ranged one behind the other. Furthermore, the cover of dust prevents to an astonishing degree the penetration of the short, heavy downpour of rain into the deeper strata."

Where herds abound, the surface of the country is a compara- 
tively level plain, but where herds are absent, as in the regions between Karibib, the Otyipatura and the Erongo, infested by the Hottentot robber hordes, the country is much dissected by rain-water streams.

Passarge thinks that it is not too much to attribute to the destructive force of the great herds of vertebrates in semiarid regions the principal rôle in the lowering of great regions and the production of gently inclined plains free from river furrows, with remnants of higher monadnocks such as the Inselberge of the Kalahari (Passarge-6: $130-I 3 I$ ).

What is true of the modern herds of vertebrates must have been equally true of the great herds of mammals of Tertiary time, and

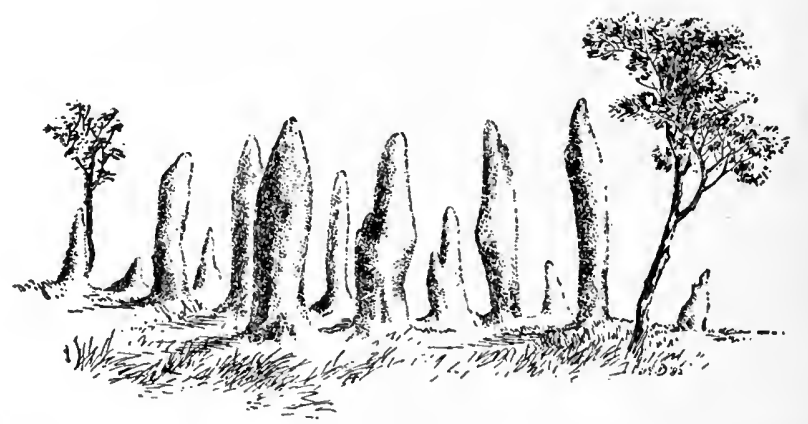

Fig. 133. White ants' nests of earth in Matto Grosso, on the plains of the upper Paraguay. (After Branner.)

perhaps to an even greater extent of the gigantic saurians of the Mesozoic. Certain it is that by their activities these creatures have furnished an immense supply of material to the winds, which would carry it to other regions and deposit it as new sediment. Burrowing mammals such as the prairie dog, rabbit, mole, badger, woodchuck, gopher and ground squirrel are also very active in tunneling the upper layers of the soil and in transferring material from below to the surface. The beaver may also be mentioned in this connection as a destructive as well as a constructive agent.

The manner in which fish, feeding on corals and nullipores, produce fine coral sand and mud has already been noted. In like manner crustacea are known to be active in breaking up the skeletons of echinoderms and other organisms, thus producing lime sand. Sponges and alga riddle shells and even rocks, forming winding passageways, which render these masses more liable to destruction by waves and other agencies. Similarly certain mollusca, Pholas, 
Saxicava, etc., bore into solid rocks or into heavy shells, thus aiding in the destruction of the mass. To a certain extent this is also true of some echini.

Earthworms are active agents in loosening and rearranging the soil particles, and to a certain extent in destroying the rock masses. According to Darwin, in many places over 50,000 earthworms are at work in a single acre of soil. The amount of material which they transport to the surface each year was estimated by Darwin to be over I 8 tons per acre. (4.) The lugworms or lobworms, crawling through the sands along the shore, are similarly active in

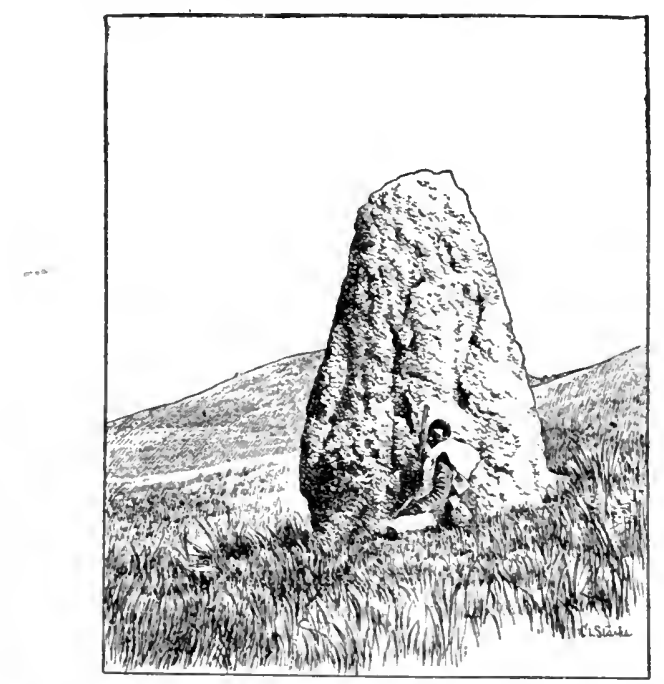

FIG. 134. Mound of white ants in the laterite region of Africa. (After Branner.)

working over the soil. They leave behind casts of sand, and the amount of soil they work over has been estimated to be sometimes as much as 3,147 tons per acre. (Davison-5:49I.) Ants and termites are also important agents in the rearrangement of the soils, especially in tropical regions, where, according to Branner, they "are vastly more important as geologic agents than the earthworms of temperate regions." ( $1: 152 ; 2 ; 3$.) In Brazil the ants excavate chambers and galleries, which radiate and anastomose in every direction, and into these they carry great quantitics of leaves. The mounds resulting from these excavations are often from 15 to 30 meters long, from 3 to 6 meters across and from one-third to over one meter high, and contain tons of earth. In the forests the 
mounds are sometimes I4 feet high ( $4^{\mathrm{T}} / 2$ meters), and from Io to 30 feet ( 3 to 9 meters) in basal diameter. They are often so close together that their bases touch each other. Branner has estimated $(3: 469)$ that in an area of 10,000 square meters on which 53 mounds occurred the amount of earth brought up by ants and built into mounds would cover the area with a layer 22.25 centimeters in thickness.

The termites' nests rise to $3^{\mathrm{T} / 2}$ meters in height, and may be 3 meters in basal diameter. They, too, are often closely set, those along the upper Paraguay being not over 3 meters apart. (Fig. I33.)

A comparison of the work of earthworms and ants gave the following result (Branner-3:493). Total weight of earth brought to the surface in roo years over I hectare (I0,000 square meters):

By worms in England (Darwin-4), 2,598,500 kilograms.

By ants in Brazil (Branner-3), 3,226,250 kilograms.

The work of ants on the soil and subsoil is summarized by Branner as follows $(3: 494)$ :

Directly:

I. "By their habits of making underground excavations that radiate from. a central nucleus and often aggregate several miles in length.

2. "By opening the soil to the atmospheric air and gases.

3. "By bringing to the surface large quantities of soil and subsoil.

4. "By introducing into their subterranean excavations large quantities of organic matter, which must yield acids that affect the soil and the subjacent rocks.

5. "By using these excavations for habitations and the production of gases that attack the soil and its contained minerals."

Indirectly.

6. "By the periodic passage and circulation of meteoric waters through their extensive tunnels.

7. "By affecting the availability of the soil for agricultural purposes.

8. "By affecting the habitability of the land by man.

9. "By the destruction of crops.

Io. "By the consumption (by the termites) of dead" plants and of timbers and lumber used in houses and for the manufacture of furniture, machinery, etc."

In temperate regions ants are less active, though, according to Shaler, they transfer annually half a centimeter of material from the subsoil to the surface, in certain fields in Massachusetts. 
Plants also are destroyers of rocks, though their work is normally very slow. Lichens growing on smooth rock surfaces will eventually roughen them by appropriating some of the material. Roots of higher plants often penetrate into the rock, especially limestones, to an astonishing extent. In sandstones they have been found to penetrate several meters. Growing saplings in fissures tend to disrupt the rock masses. Finally bacteria abound in the upper soil layers $(2 \mathrm{r} / 2$ millions have been estimated in a cubic centimeter of soil in the surface layers), and these are active agents in modifying the soil.

It thus appears that the work of organisms is by no means a negligible factor, and will in the course of time produce important results. Of these organisms man is of course the most important, and it is not going too far to say that on the whole he is the most powerful geological agent at work in modifying the surface of the land.

\section{BIBLIOGRAPHY XVI.}

I. BRANNER, JOHN C. I896. Decomposition of Rocks in Brazil. Bulletin of the Geological Society of America, Vol. VII, pp. 255-3 I4.

2. BRANNER, J. C. 1900. Ants as Geological Agents in the Tropics. Journal of Geology, Vol. VIII, pp. I5I-I53.

3. BRANNER, J. C. I9 Io. Geologic Work of Ants in Tropical America. Bulletin of the Geological Society of America, Vol. XXI, pp. 449-496.

4. DARWIN, CHARLES. 1883. The Formation of Vegetable Mould. D. Appleton \& Co., New York, pp. I-313.

5. DAVISON, CHARLES. I89I. Work Done by Lobworms. Geological Magazine, 3d Ser., Vol. VIII., pp. 489-493.

6. PASSARGE, SIEGFRIED. I9I I. Die pfannenförmigen Hohlformer der südafrikanischen Steppen. Petermann's Mittheilungen LVII, pt. ii, pp. 130-135.

7. PECHUEL-LOESCHE. 1884. Das Ausland.

8. SHALER, NATHANIEL S. I 892. Effects of Animals and Plants on Soils. In "The Origin and Nature of Soils," U. S. Geological Survey, 12th Annual Report, pt. I, pp. 219-345 (268-287). 


\section{CHAPTER XVII.}

\section{SUMMARY OF ORIGINAL FEATURES OF CLASTIC ROCKS.}

We may now summarize the various structural features of clastic rocks which were formed at the time these rocks were deposited and which therefore serve as guides in the determination of the mode of origin of the rocks possessing them. In dealing with each feature separately it will be possible to indicate the extent to which it is characteristic of one or the other of the types of clastic rocks so far discussed.

We may treat these characters under the following headings:

I. Stratification.

2. Cross-bedding.

3. Beach cusps.

4. Wave marks.

5. Rill marks.

6. Mud cracks (sun cracks or desiccation fissuxes).

7. Clay galls.

8. Clay boulders and pebbles.

9. Rain prints.

Io. Ripple marks.

II. Impressions made by animals in transit.

I2. Application of these structures in determining position of strata.

13. Rounding and sorting of sand grains, and wearing of pebbles.

I4. Characteristics of inclusions in sand grains.

15. Organic remains.

I6. Concretions (partly secondary).

I7. Secretions (secondary).

Nearly all of these structural characters have been generally considered as preëminently if not exclusively characteristic of marine or lacustrine hydroclastics. From the foregoing discussion, however, it will appear that many of them are far from being the exclusive features of these types of deposits. In fact, it may be said 
that, with the exception of the beach cusps, the wave marks and the clay pebbles, they are characteristic of subaërial deposits, while some of them, such as cross-bedding, desiccation fissures, rain prints and footprints, are almost exclusively confined to the formations other than marine or lacustrine. The most pronounced of the characters enumerated, stratification, is also of frequent occurrence in the endogenetic formations.

Concretions are only occasionally original structures, being for the most part secondary. Secretions are always of secondary character, but they are included here for the sake of comparison with concretions which belong here in part.

I. Stratification. In its broadest sense (IValther-23:6zo et seq.) stratification is the arrangement of rock masses in layers or strata, each one of which was at one time the latest deposit, and the top of each stratum was successively the top of the lithosphere at that point. Stratification thus defined occurs in all rocks, which are deposited in successive layers. Thus a series of lava-flows will show stratification, each flow representing a distinct stratum. These volcanic strata are often steeply inclined, as is also the case in clastic strata along the margins of coral reefs or in the alluvial fan or talus heap.

Among the pyrogenic rocks stratification is produced where lava streams of different composition succeed each other, or where streams of the same composition are separated by an interval, during which the surface of the earlier one either hardened or became altered to some extent, or again was covered by a layer of clastic material, before the second flow occurred. Atmogenic snow ice or glacial ice becomes stratified when the succeeding deposits of snow are separated by intervals during which the older layer solidified or was covered by a thin layer of dust or by other clastic material. False stratification is often produced in this rock by the formation of shearing planes, along which some of the subglacial detritus is carried up into the ice. Hydrogenic and biogenic rocks may also be stratified, this being brought about by cessation of deposition, by change in the material, through interposition of clastics, or by alternation in deposition of different classes of endogenetic materials. Examples of this are shown in the alternation of layers of gypsum and salt, or in the intercalation of layers of potash and other salts between the beds of ordinary rock salt. The numerous intercalated silt layers of the salt deposits of the Bitter Lakes of Suez further serve as an illustration. While stratification is thus not confined to the clastic rocks, it finds its most typical expression in this group. All clastic deposits may be stratified, this stratifi- 
cation being due to change in material, to change from one type of clastic to another, or to alternation of clastic with endogenetic deposits. The most typical development of stratification is in the water-laid clastics (hydroclastics), and especially in those laid down in standing water. Before considering the various kinds of stratification, however, we must first have a clear conception of the meaning of the term stratum.

Definition of Stratum. The current definitions of the term stratum vary greatly, as will be seen from the following quotations: (a) "A layer of rock; a portion of a rock mass which has so much homogeneity and is so separated from the rock that lies over and under it that it has a character of its own." (Century Dictionary.) (b) "The term stratum is sometimes applied to one layer and sometimes to all the consecutive layers of the same sort of

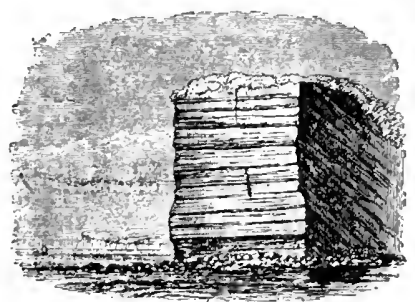

FIG. 135. A mass of stratified rocks bounded by joint faces and isolated by erosion. The strata are inclined but appear horizontal in one section.

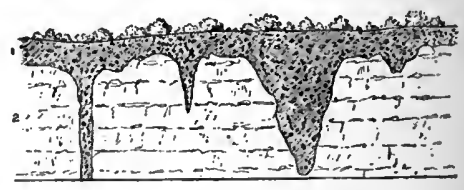

FIG. 136. Stratified chalk penetrated by pipes of sand and gravel. Kent, England. (Prestwich.)

rock." (Chamberlin and Salisbury, Geology-1 : 464.) (c) "Strata or Beds are layers of rock varying from an inch or less up to many feet in thickness. A stratum may be made up of numerous laminæ, if the nature of the sediment and the mode of deposit have favored the production of this structure ... [it] . . may be one of a series of similar beds in the same mass of rock, as where a thick sandstone includes many individual strata, varying considerably in their respective thicknesses; or it may be complete and distinct in itself, as where a band of limestone or iron stone runs through the heart of a series of shales."

"The smallest subdivisions of the Geological Record are laminæ, a number of which may make a stratum, seam or bed. As a rule, a stratum is distinguishable by lithological rather than palxontological features." (Geikie-Textbook, 4th ed.-1:635; $2: 860$.)

(d) "In the description of a formation the term stratum (from 
the Latin for bed, strata in the plural) is used for each section of the formation that consists throughout of approximately the same kind of rock material. Thus, if shale, sandstone and limestone succeed one another in thick masses, each is an independent stratum. A stratum may consist of an indefinite number of $b e d s$, and a bed of numberless layers. But the distinction of layer and bed is not always obvious." (Dana-Manual, 5th ed.-OI.)

(e) Schichten nennt man plattenförmige Lagen welche “. . . durch parallele Flächen begränzt werden, bei weiter Ausdehnung in der Regel, nur geringe Dicke besitzen, und das Product successiver Ubereinanderlagerung bilden." (Credner-Elemente, 8th ed.,-25.)

(f) "The material between two planes of stratification forms a stratum or bed, though if the deposit be very thin it is known as a lamina, and the planes are spoken of as planes of lamination (no hard and fast line can be drawn between strata and laminæ; several of the latter usually occur in the space of an inch)." (MarrPrinciples of Stratigraphical Geology-27.)

From the foregoing definitions it will be seen that there is a considerable diversity of opinion regarding the value of the term stratum. We may gain a clearer concept if we consider it in the light of its origin. Continuous deposition under the same conditions will produce a deposit nearly uniform throughout, and of a thickness commensurate with the rate of deposition, the length of time and the coarseness of the material. A sudden change in conditions will bring about an abrupt change in the character of the material deposited. It may be coarser, or it may be finer in grain, or it may be of a wholly different composition. Variation in grain, or texture, unless an abrupt change occurs, is indicative of only minor changes in physical condition of the region. But variation in the composition of the material denotes a change of some magnitude. This being the case, a decided change in the composition of the material ought to be considered a change in strata, while a change in texture, unless it be a great one, should be considered as of minor value, and therefore should constitute a subdivision of the stratum into layers. The great changes in texture which may conveniently be regarded as of stratum value are those from one to the other of the three primary textural divisions of the clastic rocks, namely, lutaceous, arenaceous and rudaceous. Thus a rudyte following an arenyte may well be considered a distinct stratum. But the change from a fine arenyte to a coarse one or vice versa is better regarded as a change in layers. Where deposition is continuous, while increase in the force of the currents and increase in the coarseness of the deposit are progressive, an arenyte may gradually 
pass upward into a rudyte, whereupon the distinction of strata is a matter of judgment. In such cases the stratum of arenyte terminates with a layer of rudaceous arenyte where the arenaceous material still predominates, while the stratum of rudyte begins with a layer of arenaceous rudyte, in which the rudaceous material has become most prominent.

A change in composition is not always of sufficient magnitude to warrant separation into a new stratum. Thus a stratum of silicarenyte or pure quartz sandstone may have interbedded layers of ferruginous, argillaceous, calcareous or glauconite material, where this material is only of sufficient quantity to produce a variety of the sandstone. Where, however, a calcarenyte or a clay rock (argillutyte) succeeds to a silicarenyte, a new stratum is produced. Where deposition is continuous, but the supplied material changes in composition, a gradation from a pure silicarenyte to a pure calcarenyte may occur, without break of continuity. In this case, as in the case of the gradation in texture, the line of division between the two strata must be drawn on the relative preponderance of materials. The stratum of silicarenyte will terminate with a layer of calcareous silicarenyte, while the stratum of calcarenyte will begin with a layer of siliceous calcarenyte.

While gradations as here discussed are not of uncommon occurrence, in the more familiar type of stratification the strata abruptly succeed each other. Thus a stratum of limestone, clastic, organic or chemical and frequently composed of only one layer, may be intercalated between strata of shales. Again strata of limestones are separated by strata of carbonaceous clay or by sandstones, the separating strata in many cases being mere films. In such cases the stratum of clayey material is represented by only one lamina. Not infrequently strata of clastic limestones (calcarenytes) are separated by a thin stratum of organic limestone in a single layer, and generally containing an admixture of clayey matter. A decided change in color may readily serve as a basis for division into strata, since such change generally indicates a marked change in physical conditions during deposition. Thus a black shale succeeding a gray or bluish one marks a change in conditions of deposition. A change from a gray to a red sandstone likewise indicates physical changes from conditions preventing to those permitting extensive oxidation, as elsewhere discussed. Finally the occurrence or indications of decided physical breaks, such as erosion surfaces and disconformities, serves to separate distinct strata.

Types of Stratification. Walther $(23: 63 I)$ recognizes two kinds of stratification, direct and indirect. The former is produced 
when the changes in sedimentation produce differences in the strata, as when, for example, volcanic ashes are deposited upon a lava flow, or when fine clay deposits are succeeded by deposits of sands from a rising flood, or when in the deep sea, after continuous deposition of Globigerina ooze, a bionomic change brings about a deposition of diatomaceous oozes. Here each stratum corresponds to the physical change which brought about the change in deposition. When, however, a rearrangement of the sediment of the shallow sea occurs, owing to the agitation of this sediment by the waves, a secondary separation of materials results, which was not dependent on original changes in sedimentation. Thus a mixed sand may be assorted into layers, according to grain, or a pebbly deposit, charged originally with sand, may be separated into a stratum of conglomerate and one of sand. Again, a deposit of mixed foraminiferal and pteropodan shells may be separated into two strata, one of Foraminifera, the other of pteropods, on account of the difference in their specific gravities. The cases just cited constitute what Walther has termed indircct stratification. Sometimes it finds expression in layers, sometimes in strata. The remarkable alternation of pure limestone and calcareous clays in the Cincinnati series of the Ordovicic of Ohio, etc., has been explained in this manner as indirect stratification. The sharp assortment of the material, the abruptness of contact and freedom from gradations would seem to indicate that this interpretation is correct. (Perry-I8.)

Stratification is often indicated only by the arrangement of pebbles, mica scales, or of fossils in interrupted horizontal lines, within a single stratum or even a single bed. The arrangement of the flints in the chalk suggests the stratification of this deposit, a single stratum appearing often of exceeding thickness, while the material is of uniform texture, this exhibiting no lamination. The same thing is true of the Lösspiippchen or concretions of the loess. but in this case it is not always the stratification which is indicated by them, but lines of permeability, which have no direct relation to stratification. This may possibly be the case also in some flint layers of the chalk, as already suggested.

2. Cross-Bending. This is most readily seen in clastics of an arenaceous texture, though rudytes sometimes show it on a large scale. It consists of an arrangement of the grains in diagonal layers with reference to the plains bounding the strata. Originally these laminæe may have been deposited at a considerable angle from. the horizontal. Above and below, these oblique layers are bounded by the planes of stratification, and they are commonly truncated on 
their upper surfaces. Successive beds may have their oblique laminæ inclined at different angles or in different directions, and horizontal layers may rest upon the truncated edges of inclined layers, thus simulating unconformity. This oblique lamination may range in magnitude from beds a millimeter or less in thickness to strata having a thickness of a hundred feet or more. In such a case the deposit was generally formed as a delta in a standing body of water, with strong currents flowing in and depositing the sands or pebbles on the growing delta front. Oblique beds formed in this manner are known as "fore-sets," and are generally truncated at the top by the currents, which deposit horizontal beds or "top-sets," generally of coarser material, upon the truncated upper edges. Basally the fore-set beds will either rest upon or directly merge into the bottom-set beds, which are made of finer material, mostly clay and silt. The angle of the fore-set beds generally decreases outward, the last fore-sets of a large delta being fine and less steeply inclined than the older ones (see ante, p. 6ro). Sinall deltas were formed in numerous localities toward the end of the last glacial epoch in standing bodies of water along the ice front. Their structure can readily be examined in many sand pits. Several types of crossbedding may be distinguished.

a. Delta Type. This type of cross-bedding, already noted, consists essentially of a single bed of diagonal layers bounded below and above by nearly horizontal beds. It appears to be characteristic of deltas deposited in a standing body of water. Whether or not this type is also characteristic of deltas formed on the sea coast depends on the strength and magnitude of the tides. It is evident that only one series of fore-set beds will be formed in any given delta, and that relatively stationary conditions alone permit the formation of the delta. If, after the building of a delta in a lake, a rise in the water level should occur, a new delta might be built up over the old one, and thus the resulting formation would show two sets of diagonal beds, separated by horizontal beds, the top sets of the first and the bottom beds of the second. Such a superimposition of two deltas is, however, difficult to conceive of on a subsiding sea coast where subsidence is accompanied by transgression, and consequent transference of the zone of delta building.

b. Cross-bedding of Torrential Deposits. Superimposition of obliquely bedded strata is, however, eminently characteristic of torrential deposits. Each succeeding deposit will be characterized by fore-set and top-set beds, and the number of such superimposed strata is chiefly dependent on the frequency of recurrence of the torrents. The length of the fore-set bed formed by a river on dry 
land is of course much less than that of a delta fore-set. Most likely a greater length than six feet is rare, while probably by far the greater number fall below a foot in length. The angle which the fore-set beds make with the horizontal varies proportionately to the coarseness of the material, but in any given case it is approximately uniform. Moreover, the angle of the fore-sets of successive strata is as a rule similar and in the same direction, while the dividing top-set beds are parallel in the successive strata. Thus a section of a torrential deposit will show a succession of obliquely bedded strata, separated and bounded above and below by strata, which make a high angle with them, are parallel to each other, and originally represented the surface slope of the deposit. The inclinations of the laminx of the successive cross-bedded strata are uniform, and the laminæ all slope in the same direction. This is the type of cross-bedding found in many ancient sandstones, and it seems to be highly improbable that any such structure could be produced by agents working on the sea coast. (Fig. 123.)

c. Cross-bedding of Eolian Deposits. Such regularity of crossbedding as is found in both lacustrine and torrential deposits is, however, not characteristic of eolian deposits. In these the laminæ when oblique show no uniformity of slope or direction within either the same stratum or successive strata. Nor are the dividing laminæ parallel to each other. Cross-bedding of eolian deposits is brought about in the following manner: A sand dune in its structure shows a series of concentric shells of sand consisting of alternating coarse and fine layers. This is a feature characteristic, according to Forchhammer (9:7), of every dune of the Jutland coast, and inferentially of the majority if not of all sand dunes. Toward the side of the wind the dune layers have an angle of $5^{\circ}$, while on the lee side the angle is as higl as $30^{\circ}$. The stratification is shown chiefly by the varying coarseness of the grains composing successive layers, this being deternined by the variable strength of the winds; to which the dune owes its origin. If through a change of the conditions which built up the dune, $i$. e., change in the force or the direction of the wind or in the amount of the sand supplied, or through other causes, the dune begins to migrate, a part of its basal portion may remain behind, as the truncated base of the dune, while upon this truncated surface a new dune may accumulate, which in turn will meet with the same fate, leaving its basal portion behind. Successive portions of this kind will eventually produce a bed of sand in which the cross-bedding is of extreme irregularity and inconstancy. (Fig. I37.) (Walther-22:715 [519].) Huntington (15) has shown that a characteristic feature 
of such cross-bedding is the tangency of the layers at the base, while at the top erosion has sharply truncated them.

This type of cross-bedding is not infrequently met with in arenytes among the strata of all ages. The Medina sandstone (Siluric) of western New York affords some excellent examples of this type, and it is highly probable that the beds showing this structure were originally wind-laid deposits. Other excellent examples of such cross-bedding are shown in the Sylvania sandstone (Upper Siluric) of Ohio, Michigan and Canada (Figs. I I9, I20) and in the White Cliff sandstones (Jurassic) of the Kanab Plateau and in the La Platte sandstone (Jurassic) of Utah. Calcarenytes, too, sometimes show this structure, as noted above, for the Junagarh limestone of India and for other modern deposits recognized as wind-laid. The cross-bedding of the Somersetshire oölite (Forest marble), referred to above (Fig. I2I), appears also to be indicative of the eolian origin of this rock. Excellent exam-

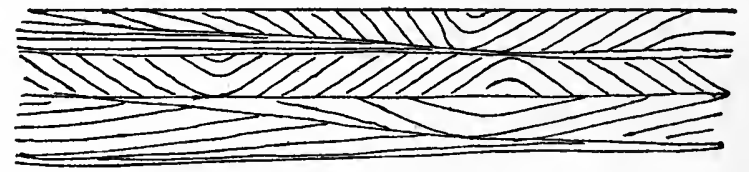

Frg. 137. Eolian cross-bedding as found in desert sands. (After Walther.)

ples of this type of bedding in a heavy-bedded, non-siliceous limestone (calarenyte) have been observed by the author in the cut through the Warsaw (Mississippic) limestone on the Missouri Pacific Railroad, south of St. Louis, Missouri. This is reproduced in Figs. I22a and b, on page 577. Compare, also, Figs. I38, I39.

Comparison of Types. A comparison of the three types of cross-bedding, i.e., the delta, the torrential and the eolian, will show the distinctive character of each, namely: uniformly sloping foreset beds in one series and generally on a large scale, for delta deposits; uniform fore-set beds of small size and in successive but similar series separated by horizontal deposits, for torrential deposits; and oblique beds, variable in angle and slope within the same and successive series commonly without horizontal dividing beds, for eolian deposits. While these types grade into each other where the deposits meet or overlap, it is not known that any one type of cross-bedding is produced by another agent. Thus the torrential type of cross-bedding cannot be readily conceived of as formed in the sea, and the same may be said of the eolian type. The bedding of a sand bar may perhaps show something analogous to the wind- 
formed cross-bedding, but conditions for the preservation of such are perhaps seldom realized. Gilbert has described the mode of formation of cross-bedding through the shifting of ripples on the

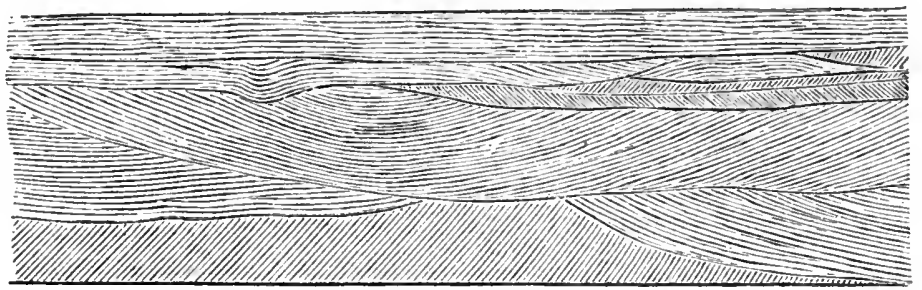

FIG. 138. Cross-bedding of the Eolian type (Orange sand or La Fayette Formation), Mississippi Central Railroad, Oxford, Miss. (After Hilgard.)

sea floor, due to a current accompanying oscillatory movements. $\mathrm{He}$ considers "that sediment may be added to a rippled surface without any disturbance of the pattern, but that there is usually a coincident gradual bodily shifting of the pattern in some direction."

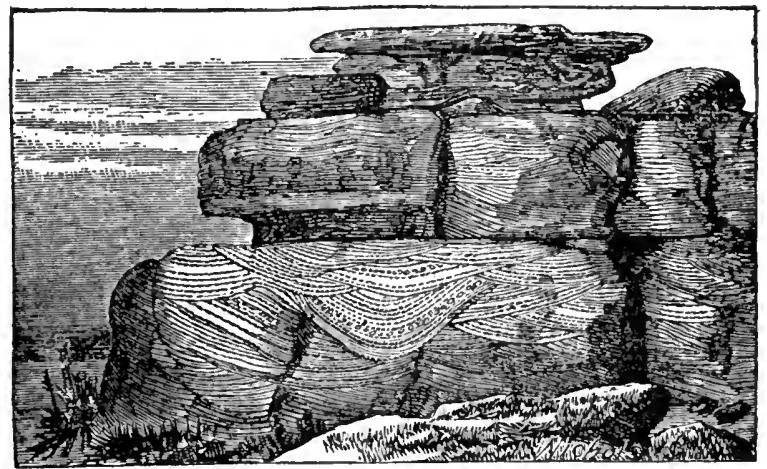

FIG. 139. Ledges of sandstone near Colorado Springs, showing Eolian crossbedding.

"The shifting of the ripple profile during the accumulation of the sediment makes the accumulation unequal on the two sides of the trough (figure 3 ), and, if the ratio of shifting to deposition exceeds a certain amount, there is deposition on only one side of the trough and erosion on the other." (Gilbert-12: 139, Figs. 3-4.) In this case two sets of oblique planes are produced, one due to deposition, the other to erosion, the latter representing the progress of the 
profile of the troughs along certain tangents. The tangent planes are often nearly horizontal, in which case the cross-bedding would approach in appearance the torrential type. The absence of dividing strata would, however, readily distinguish it. Cross-bedding of this type has been observed by Gilbert in the Medina sandstone of western New York, and referred to wave work.

"When the waves from a new direction act on a surface already rippled, they produce a new pattern, which at first combines with the old one, but eventually obliterates it. The troughs of the new pattern are formed in part by excavation from ridges of the old, and the lamination associated with the old ridges is truncated, so that the new lamination is unconformable." (I2: I40, Fig. 5.) Several such unconformities may succeed each other, and Gilbert holds that the irregular cross-bedding of the Medina sandstone, referred to above as perhaps of eolian origin, was produced in this manner. It may be doubted, however, if ripples of a sufficient magnitude to produce such a structure are ever produced under water, and still more if when produced they are accompanied by such rapid deposition as the case would seem to require. For, as Gilbert has pointed out, the formation of large ripples requires great waves, and therefore broad and deep water bodies, and in such deposition of sands is not extensive. On the whole, the structure described conforms much more nearly to the observed structure of anemoclastic deposits. It may also be questioned if the ripple crossbedding on a small scale may not with equal or perhaps greater facility be produced by the wind alone. It would seem that shifting wind ripples, which are sand dunes on a small scale, would produce the same structure that shifting sand dunes produce on a larger scale.

Strata which show the irregular type of cross-bedding must be carefully scrutinized for other evidence of eolian activity as well as for evidence of marine or fluviatile origin. The occurrence in the rock of scattered marine organisms is no conclusive evidence of the marine origin of the formation, unless it can be shown that the organisms in question lived where found or at least were carried there by currents of water and not by wind.

3. Beach Cusps. (Johnson-I6.) Beach cusps are triangular ridges extending across the beach generally at right angles to the shore front. When most typically developed the beach cusp has the form of an isosceles triangle with its base parallel to the beach, but at its upper edge, and its apex near the water. The cusp may be broad, approaching in form an equilateral triangle, but more generally it is long, narrow and extremely acute, the sides sometimes 
appearing almost parallel. "The cusps may constitute the serrate seaward side of a prominent beach ridge, or may occur as isolated gravel hillocks separated by fairly uniform spaces of smooth, sandy beach. They may be sharply differentiated from the rest of the beach, or may occur as gentle undulations of the same material as the beach proper, and so be scarcely discernible as inclependent features." "A cusp may rise from an inch or less to several feet above the general level of the beach. Nany are relatively low and flat, others high and steep-sided. Sometimes the highest part is comparatively near the apex; at other times the lighest part is far back, and from it a long, sloping rilge trails forward toward the water. As a rule, the cusps appear to point straight out toward the water-that is, the axis of the cusp is at right angles to the shore line-and neither side of a cusp is steeper than the other, except where oblique, wind-made waves have eroded one side only." (Johnson-16:605-606.) The material of the cusp varies from the finest sand to the coarsest cobblestone, there being no necessary relationship between the size of the cusp and the size of the material composing it. Gravel cusps are often found on sandy beaches, the cusps being always built of the coarser material of the beach. In size cusps vary from a length of 8 or I 2 inches to 30 feet or more. The distance between cusps, measured from crest to crest, ranges on small ponds from less than a foot to two feet or more. On sea beaches they may be less than Io feet apart, while those built by large storm waves may be roo feet apart. The spacing is fairly regular, though in some cases there seems to be irregularity in spacing, as shown by Jefferson. (Johnson-I6.) Compound cusps are also occasionally formed.

Various theories have been propounded to explain the origin of beach cusps; for a review of these the reader is referred to the paper by Johnson, where a reference to the bibliography is also found. Johnson's theory, and the one best supported by the facts, is, concisely stated, "that selective erosion by the swash develops from initial, irregular depressions in the beach, shallow troughs of approximately uniform breadth, whose ultimate size is proportional to the size of the waves, and determines the relative uniform spacing of the cusps, which develop on the intertrough elevations.' (16:620.)

Fossil Beach Cusps. Beach cusps on old shore lines are known especially from the Medina sandstone of western New York. They were described by Gilbert (I2) as giant ripples, but, as suggested by Branner (3) and by Fairchild (7), they are undoubted examples of ancient beach cusps. The spacing of these cusps varies from 
Io to 30 feet, and their height from 6 inches to 3 feet. Fairchild has found crests 80 feet apart, but it is not certain that all such structures are referable to cusps.

4. Wave Marks. On shallow coasts the advancing waves slide up onto the shore after breaking, forming the "swash." After the retreat of the wave, its furthermost advance is found to be marked by a fine, wavy line, corresponding in outline to that of the water's edge, and composed of fine particles of mica, fragments of seaweed, fine sand grains and other matter light enough to be carried along by the water. Numerous wave lines of this character may generally be seen on a shore of the type noted. In exceptional cases, as in the Medina sandstone of New York, these are finely preserved after the consolidation of the rock, appearing often as perfect as on the unconsolidated beach. (Fairchild-7.)

5. RiLl Marks. The water running off after each swash, or on the retreat of the tide, frequently cuts rills into the surface of the beach. These rills represent a river system in miniature, and gencrally consist of a number of small, quickly widening channels, which join a trunk channel at a very oblique angle, and which are in turn joined by other branches at an oblique angle.

A different type of rill marks is found where small streams debouch upon a flat, sandy or clayey plain. Here the waters of the stream will divide into innumerable fingers and fingerlets, the reverse of the river-system type. Thus before the water sinks into the ground or runs off, a series of channels, branching more and more in their lower courses, have been produced. These channels are reproductions on a small scale of the large channels spreading over the subaërial deltas at the debouchure of desert streams.

After the dying out of the streamlets which produced the rills, the conditions are generally favorable for the preservation of these in the hardening mud, and through covering by wind-drifted sand or flood deposits. On the shore conditions for the preservation of rill marks are less favorable, since the succeeding wave will generally destroy the marks left by the run-off preceding. Occasionally; however, such a preservation may occur. In either case, the filling mud or sand will on hardening show the relief of the original rill, reproducing the minutest channel as a raised ridge. These relief structures greatly resemble branching stems of plants and have sometimes been described as such. (Rogers, Lesquereux, Newberry.)

Water flowing down the beach is often checked locally by pebbles or shells lying partly buried on the beach. In such cases the water flowing down on either side of the obstruction will excavate 
characteristic depressions, or the water falling over the obstruction will gully the surface for a short distance below. Examples of these are found in the Medina sandstone.

6. Mud-cracks, Sun-cracks or Desiccation Fissures. When lutaceous deposits are exposed by the retreat of the tide, or by the shrinking or disappearance of a playa lake or a pond, or by the uncovering of the flood-plain of a river, the drying which they undergo will result in the formation of polygonally arranged cracks, and a gentle concaving of the upper surfaces of the polygons thus bounded. When the desiccated layers of mud are thin, they will often curl up like wood shavings, and may be blown away by the wind. When on reflooding of the surface or by the deposition of wind-blown material, these cracks are filled in by deposits of the same or different material, the polygons will remain more or less perfectly outlined. This desiccation fissure, sun-crack, mutd-crack, prismatic, or paving block structure, as it is variously called, is found not only in clayey rocks, but also in fine calcilutytes, like those of the Helderberg mountains (Rondout waterlimes), the Solnhofen beds (Marsh), the Cincinnati limestones (Perry-18), and in many other lutaceous deposits. They testify to the exposure of these deposits before they were solidified. (For a full discussion of this subject see Barrell-I.)

Playa Surface. Taking the areas of mud-crack formation in the order of their magnitude, the playa surface would probably stand first. Here the entire surface for hundreds of square miles becomes mud-cracked, of ten to considerable depth, on the complete drying up of the temporary playa lake. Here, too, the conditions for the preservation are most favorable. Not only is the exposure a long one, often the greater part of the year, or for many years. and for much of the time to intense heat, but the chances of proper burial are much greater. Wandering sand dunes may thus preserve the record, dust deposits may fill the fissures, or, at the next flood, sands or mud may be swept into them. In fact, the playa or takyr seems to be the ideal surface for mud-crack record, and one is tempted to refer most mud-cracked strata to such an origin. Certainly where fossil mud-cracks penetrate a formation to the depth of ten feet, as is the case in the upper Shinarump (Jura-Triassic) shales of Utah (Gilbert-11:9), it is difficult to believe that they could be formed under other conditions than those permitting prolonged exposure such as is found only in the playas of the desert, where ten years or more may elapse between rainfalls.

Permanent Lake Surface. Much less extensive, and of minor significance, are the sun-cracked areas which come into existence 
around permanent lake bodies as the result of periodic shrinking of the lake after a flooding of the adjacent lands. Such mudcracked areas will be exposed for long periods of time and so resemble the flood plains of rivers. They at best, however, form but a narrow marginal belt around the lake and the beds characterized by them would grade laterally into fresh water lake beds in which remains of fresh water organisms are found. The mud cracks of the Tertiary lake beds of Florissant may be of this type.

River Flood Plains. Next in importance to the playa, and perhaps even rivaling it in extent, is the river flood plain. Here after a great flood extensive areas may be laid bare and be subjected to desiccation and cracking during the long period of exposure before the next flood. Since, in the lower reaches of rivers, the material spread out by the flood is of the nature of a fine silt, the conditions for the formation of the mud-cracks are fully satisfied. Here, too, preserval of the mud-crack record is readily accomplished by the filling of the fissures by the sediment of the next flood.

The mud-cracked flood plain deposit would differ from the playa deposit in the more frequent presence of carbonaceous material, since vegetation is an accompaniment of river courses, but, as a rule, absent from the playa, or found only around the margin. Aquatic animals, too, should be more characteristic of the flood-plain than of the desert deposit, and would especially characterize the old stream channels dissecting the flood plain, and recognizable in the fossil state by the lines of coarser sediment-the filling of these channels--which traverse the finer deposits.

The Shore Zone. The shore zone between high and low water also may furnish conditions favorable for the formation of mudcracks. This is especially the case where, as in the Bay of Fundy, the tide recedes very far, and where large tracts remain exposed during the fortnightly interval between high spring tides. Along the margins of estuaries broad mud-flats are often exposed, and here shrinkage cracks may form between tides. The time of exposure of all but the highest parts of the shore zone, is, however, too short to allow of a sufficient hardening of the mud-cracked area to enable it to resist the softening and destroying effects of the returning tide. Moreover, in modern mud flats of this type, organisms exist in great numbers, so that we would expect to find mud-cracked rocks which are formed on the shore to be more or less fossiliferous.

On the whole, mucl-cracks are much more characteristic of continental deposits, especially of the playa and flood plain, than of 
the seashore. Only under exceptional conditions can we expect the preservation of extensive mud-cracked surfaces of the seashore. Moreover, the formation of great littoral deposits must be accompanied by a subsidence of the sea-floor, and a consequent landward transgression of the seashore with its attendant phenomena. The migration of the shore zone would thus bring about a transference of the zone of mud-crack formation, so that we could hardly expect to find a thick marine formation with repeated horizons of mud-cracked layers unless we assumed that the subsidence was so gradual a one that deposition kept pace with it.

7. Clay Galls (Thon-gallen). When the mud layers on the playa surface or on the river flood plain are very thin, drying will cause them to curl up into masses resembling shavings. Such curly mud shavings occur on river flood plains exposed to a hot sun, and they may also under favorable conditions be formed on the seashore, as in the case of the coast of the Red Sea (Walther$23: 847$ ). When thoroughly dry these shavings may be blown by the wind into neighboring sand dunes in which they become buried. Subsequent softening of the clay when the sand dune is saturated with water, as in the rainy seasons, will bring about a compression of the clay-shaving into a thin, flat pellet of clay which will lie embedded in the sand parallel to the stratification. Such clay pellets, called Thon-gallen, or clay galls, are common in sandstones of subaërial origin, especially in red sandstones. They may, indeed, be regarded as practically positive evidence of a subaerial origin of the rock containing them, though these rocks may be seashore dunes or formed far inland.

8. Clay Boulders. Clay boulders formed of plastic clay rolled about by the waves are not uncommon occurrences on the seashore. They have been recorded by Walther $(23: 847)$ and by O. Fraas (I0:277) from the coast of the Red Sea. On the coasts mentioned they represent the clay deposited during the previous high ticle, which on exposure at low tide dries and breaks up into fragments. These are rolled into balls by the returning tide and incorporated in the later sediment, where they have the appearance of concretions. Examples of such structures scem to occur in the Devonic calcilutytes of Michigan, where rounded balls of a darker color are included in lighter bedded deposits of similar character.

The author has observed the formation of clay boulders on the coast of Scotland. Here fragments of glacial clays broken from the cliffs are rolled about by the waves and fashioned into pebbles and boulders of elongate but well-rounded outline. Where these are rolled over a pebble beach, the hard pebbles are pressed 
into the clay ball which then assumes the appearance of a worn conglomerate fragment. As such it may be embedded in the succeeding formation. Frass (IO) records such boulders with shell fragments for pebbles, from the Jurassic of Spitzbergen.

9. Rain Prints. Partly dried clay surfaces and to some extent those of other lutaceous deposits, when exposed to a short, sharp rain, will receive the impressions made by the striking rain drops. When the rain drops strike obliquely a low rim around part of the impression shows where the mud was displaced more strongly, and therefore the side away from that from which the rain slanted. Thus the more pronounced marking is always on the obtuse side of the intersection of the surface and the path of the rain drop. A replica in relief of this impression is found on the under side of the layer of mud spread next above. This feature is eminently characteristic of continental mud deposits, its preservation on the sea coast being a matter of doubtful probability. Impressions apparently of this character have, however, been re-

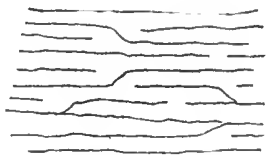

FIG. I40. Plan of Eolian rip ple-marks in fine sand. (After Walther.)

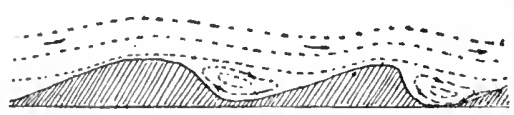

FIG. I4I. Diagram showing direction of currents and vortices in the formation of ripple-marks. (After Darwin.)

ported from the marine (shallow water) limestones of the Cincinnati region. (Perry-18:329, Fig. I.)

io. Ripple Marks. These are rhythmic undulations or waves of the sand due either to the motion of the air or of the water. Two types of ripples are recognized: I. Current ripples, formed by the wind on the surface of sand dunes, etc., or by currents of water in shallow basins; and 2. Osciilation ripples, formed by the vortices of water in the sands at the bottoms of shallow stationary water bodies.

"A current of water flowing over a bed of sand reacts on any prominence of the bed. An eddy or vortex is created in the lee of the prominence, and the return current of this vortex checks traveling particles, causing a growth of the prominence on its downstream side. At the same time the upstream side is eroded, and the prominence thus travels downstream. It is a subaqueous dune. Its upstream slope is long and gentle; its downstream slope is short and steep." (Gilbert-12:137.) The natural mold of this type of ripple 
will be difficult to distinguish from the original ripple, though the directions of the slopes will be reversed. A careful examination, however, will show that, whereas the surfaces of the normal current ripple are gently convex, those of the mold wili be gently concave.

Oscillation ripples are produced . . "by the to-and-fro motion of the water, occasioned by the passage of wind waves. During the passage of a wave each particle of water near the surface rises, moves forward, descends, and moves back, describing an orbit which is approximately circular. The orbital motion is communicated downward, with gradually diminishing amplitude. Unless the water is deep the orbits below the surface are ellipses, the longer axes being horizontal, and close to the bottom the ellipses are nearly flat, so that the water merely swings forward and back. It is in this oscillating current, periodically reversed, that the sand-ripples are formed. A prominence occasions vortices alternating on its two sides, and is thereby developed in a systematic way, with equal slopes and a sharp apex. There is a strong tendency to produce the mole laterally into a ridge, the space between ridges is definitely limited by the interference of vortices, and in time there results a regular pattern of parallel ridges equally spaced." (Gilbert-I2.) In the center of the oscillation ripple a low sharp ridge is frequently found which on the nold is represented by a groove. (Van Hise-2I : 720.) See, further, the discussion by Darwin (6) of the movements and vortices involved in ripple formation (Fig. I4I).

The amplitude of the water oscillations and their frequency control the size of the resulting ripples, as has been shown by experiment. The depth of the water has a direct bearing upon the amplitude of the wave and therefore upon the size of the ripple. No definite law has, however, been worked out as yet.

According to Siau, who studied the ripple-marks of the haven of St. Giles, on the English Channel, their crests are distant from $30-45 \mathrm{~cm}$. at a depth of 20 meters, while their troughs are from 8-I0 $\mathrm{cm}$. below their crests, and contain heavier basaltic gravel. At greater depths their size diminishes. The greatest depth at which they were observed was 188 meters. (Hunt-1 +.)

In cross-section the oscillation ripple presents regular concavities divided by sharp ridges, and a faint central ridge in many cases. This type is distinguished from the mold of the current ripple chiefly by the asymmetry of the concavity of the latter, one side being shorter and steeper than the other in the mold of the current ripple. The central ridge when present is likewise a characteristic feature. A mold of the oscillation ripple would show 
gently rounded or convex ridges often with a groove on top, and separated by sharp depressions. This mold is distinguished from the normal current ripple mainly by its symmetry. In the desert, wind ripples of all dimensions and of great variety of form occur. They vary in width from $2 \mathrm{~cm}$. or less to a meter or more. Sometimes they are sharp angled, at others. round. They generally occur in long parallel series, often branching repeatedly, the branch running parallel to the main stem. (Walther-22:523 [ I79].) (Figs. 140, 142.)

The width and height of the ripple-mark are dependent on the size of the grain of sand and the strength of the wind. Uniform currents will produce an elongation of the ripple which always extends at right angles to the direction of the wind. (Hunt-14.) In many respects the arrangement of wind ripples and of sand

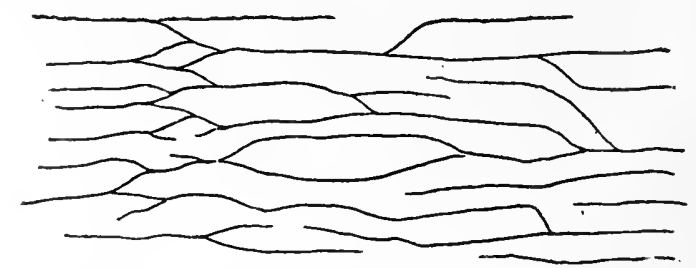

FIG. I42. Plan of Eolian ripple-marks in coarse desert sand. (After Walther.) (Compare with Fig. I40.)

dunes in deserts is very similar, the former being reduced replicas of the latter.

In the distribution of the material of the wind ripple, there appears also to be a distinctive character, in that the coarser material is found on the crest of the ripple, instead of in the trough, as in subaqueous ripples.

i i. Impressions of Animals and Plants in Transit. Animals walking or crawling over a surface of mud or sand commonly leave characteristic impressions. Plants rafted along by the wind or waves, and medusæ floating and dragging their tentacles, also make characteristic markings, though these are not always readily determinable. All such markings are depressions, and they will be reproduced in relief on the under side of the next overlying stratum. Occasionally the burrows of certain animals will be marked by elevations or knobs. These structures will be discussed in their biological relations in the chapter on fossils, and they are mentioned here only to complete the survey of minor original features of sediments. 
As to their occurrence, it may be repeated that footprints of terrestrial animals are best preserved in the clays of the desert playas, and the flood-plains of rivers, while those formed on the seashore are commonly obliterated again by the action of the returning tide and the waves. Tracks and burrows of worms, and trails of molluses and crustacea, on the other hand, point more generally to a seashore or the borders of interior tideless seas, or, again, more rarely to river flood-plains.

i2. Application of These Structures in Determining Position of Strata. The importance of discriminating between the original structure as here described and its reproduction in reverse, in the overlying stratum, will be appreciated when it is considered that strata often stand vertical, and are even overturned. The determination of the upper and lower surfaces of the strata may be the only means for recognizing the superposition of the strata of a region. In all cases, the surface on which the structure (ripple-mark, impression, etc.) was originally made is the upper surface of the stratum, while the surface having a reverse reproduction of the structure (raised footprint, mold of ripple-mark, etc.) is the lower surface of that stratum.

13. Rounding and Sorting of Sand Grains and Wearing of Perbles. This subject has already been discussed in previous sections, but may be briefly summarized here. Sand grains under o. I $\mathrm{mm}$. in diameter will not be rounded by wave action upon the coast, for they are held in suspension, and, moreover, capillarity provides the adjacent grains with a separating cushion of water which prevents mutual attrition. Larger grains may under favorable conditions be rounded by the waves. They are even better situated in this respect in river beds. The most efficient agent of all in the rounding of grains is the wind, as it it is also the most efficient sorting agent.

Pebbles are rounded largely by the action of ruming water and by waves. That the wind is able to do work in this direction is shown by the rounded pebbles of the Hamada or stony desert, where water activity is absent. It has been repeatedly asserted that there is a decided difference in form between pebbles of river bottoms and those of the shore. The former are said to be typically flat, from the fact that they are shoved along on the bottom of the stream, while the latter are rounded because they are rolled about by the waves. The reverse has also been held. Until more detailed observations on modern shores and river bottoms are made, no such general criterion can be accepted. As a matter of fact, flat pebbles abound on many shores where the material from which 
they are derived is a thin-bedded rock or tends to split into thin layers. Here the pebbles are shoved up the beach and dragged back, rolling being seldom seen. Pebbles formed from angular fragments, on the other hand, are rolled about on the beach. Thus it appears that the original form of the material is of more significance than the agent active in the rounding.

I4. Characteristics of Inclusions in Sand Grains. In tracing the source of the quartz grains in sands and sandstones Mackie (I7) has advocated the use of inclusions found in the quartz or their absence. He divides the inclusions into:

(I) Regular inclusions, of quartz, chlorite, muscovite, biotite, rutile, apatite, zircon, garnet, magnetite, titaniferous iron, etc. Characteristic of the quartz of schists.

(2) Acicular, or fine needle-like inclusions of doubtful mineral, capable of being subdivided according to arrangement of the needles. Characteristic of granites.

(3) Irregular inclusions, mostly fluid lacunæ with or without gas bubbles. Characteristic of granites, but more readily subject to disruption by changes in temperature or to crushing than the others, and, hence, diminishing in proportion with the age of the formation, and the repeated reworkings of the grains.

The absence of inclusions in quartz suggests vein quartz as the source, or the quartz of schists. After a determination of the inclusions in the quartz grains of the crystallines which might have furnished the sands of the Rothes Burn, and the determination of the percentage of feldspar, garnet, staurolite, mica, hornblende, chlorite and magnetite in the sands of this stream, together with the inclusions in the quartz grains, Mackie concludes that $23 \%$ of the sand was derived from granite, $57 \%$ from schist, and $20 \%$ from diorite. The matrix of the Lower Old Red conglomerate of Gollachy Mill was in like manner determined as derived $20 \%$ from granite, $77 \%$ from schist, and $3 \%$ from diorite and volcanics. In these analyses the feldspar was divided between the granite schist and diorite, the garnet, staurolite, mica, chlorite and the quartz with regular inclusions and without inclusions were referred to schists, while the hornblende and magnetite were referred to diorite. Analyses of the sand grains of successive members of both the lower and upper Old Red Sandstone showed that, during the process of erosion of the lands supplying the material of this formation in northern Scotland, different sand-supplying forma- 
tions were uncovered, the first or highest of which supplying material for'the oldest beds was non-granitic.

From the nature of the inclusions Berkey has been enabled. to determine that the quartz grains of the St. Peter sandstone were derived from the gneisses and granites of the Canadian Old Land, and that the Sylvania sands were most probably derived from the older St. Peter sands, with which they agree in all respects.

I5. Organic Remains. Abundant remains of marine organisms are generally a good criterion for the marine origin of the strata containing them. There are, however, important exceptions to this. Thus the foraminiferal limestones of India and South Africa are formed as eolian deposits upon dry land, and often at a distance from the shore, though the reniains themselves are all of marine types. Marine types may also be included in a terrestrial deposit as a result of derivation from older marine strata by weathering or erosion. Again shells of marine organisms may be carried inland by birds and other animals (including man) and become embedded in later deposits. Man-made shell heaps are generally recognizable by the presence in them of human implements as well as evidence of fire, but shells carried inland by birds are not readily recognizable as such. The occurrence of organisms of marine types in relict seas distant from the coast must be considered. This subject will be more fully discussed in a subsequent chapter.

Occasional intercalation of marine layers in delta formations otherwise of non-marine origin must also be noted here. Such intercalations have been used to prove the marine origin of an entire formation, the bulk of which is most probably of terrestrial origin.

Fresh water and terrestrial organisms when exclusively found in a formation indicate a continental origin. But such remains may be as characteristic of fluviatile as of lacustrine deposits and often more so. Thus the remains of land vertebrates and of plants in a formation indicate more commonly river, flood-plain, swamp, or, in the case of the vertebrates, steppe deposits, the remains being embedded in the river muds or covered by blown sands. Abundant remains of fresh water molluscs, Crustacea, etc., of Chara and other fresh water plants, indicate a lacustrine or paludal origin of the formation containing them.

Terrestrial organisms, especially plants, may also be carried out to sea and so become embedded in marine formations. The same thing is true of river-inhabiting fish, Crustacea, and Mollusca. The extent of such transportation is generally determinable, as shown 
by David White (24), by the degree of injury suffered by the perishable parts, such as bark, leaves, etc. Seeds and spores of river plants, such as the water ferns or rhizocarps. may also be carried out to sea and buried in normal marine sediments. Their occurrence, however, always suggests a river-borne origin for the mud in which they are found, as in the case of the Genesee and Portage muds of the Devonic in which occur the spore cases of the water fern Protosalvinia, mingled with marine organisms.

i6. Concretrons. Concretions are segregations of mineral matter which grow in size by addition externally, internally or interstitially. From the point of view of their origin and relationship to the enclosing rocks, two types may be distinguished:

those forming as contemporaneous accumulations, afterward buried by clastic or other strata, and (2) those forming within the strata after their deposition. This second group clearly belongs to the secondary structures of rocks.

Concretions of calcium carbonate, of barite, of manganese, and concretions composed of fragmental material cemented by phosphate of lime are among the first group, forming at the present time. The phosphate concretions are most characteristic of the shore zone, while the manganese concretions are common in the deep sea. The latter (Walther-23:70I) are most abundant in the Pacific between 767 and 8,183 meters, and in the Indian and Antarctic Oceans between 2,926 and 4,754 meters depth. In the Atlantic Ocean they are found between 767 and 5,21 I meters depth, chiefly in the neighborhood of volcanic islands.

These concretions commonly constitute the uppermost layer of the lithosphere in the deep sea, and they are gradually buried by the accumulation of fine muds. Not infrequently they constitute the foundation on which corals or other sedentary benthonic organisms gain a foothold, and such a concretion in moderately deep water may serve as the nucleus about which a coral reef is built up. Chemically formed oölites and pisolites should be mentioned under contemporaneous concretions. These have been fully discussed in a preceding chapter.

The secondarily formed concretions, or those growing within the strata, and therefore of later age, are represented by clay-stone concretions, so characteristic of shale and clay beds, and readily recognized as belonging to this secondary type by the fact that the stratification lines are seen to pass through them. Large examples of these are found in Devonic and later lutaceous deposits. They have not infrequently grown about fossils. Many of these also show the septarium structure as described below. The Lösspüppchen 
and "Lössmännchen," of the German loess, the "Narlekor" and "Näkkebröd" of similar Swedish deposits, the "Kankar" of India. and the clay iron stones of the British Carbonic shales are other examples of concretions of this type.

According to their method of growth concretions have been divided by Todd into four types (20):

I. Accretions.

2. Intercretions.

3. Excretions.

4. Incretions.

Accretions grow regularly and steadily from the center outward by successive additions of materials. This type of concre-

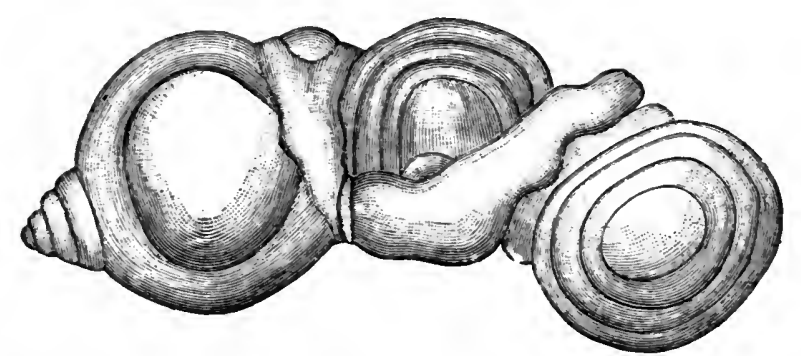

FIG. I43. Concretion (accretion) of clay stone, Connecticut Valley. (After Gratacap.)

tion will be solid from the center and if of subsequent growth will include or enmesh particles of the rock in which it forms without any considerable disturbance of it. The stratified structure may also be preserved in accretions, unless by crystallization a radiate structure is produced. Examples of this type are the remarkable concretions of the postglacial clays of the Connecticut Valley. (Sheldon-19.) (Fig. 143.)

The radial structure due to crystallization is well developed in the large spherical concretions of the Devonic black shales of Kettle Point, ${ }^{*}$ Ontario, and of Michigan. From their fibrous structure they are not infrequently mistaken for petrified wood. (Daly-5.)

Intercretions grow by accretion on the exterior and by interstitial addition, causing a circumferential expansion and resultant cracking and wedging apart of the interior of the concretion. The cracks widen toward the center and are commonly filled by mineral kettles.

* So named from the resemblance of partly exposed concretions to inverted 
matter, chiefly calcite, the accumulation of which helps to widen and extend these internal fissures. Concretions of this type are familiarly known as septaria, from the fact that when they have been worn on the surface the veins sometimes weather in relief, and thus produce a septate structure. Often, however, the veins are depressed. These concretions are sometimes thought to be petrified turtles, and in many localities are known by the name of "turtle stones." They are abundant in the Devonic shales of eastern North America and in the Cretacic beds of the interior, while the Jurassic of western Europe is famous for its remarkably beautiful examples.

Excretions are centripetal concretions "consolidation progressing inward from the exterior." (Dana-Manual, 4th ed.-98.) They are represented by nodular shells of sand cemented by iron oxide, and generally filled by more or less unconsolidated sand or contain other shells of cemented sand. Todd holds that normal accretions or intercretions of ferrous carbonate, on coming in contact with waters charged with carbon dioxide and oxygen, will begin to dissolve and a shell of ferric hydroxide will form on its surface by precipitation. The iron carbonate of the portion of the concretion within this shell will similarly be dissolved and reprecipitated as ferric hydratc, a second shell thus being added on the interior of the first. The impurities of sand or clay in the original concretion remain behind, in a loose condition. Thus while the actual thickening of the shell is on the inside, and the growth, therefore, from without inward, the molecular movement of the iron salts is from within outward, $i$. $e$., from the core of the original concretion to the inner wall of the shell. When the process is completed a loose mass of sand or other impurities alone remains behind, or, if the original concretion was free from impurities or nearly so, the resultant excretion may be hollow. Excretions formed within ferruginous sandstoncs are often the catse of puzzling hollow cavities.

Incretions. These are cylindrical concretions with a hollow core. Todd infers that these originate where the walls of a cavity, like the cylindrical tube left by a decayed root in the sand or clay, serve as the nucleus for deposition. The iron is drawn from the surrounding material and moves inward to the center, where it is added to the central cylinder, which grows in thickness outward by the addition of successive shells on the exterior, until the surrounding matrix is depleted.

Minute concretions of this type are common in the loess. They consist of carbonate of lime, and resemble clay pipe stems in size and form. 
i7. Secretions. Secretions are deposits formed on the walls of cavities in rocks, the first layer being the outcr one of the secretion. A constant supply of material may bring about the filling of the cavity, as in veins and agate geodes, while the cutting off of the supply results in the production of hollow geodes, lined with crystals.

All secretions are secondary rock structures, and they are mentioned in this chapter merely for convenience in comparison with concretions. Of the latter, incretions and excretions are secondary structures, and the same is true largely if not wholly of intercretions. Accretions are, however, extensively represented by contemporary concretions, though many kinds of true accretions are also formed secondarily in strata of various kinds.

\section{BIBLIOGRAPHY XVII.}

I. BARRELL, JOSEPH. I906. Relative Geologieal Importance of Continental, Littoral and Marine Sedimentation, Part III. Journal of Geology, Vol. XIV, pp. 524-568.

2. BERKEY, CHARLES P. I906. Paleogeography of Saint Peter Time. Geological Society of Ameriea, Bulletin, Vol. XVII, pp. 229-250.

3. BRANNER, JOHN C. 1901. Origin of Ripple Marks. Journal of Geology, Vol. IX, pp. 535-536.

4. CANDOLLE, CASIMIR DE. I883. Rides formús à la surface du sable déposé au fond de l'cau et autres phénomènes analogues. Arehives des Scienees Physiques et Naturelle, Genève. No. 3, Tome IX, pp. $241-278$.

5. DALY, REGINALD A. I900. The Calcareous Coneretions of Kettle Point, Lambton County, Ontario. Journal of Geology, Vol. VIII, pp. I35-150.

6. DARWIN, GEORGE H. 1883. On the Formation of Ripple Mark in Sand. Proceedings of the Royal Soeiety of London, Vol. XXXVI, pp. I 8-43.

7. FAIRCHILD, HERMAN L. 1901. Beach Structure in the Medina Sandstone. American Geologist, Vol. XXVIII, pp. 9-13, pls. II-IV.

8. FLEMING, J. A. 1902. Waves and Ripples in Water, Air and $\mathbb{E}$ ther. London.

9. FORCHHAMMER, G. I84I. Geognostisehe Studien am Meeresufer. Neues Jahrbueh für Mineralogie, etc., pp. I-38, t. III.

9a. FOREL, F. A. I883. Les Rides de Fond étudiús dans le lac Léman. Archives des Seiences Physiques et Naturelles, Genève, (3.) Tome X, pp. 39-72.

10. FRAAS, O. 1872. Heuglin's geologische Untersuchungen in Ost Spitzbergen. Petermanns geographisehe Mittheilungen, Bd. XVIII, pp. 275277.

I I. GILBERT, G. K. 1877. Report on t1. Geology of the Henry Mountains. United States Geographical and Geological Surveys of the Rocky Mountain Region. 
12. GILBERT, G. K. I899. Ripple Marks and Cross-bedding. Bulletin, of the Geological Society of America, Vol. X, pp. 135-139, pl. XIII 5 figs.

13. GRABAU, AMADEUS -W. 1907. Types of Cross-bedding and Their Stratigraphic Significance. Science, N. S., Vol. XXV, pp. 295-296.

I4. HUN'T, A. R. I 882. On the Formation of Ripple Mark. Proceedings of the Royal Society of London, Vol. XXXIV, pp. I-I8.

15. HUNTINGTON, ELLSWORTH. 1907. Some Characteristics of the Glacial Period in Non-Glaciated Regions. Geological Society of America, Bulletin, Vol. XVIII, pp. 35 I-388, 9 pls., I 6 figs.

16. JOHNSON, DOUGLAS W. I910. Beach Cusps. Geological Society of America Bulletin, Vol. XXI, pp. 599-624 (with review of previous literature on Beach Cusps).

I7. MACKIE, WILLIAM. I897. The Sands and Sandstohes of Eastern Moray. Edinburgh Geological Society Proceedings, Vol. VII, pp. I48172.

I 8. PERRY, NELSON W. I889. The Cincinnati Rocks. What was their Geological History? American Geologist, Vol. IV, pp. $326-336,2$ pls.

19. SHELDON, J. M. ARMS. I900. Concretions from the Champlain Clays of the Connecticut Valley. Boston, I900.

20. TODD, J. E. 1903. Concretions and Their Geological Effects. Bulletin of the Geological Society of America, Vol. XIV, pp. 353-360.

21. VAN HISE, CHARLES R. 1896. Principles of North American PreCambrian Geology. U. S. Geological Survey, I6th Annual Report, Pt. I, pp. $5^{8 I}-872$, pls. CVIII-CXVII.

22. WALTHER, JOHANNES. I89I. Die Denudation in der Wüste. Abhandlungen der königlich-kaiserlichen Gesellschaft der Wissenschaften. Mathematische-Physische Klasse, Bd. XVI, pp. 345-570 (I-225).

23. WALTHER, J. I 894. Die Auflagerungsflächen und die Entstehung der Schichtung, pp. 620-64I, and other chapters in Einleitung in die Geologie als Historische Wissenschaft, 3 Teil. Lithogenesis der Gegenwart.

24. WHITE, DAVID. I9I . Value of Floral Evidence in Marine Strata as Indicative of Nearness to Shores. Geological Society of America Bulletin, Vol. XXII, pp. $221-227$. 


\section{CHAPTER XVIII.}

\section{OVERLAP RELATIONS OF SEDIMENTARY FORMATIONS.}

Overlap, or the extension of one formation beyond the other, is a structural feature of the greatest significance in stratigrapliy. Two kinds of overlap may be recognized, the irregular and the regular or progressive. The irregular overlap of strata, resulting from sudden changes of physical conditions, is more of the nature of an accidental feature, and belongs rather to the general subject of unconformity of formations. While its recognition is of great importance in establishing the progress of events, it has not the stratigraphic significance of the other type.

\section{PROGRESSIVE OVERLAP.}

Under this term we include the regular overlapping of successive formations due either to a normal transgressive movement or to a regular regressive movement. According as we deal with marine or non-marine sediments we have (Graban-3): (A) The marine progressive or (B) the non-marine progressive overlaps. The former are the more varied in type and will be discussed first.

A. MARINE PROGRESSIVE OVERLAP. We may distinguish two types of marine progressive overlap: I. Normal transgressize overlap, due to a progressively encroaching sea ; and. 2. Regressive or retreatal overlap, due to a progressively retreating sea. Generally a regressive movement is both preceded and followed by a transgressive movement, so that as a result of this compound progressive overlap a complex type of structure comes into existence.

The progress of deposition of the clastic sediments on a normal shelving seashore is controlled by two factors: namely, the rate of supply of material, and the rate and direction of change in the relative position of sea-bottom and sea-level. According to the variation of one or both, sedimentation will vary. 
Three relations of land and sea may be recognized:

I. Subsiding land block or rising sea-level.

2. Stationary sea-level.

3. Rising land block or falling sea-level.

Each of these conditions is further complicated by variation in the rate of subsidence, or elevation, and the rate of supply of detrital material. In general, rising sea-level produces transgressive movements, except where the supply of detritus is excessive, when stationary or regressive movements are produced. Stationary and falling sea-level produce regressive movements.

\section{Rising Sea-Level or Positive Diastrophic Movement.}

A subsiding land block or rising sea-level may be either of local or of world-wide effect. Its cause may be diastrophic movements, or the gentle displacement of the water by the accumulation of sediment on the ocean floor. Such rising of the sea-level produces a continuous transgression of the sea upon the land, $i . e$., a landward migration of the shore-line. The rate of migration, other things being equal, varies inversely as the steepness of the slope of the coast. Thus a slight depression of a very gentle shore will cause a great transgression of the sea, while even a considerable depression of a steep or vertical coast may produce little or no transgression. In the following discussions, the slope of the land surface affected by the transgression will be considered as a gentle one, such as is produced by a period of prolonged erosion of an old land surface.

Wilson ( $9: 118$; Rutot-7) has tabulated the possible relationship between the rate of depression of the land (rise of the sea-level) and the rate of supply of detritus, as follows:

Rate of Depression

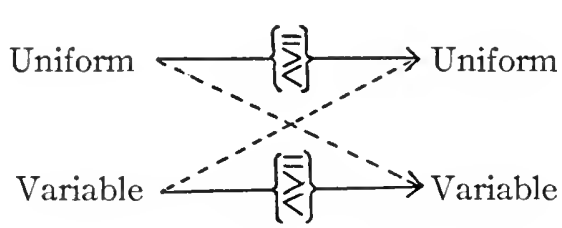

Rate of supply of detritus

The simplest conditions are those in which the rate of depression and the rate of supply are both uniform. These alone will be considered; the variable conditions of either one, or of both factors, will produce corresponding variations of the norm to an almost unlimited degree. 
With uniform rates of both subsidence and supply, three cases may be considered:

a. Rate of depression is equal to the rate of supply of detritus.

b. Rate of depression exceeds rate of supply.

c. Rate of depression is exceeded by rate of supply.

The first case would result in the production of relatively stationary conditions, if the shore-line were bounded by a vertical face, when a uniform regular amount of detritus equaling the amount of subsidence would produce a constant depth of water. With a shelving shore, on the other hand, a uniform regular transgressive movement would occur, with a regular and uniform change in the character of the deposit at any given point. The second case will produce a rapid transgressional movement with a less normal succession of formations, while the third will produce either stationary or retreating coast-line, coupled with an increasing amount of subaërial deposition.

\section{Transgressive Movements.}

a. Rate of Depression Equals Rate of Supply. Under these conditions a uniform and progressive overlapping of each later layer over all the preceding ones takes place. Each layer has a rudaceous or coarsely arenaceous texture at the shore, and grades seaward into finer arenaceous and ultimately lutaceous material. If the shore is composed of old crystalline rocks, the rudytes and arenytes resulting from their destruction will be largely siliceous, while the lutytes will be argillaceous and more or less micaceous. The coarse shoreward ends of the beds, when viewed in their ensemble, will appear as a single coarse bed resting upon the old land: From the consideration of its origin, however, it will be seen that no two portions of the bed along a line transverse to the seashore will be of the same age, each seaward portion will be younger than that lying next to it nearer the land. Thus the formation line, limiting the basal conglomerate or sandstone, will run diagonally upward through the planes of synchronous deposition. The basal bed is not generally a conglomerate, for where the sea transgresses upon an old land which has long been subject to subaërial disintegration a basal sandstone will be produced, since there is not coarse material enough to form pebbles. When decomposition has gone on for a long time prior to the transgression of the sea, and when the decomposed material is subjected to a 
thorough sorting by the encroaching waters, a nearly pure silicarenyte may come to rest directly upon the eroded surface of the crystalline old land. This is finely shown in the basal Palrozoic contact in portions of the Front Range of the Rocky Mountains, where a nearly pure quartz sandstone rests on an almost perfectly even erosion surface of granite. (Crosby-2.) Where atmospheric agencies have been sufficiently active to disintegrate a granite surface, without, however, reducing the feldspar to clay, the basal sandstone will be a feldspathic arenyte or arkose. Again examples are known where decomposition has affected the underlying crystalline old land to a considerable extent, but where little sorting of material was accomplished by the transgressing sea, so that the basal bed is a highly argillaceous arenyte. The contact of this with the underlying crystalline basement rock will in consequence not be a sharp one, the crystalline rock grading through a decomposed zone into the overlying sandstone. An example of this indefinite type of contact is seen on Presque Isle near Marquette, Michigan, where the Lake Superior sandstone passes downward into a rock produced by the consolidation of the undisturbed disintegrated surface of the basal peridotite.

A consideration of the progressive landward migration of the coarser deposits under uniform conditions will lead to the recognition that the changes in any given bed, from the shore seaward, will be exactly duplicated by the changes in a given vertical section from the base upward.* For it will be seen that the coarse bed deposited directly upon the old sea-floor of crystalline rock is succeeded upward by a somewhat finer bed, since the zone of deposition of the coarse material has, by the continuous subsidence, migrated further landward. Thus, as shown in the annexed figure (Fig. I44), the lowest coarse deposits of bed.(a) which form the shore zone of that bed are succeeded vertically by the finer deposits of. bed $(b)$ made at a somewhat greater distance from the new shore. At this new shore (of bed $b$ ) coarse deposits are accumulating, but they are beyond the belt of the former deposition of coarse material. Again an advance of the shore to $c$ transfers the shore belt of coarse (rudaceous) deposition in the same direction and by the same amount. Consequently the belt of arenaceous deposits of bed $c$ is likewise transferred shoreward and comes to

* The variation in texture of deposits due to storms and the corresponding change in the power of waves and currents discussed in a preceding chapter, are here left out of consideration, since they will at best produce only minor variations in the strata. The present discussion deals with formations on a large scale. 
rest on the belt of rudaceous deposits of bed $b$, just as the arenaceous deposits of that bed come to rest on the rudaceous deposits of bed $a$. In like manner the lutaceous deposits of bed $c$ come to rest on the arenaceous deposits of bed $b$, just as the lutaceous deposits of bed $b$ come to rest on the arenaceous belt of bed $a$. Two sections, then. made at I and II, will show precisely the same succession in coarseness and kind of material, from the botton up, the only difference being that in section II the lutaceous bed is much thicker than in section I. Erosion, however, may remove so much of the lutaccous beds of section II as to equalize the amount in the two sections. It would, of course, be incorrect to consicler each lithic unit in section $I$ to be of the same age as the corresponding lithic unit in section II, for, although there is a similar lithic succession, bed $a$, and the lower portion of bed $b$ are unrepresented in

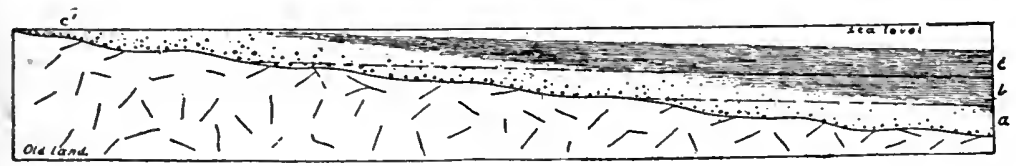

Section I.

Section II.

FIG. Iff. Diagram showing regular marine progressive overlap on an old land surface. A basal sandstone occurs everywhere, this grading upward and seaward into lutaceous deposits. At section I the series comprises beds $b$ and $c$ only, but at section II beds $a-c$ are present.

section I. In general, it is safe to assume that in a case of this kind, where continuous transgression on a uniformly shelving shore has taken place, the basal bed of the section farther up the old shore is of later age than the corresponding lithic bed of the section farther seaward. There are many cases where relationships of this type must be considered in the correlation of strata.

We have so far considered only siliceous detrital material derived from an old land composed of crystalline or other siliceous rocks. We must now consider, in addition to these, the organic rocks and their clastic derivations, which play so important a rôle in the sedimentary series accumulating on the sea bottom. As noted in an earlier chapter, purely biogenic stratified deposits are formed by the accumulation of the various organic oozes on the sea-floor, such as foraminiferal, radiolarian, diatomaceous or pteropodan. Where clastic sediments are accumulating very slowly. as at a distance from shore, these organic oozes may constitute an important part. if not most, of the sediment. In such cases, the ooze being a calcareous one, the clay and other lutaceous beds 
forming in quieter water will shade off into calcareous sediments, and may even be entirely replaced by limestones of this type. Where coral reefs or shell heaps are forming off shore, the clastic derivations of these will become commingled with, and shade off into, the terrigenous sediments near shore. As explained in Chapter $\mathrm{X}$, the coarsest fragments will remain near the reef, the calcarenytes coming next, and shading off into the finest calcilutytes. These calcilutytes may be gradually replaced shoreward by siliceous or argillaceous lutytes, or they or the calcarenytes may grade directly into the silicarenytes. Where this latter occurs, we have a seaward change from pure quartz sand (silicarenyte), through -calciferous sandstone (calcareous silicarenyte) and siliceous calcarenytes to pure calcarenytes. This change is probably more often observed in the Palæozoic series than the change from siliceous to argillaceous sediments. (Fig. I45.)

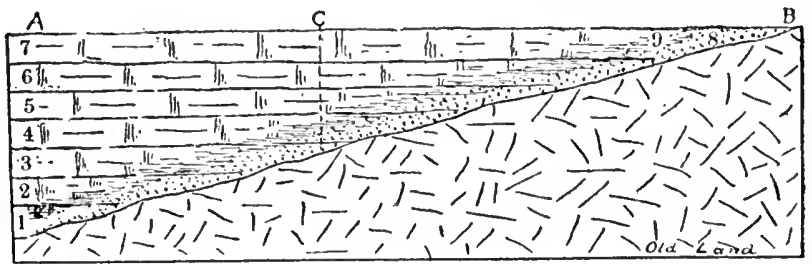

FIG. I45. Diagram showing regular marine progressive overlap; a basal sandstone is present, but this grades upward and seaward into calcareous deposits. The differences between sections $\mathrm{A}$ and $\mathrm{C}$ are readily seen.

Older examples. The type of overlap here described seems to have been by far the most general as recorded in both Palrozoic and Mesozoic deposits. An illustration is seen in the basal Ordovicic sandstone of Ontario, which on Lake Huron lies at the base of the Chazy series, but farther northeast is basal Trenton. The basal Cambric sandstone of Sweden also varies in age from Lower to Upper Cambric, though there is probably a series of unrecorded intervals during which retreat and erosion took place without the deposition of a basal sandstone by the readvancing sea. From the evidence of the dreikanter and other structural features it is known that this basal bed represents an old residual sandy covering of terrestrial origin, subsequently encroached upon by the sea. It is not improbable that wherever basal sandstones occur, extending upward through such a long series, as the entire Cambric in which there are, moreover, stratigraphic breaks, these sand- 
stones are older continental deposits slightly reworked by an advancing sea. This appears also to be the case in the Cambric of North America. The basal Cambric sandstones and conglomerates of the southern Appalachian region underlie the Olenellus-bearing shales and limestones, while those of the Oklahoma and Ozark regions underlie beds generally referred to the Middle Cambric. Finally, in the upper Mississippi Valley the St. Croix sandstone series actually contains in its upper portion the Cambro-Ordovicic transition fauna. In many cases this northern "Potsdam" sandstone shows evidence of continental origin in pre-marine time by the occurrence of well-marked torrential cross-bedding in parts which apparently have not been reworked. In the North American Cambric there are numerous distinct breaks; the magnitude of which is not yet fully ascertained, except that it is now generally recognized that above the Middle Cambric there is a hiatus corresponding to nearly the whole of the Upper Cambric of the Atlantic coast. These breaks are, as a rule, not marked by retreatal intercalated sandstones. Further examples of overlap involving large portions of a system are shown in the North American Palæozoic by the entire absence of the Lower Cambric at St. John, New Brunswick, where the basal marine clastics belong to the Middle Cambric, while only 30 miles northeastward, at Hanford Brook, the Lower Cambric (Etcheminian) has a thickness of $\mathrm{I}, 200$ feet. In Cape Breton this thickness measures several thousand feet. The well-known fact that the Cambric of Bohemia begins with the Paradoxides beds of Middle Cambric age, while Lower Cambric beds occur in western Europe, shows a pronounced eastward transgression of the Cambric sea in Europe with corresponding overlap of formations.

The basal Mesozoic sandstone of the Texas and Mexico regions furnishes another typical example of a rising basal bed in a transgressive series. In central Mexico this basal sandstone lies beneath Upper Jurassic limestones; on the Tropic of Cancer it has risen into the base of the Comanchic; on the Texas-Oklahoma line it has risen through the Lower Comanchic (Trinity) and lies at the base of the Fredericksburg or Middle Comanchic; and, finally, in central Kansas it has passed up to near the base of the Upper Comanchic or Washita series. There are, however, one pronounced (Paluxy) and several smaller sandstone members intercalated in the limestone series, and these mark either shoaling or an actual emergence of the sea-bottom.

In this case, as in the Cambric, the basal sands are most probably of continental origin reworked by the transgressing Coman- 
chic sea. These basal sands indicate by their purity a distant source and long transportation, and the time interval during the Triassic and early Jurassic periods was ample to make possible an extended accumulation of widespread river and eolian sands derived in large part from the crystallines of the Canadian and western uplands, added to no doubt by contributions from uncovered Palæozoic and older sediments. A striking case of change in lithic character with progress of transgression is seen in the Cretacic series of southeast England and in that of northeast Ircland and the west of Scotland (Mull and Morvern). (Fig. I46.) In both cases the series begins with basal conglomerates, followed by sands, clays, and

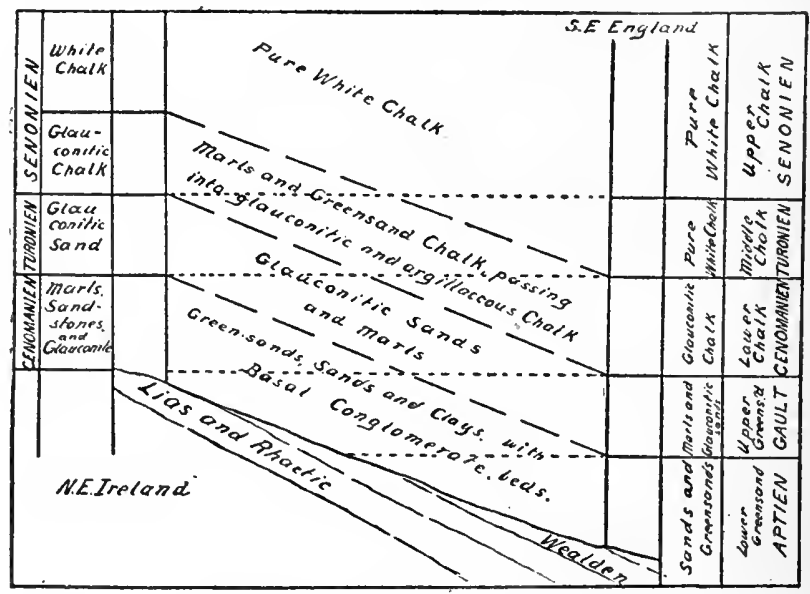

FIG. 146. Diagram showing overlap and change in lithic character of the Cretacic formations of England and Ireland, from southeast to northwest.

greensands. This is followed by (2) Glauconite sands and marls, then by (3) marls and Greensand chalk, passing into glauconitic and argillaceous chalk, and, finally, by (4) pure white chalk. In England the basal series (I) rests on the Weald clays, and is of Aptien age, while in Ireland it rests on Lias and is of Cenomanien age. In Scotland it also is of Cenomanien age. The next lithic series (No. 2) is of Albien (Gault) age in England, but of Turonien age in Ireland. The succeeding marls and Greensand chalk (No. 3) are of Cenomanien age in England, but of lower Senonien age in Ireland. Finally, the white chalk of England begins in the Turonien, but in Ireland and Scotland it occurs only in the upper Senonien. This illustrates not only the progressive overlap of the forma- 
tions, but also the progressive overlap of facies in the same direction.

b. Rate of Depression Exceeds Rate of Supply. Under these conditions there will be a rapid transgression of the sea, and the meager supply of detritus will be spread thinly over the sea-floor, or, if the depression is a rapid one, in many places deeper water deposits may accumulate upon the original old land surface. Such cases are known and are probably less infrequent than one is led to suppose from the scattered observations available in the literature. Wilson $(8: I \neq 8)$ cites the case of a calcareous conglomerate of Black River age, carrying angular quartz fragments, molds of a Cameroceras and fragments of crinoid stems, which rests directly upon the Archæan red granite near Kingston Mills, Ontario. From the basin of the Moose River, Devonic corals have been reported, with their bases attached to an Archean abyssolith. (Parks-6:188.) As under normal conditions of transgression, with an equivalent supply of detritus, the change in lithic character is a gradual one from coarse at the base to fine at the top, so, in any rapid or sudden transgression, we would expect to find an abrupt change from coarse material to fine, or from near-shore to off-shore deposits. Conversely, where we find a sudden change from coarse beds below to fine beds above, we may postulate a sudden relative change, either a sudden transgression or a sudden diminution in the supply of material. Sometimes a sudden transgression will transfer the shore zone, from which much of the detrital material is supplied, from one lithic formation to another, when the character of the -deposit will change. Thus an abrupt change of sea-level may transfer the shore from a broad outcropping belt of quartz sandstones to a parallel belt of limestones, the sandstones being covered by the encroaching sea. As a restult, the deposition of quartz sands may cease, and fine calcareous muds derived from the erosion of limestones may be deposited upon the coarse quartz sands without transition. Such a change appears to have taken place in eastern North America in late Siluric time, effecting a change from the Salina silicarenytes (Binnewater sandstones) to the fossiliferous limestones and water-limes (Rosendale cement) which overly them.

Where transgression takes place over an old peneplain surface, on which residual soil has accumulated during the long period of exposure, this ancient soil may be incorporated, without much change, as a basal bed. Where the soil is lutaceous, especially where it is a residual clay containing much carbonized vegetable material, as in the case of an old swamp-covered surface, a black carbonaceous mud will constitute the basal layer, which is suc- 
ceeded upward by other beds of fine-grained terrigenous material or by limestones derived from organic sources. Such a black basal shale may also result from the washing of the residual black soil from the surface of the plain into the shallow encroaching sea. In any case, the basal black shale will rise diagonally across the planes of synchroneity, and, although it will constitute a lithic unit, it is not a stratigraphic unit, but made up of the shale ends of a successive series of deeper water formations. This relationship is shown in the following diagram. (Fig. 147.) An example of this type of basal bed is found in the Eureka (Noël) black shale of the Mississippi Valley. This formation rests generally upon eroded Ordovicic strata, the contact being a disconformable one. Upward it passes into limestones, which in southwestern Missouri

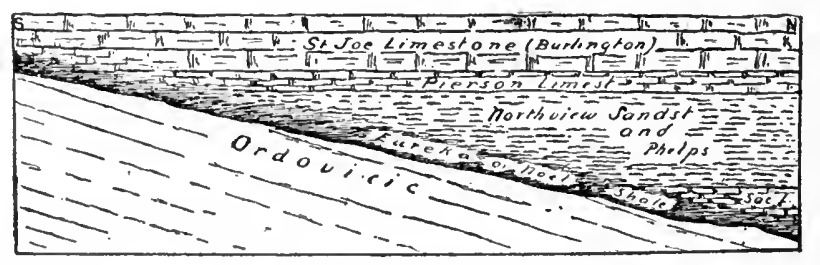

FIG. I 47. Diagram of overlap of marine strata on basal black shale in southwestern Missouri and northern Arkansas.

are of Chouteau age, the shale itself carrying Kinderhook fossils, while in northern Arkansas it is succeeded by limestone carrying Burlington fossils. The same relationship exists in the southern Appalachian region, where the black shale has risen into the base of the Keokuk, if not higher. (Grabau-3.)

\section{Regressive Movements.}

c. Rate of Depression Is Exceeded by Rate of Supply. In this case accumulation will go on so fast as to fill in the shallow shore zone, when the coarse material begins to extend seaward, progressively overlapping the off-shore deposits in a seaward direction. We will thus have a gradual change in the character of the sediment from the lutaceous material at the bottom to arenaceous and sometimes coarser terrigenous material. This material will all be land-derived, and, as it is depositcd rapidly, not a very thorough sorting can generally be expected. As the shore migrates seaward, subaërial deposits may accumulate above it. (Wilson-9: II9.) 
Local temporary increase in the rate of supply may be due to causes not readily determinable, but widespread and persistent changes must be regarded as indicative of climatic change. Before we accept such a climatic change, however, as the cause of a seaward migration of terrigenous deposits we must satisfy ourselves, if possible, that the migration in question is not. due to a change in the rate of subsidence, the climatic conditions and, therefore, the rate of supply of detritus remaining the same. For it is evident that a gradual diminution of the rate of subsidence would produce practically the same results as a corresponding increase in supply.

\section{Stationary Sea-Level.}

When the supply of detritus continues uniformly, while the sea-level remains stationary, a regression of the seashore will take place, but at a faster rate than would be the case if subsidence still continued, though at a diminished rate. The siore zone would creep out over the deeper water deposits, the transition from the one to the other being rather more abrupt than in the case of a slowly subsiding sea-floor. On the whole, however, stationary conditions produce a change of sediment differing in degree only from that incident upon a diminution in the rate of subsidence.

\section{Falling Sea-Level.}

The falling sea-level or rising land block is accompanied by a continuous regression of the seashore, and a consequent seaward migration of the shore zone with its attendant deposits. If the emergence is not too fast the waves will be able to remove much of the formerly deposited shore detritus and carry it seaward into the shoaling off-shore districts. Thus a bed of sand or conglomerate will advance seaward over the finer off-shore deposits, coming to rest upon these often without transition beds. Furthermore, the continuous movement of the clastic shore derivatives will tend, in the coarser material, to a perfect rounding off of the pebbles, and in general to a destruction of all but the most resistant materials. Thus a much washed-over sandstone or conglomerate may come to consist entirely of quartz, constituting a pure silicarenyte or silicirudyte. It is probably not saying too much that all pure quartz clastics, derived from a complex crystalline old land, and resting abruptly upon a clayey or calcareous off-shore deposit, 
represent the seaward spreading shore zone of a rising sea-floor, unless they are referable to continental deposits.

\section{Characteristics of Regressive Deposits.}

As the retreat of the sea from the land may under normal conditions be considered a process occupying a greater or less amount of time, it is evident that deposition at a distance from shore need not be interrupted. Thus, while within the zone of retreat for any given time period, no sedimentation will occur, such sedimentation may, nevertheless, go on at a regular rate beyond this zone. In other words, a certain thickness of off-shore deposits must be considered the depositional equivalent of a given time period, which in the shore zone is represented by a given amount of re-

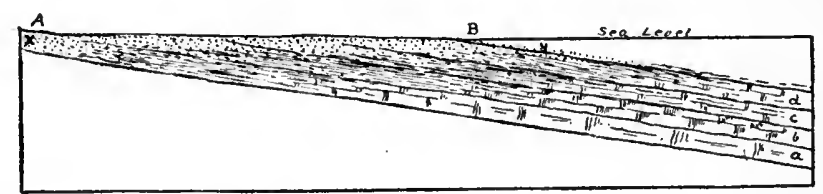

FIG. I 8 . Diagram illustrating regressive overlap (off-lap) and the formation of a sandstone of emergence $(x-v)$ into which the shoreends of the successive members of the retreatal series $(a-d)$ grade.

treat. Thus it is brought about that each successive formation of the retreatal series extends shoreward to a less extent than the preceding one. As each formation or bed passes shoreward into a coarser clastic it is evident that the shore ends of all the formations deposited during the retreat will together constitute a stratum of sandstone or conglomerate which in age rises seaward, since in that direction it is progressively composed of the ends of higher and higher formations. These relationships are shown in Fig. I48, where it will be noted that the diagonal rise of the shore-formed stratum is from the shore seaward, whereas in transgressive movements the shore-formed stratum or basal bed rises diagonally landward. In the series shown in the diagram, the beds $a-d$ were successively laid down during the retreat of the sea from $A$ to $B$. Each later formed bed comes to an end before it has reached the shoreward end of the preceding one, and each formation grades from a clayey or calcareous character landward into silicoarenaceous character. Thus $b$ reaches landward to a less extent than $a$, the shore end of which, composed of quartz sands, remains ex- 
posed. The shore end of $b$ is also composed of quartz sands, since during the formation of $b$ the shore has migrated seaward. In like manner $c$ does not entirely cover $b$, and $d$ does not wholly cover $c$, each ending in a sand facies. Thus the sand ends of all the beds will be exposed at or just above sea-level, and constitute a continuous sand formation, which, however, is not of the same age at any two points along a line transverse to the direction of the shore. Such a sand formation will, however, be mapped as a unit, and receive a formational name. If the basal portion of such a sand formation is fossiliferous, it will contain in a seaward direction the fossils of successively higher formations. Thus the portion of the sandstone formation $x, y$ in Fig. I 48 will at $x$ contain the fossils of formation $a$, and at $y$ the fossils of formation $d$, while between these points it will contain the fossils of $b$ and $c$, where it forms the end of these respective formations. When the land is sufficiently elevated during the retreat of the sea, stream erosion will set in and the material left by the retreating sea may be removed by the streams. Furthermore, if elevation of the land is responsible for the retreat of the sea, the streams coming from this higher land will bring more detritus, and hence, where erosion is not going on, deposition by rivers will further elevate the surface of the emerging coastal plain. The same thing is true also if the regressive movement is due to an increase in the supply of detrital material. In either case, pebbles and sands derived through the erosion of the old land or of old conglomerates and sandstones may be carried out for great distances over this emerging surface. while wind-assorted sands, with their grains rounded and pitted from attrition, may also accumulate over this surface. The peculiar structures of both torrential and colian sands, $i$. e., cross-bedding, ripples, etc., may thus be incorporated in this retreatal sandstone. Remains of land-plants and of land and fresh water animals may readily be entombed in the deposits thus accumulating upon the flat plain of retreat, and even coal beds may form and become embedded in sandstones the bases of which vary in age from place to place.

\section{Burial of Retreatal Sandstones by Subsequent Transgressive Movements.}

When the regressive movement of the shore has come to an end, and transgressive changes recommence, the upper partions of these migratory shore deposits may be worked over once more, and now partake of the character of a basal sandstone or conglomerate. 
As the shore zone advances landward, finer deposits will be laid down over the coarser basal bed and thus the transgressive portion of such a sandstone or conglomerate will pass diagonally across the planes of synchroneity. The deposit resulting by the time the shore zone has returned to its former position will therefore be a composite formation including within it a hiatus, which may represent a considerable time interval, but is not recognizable by any structural character. The encroaching sea will work over the sand dune deposits and thus water-laid sandstone beds, composed of rounded translucent quartz grains and well stratified, will result. In the upper part of these worked-over sandstones marine shells and other remains may be included, the age of which changes shoreward, since the transgressive portion of this sandstone represents successively the ends of higher and higher formations, after the manner of a true basal sandstone of a transgressive series.

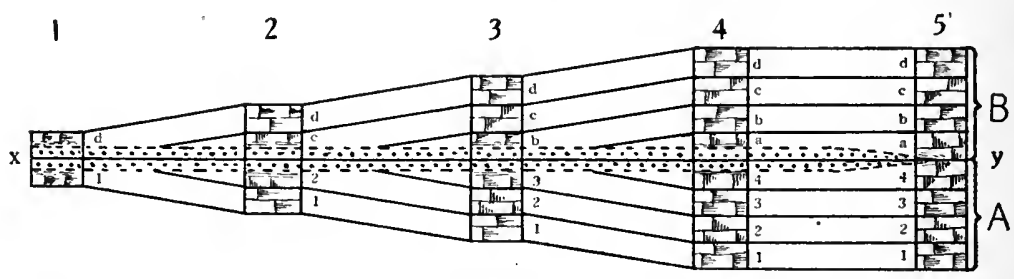

FIg. I49. Diagram showing the relationship of the strata in five successive sections, in a compound regressive-transgressive series. The intercalated sandstone $\mathrm{x} y$ encloses the hiatus. (See Fig. 150.)

The recognition of an intercalated shore formation of great areal extent between off-shore sediments as the product of combined regressive and transgressive movement must be based on a comparison of sections taken at intervals over the entire area covered by the formation in question. Such sections will show the intercalated shore formation (sandstone or conglomerate) to be in more or less intimate association with the lower beds of the underlying formation and the higher beds of the overlying formation at their shoreward ends, but, away from the shore, higher members of the lower formation and lower members of the higher formation will progressively appear until near the line of farthest retreat both lower and upper formation will be complete, while beyond that the intercalated bed will gradually lose its shore character and merge with the enclosing formations. This character of the sections is shown in the preceding diagram (Fig. I49). Formation A, consisting of divisions $I$ to 4 , and formation $\mathrm{B}$, consisting of 
divisions $a$ to $d$, are both complete in section 5, which marks the farthest limit of retreat of the sea. Bed $x$, the intercalated shore formation, fades away in this section. In section 4 all the members of both formations are represented, but divisions $f$ and $a$ are not complete, while the intercalated bed $x$ is prominent. In section 3 , divisions 4 and $a$ are wanting. and in section 2, divisions 3 and $b$ are likewise wanting. In section I, finally, all except the lowest division $(I)$ of formation $\mathrm{A}$, and the highest $(d)$ of formation $\mathrm{B}$, are missing. It would be obviously wrong to correlate division $l$ of section I with the whole of formation $A$ as exposed in section 5, or division $d$ of section $\mathrm{I}$ witl the whole of formation $\mathrm{B}$ of section 5 . Yet such correlations have not infrequently been made in the past. In each of the above sections the intercalated sandstone or conglomerate may be intimately related to both overlying and underlying formations, and contain their fossils. Such a relation would

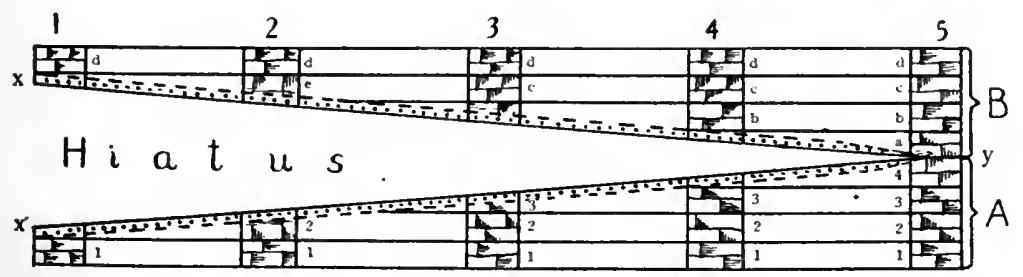

FIG. I50. Diagram of a compound regressive-transgressive series, showing the seaward decrease of the hiatus between the upper and lower part of the series. (See Fig. I49.)

show that the actual hiatus is represented by the middle part of the intercalated bed, which middle part may not infrequently be represented by continental deposits. Yet so intimate are the physical relationships between the bottom, middle and top of the intercalated formation that a separation into more than one formation is impossible. Thus in section I the intercalated formation $x$ may have all the characters of a formational unit or a single stratum, and may grade upward into division $d$ and downward into division $I$, so that to all appearance continuous deposition obtained in this locality. If the respective ages of divisions $d$ and $I$ are recognized, formation $x$ will be likely to be considered the depositional equivalent of divisions 2 to 4 and $a$ to $c$ of section 5. Such is indeed the fact, except that the central portion of $x$, the terrestrial portion, whether represented by continental deposits or an unrecognizable erosion plane, represents all but the upper fraction of division $c$, and the lower of division 2. The hiatus or stratigraphic break thus represented in 
the middle portion of the intercalated formation is a constantly decreasing one from section I to section 5. In each section it covers the interval of time between the emergence of the sea bottom at that point during the regressive movement and its resubmergence during the succeeding transgressive movement. This relationship may be expressed in the preceding diagram. (Fig. I5O.) The following diagrammatic sections (Fig. I5I) show the relation of a series of strata recording a transgressive movement followed by a regressive and again by a transgressive movement. $x-z$ is the basal sandstone bed of the transgressive series, $x$ - $y$ the intercalated sandstone of the

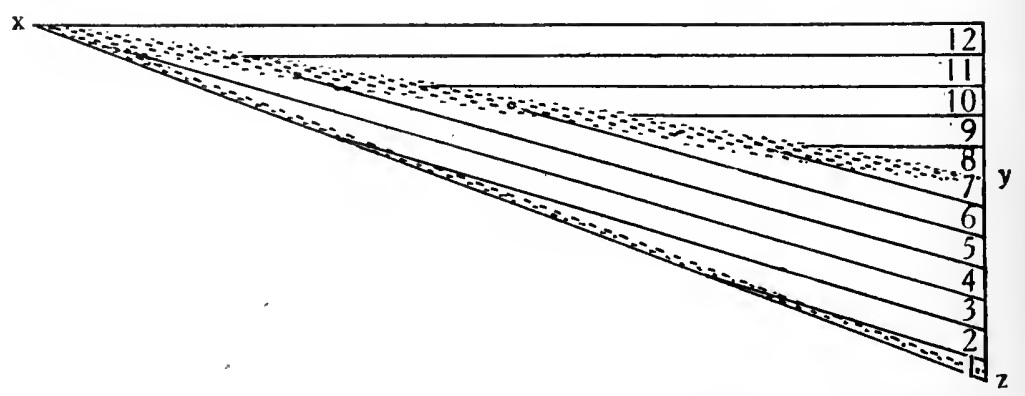

Fig. I5I. Diagram showing the relationships of the strata in a transgressiveregressive-transgressive series. Basal sandstone $x \approx$ and intercalated sandstone $x y$ are both present.

regressive-transgressive series. Beds $I$ to 3 are the first series of transgressive formations, beds 4 to 7 the regressive formations, and beds 8 to $i 2$ the second series of transgressive formations.

Examples of Intercalated Sandstones from the Palmozoic and Mesozoic Formations of North America.

The Saint Peter Sandstone. This is an exceedingly pure quartz sandstone of rounded, well-worn and pitted grains of nearly uniform size in any given region. It is widely distributed in central North America, lying generally between a member of the Chazyan and one of the Beekmantownian formations of the Ordovicic. In Minnesota it lies beneath the upper beds of the Stones River (Upper Chazyan), grading upward into and containing some of its characteristic fossils in the upper layers. Its base rests upon lower Beekmantown (Shakopee), into which it also grades in many sections, though in others it forms a sharp contact or even rests on an 
erosion plane of the dolomite. Where conformable it may contain lower Beekmantown fossils. Sometimes the lower beds are slightly disturbed, while the upper ones do not partake of such disturbance. This indicates an interval of time after the deposition of the lower beds, during which they were disturbed, and after which the higher strata were deposited upon them. Southward, higher members of the Beekmantown series come in beneath the Saint Peter sandstone and lower members of the Chazyan above it. In the Arbuckle Mountains the upper bed (here known as the Simpson formation) is about 2.000 feet thick, while the Beekmantown below the Saint Peter is of similar thickness. This sandstone thus has all the characteristics of a regressive-transgressive sandstone intercalated between limestones, and may be regarded as a typical example. (Grabau1-3; 4.) (Fig. I 52.)

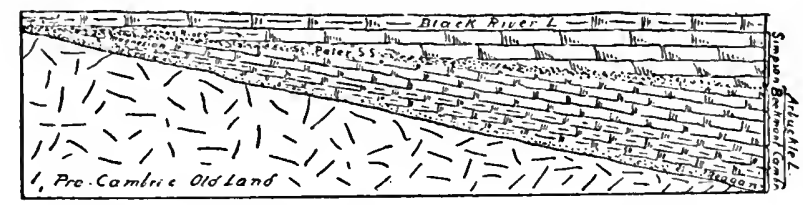

FIG. 152. Diagram representing the Cambric, Lower Ordovicic (Beekmantown), and Middle Ordovicic (Chazyan) formations, and the compound transgressive-regressive-transgressive overlaps betwcen Oklahoma and Minnesota. The intercalated sandstone is the Saint Peter.

The Dakota Sandstone. This sandstone of Mid-Cretacic age has essentially the same relation to the enclosing calcareous strata as has the Saint Peter. It contains, besides, an abundant flora of terrestrial plants, so that its value as a record of complete emergence becomes even greater. In southern Kansas this sandstone lies at the top of the Fredericksburg division of the Comanchic, while in Texas it lies on top of the Washita or Upper Comanchic. In either case there is commonly a gradation from the limestones and shales to the sandstones. The top of this sandstone passes upward into the marine Eagle Ford formation in Texas, while further north, in Colorado and the Dakotas, it grades into the much later Benton beds.

B. NONMARINE PROGRESSIVE OVERLAP. This term is applied to the large structure normally produced during the formation of a great fan or subaërial delta, from the wash carried by the streams from the mountains and deposited upon the plains adjoining. Such a subaërial fan will of course grow in extent year 
by year, and in so growing the latest deposits, whether derived from the mountain or whether obtained through the reworking of the previously deposited portion, will as a rule extend further out into the plain than did those of previous periods of deposition. In other words, each later formation will overlap the previous ones by a margin commensurate with the increase in the size of the fan, and beyond the margin of the previously formed bed it will come to rest directly upon the floor of the plain. This overlapping of later formed over earlier ones will of course be a progressive one if the growth is continuous. The essential point of difference between this type of overlap and that formed in a transgressing sea is that in the subaërial fan the formations will primarily overlap one another azvay from the source of supply of the material, while in the marine progressive overlap the overlap is toward the source of supply of the material. The following diagrams will illustrate this differ-

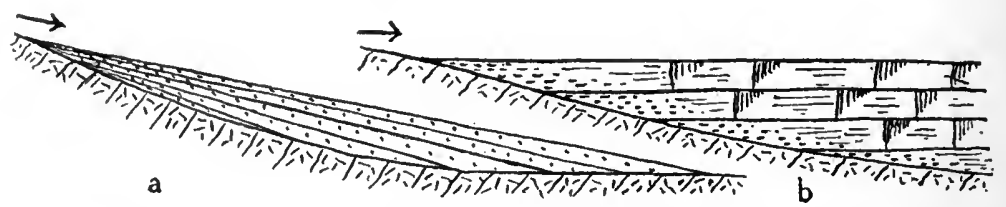

FIG. I53. Diagrams illustrating the relationship of the strata in nonmarine progressive overlap (a) and marine progressive overlap $(b)$. The source of the material in each case is on the left.

ence, the source of supply in each case being on the left. (Figs. I 53, $a, b$.) It should, however, be noted here (Barrell-I) that at the head of the delta an overlap toward the source of supply may occur, since with the aggradation of the delta plain and the consequent lowering of the river grade deposition may commence farther upstream. Such effects are seen in interior basins, where the upper beds extend farther toward the mountains from which the material has been derived. It appears to be shown also in the case of the Newark formation, where the upper beds extend farther north, overlapping the lower ones. (Kümmel-5:48.) It may, however, be questioned whether headward overlapping of the formations is ever of marked character, since it is necessarily confined to the stream channels supplying the detritus and probably does not spread greatly in a lateral direction. In any case it cannot be compared in extent and importance with the overlap on the margin of the fan, which is always away from the source of supply.

The coarsest material of the subaërial fan will of course be deposited near the head of the delta. Finer material may be carried 
out for hundreds of miles across such a delta, as is abundantly shown by the delta plains of the Indus and Ganges and of the Huang-ho River. Occasionally pebbles well rounded may be carried out to great distances, and this is especially true of the wellrounded pebbles derived from older conglomerates. When the surface of the delta has become very flat, drainage obstructions may take place, in which case swamps and the deposit of carbonized plant remains will form. Thus a fossil delta of this type ma include coal seams, the tops of which may again be eroded, or covered with a moderately coarse river deposit.

An essential feature of this type of overlap in purely nommarine sediments is the relation which the beds have to the surface on which the overlapping edges rest. If this is an old land surface,

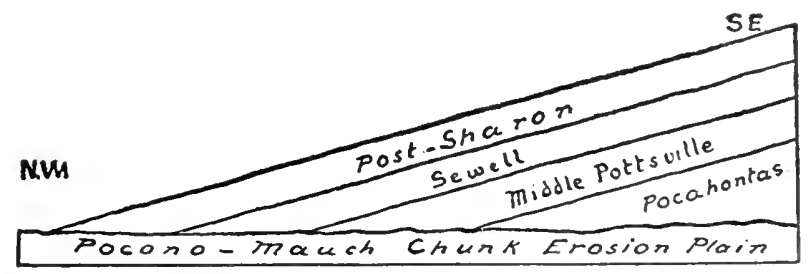

FIG. 154. Diagram showing the westward overlap of the various members of the Pottsville series of eastern North America, upon the old erosion surface of pre-Pottsville age; the surface of supply is in the southeast.

$i$. e., without contemporaneous sediments of a marine origin, the evidence of the nonmarine. origin of this overlapping series is complete. For it is manifestly inconceivable that clastic sediment will be carried across a body of water and be deposited upon the opposite shore in such a relationship as to suggest marine transgressive overlap.

The Pottsille Series, a Trifal Eximple of Nonuarine Progressi'e Orerlal. (Fig. 15 5 .).

This is a deposit of quartzose clastics, consisting for the most part of rounded quartz pebbles embedded in a matrix of sand. In the eastern area the conglomerate is coarsest, time pebbles often reaching a diameter of several inches. They consist also of a greater variety of material, but westward, where the pebbles are smaller, scarcely any but those of quartz remain. Several distinct coal beds with associated shales occur, making identification of 
horizons possible. The formation is thickest in the eastern Appalachians and thins away westward by failure of the lower beds and overlap of the higher. The lowest beds are found in two localities in the eastern area, near Pottsville, Pennsylvania, and in the Pocahontas region of West Virginia and Virginia. From these two centers the deposits spread northward, westwàrd and southwestward, each later division overlapping the preceding ones, until in western

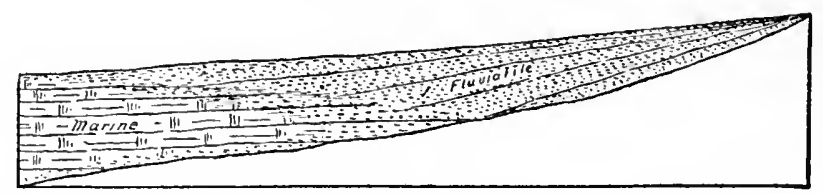

FIG. I55. Diagram showing replacing overlap of a nonmarine series over a marine one.

Pennsylvania and Ohio only the highest members of the series are present. Since the source of these beds can only be in the eastern Appalachians, where alone rocks capable of furnishing such material exist, the overlap becomes one away from the source of supply. Such an overlap might perhaps be produced under water if the overlapping marine sediments belonged to a spreading submarine delta. In this case the beds would become increasingly finer around the periphery of the submerged delta, and they would merge

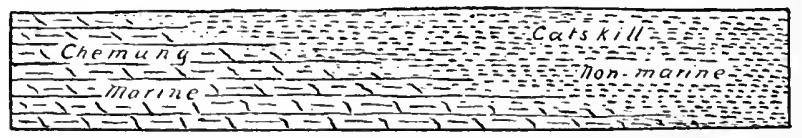

FIG. I56. Diagram showing the relationship of the nonmarine Catskill and the marine Chemung in eastern North America. A Devonic example of replacing overlap.

into deposits of purely marine origin. Nor would the delta be of a size comparable to that of the Pottsville, which by its character, its coal beds and its overlap relations is shown to be of subaerial origin. There are to be sure one or more reported horizons of marine faunas, a brachiopod fauna having been found in the middle Pottsville (Horsepen) as far north as Sewell, on New River. If these organisms really indicate marine conditions and not secondary inclusions, this can only mean a momentary invasion of the delta area from a neighboring arm of the sea. Naiadites and "Spirorbis" have been found in the Lower Lykens division of the anthracite 
region of Pennsylvania, but these organisms do not necessarily indicate marine conditions.

c. REPLACING OVERLAP. This type of overlap occurs when a series of clastic sediments of terrestrial origin replaces a typical oceanic or thalassic series, or where continental clastics re-

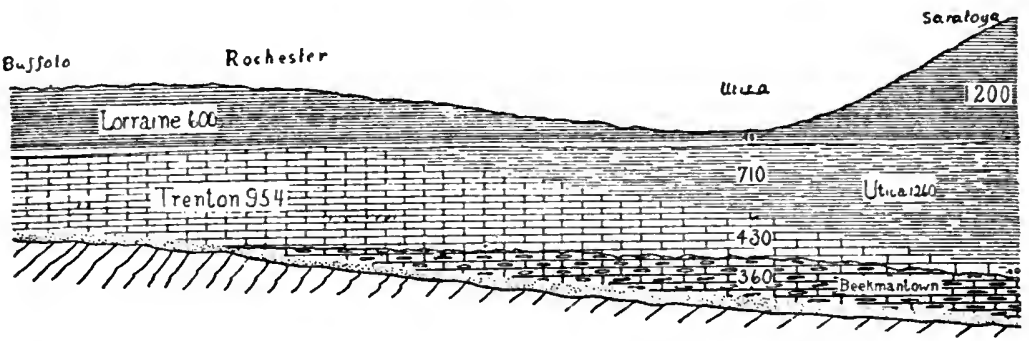

FIG. 157. Diagram showing the westward replacing overlap of the Utica shale on the Trenton limestone, both being marine formations, but one (the Utica) terrigenous and the other thalassigenous.

place those formed in the sea (Fig. 155). The latter is associated only with a retreating seashore, and the overlapping of the nommarine beds does not take place on the old land surface, but upon previously deposited and all but contemporaneous marine beds. Along the border line the two will blend, and it will appear as if the non-

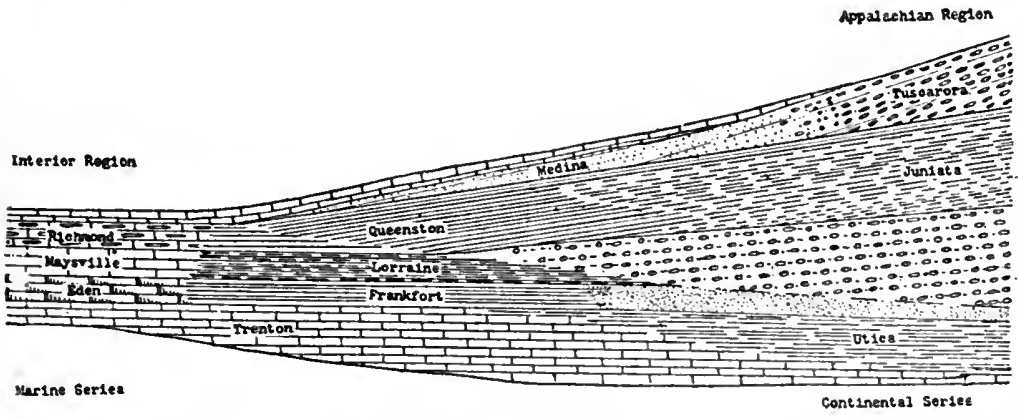

FIG. 158. Diagram showing replacing overlap of terrigenous marine, followed by continental sediments on the east over marine limestones, etc., on the west.

marine series overlay the marine series, though in reality it is a case of replacement of the one by the other. A typical example of such a progressive replacement is seen in the Catskill sandstone. which as a nonmarine formation spread westward from its centers of origin, of which it appears there were at least two. The correspond- 
ing marine beds are the Chemung sandstones and shales, which may be regarded as the submerged continuations of the Catskill beds. Oscillatory conditions are indicated by occasional intercalations of the marine between the nonmarine layers. In the eastern area the series is represented wholly by the nonmarine Catskill; in the western it is represented wholly by the marine Chemung. Between these extremes marine Chenung is always overlain by nonmarine Catskill. These relationships are shown in the diagram on page 742. (Fig. 156.)

This type of overlap, though away from the source of supply, is not, however, limited to nonmarine deposits. It may likewise be shown by a spreading clastic shore deposit, which gradually replaces a limestone of neritic origin without actual emergence of the zone of shore deposits occurring. Or a current-borne type of terrigenous sediment may progressively replace a limestone of neritic origin. Examples of such replacement are found in the changing facies of the Trenton limestones, which (Grabau-4) are gradually replaced westward by the spreading Utica* type of deposit, which is of near-shore and probably shallow-water origin. This is illustrated in the diagram on page 743 (Fig. I57). A combination of this type and the replacing by sediments of continental origin is shown in Figure 158 on page 743 , involving the Upper Ordovicic and Lower Siluric deposits of eastern North America.

\section{BIBLIOGRAPHY XVIII.}

1. BARRELL, JOSEPH. 1912. Criteria for the Recognition of Ancient Delta Deposits. Geological Society of America Bulletin, Vol. XXIII, pp. $377-446$.

2. CROSBY, WILLIAM O. I899. Archæan-Cambrian Contact near Manitou, Colorado. Bulletin of the Geological Society of America, Vol. X, pp. I4I-I 64 .

3. GRABAU, AMADEUS W. 1906. Types of Sedimentary Overlap. Bulletin of the Geological Society of America, Vol. XVII, pp. 567-636.

4. GRABAU, A. W. I9 Io. Physical and Faunal Evolution of North America During Ordovicic, Siluric and Early Devonic Time. In "Outlines of Geological History," etc., Chapter IV.

5. KUMMEL, HENRY B. I 898 . Annual Report of the State Geologist of New Jersey for I898. New Jersey Geological Survey.

6. PARKS, WILLIAM ARTHUR. 1899. The Nipissing-Algoma Boundary (Ontario). Ontario Bureau of Mines, Vol. VIII, pp. I75-196.

* Using this term in its broader sense, in which it is practically equivalent to the whole of the Trenton. 
7. RUTOT, A. 1883. Les Phenoménès de la Sédimentation Marine. Étudies dans leur Rapports avec la Stratigraphie regionale. Bulletin du Musée Royal d'histoire naturelle de Belgique, Tome II, pp. 4 I-83.

8. WILSON, A. W. G. I9oI. Physical Geology of Central Ontario, Canadian Institute Transactions, Vol. VII, pp. 139-I86.

9. WILSON, A. W. G. I I903. The Theory of the Formation of Sedimentary Deposits. Canadian Record of Science, Vol. IX, pp. II 2-I 32. 


\section{CHAPTER XIX.}

\section{METAMORPHISM OF ROCKS.}

General Definitions. The term metamorphism, from the Greek $\mu \epsilon \tau a ́$, interchange, and $\mu о \rho \phi \eta^{\prime}$ form (+ ism), has been applied to the process of alteration of rock masses in any manner whatsoever. The product of such metamorphism is metamorphic rock, often an entirely new substance so far as form and other physical characters are concerned. It is true that the term is seldom used in the comprehensive sense, metamorphism being generally considered as brought about by the agencies of heat and pressure, due to contact with heated bodies, or from being subject to dynamic disturbances. There can be no question, however, that these are only special phases of metamorphism, and that they cannot be separated genetically from the more quiet processes of alteration to which rocks are subject under ordinary physical conditions. As such, the weathering of rocks must be included. Metamorphism may bring about a change in one or more of the following characters: composition, texture, structure. The change in composition may be chemical alteration or mineralogical change, new minerals appearing in a rock as a result of metamorphism, and old minerals may disappear. Texture may be changed completely, as from compact limestone to crystalline marble, or special textures, characteristic of metamorphic rocks, may be produced, such as cataclastic, parallel orientation, etc. Original structures, such as flow structure, stratification, etc., may be obliterated and new ones produced, such as cleavage, fissility, joints, slatiness, schistosity and gneissosity (Van Hise-34).

The Forces Producing Metamorphism. The forces at work in the production of metamorphism are given by Van Hise $(34: 45)$ as: 1, chemical energy; 2, gravity; 3 , heat and light; while the agents through which these work upon the rocks are: (a) gases, (b) liquids, and (c) organic compounds. Organic compounds are mainly active in the surface belt where weathering of rocks takes 
place, but gaseous and liquid solutions * are agents everywhere present and active, within the known crust of the earth.

The Regions of Metamorphism. The regions where metamorphism of various kinds takes place are classified by Van Hise (34:43), according to depth, as follows:

I. The zone of katamorphism, or that zone in which simple compounds are produced from more complex ones, comprising (a) the belt of weathering, extending from the surface to the level of ground water, and (b) the belt of cementation, extending from the ground-water level to the next zone.

II. The zone of anamorphism, or that zone in which complex compounds are produced from simple ones.

Characteristics of the Zones of Metamorphism. The belt of weathering is the region of rock destruction; the belt of cementation is the region of rock construction and the zone of anamorphism the region of rock reconstruction. The zone of katamorphism is also the zone of fracture of rocks, where openings may exist. Van Hise has calculated that the maximum depth of this zone cannot be greater than I2,000 meters, and in most cases is probably much less. The zone of anamorphism also corresponds to the zone of rock flowage. where the pressure is greater than the strength of the rocks, and deformation will take place without fracture, but with rock flowage, which will not permit the existence of empty pore spaces.

Recent experiments on rock flowage made by Professors F. D. Adams (2) and L. V. King (2I) at McGill University. Montreal, have shown that cavities can exist at much greater depths than I0,000 meters. They placed cylinders of granite, with holes bored through them, in a testing machine, and subjected them for seventy hours to a pressure of 96,000 pounds per square inch at a temperature of $55^{\circ} \mathrm{C}$. After the experiment it was found that the hole was unchanged. The pressure obtained corresponded to that occurring at a depth of about ${ }_{5} 5$ miles, but the temperature was that estimated to prevail in the earth's crust at a depth of quly eleven miles.

* Solutions have been defined as "homogeneous mixtures which cannot be separated into their constituent parts by mechanical means" (Ostwald). They may consist of gases mingled with other gases, with liquids or with solids, of liquids mingled with liquids or with solids, and of solids mingled with solids. "The solutions resulting from these various combinations may be gases, liquids, or solids or partly two or all." (Van Hise-34:59). The gases important in rock alteration are oxygen $\left(\mathrm{O}_{2}\right)$ sulphur $\left(\mathrm{S}_{8}\right.$ to $\left.\mathrm{S}_{2}\right)$ water vapor $\left(\mathrm{H}_{2} \mathrm{O}\right)$, ammonia $\left(\mathrm{NH}_{3}\right)$, carbon dioxide $\left(\mathrm{CO}_{2}\right)$, sulphurous oxide $\left(\mathrm{SO}_{2}\right)$, boric acid $\left(\mathrm{H}_{3} \mathrm{BO}_{3}\right)$, hydrochloric acid $(\mathrm{HCl})$ and hydrofluoric acid $(\mathrm{HF})$. The liquid solutions are all water solutions. 


\section{Kinds of Metamorphism.}

Metamornhism is always a complex problem, but according to the dominant forces three distinct types have generally been recognized, viz., static, contactic (contagic), and dynamic. Static metamorphism is that process of alteration which goes on without the interference from zuithout of forces producing deformation, or the invasion of heat from contact with a molten mass. It is essentially an endogenetic process, being concerned only with those forces universally active within the mass. These include chemical energy, gravitative rearrangement within the rock mass and the pressure due to its own mass, as well as the pressure resulting from the crystallization of the mass. Further, the influence of heat caused by these changes within the mass-but not invading heat (or cold) from without-and the influence of the omnipresent water and gases within the rock mass. This complex activity is essentially metasomatic and includes in reality two quite distinct processes: the destruction of rock masses by the atmosphere and water and the construction and reconstruction of rocks by the processes going on within the mass.

The process of weathering has been dealt with at length in earlier chapters; there remain for present consideration only the constructive and reconstructive processes of metamorphism. To the static phases of these processes of alteration the name diagenesis has been applied by Johannes Walther, the name itself having been used first by Gümbel in I868 in his "Geognostische Beschreibung des ostbayerischen Grenzgebirges" for the more general processes of metamorphism. Andrée has proposed to restrict the term to those molecular and chemical transformations which the sediment undergoes under the influence of the medium in which it was deposited, and to which it is still subject after separation from this medium, through the ordinary circulating or vadose waters, in so far as these do not contain any foreign substances in solution, $i$. $e$., such substances as are derived from outside of the sediment. He would include as chief of these changes: recrystallization, formation of concretions, lithification and desalinification. In so far as this restriction excludes changes due to percolating thermal waters or waters bearing mineral solutions, changes which may affect locally parts of various rock formations, this restriction seems warranted. Such changes are to be classed under the heading of contact metamorphism and are to be placesd either with thermic metamorphism or are to be considered separately as hydrometamorphism. The 
name contact metamorphism is applied here to the reconstruction of rocks due to contact with (I) heated masses such as igneous bosses. dikes, sills, etc. (thermic metamorphism or pyrometamorphism) ; (2) mineralizing waters, or the alteration produced in the rock walls by the rising of heated or acidulated waters through fissures (hydrometamorphism). Since such fissures are generally closed shortly after by the formation of veins, no pronounced or extended alteration is produced in the wall rock. Finally, (3) vapors bearing or acting as mineralizers in passing through rock masses also produce profound local changes which would come under the same general heading of contact metamorphism (atmonetamorphism). If the rock undergoes any change in character, when in contact with a glacier or ice cover, this too is to be classed as thermometamorphism, while contact with a heated meteoric body would also belong here. In all cases this is, therefore, to be regarded as a contact metamorphism. Grabau (16) has suggested for this process the name athoballism, from aibos, fire, and $\beta a ́ d \lambda \omega$, to strike, which though emphasizing the heat element may, nevertheless, be expanded to cover all contact cases. Rocks altered in this manner would be designated æthoballic rocks. The essential of such changes is that they are local.

Dynamic metamorphism is a term restricted to the reconstruction processes initiated by tectonic movements, such as faulting, thrusting, gliding or folding of rocks. Since it generally affects extensive regions, it is also called regional metamorphism, as contrasted with the local contact metamorphism. The essential causes here are the pressure due to the tectonic movements, and the motion accompanying them, the result being a crushing, shearing and rearrangement of the component particles of rock, and often a recrystallization. A secondary factor is the heat developed during this movement. The alterations due to impact with meteoric bodies, whether hot or cold, must also be classed here, and it is not improbable that in the past they have played a considerable rôle. Finally, it must be consiclered whether the normal changes supposed to go on in the zone of flowage, under the immense pressure of the superincumbent rocks, do not in reality belong under the division of dynamic metamorphism. Grabau (I6) has proposed the term symphrattism from

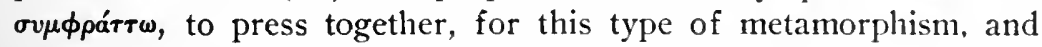
for the rocks of this type he suggests the term symphrattic rocks.

As has been repeatedly emphasized, especially by Johannes Walther, metamorphic rocks of all kinds are naturally classed with the rocks from which they are derived, and not as a separate class. 


\section{STATIC METAMORPHISM OR DIAGENISM.}

Of the diagenetic processes affecting rocks the following may be especially considered: (I) lithification, (II) recrystallization, (III) dolomitization, (IV) replacement of limestone by silica, etc., (V) desalinification, (VI) formation of concretions, (VII) hydration and dehydration.

\section{Lithification OR Induration.}

The lithification of a rock is not restricted to diagenetic processes, but may be greatly aided if not altogether caused by the other processes of metamorphism, especially the dynamic ones. Nor is lithification a natural result of aging, for time has little or no influence as a primary factor, though it may become important when lithification is primarily due to some other factors. As examples may be cited the still unconsolidated early Palreozoic sands and clays of the undisturbed plains of Russia, and the much metamorphosed Eocenic rocks of the Alps, or of the Coast Range of California. In the last two cases cited, the alteration of the rocks is of course due to the dynamic disturbances which have affected them, but consolidation by purely diagenetic processes of recent sediments is not unknown. Thus the consolidation of the coral sand of Bermuda furnishes a good example of a lithified rock of modern origin, while the Nagelfluh of Salzburg, Austria, and other districts illustrates the solidification of a clastic deposit of Pleistocenic origin. (See Chapter XIV, p. 6oI.)

Lithification takes place with varying rapidity in rocks of different origin. Thus pyrogenic rocks, lavas or intruded masses solidify comparatively rapidly through cooling. This results either in congelation into an amorphous mass or in crystallization-wholly or in part. Water solidifies with extreme rapidity by crystallization when subjected to the proper reduction of temperature. Snow crystals (atmogenic rocks) solidify somewhat more slowly from granular névé into glacier ice, a typical process of diagenetic metamorphism, though involving. to a certain extent recrystallization. The same method of solidification probably affects most hydrogenic rocks. Organic rocks are solidified at the time of their formation, except organic oozes and granular organic rocks (pulverites, granulites, etc.), which may be combined into masses much as clastic rocks are. The lithification of clastic rocks is due to pressurecohesion, to cementation, or to recrystallization. 
The methods of lithification, not confined to diagenetic processes, however, may thus be tabulated:

I. Congelation-in amorphous bodies.

2. Crystallization-chiefly in pyrogenic rocks.

3. Recrystallization-chiefly in atmogenic and hydrogenic rocks.

4. Welding or pressure cohesion-chiefly in clastic rocks.

5. Cementation-chiefly in clastic and organic rocks.

Igneous rocks solidify by congelation into an amorphous glass (obsidian, etc.) or by crystallization. Atmogenic snow crystals consolidate into firn and glacier ice by a process of recrystallization. when the smaller crystals are destroyed to the gain of the larger ones. This is also true of granular hydrogenic rocks such as rock salt and gypsum. Hydrogenic rocks are also solidified through cementation by precipitated material of the same kind. Biogenic rocks are usually consolidated by the precipitation of calcium carbonate under the influence of decaying organic matter and the formation of ammonium carbonate.

Sphærites, granulites and pulverites, of whatever origin, are generally consolidated by the same agents which consolidate the clastic strata.

Lithification or Induration of Clastic Rocks. Under this heading will also be included the granular or pulverulent endogenetic substances. The two chief methods are: (I) Pressure-cohesion, or welding, and (2) cementation. Recrystallization, especially through secondary enlargement, also consolidates loose material, but is more common in rocks already lithified. Though distinct processes, they seldom if ever occur wholly alone, both welding and cementation generally taking place at the same time, though in unequal amount. Recrystallization may accompany these processes.

I. Welding. (Van Hise-34:595-597,670-67I.) This is a process of mechanical consolidation caused either by the pressure of superincumbent rocks or by tectonic movements. This pressure results in bringing closely together the particles of which the rocks are composed. If water is present, this is squeezed out, while the mineral particles are mechanically readjusted with reference to one another. The particles will cohere, because they are brought so close together by the pressure that they are within the limit of molecular attraction of one another. This takes place especially in the zone of anamorphism, where the pressures in all directions are greater than the crushing strength of the rocks, and hence sufficient to bring the particles within the sphere of molecular attraction. 
The depth at which this occurs varies with the rock substances, being comparatively moderate for plastic substances like coal and clay, and much greater for refractory rocks like quartzites, etc. (Van Hise-34:67I.)

While universal within the zone of anamorphism, welding is not unknown in the belt of cementation of the zone of katamorphism. Here especially the lutaceous sediments are affected, the arenaceous and coarser clastics, especially when the particles are of uniform size, having too few points of contact for welding to occur. Thus quartz sandstone of nearly uniform grain may become slightly coherent by incomplete welding, with cementation weak or absent, and so constitute a "free-stone," so called on account of the ease with which it is quarried and cut. Many of the British cathedrals and abbeys, and some Continental ones as well, are built of rocks of this type, rocks which from their uniformity of grain and ready response to the gravers' tools made possible the elaborate carvings which adorn these structures. In not a few çases this rock seems to have been formed by the induration of former wind-blown sands. The slight cohesion of the round and uniform-grained Sylvania sandstone (Siluric) of Michigan, Ohio and Canada, and of the scarcely more coherent Saint Peter sandstone of the United States furnishes examples of cases where induration has scarcely been effected, though what there is may probably be referred to welding processes. This is seen in the fact that these sandstones are almost absolutely free from foreign matter, which might act as a cement, while, except in rare cases, secondary silica has not been deposited.

Cohesion may occur in lutaceous sediments without complete exclusion of water. Thus Becker $(7: I 3 I)$ has shown that, "when the films of water between the particles become very thin, they may become an important factor in the coherence of the rocks. The molecular attraction of the water films and the adjacent particles, or their adhesion, and the cohesion of the molecules of the films may be sufficient to give the rocks a certain amount of strength." (Van Hise- $34: 596$.) Thus muds and silts welded in this manner may have a marked coherence.

The squeezing out of the water, in whole or in part, the rearrangement of particles, and the partial compression of the particles themselves result in a reduction of volume. Thus a considerable reduction in the thickness of a formation may occur. Fossil shells or other organisms in such a formation may be pressed flat or crushed unless previously altered so as to be resistant. The generally flattened or crushed character of brachiopods and other shells in Palæozoic shales are good illustrations. If, however, a resistant 
structure, such as a calcareous or other concretion, exists in the rock, this will resist compression more than the enclosing mud, and so the layers of the latter may assume an upward or downward curving attitude arching over or under the concretion, or, if the latter is large, end abruptly against it, sometimes with the occurrence of slickensided surfaces on the exterior of the concretion. Stylolites also belong in this category of pressure structures. They will be more fully discussed beyond.

That rocks are ordinarily under great strain from lateral and vertical pressure has been shown by the fact that when the pressure is relieved, as in quarrying, expansion takes place, while upward bucklings of the quarry floor are also frequently observed. (Niles24 ; 25 ; Johnston-20; Cramer-9; 10.)

The further phenomena resulting from pressure will be more fully discussed under symphrattism or dynamo-metamorphisın.

2. Cementation. This is accomplished by the deposition, in the pores of the rock mass and between the particles, of a substance which will bind them together. The material is brought in solution by the percolating rain or ground water, and may be derived from a distance, from immediately adjoining formations, or from the formation in question itself. Thus the calcareous sands of the dunes on Bermuda are cemented by the rain water which percolates through them and which dissolves some of the lime only to redeposit it elsewhere in the same formation. The oölite grains of Gran Canaria in the Canary Islands are cemented by lime deposited by the sea water which is instrumental in forming these oölite grains. This, as in the similar cementation of organic lime accumulations, on coral reefs, etc., is brought about by the separation from the water of additional lime, through the decay of the organic matter and the formation of anmonium carbonates in the warm waters, this chemical reacting with the lime salts in solution in the sea water. Pleistocenic gravels are often cemented by the lime derived from a partial solution of the limestone pebbles which they contain or which are found in an overlying gravel or sand. Examples of this are not uncommon in limestone regions. The great Pleistocenic Nagefluh deposit of the Salzburg region is an example of the cementation of a deposit in this manner never buried under younger formations. The pebbles and grains of the rock are so firmly cemented that the galleries and crypts, cut into the formation and dating back to the third century, are still perfectly preserved. Pleistocenic delta deposits exposed near Lewiston, New York, and formed when the ice front rested near the Niagara escarpment, and before Lake Iroquois came into existence, have become consolidated 
by lime cementation so as to form a fairly cohesive rock, showing well the oblique bedding of the fore-set beds.

The porosity of the rock is an important factor in aiding cementation. Other things being equal, the more porous rocks will have a better chance of cementation. Thus the Columbian gravels (Pleistocenic) of the Raritan Bay region in New Jersey are frequently cemented into a hard pebbly rock, the yellowish well-worn quartz pebbles being embedded in a deep brown sandstone cemented by iron oxide, the whole resembling a giant peanut brittle. The underlying Cretacic strata, on the other hand, are unconsolidated except where locally some of the sands are bound together by iron oxide. Certain layers in the Monument Creek Tertiary sandstone of Colorado Springs are strongly cemented by iron oxide, while the remainder of the sandstone mass is free from such cement. As a result, monuments are carved by the wind out of these rocks, the iron-cemented layers forming the capping stones of these monuments. In the Miocenic deposits of Baden, near Vienna, the shellbearing pebble beds are often cemented by lime into a fairly resistant rock, while the clays are entirely unconsolidated.

The principal minerals deposited between the particles of a rock to form a cement are lime, iron and silica. Silica may be in the form of a colloidal cement, but in quartz sandstone it is far more often deposited in such a way as to have optical and crystallographic continuity with the silica of the grain it surrounds. This secondary enlargement of a quartz grain, forming more or less perfect crystals which interlock closely, is not an uncommon thing and may result in the formation of a hard and strongly indurated rock. Nevertheless, such close cohesion of new grown crystals does not always take place, and the mass will fall to pieces at the blow of a hammer, leaving a mass of angular quartz crystals which only under the microscope show that they represent the secondary development by addition of the originally more or less well-rounded quartz grains. This is not an uncommon source of angular quartz grains.

Van Hise mentions as the most important cementing substances: silica, iron oxide and aluminum oxide, among the oxides; calcite, dolomite and siderite among the carbonates, both hydrous and anhydrous silicates,* and marcasite and pyrite among the sulphides. (Van Hise-34:621-622.)

The Keweenawan sandstone of Lake Superior may be cited as a case in which the cementation is largely due to the deposition of

* Among the hydrous silicates are: (1) zeolites and prehnite; (2) chlorites; (3) epidotes; (4) serpentine and talc. Among the anhydrous silicates are feldspars, hornblende and mica. 
feldspar upon worn grains of that mineral, the old and new mineral being in optical continuity. (Van Hise-32.) The sandstone contains both orthoclases and plagioclases, and both are enlarged by deposition of new material in optical continuity with the old. Hornblende has also been found to be secondarily enlarged in old volcanic tuffs.

\section{Quartzites and Novaculites.}

When quartz sandstones are so completely cemented by secondary silica, whether deposited independently or in optical continuity with the original quartz grains, that the rock will break across the original grains rather than between them, the rock is called a quartzite. If the original grain of the quartz rock was a lutaceous one, the result oi this excessive induration is a novaculize.

\section{Lithification of Clastics Largely a Supramarine Process.}

Since lithification of clastics by cementation and recrystallization requires the active circulation of ground water, it is apparent that it is chiefly effective after the deposits in question have been lifted above sea-level, if they originally were marine. This is not entirely true for processes of recrystallization, which may go on even beneath sea-level.

\section{Recrystallization.}

Recrystallization of the mineral constituents may affect all rocks, and occur under static, dynamic or contactic conditions. As a process of diagenism it often produces marked results, though these are never carried to the extremes which are attained when it acts as a process of symphrattism. When it takes place in unconsolidated material it may become a method of lithification, but it is more commonly found in rocks already consolidated by one or the other method. As a method of change from a less stable to a more stable form of mineral it is of the greatest importance. Thus the original less stable forms of $\mathrm{CaCO}_{3}$, aragonite, ktypeit, found in marine oölites and organic deposits, are changed to the more stable form calcite. (See Chapter IX.) In the case of organic remains so altered, the finer structural features are commonly lost.

Recrystallization is especially effective in the more soluble rocks, 
such as limestones, gypsum and salt, though the secondary enlargement of quartz crystals in reality also belongs here. Gypsum, anhydrite, rock salt and granular snow are other substances easily subject to recrystallization. In this process the smaller particles are commonly dissolved and their material added to the larger ones. In the zone of katamorphism, solution and redeposition are going on throughout the limestone with the result that the entire mass is gradually recrystallized. This may affect both loose aggregates of calcite grains which thereby become consolidated, and it may affect indurated limestones which are then gradually altered toward the condition of marble. True marble is probably formed only under the influence of dynamic forces, but many recrystallizations come close to approaching this state.

It is often assumed that recrystallization has affected most of the older Palæozoic limestones, because of their lack of organic remains, which, it is argued, are destroyed by recrystallization. It may be questioned whether organic remains are ever destroyed by ordinary recrystallization, though there is no doubt of this when recrystallization under dynamic influences goes on. In the case of many of the older Paleozoic limestones, however, the absence of organic remains is a primary character. Many of these limestones were deposited as lime muds and silts derived from the erosion of still older limestones, and without the direct participation in their formation of lime-secreting organisms.

Rock salt deposits on recrystallization tend to become coarser, as in the case of the Polish deposits. The same is true for gypsum, which sometimes crystallizes out into masses of large dimensions. The largest found up to date in Utah measured in some cases I5O $\mathrm{cm}$. in greatest dimension. When deeply buried, gypsum loses its water under the influence of pressure and recrystallizes into anhydrite. This brings with it a decrease of volume of $38 \%$.

An important point for consideration lies in the fact that recrystallization is favored by pressure. The greater the pressure, the more likely is the deformation to be accomplished by recrystallization.

\section{Pressure Phenomena Due to Recrystallization.}

In rocks of homogeneous character and fine grain, recrystallization may have a deformative effect on the original structure lines and not infrequently upon the enclosing strata. This is especially well seen in the salt deposits of undisturbed regions, such as the Zechstein salt of north Germany and the Salina salt of New York. 
In the former, where the enclosing rocks are undisturbed, the layers of brightly colored bittern salts and of gypsum often show a remarkable flexuous, sinuous or lisrupted character not unlike a structure produced by strong compressive strains during tectonic deformation. That such deformation is not tectonic can often be shown by the undisturbed character of the enclosing sandstones and shales. Thus, in the Salina deposit of central New York, some of the alternating salt and gypsum layers occasionally show a pronounced flexing and overfolding. while others are wholly undisturbed. This is well shown in the following illustration reproduced from Everding (Fig. I59) and representing the endolithic deforma-

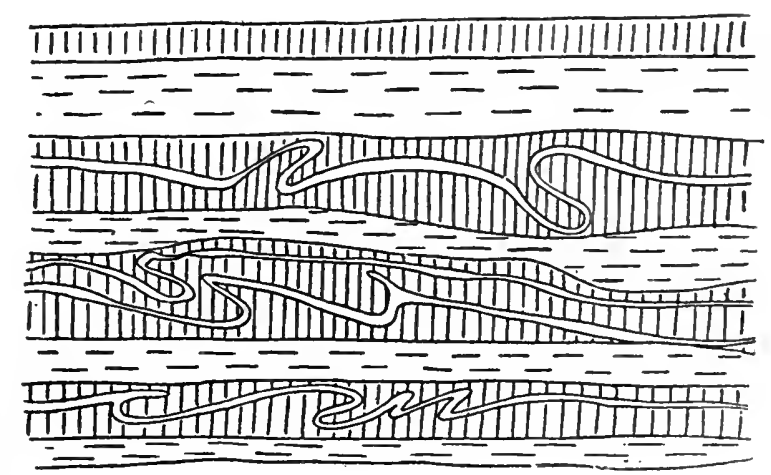

FIG. 159. Section of the potash layers of the Berlepsch shaft near Stassfurt. Scale $1: 35$. The vertically lined beds are carnallite; the beds with horizontal dashes are rock salt; the deformed layers (white) are kieserite. (After Everding.)

tion of the potash layers in the Berlepsch salt shaft near Stassfurt. Here the rock salt and the carnallite are apparently undisturbed, while the kicserite bands within the carnallite layers show most pronounced distortions in different directions. "The forces." says Arrhenius in this connection, "which have brought about this peculiar deformation, are evidently of very local character, and confined to the respective carnallite layers." Arrhenius concludes that tectonic forces cannot be the cause which produced these deformations. (Arrhenius-4.)

From the resemblance of the distorted layers to the convolutions of an intestine, this structure has come to be known in German scientific literature as "Gekröse" structure, a name first applied by Koken in 1900 . (22.) The English equivalent of this term, pro- 
posed by me some time ago, and first used in print by Hahn (I8), is enterolithic structure.

What is believed by many to represent extreme cases of deformation due to endogenetic catses is found in the remarkable salt domes of Louisiana and eastern Texas, and of North Germany, especially in middle and northern Hanover and Brunswick, extending as far as the Elbe. Similar occurrences are reported from Transylvania, on both sides of the Pyrenees, and from southern Algeria (Fig. I60).

These "salt domes" are elliptical in section, with folded, often much distorted layers of salt, gypsum, and in some sections potash salts, which rise through the enclosing strata, deforming them, and maintaining a plug-like relation to them. It is true that some writers
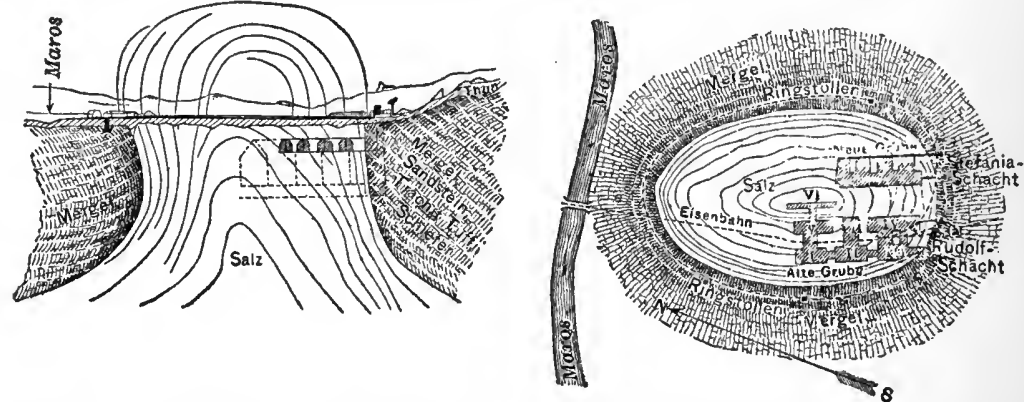

FIG. I60. Section and ground plan of a salt dome in the Moros Valley, Hungary. (After Lamprecht in Fürer's Salzbergbau.)

(Stille, papers cited by Hahn-17) have explained these relationships as due to repeated foldings, but the consensus of opinion (Hahn-I7) seems to be that, while some folding has undoubtedly occurred in certain places, the main force was the endogenetic one due to the crystallizing force of the salts and to metasomatic processes. (Arrhenius-4.)

Enterolithic structure is also a frequent occurrence in finegrained limestones or dolomites. A remarkably fine example is seen in the basal "hydraulic" limestones of the Lockport series of Siluric age, in a section opened by the canyon of Niagara. The strata are finely shown along the railroad bed on the right bank of the canyon. This structure is equally well developed (Fig. I6I) in the Upper Muschelkalk of the Neckar Valley, in Württemberg, Germany (Koken-22), and will probably be recognized in other formations. The essential feature is here, as pointed out by Hahn, that the deformation is in all directions, ${ }^{*}$ not in certain ones, as would

* The multi-gyro- and a-polar deformations of Lachmann. 
be the case in tectonic or in gliding deformations. Thus deformation is shown in whichever direction the section of the formation is cut, nor is there any evidence of slickensiding, such as is to be expected if the deformation is tectonic.

Koken, who described the disturbed layers of the Upper Muschelkalk of the Neckar Valley in detail, and originated the name Gckrösekalk for them, held that the folding and wrinkling were due to vertical pressure of overlying rocks upon the still plastic layers. He notes, however, that the folds are notably sharp and their limbs are thickened as is the case in deformations formed by swelling

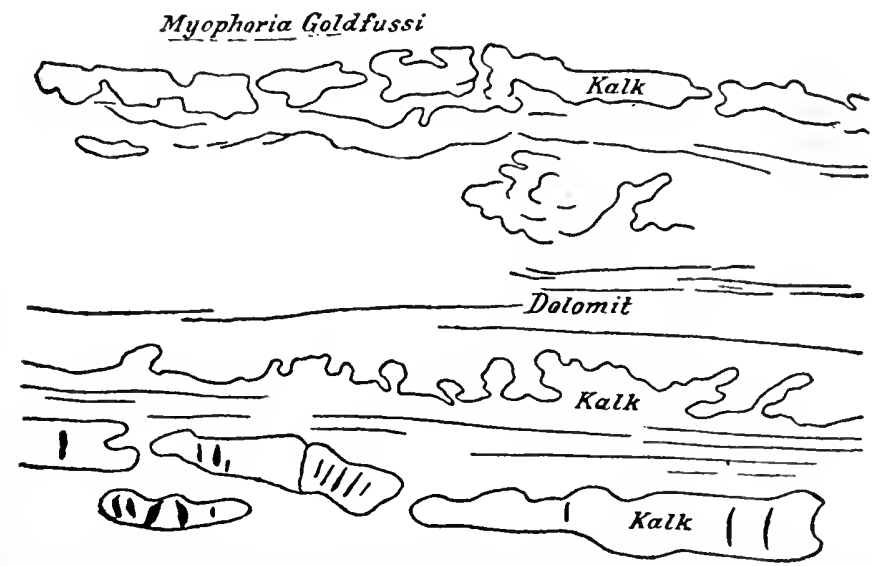

FIG. 161. Enterolithic structure in the Upper Muschelkalk (Gekrösekalk) of the Neckar Valley in Württemberg, Germany. (After Koken.)

masses, such as gypsum, but not through horizontal pressure. While it is not difficult to conceive that mere vertical pressure on still plastic layers can produce deformation of these layers, it is not quite clear what should cause the retention of plasticity in some layers and not in others. The deformed Muschelkalk layers are bluish, argillaceous calcilutytes, much like the similarly deformed layers of the Niagara section. In both cases internal pressure due to crystallization seems to have been an active agent in the deformation of the rock.

\section{Dolomitization of Limestones.}

The change of limestones into dolomites, or dolomitization, has occurred in all geologic ages and is in progress to-day. (Pfaff-26.) 
True, not all dolomites are of secondary origin, some being no doubt deposited as dolomite rock in the beginning. Among dolomites of secondary origin we may distinguish those derived by the clastation and redeposition of older dolomites and those due to the replacement of limestones. Only the latter class belongs here, but the dolomites of clastic origin deserve brief attention. Here belong the many well-bedded, fine and uniformly grained rocks with few or no fossils which abound in many Palrozoic and later formations. As a typical example may be mentioned the Monroe (Upper Siluric) dolomites of Michigan, Ohio and Ontario, which have most probably been derived by the destruction of the older Niagaran dolomites and deposited as dolomitic sand and mud. This is probably the origin of most of the fine-grained, well-bedded dolomites which, from the fact that they contain scattered fossils, are seen not to be the product of alteration of limestone.

When limestones and dolomites are found interstratified, the successive beds being sharply differentiated from one another, this seems to be most satisfactorily explained as a primary difference in the materials deposited. Suess (3I, II:262) regards this alteration in the Plattenkalke as due to alternate chemical precipitation of dolomites and limestones, but in practically all rocks of this type a clastic origin of the deposit must be postulated. In other words, the beds are calcilutytes, some of them pure, others magnesian, the mud being derived alternately from calcareous and magnesian sources. Or, again, the limestones may be of organic origin, while the enclosed dolomites are of terrigenous origin, being derived from the erosion of dolomites forming a portion of the land, and such alternation would have no more significance than alternations of limestones (of thalassigenous origin) and shales (of terrigenous origin). The possibility of secondary separation of a mixture of lime and dolomite grains by agitation of the water and the unequal settling according to specific gravity must not be overlooked.

Secondary dolomites due to diagenetic alteration processes may originate either before or after the original limestones are raised above the sea-level. (Steidtmann-3o.) Such alteration may be primarily a process of leaching, either under the sea by sea water or by the ground water circulating through the upper zones of the earth's surface. By leaching out of the lime the proportion of the original magnesian content is greatly increased. Such differential leaching is due to the fact that calcium carbonate is several times as soluble as magnesiun carbonate as first shown by Bischoff. When it occurs, one result is the rendering porous of the altered rock, which, if under pressure, may actually collapse. The process of 
alteration may on the other hand be one of secondary replacement of calcium by magnesium. Such replacement in the sea had apparently taken place in the case of coral rock reported by Dana (12: 393) from the elevated reefs of Makatea Island in the Pacific; this rock contained $38.7 \%$ of magnesium carbonate, whereas such rock usually contains less than $\mathrm{I} \%$. Similar alterations have been reported by others, thus Branner $(8: 26.7)$ found $6.95 \%$ of magnesia, equivalent to $\mathrm{I} 4.5 \% \mathrm{MgCO}_{3}$, in reef rock of Porta do Mangue, Brazil; the corals of the reef containing only from 0.2 to $0.99 \%$ of MgO. Similarly Skeats (28) reports analyses of modern coral rock from the Pacific with $43.3 \%$ of $\mathrm{MgCO}_{3}$. Such alterations have also been reported from Funafuti, the deep boring on which showed $16.4 \% \mathrm{MgCO}_{3}$ at a depth of 500 feet, $16 \% \mathrm{MgCO}_{3}$ at $6_{40}$ feet, with much smaller but variable percentages above and below. A boring at Key West showed the highest percentage of $\mathrm{MgO}$ $(6.7 \%)$ at a depth of 775 feet, the percentage of $\mathrm{CaO}$ at that depth being $46.53 \%$. At a depth of 25 feet and I, 400 feet the two minima occurred ( $0.29 \%$ and $0.30 \%$ respectively).

Metasomatic replacement through the agency of ground water is also an active means by which dolomites are produced. In some cases it is less effective than submarine replacement, principally because sea water carries more magnesium than is found in such underground circulation. Where such magnesia is supplied, however, as in regions of decomposing magnesium-bearing rocks, this ground water replacement may be very effective. The magnesia is of course obtained from the belt of weathering where it occurs as carbonate in older dolomites, etc., or as silicate in crystalline rocks and minerals (garnet, staurolite, tourmaline, chondrodite, chlorite and the zeolites, etc.). The silicates are subject to carbonation (see ante, pp. 35, 178), and the carbonate then passes into solution and is carried downward to the belt of cementation, when, on coming in contact with limestones poor in magnesia, replacement takes place.

Local dolomitizations also occur, as for example at Aspen, Colorado, where hot magnesian spring waters rising through the limestone locally alter it to dolomite. These are, however, not diagenetic, but belong to the division of contact metamorphisms. In general limestones which have suffered orogenic disturbances are more commonly altered to dolomites than those not so disturbed. Thus (Van Hise-3+:8or) the Tertiary limestones of the Coast Range of California and of the Alps are more strongly magnesian than the undisturbed limestones of the same age. This is due to the fact that disturbed and shattered strata of mountain regions 
offer better access to waters bearing magnesium, through the agency of which the replacement is brought about.

The replacement of calcite by dolomite involves a contraction of $\mathbf{1} 2.30 \%$. Dolomites due to alteration will thus show a high degree of porosity unless they have been subjected to compression during orogenesis. Such porosity is shown in the early Palæozoic dolomites of the Mississippi Valley, and also in the Siluric and the Devonic dolomites of Michigan, Ohio and Canada. When the rock is under pressure, as in the zone of anamorphism, mashings and recrystallizations close the openings. It is also highly probable that pressure promotes dolomitization, since this means a decreasing volume, a result favored by pressure.

IV. Replacement of Limestones by Silica, Iron Oxide, Etc.

Metasomatic replacement of limestone by silica is a familiar phenomenon. In most cases the replacement affects chiefly certain parts of the limestones which by their structure seem best suited to such replacement. Such are the shells, corals and other organic remains embedded in Palæozoic or younger limestones where the enclosing matrix generally remains unaffected, though the fossil may be completely replaced. Oölitic limestones also suffer replacement by silica and in them often the steps of replacement are shown by the decrease in lime and the increase in silica. A mass of such siliceous oölite occurs in the lower Palæozoic rocks of central Pennsylvania, where it covers an area of about 40 square miles, with scattered extensions over a much wider area. Locally the oölite passes into chert. These siliceous oölites have been regarded as originating in rising hot springs containing silica in solution (Wieland-36:262), but others (Moore-23; Brown) hold that they represent replacements of originally calcareous oölites. This explanation is fully borne out by the analysis, and the incompleteness of the replacement in many cases. (See also Ziegler-37.)

Replacement of limestone by iron oxide is also a frequent occurrence. In the basal Siluric beds of Wisconsin, oölites, which from their character and appearance were most probably calcareous in the first place, have been changed to iron oxide (hematite). The so-called Clinton iron ore seems to be an example of metasomatic replacement of limestones, for here the organic fragments (brachiopod shells, Bryozoa, etc.) are replaced by iron oxide. In the Genesee gorge at Rochester the steps in replacement could formerly be obscrved, these being shown by the progressive increase in iron 
oxide and a corresponding decrease in calcium carbonate. It is true that these deposits have been regarded as formed directly in lagoons and cut-offs (Snyth-29) along the sea coast of the time, the iron being brought by the wash from the crystalline old land. This theory has, however, been discarded by some recent students of the subject in favor of the older replacement theory.

The replacement of calcareous bodies of organic origin by iron pyrites and other mineral substances will be more fully discussed in a later chapter.

\section{Desalinification.}

Among other diagenetic processes of importance may be mentioned the desalinification of old marine sediments. As already noted, the amount of salt absorbed by marine sediments varies greatly, chiefly in proportion to their pore space. (Gerbing-15:85, II8.) After these sediments are raised into the zone of circulating ground water, a slow removal of these salts takes place. Under arid climatic conditions, as already noted, this may go on more rapidly, and the leached salt may be redeposited in salinas and desert salt basins.

\section{Formation of Concretions.}

This has already been discussed at some length in a previous chapter (see pp. 718-720) and need be dwelt on only briefly here. Percolating waters carrying lime, silica or other substances in solution will deposit these in the strata at favorable localities, forming concretions of lime, of clay-iron-stones, or of silica. The first are common in calcareous shales, often growing to large size, with a corresponding deformation of the enclosing layers, through the pressure of the growing concretion. Not infrequently the concretions become confluent, forming a concretionary limestone bed. The nucleus of the concretion is very often some organic fragment or a shell. In the Champlain clays of Cumberland, Ontario, entire specimens of fish are common. Fish remains are found in similar concretions of the glacial and post-glacial clays of Norway, I6 species having been recognized so far.

The common types of concretion in the Mesozoic and Palæozoic slales are the septaria already described. These are often of great size, examples to feet in diameter occurring in the Devonic of New York. They not infrequently contain a fish bone as a nucleus, 
while the smaller ones commonly have a goniatite shell at the center. Frequently the stratification of the enclosing beds on either side appears to be continuous through the concretion, while the beds above and below are arched, owing to the pressure caused by the growing septarium. Some of this arching may be due to the compression of the shale around the resistant septarium.

Calcareous clay stones are also common in the loess, where they are known as Lösspuppen or Lössmännchen, by the Germans, as Fairy stones by the Scots, and as Imatra stones by the Finlanders. They form in parallel lines, giving the deposit the appearance of stratification, though the original bedding may have been quite diverse. The lines of concretions mark rather the successive levels of ground water than any structural features of the rock itself.

Claystone concretions of very regular form are found in the Champlain clays of the Connecticut Valley, while clay-iron-stones enclosing ferns, insects, crustacean and other remains, occur in the Carbonic shales of Grundy County, Illinois, the fossil-bearing concretions of Mazon Creek having become fanıus on account of their well-preserved organic remains.

A special form of calcareous concretion is known from the black Devonic shales of Michigan and Ontario, being especially abundant at Kettle Point, Lake Huron. These are spherical, or nearly so, and are composed of radiating crystals of calcium carbonate, which, growing outward, crowd the enclosing strata until they curve about the concretion. The strueture resembles that of a fibrous wood, and fragments are not infrequently mistaken for "petrified" wood. Their manner of occurrence, growth and significance is fully discussed by Daly ( II).

Concretions of iron pyrite and of marcasite are forming in many strata. Sometimes these are globular masses composed of crystals of pyrite, at other times they have a radial structure. Generally some object of organic origin forms the nucleus around which the concretion grows. In the Cretacic clays of New Jersey pyrite concretions are forming around fragments of lignite, all stages of incrustation and replacement being observable.

Siliceous concretions are common in calcareous formations. Thus flints characterize chalk, and chert layers abound in many limestones. Flints may occur in continuous layers in massive chalk beds in which their arrangement alone indicates stratification. As in the case of the concretions in the loess, these lines of flints need not have a necessary relation to the original stratification.

In many cases, however, the flints formed around a siliceous sponge some other organism which acted as a nucleus to attract 
the silica in solution. Here the flints mark the original distribution of the organic remains in the strata. The source of the silica is to be found in the organic structures of silica scattered through the mass of the chalk. These are dissolved by the circulating waters and redeposited around the organic nucleus.

Chert concretions occupy the same relation to limestone that flints do to chalk. They too are derived from the organic silica enclosed in the deposit, and redeposited in favorable places. Confluent concretions of chert produce a more or less continuous chert bed such as is common in the Devonic limestones of eastern North America. Chert concretions may enclose organic remains, but they do not necessarily form around a visible nucleus. Van Hise holds that the heavier chert bands are formed first by the original segregation of siliceous organisms and the subsequent enrichment by silica-bearing ground waters of these siliceous strata..

\section{ViI. Hydration and Dehympition.}

Hydration, or the union with water of originally anhydrous deposits, may produce profound results. Thus anhydrite is changed to gypsum with a corresponding swelling of the entire mass (see ante, p. 177) and the production of cleformative structures. Dehydration of gypsum, on the other hand, produces a corresponding shrinking of the entire mass.

\section{CONTACT METAMORPHISM OR ÆTHOBALLISM.}

I. Pyrometamorphism. When rocks come in contact with heated igneous masses, as a result of subterranean intrusions, or of surface flows, they are more or less altered, especially along the contact, this alteration gradually decreasing in intensity away from the igneous mass, until its effect has been entirely lost. Such a phase of the contact metamorphism may be called igneo- or pyrometamorphism. It is especially manifested in the formation of new minerals along the contact zone and in the introduction of mineral substances from the igneous mass. A zonal arrangement is commonly formed, different alteration products arising at different distances from the igneous mass. Effects are felt by both the intruded and the intruding (or overflowing) rock: the former is exomorphic, the second endomorphic. The exomorphic effect from contact with dry heat is first of all a raising of the temper- 
ature of the country rock adjacent to the igneous mass, such rise in temperature reaching even fusion point. Three stages of influencing the country rock are recognized: baking, fritting, and vitrification. As a result of baking, induration of unconsolidated material will occur without fusion. Hydrous minerals are dehydrated with a corresponding change, such as limonite to hematite, gypsum to anhydrite, etc. From carbonates the $\mathrm{CO}_{2}$ is given off, changing limestone and dolomites to lime and magnesium oxides, respectively, which have a caustic reaction. Volatile gases are driven off, as in the case of coal which is changed to coke.

Fritting is partial fusion, carried to the point where the silica begins to act on the bases, forming an imperfectly melted or fritted mass. Vitrification results from complete fusion, the mass being transformed into a glass.

The effects of pyrometamorphism on clastic rocks are various. "Sandstones are decolorized and often fritted to a glistening enamel, like a porcelainic mass; where the cement is of a calcareo-argillaceous nature, this is melted into a glass; clay and mud are converted into porcelainite or brick, with marked change of color in many cases; tuffs and phonolites are so far vitrified as to acquire a character resembling that of obsidian; brown coal is altered into seam coal or anthracite, and these in other cases into a substance more resembling graphite, while in others (probably under less pressure) the coal is converted into coke; a prismatic structure is developed not only in clays and marls, but even in sandstones, in brown coal, in seam coal and in dolomite; limestones are altered into crystalline marble, often with complete effacement of their stratification and even of all traces of their fossils; the finer varieties of grauwacke and its associated shales are converted into hornstone, as in the classical region of the Brocken." (Irving-19:76.) The effects of dry heat are very limited in extent, usually penetrating the rocks only for a short distance. Where hydro- and gaseo(atmo-) metamorphism are also active, as is almost universally the case in pyrometamorphism, the alterations will be more extensive and widespread. The endomorphic effects, or those on the igneous mass itself, are largely confined to a more rapid solidification and hence the production of finer crystallization along the contact, owing to the chilling effect of the cool wall rock. The presence of water in the latter, of course, contributes to a much modified result, as already indicated in an earlier chapter (p. 312).

2. Hydrometamorphism. Contact with rising waters, whether hot or cold, carrying mineralizers, produces the second type of contact metamorphism to which the term hydrometamorphism may be 
applied. As already noted, waters carrying magnesium locally alter limestone into dolonites. Sulphuretted springs on the Sinai Peninsula and at several points along the west coast of the Red Sea alter coral limestones to gypsum, and silica-bearing waters locally alter many reef limestones into siliceous rocks, as in the Upper Devonic coral reef limestones of Grund in Harz and elsewhere.

The greatest amount of alteration is, however, produced by the highly heated waters, given off by the igneous rock, or accompanying the intrusion. Here must be classed all the phenomena of secondary enrichment of the wall rocks of fissures, by the rising waters, though the actual deposits in the fissures themselves are to be classed as hydrogenic rocks. The subject is too special to be pursued here at greater length. The student is referred to the current works on ore deposits and to Van Hise's Treatise on Metamorphism. The work of geysers and hot springs not directly associated with volcanic intrusions, in so far as it affects the wall rock, must also be classed here. The deposits formed by these agencies, however, are hydrogenic deposits.

3. Atmometamorphism. Contact with rising vapors and gases, as in solfataras, fumaroles, etc., constitutes a third type of contact metamorphism, to which the term gaseo- or atmometamorphism may be applied. In its broadest sense the weathering of rocks in contact with the great gas envelope of the earth, the atmosphere, also belongs here, having the same relation to the intrusion of gases as the surface flow has to the intruded igneous masses. Practically, however, we may confine gaseous metamorphism to the work of hot vapors and gases emitted in connection with volcanic activity and always accompanying pyrometamorphism. Such effects are visible to-day in solfataras and fumaroles where the alteration of the wall rock is proceeding at a rapid rate.

The high temperature of the vapors and their high content of active chemical agents make their work of alteration much more effective than the work of water solution would be. The work of the gases at very high temperature is called fumarolic, while the work of the gases at lower temperature is solfataric.

The most important gases active in the fissures of the rock are: water vapor, sulphurous oxide $\left(\mathrm{SO}_{2}\right)$, chlorine $\left(\mathrm{Cl}_{2}\right)$, hydrochloric acid $(\mathrm{HCl})$, hydrofluoric acid $(\mathrm{HFl})$, hydrosulphuric acid $\left(\mathrm{H}_{2} \mathrm{~S}\right)$, sulphuric acid gas $\left(\mathrm{SO}_{3}\right)$, carbon dioxide $\left(\mathrm{CO}_{2}\right)$, oxygen $\left(\mathrm{O}_{2}\right)$ and hydrogen $\left(\mathrm{H}_{2}\right)$. Nitrogen is of course an abundant but essentially useless gas, and boric acid $\left(\mathrm{H}_{3} \mathrm{BO}_{3}\right)$ is sometimes plentiful. Among the processes going on in atmometamorphism are the common ones of oxidation, hydration and carbonation. The last produces sodium 
carbonate, which is abundant at times. Chlorinization results in the formation of $\mathrm{NaCl}, \mathrm{KCl}, \mathrm{NH}_{4} \mathrm{Cl}, \mathrm{FeCl}_{3}, \mathrm{CuCl}_{2}, \mathrm{MnCl}_{2}$ and other chlorides. By the action of sulphuric acid alums are formed, of which the potash and soda alums are the most abundant. Gypsum is formed by the action of the calcium-bearing compounds and sulphuric acid, this latter also forming Glauber's salts, sodium sulphate and potassium sulphate. The hydrosulphuric acid acting upon various compounds forms sulphides, and so in turn each acid acting upon the rocks forms compounds of various kinds.

These activities are of course not always sharply isolated. Indeed, solfataric and fumarolic actions are a common accompaniment of igneous activity and thus the alteration of the rocks is a complex of pyro-, hydro- and atmometamorphism.

4. Biometamorphism. A change in the rock due to contact with organisms, or biometamorphism, is of little effect, when we remember that the change must be produced by the physiological activities of the organism. Thus the changing of clay into bricks by baking is not primarily an organic process, though directed by man. It is a case of pyrometamorphism, even though the heat is artificially supplied. Disintegration of rocks by growing organisms is perhaps their only significant metamorphic activity.

\section{DYNAMIC OR PRESSURE METAMORPHISM, OR SYMPHRATTISM.}

When rocks are subjected to orogenic disturbances, their internal structure will be affected by the movement and pressure, and to some extent by the heat developed by these processes. The effect in slight deformations is often confined to the planes of gliding along which deformation has taken place. Here smooth gliding surfaces or slickensides are formed, often with the development of a thin layer of mineral matter, and marked by striations and flutings which indicate the direction of motion. Extreme polishing sometimes results from such movements. Here belong the glacial striations and groovings which are slickensides on a large scale.

The development of a mineral coating on the polished surface of the gliding plain may be the direct result of the energy liberated by the gliding process, or it may be the secondary deposit in the fissure, when the surface of the mineral will take on the cast of the striated surface. Hematite, chlorite, calcite, pyrite and other minerals have been active in such wise. In some cases, however, the mineral may have been deposited in the fissure before slipping 
took place. In such a case, the effect of movement is seen on the mineral.

In general, when extensive dynamic disturbances take place, resulting in crushing and mashing of the rocks, new minerals and new structures are developed. The former are numerous; among the latter are cleavage, fissility, and schistosity.

Different types of rocks suffer different alterations under the influence of the mass-mechanical motion characteristic of symphrattism. A few of these alteration products may be mentioned, but the student is referred to special treatises on the subject for more detailed information.

When coarse, clastic rocks, or rudytes, are subjected to dynamic metamorphism, there will generally result a recrystallization and granulation, and the development of schistose structure. This is especially the case in the matrix in which, owing to its great range in composition, a large variety of minerals may be developed. A schist conglomerate or conglomerate schist is produced, generally with the pebbles flattened and elongated and more or less granulated and recrystallized. With extreme movement, the pebbles may be flattened into laminæ or changed into a variety of minerals according to their original composition. A quartz pebble may thus be drawn out into a lamina of granulated quartz, often only as thin as cardboard or even as paper. Granite pebbles may be transformed into a micaceous lamina with quartz and feldspar grains. The material of the original pebble may become more or less commingled with the matrix so that the outline of the pebble disappears and finally all trace of the conglomeratic character is lost, the mass being a schist with laminæ of varying composition interspersed. The matrix may become progressively slate, schist and foliated schist, the particles at first winding in and out among the pebbles, but becoming more parallel as the pebbles disappear.

Impure arenytes and lutytes may suffer changes similar to those of the matrix of rudytes. Clastic gneisses and schists are thus produced, or exogneisses and exoschists, since they are derived from exogenetic rocks. They are distinguished from endogneisses and endoschists, or those produced from endogenetic (chiefly pyrogenic). rocks, by the parallel orientation of their mineral particles, which gives cleavage to the rock. This structure is almost if not quite universal with the schists and gneisses derived by the metamorphism of sedimentary rocks, but is commonly lacking in schists and gneisses produced from igneous rocks.

The alteration of other sedimentary rocks by dynamic metamorphism may be briefly reviewed. Thus quartz sandstone changes 
to quartzite and then to quartzite schist; arkoses into arkose schists, and arkose gneisses; grits into graywackes, graywacke slates, graywacke schists and graywacke gneisses, and shales or lutytes into lutyte schists and lutyte gneisses (pelite schists and pelite gneisses). Limestones are changed to marble and soft coals to anthracites and graphites. In general, pure sediments are the least altered, while mixed sediments are likely to produce the greatest variety of new minerals under metamorphism.

\section{The Terms Slate, Schist and Gneiss.}

The term slate, though generally used as a lithological term, is strictly applied only as a structural one. A slate is a metamorphic rock of a lutaceous texture and homogeneous character, splitting into parallel leaves, and whose mineral particles are for the most part so small as to be invisible to the naked eye. (See, further, Chapter XX.) A schist has been defined as "a rock possessing a crystalline arrangement into separate folia." (Geikie-I4: 178 .) A typical schist has its cleavable minerals arranged in the same way and like one another and large enough to be for the most part visible to the naked eye. Mica is the most important cleavagemaking mineral, and the most typical schist is one composed of quartz and mica scales, a quartz mica schist, more commonly spoken of as a mica schist.

Van Hise has urged the use of the term schist in a purely structural sense, much as the terms shales and slate should be used. This is in strict accord with the definition by Geikie given above. In mineral composition and in origin schists may vary greatly. Thus we may have the ordinary quartz mica schist, which contains quartz and mica in about equal proportions. Hornblende schists are schists containing hornblende and some other minerals, generally feldspar. Thus we may have a hornblende plagioclase schist. . If the origin of the schist is known this may be indicated in the name, as arkose schist, silicirudyte schist, or if derived from an igneous rock such as gabbro it becomes a gabbro schist. Both composition and origin may be indicated, as in the name mica-quartzfeldspar-arkose-schist.

In certain petrographic circles, especially the German ones, the term schist was applied to rocks not only having a schistose structure, but also a definite composition. Thus quartz was considered essential in the formation of a schist and was assumed to be present. We thus had mica schists, hornblende schists, chlorite schists, 
etc., in which the other mineral was supposed to be quartz. If feldspar was present, the rock was called a gneiss. (Rosenbusch27.) The structural use of the term seems, however, to be the preferable one.

Gneiss was originally defined as a banded or foliated rock having essentially the composition of granite, $i$. $e$., quartz, feldspar and mica or hornblende. The quartz and feldspar were taken as distinctive minerals and the others added as qualifying prefixes. Thus, mica gneiss meant a schistose or foliated rock, consisting of quartz, feldspar and mica; and hornblende gneiss, the same combination with hornblende added or replacing the mica. Such gneisses were supposed to be metamorphic derivatives of granites. Since, however, many rocks, to which the name gneiss has been commonly applied, prove not to have the composition above given, the petrographic use of the name must be abandoned in favor of the structural use, or the use of the term gneiss as well as schist must be very much restricted. Van Hise's proposition to use the term as a purely structural one seems to be the most satisfactory solution, and accordingly we may define gneiss as a banded metamorphic rock in which crystalline structure has been developed and in which the bands are petrographically unlike one another and consist of interlocking mineral particles. The bands in different gneisses are of variable thickness, ranging from a fraction of a centimeter to many centimeters (Van Hise). There may also be a similar variation and range in thickness of the different bands of the same gneiss. Thus the fundamental distinction between gneiss and schist is the banded character of the former as compared with the homogeneous character of the latter. This homogeneous character is still more strongly expressed in the slates in which the cleavable mineral particles are not visible as they are in the schists.

Gneiss may be derived either from igneous or from sedimentary rocks. When derived from igneous rocks the parallel arrangement of the mineral particles which results in cleavage is more often lacking.

\section{General Terms for Metamorphic Rocks.}

Two terms have come into use for general designation of metamorphism in rocks. These are meta and apo. Neta is used as a prefix to any rock name and designates that the rock has been altered without stating how or to what degree. Thus we may say meta-arenyte, meta-shale, meta-granite, meta-diorite, etc. Rocks already metamorphosed to a certain degree may undergo a second 
set of changes producing meta-graywackes, meta-quartzite, etc. Here the rock was first metamorphosed to a graywacke or a quartzite, after which a second set of alterations occurred.

Apo is used as a prefix for rocks in which metasomatic changes have taken place without entire loss of original texture or structure. Thus a devitrified rhyolite is an apo-rhyolite. (Bascom-5.) This name applies especially to rocks which have undergone diagenetic alterations without loss of structure, though the chemical and mineral composition may differ greatly from those of the original rock. The term is useful to call attention to the original rock from which the new rock is derived. Thus quartzite is an apo-arenyte, graywacke an apo-grit, etc. When new structures are produced we obtain slates, schists or gneisses.

\section{Variation in Metamorphism of Strata.}

In a given series of metamorphosed strata a change may often be noted in the intensity of the metamorphism as one passes from point to point. This change may be along the strike of the strata or across it. In the first case, it is generally gradual, the profoundly metamorphosed strata of one region passing gradually into the slightly metamorphosed equivalent of another. Thus the three unconformable series of strata, the Archæan, the Lower Huronian and the Upper Huronian, are so closely mashed and altered in the western part of the Marquette district of Michigan as to appear completely conformable and suggest an inseparable series. In tracing the formations to the less metamorphosed central and eastern parts of the district, the three unconformable series are readily recognizable as well as the original character of the formations.

The change in the degree of metamorphism across the strike is generally more abrupt. "Thus the rocks at the crown of an arch or at the bottom of a trough may be only partly metamorphosed, while the same formations on the limbs of the folds may be profoundly metamorphosed, this being due to the difference in the amount of shearing in different parts of the folds, or to the dying out or change in character of orogenic movements across the strike." (Van Hise-33:598-600.) This change is well illustrated in the Hudson River series, which in the Hudson Valley is practically unaltered, but eastward across the strike in the Taconic range becomes schists and gneisses, while in Vermont and parts of eastern New York the series changes to roofing slates. 


\section{Age of Metamorphic Rocks.}

Rocks of all ages may become metamorphosed, but it may be stated for a restricted region that the metamorphosed rocks of that region are generally older than the non-metamorphosed rocks. Strictly considered, this should apply only to symphrattic rocks, since later rocks may be affected by an intrusive sheet or laccolith, the effect dying out upward and downward and thus not being noticeable in older and younger strata. Or a set of folded strata may be locally affected by intrusions which are visible in the newer and not in the older strata. Again different strata are differently affected by the heat of a dike which cuts all of them, and some in the middle of the series may be much altered, while lower strata may be less readily altered. Even symphrattic rocks are not equally altered throughout, some very resistant strata being scarcely affected by the agents which strongly metamorphose others.

While metamorphism is undoubtedly most marked in pre-Cambric and in early Palrezoic rocks, it is also known in rocks of later age, as shown by the metamorphic gold-bearing slates of Jurassic age in the Sierra Nevada and in Sonora, and the Eocenic marble of the Himalayas. See further, Correlation by Regional Metamorphism, Chapter XXXII.

\section{BIBLIOGRAPHY XIX.}

I. ADAMS, FRANK D. 1912. An Experimental Contribution to the Question of the Depth of the Zone of Flow in the Earth's Crust. Journal of Geology, Vol. XX, pp. 97-118. (See also King-21.)

2. ADAMS, F. D., and COKER, ERNEST G. 1906. An Investigation into the Elastic Constants of Rocks, more Especially with Reference to Cubic Compressibility. Carnegie Institute of Washington, Publication No. 46. Ibid. American Journal of Sciences, $4^{\text {th }}$ series, Vol. XXII, pp. 95-123.

3. ANDREE, KARL. I9I I. Die Diagenese der Sedimente, ihre Beziehungen zur Sedimentbildung und Sediment Petrographie. Geologische Rundschau, Bd. II, pp. 6I-74; I I $7-130$.

3a. ANDREEE, K. I9I2. Die geologische Bedeutung des Wachstunsdruchs Kristallisierender Substanzen. Gcologische Rundschat, Bd. III, pp. 7-I5.

4. ARRHENIUS, SVANTE. I912. Zur Physik der Salzlagerstättcn. Meddelanden från K. Vetenskapsakademiens Nobelinstitıt, Bd. II, No. 20, pp. 7-25.

5. BASCOM, FLORENCE. 1897. Aporhyolite of South Mountain, Pennsylvania. Bulletin of the Geological Society of America, Vol. VIII, pp. 393-396.

6. BASCOM, F. 1900. Volcanics of Neponset Valley, Massachusetts. Bulletin of the Geological Society of America, Vol. XI, pp. II 5-I26. 
7. BECKER, GEORGE F. 1895. The Torsional Theory of Joints. Transactions of the American Institute of Mining Engineers, Vol. XXIV, pp. I30-I38; 865-867.

8. BRANNER, J. C. I904. The Stone Reefs of Brazil, Their Geological and Geographical Relations, with a Chapter on the Coral Reefs. Bulletin of the Museum of Comparative Zoölogy, Vol. XLIV, 285 pp., 95 plates. Ibid. 1905. Geological Society of America. Bulletin, Vol. XVI, pp. I-I 2 , pls.. I-I I.

9. CRAMER, FRANK. I89o. On a Recent Rock Flexure. American Journal of Sciences, 3rd series, Vol. XXXIX, pp. 220-225.

Io CRAMER, F. I89I. On the Rock Fracture at the Combined Locks Mill, Appleton, Wisconsin. Ibid., 3rd series, Vol. XLI, pp. 432-434.

I . DALY, REGINALD A. I9oo. The Calcareous Concretions of Kettle Point, Lambton County, Ontario. Journal of Geology, Vol VIII, pp. I35-I 50 .

12. DANA, JAMES D. I890. Corals and Coral Islands, 3rd edition.

13. EVERDING, H. 1907. Deutschlands Kalibergbau. Festschrift zum Ioten Allgemeinen deutschen Bergmannstage zu Eisenach, Vol. I, pp. $25^{-1} 33$ (especially pp. 50, 83,88 ).

14. GEIKIE, A. I 893. A Textbook of Geology, 3rd edition.

15. GERBING, J. I909. Chemische Untersuchungen von MeeresbodenMeereswasser- und Luft-Proben der deutschen südpolar Expedition. I90I-I903, Bd. VII. Berlin.

I6. GRABAU, A. W. I904. On the Classification of Sedimentary Rocks. American Geologist, Vol. XXXIII, pp. 228-247.

17. HAHN, F. FELIX. 1912. The Form of Salt Deposits. Economic Geology, Vol. VII, pp. I20-I35 (and papers cited there).

18. HAHN, F. F. I912. Untermeerische Gleitungen bei Trenton Falls (Nord Amerika) und ihr Verhältniss zu ähnlichen Störungsbildern. Neues Jahrbuch für Mineralogie, u. s. w., Beilage Bd. XXXVI, pp. I-4I, taf. I-III.

19. IRVING, A. I889. Chemical and Physical Studies in the Metamorphism of Rocks. Longmans, Green \& Co., London.

20. JOHNSTON, JOHN. I854. Notice of some spontaneous movements occasionally observed in the sandstone strata in one of the quarries at Portland, Connecticut. Proceedings of the American Association for the Advancement of Science, 8th meeting, 1854, pp. 283-286.

21. KING, L. V. I9I2. On the limiting strength of rocks under conditions of stress existing in the Earth's interior. Journal of Geology, Vol. XX, pp. I I $9-138$.

22. KOKEN, ERNEST. 1902. Ueber Gekrösekalke des obersten Muschelkalkes am unteren Neckar. Zentralblatt für Mineralogie, etc., I902, No. 3.

23. MOORE, ELWOOD S. 1912. Siliceous oölites and other concretionary structures in the vicinity of State College, Pennsylvania. Journal of Geology, Vol. XX, No. 3, pp. 259-269.

24. NILES, WILLIAM H. I876. The Geological Agency of Lateral Pressure in Quarrying. Proceedings of the Boston Society of Natural History, Vol. XIV, pp. I-8.

25. NILES, W. H. I876. The Geological Agency of Lateral Pressure Exhibited by Certain Movements of Rocks. Ibid., Vol. XVIII, pp. 272-284.

26. PFAFF, F. W. I 895 . Beiträge zur Erklärung über die Entstehung des Magnesits und Dolomits. Neues Jahrbuch für Mineralogie, u. s. w., Beilage Bd. IX, pp. 485-507. 
27. ROSENBUSCH, II. I 898 . Elemente acr Gestcinslehre. Stuttgart.

28. SKEATS, E. W. 1903. The chemical composition of limestones from upraised coral islands, with notes on their microscopical structure. Bulletin of the Museum of Comparative Zoölogy, Vol. XIII, pp. 53-I26.

29. SMY'TH, C. H., JR. 1892. On the Clinton Iron Ore. American Journal of Sciences, 3 rd series, Vol XLIII, pp. 487-496.

3o. STEIDTMANN, EDWARD. I9I I. The Evolution of Limestones and Dolomite. Journal of Geology, Vol. XIX, pp. 323-345; 392-428.

31. SUESS, EDUARD. 1910. The Face of the Earth, Vol. II (English translation by Sollas and Sollas).

32. VAN HISE, CHARLES R. I 884. Enlargement of Feldspar Fragments in Certain Kewcenawan Sandstones. Bulletin of the United States Geological Survey, No. 8, pt. I, pp. 44-47.

33. VAN HISE, C. R. 1896. Principles of North American Pre-Cambrian Gcology. I6th Annual Report of the United States Geological Survey, pt. I.

34. VAN HISE, C. R. 1904. A Treatise on Metamorphism. United States Geological Survey, Monograph XLVII.

35. WALTHER, JOHANNES. 1894. Einleitung in die Geologie, Lithogenesis der Gegenwart.

36. WIELAND, G. R. 1897. Eopalæozoic Hot Springs and the Origin of the Pennsylvania Siliceous Oólites. American Journal of Science, $4^{\text {th }}$ series, Vol. IV, pp. 262 et seq.

37. ZIEGLER, VICTOR. 1912. The Silicious Oölites of Central Pennsylvania. American Journal of Science, $4^{\text {th }}$ series, Vol. XXXIV, pp. I I3-127. 


\section{CHAPTER XX.}

\section{DEFORMATION OF ROCK MASSES.}

Having in the preceding chapters dealt at length with the subject of rock formation or Lithogenesis, we must next turn our attention to the subject of rock deformation or Orogenesis, $i$. e., the making of mountain structures.

As the result of rock deformation a number of distinct structural features come into existence, some of which have already been noted in the preceding chapters. Deformation may be classed as endogenetic or exogenetic, $i$. e., produced by internal or external causes, respectively. Internal causes are diagenetic, such as chemical change, recrystallization, etc., while external causes include pressure and motion due to gravity, to tectonic disturbances, etc. The following types of deformation may be considered:

I. Endogenetic.

I. Endolithic brecciation.

2. Enterolithic structure.

3. Contractive joints (prismatic) (basaltic).

II. Exogenetic.

A. Gravitational Deformations.

a. Structures Due to Movement.

4. Intraformational brecciation.

5. Gliding deformations.

6. Surface deformation through creep.

b. Structures Due to Compression.

7. Squeezed-out strata.

8. Shaliness.

9. Slatiness.

c. Of Complex Origin.

Io. Pressure sutures and stylolites.

II. Cone-in-cone structure. 


\section{B. Tectonic or Orogenic Deformation.}

I2. Tectonic joints.

I3. Earthquake fissures.

I4. Slaty cleavage.

I5. Fissility.

I6. Schistosity.

I7. Gneissoid structure.

I8. Folding-Anticlines, synclines, isoclines, fan folds, monoclines, etc.

19. Domes and basins.

20. Faulting.

\section{Contact Deformations.}

2I. Prismatic structure.

22. Insolation joints.

D. Complex Structures Partly Due to Deformation.

23. Metamorphism.

24. Disconformity and unconformity.

\section{ENDOGENETIC DEFORMATIONS.}

I. Endolithic Brecciation. This term is applied to brecciation of strata caused by forces acting from within the mass, such as crystallization and especially swelling or hydration, as in the case of gypsum, etc. In this last case it is only the extreme of enterolithic structure. Similar structures are produced by contraction of the rock mass on drying and the disruption into blocks or cakes which are subsequently enclosed by later deposits and form an endostatic rudyte. Examples of such have recently been described by Hyde (I : 400-408) from the Coal Measures of Ohio. Beds of fresh-water limestone intercalated in the series and deposited in a playa lake were subject to periodic drying, as a result of which the surface for several acres was broken up into polygonal blocks of various sizes, the surfaces of which were frequently covered by the shells of the animals killed in the drying of the lake. The fragments seem to have been exposed for a while to weathering and were then covered by a second flooding. Where the covering deposits were muds, the limestone fragments form a striking series of pebbles in a lutaceous matrix and often weather out in relief. Many intraformational conglomerates may have such an origin. Such breccias are of course closely similar to intraformational breccias due to gliding movements as described under Section 4. 
2. Enterolithic Structure. This has already been discussed in the preceding chapter. In so far as it can be shown that this structure is a purely diagenetic one, brought about by the swelling of the mass either through crystallization or hydration, it properly belongs to endogenetic deformations. If, on the other hand, it should be proven that enterolithic structure in some rocks is produced by the pressure of the overlying mass and the consequent creep and rearrangement of the particles under pressure, such deformation must be classed under the gravitational section of the exogenetic class.

The important distinction between enterolithic and other deformations, such as folding under lateral pressure, or gliding in a given direction, lies in the fact that the enterolithic structure folds in all directions-is apolar or multipolar instead of unipolar.

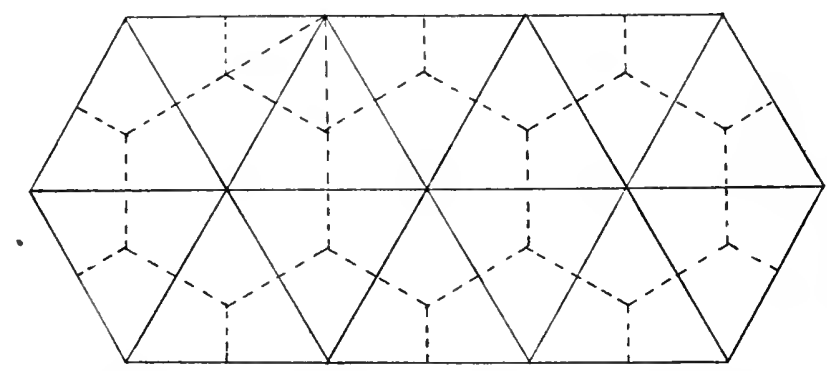

FIG. I62. Diagram illustrating the formation of contraction joints and of desiccation fissures. The normal form is hexagonal, but, as shown in the left-hand member, an irregular pentagonal form is developed when one side is suppressed.

3. Contraction Joints-Basaltic Jointing. This is seen in the formation of mud cracks in lutaceous sediments such as clay or argillo-calcareous mud and in the development of prismatic jointing in cooling basalt and other igneous rocks. In the latter case the prisms always form at right angles to the enclosing surface, such as the upper and lower surface of a sill or laccolith, when the prisms will be vertical or curved, or the lateral walls of a dike, when the prisms will be horizontal. The prevalence of six-sided forms in these prisms suggests that the crystallizing force centers about equidistant points in the magma, each of which will draw an equal amount of the surrounding matrix toward it from all sides. This results in other equally spaced points between these around which the tension in all directions is greatest. Since the points around which attraction takes place are all equally distant from one an- 
other, they form the apices of a series of equilateral triangles and the points around which the greatest tension is focused will be the centers of these triangles. The sulallest number of cracks about these central points which will relieve the tension in all directions is three. If these cracks are symmetrically arranged about the point, the angle between any two of them is $120^{\circ}$, which is the angle between the two sides of a hexagonal prism. As shown in the diagram (Fig. 162), this uniform contraction about equidistant points will result in the formation of a set of uniform hexagonal prisms. Unequal development or failure of the cracks to develop about one of the points may lead to five-sided or other irregular prisms.

Drying mud will in like manner cause a development of a series of prisms which typically are hexagonal, but from lack of homogeneity of the material through unequal drying, or from some other cause, are frequently irregular polygons. The prisms are seldom very high, though in exceptional cases the cracks may penetrate to a depth of ten feet. In general a fraction of an inch is the usual height of the dried mud prisms, the sides of which are slightly raised, giving a concave surface. (See ante, Chapter XVII.)

Prismatic jointing is also sometimes found in undisturbed hydrogenic rocks. Examples of these occur in some gypsum beds of the Paris Basin. It is quite probable that this structure is due to pressure exerted by hydration of anhydrite and so belongs to the diagenetic processes.

\section{DEFORMATIONS DUE TO EXTRANEOUS CAUSES- EXOGENETIC DEFORMATIONS.}

This type may be divided into (A) Gravitational, (B) Orogenic, and (C) Contactic.

\section{A. Gravitational Deformations.}

\section{a. Structures Due to Moz'ements.}

4. Intraformational Brecciation. This has already been discussed in the chapter on Autoclastic rocks, but is again mentioned here as a structural feature. It is probably in all cases an extreme of the next type, and so may be considered in connection with that subject. Here belong the edgewise conglomerates of many limestone formations. 
5. Subaquatic, Gliding-deformation. Offshore deposits of sediments on a gently sloping sea or lake bottom may suffer from time to time deformation of the surface layers through gliding or slipping down the gently inclined sea floor. Such deformation has been repeatedly observed in modern deposits. The best known modern examples are those which affected the village of Horgen on the lake of Zurich in 1875 , and the village of Zug in 1887 . Both of these have already been described in Chapter XV, p. 658. The most remarkable fact about the gliding in Zug was that it took place on an average grade of $6 \%\left(3^{\circ} 26^{\prime}\right)$, while the larger and more

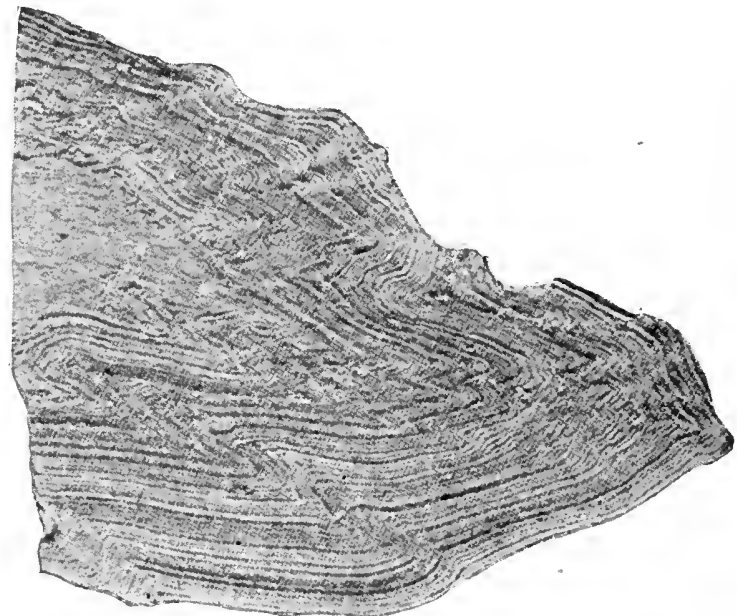

FIG. 163. Folding accompanying subaquatic gliding in Miocenic marl of Oeningen-natural size. (After Heim.)

pronounced movement occurred on a grade as low as $4.4 \%$ (a trifle over $\left.2^{\circ} 3 \mathrm{I}^{\prime}\right)$. The material which thus slid into the lake was brecciated and folded with overfolds, overthrusts, reversals of layers, excessive strata, etc., and furnishes an excellent guide to the interpretation of similar movement in the past. Among the chief points in which these folds differ from those produced diagenetically by swelling of gypsum, or by pressure of overlying masses, is that they are of the nature of normal folds due to lateral compression and so show movement in one direction only, whereas in the case of the other deformations movements in several directions are shown. Furthermore, the axes of the folds are thickened in the gliding as in normal tectonic folds, instead of the limbs, as is the case in folds due to swelling. 


\section{Examples of fossil subaqucous solifuction.}

A. Miocenic sublacustrine glidings of Oeningen. The Miocenic marls of Oeningen, noted for their wonderful remains of insects, etc., show in the midst of these berls a strongly folded layer, lying between horizontal berls of the same character. These foldings are so pronounced that they inevitably suggest lateral compression as the cause of their production, yet the entirely undisturbed charac-

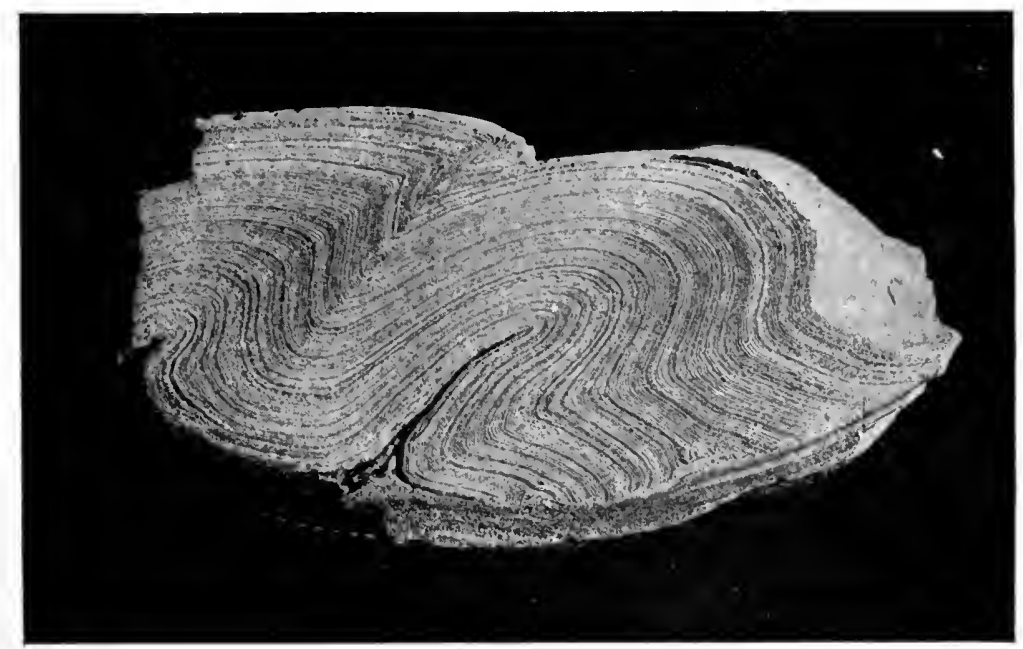

Fig. I64. Folding accompanying subaquatic gliding in Miocenic marl of Oeningen. One-half natural size. (After Heim.)

ter of the enclosing strata forbids such an assumption. Another feature which indicates gliding is the independence of the folded beds from the basal beds, against which the limbs commonly abut directly. The axes of the folds are notably thickened, while the limbs are thinned by compression exactly as in tectonic folding. (Figs. I63, I64.)

B. Jurassic deformations of this type are known from the Solnhofen Plattenkalke, where the so-called distorted layer (krumme Lage) furnishes a good example. The zone las a thickness of $I$ to 1.5 meters, and in it are found all the phenomena of folding, including folds 5 meters in length. Here the glidings took place in the periodically submerged lagoons within the reefs and the 
calcareous nature of the material probably insured a partial cementation before the gliding took place. (See Fig. 95, p. 440.)

C. Triassic cxamples are known from the Muschelkalk of Germany, especially the Main region, but not all of the disturbances found in this formation and so fully described by Reis (20) belong

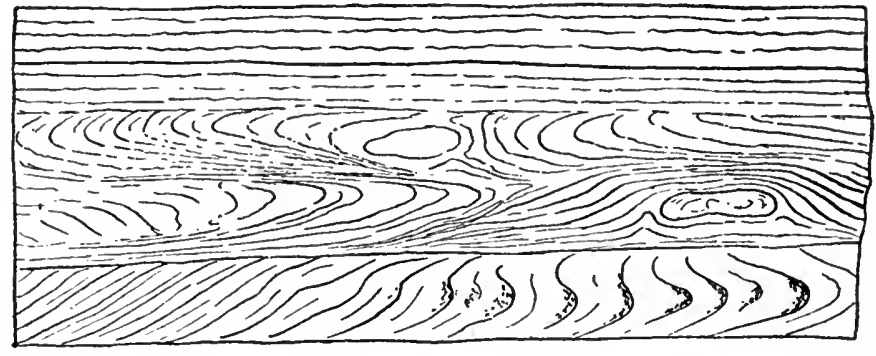

FIG. 165. Deformation due to subaqueous gliding, Muschelkalk, Franken (Germany) I:5o. (After Reis.)

here. The enterolithic structure described by Koken (I3) from the Neckar Valley must certainly be removed from this category of deformation due to submarine glidings.

D. Devonic examples of this class have been figured by Sir Wm. Logan from the Cape Bon Ami limestones of Lower Devonic age from Gaspé (Logan-I5:392) where in division 4 and less

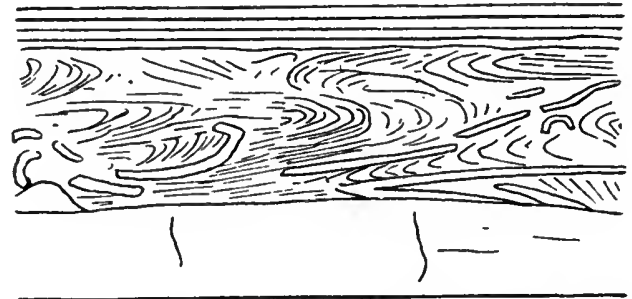

FIG. I66. Deformation due to sttbaqueous gliding, Muschelkalk, Franken (Germany) I :50. (After Reis.).

than 400 feet above the base of the entire series is a bed seven feet thick made up of several thin layers of limestone and limestone shale and presenting a series of wrinkles or contortions from which the overlying and underlying beds are free.', The series now dips at an angle of $24^{\circ}$ southwest. The folding in some cases has been so intense as to cause a brecciation of the limestone beds. (Fig. I67.) 
E. Ordoricic cxamples of this type are beautifully exposed in the walls of the gorge of East Canada Creek at Trenton Falls, N. Y. Here there are at least three such disturbed zones, one well
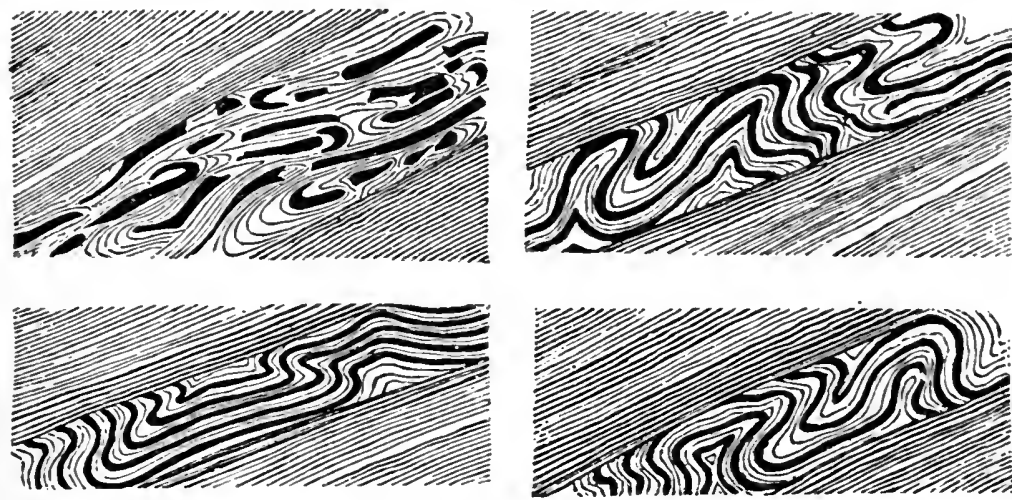

Fig. 167. Corrugated limestone beds, showing the effects of subaqueous gliding. Gaspé limestone, Canada. Scale about i :200. (After Logan.)

shown below the Lower or Sherman Falls, one just below the High Falls (now replaced by a high dam), and a third higher up. All of these show a wonderful series of folds and overthrusts, the zones varying in thickness up to 4 meters, and, as is to be expected, dying

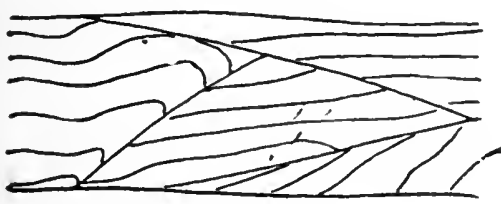

FIG. I68. Deformation due to subaqueous gliding. Trenton lime-
stone, Trenton Falls, N. Y. I $: 75$ (After Hahn.)

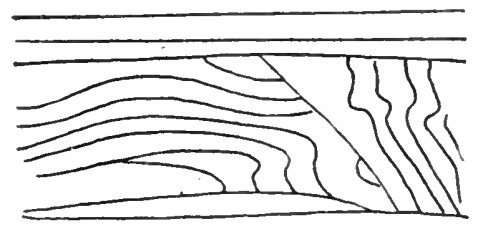

Fig. I69. Deformation due to subaqueous gliding, Trenton limestone, Trenton Falls, N. Y. I :I00. (After Miller.)

out after a while, though traceable for some considerable distance. The upper and lower layers are not disturbed, but absolutely nornal, not even showing evidence of excessive compression. The layers involved in the folding are not always the same, sometimes they are granular limestones with abundant organic remains, but 
more often they are calcilutytes. The fossils are often broken, but no recrystallization occurs; the appearance is such as would be expected from the result of gliding of a mass of imperfectly lithified lime mud. The overlying layers have all the characters of normal deposits on the deformed layers, there being thus a struc- . tural unconformity, though without a hiatus. (Figs. I68, I69.) These disturbances at Trenton Falls have been variously explained, the general conclusions of geologists being either: (I) that they were truly tectonic-lateral pressure having resulted in the folding of certain strata while others took up the thrust without deformation, or (2) that they were due to squeezing out of certain layers under the weight of the overlying rock masses. Both explanations are unsupported by the detailed characteristics of the folds and their

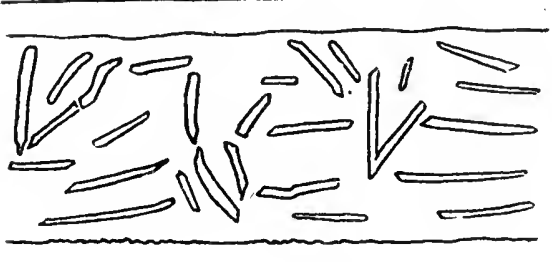

FIG. 170. Edgewise conglomerate, Beekmantown limestones, Center county, Pennsylvania. (After Hahn.)

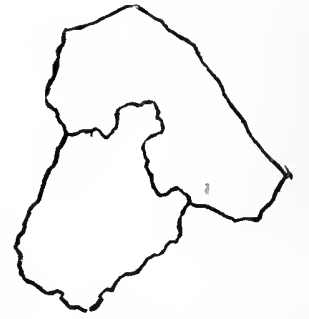

FIG. I7I. Section across the two interlocking stylolites, shown in Fig. 172, much reduced. (After Wagner.)

relationship to the enclosing layers. The recognition of these layers as gliding surfaces, analogous to the Horgen-Zug occurrences, and comparable to the Oeningen folds, is to the credit of Dr. F. Felix Hahn, at that time curator in Palæontology in Columbia University. (Hahn-7.)

F. A Cambric or earlier example of such movements seems to be indicated by the folded layers of the Biri limestone of Mjösen, Norway, described by Rothpletz (2I). This limestone contains certain layers "which are deformed in a singular manner without the enclosing layers partaking of such deformation. It appears as if, during the tilting, these layers had not enough stability, and collapsed within themselves, so that between the more stable layers there occurred a movement in which the enclosing strata had no part." (Rothpletz-21:28.) The characters of these foldings seem in every way analogous to those of the younger formations described. 
Finally, it should be mentioned that in the unconsolidated deposit of the Pleistocenic such deformations occur, though some of them, no doubt, are due to glacial thrust. The deformation of the Tertiary beds of Martha's Vineyard may possibly belong to this category.

Deformation through gliding may result in complete brecciation of the deformed layers. The fragments may lie in all positions, as in the case of ordinary "intraformational conglomerates," or they may consist of thin cakes, many of which in the gliding process have assumed a vertical position in the mass. This forms the so-called "edgewise conglomerate" common in the Ordovicic limestones of the Appalachian region. The characteristics of all these formations seem to point to rather shallow water as the place of deposition of these strata, and the possible periodic exposure and partial hardening of the surface layers. A different explanation has, however, been given for these by Seely and amplified by Brown (I).

6. Surface Deformation Due to Creep. As already noted (p. 543 ), vertical strata, especially of a shaly or slaty character, are subject to deformation in portions of their exposed ends by the creep of the surface soil down a sloping hillside composed of thin strata. A bending in the direction of movement is generally found to occur after a while. Such deformation is of slight importance, and is probably never preserved in the older rocks.

\section{b. Deformations Due to Vertical Pressure of Overlying Rock Masses.}

7. Squeezing Out of Layers. This may occur in cases where certain beds are especially susceptible to such deformation. Finegrained, homogeneous strata seem to be most readily affected in this way. An enterolithic structure similar to that produced by swelling masses (gypsum, salt) is thus produced, the effect being similar whether the pressure originated from the swelling of the mass itself or from the weight of the overlying rock. Koken believes that the enterolithic structure in the Muschelkalk of the Neckar Valley (Gekrösekalke) is due to vertical pressure and squeezing out of these layers. (Ante, Fig. I6r.)

8. Shaliness is the property of lutaceous rocks, rich in clay, to split with concave or "shelly" surfaces in a gencral way parallel to the bedding planes. The structure is a secondarily derived one, due to vertical pressure and the character of the rock. It scems to be best developed in calcareous shales. That it is a secondary structure is shown by the fact that the splitting will sometimes pass 
across a fossil, a part of which remains with either portion of the split mass.

9. Slatiness. This term is applied to the structure developed by many siliceous and carbonaceous argillutytes of splitting into thin layers or plates parallel to the bedding and with essential regularity of surfaces similar to true slaty cleavage. The Genesee and Black Portage shales of New York, the Black Shale of Ohio and Michigan and others of their kind show this feature well. It is shown in the undisturbed Jurassic lutytes of Württemberg, which are split into slate blocks to all appearance comparable to slates from disturbed

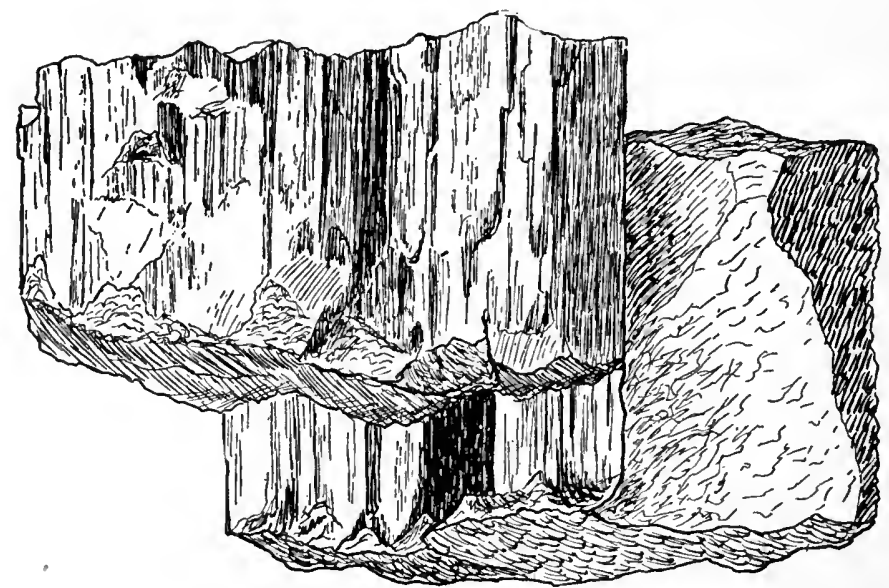

FIG. I72. Stylolite from Trigonodus limestone (Muschelkalk) of Frauenthal. Three-quarters ṇatural size. (After Wagner.) (See Fig. I7I.)

regions. Finally a certain slatiness is observed in the Plattenkalke of the Upper Jura in the Solnhofen region, where layers are split thin enough for roofing slate purposes.

In all these cases the region is undisturbed, and the slaty structure is parallel to the bedding. It is apparently developed as the result of pressure of the overlying rock masses, and, when exposed to erosion, it is developed by the weather in the same way that slaty cleavage is developed by the weather.

\section{c. Of Complex Origin.}

Io. Pressure Sutures and Stylolites.* In massive limestones are not infrequently found irregular sutures or seams, which pene-

* For a recent comprehensive survey of the subject together with discussion of all the theories of origin advanced, and reference to literature, see Wagner-24. 
trate the rock usually in a direction parallel to the bedding planes. These sutures (Drucksuturen of the Germans) range from a scarcely visible size to projections an inch or more in length. They interlock on opposite sides in a most complicated manner, which has led to their comparison with the sutures of a skull (Vanuxem). Such sutures have been found in linjestones of widely varying geological ages and in different parts of the world. They seem to pass by gradation into the true stylolite structures which generally occur in the same or in similar limestone beds. Stylolites generally occur along a horizontal plane of separation, and consist of flutes and slickensided columns of limestone, varying in length up to 4 inches or more, and in diameter up to two or more inches and projecting alternately from the upper and from the lower layer at right angles. At the end of each column is usually a cap of clay, which weathers out in the cliff, leaving hollow cavities. That these structures are due to pressure is suggested by the fact that the fracture line often passes across recognizable organic remains, the two parts of which are displaced in opposite sides of the fracture plane. The structure thus resembles minute faulting, the flutings on the sides of the column being analogous to the slickensides formed at the fault planes. Stylolites are often mistaken for corals or other organic remains. Not infrequently a shell or other fossil remains caps the stylolite, and determines the outline of the fluted column.

Ordinary pressure work has, however, not taken place here, for nowhere is there any evidence of deformation of the beds by crowding or compression above the columns, which project from one face of the suture into the hollows of the other. In other words, if the interlocking of the notch-like projections were due to simple compression before or after solidification, then wherever a hollow occurs there should be evidence above and around that hollow of compression and movement to crowd away the material so as to produce that hollow.

That the structure was produced after the solidification of the rock is shown by the fact that the surfaces of separation are sharp, that the sides are striated and that all evidence of massive deformation or squeezing is wanting. The most satisfactory theory yet advanced to explain these remarkable structures is that they are the result of unequal solution along sutures or fracture planes. If solution takes place on the concave surfaces of both the upper and lower face of the fracture, the result must be the production of a series of tooth-like projections from both sides of the fissures, which, owing to the pressure of the overlying rock, interpenetrate more and more as room is made by solution. In other words, the rock opposite the 
end of each tooth-like projection is dissolved away-the hollows are deepened, and thus the teeth, by gliding under pressure, penetrate deeper and deeper into the opposite bed, while at the same time they become longer by the deepening of the hollows which surround and isolate them. The residual clay, left on solution, comes to rest as a cap on the top of the stylolite, protecting this top from solution.

It is not necessary that the suture or dividing plane should be irregular to begin with. Unequal solution on opposite sides of the plane is sure to occur, since rocks are seldom so homogeneous that all parts are equally soluble. Such irregularity once produced, it will continue to be augmented, for the greatest amount of pressure

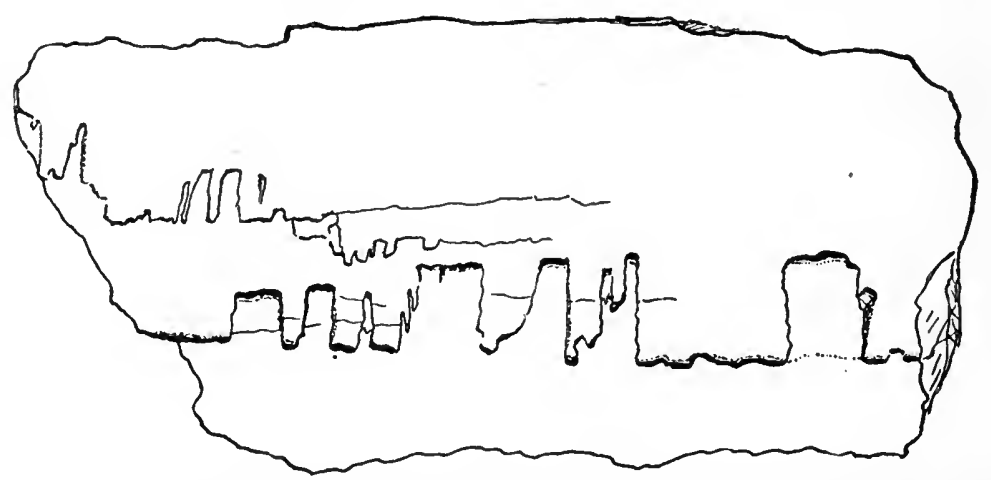

FIG. I73. Sketch of a portion of a limestone face of white Jura $\beta$ in Talheim, showing stylolites. (After Wagner.) The spaces resulting (black) are filled with calcite. (After Wagner.) (Much reduced.)

will occur where the rocks on opposite sides come in contact. The projecting mass, especially if it is crowned by a fossil which is less readily soluble than the enclosing rock, generally suffers the least solution, while the hollow opposite into which it presses suffers the largest amount of solution. The protecting cap of clay also helps this process. The sides of the growing teeth are free from pressure, so solution is absent here, and deposition even may occur. (Figs. r7I-I73.)

The length of the individual stylolite tooth serves as a fair measure of the amount of material removed by solution from both sides of the fracture plane.

II. Cone in Cone. This is a structure sometimes found in lutaceous rocks, particularly in calcareous or ferruginous argillutytes. It consists of a number of crenulated or corrugated conical 
layers one within the other. In the beds they are seen to consist of two sets interlocking from opposite sides, the top and bottom of the beds affected being formed by the bases of the two sets of cones.

Professor Marsh ( 16 ) has suggested that this structure is the result of concretions forming under pressure. It has also been held that crystallization of the calcium carbonate in the bed is responsible for the formation of this structure.

\section{B. Tectonic or Orogenic Deformations.}

Of late the term tectonic has come to be more specially applied in geology to larger rock structures, due to disturbances such as accompany and bring about the formation of mountains. In other words, orogenic disturbances have come to be considered the chief causes in the production of tectonic features. Lateral pressure seems to be the chief active agent responsible for such deformation, but it is by no means certain that the products of such lateral compression are always distinguishable from those of vertical compression by the superincumbent strata.

The various types of tectonic deformation will be considered, beginning with tectonic jointing.

\section{d. Deformation Resulting in Fractures and Related Structures.}

12. Joints. Rocks separated into more or less regular blocks by natural fissures are said to be jointed. Joints may be due to shrinkage on cooling, or on desiccation, forming shrinkage joints, already discussed, or they may be caused by folding or other tensile stresses, giving tension joints, or finally they may be due to compression on folding, forming compression joints. Both tension and compression joints frequently occur together. In tension joints the surfaces will be rough if the rock is arenaceous or rudaceous and the grains weakly held. If the rock is lutaceous or otherwise a strong, tolerably homogeneous rock, the fracture will be smooth and sharply cut. Faulting and slickensiding may develop along such joints when subjected to pressure, and deposit of mineral matter will take place along the joint surfaces.

Daubrée (3) has shown by experiments with glass plates that, if a brittle stratum is subjected to torsion, when the limit of elasticity is reached it will break, with two sets of parallel fractures forming nearly a right angle with each other (Figs. 174, 175). 
Crosby (2) has shown that, if a shock were sent through the strata before this limit was reached, the fracture would be produced in a similar manner. The shock may be produced by the giving way of the first portion of the bed, in which torsion has been carried beyond the resisting strength of the bed, or it may have extraneous causes.

The slight amount of torsion required in a brittle bed is easily accounted for by differential uplift of the bed. It may be illus-

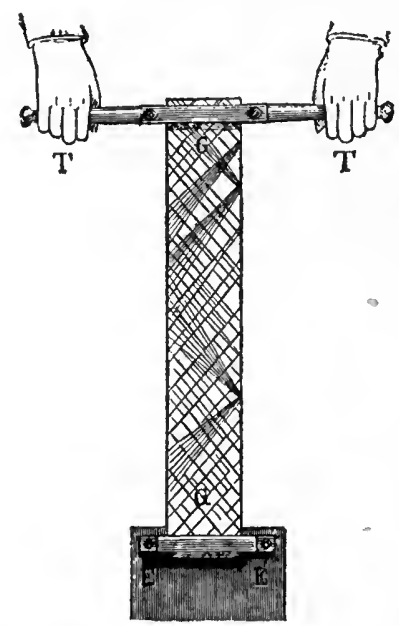

FIG. I74. Illustration of Daubrée's method of breaking a sheet of glass by torsion to produce intersecting joints.

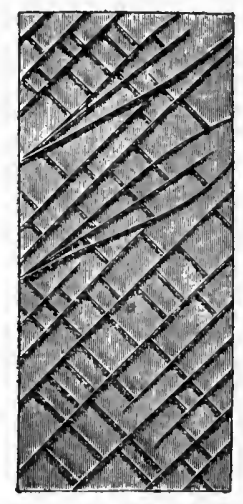

FIG. I75. Arrangement of fractures in glass plate broken by torsion. (Daubrée.)

trated by the torsion produced in a large sheet of stiff cardboard lifted slightly by one corner.

Compression joints are produced in the folding of rocks. Simply folded rocks will have joints in two planes at right angles to each other. Joints of this kind are closely related to fissility, which is distinguishable only by the greater number and closer approximation of the shearing planes. "The same compression might produce fissility along one set of shearing planes and joints along another." (Van Hise-23:67I.)

\section{Minor characteristics of joint faces.}

Feather fracture. This, as shown by Woodworth (26), is characteristic of the joint surfaces of certain fine-grained phyllites or 
siliceous lutytes. It consists of a "delicate tracery of feathery lines diverging from a roughly outlined axis, which traverses the face of the joint block in a plane parallel with the stratification. When the axis of the feather fracture departs from this plane it becomes sinuous." (Woodworth-26.)

Dendritic markings. These are formed on the joint planes of fine-grained rocks, and are due to the arborescent deposit of earthy oxide of manganese or of iron. They may be compared to the plumose frost traceries on window panes. In the so-called landscape marble, this deposit has penetrated the entire rock, and is seen on all polished sections. Dendrites of iron pyrites and other minerals are also known. Not infrequently they are mistaken for vegetable impressions.

\section{Widening of joints.}

Joints of tectonic origin may be widened by separation of the blocks, by solution or erosion of their sides, and in other ways. The Olean conglomerate on the hills of southwestern New York furnishes a good illustration of widening of joints by separation of the blocks. Here huge masses 40 feet in height and of similar basal dimensions have been formed in the coarse conglomerate, and the blocks have in many cases slid far enough apart to open passageways between them. These street-like passageways betwcen the blocks have given the region the name of Rock City. The gliding of the masses is favored by the soft, clayey strata underlying and by the constant erosion which is going on on the hillsides.

Joints in limestones are commonly widened by solution of the wall rock, which when continued long enough will produce cavernlike passages and eventually caves. The peculiar character of the Karst regions of the world is accounted for by such solution. (See ante, p. I33.) Not infrequently partly widened fissures are filled with clay, sand, gravel or other substances from above, constituting a clastic "dike." Sandstone dikes are especially common, though not always originating in solution fissures (see beyond). Fissures thus filled are common in most modern limestone masses, covered by drift deposits. A remarkable example of a Devonic fissure in Niagaran limestone, filled with fossiliferous Upper Devonic shales, has been described by Weller from Illinois (25).

Widening of joint fissures by erosion is of common occurrence. The most active agent is often the wind, which cuts away at the sides of the prism produced by the joints, and narrows it until only a pillar, isolated from its neighbor, remains behind. All stages of 
such erosion along joint cracks may be seen in the Tertiary sandstone of Monument Park, Colorado, where in the ledges the beginnings of this erosion work are seen, while scattered through the park are numerous isolated stone pillars, generally capped by a ferruginous block of greater resistance, the last remnants of an extensive formation which formerly covered the entire region.

I3. Earthquake Fissures. A well-known phenomenon accompanying more or less violent seismic disturbances is the opening of fissures in the rock by the tearing asunder of the mass. Such fissures may remain open or be filled subsequently by the washing into them of surface material, or they may be filled at the time of formation by material violently injected into them from above. Recent fissures have been described by Whimper and others. (See Chapter XXIII.) Examples of such fissures are sometimes found in the fossil state. Thus the Upper Siluric limestones and dolomites of western New York and Ontario are traversed by vertical fissures, which show evidence of violent disruption, and into these fissures sands representing the Oriskany period were injected. These sands apparently rested on the old erosion surface of the Siluric limestone before the shock came. The shock was a pre-Middle Devonic one, for Middle Devonic (Onondaga) strata rest upon this mass without showing any evidence of being affected by the shock. One of the best examples of this group has been described from the cement quarries of North Buffalo.

"The total depth of the fissure as now exposed with its filling of sandstone is in the neighborhood of Io feet. The dike is squarely cut off at the top, where the Onondaga limestone rests on its truncated end and on the limestones flanking it. The Onondaga limestone is entirely unaffected by the dike, being evidently deposited after the formation and truncation of this remarkable mass of sandstone. The width of the fissure is scarcely anywhere over 2 feet, but lateral offshoots extend for many feet into the walls of Bullhead [and Bertie] limestone. These offshoots or rootlets of the dike are irregular, commonly narrow, and often appear as isolated quartz masses in the Bullhead or Waterlimes, the connection with the main dike not being always observable. Such masses of sandstone have been noted at a distance of 20 or 30 feet from the main dike. They are always small. The dike itself has been traced for more than 30 feet in an east and west direction in the sloping walls of the quarry. The walls of this ancient fissure are very irregular, angular masses of the limestone projecting into the quartz rock, while narrow tongues of sandstone everywhere enter the limestone. Extensive brecciation of the limestone has occurred along the mar- 
gin, and the sandstone there is filled with angular fragments of the limestone, which show no traces of solution, or wear by running water. These limestone fragments are themselves frequently injected with tongues of the quartz sand. The nature of the contact between the quartz and the limestone, the trituration of the latter, and the inclusion of individual grains of quartz sand in a triturated mass of limestone, the presence of cavities along the contact filled with recrystallized calcite, the presence of elongated limestone "streamers" in the quartz mass near the contact, all "point to a cataclysmic origin of the fissure . . . and a more or less violent injection of the sand. . . . It seems also certain that the fissure was formed after the deposition of a considerable mass of sand over the ... limestone, and that the formation of the fissure and the injection of sand from above occurred simultaneously. In no other way can we account for the inclusion of horses of the wall rock, often of considerable size, and the injection of the sand into all the fissures and crevices; nor can we readily explain on any other hypothesis the trituration of the limestone along the borders, which clearly indicates a violent contact between the sand and the already consolidated limestone. The supposition that the fissure is due to a violent disruption of the wall . . . is further borne out by the numerous minute faults which occur in the Waterlimes in the vicinity of the fissure and elsewhere." (Grabau-5:360-36r.)

I4. Slaty Clcavage. Slaty cleavage (Leith-I4) is the property of strata to split or "cleave" along certain planes which as a rule have no relation to the planes of stratification. This property is especially well developed in argillutytes, resulting in the formation of "slates," from which the term slaty cleavage has been derived. Slate is therefore a structural term, and has no lithic significance, except in so far as the structure is best developed in the clastic rocks of lutaceous texture, and generally in part at least of argillaceous composition. This rock structure has been explained as "due to the arrangement of the mineral particles with their longer diameters or radial cleavage, or both, in a common direction, and that this arrangement is caused, first and most important, by parallel development of new minerals; second, by the flattening and parallel rotation of old and new mineral particles, and, third, and of least importance, by the rotation into approximately parallel positions of random original particles." (Van Hise-23:635.) (See also page 7\%o.)

The original cause of these changes is the lateral compression of the rocks due to orogenic disturbances. Cleavage may be considered as separation of the laminx, potentially developed in the rock. The 
actual cleavage or splitting is subsequently developed by the frost, or other atmospheric agent, or by the hand of man.

Coarse-grained rocks are seldom affected by cleavage. Limestones likewise offer great resistance to compression, and are not generally cleaved. Thus cleavage may often be developed in a stratum of argillaceous lutytes, while adjoining arenytes or calcareous beds will be unaffected. This sometimes gives rise to the appearance of an unconformity.

Cleaved strata commonly have their original bedding structure obliterated. Only in exceptional cases are the bedding planes preserved, when the strata are differently colored or when a change in texture occurs. In such cases ribbon slates or banded slates are produced. In cleaved fossiliferous strata the fossils may sometimes be detected on the weathered surfaces of the bedding plane, the position of which they indicate. A very general distortion of the fossils accompanies the formation of cleavage, so that in many cases the remains are no longer recognizable.

Unless the relation of cleavage to the bedding is detected, an erroneous conception of the structure of a country is obtained. Strata which are strongly cleaved generally appear to be vastly thicker than they really are, and unconformities are sometimes considered to exist between strata, where in reality the bedding planes are perfectly concordant. If, however, a formation with slaty cleavage is overlain by one without such structure, although of a composition which would permit its development as readily as would the underlying rock, a discordance of relation is indicated, though in the absence of other evidence this is not fully demonstrated. (Van Hise$23: 726$.

I5. Fissility is the structure found in some rocks, "by virtue of which they are already separated into parallel laminæ in a state of nature." It thus differs from cleavage, where this separation is only potential. Fissility belongs in the zone of fracture, while cleavage belongs in that of flowage. Both occur and grade into each other in the zone of combined fracture and flowage.

16. Schistosity. This structure is the result of intense metamorphism under pressure, and is characterized by the development of planes of cleavage due to the presence of large, cleavable particles. It is essentially comparable to slaty cleavage, except that metamorphism has gone farther and the rock has become crystalline. Schistosity may be developed in rocks of many kinds, both clastic and igneous. Foliation is another term applied to these rocks.

The structure is essentially due to recrystallization of the rock 
on mashing. It is often not apparent in fresh rocks, but, as in the case of slaty cleavage, is developed on exposure to the atmosphere.

17. Gneissoid Structure. This structure, like schistosity, results from intense mashing and recrystallization of rocks subjected to symphrattic metamorphism. Gneissoid structure is essentially characterized by banding, the bands being of unlike composition. The mineral particles also interlock so that the cleavage is much less perfect than in schists. Usually it is parallel to the banding, but this is not always the case. Gneissoid structure may be developed in igneous and in clastic rocks. In the former case we have granitegneisses, diortite-gneisses, etc., in the latter arenyte or sandstone gneisses, rudyte gneisses or conglomerate gneisses, etc.

\section{e. Deformations Due to Folding, and to Folding and Erosion.}

18. Folding. Rock folds are among the most conspicuous and easily recognized tectonic features. They vary greatly in magnitude, from the minute wrinkles formed in the axes of larger folds, to those whose limbs are many miles apart. In regions of erosion generally only a part of the fold is found, the folded strata having been truncated and cut down until only portions of the limbs remain. In this way the appearance of tilted strata is produced, these tilted strata being, however, only the remnants of great folds.

The form of folds is very variable, but it has been possible to select a number of distinct types, of which the others are variants. These distinct types are (a) anticline, (b) synclines, (c) isoclines, (d) fan folds, and (e) monoclines. Compound anticlines are anticlinoria and compound synclines are synclinoria.

(a) Anticlines. In this type the sides or limbs of the fold typically slope away from the plane of the axis on either side. The sloping portions are known as the limbs of the anticline, and the amount of slope as compared with the horizontal is the angle of dip. All folds are wrinkles in the earth's crust, and.if followed far enough along the axis they will die out. The amount of inclination of the axis of the fold, also measured from the horizontal, is called the pitch. Every anticlinal axis pitches in two directions, i. e., toward the two ends of the folds. A short anticline in which the two axes are of approximately equal length is a dome.

(b) Synclines. When the limbs of the fold dip toward the axis a trough fold or syncline is produced, the axis of which pitches toward the center of the fold. A short syncline, in which the two axes are of nearly equal length, is a basin. 
Anticlines and synclines may be either symmetrical or asymmetrical, according as the limbs are equal in length and inclination, or unequal. Anticlines may be erect or recumbent. In the latter case one limb of the anticline is overfolded, and the strata composing it are overturned.

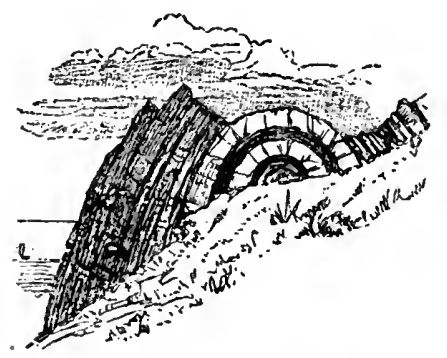

FIG. I76. Anticlinal fold near St. Abbs Head, Scotland. (Geikie.)

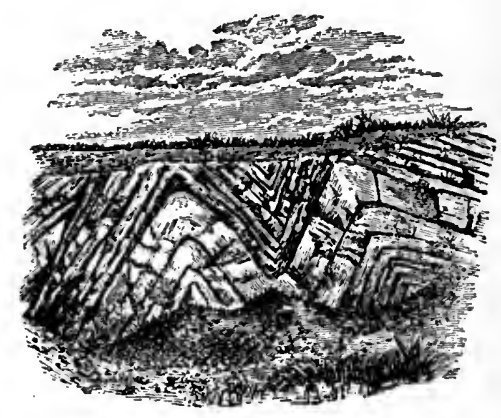

FIG. 177. Two anticlines enclosing a sy ncline truncated above. (Geikie.)

(c) Isoclines. When the limbs of a fold are parallel an isocline is produced. The limbs of such a fold may stand vertically or they may be inclined. In the latter case some portion of the strata involved will always be overturned, $i$. $e$., their original surface now

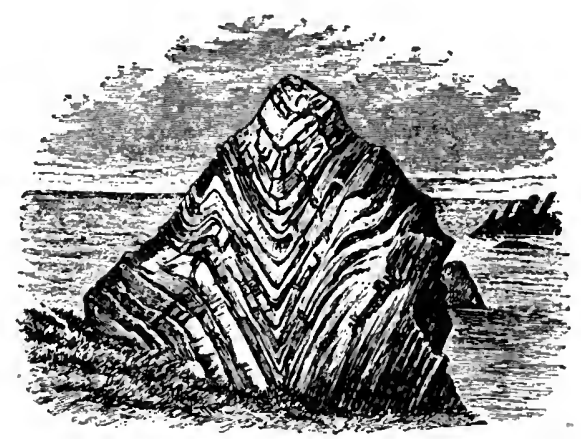

FIG. I78. Synclinal fold near Banff, Scotland. (After Geikie.)

lies below. Nearly horizontall isoclines are produced by overfolds and underfolds.

In a region of isoclinal folds, the most important problem confronting the stratigrapher is the recognition of the repetition of strata and the proper relationship between them. It is evident that a succession of strata, such as is shown in Fig. I79, $a$, may be inter- 
preted as all belonging to one limb of a fold, and therefore representing a continuous series, or as representing one or more isoclinal folds. According to the first interpretation, the sediments have great thickness, and there is a recurrence of similar beds, while, according to the second interpretation, the series is much thinner and the recurrence of beds is only apparent, there being an actual repetition of the same beds. The problem is often a difficult one to solve, and depends upon the identification of the similar beds as parts of the same bed. A knowledge of the degree of folding characteristic of the region in question and a knowledge of the characters and thicknesses of the formations involved in other and undis-

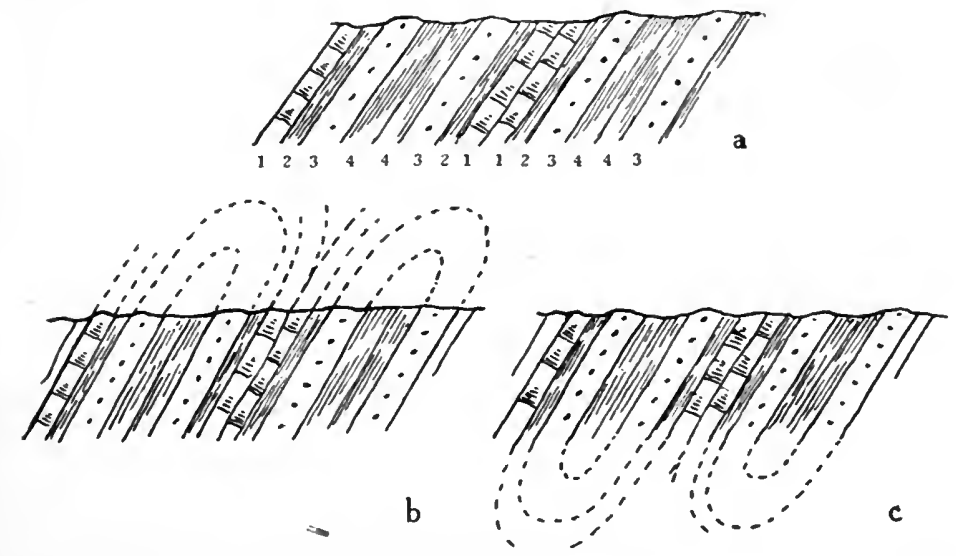

Fig. 179. Isoclinal strata, showing repetition of strata $(a)$ and two methods of reconstructing them $(b, c)$.

turbed regions will often serve to settle the question. If more than two kinds of beds are involved, the order of repetition will often give a clue to the original condition. Thus in a closely folded district, the strata within the same fold will be repeated in inverse order, as shown in Fig. I79, $a$.

This generally is conclusive evidence of repetition by folding. If this point is settled, the next question is: Which bed is the upper and which is the lower of the series? If the character of the folds can be determined by inspection, the proper relation will at once appear, for if, when beds 4 and 4 come in juxtaposition, they present the upper ends of the fold, $i$. $e$., they are parts of an anticline, bed 4 is the oldest and originally the lowest of the series (Fig. $179, b)$.

If, however, the two limbs of the folded bed 4 join below the 
surface in a concave or synclinal fold, bed 4 is the youngest of the series, and formerly overlay all the others. When the actual type of folding cannot be observed, an examination of the beds themselves will often reveal their relationships. Thus, if bed 3 shows normal ripple marks, footprints or other markings (see Chapter XVII) on the surface of any layer facing bed 2 , it is evident that the surface of 3 next to bed 2 was the upper surface of that bed, and that the strata are related, as in Fig. I79, $b$, bed 3 being older than bed 2. If, however, bed 3 shows on the side of its layers facing bed 2 the natural molds or reverse impressions of the markings named, it is evident that that is the lower side of the bed, and that 3 therefore overlies 2 and is younger, as shown in Fig. I79, $c$.

(d) Fan folds. In regions of sharp folding a fan type of fold

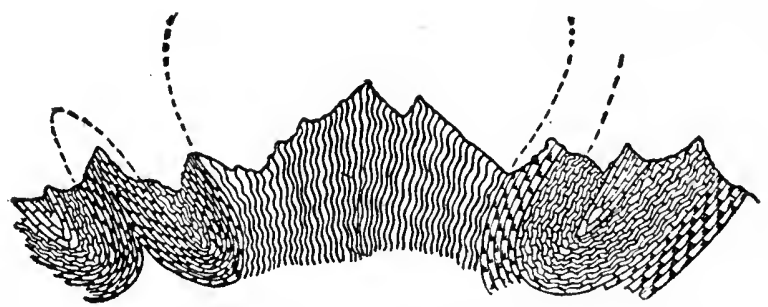

FIG. 180. Generalized section of the fan fold of the central massif of the Alps. (After Heim.)

may be produced, in which the limbs of the arch dip toward each other for a certain distance. Here the lower or concave portions of the fold are pressed inward with the result that the beds at the center of the fold are squeezed out or pinched. This type of fold is characteristic of the Alps and other strongly folded districts (Fig. I80).

(e) Monoclines. Typically a monocline is a part of an anticline, cut off by faulting or erosion. Simple monoclines are those in which the strata have no further continuation. Thus the Front Range of the Rocky Mountains is flanked by a series of simple monoclines, all of which face, with their erosion slopes, the crystalline axis of these mountains. In many cases the continuation of these folds is, however, on the opposite side of the crystalline axis. The Blue Ridge extending from New Jersey for the entire length of the Appalachians is a variable series of eastward facing monoclines. The Appalachians themselves are for the most part composed of complementary monoclines, these representing the opposite limbs of anticlines with the axis opened by erosion. Simple 
flexures of strata are sometines spoken of as monoclines, but these are in reality strongly asymmetrical anticlines. They may be spoken of as monoclinal flexures, but should not be spoken of as monoclines. (Figs. I8I-I83.)
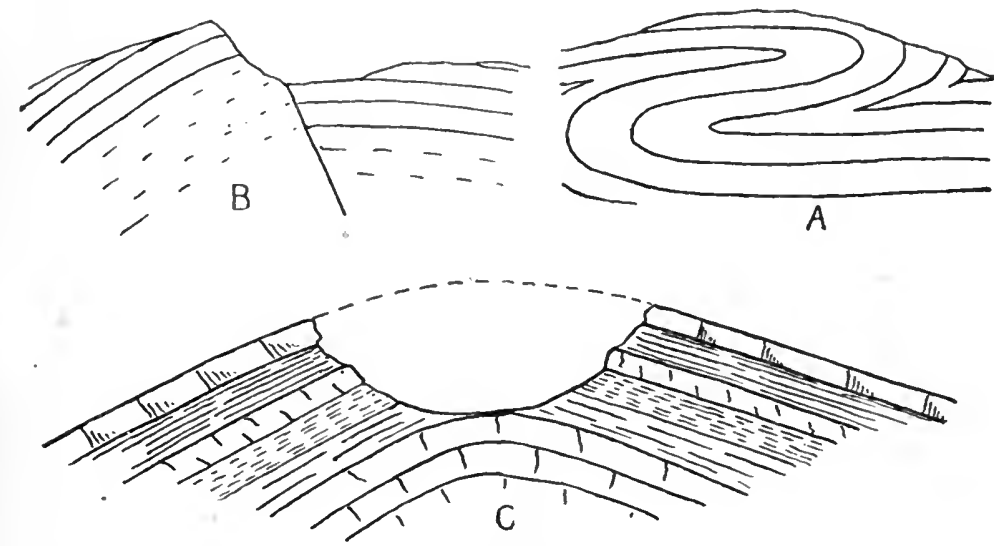

Frg. I8r. A, recmubent isoclinal fold, with over- and underfolds. B, monocline due to faulting. C, corresponding monoclines, due to erosion of an anticline.

Anticlinoria and synclinoria. When a succession of anticlines has suclf a relationship as to make a large anticline, it is called an anticlinorium. The central massif of the Alps may be taken as an illustration. In like manner a large synclinal fold composed of a succession of minor folds is a synclinorium. Such a condition exists

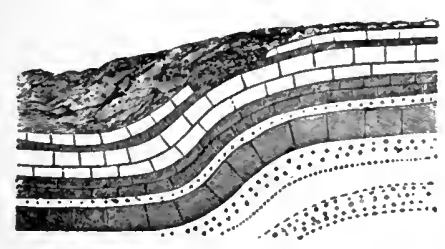

Fig. 182. A simple monoclinal flexure.

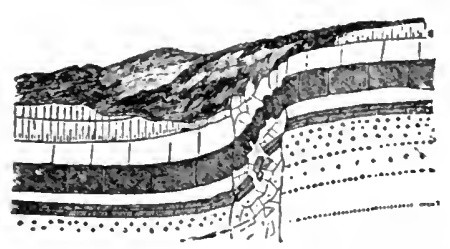

FIG. 183. The same passing into a fault.

in the Mount Greylock massif of western Massachusetts. (Figs. I84, I85.)

Geosyncline and foredecp. The term "geosyncline" was proposed by Dana for the long trough which formerl to the east of the Appalachian old land during Palæozoic time. In this trough some 
40,000 feet of strata, partly of marine and partly of continental origin, were deposited. It is evident that there must have been a gradual downbending of the old land to permit this extensive series of deposits to accumulate. This depression should not, however, be regarded as primarily of tectonic origin. It is much more likely that it represented the slow sinking of the crust under loading and that its formation was due to the progressive reëstablishment of isostatic equilibrium. The foredeeps, which are situated off the continental margins, are probably of a different character. Here we have in general downward-bending troughs, next to the land mass, where, however, there is no great amount of deposition. Such down-warping of a part of the ocean bed may well be regarded as

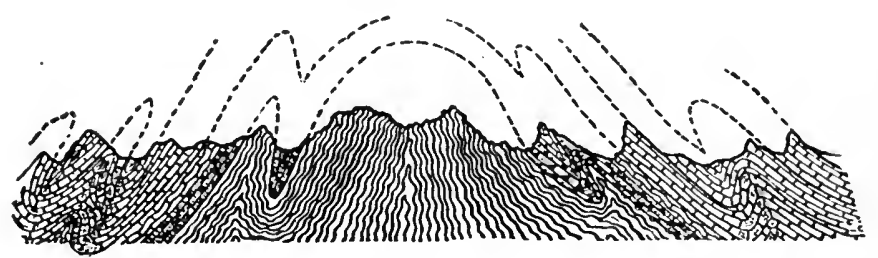

FIG. I84. Anticlinorium. Generalized section in the Alps. (After Heim.)

of tectonic origin, serving to relieve the accumulating stresses in the earth's crust. An examination of the ocean bottom charts will locate the existing foredeeps. (See further, Chapter XXIII.)

\section{Relation of dip, strike and outcrop.}

Dip has already been defined as the inclination of the strata from the horizontal. Strike may be defined as the compass-bearing of the line of intersection which the stratum in question makes with a horizontal plane. It may also be spoken of as the compass-bearing of the edge of the inclined bed when cut off by a horizontal plane. The direction of strike is determined by conpass, with reference to the true north and south line, $i . e$., the meridian. A wrong direction is often furnished by the outcrop of the stratum on a sloping surface. If the slope of the surface and the dip of the strata are in the same direction, varying only in amount, or if the slope and dip are in exactly opposite directions, no difference will be observed between outcrop and strike. (Fig. I86a.) Again. if the strata stand vertically, no difference will be observed between 
outcrop and strike (Fig. I86b), no matter what the surface slope. In all other cases, however, the outcrop on a sloping surface will differ in direction from the true strike of the strata, and is apt to mislead unless this fact is borne in mind. In general, it may be said that the lines made by the intersection of inclined strata with a sloping surface have their down-slope end deflected in the direction of the dip of the strata. (Fig. I86c.) If the dip is vertical, this deflection will not alter the direction. If the lines of inter-

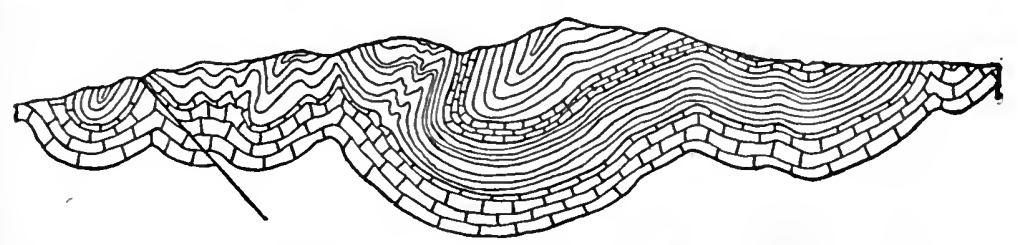

FIG. 185. Synclinorium. Mt. Greylock, Mass. (After Dale.)

section run at right angles to the slope of the surface, there is no down-slope end, and hence no deflection. (Fig. 186a.) Again, it should be stated that the true strike and the true dip are always at right angles to each other, and any slope whose intersection with the inclined stratum makes a line at right angles to the line of dip must show the true strike in the outcrops in its surface. (Fig. 186a.)

In the diagram, Fig. I 86c, the inclined plane, $\mathrm{A} \mathrm{B} \mathrm{C} \mathrm{C} \mathrm{C}^{\prime} \mathrm{A}^{\prime}$ has its outcrop and strike coinciding where cut by the horizontal surface

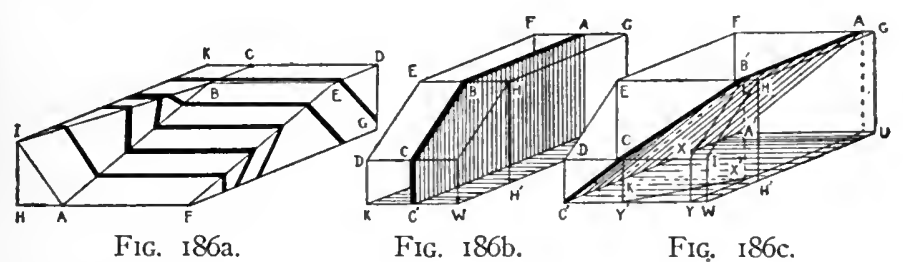

E F G H, but where cut by the inclined surface D E H I the outcrop is deflected toward the down-dip side. It is evident from comparison with Fig. I86b that any vertical plane, as A B X Y Z, whose intersection with the horizontal surface coincides with that of the inclined plane $\mathrm{A} \mathrm{B} \mathrm{C} \mathrm{C}^{\prime} \mathrm{A}^{\prime}$, will intersect the inclined surface along a line $\mathrm{B} X$ continuous with the line A B and having the same compass direction. This is evidently the true strike, and the angle X B C marks the angle of deflection from this direction of the intersection of the inclined plane on the sloping surface, $i$. $e$., the 
angle of deflection of the strike. Its projection on a horizontal plane is the angle $\mathrm{Y}^{\prime} \mathrm{X}^{\prime} \mathrm{Y}$.

The amount of deflection of the strike, by a sloping surface, may be seen by the following consideration: Given a stratum dipping due west, at an agle of 45 degrees, a horizontal surface intersecting this will show the true strike due north and south. Given a second surface, whose intersection with the horizontal surface is at right angles to the strike, $i$. $e$., due east and west in the given case, and which also intersects the inclined plane. If this surface is tilted to the vertical, $i$. e., if the beds are seen in vertical section at right angles to the strike of the inclined bed, the outcrop or intersection of this stratum with the surface will coincide with the dip, $i . e$., the

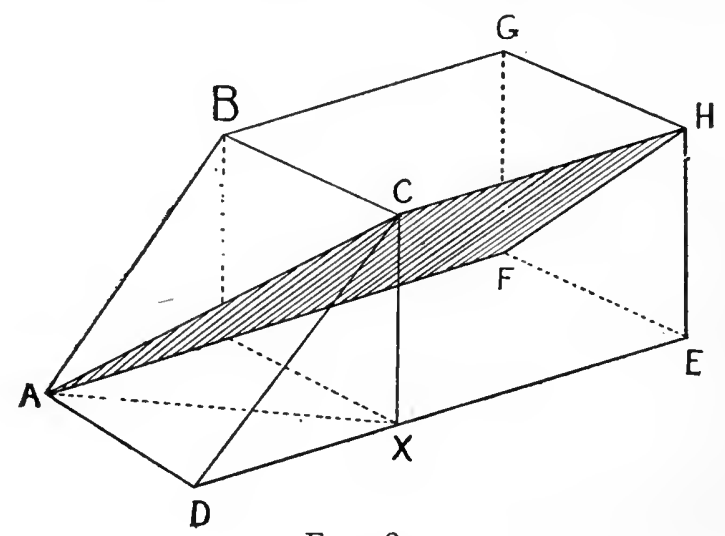

FIG. 187.

line of outcrop as inarked by compass direction has been deflected $90^{\circ}$ by a tilting of the surface to the extent of $90^{\circ}$. If the surface is tilted $45^{\circ}$, the line of intersection as marked by compass direction will evidently lie halfway between the two or N. $45^{\circ} \mathrm{E}$. by $\mathrm{S}$. $45^{\circ}$. (Fig. 187.) Thus in the model the shaded bed A C $\mathrm{H} \mathrm{F}$ is inclined at $45^{\circ}$ from the horizontal, while the surface A B $\mathrm{C} \mathrm{D}$ is also inclined $45^{\circ}$ from the horizontal, but in a direction at right angles to that of the bed $\mathrm{A} \mathrm{C} \mathrm{H} \mathrm{F,} i$. $e$., its intersection with the horizontal surface is at right angles to the strike of the bed. Thus, by construction, $\mathrm{X} \mathrm{Y}=\mathrm{X} \mathrm{C}=\mathrm{X} \mathrm{D}$, hence A X, being the diagonal of the square A D X Y, makes an angle of $45^{\circ}$ with $\mathrm{DXE}$ and with the direction of $\mathrm{C} \mathrm{H}$. It is evident that the line of intersection $\mathrm{C} \mathrm{H}$ between the inclined bed and the horizontal surface $\mathrm{B} \mathrm{CH} \mathrm{G}$ is the true strike. It is also the strike of the vertical bed C H E D. The line C D, the intersection of this vertical plane with 
the sloping surface A B C D, has the same compass direction as $\mathrm{C} \mathrm{H}$, and hence represents the true strike. The line $\mathrm{A} \mathrm{C}$, however, the intersection between the surface A B C D and the plane A C $\mathrm{H} \mathrm{F}$, is deflected $45^{\circ}$ from that direction, since its direction corresponds to that of the line A X, the diagonal of the square A D X Y.

With a constant surface, as given, and sloping at $45^{\circ}$, the outcrop of a vertical stratum will have no deflection from the line of strike. As the stratum becomes inclined from the vertical the downslope end will be deflected in the direction of dip, a degree for every degree of departure of the dip from $90^{\circ}$. When $45^{\circ}$ of dip are reached the deflection will be $45^{\circ}$. With decreasing dip, $i$. e., its approach to $0^{\circ}$, the deflection will approach $90^{\circ}$, which is reached when the strata are horizontal. When the slope of the postulated surface is other than $45^{\circ}$ the deflection of the strata must be calculated. Designating the dip of the stratum by $\theta$, the angle of inclination of the sloping surface from the horizontal by $\phi$ and the deflection of the outcrop by $\psi$, we have $\tan \psi=\cot \theta \tan \phi$ or $\psi=$ $\tan { }^{1}(\cot \theta \tan \phi)$.

It sometimes happens that only the outcrop of inclined strata is visible on the surface of a region, the angle of dip not being ascertainable. In such a case the angle of deflection $(\psi)$ can often be measured directly by taking a reading of the true strike on a horizonta1 portion of the surface and another of the apparent strike on a sloping surface, where the intersection with the horizontal is at right angles with the strike. The angle of slope of this surface $(\phi)$ must also be read by the clinometer. Thus with the values of two terms of the equation ascertained the third or angle of dip ( $\theta)$ may be readily found by the formula $\tan \theta=\tan \phi \cot \psi$ or $\theta=\tan -1(\tan \phi \cot \psi)$.

An example may further illustrate this: Given an inclined stratum of which the true strike as shown by the intersection with a horizontal surface is $\mathrm{N}$. $10^{\circ} \mathrm{E}$., while the apparent strike on an inclined surface of the postulated direction of slope is N. $30^{\circ} \mathrm{W}$., the angle of deflection of outcrops between horizontal and inclined surface, $i . e ., \psi$, is therefore $40^{\circ}$. The angle of slope of the inclined surface may be assumed as $30^{\circ}$. Thus the dip is: $\tan \theta=\tan$ $30^{\circ} \cot 40^{\circ}$ or $0.6882608 ; \therefore \theta=$ about $34^{\circ} 32^{\prime}$. The direction of dip is to the east, since the deflection was to the west.*

The above formulas apply only to the case where the inclined surface intersects the horizontal along a line at right angles to the true strike, $i$. $e$., when the directions of slope of the inclined strata and surface are at right angles to each other. When the direction of slope of surface varies from this, the amount of deflection will 
increase or decrease according as the direction varies toward or away from that of the inclined strata. Thus the more nearly the direction of slope of the inclined surface approaches that of the inclined strata, the more nearly will the amount of deflection approach 90 degrees, while the more the direction of slope approaches the opposite of that of the strata the more nearly will the true strike be approached. The following formulas will serve in such a case. In Fig 188.

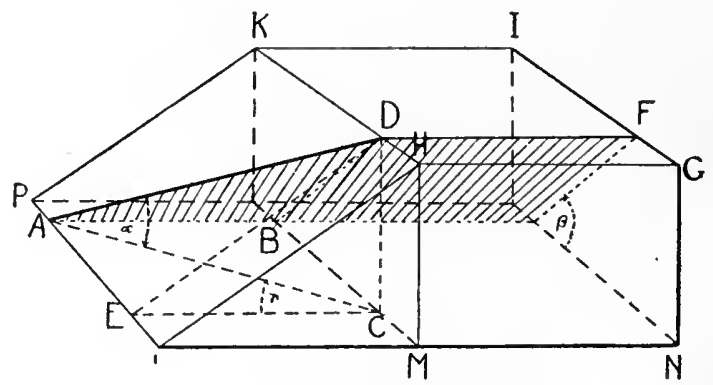

FIG. 188.

Let A D represent the outcrop of a stratum along a sloping hillside.

D B represent the dip of the stratum.

$a=$ outcrop dip, or the angle C A D made by the line of outcrop A D with a horizontal plane obtained by placing the clinometer on the line of outcrop A D.

$\beta=$ the angle of dip of the stratum, B D K or C B D in diagram.

$\gamma=$ the angle by which the outcrop is shifted by the slope of the hill (A C E).

$$
\begin{aligned}
& \text { Then } \sin \gamma=\frac{\tan \alpha}{\tan \beta} \text { or } \gamma=\sin -^{-1}\left(\frac{\tan \alpha}{\tan \beta}\right) \\
& \text { and } \tan \beta=\frac{\tan \alpha}{\sin \gamma} \text { or } \beta=\tan -^{-1}\left(\begin{array}{c}
\tan \alpha \\
\sin \gamma
\end{array}\right)
\end{aligned}
$$

* It should be noted that, as viewed from above, the deflection is in the direction of the dip, but, as viewed from below, looking up the plane, the deflection is in the opposite direction. This must be borne in mind when the compass direction is read; that on a northward sloping plane will be read from above, that on a southward sloping plane from below. 
The following method is given by Keilhack $(12: 65,66)$ for the determination of the true dip and strike when observations are possible only on vertical cliffs or quarry walls (Fig. 189):

Given two dip observations on vertical quarry walls, one of $65^{\circ}$, on a wall, the compass alignment of which is N. $45^{\circ}$ W., and one of $45^{\circ}$ on a wall, the alignment of which is N. $65^{\circ}$ E. Draw two lines at $a b$ and $a c$, the former at an angle of N. $45^{\circ} \mathrm{W}$., and the latter N. $65^{\circ} \mathrm{E}$., so that they intersect in the point $a$. At the point $a$ erect perpendiculars to $a b$ and $a c$. Lay off equal distances on these from $a$, locating the points $e$ and $d$, respectively. At $d$ lay off the

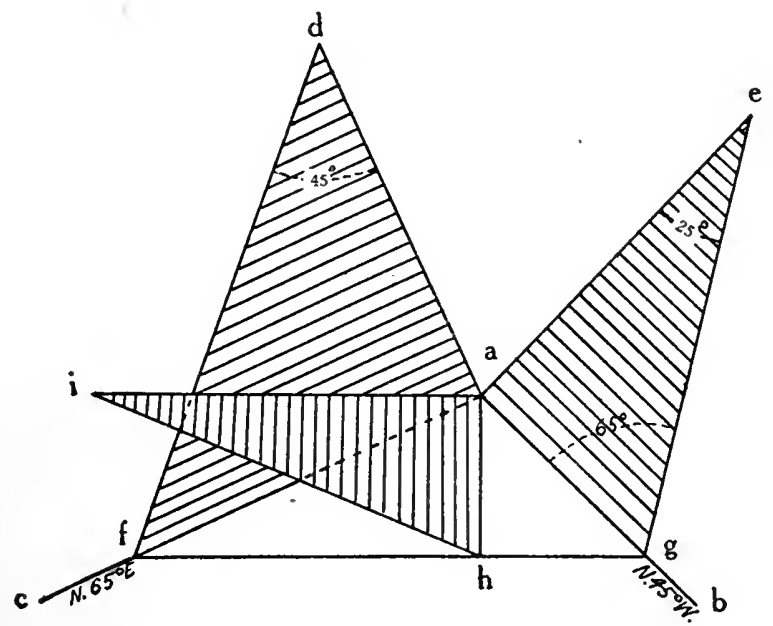

FIG. I89.

complement of the angle observed on the wall represented by $a c$, that is, the complement of $45^{\circ}$, which is $45^{\circ}$. At $e$ lay off the complement of the angle observed on the wall represented by the line $a b$, that is, the complement of $65^{\circ}$, which is $25^{\circ}$. Complete the right angle triangles by continuing the hypothenuses until they meet the lines $a c$ and $a b$, at $f$ and $g$, respectively. Join $f g$ by a line which represents the true strike of the strata, which if $a c$ and $a b$ are properly oriented can be readily measured. Drop a perpendicular $a h$ from $a$ to $f g$. This is the direction of dip toward either $a$ or $h$, as the case may be. Erect a perpendicular to $a h$ at $a$, and lay off the length $a d(=a e)$, on it, locating point $i$. Connect $i$ and $h$, then the angle $i h a$ is the angle of true dip. This will be readily understood if the three shaded triangles are bent at right angles to 
the plane of the paper, either up or down, until the three sides $a d$, $a e$ and $a i$ coincide with the apices of all three $(d e i)$, meeting in a common point. The triangles $a d f$ and $a e g$ would then represent the walls of which the original dip measurements were made, the angles in each case being represented by the angles $a f d$ and $a g e$, respectively. A plane resting on the three hypothenuses would represent the inclined stratum.

Strike as affected by pitching axis of folds.

As long as the axis of an anticline or syncline continues horizontal, the outcrops of the beds exposed by planing off the summit of the fold in a horizontal surface will be in the form of parallel bands, the lowest appearing at the center and the repetition of the

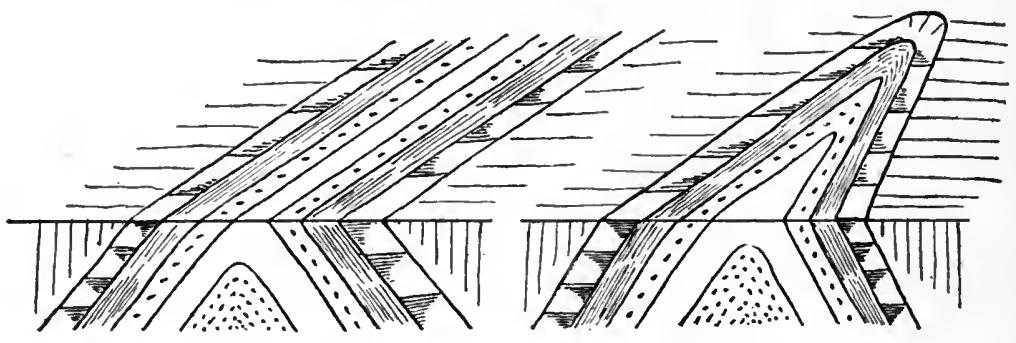

a

b

FIG. 190. $a$, Eroded anticline with horizontal axis. $b$, Eroded anticline with pitching axis, showing resulting outcrops of strata.

beds being in the same order from the center outward in both directions. (Fig. I90, a.)

When the axis of the fold is inclined the strike of the strata on opposite sides of the axial plane will converge and finally meet. (Fig. I90, b.) In an anticlinal fold the inner strata are the older; in a synclinal fold the inner strata are the younger.

\section{Folding as indication of unconformity.}

In a complexly folded region an unconformity may sometimes be detected between two formations not actually seen in contact by the fact that the lower formation is folded much more strongly than the upper one. In this case it is apparent that the lower formation was folded and truncated before the upper one was deposited, after which both were again folded. (See Fig. I9I.) 
The trend of the Appalachian folds.

The Appalachians furnish a good example of an extended line of folding formed at approximately the same time, $i$. $e$, , the end of the Palrozoic. They show a remarkable series of curves of varying size, which, with reference to the land, may be called convex or land lobes, when they bulge seaward, and concave or sea lobes, when they extend back into the land. (See the map, Fig. 192.) Beginning in the southwest, we have the following:
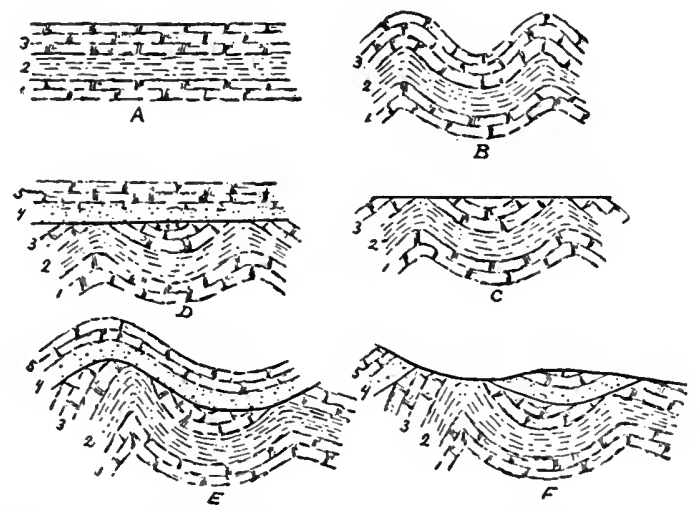

FIG. 19I. Diagrams showing the steps by which complexly folded strata are produced. A-C, deposition, folding and truncation of first series; $\mathrm{D}-\mathrm{F}$, deposition, folding and erosion of second series, the folding and erosion also affecting the first series.

I. Louisiana sea lobe, extending from Texas to central Mississippi with the apex near Little Rock, Arkansas, and with probably a subordinate land lobe at McAlester in Oklahoma.

Ia. Mississippi land lobe, extending through northern Mississippi and northwestern Alabama.

2. Birmingham sea lobe, a small lobe in central Alabama.

2a. Rome land lobe with a moderate curve.

3. Knoxville sea lobe, with its apex looping around the Knoxville area.

3a. Alleghany land lobe-along the main line of the Alleghany Mountains of Virginia.

4. Pennsylvania sea lobe, a marked lobe with the apex in central Pennsylvania, the trend changing to nearly east.

4a. New York land lobe, the apex being near New York City.

5. Champlain sea lobe, east of the Adirondacks. 
5a. Maine land lobe, along the northwesern boundary of Maine.

6. Gaspé sea lobe, a pronounced lobe, the trend actually changing to southeast $\left(40^{\circ}\right)$.

6a. Cape Breton land lobe, the change of trend being near Sydney, Cape Breton, the trend again turning northeastward and continuing thus through Newfoundland.

19. Domes and Basins. Domes are shortened anticlinal structures with the dip of the strata away from the center in all directions or quaquaversal. These dips may vary greatly in different domes. In some cases they are so low as to be scarcely or not at all perceptible (Cincinnati dome); in others they may be $45^{\circ}$ or over (Black Hills dome). Many of the low-clipping. domes are perceptible as such only by the erosion which has removed their central portion, often leaving a topographic depression. Such low domes have also been called parmas, after one of the low east and west ranges which project from the western side of the Urals (which have a north-south trend), and which are formed by gently folded strata, the folds dying out in the plains.

Basins are the reverse of domes, the strata all dipping toward the center. As a rule, basins are composed of gently dipping strata only so that their basin character is recognized only by the rimming outcrops of the lower strata after erosion (Michigan basin, Paris basin, etc.). Between two basins lies generally a more sharply marked anticline, while between two domes a pronounced syncline often occurs. Sometimes the basin structure is ascertained by the location by borings all over the area of the summit (or bottom) of a certain formation, such as a coal bed or a marked sandstone. Thus the basin structure of Iowa is beautifully brought out by the series of contours connecting areas of equal depression beneath the surface of the summit of the St. Peter sandstone. (Iowa Geol. Survey, Vol. VI, p. 3 I 6 , map.)

Eastern North America is marked by a number of distinct basins and domes, many of which are indicated by the outcrops, while others are recognized only from their general relationship and the occurrence of separating anticlines or synclines. All of these basins and domes owe their final character to the Appalachian folding, but some of them apparently existed during much of Palæozoic time. The accompanying map (Fig. 192) shows the location of these dones and basins. It will be observed that the outermost basins are generally embraced by convex lobes of the Appalachian system, while the concavities of that system are opposite domes or opposite anticlines separating basis. (See also Ruedemann-22; Willis-3o.)

The principal basins so far determined are in the northeast, the 


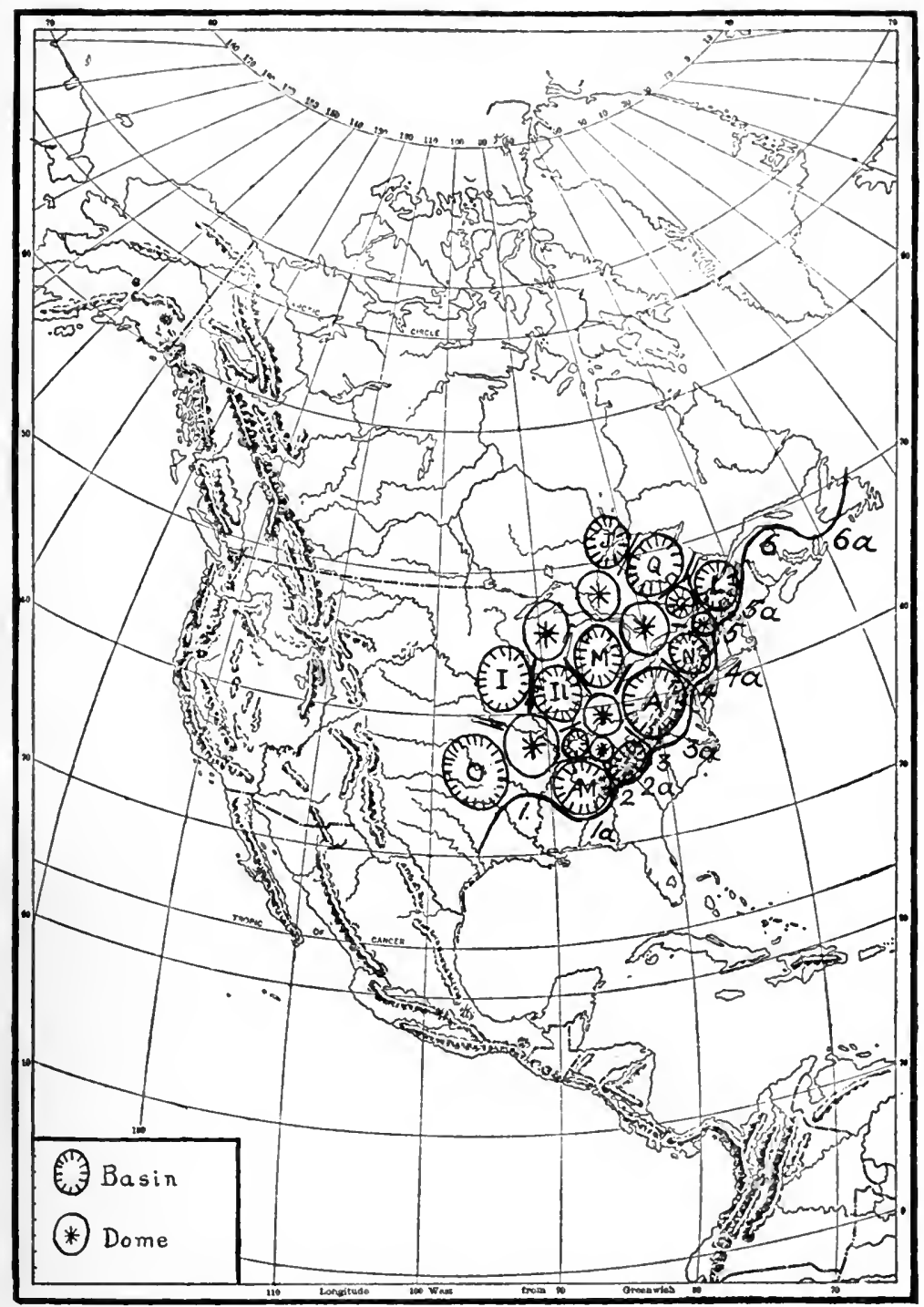

Fig. 192. Map of North America, showing the sinuous trend of the Appalachian folds (see text) and the domes and basis. $\mathrm{A}=$ Alleghany basin; A.II=Alabama-Mississippi hasin; I=Iow'a hasin; $\mathrm{I}=$ Illinois basin; $\mathrm{J}=$ James Bay basin; $\mathrm{L}=S t$. Lacrerence basin (Montreal, etc.); $\mathrm{M}=$ Michigan basin; $\mathrm{N}=\mathrm{N}_{\mathrm{c}}$ ' York basin; $\mathrm{O}=$ Oklahoma basin; $\mathrm{O}=$ Ottarwa basin; $\mathrm{Q}=\mathrm{Qucbcc}$ basin. The line or lines between basins represent anticlines. The domes are: The Adirondack; west of this the Ontario; north of this the North Ontario; southwest of this the Wisconsin dome. In the southern area are: the Cincimati, the Nashille, and the Ozark domes. 
St. Lawrence, the Quebec, the Ottawa, and the New York. The Frontenac axis separates the last two basins, and joins the Adirondack dome to the Ontario dome. Northwest of the latter is the North Ontario dome, the Temiscaming syncline separating the two. To the north of this is the James Bay Basin. Next southward of this series is the Alleghany basin, embraced by the Alleghany land lobe of the Appalachians on the east. Northwest of this is the Michigan basin, these two being separated by the Toledo anticlinals. Nortlowest of the Michigan basin is the Wisconsin dome, which is separated from the North Ontario dome by the deep Superior synclinals. Southwest of the Wisconsin dome is the Iowa basin, and southeast of this the Illinois basin, with the Keokuk anticline between. The Illinois and Michigan basins are separated by the Kokomo anticline. The Cincinnati dome is enclosed by the Illinois, Michigan and Alleghany basins, and south of it is the smaller Nashville dome, with small basins on either side. The southern tier is formed by the Alabama-Mississippi basin in the embrace of the Mississippi land lobe, the Ozark dome, and the Oklahoma basin.

\section{f. Deformations Due to Dislocation of Strata. Faulting.}

20. Faults. "A fault is a fracture in the rock of the earth's crust accompanied by a displacement of one side with respect to the other in a direction parallel with the fracture." (Reid, etc.-I8; I9.)

"A closed fault is one in which the two walls of a fault are in contact."

"An open fault is one in which the two walls of a fault are separated. The same fault may be closed in one part and open in another."

"A fault surface is the surface of fracture. It is rarely plane, but where it is without notable curvature over any area it may be called a fault plane for that area.

"A fault line is the intersection of a fault surface with the earth's surface."

"The shear zone: When a fault is made up of a number of slips on closely spaced surfaces, the section of the earth's crust containing these minor faults is called 'shear zone.' This name would also apply to the brecciated zone, which characterizes some faults."

"A horse is a mass of rock broken from one wall and caught between the walls of the fault. (Fig. 193a.) 
"The fault strike is the direction of the intersection of the fault surface, or the shear zone, with a horizontal plane." The same precautions apply here as in the case of the strike of the strata on a sloping hillside. (See p. 8oo.) The term "trend" would be better and would avoid confusion.

"The fault dip is the inclination of the fault surface, or shear zone, measured from a horizontal plane. It is never greater than $90^{\circ} . "$

"The hade is the inclination of the fault surface or shear zone, measured from the vertical ; it is the complement of the dip." Hade is to be preferred to dip to avoid confusion with dip of strata. (See beyond.)

"The hanging z'all is the upper wall of the fault." It generally overhangs the vertical.

"The foot wall is the lower wall of the fault." It generaily projects footwise at the base.

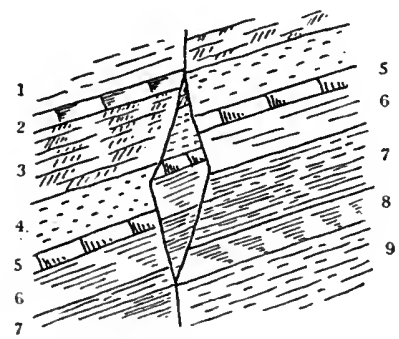

FIG. 193a. A horse.

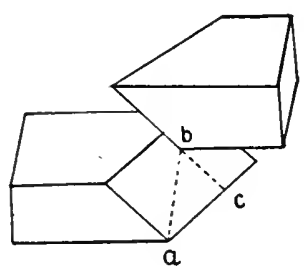

FIG. 193b.

In stratified rocks faults may be parallel in strike to the strike of the strata, when they are called strike faults, or the strike may be approximately at right angles to the strike of the strata, when they are called dip-faults. The bedding fault is a special type of strike fault, in which the fault plane and bedding plane coincide. Between the strike faults and the dip faults are many directions giving oblique faults. When the general structure of a region is considered, the faults may be called longitudinal, when their strike (or trend) is parallel to this structure, or transverse, when it is across the structure.

The slip of a fault is the displacement on the fault surface. The net slip is the actual amount of movement between points on the opposite walls originally in contact. The $s t r i k e^{*}$ slip (trend-slip)

* Strike and dip here refer to the strike and dip of the fault, not of the strata. Trend and hade would be better. 
is the component of the slip parallel with the strike, and the dipslip (hade slip) the component parallel with the dip. Thus (in Fig. I93b) $a b$ is the net slip, $a c$ the strike-slip and $b c$ the dipslip.

The shift is the relative displacement of the rock masses outside of the zone of displacement, and is used when there are many minor slips making up the shear zone or when the strata in the neighborloood of the fault are bent. It is the relative displacement which would exist had there been only one slip of the same magnitude as the combined minor slips.

Features shown in section of faults.

Throw is the vertical displacement of the strata, as seen in sections, even if the slip is inclined, $d e$ in the figures (No. 194, A B).

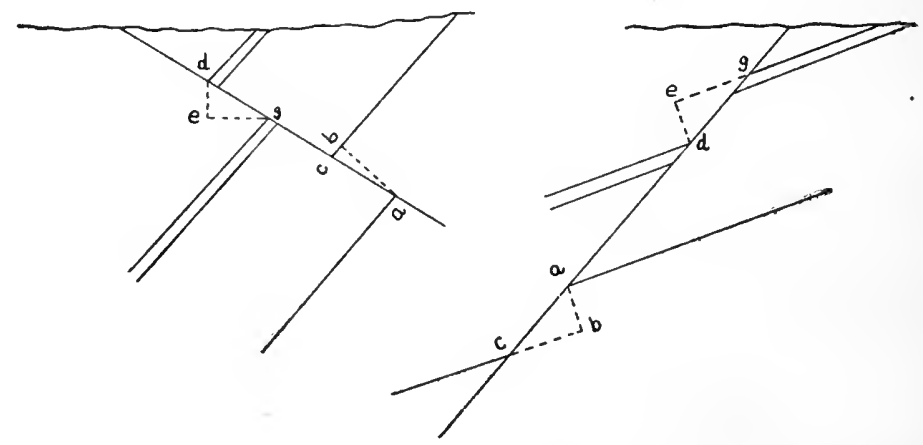

A

B

FIG. 194. Sections of faults: A, with dip of fault plane across strata; B, with dip of fault plane in same direction as dip of strata.

Heave or horizontal throw is the horizontal displacement of strata seen in section, as $e g$ in the figures (No. 194, A B).

Stratigraphic throwe. This is the distance between the two parts of a disrupted stratum measured at right angles to the plane of the stratum. ( $a$ b, Fig. I94, A B.)

The stratigraphic heave, or dip throw, is the displacement of the strata in section in the direction parallel to the strata, as $c b$ in Fig. I94, A B. In Fig. A it signifies shortening and overlapping of the strata, in Fig. B, lengthening by separation of the strata. 
Features shown in surface appearance of faults, i. e., map features of faults.

These features are seen in strike and oblique faults. In the former the apparent horizontal displacement or offset is measured along the fault line, and is the same as the actual horizontal distance between the ends of the corresponding strata $(a b)$. (Fig. I95 A.) This is the same as the trend-slip, but is probably never or but seldom the actual or net slip. In oblique faults the offset is

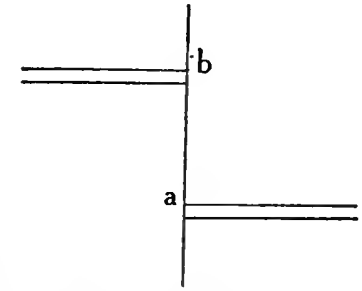

A. Map of Strike Fault

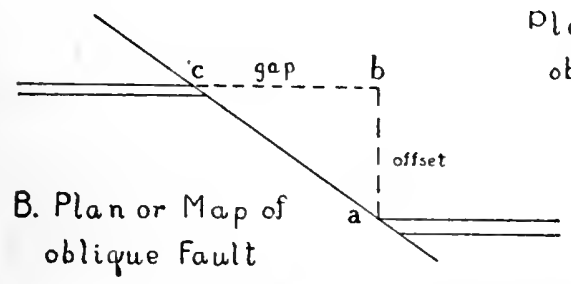

Fig. 195. Map or surface views of faults.

measured at right angles between the two ends of the disrupted strata, as $(a b)$ in. Figs. $195 \mathrm{~B}$ and $\mathrm{C}$, where the trend-slip is marked by $a c$. In Fig. B, the strata are disrupted and pulled apart; the distance thus separated is the gap. In Fig. $C$ the ends are pushed past each other, making an overlap, $c b$.

\section{Classification of faults.}

Faults have been classified with reference to direction, as strike (and bedding), dip and obliaue faults. With reference to their movements, they nay be classified into normal and reverse faults, 
and with reference to the force producing them they may be classified as gravity and thrust faults. $V$

With reference to direction. The classification with reference to direction has already been in part explained. It includes strike faults, dip faults and oblique faults, with reference to the strata. With reference to each other, they may be parallel, intersecting or radial, the last when radiating roughly from a point. With reference to a geological region whether raised or depressed (geologically, but not necessarily topographically), they may be peripheral, when running along the periphery of the geological formation, or cross-faults when they cut across it.

With reference to movement. Movement is relative. If the stratum of the hanging wall in any given section is lower, it is designated a normal fault. If the stratum of the hanging wall is higher, it is a reverse fault.

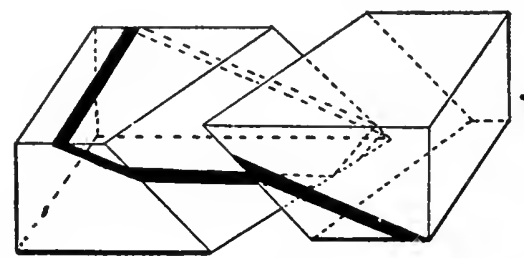

A

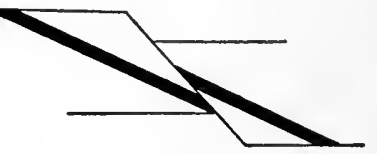

B

FIG. Ig6.

With reference to cause. In most cases normal faults probably mean a tension and a down-sinking of the hanging wall, accompanied by an elongation of that part of the crust. In this case the normal fault would also be a gravity fault. In like manner the reverse fault generally implies an upward movement of the hanging wall with consequent foreshortening of the crust by overlapping under pressure. In such a case the reverse fault is also a thrust fault. Under certain conditions, however, a gravity fault may in section show the conditions of a reverse fault (Figs. 196, A B), for, though the hanging wall has slipped down, owing to the oblique character of the displacement and the dip of the strata, the beds seem actually to have slipped up over each other.

In like manner a thrust fault may in section show the characters of a normal fault, the ends of the strata on the hanging wall being actually lower than on the foot wall. This is shown in Figs. 197, A B. 
Terms applied to rock masses formed by or bounded by faults-but not topographically distinguishablc from surrounding masses.

I. A horst is a mass geologically elevated relatively to the surrounding region and separated from it by faults.

2. A fault basin is a region geologically depressed relatively to the surrounding region from which it is separated by faults.

3. A fault block is a mass bounded on at least two opposite sides by faults. It may be geologically elevated or depressed relatively to the adjoining region, or it may be geologically elevated

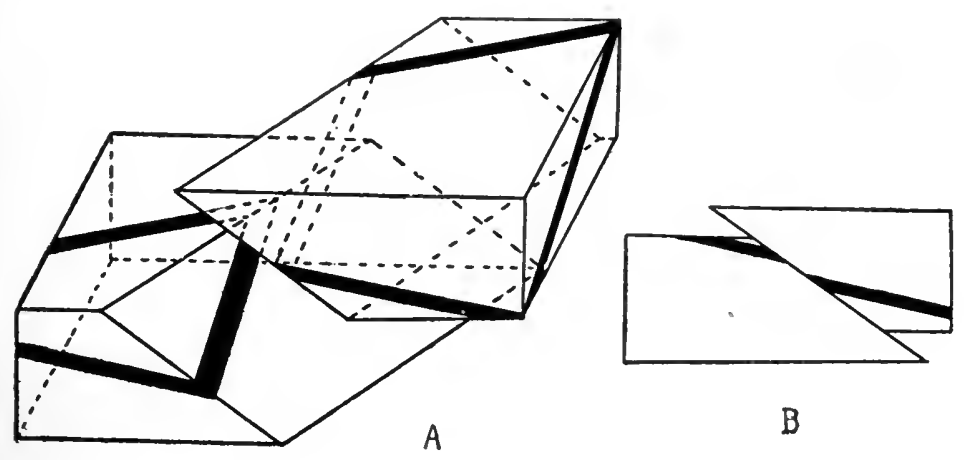

FIG. 197.

relatively to the region on one side and depressed relatively to that on the other.

4. A fault ridge is a relatively elongated fault block lying between two faults with roughly parallel trends.

5. A fault trough is a relatively depressed (geologically) fault block lying between two faults with roughly parallel trends.

Terms applicd to the topographic expression of faults.

I. Fault scarp-a scarp or cliff presenting the original surface form of the displacement.

2. Graben, or fault scarp valley-a long, narròw topographic depression, the surface expression of a new fault trough. Ex. Rhine Graben; Purgatory Chasm, near Sutton, Mass. It is bounded on both sides by fault scarps facing inward. 
3. Fault scarp ridge-a topographic ridge bounded by two roughly parallel fault scarps which face outward or toward the surrounding low country.

4. Fault scarp block-a topographic block bounded on all sides by outward facing fault scarps.

5. A tilted block-a topographic block bounded on all but one side by fault scarps facing outward. The excepted side may be faced by the fault scarp of another tilted block.

6. A fault scarp basin-a topographic basin bounded on all sides by fault scarps facing inward.

7. A complex scarp basin-a topographic basin boinded on

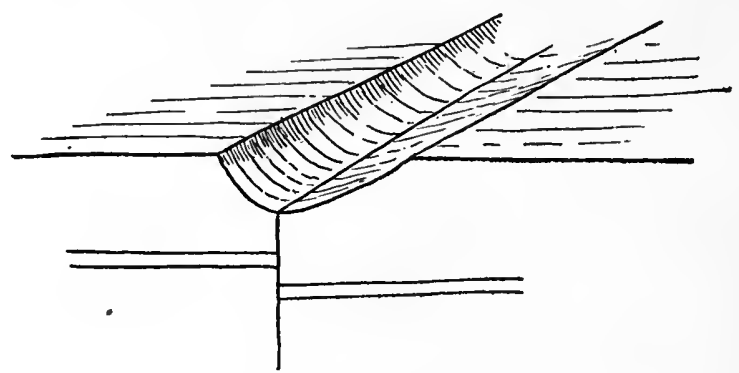

FIG. 198. A fault-line valley.

most of its sides by fault scarps facing inward, but bounded by warpings or in other ways on one or more sides.

\section{Secondary features due to erosion.}

I. Fault-line scarp. (Davis-4.) This is the fault scarp resurrected in the second cycle of erosion, after the obliteration of the original fault scarps. This may face either way and may be greater or less than the original fault scarp. If it faces in the same direction as the original fault scarp it is resequent; if in the opposite direction it is obsequent.

2. Fault-line valley-a valley cut out along an old fault-line after the obliteration of the original fault scarp. (Fig. 198.)

3. The graben and fault scarp basin, the fault scarp ridges, fault scarp block and tilted block may all be destroyed by erosion and then resurrected in the second cycle of erosion. Such cases may be designated by prefixing the word erosion-an erosion graben, erosion fault scarp basin, erosion fault scarp. ridge, etc. See, further, Davis (4) and Hobbs (9a); also Chapter XXI. 
Stratigraphic significance of faults.

From the stratigraphic viewpoint, strike faults are of the greatest importance, for they often lead to a duplication of strata or to the elimination of certain beds. Many mistakes in stratigraphy have been made because of the nonrecognition of such faults. The Ogden quartzite, for example, regarded as a distinct formation in the western Ordovicic, has been shown to be a repetition of a lower formation due to overthrust. In the Helderberg region of New York, near Kingston, duplication by overthrust has led to the confusion of the stratigraphy. The overthrust New Scotland beds were originally described as the Upper Shaly (Port Ewen), and the higher formation was held to have the same fossils as the lower one.

In discussing the effects of strike faulting on the apparent succession of strata, eight principal cases may be considered :

A. Gravity faults. (Figs. I99, A-G.)

I. Dip of fault plane with dip of strata, but at greater angle. (Fig. A.) In this case elimination of beds will take place.

2. At smaller angle. In this case repetition of beds will. take place. (Fig. B.)

3. Dip of fault planes against dip of strata. In this case repetition of beds will result. (Figs. C-E.)

4. Dip of fault plane vertical (hade o). The "down dip" portion descends. In this case elimination of beds results. (Fig. F.)

5. The "up dip" portion descends. In this case repetition results. (Fig. G.)

B. Thrust faults. (Figs. I99, H-J.)

6. Dip of fault plane with dip of strata, but at greater angle, repetition results. (Fig. H.)

7. Dip at smaller angle-elimination results. (Fig. I.)

8. Dip of fault plane against dip of strata. In this case elimination of strata results. (Fig. J.)

A consideration of the diagram, Figs. A to J, will show that the plane of faulting cuts the inclined strata so as to leave a portion which is limited below by the fault-plane, but may extend indefinitely upward except as limited by the earth's surface. This portion may be called the "up-dip" end of the strata ( see the figures). The other part is limited above by the fault plane, and may extend indefinitely downward. This is the "down-dip" end $(d)$ of 
the strata. When the fault plane cuts the obtuse angle between the strata and the surface, $i$. $e$., when its dip is greater than that of the strata, the "up-dip" end lies on that side (to the right of the plane in the figures). When it cuts the acute angle, $i$. $e$, dips at a less angle than the strata, the up-dip end lies on the acute side (left side of the fault plane in the figures). With the part thus oriented, the
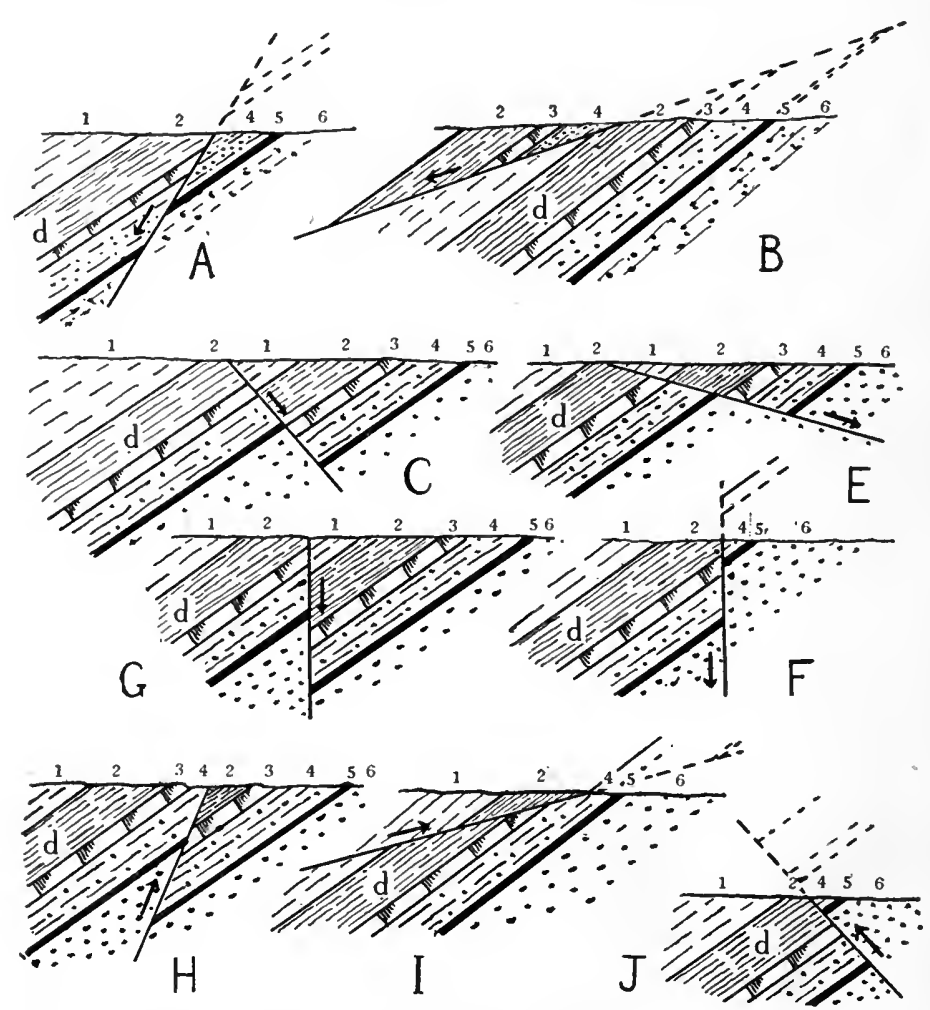

FIG, 199. Sections showing the effects of strike faults in eliminating beds $(\mathrm{A}, \mathrm{F}, \mathrm{I}$ and $\mathrm{J})$ and in repeating beds (B, C, E, G, and $\mathrm{H}$ ).

general law may be stated that, if the "up-dip" end moves down, we have repetition of strata, while, if the up-dip end moves up, elimination of strata results. Conversely, when strata are repeated or eliminated, the up-dip end must be assumed as having moved either down or up. If the angle of the fault plane is ascertained, the fault will appear to be either thrust or gravity, according to the greater or less angle of inclination of the fault plane, as compared with the 
strata, and the repetition or elimination of the strata. The general rule can be easily ascertained at any time by a consideration of the simple case shown in Figs. F-G. There it will be readily seen that, when the up-dip end is moved up, elimination results, and when it is moved down repetition occurs, or, to put it the other way, when the down-dip end moves up repetition occurs, but when the downdip end moves down elimination occurs.*

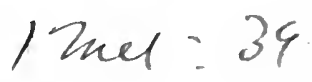

\section{Faults as indications of unconformity.}

If in two superposed formations of similar character and susceptibility to faulting the lower is more complexly faulted than the upper, the indications are that the lower was faulted before the upper was deposited upon it, and that then the two formations are unconformably related.

\section{Relation of folds, faults, cleavagc, fissility and joints.}

Van Hise has emphasized the close relationships existing between these structures, which may in general be considered as different manifestations of the same forces-thrust and gravity-acting upon heterogeneous rocks under varying conditions. When rocks are under less weight than their ultimate strength, while being rapidly deformed, they will break, with the formation of crevices, of joints, faults, brecciations or fissility, as a result of extensive fracturing. Such rocks are then regarded as being in the zone of fracture. When rocks are buried to such a depth that the weight of the superincumbent strata exceeds their ultimate strength, they will flow as plastic material under deforming strains and folding without fracture results. The depth at which this takes place marks the position of the zone of plasticity and flowage. The depth at which flowage occurs varies with the character of the rock. For soft shales, Van Hise estimates that probably 500 meters or less of overlying strata will prevent the formation of crevices and fractures to any considerable extent, while for the strongest rocks a depth of perhaps 10,000 meters is required to reach this condition. Cleavage normally belongs in this zone. Between these two is the zone of combined fracture and plasticity. In this zone all the structures occur together in complex relationship. Folds may pass into faults and faults into folds. Fissility and cleavage occur side by side.

* This may be condensed into the slogan-down, down, out. 
Downward probably most faults pass into flexures, these flexures dying out at still greater depth. Van Hise thinks that 5,000 meters is a possible depth, at which important faults disappear, though some may extend to the depth of a number of miles. Others, however, regard the necessary depth as very much less.

\section{Contact Deformations.}

Under this heading may be placed changes in the rock mass as a whole, produced by contact with a deforming agent. The deforming force is heat or cold, and the agents conveying the former are igneous masses (intruded or extruded), hot waters or gases, and the direct rays of the sun. Heating rock masses by any of these agents results in expansion of the rock. The agents conveying cold are glaciers and the cold atmosphere. Their action on the rocks results in contraction. The chief structures produced by these agents singly or in conjunction are prismatic jointing and insolation joints.

21. Prismatic Jointing Due to Contact with Igneous Masses. When igneous masses come in contact with sedimentary rocks a prismatic structure is not infrequently developed. This has been noted in clays, marls, sandstones, brown coal, seam coal and even in dolomites. Beautiful examples of this structure are found in the coal seams of Ayrshire.

In all cases of prismatic jointing thus produced, the columns diverge perpendicularly from the surface of the igneous mass which caused the alteration. When the latter is vertical, the columns are horizontal; when it undulates, the columns follow its curvation. It is most probable that this structure is developed as the result of expansion of the heated rocks. That such structure can develop under pressure due to expansion is shown by an experiment in which prismatic structure is formed in a box of powdered starch, stored for some time in a moist region. The swelling of the starch exerts a pressure in all directions against the sides of the enclosing box, and after a time a series of prismatic columns is developed which radiate from the center outward, being at right angles in most cases to the enclosing walls. Prismatic structure produced by swelling seems also to have occurred in nature, as is shown in the gypsum beds of the Paris Basin (probably originally deposited in part at least as anhydrite), where, as observed by Jukes, some beds are divided from top to bottom by vertical hexagonal prisms. If this structure is due to swelling on hydration, as in the case of the 
starch cited, it belongs properly under the subject of diagenetic alterations. Thus there are at least three ways in which prismatic structure is produced:

r. Contraction and shrinking, on cooling or drying.

2. Expansion and pressure by heating from without.

3. Expansion and pressure by swellings from hydration.

22. Insolation Joints. These are joints produced in massive rocks, such as granite, etc., by the alternate expansion and contraction to which they were subjected under the diurnal heating and cooling. Such joints are parallel to the surface subjected to change in temperature, and are close together in the outer portion of the mass, but farther apart at a depth. They serve an excellent purpose in quarrying operations, which in such rocks would be more difficult otherwise.

\section{Structures in Part Due to Deformation and in Part to Erosion.}

23. Disconformity and Unconformity. Strata separated by an unrepresented time interval are generally spoken of as unconformably related. Two types of such unconformable relation may be recognized, the stratic where the stratification of the formation on both sides of the plane of nonconformity is parallel or nearly so, and the structural, where the two sets of strata are inclined at a greater or less angle with reference to each other.

For the first type, in which no folding of the older set of strata is involved, the term disconformity has been proposed (Grabau-6: 534), with the corresponding limitation of the term unconformity to the second type, or that in which folding plus erosion of the first set of strata precedes the formation of the second set.

Crosby (2a) has called attention to the unsatisfactory character of the prefix dis, since it means divergence rather than parallelism. He prefers to divide unconformity into para-unconformity (parunconformity) - the disconformity of Grabau, and clino-unconformity (clinunconformity) for the angular type with discordant strata. Heim (9) had previously proposed the term paenaccordani for approximate conformity with the strata nearly parallel. This, as Crosby says, is not quite the equivalent of the parunconformity, which implies crustal oscillation, rather than deformation, whereas Heim's term suggẹsts rather gradation between true conformity or accordanz, and unconformity or discordanz. 
Disconformity (Parunconformity, Paenaccordans). When strata are elevated without folding or other disturbances, and subjected to a prolonged period of erosion, after which their truncated edges are covered by other strata, either marine or nonmarine, a stratic unconformity or disconformity (parunconformity, paenaccordanz) is produced. Here a hiatus, measured by the length of time during which the lower strata were exposed to erosion, plus the amount worn away during this exposure," separates the two series. While this hiatus measures the unrepresented strata it must be borne in mind, however, that it does not represent the length of time during which deposition was interrupted in the region in question. The amount of nondeposition can be determined only when the

\begin{tabular}{|c|c|c|}
\hline$b$ & & $b$ \\
\hline$a$ & & $a$ \\
\hline$A$ & $I$ & $B$ \\
\hline
\end{tabular}

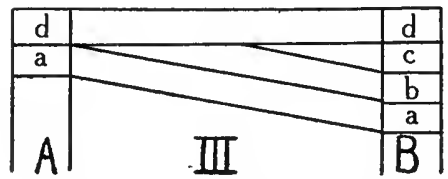

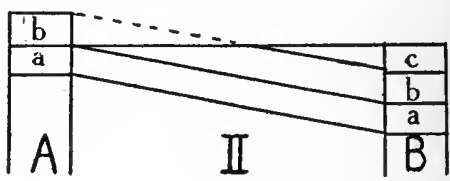

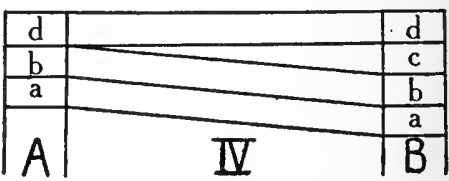

FIG. 200. Diagrams illustrating the development of disconformities.

amount of erosion during the elevation of the region is known. We may assume two locations A-B, where elevation may occur or some other changes by which deposition continued uninterruptedly at B, while erosion replaced it at A. (Fig. 200, I-IV.) Under assumed conditions a formation $c$, equal in thickness to formation $a$, may be deposited at $\mathrm{B}$, while $b$ is eroded at $\mathrm{A}$. If later deposition becomes uniform again in both localities, $d$ will rest conformably on $c$ at locality $\mathrm{B}$, but disconformably on $a$ at $\mathrm{A}$. The hiatus at locality A comprises formations $b$ and $c$, but the actual time interval is measured only by the deposition of formation $c$ at locality $\mathrm{B}$. In this case the erosion at $\mathrm{A}$ was assumed to equal the amount of deposition at $B$, and hence the hiatus at $A$ represents twice the amount of the time interval involved, as developed at $\mathrm{B}$.

If erosion at $A$ exceeds deposition at $B$, then the hiatus at $A$ representing a definite time interval will be greater than twice the depositional equivalent of that time interval at $\mathrm{B}$, by an amount proportional to the excess of erosion over deposition. If erosion at $\mathrm{A}$ 
is exceeded by deposition at $\mathrm{B}$, then the hiatus at $\mathrm{A}$ will be smaller than twice the depositional equivalent by a corresponding amount. When the amount of erosion is zero at $\mathrm{A}$, the hiatus will be represented by the deposit at $\mathrm{B}$ above, when formation $d$ will rest disconformably on $b$ at $\mathrm{A}$, instead of resting on $a$. (Fig. 200, IV.)

The disconformity at A may be scarcely indicated in the strata, and, if it were not for the fact that formations elsewhere found intercalated between the two strata (as at B) are missing here, the disconformity would not be recognized at all. Very many such disconformities exist in our formations, but few of them are readily recognized on account of the parallelism of the strata. Sometimes an erosion interval and the subsequent encroachment of the sea are indicated by the existence of a basal conglomerate in the later formation, which includes fragments of the earlier one. In some cases, where a rapid transgression of the sea took place, or where fine, residual soil on the old surface is but slightly reworked, such basal rudytes may be wanting; and the two formations follow apparently with perfect conformity upon each other. This is the case with the black Chattanooga shale, where it rests upon the Rockwood clays in the Appalachians. The hiatus here comprises the whole of the Devonic and part of the Siluric as well, yet the contact, though abrupt, appears like a conformable one. Careful examination should, however, reveal in such cases a more or less imperfect upper surface of the lower bed, where some traces of erosion are still visible. When this upper surface is an undoubted deposition surface, $i$. $e$, when it shows no traces of erosion whatever, and when furthermore the succeeding beds show no evidence of derivation from the underlying bed, the existence of a disconformity may be doubted.

Examples of contacts where disconformities have been assumed, but are not supported by evidence of erosion, are the contact between the pyritiferous Brayman shale and basal Siluric sandstone (Binnewater) in the Schoharie region, and the Oriskany-Esopus contact in the Helderbergs of eastern New York. In the former case the Brayman shales are known to be of Salina age, while the sandstones on which they rested were regarded as of Lorraine age. There is, however, no evidence of a hiatus comprising most of the Siluric between these two formations, the basal arenyte being too intimately related to the shale and of the same age. The hiatus, known to exist in this region, occurs at a lower level, unless, indeed, as has recently been suggested by Ruedemann and others, the Brayman shale is Upper Ordovicic. The Oriskany-Esopus contact of the Helderbergs also has the aspect of a conformable one. This 
conformity if fully established has even a more far-reaching significance. Where a marine formation is abruptly succeeded by a continental formation, the existence of a possible hiatus between the two must be taken into consideration. Recently the tendency has manifested itself in certain quarters to greatly multiply the number

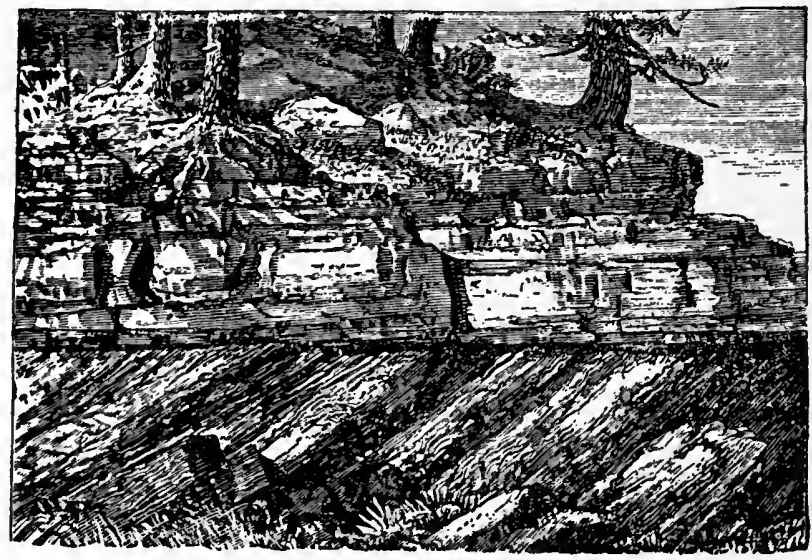

FiG. 20I. Basal Palæozoic sandstone resting unconformably upon gneissuid granite, Williams Canyon, Colorado. (After Hayden.)

of disconformities. (Ulrich-22a.) In many cases the apparent absence of a formation between two others is merely due to a change in facies so that the formation is actually present, but in a different lithic or faunal facies or both.

Unconformity (Clinunconformity, Discordanz). (Figs. 20I-202.)

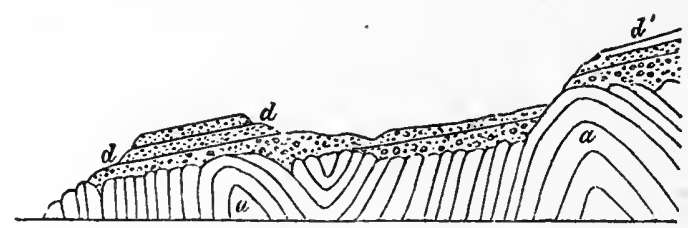

FIG. 202. Unconformity at Siccar Point, Scotland. $a$ a, Ordovicic strata, $d, d, d$, Old Red Sandstone. (After Lyell.)

The structural unconformity is readily recognized and the one generally detected wherever it occurs. This type of unconformity involves the folding of the older strata, and the subsequent erosion of the folds followed by the deposition of the later strata upon the eroded edges of the older beds. This type of unconformity 
may often become complicated by further folding and crosion, when the complex relationship shown in Fig. I9I is produced.

In all cases of structural unconformity a considerable time in-

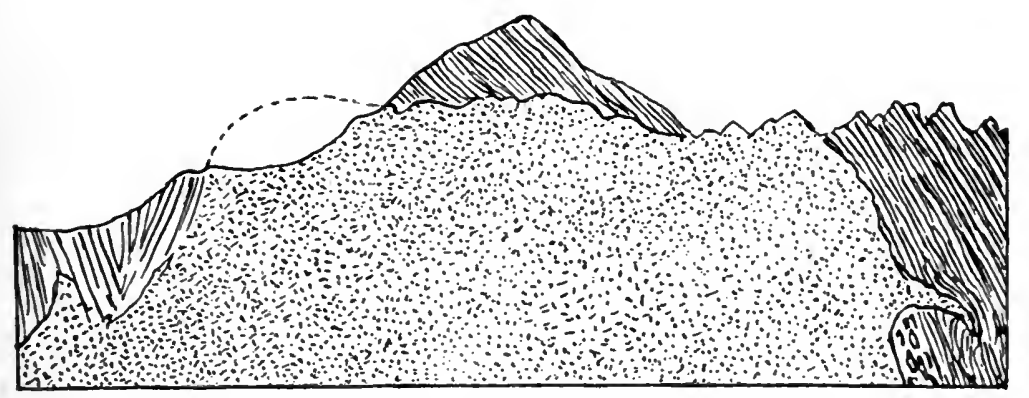

FIG. 203. Cross-section of the Aletschhorn, showing inverted unconformity of schists upon the laccolithic crystallines. (After Baltzer.)

terval remains unrecorded. This is measured by the amount of folding and erosion which the strata have undergone. In this circumstance it is often the case that the last deposited strata prior to the time that folding and erosion commenced were folded down to

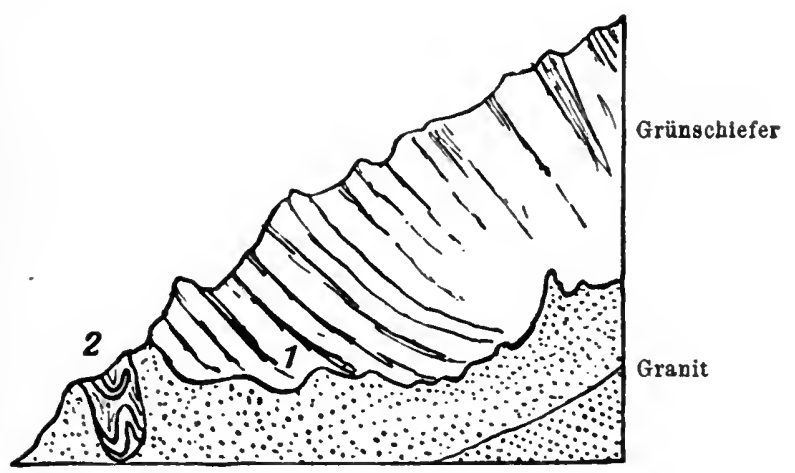

FIG. 204. Detail of the peak of the Aletschhorn. I, dragging of greenslate at granite contact; 2 , infolding of greenslate into the granite.

such an extent that they were preserved from complete removal by erosion. Especially is this the case when the folding has been so intensive as to place the strata in parallel positions, $i$. $c$., isoclinal folding. In this case the actual time interval, during which no deposition went on in the region in question, may be determined by a comparison of the ages of the youngest stratum in the folded 
series with that of the first stratum unconformably overlying the series.

Unconformities and disconformities are often suggested by the occurrence of dikes of igneous material in the. lower rocks, which do not penetrate the upper beds. Stronger folding or faulting in the lower than in the upper series also suggests an unconformity, as shown below. As a unique example of an indicated disconformity may be cited the sandstone dikes filling fissures in the Siluric limestones of western New York and Canada, the overlying beds being wholly unaffected by these fissures and dikes because a later deposit. Faulting affecting a lower set of strata, but not a higher one, also indicates a disconformable relationship, and a hiatus representing a sufficient time interval to allow for the removal of the fault scarps of the lower series.

The appearance of an inverted.unconformity, where the later strata end abruptly against the older ones, may be produced by intense folding of the rocks of a complex region, as shown in the figures of the structure of the Aletschhorn on page 825. (Figs. 203204.)

Conformable or accordant strata may also show a variety of aspects. Crosby has shown that on the Atlantic coastal plain of North America, the strata wedge out landward.* This wedging conformity, where the formations are thinner in one locality than in the other, though fully represented, Crosby has called sphenoconformity, and its correlative, where the strata are of uniform thickness, he calls planoconformity. If contemporaneous faulting of the older series goes on with the deposition of the newer, fractoconformity is produced.

\section{BIBLIOGRAPHY XX.}

I. BROWN, THOMAS C. 1913. Notes on the Origin of Certain Palæozoic Sediments, Illustrated by the Cambrian and Ordovician Rocks of Center County, Pennsylvania. Journal of Geology, Vol. XXI, pp. 232-250.

2. CROSBY, WILLIAM O. I893. The Origin of Parallel and Intersecting Joints, American Geologist, Vol. XII, pp. 368-375.

2a. CROSBY, W. O. I9I2. Dynamic relation and terminology of stratigraphic conformity and unconformity. Journal of Geology, Vol. XX, No. 4, I912, pp. 289-299.

3. DAUBRÉE, AUGUSTE. 1879. Etudés synthétiques de Géologie Experimentale, pp. 300-374.

4. DAVIS, WILLIAM M. I9I3. Nomenclature of Surface Forms on Faulted Structures. Bulletin of the Geological Society of America, Vol. XXIV, pp. $187-216$.

* A part of this is no doubt due to actual breaks in the series, which disappear seaward. 
5. GRABAU, AMADEUS W. 1900. Siluro-Devonic Contact in Erie County, New York. Bulletin of the Geological Society of America, Vol. XI, pp. 347-376.

6. GRABAU, A. W. 1905. Physical Characters and History of Some New York Formations. Science, N. S., Vol. XXII, pp. 528-535.

7. HAHN, F. FELIX. 1912. Untermeerische Gleitung bei Trenton Falls (Nord Amerika) und ihr Verhältniss zu Ähnlichen Störungsbildern. Neues Jahrbuch für Mineralogie, etc. Beilage Band XXXVI, pp. 1-41, Taf. I-III, I9I2.

8. HEIM, ARNOLD. I908. Ueber rezente und Fossile Subaquatische Rutschungen und deren Lithologische Bedeutung. Neues Jahrbuch für Mineralogie, etc., 1908, pt. II, pp. I36-157.

9. HEIM, ARNOLD. I908. Die Nummuliten- und Flysch-bildungen der schweizer Alpen (discusses Accordanz, Discordanz, Paen-accordanz). Abhandlungen der schweizerischen Palæontologischen Gesellschaft, XXXV, 1908, p. 173 .

9a. HOBBS, WILLIAM H. I9I1. Repeating Patterns in the Relief and in the Structure of the Land. Bulletin of the Geological Society of America, Vol. XXII, pp. I23-176, pls. 7-I3.

Io. HOW, JOHN ALLEN. I9I3. Joints. Encyclopedia Britannica, I Ith edition, Vol. XV, pp. 490-49I.

II. HYDE, J. E. 1908. Desiccation conglomerates in the Coal Measureslimestone of Ohio. American Journal of Science, Vol. XXV, pp. $400-408$.

12. KEILHACK, KONRAD. 1908. Lehrbuch der Praktischen Geologie, 2te auflage, Stuttgart.

13. KOKEN, E. 1902. Ueber die Gekrösekalke des Obersten Muschelkalkes am Unteren Neckar. Centralblatt für Mineralogie, etc., 1902, pp. 74 et seq.

14. LEITH, C. R. 1905. Rock Cleavage. Bulletin of the U. S. Geological Survey, no. 239.

15. LOGAN, Sir W. I863. Geology of Canada, I 863, pp. 391 et seq.

16. MARSH, OTHNIEL C. I868. On the origin of the so-called lignites or epsomites. Proceedings of the American Association for the Advancement of Science, Vol. XVI, pp. I35-1 43 .

17. MILLER, W. J. I909. Geology of the Remsen Quadrangle. New York State Muscum Bulletin I 26, 1909.

18. REID, H. F.; DAVIS, W. M.; LAWSON, A. C.; and RANSOME, F. L. 1912. Proposed Nomenclature of Faults. Advance Publication, Geological Society of America, Bulletin 24.

19. REID, H. F.; DAVIS, IV. M.; LAWSON, A. C., and RANSOME, F. L. 1913. Report of the Committee on the Nomenclature of Faults. Geological Society of America Bulletin, Vol. XXIV, pp. I63-I86.

20. REIS, OTTO M. I909. Beobachtungen ueber Schichten-folge und Gesteins-ausbildungen in der frönkischen Unteren und Mittleren Trias. I. Muschelkalk und Untere Lettenkohle. Geognostische Jahreshefte, Bd. XXII, I909 (I9I0), pp. I-285, plates I-XI.

2I. ROTHPLETZ; A. I910. Meine Beobachtungen ueber den Sparagmit und Birikalk am Mjōsen in Norwegen-Sitzungsbericht. K. bayrischen Akademie der Wissenschaften, Mathematisch-Naturwissenschaftliche Klasse, $\mathrm{Bd}$. XV, 1910, 65 pages and maps.

22. RUEDEMANN, RUDOLF. I910. On the Systematic Arrangement in the elements of the Palæozoic platform of North America. New York State Museum of Natural Histury, Bulletin $1+0,5 p$. I $+1-1+9$. 
22a. ULRICH, E. O. Revision of the Palæozoic Systems. Bulletin of the Geological Society of America, Vol. XXII, pp. 28I-680.

23. VAN HISE, CHARLES R. I9O4. A Treatise on Metamorphism. United States Geological Survey, Monograph XLVII.

24. WAGNER, GEORG. I9I3. Stylolithen und Druck-suturen. Geologische und Palæontologische Abhandlungen (Koken), N. F., Band XI (XV), Heft 2, pp. IOI-I27, taf. X-XII. (With literature.)

25. WELlER, STUART. I899. A Peculiar Devonian Deposit in Northeastern Illinois. Journal of Geology, Vol. VII, pp. 483-488.

26. WOODWORTH, J. B. I896. On the fracture system of joints, with remarks on certain great fractures. Boston Society of Natural History Proceedings, Vol. XXVII, pp. I63-I 83, pls. I-5.

\section{Supplementary.}

27. BÖHM, A. (Edler von Böhmersheim) r9ro. Abplattung und Gebirgsbildung. Leipzig und Wien; p. 83 .

28. POKELS, F. I9I I. Aenderungen der Rotationsgeschwindigkeit der Erde als geologischer Faktor. Geologische Rundschau, Band II, pp. 14II 44 .

29. TAYLOR, F. B. I885. On the Crumpling of the Earth's Crust. American Journal of Science. 3rd ser., Vol. XXX, pp. 259-277.

30. WILLIS, BAILEY. I907. A Theory of Continental Structure Applied to North America. Geological Society of America. Bulletin Vol. XVIII, pp. 388-4I2. 


\section{CHAPTER XXI.}

\section{THE PRINCIPLES OF GLYPTOGENESIS, OR THE SCULPTURING OF THE EARTH'S SURFACE.}

During every geological period the complementary processes of erosion and deposition were in evidence, sometimes the one predominating and sometimes the other. Deposition added material to the crust locally, erosion removed it elsewhere. The results of erosion in terms of form are the relief features, and the process viewed from this angle is a process of sculpturing. The genesis of land forms is thus in large part a genesis by sculpturing or glyptogenesis.*

At all times, wherever land existed, erosion produced its characteristic forms, controlled to a large degree by the character of the material on which the forces of erosion were at work. Many of the old erosion forms were buried beneath accumulations of new rock material, and were thus preserved in a fossil form. Where much deformation and alteration of the rocks has since occurred, those older land forms may have become unrecognizable. Nevertheless, in many cases they are still in part preserved, and from a study of modern types we may gain a sufficient insight into the order of the development to enable us to reconstruct ancient examples from partly preserved remains.

The Cycle of Erosion. It is needful at the outset for us to have a clear conception of the entire cycle of erosion as expressed in land forms. Beginning with the young or newly formed land, which may be a recently emerged coastal plain, a dome, anticline, fault block, etc., the development of a drainage system as outlined in Chapter III brings with it a progressive sculpturing and the production of a series of topographic features, which carries the landscape through all stages of youthfulness to maturity and on toward old age. With the completion of the cycle in a moist climate the condition of a peneplain is reached, when the region is worn down to essential uniformity, with but little elevation above sea-level.

* From $\gamma \lambda \nu \pi \tau \delta$ s, carved, and $\gamma \dot{t} v \leftarrow \iota \sigma \iota s$, origin 
The encroaching sea may finish this surface into an almost absolutely level plane of marine planation. In an arid climate a more or less sloping plane (chonoplain) or a series of planes will be formed in the old age of the landscape, these depending for their character, slope, and elevation on the forces controlling the local base level of erosion.

After the cycle has thus been completed, a new one may be inaugurated by an uplift of the land or lowering of the sea-level or other base-level of erosion or by a climatic change, etc. Thus a second cycle of erosion will be inaugurated which, if left undisturbed, will continue to its end, and a second peneplain or chonoplain is produced. The cycle may at any time, however, be interrupted by a premature rejuvenation, the earlier cycle remaining thus incomplete.

Considering the principal land forms resulting from land sculpture, we may first note the characteristics of immature stages, and later on those of the completed cycle. Strata unaffected by orogenic disturbances will be considered first, and later on those which have suffered deformation. The types to be discussed include the forms resulting from the normal sculpturing of $\mathrm{I}$. the coastal plain, 2 . the monoclinal strata, 3. the dome, 4. the anticline, 5. the basin, and 6 . the syncline. Faulted structure ( 7 ) will be briefly noted, and after this the peneplain (8) will be considered more at length.

\section{A. EROSION FEATURES IN UNDISTURBED STRATA.}

\section{The Coastal Plain.}

The submerged deposits on the continental or island margin, of which the sub-coastal plain is composed, represent most typically a series of clastic sediments, in part land-derived and in part thalassigenous or derived from organic or biogenic, rarely chemical, deposits formed in the sea. Stratification is well developed, and the phenomenon of progressive overlap is generally well marked. Regressive phenomena, accompanied by landward erosion and seaward retreat of shore features, and transgressive phenomena accompanied by overlap of the upper beds of later formations on the eroded surfaces of earlier ones, are all commonly represented in the structure of the sub-coastal plain. When this is elevated into a coastal plain by epeirogenic movements, or into a mountain by orogenic disturbances, these structures will to a greater or less extent influence the erosion topography induced upon these surfaces.

The coastal plain has normally a gentle dip seaward, while, close 
to the margin of the old land, the upper thin edges of the last deposited layer, provided continuous subsidence precedes the elevation of the coastal plain, lap over the earlier layers and rest directly upon the old land. These overlapping edges of the strata are generally the first to be removed again, and in their place will appear a shallow valley running parallel to the upper edge of the coastal plain, the inner lowland of the normal coastal plain erosion topography.

Dissection of the Coastal Plain. Streams originating upon the coastal plain as the "run-off" of the rain and snow-fall, continue down the slope of the surface to the sea in more or less parallel lines, and with more or less directness, according to the angle of slope. These consequent streams, together with the extended consequents, $i$. $e$., the old streams of the old land, now extended across the coastal plain to the new sea margin, will incise more or less

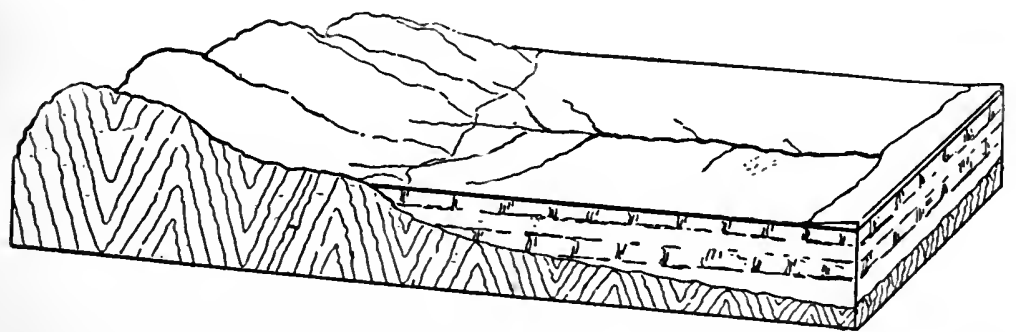

FIG. 205. The emerged coastal plain with the youthful consequent streams bearing a few simple insequents.

parallel channels across the coastal plain. When these channels are cut down to the level of the "ground water," they will be supplied by springs with a permanent stream, whereupon down-cutting may proceed at an accelerated pace. Along the margin of the main streams, lateral tributaries will begin, and, cutting headward, will soon diversify the original channel of the streams. These lateral branches are the "insequent" streams of the physiographer, since they are not consequent upon a constructional slope. Insequent streams, furthermore, cut their channels backward from the edge of a stream, and only deepen their channels as the channels of the consequents to which they are tributary are deepened. Consequent streams, on the other hand, cut their channels downward, headward extension being generally a secondary mode of growth. Near the old land the insequents will remove the feather edges of the coastal plain strata, as indicated above, and here will come into existence a stripped belt, expressed topographically in a broad, shallow valley, the inner lowland, containing the enlarged insequents, now more 
generally spoken of as the subsequents. This inner lowland is bounded on one side by the stripped slope of the old land and on the other by the cut edges of the coastal plain strata. If these latter contain resistant members of limestone or sandstone, they will present an escarpment or cliff of some steepness. As the inner lowland is widened and deepened the cliff increases in height because lower and lower members of the coastal plain series are discovered by the removal of the overlapping higher members. This will continue until the consequent has reached a condition of grade, and so will arrest further deepening of the channels of its tributaries. Beyond this point the cliff will be gradually lowered, through continued backward pushing, until the plane of erosion and the sloping

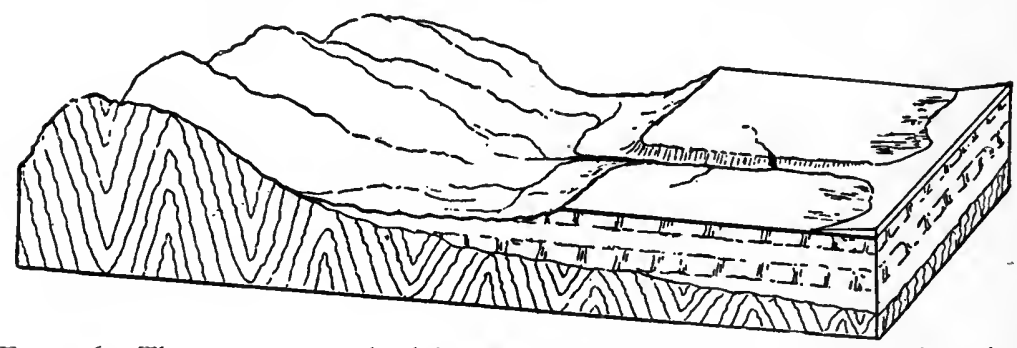

FIG. 206. The same coastal plain as shown in Fig. 205. After dissection and the formation of the cuesta; the broad inner lowland is occupied by the subsequents.

surface of the coastal plain intersect near the seashore, when the condition of peneplanation is reached.

The topographic element produced by the dissection of the coastal plain is known as the cuesta. Its main elements are the "inface" or cliff facing the old land, and the gentle outward slope conforming to the slight inclination of the coastal plain strata, and formed by its top member. Between the cuesta and the old land is the stripped belt or inner lowland, occupied by the subsequent stream. This is tributary to the consequent stream, which dissects the cuesta transversely. (Figs. 205, 206.)

Deposition in dissected coastal plain. A moderately dissected coastal plain in which transverse consequent and longitudinal subsequent valleys are formed may be affected by partial subsidence, in which case erosive activity not only comes to a standstill, but deposition will actually take place in the valleys, if subsidence has been sufficient to result in the entrance of the sea into the valleys, and the consequent drowning of the same. Examples of drowned consequent valleys are seen to-day in Chesapeake and Delaware 
bays which dissect the Atlantic coastal plain of North America. A drowned subsequent valley or inner lowland is seen in Long Island Sound, the northern edge of Long Island forming the more or less ice-disturbed and moraine-covered escarpment, the inface of a normal cuesta, now largely submerged. Deposits of the present geologic epoch are being formed within these valleys, which were cut in the partly consolidated Tertiary and Cretacic clays and sands, the stratification of which is almost horizontal. The result of such deposition will be that horizontally stratified modern deposits come to rest upon the Cretacic or later strata of similar position which form the bottoms of these eroded valleys, and that laterally they will become continuous with or merge into the horizontal beds of Cretacic or Tertiary age, of the valley sides and of the rewashed material of which these modern strata will in part at least be composed. Since these old drowned valleys have in places a width of a score of miles or more, and since it is not at all unlikely that conditions like the present one may have existed at different stages in the formation of the Atlantic coastal plain, of North Americanot to mention earlier coastal plains of this and other countriesthe significance of these facts becomes apparent. The commingling of the older and newer organic remains is another feature characterizing such deposits. Thus, in Chesapeake Bay, modern oyster shells are found attached to oyster shells of Miocenic age.

Effect of dissection and peneplanation of coastal plain strata on outcrop. Where normal deposition with continuous subsidence and progressive overlapping of strata occurs the undissected coastal plain will show on elevation the highest stratum only, which then rests directly by overlap against the old land. The formation of the inner lowland results in the exposure of a belt of lower strata next to the old land, while the edge of the higher stratum is farther and farther removed from the old land. As the inner lowland is widened and deepened, lower strata appear by erosion of the overlapping ones, and the map of a strongly dissected coastal plain region will show several belts of strata next to the old land, the lowest exposed one being nearest it. These belts of strata will also appear on the banks of the consequent streams, but will progressively disappear below the valley bottoms in a seaward direction and from the lowest to the highest. When the coastal plain has been reduced to a peneplain, the various strata composing it will outcrop in a series of more or less parallel bands from the lowest next to the old land to the highest of the series. This last will appear as a belt near the point where the coastal plain passed beneath the sea-level at the time the peneplanation was completed. Thus a 
glance at the geologic map of New York State shows a series of color bands representing the various strata of an ancient (Paleozoic) coastal plain, the lowest appearing around the Adirondack old land and along the border of the crystallines north of Lake Ontario, while each later one is further and further removed southward, until the latest, the Carbonic strata, scarcely extend into New York State at all. Now, most if not all of these strata once extended far toward, if not entirely to, the Adirondacks, and to the Laurentian old land in Canada. Their present distant outcrop is in large measure due to peneplanation across gently inclined strata. Subsequent erosion has, of course, pushed the edges of many of these strata further south than where they were left at the end of the period of peneplanation, but the amount of this later removal was small as compared with the greater separation of outcrops effected by peneplanation. It was formerly thought that the outcrop of the edges of strata along the margin of the old crystalline land marked their former extent. Since the strata of eastern North America crop out in a series of belts margining the old-land, each later formation falling short of the preceding one, it was believed that North America rose by a series of steps, the sea, at the end of each period, retreating to the region near which the next later formation now comes to an end. From the characters of the formations, however, it appears that they accumulated in a subsiding sea, and that each formation in turn overlapped the preceding ones, with few exceptions.

The present appearance of the outcrops is due wholly to erosion, the higher formations having suffered most. Many of the later Palæozoic strata of the eastern United States derived their clastic material from the Appalachian region on the southeast, and their northwestward limit in some cases was far beyond the border lines of the present Canadian old land, a great portion of which may in fact have been entirely submerged during a part of the Palæozoic. That the erosion of the strata continued until peneplain conditions were reached is shown, not only by the fact that the remnants of this old surface in the eastern United States form parts of a somewhat warped plain rising southward, but also and more especially by the fact that this surface is not formed by a single hard stratum, but by various hard beds which have been beveled across. Thus the Alleghany plateau of western New York, which is a characteristic part of this old peneplain, is composed of the beveled edges of successively higher southwestward dipping strata as shown in the following diagram. (Fig. 207.)

This beveling of the strata can be interpreted only as the result 
of peneplanation, in other words, when the level of crosion was reached, erosion could go no further because this surface stood so close to sea-level that the streams could not cut lower. Subsequent elevation would permit of the cutting of lowlands on the softer strata (5, 9 and 12 ), leaving the harder ones in relicf.

That this beveling of the strata is due to erosion and not to a

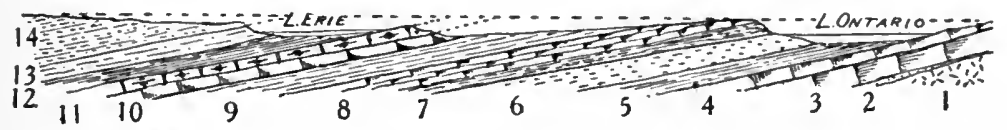

FIG. 207. Section across New York State, from Ontario to the Pennsylvania line, showing the peneplanation of the strata along the dotted line, and the subsequent carving of valleys on the softer strata. I, Archæan ; 2, Potsdam or Beekmantown; 3 and t, Black River-Trenton; 5, Utica-Lorraine; 6, Queenston; 7, MedinaClinton-Rochester; 8, Lockport-Guelph; 9, Salina; Io, BertieCobleskill; II. Onondaga; 12, Narcellus; I3, Hamilton; I4, Genesee-Portage-Chemung. 2-6, Ordovicic; 7-IO, Siluric; II-I4, Devonic.

shoreward thinning is shown by the fact that the material of the strata does not change toward the beveled portion as it would if that part had marked a progressively retreating shore accumulation, while the fact that the lowest portion of the beds extends farther than the higher portions shows that the thinning cannot represent an overlapping transgressive series. The following diagrams illustrate the thinning of the strata by overlap and by beveling. (Figs. 208, A B.)
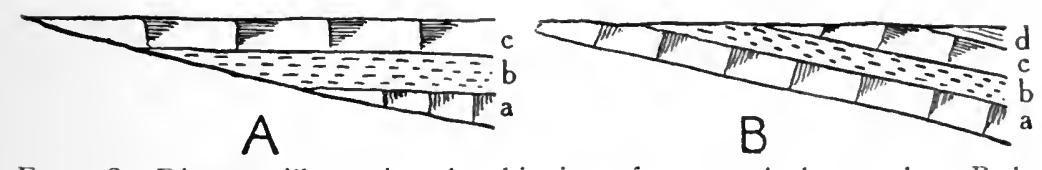

F1G. 208. Diagram illustrating the thinning of strata: A, by overlap; B, by beveling through erosion.

\section{Ancient Coastal Plains Shoring Cuesta Topography.}

Looking over the geological maps of the world, many examples of ancient coastal plain strata, in which a cuesta topography has been revived after peneplanation, are found. The Palicozoic strata of New York and Canada furnish excellent examples, though part of the topography is drowned, or obliterated by subsequent deposits. (Figs. 209, 210.) 
A nearly continuous cuesta inface may be traced along the south shore of Lake Ontario from Rochester to Niagara, and thence northwestward through Canada, the Indian Peninsula between Georgian Bay and Lake Huron, and across'the Manitoulin Islands. Turning westward on these islands, it passes through the Northern Peninsula of Michigan, and then turns southward, forming the peninsula between Lake Michigan and Green Bay, beyond which it continues southward through eastern Wisconsin.

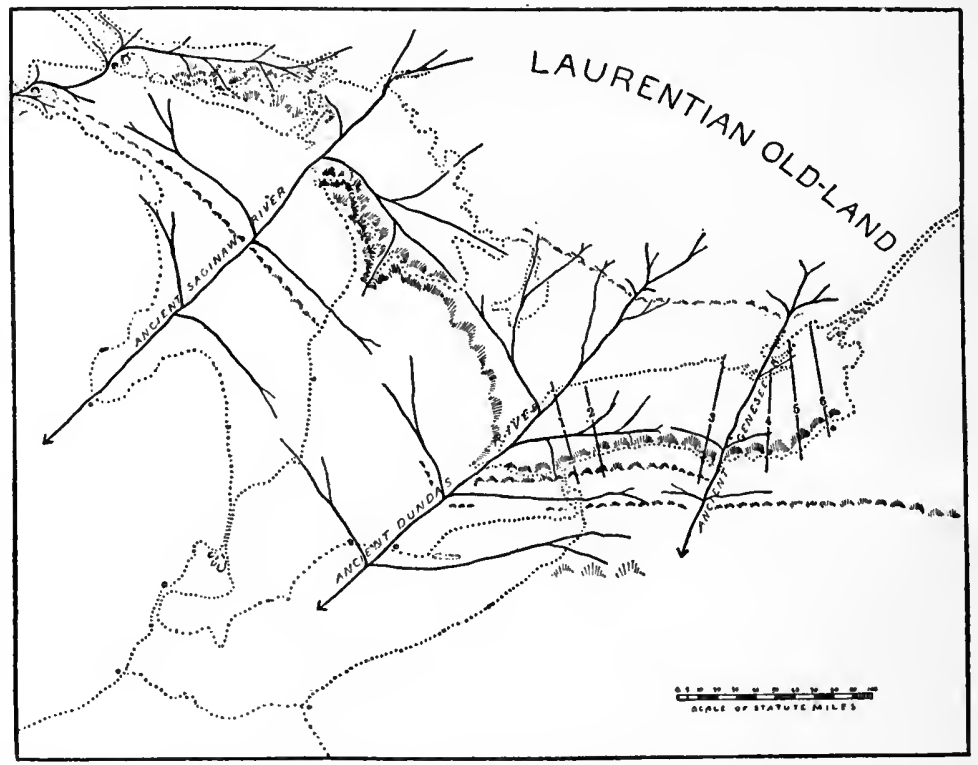

FIG. 209. Map showing the probable drainage and topography in eastern North America during Tertiary time, when a revived cuestatopography was produced.

The cuesta is cut out of the Lower Siluric formations which here consist of the capping hard Niagaran (Lockport) limestones and dolomites, underlain by softer shales and sandstones, into which the inner lowland has been cut. In New York the softer strata are thickest while the overíying hard beds thin eastward. Here the inner lowland is very deep, approaching in places a thousand feet below the top of the cuesta. Most of it is submerged by the waters of Lake Ontario. Eastward fronı Rochester the cuesta becomes less defined, owing to the failure of the hard capping stratum, and it finally unites with the next higher cuesta to the south, to form 
the Helderberg escarpment. "Nestward the limestone thickens, and hence the escarpment hecomes bold, but the inner lowland suffers. In Western Ontario this inner lowland is largely obliterated by drift deposits, but it appears again in the basin of Georgian Bay. The basin of Green Bay likewise occupies a part of the inner lowland in its western extension, south of which the deposits of drift somewhat obscure it. There is, however, a chain of small lakes (Winnebago, etc.) which shows its continuation. Lake Winnipeg

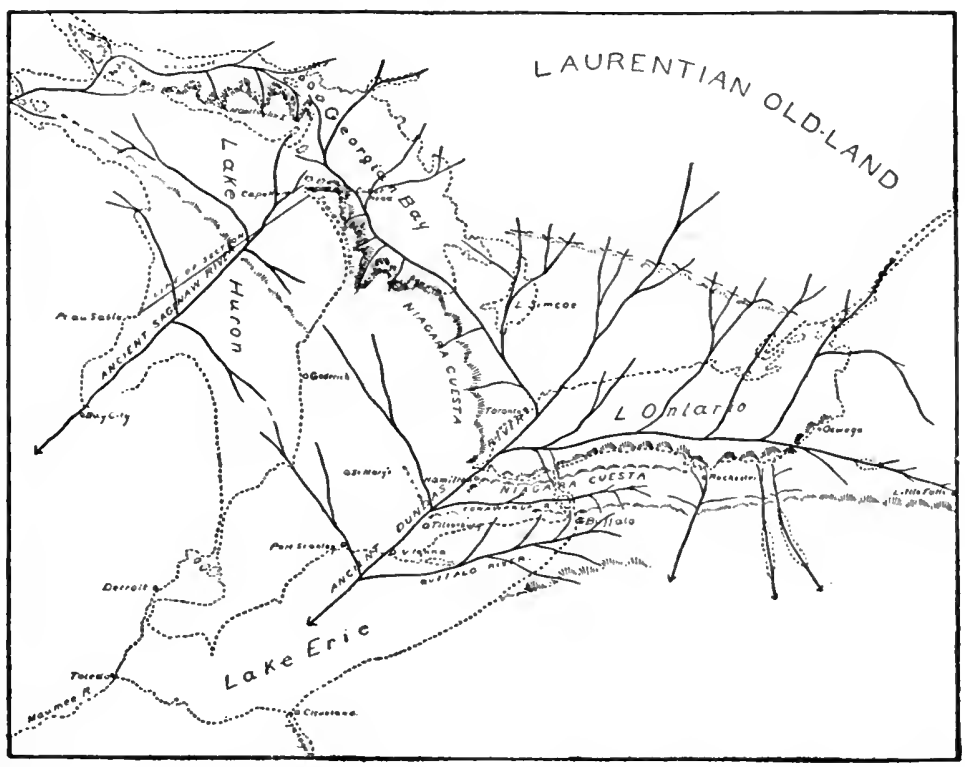

FIG. 210. A later stage, showing probable river adjustment by capture, etc., as deduced from the present topography. The partial blocking of the valleys by glacial drift, the glacial over-deepening of others, and the subsidence of the land on the northeast, produced the present topography and drainage.

in Canada lies in a similar inner lowland faced on the west by a cuesta inface of the Niagaran formation. In a few places the cuesta is broken by ancient or by modern stream channels. The most pronounced of the former is at the western end of Lake Ontario (Dundas Valley) and in the channel connecting Georgian Bay with Lake Huron, and continued in Saginaw Bay (Saginaw River Valley). (Grabau-16:37-54.) The most pronounced of the modern stream channels are those of the Genesee and the Niagara.

North and west of this cuesta series, $i . \mathcal{c}$., nearer to the old land, 
are several smaller cuestas, less continuous, but still in places quite pronounced. These are carved out of the Ordovicic limestones, where they rest on softer shales or sandstonés. (Wilson-3I.) South of the Niagara cuesta are several others cut into the Devonic strata. The most pronounced is that of the Onondaga limestone crossing the Niagara River at North Buffalo and extending east across the State until it culminates in the Helderberg edge northwest of Albany. This extends northwestward from Buffalo, and crosses Lake Huron as a submerged ridge, finally reappearing in Mackinac Island, beyond which it merges with the cuesta formed by the Hamilton strata, which continues southward along the eastern border of Lake Michigan.

Throughout western New York and Canada this cuesta is buried under drift, but in Lake Huron, though submerged, it forms a cliff 400 feet high. (Fig. 2II.) A still higher but generally less

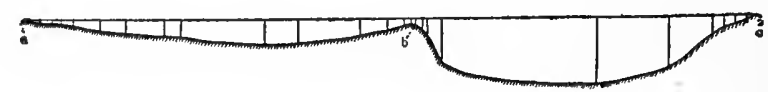

FIG. 21I. Cross-section of Lake Huron, from Point au Sable (a) across ninefathom ledge (b) to Cape Hurd (c), showing the submerged cuesta and inner lowland.

pronounced cuesta extends eastward across central and southern New York, formed by the sandy Upper Devonic strata. Eastward this, too, merges into the Helderberg escarpment.

The Palæozoic outcrops of northern Europe also fall into line as parts of a series of discontinuous cuestas. Thus the drowned region of the Baltic shows an Ordovicic cuesta series, partly submerged in the islands of Öland, Dagö and the coast of Esthonia, the infaces of which faced the old land of Sweden and Finland. The drowned inner lowland includes the Kalmar Sund in Sweden and the Gulf of Finland in Russia. A second discontinuous cuesta formed of Siluric rocks runs in a general way parallel to the first and farther to the south and east. This comprises the islands of Gotland and Ösel, and continues in the Baltic provinces of Russia. Central Europe has its main Mesozoic cuestas in the Swabian Alp which extends across southern Germany as a bold escarpment of horizontal Jurassic limestones from Württemberg to the borders of the Bohemian forest.

England, too, has its Palæozoic cuesta in the westward facing Wenlock Edge of Siluric strata. It has two distinct Mesozoic cuestas: one in the range of oolite cliffs which extends from Dorset 
to the Yorkshire coast and forms the Cotswold hills of midflle England with the Worcester lowland in front of it, and the other in the chalk cliffs which extend in like manner from the Channel to Flamborough Head, and forms the Chiltern hills of middle England, the Oxford lowland lying to the west of them. (Fig. 2I2.)

All of these topographic features are revived, being probably in the second if not later cycle of erosion. The coastal plain of Alabama, on the other hand, furnishes an example of a cuesta apparently in the first cycle. The cuesta itself is formed by the Tertiary strata of the coastal plain, the inface rising rather abruptly 200 feet above the lowland and being locally known as Chunnenugga ridge. On the broad upland dissected by short streams running down the

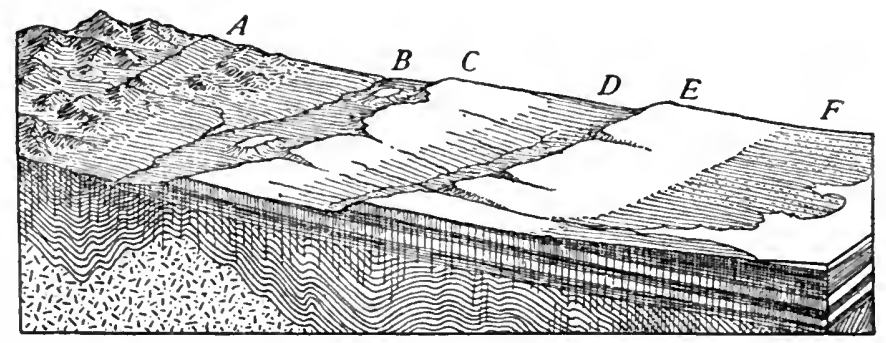

F1G. 212. . Stereogram of the Mesozoic coastal plain of central England: A, old land of Palæozoics (Wales) ; B, Worcester lowland on Triassic sandstone; C, Cotswold hills or Oolite cuesta; D, Oxford lowland on Upper Jurassic and Lower Cretacic clays, etc.; E, Chiltern hills or chalk cuesta; F, Tertiary coastal plain. (After Davis.)

inface (obsequent streams) lie the "hill prairies," the surface being formed by a resistant limestone bed. This slopes south to the coast and supports the "coastal prairies." Extensive pine forests also grow on this surface. The inner lowland, which lies between the inface and the old land formed by the rocks of the Appalachians. is so level that rainfall drains slowly and roads are impassable in wet weather. "It is called the 'Black Prairie' from the dark color of its rich soil, weathered from the weak underlying limestone. This belt includes the best cotton district of the state." (Davis$5: 135$.

Minor Erosion Forms of Horisontal Strata. Among these is the mesa or flat-topped table mountain. the surface of which is formed by a resistant capping stratum. It is limited on all sides by erosion cliffs, and it may constitute one of the last remnants of a once widespread series of formations. The name "mesa" is also 
sometimes applied to a tableland cut out of a peneplaned region, where the strata are disturbed or where the material is crystalline rock. Its restriction to an erosion remnant of horizontal strata is desirable. When the mesa has been reduced to small dimensions so that it has no longer an extended flat top-the name butte applies, though here again the designation is not always uniform, for the name is applied to hills of varying origin, even to volcanic cones. Restriction here would serve the cause of accuracy and precision.

A tepee-butte is a conical erosion hill, so named from its resemblance to the Indian wigwam or tepee. Tepee-buttes abound in the region east of the Front Range in Colorado, where they are formed by the resistance to erosion of a core of organic limestone which is surrounded by soft, easily eroded shale. These have been described and figured in Chapter $\mathrm{X}$ and the student is referred to the paper by Gilbert and Gulliver there cited.

\section{B. EROSION FEATURES IN DISTURBED STRATA.}

\section{The Monocline.}

When the old land, together with the edge of the coastal plain lapping onto it, suffers an uplifting which does not affect the coastal plain strata at a distance from the old land, a monoclinal structure

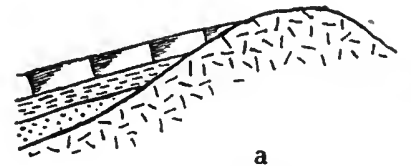

a

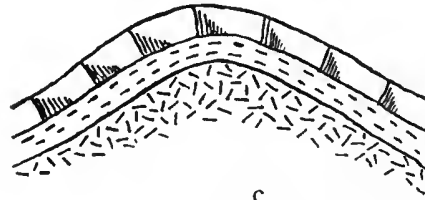

c

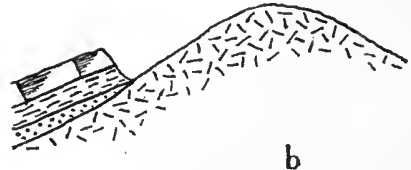

b

FIG. 2I3. Diagrams illustrating the formation of a simple hog-back (a, b), and of complementary hog-backs $(c, d)$.

is given to the edge of these coastal plain strata. On these upbending ends of the strata erosion will proceed in much the same manner as in the normal coastal plain, and a topography comparable to the cuesta and differing from it only in the greater inclin- 
ation of the component strata will be produced. The resistant stratum will produce a ridge, one side of which is composed of the steeply dipping surface of the resistant stratum and comparable to the gentle outward slope of the cuesta surface, while the other is formed of the eroded edges of the strata composing the ridge, and is comparable to the inface of the cuesta. (Fig. 213, a b.). Topographic elements of this type are common on the flanks of the Rocky Mountain Front Range where they are familiarly known as "hog-backs." In some cases these hog-backs may, however, be parts of normal anticlines of which the crystalline mountain mass was the original core. The outcropping edges of the component strata will not appear different on the map from those of the normal cuesta, and the phenomenon of overlap is perhaps as frequently preserved in this case as in that of the dissected normal coastal plain.

\section{Erosion features of the Structural Dome.}

Wherever strata are locally uplifted into the form of a broad, flat dome, as in the case of the Black Hills, a radial arrangement of consequent streams will come into existence, and a series of radial consequent valleys will be incised in the surface of the dome. The birth of numerous insequent streams at the summit of the dome will cause a gradual opening up of a series of summit valleys. If the surface stratum is a resistant one, while the stratum next below is readily eroded, a compound summit valley, drained by tributaries of the various consequent streams, will come into existence on the soft stratum, while the eroded edge of the hard stratum will surround this valley as a series of ramparts broken at intervals by the breaches through which the drainage is carried out. The character of the enclosing rampart will be that of a breached circular hogback with an erosion inface and a steeply inclined outward slope. Continued erosion by the tributary (subsequent) streams will widen the circumference of the rampart by pushing it down slope, and thus increasing the size of the summit valley. If a second resistant layer is discovered beneath the soft layer on which the valley was opened, it may be breached in a manner similar to the first, and a second inner set of encircling hog-back ridges may come into existence surrounding an inner valley opened up on a second soft layer. 'Several sets of such encircling hog-backs may thus be produced, two sets always being separated by a circular valley which drains through one or more branches in the outer hog-back ring. If the level to which erosion is carried, $i$. $e$., base-level, is reached while 
the center is still composed of a soft stratum, a central lowland will remain as in the case of the Weald of southeastern England. If, however, erosion goes on until the underlying crystallines are exposed a central mountainous area will remain as in the case of the Black Hills. (Fig. 2I4.)

In outcrop, an eroded dome will show the strata in a series of concentric rings, the oldest at the center and the youngest outer-

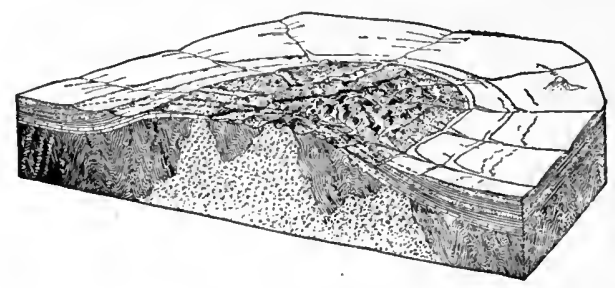

FIG. 214. Stereogram of the Black Hills dome, showing the mountainous center formed by the resistant crystallines, and the rimming hog-backs and valleys. (After Davis.)

most. As in the case of the cuesta and the monocline, the ultimate result of erosion of such a dome is the obliteration of the ridges, and the reduction of the dome as a whole to peneplain condition. When that has occurred all the strata involved will be beveled off toward the center of the dome, their lower edges projecting farthest up onto the dome. (Fig. 2I5, A.) A structure of this kind is not infrequently mistaken for a marginal thinning of strata on the shore
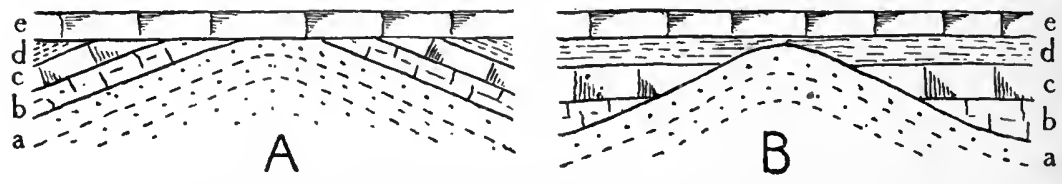

FIG. 215. Diagrams illustrating the thinning of strata under cover toward the center of a dome: A, by erosion; B, by overlap.

of an island. In this case, however, the strata should overlap each other, and the higher portions reach farthest onto the dome. (Fig. 2 I 5 , B.) The thin overlapping edges, moreover, should be of a clastic character, and composed in part of material derived from the shore of the island, while, in the case of the eroded dome, the strata on both sides, being part of a formerly continuous whole, should be of the same character, and show no shore features on the thin edge. Furthermore, strata deposited in this area, subsequently to 
the erosion of the dome (Fig. $215, \mathrm{~A}, \mathrm{~b} \mathrm{~d}$ e) would progressively come to rest upon the beveled edges of older and older strata, in the direction of the center of the dome, the relation being an unconformable one. This same type of structure might, of course, be produced by a gradually retreating sea from a rising island, so that each succeeding stratum reaches to a less distance than the preceding. In that case, however, the ends of the successive strata would show shore characteristics, and fragments of the lower might be enclosed in the higher formations.

The Cincinnati and Nashville domes are typical examples of low domes with very gently inclined strata formed and eroded during Palæozoic time. As pointed out repeatedly by Dr. Foerste (15) and others, the lower Siluric (Niagaran) strata found on the flanks of the dome conform in character to the first of the two cases cited, all the evidence pointing to the fact that the Niagaran strata formerly extended across the domes, which therefore formed in late Siluric or early Devonic time. As the eroded edges of the strata are disconformably overlain by Mid-Devonic limestones, or by Upper Devonic or younger black shales, it is evident that the erosion of the dome preceded Mid-Devonic time. This probably occurred during the Helderberg period, while the greater part of North America was above sea-level.

Subsequently to the deposition of the higher Palæozoic over this pre-Devonic truncated dome, one or more additional domings took place, followed by erosion which again exposed the lowest central strata.

\section{Erosion Features on the Anticline.}

The anticline differs from the dome chiefly in the fact that the longitudinal axis is many times longer than the transverse. Since the anticline must come to an end in either direction by a downward pitching of the axis, the characteristics of the simple anticline may be considered those of an excessirely elongated dome. While domes. however, generally occur singly, anticlines occur most commonly in series, a number of parallel anticlines being separated by synclines. The erosion structure of such anticlines is in general similar in each anticline to that of the dome, except that the subsequent valleys and the hog-back ridges are parallel, instead of circumferential, and the transverse consequent gorges in the ridges are parallel instead of radial. The most important difference lies in the duplication of the structure in each anticline and its complication by the 
intervening synclines. The resultant outcrops have been discussed in the preceding chapter.

When anticlines are partly eroded a series of monoclines or hog-backs results, similar in character to that formed by the uplifted upper end of the coastal plain as above described. Monoclines formed by breached anticlines usually occur in pairs opposing each other as in the Appalachians of to-day, but monoclines without a corresponding opposite occur which in reality represent one limb of an anticline of which the other limb has been entirely removed. (Fig. 2I6.) Thus the monocline which forms the Front Range of the Appalachians in New Jersey, Pennsylvania and southward

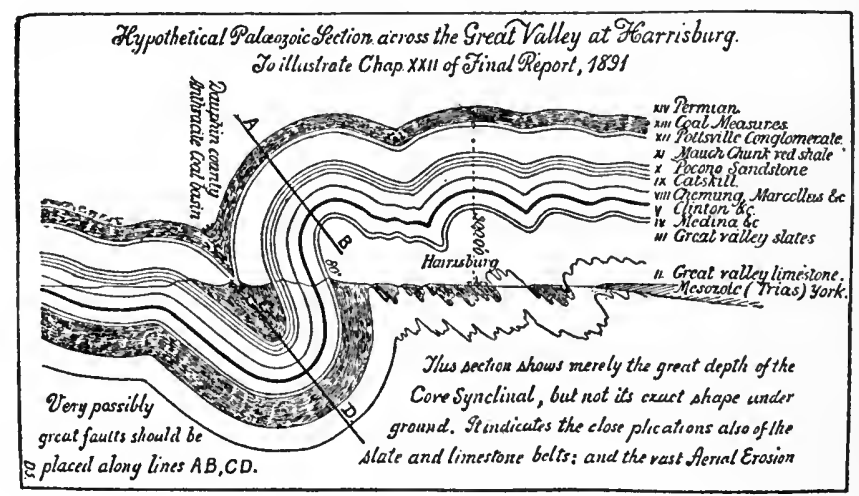

FIG. 216. Section of the Appalachian folds near Harrisburg, to show the removal of the eastern part of the folds by erosion.

represents merely the western limb of an anticline, the eastward continuation of which has been entirely removed by erosion. This was accomplished by peneplanation which cut below the axes of the synclines into the underlying more intensely folded rocks in which the Appalachian folds are not recognizable. The same is in part true of the monoclines facing the Front Range of the Rocky Mountains. The Triassic and Cretacic strata most probably once extended across what is now the front range axis, and this was perhaps true of much of the Palæozoic series as well. From the fact that the axis of the long Front Range anticline was a granite one, erosion, which removed the formerly continuous sediments, left it in relief, so that it holds the same relation to the flanking monoclines on either side that the central crystalline mass of the Black Hills holds to its encircling hog-backs. (Fig. 213, c, d, p. 840.) The completion of the cycle of erosion in a region of monoclinal flexures 
results in the formation of a peneplain across which rivers wander with little or no regard to the underlying structure. As already outlined, the mapping of the outcrops of the strata on such a surface would form a series of color bands parallel for a long distance, but uniting when the pitch of the anticline carried the strata below the erosion surface. The central color band of the eroded anticline would, of course, represent the oldest formation, while on either side of this would be bands corresponding on opposite sides and representing the successively younger formations from the center outward (Fig. I90, a, b, p. 806; see also Figs. 217, 218.)

Elevation of the peneplain and renewal of the erosive processes will result in the revival of the topography, since the harder layers

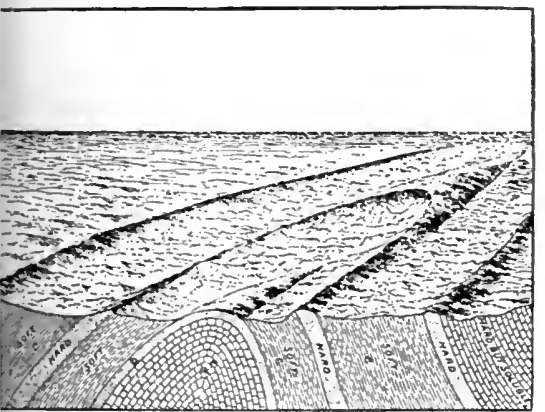

FIG. 217. Anticlinal fold with pitching axis, truncated across the top. The harder beds form monoclinal ridges; the valleys were cut on soft strata. (After Willis.)

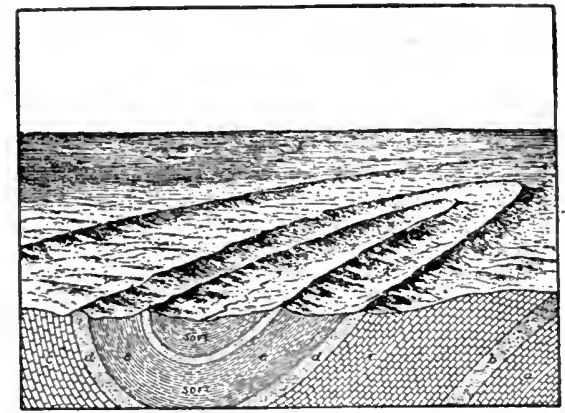

FIG. 218. Synclinal fold with pitching axis eroded. The harder beds form monoclinal ridges. (After IVillis.)

will again be carved into relief by the concentration of the erosive processes on the softer layers. The Appalachians furnish an instructive example of such a revived topography-they are at present in the second if not in a later cycle of erosion.* This fact is well brought out by the numerous entrenched transverse streams which cross the monoclines more or less at right angles. These streams, of which the Susquehanna is a good example, came into existence on the tilted peneplain, and their constant downward cutting made possible the openings of the longitudinal valleys on the softer strata, by the tributary streams.

* This is graphically expressed by the formula $n^{\text {th }}+1$ cycle suggested by Davis for such cases, where it is known that the region is not in the first cycle of erosion, but where it is impossible to say how many cycles have been completed. Thus $\mathrm{n}$ may stand for one or for more than one. 


\section{The Basin.}

The basin is the complement of the dome, representing the downward arching of the strata. As in the dome, the basin may be gentle, with strata so slightly inclined as to seem horizontal or it may be a pronounced one with highly inclined sides. The former is represented by the Paris Basin and the Michigan Basin and is in many respects the most significant type to the stratigrapher, being often difficult to detect. The Paris Basin represents a case in which the successive strata have been breached by radial consequent streams rumning from the surrounding higher old-land to the lower center, while their tributaries carved out circumferential valleys bounded by outward facing cliffs of the "inface type." The dissected basin at this stage differs from the dissected dome in having its oldest formations on the outside, the circumferential valleys

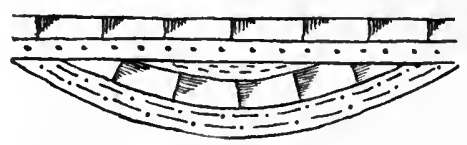

FIG. 219. Strata of a basin, trun-
cated and covered by horizontal strata.

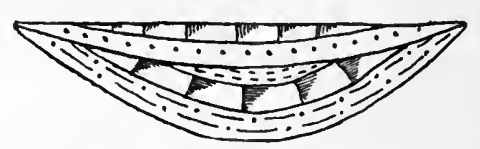

FIG. 220. The same series after a second folding and truncation.

being cut out of higher and higher strata toward the center, while in the dome the youngest formations are on the outside, and the successive circumferential valleys are cut on lower and lower strata toward the center. In the basin the infaces or escarpments face outward; in the dome they face inward. The Paris Basin is most probably to be regarded as a region in the second cycle of erosion, having been peneplained once, after which the topography has been revived by a resumption of stream activity.

The Michigan basin forms an interesting example of a compound type. At the beginning of Devonic time, the basin was formed, after which erosion beveled off the margins, leaving the successive formations superimposed after the manner of a nest of plates, the highest being the smallest, while the edges of the successively lower ones project beyond the higher. Across this series were deposited the Devonic and later strata, after which a second downward arching took place, followed by beveling of the edges of this later formed basin. Thus the highest formations occupy the center of the area and are surrounded by the rims of successively 
lower formations. (See Figs. 219 and 220.) The dome and basin have generally a definite relation to each other. Thus in Europe the Weald dome lies north of and immediately adjacent to the Paris Basin, while in North America the Michigan Basin is surrounded by domes. As already outlined in the preceding chapter (see map, Fig. 192), these domes and basins suffered simultaneons deformations at at least two distinct periods, but some of the domes and perhaps some of the basins may have suffered repeated deformations throughout Palæozoic time.

\section{The Syculine.}

This corresponds to a much elongated basin, and the characteristics it exhibits will be essentially those of the basin except that, instead of radiality or concentric arrangement, many of the features will be characterized by parallelism of arrangement. The characteristics of synclines as of anticlines are best exhibited in the Appalachian region of North America and the Jura Mountains of Europe.

\section{Erosion Features in Faulted Strata.}

These have already been discussed. to some extent in Chapter XX. Some special features are shown in Figs. 22I and 222.

\section{The Completion of the Cycle.}

The Peneplain. When the surface of a country is worn to so low a relief that the streams have practically ceased eroding and are throughout in a graded condition, the surface of the region may be considered as in the peneplain state. This is by no means a perfectly level surface, but rather one of a rolling or undulating topography, and not infrequently erosion remnants or monadnocks rise considerably above the general level of the peneplain. Since streams erode their beds until every portion is graded, the stream bed represents a continuous gentle slope to sea-level. As long as the relative position of land and sea remains stable, reduction of the relief will progress, and the surface of the land will approach closer and closer to the level of the sea. If that could be reached, the region would be reduced to base-level. It is obvious, however, that as the relief is reduced more and more, the rate of reduction rapidly de- 
creases, so that the process of base-leveling goes on at a progressively diminishing rate.

While the harder or more resistant strata of any region are the last to be reduced to the level of the peneplain, they eventually also succumb, and the surface of the peneplain thus shows a lack of conformity to the structure of the country. This lack of conformity to structure is one of the most characteristic features of a peneplain, and the one by which it is most readily recognized. When the peneplain is gradually submerged beneath a transgressing sea, the final inequalities may be smoothed off by marine planation. In this manner erosion surfaces of remarkably level character may be produced, such as are seen on the Archæan granites of the Manitou
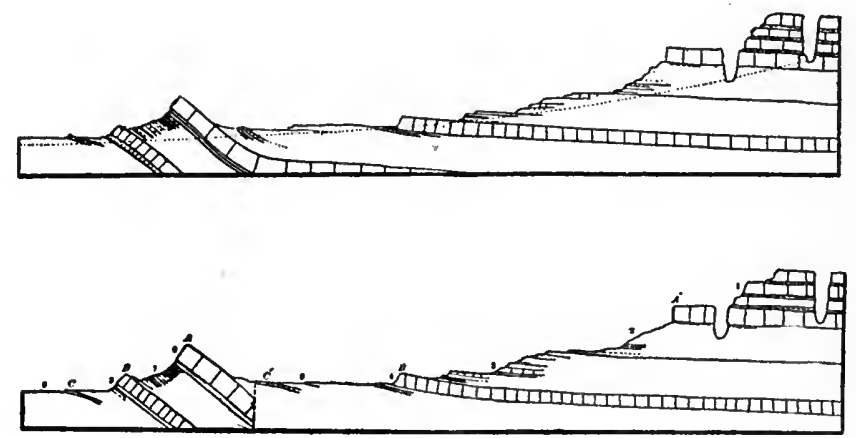

FIG. 221. Section on San Juan River, Colorado, showing erosion escarpments in horizontal and tilted strata.

FIG. 222. The same section interpreted by the assumption of a fault.

region in Colorado, where the early Palæozoic sandstones rest upon a surface almost as level as a table top. (Crosby-r.) (Fig. 52, p. 310.) Where transgression of the sea is gradual and uniform on a peneplain surface, a basal conglomerate or sandstone is formed which everywhere rests directly upon the old peneplaned surface. The age of this sandstone or conglomerate will, however, vary as pointed out in Chapter XVIII, being younger shoreward and older seaward. Where monadnocks rise above the level of the submerged peneplain, these will be gradually buried under the accumulating coastal plain strata, which along their contact with the monadnock will be of a more or less coarsely fragmental character. A typical example of a monadnock buried in coastal plain strata, and now partly resurrected by erosion, is found in the Baraboo ridges of southern Wisconsin. An example of a monadnock being partly buried by marine sediment is found in the island of Monhegan, off 
the coast of Maine, which is still partly above the level of the sea, though the peneplain from which it rises is here completely submerged.

In an old region, where peneplanation has long been in progress, the surface is formed by a layer of atmoclastic material of greater or less depth. With this are mingled peat and other phytogenic material, while here and there may occur a deposit of wind-blown matter. On this surface the rivers will assume a meandering course which has no regard to the underlying structure. When such

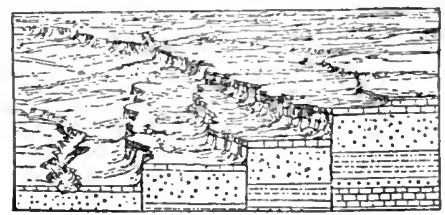

Section across a branching fault.

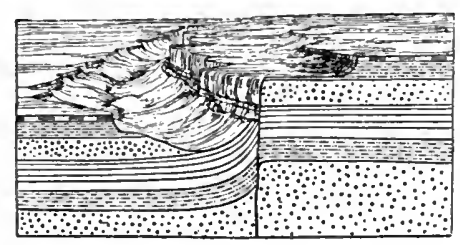

Fault with thrown beds flexed upward-a dragged faule.

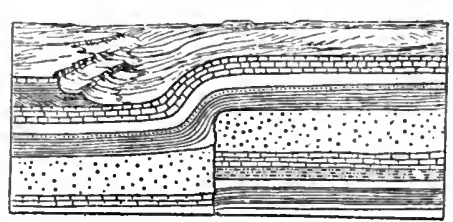

Fan1t and Monocline.

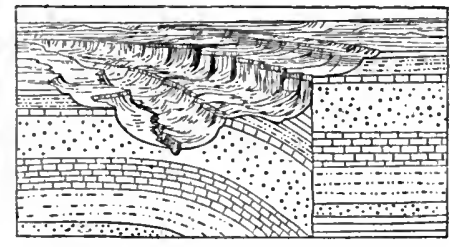

Fanit with thrown beds flexed downward.

FIG. 223. Erosion scarps formed in horizontal and in flexed strata, compared with erosion and fault scarps in faulted strata.

material is exposed to the activities of a slowly encroaching sea, it will be pretty thoroughly sorted and the finer material carried seaward to settle in quieter water. But if transgression is rapill, other sediments may be deposited over the ancient soil, which will remain relatively undisturbed. Such ancient buried soils are sometimes met with in the geological series marking former periods of extended peneplanation.

The Relation of the Peneplain to Sedimentation. A region of low relief will furnish only the finest material for its rivers to carry, and hence the sea bordering a peneplained country will receive only the finest lutaceous sediment which is washed from the lands by the rains and swollen streams. Thus lutaceous sediments, often heavily charged with decaying organic matter, may accumulate in the form of extensive mud flats or deltas. The pres- 
ent Mississippi and Nile deltas are examples, being composed only of the finest mud. The Black Devonic shale of Michigan and Ohio also appears to represent a deposit of this type, as already outlined in a previous chapter.

When the continent has been worn so low that little or no sediment is carried into the sea, organic deposits may accumulate close to the shore. Since rivers, even in low countries, are probably never without their modicum of silt, it follows that pure organic accumulations can be formed near shore only where large rivers do not discharge. A consideration of the chalk beds of England and Ireland shows them to be part of a series of coastal deposits in a slowly westward transgressing sea. This is partly shown by the westward overlapping of the suecessive members on an eroded preCretacic peneplain. Thus while the basal conglomerates, sands and greensands of southeastern England are of Aptien age and rest disconformably upon the Wealden, the basal Cretacic conglomerates, sandstones and greensands of northeast Ireland and of Mull and Morvern in Scotland are of Cenomanien age. Here the Aptien and the Gault have been overlapped, while the Cenomanien of the northwest has the characteristics held by the Aptien in the southeast. The Cenomanien in the southeast is a glauconitic chalk, and is succeeded by the pure chalk which begins with the Turonien. In the northwest the Turonien is still a glauconite sand to be succeeded by lower Senonien glauconitic chalk and only toward the last by pure chalk. (See Fig. 146 in Chapter X.VIII, page 730.)

It is thus seen that the great mass of organic material which forms the chalk was deposited in comparatively shallow water not very remote from the coast, and this suggests that the land of that time must have been in a state of peneplanation. The microorganisms of the chalk bear out this interpretation, for shallow water benthonic forms predominate. The possibility of eolian deposition of some chalk beds, mentioned in an earlier chapter, must not be overlooked.

Dissection of the Pencplain. If a peneplain is elevated, with or without tilting, a new cycle of erosion commences; all the streams will be revived, and they will incise their valleys, thus dissecting the peneplain. At first the stream valleys are relatively insignificant as compared with the broad, gently rolling upland of the elevated peneplain. But as the valleys are widened, the interstream portions are reduced and the upland dwindles into a series of ridges and peaks which eventually become lowered, so that a new peneplain is produced. Thus the second cycle of erosion is completed. While the upland portion of the elevated peneplain is still broad, the char- 
acter of the old peneplain surface is easily seen. As the valleys become widened and the interstream portions reduced, the old peneplain level is less and less readily recognized, the uniform agreement in height of the interstream ridges being the most conspicuous feature. It can, however, be shown that uniform height of interstream ridges may also be brought about in a country where the original surface was very diverse, if the streams are uniformly spaced. (Shaler-27.) This is especially true if the streams are of approximately equal power, and the rate of erosion is thus more or less uniform.

Age of the Peneplain. It is evident that the peneplain is of later age than that of any of the strata affected by the erosion in the formation of the peneplain. In the case of folded strata which have become peneplaned the commencement of peneplanation may be regarded as simultaneous with the folding, and since in a stiongly folded region even the latest strata deposited may be involved in the folds and so protected from complete erosion, we may not be far wrong in considering that folding and peneplanation begin shortly after the deposition of the youngest stratum involved. It nust, however, be borne in mind that folding of strata without fracture takes place at some distance below the surface (see Chapters XIX and XX), and that therefore a series of perfect folds in any given series of strata suggests that these strata were at considerable depth below the surface at the time of the formation of the folds. Under such conditions, when perfectly folded strata are found near the surface of a peneplain, it is not likely that the later strata, deposited before the conmencement of folding, are included within the folds. Thus within some of the strongly folded strata of the Hudson River group in Albany County, N. Y., only middle and earlier Ordovicic strata are involved so far as known, though there is every reason for believing that the folding did not take place until late Ordovicic, if not early Siluric time.

In the case of horizontal strata which have been peneplained, the latest preserved stratum is not to be regarded as the last one deposited before elevation and erosion, for this would allow no removal of strata by erosion during the peneplanation. In general we may consider that the amount of rock removed from a given region during a stated period of elevation and erosion is proportional to the distance of that region from the point where erosion was replaced by deposition, $i$. $c$., from the seashore or piedmont plain of the period. Exceptions to this must, however, be recognized where local conditions limited or accentuated erosion, as in the case of a warped surface where some portions of a given formation 
were raised excessively and so became subject to pronounced erosion, or where other portions were proportionally more depressed and so escaped great erosion, or where other causes were active.

The end of the period of peneplanation is commonly marked by the age of the strata overlying the peneplain surface. Here, however, it must be borne in mind that slow subsidence of a peneplain surface produces a gradual deposition of formations which successively overlap each other, each later one in turn coming to rest upon the old peneplain surface beyond the edge of the preceding one. Thus, the pre-Cambric peneplain of North America is overlain by Lower or Middle Cambric strata in the southern United States, by Upper Cambric strata in the Upper Mississippi Valley and northeastern New York, by Lower or Middle Ordovicic in northwestern New York, by Middle, and later Ordovicic, in portions of Canada, and by later formations in other parts. In each case the age of the peneplain terminates with the age of the overlying bed, while the part still above water continues to be subject to erosion. Thus these higher portions continued to be peneplained, though at an exceedingly slow rate, long after the southern end of the peneplain was buried under thousands of feet of strata.

Highi-Level Plains of Arid Regions. In arid regions, where the rainfall is insufficient, and where a large part of the erosive work is done by wind, high-level plains of erosion comparable to peneplains, but having no definite relation to sea-level, may come into existence. Under the influence of arid erosive forces, the initial relief of even a rugged region will gradually become extinct, partly by erosion and partly by filling of the desert basins with waste. The process has been fully described by Davis (12) and enlarged upon by others. A few quotations from Davis will serve to point the essentials of the process and its results: Under the conditions cited "the most perfect maturity would be reached when the drainage of all the arid region becomes integrated with respect to a single aggraded basin-base-level, so that the slopes should lead from all parts of the surface to a single area for the deposition of the waste. The lowest basin area which thus comes to have a monopoly of deposition may receive so heavy a body of waste that some of its ridges may be nearly or quite buried. Strong relief might still remain in certain peripheral districts, but large plain areas would by this time necessarily have been developed. In so far as the plains are rock-floored, they would truncate the rocks without regard to their structure." ( $12: 389$.)

"As the dissected highlands of maturity are worn down, the rainfall decreases, and the running streams are weakened and ex- 
tinguished: thus... the winds in time would appear to gain the upper hand as agents of erosion and transportation. If such were the case, it would seem that great inequalities of level might be produced by the excavation of wide and deep hollows in areas of weak rocks. As long as the exportation of wind-swept sand and of wind-borne dust continued, no easily defined limit would be found for the depth of the hollows that might thus be developed in the surface, for the sweeping and lifting action of the wind is not controlled by any general baselevel. In an absolutely rainless region there appears to be no reason for doubting that these abnormal inequalities of surface might eventually produce a strong relief in a still-standing land of unchanging climate; but in the actual deserts of the world there appears to be no absolutely rainless region; and even small and occasional rainfalls will suffice, especially when they occur suddenly and cause floods, as is habitual in deserts, to introduce an altogether different régime in the development of surface forms from the rock hills and hollows which would prevail under the control of the winds alone. The prevailing absence of such hill-and-hollow forms, and the general presence of graded wadies and of drainage slopes in desert regions, confirm this statement."

"As soon as a shallow wind-blown hollow is formed, that part of the integrated drainage system which leads to the hollow will supply waste to it whenever rain falls there; the finer waste will be blown away, the coarser waste will accumulate, and thus the tendency of the winds to overdeepen local hollows will be spontaneously and effectively counteracted. As incipient hollows are formed in advancing old age, and the maturely integrated drainage system disintegrates into many small and variable systems, each system will check the deepening of a hollow by wind action; hence no deep hollow can be formed anywhere, so long as occasional rain falls." (I 2-39I-392.)

With the continuance of the processes and the further disintegration of the drainage, the surface is slowly lowered, leaving only those rock masses projecting as monadnocks or "Inselberge" which most effectually resist dry weathering. The production of the Inselberg landscape chiefly by eolian agencies has already been considered in an early chapter.

"At last, as the waste is more completely exported, the desert plain may be reduced to a lower level than that of the deepest initial basin" which originally was a temporary recipient of the waste, "and then a rock-floor, thinly reneered with waste, unrelated to normal baselevel, will prevail throughout-except where 
monadnocks still survive." (12:393.) This condition of widespread desert-leveling has actually been reached in the Kalahari region of South Africa, as described by Passarge-and these examples of the final stage, Davis holds, justify the assumption that the various stages, through which they must have passed to reach this last stage, and the characters of which can easily be deduced theoretically, may actually find representation in the arid regions of the world. Furthermore, fossil examples of such desert-leveled plains, as well as examples of stages which precede the final stage, ought to be looked for in the sections of the earth's crust, and we can no longer assume that any level plain, recent or fossil, is a normal peneplain; the possibility that it may be a high-level desert plain must not be overlooked.

Some criteria for distinguishing modern peneplains from desert plains are given by Davis.

"A plain of erosion lying close to sea-level in a region of normal climate, and therefore traversed by rivers that reach the sea, but

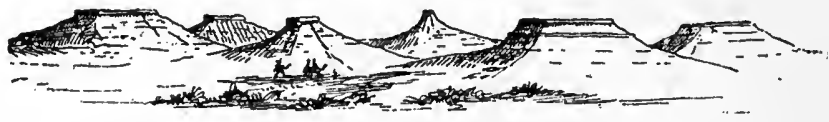

FIG. 224. Erosion-buttes (Zeugenberge) near Guelb-el-Zerzour. The erosion is mainly eolian. (After Walther.)

that do not trench the plain, might conceivably be a depressed desert plain standing long enough in a changed climate to have become cloaked with local soils; but it is extremely unlikely that the depression of a desert plain could place it so that it should slope gently to the seashore, and that its new-made rivers should not dissect it, and that there should be no drifted sands and loess sheets on adjoining areas, and no signs of submergence on neighboring coasts. An untrenched plain of erosion in such an attitude would be properly interpreted as the result of normal processes, long and successfully acting with respect to normal baselevel." (12: 397-398.)

"In the same way a high-standing plain of erosion in a desert region might be possibly explained as an evenly uplifted peneplain whose climate had in some way been changed from humid to arid, whose deep weathered soils had been removed and replaced by thin sheets of stony, sandy, or saline waste, and whose residual reliefs had been modified to the point of producing shallow basins. But in this case there should be some indications of recent uplift around the margin of the area, either in the form of uplifted marine 
formations whose deposition was contemporaneous with the erosion of the peneplain, or in the form of fault-escarpments separating the uplifted from the non-uplifted areas. Moreover, it is extremely unlikely that the uplift of an extensive peneplain could place it in so level a position that it should not suffer dissection even by desert agencies; hence a ligh-standing desert plain is best accounted for by supposing that it has been leveled in the position that it now occupies." (I $2: 398$.)

"It should not, however, be overlooked that there is some danger of misreading the history of a depressed desert plain which has been by a moderate amount of normal weathering and erosion transformed into a normal peneplain; and of an uplifted peneplain which has been by a moderate amount of arid weathering and erosion transformed into a typical desert plain; the danger of error here is similar to that by which a peneplain, wave-swept and scoured during submergence, might be mistaken for a normal plain of marine abrasion." (12:399.)

"If an old rock-floored desert plain be gently warped or tilted, marine submergence is not likely to follow inmediately, but the regular continuation of general degradation will be interrupted. The patches and veneers of waste will be washed from the higher to the lower parts of the warped surface; the higher parts, having an increased slope, might be somewhat dissected, and would certainly be exposed to more active degradation than before, untii they were worn down to a nearly level plain again. The lower parts would receive the waste from the higher parts, and the continuance of this process of concentration would in time cause the accumulation of extensive and heavy deposits in the lower areas. Such deposits will be, as a rule, barren of fossils; the composition, texture and arrangement of their materials will indicate the arid conditions under which they have been weathered, transported, and laid down; their structures will seldom exluibit the regularity of marine strata, and they may reach the extreme irregularity of sanddune deposits. If warping continues, the desert deposits may gain great thickness; their original floor may be depressed below sealevel, while their surface is still hundreds or thousands of feet above sea-level." (I2:400-40I.)

Examples which serve to illustrate such deposits have been described from South Africa (Passarge) and West Australia, where barren sandstones of continental origin surround the monadnocks ("Inselberge"). Ancient examples seem to occur in the great deposits of barren Uinta sandstones 12,000 to 14,000 feet thick in some localities which lie at the base of the Palrozoic series in the 
region of the present Wasatch Mountains. The basal Palæozoic sandstones of eastern North America, from a few feet to over a thousand feet thick ("Potsdam" sandstone), also have many characters pointing to such an origin. In this case, of course, the transgressing Palæozoic sea modified the deposits to a certain degree and redeposited a part of them as fossiliferous marine sands and clays.

"If a change from an arid toward a moister climate causes a drainage discharge to the sea, a dissection. of the plain will ensue. The valleys thus eroded cannot expectably exhibit any great degree of adjustment to the structures, because the stream courses will result from the irregular patching together of the preëxisting irregularly disintegrated drainage. This peculiar characteristic, taken together with the absence of neighboring uplifted marine deposits, will probably suffice in most cases to distinguish desert plains, dissected by a change to a moister climate, from peneplains dissected in consequence of uplift; but there still might be confusion with peneplains dissected by superposed streams." (I2:40r.)

Locally, around individual mountains in an arid climate, a surface sloping outward in all directions partly due to erosion and partly to deposition is produced by the forces operative under such conditions. Such a plane, though never very perfect, will have the appearance of a broad-based cone-the center of which is the undissected mountain remnant. Dr. Ogilvie (2I) has described these as forming around the laccoliths of the Ortiz Mountains in New Mexico-and has named them "conoplains." They are essentially elements in the stages of desert planation.

\section{MINOR EROSION FEATURES.}

Many of these have already been noted in previous chapters. We may recall the grooves formed by eolian corrasion in the Libyan limestone plateau and the erosion needles capped by Operculina in the Libyan desert (p. 52); the Yardangs of central Asia and

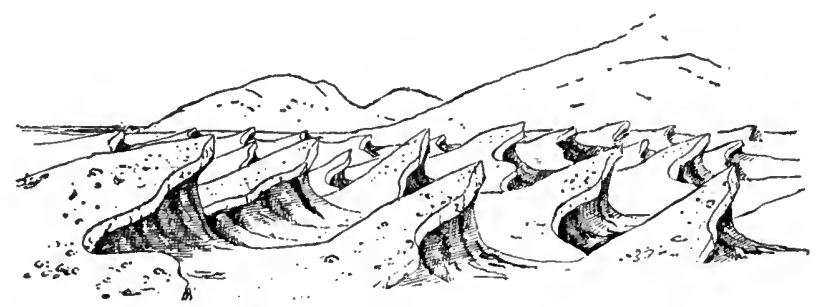

FIG. 225. Erosion features (Schichtenköpfe) in inclined Cretacic limestones. Chiefly eolian. Abu Roasch. (After Walther.) 
the erosion monuments of Mlonument Park, Colorado (p. 53); the facetted pebbles ( $\mathrm{p} .54$ ); erosion forms produced by solution (pp. $\left.\mathrm{I} 74^{-1} ; 6\right)$, by waves (Pp. 22I-226), by rivers (pp. 246-257), and by ice (pp. 263-265). A striking example of eolian erosion is further shown in Fig. 225, where alternating hard and soft limestone strata

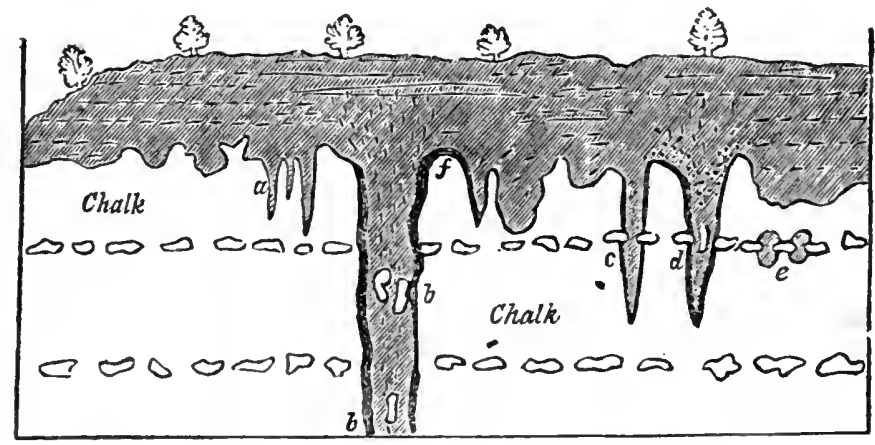

FIG. 226. Solution fissures in clalk, forming organ-pipe structure. The hollows are filled with sand and clay from above. (After Lyell.)

inclined at a considerable angle were carved into fantastic forms by wind. Another example, illustrating the effect of solution on limestone, is given in Fig. 226, which shows the solution fissures in chalk and other limestone regions where cylindrical depressions often occur in great numbers, and close together, forming geological "organ pipes" (Geologische Orgeln) (Fig. I 36, p. 698). Broad kettle-like hollows or dolinas are also produced by solutions on joint-cracks. These may be up to $\mathrm{I} \mathrm{km}$. in diameter and 30 meters in depth.

\section{BIBLIOGRAPHY XXI.}

I. CROSBY, WILliAM O, I899. Archæan Cambrian Contact near Manitou, Colorado. Geological Society of America Bulletin, Vol. X, pp. I4I-I64.

2. DAVIS, WILLIAM MORRIS. 1896. Plains of Marine and Subaerial Denudation. Geological Society of America Bulletin, Vol. VII, pp. 378-398.

3. DAVIS, W. M. I899. The Peneplain. American Geologist, Vol. XXIII, pp. 207-239.

4. DAVIS, W. M. 1899. The Geographic Cycle. Geographical Journal (London), Vol. XIV, pp. $48 \mathrm{I}-584$.

5. DAVIS, W. M. I 899 . Physical Geography. Ginn \& Co.

6. DAVIS, W. M. I899. The Drainage of Cuestas. London Geologists' Association Proceedings, Vol. XVI, pp. 75-93, I6 figures.

7. DAVIS, W. M. I900. The Physical Geography of the Lands. Popular Science Monthly, Vol. LVII, pp. I57-170. 
8. DAVIS. W. M. I90I. Peneplains of Central France and Brittany. Geological Society of America Bulletin, Vol. XII, pp. 480-487.

9. DAVIS, W. M. I90I. The Geographical Cycle. Verhandlung des 7 ten Internationalen Geographischen Kongresses, pt. II, pp. 221-23I.

Io. DAVIS, W. M. I902. Base-level Grade and Peneplain. Journal of Geology, Vol. X, pp. 77-109.

I1. DAVIS, W. M. I905. Leveling without Base Leveling. Science, N. S., Vol. XXI, pp. 825-828.

I2. DAVIS, W. M. I905. The Geographic Cycle in an Arid Climate. Journal of Geology, Vol. XIII, No. 5, pp. 38I-407.

13. DAVIS, W. M. 1905. The Bearing of Physiography on Suess' Theories. American Journal of Sciences, Vol. XIX, pp. 265-273.

14. DAVIS, W. M. I905. The Complication $0^{\circ}$ the Geographical Cycle. Compte Rendu, 8th International Geographical Congress, pp. I50-I63.

15. FOERSTE, A. E. I902. The Cincinnati Anticline in Southern Kentucky. American Geologist, Vol. XXX, pp. 359-369.

16. GRABAU, A. W. I90I. Geology and Palæontology of Niagara Falls and Vicinity. N. Y. State Museum Bulletin No. 45.

17. GRABAU, A. W. I908. Pre-Glacial drainage in Central Western New York. Science, N. S., Vol. XXVIII, pp. 527-534.

18. JOHNSON, DOUGLAS W. 1903. Geology of the Cerillos Hills. (Laccolith and Dome Mountain Dissection.) School of Mines Quarterly, Vol. XXIV, pp. I 73-246; 456-600.

19. JOHNSON, D. W. 1905. Youth; Maturity and Old Age of Topographic Forms. American Geographical Society Bullatin, XXXVII, pp. 648-653.

20. KEYES, C. R. 1903. Geological Structure of New Mexican Bolson Plains. American Journal of Science, Vol. XV, pp. 207-2 ro.

21. OGILVIE, IDA H. I905. The High Altitude Conoplain: A topographic form illustrated in the Ortiz Mountains. American Geologist, XXXVI, pp. 27-34.

22. PASSARGE, SIEGFRIED. 1904. Die Kalahari. Berlin.

23. PASSARGE, S. I904. Rumpfläche und Inselberge. Zeitschrift der deutschen geologischen Gesellschaft, Bd. LVI, pp. 193-209.

24. PASSARGE, S. 1904. Die Inselbergelandschaft im tropischen Africa. Naturwissenschaftliche Wochenschrift. N. F., Bd. III, pp. $657^{\circ}-665$.

25. PENCK, A. I883. Einfluss des Klimas auf die Gestalt der Erdoberfäche. Verhandlungen des 3 ten deutschen Geographentages, pp: 78-92.

26. PENCK, A. 1905. Climatic Features in the Land Surface. American Journal of Science, Vol. XIX, pp. 165-174.

27. SHALER, N. S. I 899. Spacing of Rivers with Reference to the Hypothesis of Base-Leveling. Geological Society of America Bulletin, Vol. X, pp. 263-276.

28. WALTHER, JOHANNES. I891. Denudation in der Wüste. (See Bibliography II.)

29. WALTHER, JOHANNES. 1900. Das Gesetz der Wüstenbildung (2nd ed., I9I2).

30. WILSON, ALFRED W. G. 1903. The Laurentian Peneplain. Journal of Geology, Vol. XI, pp. 6I5-669.

3I. WILSON, A. W. G. 1904. Trent River System and St. Lawrence Outlet. Geological Society of America Bulletin, Vol. XV, pp. 2 I I-242.

32. WILSON, A. W. G. I905. Physiography of the Archæan Areas of Canada. International Geographical Congress, 8th report, pp. 116-I35. 


\title{
D. THE PYROSPHERE.
}

\author{
CHAPTER XXII.
}

\section{GENERAL SUMMARY OF PYROSPHERIC ACTIVITIES.}

The activities of the pyrosphere are judged by their surface manifestations, and by the observations on results of igneous activities in the past. So far as the pyrosphere itself is concerned direct observation is, of course, out of the question, nevertheless much may be learned regarding its probable character by experimentation and the study of igneous activities in the laboratory, as well as in the field, while much more may be inferred from a logical interpretation of past igneous work in portions of the earth's crust exposed as a result of dislocations, or of prolonged erosion, or of both. No attempt is made to discuss volcanic activities in anything more than a summary manner, though the subject is of vast geological importance. "The science of pyrology or vulcanology has already developed a literature which only a specialist may hope to master. The list given at the end of this chapter is an extremely fragmentary one, but it contains a sufficient number of general works in which the subject is treated from a comprehensive viewpoint, and which will open for the student the gateways to the special fields of research in which ground has been broken.

\section{VOLCANIC ACTIVITIES.}

TYPES OF VOLCANIC ACTIVITIES. These may be purely explosive or purely extravasative or, what is more frequent, a combination of both in varying proportions. According as the one or the other prevails, the form of the resulting deposit will vary from simply conical in the first to flat and plain-like in the second case.

Subdivision with Reference to Location. Volcanic manifestations may take place either on the surface of the lithosphere (effusive) or within the earth's crust (plutonic, intrusive). In 
the latter case direct observation of such manifestations is impossible, but their characters may be inferred from the results of past intrusive and plutonic manifestations as indicated by the characteristics of intrusive and deep-seated (plutonic) igneous masses. (See ante, Chapter VII.)

Extrusive manifestations may further be divided into the terrestrial and the submarine, the latter again being withdrawn from direct observation, except when their results appear above the surface of the sea, after prolonged existence. Indirect observation on the results of submarine eruptions is likewise scanty, mainly because, in the case of older volcanics, it is at present difficult to distinguish with certainty between submarine and subaerial eruptions, and many so-called submarine lava flows must probably be relegated to the subaerial type.

In discussing the types of eruptions, the primary division into explosive and extravasative will be kept in mind, and under each of these will be noted the subaerial or terrestrial and the submarine types.

\section{Explosive Eruptions.}

Terrestrial Type. Volcanoes of purely explosive type are probably very rare, though the "maare" craters may be classed here. In the typical examples of the Eifeler Maare, no volcanic cone exists; instead, there is merely a more or less circular opening, the result of the explosion, and this has subsequently been filled with water. Lapilli, bomblets, and even large bombs often abound in the neighborhood of the maare craters, but lava flows are typically absent. The coarse and fine lapilli of the maare region in the Eifel and Rhein districts form stratified deposits which have all the appearance of stratified sands of clastic origin. As outlined in Chapter VI, the lapilli are not to be regarded as pyroclastic in the true sense of the word, but rather as granular pyrogenics, being primarily of endogenetic origin, and classifiable as pyrogranulites rather than as pyrarenytes. True pyroclastics are, of course, also associated with the deposits of lapilli and bombs, these resulting from the clastation, by eruptive explosion, of already consolidated rock masses, either of igneous or of "sedimentary" origin. The vicinity of the Laacher See, the largest and most picturesque of the explosive craters of Germany, is characterized by deposits of volcanic bombs and tuffs, of trachyte, mingled with clastic fragments of granite and various metamorphic rocks, brought up by the explosion from great depths below the cover of Devonic strata. 
Some of the bombs consist of a remarkable mixture of crystals, characteristically developed at great depth within the earth's crust, such as sanidine, olivine, hornblende, garnet, etc. (Walther-4I : $I 70-I T I$.

A modern case of such an explosion without lava extrusion occurred in Japan in 1888 , the explosion being a sudden and violent one, and tearing away the side of a volcano which had not been active for at least a thousand years. The air was filled with ashes and débris as in a typical volcanic eruption, and a large tract of the adjacent region was devastated and many lives lost.

Coon Butte, in Arizona, has also been regarded by Gilbert (II:I87) as a possible example of such an explosive eruptionthough he also suggests the possibility that it was formed by the impact of a meteorite. Both theories have had their advocates, the former origin being favored by Chamberlin and Salisbury $(4: 596)$, while the latter is especially defended by Fairchild (8).

The cinder cone. While the explosion-craters seen in the Maare represent probably a single eruption, or one which, with slight intervening pauses, lasted only for a comparatively short time, the more general examples of explosive volcanoes last sufficiently long to build up a cinder cone. Such eruptions may be of comparatively limited duration, and may occur at short intervals, as in the volcano Stromboli in the Eolian Islands north of Sicily (Strombolian type), where the interval of explosion is from I to 20 minutes, as shown by the "flash" of this "Lighthouse of the Mediterranean"; or it may be of a more violent character and occur at great intervals with dormant or "strombolian" periods intervening. Such is the case in Vulcano of the same group of islands, and in other violent volcanoes (Vulcanian type) which have an interval of decades (moderate phase), or of centuries (grander phase).

Material of the cinder cone. This includes the bombs, the lapilli, and the volcanic sand, ash, and dust which fall in the immediate vicinity of the crater. Not all the ejected material falls here-much being carried to a distance, this distance increasing with increasing fineness of material. Even large bombs may be hurled beyond the actual radius of the cinder cone, one such, fully three feet in diameter, being hurled to a distance of a mile and a half during the eruption of Vulcano in 1888 (Hobbs-15:1 19). A remarkable example of the propulsion of volcanic ejecta has been described by Hovey (I7:560) in the eruption of Mont Pelée in 1902. Frequent explosions of clust and lava-laden clouds have brought material enough from the crater to fill the gorge of the Rivière Blanche. "The lower portion of the gorge has been entirely 
obliterated and the adjoining plateau elevated, while the upper and deeper portion near the center has been almost filled by ejecta. The dust-flows are the material left behind by the dust-laden clouds of steam. The exploding clouds of steam were so overloaded with dust and larger fragments of comminuted lava, that they flowed down the slope of the mountain and the gorge, like a fluid propelled at a high velocity by the horizontal or partly downward component of the force of the explosion. Many large fragments of solidified lava were carried down the gorge by these clouds. Such blocks IO to I 5 feet in diameter were not uncommon" ( $17: 560$ ).

Lapilli vary in size from that of a walnut to dust. The term is somewhat loosely used, and should be restricted to pyrogenic material in a state of division, $i . e$., pyrogranulytes and the smaller pyrosphærytes (more rarely pyro-pulverytes) which by their appearance show that they were unconsolidated or at least in a plastic state on eruption. (See ante, Chapters VI and XII.) The sand and dust are, for the most part, true pyroclastic material characterized by angularity of outline and density of material.

The forms of cinder cones. Cinder cones are essentially local accumulations of unconsolidated materials, and so their form is determined by the general laws which govern the accumulation of such material, modified, of course, by the special influences characteristic of the mode of accumulation. The form will also vary in accordance with the prevailing size and character of the material, being steeper for coarse and gentler for fine material, and gentler also for rounded material (lapilli) than for angular. There will be further variation induced by the abundance or scarcity of water vapor, condensed into rain in the vicinity of the eruption, the variation being analogous to that found in the slopes of alluvial cones and dry "cones of dejection," or between that of alluvial cones of dry and pluvial regions. "Speaking broadly, the diameter of the crater is a measure of the violence of the explosion within the chimney. A single series of short explosive eruptions builds a low and broad cinder cone. A long-continued succession of moderately violent explosions, on the other hand, builds a high cone with crater diameter small if compared with the mountain's altitude, and the profile afforded is a remarkably beautiful sweeping curve." (Hobbs-I5:123.) Owing to the fact that material near the summit lies at the maximum angle of repose, while that lower down generally has a lower angle-the product of change wrought by time and by the addition of material fallen from the sky upon the surface of the original slope-the form of the lateral curve of the cinder-cone will be a faintly concave one, whereas that of a lava 
cone is more typically convex. This is shown in the following sketch of a cinder cone (Fig. 227) and appears further in Fig. 232.

Monte Nuovo, in the Bay of Baie, near Naples, is an example of a cone composed almost entirely of loose cinders. This volcano had its birth within historic time, arising on the borders of the ancient Lake Lucrinus on September 2O, I538, and attaining a height of 440 feet. Other volcanoes largely composed of cinders have arisen within the knowledge of man. Among them are Jorullo (Mexico), I759; Pochutla (Mexico), I870: Camiguin (Philippine Islands), I87I; a new mountain of the Ajusco Mountain group (Mexico), I88I ; and the new mountain of Japan formed on September 9, I9Io, and rising to a height of 690 feet.

Both Jorullo and the new Camiguin volcano started from fissures in level plains. The former arose in the night of September 28, I759, 35 miles distant from any then existing volcano, and its sum-
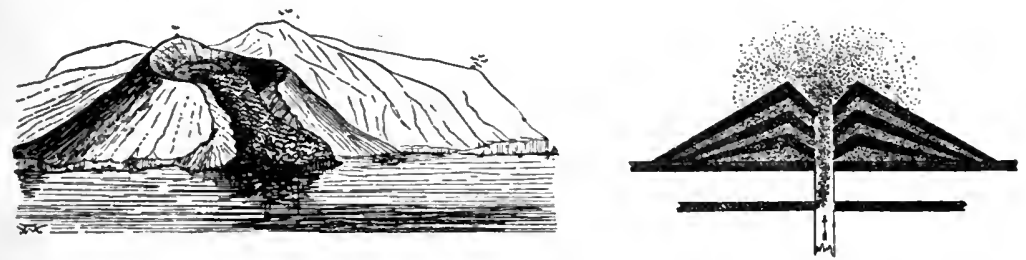

FIG. 227. Campo Bianco, in the Island of Lipari. A pumice-cone, breached by the outflow of an obsidian lava stream.

FIG. 228. Experimental illustration of the mode of formation of volcanic cones composed of fragmental materials. (After Judd.)

mit has since reached an elevation of 4,265 feet above sea-level. The Camiguin volcano had a growth period of four years during which it reached a height of about I,80o feet.

Consolidation of cinder cones. Unless extravasations of lava should punctuate the eruptions of cinders, the cinder-cone is not likely to be thoroughty consolidated, but remains rather in the condition of an asi or sand heap. Diagenetic processes will, of course, go on throughout the mass and thus consolidation may be brought about, aided by the metamorphosing effect of the steam and lot vapors accompanying each eruption, and penetrating more or less through the mass of accumulated material (atmo-netamorphism).

Submarine Explosive Eruptions. Explosive eruptions are probably as common in the littoral belts of the sea as they are on land, and, indeed, near the margins of the lands they, in common with the extravasative eruptions, may be more frequent than elsewhere, as discussed beyond. There is no reason for doubting that explosive eruptions also occuir on the floor of the deeper sea-though exam- 
ples of such cinder-cones rising from the abyssal sea-bottom are unknown.

The Mediterranean has been the region best known for submarine volcanic eruptions. Of these a number have been of the explosive type, though more generally the compound (explosive and extravasative) type prevailed. The most noted of the recorded submarine eruptions "occurred in the year I83I, when a new volcanic island (Graham's Island, Ile Julia) was thrown up, with abundant discharge of steam and showers of scoriæ, between Sicily and the coast of Africa. It reached an extreme height of 200 feet or more above sea-level ( 800 feet above sea-bottom) with a circumference of 3 miles, but, on the cessation of the eruption, was attacked by the waves and soon demolished, leaving only a shoal to mark its site." (Geikie-9:25o.). "The upper part of this volcanic cone, above the sea at least, seemed to have been solely composed of ashes, cinders, and fragments of stone, commonly small. Among these fragments of limestone and dolomite, with one several pounds in weight, of sandstone, were observed. (De la Beche-6:95.) These fragments were broken off from the rocks through which the eruption passed on its upward way. "During the time that this volcanic mass was accumulating, a large amount of ashes and cinders must have been mingled with the adjacent sea before it reached its surface, and no slight amount would be distributed around, when ashes and cinders could be vomited into the air. Add to this the quantity caught up in mechanical suspension by the breakers and there would be no small amount to be accumulated over any deposits forming, or formed, on the bottom around this locality . . (De la Beche-6:95, 96). These deposits included, of course, abundant remains of organisms, killed by the explosive eruption. Another example of a volcano formed in the historic period is Sabrina Island in the Azores, off the coast of St. Michaels. Here a submarine eruption built a cone of loose cinders to a height of about 300 feet, and a circumference of about a mile. This, too, soon disappeared under the subsequent attack of the waves.

"The formation of this island was observed and recorded. It was first discovered rising above the sea on the thirteenth of June, I8II, and on the seventeenth was observed by Captain Tillard, . . from the nearest cliff of St. Michael's. The volcanic bursts were described as resembling a mixed discharge of cannon and musketry: and were accompanied by a great abundance of lightning." (De la Beche-6:I23.) A sketch made at that time is here reproduced (Fig. 229). A similar occurrence is recorded from 
the west coast of Iceland, where, in the early summer of 1783 , arose an island of volcanic nature about thirty miles from Cape Reykjanaes. In less than a year, however, it had again been washed away by the waves, leaving only a submerged reef or shoal from five to thirty fathoms below sea-level.

Numerous submarine eruptions which never reach the surface no doubt occur over many portions of the ocean floor. In these both cinders and lava enter, sometimes one and sometimes the other

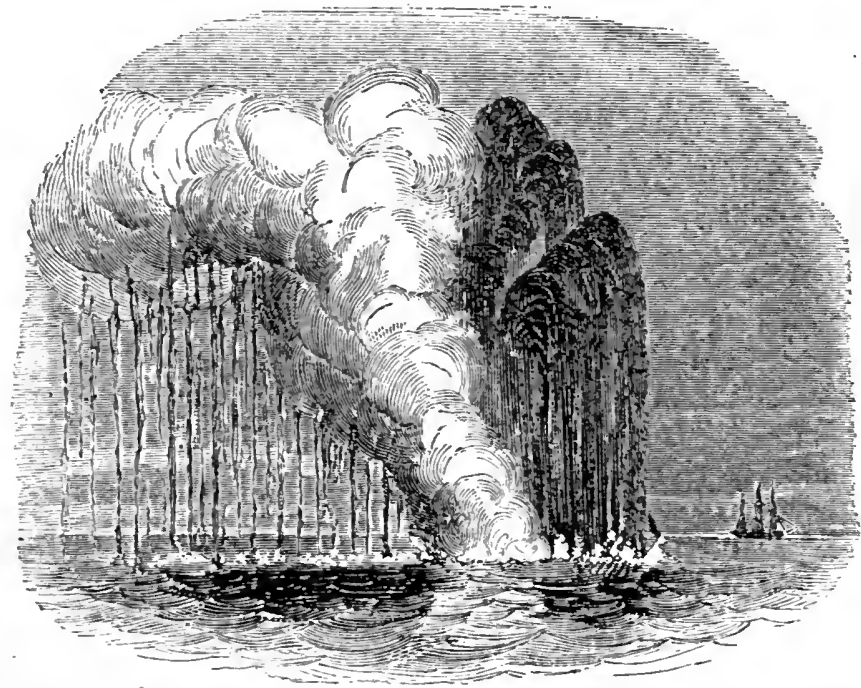

FIG. 229. Sketch of the submarine volcanic eruption which, in June, I8II, formed Sabrina Island, off St. Michaels in the Azores. (After De la Beche.)

predominating. On the floor of some parts of the deep sea volcanic ejectamenta are abundant, and these are in pari at least due to submarine explosive eruptions.

\section{Extraz'asatize Eruptions.}

Terrestrial Type-Fissure Eruption. The fundamental characteristics of this type are best developed in the great fissure eruptions which have resulted in the formation of extensive lava fields, and in the broad flat lava domes of the Hawaiian group. The fissures from which the great lava extravasations take place are generally ranged parallel with and near to the coast and seem to be especially prevalent where the edge of the land drops off rapidly 
to deep sea. The most stupendous modern examples of fissure eruptions are those of eastern Iceland. In this island occur a number of distinct and parallel clefts arranged in two dominant series, one extending northeast and southwest, the other north and south. "Many such fissures are traceable at the surface as deep and nearly straight clefts or gjâs, usually a few yards in width but extending for many miles. The Eldgja has a length of more than I8 English miles and a depth varying from 400 to 600 feet." (Hobbs-I 5 :99.)

According to Thoroddsen, the lava wells out quietly from the whole length of some of these fissures, overflowing on both sides without the formation of cones. These fissures, therefore, constitute connecting dikes, such as are known to occur under the older lava flows of this type. At three of the wider portions of the great Eld cleft of Iceland the lava has welled out quietly without the formation of cones, flooding an area of 270 square miles. Upon the southern narrower prolongation of the fissure, however, a row of low slag cones appeared, and this is a feature characteristic of other fissures in Iceland, as well as the great Skaptar fissure reopened in 1783 , emitting great volumes of lava. Subsequently the eruptive processes became concentrated at the wider portions of the fissure and a row of small cones was left over the line of the fissure. Upon this fissure, too, stands the large volcano of Laki. The great eruptions and the larger volcanoes are generally found at the intersection of two fissures, as in the case of the great eruption of Askja in 1875, and of the volcanoes of Java. On a small scale, the formation of volcanoes along fissures is shown in the frozen surface of the lava lake in the caldron of Kilauea, where miniature volcanoes form whenever the crust which hardens in the lava-lake becomes fissured.

The connection of volcanic activities with fissuring of the earth's surface is further shown in the great rift-valley of eastern Africa, where extensive outpourings of lava have covered portions of the valley floor, while volcanoes of great height and comparatively recent origin have arisen within the valley, as in the case of the Mfumbiro Mountains, already referred to, which block the riftvalley north of Lake Kivu and which rise to great altitudes, the crater rim of the still active volcano Kirungo-cha-Gongo rising to Ir,350 feet above the sea-level, while Karisimbi reaches an altitude approaching 14,000 feet. (Fig. 21, p. 125.) The valley floor on which these volcanoes arose was considerably less than 4,000 feet above sea-level; indeed, this same valley floor in the region of Lake Tanganyika to the south actually descends below sea-level. 
The most gigantic outpouring of lavas from fissures occurred in late Tertiary or early Quaternary time in western North America. There lava floods formed the great plains of the Snake River region in southern Idaho, and the vast basaltic plateau of Washington, Oregon, and northern California. This lava field has more or less interrupted extensions through Nevada, Arizona, New Mexico, and the western half of Mexico south into Central America and northward through British Columbia to the Alaskan Peninsula and the Aleutian Islands. (See the Geological Map of North America.) The main lines of fissures were probably parallel to the Pacific coast, but of this nothing is visible, except the general trend of the lava sheets from north to south. The area covered by the lava outpourings aggregates 200,000 square miles, while the thickness of the sheet averages 2,000 feet and reaches in some places 3.700 feet. The comparatively recent origin and the location of the lava plateau have precluded much destructive work by the surface agents, although the Snake River has cut a series of picturesque gorges through it. The cones now rising from this surface indicate localization of eruption subsequent to the outpouring of the lava floods. Prismatic structure is well developed in parts of these lava sheets. Intercalated river sediments often separate successive flows.

Remnants of early Tertiary basaltic lavas are now found in numerous places in northeast Ireland, western Scotland, the lower Hebrides, the Faroe islands, and faraway Iceland. These, famous for their columnar partings (Giants' Causeway, Fingal's Cave, etc.), were probably part of a once continuous lava field. now dismembered by the agents of erosion, not the least of which is the sea. Numerous dikes of similar material occur in regions from which this lava has apparently been eroded, and these dikes probably mark the fissures through which this welling-up of the lava took place.

These dikes are extremely abundant in the northwest of Scotland (Peach and Horne-28) and range eastward across Scotland and the north of England and Ireland. They have been traced from the Orkney Islands southward to Yorkshire and across Britain from sea to sea over a total area of probably not less than 100,000 square miles. This may indicate the former wide extent of this basaltic lava field which then rivaled the younger one of western America. When erosion has been carried far enough in the great lava plateau of western North America, to remove a considerable portion of the lava sheet, there will no doubt appear an equally 
vast number of dikes, which represent the filling of the fissures through which the lava reached the surface.

A Cretacic example of such outpouring of basic lava, rivaling in extent that of the northwestern United States, is seen in the great bed of Deccan trap which forms the surface of the Deccan Platean in India. Here the depth of the lava is from 4,000 to 6,000 feet. Where the basement rocks on which this trap sheet rest are exposed by erosion along the margin of the plateau dikes of basalt are seen penetrating them, representing in part the fissures through which

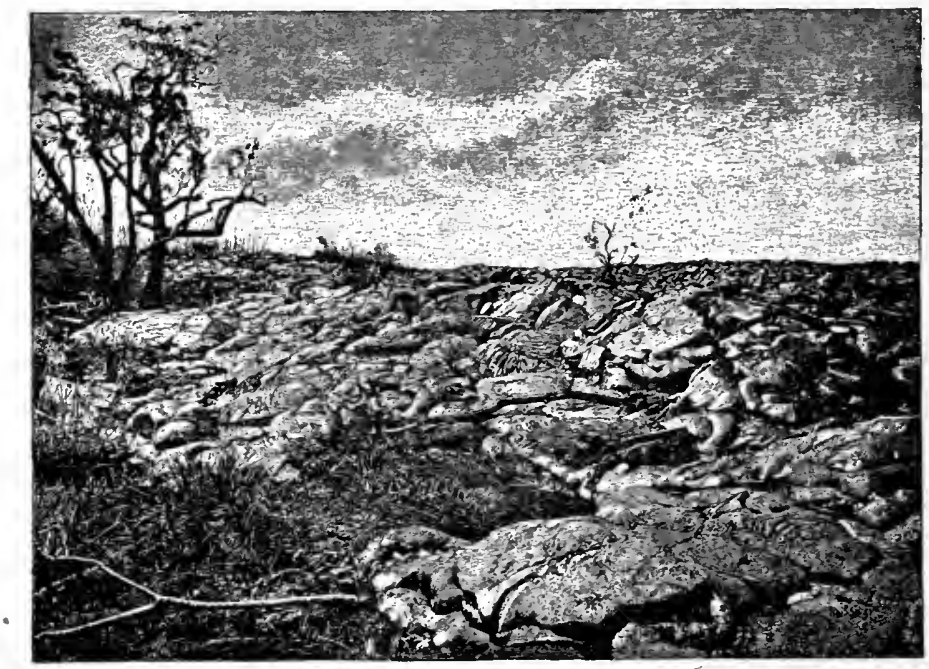

FIG. 230. End of the lava flow of 188ז near Hilo, Hawaiian Islands. The lava surface is a typical pahoehoe surface. (After Dutton.)

the lava reached the surface. No cones or definite vents have been found.

What appears to be a pre-Palæozoic example of such eruptions is seen in the great Keweenawan lava sheets which represent a prolonged succession of outpourings in the Lake Superior region, aggregating an enormous amount variously estimated as reaching the great thickness of 15,000 or 25,000 feet. Here, too, there is little evidence of explosive or other concentrated volcanic activity.

The lava dome. Where eruptions are concentrated about a single opening a mountain of lava will be built up which rises in proportion to the frequency of the eruption and the volume of lava poured out. Where fragmental material is absent, as in the Hawaiian volcanoes, the slope is a very gentle one, though the actual 
height is great. Though now rising to nearly 14,000 feet above sealevel these volcanoes began as submarine eruptions, starting on the floor of the deep sea and having a total height of 20,000 or 30,000 feet. The visible portion is less than a hundred miles in diameter, but the actual base is probably much more than twice that. The two active volcanoes are Mauna Loa, the rim of which is 13,675 feet above sea-level; and Kilanea, which is less than 4,000 feet high and appears to rest on the flanks of the larger volcano. The craters, or caldera, have each a circumference exceeding seven miles, being irregularly elliptical in outline with the sides descending in a series of steps to the central pit, which is formed by the "frozen" surface of the lava. The floor of the pit of Kilauea is a "movable platform" of frozen lava which rises and falls with the variation in

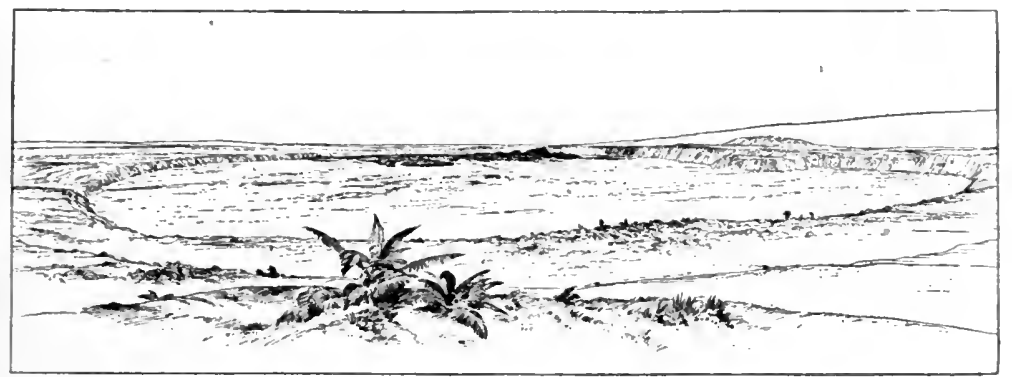

FIG. 231. View of Kilanea caldera from the Volcano House. (After Dutton.)

the pressure of the lava beneath. The difference in height between 1823 and 1884 was estimated by Dutton $(7: 127)$ to be nearly 400 feet.

"Beneath the floor of the caldera," says Dutton, "we may conjecture the existence of a lake of far greater proportions than those which now expose a fiery surface to the sky. The visible lakes might be compared to the air-holes in the surface of a frozen pond." The proof for this is found in the fact that new eruptions are not overflows of the open pools of lava, but break out anywhere in the floor of the caldera. (Fig. 23I.)

Acid lava domes. Lavas of the acid type are, as a rule, too viscous to form mountains of gentle slope, occurring more often as steep-sided domes, especially if the lava is only semi-fluid. This is well shown in Figure 232, where, in the Auvergne district of France, a trachyte cone of highly viscid lava was extruded between cinder cones. The domed character of the extravasated pustular 
cone contrasts strongly with the concave surfaces of the cinder cones. The results of experiments recorded in ligures 228 and 233 show the fundamental differences between fragmental cones and domes of pustular lava.

The spine of Pelée. What is regarded by many as a most stupendous example of the extravasation of a viscous mass of andesitic lava-which cooled as it was extravasated-is found in the remarkable spine of Mont Pelée which formed after the great eruption of 1902 . According to Hovey ( $16 ; 17 ; 18$ ), this spine was a lava mass pushed up vertically without spreading, the mass cooling either in the upper part of the conduit or upon its appearance at the surface, so that no extended flow was possible. The spine grew at an average of forty-one feet per day during a period

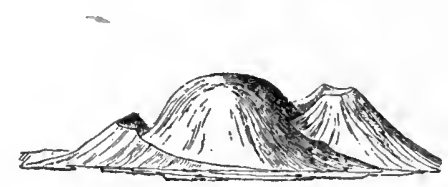

Fig. 232. The Grand Puy of Sarconi, in the Anvergne, composed of trachyte, rising between two breached scoria-cones. A typical example of a pustular cone formed of highly viscid lava.

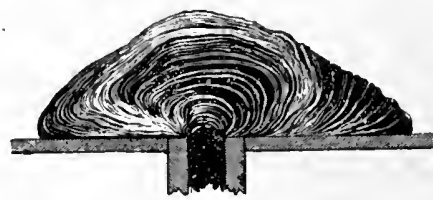

FIG. 233. Experimental illustration of the mode of formation of volcanic cones composed of viscid lavas.

of eighteen days out of the new cone, which itself had attained a height of I,600 feet during the last ten clays of May, and was of the same character as the spine. As the spine rose I, Ioo feet above this new cone in October it appears that the total elevation of this mass above the top of the cone as it existed prior to the eruption of May, 1902, was 2,700 feet. (See, further, Heilprin-12; HillI2a; Jaggar-20 and Russell-34a.)

\section{Composite Lava and Cinder Cones.}

Volcanic cones built by a combination or an alternation of the explosive and extravasative activities are by far the most common. They generally have pronounced slopes and are more resistant than cones built wholly of cinders, because the lava binds together the loose material into a complex mass. This is sometimes accomplished by the formation of radial dikes, as in the case of Etna. These represent lateral fissuring of the cone and the filling of these fissures 
by lava (Figs. 234, 235). The lava sometines extended through these fissures, building up secondary cones or monticules on the flank of the main cone, as in the case just cited. Fissuring of the cone is of common occurrence in volcanoes, the lava of many of them rarely or never overflowing the crater, but finding an outlet at a lower level through the side of the volcano. If parasitic cones (monticules) are built up over such a fissure these may remain the site of eruption for a long period, but sooner or later they are likely to become extinct, and then they may be buried by later flows and ejectamenta. Cinder cones, which are relatively weak structures, will be breached if a subsequent lava stream is poured out, and this

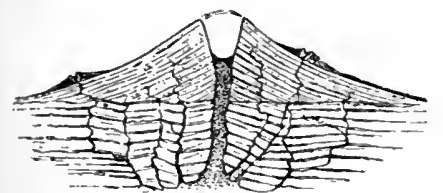

FIG. 234. Diagram illustrating the formation of parasitic cones (monticules) along lines of fissures formed in the flanks of a great volcano. (After Judd.)

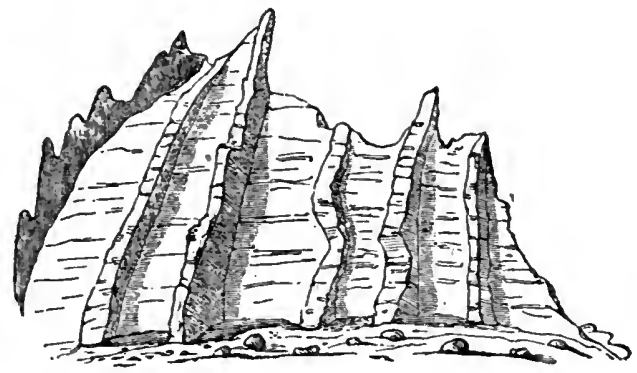

FIG. 235. Basaltic dikes projecting from stratified scoria or tuff in the walls of the Val del Bore, Etna.

will issue from their sides. (Fig. 227.) Large composite cones may be breached by explosive eruptions and the shifting of the center of the eruption. A new cone may be built up within the breached outer rim of an original large caldera, as in the case of Vesuvius, which was built within the breached rim of the extinct Monte Somma. The displacement of the eruptive point may be a gradual one, when a series of adjoining cones will result, all but the youngest being breached on the side toward the direction of migration of the cones. Examples of such consecutively breached cones are found in the volcanic region of central France (Mont Doré Province), and elsewhere. Many variations and combinations occur, and the student is referred for the details of these phenomena to the numerous general treatises, some of which are listed at the end of the chapter.

Compound volcanoes, such as Vesuvius, have alternating periods of light (or Strombolian) and violent (or Vulcanian) activity. Dur- 
ing the former cinder cones are built up which are destroyed again, in part or entirely during the violent periods, when crater formation is the marked characteristic. It is during this period of activity that the extravasative eruptions are in the ascendency, and at this time also fissuring of the volcano takes place, with all the varied activities which accompany such a state.

Submarine Cones. Submarine cones of pure extravasation are apparently illustrated by the Hawaiian Islands, though the early history of many of these volcanoes is shrouded in obscurity. Submarine cones of the composite type are well known, however. Probably many of the volcanoes of the Mediterranean began as submarine volcanoes and subsequently reached the surface. Volcanoes of this type are also known from the Aleutian island group (Jaggar-2I), while volcanoes apparently rising from the abyssal portions of the sea abound in the western Pacific. A singular example of a volcanic peak projecting from mid-ocean is seen in the little island of St. Paul, which rises from the Indian Ocean midway between the southern end of Africa and the west of Australia and more than 2,000 miles distant from Madagascar, the nearest mass of dry land. This little island, scarcely $2 \frac{1}{2}$ geographical miles long and about $I^{T} / 2$ miles broad, is the mere summit of a volcano. The crater has been breached by the waves and is now occupied by the sea, the break in the rim being nearly dry at low tide. (Figs. 236, 237.)

Mud Volcanoes. Of an origin fundamentally the same as that for lava volcanoes are the mud volcanoes found in various regions of the world, but not associated with igneous eruptions. They occur in Sicily, the Apennines, Caucasus, and on the peninsulas of Kertch and Taman bordering the Black Sea, as well as in India. They find their chief activity in the escape of various gases, which play much the same part as does the escaping steam in igneous volcanoes. Hydrocarbons, carbon dioxide, nitrogen, and naphtha are some of the gases emitted. The mud volcanoes of Sicily have been explained as due to the slow combustion of sulphur beneath the surface. Whatever the causes, these volcanoes are manifested on the surface in mounds or hillocks of mud. They generally occur in groups and range in elevation up to several hundred feet, while during periods of explosion they throw mud and stones up into the air to much greater heights. They are built up by successive outpourings of mud, which harden and form a foundation for later mud flows. "In the region of the Lower Indus, where they are abundantly" distributed over an area of 1,000 square miles, some of them attain a height of 400 feet, with craters 30 yards across." 
(Geikie-9:245.) These are not to be confused with the mud flows which form on the sides of volcanoes from the saturation of dust

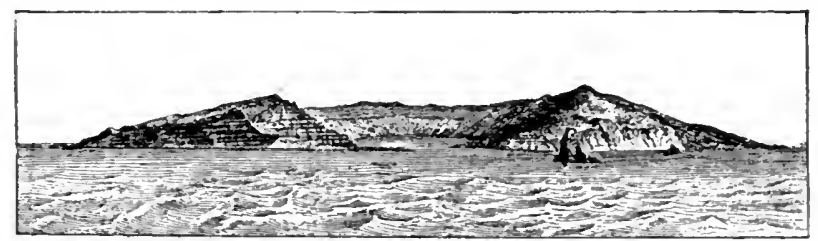

FIG. 236. View of the Island of St. Paul in the southern Indian Ocean, showing the breach in the rim of the extinct volcano and the crater flooded by the sea. (From a sketch by Charles Vélain in Haug.)

and cinders by rain. Such flows always occur in regions of igneous extrusion on the sides of igneous volcanoes, while mud vo!canoes may occur in any region where gases accumulate beneath the sur-

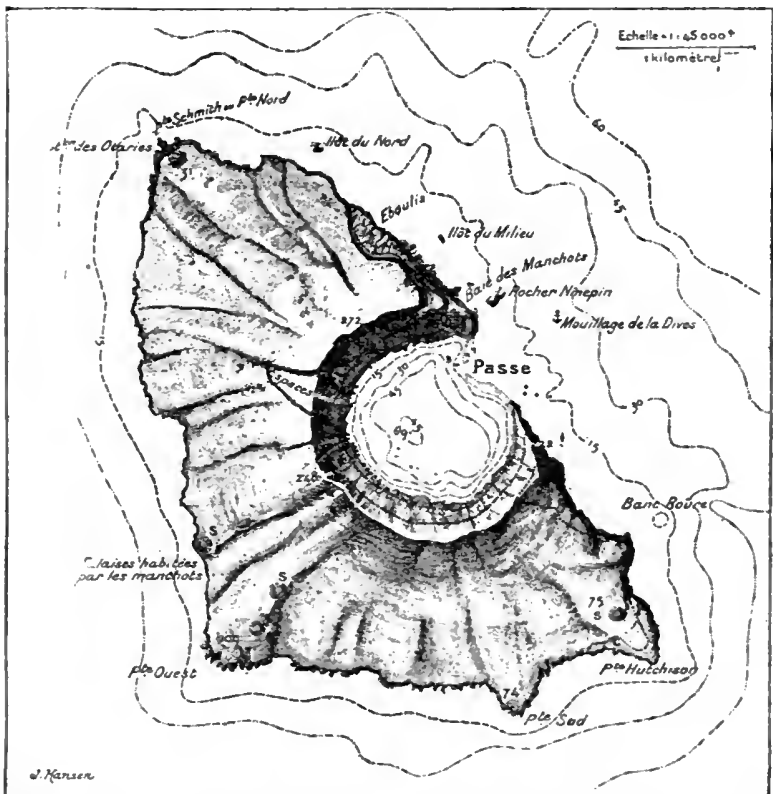

FIg. 237. Map of the Island of St. Paul in the southern Indian Ocean. A breached volcano. (After Charles Vélain in Haug.)

face in large enough quantities to be forced out. Neither should these mud volcanoes be confused with mud mounds, cones, or craterlets which form along earthquake fissures where the release 
of pressure sends forth a stream of water carrying sand and mud with it. (See farther in Chapter XXIII, on Seismology.)

Dissection of Volcanoes. When volcanoes have become extinct the ordinary forces of erosion set in and progressive destruction goes on. The rapidity with which this takes place varies, of course, with the nature of the material, the prevailing strength of the erosive forces, and with other fäctors. Many of the Tertiary volcanoes of the Eifel in Germany and of the Auvergne district in France are still almost perfect, while others of earlier date show all stages of dissection. Of interest in this connection is the Kammerbühl near Franzensbad in northern Bohemia, which

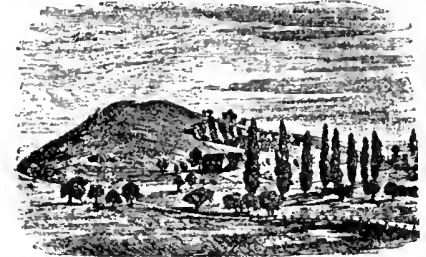

FIG. 238. The Kammerbühl, an old volcanic hill in Bohemia.

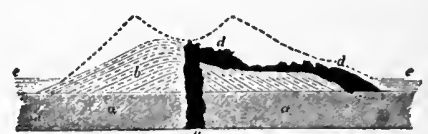

FIG. 239. Section of the Kammerbiihl, showing the probable former outline of the volcano: $a$, metamorphic rock; $b$, basaltic scorix ; $c$, plug or neck of basalt ; $d$, stream of basalt; $e$, alluvial beds.

Goethe pronounced an extinct volcano, though Werner had explained its character as originating, in common with those of others of similar aspect, through the combustion of a bed of coal. Goethe predicted the finding of a core of volcanic rock in the center of this hill were a tunnel driven into it horizontally. The excavating of this tunnel in 1837 verified this prediction, while more recent excavations have revealed the entire structure, showing that the small lava stream on the side of the hill was connected with the central plug or neck and rested on basaltic scoria. The above figures show the appearance of this hill and the structure ascertained by these excavations. (Figs. 238, 239.)

In extensively dissected volcanoes often only the central neck • or plug remains, as in the case of the volcanic necks of the Mount Taylor Region in New Mexico (Johnson-22:303-324), the Leucite Hills of Wyoming (Kemp-25), and many others of this type. Dikes dissecting the tufa beds of old volcanoes often stand out in bold relief owing to the steady removal of the easily eroded tufa enclosing them. Examples of such are known from many localities. The geological map of the Spanish Peaks region in Colorado shows excellently the numerous radiating dikes which center in the old volcanic necks of that region. 
Where extinct volcanoes have been subject to the attack of the waves of the sea sections are often cut which reveal their structure. This is the case in the island of St. Paul, already noted, and in Vulcanello on the shores of the Island of Vulcano in the Mediterranean. Some of the outlying islands of the Sandwich or Hawaiian group likewise represent partly dissected extinct volcanic cones whose sides, moreover, are deeply gullied into a series of parallel valleys so sharply divided one from the other as to effectively isolate certain of the organisms inhabiting them. (See Chapter XXIX.)

Finally, the destruction of volcanoes by their own explosive activity may be noted. Examples are furnished by the Vesuvian eruption of A. D. 79, which shattered the cone of Monte Somma; by the Japanese volcano Bandai-san, of which a considerable portion was blown out in I888; and by the Javanese volcano Krakatoa, which was practically blown to pieces on August 26 and 27, I883. furnishing the most stupendous example of volcanic activity in modern times. "After a series of convulsions, the greater portion of the island was blown out with a succession of terrific detonations which were heard more than 150 miles away. A mass of matter estimated at about $\mathrm{I} / 8$ cubic miles in bulk was hurled into the air in the form of lapilli, ashes, and the finest volcanic dust.

The sea in the neighborhood was thrown into waves, one of which was computed to have risen more than roo feet above ticle-level, destroying towns, villages, and 36,380 people." (Geikie-9:2I2.) The oscillations of the wave were noted at Port Elizabeth, South Africa, 5,450 miles away, having traveled with a maximum velocity of 467 statute miles per hour. The air waves generated traveled from east to west and are supposed to have passed three and a quarter times around the earth $(82,200$ miles $)$ before they dierl away. The barometric disturbances, passing round the globe in opposite directions from the volcano, proceeded at the rate of almost 700 miles per hour.

Special Erosion Fcatures. An interesting type of erosion has been observed on some steep-sided volcanoes, stuch as those of the islands of St. Vincent and Martinique. Vast amounts of dust were deposited during the eruption of May, 1902, and these formed a bed varying from a few inches to many feet in thickness, and extending over an area of 50 square miles on each island. The heavy rains that followed the eruption turned this dust into a cement-like mud which was firm enough to remain in place and which, during the eruptions of September and October of the same year, was covered by a new layer of coarser ejectamenta. In the 
valleys the permanent and periodical rivers were loaded with the new ash to such an extent as to form viscous streams, which, however, had great powers of erosion, on account of the steep slope of the declivities down which they flowed. The bottoms and sides of the gorges were deeply grooved by the sand carried down in this manner by the flowing water.

"During the great eruptions the ejected material was drifted into large beds in the gorges extending radially down the Soufrière [on St. Vincent Island]. The massing of material was most important in the gorge of the Wallibou River. on the west, and in that of the Rabaka River on the east, side of the island. In these gorges the bed of new material reached a thickness of from 60 to IOO feet. This enormous amount of material was almost entirely washed out of the gorges during the first rainy season following the eruptions of I902. Not less than I50,000,000 cubic feet of ashes have been washed out of the Wallibou gorge itself, without taking into account the thousands of cubic yards of fresh ash removed from the watershed of the river during the same period. All this material was, of course, transported directly to the ocean." (Hovey-I8:560.)

\section{FORMATION OF THE LAVA.}

Since it is very unlikely that at any point within the earth's crust the temperature is sufficiently high to melt rocks (see Chapter I) at the increased fusing point caused by the increase in pressure downward, it follows that some other factors must be taken into consideration in explaining the liquefaction of rock. We must, therefore, seek either for causes producing an increase of temperature, or for such producing a decrease of pressure. The former may be found in the energy liberated by radio-active substances, such as are found in practically all the rocks of the earth's crust, as well as in the water and the air. Since, says Chamberlin $(3: 679)$, "radio-activity increases as we go from air to water, from water to sediment, and from sediment to igneous rock, it might be inferred . . that radio-activity would be found to reach its maximum concentration in the heart of the earth, and certainly that the deeper parts would be as rich as the superficial ones." This, however, would imply a more rapid increase in temperature than observation indicates. Strutt (quoted by Chamberlin) has computed that, if. the quantity of radio-active substances known to exist in surface rocks is also found throughout the rocks of the upper 45 miles 
of the earth's crust, the rise in temperature equal to that observed in deep wells and mines would be produced hy this cause alone, irrespective of any other source of heat. Whether this distribution is equal, or whether it increases or decreases downward, can not, at present, be determined; but it is seen that if we start with an original increase in temperature downward the anount added to it by radio-activity might serve, locally, to orercome the opposing effects of pressure in raising the fusing point, whereupon reser-. voirs of molten rock would be formed which would become the source of volcanic activity.

If excessive temperature increase is not to be accepted as the cause of rock fusion at a depth, we must turn to a local decrease of pressure to permit the lowering of the fusing point of the rocks. This would be effected by the formation, locally, of rock arches within the crust capable of maintaining the weight of the superincumbent portion of the crust. Such arches, or domes, by relieving the pressure, would permit the liquefaction of the rock mass for some distance beneath them, provided the temperature is sufficiently high, and so furnish the requisite conditions for volcanic activities.

Arches of this type might be expected to form along the margins of the continent where the down-warping of the continental edges takes place. Now, it is precisely along these lines, where the continental margin drops off steeply to the deep sea, that the great volcanic phenomena of the past have been located, while the distribution of most of the modern volcanoes of the earth is essentially in harmony with this idea. Thus by far the largest number of still active or but recently extinct volcanoes are ranged in belts or lines parallel to the margins of the continents or within the oceanic areas. The most important belt of volcanic activity surrounds the Pacific Ocean, the dcepest and perhaps the oldest of the oceans of the earth, and the one which has experienced the least change. This belt inclucles the volcanic mountains of the west coasts of South and Central America, of Mexico, and of the western United States and Canada to Alaska and the Aleutian Island chain. It is continued along the eastern coast of Eurasia, and through the Malaysian islands to New Zealand, the belt being finally closed by the volcanoes of Victoria Land, King Edward Island, and West Antarctica. It is significant that the belt for the most part is paralleled by an inner one of exceptional depressions the great fore-deeps of the marginal Pacific. That these are produced by downwarping or faulting seems certain, and this would imply an arching or unwarping of the adjoining continental margins. 


\section{BIBLIOGRAPHY XXII.}

I. ANDERSON, TEMPEST. I903. Volcanic Studies in Many Lands. John Murray, London.

2. BONNEY, T. G. I899. Volcanoes, Their Structure and Significance. John Murray, London.

3. CHAMBERLIN, THOMAS C. I9I. The Bearing of Radioactivity on - Geology. Journal of Geology, Vol. XIX, pp. 673-695.

4. CHAMBERLIN, T. C., and SALISBURY, ROLLIN D. I906. Geology, Vol. I. Henry Holt \& Co., New York.

5. DANA, JAMES D. I 890 . Characteristics of Volcanoes, with contributions of Facts and Principles from the Hawaiian Islands. Dodd, Mead and Company, New York.

6. DE LA BECHE, HENRY T. I85I. The Geological Observer, Philadelphia.

7. DUTTON, CLARENCE E. I 884. Hawaiian Voleanoes. Fourth Annual Report of the United States Geological Survey, I 882-83, pp. 81-219.

8. FAIRCHILD, HERMAN L. 1907. Origin of Meteor Crater (Coon Butte), Arizona. Bulletin of the Geological Society of America, Vol. XVIII, pp. 493-504, pls., 54-56.

9. GEIKIE, ARCHIBALD. I 893. Text-book of Geology, 3rd edition. Macmillan \& Co.

I0. GEIKIE, A. I 897. The Ancient Volcanoes of Great Britain, 2 vols. Macmillan \& Co.

I I. GILBERT, G. K. I893. Report on Coon Butte, Arizona. Fourteenth Annual Report of the United States Geological Survey, pt. I, p. 187.

12. HEILPRIN, A. 1904. The Tower of Pelée. Philadelphia.

12a. HILL, R. T. 1905. Pelée and the Evolution of the Windward Archipelago. Bulletin of the Geological Society of America. Vol. XVI, pp. $243^{-288,5}$ pls.

I3. HITCHCOCK, C. H. I909. Hawaii and Its Volcanoes. Honolulu.

14. HOBBS, WILLIAM H. I906. The Grand Eruption of Vesuvius in 1906. Journal of Geology, Vol. XIV, pp. 636-655.

15. HOBBS, W. H. 1912. Earth Features and Their Meaning, an Introduction to Geology. Macmillan Company, New York.

16. HOVEY, E. O. I903. The New Cone of Mont Pelée and the Gorge of the Rivière Blanche, Martinique. American Journal of Science, Vol. XVI, pp. 269-281.

17. HOVEY, E. O. 1904. New Cone and Obelisk of Mont Pelée. Bulletin of the Geological Society of Ameriea, Vol. XV, pp. 558-560.

18. HOVEY, E. O. I90. Some Erosion Phenomena Observed on the Islands of Saint Vincent and Martinique in 1902 and 1903 . Ibid., pp. 560-56I, pls. $57-58$.

19. HOVEY, E. O. 1905. Present Conditions of Mont Pelée. Bulletin of the Geological Society of America, Vol. XVI, pp. 566-569, pl. 92.

20. JAGGAR, THOMAS A. 1904. The Initial Stages of the Spine on Pelée. American Journal of Scienee, $4^{\text {th }}$ series, Vol. XVII, pp. 39 et seq.

2r. JAGGAR, T. A. I908. The Evolution of the Bogoslof Volcano. Bulletin of the American Geographical Society, Vol. XLV, pp. 385-40o, 8 figs.

22. JOHNSON, DOUGLAS W. I907. Volcanic Necks of the Mount Taylor Region, New Mexico. Bulletin of the Geological Society of America, Vol. XVIII, pp. 303-324, pls. 25-30. 
23. JOHNSTON-LAVIS, H. J. I891. The South Italian Volcanoes. Naples. 342 pp.

24. JOHNSTON-LAVIS, H. J. 1909. The Eruption of Vesuvius in April, 1906. Transactions of the Royal Dublin Society, Vol. IX, pt. VIII, pp. 139-200.

25. KEMP, JAMES F., and KNIGHT, W. C. 1903. Leucite Hills of Wyoming. Bulletin of the Geological Society of America, Vol. XIV, pp. 305-336, pls. $37-46$.

26. MOORE, J.E. S. 1903. The Tanganyika Problem. Hurst and Blackett, London.

27. OMORI, F. I9II. The Usu-san Eruption and Earthquake and Elevation Phenomena. Bulletin of the Earthquake Investigation Committee, Japan. Vol. V, pp. I-37.

28. PEACH, BENJAMIN, and HORNE, JOHN. 1907. The Geological Structure of the North-west Highlands of Scotland.

29. RATH, G. VON. I872. Der Aetna. Bonn.

30. RECLUS, JEAN JACQUES ÉLISÉE. I906-1910. Les Volcans de la Terre. Belgian Society of. Astronomy, Meteorology and Physics of the Globe.

3r. ROYAL SOCIETY OF LONDON. 1888. The Eruption of Krakatoa and Subsequent Phenomena. Report of Special Committee. London. $494 \mathrm{pp}$.

32. RUDOLPH, E. 1887. Ueber Submarine Erdbeben und Eruptionen. Gerlands Beitrāge zur Geophysik, pp. 133-365; ibid., 1895, pp. 537-666; ibid., I 898, pp. 273-336.

33. RUSSELL, I. C. 1897. Volcanoes of North America. Macmillan, New York.

34. RUSSELL, I. C. 1902. Geology of Snake River Plains, Idaho. Bulletin United States Geological Survey, No. 199. (Abstract: Bulletin of the Geological Society of America, Vol. XIII, 1902, p. 527; and Science, Vol. $\mathrm{XV}$, 1902, pp. 85-86.)

34a. RUSSELL, I C. 1905. The Pelée Obelisk. Science N. S. Vol. XVIII, pp. 792-795.

35. SCROPE, PAULET. 1858. The Geology of the Extinct Volcanoes of Central France. John Murray, London.

36. THORODDSEN, TH. 1905. Die Bruchlinien und ihre Beziehungen zu den Vulkanen. Petermann's Mittheilungen, Bd. LI, pp. I-573.

37. THORODDSEN, TH. I906. Island, IV. Vulkane. Petermann's Mittheilungen, Ergānzungsheft I 53, pp. Io8-I I I.

38. THOULET, J. 1903. Les Volcans sousmarins. Revue des Deux Mondes. $73^{\text {ième }}$ année, $5^{\text {ième }}$ période, T. XIII, pp. 6I I-624.

39. VERBECK, R. D. M. 1885. Krakatau. Batavia. 557 pp., 25 pls.

40. WALTERSHAUSEN, SARTORIUS VON. I88o. Der Aetna. Leipzig. 2 vols.

41. WALTHER, JOHANNES. 1910. Lehrbuch der Geologie von Deutschland. Quelle und Meyer. Leipzig. 


\title{
E. THE CENTROSPHERE OR BARYSPHERE.
}

\author{
CHAPTER XXIII.
}

DIASTROPHISM, OR THE MOVEMENTS TAKING PLACE WITHIN THE EARTH'S CRUST AND THEIR CAUSES.

In discussing the subject of diastrophism under the heading of the Centrosphere, it is intended to emphasize the fact that the great mass of such movements is directly or indirectly induced by gravity, $i . e$., the terrestrial phenomenon of weight or downward acceleration,* which has for its two components the gravitation or attracting force between bodies and the centrifugal force due to the rotation of the earth on its axis.

Other forces which induce earth movements have their origin in the interior heat of the earth; in chemical combination; in molecular attraction and repulsion; in radio-activity; in electrical and vital energy; in the centrifugal energy due to the rotating of the earth on its axis and its revolution around the sun; in the attraction of the moon and sun; and in the radiant energy of the sun. Impact with heavenly bodies may be further mentioned as a source of possible energy. But all of these, except perhaps the last, are of minor significance as compared with gravity as the great source of energy influencing earth movements. The displacement of the earth's center of gravity through any cause, and the consequent displacement of the earth's axis, would also be a direct cause of the setting free of a vast amount of available energy.

\section{CLASSIFICATION OF EARTH MOVEMENTS.}

Earth movements may be classified either as local disturbances or as widespread or regional ones. The movements are manifested

* The amount of downward acceleration is about 385.I inches (978 centimeters) per second at sea-level at the equator, and 387.1 inches at sea-level at the poles, diminishing slightly on mountain tops. The centrifugal force at the equator is $\frac{I}{289.4}$ of gravity. 
as seismic disturbances, of which earthquakcs and sea-quakes are the recognized effects, while the products of the disturbances are tectonic structurcs.*

Not all tectonic structures are accompanied in their formation by seismic disturbances, for some deformations may go on so gradually, and at such a uniform rate, that no surface manifestations are felt. In this class fall especially the large or epeirogenic earth movements, and the bradyseisms noted below.

\section{Classification of Seismic Disturbances.}

Not all seismic.disturbances are due to earth movements, as the term is here used, for volcanic activities, especially of the explosive type, may generate such disturbances, these being sometimes of considerable magnitude, as in the case of the explosive eruption of Krakatoa in 1883. As there illustrated, the three inorganic spheres - the litho, hydro, and atmosphere, not to mention the biosphere-were disturbed by this explosion, and carthquakes, seaquakes, and air-quakes $\dagger$ resulted. The air-waves which characterized the last passed around the earth several times, while the sea disturbances or tsunamis + generated were noticeable more than five hundred miles away.

Recognizing the different modes of production of earthquakes, seismologists have divided them according to origin into: (Suess38.)

I. Dislocation or fault earthquakes.

2. Volcanic, or explosive earthquakes.

* The term tectonic, originally applied to all structures, has come of late to be more especially applied to structures due to earth movements, or deformation structures. These include faults, folds, torsion joints, etc., but not stratification, unconformity, overlap, flow-structure, or any other original structures, nor such secondary structures as concretions, enterolithic deformation, or any other structures due to diagenetic or contactic metamorphism.

$\dagger$ If we consider that the term seisma refers to the trembling or shaking of the geos, or earth as a whole (geoseism), and not merely to the tremblings of the land, we may extend the meaning of the term seismology so as to cover the shaking or trembling of any portion of the earth as the result of such disturbances. We could thus distinguish: lithoseisma, or carthquakes proper (land-quakes); hydroor thalassoseisma or sea-quakes and atmoseisma, or air-quakes. The bioseisma arc, of course, a universal accompaniment of all these disturbances.

$\ddagger$ The Japanese term for the "tidal wave," or "sea-wave" of sea-quakes. Suggested for general adoption by Hobbs (I 7 ). 
The first type of seismic disturbance may be spoken of as baryseismic, ${ }^{*}$ and the second as pyroseismic. $\dagger$ these terms indicating the relationship of the disturbances to the respective spheres. Hoernes (19) has designated as a third type the results of incaving of the roofs of fissures (Einsturabeben) which characterize the Karst region of the Dalmatian coast. This, however, is to be classed as a special phase of the dislocation (baryseismic) type, since such cavings-in of cavern roofs are merely special phases of faulting. In the same way, we must class under the volcanic or explosive (pyroseismic) type the tremors resulting from explosions of $\mathrm{g}^{\mathrm{n}} 11 \mathrm{-}$ powder or dynamite, and of gases, in mines and elsewhere, which may not be sufficient to affect the seismograph, but are certainly noticeable as sea-quakes (submarine explosions) and as air-quakes. These, as well as the disturbances due to incaving, may be dismissed without further notice.

The Volcanic or Pyroseismic Type of Earthquake. This is, of course, an accompaniment of volcanic activities; but such disturbances are not necessarily always felt, for, even if they occur, they may be so slight as to escape notice.

The Tectonic or Dislocation (Baryseismic) Earthquake. This is a jar occasioned by the breaking of rock under strain. "The strain may be caused by the rising of lava in a volcano or by the forces that make mountain ranges and continents." The rupture of the rock mass "may be a mere pulling apart of the rocks, so as to make a crack, but examples of that simple type are comparatively rare. The great majority of ruptures include not only the making of a crack but the relative movement or sliding of the rock masses on the two sides of the crack; that is to say, instead of a mere fracture, there is a geologic fault." (Gilbert-13:2.)

The walls of the fault plane may eventually become cemented together, but they will remain as a plane of weakness for a long time, so that repeated slipping may take place, making the region one of frequent earthquakes. This has been the case in the repeated California earthquakes, of which the San Francisco quake of 1906 is the most recent. The fault-line there extends for several hundred miles northwest and southeast and nearly parallel to the coast. The "Fossa Magna" crosses Japan from north to south, while the southern border lands of Afghanistan have such an habitual earthquake-producing fault-line extending for 120 miles.

The faulting or slipping which produces the earthquake may

*From the Greek $\beta a \rho u ́ s=$ heavy, $+\sigma \epsilon i \sigma \mu a=$ earthquake; signifying that weight or gravity is the dominant factor in their production.

$\dagger$ From the Greek $\pi \tilde{v} \rho=$ fire,$+\sigma \epsilon i \sigma \mu \alpha=$ earthquake. 
be deepseated or may reach the surface. The depth to which the dislocation penetrates may be very great-it may pass from the zone of fracture into that of flowage; but the origin of the shock is probably never deeper than 30 geographical miles, and usually does not exceed 5 to 15 miles. (Hovey-2I :244.) The point or locus of origination of the earthquake is variously called the seismic center, centrum, hypocenter, origin, or focus. This, though conveniently regarded as a point, is really a space of three dimensions which in different cases varies much in size and shape and may be of great magnitucle. The part of the earth's surface which is vertically above the center is the epicentcr or epicentral or epifocal tract.

\section{Surface Manifestations of Baryseismic Disturbances.}

The surface manifestations of an earthquake-producing fault or other tectonic movement may, so far as the lithosphere is concerned, be classed as rifting, as slipping, and as disruption. The first is mere separation, the second involves displacement. It is to the latter movement that the term faulting is commonly applied.

\section{Rifting.}

As a result of rifting. fissures will open in the earth (Fig. 240) and these may remain open or be filled by injected material. So far as arrangement is concerned these fissures may be in parallel series, as in the case of the fissures formed by the earthquake of Sinj, Austria, in 1898, in which slipping also occurred along each rift. Or, again, these fissures may radiate from a center, branching repeatedly. Such fissures were formed during the Calabrian earthquake of 1783 . Finally, fissures formed during earthquakes may be irregularly intersecting, forming a network. This type has been observed at Aigon in the Balkans after the earthquake of December 26, I86I $\mathrm{in}$ Owens Valley, California, after the earthquagke of 1872 (Whitney): and in Ecuador, where it is a very characteristic feature of the Andes region. Whimper (43) says of these: "In no other part of Ecuador is there anything equaling this extraordinary assemblage of fissures. intersecting one another irregularly and forming a perfect maze of impassable clefts . . . the cracks are all $\mathrm{V}$-shaped and, though seldom of great breadth, are often very profound, . . Several, at least, have been formed within the memory of man, while others are centuries old." 
These intersecting fissures are locally known as earthquake "quebradas."

Fissures often open and close repeatedly, even during the same

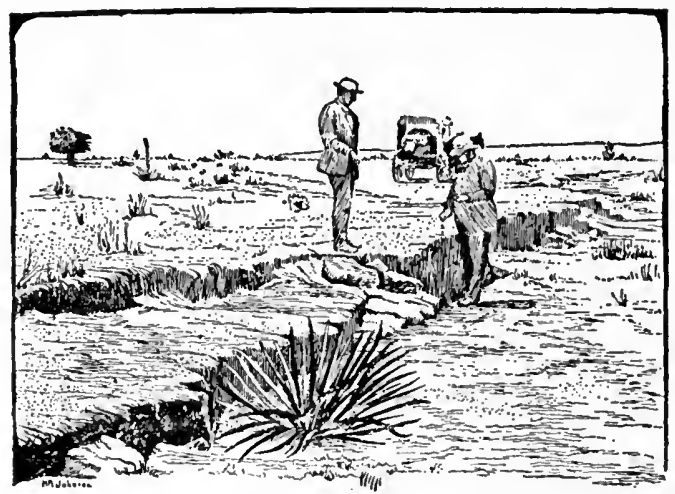

FIG. 240. Small earthquake fissure and fault in the Arizona desert. (After Branner.)

disturbance; sometimes in closing, the walls are pressed violently together, while shattering of the adjoining rock masses occurs, with the formation of autoclastic material or fault-breccias. This gen-

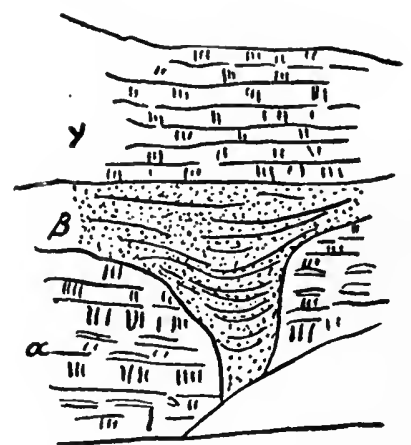

FiG. 21. Section of one of the sandstone pipes in limestone on the eastern coast of Anglesey in Wales. (After Greenly, from Hobbs.) $\alpha$, cherty limestone; $\beta$, sandstone pipe; $\gamma$, cherty limestone.

erally falls into the fissure, more or less filling it, or it marks the sides of the fissure for some distance outward.

Filling of the Fissures. Sandstone Dikes. Fissures formed by earthquakes may remain open for a longer or shorter period of 
time, becoming gradually filled up by débris which falls in from above, or is washed into them. Such is the case in several vertical fault fissures at Meriden, Connecticut, which have been filled by infiltration of trap fragments and sandstone from above. (Davis, in Diller-8:442.)

Davis says: "These fractures traverse a sheet of lava and are chiefly filled with angular trap-fragments, but the interstices are occupied with sandstone, not in fragments as if it had fallen in with the pieces of trap, but in a close-fitting mass, as if it had settled down in the form of separate particles derived from the sandstone originally overlying the trap sheet, thus, in a general way, taking a structure conformable to the blocks of trap that it surrounds, but showing also a tendency to a transverse or horizontal stratification. It seems probable that these fissures were filled gradually by infiltration from above . . ."

In some cases, however, such fissures are filled at the time of their formation by sand violently injected into them either from below or above. Cases of mud and sand welling up from volcanic fissures have been frequently observed, and seem to be a general accompaniment of such fissures near the surface. In some cases, as in the earthquake of Chemakha, Turkestan (Feb. I2, I902), "salty plastic mud exuded from the open faults and built up high hillocks of the pasty material, which were surmounted by craters" (Hobbs18:134). Subsequent movement along the plane caused a displacement in these "mud volcanoes" to the extent of 1.5 meters in some cases. Sand and mud injections of this type are known from older geological formations, where they form sandstone dikes. Thus Newsom (33:233) describes a sandstone dike $2 \frac{1}{2}$ to 5 feet wide from California, in which the upward bending of the shales on either side is regarded as proving its injection from below. Others from the same general region are also described. Violent injection into an earthquake fissure of loose sand, which covered the surface of the rock, seems to have taken place in the case of the Lower Devonic sandstone dike (injected into Upper Siluric strata) at Buffalo, as described in a preceding chapter. For a general summary of sandstone dikes with references to the literature, the student is referred to Newsom's article (33).

Craterlets. Analogous to the injected sandstone dikes are the craterlets formed by sand and mud ejected with water from earthquake fissures. One such has already been noted in connection with the Chemakha earthquake. Others were noted in the Charleston earthquake of 1886 . Some of these which were aligned along fissures measured 20 feet in diameter, while the water and sand 
ejected from them shot in some cases 20 feet into the air. Many of the craterlets, especially those formed during the Calabrian earthquake, are merely funnel-shaped holes in the ground, and.so resemble the volcanic explosion craters. (Fig. 242.) Such craterlets formed in the Mississippi Valley during the earthquake of I8I I. They were commonly surrounded by a ring of sand and carbonized wood, sometimes as much as 7 feet in height. They have a diameter ranging from 20 to 100 feet, and some were sounded to a depth of 20 feet or over.

Much sand and water is ejected from these and is spread over the surrounding country, which may thus be blanketed by a

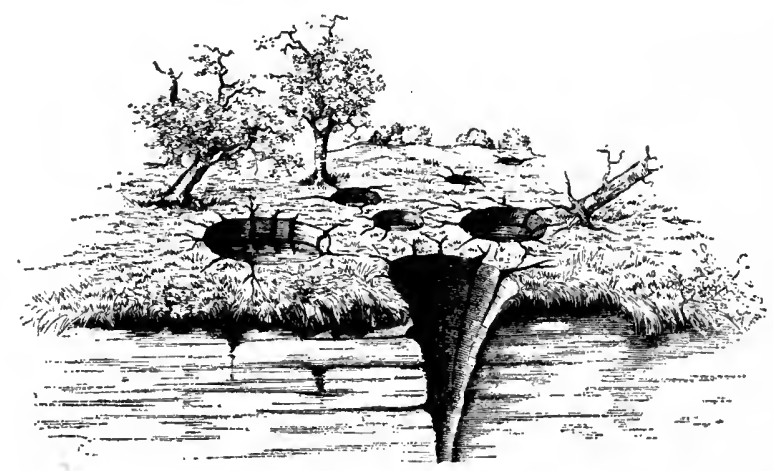

FIG. 242. Funnel-shaped holes formed during the Calabrian earthquake of 1783. (C. Vogt.)

layer of sand brought from below, the analogue of a lava flow. Sulphuretted hydrogen frequently accompanies these eruptions.

Fossil examples. Ancient craterlets of the type above described have been noted in some cases. Thus, on the coast of East Anglesey, in Wales, sandstone pipes have been observed, penetrating the Ordovicic limestones, and having a general funnel form comparable to the funnels formed by the Calabrian earthquake. They are continuous above with a spreading blanket of sandstone, which may be the ejected layer of sand. The entire series is again covered by the Ordovicic limestones of the region. A section of this, copied from Hobbs, is shown in Fig. 24I. Care must, however, be exercised to distinguish these fissures from the solution fissures subsequently filled by sand and forming the organ-pipe structure described in a preceding chapter. 


\section{Slipping.}

When differential movements of the two sides of a fracture occur a fault results. This movement may be horizontal, diagonal, or vertical. The displacement may be profound or very slight. It may be sudden or by a series of progressive slips, or it may be the resultant of a series of slips in various (even opposite) directions, and of varying amounts. The California earthquake of 1906 and the Japanese earthquake of I8I I were caused by slips of large amplitude along well-defined seismotectonic lines. The frequent New England quakes are due to a relatively large number of slight adjustments along joint planes. These minor slippings may be so slow as to produce no perceptible seismic disturbances, though they may find a surface expression in minute faults. Here, probably, belong the numerous minute post-glacial faults of New England and eastern New York. (Woodworth-45.)

The local rise and fall of the land in response to adjustment to stresses, but without violent shocks, or abrupt ruptures, may be considered as forming one end of the series of earthquakeproducing disturbances. To these the name bradyseisms has been given, and they are well illustrated by the changes of level recorded in the ruins of the Temple of Jupiter Serapis in the Bay of Naples, already referred to in an earlier chapter.

On the surface the fault is expressed by the dislocation of structures, such as fences, roadways, and parts of buildings, bridges, railroad tracks, or of natural objects, such as trees, etc., while if the slipping has a vertical component, a fault scarp will result. These phenomena, and the types of faults and their effects, have been discussed in Chapter XXI. When successive shocks from various directions are experienced, a vortical movement of objects may result, as in the case of statues turned on their pedestals. The various effects of such shocks on buildings and other structures are fully illustrated in the reports on the recent Californian and other earthquakes.

Block Movement. The faulting may be manifested as a block movement, strips of land dropping or rising and forming rift valleys (Gräben) or fault blocks. On a large scale, these form fault-block mountains. Such faulting occurred in connection with the Owens Valley earthquake of 1872 , the resulting scarps reaching in some cases a height of ten feet or more. At Big Pine, California, a tract of land 200 to 300 feet wide sank, some portions being depressed 20 feet or more, leaving vertical walls on either side. 
(Johnson-23.) During the earthquake of Yakutat Bay, Alaska, in I899, great sections of the country moved as individual masses, some blocks being elevated, some depressed, the extent of the differential movement reaching 30 to 47 feet. Portions of the seashore were elevated; beaches only recently abandoned being now at a considerable height above the sea, while many of the depressed areas became submerged. Similar block movements occurred during the great Icelandic earthquake of 1806 .

\section{Disruptive Effects of Earthquakes.}

The more pronounced earthquake shocks often have a very destructive effect on the rocks of the earth's surface. Land slips of great extent may be set in motion by them. A piece of land one mile long fell from the cliff at Scilla during the Messina earthquake.

Darwin describes the overwhelming forces of the earthquake of February 20, 1835, in Chile. He particularly notes the effects on the islands in Concepcion Harbor, where upward of a hundred villages were destroyed and where rocks from beneath the sea were broken off and cast high up on the shore. "One of these was six feet long, three broad, and two thick." Darwin describes the destruction on Quiriquina Island as follows: "The ground in many parts was fissured in north and south lines, perhaps caused by the yielding of the parallel and steep sides of this narrow island. Some of the fissures near the cliffs were a yard wide. Many enormous masses had already fallen on the beach, and the inhabitants thought that when the rains commenced far greater slips would happen. The effect of the vibration on the hard primary slate, which composes the foundation of the island, was still more curious: the superficial parts of some narrow ridges were as completely shivered as if they had been blasted by gunpowder. This effect, which was rendered conspicuous by the fresh fractures and displaced soil, must be confined to near the surface, for otherwise there would not exist a block of solid rock throughout Chile . . . I believe this convulsion has been more effectual in lessening the size of the island of Quiriquina than the ordinary wear-and-tear of the sea and weather during the course of a whole century." (Darwin-6, Chap. XIV.)

\section{Effects of Earthquakes on Topography.}

Many minor changes in topography in regions of frequent seismic disturbances may have their origin in the earth tremors. 
Changes due to displacement are not to be classed in this category, as they are due to the same cause which is responsible for the earthquake, namely, the faulting. But topographic changes caused by the shaking of the earth are properly classed here. Such are the formation and sudden drainage of lakes; the blocking of rivers by land slips; the shifting of river channels in level delta regions, and other changes. After the Indian earthquake of 1897 no less than 30 earthquake lakes were produced. The earthquakes of I I I-I2 caused the appearance of many new lakes along the lower Mississippi, owing, probably, to the local settling of the river sediment. One of these is Reelfoot Lake, in Obion county, Tennessee, which has a length of more than 20 miles and a width of seven miles; the water in places covering the tops of submerged cypress trees. Near Little Prairie a lake, many miles in length but only from 3 to 4 feet in depth, came into existence. Upon its disappearance it left behind a stratum of sand. On the other hand, Lake Eulalie, 300 yards long and Ioo yards wide, was suddenly drained through parallel fissures which opened in its bottom. Many other examples of this kind might be cited.

This same earthquake was responsible for a local and temporary reversal of the current of the Mississippi. Similar phenomena have been observed in other rivers.

\section{Submarine Earthquakes and Sea-quakes.}

As might be expected, seismic disturbances are common along the borders of the Pacific, where, as before noted, we have the regions of down-warping, and, therefore, the region of stresses and of readjustments to these stresses. From their proximity to the sea the latter is, of course, strongly affected by the shocks, and seaquake waves, or tsunamis, are the result. These, on account of their height and velocity, are exceedingly destructive. Perhaps the most memorable one is that which destroyed Lisbon in I775. The seaquake originated on the ocean floor fifty or more miles off the coast of Lisbon, and the vibrations were transmitted along the surface of the water in a series of monstrous waves. The greatest of these was sixty feet high, and was followed by others of decreasing height. Spending their strength on the coast of Spain the waves passed on with diminished amplitude, but were felt even on the shores of the West Indies, across the whole expanse of the Atlantic. 
Even greater distances have been traveled by tsunamis, as, for instance, those originating in an earthquake at Concepcion, Chile, which "set in motion a wave that traversed the ocean to the Society and Navigator Islands, 3,000 and 4,000 miles distant, and to the Hawaiian Islands, 6,000 miles." (Dana-5:213.)

The velocity of these mighty waves has been ascertained, and is seen to be far greater than that of ordinary sea-waves, though it does not equal that of earthquakes proper. "The waves of the Japan earthquake crossed the Pacific to San Francisco, a distance of 4,525 miles, in a little more than twelve hours, and, therefore, at a rate of 370 miles per hour, or over six miles per minute. The waves of the South American earthquake of I868 ran to the Hawaiian Islands at a rate of 454 miles per hour." (Le Conte$26: 13 I$.)

Seismic disturbances are not confined to the shore, however, but also occur under the sea. Both pyroseismic and baryseismic disturbances are likely to affect the water and produce pronounced disturbances. That faulting occurs on the bottom of the deep sea is shown by soundings and studies of cable routes. The frequent breaking of the cables, accompanied by thrusting and fraying, furnishes visible evidence of such disturbances. Precipices from 3,000 to 5 ,000 feet in height have been detected by soundings in the Mediterranean, a difference in depth of 2,000 feet having been noticed between the bow and the stern of the cable repair ship. The earthquake of October 26,1873 , caused the cable to break 7 miles from the cable office at Zante, Greece, by the formation of a submarine fault scarp 600 feet in height, the change in depth being from 1,400 to 2,000 feet. Similar breaks, with the formation of submarine fault scarps more than a thousand feet in height, have been reported from the same region. Submarine earthquakes ought to be distinguished from sea-quakes proper. The latter always accompany the former and may even accompany earthquakes originating in the land near the sea. On the other hand, true sea-quakes, or thalassoseisma, may be formed by causes which will not produce earthquakes, as, for example, submarine explosions. The latter represent a submarine pyroseismic disturbance (whether of a submarine volcano or a submarine mine), and this is the only kind of directly induced sea-quake or thalassoseisma possible. Secondarily induced or communicated thalassoseisma are, however, the most frequent type, and here belong, besides the effects of many volcanic explosions on the sea coast (e.g., Krakatoa), the great series of baryseismic disturbances or tectonic faultings. 


\section{Air-gunkes.}

What is true of the sea is in an even greater measure true of the atmosphere. This, like the water, is too mobile to permit the setting up of strains within its mass, and so baryseismic disturbances cannot originate in the atmosphere any more than they can in the hydrosphere. Such disturbances may, however, be communicated from the baryseismic disturbances of the land. Originally induced pyroseismic disturbances are, however, as readily produced in the air as in the water, and they are more readily transmitted, owing to the greater mobility of the atmosphere over that of the water.

\section{Periodicity of Earthouakes.}

Periods of strong seismic disturbances (macroseisms) are known to alternate with periods of relative quiescence, or only minor disturbances (microseisms). In Japan the seismic periods recur about once in thirteen years, though observations at Kioto indicate a period as short as six and one-fourth years. Too little is yet known to warrant predictions of recurrences of earthquakes.

Movements Due to Displacement or Migration of the Poles.

The theory of pole migration, or the shifting of the earth's axis of rotation with reference to the earth itself, together with the accompanying changes in the form of the earth, in distribution of land and sea and in climatic belts, has ever proved attractive to speculative geologists who sought for means of accounting for the ascertained variations in the surface characters of the earth in the past. Thus, evidence is accumulating which points to a widely different position of the earth's axis during Palrozoic time from that which it held during the Mesozoic and subsequent periods. This evidence is furnished in part by the occurrence of mild climate, and even of tropical vegetation, in regions having an arctic climate at present, and in part by the presence of glacial deposits where tropical conditions prevail to-day. It is further found in the occurrence of sediments which indicate the existence during Palæozoic time of easterly winds where now the westerlies prevail. (See ante, Chapters II and XIV, also Fig. I28, page 636.)

A wealth of biological evidence has been accumulated which 
also seems to point to the phenomenon of polar migration. (Simroth-37.) The signs further point to the existence, in the border regions of the present Atlantic, of large continental masses which became submerged with the close of the Palæozoic. Thus Appalachia, the source of clastic sediments in eastern North America during the whole of Palæozoic time, disappeared at the end of that period; the disappearance being coincident with, or closely related to, the formation of the Appalachian folds. Similar conditions have been ascertained for western Europe. As demonstrated in an earlier chapter, the clastic sediments of North America indicate that in Palæozoic time this continent came under the influence of the trade winds, at least so far as the eastern portion is concerned, while in Mesozoic and later time it had passed into the region of the westerlies. This suggests that the end of Palæozoic sedimentation was brought about by a profound change in physical geography which affected not only North America, but also the earth as a whole. A comparatively rapid shifting of the position of the earth's axis would be sufficient explanation of the profound changes which brought about the all but universal extinction of life, so that only the pelagic and deep-sea types of the oceans (especially, of the Pacific), and the terrestrial types in the interior of the continents, remained unaffected. These probably formed a source from which the earth was repopulated after the widespread extermination of life on the margins of the continents and in shallow water. That migrations of the poles occurred before and after this great cataclismic shifting is indicated by the nature of the sediments, the changes in climate and life during the successive periods, and, especially, by the occurrence of glacial conditions in Pleistocenic times in regions not now subject to such conditions. (See ante, Chapters II and VIII.) The map (Fig. 245), copied from Walther, shows the location of the Pleistocenic ice sheets, and the suggested position of the pole, to account for its occurrence. All such wanderings of the poles, however, if they occurred, are insignificant in comparison with the catastrophic change which brought to an end the period of Palæozoic sedimentation and biologic development.

The Pendulation Tileory. Though frequently suggested as a possible cause of changes in the geologic development of the earth, the theory of polar migration seems to have been first definitely formulated by Paul Reibisch in I901. Reibisch developed the theory of polar pendulation, or swinging, i.e., a back and forth migration of the poles along certain well-defined paths. Dr. Heinrich Simroth, of the University of Leipzig, developed this theory 
more fully in his book, "Die Pendulations Theorie," fortifying it by a wealth of illustrations furnished by the distribution of animals and plants in both the present and past geologic periods. Simultaneously with Reibisch, the theory of polar migrations was formulated by Dr. D. Kreichganer (25), who approached the subject from a purely geological point of view. He endeavored to explain the changes of climate in past geological periods by a change in the position of the earth's equator and therefore a shifting of the north pole, which he thought had migrated $180^{\circ}$ since Cambric

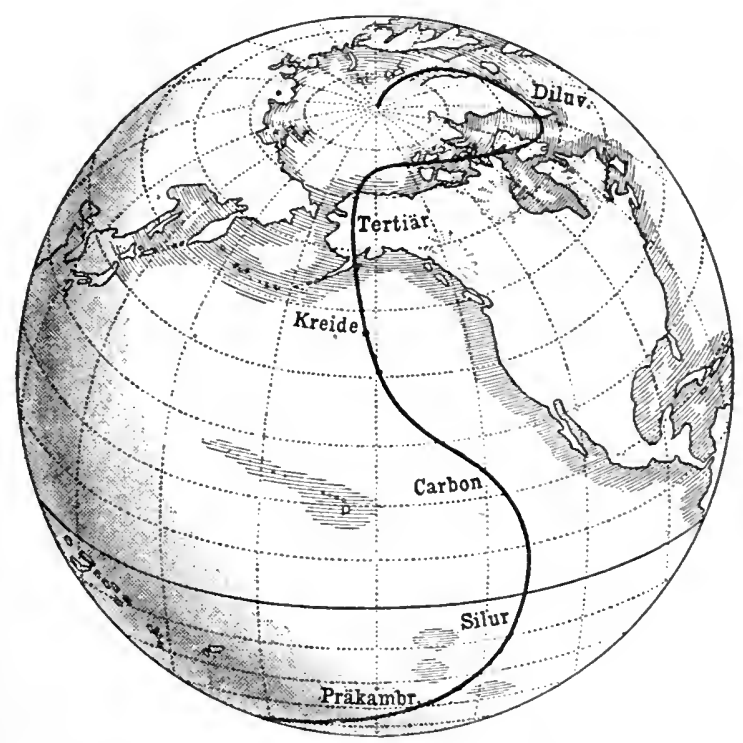

FIG. 243. Map showing the hypothetical wanderings of the earth's North Pole during the successive periods of its history. (After Kreichgauer.)

time, having been at the beginning of that period where the south pole is now. Kreichganer's map, showing the migration of the poles, is here reproduced. (Fig. 243.) As Simroth points out, however, Kreichgauer did not consider the phenomenon of polar pendulation.

The theory of polar pendulation, as formulated by Reibisch (34) and developed by Simroth (37), postulates the existence of two "oscillation poles" (Schaingpole) in adclition to the two rotation poles. These oscillation poles lie in the region of modern Equador, on the one hand, and of Sumatra, on the other. The 
meridian which passes through the rotation and oscillation poles forms the culmination circle (Kulminationskreis), and it divides the earth into a Pacific and an Atlantic-Indian hemisphere. (Fig. 244.) Each hemisphere is again divided by the equator into a northern and a southern quadrant. The meridian of $10^{\circ} \mathrm{E}$. longitude from Greenwich,' which bisects each hemisphere, is called the oscillation circle, because it is upon it that the poles swing back and forth. The culmination circle is so called because each point reaches its closest approximation to the poles when it crosses this circle.

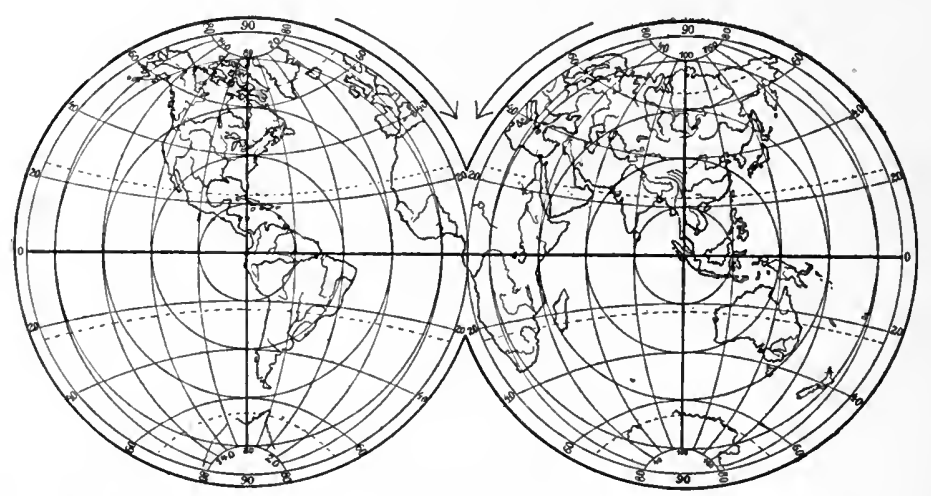

F1G. 244. Map of the earth, divided by the oscillation circle (near the meridians of $10^{\circ} \mathrm{E}$. and $170^{\circ} \mathrm{W}$. of Greenwich) into two hemispheres, according to the theory of $\mathrm{P}$. Reibisch. The oscillation poles form the centers of the hemispheres. The vertical meridian is the culmination circle $\left(80^{\circ}\right.$ on the left, $100^{\circ}$ on the right). The concentric rings around the oscillation axis mark the paths along which the points cut by them move during the pendulation. (After Simroth.)

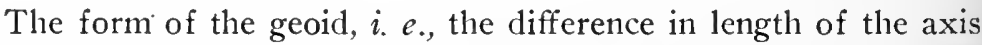
of rotation and the equatorial diameter, amounting to more than 40 kilometers ( $43 \mathrm{~km}$., or nearly 27 miles; see ante, Chapter I), is responsible for the transgressions and regressions of the sea, and the elevation and subsidence of the land. The sea, the mobile element, assumes the flattened geoid form with every position of the axis of rotation, but the land, owing to its greater rigidity, does not so readily assume this form. Hence, as every point approaches the pole during the pendulation, the waters recede from it, while at the same time they rise over the points approaching the equator. The differences between rise and fall of the water are greatest on the oscillation circle and decrease progressively to the oscillation 
poles, where they are zero. A point on the oscillation circle, which lies I0,000 meters below sea-level when under the equator, would, by the time that it has come to lie at the pole (after a rotation of $90^{\circ}$ ), lie I0,000 meters above sea-level. It must be remembered that every point on the globe is nearest to the pole as it crosses the culmination circle, which, together with the ends of the axis of rotation, may be regarded as having a fixed position in space. At the moment of crossing, therefore, the point has its greatest elevation above sea-level, while, as it passes away from the culmination circle, the sea-level will rise, where previously, during the approach, the sea-level fell. This seems to be illustrated by Florida, which at present lies under the culmination circle. The eastern half has a rising sea-level and would, therefore, be passing awayn from it, while the western half has a falling sea-level, $i . e$., the land emerges, and this section would, therefore, be approaching the culmination circle. All this would indicate that the earth is swinging in such a way that the north pole is migrating toward Behring Sea, which thus becomes a region of emergence, and away from the Greenland-Iceland region, where, it has been supposed, the pole had its location in Pleistocenic time. (Fig. 245.) (See ante, Chapter II.)

Owing to the proximity of Florida to the oscillation poles (where emergence and submergence are zero), the total amount of oscillation of the sea was never great, and hence old coral reefs which grew near the surface go only to the depth of 50 feet. In Funafuti, on the other hand, which lies not far from the oscillation circle (under which the greatest variation of sea-level occurs), the reef corals grew to a depth of more than 600 feet. (See ante, Chapter X.) The coral islands of the North Pacific lie in the quadrant approaching the pole and the culmination circle, and hence they show at the present time a retreating sea-level; as in the case of the Hawaiian Islands. The islands of the South Pacific, on the other hand, are moving toward the equator, and hence, in this case, submergence is taking place. In the Indian Ocean, again, the region north of the present equator is one of rising sea-level (submergence of reefs and islands), while that south of the equator is one of falling sea-level (emerging reefs). This would explain why the Maldives, north of the equator. are apparently being submerged, while the Cocos Islands to the south are rising out of the water.

The regions around the oscillation poles were always tropical regions, as compared with the regions near the oscillation circle. In the former, therefore, life conditions clianged little and slowly, 
and so they are the regions where ancient types persisted, while the region near the oscillation circle (northern North America, northern Eurasia, western Europe, Africa, and Antarctica), on the contrary, showed the greatest oscillation in climate and in life during the successive periods of the earth's history.

When we next consider what effects the shifting of the poles would have on the form of the lithosphere we realize that, while it would be more gradual than the effect on the hydrosphere, it

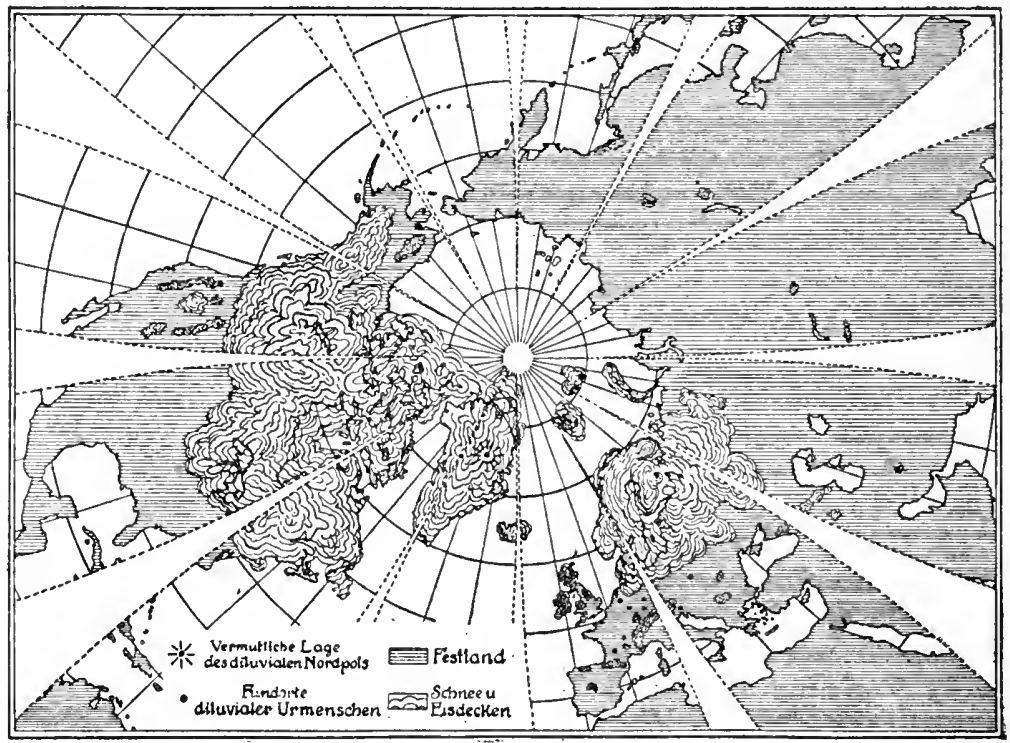

FIG. 245. Map of the Pleistocenic Tce Period, showing the distribution of the ice and the hypothetical North Pole. (After Walther.) The black dots in western Europe indicate the localities where remains of early man have been found.

must still result in a series of important changes, if the hypothesis of pendulation is correct. The influence of the centrifugal force on the equatorial region is manifested by an expansion or stretching of the equatorial zone, and this will result in the formation of (lepressions, through the sinking of fault blocks. Depressions in the present surface of the lithosphere are most marked in the quadrant now approaching the equator, near which lie all the large terrestrial or submarine trenches and deeps. Thus the great submarine depressions of the present day, the Tonga and Kermadec deeps, lie in the South Pacific quadrant, whereas similar depressions 
in the land, such as the Caspian and the Dead Sea, etc., lie in the North. Atlantiç quadrant, which also approaches the equator. It should be noted, however, that the Marian depression with the deepest submarine pit, the Nero deep, lies mostly north of the equator and therefore in the opponent quadrant. However, its proximity to the equator (less than $20^{\circ} \mathrm{N}$.) is evident, and it may be regarded as still retaining the characters acquired as it passed under the equator. In like manner, the greater part of the African rift valley lies in the south Atlantic-Indian quadrant, though again within 20 degrees of the equator.

Conversely, regions approaching the poles are regions of shrinking land, and hence regions where mountain-making through folding is marked.

Ingenious and suggestive as this theory is, and much as it seems to throw light on many geological as well as biological phenomena. it is still too new and too little tested to reccive more than respectful attention. As a working hypothesis in the attempt to interpret the history of the earth, it is likely to be of much value. (See the application of this theory by Yokoyama to the interpretation of the Pleistocenic problem, given in Chapter II.)

In this connection may also be mentioned the recent studies by Eugenio Jacobitti (22), who, attacking the problem as a study in geology, finds the wanderings of the poles to be of a more irregular character, through the various geological periods, as illustrated in the subjoined figures reproduced from his paper. (Figs. 246, 247.) $\mathrm{He}$ also reconstructs a series of charts showing the position of the equator in the successive periods. All such reconstructions are, of course, premature, and must be taken as suggestions rather than as demonstrations. What is probalyly the most complete attempt at restoration of the earth's surface during a period of different polar location is that made by Koken (23a) for the Permic. His map not only locates the poles but also the lands and seas of the period, as well as the ocean currents, etc. See ante, page 536 .

It may again be remarked here, as was stated in Chapter II, that astronomers have generally looked with disfavor on such speculations, though George Darwin concedes the possibility of the pole having wandered some Io or 15 degrees from its original position. provided the degree of rigidity of the earth is not so great as to be inconsistent with a periodic readjustment to a new form of equilibrium. Sir William Thompson (Lord Kelvin), for one, readily entertained the idea of such changes. He says: "We may not merely admit, but assert as highly probable, that the axis of maximum inertia and axis of rotation. always very near one an- 
other, may have been in ancient times very far from their present geographical position, and may have gradually shifted through 10,

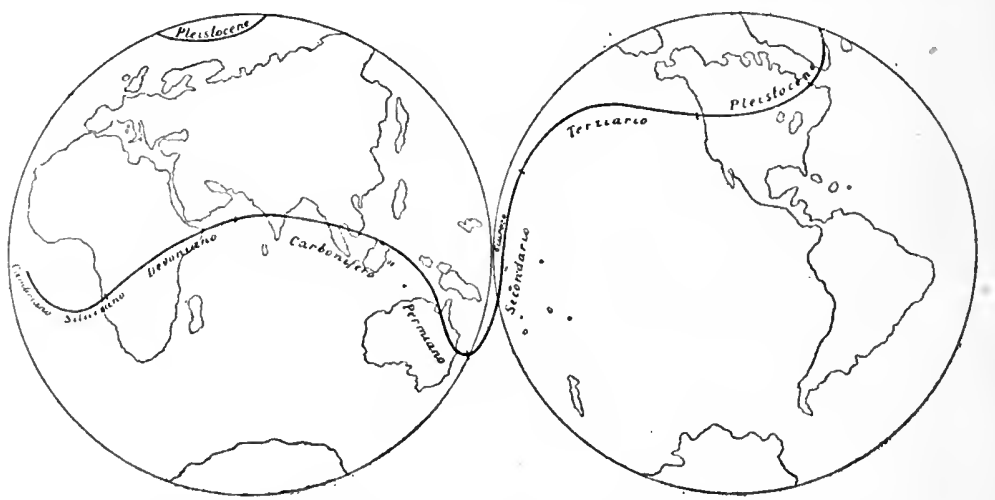

Fis. 2.6. Map of the hemispheres, showing the hypothetical migration of the "North Pole during the successive geologic periods. (Jacobitti.)

20, 39, 40, or more degrees, without there being at any time any perceptible sudden disturbance of either land or water." (42:II.)

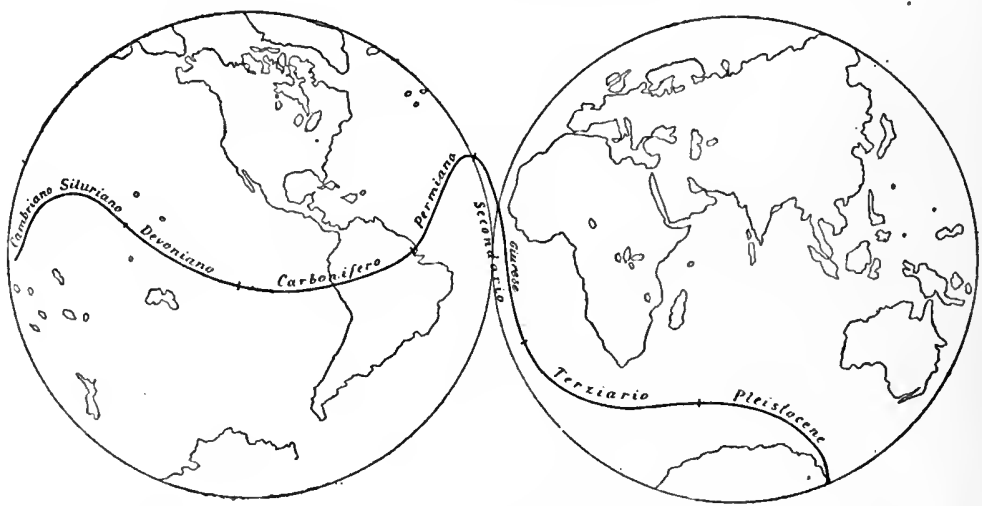

FIG. 247. Map of the hemispheres, showing the hypothetical migrations of the South Pole during the successive geologic periods. (Jacobitti.)

Various theories have been advanced to account for and explain such wanderings of the poles, but at present the whole subject is too little investigated to make their discussion profitable. Geologists must first gather a larger body of facts, which will tend 
either to prove or disprove these theories, before the discussion of causes need be undertaken.

\section{Determined Migrations of the Poles.}

That the poles, $i$. $c$., the points of intersection between the earth's axis of rotation and the surface of the earth, are not actually fixed, but wander about within small limits, was first recognized towarl the end of the nineteenth century. From thousands of careful observations on latitude made in recent years in

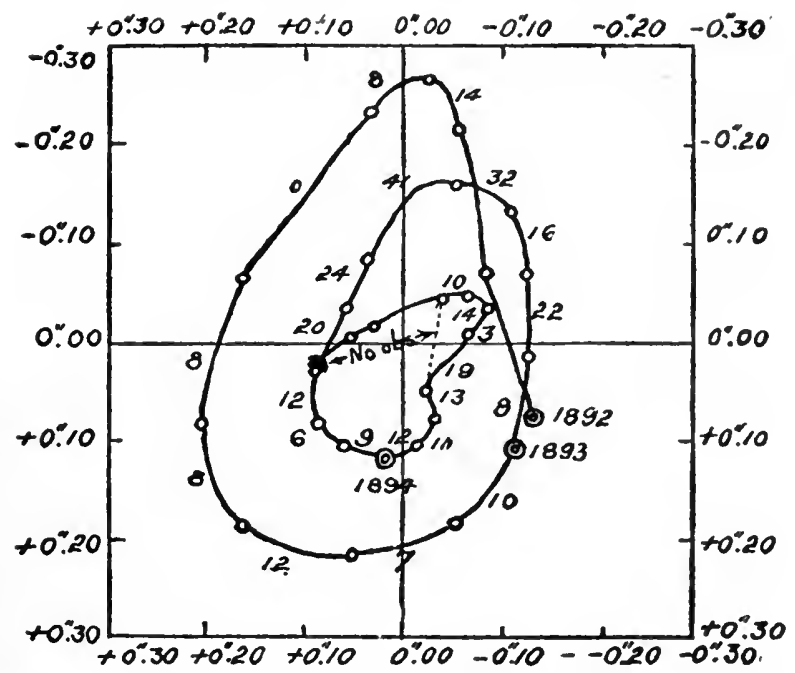

FIG. 248. Map showing the ascertained migration of the North Pole from 1892 to 1894 (after Milne); the figures indicate the number of large earthquakes in each period.

Europe and America this wandering has been determined to lic within a circle 40 or 50 feet in diameter. It has a curiously irregular, but somewhat spiral path, and completes its erratic circuit in about 428 days. The path described by the North Pole between the years 1892 and 1894 is shown in the above map by Milne. in which each year is divided into ten parts. (Fig. 248.) The figures show the number of earthquakes which occurred in each period, the largest of them, as John Milne has pointed out, coinciding with the sharpest curvature in the path of the pole. As Milne suggests, both the abrupt curvature and the sharp earthquake 
may be the result of sudden readjustments, due to the redistribution of material on the earth's surface by currents and by meteorological agents.

Accompanying the changes of position of the poles, is, of course, a change in the position of the equator, the plane of which is always at right angles to the axis of rotation of the carth. A further result of such changes is a variability of terrestrial latitudes generally.

It is now commonly admitted that the movement of large bodies of water, or of air, over the surface of the globe, and, more especially, an accumulation of vast masses of snow and ice in different regions, may all be causes effecting slight displacements of the earth's axis. More pronounced effects might follow from widespread upheavals or depressions of the surface of the lithosphere.

If the earth's center of gravity should be sensibly displaced, momentous rearrangements, accompanied by pronounced wanderings of the pole, would result. It has long been known that the center of gravity does not coincicle with the center of figure of the earth, but lies to the south of it. This is due to the greater aggregation of dense material in the southern hemisphere, but whether this is a result of original distribution of matter, or is due to later readjustments, cannot be said. Simroth has even suggested that the in-falling of a satellite, or second moon. into the earth in the $\Lambda$ frican region may have been a possible cause of the displacement of the center of gravity, and that the pendulations of the earth's axis were the result of a gradual readjustment. That meteoric or extra-telluric bodies reaching the earth in great numbers may sensibly affect the center of gravity, and hence the position of the carth's axis, cannot be doubted.

\section{Eartir Movements and Geosynclines.}

As already noted in Chapter XX, the term geosyncline was applied by Dana (in I873) to the great earth troughs, whether simple or compound, which are formed in regions of excessive deposition, the Appalachian region being taken as the type of such troughs. The idea of great downward bowings under heavy load was developed much earlier by James Hall, who held that this downwardbending was in direct response to the load added by the sediment, and thus, in effect, constituted an isostatic readjustment. Dana, on the other hand, regarded the downward bending as primary, and of the nature of a fold due to compressive strains, and the 
filling by sediment as a secondary consequence. Among subsequent authors, Haug (14, 15) has greatly extended this idea, and has included under this title all great submarine depressions parallel to land areas, such as the great depressions of the Pacific coast. (See Chapter III and Figures 16 and 17, pages IOI and 105.) These "fore deeps" (Vorticfon) are undoubtedly the direct result of deformation under strain, but they are not areas of excessive deposition. Indeed, sedimentation here goes on with extreme slowness, and is confiried to materials normal to the deep sea. Haug has identified among many of the deposits bathyal sediments (see Chapter XV), which he regards as accumulations in geosynclines, and he holds that the great thickness of these deposits indicates a progressive deformation of the region of deposition. He finds that many bathyal sediments pass laterally into neritic or shallow-water deposits, though other deposits in the geosynclines are throughut of

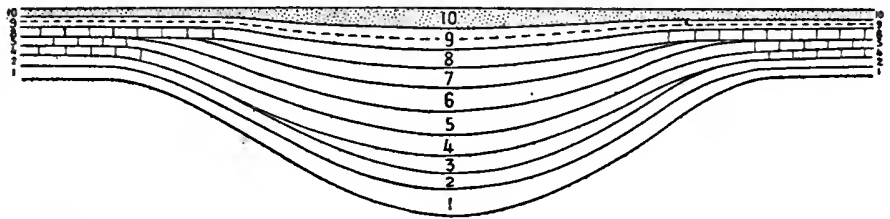

Fig. 249. Diagrammatic section of a geosyncline according to Haug. The numbers I-Io indicate the successive strata, which are complete in the center of the geosymcline but incomplete on its margins, where thinning away of beds and overlap of others is characteristic. (After Haug.)

neritic origin. Haug does not, apparently, recognize the presence of continental sediments in the geosynclines, though he finds these on the margins. This type of sediment is, however, eminently characteristic of the Appalachian region throughout, and is included in the main mass of the sediment itself.

The bathyal origin of many of the sediments in the geosynclines of the Alpine region and elsewhere is by no means wholly established, and it may be questioned whether, on the whole, sediments of that class are abundant or widespread. The frequent marginal disconformities in the sediments of most geosynclines lead one to the supposition that. after all. many of the so-called bathyal deposits may be of littoral (neritic) origin. and that, furthermore, repeated laying bare of the margins of the geosyncline permitted erosion of the already deposited sediments.

Haug recognizes the shading away of the sediments by overlap and by thinning toward both sides of the geosyncline (Fig. 249) 
and he explains this by the supposition that the geosyncline was located between two continental masses and not, as held by American students, on the borders of the continent. He holds that the geosynclines are zones of weakness and mobility between two relatively stable masses.

The Himalayas are chosen by Haug as an illustration of a great geosyncline (in pre-mountain time) formed, not on the border of a sea, but between two continental masses, the stable Indian land mass on the south and a similar land mass on the north. In spite of this location, he holds that Palrozoic and Mesozoic sediments in this geosyncline are none of them of a littoral (neritic) character. The chains of central Europe are in like manner regarded by Haug as occupying the sites of former geosynclines. If the expanded Mediterranean basin of Mesozoic time is to be considered in the light of a geosyncline, the bathyal nature of some of the sediments therein, or at any rate their thalassogenic character, may be readily conceded. It may be questioned, however, if the use of the term geosyncline for an intracontinental sea with abyssal regions $(i . e$., a mediterranean) is permissible. Certainly such a condition did not prevail in the Palieozoic of the Appalachian region. Here an accumulation of 40,000 feet of sediment was accompanied by a downward bowing of the sea-floor bordering the old Appalachian continent. But this was probably never of great depth, nor was there, as a rule, a land mass to the west of the region of sedimentation. Indeed, as has already been pointed out, and, as has elsewhere been discussed by the author in great detail, the prevailing sediments were of shallow water and terrestrial type. As stated in Chapter XX, it "seems best to restrict the name geosyncline to such regions of deposition, and use the name fore-deep for regions known to have descended to bathyal or abyssal depths. That these fore-deeps are due to tectonic movements is freely conceded, but the geosyncline of the Appalachian type is most probably due to isostatic readjustments incident upon the loading of the earth's surface along the line of subsidence. This does not imply, however, that the subsequent folding of these strata is due to any other cause than that of yielding under conpressive strain. Such an origin alone seems to be possible, in view of the many features which can be explained only as originating under compressive stresses.

Geosyclines tile Sites of Orogenic Disturbances. As long ago pointed out by Hall and Dana, and as emphasized by Haug, the geosynclines are the sites of subsequent foldings of the strata, or, conversely, the regions of folded mountains are the sites of 
former geosynclines. Bailey Willis (44) has pointed out that the gradual downward sinking of the strata in the geosyncline gives then an individual steepness along the margin of the depression, and that this initial dip forms the beginning of the deformation, and determines the subsequent folding under the influence of lateral pressure. The folds of the Appalachians are asymmetrical anticlines, with the steeply inclined, vertical, or even overturned limb on the northwest or away from the present ocean. It must, however, be remembered that the present Atlantic coast is near the western border of the old Appalachian land, and that hence if the folds occurred before this land mass disappeared by subsidence, the thrusting, which was from the east or southeast, was performed or transmitted by this ancient land mass. In this westward thrusting many folds were not only overturned, but thrust-faults of considerable magnitude were developed. Thus the crystalline range of the Hudson Highland was thrust northwestward over the Palæozoic strata (Berkey) and numerous other overthrusts were developed in the Palæozoic and older strata along the entire Appalachian range.

Foreshortening of the Crust. During the folding of the Appalachians there was, of course, a considerable amount of foreshortening of the earth's crust. Lesley long ago estimated the movement to have extended over a distance of forty miles, while Claypole, considering the major folds, arrived at the approximate conclusion that a section of the earth's surface measuring originally one hundred and fifty-three miles had been compressed into sixty-five miles. (4.)

Recently R. T. Chamberlin (2) has published the results of some careful measurements of the Appalachian folds in the district between Harrisburg and Tyrone, Pennsylvania. and these have furnished more exact data for the estimation of the amount of crustal foreshortening, and have likewise thrown some light on the form and thickness of the crust involved in the folding. He concludes that, so far as his measurements warranted, and postulating the correctness of the assumed basis of investigation, the region west of Harrisburg showed 81 miles of strata compressed into 66 miles. The uncertainties of this result lie in the difficulty of eliminating the amount of loss due to thickening and thinning of strata in various parts of the fold; the variation in closeness of folling; or the subsequent relaxation of the strata under the influence of gravity, with resultant gliding on the limb of the fold. These uncertainties can make such estimates only approximate.

Height of the Folds. Assuming that, when the folding of 
the Appalachians commenced, the strata were practically horizontal and the upper surface of the youngest beds essentially at sealevel, and assuming, furthermore, that the higher Carbonic and Permic beds of the region (above the Pottsville) was I, IOO feet thick, Chamberlin concludes that 3 miles represents the average height of the top of the restored Pottsville conglomerate over the area from Tyrone to Harrisburg, $i$. $c$., the vertical deformation was of that amount.

There are here several assumptions which need careful consideration before we can regard this as anything more than a very general estimate. In the first place, if we regard the late Palrozoic sediments as terrestrial in type rather than marine; as their nature seems to indicate, we can not assume an initial horizontality with the upper strata at sea-level throughout. Even on the basis of the gentle gradient of the present delta-fan of the Huang-ho the elevation at the heads of the delta plains would be some 500 feet or more above sea-level, and from the coarseness of the material in the deposits it is likely that this elevation was a thousand feet, if not more.

In the second place, it appears that the estimate of the original thickness of the post-Pottsville Palæozoic is much too low. A comparison of the thickness of the Pottsville and Kanawha formations between the eastern and western portions of their outcrops shows the thickness of these two formations in the western region to be only one-fifth or one-sixth that of the part preserved in the eastern Appalachians. Since the sediment of the later formations was also derived from the Appalachian old land, and since the nature of the deposit suggests a similar origin of the later strata, it does not seem amiss to consider that a similar eastward increase in thickness originally obtained in the case of these higher strata as well. This would make the Allegheny alone some 1,500 or more feet in thickness in the Appalachian region, while the remaining formations, if increased at the same rate, would aggregate II,OOO or 12,000 feet, making a total above the Pottsville in round numbers of about 13,000 feet of strata. This is not an improbable thickness when we consider the I5,000 feet of late Tertiary delta deposits of the Siwalik formation of India (see ante, Chapter XIV).

Character and Thichness of the Deformed Mass. On the assumed elevation of about 3 miles for the entire area, Chamberlin figures out the thickness of the part of the crust involved in the folding. Since different sections have been differently affected, he considers each independently with the following results: 


\begin{tabular}{r|c|c|c|c|c|c}
\hline Section Number & I & 2 & 3 & 4 & $5 \mathrm{a}$ & $5 \mathrm{~b}$ \\
\hline $\begin{array}{r}\text { Original length of tract, in } \\
\text { miles }(a) \ldots \ldots \ldots \ldots \ldots \ldots .\end{array}$ & 17.8 & 16.3 & 13.56 & 14.44 & 9.6 & 9.5 \\
$\begin{array}{r}\text { Length after folding, in } \\
\text { miles }(b) \ldots \ldots \ldots \ldots \ldots \ldots\end{array}$ & 14.9 & 15.2 & 12.1 & 12.10 & 7.37 & 4.75 \\
$\begin{array}{r}\text { Mean elevation through fold- } \\
\text { ing, in miles }(c) \ldots \ldots \ldots .\end{array}$ & 3.45 & 2.37 & 2.88 & 2.71 & 2.36 & 5.75 \\
$\begin{array}{r}\text { Deduced thickness of crustai } \\
\text { block, in miles }(x) \ldots \ldots \ldots\end{array}$ & 17.7 & 32.7 & 23.8 & 14.00 & 7.8 & 5.71 \\
\hline
\end{tabular}

The formula for ascertaining $(x)$ is $x=\frac{b c}{a-b}$

The following diagram, copied from Chamberlin, shows the location of the sections, the extent of the folding and the cal-

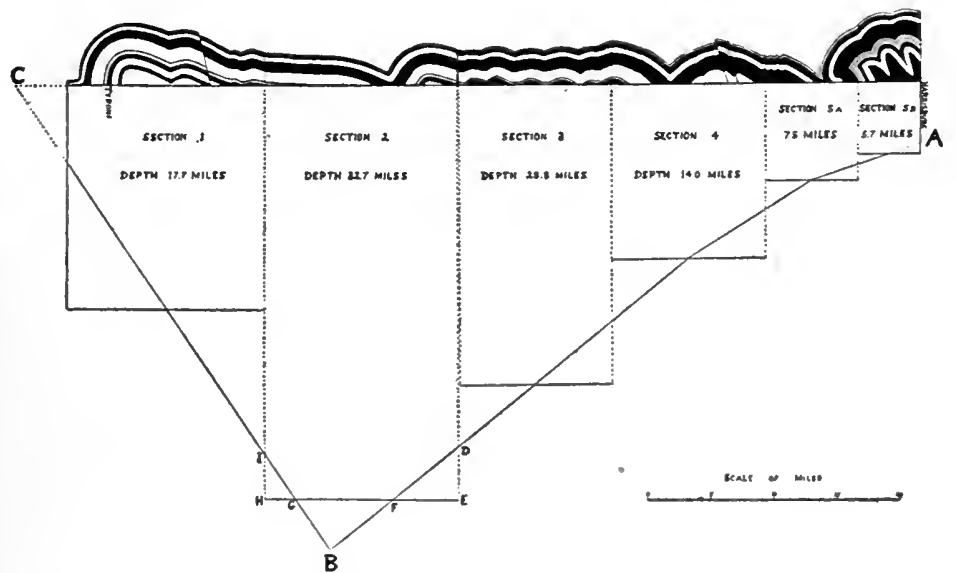

Fig. 250. Plot of the Tyrone-Harrisburg folded section, representing the thickness of the deformed shell beneath each of the six blocks as developed by Chamberlin's method of measurentent. The lines $\mathrm{A}-\mathrm{B}$ and $\mathrm{B}-\mathrm{C}$ are drawn through the middle points of the botton lines of each of these blocks, except section 2, the apex block. The triangle $G, B, F$ is drawn equal in area to the sum of the triangles $\mathrm{G}, \mathrm{H}, \mathrm{I}$ and $\mathrm{D}, \mathrm{E}$. F. The whole deformed mass appears, subject to the necessary limitations, to be the triangular block A, B, C. (After R. D. Chamberlin.)

culated thickness of the block affected. (Fig. 250.) It shows strikingly the fact that, where the crust is folded intensely, the thickness of the crust involved is least; where folding is slight, it is 
greatest. In any case, folding is shown to be a superficial phenomenon, a conclusion which must have an important bearing on the mechanics of folding. As shown by the section, the eastern portion suffered most, the western portion was the next most affected, while the intermediate ones suffered the least. The form of the entire block affected is that of a triangular prism, the lower bounding planes being shear-zones. This is the form which such a block should assume theoretically, two sets of planes of greatest tangential stress developing at right angles to each other, and approximately at an angle of 45 degrees to the direction of greatest pressure, though varying with the nature of the material and other factors. (Becker-I :50; Hoskins-20:865; Leith-27:I21.) Experiments by Daubrée have shown this to be the type of fracture developed in compressed blocks where a triangular prism is developed with faces approximately at 45 degrees to the direction of pressure. In the experiment the prism was lifted without folding, the other parts being thrust under it on both sides (Fig. 25I). The extensive development of over (or under) thrusts along the western margin of the folded Appalachian region is quite in harmony with this principle. It should, however, be mentioned here that there is some evidence that the folds of the Appalachians were not purely asymmetrical anticlines, modified by overthrust, but that the Appalachians had originally a fanfold structure.

\section{Changes Due to Extra-Telluric Influences.}

The impact of a mass of meteoric matter upon the surface of the earth would form an effective source of energy, which would set into motion geological agents of vast magnitude. If the mass is sufficiently large, as in the case of a satellite, a great displacement of the earth's center of gravity would result, with the attendant phenomena already outlined. If the earth were bonbarded by a vast number of meteoric bodies, if, in other words, a swarm of meteors should descend upon the earth, changes affecting the entire earth might take place. Among these might be the all but universal extermination of life, as well as the modification of the lithosphere and hydrosphere. and perhaps the atmosphere as well. The heat of impact might result in nearly universal metamorphism of the rock masses of the earth, with the accompanying destruction of the record of life in these rocks. It might be asked if some such catastrophe may not have altered the surface of the earth in pre-Cambric time, inaugurating the forces which 
produced the widespread metamorphism and exterminating most of the organisms which had reached a high state of development prior to the opening of Palæozoic time. Such catastrophic occurrences are within the range of possibility, and, indeed, the rising school of astro-geologists regards the origin of the earth itself as due to accretion of planetary matter, rather than to the development by condensation from an original nebular condition. If the accre-

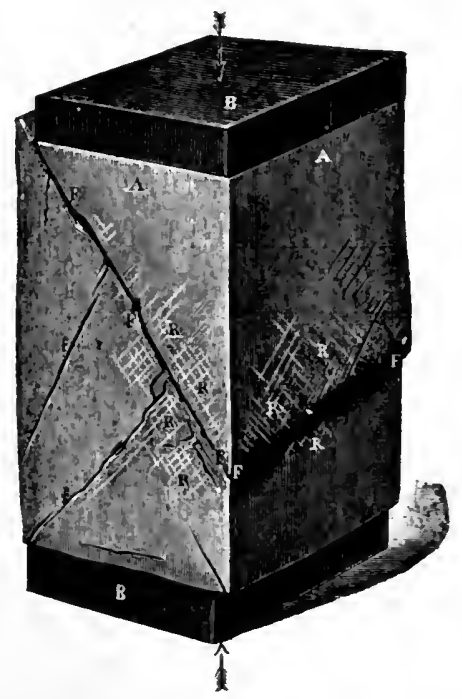

Fig. 251. Prism of wax, deformed uncler pressure, between two iron plates (B. B) and exerted in the direction shown by the arrows. Two main sets of fissures are formed nearly at right angles to each other ( $F F, f$ ) leaving a triangular prism between them. RR, plexus of fine fissures at right.angles to one another. Scale I:75. (After Daubrée from Haug.)

tion theory of earth-building. whether from planetesimals or from meteorites, should become established, the recurrence of such an event-the repetition of the celestial bombardment to which the earth owed its origin-is brought within the range of probability. and thus the stupendous problem of the origin of the great difference everywhere observed between the Cambric and the undoubted pre-Cambric * rocks may be brought a step nearer solution.

* Some of the undisturbed clastic rocks now referred to the pre-Cambric have not yet been proven to be sich. The occurrence of disconformities between Middle Cambric or late lower Cambric and underlying unaltered sediments is not conclusive evidence of the pre-Cambric age of these sediments, especially if they are of continental origin. 


\title{
BIBLIOGRAPHY XXIII.
}

\author{
(See also Bibliography xx, pp. 826-828.)
}

I. BECKER, G. F. I893. Finite Homogeneous Strain, Flow and Rupture of Rocks. Bulletin of the Geological Society of America,Vol. IV, pp. 13-90.

2. CHAMBERLIN, ROLLIN T, rgro. Appalachian Folds of Central Pennsylvania. Journal of Geology, Vol. XVIII, No. 3, pp. 228-25I.

3. CHAMBERLIN, THOMAS C., and SALISBURY, ROLLIN D. 1906. Geology, Vol. I.

4. CLAYPOLE, E. W. 1885. Pennsylvania Before and After the Elevation of the Appalachian Mountains. American Naturalist, Vol. XIX, pp. 257-268.

5. DANA, JAMES D. I895. Manual of Geology, 4th edition. American Book Co.

6. DARWIN, CHARLES. 184r. The Voyage of the Beagle.

7. DAVISON, CHARLES. 1905. A Study of Recent Earthquakes. Contemporary Science Series, Lóndon.

8. DILLER, J. S. r889. - Sandstone Dikes. Bulletin of the Geological Society of America, Vol. I, pp. 4II-442, pls. 6-8; with discussion by Davis.

9. DUTTON, CLARENCE E. 1904. Earthquakes in the Light of the New Seismology. New York and London.

10. FALB, R. 187 r. Grundzüge einer Theorie der Erdbeben und Vulcanenausbrücke. Graz.

11. FALB, R. 1874. Gedanken und Studien über den Vulkanismus, etc.

12. GILBERT, GROVE KARL. I893. Contincntal Problems. Bulletin of the Geological Society of America, Vol. IV, pp. I 79-190.

13. GILBERT, G. K.; HUMPHREY, RICHARD; SEWELL, JOHN S., and SOULE, FRANK. The San Francisco Earthquake and Fire of April r8, 1906, and their Effects on Structures and Structural Material. United States Geological Survey Bulletin 324.

14. HAUG, ÉMILE. I900. Les geosynclinaux et les aires continentales. Contribution à l'étude des transgressions et des régressions marines. Bulletin de la société géologique de France, 3rd series, Vol. XXVIII, pp. 6I77 II, 3 figs.

15. HAUG, E. I907. Traité de Géologie. T. I.

16. HAY, ROBERT. I892. Sandstone Dikes in Northwestern Nebraska. Bulletin of the Geological Socicty of America, Vol. III, pp. 50-55.

I7. HOBBS, WILLIAM H. 1907. Origin of the Ocean Basins in the Light of the New Seismology. Bulletin of the Geological Socicty of America, Vol. XVIII, pp. $233^{-25}$, pl. 5 .

I 8. HOBBS, W. H. 1907. Earthquakes. D. Appleton and Company, New York.

19. HOERNES, RUDOLPH. r893. Erdbebenkundc. Die Erscheinungen und

- Ursachen der Erdbeben, die Methoden ihrer Beobachtung. Leipzig.

20. HOSKINS, L. M. 1896. Flow and Fracture of Rocks as Rclated to Structure. Sixteenth Annual Report of the United States Geological Survey, I 894-95, Pt. I, pp. 845-872, figs. I63-I69.

2r. HOVEY, E. O. 1909. Earthquakes: Their Causes and Effects. Proccedings of the American Philosophical Society, Vol. XLVIII, No. 192, pp. $235^{-2} 5^{8}$.

22. JACOBITTI, EUGENIO. Mobilitá dell 'Asse Terrestre. Studio Geologico. Torino. 
23. JOHNSON, WILLARD D., and HOBBS, W. H. 1908. The Earthquake of 1872 in Owens Valley, California. Abstract: Science, N. S., Vol. XXVII, p. 723 .

23a. KOKEN, E. 1907. Indisches Perm und die permische Eiszeit. Neues Jahrbuch für Mineralogie, etc., Festband, pp. 446-545, Map.

24. KOTO, B. I893. On the Cause of the Great Earthquake in Central Japan, I891. Journal of the College of Science, Imperial University, Tokyo, Vol. V, pp. 295-353, pls. XXVIII-XXXV.

25. KREICHGAUER, D. I 902 . Die Aequatorfrage in der Geologie. Steyl.

26. LE CONTE, JOSEPH. 1902. Elements of Gcology, 4th edition. D. Appleton.

27. LEITH, C. K. 1905. Rock Cleavage. United States Geological Survey Bulletin 239.

28. MARTIN, LAWRENCE. I9I0. Alaskan Earthquakes of I899. Bulletin of the Geological Society of America,Vol. XXI, pp. 339-4o6, pls. 29-30.

29. MALLET. 1862. The Great Neapolitan Earthquake of 1857.2 vols.

30. McGEE, W. J. I893. A Fossil Earthquake. Bulletin of the Geological Society of America, Vol. IV, pp. 4II-4I4.

31. MILNE, J. I898. Earthquakes and Other Earth Movements. 4th edition.

32. MONTESSUS DE BALLORE, F. DE. 1906. Les Tremblements de Terre. Paris.

33. NEWSOM, JOHN F. 1903. Clastie Dikes. Bulletin of the Geological Society of America, Vol. XIV, pp. 227-268, pls. 2I-3I.

34. REIBISCH, PAUL. I90I. Ein Gestaltungsprincip der Erde. 27ter Jahresbericht des Vereins für Erdkunde zu Dresden, I90I, pp. 105-124; II, ibid., 1905, pp. 39-53.

35. ROSSI, M. S. DE. 1879 and 1882. La Meteorologia Endogena. 2 vols.

36. RUDOLPH, E. I $887-1898$. Ueber submarine Erdbeben und Eruptionen. Beiträge zur Geophysik. Vol. I, I 887, pp. 133-365, pls. IV-VII; Vol. II, I 895, pp. 537-666; Vol. ill, I 898, pp. 273-336.

36a. SIEBERG, AUGUST. 1904. Handbuch der Erdbebenkunde. Braunschweig.

37. SIMROTH, HEINRICH. 1907. Die Pendulations-theorie. Leipzig.

38. SUESS, EUARD. 1875. Die Entstehung der Alpen. Vienna.

39. SUESS, E. I886. Ueber unterbrochene Gebirgsfaltung. Sitzungsberichte der königlichen Akademie der Wissenschaften zu Wien. Bd. XCIV, Abth. I, pp. III-I 17.

40. SUESS, E. I 898 . Ueber die Asymetrie der nōrdlichen Halbkugel. Ibid., Bd. CVII, Abth. 1, pp. 89-102.

4I. TAYLOR, FRANK BURSLEY. 1903. The Planetary System. Published by the author, Fort Wayne, Indiana.

42. THOMPSON, SIR WILLIAM. I876. Report of the British Association. Report of Seetion $8 \mathrm{I}$.

42a. VAN HISE, C. R. I898. Earth Movements. Wisconsin Academy of Arts, Sciences and Letters, Transactions, Vol. xi, pp. 465-516.

43. WHIMPER, EDWARD. I892. Travels Among the Great Andes of the Equator. 2nd edition.

44. WILLIS, BAILEY. 1893. Mechanics of Appalachian Structure. Thirteenth Annual Report of the United States Geological Survey, Pt. II, pp. 2 I I-28I. (See also reference 30 , on page 828.)

45. WOODWORTH, J. B. 1907. Postglacial Faults of Eastern New York. New York State Museum Bulletin Io7, pp. 5-28, 5 pls. 


\title{
F. THE BIOSPHERE.
}

\author{
CHAPTER XXIV.
}

SUBDIVISION OF THE BIOSPHERE. CLASSIFICATION AND GENERAL MORPHOLOGICAL CHARACTERS OF ORGANISMS.

The organic world or biosphere falls naturally into two great subdivisions or kingloms, the phytosphere, or plant kingdom, and the zoösphere, or animal kingdom, though organisms occur or have occurred which are not readily placed in either division. The detailed study of organisms has developed the sciences of phytology (botany) and zoölogy, with its many subordinate sciences. As ordinarily understood, these sciences deal with the plants and animals of the present, or Holocenic, geological epoch, while those of the many epochs of the earth's history anterior to the present are reserved for the paleontologist. Such a division, however, is illogical, for the life of the earth has been continuous and its development has been progressive from the earliest time to the present day. The scientific palæontologist can not neglect the study of the existing organisms, nor can the scientific zoologist and botanist, or student of the present living world, neglect the organisms of the past. Palæozoölogy cannot be divorced from zoölogy, nor palzobotany from botany. From the nature of the organic remains of former periods it follows, however, that the palrontologist lays most stress upon the hard parts of organisms, or those capable of preservation, in former as well as the present geological periods, while the botanist and zoölogist in the study of the modern floras and faunas tend to lay more stress upon the soft tissues which perish readily and so are not, or only rarely, preserved in the case of ancient forms of life.

There are, however, good reasons for believing that the hard parts of organisms form in some respects a more reliable index to their relationship than do the soft parts. This is especially the case in animals which build external hard parts which increase by serial addition, without change of the older parts deposited. In 
such cases we are certain to get a complete record of the individual development of the animal from the youngest stages in which such structures are formed to the adult or even old age stage. Thus, in the case of the molluscan shell, for example, we have a complete record of the individual development or ontogeny, all the changes being indicated in the successive whorls or areas of the sheil, from the initial shell-plate to the adult. Noreover, such shells will preserve the detailed features assumed necessarily by the mantle of the animal in conformity with development and increase of internal organs, features which are eranescent in the soft parts and can in many cases not even be observed.

What has just been stated is true mainly of animals whose hard parts are external structures, retained throughout life and increased by addition in one region only. Such additions are recognizable by the formation of growth lines, and they are typically shown in the shells of the Mollusca, as already noted. Brachioporla also show such changes in external form but there are, in addition, changes in interior structures, for the study of the development of which a complete series of individuals, representing all the stages, is needed. Corals likewise show their growth lines, and sections made across the older part in most cases show the progress of development of the individual. Other invertebrates are less satisfactory. While the serial development of parts can be made out in the plates of an adult echinoderm, yet the fact that each plate changes with the progress of development interposes certain difficulties in the study of the life history, and for its complete determination individuals of various age stages are needed. This is also true of the vertebrated animals where the internal skeleton or external armor changes with the growth and development of the individual, and where, therefore, skeletons of the young as well as the adult are needed to determine the entire life history.

Plants and Animals as Indicators of tile Age of the Period in Wilich They Occer.

Since we have realized, by a prolonged study of modern as well as ancient organisms, that aninals and plants have gradually increased in complexity of structure and diversity of form, from the earliest times to the present, it has become possible to use the remains of organisms embedded in the strata as indices of the chronology of the earth's history, and by extensive collection of facts from all geological levels, and over wide areas, to build up an 
organic succession which parallels the stratigraphic succession in the development of the earth's crust. It has been found that certain groups of organisms did not extend beyond a certain time period in the earth's history, and so their occurrence in the strata indicates the upper age limit of these strata. Thus, trilobites are known only from Palaeozoic formations-hence the finding of one of these extinct organisms stamps the strata in which it occurs as of Palæozoic age. More restricted occurrences of special forms have made it possible to recognize the geological levels with greater precision, thus the trilobite Paradoxides characterizes only the Middle Cambric rocks of the earth's crust in certain regions, while the trilobite Holmia characterizes the lower Cambric strata in the same regions. Again, the Hydrozoan Dictyonema flabelliforme is of world-wide distribution in the basal Ordovicic strata. Organisms used in this manner become indices of geological horizons and, since all but those of the present geological period occur only in fossil form, the term "index fossil" is properly applied to them. This subject will be considered further in a subsequent chapter.

\section{CLASSIFICATION OF PLANTS AND ANIMALS.}

The classification of plants and animals is a process of assortment into natural groups, or groups of related types, and the arrangement of these groups in a natural order, according to their genetic relationship. Groups of various denominations are recognized, the smallest of those in general use being the species. Smaller groups, known as varieties or as mutations, are, however, included within the species. Species are grouped into genera, each genus comprising one or more species. The generic and specific name of an organism are always used together in speaking of any particular species, since the same specific name may be used for a species of another genus. Thus, the fossil brachiopod genus Productus includes among its many species Productus muricatus. Likewise the fossil pelecypod genus Actinopteria has among its species Actinopteria muricata, while another brachiopod genus, Strophalosia, also has a species Strophalosia muricata. These three species, though they have the same specific name, are not at all related to each other, belonging to distinct genera, one of which belongs to a different division or phylum of the animal kingdom from that to which the other two belong.

Naming of genera and spccies. (18.) The generic name is always a noun, and is commonly derived from the Greek, though 
generic names derived from the Latin are not uncommon. Names compounded from the two languages are undesirable. The name should always express some prominent character of the genus, as Orthoceras, from the Greek o $p \theta$ ós (orthos), meaning straight, and к'́pas (ceras), meaning horn, the essential form of the genus being that of a straight horn. Names are, however, not always chosen with such direct meaning, while not infrequently the derivation of the name is obscure or fanciful. Proper names are frequently chosen for generic names, as Hyattella for a genus of brachiopods, the name being given in honor of the great American palrontologist, the late Alpheus Hyatt. In the formation of stich names the original name is reduced to the genitive case, and the termination is in $a(a, i a, i i a$, oia, c $a$, clla, etc. $)$. When the original name ends in $y$ this letter is treated as a consonant and the termination is added. Example: from Gray we may derive Grayia, Crayella, Graysia, etc. In all cases the form of the word must be the Latin form, the Latin equivalent of the original Greek being used. The gender of the generic nane is the same as in the language from which it is derived. If the generic name is a compound of two or more words, the terminal word determines the gender. Thus, in Orthoceras, the terminal ceras is neuter in the Greek, and hence all names ending in this manner are neuter. The same is true of the words nema (thread), stoma (mouth), and desma (band), often employed as endings. Special uniform endings are of ten employed in the naming of genera within certain classes, such endings having reference to the class. Thus pora and phyllum are the common terminations for corals, the former being used in the poriferous corals, as Aulopora, Syringopora, Tubipora, etc., and the latter in the septate corals, especially the Tetraseptata; example: Cyathophyllum, Heterophyllum, etc. In graptolites the termination graptus is common. In Cystoidea, Blastoidea, Crinoidea and Echinoidea the common terminations of the generic names are cystites, blastus, crinus, and echinus, respectively, though these are by no means exclusively employed. Examples are: Pleurocystites, Cryptoblastus, Encrinus, Eucalyptocrimus, etc., and Rhö̈chimus. In Bryozoa trypa and pora are frequent endings; example: Callotrypa, Bythopora. In Cephalopoda ceras is the prevailing termination, as in Orthoceras, Gephyroceras, Phylloceras, Lytoceras, etc., though in some orders of ammonites (e.g., Discocampyli) the termination ites, is the prevailing one; example: Coratites, Stephanitcs, etc. Among Reptilia saurus is a common termination; example: Mosasaurus, Stegosaurus, etc., and names of fossil birds not infrequently 
have the termination ptery.r (wing): example: Archaopteryx, Megaloptory, etc.

The generic name is always written with an initial capital. Specific names, on the other hand, have the value of adjectives and should always be written with a small initial letter, even thongh they are derived from proper names. It should be noted, however, that this rule is not universally accepted.

The gender of the specific name, as expressed in its termination. should agree with that of the generic name. Thus, the specific name in the above examples is muricatus in Productus, which is masculine, and muricata in the other two genera, which are feminine. In general, the specific name is derived from the Latin, while all other words are rendered in the Latin form. Names of persons are frequently used for the formation of specific names, an appropriate termination being added. Geographical names likewise are commonly used for the formation of specific names. The more common terminations of specific names thus derived are: anus, $a$, um (pertaining to), as amcricanus, linncanus; further, ensis, is, $e$ (belonging to a locality), as cincimnatiensis, canadensis, chicagocnsis, kentuckicnsis (final a or e when occurring in the original word is dropped and terminal $y$ changed to $i$ ); and, finally, $i$ as halli, knighti, etc., a common termination for names derived from persons. Common terminations for names derived from other words are: atus, a, um, as costatus, lobatus, galeatus; formis, is, $e$, as tubiformis, filiciformis, etc.; inus, a, um. ex: rugatinus; oides (added only to words derived from the Greek), as discoides, etc., and others.

Priority and Synonymy (13; 14; 15). Since there is such a vast number of specific names in natural history, and since it often happens that the same species receives "distinct names by different authors, owing to ignorance or ignor'ance of each other's works, it is necessary to have a fixed standard by which the name which is to survive is invariably chosen. The standard is priority-the name used in the first description of the species being adopted, even if a later proposed name is more suitable. All later names become synonyms. In certain cases, however, exceptions to this rule are allowed. Thus, if the original description is too poor, so that the true characters of the genus and species cannot be ascertained, a later name, proposed with a better description or illustration, is often accepted. Where a name has long been in general use the discovery of a prior name ought not to overthrow the established usage, especially if the older name has itself come into use for another species. Thus Spirifer mucronatus has become the widely 
accepted name for the species described by Conrad as Delthyris mucronata in I84I. One of the numerous varieties of this species had, however, been described by Atwater in 1820 as Terebratula pennata, and it has hence been argued that Spirifor pennatus and not Spirifor mucronatus should be the name of the species. Spirifer pennatus has, however, come into use for another species, described under that name by Owen in 1852 . The adoption of Atwater's name requires not only the discarding of a well-known and appropriate name, but also requires the substitution of another name for Owen's Spirifer pennatus. This strict adherence to the rule of priority in this case would lead to so much confusion that it is much better to make an exception and retain the names which have been so extensively used in the literature.

In the example cited, the name pennatus has been given to two species of Spirifer by different authors. That we may know which species is meant, it is necessary to write the name of the author after the specific name. Thus, in the case cited, the names should be written: Spirifer pennatus (Atwater) and Spirifer pennatus Owen. This custom of adding the author's name is a general one, and should always be observed in all but the most general discussions. When the author of the species has placed it in the wrong genus, or if the species is subsequently referred to a new genus, the author's name after the species is placed in parentheses, and frequently the name of the person who first placed the species in the correct genus is added. Thus, in the examples cited above, Conrad described his species under the generic name Delthyris, but it belongs to the genus Spirifer; hence the name is written Spirifer mucronatus (Conrad). Since Billings was the first to place the species in the genus Spirifer, his name may be added, viz.. Spirifer mucronatus (Conrad) Billings: but this method is not always adopted. . Sometimes the form Spirifer mucronatus Conrad sp. is used.

\section{Synonymy.}

No genus can have two species of the same name. If two authors describe, under the same name, two different species of the same genus, the one to which the name was first applied retains it, the name becoming a synonym so far as the other species is concerned; for this later-described species a new name must be proposed. When reference to the first-described species is made, it is often desirable to note the fact that the name has been applied to another species to avoid possible confusion. Thus Dunker in 1869 
described and named Fusus meycri, a modern species, and Aldrich in 1886 described a Tertiary species as Fusus meyeri. Reference to the former would thus be made as follows: Fusus meyeri Dunker I869 (non Aldrich I886). Since Aldrich considered his species a true Fusus he was forced to change its name on discovering that the name had been preoccupied for that genus. So in 1897 he proposed the name Fusus ottonis for this species. It appeared, however, that Aldrich's species is not a true Fusus, but belongs to a series of distinct origin. The name Falsifusus (Grabau) was, therefore, proposed for it, with the present species as the type, and, since this genus has no other species by the name of meyeri, it became proper to retore that specific name to its original rank. Thus we now have the synonymy of this species as follows (omitting references to authors which did not change the name) :

\section{FAlsifusus Meyeri-(Aldrich) Grabau.}

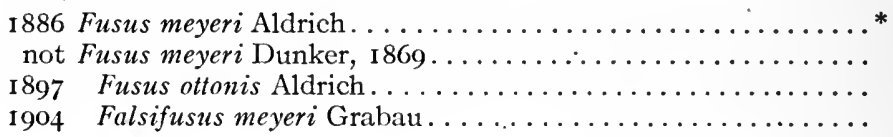

In this case the specific name ottonis not only becomes a synonym, but, so far as Fusus is concerned, it is dead and cannot be used again, even for a new species of Fusus. Unless this rule is observed much confusion is likely to arise. Should the generic name Falsifusus be found invalid, however, the type species Falsifusus meyeri being proved a true Fusus after all, the specific name ottonis will have to be restored to its original rank, the species in question being then Fusus ottonis. The general rule is that no specific name which has become a synonym in a genus can ever be used again for another species of that genus, though it may be used for species of other genera. If an old comprehensive species is divided into a number of species the original name is retained for that subdivision to which it was originally applied, or to which the diagnosis corresponds most closely. For the other subdivisions new names must be proposed. If two authors describe the same species under different names, the name given in the earlier description is retained, the other one becoming a synonym. If a species is transferred from one genus to another, in which there is already a species of that name, that one of the two species to which the specific name in question was first applied retains it, while the

* The dotted lines take the place of the reference to the literature where this name was used. 
other species takes the oldest tenable synonym applied to it, if such exists, otherwise it receives a new name.*

Manuscript Names, List Names (Nomina Nuda). Sometimes authors propose names in manuscript, or in lists with the intention of giving descriptions later, but the manuscripts are not published or the descriptions not written. Such a nomen nudum has no standing, unless a subsequent describer chooses to adopt it and give the original proposer credit for the name. Thus L.P. James in 187 I listed Ambonychia costata in his catalogue of Lower Silurian (Ordovicic) Fossils of the Cincinnati group, proposing the name without description. Meek in 1873 described the fossils for which James had proposed the above name, which Meek adopted, and credited to James. In this case the description was based on the material originally named by James, so that there could be no question regarding the applicability of the name. Even so, many subsequent writers have credited the name costata to Meek, refusing to recognize James' claim to priority. In general, manuscript names and list names are best discarded.

Generic Names as Synonyms. As a general rule, a generic name can be used but once in natural history, even if the genus to be named belongs to a wholly distinct phylum of the animal or plant kingdom. Thus in 1835 Swainson proposed the generic name Clavella for an Eocenic gastropod shell, but this name had been preoccupied in 1815 by Oken for a crustacean. The name Clavilithes was therefore proposed by Swainson in 1840 for his shell. Many authors, however, consider that preoccupation of a name disqualifies it for subsequent use only if both cases are within the same phylum, and in the case cited Clavella is retained by some for the gastropod as well as for the crustacean. The stricter rule, however, which allows one name to be used once only is the better, since it a voids all ambiguity. $\dagger$ When species described under different generic names are found to belong to one genus, the oldest of the generic names applied to them is retained, the others becoming synonyms. Such synonyms ought not to be used again, but relegated to the limbo of invalid terms. If, however, the supposed generic identity of the species is shown to be untenable, the original name or names must be restored to rank. Thus naturalists have commonly regarded the generic name Cyrtulus, proposed by Hinds Science.

$\dagger$ For the generic names used in zoology up to 1879 , see Scudder (25). For those used subsequently see the annual lists published by the Zoological Society of London in the Zoological Record (complete index every ten years, I865-1906), continued in the International Catalogue of Scientific Literature since 1907. 
in 1843 for a modern gastropod, as a synonym of Clavilithes, proposed by Swainson in 1840 for a Tertiary one, and relegated the name Cyrtulus to the limbo of dead terms. As the types of these genera are, however, widely distinct, the name Cyrtulus must be restored to its original significance.

When a genus includes several distinct groups of species, each of which is subsequently raised to the rank of an independent genus, the original name should be retained for the group considered most typical by the original author, or corresponding best to his diagnosis. New names must be given to the other groups. Thus the name Clavilithes has been restricted to that group to which the generic characters, as described by Swainson, best correspond (C. parisiensis, etc.), while another group included by Swainson under the same generic name has been separated under the term Rhopalithes (R. now, etc.).

\section{TyPES.}

A type in natural history is the material used in describing, defining, and illustrating a species or genus, etc. Two kinds of types are recognized-Primary or Proterotypes and Secondary or Supplementary types or Hypotypes (Apotypes). Typical specimens (Icotypes) not used in the literature, but serving a purpose in identification, are further recognized.

Terms Used for Specific Types. The following terms have been proposed and have come into more or less general use (24) for types of species:

I. Primary types (Proterotypes).

a. Holotypes.

b. Cotypes (Syntypes).

c. Paratypes.

d. Lectotypes.

II. Supplementary types (Hypotypes or Apotypes).

e. Autotypes (Heautotypes).

f. Plesiotypes.

g. Neotypes.

III. Typical specimens (Icotypes).

h. Topotypes.

i. Metatypes.

j. Idiotypes.

k. Homøotypes.

1. Chirotypes.

IV. Casts of Types (Plastotypes). 
I. Among the primary types a holotype is the original specimen selected as the type, and from which the original description (protolog), or the original illustration (protograph), is made. A cotypc (syntypc) is a specimen of the original series when there is no holotype, the describer having used a number of specimens as of equal value.

A paratype is a specimen of the original series when there is a holotype. When the original describer selected one specimen out of the number used to be the type par excellence, $i$. $c$., the holotype. the remainder of the specimens used in the original description constitute the paratypes.

A lectotype is a specimen chosen from the cotypes subsequently to the original description to represent the holotype.

II. Among the supplementary types:

An autotype (heautotype) is a specimen not belonging to the primary or proterotype material and identified with an already described and named species and selected by the nomenclator himself for the purpose of further illustrating his species.

A plesiotypc is a similar specimen but selected by some one else than the original describer of the species.

A neotype is a specimen identified with an already described and named species, and selected to represent the holotype in case the original naterial (all the proterotypes) is lost or too imperfect for determination. A neotype must be from the same locality and horizon as the holotype or lectotype which it represents.

III. Among typical specimens or Icotypes:

A topotype is a specimen (not used in the literature) from the same locality and horizon as the holotype or lectotype.

A metatype is a topotype identified by the nomenclator hinself.

An idiotype is a specimen (not used in the literature) identified by the nomenclator himself, but not from the original locality or horizon of the holotype or lectotype with which it is identified, $i$. $e$., not a topotype.

A homotype (homocotype) is a specimen (not used in the literature) identified by a specialist, after comparing with the holotype or lectotype.

A chirotype is a specimen upon which a chironym or manuscript name (a name never published) is based.

IV. Casts of type material (plastotypes) nay be used or not in descriptions or illustrations. They are accordingly holoplastotype or any other protoplastotype. Hypoplastotypes and icoplastotypes also may be made, but are generally of comparatively little value. 
Generic Types. Species upon which genera are based are genotypes.* Three kinds of genotypes may be recognized:

Genoholotype-the original species on which the genus is founded, or the species selected by the author from those originally described as the type of the genus.

Genosyntype-one of a series of species upon which a genus is founded when there is no genoholotype.

Genolectotype-a species subsequently selected from the geniosyntypes to represent the genoholotype.

\section{Selection of the Genotype or Type Species of a Genus.}

Many genera are monotypic, $i$. $c$., had only one species when founded, though others may subsequently have been referred to them. The original species upon which the genus is founded in such a case is the true genotype or genoholotype. When a genus is founded on a group of species (hetenotypic) the originator of the genus should select one species as the genoholotype. This has not always been done, especially in the case of the older genera, the genus being founded on a group of species or genosyntypes described at the same time. It then becomes the duty of the first reviser of the genus to select the type species (genolectotype) from the original species (or genosyntypes). Two principal methods are used by naturalists in such cases-the first species method and the elimination method. The first of these methods appears to be the simplest one, since the species first described by the author of the genus is taken as the type. It sometimes happens, however, that the first species is not the most typical of the genus as defined by the author, or it may have been subsequently separated from the other species and perhaps placed in a genus by itself, the diagnosis of which differs from the original one, or is more circumscribed than it. In such a case it is the practice to choose the genolectotype from the renaining species of the original group. Often several sections have been separated from the original group and placed in distinct genera. By this process of elimination the genotype thus becomes restricted to the remaining species (genosyntypes), one of which must be selected. This selection is to be done by the first reviser of the old genus and his designation of the genolectotype will stand. Occasionally it may happen that all the original species have been removed to new genera, in which case the last one so

* This name has recently been employed by zoölogists and botanists in a very different sense (see Osborn-19). 
removed is to be taken as the type of the restricted genus, the new name applied to it beconing a synonym.

The application of the first species rule to the determination of the type of the genus may lead to a great many unnecessary and undesirable changes, but where possible it is best applied, as being the most readily carried out. Where, however, this would lead to confusion in the nomenclature, the elimination rule is best followed. (For illustration and discussion see Stone-26; Allen-12 and subsequent articles in Science.)

\section{Union of Genera into Groups of Higher Taxonomic Value.}

Sub-families, Families, Super-families. Genera are united into families, the name of the family being generally derived from its principal genus or the one longest known. The terminaticn of families in zoölogy is generally ida (short i), as Terebratulida from Terebratula. Fanilies are often divided into sub-families, the names of which terminate in inc (long i), as Terebratulinc. In Botany the family generally ends in acea, as Rosacec, but there are a number of exceptions to this rule. Sub-families in botany end in $e \mathfrak{c}$ or inea, the name in each case being derived from the principal genus. Super-families-in which a small group of related families are united, are sometimes made use of. The names of these end in acea, the name being derived from the principal family. Ex.: Terebratulaceà.

Subsorders, Orders. The important division of next higher rank is the order, which often comprises a number of sub-orders. The names of these divisions have no uniform ending in zoölogy, though the terminal letter is commonly $a$, the termination ata being most common. Other terminations are: ia, oida or oidea, acea, era, etc. In botanical nomenclature the orders end in ales.

Groups of Higher Rank. Above the orders we have in ascending rank: (super-orders), (sub-classes) classes, (sub-types) phyla (or types), sub-kingdom, kingdom. When a taxonomic division of higher rank takes its name from a genus the name of which is afterward found to have been preoccupied, and so has to be changed, the name of the higher division must also be changed.

The law of priority is not strictly applied to names of divisions of higher rank than genera, since newly discovered facts often make a change in the classification necessary when the substitution of a new for an old term becomes desirable. A uniform termination for the names of divisions higher than families is much to be desired. 
Faunas and Floras. An association of all the animals in a given locality constitutes the fauna of that locality, while a similar association of the plants produces the flora. In the study of past geologic epochs it is often necessary to speak of the totality of animal or plant life in any given formation. This constitutes the fauna and flora, respectively, of that formation. It matters not whether the formation is great or small-whichever is considered-all the animal remains found in that formation together make up the fauna of that formation, and all the plant remains constitute its flora. To designate the fauna and flora of a time period we may conveniently employ the terms chronofama and chronoflora, or chronobios for both. Each chronofauna or flora comprises numerous geographic faunas or floras, and these may be designated the locofauna and locoflora, or, in its entirety, the locobios. We must, of course, realize that the terms fauna and flora refer to the assemblage of animal and plant life as a whole, in the time-period of the formation, and at the locality where the formation now occurs, and that therefore the fossil remains of a given bed do not adequately represent the fauna or flora of that time, since. many types have not been preserved. Hence the term fossil faunas is useful as indicating that only a certain portion of the original fauna, $i$. $e$, that preserved as fossils, is spoken of. Thus we may speak of the fossil fauna of the Hamilton period of western New York, by which we would mean that portion of the western New York locofauna of the Hamilton chronofauna which has been presẹrved.

Table I. Subdivisions of the Plant Kingdom.

Phanerogamous plants.

Phylum V. Spermatophyta or seed plants.

Class 2. Angiosperma (covered seed-plants).

Sub-class 2. Dicotyledoneæ (seed-leaves 2).

Sub-class I. Monocotyledoneæ (sced-leaves 1).

Class I. Gymnosperma (naked-seeded plants).

Order V. Ginkgoales

Order IV. Gnetales (joint firs).

Order III. Coniferales.

Family 2. Pinacex.

Family I. Taxacea.

Order II. Cycadales (cycads, sago palms).

Order I. Cordaitales (Cordaites).

\section{Cryptogamous plants.}

Phylum IV. Pteridophyta or Fern Plants (Vascular Cryptogams).

Class 6. Felicine:

Order IV. Marattiales (Ringless Ferns).

Order III. Feliciales (True Ferns). 
Order II. Cycadofiliciales.

Order I. Hydropteridiales.

Family 2. Salviniaceæ.

Family I. Marsiliaceæ.

Class 5. Ophioglossina.

Order I. Ophioglossales.

Class 4. Lycopodince.

Order IV. Isoëtales.

Order III. Lepidodendrales.

Family 2. Sigillariacea.

Family I. Lepidodendracex.

Order II. Selaginellales.

Order I. Lycopodiales (Club-mosses).

Class 3. Psilotince.

Order I. Psilotales.

Class 2. Sphenophylline.

Order II. Cheirostrobales.

Order I. "Sphenophyllales.

Class I. Equisetince

Order II. Equisetales (Horsetails).

Order I. Calamariales (Calamites).

Phylum III. Bryophyta or Moss-plants.

Class 2. Musci (Mosses).

Order IV. Bryales.

Order III. Phascales.

Order II. Andreaales.

Order I. Sphagnales (Peat-moss).

Class 1. Hepatica (Liverworts).

Phylum II. Thallophyta or Thallus plants.

C. Lichens.

Class 2. Basidiolichenes.

Class I. Ascolichenes.

Sub-class 2. Discholichenes.

Sub-class I. Pyrenolichenes.

B. Fungi.

Class 2. Mycomycetes (Truc Fungi).

Order III. Basidiales (Mushrooms, etc.).

Order II. Ascomycetes (Milclews).

Order I. Ustilaginales. (£cidiomycetes, rusts).

Class 1. Phyco-mycetes (Algo-fungi).

Order II. Zygomycetes.

A. Algi.

Order I. Oomycetes.

Class 3. Rhodophycere (Red algæ).

Class 2. Phaophycee (Brown algx).

Order IV. Euphæophycex.

Order III. Cryptomonadacex.

Order II. Diatomacex.

Order I. Peridiniaceæ. 
Class I. Chlorophycea (Green algæ).

Order III. Characeæ.

Order II. Euchlorophycea.

Order I. Conjugataceæ.

Phylum I. Protophyta.

Class 3. Myxomycetes (Slime-molds), sometimes regarded as Protozoa (Mycetozoa).

Class 2. Flagellata (more generally regarded as Protozoa).

Class I. Schizophyta.

Order II. Cyanophyceæ (Blue-green algæ).

Order I. Schizomycetes (Bacteria). 


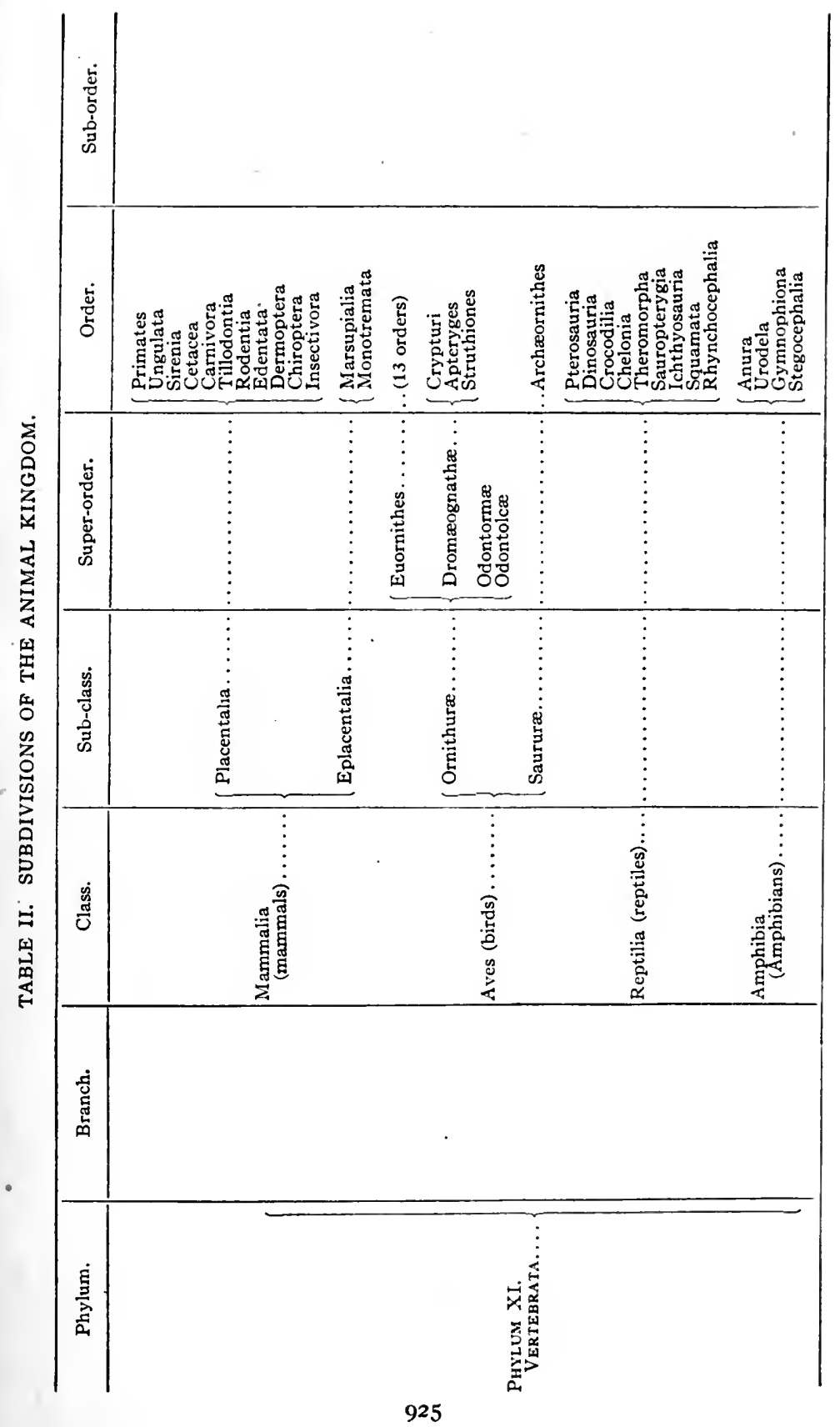




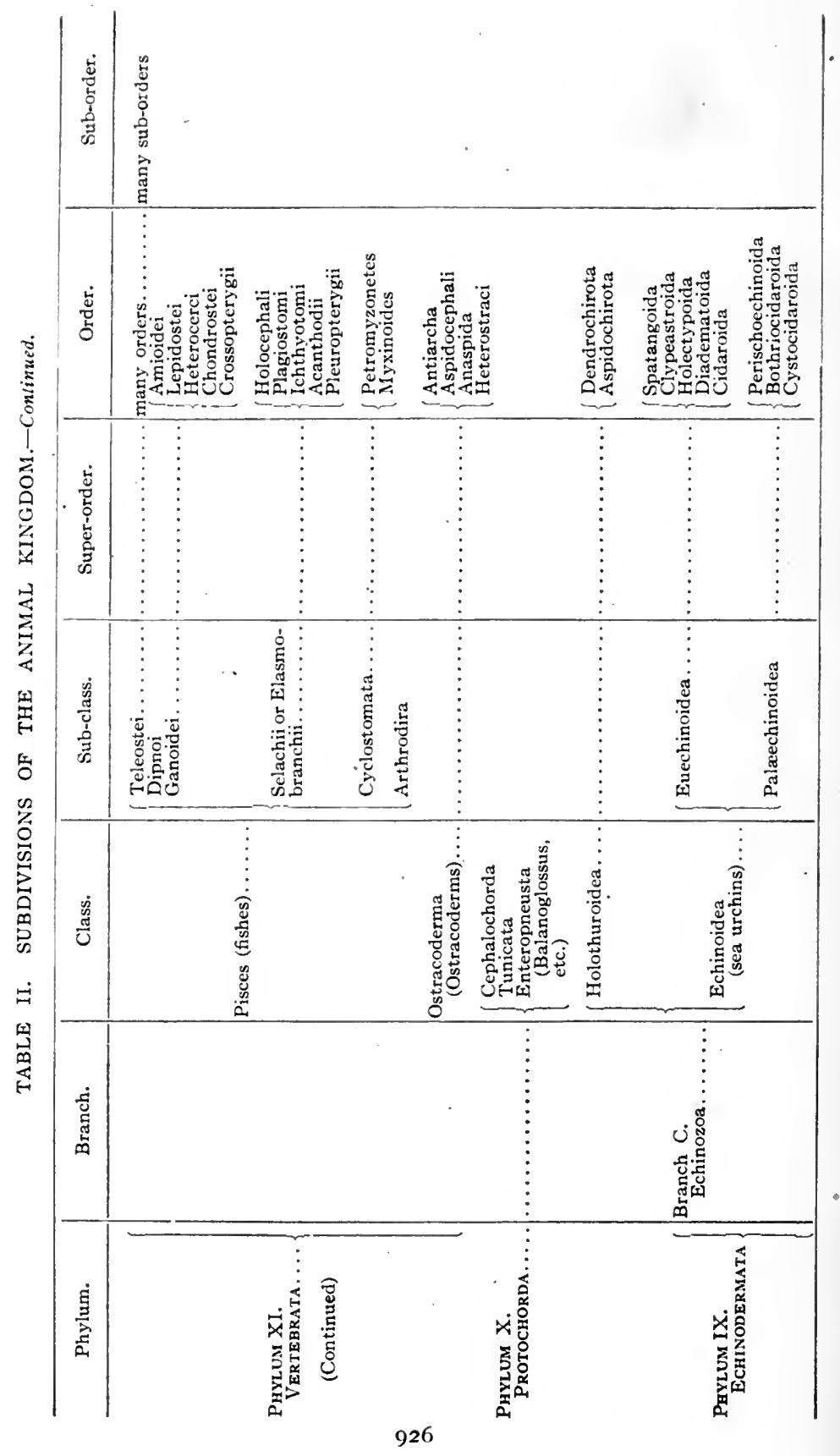




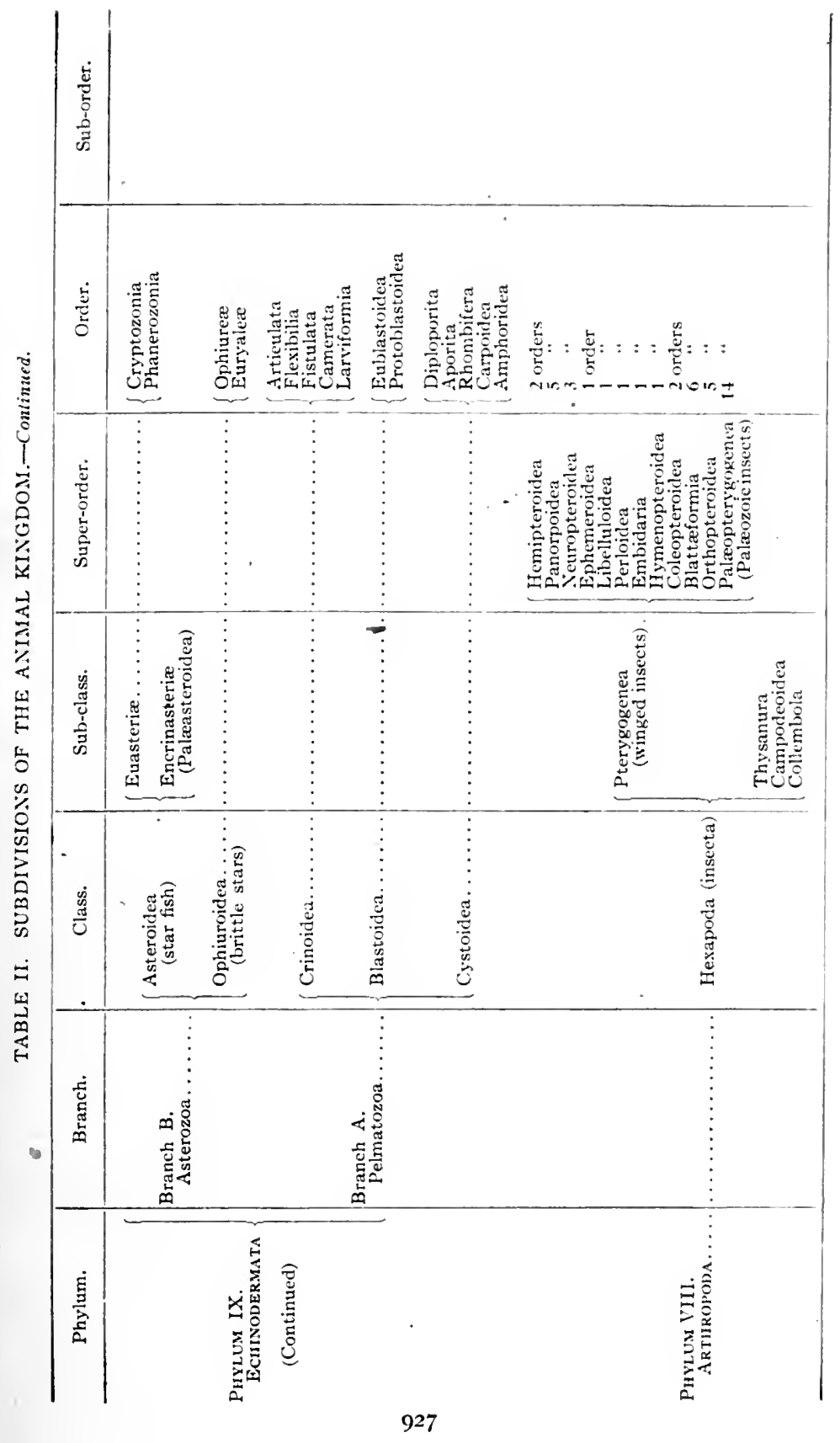




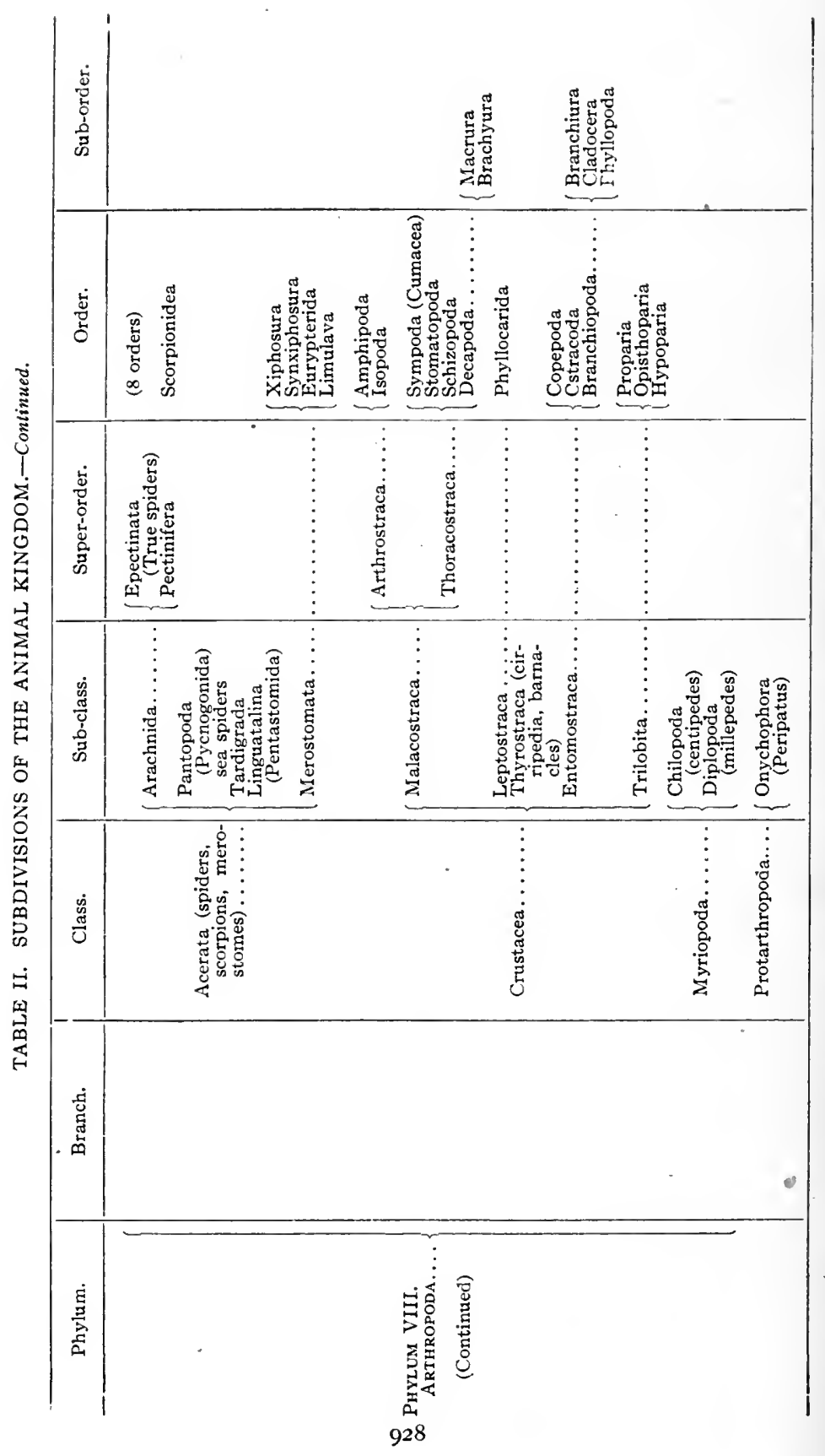




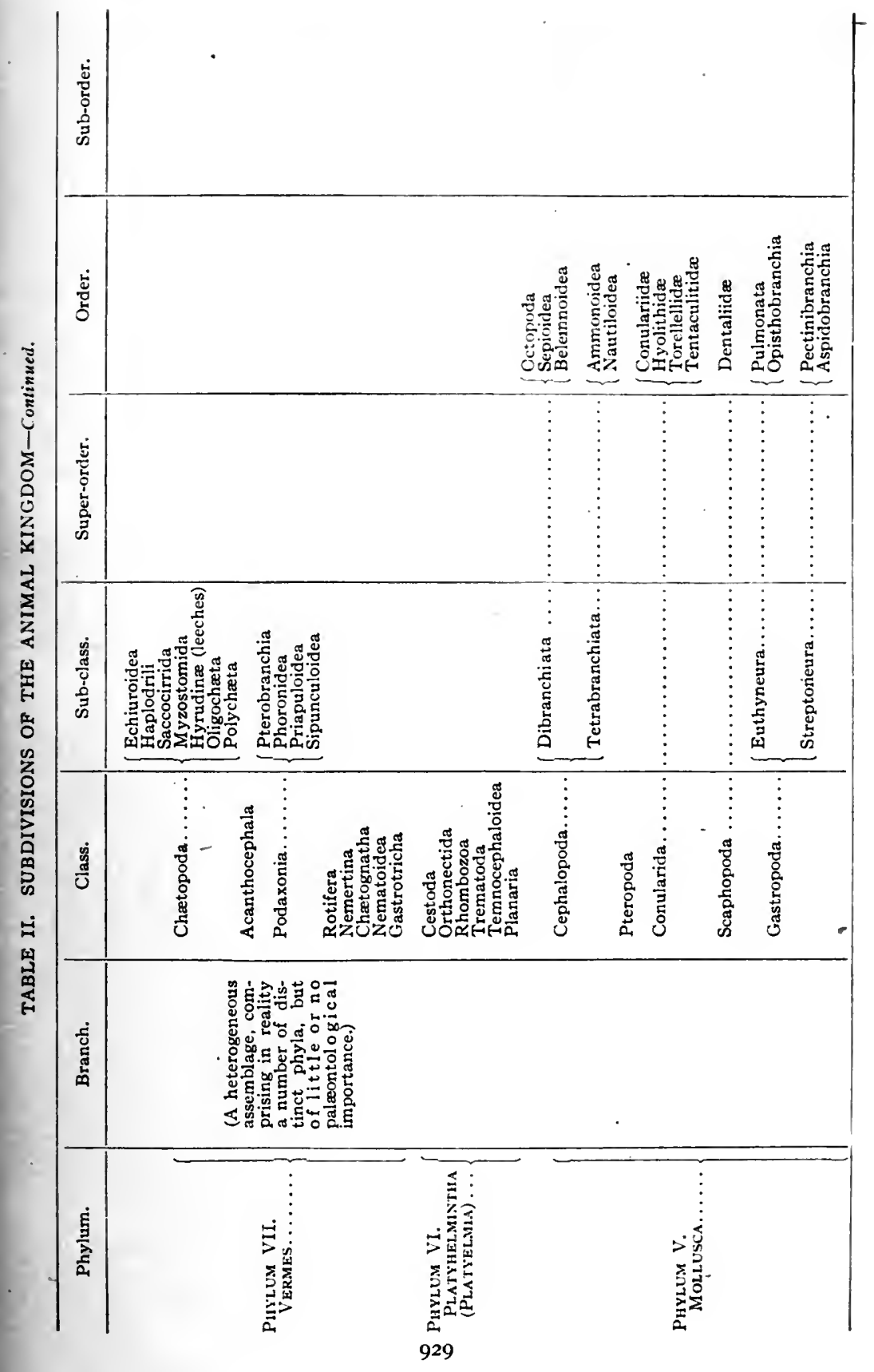




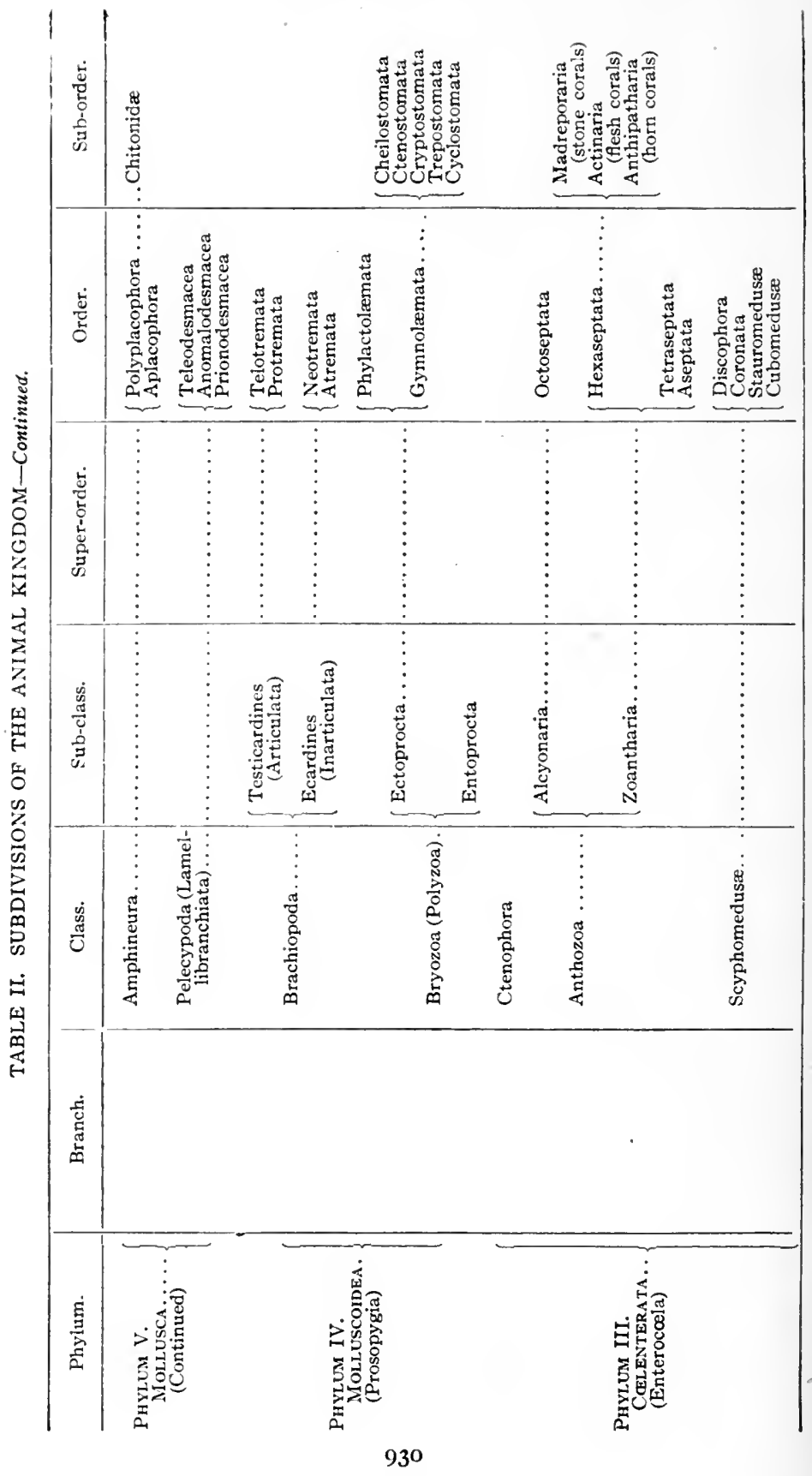




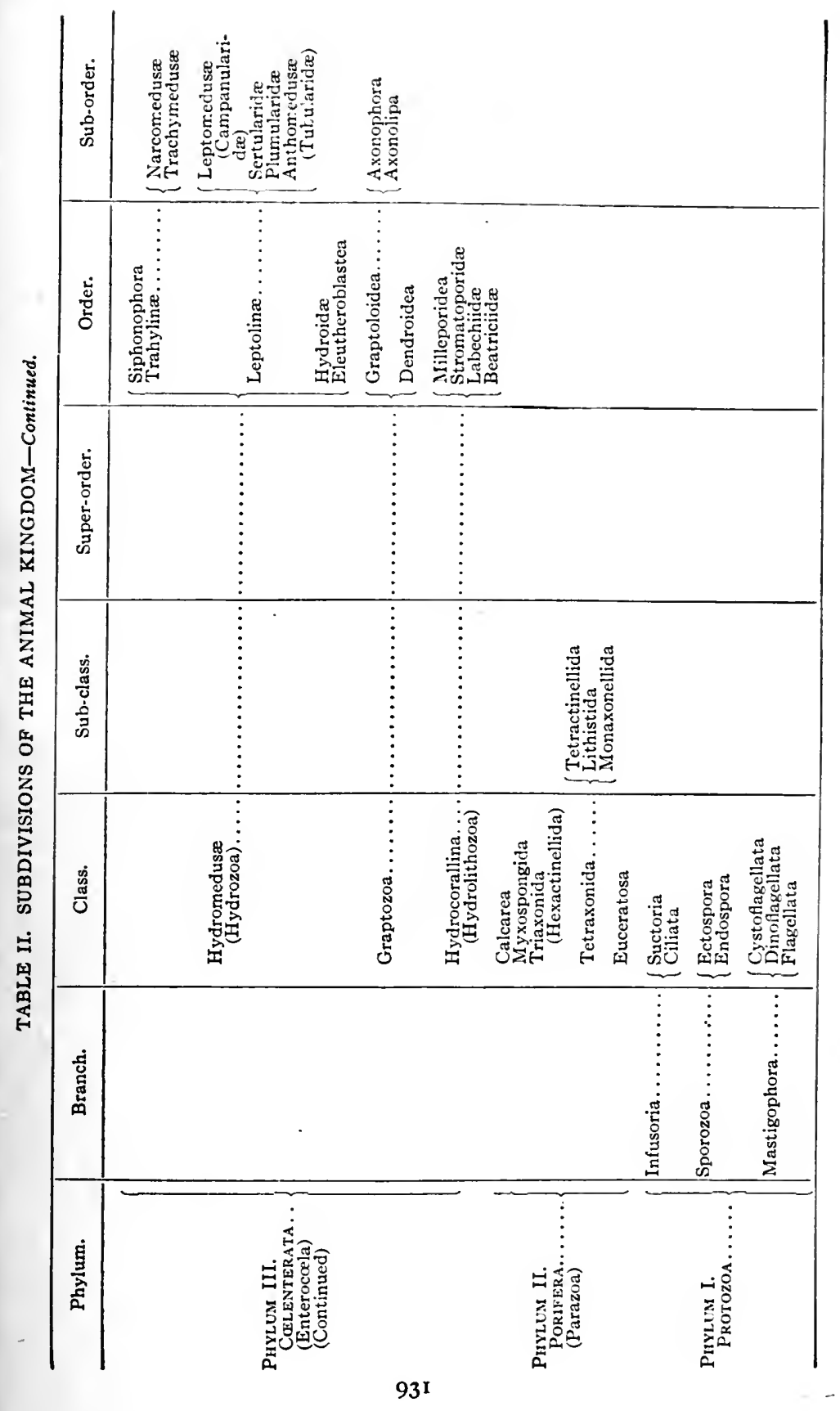




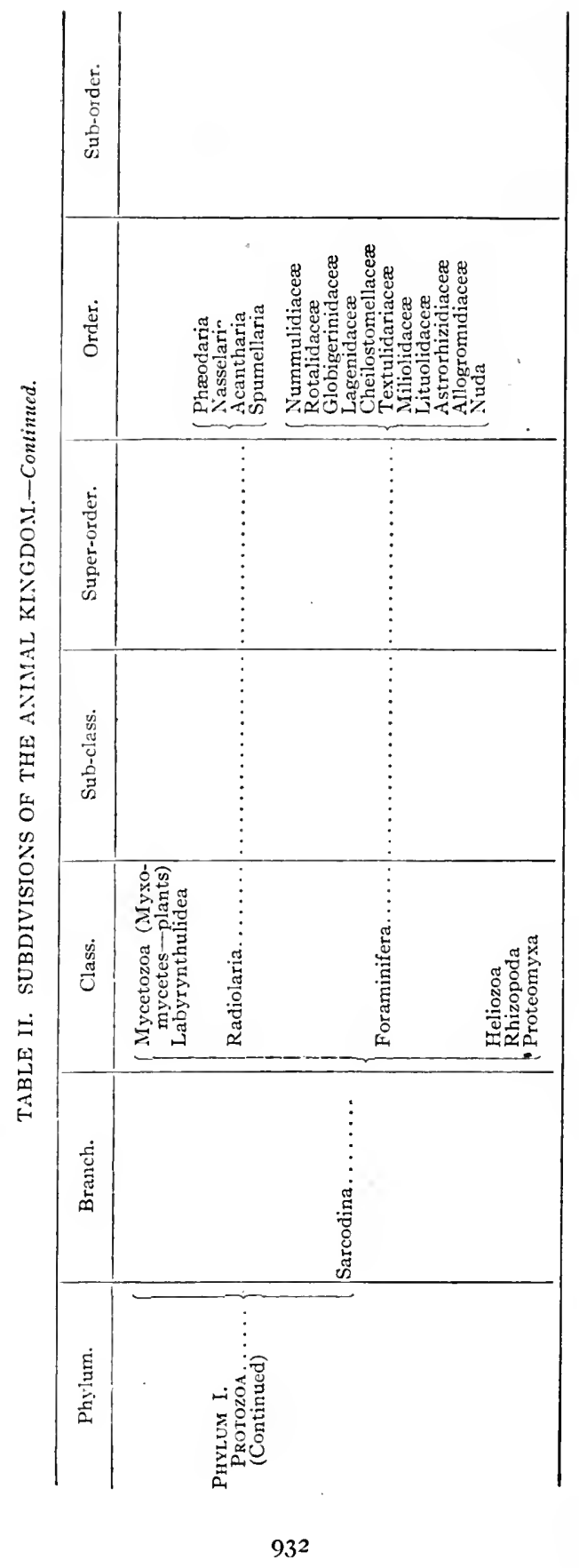




\section{BRIEF SUMMARY OF THE MORPHOLOGICAL CHAR- ACTERS OF THE PHYLA OF PLANTS AND ANIMALS.}

\section{A. Plants.}

Phylum I-Protopnyta. This division is not often employed, the members here classed under it being referred either to the algae or to the fungi. It is, however, a convenient division for those simple plants which have not the true cluaracters of either of the other two groups. In this group are placed organisms which combine characteristics of both plants and animals. Such are the Flagellata, which more generally are placed among the Protozoa, and the Myxomycetcs, which are also regarded by some zoölogists as Protozoa under the name Mycetozoa. The Flagellata are aquatic, and so named from the fact that their dominant phase is a "flagellula" or cell-body provided with one, few, or, rarely, many, long, actively vibratile processes. They are attached or free and some of them (Volvocacce, etc.) develop chlorophyll, and in this, and in the mode of multiplication, they have the characters of undoubted unicellular plants. Some types placed here (Coccolithophorid(c) (Fig. 104) have their bodies invested in a spherical test strengthened by calcareous elements or tangential circular plates which are variously named coccoliths, discoliths, cyatholiths, or rods called rhabdoliths. These are often found in the Foraminiferal ooze and in chalk.

Flagellates are frequently considered as forming the starting point for unicellular plants on the one latnd and l'rotozon on the other. That they have given rise to both groups is held by good authorities. The largest species range 11p to $130 \mu$ in length, exclusive of the flagellum, though a large number of them rarcly exceed $20 \mu$ in length.

The Myromy'ctes (Mycetozoa), or slime molds, are sonctines classed with the Fungi and also with the l'rotozoa. They are terrestrial and devoid of chlorophyll and reproduce by spores, which are scattered by the air, at in Fungi. The spore hatches out as a mass of naked protoplasm, which assumes a free-swimming flagellate form, multiplies by division, and then passes into an anceboid stage. By fusion of many amceboids the plasmodium is formed, which is a mass of undifferentiated protoplasm without envelope and endowed with the power of active locomotion. It penetrates decaying vegetable matter or spreads over the surface of living fungi, 
and may reach an expanse of several feet, though generally small.

The Schisophyta form a group distinct from the preceding and unconnected with them or higher types. Bacteria are minute unicellular plants, devoid of chlorophyll, and multiplying by repeated division. In form they, are spherical, oblong, or cylindrical, often forming filamentous or other aggregates of cells. The absence of an ordinary nucleus, of the ordinary sexual method of reproduction, and the manner of division, unite them with the Cyanophycce, or blue-green algæ. Some forms (Sarcina) show relationship to, or analogies with, green algæ (Palncllacea), while others suggest relationship to myxomycetes. Again, certain features suggest some flagellates and many forms exhibit a power of independent movement when suspended in a fluid. The group is no doubt a heterogeneous one, including at present primitive forms of many types of plants. Their size is commonly $I \mu^{*}$ in diameter and from two to five times that length, though smaller and larger forms are known. They occur fossil since Devonic and probably earlier time.

The Cyanophycece are unicellular or multicellular and contain, besides chlorophyll, a blue-green coloring matter, hence their name, though the actual color of some ranges from yellows to browns, reds, purples, or violets of all shades. Generally the single cells are held together in a common jelly. Some members of this division secrete lime (Gloocapsa, Gloethece) and serve to build up considerable deposits (see organic oölites, Chapter XI). Nearly a thousand species of Cyanophycea are known. No fossil representatives are known, though they must have existed in earlier ages.

Pinlum II-Thallomista. The vegetative portion of these plants consists of one or many cells forming a thallus, often - branched. There is no differentiation of the body into a root, stem, or leaf, while the internal structure is comparatively simple. lioth sexual and asexual reproduction take place. In many classifications the Bacteria, the Cyanophycece, and the Myxomycetes are also classed here, and, besides them, the following classes are made: 1. Peridince, 2. Conjugata, 3. Diatomacere (Diatoms), 4. Heterocontea, 5. Chlorophycea (Green alga), 6. Characea (Stoneworts), 7. Rhodophycce (Red algæ), 8. Eunnycetes (Fungi), 9. Phycomycetes (Algal fungi), 10. Phcophycece (Brown alga). The older division into the three classes of a, Alga, bearing Chlorophyll; b, Fungi, without Chlorophyll; and c, Lichons, symbiotic colonies of algee and fungi, is the most familiar and will be used here.

* One micromillimeter or $0.001 \mathrm{~mm}$. 
a. $A \lg a$.

Algæe, or seaweeds, are thallophytes characterized by the presence of Chlorophyll, or leaf-green, though the color is by no means always green. They are largely aquatic in habitat, most of the more striking forms occurring in the sea. According to the prevailing color, three divisions are made-the Green Alga, or Chlorophycec; the Brown Algre, or Phcophycea; and the Red Alga, or Rhodophycea. The Cyanophycea, or blue-green algæ, are also frequently included under the algæ.

The Chlorophycea include three forms in which the chlorophyll is not accompanied by other coloring matter. With the typical green algæ (Euchlorophycec) are generally included the divisions Conjugatacese and Characes, which have a separate phyletic standing. The common green sea-lettuce, Ulva, is a good example of an expanded form, but in many of the green algre (especially the Confervales), the thallus consists of filaments, branched or unbranched, attached at one extremity and growing almost wholly at the free end. Some forms (Halimeda, Acetabularia, etc.) are encrusted with lime and are important on "coral" reefs. The Pond-scums, or Conjugatce (so named from their method of reproduction) include the Desmids, which have the power of independent movement.

Quite distinct from the others are the Characece, the most highly differentiated of the green algæ. Of these the common stonewort. Chara, growing in fresh water lakes, is the typical form. This is attached to the bottom of pools by rilizoids and grows upward by means of an apical cell forming a pointed axis, which gives off whorled appendages at regular intervals. Long branches occur in each whorl, and these give off secondary whorls of jointed appendages. The distance between the nodes from which the appendages arise may be several centimeters. All are encrusted with lime. The reproductive organs are also highly differentiated. Antheridia and oögonia are formed at the nodes of the appendages. The egg cells, or oögonia, when ripe are surrounded by five spirally twisted cells, and crowned by a circle of smaller ones, which afterward separate to allow fertilization. The outer cells become very hard and calcareous and are extensively preserved, in some cases contributing to the formation of limestones.

Over 1,600 species of true green alge are known. The Pond Scums, or Conjugate, ald nearly 1,300 species more, while the stoneworts, or Characex, are represented by only about iso species, making a total of over 3,000 species. 
The Phaophycea, or brown algæ, are distinguished by the possession of a brown coloring matter in addition to the chlorophyll. The Peridiniacece and Diatomacea are included here, together with the Cryptomonadacece, all of them unicellular plants with little except color in common with the true brown alga (Euphaophycea), which are multicellular. Familiar examples of the last class are Fucus, Laminaria, and Sargassum. The kelps (Laminaria) develop large round "stems" which branch root-like at the base and have an oar-like expansion at the top. The rock-weels (Fucus) develop air-bladders which serve for purposes of flotation. They are attached to the rock by means of a disc or root-like expansion; have a stem of rough leathery texture which forks regularly; and are expanded in a leaf-like manner with thick mid-ribs. The Gulfweeds (Sargassum) have distinct stems, leaves, and stalked airbladders, and strikingly resemble land plants.

The diatoms are microscopic unicellular plants of a yellow or reddish-brown color, and not closely related to the other algæ except perhaps to the desmids. The cell wall is impregnated with silica, so that its shape is preserved after the death of the plant. The "shell" consists of two parts, one overlapping the other like a pillbox and cover. These show great variety of form and have the power of locomotion.

Of the true brown alga there are only about 620 species. The Peridiniacea and Cryptomonadacea comprise only about 220 species, but the diatoms, recent and fossil, include about 5,000 species.

The Rhodophycea, or red algæ, also called Floridece, are so named from the presence of a red color besides the chlorophyll. Species growing near high-water mark are generally of a dark hue and may be mistaken for brown alga. The Irish moss, Chondrus, is a good example. Those growing near low-water, or in the shade of other alga, are bright colored. They are all multicellular and mostly microscopic in size, but some large species occur. Limesecreting forms are common, the branching Corallina, the encrusting Melobesia and Lithothamnion abounding both in recent and fossil state. The total number of species of red algæ is about $I, 400$; this, together with the brown algæ, 840 species, the diatoms, 5,000 species, and the 3,000 species of green algx, makes a total of over IO,200 species of algæ.

Fucoids. This is a general term applied to impressions on rocks, suposed to represent sea-weeds. In some cases land plants and even traces of inorganic structures have been included here. Ex.: Fucoides vierticalis of the Portage, probably a land plant; 
Arthrophycus harlani of the Medina, probably a trail; Dendrophycus triassicus of the Newark sandstone, a rill-mark impression.

\section{b. Fungi.}

Fungi or mushroom-plants are thallophytes devoid of chlorophyll, and growing often in the dark. They arise from spores, and the thallus is either unicellular or composed of tubes or cellfilaments (hyphæ), which may be branched, and have an apical growth, or, again, they are composed of sheets or tissue-like masses of such filaments, forming a mycclium. True tissue may develop in some cases by cell-division in the larger forms. Two classes are recognized: Phycomycetes, which are alga-like, with unicellular thallus and well-marked sexual organs, and Micomycetes, or higher fungi, with segmental thallus and sexual reproduction. Some of them (Polyporus, Dædelia) form resistant, more or less woody, structures growing on dead trees.

The number of species of Fungi is probably around 20,000. though some have placed it as high as 50,000 or even 150,000 . Fossil forms extend back at least to the Carbonic, where they occur as hypha in fossil wood. Good specimens are also found in amber of Tertiary age.

\section{c. Lichens.}

The lichens are terrestrial thallophytes, composed of alga and fungi living together symbiotically. The fungi are generally Ascomycetes, the higher class of Basidomycetes seldom taking part, while the algæ are either the blue-green alge, Cyanophycece or the green alge, Chlorophycese. The same alga can combine with different fungi io form different lichens. The fungal portion always forms the reproductive organs, though the alga may do so when separated from the association, and growing frec. Reproduction is also carried on by fragmentation, $i$. $c$., the brcaking off of parts capable of starting new plants. There are some thousands of existing species, but fossil forms have not been recognized except from very recent formations. It is not inlikely, however, that lichenous plants formed a chief element of the ancient land vegetation.

Phylum III-Bryophyta. The Bryophyta include the mosses and liverworts, both terrestrial plants. In the former, and in some of the latter as well. the plant consists of a stem bearing small leaves, though in many liverworts this distinction is not present. 
but a thallus is formed closely applied to the substratum. The attachment of the bryophytes is by rhizoids, true roots being absent. These rhizoids resemble the root-hairs of higher plants. The reproductive organs are antheridia and archegonia, serving for sexual reproduction. The former are stalked and develop the spermatozoids, while the archegonia are flask-shaped, with long neck, the egg-cell lying at the bottom. From the fertilized ovum a capsule arises, generally borne on a stalk, and within this the spores are developed. There is thus an alternation of generation - the sexual stage, or gametophyte, developing from the spore, and the asexual, or spore stage (sporogonium or sporophyte), developing from the fertilized egg of the gametophyte, and, in turn, producing the spores. The spore-bearing generation is throughout life dependent on the gametophyte, whereas in pteridophytes it becomes an independent plant. The order Sphagnales contains the single genus, Sphagnum, with numerous species known as bog-mosses. The order Andrecales also contains a single genus, Andrexa, for the most part an Alpine and Arctic plant, growing on bare rocks. The order Phascales includes a few small species, chiefly of the genus Phascum. The order Bryales, on the other hand, contains a very large number of genera and species.

Fossil mosses, especially of the genus Hypnum, have been obtained from the Miocenic and Quaternary deposits of Europe and the Arctic region, and also from western America (Green River beds). They are doubtfully represented in Mesozoic and earlier deposits.

Phylum IV-Pteridorirtes. The pteridophytes, or vascular cryptogams, form the highest division of the flowerless plants. Their internal vascular structure allies them with the higher plants. In them alternation of generation has been carried farthest, in that the first stage to develop from the germinating spore is the gametophyte, known as the prothallus. This is a small, flat, green plant-organism which carries on its under side the archegonia and antheridia, together with the rootlets or rhizoids. This sexual plant is independent of the "sporophyte or asexual generation, while the latter at first draws nourishment from the prothallus but becomes physiologically independent when its roots develop. This independence of the two generations is the distinctive feature of the pteridophytes, whereas in bryophytes the sporophyte is throughout its life attached to the gametophyte, while in the spermaphytes the more or less reduced gametophyte remains enclosed within the tissues of the sporophyte.

The Equisetales, including the single living genus, Equiset'm, 
with about 25 species, and the extinct Calamites, represent a range in height from a few inches in the modern forms to from 30 to 60 meters in the extinct Calamites. Equisetum arises from a subterranean rhizome, which may be a meter in length, and is jointed; the aërial shoot consists of hollow internodes, with whorls of leaves near the top of each, the leaves cohering, except near their tips. In section the aërial stem shows a hollow central cylinder, around which is arranged a circle of fibrovascular bundles, triangular in section, with the point inward. The inner end is occupied by a large air space, and outside of this again is a circle of long air tubes alternating with the fibrovascular bundles. These latter extend into the leaves, equaling in number the leaf teeth.

The stem of the extinct Calamites had essentially the same structure, but with secondary growth in thickness. In all large specimens a broad zone of wood is added, with a structure comparable in the true Calamites to that of the simplest conifers. The vascular bundles project into the pith as in Equisetum, and from their more resistant character they will remain when the pith breaks down. A rock-filling of the hollow cylinder thus made will be marked by longitudinal grooves, representing the projecting vascular bundles. In Calamites proper these grooves alternate at the nodes, while in Archrocalamites they are continuous. This shows that in the latter the leaves were superposed, while in Calamites they were alternating. In modern Equisetum both fertile and sterile branches arise from the rhizomes. The sterile are more slender than the spore-bearing ones, and bear numerous whorls of branches, which form a bushy plant, from which the nane "horsetail" originated. The fertile branches bear a terminal "strobilus," or cone of sporangiophores, each of which consists of a hexagonal disk, attached by a stem to the axis and supporting on its under side six to nine large spore-cases or sporangia. The outer surfaces of the hexagonal plates form the solid outer surface of the cone, the sporangia extending inward toward the axis. They are not visible until the cone separates into its component parts. Some Calamites (Archrocalamites) agree closely with this mode of organization, but in others the structure of the cones was more complicated, this being brought about chiefly by the insertion of whorls of sterile bracts between those of the sporangiophores.

The Sphenophyllina, known only from the Palreozoic, and represented by the genus Sphenophyllum, had some characters of the Equisetales. The slender, little-branched, and probably clinging stem had from six to eighteen wedge-shaped or linear leaves at the swollen nodes, the leaves of successive whorls not alternating. 
The structure of the stem is, however, more like that of lycopods, but the cone again suggests affinities with the Equisetales. The sporangiophores, however, spring from the bracts instead of the axis. The class combines the characters of ferns, lycopods, and Equisetales. Their nearest living relatives are probably the Psilotales (Psilotum and Tmesipteris) formerly classed with the Lycopodiales.

The Lycopodinc are represented by three living and one extinct orders. The Lycopodiales are represented by two genera-Phylloglossum with one species, and Lycopodium with nearly a hundred. Selaginella with between 300 and 400 species and Isoëtes with about 50 , mostly aquatic, species are each the sole representatives of their respective orders. The modern genera are small forms, but the extinct orders contained some of the largest Palæozoic trees, reaching 100 feet or more in height. A general external characteristic of these plants is the simple form of the leaves, which are generally of small size, while the sporangia are situated on the upper surface of the sporophylls. In structure the stem is a single cylinder (monostelic) with a centripetal development of woody tissue (xylem). The earliest, or protoxylem, is at the periphery of the stele. In Selaginellales the stem contains one, two, or several stele, while the Lepidodendrales are monostelic, as in Lycopodium. A section of a Lepidodendron stem shows the central pith, often destroyed, surrounded by a zone of primary wood, and outside of this, in most cases, a zone of secondary wood, sharply defined from the inner zone by the layer of protoxylem. In some of the smaller species the wood was solicl, without central pith. The cortex or bark surrounds this and is bounded externally by the persistent leaf scars. In Sigillaria the ring of primary wood is narrower. The leaf scars are arranged spirally in Lepidodendron, but in vertical rows in Sigillaria. Both were attached to large creeping root-stocks or stigmaria, which were provided with numerous cylindrical "roots" which penetrated the soil on all sides.

The spores of lycopods are formed in sporangia of considerable size, which are situated on the upper surface and near the base of the sporophylls. These are arranged in definite terminal cones, or they may resemble the foliage leaves and occur in alternate zones with them. In Selaginella the sporophylls arc arranged radially in the cones, these terminating the branches. A single sporangium is borne on the axis just above the insertion of each sporophyll. Large and small spores (mega- and micro-spores) occur in this genus, but in Lycopodium they are all of one kind. 
In the Lepidodendrales they were heterosporous, at least in some cases. The cones of Lepidodendron and allied forms (Lepidostrobus) vary from an inch to a foot in length, according to species, and are borne on ordinary or on special branches. The sporophylls are arranged spirally upon the axis and each carries a single large sporangium on its upper surface, which in turn carries either an enormous number of minute or a small number of large spores. The upturned and overlapping laminie from the sporophyllæ form the exterior of the cone. The Lepidodendracese range from the Devonic to the Permic, while the Sigillariacex range through the upper Palæozoic above the Devonic.

The Ferns are among the most varied of existing pteridophytes and exhibit a wide range in size, from the little epiphytic Hymenophyllacea, whose fronds are hardly a centinueter in length, to gigantic tree-ferns, 80 feet or more in height. The leaves or fronds vary from simple to highly compound, each pinna or pinnule being characterized by a mid-vein, and by forking lateral veins. The sporangia are borne on the under side of the frond, or on separate fronds. In the Ophioglossales a separate spike is produced. In some of the Palæozoic Cycadofilices (comprising most of the ferns of that period $*$ ) actual seeds instead of spores were produced, the forms also being intermediate in structure of the stems, etc., between ferns and cycads. The water-ferns or Rhizocarps (Hydropteridiales) produce both mega- and micro-spores. The former produce female, the latter male, prothallia. The common pepperwort, Marsilea, looking like a small four-leaved clover, is a good example.

Phylum V-Spermatophyta. The true flowering plants (Phanerogams), or seed-plants (Spermatophyta), comprise the gymnosperms and the angiosperms. Conifers are the most abundant representatives of the gymnosperms in the northern regions, while the palm-like cycads occur in tropical districts. They are, however, abundant in the Jurassic and other Mesozoic deposits of America and Europe. The late Palæozoic Cordaitales were large trees with wood of a coniferous type (Daxoxylen wood) and long strap-shaped leaves.

The angiosperms, including all the true flowering plants, are divided into the Monocotyledons, which include the grasses, palms, lilies, etc., with parallel-veined leaves, and the Dicotyledons with net-veined leaves. The latter make their first appearance in $\mathrm{Co}$ manchic time.

* Also classed as a separate order Pteridosperme under the gymnosperms. 


\section{Animals.}

Phylum I-Protozon. The Protozoa are unicellular animals either naked or enclosed in a cell membrane. In addition, many rhizopods secrete calcareous or siliceous structures, or, by cementation, form a covering of foreign substances. One or more nuclei are generally present, and reproduction is by fission. The Rhizopoda include the Foraminifera, which secrete shells of carbonate of lime, or build them by cementing sand grains, etc. The shells lave one or more chambers (unilocular or multilocular). If many, they increase in size successively, and are arranged in various ways, including nautilian and spiral coiling. In many forms the surface is pierced by fine pores-the foramina-through which protoplasm is extruded in fine streamers forming the pseudopodia. In size the Foraminifera shells vary from minute shells to those an inch or more in diameter (Nummulites). They range from the Cambric to the present with several thousand species.

The Radiolaria secrete horny or siliceous internal structures, whicli form a much perforated latticework, ornamented by spines, bosses, etc. They also range from the Cambric to the present.

Phylum II-Porifera (Sponges). The sponges are aquatic multicellular animals in which the body is penetrated by a complex set of canals, into which water enters, through pores in the outer wall. From the canals are given off, at intervals, digestive sacs, and these finally converge into one or more main canals, with large external excurrent openings or oscula. Modern sponges generally secrete a skeleton of horny substance (chitin) and, in addition, many secrete siliceous or calcareous rods or needles (spicules) which are often compound in form. In many older and some modern forms, these unite into solid structures so that the form of the sponge is preserved. They abound in all marine formations, from the Cambric to the present. The number of extinct and living species is very great.

Phylum III-Calenterata. The cœlenterates have a body composed of two cellular layers, the ectoderm and endoderm, the latter enclosing the colomic cavity into which the mouth opens. An intermediate non-cellular or imperfectly cellular layer is often present but no true body cavity occurs. The animals (polyps) have a simple body in the Hydrozoa-the mouth generally at the end of a proboscis-like elevation, and surrounded by tentacles. Generally they are compound, many polyps being united by hollow tubes. Special polyps for reproduction (gonopolyps) are commonly developed, and these often give rise to medusa, or jelly-fish 
-a free-swimming sexual generation, which, however, sometimes remains attached to the parent. Many Hydrozoa secrete a horny or chitinous envelope, which ends in many cases in cups or hydrothece. In the fossil graptolites these horny structures alone are preserved, as compressed carbonaceous films. In other cases (Hydrocorallines) a calcareous structure is secreted, which may be important as a reef-former (Nillepora). The stromatoporoids of the Palæozoic are believed to belong to this group. They represent enormous accumulations of lime taken by minute organisms from the sea-water and built into their structures. These are often heads of great size, some attaining a diameter of ten feet.

The coral or anthozoan polyp is more complicated, there being, in addition to the parts found in the hydroid polyp, an enteric sac, or stomodaum, formed by invagination of the mouth area, and a series of fleshy septa or mesenteries, dividing the body radially. Many anthozoan polyps secrete a calcareous structure (coral) which typically is characterized by a series of radially placed calcareous plates or septa, variously united by transverse structures and surrounded by one or more calcareous walls. In Palæozoic time these were built mostly on the plan of four and grew into isolated horn-shaped structures on the broad septate end of which the polyp rested (Tetraseptata). In later times to the present the plan of six (Hexaseptata) or eight (Octoscptata) became the dominant one, and the forms became compound, so that in some modern coral heads thousands of individual polyps participate. A fourth group in which the septa were absent or represented by spines only, while the walls were provided with pores (Aseptata), was chiefly confined to the Palæozoic. The reproduction of the Anthozoa is carried on by fission and by ova.

Phylum IV-Molluscoidea. The Molluscoidea comprise two classes which are widely different in their external adult characters but closely similar in their early life history. The Bryozoa are commonly compound aquatic forms, either encrusting other objects or forming solid masses not unlike in form to some early corals, with which they have sometimes been united. The colony, or zoarium, consists of cells (zoxcia) generally of lime and loosely or closely aggregated, in the latter case often becoming prismatic. They are hollow or divided by transverse calcareous partitions or dissepiments and have various other structures. Smaller tubes (mesopores) are present in some cases. Colonially the Bryozoa may constitute a solid mass or head, a flat expansion, a network, in which large open spaces are left between series of zoœcia (as in Fenestella, etc.), or a great variety of other forms. In Palæozoic 
time, when the number of specimens was considerably over a thousand, they often acted as important reef-formers. Mesozoic and Cenozoic Bryozoa (close to a thousand species) also contributed largely to calcareous reefs. (See Chapter X.) The animal differs from the coral polyp by the possession of a well-marked body cavity and a definite alimentary system.

The Brachiopoda are simple animals encased in a shell with dorsal ventral and sometimes accessory valves. In general, the ventral valve is larger and some provision is afforded for the emission through a foramen or otherwise of the fixing organ, or pedicle. It is, hence, called pedicle valve. The other valve carries supports (crura brachidia), from which the soft internal respiratory organs, the brachica, or arms, are suspended; hence the name brachial ralze is applied. The accessory pieces are either a third shell plate (podicle plate, deltidial plate) secreted by the pedicle, or a double set of plates. (deltidial plates) meeting in the center below the foramen. These accessory plates are commonly very small and situated below the beak of the pedicle valve. Opening and closing of the valves is effected by muscular systems. Surficially the shells are either smooth or variously plicated, and sometimes spines are developed. There are about I4O living and over 6,000 fossil species.

Piiylum V-Mollusca. The molluscs are soft-bodied animals generally enclosed in a calcareous shell. The headless molluscs, or Pelecypoda, have a shell of two, generally symmetrical valves placed right and left and united dorsally by a hinge, which generally includes a series of interlocking hinge-teeth and sockets. The valves are opened either by an external ligamental structure variously arranged or by an internal compressible resilium which often has special supports or resilifers developed. The shell is closed by the adductor muscles, of which there are typically an anterior and a posterior one (dimyarian), or only one, situated subcentrally (monomyarian). Externally the shell is smooth, showing only growth lincs, or it may be ornamented by radiating plications or striations, or by marked concentric ribs parallel to the growth-lines. A horny outer covering, or periostracum, is generally present. The animal is provided with an anterior hatchet-shaped foot, and with gills which hang in pairs on opposite sides of the abdomen, and with a mantle, the attachment of which to the shell is marked by the pallial line, and the outer portion of which secretes the shell. The remainder of the mantle secretes the inner shell layer (nacreous layer), which is often iridescent. A pair of siphons (excurrent and incurrent) is frequently formed, their presence being generally 
indicated by a pronounced reëntrant in the pallial line below the posterior adductor impression (pallial sinus).

The cephalophorous mollusca build a shell of only one part, though extra horny or shelly pieces, not secreted by the mantle, may occur. Such are the opercula of certain gastropods and the aptychi of ammonite cephalopods. In the gastropods the animal is provided with a lingual ribbon, or radula, beset with teeth and having a rasping function. In the cephalopods horny jaa's are developed. In Gastropoda the shell is normally a spiral one, though in some cases the coiling is in a single plane, as is typical of coiled cephalopods. Both right- and left-handed coils occur, the former being more common, while the left-handed coils are variations in some cases, but fixed types in others. The apex of the shell is formed by the protoconch, generally somewhat differentiated from the conch. The latter may be smooth (except for growth lines) but is more generally ornamented by plications (spirals) and by ribs which extend across the whorl from suture to suture. The ribs may become concentrated into spiral rows of nodes, or spines (hollow emarginations of the shell-lip) may result. Temporary resting stages in shell growth are often marked by varices consisting of abrupt deflections of the lip, or by rows of spines (Murex). The mouth of the shell is in many cases drawn out into an anterior notch or a long canal. The inner or columellar lip of specialized types is marked by oblique plications. Old age or phylogerontic forms often have the last whorl loose-coiled or straight. The shell of primitive cephalopods is a straight cone (Orthoceras) divided regularly by transverse septa, which are pierced by the siphuncle. All the resulting chambers are empty, representing cut-off space as the shell became too small for the growing animal, which finally occupied only the large outer or living chamber. When the chambers are all filled with hardened mud and the shell is broken away, the edges of the septa are seen, forming the suture. In Nautiloidea this suture is generally simple, but in Ammonoidea it is often much fluted so as to produce a complicated pattern. The siphuncle of nautiloids is generally at or near the center, while that of the ammonoids is external. Curved forms (Cyrtoceras), loose-coiled (Gyroceras), and close-coiled (Nautilus and Ammonites) shells are progressively developed. Old age individuals, or phylogerontic groups, generally lose the power of coiling in the last whorl, which may be loose-coiled or even straight.

Baculites, one of the last survivors of the ammonoids, was straight except for the very earliest portion, which was coiled. The ammonoids are all extinct, ending with the Cretacic. Nautil- 
oids are represented by the living Nautilus. These two groups are classed as Tetrabranchiata. The Dibranchiata are represented by the living Argonauta, the Octopus, Squid, Cuttlefish, and Spirula. The last is an internal loose-coiled shell with septa and siphuncle. A straight-coiled ancestor, the Jurassic and Cretacic Belemnites, had its shell, which was straight, protected by a heavy calcareous outer guard, often cigar-shaped, and when perfect showing the hollow at one end occupied by the shell. A modified portion of the guard alone remains in the cuttlefish, the so-called cuttlefish bone, which is embedded in the fleshy mantle of the animal.

The Pteropoda have thin transparent shells of various shapes, but rarely coiled. The "foot" of the animal is divided into two winglike appendages by which these "Butterflies of the sea" keep themselves afloat on the water. The shell of the Conulariida and Hyolithidce was coarser and generally rectangular in section in the former and variously shaped in the latter. The Scaphopoda (Dentalium, etc.) have conical, often curved, shells, open at both ends, which begin as a saddle-shaped structure growing into a ring and increasing in length. In the Polyplacophora (Chiton, etc.) the shell is composed of several pieces arranged serially.

Pelecypoda are rare in the Cambric but become abundant in the succeeding horizons. There are about 10,000 fossil species and about 5,000 recent ones. The Gastropoda are likewise sparsely represented in the Cambric. They appear to be at their acme of development at the present time, there being some 15,000 living species, as compared with about half that number or less of fossil ones. Only one cephalopod is known from the Cambric. They abound in the Ordovicic, at the end of which period many races died out, while new ones arose. The Ammonoidea begin in the Devonic, reach their acme in the Jurassic and die out in the Cretacic. The Nautiloidea and Dibranchiata (the latter appearing first in the Trias) have modern representatives.

Phylum VI-Platyhelmintha, nnd VII-Vermes. - The platyhelminths, or flat-worms, are soft-bodied, worm-like animals without body cavity or coelom. They have no hard parts, and nothing is known of their geological history. The great mass of animals classed together as Vermes is in reality a heterogeneous assemblage, many of the groups having no direct relationship with others placed here. Typical worms (chætopods) have a distinct body cavity from which the enteric and digestive tracts are separated. The body is divided into many similar segments, each of which, except the oral one, carries on each side two bundles of bristles or setæ, a dorsal 
and a ventral one, placed typically on elevations or parapodia. The head segment carries appendages varying in the different subclasses. Aquatic worms possess gills for breathing, but these become more or less modified or even entirely lost in the mud- and earth-worms. The alimentary system consists of an anterior mouth, an intestinal canal, divisible into fore-gut, mid-gut and hind-gut, and ending in the posterior anus. In some parasitic forms, this system is much degenerated. In some chatopods a series of horny œsophageal teeth is developed, and these are often preserved in great perfection. The conodonts may be of this orcler.

Many worms build tubes of agglutinated sand, either free, or in the sand, while others secrete calcareous tubes. These are often well preserved and show the presence of these organisms in Cambric times. Trails left by errant worms on mud and the peculiar form of the string of sand. which has passed through the annelid body, all serve as evidence of the existence of the worms in former periods.

Phylum VIII-Arthropoda. The arthropods, or jointedlegged invertebrates, comprise a number of distinct assemblages of organisms, as indicated by the several classes included. The crustaceans are in many respects the most characteristic, but even they comprise a number of subclasses of very diverse characters. The Myriopoda and Peripatus are worm-like. The former occur first in the Old Red Sandstone (Devonic) and are common in the Carbonic. The oldest, and in some respects the most generalized, of the Crustacea are the Trilobites, which are already highly developed and very numerous in the Cambric. They do not extend beyond the Palrozoic. The organism is covered by a chitinous exoskeleton in which a head or cephalon, a thorax and an abdomen or pygidium are distinguishable. Each division consists of a median axis and lateral lobes and hence shows a trilobate division. The axis of the head constitutes the glabella and the lateral portions are commonly divided into fixed and free cheeks, the latter generally carrying the compound eyes. The thorax is divided into a number of movable rings, but the pygidium is a single though grooved piece. The mouth is ventral and the head is provided with antenne. Jointed thoracic legs were also present. The Entomostraca are modified crustaceans with a shell-like carapace. They are represented in all geological horizons. The Ostracoda, with a bivalve shell, were especially abundant in the Palrozoic. The barnacles also had representatives in the Palæozoic but are more typical in later horizons. The animal is degenerate, attached either directly or by a fleshy stalk. In the former case a circle of shell-plates is 
developed, forming the corona. The Phyllocarida were of great importance in the Palrozoic. They generally had head and thorax enclosed in a carapace consisting mainly of two valves, with accessory pieces. The ringed abdomen and the tailpiece or telson (often triple) projected beyond the carapace.

The Decapoda have head and thorax united into a cephalothorax, and covered by a single carapace, or with one segment free. Each of the thirteen cephalothoracic segments has a pair of jointed appendages, some of which are modified into antennæ or mouth-parts. The abdomen consists of seven segments, the terminal one being a telson. In the Macrura (lobsters, crayfish, etc.) these segments are all visible, but in the Brachiura (crabs) they are generally turned under the carapace. Locomotor appendages (pereiopoda) are in five pairs, and with few exceptions each consists of seven joints. Some of the final joints are claw-like, others paddle-like, and others again merely pointed for walking purposes. Six pairs of abdominal legs occur. The claws are often found fossilized separately. Decapods first appear in the Triassic. The remaining orders show various modifications of the decapod type. They are mostly rare as fossils.

Among the Acerata the Merostomata are in many respects of greatest interest. Some Euryptcrida in the Devonic reached a length of six feet, but were smaller in other horizons. The Limulava are known only from the Middle Cambric. They combined trilobite with eurypterid characters. The eurypterids had a short cephalothorax, a ringed abdomen and a telson, the body, as in Crustacea, being covered with a chitinous exoskeleton, which was repeatedly shed. A pair of compound eyes and a pair of median simple eyes or ocelli formed the chief dorsal features of the carapace. Ventrally this bore six pairs of jointed appendages, the first preoral and chelate, the others non-chelate, the last usually forming a large paddle. The first six segments of the abdomen bore broad, leaf-like appendages, referable to "gills." The posterior segment and telson were without appendages. The number of known species is over 150 . The Synxiphosura (Cambric to Siluric, few species) had a trilobitiform abdomen, which, in the adult Xiphosura, of which Limulus, the horseshoe crab, is the only living example, was fused into a single piece, though still indicating the segments and trilobation. The fossil species ( $\mathrm{few}$ in number) have been obtained from the Upper Devonic, the Carbonic, and (genus Limulus, only) from the Mesozoic and Tertiary of Europe.

The scorpions and spiders are more complex Acerata adapted 
to a terrestrial life. The former are known from the Siluric (Upper), the latter from the Coal Measures on.

Altogether more than 300 fossil species of arachnids and several thousand modern species are known.

Insects are known from the Ordovicic graptolite slates of Sweden and from the Siluric of France. They are especially well preserved in the Carbonic and later terrestrial formations. The Palæozoic forms constitute a distinct group with if orders, all extinct. Two other orders were, however, also represented in the late Palæozoic, the cockroaches (Blattoidea) being especially well represented on account of the hard coriaceous character of the front wings or tegmina. The number of known Palreozoic insects is close to I,O00 species while the Tertiary and Quaternary have furnished over 5,800 species. There are over 384, ooo living species (Handlirsch).

Phylua IX-Echinoderumats. The echinoderms or spinyskined animals are characterized generally by an apparently radial form, by the possession of calcareous plates or sclerites in the integument, and by an elaborate internal structure, the most marked portion of which is the highly developed water-vascular system. The oldest known forms are the Cy'stoidea (Cambric to Carbonic) in which the body was enclosed in a calyx of irregular plates, closely united by sutures and generally supported on a stem. Arms were rudimentary and the respiratory and watervascular system were not pronounced. The Blastoidea (Ordovicic to Carbonic) were more regular in the arrangement of plates and were arnless. The calyx was, however, provided with five petaloid ambulacral areas radiating from the mouth. The Crinoidea (Ordovicic to Recent) were mostly stemmed, though some had the power of separation in the adult. The calyx is composed of regular plates generally arranged in five series and terminated by branching or simple arms often of great length. The mouth of many Palreozoic forms (Camerata) was under a vaulted arch or tegmen, and the anus was often placed at the end of a tube or proboscis. The brittle-stars and starfish have the body cleft into five or more movable rays, which are supplied with branches from the waterrascular system and diverticula from the other body organs. The branch begins in the Ordovicic, but has few fossil representatives. The sea-urchins or Echini, on the other hand, are abundantly represented in the Mesozoic and later strata. Palæozoic forms occur as early as the Ordovicic (Bothriocidaris). In them the body is generally covered by a large number of plates, which, however. fall into ten zones, five aimbulacral, witl plates pierced for the tubed 
feet or ambulacra, and five interambulacral. The whole forms a more or less solid corona. In the post-Palæozoic types each zone is generally composed of two columns of plates, so that there are in all 20 columns, forming 5 ambulacral and 5 interambulacral zones. The mouth and anus are generally opposite each other in the Palcechinoidea, and in the Cidaroidea and Diadematoidea. In the others the anus migrates toward the mouth. The Clypeasteroidea and Spatangoidea show an elongation of form, with a pronounced bilateral symmetry. In most of the Spatangoidea the mouth passes forward, so as to lie no longer in the median axis. In the Holothuroidea the plates of the integument are not united, the body thus being soft and changeable in form by inflation. The separate plates are found fossil as early as the Carbonic.

Phylum X-Protochorda. These are soft-bodied animals, some of them, as the Tunicates, degenerate, but showing affinities with the vertebrates, in the possession of a notochord, branchial slits, and a central nervous system. The Cephalochorda (Amphioxus) are fish-like and readily mistaken for a vertebrate, while the Enteropneusta (Balanoglossus) are worm-like. While some of these have been considered ancestral to vertebrates, it is not at all impossible that the suggestive characters are independently developed. Vertebrates arose in the Palæozoic, and no modern form is likely to preserve intact all the primitive characters of a class.

Phylum XI-Vertebrata. This, the most highly specialized phylum of the animal kingdom, has its most primitive representative in the Ostracoderma of the early Palæozoic (Cephalaspis, Pterichthys, Bothriolepis, etc.). Known definitely from the Devonic and Siluric, there are fragments indicating their existence in the Upper Ordovicic of America. They retain many characters of invertebrates and seem to unite the fish with the eurypterids, a group of Merostomes, which flourished at the same time. (See Patten-2I ; 22.) Their most striking characteristic was a welldeveloped armor, or exoskeleton of bony plates, which covered the head and anterior portion of the body. The endoskeleton was not calcified and the mouth without hard parts. Hence all we know of them is from the external plates and scales. The Devonic Arthrodira have also been regarded as an independent class, differing from fishes in that their jaw elements are merely dermal ossifications and are not articulated with the skull (Dean). The head and trunk are covered by symmetric bony plates, the head-shield is movably articulated with the body-shield. The endoskeleton is superficially calcified, and paired fins are rudimentary or absent. The Devonic Coccosteus, Dinichthys and Titanichtlys are examples. 


\section{Pisces.}

The Cyclostomata (Agnatha) represented to-day by the lampreys, appear to have had some representatives in the remarkable Palrospondylus of the Old Red Sandstone. The Conodonts have been regarded as teeth of myxinoids. The elasmobranchs, or sharks, were well represented in the Devonic and later. beds, the first three orders being wholly confined to the Palxozoic. The endoskeleton is more or less cartilaginous, the exoskeleton and teeth structurally identical (placoid scales). Generally only teeth, calcified vertebra and dermal spines are preserved. The true sharks and rays (Plagiostomi) are mostly Mesozoic and later, but examples from the Carbonic and even the Mississipic are known. The chimæras, however (Holocephali), had representatives from the Devonic on.

The ganoids are remarkable in that their trunk and tail are usually covered with scales, consisting of a thick bony inner layer, and an outer layer of enamel, the scales being in some groups articulated by a peg-and-socket arrangement, and in others overlapping. The skull is covered with dermal bones, or completely ossified. The vertebral column is cartilaginous or shows various degrees of ossification. Most of the Palrozoic ganoids belong to the order Crossopterygii or fringe-finned ganoids. Such are the Devonic genera Holoptychius and Osteolepis-and numerous Mississippic to Permic genera. Other crossopterygians occur in the Mesozoic, and two genera (Polypterus and Calamoichthys) are still living in the rivers of tropical Africa. The cartilaginous ganoids (Chondrostei) range from the Mesozoic to the present time, a number of genera being still extant, such as the sturgeons and paddle-fish.

A considerable number of Palæozoic forms also belong to the Heterocerci, an order ranging from the Devonic (Cheirolepis) to the Upper Jurassic (Coccolepis of the Lithographic beds). Many Carbonic and Permic species (including Palæoniscus, Platysomus, etc., the common forms of the Kupferschiefer of Thuringia, etc.), belong to this order, as well as the Triassic Catopterus of North America. The Lepidostei include the "bony pikes" (Lepidosteus) of the North American rivers, and many Cenozoic and Mesozoic genera, but only one genus (Acentrophorus) has Permic representatives. Here belong the widely distributed Triassic Semionotus and the many common Jurassic genera (Dapedius. Lepidotus. Eugnathus, Caturus, etc.), the order being at its height at that time. The Amioidei also have a surviving genus (Amia) in the rivers of 
the southern United States and Central America, while other members extend as far back as the Lias.

The Dipnoi, or Lung-Fishes, range from the Devonic to the present time. Their skeleton is chiefly cartilaginous, but the upper and lower vertebral arches, the ribs and fin-supports exhibit a tendency toward ossification. They have paddle-shaped, paired fins and a highly specialized air-bladder which serves as a lung. Dental plates are common in the Devonic (Dipterus) and Carbonic (Ctenodus), while many perfect specimens also occur in these deposits.

These fish may be considered as approaching Amphibians in many respects. The Teleosts, or bony fishes, appear first in the Triassic deposits, and increase in prominence until they are the leading type to-day.

\section{Amphibia.}

The Amphibia are cold-blooded terrestrial vertebrates, with partly branchial respiration, in early stages, while in some forms gills remain functional throughout life. The limbs are never fins and are rarely absent. The Stegocephalia (Carbonic to Upper Trias) comprise the largest known Amphibians, and were protected by a dermal armor of bony scales or scutes. The teeth were sharply conical, with a large pulp-cavity, and the walls were sometimes highly complicated by infolding of the dentine (Labyrinthodonts). The Gymnophiona or coecilians are vermiform amphibia, covered with scales and without limbs. They are restricted to the South American and Indo-African tropics. The Urodeles are naked bodied, usually with two pairs of short limbs and persistent tail. Gills often remain throughout life. The vertebra are usually completely ossified. This group appears first in the Upper Jurassic (Wealden), and has living representatives in the newts and salamanders. The Anura (frogs, toads) are tailless and develop by metamorphosis. The oldest fossil forms are from the Eocenic.

\section{Reptilia.}

Reptilia are cold-blooded, naked, scaly or armored vertebrates of terrestrial or aquatic habit, and breathing exclusively by lungs. There is no metamorphosis during development. The Rhynchocephalia date from the Permic, but were most extensively represented in the Trias. A single living genus (Hatteria or Sphenodon) occurs in New Zealand. The body was lizard-like, long- 
tailed and sometimes scaly. The Squamata comprise the lizards and snakes and two extinct groups of aquatic reptiles from the Cretacic (Mosasaurus, etc.). The lizards (Lacertilia) have I,925 living species but few fossil ones are known, the oldest being from the late Jurassic. Of the snakes (Ophidia) nearly $\mathrm{I}, 800$ recent species but only about 35 fossil ones are known, chiefly from the Tertiary, though some Cretacic forms are probably referable to snakes. The Ichthyosauria are entirely extinct reptiles which inhabited the Triassic, Jurassic, and Cretacic seas. Their body was in general whale- or fish-like and the jaws were furnished with numerous conical teeth.

The Sauropterygia, also restricted to the Mesozoic, were mostly marine, lizard-like reptiles, with long necks and well-developed limbs, with five normal digits (Nothosaurid(c Triassic) or paddleshaped, the digits elongated by supernumerary phalanges (Plesiosaurida, Trias to Cretacic). The Theromorpha were primitive land reptiles with many mammalian characters and often of grotesque forms and proportions (Pareiasaurus, Dicynodon, etc.). They lived in the Permic and t'ue Triassic of North Anerica, Europe, and South Africa.

The Chelonians or turtles are characterized by the possession of a more or less complete bony shell. partly composed of modified neural spines of the dorsal vertebræ and partly of dermal ossifications more or less intimately united with the former. The limbs, tail, and generally the neck and head can be withdrawn into this shell. In general a dorsal shield, or carapace, and a ventral one, or plastron, composes this shell and both are, as a rule, superficially covered by a horny or leathery epidermal layer divided by grooves or sutures into a few large scutes or shields. Their arrangement is independent of the underlying osseous plates. Turtles first appeared in the Upper Triassic (Keuper) of Europe.

The Crocodilia are lizard-like reptiles with the highest internal organization of the class. Their skeletal structure differs widely from that of lizards, and their respiratory organs resemble those of birds. The entire body is covered with horny scales. The most primitive groups (Parasuchia), resembling the Rhynchocephalia, occur in the Trias of America (Belodon or Phytosaurus, and Episcoposaurus); of Scotland (Stagonolepis): and the Gondwana formation of India (Parasuchus). There are also more specializerl Triassic forms, such as the little Aëtosaurus (of which 24 complete individuals occur on a single block of Stuben-sandstone [Upper Keuper] in the Stuttgart Museum), and others from the Trias of Elgin, Scotland. 
Typical marine Crocodiles occur in the Jurassic and Comanchic (Mesosuchia), while in the Cretacic-Tertiary and modern times these crocodiles (Eusuchia) again lived chiefly in fresh water and on the lancl. They include both long-snouted (longirostral) and broad-snouted (brevirostral) forms, the latter comprising the alligators.

The Dinosauria were long-necked and long-tailed reptiles with limbs adapted for support of the body. The earliest species were Triassic, the latest Cretacic. A bony exoskeleton was developed in some forms, consisting of isolated bony plates or spines, or of interlocking scutes forming a continuous shield. Most dinosaurs, however, were naked or covered by scales. The skull of most forms was extremely small in proportion to the body, while the legs in many cases were exceedingly massive.

The Pterosauria, or winged lizards, ranged from the Trias to the Cretacic, and their whole organization was adapted to an aërial existence. They ranged from the size of a sparrow to forms which had a spread of wing of nearly six meters. The skull was bird-like and generally fitted with sharp, conical teeth, mostly long and sharply pointed in front (Pteranodon, Nyctodactylus, Ramphorhynchus), but sometimes blunt (Dimorphoden). The neck and tail were generally long. The fifth digit of the hand consisted of four enormously elongated phalanges, which were turned backward to support the wing membrane. Three families are known: Rhamphorhynchide (Jurassic), Pterodactylide (Upper Jurassic and Cretacic), and Ornithocheirida (Pteranodon, etc.) Cretacic.

Aves.

The birds form a homogeneous and circumscribed class derived from the reptiles and partaking of their character in the Jurassic and Cretacic, where teeth and a vertebrated tail still existed. The exoskeleton consists of feathers, horny coverings for the beak, claws, etc. The endoskeleton is compact but light, the bones being permeated by air-cavities with thin but dense-textured walls, rich in calcium phosphate. The vertebre have peculiar saddle-shaped articulations which allow great freedom of movement. The bones of the forearm are modified into wings. The oldest bird, Archæopteryx of the Jurassic, had its jaws provided with conical teeth like those of reptiles, and its vertebral column had about 20 caudal vertebræ. The Odontolcæ (with Hesperornis) and Odontorme (with Ichthyornis) also had toothed jaws, but other birds were free from 
them. The Struthiones, or ostriches, rheas, cassowaries and emus are all large, flightless birds with small wings, a keelless sternum, and well-developed walking legs. They also include the extinct Epyornis and the equally extinct moas (Dinomithida), without or with extremely rudimentary wings and pectoral arch and with massive legs. The Struthiones appear first in the Tertiary. The New Zealand Apteryx, a small flightless bird, represents the order Apteryges and the living tinamous the order Crypturi. Both have only fragmentary fossil representatives. The super-order Euormithes, with 13 orders, includes most of the existing birds. A few representatives (cormorants, etc.) occur in the Cretacic, but the great majority of types are not known before the Eocenic and many not until later.

\section{Mammalia.}

The manmals are warm-blooded animals with the body typically covered by hair, and in nearly all cases they bring forth their young alive, the monotremes alone laying eggs. All, however, suckle their young. The marsupials (opossum, kangaroo, etc.) bear their young in an inmature state, and these are then placed in a pouch or marsupium. The placental mammals bear perfect young. The Insectivora go back to the Eocenic; they comprise the moles, shrews, hedgehogs, etc. The Chiroptera, or bats, also go back to the Eocenic. The Dermoptera are characterized by a cutaneous expansion, extending from the wrists to the ankles and forming a parachute. They are generally called flying lemurs and are unknown in a fossil form. The Edentata, chiefly restricted to South America, are nearly or quite toothless and include the living anteaters and sloths, the armadillos, with jointed armor, and the extinct Glyptodon with solid armor. Here also belong the giant sloths, the Megatherium, the Mylodon, and Grypotherium-all of them but recently extinct.

The Rodentia comprise the gnawing types with long, sharp curved incisors. They go back to the Eocenic. The Tillodontia are extinct forms from the North American Eocenic. They are related to the rodents. The Carnizora, or flesh-eaters, comprise a large number of living and extinct types, such as the Creodontia, of the Tertiary; the Fissipedia, including Canide (dogs). Ursida (bears), Viverrida, Mustelida (otters, etc.), Hyicnidc (Hyanas) and Felide (cats, tigers, lions, panthers, ctc.): and the Pinnipedia, or marine carnivores, such as seals, sealions, etc. Many of these have representatives in the Tertiary. The Cetacea, or whales, dol- 
phins, etc., are áquatic (mostly marine) mammals, and occur as far back as the Miocenic. Squalodon and Zeuglodon are fossil representatives. The Sirenia are herbivorous aquatic mammals represented by the living manatee and dugongs, and the recently extinct sea-cow (Rhytina), etc. The Ungulates, or hoofed mammals, comprise: (I) the Eocenic Amblypoda (Coryphodon, Tinoceras, etc.), large, heavy creatures; (2) the Proboscidea, or elephants (Dinotherium, Mastodon, Stegodon, Elephas, etc.); (3) the Condilarthra (Phenacodus) ; $(4)$ the Perissodactyla, or unevenly-toed ungulates (Tapir, Rhinoceros, Titanothere, and the horse family); (5) the Artiodactyla, or even-toed ungulates, divided into the Bunodontia (pigs, hippopotamus, Anthracotherium, etc.) ; and Selenodontia, (Oreodon [Tertiary], camels, deer, etc.; giraffes, antelopes, goats, sheep, cattle, etc.); (6) Toxodontia-Tertiary forms, including Toxodon, Typotherium, etc.

The final order of the mammals is that of the primates, which includes Quadrumana (apes, monkeys, etc.), and the Bimana, or man.

\section{BIBLIOGRAPHY XXIV.}

(Text-books of Palæontology, etc.)

I. BERNARD, FELIX. I895. Eléments de Paléontologie. Baillière et Fils, Paris.

2. GRABAU, A. W., and SHIMER, H. W. 1909-1910. North American Index Fossils. 2 vols. A. G. Seiler and Company, New York.

3. GÜRICH, GEORG. 1908-09. Leitfossilien. 2 parts. Gebrüder Borntraeger, Berlin.

4. KOKEN, ERNEST. I896. Die Leitfossilien. Hermann Tauchnitz, Leipzig.

5. NICHOLSON, ALLEYNE, and LYDEKKER, RICHARD. I889. A Manual of Palæontology. 2 vols. W. Blackwood and Sons, Edinburgh and London.

6. OSBORN, HENRY F. 1910. The Age of Mammals. Macmillan Company, New York.

7. STEINMANN, GUSTAV. 1903. Einführung in die Palæontologie. Wilhelm Engelmann, Leipzig. 2nd edition, 1907.

8. STROMER, ERNST. I909, I9I2. Lehtbuch der Palæozoologie. 2 parts.

9. ZITTEL, KARL A. VON. 188I-85. Handbuch der Palæontologie. French translation, Traité de Paléontologie, by Charles Barrois, Paris.

Io. ZITTEL, K. A. VON. I 895. Grundzüge der Palæontologic. 2nd Edition, 1910-11. 2 vols. Munich.

I I. ZITTEL, K. A., VON. 1900. Text-book of Palæontology. Translated by Charles R. Eastman with collaboration by many spccialists. 2 vols. Macmillan Company, New York.

\section{(Classification, etc.)}

12. ALLEN, J. A. 1906. The "Elimination" and "First Species" Methods of Fixing the Types of Gcnera. Science, N. S., Vol. XXIV, pp. 773-779. 
13. AMERICAN ASSOCIATION FOR THE ADVANCEMEN'T OF SCIENCE. 1877. Report of the Committee on Zoölogical Nomenclature. Nashville Meeting.

14. BRITISH ASSOCIATION FOR THE ADVANCEMENT OF SCIENCE. 1842. Report of the Manchester Meeting.

15. BRITISH ASSOCIATION FOR THE ADVANCEMENT OF SCIENCE. 1865. Report of the Birmingham Meeting.

16. BUCKMAN, S. S. I909. Yorkshire Type Ammonites, Part I.

17. ENCYCLOPAEDIA BRITANNICA. Eleventh edition. Articles on Zoölogy and various Phyla, Classes and Orders. Also Palieontology and Palæobotany.

I8. MILLER, S. A. 1889. North American Geology and Palieontology.

19. OSBORN, HENRY F. 1912. First Use of the Word "Genotype." Science, N. S., Vol. XXXV, No. 896, pp. 340-34I.

20. PALAONTOLOGIA UNIVERSALIS. 1904. Edited by D. P. Ochlers.

21. PATTEN, W. 1912. The Evolution of the Vertebrates and Their Kin. P. Blakiston \& Co., Philadelphia.

22. PATTEN, W. I9I3. A Problem in Evolution. Popular Science Monthly, Vol. LXXXII, pp. 417-435.

23. SCHUCHERT, CHARLES. On Type Specimens in Natural History. Catalogue, etc., of Fossils, Minerals, etc., in U. S. National Mluseum, Pt. I, pp. 7-I 8, with bibliography of literature on type ternts.

24. SCHUCHERT, CHARLES, and BUCKMANN, S. S. I905. The Nomenclature of Types in Natural History. Science, N. S., Vol. XXI, pp. 899-901.

25. SCUDDER, SAMUEL. 1882. Nomenclator Zoologicus. Bulletin of the United States National Museum, No. 19.

26. STONE, WITMER. 1906. The Relative Merits of the "Elimination" and "First Species" Method in Fixing the Types of Genera, with special reference to Ornithology. Science, N. S., Vol. XXIV, pp. 560-565. 
CHAPTER XXV.

\section{BIOGENETIC RELATIONS OF PLANTS AND ANIMALS.*}

The Conception of Species.

A species is commonly held to comprise a group of individuals which differ from one another only in a minor degree. The degree of individual difference admissible within the species is commonly a matter of personal opinion and probably no two systematists always agree as to the precise taxonomic value of a character in different cases. In pre-modern days the idea of permanence and immutability of the species, or, in pre-Linnæan days, of the genus, dominated the minds of naturalists generally, though there were not wanting, at nearly all times, observers to whom the fixity of specific characters appeared as a dogma unsupported by facts. That variation existed within the specific limits was admitted, but the believers in the special creation and immutability of species would not admit that this variation could exceed certain limits, though what these limits were was a matter of diverse and, moreover, of constantly changing opinion. No matter how different the end members of a perfectly graded series of individuals were, if that gradation was established all those members were placed within. the limits of the species. Even if some of the members of the series were originally described as distinct species or placed in distinct genera the discovery of intermediate forms, or "connecting links," caused them all to be referred to one species. The differences originally deemed amply sufficient for specific or even generic distinction at once dwindled in taxonomic value to the rank of varietal characters of a very variable species. A classic case in point is that of the Tertiary species of Paludina (Vivipara) from Slavonia. (Neumayr and Paul-29). (Fig. 252.) In the lowest nembers of the Paludina beds P. neumayri (Fig. a), a smooth,

* The principles here outlined will be more fully discussed in "The Principles of Palæontology" by Henry F. Osborn and Amadeus W. Grabau, to be published shortly. 
round-whorled species, is the characteristic form, while the highest beds are characterized by $P$. hoernesi (Fig. $k$ ), an angular-whorled, strongly bicarinate type, which had been separated under the distinct generic name of Tulotoma. Certainly these end-forms are widely separated, yet from the intermediate beds individuals constituting a complete gradational series from one to the other have been obtained. This discovery led many to reconsider the classification of these forms and to group them all as varieties under one species.

The belief in the mutability of species was gradually accepted
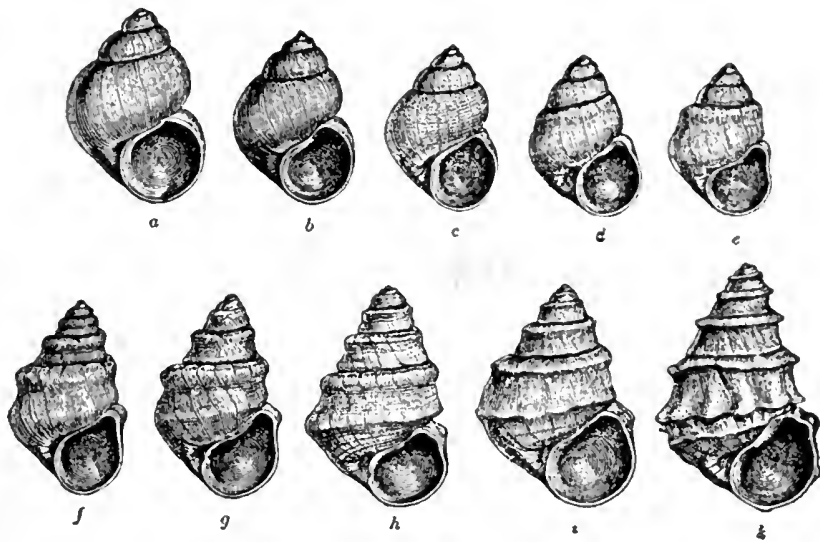

FIG. 252. Series of Paludinas (Vivipara) from the Lower Pliocenic deposits of Slavonia. (After Neumayr.) a. Paludina nemmayri, $k . P$. (Tulotoma) hocmesi from the highest beds. $b-i$, intermediate forms, showing gradation, from the intermediate beds.

by naturalists after the publication of "The Origin of Species" in 1859. To-day there is scarcely a naturalist of prominence who does not unhesitatingly affirm his belief in the mutability of species. Nevertheless, we may ask, with Farlow: " . . . is our belief in evolution merely dogmatic, like some of the theological doctrines which we believe thoroughly but which we to not allow to interfere with our daily life, or, . . . has our belief modified the manner in which we treat what we call species?" (IO) When we note how unwilling systematists are to-day to recognize more than one species in a series whose end forms differ widely, when a sufficient number of members are known to bridge over all the more striking gaps, we are forcibly impressed with the fact that, unconsciously though it may be, the majority of systematists are still 
influenced by the old inherited ideas of the fixity of specific limits. Palæontologists are, as a rule, no freer from the shackles of inherited ideas than are the workers in the morphology and taxonomy of living plants and animals. This may in large measure be accounted for by the fact that the very recognition of such a thing as a species carries with it the impression of an entity, and the recognition of certain characters as belonging to a species, in a measure carries with it the conception that, if those characters are modified or supplanted by others, the organism in question no longer belongs to that species.

That the Linnean species is a fragment or group of fragments of one or more evolutional series separated from other fragments. in space or time, by the extermination of the connecting links, is pretty generally recognized by naturalists of a philosophical turn of mind. Among such the belief in the nonexistence of species is, theoretically at least, widely held. In other words, naturalists have come to the conclusion that what we call species are merely "snapshots at the procession of nature as it passes along before us, and that the views we get represent but a temporary phase, and in a short time will no longer be a faithful picture of what really lies before us." "For the procession is moving constantly onward." (Farlow-Io.)

\section{The Mutation of Waagen.}

Waagen in 1868 (44) recognized two kinds of variation within the species-geographic and chronologic. To the former, which comprises the variable members appearing together in the same time period, though they may be geographically separated, he restricted the term variation or variety, while for those occurring in chronological succession he proposed the term "mutation." A mutation may then be defined as a slightly modified form of the species appearing in a later time-period, and in this sense it has been commonly used by palæontologists. As an example of a number of mutations appearing in successively higher horizons, the Tertiary series of Paludinas (Vivipara), already referred to, may be cited.

Palæontologists, whose business it is to study large series of forms from each successive horizon, have since recognized that what Waagen called varieties, in the belief that they had no very definite relationship to each other, are really secondary mutations or sub-mutations (Grabau-17). Thus each developing series has, on reaching a higher horizon, become modified in a certain definite 
way and within this horizon the derivatives of this species will tecome modified in certain definite directions.

As an illustration may be chosen the Linnæan species of brachiopod Spirifer mucronatus of the Middle Devonic of eastern North America (Fig. 253). This is represented by at least five distinct mutations in successive horizons, or in distinct basins. Each of these five mutations differs from the others in certain more or less constant characters, which, however, are the result of definite modifications of the preceding more primitive types, chiefly by the appearance of new characters.* Thus these mutations are readily
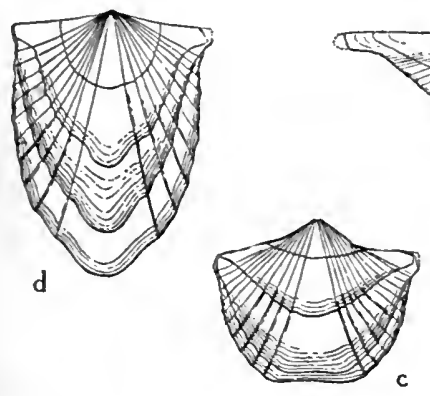
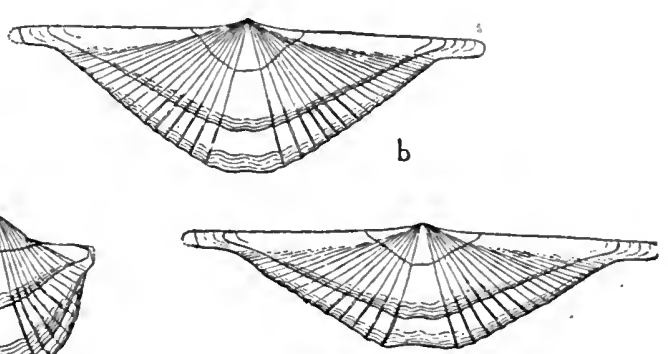

a

FIG. 253. Spirifer mucronatus, a. primitive mutation-b.-d. mutation thedfordense. $b$. Long-winged retarded submutation, shell index I.7. $c$. The most accelerated submutation (shell index 0.73). $d$. The same drawn with curvature eliminated so as to show full length. The more transverse character (higher shell index) of the younger stages is shown in each.

recognizable and separable from one another with comparative ease. Within each mutation, however, there is a long series of variants, which are modified by a progressive change in the relative proportion of width and height-a modification or change of quantitative rather than qualitative character-a type of change to which Osborn has applied the term allometric, while the resulting characters are allometrons. The change in proportion in each of these successive mutations is from broad-winged to short-winged types, or allometrons. Expressed in shell indices, derived by dividing the entire width along the hinge-line by the height measured on the curvature, the change is from a high shell index to a lower one. In each mutation the change is in the same direction, and in each a dominant type can be designated which, as a sub-mutation, represents, for the mutation to which it belongs, that index to which the

\footnotetext{
* Termed, by Osborn, Rectigradations. (Sec beyond.)
} 
majority of individuals of that fauna approximate. The dominant sub-mutation of a higher mutation will be found to have a smaller index than the dominant sub-mutation of a lower mutation. In the same way, the most primitive sub-mutation of the higher mutation, $i$. $c$., the one with the largest shell index, has a smaller index than the most prinitive sub-nutation of the lower mutation. In like manner the most specialized sub-mutation of the higher (geologic) mutation will have a smaller index than the most specialized sub-mutation of the lower mutation. In other words, not only has the dominant sub-mutation of the higher mutation advanced beyond

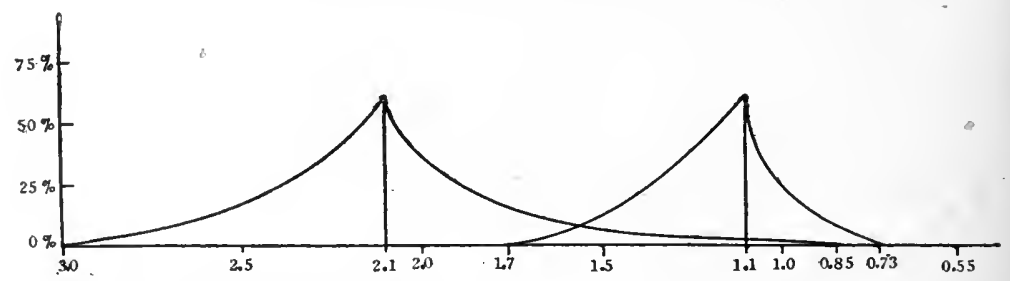

FIG. 254. Curves representing the range in shell index of two mutations of Spirifer mucronatus.

that of the lower mutation in the same dircction of modification of proportions, but also the most primitive and the most specialized sub-mutation and all the intermediate sub-mutations of the later mutations are ahead of the earlier one. This may be expressed in the accompanying diagram (Fig. 254), where the height of the curve represents the percentage of individuals and the base the decline in shell index from 3.0 to 0.5 .

\section{Mutation Tileory of De Vries.}

In I901 Professor Hugo De Vries published his epoch-making book "Die Mutations-theorie" (6) in which he recognized that the Linnæan "species" was in reality a compound of innumerable groups of more restricted relationship. These minor groups, which have generally been classed together as a "species," are really entities composed of very definite associations of minute characters, and to them the name clementary spccies applies. Of these elementary species there may be very many in a Linnzean species. These elementary species De Vries thinks arose suddenly by a new combination of the elements of which the characters of organisms are made up. These elements (Einheiten) are sharply separated 
from one another and the resulting combinations or elementary species are likewise distinct and definite and without transitional connecting forms. They are constant and transmit their characters truly. The sudden appearance of these new forms is a process which De Vries calls "mutation," thus using Waagen's term for a process instead of a result, as originally proposed. The "elementary species" as defined by De Vries is, in a measure, identical with the mutation of Waagen, in that the variation is a slight and definite one; but in so far as De V ries believes in the stability and immutability of the elementary species, they do not correspond to the mutation and sub-mutation (allometrons) as used by most palxontologists. to-day.

\section{Orthogenesis and the Concept of Speches.}

The doctrine of definite directed variation, or Orthogenesis, which finds many adherents, especially among palæontologists, has led to a very logical conception of the method by which species become differentiated. Though independently formulated with more or less precision by many naturalists this doctrine was most consistently and vigorously championed by the late Professor Theodor Eimer of Tübingen. Eimer's illustrations were chiefly drawn from the color patterns of recent animals, especially lizards and butterflies (9). He found that the color patterns of organisms may be reduced to four types, which always appear in the individual development in a definite succession, viz.: (I) Longitudinal stages, (2) spots, (3) cross stripes, and (4) uniform coloration. Each succeeding type is developed out of the preceding one and replaces it to a greater or less extent. When in a large number of individuals all developing in the same direction (orthogenetically) a complete cessation of development occurs in different groups at individual stages, the individuals thereafter only increasing in size, but not changing, a large number of distinct species will originate which differ from one another to the extent by which one group continued to develop beyond the other. If a number of characters develop, each in a given direction, and at a given rate in a large group of individuals, all starting from the same point, cessation of development of different characters at different times will soon result in the formation of a great number of species varying in one or more characters.

We may assume, by way of illustration, a case in which there are three structural characters, which we may designate characters (a), (b), and (c), in a given group of individuals, each changing 
in a definite order and at a uniform rate. A certain percentage of these individuals may, after a while, cease to develop character (a) while characters (b) and (c) continue to develop. Later in some of these, character (b) may cease to develop further and (c) continue alone, while in others (c) ceases to develop and (b) continues. In another portion of the original group character (b) may cease to develop first and (a) and (c) continue, after which character (a) may stop in some and (c) in others-the other character continuing. The combinations possible by this method will be readily recognized and the number of different types-mutations, varieties, or species, according to the rank to which they are admitted-will be readily seen. The possibilities of differentiation will be further recognized when it is considered that the length of time during which each character develops may also vary greatly. Complete cessation of development of characters has been termed genepistasis by Eimer, and the differential cessation heterepistasis.

\section{Acceleration and Retardation in Develophent (Tachygene- Sis and Bradygenesis).}

Another principle which is of great importance in this connection, and which was first clearly recognized by Hyatt and by Cope, is acceleration or tachygenesis.* Instead of a uniform rate of development some organisms may develop more rapidly and so are able to reach a higher stage in development. Differential acceleration may obtain between the different characters. Again, retardation (bradygenesis *), first recognized by Cope, may progressively diminish the rate of development, so that certain individuals in some or all of their characters may fall more and more behind the normal rate of progress.

Illustrations of Orthogenetic Devclopment:- Some of the most satisfactory series, showing development in definite directions, have been brought to light by the labors of paleontologists. Such series are especially well known among the ammonoids, a class of cephalopodous Mollusca which began its existence in the Devonic, culninated in the Jura; and had its last representatives in late Cretacic time.

Some of the earliest studies of the developmental changes of this group were carried on by Alcide d'Orbigny (8), who recognized a distinct succession in the form and ornamentation of the shell

* From $\tau a \chi u ́ s=$ fast and $\beta \rho a \delta \dot{u}^{\prime}=$ slow, $\gamma \epsilon \nu \epsilon \sigma i s=$ birth. The term bradygenesis was used by Grabau in I9IO (I6) as a complement of the term tachygenesis. 
from rounded and smooth in youth; through ribbed, and tubercled, with angular and, later, keeled whorls; to old age, which was marked by a complete loss of all ornamentation. The late Professor Alpheus Hyatt was, however, the first to recognize the significance of these changes and to point out that they recapitulated the adult characteristics of successive ancestors. The number of recognizable characters of which the development may be studied is exceptionally large in the Ammonite shell. Thus there is the degree of coiling or involution, which varies from the condition in which the whorls do not even touch each other through whorls in contact and whorls impressed on each other to complete involution, in which the last whorl covers all the preceding ones. Then there is the form of the cross-section of the shell and the character of the outer or ventral surface of the shell, which varies from rounded through angulated to various degrces of channeled and keeled. Again the surface ornamentation varies from smooth to ribbed, noded, or even spinous, and, finally, and in many respects most significantly, there is the progressive change in the complexity of the septal sutures, from simple in the young to often highly complex in the adult. In addition to these, the form and position of the siphuncle often show a definite variation, which may be of considerable importance. To give a concrete cxample of the changes in the individual development of the shell and the correlation of the various stages with the adult stages of ancestral forms, we may select a closely related series of ammonites of the family Placenticeratida, all of which are characteristic of the Cretacic formations of North America. The changes here are chiefly in the form of the cross-sections and the characters of the surface ornamentations. The most advanced form of the series is Stantonoceras pseudocostatum Johnson, a large, robust ammonite with a broad, rounded venter and rather ill-defined, coarse, rib-like elevations on the lateral surfaces of the whorls. When this form is broken down it is found that the next inner whorl has a flattened ventral band bordered by a row of faint elongated nodes on either side and a large row of tubercles on the ventro-lateral angles. At this stage the species has the characters of the adult Stantonoceras guadalupa (Roemer), which may be regarded as an immediate ancestor. A still earlier whorl shows a very narrow flattened venter, with a strong row of elongated nodes on either side of the flattening, the surface being otherwise smooth. This corresponds to more primitive species, Placenticeras intermedium Johnson, and $P$. planum Hyatt, one or the other of which was probably in the direct line of ancestry. At a still earlier stage in these shells the venter is 
hollowed and bordered by smooth ridges, while the surface is smooth-features characteristic of the adults of certain species of the genus Protengonoceras of the Lower Cretacic. In all these types the sutures show close relationship and increasing complexity with the progressive changes of the form of the shell. At a still earlier stage the venter is flattened without channel, the section of the whorl being helmet-shaped, while the earliest marked stage shows a rounded venter. The sutures of this early stage are very simple, corresponding in general to the adult suture of Devonic or Carbonic Goniatites, which the form of the shell also recalls. As
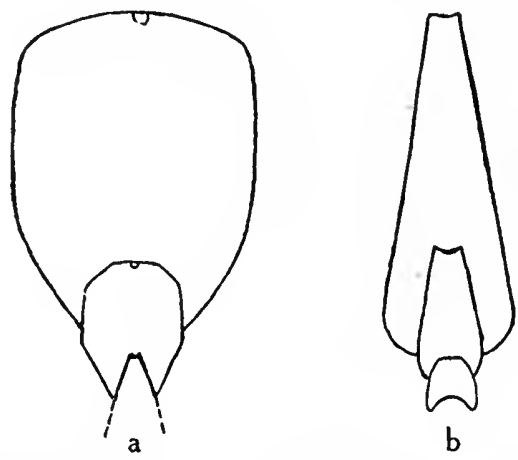

FIG. 255. a. Cross-section of the three outer whorls of Stantonoceras pseudocostatum reduced. (After Johnson.) b. Cross-section of the inner whorls of Stantonoceras guadalupa, enlarged. (After Hyatt.)

the form changes the complexity of the sutures increases until the complex adult suture is developed. The cross-sections of the various stages are shown in Fig. 255. The early "Goniatite" stages of Schloenbachia aff. chicoensis Trask, a highly developed ammonite of the Lower Cretacic of Oregon, are, according to J. P. Smith, as follows (43:52I): The first suture (immediately succeeding the protoconch) has narrow lateral lobes and saddles* and a broad ventral saddle. The second suture has a small lobe in the center of the broad ventral saddle, which is thus divided. This corresponds to the adult suture of the Devonic genus Anacestes, a simple form of "goniatite" which Hyatt considers the immediate radicle of the ammonoid stock. The third and fourth sutures show

* Lobes are the backward loops of the suture and saddles the forward loops, $i$. e., those convex toward the mouth of the shell. The ventral border is the outer border of the shell; the space between the inner margins of the whorl is the umbilicus, in which can be seen the earlier coils. 
accentuation of the lobes and saddles, and recapitulate the adult sutures of such later Devonic types as Tornoceras and Prionoceras. The fifth suture is transitional to the sixth, which is claracterized by a divided ventral lobe, one lateral lobe on each side, and another on each side of the umbilical border. Here, then, the lobe which complicated the original ventral saddle is itself divided by a second low ventral saddle. The shell at this stage has a low, broad, involute whorl, and in this and the character of the suture recalls the adult of the older species of Glyphioceras. The typical Glyphioceras condition is represented by a somewhat later suture, and still later, with the appearance of a second lateral lobe next to the umbilicus, the shell begins to resemble the late Carbonic goniatite Gastrioceras, and at a still later stage, when the diameter of the shell is $2.25 \mathrm{~mm}$., a third lateral lobe appears next to the umbilicus which subsequently widens, while the whorls become higher and narrower. In this stage it recalls the genus Paralegoceras. The next stage ushers in true ammonitic ornamentation in the form of a ventral keel $(2.7 \mathrm{~mm}$. diam.), while the suture still remains goniatite-like. But when the shell has reached a diameter of $3.2 \mathrm{~mm}$. the first lateral saddle becomes indented, a true ammonoid suture thus coming into existence. The future development is along the line of increasing complexity of suture.

A consideration of the possible mutations which may come into existence by the operation of the law of heterepistasis, or differential arrestation in development, and by the operation of the laws of differential acceleration and retardation of characteristics, will convince one that all the known types of ammonites, as well as many yet unknown types, may be accounted for in this manner. Not only all so-called species, but every individual variation will fall into its proper determinate place in the series when the method of analysis of individual characters has become sufficiently detailed.

Another example, taken from the gastropods, may serve to further illustrate the principles here discussed (Fig. 256). The modern Fulgur caricum, a large gastropod occurring on the Atlantic coast between Cape Cod and the Gulf of Mexico, begins its embryonic existence with a smooth shell drawn out anteriorly into a canal and not unlike in.form to some smooth Fasciolarian shells (Fig. $256, b, c)$. At a very early age the shell is furnished with ribs and then an angulation appears in the outer whorl. On this angulation the ribs are soon reduced to rounded tubercles. This condition recalls the adult characters of Lower Miocenic species of this genus. which never pass beyond the tubercled stage. This stage in the 
modern species is succeeded by one in which strong spines occur, caused by periodic notchings or emarginations of the shell margin along the line of the angulation. The tubercles and spines pass the one into the other by what appears to be a process of enlargement of the tubercles.

When we come to consider the series of forms which lead up from the tubercled (Tertiary) species ( $F$. fusiformis, $F$. tuberculatum) to the modern form, we find that certain intermediate characteristics have been omitted. As shown by the specimen of

b
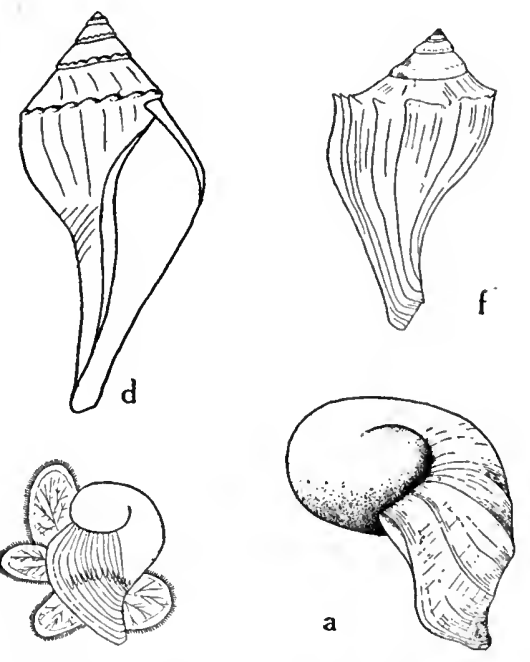
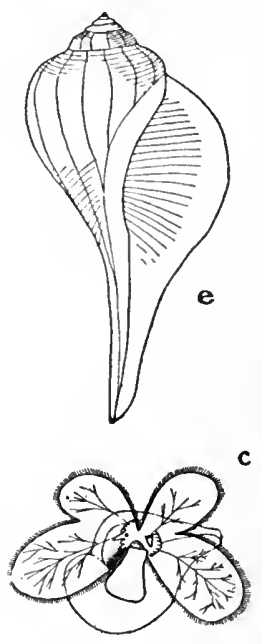

FIG. 256. Development of the gastropod shell (Fulgur and Sycotypus). a. Protoconch of Sycotypus canaliculatus. $b, c$. The same before hatching, showing smooth shell; animal with velum. (The early stages of Fulgur caricum are identical with these.) d. Fulgur fusiformis. e. F. rapum (representing $F$. maximum). $f . F$. tritonis.

F. fusiformis figured (Fig. 256, d), the last part of the last whorl has already lost the tubercles and has become smooth and rounded in outline. This is prophetic of the form next to be noted, $F$. maxi$m u m$ (Fig. 256,e). In this shell the tubercled stage is passed through quickly - a case of acceleration in development-and the smooth, rounded whorl stage makes up the greater part of the shell. Thus the normal characters of $F$. fusiformis have become condensed to a few whorls, in this manner making room for the smooth whorl which characterizes the shell. It is in certain advanced accelerated individuals of this type that the emarginate spines so characteristic 
of the modern $F$. caricum first make their appearance. In a more advanced type. F. tritonis (Fig. 256, f), the characteristic round "maximum" type of whorl has become restricted to a few earlier whorls, the adult whorl being marked by the spinous "caricum" type of whorl. Different individuals show progressive encroachment of the "caricum" type on the "maximum" type, until the latter has been completely superseded, the spines then following immediately upon the tubercles; and, in still more advanced forms, becoming telescoped with them. This is the character of the modern type, where the tubercles pass imperceptibly into the earliest spines. It is thus only by the consideration of the intermediate Tertiary

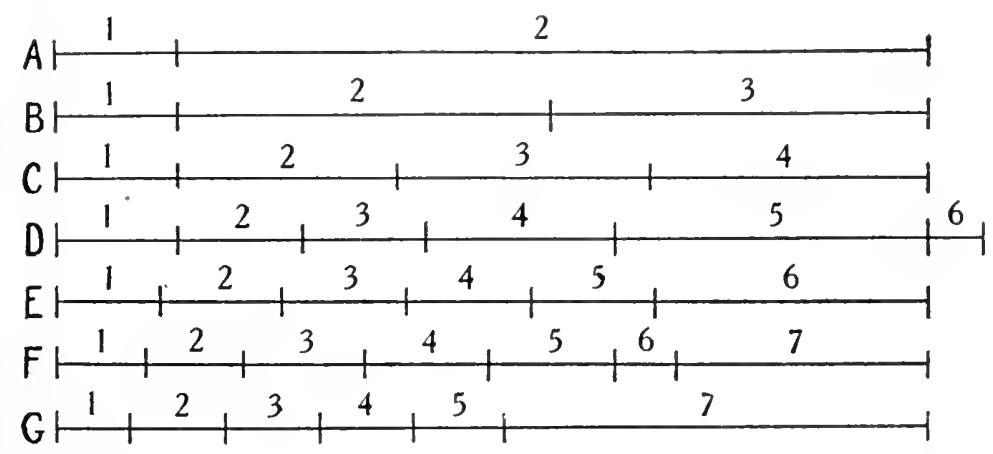

FIG. 257. Diagram illustrating the development of the Fulgur series.

Stage I is the protoconch which persists throughout.

Stage 2 is the smooth shell stage which in the primitive species A forms the adult, but in B is shortened.

Stage 3 is the ribbed stage, which is wanting in A, but in a somewhat more advanced species B is well developed in the adtult.

Stage 4 is characterized by an angular whorl, the ribs still continuing. It is the adult character of species $\mathrm{C}$, in which stages 2 and 3 are condensed.

Stage 5 is the tubercled stage characteristic of the adult of F. fusiformis.

Stage 6 is the smooth round-shelled stage found in the old age of species D and the adult of $\mathrm{E}$.

Stage 7 (F. maximum) shows the caricum spines well developed in species $F$ while in species $G$ the modern $F$. caricum, Stage 6 , has been eliminated and Stage 7 follows directly upon the tubercles (Stage 5).

types that the true history of the development of the Fulgurs is learned, the individual life history of the modern F. caricum being an abbreviated and incomplete recapitulation of the history of its race. Here acceleration has been so pronounced as actually to eliminate certain stages in the sequence of development. The pre- 
ceding diagram (Fig. 257) will stmmarize this method and also give a graphic illustration of the law of acceleration.

Origin and Dezelopment of Characters the Important Question: Rectigradations and Allomctrons. As pointed out by Osborn, the origin and development of individual characters or parts is the important subject for investigation, the species question being of minor significance. It has been shown in the preceding sections that characters develop more or less independently of each other, and also that they develop in recognizable directions, or orthogenetically. Such definitely developing characters when arising as new characters are termed by Osborn rectigradations; whereas, if they are due to a change in proportion of such characters, they are termed by him Allometrons (30:32).

\section{Nomenclature of Stages in Development.}

Ontogenetic Stages and Morphic Stages. In the preceding examples it will be noted that the stages dealt with are form stages or morphic stages only, and that they have no constant relation to the actual stages in successive ontogenetic development. Thus, one and the same morphic stage, $i . c$., stage characterized by certain morphological characters, as, for example, ribs, tubercles, or spines, etc., may be characteristic of the adult of one individual, and, of a more youthful stage, of another. In dealing with changes in form it is desirable to refer each morphic stage to the corresponding adult stage of an ancestor, and to designate it by the name of that ancestor. Thus the tubercled stage of Fulgur tritonis (Fig. $256, f$ ) is designated the $F$. fusiformis stage, since the feature in question characterizes the adult of that species. In like manner, the smooth morphic stage of $F$. tritonis is designated the maximum stage, and the spinose stage the $F$. caricum stage, from the species in which these characters belong to the adult. The development of each individual (ontogeny) comprises a series of stages which develops from birth to old age. These ontogenetic stages, or onto-stages, are similar in time-duration for related organisms and are further characterized, in a general way, by a correspondence in the proportional rate of growth in closely related types. They are, however, independent of the morphic characters, for, as already shown, a certain morphic character may appear in one individual in the adult stage and in another more accelerated individual in a more youthful stage. (Grabau-I Ia.)

Simple Organisms. Hyatt and others have given us a set of 
terms which are applicable to the ontogenetic stages of development of all non-colonial organisus, and hence deserve to be widely and generally used. The ontogenetic cycle, or cycle of individual development (Hyatt-20), is divided into the Embryonic and the Ep-embryonic periods, and each is further subdivided into ontostages and sub-stages, as follows:

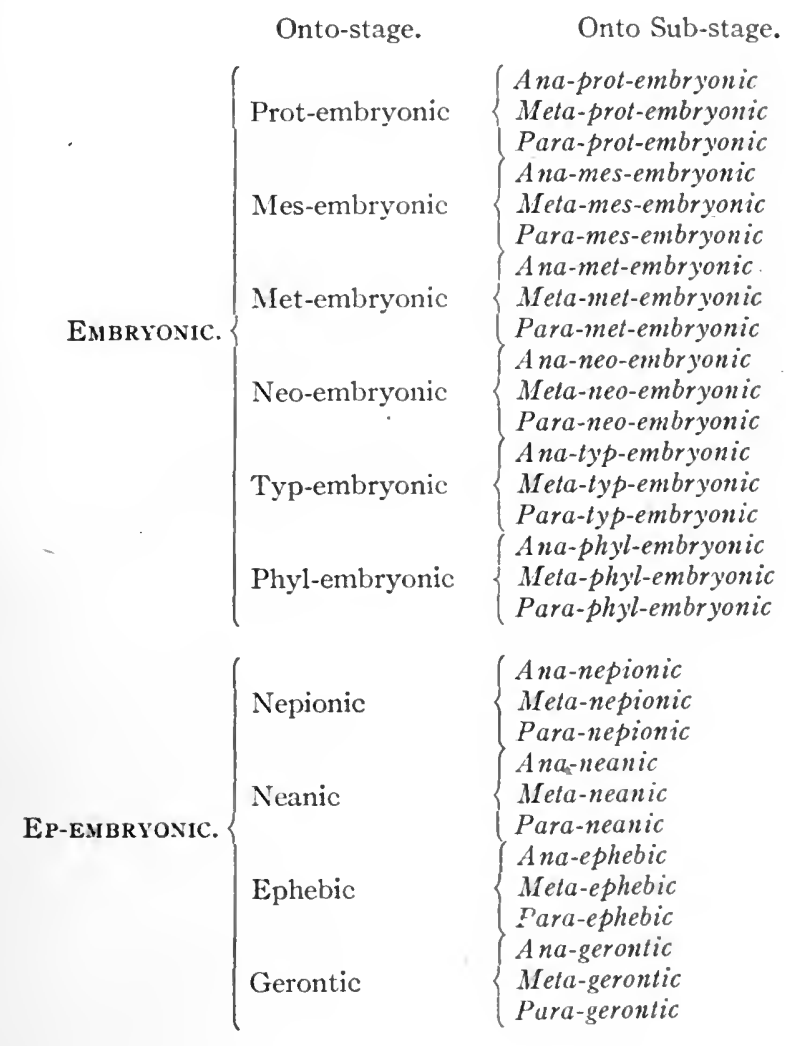

The sub-stages ana, meta, and para, or the carly. intermediate. and later sub-stages, are useful for more detailed subdivision than is possible with the stages alone. The pllyl-embryonic is the only embryonic stage with which the paleontologist has to deal. It is the first stage in which hard parts capable of preservation are generally formed. The phyl-embryonic stages of the following classes of invertebrates have been definitely recognized and named: 


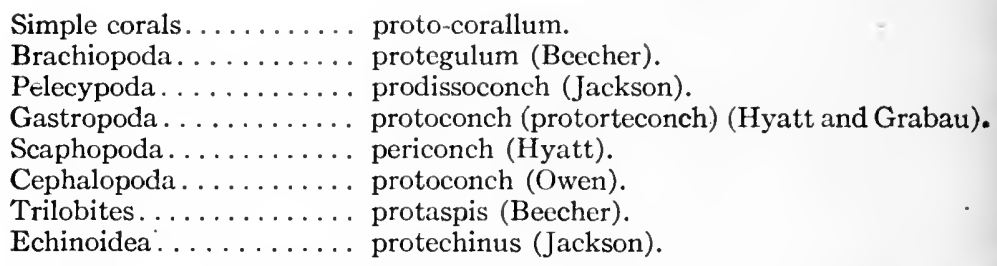

The Nepionic Stage is the babyhood stage of ep-embryonic existence. Its exact limitation cannot be defined in general terms, as it is different in different classes of organisms. In general, it may be said that, for ammonites, it covers most, if not all, of the morphic stages in which the suture is of the goniatite type. In the case of Schloenbachia, cited above, the morphic stages, up to the point where the young ammonite resembles in its sutures the genus Paralegoceras, are considered by Smith to belong in the nepionic stage. Here the neanic stage begins shortly before the suture has lost its goniatite character, but an ammonite character has made its appearance in the form of a keel. In Fulgur caricum and other advanced species of this group of gastropods the nepionic stage may be regarded as completed with the end of the tubercled condition ( $F$. fusiformis, morphic stage).

The neanic is the youthful or adolescent stage, which comprises the interval during which the organism acquires all the characteristics of maturity. When this condition is reached the organism enters on the ephebic, or adult, stage. Long-lived individuals of ten show old age or senile characteristics, which consist especially in the loss of ornamentation and a degenerate change in the manner of growth. This is the gerontic stage in the ontogenic cycle, and it is followed by death.

Gerontic characteristics may appear early in the life of individuals of a specialized race. Thus the loss of characters and the degenerate change in growth may occur while the individual is still in the adult (ephebic) stage or even earlier. Such races are said to be phylogerontic and are approaching extinction. Thus the late Cretacic cephalopods, which lost the power of coiling either partly (Heteroceras, etc.) or wholly in the adult (Baculites), represent the phylogerontic terminals of the degenerating race of ammonoids.

It must, however, be clearly borne in mind that the existence of phylogerontic lines or races at any time does not indicate that the phylum or class as a whole is gerontic. Even within the same genus there may be found species showing a gerontic tendency. The phylogerontism here applies only to the particular branch in question, while the rest of the evolutional tree of this phylum may 
be perfectly sound. Many early Ordovicic nautiloids show a loss of the power to coil, and so indicate the existence of degenerating or phylogerontic branches at a time when the class of cephalopods as a whole had not yet permanently acquired the power of coiling. Gastropods with the last whorl not coiled are found throughout the geologic series, even in Lower Cambric time, where coiling had but just begun. Such senile branches are, of course, to be expected in any developing series where wrong or too hasty experiments may be made by individual genetic lines. (See illustrations in North American Index Fossils.)

Colonial Forms. These require a specially modified nomenclature since we deal not with individuals, but with groups of individuals. In these we must keep separate the individual life history or ontogeny and the life history of the colony, $i . e$. , colonial ontogeny (astogeny or astogenesis). The first form considered in such cases is nepionic so far as the colony is concerned. To express this fact Cumings (5) has coined the terms nepiastic, neanastic, ephebastic and gerontastic,* which express for the colony what the Hyattian terms express for the individual. The first completed individual of a colony may be dignified by a distinctive term, though it cannot be considered homologous with the phyl-embryonic stage of the individual. In Hydrozoa and in compound corals the first completed individual is the prototheca (the sicula of graptolites, the initial pipe-like corallite of the Favositid corals), and in Bryozoa it is the protacium. (Cumings-5.)

\section{Intracolonial Acceleration and Retardation.}

Colonial organisms may suffer differential acceleration or retardation when certain groups of individuals develop either more rapidly or more slowly than others. This leads to the formation. within the same colony, of two or more types of structure. normally characteristic of distinct species. In this manner we can explain such phenomena as the occurrence of different types of leaves upon the same plant, and different groups of individuals in the same colony of animals where some individuals retain ancestral characters, while others develop further. Among plants the tulip tree (Lyriodendron tulipifera) may be taken as an illustration. The two and four-lobed types of leaf are characteristic of ancestral Cretacic species. Modern trees, with normally 6-lobed leaves, also

\footnotetext{
* From a $\sigma \tau v$ (asty), a group of dwellings.
} 
contain adult leaves and sometimes entire branches in which the leaves never pass beyond the four-lobed or even two-lobed type. By retardation the ancestral characters are retained side by side with the normal characters of the modern species. Eight-, IO-, I2-, and sometimes I4-lobed leaves also.occur, evidencing local intracolonial acceleration.

An example among colonial animals will further make this clear. Favosites canadensis of the Onondaga limestone is characterized by small corallites with polygonal openings, while among these are scattered at regular intervals larger ones with nearly circular openings. Favosites placenta of the middle Hamilton of

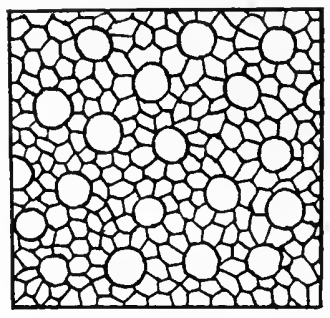

a

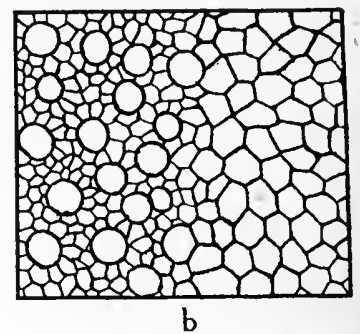

b

FIG. 258. Portions of the surfaces of two colonies of Favosites, somewhat enlarged, to show intracolonial acceleration. $a$. F. canadensis, showing the regular distribution of the large cylindrical corallites among the smaller prismatic ones. $b . F$. placenta, showing the $F$. canadensis condition on the left, and the large prismatic corallites on the right.

Canada when young (nepiastic) has the characteristics of adult $F$. canadensis, but when colonially adult it has retained the $F$. canadensis type in certain portions of the colony only, other portions having developed a uniform series of large corallites with polygonal apertures. Here, then, certain portions of the colony have been retarded in their development, retaining ancestral characters, while others have continued to develop. In the upper Hamilton a species of the $F$. placenta type ( $F$. placentoides) occurs with all the corallites uniform, large and angular in aperture (Fig. 258).

Acceleration in certain portions and retardation in others when occurring in more or less regular manner result in the formation of colonial ornamentation, such as is so characteristic of Bryozoa.

Atavism or Reversion. Not inf requently among a large number of individuals of a species characterizing a certain horizon a few will be found in which ancestral characters occur in the adult, thus recalling species of a lower geologic horizon. This atavism or 
reversion of the species to ancestral characters may often be seen to be nothing more than an arrestation of development at an immature morphic stage, when the characters of the young are like those of the adult ancestor of earlier geologic horizons. This arrestation of development or genepistasis is only a step removed from progressive retardation in development of which it forms the distal limit. In either case, whether complete or partial arrestation (heterepistasis) occurs, or whether development is retarded altogether or along certain lines, the resultant form will seem out of place in the horizon characterized by the more advanced species, and may sometimes lead to mistaken classification of the strata containing them.

As an example of atavistic individuals occurring in a horizon above their normal may be cited the case of the Devonic brachiopod Spirifer mucronatus and its derivatives already mentioned. This species, so far as known, is represented by the elongated, strongly mucronate type in the lower Hamilton beds of eastern North America. In the Upper Hamilton of Ontario occurs the mutation $S$. thedfordense, which in its younger stages has all the features of the typical lower Hamilton form, but in the adult it is proportionally much less extended, without mucronate points, without the characteristic plication in the median sinus of the pedicle and groove in the median fold of the brachial valve, and with strongly marked, regular lines of growth. With this species occur a number of individuals which have been retarded in their development and which, hence, recall the ancestral type in some of their charactersnotably the strong mucronate lateral extensions. In the New York province of the Middle Devonic the chief developmental changes acquired by $S$. mucronatus consist in the relative shortening of the mucronate angles as the shell approaches the adult stage. until from a width several times its height it had changed to a form in which the width was more nearly equal to the height, and in which the mucronations were wholly obliterated. In other respects the changes were very slight. With this mutation occurs not infrequently a form showing arrestation of development (genepistasis) at an early stage, and hence it retains into the adult its youthful mucronate character, which recapitulates the ancestral condition. These arrested individuals thus recall in practically all respects the prinitive mucronate type from which they are derived.

An example of a retarded individual from the Karnic limestone of the California Trias is cited by J. P. Smith. This was an immature specimen of the ammonoid genus Trachyceras which had persisted unusually long in the ancestral Tirolites stage, thus 
resembling the adult of that genus which belonged in a lower horizon. This occurrence threatened to cause difficulty in correlation.

\section{Parallelism and Convergence in Development.}

Homcogenesis. One of the most important of the many facts brought to light by the researches of palæontologists is that many groups of organisms develop independently in similar directions,
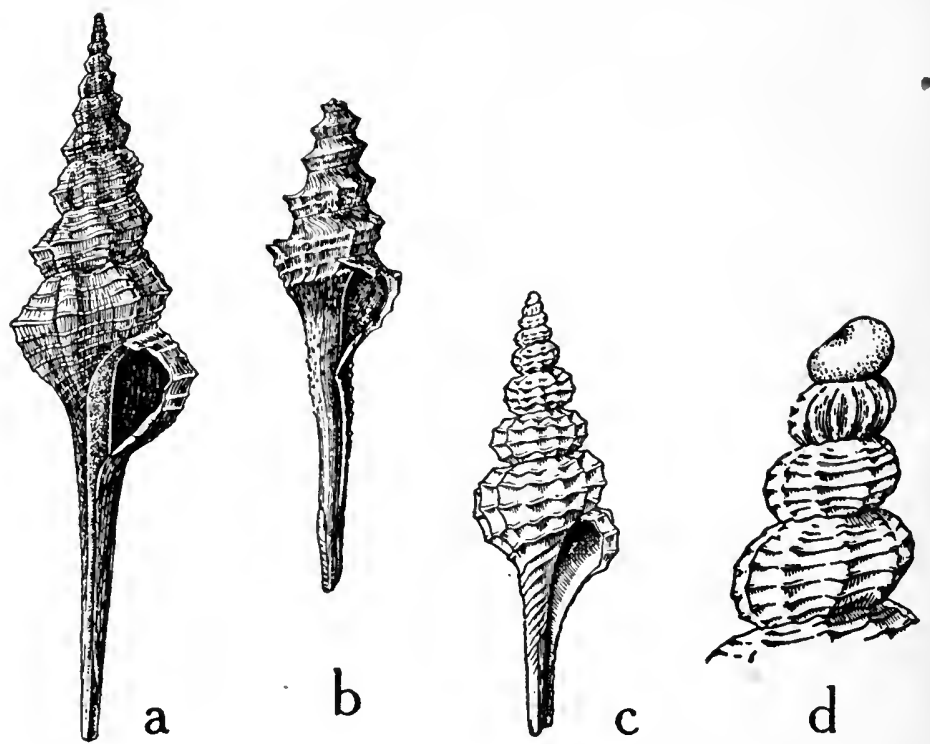

FIG. 259. Illustration of parallelism. A series of Eocenic Fusoid shells, belonging to different genera, but readily mistaken for members of the same genus Fusus under which they were originally described. a. Falsifusus meyeri; b. Fulgurofusus rugatus. $c$. Fusus asper $\times \mathrm{1}^{2} / 3 . \quad d$. Early whorls of same, enlarged $\times 10$.

and that hence in disconnected series species with similar adult characteristics may develop. These morphological equivalents, as Hyatt has termed them (or Homœomorphs of Buckman), are often so much alike that they have been united under the same generic or even specific name. The Eocenic fusoid shell Falsifusus, from the Gulf Coast of the southern United States, is, an example of this, the adult form having all the characteristics of the genus Fusus, though, as shown by the young stages, the American form 
is probably derived from a Pleurotoma-like ancestor, and not a true Fusus at all.* (Fig. 252.)

The Eocenic genus Clavilithes furnishes a number of striking examples of this similar development or homcogenesis, as Eimer has termed it. $\dot{\dagger}$ (Fig. 260.)

The typical species of this genus, $C$. parisiensis, from the Calcaire Grossier of the Paris Basin, finds its almost exact equivalent in the modern Cyrtulus serotinus, Hinds, of the Marquesas region in the South Pacific. Clavilithes became extinct in the Eocenic, while Cyrtulus is a derivative from the modern stock of Fusus. But by far the most interesting type of this complex series is
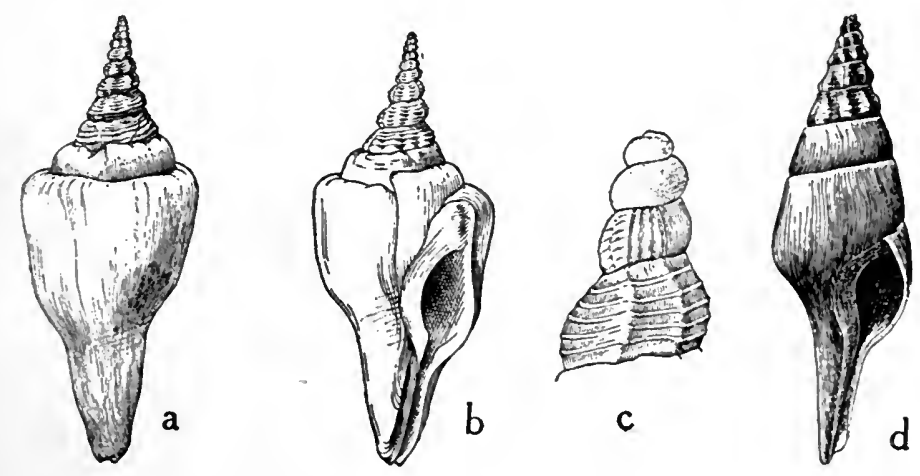

FIG. 260. Clavilithoid shells showing "convergence." $a, b$. Cyrtulus scrotinus. A modern clavilithoid, being the phylogerontic terminal of the Fusus series (slightly reduced). c. The protoconch and early conch stages of Clavilithes parisiensis, an Old World Eocenic clavilithoid (enlarged). d. Clazilithes (?) kennedyanus, a New World Eocenic clavilithoid of independent origin (slightly reduced).

Clavilithes scalaris (Lamarck), from the Sables Moyens of France. This species is characterized by a projecting rim or flange on the shoulder of the adult whorl. This same feature is reproduced in Clavilithes longavus (Solander) of the Barton Beds of England. which is of wholly independent origin. Again, Clavilithes? chamberlaini, Johnson and Grabau, from the Lower Claibornian of Texas, shows the same type of structure, and here. too it is independently derived. Finally, Rhopalithes japeti (Tournouer) represents this same feature in a genus entirely distinct from Clavilithes

* The distinction is not accepted by all. (Grabau-14.)

$\dagger$ The controversy regarding this and the other species mentioned here is dealt with by Grabau (13:622 et seq.) in the Studies of Gastropoda III. 
Examples of such equivalents could be multiplied indefinitely. In the majority of cases, where classification has taken account only of the adult characters, such homœogenetic types have been classed together as of the same genus or species, and sometimes even as varieties of the same species.

It is hardly going too far to say that the majority of classifications of invertebrates now in vogue may be likened to a more or less warped plane passed through the crown of a tree; all the points of intersection of the branches and the plane are considered as species, while all the neighboring and some distant ones are grouped together in a genus, or family. The illogical nature of this method, which is the natural result of a consideration of adult characters only, must be apparent.

Morphologic equivalents have been recognized most frequently among ammonoids. Formerly all types in which the suture was composed of simple lobes and saddles were classed as Goniatites. All those in which the lobes were crenulated as Ceratites, and all those in which both lobes and saddles had become compound were placed in the genus Ammonites. It is now known that many and diverse genetic series started with genera of the goniatite type, branched out in diverse genera with ceratite sutures and that from these latter were derived the genera in which the suture was ammonitic. Again, similar types of ornamentation and sinilar degrees of coiling or involution appeared independently in distinct genetic series, thus producing species which often closely resembled each other in the adult type, but which had a wholly distinct ancestry.

Among vertebrates many cases of similar independent morphological equivalents have been discovered, especially in the class of mammals, and in that of reptiles. It sometimes happens that it is impossible or impracticable to separate such heterogenetic homøomorphs into their respective genera. In such cases a generic name is retained for this polyphyletic group, but it must not be considered a genus. The name Circulus (Bather) has come into use for such groups of homoomorphs. Platyceras is an example of a circulus among gastropods; it is commonly given the value of a genus, but its species are phylogerontic terminals of a number of genetic series. Many of the generic names applied to graptolites, such as Tetragraptus, Dichograptus, etc., are really circuli, for they represent similar stages in development in different genetic series. Since they occur at the same geologic horizon they have also been called "Geologic genera" (Ruedemann-39).

A distinction has commonly been maintained between cases in 
which related animals or plants have developed in a similar manner but independently and those in which unrelated animals or plants have developed similar characteristics which apparently bring them more closely together. To the former the term parallelism has generally been -restricted, while the term convergence has been applied to the latter case. Of course, it is understood that the use of this term does not imply that the organisms in question actually converge in their relationship, as seems to have been assumed by some, but merely that the convergence is only a morphologic one and may lead to mistaken ideas of relationship. The similar independent development of the projecting flange in the species of Clavilithes, cited above, may be considered a case of pure parallelism, while its development in Rhopalithes nay be considered a case of convergence. A similar case of convergence is seen in the American Eocenic Falsifusus and the British Eocenic Fusus, already cited, both of which have adult characteristics which have led to their being classed in the same genus. That they are of independent ancestry, however, seems to be established.*

\section{BIBLIOGRAPHY XXV.}

1. BEECHER, CHARLES E. 1901. Studies in Evolution. Charles Scribner's Sons, New York.

2. BUCKMANN, S. S. 1909. Yorkshire Type Ammonites.

3. CLARK, WILLIAM B. IgIo. Contributions to Morphology from Paleontology. The Paleontological Society Conferences on the Aspects of Paleontology. First Annual Meeting, Cambridge, Mass. Dec. 29, 1909. Reprinted from Popular Science Monthly, June to November, 19 I0.

4. CUMINGS, EDGAR R. 1903. The Morphogenesis of Platystrophia, a Study of the Evolution of a Palæozoic Brachiopod. American Journal of Science, 4th series, Vol. XV, pp. I-48, I21-136.

5. CUMINGS, E. R. 1904. Development of Some Palæozoic Bryozoa. Ibid., Vol. XVII, pp. 49-78.

5a. CUMINGS, E. R. I9I0. Paleontology and the Recapitulation Theory. The Paleontological Record, pp. 57-63, Reprinted from Popular Science Monthly. Ibid. Proceedings of the Indiana Academy of Science, I909 Meeting, pp. $\mathbf{I}-36$.

6. DE VRIES, HUGO. 190I. Die Mutations-theorie. Leipzig.

7. DE VRIES, H. I905. Species and Varieties. Their Origin by Mutation. Open Court Publishing Company, Chicago.

8. D'ORBIGNY, ALCIDE. I840. Palæontologie Française. Terrains, Crétacés Cephalopodes. Paris.

9. EIMER, TH. I 898 . On Orthogenesis, and the Impotence of Natural Selection in Species-forming. Open Court Publishing Company, Chicago.

I0. FARLOW, W. G. 1898. The Conception of Species as Affected by Recent Investigations on Fungi. Vice-Presidential Address before the American Association for the Advancement of Science, 1898. Section of Botany.

* See the controversy above referred to. 
II. GRABAU, A. W. 1902. Studies of Gastropoda. American Naturalist, Vol. XXXVI, pp. 9I7-945.

I1a. GRABAU, A. W. I903. Studies of Gastropoda II,Ibid. Vol. XXXVII, pp. 5I 5-539.

12. GRABAU, A. W. 1904. Phylogeny of Fusus and Its Allies. Smithsonian Miscellaneous Collections, part of Vol. XLIV.

13. GRABAU, A. W. 1907. Studies of Gastropoda III. On Orthogenetic Variation in Gastropoda. American Naturalist, Vol. XLI, No. 490, pp. $607-651$.

14. GRABAU, A. W. IgIo. Studies of Gastropoda IV. Value of the Protoconch and Early Conch Stages in the Classification of Gastropoda. Seventh International Zoölogical Congress, Proceedings, Boston, 1907. Advance sheets.

I5. GRABAU, A. W., and REED, MARGARET. I9io. Mutations of Spirifer mucronatus. Seventh International Zoölogical Congress Proceedings, Boston, 1907. Advance sheets, 1910.

I6. GRABAU, A. W. I9Io. Palæontology and Ontogeny. The Palæontologic Record, pp. 54-57. Reprinted from Popular Science Monthly.

17. GRABAU, A. W. I9I3. An Illustration of Waagen's Theory of Mutations. American Naturalist (in press).

18. HUSSAKOF, L. I9Io. Vertebrate Paleontology and the Evidences for Recapitulation. The Paleontologic Record, pp. 63-66. Reprinted from Popular Science Monthly.

19. HYATT, ALPHEUS. 1889. Genesis of the Arietidæ. Smithsonian Contributions to Knowledge, $673 . \quad 238$ pp., I4 pls.

20. HYATT, A. I 894. Phylogeny of an Acquired Characteristic. Proceedings of the American Philosophical Society, Vol. XXXII, pp. 349-647, pls. I-I 4 .

21. HYATT, A. 1897. Cycle in the Life of the Individual (Ontogeny) and in the Evolution of Its Own Group (Phylogeny). Science, Vol. V, pp. I6II 7 I. Proceedings of the American Academy, Vol. XXXII, pp. 209-224.

22. JACKSON, ROBERT T. 1912. Phylogeny of the Pelecypoda; the Aviculidæ and Their Allies. Memoir of the Boston Society of Natural History, Vol. IV, No. 8.

23. JACKSON, R. T. 1912. Phylogeny of the Echini, with a Revision of Palæozoic Species. Memoirs of the Boston Society of Natural History, Vol. VII.

24. JACKSON, R. T. I9I3. Alpheus Hyatt and His Principles of Research. American Naturalist, Vol. XLVII, pp. 195-205.

25. JOHNSON, DOUGLAS W. 1904. Geology of the Cerrillos Hills, New Mexico. School of Mines Quarterly, I903-04, Part II, Palæontology.

26. LOOMIS, F. B. I9Io. Ontogeny: A Study of the Value of Young Fea tures in Determining Phylogeny. Paleontologic Record, pp. 5I-53. Reprinted from Popular Science Monthly.

27. LULL, RICHARD S. I910. Relation of Embryology and Vertebrate Palæontology. Ibid., pp. 47-50.

28. MORGAN, THOMAS HUNT. 1903. Evolution and Adaptation. Mac millan Company, New York.

29. NEUMAYR, MELCHIOR, and PAUL, C. M. I875. Congerien und Paludinen-schichten Slavoniens. Abhandlungen der königlich-kaiserlichen geologischen Reichsanstalt. Bd. VII, Heft 3.

30. OSBORN, HENRY F. 1907. Evolution as It Appears to the Paleontologist. Seventh International Zoölogical Congress Proceedings. Boston 
Meeting, 1907. Advance sheets, 1910. Also Sciencc N. S., Vol. XXVI, No. 674, pp. $744-749$, Nov., 1907.

31. OSBORN, H. F. I908. The Four Inseparable Factors of Evolution. Science N. S., Vol. XXVII, No. 682. Jan., 1908, pp. I48-150.

32. OSBORN, H. F. 1908. Coincident Evolution through Rectigradations. Ibid., Vol. XXVII, No. 697, pp. 749-752.

33. OSBORN, H. F. 1910. Paleontologic Evidences of Adaptive Radiation. The Paleontologic Record, pp. 34-38. Reprinted from Popular Science Monthly.

34. OSBORN, H. F. 19II. Biological Conclusions drawn from the Study of the Titanotheres. Science N. S., Vol. XXXIII, pp. 825-828.

35. OSBORN, H. F. I912. The Continuous Origin of Certain Unit Characters as Observed by a Palæontologist. American Naturalist, Vol. XLVI, pp. I 85-206, 249-278.

36. OSBORN, H. F. 1912. First Use of Word "Genotype." Science N. S., Vol. XXXV, pp. 340-34I.

37. OSBORN, H. F. I9I2. Tetraplasy, the Law of the Four Inseparable Factors of Evolution. Journal of the Academy of Natural Scitnces, Philadelphia. Vol. XV, second series, pp. 273-309.

37a. OSBORN, H. F. Assisted by Grabau, A. W. 1911. Article on Palæontology. Encyclopædia Britannica, i Ith Edition, Vol. xx, pp. 579-591.

38. PENHALLOW, D. P. I910. The Relation of Paleobotany to Phylogeny. The Paleontologic Record, pp. 67-72. Reprinted from Popular Science Monthly.

39. RUEDEMANN, RUDOLF. 1904. Grapholites of New York. Memoir VI of the New York State Museum, Part I, Vol. I.

40. RUEDEMANN, R. I9IO. Anatomy and Physiology in Invertebrate Extinct Organisms. Paleontologic Record, pp. 39-42.

4I. SHIMER, H. W. I906. Old Age in Brachiopoda. American Naturalist, Vol. XL, pp. 95-12I.

42. SHIMER, H. W. 1908. Dwarf Faunas. Ibid., Vol. XLII, pp. 472-490.

43. SMITH, JAMES PERRIN. 1897. Development of Schloenbachia. Journal of Geology, Vol. V, pp. 521 et seq.

44. WAAGEN, W. I868. Die Formenreihe des Ammonites subradiatus. Beneckes Geognostisch-Palæontologische Beiträge, Bd. II, pp. 179256 (185-6). 


\section{CHAPTER XXVI.}

-

PHYSICAL CHARACTERISTICS OF THE INHABITABLE EARTH.BIONOMIC CHARACTERS OF THE ENVIRONMENT.*

- A comprehensive survey of the inhabitable world shows its divisibility into three great bionomic realms, each of which has its peculiar characteristics and its specially adapted forms of animal and plant life. The essential character of each is determined by the nature of the medium in which the organisms live, $i . e$., whether salt water, fresh water, or air. We have, accordingly:

I. The Marine, or Halo-biotic realm.

2. The Fresh Water, or Limno-biotic realm.

3. The Terrestrial, or Atmo-biotic (also called Geo-biotic) realm.

While each of these is distinct from the others, they also grade into one another to a greater or less extent along their lines of intersection. Thus the marine and fresh-water realms intergrade in the estuaries of rivers, where the water is brackish. The marine and terrestrial realms intergrade at the shore, where organisms are periodically exposed between tides first to the one and then to the other medium. Again, the terrestrial and fresh-water fluvial, lacustrine, etc., realms intergrade along the margins of streams, and the shores of lakes.

Each one of the bionomic realms may be further subdivided into a light, or photic region, and a dark, or aphotic region. Between these two may frequently be determined a dusk, or dysphotic region. Schimper (6) has defined these regions in the marine realm on the basis of plant life as follows:

The photic region extends over such depths wherein the intensity of sunlight is sufficient for the normal development of macrophytes. The dysphotic region is insufficiently lighted for the

* This and the succeeding two chapters are in part a reprint, with additions and emendations, of a paper published by the author in 1899 under the title Relation of Marine Bionomy to Stratigraphy. Bulletin of Buffalo Society Natural Sciences, Vol. VI, pp. 319-365. 
normal development of macrophytes, which exist there but scantily or not at all, while certain moderately assimilating microphytes, especially diatoms, still exist. The aphotic region comprises that part of the sea where only the non-assimilating vegetable organisms can exist. The depth at which these regions pass into one another varies with the locality and the purity of the water. In the open sea the dark region begins at a depth of about 200 fathoms. In the fresh water realm the aphotic region is not often found, though deep lakes, like Lake Superior and Lake Geneva, extend to depths not penetrated by sunlight. Such cases are, however, comparatively uncommon. A limno-aphotic region is further found in the streams and lakes of caves where the sunlight is shut out by the roof of the cavern. Caverns, too (natural and artificial), constitute the only aphotic region of the terrestrial realm, and they are often peopled with a well-adapted fauna and flora.

The final division into life districts depends on the absence or presence of a substratum, and this division can be equally well carried out in the marine, fresh water, and terrestrial realms. The absence of a substratum compels the organism to float or swim in the medium, and for this purpose special organs and a specially modified body-form commonly exist. The substratum may be visited for food or other purposes, but the organism is perfectly at home in the medium.

Each realm may, then, be divided into the following life-districts, the medium being salt water, fresh water, or air, according as the marine, fluvio-lacustrine, or terrestrial realms are considered:

I. Littoral district: Light; substratum present.

2. Pelagic district: Light; substratum absent.

3. Abyssal district: Dark; substratum present.

4. Abysso-pelagic district: Dark; substratum absent.

\section{The Littoral Districts.}

A. Marine. The marine littoral district extends from the shore at high-water mark to the edge of the continental shelf. where it quickly merges into the abyssal district. The depth to which the littoral district extends is approximately 200 meters, though the hundred-fathom line is commonly taken as the seaward boundary of this district. Around oceanic islands and young continents the littoral district is very narrow, the ocean floor soon falling off to deep water. The origin of this district is to be sought in the activities of various geologic agencies, chief among 
which are the inland cutting of waves and currents, thus extending the sea landward; and the deposition of the land-derived detritus on the edge of the continental shelf, thus pushing this edge seaward and widening the submarine platform. Subsidence of the land permits the advance of the sea over the low country, and broad epicontinental seas are formed, which fall entirely within the littoral life district. In mediterrancans, too, the littoral belt is generally a broad one, only the central portion descending to abyssal depth. (See further, Chapter III.)

The conditions become more favorable for the development of littoral life as the continent grows older, provided, of course, that no important oscillatory movements occur. As time progresses the breadth of the submerged continental shelf increases, both by landward cutting and by seaward building, and the surface of the land becomes more and more reduced, thus causing a decrease in the amount of detrital material which can be carried into the sea, and a concomitant increase in the purity of the water. When peneplanation, or the reduction of the land to base-level, has been accomplished, the amount of detritus carried into the sea is practically nil; and any organisms, like corals, adapted only to pure water, can flourish close to the continental shore, and deposits of a purely organic nature, such as extensive deposits of pteropod or foraminiferal shells, may form in comparatively shallow water.

The epicontinental sea and the littoral belt of the mediterraneans are especially adapted for the development of local or provincial faunas. Such provincializing of faunas is most marked if, by some oscillatory movement of the land or some other physical change, the basins of these intracontinental seas become separated from the littoral district of the ocean sufficiently to prevent intercommunication between the organisms of the two provinces. A barrier is thus formed, which need not necessarily be a land barrier, and a great diversity of faunas may result. A rather marked diversity of fauna existed in early Tertiary time between the Mississippi embayment and the Atlantic coast, and in Palæozoic time between the Bay of New York and the central interior sea. Recent provincial faunas are frequently met with. It requires only a comparatively slight elevation of the sea-floor, or a moderate deepening of the abyssal oceanic basins, to draw off the water from the shallower regions and lay dry large portions of the littoral district. Such a change would, of course, result in an almost complete extinction of the littoral flora and fauna thus exposed and force the survivors to accommodate themselves to a narrower field. Revival of stream activities, consequent upon elevation of the land, would result in 
carrying a large amount of débris into the sea and thus produce conditions unfavorable to the existence of many organisms.

Landward the littoral district interlocks with the corresponding districts of the terrestrial and fluvial realms, the faunas and floras of all more or less intermingling. It is in this portion of the littoral district that an important subdivision must be considered; namely, the shore. The shore, as already noted (ante, Chapter XV), is that part of the littoral district which lies between the highest water mark (often considered as including even the highest point of the wave mark) and the lowest line drawn during the lowest ebb. In the greater part of this division of the littoral district there is a change of medium twice every twenty-four hours, and a change of the consequent physical conditions attendant upon the character of the medium. Organisms living in this portion of the littoral zone must be capable of withstanding the effects of the partial or complete removal of their normal medium for a greater or less time. It is here that the interlocking of the terrestrial and marine floras and faunas becomes most marked, and an intermingling and a migration from one district into the other occur. Migration from the land to the sea is exemplified by the whales, seals, and other aquatic mammals, which have become marine in so far as their mode of locomotion is concerned. Owing however, to the inability of air-breathing animals to adapt themselves to a water-breathing habit, all terrestrial animals passing into the sea must assume a pelagic life, where they can retain their normal method of respiration.

Among other animals which have exchanged their normal terrestrial habit for a prevailingly marine one may be mentioned several birds, such as the Penguins and the Albatross; certain snakes, turtles, and crocodiles, and a number of insects. The birds and insects here considered represent a passage from the aerial to the marine pelagic district; while the reptiles, like the mammals, illustrate a passage from the land to the pelagic district of the sea.

While thus the land fauna, in advancing into the sea, naturally takes to a pelagic life, the land flora can adapt itself to the conditions of the littoral district. This is well shown by the eight species of phanerogams, which have acquired a wholly marine habit, and are now known as eel grasses or sea grasses. In the case of these plants the adaptation is so complete that they can no longer live out of their adopted habitat. The mangrove plants, on the other hand, are only partially accommodated to the conditions of the marine littoral district, for it is necessary that their crowns of leaves should be above water. 
Marine animals and plants, likewise, attempt migrating from the sea to the land. In their adaptation to the new habitat the animals are the more successful, just as the plants are the more successful in migrating the other way. Thus two genera of fish, Periophthalmus and Boleophthalmus, are able to pass the greater part of their lives out of water. They "skip along close to water-line on the seashore, where they hunt for molluscs (Onchidium) and insects." (Semper-7:I89.) The large branchial cavity of these fishes is not completely filled by the gills, but serves in part as an air cavity or primitive lung. In a number of fishes, such as Anabas scandens of the Philippines, this gill-cavity is further modified into a "labyrinthine organ," or much prolonged cavity, the mucous membrane of which is thrown into complicated folds, thus greatly increasing the surface. These fish can exist for days out of water and are able to make long overland excursions. Semper holds that these fish may be regarded "as Amphibians with quite as much reason as toads and frogs, or even better, since they are capable of changing the nature of their respiration-of air, that is, or of water-at will, and suddenly without any interruption." Several of our littoral gastropods, $e$. g., Littorina, Ilyanassa, etc., are capable of existing out of water for a considerable time. In Brazil Littorina climbs the trees of the mangrove high above water and oysters and other bivalves are attached to the roots of these trees and are laid bare at low tide. Ampullaria forms a connecting link between sea and land snails, for it not only breathes by means of a gill but also has a pulmonary sac like that of the land snails into which air is carried by means of a long breathing-siphon.

The possibility that related species of marine gastropod Mollusca may leave the sea in different parts of the world and give rise to terrestrial forms, which, though differing from their marine ancestors, may be very similar to each other, deserves attention. In this way some of the puzzling problems of distribution of terrestrial gastropods on widely distant oceanic islands may be accounted for.

Among the Crustacea there are several species of crabs (e. g., Birgus latro, etc.) which live in lamp woods far from all water and whose respiration is carried on chiefly without the intermediation of their normal medium.

The advent of marine vegetation on the land has occurred only up to the limit of the salt spray on exposed shores, and here the number of species is small. But at, or just below, high-tide limit a number of algæ find a congenial abode, and grow there in luxuriant masses. Chief of these in our northern latitudes are the Fuci, 
with Fucus vesiculosus and Ascophyllum nodosum predominating. At low-tide these hang like a wet fringe over the exposed rocks and give shelter to numerous species of the smaller littoral animals, as well as other alga.

The littoral districts of the marine and fluvial realms also interlock along the shores where streams mouth into the sea or expand into broad estuaries. Here marine animals will venture up into the fresh water littoral district, while, similarly, fresh water animals pass into the littoral district of the marine realms. The common meeting-ground of the two approaching floras and faunas is in the estuarine or brackish water facies of the littoral districts.

The neritic zone, "Flachsee," or thalassic zone, is that portion of the littoral district which is never uncovered. It is separated as a distinct district by Walther, Haug, and others, who restrict the term littoral to the shore zone. It is, however, so intimately connected with the shore zone in all its physical and bionomic characteristics that a separation is not natural. The bottom of the neritic zone of the littoral district is less diversified than that of the shore zone. In its upper portion and in its shoals it may partake of the character of the shore zone, but in its deeper portions the character of the bottom is usually more uniform, being either rocky or, what is more common, composed of fine detrital material mingled with organic matter in various stages of dissolution. According to the character of the bottom, plant life will vary and with it, to a greater or less extent, animal life.

Taken as a whole, the littoral district is the most important portion of the sea, both from a bionomic point of view and from its bearing on palæontology. "The littoral region," says Lovèn $(4: 86)$. "comprises the favored zones of the sea, where light and shade, a genial temperature, currents changeable in power and direction, a rich vegetation spread over extensive areas, abundance of food, of prey to allure, of enemies to withstand or evade, represent an infinitude of agents competent to call into play the tendencies to vary which are embodied in each species, and always ready, by modifying its parts, to respond to the influences of external conditions." This district may perhaps be regarded as the cradle of organic life, from which were peopled the abyssal and pelagic districts, on the one hand, and the terrestrial and fluvial realms and their various districts, on the other.

B. Fresh Water. The littoral district of the fresh water realm is almost coextensive in area with that of the streams and fresh water lakes and ponds of the world. The only exception to this is found in those portions of very deep lakes where sunlight does not 
penetrate to the bottom and in the subterranean streams and lakes. The fauna of the limno-littoral district is much less diverse than that of the corresponding district in the sea. Whole classes of animals, like those of the Echinodermata, the Anthozoa, the Brachiopoda, Cephalopoda, Pteropoda, Scaphopoda, etc., are normally absent from fresh water, while most of the remaining ones are poorly represented by genera and species, though often prolific in individuals. Plant life, on the contrary, is abundantly represented, not only by desmids, diatoms, and fresh-water alga, but also by the large number of swamp plants which grow partly submerged and represent the transition zone between the terrestrial and limnolittoral districts.

C. Terrestrial. The terrestrio-littoral district is coextensive with the surface of the land. No other life district comprises such a range of physical characteristics, and no other district is inhabited by such a variety of highly specialized types of animal and plant life. Here we pass from the cold of the arctic snow-fields to the burning sands of the tropics, from the land of nearly continuous rains to the rainless desert regions, parched by the continued drought of years, and from the region of plentiful food supply to the stony, arid wastes, where the nature of the soil is hostile to practically all forms of plant life. It is to be expected that under such widely varying conditions a fauna and flora should develop which in its variety outruns that of any other life district, and which in its own extremes reflects the range of its environment.

\section{The Pelagic Districts.}

A. Marine. The marine pelagic, or halo-pelagic district, is the common meeting-ground of most of the life districts. It touches all shores and communicates with the corresponding districts of both the terrestrial and fluvial realms. It has direct communication with the littoral district, many inhabitants of which leave the bottom at times to lead a temporary existence in the pelagic district; while many pelagic animals, in turn, visit the bottom or shores for food. Occasionally inhabitants of the pelagic district enter for a time the corresponding district of the terrestrial realms, $i$. $e$., the aerial; as, for example, the so-called flying-fish; and, in turn, as already noted, many aerial animals spend a part of their lives in the marme pelagic district, or at least show a decided preference for a pelagic life. The passage of land animals to the halo-pelagic district has already been noted. Similar in- 
termingling of fresh water, or limno-pelagic, and salt water pelagic types occurs in the estuaries and stream mouths, and it is notorious that halo-pelagic fish will enter the limno-pelagic district in breeding time. It is quite probable, as Sir William Flower suggests, that the Cetacea, in their transition from a terrestrial to a marine life, passed through a stage in which they lived in fresh water. A similar transition for the sea-grasses is not improbable, though they can no longer live in fresh water. Intercommunication between the abysso-pelagic and pelagic districts also occurs, as well as between the abysso-pelagic and abyssal.

B. Fresh Water. The pelagic life of ponds, lakes, and rivers is much less varied than that of the sea, though, as will be seen later, the number of individuals of a given species may often be very great. In ponds and lakes no very distinctive characteristics not found in shallow seas exist, aside, of course, from the distinctions due to the difference in degree and kind of salinity. In rivers, on the other hand, we must consider the importance of currents, which vary greatly in strength, but are essentially constant in direction. It is this constancy which, as Chamberlin has pointed out, favors the development of a special body form, the resistance of which to the current is at a minimum. Such a body form is found in fish and in the ancient Eurypterida, and it is a possibility not to be lightly set aside that both fish and eurypterids originated in the rivers of the Palæozoic and earlier lands. Indeed, this is all but definitely proven for the Eurypterida (O'Connell-5) and seems to be indicated for the fish as well. Significant in this connection is the fact that the early remains of fish as of eurypterids are not found in normal marine deposits, but in those which are at least open to the suspicion that they are formed by rivers or at least at the mouths of rivers, while the best preserved remains, and the most abundantly represented in the Palrozoic, are found in river flood-plain deposits and in deltas. This subject will be more fully discussed in the next chapter (Graban-3).

C. Terrestrial. The pelagic life of fresh water is, as we have seen, much less abundant than that of the sea, and, again, the aerial life, or that of the pelagic district of the land, is much less prominent than that of the streams and lakes. This gradation is in direct correspondence with that observed in the gradation in the density of the medium. Moreover, in the terrestrial realm the pelagic district is only temporarily inhabited, few, if any, terrestrial animals or plants spending their entire existence suspended in the air. The most familiar examples of animals spending a part of their lives at least in the atmo-pelagic district are: insects among invertebrates, 
pterosaurs among reptiles, the birds, and, among mammals, the bats.

\section{The Abyssal Life District.}

A. Marine. The marine abyssal districts comprise the lightless depths, or generally those depths exceeding two hundred fathoms. (Chapter III.) As assimilating plant life is absent in these districts the food supply of the organisms existing in them must be wholly derived from the districts in which such assimilating vegetation exists. A large proportion of the food of the abyssal animals is contained in the organic oozes and sediments which constantly settle down in a more or less.decomposed state from the lighted districts. The abysso-pelagic district is frequently invaded by organisms from the pelagic district, which descend into the dark regions during the day.

B. Fresh Water and C. Terrestrial. In the non-marine realms the lightless districts are sparingly represented. Lakes of great depth, whose bottom is in perpetual darkness, do exist, but the life of these dark regions is nostly unknown. Cave life, on the other hand, both fluvio-lacustrine and terrestrial, has been made the subject of much study, and its characteristics are known to harmonize with the peculiar conditions which give these districts their especial stamp.

\section{BIBLIOGRAPHY XXVI.}

I. CHAMEERLIN, THOMAS C. I900. The Habitat of the Early Vertebrates. Journal of Geology, Vol. VIII, pp. 400-412.

2. GRABAU, A. W. I 899 . The Relation of Marine Bionomy to Stratigraphy. Chapter III in the Geology and Palæontology of Eighteen-mile Creek. Bulletin of the Buffalo Society of Natural Sciences, Vol. VI, pp. 319-365.

3. GRABAU, A. W. I913. Ancient Delta Deposits of North America. Bulletin of the Geological Society of North America, Vol. XXIV pp. 498-526.

4. LOVËN, SVEN. 1883. On Pourtalasia, a Genus of Echinoidea. Stockholm.

5. O'CONNELL, MARJORIE. 1912. The Habitat of the Eurypterida. Paper presented before the New York Academy of Sciences. Also in Grabau (2), pp. 499-5I5.

6. SCHIMPER, A. F. W. 1898. Pflanzengeographie auf physiologischer Grundlage. Jena. English translation by W. R. Fisher. Plant Geography, Oxford, 1903.

7. SEMPER, KARL. I881. Animal Life as Affected by the Natural Conditions of Existence. Appleton International Scientific Series, Vol. XXX. 


\section{CHAPTER XXVII.}

\section{BIONOMIC CLASSIFICATION OF PLANTS AND ANIMALS.}

A bionomic classification, or one based on the relationship of the organism to its environment, cannot agree with one based entirely on anatomic characteristics. It is a more primitive classification, but a very useful one from many points of view.

\section{Subdivisions.}

Primary Divisions. The primary divisions of the organisms agree with the primary divisions of the life districts, $i$. $e$., the marine, fresh water, and atmospheric or terrestrial. We have, accordingly, halo-bios, limno-bios, and atmo-bios (geo-bios), each of these including the plants and animals of the respective realms.

Secondary Divisions. The next division is based on the relation of the organism to the substratum, where we have floating types or plankton, swimming types or nekton, and bottom types or benthos. The first two belong to the pelagic and abysso-pelagic districts, the third to the littoral and abyssal. Their further subdivisions and relationships are as follows:

(1. Holoplankton: organisms spending all their lives as plankton (ex., jelly fish).

2. Meroplankton: organisms leading a planktonic life during larval stages only (ex., Crustacea, echinoderms, cœlenterates).

A. Plankton(floating organisms)..........

B. Nekton(swimming or flying organisms).... r. Holonekton.

3. Pseudoplankton: organisms normally attached but floating through accident, as the Sargassum, leaves and trunks of trees, or parts of dead organisms, such as shells of molluses, etc.

4. Epiplankton: organisms living upon or attached to floating objects (ex., Crustacea and hydroids of the pseudoplanktonic Sargassum; Lepas attached to floating logs, etc.

2. Meronekton.

3. Epinekton: organisms parasitically or otherwise attached to swimming or flying animals. 


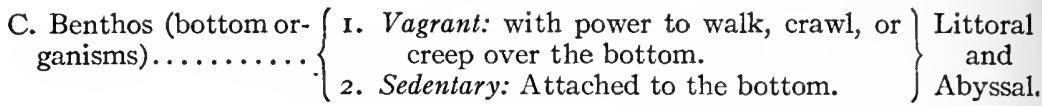

According to the realm in which the organism lives we have, therefore:

I. Marine or Halobios, including
A. Haloplankton
B. Halonekton
C. Halobenthos

II. Freshwater or Limnobios, including

D. Limnoplankton

E. Limnonekton

F. Limnobenthos

III. Terrestrial or Atmobios (Geobios), including

G. Atmoplankton

H. Atmonekton

I. Atmobenthos

With reference to depth, we may further subdivide marine plankton, etc., into anoplankton (from ävw, upward*) or that occurring above the roo fathom-line; this may be divided into anoholoplankton, anomeroplankton, anopseudoplankton and anoepiplankton. Below 100 fathoms we have the mesoplankton (from $\mu$ '́ros, middle), and again, just above the abyssal depths may occur the hypoplankton (from inó, under), anonekton, mesonekton and hyponekton, as well as anobenthos (littoral district), mesobenthos (bathyal district) and hypobenthos (abyssal district) may also be recognized.

Each of these divisions may now be considered in detail.

\section{A. Haloplankton.}

I. Holoplankton. The term plankton was introduced by Victor Hensen in I887. It is derived from the Greek $\pi \lambda a \gamma \kappa \tau$ ós, which means wandering or drifting about aimlessly. The true plankton, or holoplankton, is most typically developed in the sea. It comprises those organisms which spend their lives in the sea drifting about from place to place, without power to direct their own

* The term epiplankton was proposed for this by George H. Fowler in I9I I (Encyclopedia Britannica, I Ith ed., vol. xxi, p. 72I), but was preoccupied by Grabau in 1909 as above defined (3). Hence the names anoplankton and anobenthos are here proposed. The names mesoplankton, mesobenthos, hypoplankton and hypobenthos, also proposed by Fowler, are, however, acceptable. 
course. These organisms range in size from creatures of microscopic dimensions to medusæ $50 \mathrm{~cm}$. in diameter. While some of the larger animals of this group have power to propel themselves through the water, they nevertheless are subject to the force of strong waves or currents, which render them helpless. Holoplanktonic organisms are wholly pelagic, and are characterized by a more or less transparent body and by the absence of opaque skeletal structures, only a few forms retaining delicate calcareous shells, inherited from their benthonic ancestors. In its horizontal distribution the holoplankton of the sea is dependent chiefly upon the marine cur'rents, as the organisms composing it are practically unable to carry on independent migrations, though many of them can dart about in quiet water. Hence they fall an easy prey to actively predaceous animals. The occurrence of holoplanktonic animals in swarms is also accounted for by their lack of independent locomotion, for the eggs, liberated by the floating parent, commonly develop without separating far from the parent, with which they are carried along by the currents of the sea. These animals have, however, the power to rise and descend in the water, and during the day many of them live at a depth of from fifty to one hundred and fifty fathoms, coming to the surface only on quiet nights. The animals of this class also occur in the abyssopelagic district.

2. Meroplankton. This term (from $\mu$ ćpos, a part) was introduced by Haeckel in I890 (4) and is applicable to the larvæ of benthonic animals which lead, during the larval stages, a truly planktonic existence and which occur with and suffer the same vicissitudes as the true or holoplankton. The upper levels of the ocean are usually crowded with such meroplanktonic organisms, and to them is due the horizontal distribution of benthonic species. Floating about in the sea in perfect clouds or swarms these meroplanktonic organisms pass their short existence a sport of the waves and currents. Sooner or later, however, they sink to the bottom, a veritable rain of seedling organisms; and, if they fall on a fertile soil, if they reach the proper facies of the substratum, they develop into the benthonic adult; but, if they fall upon an unfavorable bottom, or if the food supply is scarce, they perish. Thus, other things being favorable, wherever the facies of sea-bottom normal to a particular species of benthonic organism exists, the bottom may be peopled with that species by the larva which reach it from the upper waters, where they were carried by waves and currents during their meroplanktonic wanderings. As Walther says, should unfavorable circumstances temporarily destroy a whole fauna, its depopulated home would at once be surrounded by swarms of 
delicate larvæ, and, as soon as the old conditions are reëstablished, this fauna will again appear with countless individuals. This explains the sudden reappearance in later strata of the fauna of an earlier bed, even though it was absent from the intervening strata.

From a stratigraphic point of view the meroplankton is of vast importance, for to it is due the wide dispersal of the benthonic organisms, which of all marine life forms are the best indices of the physical conditions of the sea bottom. It is during the larval period that benthonic marine invertebrates spread in all directions from their center of occupancy, and that they have an opportunity to enter and occupy distant regions.

3. Pseudoplankton. This term was introduced by Schütt (8) for such organisms which, like the Sargassum, are normally or in early life benthonic, but continue their later existence as plankton. Walther has extended the meaning of the term so as to include those organisms which are carried about by floating objects, to which they are either attached as sedentary benthos or which serve them as a substratum on which they lead a vagrant benthonic existence. This group, however, is distinct, and is separated here under the name of epiplankton.

Under pseudoplankton may, however, be included those benthonic or nektonic organisms which become planktonic only after death; $i$. $e$., that portion of the plankton which consists of the floating parts of dead organisms, such as the leaves and trunks of trees, dead insects and carcasses of vertebrates, and, above all, the shells of molluscs, which, on the death of the animal, are distributed more or less widely, according to the nature of the shell. Thus the shell of Spirula is widely distributed and embedded in contemporaneous sediments where the organism never lived, and leaves of terrestrial plants are found in sediments far from land. Tree trunks from tropical America are carried to the northeast coast of Iceland, where they become embedded in contemporaneous sediments.

4. Epiplankton. This term (from $\dot{\epsilon} \pi \iota$, upon) was proposed (Grabau-3) for those organisms which live upon a floating substratum, to which they are either attached or upon which they lead a vagrant existence. The substratum may be holoplanktonic or pseudoplanktonic, the latter being the most frequent. Examples of epiplankton are the algæ, hydroids, and bryozoans attached to the floating Sargassum and other algæ; and the Crustacea, molluses, and other animals living among their branches; and the organisms attached to floating tree trunks and other psendoplankton.

A large number of algæ, especially the shallow-water forms, 
have attached to them sedentary animals as well as other species of algæ. Among the animals, hydroids and bryozoans are the most common, though other sedentary aninals, such as Spirorbis, are frequently abundant. Animals belonging to the vagrant type of the benthos are by no means rare. The large fronds of the Laminaria cast up on our northern shores diring every storm are frequently veritable menageries of invertebrate life, which, under favorable conditions, may float about for days. These fronds, for example, are commonly covered with a dense growth of the delicate littoral hydroids Obelia and Campanularia, while Bugula and other Bryozoa and Spirorbis are usually common. The hollow stem is commonly surrounded by an extensive growth of Membranipora, while not infrequently tubularian and other hydroids find this a suitable resting place. The root-like base of the stem often embraces the shell of Modiola or Cyprina, which in turn is overgrown with coralline alga. Sponges are also found among the "roots" of the Laminaria, and Acmæa, Chiton, Crepidula, Anomia, and other molluscs are attached to the shell, or to the stone which frequently takes its place. Finally, worms and crustaceans are not rare inhabitants of the sheltering space between the branches of the "roots"; and sea anemones, small star-fisll, brittle-stars, and sea urchins also occur, both on the basal portion of the stem and on the frond itself. Such floating menageries may be carried far out to sea or, what is perhaps more frequent, may be driven ashore. Not infrequently they are carried far up into the estuaries and, becoming stranded, are buried in the mud; or else they are cast up on mud flats behind some sheltering bar or ledge.

While these cases illustrate an epiplanktonic existence due to accident, the cirriped Lepas illustrates a habitually epiplanktonic existence; this barnacle rarely occurring except attached to floating objects. Many of the animals found on the Sargassum scem to be characteristic of it in its floating condition, not occurring on it in its native haunts. (Ortmann-7.) Walther has adduced evidence which goes to show conclusively that many of the larger fossil Pentacrini, and perhaps other crinoids, occurred with their stems wound around floating timbers, and he explains the occurrence of these marine animals in fresh water coal strata as due to stranding in estuaries of species leading an epiplanktonic existence.

The marine or haloplankton forms one of the chief sources of food for many marine animals and is everywhere devoured in vast quantities. Dead organisms which sink to the sea-floor in an incomplete state of (lecomposition form the chief clement of the organic oozes which furnish food to many littoral as well as abyssal 
animals. The skeletal portions of the dead plankton often accumulate in vast quantities on the bottom, and, in the greater depths where terrigenous sediments are absent, they usually form diatomaceous, radiolarian, globigerina, pteropod, and other oozes. The purity of such oozes, $i$. e., their freedom from clastic sediment, is usually an index of the purity of the water in which they were deposited, but from this we cannot always decide that such oozes, when found in fossil state, indicate deep sea. The absence of clastic sediment may be due to the low relief of the land, which may have been worn down to base-level, thus allowing water of moderate depth near shore to be free from detrital material.

\section{B. Halonekton.}

The term nekton, derived from the Greek vүкrós, which means swimming, was introduced by Haeckel in 1890 (4), for those animals which lead an actively swimming life. The group is typified by the class of fishes. A torpedo-like form, terminating anteriorly in a head, and perfect bilateral symmetry are the chief characteristics of these animals. A strong musculature for propulsion is usually situated in the posterior portion of the body, while appendages for balancing and steering are also usually present. The body is.non-transparent and a calcareous supporting skeleton is ordinarily developed. Typical nektonic animals of the modern sea are: the squids, the fish, and the degenerate mammals-whales, porpoises, etc. Besides holonektonic forms there are in the sea epinektonic ones, $i$. e., sessile forms more or less pemanently attached to a swimming host. The whale barnacle, attached to the under side of whales, and the ship's barnacles are examples among invertebrates, while the Pilot-fish attached by suckers to sharks represent this type among vertebrates.

\section{Halobenthos.}

The term benthos, from $\beta^{\prime} \nu \theta_{0 s}$, the depths of the sea, was likewise introduced by Haeckel in $I 890$ (4). It covers those organisms which inhabit the sea-bottom. We may divide the benthos into sedentary and vagrant (vagile) benthos, the former attached to the bottom, the latter moving over it. Living in such intimate relation with the sea-bottom, halobenthonic organisms are to a high degree dependent upon its facies, and their remains are generally cntombed in the region where they have lived, instead of being 
deposited anywhere else, as in the case witl p planktonic and nektonic organisms. The sedentary benthos is, to a large degree, dependent for food on those organisms which are swept within its reach by the currents, while the vagrant benthos is more actively engaged in seeking out its food. Large numbers of sedentary benthonic animals have assumed a radial structure, especially well typified in corals and crinoids, and also shown in the corona of the barnacle; while others, such as brachiopods, have a bilateral symmetry of high degree. Some of the lower vagrant benthonic animals, $c . g$., the Echinoidea, are also built on the radial plan, but the majority of the free benthonic animals are bilaterally symmetrical. Among the vagrant benthos the struggle for existence is most intense, and, as a result, the variety of adlaptations and the wealth of form and color are almost unlimited. Transitions from the vagrant benthos to the nekton are numerous, and it sometimes becomes difficult to decide if an animal belongs to the vagrant benthonic or to the nelitonic type. The gradation is just as complete as between nekton and plankton. In. general, a radial form may be said to be characteristic of the sedentary benthos, while a bilaterally symmetrical form is as characteristic of the vagrant benthos. Examples of change of form with change of habit occur in many classes. Both plants and animals, themselves belonging to the sedentary benthos, may lead, secondarily, a vagrant life by being attached to vagrant benthonic forms. These may be regarded as vagrant epibenthos. Among plants, algæ are the most familiar examples, while among animals hydrozoa (Hydractinia on shells inhabited by hermit crabs), actinians, and bryozoans furnish the most characteristic examples.

\section{Limnoplankton.}

Fresh water plankton is met with in all fresh water lakes, ponds, and streams. It not infrequently occurs in surprising amounts. Thus studies of the Illinois River and its tributaries have shown that it averages 2.7 parts per million of the water in the stream, and that the total average moving down stream past any given point aggregates 75,000 tons per annum, or about 8.5 tons per hour (6). The holoplankton here is largely composed of minute plants, while the meroplankton, consisting both of larval plants and animals, constitutes a very large percentage of the mass. Finally, the pseudoplankton makes up a not inconsiderable portion of this mass. The term limnoplankton has been restricted 
to the plankton of the larger fresh water seas by a number of writers, notably O. Zacharias, who uses the term helcoplankton for the plankton of shallow ponds and potamoplankton for that of rivers.

\section{E. Limnonekton (Heleonekton, Potamonekton).}

The nekton of fresh water, like that of the sea, is typically represented by the fish, though other classes of animals, such as the aquatic mammal, are also represented. The merostomes of the Palzeozoic also appear to belong here. An interesting example of a meronektonic life is evidenced by the tadpole, while an epinektonic condition exists in the larval fresh water mussel (Unio) which attaches itself to the gills of fishes.

\section{F. Limnobenthos (Heleobenthos, Potamobenthos).}

Both sedentary and vagrant benthos occur in fresh water; the former is chiefly represented by plants, but a number of invertebrates also belong here. Such are the sedentary infusoria, rotifers, and bryozoa, and the fresh water sponges and hydrozoa, though the principal nembers of the latter. class are only temporarily attached and may move abott at will. The vagrant benthos, on the other hand, is well represented by molluscs, worms, and crustacea, though the crawfish also leads at times a benthonic life.

\section{G. Atmoplankton. H. Atmonekton. I. Atmobenthos.}

Among the air-breathers permanent planktonic and nektonic types are unknown, though many unicellular plants, especially bacteria, live in the atmosphere for a considerable period of time, and must during that period be classed as atmoholoplankton. The meroplankton, however, is well represented, chiefly by the spores and seeds of plants, which are wafted about by the winds, and so become widely dispersed. Terrestrial nekton is represented by insects, birds, flying reptiles, and bats. None of these lead a permanently nektonic life in the air, for all return, more or less frequently, to the substratum. Nevertheless, during their period of flight, which often is very long, they must be considered as nekton of the air. The benthos of the earth's surface is pretty sharply divided into sedentary benthos, or plants, and vagrant benthos, or 
animals, though some exceptions occur among the lowest plants, while some animals lead a temporary or permanent (parasitic) attached existence.

\section{BIBLIOGRAPHY XXVII.}

(See also Bibliographies XXVI and XXVIII.)

I. CHUN, CARL. I890. Die pelagische Thierwelt in Grossen Tiefen. Verhandlungen der Gesellschaft deutscher Naturforscher und Acrzte. Bremen.

2. GRABAU, A. W. 1899. The Relation of Marine Bionomy to Stratigraphy. Chapter III in Geology and Palæontology of Eighteen-mile Creek. Bulletin of the Buffalo Society of Natural Sciences, Vol. VI, pp. 319-365.

3. GRABAU, A. W. 1909. Some New or Little Known Geological Terms and Their Application in Stratigraphic Writing. Abstract: Science, N. S., Vol. XXIX, p. 750 .

4. HæCKEL, ERNST. 1890. Planktonstudien. Vergleichende Untersuchungen über die Bedeutung und Zusammensetzung der pelagischen Fauna und Flora. Jena.

5. HENSON, VICTOR. I 887 . Ueber die Bestimmung des Planktons, oder des im Meere treibenden Materials an Pflanzen und Thieren. (V. Bericht der Commission zur Wissenschaftlichen Untersuchungen der deutschen Meere.)

6. ILLINOIS STATE LABORATORY OF NATURAL HISTORY. Bulletin, Vol. VI, Art. II.

7. ORTMANN, ARNOLD. 1895. Grundzüge der marinen Thier-geographie. Jena.

8. SCHÜTT, F. 1893. Das Pflanzenleben der Hochsee. Plankton Expedition, Vol. I. Leipzig.

9. WALTHER, JOHANNES. 1894. Einleitung in die Geologie als historische Wissenschaft. I. Bionomie des Meeres. II. Die Lebensweise der Meerestiere. Jena. Gustav Fischer. 


\section{CHAPTER XXVIII.}

\section{BIONOMIC CHARACTERISTICS OF PLANTS AND ANIMALS.}

A bionomic consideration of the different classes of modern plants and animals is of the utmost importance to the stratigrapher, since it is from such studies that he is enabled to interpret the conditions of the past, in so far as they are indicated by organisms. The present chapter will, therefore, deal somewhat at length with the bionomic characters of the various classes, special stress being laid on those types which are capable of fossilization.

\section{BIONOMIC CHARACTERS OF PLANTS (Schimper-25).}

\section{Protophyta.}

The majority of these primitive plants are not adapted for preservation, and hence are unknown in the fossil state. The slime molds, or Myxomycetes, occur on decaying logs, in damp wood, on rotting leaves, etc. The Schizophytes or bacteria are everywhere present. They are abundant in the plankton of the shallower portions of the sea, but rare in the open sea. In fresh water, in the air, and in the soil, as well as in all decaying substances, they occur, themselves forming the principal agents of decay. Their work in the formation of iron ore deposits has elsewhere been referred to. The Cyanophyceæ occur in the sea, in fresh water, on moist earth, on damp rocks, and on the bark of trees. They enter the intercellular spaces of higher plants, and may enter into the structure of the lichen thallus. Some species flourish in hot springs with a temperature as high as $85^{\circ} \mathrm{C}$. Volvox and other flagellates, most of which are generally regarded as animals, are especially at home in stagnant water, and amidst putrefying organic matter in the sea or in fresh water. Many flagellates are also parasitic and the spores of some may survive a temperature of $250^{\circ}$ to $300^{\circ} \mathrm{F}$. for ten minutes, though the adults are killed at $180^{\circ}$. 


\section{Thallophyta.}

ALGX. The lowest of the green algæ (Protococcaceæ) constitute, with the diatoms, the Cyanophycex, and the bacteria the chief holoplanktonic plants, though many of them also have a benthonic habit, being attached chiefly to othẹr plants, or encrusting stones, as in the case of some fresh water Cyanophycex. They are mainly inhabitants of fresh water, though diatoms are also abundant in the sea. Protococcus itself is terrestrial. The Charophycea, often classed with the green algae, secrete lime. This is especially true of Chara, which occurs in fresh water lakes from two meters down, and which is probably an important factor in the formation of fresh water limestones.' (See ante, page 47r.) The majority of the green algæ belong to the benthos, being equally abundant in the marine and fresh water realms. The red alga are benthonic and chiefly marine, though some species occur in fresh water. Lime-secreting types also occur in this class, constituting the nullipores or coralline seaweeds which inhabit the littoral district of the sea, chiefly in tropical regions but to some extent also in temperate climates. They occur as jointed fronds of a red color (Corallina), as crusts on other algæ (Melobesia), or as extensive pink incrustations on stones or shells (Lithothamnion). They are especially characteristic of depths between 15 and 35 (or 50) fathoms, where they constitute the "coralline zone" of the littoral district. The brown algæ are mainly marine benthonic types, usually attached to a rocky substratum. The common brown algx of the northern coasts (Fucus, Ascophyllum) have already been referred to as clothing the rocky ledges and forming a substratum for Hydrozoa, Bryozoa, sponges, etc., as well as other alga. Though typically attached, some forms, like the Sargassum, will continue to grow and multiply, even after they have been torn from their anchorage and carried into mid-ocean. The Sargassum is thus typically pseudoplanktonic, as are also all the other alga attached to it. Many of the brown seaweeds grow to great size. A familiar example is the common kelp (Laminaria) of the Atlantic coast, which generally grows to ten or more feet in length, while the giant kelp of the Pacific (Macrocystis) is said sometimes to reach a length of three hundred meters. The Laminarians are typical of the littoral district down to fifteen fathoms, this interval being known as the zone of Laminarians. The large species all grow in the deeper portions of this zone, where they are anchored by their "roots" to stones, shells, or other objects of support. They 
often hold on to objects small cnough to be carried away with the seaweed during a violent storm; and since the stipe and frond of the seaweed are commonly covered with sedentary benthonic animals, this seaweed forms a ready agent for the wider dispersal of such organisms.

In general the larger algæ are attached to a rocky or other hard substratum or to other algx (epiphytic). On muddy or sandy bottoms algx are rare, though stranded alga may be buried in numbers in mudflats. The large alga (macrophytes) are mostly restricted to the photic region, where they are distributed in the two belts, the perpetually submerged (i.e., below low tide) and the periodically emerging belt (between tides). Marine alga are found to the height of the salt spray on the shore, while terrestrial alga are known from the tropics, where they live as epiphytes on leaves, especially in the rainy districts. In the temperate regions they are associated symbiotically with fungi to form lichens, which increase in numbers and importance as the climate becomes cooler. They and the mosses constitute the chief epiphytes and epiliths in the temperate and cooler clinates. Lichens sometimes form structures which under favorable conditions may be preserved. In the arctic regions microscopic reck and brown algæ (Sphærella, etc.) often color the snow and ice and, together with many other microphytes, form a characteristic element of the vegetation of these regions.

Diatoms are important rock-builders, since their siliceous skeletons or frustules are readily preserved. They occur both in fresh and salt water, no ditch, pond, or pool being without them, and they form a characteristic member of the marine plankton. A great many types, however, are benthonic, forming yellowish-brown films on the mud in shallow pools, or growing attached by slender stalks to other plants. They commonly possess the power of motion found also in desmids and other unicellular plants. Fossil diatoms are abundant in the Tertiary of many localities, often forming extensive beds of nearly pure frustules, generally of fresh water origin. Underlying the city of Richmond, Virginia, is a bed of these organisms eighteen feet thick, while other extensive deposits occur in the coastal plain of Maryland and New Jersey, as well as in many other parts of the world. In Mesozoic deposits they are less abundant, and they are not known positively from Palaeozoic deposits, probably owing to alteration of the frustule. Diatomaceous deposits are often erroneously spoken of as infusorial earth.

FUNGI. The members of this group are destitute of chlorophyll and, consequently, are dependent upon organic matter for food, be- 
ing either parasites (growing upon living organisms) or saprophytes (growing upon dead organic matter) or both parasitic and saprophytic. Fungi can thus grow in the dark regions of the earth, sunlight not being essential. They are mostly terrestrial (when not living within their host), though some marine representatives are known, and certain of the molds (phyconycetes) form on decaying animals in fresh water or sometimes on living fish or crustacea. The large terrestrial fungi are most characteristic of the temperate zones, the tropical species being mostly small.

Lichens. Lichens are terrestrial plants growing chiefly upon the bark of trees, rocks, the ground, mosses, and, more rarcly, upon perennial leaves. In large forests they hang as a dense growth from the trees (Usnea), but in other cases they encrust the rough bark of the trees. They may also occur on the smooth bark of young trees or shrubs, and sometimes on decayed or decaying wood. All of these are classed as corticolous lichens. Saxicolous lichens grow on rocks and stones, which they disintegrate. They comprise the calcicolous forms, growing on limestones, or other calcareous rocks, on the mortar of walls, ets., and calcifugous forms which grow on rocks of non-calcareous character. Terrestrial lichens grow on all kinds of soil, some preferring peaty, some calcareous, some sandy, and some granitic soil, but none grow on cultivated soil.

Muscicolous lichens grow on decaying moss, such as the dead peat mosses, while epiphyllous species grow on perennial leaves, whose vitality they do not affect. The distribution of lichens is greater than that of any other class of plant, occurring from the poles to the equator, practically wherever land exists. Lichens may be dried so thoroughly that they can easily be reduced to powder, yet their vitality is only suspended, and moisture will restore them to renewed activity. Their growth is extremely slow, and the life of the plant seems to be very long, in some cases many hundreds of years.

\section{Bryophyta and Pteridophyta.}

These are wholly absent from the sea, but in fresh water a few bryophytes are known. The peat-moss (Sphagnum) grows abundantly in wet woods or in bogs. The growing ends increase while the old portion dies off. Among the pteridophytes the class of Filicinæ has an aquatic group in the rhizocarps, or water ferns (Hydropterideæ), which grow partly submerged or floating. The spores of these plants are widely distributed by flotation and 
may become enclosed in the finer lutaceous sediments. Spores referred to rhizocarps (Protosalvinia) are found in abundance in the black Devonic shales of North America, and it has been held that the black color and petroliferous character of these shales are wholly due to the spores of these plants. If the spores are, indeed, those of rhizocarps, they would be an indication of the formation of the black shales in the estuaries of rivers, since these plants are found only in fresh water.

Ferns are most abundant in the tropics, where they develop an extraordinary wealth of form, and vary in their dimensions from small moss-like plants to trees. They are especially characteristic of humid forests.

Equisetinc, or horse-tails, are represented by the living Equisetum and by the extinct Calamites, which latter often grew into large trees. Equisetum to-day grows in low moist ground and in the sand and gravel of railroad embankments, and along road sides. Much silica is present in the epidermis of the plants, giving to it a rough, harsh feel.

Lycopodiacea, or club-mosses. These are to-day represented by small prostrate plants found mainly in the deeper woods. In late Palæozoic time, however, they were represented by forest trees (Lepidodendron, Sigillaria, etc.) A few aquatic lycopods exist (quill-worts, Isoetr). These plants grow either partly or completely submerged, and in general resemble the smaller club-mosses.

Both Equisetx and Lycopodiacex are characteristic of the tropic and temperate zones, the Lycopodiacex being imore prominent in the tropics.

\section{SPERMATOPHYTA.}

By far the greater mass of spermatophytes or phanerogamous plants are terrestrial in habitat, though a not inconsiderable number live in fresh water. Certain members of the pondweed family (Potamogetonaceæ) and the frog's-bit family (Hydrocharitaceæ), comprising about twenty-five species in all, have become wholly adapted to a marine benthonic habit and are known as sea-grasses. The pondweed family is represented on the Atlantic coast by the eel-grass (Zostera marina L.) and the ditch-grass (Ruppia maritima L.), both of which are extremely common, and both of which are concerned in the gradual choking of the marshes. A number of species are partly marine, as the marsh-grass (Spartina) growing within the limit of tide-water. The mangrove, as already noted, is partly adapted to a marine habitat, all of it but the leaves being periodically submerged. 
All degrees of freshwater phanerogams are found, from those having only their roots in the water, as many of the larger swamp plants, to those nearly or entirely submerged. Parasitic, saprophytic, and epiphytic phanerogams are further characteristic types adapted to peculiar habitats. In short, the variety and adaptability of the spermatophytes are as multitudinous as the variation in the character of the terrestrial realm.

The coniferous gymnosperms are almost wholly confined to temperate climates, especially the colder belts, but cycads are most characteristically tropical plants. Both monocotyledons and dicotyledons are more commonly represented by trees in the tropical than in the temperate zone, the number of trees diminishing toward the colder belts, where the conifers increase in number.

Arboreal vegetation is characteristically unknown in regions where the sub-soil is permanently frozen, $i$. $c$., where the mean summer temperature is below $10^{\circ} \mathrm{C}$. Such is the character of the treeless plains of northern Canada, the coldest part of the North American continent, where the mean annual temperature is below $-8^{\circ} \mathrm{C}$. and the mean summer temperature below $10^{\circ} \mathrm{C}$. Here sedges, grasses, and lichens predominate, while trees and sphagnum-bogs are conspicuously absent.

The present northern extent of the forest regions of Canada is limited by the mean summer temperatures of $10^{\circ}-15^{\circ} \mathrm{C}$. Here the poplar (Populus tremuloides and $P$. balsamifera), the birch (Betula alba), spruce (Picea alba and P. nigra), pine (Pinus banksiana), and larch (Larix ancricana) occur, while beneath them the ground is often an extensive sphagnum swamp. "Poplar, birch, and pine extend northward as far as the heary forest extends, while larch and the true species of spruce extend northward to the northern limit of trees, becoming small and dwarfed before they finally disappear." (Tyrrell-28:389-9I.)

South and west of the forested area are the grassy plains, which, because of their dryness, do not support trees or sphagnum bogs. As these plains were in the condition of the frozen tundra after the retreat of the ice, and with the amelioration of the climate became dry, no trees or sphagnum bogs ever developed there.

\section{Ecology and Ecological Adaptations of Sphermatophytes.}

Modern spermatophytes, as a whole, are livisible into a numiber of habitudinal types, among which the following are the most important : 
I. Hydrophytes and Hemilhydrophytes. Aquatic plants are marine, or brackish, or fresh water. The marine types comprise the grass-wracks or eel-grasses (Zostera marina, and $Z$. nana). A few plants are confined to a brackish-water habitat (Ruppia maritima, etc.), while others are adapted to both fresh and brackish water. The aquatic vegetation of ponds and lakes may be divided into types with: (a) submerged leaves, (b) submerged and floating leaves, (c) floating leaves, (d) submerged leaves and erect leaves or stems, (e) erect leaves or stems, and lastly (f) marsh plants.

2. Xerophytes. This group includes the plants which have devices for procuring or for storing water, or for limiting transpiration, adaptations related to dry habitats. They have frequently long tap roots which, in some cases, reach down to a subterranean water supply. There is also often a superficial root system. Xerophytes of the deserts often have succulent stems, like the cacti of southern and central America. In other deserts, such as the Sahara, succulents are not prominent. A spiny character also characterizes many Xerophytes.

3. Bog Xerophytes. 'These are plants living in the peaty soil of fens and moors, which, though physically wet, are physiologically dry. Such plants can survive a partial or complete drying up of the bog.

4. Tropophytes. These are plants with a xerophytic character during the unfavorable season. Thus decicluous trees are xerophytic during the leafless period of winter while other plants survive the unfavorable period by means of their bulbs, rhizomes, or other special structures.

5. Hygrophytes. These are intermediate between Xerophytes and hydrophytes and are sometimes called Mesophytes. Assimilation goes on throughout the whole year, except during periods of frost or when buried by snow.

6. Sciophytes. These are plants growing in the shade of forests. They may be hygrophytes or they may be herbaceous tropophytes.

7. Halophytes. These are plants growing in saline soils, and they are characterized by xerophytic adaptations. Many of them are succulent, their leaves and, to some extent, their stems having much water-storing tissue.

8. Calcicole and Calcifuge Plants. Plants invariably inhabiting calcareous soils are said to be calcicoles, while calcifuge species are rarely or never found in calcareous soil. They are sometimes termed silicicoles. 


\section{BIONOMIC CHARACTERISTICS OF ANIMALS.*}

\section{ProtozoA.}

ForAMINIFERA. The Foraminifera are typically marine organisms, though a considerable number of species has become adapted to brackish water, living in estuaries and near the mouths of streams, while many species, commonly placed in this class, live entirely in fresh water. Their distribution is so great that scarcely any marine sediments are wholly free from the shells of these animals. Most Foraminifera belong to the vagrant benthos, though sedentary benthonic forms also occur. Only something over twenty living planktonic species are known, these belonging chiefly to the genera Globigerina, Orbulina, and Pulvinulina (Figs. IOI-IO3), the first predominating. The small number of species is, however, counterbalanced by the enormous number of individuals. The benthonic Foraminifera are confined chiefly to the littoral district, where the character of the bottom and the temperature of the water exert important influences on the distribution of these organisms. A muddy facies of the sea-bottom seems to be conducive to the existence of a large number of species, but the rocky bottoms are not without their types; while alga and sea-grasses commonly form the home of vast numbers of these organisms. The coarse, sandy and gravelly bottoms are not generally inhabited by these animals, though their dead shells are not uncommon in the sands along our beaches; while along some shores, they are so abundant as to constitute the greater portion, if not the whole, of the deposit. Dana (9) states that in the Great Barrier-reef region of Australia the shells of Orbitolites are so abundant that . . . "they seemed in some places to make up the whole sand of the beaches, both of the coral islets and of the neighboring Australian shore."

The vertical range of the benthonic Foraminifera is very great, species sometimes passing through a range of several thousand fathoms. In such cases there is often a change in the size or thickness of the shell with the change in depth. Although the planktonic Foraminifera comprise so few species, the number of their individuals is enormous. From their shells the Globigerina oozes form in deep water, where no sediment is carried; but it is evident that, in a region where the land is reduced to near baselevel, so that little or no sediment is carried into the sea. pure accumulations of such shells will occur near shore, thus, forming a

* Only those represented by fossils are taken into account here. 
foraminiferal ooze in shallow water. But not only planktonic shells but the benthonic species as well may form a pure accumulation of foraminiferal shells, as has been the case in the chalk, in which the planktonic species are practically wanting. (Walther-29:215.) Reproduction of the Foraminifera is carried on by fission, budding, and spore formation. In the first two cases, the resulting part and the buds have the characteristics of the parent, except its size, and there are no special structures which serve for the greater distribution of the species. When spores are formed, these may be provided with a flagellum, whereupon the organisms pass through a mero-planktonic stage.

While the geographical distribution of the benthonic species is very restricted, and influenced by the facies of the sea bottom, the geographical distribution of the pelagic species is prevented from being world-wide only by the changes in the temperature of the water and by the ocean currents. The pelagic species are extremely abundant in tropical regions, and their shells form vast accumulations on the sea-bottoms over which they live. In the great depths these shells are absent, for they may be completely dissolved while they sink to the bottom, or shortly after reaching it.

Radrolaria. . The Radiolaria are marine planktonic Protozoa. They inhabit principally the open sea, where they occur at the surface or at various depths below it. In regions of terrigenous sedimentation, or where an influx of fresh water occurs, these animals are seldom met with. Hence their siliceous shells occur in abundance only in the deposits found at a distance from shore, and in deep water, where they may constitute as high as seventy per cent. of the mass. The greatest abundance of radiolarian skeletons was found by the Challenger expedition at a depth between 2,000 and 4,475 fathoms-the greatest depth sounded. In many places in the Pacific the bottom ooze is almost entirely composed of radiolarian shells with some intermixture of sponge spicules. The celebrated Barbados earth, a Tertiary deposit, is likewise composed of radiolarian remains, to the exclusion of almost every other organism.

Fission, budding, and spore formation constitute the methods of reproduction in Radiolaria. The spores may be provided with flagella, constituting "swarm spores," which, like their progenitors, lead a planktonic existence.

\section{Porifera.}

The sponges are marine or fresh-water animals, of a sedentary benthonic habit. In general only such species as secrete a calcare- 
ous or siliceous skeleton-either continuous or consisting of separate spicules-are capable of preservation in a fossil state. The vertical distribution of marine species ranges from the shore zone down to the greater depths of the sea. Not infrequently species are found which regularly undergo an exposure of several hours between tides, though most littoral species occur below low-water mark, or in tide pools from which the water is never drained. Sponges will grow wherever a suitable surface for attachment is found, the most usual substratum chosen being cliffs, boulders, shells, or the stems and "roots" of the larger algæ. In deeper and quieter water. the sandy and gravelly bottoms are inhabited by sponges, and in the great depths they occur on the oozes and other soft deposits. A pseudovagrant (epi-vagrant) benthonic habit is assumed by a number of species, which attach themselves to the carapaces of Crustacea. Certain sponges bore into shells and other calcareous substances, forming extensive galleries and commonly destroying the shell. Clione sulphurea, common on our Atlantic coast, completely riddles shells, and then forms large irregularly rounded masses of a sulphur yellow color, often entirely enveloping the shell.

The reproduction of the sponges is either asexual or sexual. In the former case, buds are formed, which, growing larger, without detaching themselves, put out buds of their own, thus forming a colonial aggregation. Sponges torn into several pieces will frequently form as many new individuals, and sponges which were placed in close juxtaposition by Bowerbank in a relatively short time united into one. A method of internal gemmation occurs, in which groups of cells, or gemmulæ, become detached and after a time develop into complete sponges. Sexual reproduction, from either hermaphrodite or sexually distinct parents, leads to a free swimming blastula. This develops into a gastrula, which attaches itself and develops into the adult. Thus a mero-planktonic stage occurs in sponges, which serves as a means of extensive distribution.

\section{iII. Coelenterata.}

HydrozoA. The Hydrozoa are typically marine Coelenterates. though a few species occur in fresh water, $e . g .$. Hydra iridis and H. fusca, Cordilophora lacustris and the fresh water medusa of Lake Tanganyika: Limnocnida tanganyika. Some Scyphomedusx (Aurelia, Cyanea), according to Moseley, seem to prefer to float near the mouths of fresh water streams; while in New South Wales 
these medusæ were observed floating in shoals where the water was pure enough to be drinkable. The majority of species have a sedentary benthonic stage, the hydriform stage, which is generally colonial, the compound polyp stock being attached to rocks, algae, shells, timbers, or other objects of support, by means of a threadlike branching root-stock or hydrorhyza, which spreads out over the object of support and from which the individual polyparia arise, each with a distinct stem or hydrocaulus. A few forms, like Hydractinia polyclina and some Podocoryne, are pseudo-vagrant benthos, being attached to the shells of gastropods carried about by hermit crabs. Some species, like Bougainvillia fruticosa, prefer an epiplanktonic habit, becoming attached to floating timbers, a similar habit being assumed by those hydroids which live attached to the floating Sargassum. An epi-nektonic manner of life may perhaps be considered the habit of Hydrichthys, which lives parasitically upon a fish. Corymorpha pendula, though not attached, lives partly buried in the mud of the shallow sea; while Hydra leads, at times at least, a kind of vagrant benthonic life, though its journeyings are probably never very great.

Many, if not most Hydrozoa have a distinct medusiform person which, when perfect, is perhaps the best type of a holo-planktonic organism. In a few Hydrozoa-Hydra Sertularidx-the medusiform stage is wanting, in others it is degenerate, never becoming free (Clava); but in a large number of species it is a free individual. Again, in the Narco- and Trachymedusæ, as well as in some others, only the medusa occurs, the hydroid being suppressed. Compound medusæ occur as well as compound hydroids. The former are the Siphonophora in which, by budding from the parent medusa, a compound colony is formed which leads a holo-planktonic existence. Lucernaria is an example of a medusa attached to foreign objects. The medusæ, whether free or attached, produce the sexual products which give rise to new hydroid colonies or directly to new medusæ. The egg develops into a ciliated planula which leads a mero-planktonic existence before it settles down to become a benthonic hydroid, or before it develops into the medusa. A number of hydroids grow attached to rocks and sea-weeds, or to bridge piles, in such a position as to become regularly exposed for several hours each day during ebb tide. Even the delicate and unprotected Clava of our northern shores delights to live under such conditions, and is rarely found in deeper water or in tide pools. Most hydroids, however, can not withstand such exposure, and hence they are found only in the deeper waters or the deeper tide pools.

The majority of hydroids are inhabitants of the littoral district, 
and they usually occur in the more moderate depths. The tubularian hydroids probably never extend to any considerable depths, the deep-water forms belonging chiefly to the Plumularidx. (AgassizI, ii:35.) One of the abyssal Plumularians was obtained by the Blake at a depth of 1,240 fathoms, which exceeded by more than 300 fathoms that at which Plumularians were obtained by the Challenger. (Agassiz-I.)

The Paleozoic class of graptolites or Graptozoa is the most important group of the Coelenterata from a stratigrapher's point of view, for it constitutes one of the most important classes of index fossils known.

Lapworth (Walther-29) holds that the majority of dendroid graptolites (Dendroidea) undoubtedly grew attached to sea-weeds, rocks, or other supports, in the manner of most modern hydroids, but some were attached to floating algæ, leading an epi-planktonic existence. Cases of such attachment have been observed among these fossils.

Lapworth argues that, if the sicula was attached by means of the slender basal thread, the nema, to floating objects of support, whether disc or sea-weed, the second and succeeding hydrothecre. growing in the same direction as the sicula, would open downward. This suggests that the earlier graptolites were not planktonic, but grew attached to sea-weeds and rocks after the manner of modern hydroids. This view is taken by Hahn (16) with reference to Dictyonema. In later genera of graptolites, however, which may have been attached to floating objects (epi-plankton), the branches either bent backward, so as to cause the later hydrothecæe to open in an opposite direction from the sicula and early hydrotheca: or the direction of growth was reversed, the second and succeeding hydrothecx growing backward along the nema, which became the supporting rod or virgula.

Some of the graptolites appear to have led a holoplanktonic existence, the nema being attached to a central organ or lisc, which probably served as a float. This was long ago demonstrated in a number of species by Professor Hall, and lately has been shown in great detail in Diplograptus by Ruerlemann. This observer holds that this mode of attachment was characteristic of the virgulate graptolites (Axonophora) as a whole, while the Axonolipa he thinks were attached to seaweeds. (Ruedemann-25:5I5.) Whether holo-planktonic or epi-planktonic, either method of life accounts for the wide distribution of the graptolites. The fact that they are almost universally found in carbonaceous shales suggests that floiting alga may have been the principal carriers of these organisms. 
the decaying vegetable matter furnishing the carbon for coloring the muds in which the organisms were buried. On the other hand, it is not improbable that much of the carbonaceous material was derived from the graptolites themselves. The general slight thickness of these beds, and the fact that in successive beds the species change, indicate a slow accumulation of the deposits in relatively quiet water.

According to Ruedemann's observations (23), the young Diplograptus, on leaving the gonophore, has already advanced into the sicula stage, so that a free-swimming planula stage appears not to exist. It is probable that this is true of most, if not all, graptolites, and that hence the distribution of these animals is such as will be accounted for by the vicissitudes which they met with as a floating colony.

Anthozod. The Anthozoa are typically marine sedentary benthonic animals, inhabiting the warmer waters of the oceans. A large number are without hard supporting parts, and consequently leave no remains, while others, probably the majority of Anthozoa, secrete a calcareous or horny corallum, which is capable of preservation. Among the Actinaria, or fleshy polyps, a certain amount of locomotion of a creeping or gliding nature is often observable (Metridium, etc.), the individuals possessing this ability thus passing from a normal sedentary to a vagrant benthonic life. A few forms are also met with among the plankton. Occasionally epi-planktonic individuals are met with, attached to floating alga or timbers; and epi-vagrant benthonic individuals attached to moving crustaceans are not unknown. The Madreporaria, or stone corals, are normally sedentary forms, though they are not necessarily attached, but may rest upon the sands. (Fungia, some Porites.)

Though the normal meditm of the Anthozoa is salt water, a few are known in brackish and even in tolerably fresh water. Cilicia rubeola is reported by the Challenger (Vol. XVI, pt. II ; 36) in the river Thames in New Zealand; and Dana (9:I20) states that “. . . upon the reefs enclosing the harbor of Rewa (Viti Lebu), where a large river, three hundred yards wide, empties. which during freshets enables vessels at anchor two and a half miles off its mouth to dip up fresh water alongside, there is a single porous species of Madrepora (M. cribripora), growing here and there in patches over a surface of dead coral rock or sand. In similar places about other regions species of Porites are most common." Several species of corals grow at the mouth of the Rio de la Plata.

Porites limosa flourishes in muddy water, and Astrea bower- 
banki does not seem to mind mud or sediment, or even muddy brackish water, growing on, and encrusting the stones at the mout $\left.\right|_{1}$ of the Mangrove Creek, Australia, these stones being covered with mud and slime, and being washed over twice in the twenty-four hours by muddy, brackish water. (Tenison-IVoods.) A common Red Sea coral, Stylophora pistillata, is recorded by Milne-Edwards and Haime from the intensely salt and dense waters of the Dead Sea.

The simple corals (Caryophyllia, etc.) are chiefly found on muddy bottoms, often attached to a shell or other object resting on the mud. The bathymetric distribution varies from shallow water to a thousand fathoms or more. This method of life corresponds well with what is known of the Palæozoic Tetraseptata, which commonly lived on a muddy bottom, with their bases not infrequently showing signs of attachment to shells or other foreign objects. The compound corals build heads or stocks often of great size and weight. They are generally attached to stones, shells, or to the rock bottom and, through rapid increase by budding or division, masses of great size may be formed over a small object of support. Even on muddy bottoms a small object of support may serve as the nucleus around which a coral mass will grow, which, as it increases in size and weight, will sink to a greater or less depth into the mud on which it rests.

The typical compound or reef corals are very restricted in their bathymetric distribution. They do not normally occur below fifty fathoms, and the majority live in less than twenty fathoms of water. Very many, indeed, live so close to the surface as to be exposed at the lowest tides. A minimum annual temperature of twenty degrees centigrade marks the regions in which most reefbuilding corals occur, though in a few cases colder regions are known to be inhabited by true reef-builders. In all seas, howevcr. which are subject to freezing, or are regularly invaded by floating ice, reef-building corals cannot thrive, and hence the occurrence of modern or ancient coral reefs is a reliable indication of a minimum winter temperature above freezing.

The reproduction of the Anthozoa is both asexual and sexual. The asexual method is carried on by fission and budding, the newformed corallites usually remaining united with their parents, thits producing colonial forms. In some cases, however, the buds become free and begin an independent life (Fungia. Balanoplyyllia, etc.). New colonies, however, are mostly begun by sexually generated individuals. From the fertilized egg develops a meroplanktonic ciliated embryo, in appearance not unlike the planula of the hydro- 
zoa. After attachment this develops into the polyp, which early begins to secrete its horny or calcareous corallum.

\section{Molluscoidea.}

BryozoA. The Bryozoa or Polyzoa are marine or fresh water, chiefly colonial, benthonic animals. A few occur parasitic on a living substratum, but the majority of species are epiphytically attached to algæ, to hydroids, etc. (epizoön), or to inorganic objects (epilith), either basally or in an encrusting manner. The majority of species are marine; and their bathymetric distribution ranges from the shore zone, where they are exposed at low tide, to the abyssal depths, a species of Bifaxia having been obtained below 3,000 fathoms. The majority of species, however, live in moderate depths. While the Bryozoa normally lead a strictly sedentary benthonic life, a few species may drift about with the sea-weed to which they are attached, thus assuming an epi-planktonic habit. Holoplanktonic forms are, however, unknown.

Many of the Palaozoic species resembled and had a habitat similar to that of certain corals, often forming extensive beds or even reefs composed of few species but of an enormous number of individuals.

The egg of the bryozoan develops into a meroplanktonic ciliated larva, which later on settles down, becomes attached, and develops into a full-grown individual which, by budding, produces the colony.

BRACHIOPODA. The brachiopods are marine benthonic organisms, of exceptional stratigraphic importance, since they are to a high degree dependent on the facies of the sea bottom. Some species of Terebratula and Lingula can withstand a considerable exposure, the former having been noted out of water for hours together at low tide. Lingula is buried, by means of its long fleshy peduncle, in the sand near shore; Crania is attached to rocks and shells by one of its valves; but the majority of brachiopods are attached by their fleshy pedicles to rocks, shells, corals, or to one another. They seldom live on muddy or sandy bottoms, but are readily embedded in these, by becoming detached, after death, from the rocks or other objects to which they adhered.

The bathymetric distribution of the Brachiopoda ranges from shallow water to 2,900 fathoms (in one case); the majority of species occurring, however, above the hundred-fathom line, while a goodly number have been obtained in depths of ten fathoms or 
less. A number of species have an individual range of several hundred fathoms, this range in one of two cases being nearly 800 fathoms.

The mero-planktonic larva of brachiopods is known as the cephalula, and consists of a ciliated umbrella-like anterior end, carrying four eyes; a middle portion carrying the mantle lobes; and a posterior portion. When the larva becomes attached by the posterior end, which develops into the pedicle of the adult, the anterior end becomes enveloped by the forward-turning mantle lobes and develops into the body of the brachiopod.

\section{Mollusca.}

Pelecy poda. The pelecypods are marine or fresh-water benthonic molluses, which lead either a sedentary or a vagrant life. The majority of species live in the sea, but of these some can adapt themselves to brackish or even fresh water. Thus species of Cardium, Solen, Mya, and other marine pelecypods have been obtained in fresh, or nearly fresh, water; while Unio, on the other hand, has been found in the Brisbane river within reach of the flood tide. In the neighborhood of Rio Janeiro, Solen, and Mytilus, were found living with fresh-water Ampullaria in brackish water (Darwin-Io).

A number of pelecypods inhabit the shore zone, but the majority of these live buried in the sands and muds, and so are protecterl from desiccation at low tide. Mytilus edulis, however, is a goorl example of a shore pelecypod, for it habitually grows in positions where it will periodically be exposed at low ticle; while Modiola plicatula is especially common in salt marshes, where it is covered only for a short period at high water. The closely related Modiola modiola, which occurs on our northern shores, is, however, seldom exposed, growing either in deep water or in tide pools which are never drained.

Ostrea arborea is another striking shore mollusc, growing in vast quantities on the free roots of the mangrove, and withstanding a periodic exposure under a tropical sun. Ostrea borealis, on the other hand, is at home only in water of several fathons' deptli.

The bathymetric range of the pelecypods is very great, and even a single species may have a range of considerable magnitude. Thus, while Mytilus edulis does not occur below fifty fathoms. another species, $M$. phaseolinus, ranges from the shore to a depth of 3,000 fathoms. In the greater depths, the pelecypods are com- 
monly characterized by exceeding delicacy of shell and sculpture, the shell being often quite transparent. Some deep-ivater species show bright colors, but the majority are pale. Altogether there are to be found among these deep-water species "innumerable illustrations of beauty, adaptation, or unusual characteristics ..." (Agassiz). In the littoral district, on the other hand, the thickshelled pelecypods predominate, and this is especially true of the shore zone.

Pelecypods, like brachiopods, are excellent facies indicators, for, though they live on all kinds of sea bottom, the species, or at least the faunal combinations, are dependent on, and characteristic of, the particular facies on which they live. The majority of pelecypods are free animals, a few, such as the oyster, mussel, and the like, being attached to foreign objects-either by direct cementation or by a byssus. The free pelecypods often have the power of locomotion, Unio, Mactra, and others traveling occasionally for considerable distances. Generally, however, these molluscs lie buried wholly or partially in the sand, and never change their location except when disturbed by storm waves. Some few pelecypods (Pecten, Lima) have the power of swimming short distances by the opening and closing, in rapid succession, of their valves, and the forcible ejection of water. Even Solen, though normally a burrowing animal, will swim for some distance in search of the proper bottom, and it may often be seen circling around in an aquarium, by a series of jerks, due to the periodic ejection of the water from the siphons. A number of pelecypods bore into wood or stone (Teredo, Lithodomus, Saxicava, etc.), leading a sedentary life within the habitation thus formed.

The bivalve molluses have many enemies which prey upon them. Not the least of these are the carnivorous gastropods, whose depredations are usually marked by the vast number of shells with round holes bored into them, scattered along our beaches. Boring sponges will riddle the shells of littoral species, and corallines, Bryozoa, worms, and hydroids will attach themselves to the shells. There is abundant evidence in the riddled and punctured shells that even the Palæozoic molluscs were subject to similar attacks of boring sponges and carnivorous gastropods. When the animals die, their valves usually fall apart; and from their position, and the character and direction of the waves and currents, one valve may be carried shoreward, the other, seaward. This explains the frequent predominance, along the shore and in certain local portions, of fossiliferous beds of one valve, the other being entirely absent or at least very rare. 
The marine pelecypod normally passes through a mero-planktonic larval stage-the trochophore-in which the young.is provided with a velum, furnished with vibratory cilix (veliger stage). At certain seasons of the year these ciliated embryos swarm in the pelagic district, especially in the neighborhood of the shores, where they become the sport of the currents, which distribute them far and wide. When they finally settle down upon the sea bottom, on the loss of the velum, they develop further if they reach the proper substratum, other conditions being favorable. Vast numbers of the larvæ are destroyed before they reach the bottom, serving as food for all kinds of animals, or succumbing to unfavorable conditions; and vast numbers of others die from falling on an unfavorable bottom. That most species nevertheless develop to the fullest extent is due to the enormous fecundity of most pelecypods. As an extreme example may perhaps be mentioned our common northern oyster, Ostrea virginiana, which, according to Brooks (2: xxviii), produces nine millions of eggs. In fresh-water pelecypods the mero-planktonic veliger larva exists in one species only (Dreissensia polymorpha), which is believed to have migrated from salt to fresh water in recent geologic times. (Lang-19.) In the other freshwater pelecypods the development proceeds in a different manner, special adaptations to special modes of life being met with. In some cases (Pisidium, Cyclas) the eggs develop in special broodcapsules in the gills of the mother, which they leave with shell fully formed, as young bivalves. In these genera the velum remains rudimentary, the animal passing through the trochophore stage within the gills of the mother. In the Unionidre the embryo passes through its several stages in the gill of the mother, leaving it with a bivalve shell, which is, however, furnished with a triangular process on the ventral border of each valve, by means of which the embryo attaches itself to the fins (Anodonta) or gills (Unio) of fishes. In this manner the animal leads an epinektonic existence, becoming enclosed by the rapid growth of the epithelium of the part where the embryo is attached, and leading then a truly endo-parasitic life. After several weeks the embryo has become transformed into a young mussel, which, breaking through the enclosing tissue of its nest, falls to the bottom of the water, there to develop into the adult.

Scaphopoda and Amphineura. The first of these classes is represented by the Dentalidæ; the second by the Chitonidx, which alone are important palæontologically. Both are marine, being of a sedentary benthonic habit, though not permanently attached. Dentalium lies buried in the mud and sands usually at great depths, 
while Chiton and its allies cling to stones, shells, etc., and are rare in deep water, where only their more archaic representatives occur. A few species of Dentalium occur in moderately shallow water, but most of them live below the hundred fathom line, some reaching a depth of 2,000 fathoms or more. Chiton seldom extends below 500 fathoms. In both groups a mero-planktonic larva occurs.

GASTROPODA. The gastropods are typical benthonic animals, inhabiting the sea, fresh water, and the land. They almost invariably belong to the vagrant benthos, though the degree of locomotion varies greatly among the different species. Among the exceptions to the general vagrant habit are Vermetus and some other genera, which lead a truly sedentary benthonic life, being attached to rocks or shells. Some genera, like Capulus, adhere continually to shells and the tests of echinoderms and Crustacea; while the limpets, though adhering powerfully to rocks and shells by the muscular foot, are, nevertheless, in the habit of crawling about in search of food. Swimming and floating gastropods are also known, the latter (Janthina, Glancus, etc.) belonging to the true plankton.

The number of species living on land and in fresh water is relatively small, though the individuals often occur in great numbers. The sea is the home of most gastropods, though some marine forms can live in fresh water, while conversely fresh-water forms have been found in water temporarily salt. Thus Limnæa was found by Darwin (IO) in Brazil, in a fresh-water lake to which the sea had access at least once a year.

Among the normally fresh-water gastropods several occur which have become adapted to a marine life. Thus Planorbis glaber was found at a depth of I,4I5 fathoms at Cape Teneriffe, and two species of Nerita have been found in the sea. Limnæa and Neritina live in the Baltic, where the water contains from ro to 15 permille of salt.

The variety of form and coloration is exceedingly great among the gastropods, a fact which can easily be correlated with their high degree of cephalization and actively vagrant life. They occupy all parts of the sea, being much less dependent on the facies of the sea bottom than the pelecypods are. The division into carnivorous and herbivorous forms is also much more strongly emphasized than in the pelecypods, which live largely upon the plankton.

The shore zone is occupied by a number of species, which can withstand periodic exposure. Many of them require this exposure and will invariably crawl to the surface if kept in confinement, even if the water is kept cool and well aerated. Other species, 
again, live in shallow water, even if stagnant, and will not stand a long exposure.

Various species of Neritina ( $N$. dubia, $N$. zic sac, etc.) live habitually high up on the trees of the mangrove swamps, depositing their eggs, however, on the surface of the water. Others occur on the dry land, far from any water. (Semper-26.)

Nassa obsoleta covers the gentle muddy beaches at low tide, where dead organisms remain for it to feed upon, and it also abounds on every exposed mud flat on our northern coast. Littorina rudis and L. palliata are commonly found on the New England shore clinging to rocks or to the stems of the marsh-grass (Spartina), high up, where they are exposed to the air for half the day. The lack of a siphon forces these animals to live above the mud (12:I68). On the marshes of Cold Spring Harbor, these species of Littorina occur in places where they are "submerged for only a short time at high tide, and then under water that is nearly fresh." (Davenport-12:I69.) In the Mississippi sound Davenport found nearly all of the individuals of Littorina irrorata "living on the stems of the short marsh-grass twenty to thirty centimeters above the water level and exposed to the sunlight." Littorina rudis lives prevailingly where it is much exposed. On the English Channel it has been found two meters above the other marine animals, where it is moistened only by the highest tides (Fisher-13:I82); and on the New England coast it is sometimes found in similar positions. Species of Littorina are reported as passing the winter out of water, with their gill chambers full of air. (Simroth-27:84.)

The majority of gastropods are shallow-water forms, though a number of them range to depths of between I,000 and 2,000 fathoms. The deep-sea gastropods are characterized by faint colors, though often this is counterbalanced by the brilliancy and beauty of the iridescence, and even the non-iridescent abyssal species give out "a sort of sheen which is wanting in their shallowwater allies." (Agassiz-I, ii:63.) The coarse ormamentation by knobs, spines, etc., so common in shallow-water species, does not occur in the deep-sea forms, where the ornamentation is more delicate, and often of exquisite richness and beauty. Gastropods feeding on vegetable matter are wanting in the deep sea, where no vegetable matter occurs, except what is brought down as sediment. The food of deep-sea molluscs is largely confined to soft-tissued animals, since thick shells and other hard armors are generally absent in these depths. Agassiz states that the Pleurotomidx outnumber any other group of molluses in the abyssal fauma. These gastropods are cliaracterized by a notch in the outer lip near the 
suture, which serves for the discharge of the refuse, thus preventing fouling of the water used for respiration. Some of these molluscs are provided with hollow barbed teeth and poison fangs, which they use to kill their prey. This apparatus "is even more fully and generally developed in the related group of the Conidæ, few of which reach any great depth.” (Agassiz-1, ii :66.)

A few gastropods are viviparous (Paludina vivipara, Littorina rudis), producing their young in advanced state of development.

In nearly all the marine gastropods a veliger larva occurs, the velum being generally large, wing-like, and fringed with cilia. This velum may be retained until the shell is long past the protoconch stage. While in most marine gastropods the veliger larva leads a mero-planktonic existence, some marine forms (Fulgur, Sycotypus), and the oviparous, land, and fresh-water gastropods pass through their veliger stage within the egg capsule, losing the velum and other larval organs before passing from the capsule, which they leave as young gastropods with well-developed shells.

In the case of the marine forms cited, the velum, though of no use to the animal as a locomotor organ, is very large, and is lost only just before the embryo leaves the egg capsule. In terrestrial and fresh-water forms, on the other hand, the velum is reduced to a single ring of cilia or to two lateral ciliated streaks. (Lang-19, ii:257), while in some terrestrial species it is wanting entirely. It is obvious that the distribution of species thus deprived of a temporary pelagic life must be more restricted, other things being equal, than that of species having a free veliger stage of greater or less duration.

Land snails generally require a considerable amount of moisture in the atmosphere in order to be able to live an active life. Hence they are found most abundantly near streams and in damp woods and ravines, where they live on the ground or on the vegetation. Nevertheless they can withstand a considerable amount of desiccation by burying themselves in the soil or closely clinging to rocks or trees. Even the deserts have their species, which obtain their required moisture chiefly from the dew, and from the succulent plants on which they feed. Hence the presence of snail shells in loess deposits is not necessarily indicative of deposition by water. Some remarkable cases are recorded by Woodward (3I:I4), of the suspension of vitality in snails and their subsequent revivification. Thus a specimen of a desert snail which had been affixed to a card in the British Museum for a period of four years (I846-1850), again came to life upon being immersed in tepid water.

Pteropoda. The pteropods are marine planktonic molluscs 
which live in vast numbers in the pelagic district, usually some distance from shore. While able to swim about in the water, they are, nevertheless, at the mercy of the waves and currents. Their food consists of pelagic organisms, and not unconmonly one species of pteropod will prey upon another. They shun the light, descending during the day to the regions of perpetual twilight or even darkness, some descending as far as 700 fathoms. Nearly all the shelled pteropods of the present time are confined to warmer waters, and are especially abundant in the warm ocean currents. Their shells often accumulate in vast numbers on the ocean bottom. A veliger larva, similar to that of the gastropods, occurs.

CEPHALnPoda. The cephalopods are marine nektonic or benthonic molluses inhabiting water of moderate depths. Swimming is accomplished by the forcible ejection of water from the hyponome, and probably also by the use of the arms. Among the dibranchiata the majority of Sepioidea (Squids, Calamaries) are active swimmers, usually inhabiting the open sea, but appearing periodically on the coasts in great shoals. They live mostly on small fish. The Octopoda are less adapted to active swimming, lying usually in wait for their prey on the sea-bottom or in crevices and hollows. The Argonauta is, however, a partial exception to this, for, though it crawls about on the sea-bottom like other octopods, it is often met with swimming at or near the surface, by the ejection of the water from its hyponome. Argonauta is, therefore, like other cephalopods, at times a vagrant benthos, at others a nckton, inclining perhaps more to the latter, as do the decapods; while other octopods are commonly benthonic. Among the less active decapods, Sepia may be mentioned as more normally a vagrant benthonic form, crawling about on the sea-bottom, though able to swim as well. A sedentary benthonic cephalopod is also known. This is Spirula, which attaches itself to rocks like an actinia (Agassiz, Walther), or lies partly buried in the mud, with its beautiful coiled and chambered shell wholly concealed by the fleshy parts. A perfect specimen was dredged off Grenada in the Caribbean by the Blake, from a depth of $95^{\circ}$ fathoms. (Agassiz-I, ii : $6 r$.)

Spirula would seem to be a widely distributed form, judging from the occurrence of its shell in almost all parts of the tropical and temperate seas. The animal is very rare, however: only one specimen with soft tissues preserved having been obtained by the Challenger expedition. This was taken close to the island of Banda in 360 fathoms (Challenger Narrative). Altogether perhaps only half a dozen animals with the soft parts preserved have been 
obtained. The wide distribution of the shell of Spirula is due to the fact that after the death of the animal the shell ascends to the surface, owing to the air-filled chambers, and then becomes a part of the plankton. It is carried hither and thither by the currents and waves, and finally may reach the sea-bottom in regions remote from its original home, and be buried in sediments of every description, and under conditions in which the animal never existed. Thus the shell of Spirula becomes an excellent index fossil, being widely distributed and buried in all kinds of sediment.

To a more restricted degree this method of pseudo-planktonic distribution of the shell, after the death of the animal, occurs also in Nautilus, the only modern representative of the tetrabranchiate cephalopods. The animal belongs to the benthos, living in shallow water in the tropics. Occasionally it swims near the surface, but before long it returns to the bottom, where it crawls about with its shell uppermost, feeding on crustacea and other animals. On the death of the animal the shell may float for a considerable time on the surface, buoyed up by the air in the chambers, and thus it may be carried for a greater or less distance before it settles to the bottom, where it will be buried in all kinds of sediment (Walther). The verity of such statements has, however, been questioned by Ortmann and others, who believe that the Nautilus shell is seldom carried far from the region inhabited by the living animal.

What is true of the shells of Nautilus and Spirula is true of the shell of Sepia, and was undoubtedly true of the shells of Ammonites as well. (Walther-29:509; 30:258 ct seq.) In fact, we may even believe that the shells of the Ammonites were better floaters than either those of Spirula or Nattilus, for these two genera are retrosiphonate, the siphonal funnels passing backward and thus giving more ready access to the water; while the shells of the Ammonites were prosiphonate, their siphonal funnels bending forward like the neck of a bottle, and thus making the entrance of water more difficult. This conception of the planktonic wanderings of the shells of cephalopods after the death of the animal furnishes a satisfactory explanation of many anomalies observed in the occurrence of these animals in the geologic series. It accounts, especially, for the sudden appearance and disappearance of the same species in widely separated localities, irrespective of the character of the rock, and of its normal faunal contents. This widespread distribution of these shells makes them excellent indexfossils, so that even small formations may readily be correlated by their species of Ammonites, even though widely separated.

It does not follow, of course, that ammonoid shells must always 
be regarded as strangers which have drifter to their present position; in fact, it is often easy to see that such has not been the case in any particular locality, from an examination of the shells themselves, as well as from the extraneous evidence. Thus, according to Clarke ( $5: 135$, et seq.), the ammonoids of the Naples beds of western New York " . . . bear sufficient demonstration in themselves that they have lived and died in these sediments." Many of the most delicate shells retain their apertures unbroken, and their suface ornamentation uninjured, a fact which is not consistent with transportation by waves and currents. The presence of the young in all stages of development further argucs for an indigenous occurrence. "On the other hand," says Clarke, "there are excellent reasons for regarding the prenuncial Intumescens fauna, that of the Styliola [Styliolina] limestone, as due to transportation from some adjoining province not yet known to us." The Goniatites of this fatna are associated with the millions of holo-planktonic Styliolina, with floated logs, and probably other pelagic organisms, and the sediment in which they were embedded was such as probably was not conducive to the well-being of such animals, so that their occurrence is best explained by the hypothesis of flotation.

Of the embryology of Nautilus, and hence of the whole group of Tetrabranchiata, nothing is known. The Dibranchiata develop directly within the egg capsule, no veliger stage occurring.

\section{Platylelmintha. Vil. Vermes.}

These worms are marine, fresh-water, or terrestrial animals. They belong chiefly to the benthos, though some marine forms lead a partially nektonic existence, while others are typically planktonic. Several oligochætous annelids have become adapted to a marine life, though the group is normally fresh-water or terrestrial. Among the benthonic species all grades of a sedentary life are observable, from the tube-building orders, which live permanently in attached tubes, to those which only temporarily occupy a given area. Tubicolous worms, which, like Spirorbis, attach their tubes chiefly to algæ, may often lead an epi-planktonic existence when the algæe are torn from their anchorage and washed away by currents.

A muddy bottom seems to be the favorite haunt of the littoral species, except such forms as build attached tubes ( $c$. g.. Serpulidie. etc.), which occupy stony and shelly bottoms. These latter often build extensive reefs of interwoven calcareous tubes. 
Besides calcareous tubes, many worms build tubes of agglutinated sand grains or shell particles, and worms living in the shells of dead molluscs are frequently met with. These agglutinated sand tubes are often very resistant, sometimes, with the castings, covering the mud flats and beaches in great numbers, and not infrequently being heaped together in windrows. The dredge brings large numbers of these tubes, together with numerous castings, from the deeper water. The bathymetric distribution of the worms is varied. The majority are undoubtedly littoral species, but deep-sea forms are also common. Beyond the hundred-fathom line the tubicolar annelids are the most characteristic, specimens having been obtained from a depth of 4,000 fathoms off Teneriffe (Challenger). Other worms also occur. Even species of the same genus have a widely varying distribution in depth. Thus the tubicoloid genus Spirorbis has its littoral species growing within the shore zone; while another species, $S$. nautiloides, has been dredged at a depth of 700 fathoms. Similarly, the Sipunculid Phascolosoma is represented along our northern shores by a species living in mud and sand above low tide, while the Blake brought up a species in a Dentalium shell from a depth of 1,568 fathoms. (Agassiz-I, ii :53.) The Myzostomidæ are parasitic on living Comatula, and also have been found on the column segments of Jurassic crinoids (Graff).

Among the annelids, the family Eunicida is of particular interest, in that its several members are characteristic of different bathymetric zones, thus furnishing, in a measure, an index to the bathymetric position of the fauna which they characterize. This family is well represented in the lithographic shales of Bavaria. (Ehlers.)

Among the worms regeneration of lost parts and generation of new individuals from fragments of old ones are not uncommon. Thus, in one of our common halo-pelagic worms, Autolytus, swimming buds carrying the sexual products are periodically constricted off, each regenerating a new head, with highly developed eyes at the anterior end. The oligochæte Lumbriculus in autumn falls into pieces, all of which are able to regenerate into complete animals. (Lang-19; i :267.)

A mero-planktonic ciliated larva, the trochophore, is characteristic of worms, this being the product of a sexual mode of reproduction. These larva are often obtained in vast numbers in the tow-net, together with other mero-planktonic and many holo-planktonic forms.

The œsophageal teeth of annelids are abundantly represented in many bituminous shales, from the Palrozoic on. Some of these 
objects, known as conodonts, were formerly regarded as the teeth of mixinoid fishes or as radula of gastropods.

\section{Arthropoda.}

\section{Crustacea.}

Trilobitc. The trilobites are extinct Palrozoic Crustacea of an undoubted marine habitat, probably able to swim as well as crawl, and so belonging at one time to the nekton, at another to the vagrant benthos. Whether or not a mero-planktonic larva existed is not known, but it might be assumed from the wide distribution of some species. Since trilobites cast off their exoskeletons, as does Limulus, some of these may have floated a considerable distance, comnng to lodge where trilobites never lived. It is certain that from the number of fossil trilobites we cannot judge the number of indivicluals existing at a given place, since a number of specimens may represent the cast-off exoskeletons of one individnal. Trilobites, like many modern Crustacea, probabiy turned on their backs while sinking to the sea-floor, this accounting for the frequent overturned position in which their remains are found.

Phyllopoda; Copepoda. These belong largely to the plankton. the phyllopods occurring mostly in fresh water, the copepods having fresh water (Cyclops) and marine representatives. The copepods further comprise commensal forms, which live in the branchial cavity of Ascidians (Notodelphus) or on the carp (Argulus); and a large number of parasitic types. Some of them, however, are only occasionally or temporarily parasitic. Some phyllopods have a bivalve shell (Estheria, etc.), which is frequently preserved in the finer fresh water sediments of continental formations. A planktonic nauplius larva occurs. The eggs of some phyllopods have the power to withstand desiccation for years. In fact. the eggs of Apus do not develop unless they lave been subjected to desiccation for some time (Semper). This accounts for the periodic reappearance of these organisms in the temporary water bodies of desert regions. The occurrence of such types (Estheria) in otherwise unfossiliferous deposits thus indicates that these deposits may be of desert origin.

Ostracoda. The ostracods are marine or fresh-water, planktonic or vagrant benthonic Crustacea whose imperfectly segmented body is enclosed in a bivalve shell. The majority of the marine forms are holo-planktonic, living in shallow water or in moderate depths, 
though a few species were found by the Challonger at depths exceeding 2,ooo fathoms. Some species are cosmopolitan and the order is represented in nearly all waters, their shells occurring in nearly all the bottom deposits. The animals are also abundant on alga, over which they erawl slowly. The fresh-water Cypris swims about, stuject, lowever, to the influcnces by which other nembers of the plankton are affected: or it crawls about on the vegetation. Cypris is also represented in brackish and salt water. Its eggs lave the power to withstand desiccation for a long time, and henee the species can continue in water bodies which become periodically dried tup, as in desert regions. The larva of the ostracods is a pelagic nauplius.

Cirripedia. The cirripeds, or barnacles, are marine sedentary benthonic Crustacea which have degenerated much from the true type of crustacean, owing, no doubt, to their attached mode of life. The body is covered with calcareous plates varionsly arranged, which fall apart after the death of the animal; after which, from single picces, it is quite impossible to determine the species, owing to the great variation of the skeletal parts. (Darwin.) Balanus and its congeners are sessile, being attached to the rocks and other solid supports along the shorc, seldom venturing into water of great depth. Sonse species are periodically exposed for many hours at low tide, some, in fact, never being covered more than one or two hours at flood tide, so high up on the shore do they attach themselves. Balanus has been found at a depth of 500 fathoms, but it usually lives in lesser depths. Balanus improvisus occurs also in brackish water, and some species of this barnacle have been reported from fresh water (Tscherniansky). Coronula diadema leads an epi-nektonic life, attaching itself to the body of whales. Verruca incerta, a common West Indian type, occurs in the Globigerina ooze. Lepas and its congeners are pedunculate, attaching themselves by a fleshy peduncle, which represents the elongated head end. The majority of the Lepadidx are pelagic, leading an epi-planktonic existence, attached to floating logs, pumice, or other objects. Three species of Lepas were found by the Challenger attaclied to the Sargassum. Some members of this family descend into deep water, Scalpcllum regium having bcen dredged by the Challenger from nearly 3,000 fathoms. These abyssal cirripeds are usually attached to nodules, dead or living shells, corals, large Crustacea, to spines of sea urchins and other objects. (AgassizI, if : ${ }^{\circ}$.) The cirripeds, upon hatching from the egg, pass througit several larval stages, the first of which is the nauplius stage. In this the body is unsegmented, with median frontal eyes, dorsal 
shield, frontal sensory organs and three pairs of limbs. After a series of moults the Cypris stage is reached, in which the larva is enclosed in a bivalve shell, like that of the Ostracola. During these stages the larva belongs to the mero-plankton. When it settles down and becomes attached it passes through a pupa stage. during which the transformation of the larva into the cirriped takes place.

Phyllocarida. These are mostly extinct forms, represented in all the divisions of the Palieozoic. Several living genera (Nebalia, etc.) are regarded as belonging here, and these are marine. They are swimmers, and their development is direct, without metamorphosis. Some of the Paleozoic forms referred to this class were undoubtedly marine (Stenotheca, Ribeiria), but the majority seem to have been fresh water forms living in the rivers of the Palieozoic lands. This is inferred from their peculiar occurrence in sediments which could only have been formed at the mouths of streams and in playa-like basins. At any rate, they did not seem to be normal inhabitants of the open sea, but, if marine at all, lived near the mouths of great streams.

Schizopoda, Stomatopoda, Sympoda. These are marine Crustacea, capable of swimming about by the use of their abdominal legs and caudal fin. Larval stages are often wanting.

Decapoda. The decapods belong chiefly to the benthos, inhabiting either fresh or salt water, rarely the land. Pelagic species also occur, some of which are good swimmers; while a few belong to the plankton and others to the epi-plankton, living on the Sargassum. They commonly feed on living or dead animal matter. The bathymetric distribution varies greatly, though the majority of species are confined to comparatively shallow water, generally not exceeding fifty fathoms. A considerable number, nevertheless, are abyssal. The range of individual species is often great; Alpheus avarus, for example, is said to range on the Australian coast from less than ten to about 2,500 fathoms (Challenger), though this is questioned by Ortmann (2I:75). Among the hermit crabs occur some forms which have left their native element and have taken to the land. The Challenger found some of them in the mountains of the Antilles, up to 300 meters. They sometimes inhabit the shells of land snails and have been seen climbing trees. Among the true crabs, or Brachyura, shallow-water species predominate, comparatively few occurring below 400 fathoms. A number of species live in fresh water or on land. The majority of decapods leave the egg in the zoëa stage, in which the abdominal region is perfectly segmented, though still without appendages, except per- 
haps the rudiments of the sixth pair. The compound eyes are stallied. Other larval stages follow until the adult is reached. These larve often occur in vast quantities in the plankton.

Arthrostraca. This super-order includes mostly marine forms, though the order Isopoda comprises marine, fresh water, and terrestrial types. The latter occur in damp woods, under moss, stones, or logs, and are also abundant in the crevices of rocky cliffs. The marine Isopods are common in shallow water, on alge, or swimming about in tide pools. Chiridotea coca lives on sandy shores, moving about just below the surface of the sand, and leaving a meshwork of curious trails in its wake. Some of the lower sand flats are often found covered with these markings. The animal is usually found at the end of the trail, its whereabouts being indicated by a little lump of sand. Limnoria lignorum eats its way into driftwood or bridge piles, of ten completely riddling and destroying the wood. Caprella clings to hydroids and slender seaweeds. Though chicfly found in the littoral district, some abyssal species are known, several having been obtained at a depth of over 3,600 meters. Sometimes different species of the same genus range from shallow water to great depths. Blind species are common in the Mammoth and other caverns. A number of types are parasitic on fishes. The Amphipods are chiefly marine, though fresh and brackish water species also occur in marine genera (Gammarus). Cyanus is parasitic on the skin of whales. Several species live on the beach just above the reach of the ordinary ticle, where they hide under the dead seaweed or burrow in the sand (Orchestia). They generally move about by leaps and hence are commonly known as beach fleas. Talorchestia lives in a similar manner just a little below high-water mark and the beach at low tide is often completely riddled by its burrows. A number of Orchestidie can live wholly out of the water in damp woods or in the dry stream beds.

\section{Acerata.}

Merostomata. The Xiphosurans are represented by the single living genus Limulus, which is a marine vagrant benthonic animal, though often swimming on its back when young. The usual habitat of this animal is in shallow water, where it is often partly buried in the mud or sand. Portions of the coast are often strewn with the cast-off exoskeletons of Limulus, which usually lie on their backs, a position which these structures will naturally take on sinking to the bottom. 
The young Limulus on hatching is a trilobitiform, free-swimming, commonly meroplanktonic organism without caudal spine (J. S. Kingsley).

Modern Limulus is restricted to the eastern shores of America and Asia. A Tertiary species (L. decheni) is known from the Oligocenic brown coal of Teuchern, near Merseburg, in Saxony, an occurrence scarcely suggestive of marine habitat. A marine species ( $L$. walchi) is abundant in the lithographic slates of Bavaria, associated with land forms, however. A small species occurs in the Bunter Sandstein of the Vosges, a formation chiefly of terrestrial (river) origin, and suggesting that Limulus in the Trias was still a river animal. This was most probably true also of Protolimulus, which occurs in the Chemung delta deposits of Pennsylvania. The Carbonic Xiphosurans. Prestwichia. and Belinurus were undoubtedly fresh-water (river) organisms, occurring in the non-marine coal deposits. Cyclus, on the other hand, is found in the interbedded limestone of the Coal Measures, as well as in the Coal Measures themselves. The habitat may have been marine, but not necessarily so, since these carapaces could easily have been washed from the land.

Altogether it seems as if the early Xiphosurans were river-living animals, venturing perhaps occasionally into the sea (euryhaline) and assuming their marine habitat in the Mesozoic and modern times.

The Synxiphosurans may have been partly marine and partly fresh water. The Upper Cambric Aglaspis stggests their derivation from the trilobites. This occurs in the St. Croix sandstone of Wisconsin, a terrestrial deposit reworked by the sea. The Siluric genera Neolimulus, Bunodes, Hemiaspis, and Bunodella occur in deposits which are partly marine and partly of delta type. It is not improbable that most of them were derived from the landwaters and buried in the sea margin deltaic deposits. The possibility of a marine character for some can, however, not he denied. Pseudoniscus, on the contrary, in America ocums in the Pittsford black shale deposits, which are most suggestive of influx of fresh water, and hence a non-marine hahitat is indicated. The European species are from Oesel and their real habitat is doubtful. (O'Connell-2o.)

The Euryptericla have generally been considered marine, but the elaborate study of the habitat of these organisms mate by Miss O'Connell (20) points unmistakably to a non-marine habitat of these merostomes since pre-Cambric time. The majority of forms occur in rocks not explainable as normal marine sediments, but as 
delta or as playa-lake deposits without direct connection with the sea. Individuals are occasionally found in marine deposits which cannot be interpreted as deltas, but in such cases the remains are of single individuals or are fragments. Since all known specimens of this kind represent merely the exoskeleton (Clarke and Ruedemann-6), it is easy to see that they may have reached their resting place as pseudoplankton. A characteristic mode of occurrence of these organisms is in the black muds intercalated in torrential conglomerates and sandstones. The geographic distribution, too, is of such a character as to indicate a river rather than a marine habitat. For further discussion of this probiem see page 1043 and the references there cited.

The Limulava are known only from the Cambric, where they are found in a remarkable state of preservation in black bituminous shales (sapropellutytes), together with trilobites, worms and other animals suggesting a marine habitat.

Arachnida; Pantapoda. The spiders and scorpions are typically terrestrial animals, breathing by means of trachæa. The Pantapoda (Pyenogonida), or sea-spiders, however, constitute a class of marine organisms, resembling in many characters the Arachnida, of which class they are often considered relatives. There is also a true spider. Argyroneta aquatica, which leads an aquatic life in fresh water. Scorpions first appear in the Siluric, where they are associated with eurypterids, from which they may have been derived. Spiclers are known from the Coal Measures, but insects date from the Ordovicic graptolite slates of Sweden (Protocimex).

\section{Myriopoda and Insecta.}

These are also terrestrial tracheates, but with marine representatives.

Larva of insects also live in the sea, and a number of adult insects are marine in habit, though continuing to breathe air. Nany insects and spiders have been met with in the open sea, far from land, swimming in great numbers on the surface, while others have been found creeping between rocks under water by the shore. The bug Halobates comprises some fourteen species living on the surface of the sea, rumning about like the fresh-water bug Hydrometra, often hundreds of miles from land. In the Upper Siluric of lirance a primitive cockroach, Palcoblattina, has been obtained. Myriopods have been found in the Devonic, but more abundantly in the Carbonic. The Paleozoic myriopods, like the Paleozoic insects, 
were distinct from the Mesozoic and recent forms. The modern Chilopoda date from the Tertiary; the Diplopoda from the Cretacic.

\section{Echinodernata.}

Cystoidea and Blastoidea. These classes are entirely extinct, being confined to the Palæozoic. They were undoubtedly marine organisms like all the echinoderms.

CRINOIDEA. The crinoids are without exception marine organisms, though Antedon rosacea has been taken in water containing only 25 permille of salts, or nearly a third less than in normal seawater. The majority of crinoids belong to the sedentary benthos, being anchored or attached to the sea-bottom either by a stem or by the base of the calyx. Antedon must be classed with the vagrant benthos for, although it ordinarily rests on the sea-bottom or other stationary objects of support, it is able to walk abott on the bottom by means of its arms; and also to swim with graceful movements through the water. Planktonic crinoids appear to have existed in the Mesozoic seas (Saccocoma, Uintacrinus), and, as already noted, Walther has furnished evidence which indicates that some of the stemmed Pentacrini of the Lias led an epiplanktonic life, growing attached to floating timbers with which they were carried about, calyx downward.

Kirk (18) has recently brought forward evidence to show that many Palæozoic as well as later crinoids separated from their stcms late in life and assumed secondarily a planktonic existence, the crowns floating away, while the dead stems remained behind to separate into their component ossicles and form a bed of crinoidal limestone.

The bathymetrical distribution of the modern crinoids ranges from shallow water to 2,000 fathoms, rarely more. One species of Antedon (A. abyssicola, Carp.) has been obtimed at a depth of 2,900 fathoms, but most of the species of this genus live in shallow water, $A$. loveni, occurring in three to four fathoms. This genus is perhaps the most cosmopolitan of the modern crinoids, its geographic range being between eighty degrees northern and fiftytwo degrees southern latitude. The following modern stalked crinoids have been obtained in less than ninety fathoms of water (Wailther-20:208-300) :

Eudiocrinus indizisus Semp., 30 fathoms (5t meters). Mctacrinus rotundus Carp., 70 fathoms (128 meters). 
Pentacrinus asterius L., 80 fathoms (range 80-320 fathoms equals 146-584 meters).

$P$. decorus Wy. Th., 84 fathoms (range $84-667$ fathoms equals I 53 to I,219 meters).

P. miilleri Oerst, 84 fathoms (range $84-53$ I fathoms equals 153 to 970 meters).

Promachocrinus kerguelensis Carp., 28 fathoms (range 28-120 fathoms equals $5 \mathrm{I}-2 \mathrm{I} 8$ meters).

Rhizocrinus lofotensis Sars, 8o fathoms (range 80-I,900? fathoms equals $146-3,474$ meters).

R. rawsoni Pourt., 73 fathoms (range $73^{-1,280}$ fathoms equals I33-2,340 meters).

The egg of Antedon develops into an egg-shaped mero-planktonic larva, which has a tuft of long flagella on the anterior end and five ciliated rings surrounding it; no mouth or anus is present. This embryo swims about for a period of time, varying from a few hours to several days, and, on settling down to a benthonic life, attaches itself at a point on the ventral side between the first and second ciliated rings. The whole anterior part, as far as the third ciliated ring, becomes the stalk, the posterior part developing into the calyx. In Antedon the stem is retained only during the early stages of development, the adult animal being free.

Asteroidea; Ophiuroidea. These belong to the marine vagrant benthos, living mainly in shallow water or in moderate depths, though some species descend to depths of 2,000 fathoms or over. Some littoral starfish can undergo an exposure for several hours in regions laid bare by the tide. A muddy or sandy bottom seems to be the most characteristic facies for these animals, and from such bottoms hundreds are often brought up in a single haul of the dredge. Their relative scarcity in beds in which they are known to occur is probably due to the fact that, after the death of the animal, the skeleton quickly falls apart into its component plates, which become separately embedded in the sediments. In the majority of the Asterozoa meroplanktonic, bilaterally symmetric, ciliated larvæ occur, which in the Asteroidea are known as bipinnaria and brachiolaria, and in the Ophiuroidea as pluteus. These are often found in great numbers in the pelagic fauna.

Echinoidea. The Echinoids, or Sea Urchins, are without exception marine vagrant benthonic animals, living usually in large numbers in moderate depths. A few species descend to depths between 2,000 and 3,000 fathoms, but the majority prefer the shallow portions of the littoral districts. On the coast of Maine 
thousands of Strongylocentrotus dröbachiensis are exposed at very low tides, lying among stones and covered with fragments of shells and small pebbles. The Echinoidea delight in a sandy bottom, from which they are brought up in vast numbers at each haul of the dredge. Some species prefer fine mud, in which they are often buried to some extent. When living on rocks they commonly excavate holes for themselves, and even the solicl granite has been known to be thus attacked by the animal. If corners and crannies are available, these are often occupied by the animal in preference to the drilled hole.

The larva of echinoids is known as a pluteus, and is a meroplanktonic, bilaterally symmetrical, usually more or less ciliaterl organism, with a number of processes or arms. It is often carried by marine currents to great distances, remaining in some cases afloat for several weeks before settling down.

Holothuroidea. The holothurians, like the echinoids, are marine benthonic organisms, but their habit of life is often more sedentary than vagrant, the animals being buried in the sand and mud, though never attached. Their bathymetric range is from the shore zone, where they may be dug out of the sand at low tide, to the depths of the abyssal district. Sandy or muddy bottom is usually preferred by these animals, though many live among coarse blocks, and vast numbers occur among the coral masses of every coral reef. The ciliated larva, or auricularia, of the holothurians is a mero-planktonic organism with definite mouth and anal opening.

From the fact that only isolated plates occur in the skin of the holothurians, they do not constitute any important part of marine deposits.

\section{Protochordata.}

These animals are all marine and unknown in the fossil state.

\section{Verterrata.}

Ostracoderma. These extinct fish-like animals appear to have led primarily a fluviatile and lacustrine existence. if we may julge by the strata in which they occur. The earliest remains are fragments from an Upper Ordovicic sandstone (Harding sandstone) of Colorado, which was probably deposited as a terrestrial sediment and subsequently in part reworked by the advancing sea. The late Siluric transition beds of Great Britain and eastern North America, 
and the beds of the Old Red Sandstone type of the same countries, show the best preserved representatives, these beds being strictly non-marine deposits. Some of the best preserved specimens of Bothryolepis are from the fresh water (river, flood-plain and delta) deposits, which constitute the Gaspé sandstone of .eastern Canada.

The Upper Siluric bone-bed (Ludlow) of England also furnishes these remains, and this deposit may have been formed in an estuary, or an enclosed basin near the sea. A few fragmentary remains have been obtained from marine Siluric and Devonic strata, but these, like the similar occurrences of eurypterids, are not satisfactory evidence of the marine character of these fishes. In Pennsylvania, remains occur in sandstone beds, most probably of river origin, belonging in the Upper Siluric (Monroan) horizon.

Pisces. The earliest true fish appear in the Siluric, but are more typical of the Devonic. Here the Arthrodires were especially abundant, many of them still inhabiting the rivers of the continent. They began to migrate into the sea, however, judging from the more numerous remains found in open sea deposits, such as the Onondaga limestone. The abundant fish fauna of the Upper Devonic shales of Ohio is associated with tree trunks, spores of land plants, etc., in sediments suggesting a river delta rather than open sea. These Upper Devonic fish did, however, live in the seas of that time as well, for their remains are also found in undoubted marine strata. The Cyclostomi (or Lampreys) seem to be first represented by the remarkable Palacospondylus of the Old Red Sandstone of Caithness, Scotland. The Elasmobranchs, or sharks, also lived in the rivers of Old Red Sandstone time, and their remains are found in the semi-terrestrial deposits of the Upper Siluric in Europe and America. These fish, however, entered the sea in Devonic, if not in Siluric, time, and thereafter became chiefly marine organisms, continuing so down to the present time.

The living ganoids either inhabit fresh water rivers exclusively, or, as in the case of the sturgeons, enter the rivers from the sea. In Paleozoic and Mesozoic time they were marine and fluviatile. The living Dipnoi inhabit the tropical swamps of South America (Lepidosiren) and of Africa (Protopterus) and also the rivers of Queensland (Ceratodus). Ceratodus also occurs in the Bunter Sandstein of IVürttemberg, the Keuper of Austria, the Stonesfield slates of England, and the fresh water Jurassic of Colorado. It also occurs in the Kota-Maleri beds of India and in the Karoo formation of South Africa. All of these formations represent river deposits. With few exceptions the other Dipnoans (Ctenodipterini) also occur in fresh water (chiefly river) deposits, such as the Old 
Red Sandstone, the Devonic sandstones of Canada, the Coal Measures and the continental Permic deposits. The living Protopterus of Africa regularly spends the dry season of several months in its crust of dried mud, leading a latent existence or summer sleep until the rains again soften the crust and release the fish.

The various species of mud-fish are examples of fishes leading an amphibious life, for these have been transported in their "nest" of dried mud halfway round the world without suffering. Dean believes that the vitality of these fish becomes exhausted by being kept in water all the time, which deprives them of their periodic summer rest. Many fresh-water fish regularly swallow air and will die if prevented from doing so. even more quickly than frogs which have been similarly placed, although the latter are provided with true lungs.

A few other types of fish are able to live in the air for a sertain length of time, as, for example, the tropical fish (Periophthalmus and Boleophthalmus), referred to in the preceding chapter, which spend a good part of their existence on the beach, and Anabas scandens of the Philippines is able to exist for days out of water.

Many fresh-water fish periodically visit the sea, while marine fishes as frequently ascend fresh-water streams.

Aмрнив. The amphibians are cold-blooded, aquatic or terrestrial vertebrates, usually without dermal covering, which, however, is present in some forms as a corneous or osseous structure. These animals breathe by gills and by lungs, the former remaining functional throughout life in some species. True limbs are generally present in the Amphibia, and are used for swimming or walking.

The Carbonic and Triassic Stegocephalia were mostly armored, especially on the ventral side. They lived on land or possibly in fresh water. The larger forms were predatory and probably fed on other amphibians, fishes, and Crustacea. The Cocilians (Gymmophiona) are worm-like, legless amphibians confined to the tropics. They are unknown in the fossil state. The Urodeles are naked-bodied types with generally two pairs of limbs and persistent tail. They inhabit fresh water (newts), where the gills remain permanent; or clamp. shady places on the land (salamanders), where they lose their gills. They subsist on worms, gastropods, small aquatic aninals, and fish spawn. Permanent larval forms (Axolotl) of the land form, Amblystoma, inhabit the lakes and ponds of Mexico and other countries. These have the form of large tadpoles about to be transformed, with legs and external gills. They reproduce in this state, some of them never 
reaching the Amblystoma stage. The Urodeles began in the Cretacic and continue to the present.

The Anura (frogs and toads) pass through a tadpole stage, during which they breathe by means of gills and lead an aquatic life. On transformation they lose the gills and the tail and become air-breathers, though frogs can remain under water for a very long period of time, absorbing oxygen through the skin. The Anura are wholly post-Mesozoic in age. No marine amphibians are known.

Reprilis. The Rhynchocephalia comprised terrestrial and aquatic forms, often of great size. The Squamata include two Cretacic groups of marine reptiles, some of which, like the mosasaurs, were of large size. The lizards (Lacertilia) and snakes (Ophidia) are chiefly terrestrial reptiles, though some of the latter (Hydrophide) live in the water. Some Pleistocenic species attained a length of Io meters, but modern forms are all small. The lizards are mostly provided with legs, while the snakes are legless. At the present time, lizards are chiefly restricted to the warmer regions of the earth's surface. Comparatively few forms pass beyond the fortieth parallel, while above the sixtieth parallel lizards are practically absent; though Lacerta vivipara, a species ranging over nearly the whole of Europe, extends northward to the seventieth parallel in Norway, and, together with the blind-worm (Angius fragilis) occurs in Lapland but is absent from the New World. Both groups probably appeared in the Cretacic. The fish-lizards (Ichthyosauria and Sauropterygia) were wholly nektonic in habit, living in the sea, but breathing by means of lungs. They were, therefore, neither true holo-nekton nor atmo-nekton, but a transitional type between the two, as are other veriebrates which lead a permanently nektonic life (e.g., whales, etc.). Some species inhabited fresh or brackish water.

The Theromorplss were habitually walking animals. It is believed by many that the mammals have arisen from these reptiles.

The Chelonia or turtles are terrestrial or aquatic in habit, but, like all other reptiles, are air-breathers. A few types are exclusively marine, but the larger number live in fresh-water lakes or rivers. It has been supposed that the ancestral species were aquatic, living in swamps and shallow water, like modern crocodiles; and that from these descended the fluviatile types, from which in turn were derived the early marine types, on the one hand, and the terrestrial, on the other.

The modern crocodiles are aquatic reptiles living in fresh water, swamps and streams. The oldest Triassic crocodiles (Parasuchia 
and Pseudosuchia) are all found in terrestrial-partly fluviatile and partly eolian-deposits, such as the Newark beds of eastern North America, the Stuben Sandstein of Germany, the Elgin sandstone of Scotland, and the Gondwana beds of India. They appear to have been land and river forms. The Mesosuchia in Jurassic and $\mathrm{Co}^{-}$ manchic time had taken to a marine life, but in the Cretacic and later periods, the crocodiles were chiefly fluviatile or terrestrial. In the Pliocenic alligators and crocodiles became extinct in E11rope, but in America they continued in the tropical and sulh-tropical districts. The crocodiles inlabit, further, nearly all the larger streams and many lakes of Africa, India, and the nortl coast of Australia (Heilprin). The Dinosaurs are wholly confined to the Mesozoic, where they were represented by a wealth of types. They comprise three groups: Ist, carnivorous land forms (Theropoda), varying in size from that of a cat (Compsognathus) to that of an elephant (Megalosaurus, Trias to Cretacic), and mostly very grotesque in appearance. They walked upon their hind limbs, the shorter fore limbs being lifted from the ground and the body being -further balanced and supported by a huge tail. Some leaping or kangaroo-like forms likewise occurred (Trias to Cretacic). $2 \mathrm{~d}$. Massive herbivorous quadrupedal forms without dermal armor (Sauropoda, Middle and Upper Jurassic and Lower and Lpper Cretacic), and comprising some of the most prodigious land animals known; Brontosaurus having a length upward of 18 meters, and Diplodocus upward of 20 meters. 3d. (Predentata). Large herbivorous unarmored bipedal (Iguanodonts), and armored quadrupedal forms with small skulls (Stegosaurids), or witl large horned skulls (Ceratopsida). The carnivorous dinosaurs were frequenters of the estuaries and deltas of rivers, and roamed about the low, flat, and muddy flood plains of rivers, as shown by the countless footprints preserved in the rocks of the Newark system, the Bunter Sandstein, and other non-marine (leposits of early Mlesozoic age. The Pterosauria or Ornithosaurs (Jurassic and Cretacic) were a remarkable group of bird-like lizards, with hollow bones and fore limbs adapted for flight, after the manner of bats; some forms being strong and others weak flyers.

Aves. Birds are essentially aerial nekton. A number of living and extinct forms (Dromcognathe, with the Struthiones, the New Zealand Apteryx and the South American Tinamons), are either nearly wingless or have wholly or to a considerable extent lost the power of flight, even though possessing small wings. To compensate for this loss the legs are generally powerfully developed. especially in the Struthious birds (ostriches, rheas, cassowaries. 
cmus, and the extinct Epyornys and the Moas). The majority of birds have the power of flight to a greater or less extent, some forms being able to remain in the air for a long time (gulls, petrels), though flightless forms exist in several orders of the Euornithes. Some are especially adapted to a natatory existence (penguins, (lucks, etc.), while others spend much of their life wading in streams and ponds (herons, storks, ibises, cranes, snipes, etc.).

Mammalis. This, the highest class of vertebrates, is primarily adapted to a terrestrial life, though volatorial or atmonektonic types (Chiroptera, or bats) and natatorial or halo- and limnonektonic (hydronektonic) types (Cetacea, or whales, and Sirenia, or sea-cows) are also known. Among the terrestrial mammals, climbing or arboreal types, running and walking or cursorial types, leaping or saltatorial types, and burrowing or fossorial types are distinguishable.

\section{BIBLIOGRAPHY XXVIII.}

I. AGASSIZ, ALEXANDER. 1888. Three Cruises of the Blake. 2 vols. Bulletin of the Museum of Comparative Zoology, Vols. XIV, XV.

2. BROOKS, W. K. 1881. Développement de l'huitre Américaine. Archives de Zoologie Expérimentale et Générale, T. IX. Nótes et Revue, pp. xxviii-xxix.

3. CHAMBERLIN, THOMAS C. I898. A Systematic Source of Evolution of Provincial Faunas. Journal of Geology, Vol. VI, pp. 597 et seq.

4. CHUN, CARL. I888. Die pelagische Thierwelt in grösseren Meerestiefen und ihre Beziehungen zu der Oberflächen Fauna. Bibliothoca Zoologica, Heft $\mathrm{I}$.

5. CLARKE, JOHN M. The Naples Fauna, Pt. I. Fifteenth Annual Report of the New York State Geologist.

6. CLARKE, J. M., and RUEDEMANN, RUDOLF. 1912. The Eurypterida. Monograph of the New York State Museum, No. XIV, and plates.

7. CONN, H. W. I885. Marine Larvæ and Their Relation to Adults. Studies of the Biological Laboratory of Johns Hopkins University, Vol. III, pp. 165-192, pls. VIII, IX.

8. DALL, WILliAM H. I89o. Deep Sea Molluses and the Conditions Under Which They Live. Presidential Address. Biological Society, Washington. Proceedings, Vol. V, pp. I-27.

9. DANA, JAMES D. I872. Corals and Coral Islands.

Io. DARWIN, CHARLES. I84I. Voyage of the Beagle.

I1. DAVIDSON, TH. I886. A Monograph of the Recent Brachiopoda. Transactions of the Linnæan Society of London. Zoology, IV.

12. DAVENPORT, C. B. 1903. Animal Ecology of the Cold Spring Sand Spit. University of Chicago, Decennial Publication, X.

13. FISCHER, PAUL. 1887. Manuel de Conchyliologie. Paris.

I4. FUCHS, TH. I882. Ueber die pelagische Flora und Fauna. Verhandlungen der königlich-kaiserlichen geologischen Reicnsanstalt in Wien, pp. 49-55. 
I5 HACKEL, ERNST. I 893. Planktonic Studies. Translated from the German by George W. Field. Report of United States Fish Commission, I 889-I 89 I, pp. 565-64I.

I6. HAHN, F. FELIX. I912. Dictyonema Fauna of Navy Island, New Brunswick. New York Academy of Science, Annals, Vol. XXII, pp. $135^{-160,}$ pls. xx-xxii.

17. IIENSEN, VICTOR. I890. Einige Ergebnisse der Plankton Expedition der Humboldt Stiftung. Sitzungsherichte der Berliner Akademie der Wissenschaften, von 13 ten. März, 1890 , pp. 243-253.

I8. KIRK, EDWIN. I9I I. Some Eleutherozoic Pelmatozoa. United States National Museum Proceedings, Vol. XII, pp. 1-137. Contributions from the Geological Department of Columbia University, Vol. XXI, No. 6.

19. LANG, ARNOLD. I89I-1896. Text Book of Comparative Anatomy. Translated by H. M. and M. Bernard, Vols. I, II. London, Macmillan.

20. O'CONNELL, MARJORIE. 1912. The Habitat of the Eurypterida. Paper presented before the New Academy of Sciences, November meeting.

21. ORTMANN, ARNOLD E. I896. Grundzüge der Marinen Tiergeographie. Jena, Gustav Fischer.

22. ORTMANN, ARNOLD E. I896. An Examination of the Arguments Given by Neumayr for the Existence of Climatic Zones in Jurassic Times. American Journal of Science, 4 th series, Vol. I, p. 257.

23. RUEDEMANN, RUDOLF. I895. Development and Mode of Growth of Diplograptus. McCoy. Fourteenth Annual Report New York State Geologist, pp. 219-249, pls. I-5.

24. RUEDEMANN, R. I904. Graptolites of New York, Part I. New York State Museum Memoirs, Vol. VII.

25. SCHIMPER, A. F. W. 1898. Pflanzengeographie auf Physiologischer Grundlage. Jena, G. Fischer. English Translation (Plant Geography) by W. R. Fischer, Oxford, I903.

26. SEMPER, KARL. I88I. Animal Life as Affected by the Natural Conditions of Existence. International Scientific Serics, Vol. XXX.

27. SIMROTH, HEINRICH. I891. Die Entstehung der Landtiere. (See also Die Pendulations-theorie, 1907.)

28. TYRRELL, J. B. 1910. Changes of Climate in Northwestern Canada Since the Glacial Period. In Veränderung des Klimas, etc. Stockholm, pp. 389-391.

29. WALTHER, JOHANNES. I 897. Ueber die Lebensweise fossiler Meeresthiere. Zeitschrift der deutschen geologischen Gesellschaft. Band XLIV, Heft II, pp. 209-273.

30. WALTHER, J. 1894. Einleitung in die Geologie als historische Wissenschaft. I. Bionomie des Meeres. II. Die Lebensweise der Meeresthiere.

31. WOODWARD, S. P. 1880. Manual of the Mollusca. 


\section{CHAPTER XXIX.}

CHOROLOGY, OR THE PRINCIPLES OF THE GEOGRAPHICAL DIS TRIBUTION OF ANIMALS AND PLANTS.

Having briefly considered the life districts of the habitable earth, and the bionomic characters of plants and animals, we may now enquire into the laws which govern the geographical distribution of organisms. It is clear that, whatever the present distribution of plant and animal life, it has not always been so. Even the most cosmopolitan species had its circumscribed center of origin, for it is extremely unlikely that the same species originated in more than one locality.* From this locality, its center of dispersion, it spread to occupy whatever territory was available. Occupancy of new territory, however, is possible only if this territory corresponds in facies to that from which the species is derived, in the degree in which the species is dependent upon the facies. Hence the exodists from their land of birth are not always able to find a suitable place of settlement, and, though their numbers may be vast, a large proportion is sure to perish.

The factor of greatest importance in determining whether or not an area is to be permanently occupied by the members of a newly arrived species is the organic factor, or the question of food supply and protection from enemies. If the food supply is insufficient, or if contending species hold the ground, the new arrivals may be prevented from occupying the territory, even though the facies is otherwise adapted to their needs.

* Strictly speaking, of course, a species is monophyletic and can arise oniy in one locality. But types so similar that they may easily be mistaken for the same species may arise in different localities. Thus, what appears to be the same species of Fusus ( $F$. closter) occurs in the West Indies and in the Red Sea, but they are most probably of independent origin. Organisms of such similar characteristics that they are commonly mistaken for members of the same genus are frequently met with in widely separated localities, where they have arisen independently. The independent origin of horses in America and in the Old World was advocated by Cope but rejected by others. Some widely separated pulmonate gastropods, placed in the same genus, may have arisen independently from marine ancestors. 


\section{Dispersal and Migration.}

It will help us to realize the dependence of organisms on their environment if we distinguish two modes of distribution, the involuntary and the voluntary. The former may be called dispersal; the latter, migration.

Dispersal is the distribution of animals and plants by causes not primarily involving the activities of these organisms, as the carrying of the seeds of plants by the wind, the carrying of marine or fresh water planktonic or meroplanktonic organisms by currents and the like. Migration, on the contrary, is accomplished by active movements in search of food, or to escape from enemies, and is confined chiefly to animals, though stolonal propagation of plants may also be classed as a species of migration. Migrants are composed of the nekton and the vagrant benthos, while dispersants comprise the holoplankton, the epiplankton, and the meroplankton. Sedentary benthonic organisms cannot migrate, but they may be carried by a floating sub-stratum, and their mero-planktonic young may be dispersed and thus settle in other districts. Migrating organisms require a continuity of the conditions of existence in space, such as continuous shores for the marine vagrant littoral benthos, or a more or less uniform medium for pelagic migrants. The involuntary dispersal of organisms, on the other hand, may often go on in spite of barriers which migrants could not surmount. Thus, as already pointed out, the meroplanktonic young of the vagrant benthos may have a much wider distribution than could ever be brought about by the migration of the adults, who are often restricted by barriers not present in the pelagic district. Fresh-water molluscs, for example, are dispersed widely in streams, lakes, and ponds which are discontinuous, and to which the adults could not migrate. Again, plants may, by the dispersal of their seeds, surmount streams or other barriers, which root or stolonal migration. could never bring about. The wide dispersal of cocoanut palms, by flotation of the nut, is a good example.

Littorina littorea may be instanced as a type which has migrated down the Atlantic coast within the space of a few years. Originally introduced from England, it characterized Halifax harbor in 1852 and slowly made its way southward and northward. In 1855 it was noted at Bathurst, Bay of Chaleur; in 1868 on the coast of Maine, appearing at Portland in 1870. At Salem, Massachusetts, it was first noted in 1872 , and at Barnstable, Cape Cod, in 1875 . It was rare at Woods Hole in 1875 . common in 1876 , and 
appeared at New Haven, Connecticut, in 1880 (Morse-33). In 1898 Littorina rudis and L. palliata were still the predominant types on the Long Island coast, but by I90 I L. littorea had gained a marked predominance (Balch- -3 ), and it is still rapidly advancing. (Davenport-I I:I68.) Since the opening of the Suez Canal in I 869 many Mollusca of the Mediterranean have migrated into the Red Sea.

Barriers to Migration and Dispersal. Under barriers to migration and dispersal we may place topographical barriers first, such as northward and southward stretching continents for marine organisms, desert tracts for fresh water organisms, and great bodies of water for terrestrial organisms. But topographical barriers are not the only ones, nor in many cases the most important. Differences in temperature, character, and direction of winds and ocean currents, improper facies of the substratum, and insufficient food supply, as well as hostile species, constitute some of the chief barriers to distribution. If by some means or other a barrier is surmounted, and a new colony is established, the new colony may become more or less isolated, the barrier proving too effective for all but a few individuals. "Migration," says Ortmann $(38: 186)$, "is often slow or only possible under peculiar circumstances, often it is acciclental, and only a few individuals can transgress the original limits on rare occasions; then even migration acts as a means of separation. The few individuals occupying a new locality are afterward practically separated from the original stock remaining in their native country, and thus they may develop separately into a different species, even in the case that immigration from the original stock is not altogether impossible, since any rare individuals of the latter reaching the new colony from time to time are soon absorbed by the new form and their characters disappear by the contintous crossing with the modified individuals and by the transforming power of the external conditions."

Where barriers are numerous, the number of species of a given group of animals or plants is, as a rule, much greater than where barriers are few. Thus in the eastern United States, where important barriers are wanting, only one true species of chipmunk occurs; while in California, where barriers are numerous, a dozen or more species and sub-species are found (Jordan-25). On the other hand, the fauna and flora of a region with few barriers are likely to show a greater variety of organisms of types which do not interbreed than is found in a region with many barriers, since immigration of many different types is possible into an open region, but prevented by the barriers of a closed region. Where separation by barriers has brought about the formation of distinct species, nearly 
related species are normally found in adjoining districts, and not generally in the same or in wiclely separated clistricts. It is universally true that in such cases the species of a genetic series within the same chronofauna, or fauna of the same geological time division, differ more widely the further they are removed in space, and are closely related in immediately adjoining locofaunas. This is beautifully illustrated by the mutitions of the Hawaiian Achatinellidæ, a group of brilliantly colored tree snails, different species of which inhabit the different rugged valleys incised in the margins of the extinct volcanic craters of these islands. The most nearly related mutations of these snails live in adjoining valleys, where, nevertheless, they are almost wholly isolated from the inhabitants of the neighboring valleys. Here the amount of divergence in characters between the occupants of two valleys can, as Gulick says, be roughly estimated by measuring the number of miles between the valleys. Recently Gulick has formulated this in the following law: "Forms that are most nearly related, and are. therefore, the least subject to sexual and impregnational isolation, are distributed in such a manner that their divergence is directly proportional to their distance from each other, which is also the measure of the time and degree of their geographical isolation; while those most manifestly held apart by sexual instincts and impregnational incompatibilities do not follow this law." (Gulick-19:2?I.) The trout of the modern (Holocenic) clironofauna furnishes a good illustration of this law. Thus Salmo clarki, the cut-throat trout of the Columbia and Missouri rivers-which interlace at their headwaters-has its nearest relatives in the basin of Utah ( $S$. rirginalis) and in the Platte ( $S$. stomias). "Next to the latter is Salmo spilurus of the Rio Grande, and then Salmo pleuriticus of the Colorado. The latter in turn may be the parent of the Twin Lakes trout, Salmo macdonaldi. Always the form next away from the parent is onward in space across the barrier." (Jordan-25: 547.) The distribution of the fossil eurypterids of the American Siluric in such a manner as to parallel the distribution of the trout above mentioned has been cited as a proof of the river habitat of these organisms. (Grabau-18.) It should be emphasized, however, that isolation cannot always be determined to be a factor in the production of species, and, indeed, if variation is orthogenetic, the development of new mutations in a progressive series can very well go on within one area. Thus many of the pronounced mutations of Planorbis in the Steinheim strata occurred within the same Tertiary locofauna. In the Eocenic locofauna of the Paris basin a large number of successive mutations in each of a number of 
genetic series of molluscs occurred side by side, and the same is also true to some extent of the corresponding molluscan fauna of the Gulf States of America.

FaUnal Grours. The fauna of any area may be considered as belonging to one or more of the following groups: endemic species, inmigrants and erratics, and relicts. Endemic species are those which originated in the locality in which they are found. Immigrants have invaded the region, and erratics have been carried there accidentally, and both have established themselves in the new region. Relicts are remmants, in favored places, of a once widely distributed fauna. which, by the breaking up of the area which they occupied, became resolved into a number of local remnants, which remain separated.

Factors Governing Dispersal and Migration. In all cases when considering the laws which govern the distribution of organisms it is necessary to consider two phases of the subject: first, the chemical, physical, and organic characters of the localities; and, second, the nature and habits of the organisms-their bionomic characteristics. If the two are harmonious in a given case, it is evident that the locality considered can be inhabited by the organism in question. Under chemical characters we must consider the composition of the medium and its variation; and under physical characters we comprise climate and topography of the substratum; while under organic characteristics we include the presence of suitable food in sufficient quantity, and absence or paucity of competing organisms.

\section{Inorganic Factors. The Medium.}

Composition of Medium. Under this heading we include the salinity of the sea; the inclusion of air and other gases in the water, and of water and carbon dioxide in the air. The salinity of the sea is its most characteristic bionomic feature. On the whole, salinity is a pretty constant factor, varying but slightly in surface extent or in depth in the open sea. Along the continental margins, however, in the bays and marginal seas, a great variation is observable. The question of variation has already been discussed at length (Chapter IV), but a few salient points may here be repeated. Thus in the Red Sea, where the supply of water is scanty, and the evaporation great, the salt constituent is 4.3 per cent. or 43 permille; while in the Baltic, where the supply of fresh water is abundant and evaporation is small, the surface-salinity is very low, averaging 7 permille. The decrease in salinity eastward is very striking; thus it 
is 34 permille in the Skagerak, 22 permille in the Kattegat, 6 permille at Riga and 3 permille at the northern end of the Gulf of Bothnia (Uleâborg). The vertical range is also greater than in the open sea, the salinity in the "Great Belt" of the Baltic increasing downward from Io permille on the surface to 30 permille at the bottom (66 meters).

Stenohalinity and euryhalinity. Many animals cannot live in water with less than 30 or 35 permille of salts: $i$. $e$, that of the normal open sea. These stenohalic* types will die when the salinity is lowered or raised. Euryhalic $\uparrow$ types, on the other hand, can suffer a considerable freshening of the water, and will live as long as any salt remains. Brackish-water organisms are adapted to a small amount of salt and will suffer if the amount is increased. The brackish state of water has never been definitely delimited, but probably a salinity of 2 or 3 permille (.2 to .3 per cent.) would be the upper limit. Of other mineral matter besiles the normal salts iron in the form of ferrous carbonate $\left(\mathrm{FeCO}_{3}\right)$ may sometimes be present in considerable quantity, especially in more or less land-locked portions. Such excess of iron or of other minerals in solution appears to have a distinct effect on the growth of the fauna living in the water, resulting in its dwarfing, as has been repeatedly found by experiments. As an example may be mentioned the fauna of the Clinton iron ore layer of Rochester, which consists of individuals having "an average of about one-third the diameter of the same species in the beds just above and below" (Loomis-28:895). The fauna of the Tully pyrite layer of western New York, consisting of upward of forty-five species, is composed of individuals "on an average only one-fifteenth the size of the same species in the normal and preceding Hamilton fauna." (Loomis-28:920.) In this case the dwarfing was undoubtedly in part effected by the $\mathrm{H}_{2} \mathrm{~S}$ liberated by sulpho-bacteria from decaying organic matter. The reaction of this upon the iron carbonate produced the pyrite which enclosed the fauna. $\left(\mathrm{FeCO}_{3}+2 \mathrm{H}_{2} \mathrm{~S}+\mathrm{O}=\mathrm{FeS}_{2}+\mathrm{CO}_{2}+2 \mathrm{H}_{2} \mathrm{O}\right.$.)

Quantity of Air. The quantity of air in the water, both salt and fresh, depends upon the depth and the amount of agitation. Deeper strata of water have necessarily less air than those nearer the surface, while agitated water will include more air than still water. It is upon the oxygen of this included air that all aninals are dependent, and when it is present in insufficient quantity the animals generally perish, though some will come to the surface for more air. In partially enclosed bodies of water where the density

* From $\sigma \tau e w s$ s = narrow and $a \lambda s=$ the sea, (salt.

† From eúpús = broad. 
of the bottom layers is greater than that of the surface, vertical currents are slight, and hence the lower strata are poor in oxygen and unable to support animal life. Thus in the Black Sea animal life is practically absent below a depth of I25 fathoms, though dead planktonic organisms sink to the bottom, where they are decomposed by anærobic bacteria. The great depths of the Black Sea are covered by a layer of black mud, from which $\mathrm{H}_{2} \mathrm{~S}$ is abundantly separated and which is rich in pelagic diatoms and fragments of very young pelecypods from the meroplankton. The presence of abundant $\mathrm{H}_{2} \mathrm{~S}$ in these depths is characteristic. It is separated by the sulphobacteria from the dead organic matter and the sulphates of the sea water. Accompanying it is the formation of iron sulphide and the separation of carbonates, especially $\mathrm{CaCO}_{3}$. Pure atmospheric air contains almost 2I per cent. of oxygen and about 79 per cent. of nitrogen (see ante, Chapter II). There is always, however, some carbon-dioxide and water vapor present, the quantity varying with the temperature and the movements of the air, besides being very variable in different localities.

Carbon-dioxide, while necessary to plant life, is injurious to the higher types of animals, if the proportion is above I to 2,000 of volume. A somewhat larger quantity, however, has no serious effect on some lower forms of terrestrial animals, and in some cases it may even be beneficial to them. The moisture in the air is necessary to the existence of most terrestrial organisms, many, indeed, being unable to exist in a region where the percentage of water vapor in the air is low. Nevertheless, some animals are found in extremely dry regions, and these are not infrequently types which belong normally to moist climates. Land snails, for example, generally require much moisture, and large numbers of such animals perish during the dry summers, or survive only by burying themselves in the earth or in crevices of rocks, and closing the mouth of the shell with a membranous operculum. In deserts these snails can obtain moisture only during the night or early morning from the heavy dews which result through excessive radiation, and it is only during these times that they lead an active life.

In the saturated atmosphere of the tropical forests are found many types of animals which are normally aquatic. Thus a type of leach, allied to the medicinal leach of the fresh water ponds, lives on trees in the moist forests of India and the Indian islands; and a number of species of land planarians are known, mostly from the tropics. Nany amphipod Crustacea of the family Orchestidæ, or beach fleas, live exclusively on land, though they have the gills of the true water species. These require a very moist atmosphere. 
Numerous other types of normally aquatic animals can live on land in a moist atmosphere. Some of these animals which have become adapted to a terrestrial life can be drowned by being kept under water; and this is true even of a number of fish, which habitually come to the surface to swallow air.

Volume of Viter. The volume of water has in many cases a direct effect upon the size of the animals living in it, the controlling factor being the amount of water allotted to each individual. Thus in experiments on the common fresh water snail, Limncea stagnalis. Semper found that if a large number of individuals developed in a given quantity of water, the size of their shell will be smaller than that of a smaller number occupying the same amount of water. Again, a number of individuals developing in a limited amount of water will have smaller shells than the same number of individuals developing in a larger amount of water. This would be noticeable in a gradually filling lake basin. where the shells in the lower strata would be larger than those of the upper strata. Here the diminishing food supply, which may be supposed to characterize a shoaling lake, would be another factor contributing to the same result. In Semper's experiment it was found "that the favorable effect of an increase of volume of water is highest between 100 and 500 cubic centimeters for each individual, and that it then gradually decreases, till, at 5,000 cubic centimeters, it would seem to cease entirely; $i . \mathcal{c}$., an increase of volume above this maxinum has, as it appears, no further effect whatever upon the rapiclity of growth." Fouling of a limited quantity of water by the excretions of the animals also causes dwarfing. The number of eggs produced under unfavorable conditions is also smaller.

\section{Climate.}

Climate and Temperaturc. The climate of the sea is much more uniform than that of the land. It is true that, in the very shallow parts of the sea, the water is often leated to such a legree as to make these regions uninhabitable for most animals. Ordinarily. however, the continual change of water, due to tidal and other currents, is sufficient to keep the temperature at a moderately low. and more or less uniform, degree. The daily range of temperature in the sea is of less importance to organisms than the total amount of heat received; for daily changes affect chiefly the upper strati of the water. which are directly influenced by the heat of the sum. A.t a moderate depth below the surface, the stratum of mean 
temperature is reached; this, where not affected by oceanic currents, varying mainly with the change in latitude. It is to this region of unvarying temperature that many of our littoral vagrant benthos descend on the approach of winter; so that, as every collector knows, many tide pools and sandy bottoms of moderate depth become deserted during the colder months. Many marine organisms are eurythermal, i. e., able to bear a considerable range of temperature. Others, again, are stenothermal, a comparatively slight deviation from the normal temperature of their medium being fatal to them. The larva or eggs of stenothermal animals are often able to resist very great changes of temperature which would destroy the adult animal. Thus the winter eggs of some of the lower Crustacea, the germs of Bryozoa and of fresh water sponges, resist any degree of cold, while the full-grown individuals perish in the autumn. Many insects cannot survive the winter, though the eggs and the embryo within the eggs commonly withstand the severest cold. On the other hand, the young may be more susceptible to changes in temperature than the adult. Brooks found that, in the case of the oyster, the difference of $2^{\circ}$ or $3^{\circ} \mathrm{F}$. in the temperature of the water was sufficient to kill the whole larval brood. Thus, as Dall says, "By inhibiting natural increase . . . a species may be as sharply limited in its permanent range as if material barriers interposed." (Dall-9:2I8.)

Cold-blooded animals can usually withstand a lowering of temperature better than warm-blooded animals. Thus frogs and toads can be frozen into the ice and survive, and so can certain fishes (e. g., Salmon, etc.).

In all cases a rapid change of temperature is more fatal to organisms than is a gradual one; for many normally stenothermal types can by degrees adapt themselves to a higher or lower temperature. When once acclimatized it is the change from the normal temperature of the new habitat which affects the organism. Thus members of a species acclimatized to more tropical regions will be affected by a fall of temperature to a point where members of the same species in more northern regions are wholly unaffected.

Currents. One of the marked features of the media characterizing the three organic realms is the frequent presence of currents within them. These may be temporary or fixed, and, according to this characteristic and their strength, they become powerful factors in the influence which they exert upon the distribution of organisms in the realms in question. In the air, currents are most numerous and also more variable, though certain air currents, as the "trade winds," have a great constancy within certain limits. Irregular 
and variable air currents often greatly influence the migration of aerial organisms, even the strongest flyers being carried away by them. But the greatest influence exerted by air currents on organisms is in the dispersal of seeds of plants, which thus may become widely scattered. Air currents are the chief cause of the persistent ocean currents, which are of such importance in the distribution of life. In fresh water lakes temporary currents may be set up by the winds, but these are of minor significance. The important currents in fresh waters are those due to gravity, as exemplified in every stream and river. That river currents are of great importance in the distribution of fluvial life, as well as in the transportation of terrestrial animal and plant life, is a matter of common knowledge.

By far the most important currents affecting the life districts of the earth are the ocean currents, for they not only aid in the distribution of organisms, but they are also instrumental in imparting to sea and land characters which they would not otherwise possess.

The characteristics of the ocean currents of the present geologic period (Holocenic) may be taken as an illustration, especially since it is highly probable that similar conditions prevailed throughout most of Tertiary time. The depth of the moving bodies of water constituting the oceanic currents is from 50 to 100 fathoms: and the direction of motion corresponds to that of the prevailing winds. As already discussed at length in Chapter $V$. each of the great oceans has its own eddy-like current, moving slowly around it and leaving the central portion in a relative state of quiescence. In the northern hemisphere the currents move in the direction of the hands of a clock, i. e., clockwise; in the southern hemisphere, counter-clockwise. As a result, the motion of the waters is westward at the equator, both north and south of it, and eastward in the polar ends of the north and south oceans, respectively. Hence dispersals of organisms dependent on ocean currents would be from east to west in the equatorial regions, as from the west coast of Central America to the east coast of Asia, and from the west coast of South America to Polynesia and Australia. It is true that the equatorial counter-current sets eastward between the north and south equatorial currents, but this is a relatively weak current. The comparatively warm drift across the north Pacific (Kuroshiwo drift) is an aid to eastward migration and dispersal across the north Pacific, and this would probably be much more effective if the cold water from the Arctic were shut off by the closure of Behring strait. Such conditions existed during part of Tertiary time, and thus may have greatly aided migration of marine organisms in this direction. The cold west-wind drift or 
Antarctic stream of the South Pacific, together with the cold Peruvian current of the west coast of South America, acts as a barrier to migration of warm water animals and plants from Australia to South America, and probably did so throughout Tertiary time.

In the Atlantic the peculiar conformation of Africa and South America results in the splitting of the South Equatorial current into the Brazilian current, flowing southward along the east coast of South America, while the main current crosses the equator into the Caribbean Sea and the Gulf of Mexico. Here again the cold west-wind drift and the cold Benguela current on the west coast of South Africa prevent dispersion between the southern portions of these continents of all warm water types. The presence, however, in the modern fauna of gastropods on the east coast of South America, which appear to be derived from species inhabiting Indo-Pacific waters, suggests that migration of tropical animals up the west coast of Africa is possible under certain conditions, in spite of the cold Benguela current. In the North Atlantic, the Gulf Stream, with its northeastward drift, favors dispersal of species from the east American to the west European coast; while the return Canary and North Equatorial currents may well be effective in carrying planktonic organisms from the northeast African coast and the Mediterranean to the West Indian waters of tropical America.

A factor which must be taken into consideration is the varying rapidity of flow of the currents. Thus the Gulf Stream, as it issues from the Florida straits, has an average velocity of 80 or 90 miles a day, ${ }^{*}$ while the drifts, like that crossing the middle North Atlantic, may have a velocity of only from ten to fifteen miles per day. If the meroplanktonic stage of a normally benthonic animal is passed through very quickly it is evident that before the creature can be carried very far it will end its pelagic existence and sink to the bottom. In the case of such larva carried by the transoceanic currents, the depths to which they will settle after having been carried for a few days is likely to be such as to prove destructive to the organism. Thus organisms taken up by the Gulf Stream as it leaves the Florida coast would, even if the stream retained its maximum velocity, have to travel considerably over a month before they could reach the European coast, while with the actually diminishing velocity of the drift in the North Atlantic the time required will be many months. Before that time most meroplanktonic organisms will have completed their metamorphosis and have perished on an uncongenial bottom. Holoplanktonic types, however, and even nektonic animals are widely dispersed by these cur-

* It varies from $\mathbf{I} .5$ to $\mathbf{2 . 5}$ meters per second. 
rents. Thus even Middle and South Atlantic fish are carried by the Gulf Stream to the Norwegian coast, though these do not generally propagate themselves in these northern waters.

One mode of dispersal that must not be overlooked is that effected by the epiplankton. The transportation of the Crustacea, Hydrozoa and other organisms, with the Sargassum, from the Bahamas to the middle North Atlantic, is an example. Trunks of trees from the forests of the Mississippi and the Orinoko are carried northward by the Gulf Stream, past the coast of Norway, as far as Spitzbergen, whence they are again carried southward and cast ashore on the northeast coast of Iceland. Sea-weeds, molluscs and other organisms are frequently found attached to these trees, having made the long journey on their floating substratum. Seeds of land plants commonly accompany these woods.

The warm ocean currents also have an important influence on the relative abundance of the benthonic life in the regions traversed by them. Being rich in plankton, and thus supplying an abundance of food to the animal life inhabiting the sea-botton below it, it is not surprising to find that here the bottom life is cleveloped in the greatest luxuriance, and that vast accumulations of organic limestones occur in the littoral regions thus affected. This is true, however, only of those portions of the littoral district which lie at a sufficient depth below the surface to escape the motion of the streaming water, which might otherwise prevent the attachment of the benthos as it settles down. Thus, off Charleston, South Carolina, in depths from 100 to 350 fathoms, the sea-floor is but sparsely settled beneath the Gulf Stream.

Topography. Next to the climate of the sea the topography of the sea-bottom, and that of the adjacent land, are the most powerful factors in determining the distribution of marine organisms. The facies of the ocean floor, or the material of which it is composed, is perhaps the most significant part of sea-bottom topography, though submarine ridges and barriers are of great importance, especially when such barriers cut off marginal bodies of water, the inhabitants of which may be prevented from intermingling. The separation thus produced may lead to the development of local faunas and floras. The importance of the greater inequalities of the sea-bottom and the submarine continental shelves and deep oceanic basins that result from them, as well as the conformation of the coast-line, with its varying facies, has already been considered. (See Chapter III.)

Of all topographical features which influence the distribution of marine organisms, northward and southward stretching bodies of 
land, like the continents of North and South America, are perhaps the most important. For since they form a continuous barrier across the warmer portions of the ocean, extending into the cold regions, the migration of the warmer-water species from one side to the other is prevented. Thus the marine faunas on the opposite sides of North or South America differ widely.

By the application of this principle to the Cambric faunas of North America and Europe, it has become apparent that a more or less continuous land mass, sufficient to prevent intermingling of faunas, separated the Atlantic and Pacific oceans in Cambric time. This land barrier must have extended from New England northeastward, joining this land-mass to the Scottish highlands, and southward, forming the Appalachian old-land, which was joined with the continent of South America. On opposite sides of this land-mass different faunas flourished; in the lower Cambric the Olenellus fauna on the west and the Holmia fauna in the Atlantic; in Niddle Cambric time the Olenoides and Paradoxides faunas flourished in these respective basins (see the maps in Grabau-17). (See also Figs. 264a-c.)

The only topographic element of importance in lakes and other bodies of standing fresh water is the enclosing land mass, which prevents direct migration from one lake into another. In rivers the presence of rapids and falls may become a barrier to all but the most agile of swimmers. Here, however, the barrier is most effective against upstream migration. The banks likewise constitute barriers.

Terrestrial animals and plants are often prevented from migrating or becoming dispersed by the existence of topographic barriers in the form of mountains of great height and consequent range in climate; by large bodies of water, deep river gorges and impassable streams; and by extensive desert tracts; the last being produced by a combination of the topographic and climatic factors. For animals of a more limited range of habitat, minor topographical barriers become restrictive, as shown by the distribution of the Hawaiian tree snails (Achatinellida), already referred to, for which the exposed ridges separating adjoining ravines form almost impassable barriers.

\section{The Organic Factors.}

The organic conditions of the three realms likewise exert an important influence on the distribution of animal and plant life. 
By organic conditions is meant the nature and abundance of food supply and the relative importance of competing organisms. Since plants primarily furnish the food supply of animals, those regions rich in plant life are, in general, well adapted for the existence of animal life. Yet even in regions where plant life is wholly absent, as in the deep sea, an abundant fauna exists, the food supply of which, however, is derived from the illuminated regions where plants grow.

Closely related to the food supply is the struggle for a living among species and individuals. It is a well-known fact that most of the lower animals have such an enormous offspring that, supposing none were destroyed, in a short time all the space in a given region would be occupied by the progeny of a single pair; and the number would be such as to exceed enormously that pernitted by the food supply. Migration to new regions is therefore a necessity, and emigrants are continually sent out in all directions from the mother country. If no other occupants were in the region, an intraspecific struggle for existence would be witnessed in every locality settled by these migrants-members of the same species fighting among themselves for a living. Such a struggle would, of course, result in the destruction of vast numbers and in the enigration of others. But, when the newly opened area is entered simultaneously by several species, or if the area is already occupied by other species, an interspecific struggle occurs, the outcome of which depends on the relative ability of the contending species to hold their own. The resident species may be driven out by the newcomer, or it may hold its own and prevent the intruder from settling; or, again, what is perhaps more common, the two species may accommodate themselves side by side and jointly occupy the disputed area.

An example of a struggle between resident and invading species is found in the faunas of the Portage beds of New York State. The resident fauna was the Ithaca fauna, derived by modification from the preceding Hamilton fauna. The invading fauna came from Eurasia, invading the New York area from the northwest. The interspecific, or interfaunal, struggle continued throughout Portage time, the invading species gradually acquiring the mastery.

Biogeographical Provinces.

At each period of the earth's history, zoögeographic and phytogeographic provinces existed which were more or less distinctly sep- 
arable from one another and which varied from period to period. Even within the same period the geographic provinces are not constant for all animals or plants, because some groups of animals and plants are not affected by barriers which are restrictive to others. Nevertheless a general division of the earth's surface into biotic provinces is possible, up to a certain extent; at least within the marine and terrestrial realms. Within these two realms the distribution of organisms is the resultant of migration and dispersal, not only of the organisms themselves, but also of their ancestors in preceding geologic periods. Thus the problem. of geographic distribution of a given group of organisms resolves itself into a study of the migrations and dispersions of the ancestral types of these organisms from the point of their origin in past time. From the point of origin or center of distribution a process of adaptive radiation has carried the organism outward and onward in space and time. Barriers arising across the path of distribution break the continuity of the range; and from these separated remnants, or relicts, arise new diversified types, along a number of distinct lines radiating from the central stock, the resultants being in general well adapted each to a particular phase of the environment. In other distinct provinces similar lines of evolution may give rise to parallel series of modifications: so that, in provinces widely separated, similar lines may arise independently, the closeness of the resemblance seemingly indicating a close geographic connection between the provinces. The species of the gastropod genus Clavilithes are an excellent example of this phenomenon. This genus is represented by a number of very marked species in the Eocenic strata of the Paris Basin. A parallel series occurs in the LondonHampshire Eocenic basin, but there are scarcely any identical species. Another parallel series occurs in the Gulf Eocenic of the United States, a province entirely distinct from, and without communication with, the European provinces, which themselves were closely circumscribed. Nevertheless, the American series has the same specific types as the Paris series, corresponding species of the two generic stocks being scarcely distinguishable, so far as the specific characters are concerned; though it is an easy matter to separate them generically-that is, to place each species in its proper genetic series. If, as seems highly probable, these two groups of Clavilithids had a common ancestor, in early Eocenic, Palæocenic, or late Cretacic time, they became entirely separated in mid-Eocenic time, and the parallel specific types arose independently. 
Marine Provinces.

The following are the marine zoögeographical regions of the present geologic epoch, as given by Ortmann $(38: 66)$ :

\author{
I. Littoral life-district \\ I. Arctic region \\ 2. Indo-Pacific region \\ 3. West American region \\ 4. East American region \\ 5. West African region \\ 6. Antarctic region \\ II. Pelagic life-district \\ 1. Aretic region \\ 2. Indo-Pacific region \\ 3. Atlantic region \\ 4. Antarctic region \\ III, Abyssal life-district \\ No regions distinguishable.
}

Marine geographical provinces have been distinguished for several classes of organisms by different authors. Among these the following may be mentioned:

I. Corals. Dana recognized three principal regions: (I) Red Sea and Indian Ocean; (2) the whole of the Pacific Islands and the adjacent coasts of Australia: (3) the W'est Indies. The last region is the most isolated and it contains the largest proportion of peculiar forms.

II. Higher Crustacea. Prof. J. D. Dana also proposed to divide the oceans into the three main areas, based on the distribution of the Crustacea. These are: (I) the Occidental: (2) the AfricoEuropean, comprising the western shores of the Atlantic, both African and European; and (3) the Oriental, which inclucles the vast area from the east coast of Africa to the Central Pacific. Each region is subdivided into local and climatic provinces.

III. Barnacles. Darwin, considering the distribution of the species of barnacles, divided the oceans into the following regions: (I) The North Atlantic, comprising North America and Europe down to N. lat. $30^{\circ}:$ (2) the West American, from Behring Strait to Tierra del Fuego; (3) the Malayan, from India to New Guinea : (4) the Australian, comprising Australia and New Zealand. The third and fourth regions are the richest in species.

IV. Mollusca. S. P. Woodward (6I) divided the oceans into three main divisions or regions: (I) The Atlantic: (2) the IndoPacific, corresponding to Dana's Oriental region for crustacea; and (3) the West American. The following is the modified system of Woodward (Lydekker-29:IOI6) : 
Molluscan Regions.
A. Atlantic and Circumpolar regions...... $\left\{\begin{array}{l}\text { I. Arctic sub-region } \\ \text { 2. Boreal " " } \\ \text { 3. Celtic " " } \\ \text { 4. Lusitanian sub-region } \\ \text { 5. West African " " } \\ \text { 6. South African " " }\end{array}\right.$

B. Indo-Pacific regions. . $\ldots \ldots \ldots \ldots \ldots\left\{\begin{array}{l}\text { I. Indo-Pacific sub-region. } \\ \text { 2. Japanese sub-region }\end{array}\right.$

C. Australian regions............. $\left\{\begin{array}{l}\text { I. Australian sub-region } \\ \text { 2. Neozealandian sub-region }\end{array}\right.$

D. American regions

\begin{tabular}{|c|c|c|}
\hline I. Aleutian & sub- & gion \\
\hline 2. Californian & " & \\
\hline 3. Panamic & " & $"$ " \\
\hline 4. Peruvian & " & “" \\
\hline 5. Magellanic & “" & “ \\
\hline $\begin{array}{l}\text { 6. Argentinian } \\
\text { 7. Caribbean }\end{array}$ & " & “ \\
\hline 8. Trans-Atlanti & & " \\
\hline
\end{tabular}

V. Fishes. Günther (2o) recognized the following marine zoölogical regions based on the distribution of shore-haunting fishes:

I. Arctic ocean. 2. Northern temperate zone divided into: (a) the temperate North Atlantic and (b) the temperate North Pacific with further subdivisions of each. 3. Equatorial zone, divided into: (a) Tropical Atlantic, (b) Tropical Indo-Pacific, and (c) Pacific coast of tropical America with further subdivisions. 4. Southern temperate zone with several subdivisions, and 5. Antarctic ocean.

VI. Marine Mammals. The following marine geographic regions based on the distribution of seals, sea-cows, and cetaceans have been recognized by Sclater (43):

I. Arctatlantica (seals of the sub-family Phocinæ).

2. Mesatlantica (monk seal and manatis).

3. Philopelagica (Indian ocean, etc.), characterized by the presence of dugongs and absence of seals.

4. Arctirenia (North Pacific) with Phoca, and sea-bears and sea-lions, formerly the northern sea-cows (Rhytina) now also the gray whale (Rhachianectes).

5. Mesirenia (Mid-Pacific) without sea-cows, but with the elephant-seal (Macrorhinus).

6. Notopelagica (Southern ocean) with four peculiar genera of seals, numerous sea-bears and sea-lions, and two peculiar whales, the pigmy whale and Arnoux's beaked whale. 


\section{Former Marine Geographic Provinces.}

The most elaborate attempt to divicle the world into marine zoögeographical provinces for one of the past geological periods of the earth's history is that of the late Victor Uhlig of Vienna, in his "Die marinen Reiche des Jura und der Lntern Kreide" (52). He recognizes at least four large faunal districts, based mainly on the distribution of fossil cephalopods, namely:

I. The boreal.

2. The Mediterranean-Caucasian.

3. The Himamalayian.

4. The Japan Province.

5. The South Andine realm.

The boreal realm of the Jurassic time originally defined by Neumayr was circumpolar in the arctic region with extensions into the heart and the northern region of Russia to the east of the Urals and westward to Greenland, including the Urals and Scandinavia as probable islands. A narrow southward extension included the region of the Lena River and the lower Amur. The Pacific extension of this realm comprises Alaska and the western coast of America (California, Nevada, etc.) to the head of the Gulf of California and with an epicontinental lobe extending into Montana, Wyoming, Idaho and eastward to the Black Hills (Logan Sea). This region has been separately named the North Andine Province. On the whole, the boreal was a shallow sea, with a peculiar and uniform fauna. Coral reefs were conspicuously absent.

The Mediterranean-Caucasian realm comprised the expanded Mediterranean area, which extended eastward to the borders of India and northward to the Caucasus Mountains. It included the Jurassic formations of the Alps. Between it and the Boreal realm of Russia lay the mid-European province of Neumayr, which, by Haug, Uhlig, and others, is regarded as a neritic border zone of the deeper Mediterranean sea. The characteristic genera of ammonites of the Mediterranean realm (Phylloceras, Lytoceras) are regarded by Haug as stenothermic and able to live only in the deeper waters where temperature changes are slight; while the other genera were eurythernic and so liad a wider distribution.

The Himamalayian realm comprised northern India and the Himalayan region, and extended thence to the Malay archipelago. In it are recognizable an argillo-arenaceous and à calcareous facies, a part of the latter being often considered as abyssal. Two related 
provinces are recognized: (a) the Ethiopian, comprising the east coast of Africa and part of Madagascar; and (b) the Maorian, in Oceanica. The Japan Province is a small one limited to the Japanese archipelago and Korea. It is characterized by a commingling of boreal and Malayian features, though less markedly related to the latter. The South Andine realm comprised Central America and the whole west coast and the southern end of South America, and appears to be likewise represented in the southern coast of Africa.

Considering these realms as a whole it appears that the faunas of the last four are more closcly related to each other than they are to the boreal. Haug has united the Mediterrancan-Caucasian, the Himamalayian, and the North Andine realms into a single broad equatorial faunal and climatic belt which is sharply contrasted with the flolarctic-liorcal belt. Stich a broad zonal division is favored by Chlig.

On the whole, it appears, as Koken $\left(27: 33^{\circ}\right)$ pointed out, that the distribution of marine faunas is less dependent on climatic differences than on the distribution and development of coast lines.

\section{Present and Former Biogeograplic Provinces of the Land.}

The terrestrial provinces of the present time are generally comprised within three great divisions or sub-realns, as first proposed by Blanford, and under these are included a number of distinct regions. As commonly accepted, these are:

I. Arctogrea, or northern sub-realm, with

I. Arctic, or circumpolar region.

2. Ethiopian, or African region (south of the Sahara).

3. Indo-Malayan, or Oriental region (including southern Asia and the Malayan islands).

4. Malagasian, or Madagascar region.

5. Nearctic, or North American region.

6. Paliearctic, or Eurasiatic region.

II. Notogrea, with four regions:

I. Austro-Malayan.

2. Australian.

3. Polynesian.

4. Hawaiian.

III. Neogæa, comprising South America, with one region:

I. Neotropical. 
To these may be added the Antarctic continent, or Antarctogaa, the former existence of which, connecting most of the other regions, seems to be demonstrated by a number of independent lines of evidence, as developed in the study of the distribution of a great variety of types of organisms.

\section{Fresh Water Biotic Provinces.}

Simpson (47) has proposed the following regions as subdivisions of the fresh water realm, based on the distribution of the fresh water mussels or Lnios in the present chronofauna.

I. Palaearctic.

2. Ethiopic.

5. Neotropic.

3. Oriental.

6. Central American.

4. Australian.

7. Mississippian.

8. Atlantic.

The Palcarctic region comprises Europe, North Asia, and western North America; the Oriental includes the Malaysian Islands to New Guinea. Simpson holds that the mussels originated in North America in the Triassic, whence they migrated or dispersed into South America, from which region they passed by an old Antarctic land bridge to New Zealand and Australia, thence to southern East Asia, whence they entered the remaining part of Asia, Europe and Africa. In early Tertiary time they migrated across northeast Asia to northwest America.

It should be noted in this connection that the active migration of the adult is a comparatively slow process, and is, of course, confined to streams. The young are attached to the gills of fishes and so are much more rapidly distributed. Here, too, of course, continuous water bodies are required. But there are other methods of dispersal by means of which these shells can transgress land barriers often of considerable extent. Notable among these are the dispersal of the eggs and young shells by water birds, to whose feet they become attached, and by large water beetles and other insects. Thus, while large bodies of sea water cannot be traversed in this way, narrow straits could easily be covered.

Perhaps a better index to the former land connections is found in the distribution of the fresh water crayfish. Their migrations were traced to a certain extent by Huxley (24), later by Faxon, and most recently by Ortmann (39).

The distribution of the family Potamobiida Huxl., comprising two genera, Cambarus and Potamobius, may be briefly con- 
sidered. The first of these genera includes 67 species, and is found only in the eastern parts of North America, Mexico, and Cuba. The genus is divisible into five groups, the smallest of which contains three species and the largest twenty-six. The first group of sixteen species is restricted chiefly to the southern parts of the United States and Mexico. The most primitive species belong chiefly to the southwest; and in fact this is also true of the primitive species of the second and fifth groups. This fact points to an origin of the genus in the sonthwest, its starting point being apparently in Mexico. The second genetic group, with eight species, shows a striking discontinuity of distribution, isolated representatives being found in Mexico, the Gulf States, the southern Atlantic States, and Cuba; all of them separated from the members of the group found in the southwestern and central States. This indicates that, after the migration of the species of this group from Mexico into the United States, unfavorable physical conditions at intermediate points broke up the former continuous range. The third group, with thirteen species, has a continuous distribution in the Alleghany mointains and in the east; a single species reaching north to the Gulf of St. Lawrence region. It also extends northward in the Mississippi region, but is less prominent, and is represented at only one station in the southwest, and there by a single species. The fourth group, with twenty-six species, is also scarce in the south and southwest, but is abundant in the Upper MississippiMissouri-Ohio basin. Eastward it extends up the Ohio into Pennsylvania, Virginia, Maryland, New Jersey, and New York, its northeastern limit being near Montreal. In the central region it extends northward to Lake Winnipeg and the Saskatchewan River, the most northerly locality known for this genus. Westward it extends to Wyoming. The fifth group consists of three species, one occurring near New Orleans, the other two in Mexico. On the whole, the most primitive species are in the Mexican region, the probable birthplace of the genus, as has already been suggested. Here also has remained a rather primitive side branch, group 5 . The other groups advanced northward and northeastward, the most specialized becoming discontinuons on account of adaptation to a changed environment.

Cambarus appears to be derived directly from a less specialized fresh water crayfish, Potamobius, which has a strikingly discontinuous distribution, one group of seven species occupying a continuous area in Europe and western Asia, and another in western North America. A third group, separated as the subgenus Cambaroides, occurs in northeastern Asia; this group, according to 
Ortmann, forming a morphologic equivalent (homœomorph) of Cambarus, though not closely related to it. Ortmann believes that the three groups originated from a common ancestor whose home was in eastern Asia. A branch was sent out westward, which finally reached Europe; while another branch migrated eastward, reaching western America by means of a land area connecting Asia and America. Of these migrants a single species has remained behind in Unalaska. When finally, by geographical changes, the European and American branches became separated from the Asiatic one, each developed independently, the result being three distinct groups, as above stated. From members of the American group, which had reached Mexico, the genus Cambarus developed, in a remote period, becoming differentiated into five groups, through processes of geographical isolation.

From the distribution of these and other fresh water decapods Ortmann concludes that the following land connections must have existed in the near past.

I. Northeast Asia with Northwest America across the Behring Sea.

2. East Asia with Australia.

3. South Asia with Madagascar and Africa.

4. New Zealand with Australia.

5. Australia with South America.

6. West Indies with Central and South America.

7. South America with Africa.

Ortmann holds that the above connections were necessary; for, while a few species of fresh water crayfish or crabs have been found in brackish or even salt water, this occurrence is very exceptional, the animals being preëminently dwellers in fresh water, so that a migration across oceans or parts of oceans is practically precluded. Furthermore, since these animals cannot live out of water for any great length of time, deserts or waterless tracts form ahsolute barriers for them: The eggs of these creatures are carried under the abdomen of the female, and the young hatch in a state similar to the parents. While water fowl or other agents may occasionally effect a passive transport, such cases are rare and have never been observed. "The whole character of the distribution of the different species is against the assumption of exceptional means of dispersal." (Ortmann-39.) The connection of Asia and northwest America by way of Behring Sca is also indicated by the distribution of mammals and other land animals. The connection continued probably through the whole of Tertiary time. The connec- 
tion between eastern Asia and Australia is also indicated by the distribution of the snails (Helix). This bridge appears to have existed before the Upper Cretacic. The connection between Africa and India demanded by the distribution of the fresh water decapods seems to have been in mid-Cretacic time or earlier. Other facts show that this union continued through Eocenic time. The connection between New Zealand and Australia is believed to have been by way of New Caledonia and New Guinea, and belongs to pre-Eocenic time; while that between Australia, New Zealand and South America, generally assumed by students of zoögeography, is believed by Ortmann to have been across the Pole, and to have continued to the end of Mesozoic time. There are indications that the West Indies, Central America, and the northern margin of South America formed the "Antillean continent" during Jurassic and Cretacic time, a remnant of and successor to Appalachia; after this was broken up, the northern remnant, consisting of the Greater Antilles and parts of present Central America, probably remained a unit up to the Eocenic, after which it was dismembered, to be once more established in Pleistocenic time, and finally destroyed in the present. Finally, the connection between South America and Africa is believed to have existed in Jurassic and early Cretacic time, but was severed in subsequent periods.

Terrestrial animals, especially mammals, are even better indices of former land connections than the fresh water animals cited, inasmuch as even moderate dividing straits form absolute barriers to the majority of types. For an extensive account of this subject the student is referred to Lydekker's "Geographical Distribution of Mammals."

\section{RELICTS.}

Relict Faunas and LAKEs. The occurrence of halo-limnic organisms or animals or plants normally of marine type in continental seas or lakes has been a matter of great scientific interest ever since Lovén, in I860, announced the presence of Crustacea closely related to marine types in the great fresh water lakes of Sweden, and showed by the geological structure of the region that these organisms entered the lakes at a time when they were connected with the sea. They, therefore, constituted the relics of a former marine fauna, which had mostly become extinct by the gradual freshening of the waters of the lakes after the connection with the sea was broken. Similar left-over marine faunas or relicts were discovered in many other continental seas, both fresh and 
salt; some of these occurrences, like that of the sea-dog, or harbor seal, Phoca, in the Caspian and other seas, had been known previously, and used by Pallas and V. Humboldt to demonstrate the former connection of these lakes with the oceans. Oscar Peschel (4I) in 1875 applied the name relict seas (Reliktenseen) to these bodies of water, which he regarded as derived from the sea by the growth of enclosing land. He and most anthors since his time regarded all continental seas containing marine organisms as relicts, even though some of these seas are far inland. Credner (8), however, strongly opposed this view, evidently believing, with Penck, that a distinction should be made between a relict fauna and a relict sea. The former may enter the lake by a process of migration, as is believed to be the case in many instances where the seals (Phoca) are found in fresh water lakes the geologic surroundings of which show that they never were a part of the ocean; or where a marine fauna has entered a lake basin of independent origin through a temporary connection with the sea. Such is the case with the Great Lakes of North America, some of which are known to have been temporarily invaded by the sea by way of the Hudson-Champlain depression during early Pleistocenic time, but the origin of which was wholly independent of the sea (I6). Thus Lake Ontario was a fresh water lake before it became temporarily connected with the sea. Credner classes as true relict seas all those which at one time were a part of and connected with the oceans. He makes the following divisions:

I. Relict seas due to damming and isolation of parts of the sea. through a growth to above the sea-level of enclosing rock masses.

II. Relict seas due to isolation of basin-like depressions in the sea-floor, owing to a negative change in the sea-lerel. Emersion lakes.

III. Relict seas due to shrinking of former mediterraneans.

The first division includes (a) coastal lakes due to danming of bays and inlets, by growth of deltas (Lake Akiz), or by the enclosure of bodies of water between the growing delta and the open coast (Lake Pontchartrain and others in the Mississippi delta); (b) coastal lakes or lagoons (barachois) due to the growth of sand-bars (Kurische Haff) and barrier reefs: (c) atoll seas or coral island lagoons, and others.

Under the second division are comprised the marginal lakes of the fjord type, as on the coast of Norwaty. Scotland (I Loch Lomond), Iceland (Lagarfljöt), and others. Credner classes Lake 
Champlain in this group, but this basin can hardly be said to have been a part of the sea in the sense that the marginal fjord lakes are. It is an ancient erosion basin of truly continental origin, as is the case with most of the Great Lakes. The Champlain valley was temporarily invaded by the sea, as was Lake Ontario, both being primarily continental basins due to erosion and damming. For this group a separate division-that of relict seas due to invasionmight be erected. In this category may belong Lake Venern and Lake Vettern of Sweden, both of which are old erosion basins and may have been lakes before the marine invasion. This group of relict seas is more nearly related to the true lakes which contain a relict fauna.

Among other lakes containing a pronounced relict fauna, Lake Baikal of central Asia and Lake Tanganyika of central Africa are perhaps the best known. The relict nature of the former basin has been much questioned (Credner-8, ii:25), but the relict nature of a part of the fauna is commonly conceded (Hoernes-22). Besides the seal Phoca baikalensis, B. Dyb., and a number of fish, among them Salmo migratorius Pallas, planarians, and sponges are represented by types more closely related to marine than to fresh water forms. One of the sponges especially (Lubomirskia baikalensis, W. Dyb.) is a truly marine type, occurring in Behring Sea. The molluscan fauna of Lake Baikal is especially peculiar. Of the twenty-five described species of gastropods only three are found elsewhere, but none outside of Siberia (Dybowski, W.-I3). There is a marked resemblance, however, between this fauna and that of the Tertiary fresh water lakes of eastern Europe, which most probably were the source whence the Baikal fauna migrated.

The relict fauna of Lake Tanganyika is a most interesting and remarkable one (Moore-32). It includes the fresh water medusa Limnocnida tanganyica, the first and almost the only jelly-fish found outside of the sea; and a number of molluscs which can be traced back to ancestors probably in the Jurassic seas of that region. Some of these would unhesitatingly be classed as marine types if found in a fossil condition, which is particularly true of the Fulgurlike genus Holacantha, of which four species inhabit this lake; and of the trochoid genus Limnotrochus, also represented by four species (Bourguignat-4). This association, with Planorbis, Physa, Vivipara, and other normal fresh water forms, would, if found embedded in the strata, lead to some interesting speculations regarding the conditions of deposition.

The relict fauna of the Scandinavian and Finnish lakes, of which there are no less than thirty-one, comprises seven Crustacea, 
three fish, and one seal (Phoca annellata Nilss). The Crustacea are especially interesting. Mysis oculata Fabr. var. relicta is the most widely distributed type. It is a variety of a true marine form which occurs in the northern seas on the coast of Labrador and Greenland. The same variety occurs in lakes Superior, Michigan, and Ontario, in the Gulf of Bothnia, and in the Caspian Sea. The other marine Crustacea of the Scandinavian-Finnish seas are three amphipods: one isopod, one phyllopod, and one lophyroporl.

Relict seas derived from the shrinking of former mediterraneans are found in the Caspian and Aral seas, which are still shrinking. These seas are fragments of a once extensive southeast EuropeanAsiatic mediterranean of later Tertiary time (Sarmatien). The relict fauna of the Caspian includes, besides the seal (Phoca caspica), sixteen species of molluscs, including Cardium, Adacna, Venus, etc.; two Crustacea, four sponges, and a number of fish. These seas are further characterized by having salty or brackish, instead of fresh, water.

Marine Relicts-Bipolar Faunas. "Bipolarity in the strict sense," says Ortmann, " $i$. $e$., the presence of an identical species at the North and South Poles, while it is absent in the intermediate regions, is extremely rare, and there are hardly any well-established cases. Bipolarity in a wider sense-presence of closely allied species at the poles, while in the intermediate regions allied forms are absent-is a well-established fact." The known cases are chiefly of pelagic animals. Ortmann thinks that, in some cases, as medusæ, pteropods, and tunicates, the ancestors lived in the tropical seas of Tertiary time, and their descendants migrated both north and south, the tropical forms subsequently becoming extinct. The difference between the north and south polar types in other cases is explained by Ortmann as due to different sources of the migrants. the Arctic faumas being derived from the old Mesozoic Mediterranean waters, and the Antarctic from Pacific waters. Other examples of marine relicts, or the occurrence of faunas in basins of the sea, while they have become extinct in the neighloring region, is shown by the fauna of Quahog Bay near Portland. Maine: and in the southern parts of the Gulf of St. Lawrence, as about Prince Edward's Island, and the opposite const of Nova Scotia, where the water is shallow and much warmer than on most parts of the Maine coast. Hcre Venus mercenaria is found in some abundance, associated with oysters and other southern species which are absent from the New England coast. They constitute "a genuine southern colony, surrounded on all sides, both north and south, by the boreal fauna." (Verrill and Smith-54:360.) 
TerRestrial Relicts. These are faunas and floras which have migrated into certain regions during a period of different climatic conditions, and then became stranded in certain spots where the enviromment remained uniform, while the surrounding area changed. The Arctic plants and butterflies of Mount Washington in New Hampshire are examples. These occupied the region during the general refrigeration of the climate in the last glacial period, and on the retreat of the ice were left stranded on the higher points where these conditions were more nearly normal for them. According to Professor Asa Gray, 37 northern species of plants still remain and thrive on the summits of the White Mountains of New Hampshire, and part of them also on the Adirondack and Green Mountains. A number of these species were found on a Greenland nunatak by the Jensen expedition of 1878 .

\section{Dwarf Faunas and Micro-faunas.}

These are faunas in which all the individuals are of much smaller size than their norm, and which therefore clearly lived under conditions preventing the organisms from reaching their full size. That such conditions are primarily environmental is indicated by the fact that all the organisms are affected, whereas, if individuals only were dwarfed, or only members of one species, this might be considered as more likely an individual response. Micro-faunas are associations of small species determined by the peculiarity of physical conditions and not due to dwarfing of normally large species. While dwarfed forms of known larger species are readily enough recognized, it is not always easy to say whether a given fauma-not known elsewhere-is dwarfed or is a micro-fauma due to selection.

Shimer (45) has listed the chief agencies of dwarfing noted in recent and fossil marine invertebrate faunas, as follows:

I. A change in the normal chemical content of the sea water. (a) Due to freshening of the sea water.

(b) Due to a concentration of the salt, iron, etc.

(c) Due to an increase in $\mathrm{H}_{2} \mathrm{~S}$ and other gases.

2. Presence of sand and other mechanical impurities in the water.

3. A floating habitat.

4. Variation in temperature.

5. Extremes in deptli of water and variation in amount of water per individual. 
As an illustration of the dwarfing due to the freshening of sea water Shimer cites the organisms of the Black and Caspian Seas. which are freshened by the influx of stream water (see tables of salinity, pp. I46, I54). As shown by Forbes (I4), the species of molluscs in the Black Sea are all smaller than those same species in the British seas. Cardium edule, the common cockle of the British coast, is dwarfed when it lives in the brackish water of the estuaries. The shell is not only reduced in size, but becomes thin and has its external character less strongly marked. The cockles of the Caspian Sea are small, thin, and smooth, with lateral or central teeth or both suppressed. The cockle of the Greenland estuaries is likewise thin, smooth and almost edentulous, the rudiments of hinge-teeth occurring in the young lut disappearing in the adult. This species is abundant in the Pliocenic Crag deposits of Suffolk and Norfolk, especially in the fluvio-marme portion. Among other species dwarfed by brackish water are $M / y a$ arenaria and Littorina littorea.

Shimer described a diminutive Pleistocenic? fauna from the estuarine clays of the Hudson bottom opposite Storm King, 40 feet below the bed of the river. This fauna consisted mainly of large numbers of Mulinia lateralis (Say) and a lower development of Trivia trivittata Say. These species live at present off the New England and New Jersey coasts in normal marine or but slightly freshened water, where their size is almost twice that of the Hudson estuary specimens.

Dwarfing due to concentration of salt, i. c., increase in salinity, is shown to some extent in the Mediterranean, which, with a salinity of 39 permille, has many of its species smaller than their representatives in the open water of the British and Spanish coasts. The dwarfed faunas of the European Permic have in part been ascribed to such concentration of the water. The possibility of dwarfing of faunas through an excess of iron salts has been shown by experiments upon fishes and tadpoles, which in eight months were retarded in growth from 3 to $5 \mathrm{~mm}$. Fossil examples are found in the Pyrite layer, which in the Genesee Valley and westward in New York replaces the Tully limestone of the Upper Devonic. In this the fauna of 45 species was found by Loomis (28) to be on the average only one-fifteenth the size of the normal form. The dwarfing was apparently due to presence of much iron in solution, in the form of ferrous carlonate. and this was precipitated as pyrite by sulphuretted hydrogen derived from the decaying organic matter $\left(\mathrm{FeOCO}_{2}+\mathrm{H}_{2} \mathrm{~S}=\mathrm{FeS}+\mathrm{CO}_{2}+\mathrm{H}_{2} \mathrm{O}\right)$. The 
Clinton iron ore also contains a somewhat dwarfed fauna which may have been due to the presence of much iron in the sea water.

Dwarfing effects due to an abundance of $\mathrm{H}_{2} \mathrm{~S}$ in the water are shown in the Black Sea, where, owing to the slight vertical currents, much stagnation occurs, and much $\mathrm{H}_{2} \mathrm{~S}$ is separated out (see ante, Chapter IV). Here life below a certain depth is practically absent, while the bottom deposits are strewn with young shells from the plankton. The dwarf faunas of the Palaeozoic Black shales have been considered as produced by conditions such as now exist in the Black Sea, but the depth during the formation of most of them was probably slight, though stagnation was no doubt marked.

The presence of mud or other mechanical impurities likewise exerts a dwarfing effect on many organisms. This is illustrated by the fauna of the eastern part of the Mediterranean, where a large quantity of fine mud brought in by the Nile is held in suspension. (De Lapparent-12:I32.) Shimer thinks that the dwarfed faunas of the late Siluric rocks of eastern New York (Rosendale, Cobleskill, Rondont, Manlius) are due to the presence of an abundance of lime-mud, of the same kind of which the strata are composed. This is a general characteristic of Palæozoic calcilutytes.

Dwarfing of organisms due to a floating habitat is seen in the case of a California coast Pecten ( $P$. latiauritus), which when growing near the coast is large and more strongly sculptured than when fastened to floating kelp far from the coast (var. fucicolus). The molluscs, living on and among the sea-weed which crowds the eastern shallower part of the harbor of Messina, are throughout of smaller forms, but are present in enormous number of individuals. (Fuchs-15:204.) Walther (56) remarks upon this that the physical conditions of a special type of plant life here cause indirectly the origin of the micro-fatua. The micro-fatma here is not so much a dwarf fauna as one due to selection of small species by the peculiar characteristics of the habitat.

The influence of variation in temperature on the size of the individuals is illustrated by the experiment of Semper (44) on Limnca stagnalis, in which he found that growth began at a temperature of $12^{\circ} \mathrm{C}$., but that a lower temperature retarded or completely arrested growth, though not affecting the life of the animal. "If," says Semper "a Limnea came to be placed in a pool or stream where for only two months of the year the temperature is higher than the minimum $\left(12^{\circ} \mathrm{C}\right.$.), growth will be checked throughout the greater part of the year, and a diminutive race result, since sexual maturity cannot be reached with a lower tem- 
perature." Excessive temperature also causes dwarfing, for polar species entering waters the temperature of which is higher than their optimum will remain smaller than normal. Thus northern species of Pecten never reach the same size in warmer southern waters. The same rule holds for mammals and birds. The dwarfing of the faunas of the Black and Caspian seas may be in part caused by the extremes of temperature in these waters.

Variation in the amount of water supplied likewise affects the size of aquatic animals. Thus Semper found, in experimenting with Limnca stagnalis, that "the smaller the volume of water which fell to the share of each animal the shorter the shell oremained." (Semper-44:16I.) With the same number of whorls, the average length of shell for a given number of animals in roo c.c. of water was $1 / 4$ inch, while the same number of animals in 2,000 c.c. of water had an average shell length of $3 / 4$ inch.

Deep-water individuals are also, as a rule, smaller than the shallow-water forms, various factors, such as difference in temperature, density and salinity of water, of food supply, etc., being operative here.

The dwarf faunas of the Windsor limestone (Mississippic of Nova Scotia) and of the Magnesian limestone or Zechstein of Europe, is probably due to several causes, notably the decrease in volume of water and the accompanying increase in salinity of the water, these deposits being intercalated between continental sediments. Similar clwarfed faunas are obtained from the Cretacic of New Mexico and southern Colorado. (Stanton-49; Shimer and Blodgett-46:67.)

\section{BIBLIOGRAPHY XXIX.}

1. AGASSIZ, ALEXANDER. 1888. Three Cruises of the Blake, 2 vols Bulletin of the Museum of Comparative Zoology, Vols. XIV, XV.

2. ANDRÉE, KARL. I912. Probleme der Ozeanographie in ihrer Bedeutung für die Geologie. Naturwissenschaftliche Wochenschrift, No. I6, pp. 24I-25I.

3. BALCH, FRANCIS NOYES. Igor. List of Marine Mollusca of Coldspring Harbor, Long Island, with descriptions of one new Genus and two new Species of Nudibranchs. Proceedings of the Boston Society of Natural History, Vol. XXIX, pp. I33-162, pl. I.

4. BOURGUIGNAT, J. R. I890. Histoire Malacologique du Lac Tanganyika. Annales des Sciences Naturelles, série $7^{\text {me }}$ Tome X.

5. CHUN, CARL. I886. Ueber die geographische Verbeitung der pelagisch lebenden Seethiere. Zoologischer Anzeiger, Nr. $214,215$.

6. CLARKE, JOHN M. 1897. The Stratigraphic and Faunal Relations of the Oneonta Sandstone and Shales, the Ithaca and Portage Groups in Central New York. Fifteenth Annual Report of the New York State Geologist, pp. 27-82; also, Sixteenth Annual Report, 1898. 
7. ClARKE, J. M. 1910. Paleontology and Isolation. Paleontologie Record, pp. 72-75. Reprinted from Popular Science Monthly.

8. CREDNER, RUDOLF. I887-88. Die Reliktenseen. Petermann's Mittheilungen, Ergänzungs-Band XIX, Nos. 86 and 89.

9. DALL, W. H. I9I I. Nature of Tertiary and Modern Marine Faunal Barriers and Currents. Proceedings of the Palicontological Society. Bulletin of the Geological Society of America, Vol. XXII, pp. 218-220.

10. DARWIN, CHARLES. I841. The Voyage of the Beagle.

II. DAVENPORT, CHARLES B. 1903. The Animal Ecology of the Cold Spring Sand Spit. University of Chicago, Decennial Publication X.

I2. DE LAPPARENT, A. I90o. Traité de Géologie. 4th edition, Vol. I.

13. DYBOWSKI, W. I875. Die Gastropodenfauna des Baikal Sees. Mémoires de l'Académie impériale-de St. Petersbourg. 'T. XXII, No. 8.

14. FORBES, EDWARD. 1859. Natural History of the European Seas, edited and continued by R. A. C. Godwin-Austen.

15. FUCHS, TH. I87I. Verhandlungen der königlich-kaiserlichen geologischen Reichsanstalt.

16. GRABAU, AMADEUS W. 190I. Geology and Palæontology of Niagara Falls and Vicinity. Bulletin of the New York State Museum of Natural History, No. 145 .

17. GRABAU, A. W. 1910. Ueber die Einteilung des Nordamerikanischen Silurs. Compte Rendı du XIme Congrès Géologique International, pp. 979-995.

18. GRABAU, A. W. 1913. Ancient Delta Deposits. Bulletin of the Geological Society of America, Vol. XXIV, pp. 339-528.

19. GULICK, JOHN T. I905. Evolution, Kacial and Habitudinal. Publication 25, Carnegie Institution of Washington.

20. GÜNTHER, A. C. L. G. I 880. The Study of Fishes. London.

21. HEILPRIN, ANGELO. I887. The Geographical and Geological Distribution of Animals. International Scientific Series, Vol. LVII.

22. HOERNES, RUDOLF. 1897. Die Fauna des Baikalsees und ihre Relicktennatur. Biologisches Centralblatt, XVII, pp. 657-664.

23. HOLLICK, ARTHUR. 1893. Plant Distribution as a Factor in the Interpretation of Geological Phenomena, with Special Reference to Long Island and vicinity. Contributions from the Geological Department of Columbia College, No. X. Transactions of the New York Academy of Sciences, Vol. XII, pp. I89-202.

24. HUXLEY, THOMAS. I879. The Crayfish. London.

25. JORDAN, D. S. 1905. The Origin of Species through Isolation. Science, N. S., Vol. XXII, Nov. 3, pp. 545-562.

26. KIRCHOFF, ALFRED. I 899. Pflanzen und Tierverbreitung. Hann, Hochstetter und Pokorny, Allegemeine Erdkunde, 5th edit., Vol. III. Leipzig.

27. KOKEN, ERNST. 1893. Die Vorwelt und ihre Entwickelungsgeschichte. Leipzig.

28. LOOMIS, F. B. 1903. The Dwarf Fauna of the Pyrite Layer at the Horizon of the Tully Limestone in Western New York. New York State Museum. Bulletin 69, pp. 892-920.

29. LYDEKKER, RICHARD. I9II. Zoological Distribution. Encyclopredia Britannica, eleventh edition, Vol. XXVIII.

30. MARR, J. E. I 892. Life-zones in Lower Palæozoic Rocks. Natural Science, pp. 124-13I. 
31. MERRIAM, JOHN C. I9IO. The Relation of Palæontology to the History of Man, with Particular Reference to the American Problem. The Palæontologic Record, pp. 88-92. Reprinted from Popular Science Monthly.

32. MOORE, J. E. S. 1903. The Tanganyika Problem. Hurst and Blackett, London.

33. MORSE, E. S. I880. The Gradual Dispersion of Certain Molluses in New England. Bulletin of the Essex Institute, Vol. XII, pp. 3-8.

34. MOSELY, H. N. 1882. Pelagic Life. Address at the Southampton Meeting of the British Association. Nature, Vol. XXVI, No. 675, pp. 559 et seq.

35. MOSELY, H. N. I885. The Fauna of the Sea Shore. Nature, Vol. XXXII, pp. 417 et seq.

36. MURRAY, JOHN. I885. Narrative of Cruise of H. M. S. Crallenger, with a General Aecount of the Scientific Results of the Expedition. Challenger Report, Vols. I, II.

37. ORTMANN, ARNOLD E. I895. Grundzüge der Marinen Tiergeographie. Jena. G. Fiseher.

38. ORTMANN, A. E. I 896. On Separation and Its Bearing on Geology and Zoögeography. American Journal of Seience, $4^{\text {th }}$ scries, Vol. II, pp. 63-69. Also: On Natural Selection and Separation. Proceedings of the American Philosophical Society, Vol. XXXV, pp. 175-i92.

39. ORTMANN, A. E. I902. The Geographical Distribution of the Freshwater Deeapods and its Bearing upon Ancient Geography. American Philosophical Society Proceedings, Vol. XLI, pp. 267 et seq.

40. OR'TMANN, A. E. I9Io. The Double Origin of Marine Polar Faunas. Seventh International Zoological Congress, 1907 .

4I. PESCHEL, OSCAR. 1875. Entwiekelungsgesehichte der Stehenden Wasser auf der Erde. Ausland, March I5, I875.

42. REED, F. R. COWPER. I910. Pre-Carboniferous Life-Provinces. Records of the Geological Survey of India, Vol. XL, pt. I, pp. I-35.

43. SCLATER, P. L. and W. L. I 899. The Geography of Mammals. London.

44. SEMPER, KARL. 1888. Animal Life as Affected by the Natural Conditions of Existence.

45. SHIMER, HERVEY W. 1908. Dwarf Faunas. American Naturalist, Vol. XLII, No. 499, pp. 472-49o.

46. SHIMER H. W. and BLODGETT, M. E. I908. The Stratigraphy of the Mount Taylor Region, New Mexico. American Journal of Science, XXV, pp. 53-67.

47. SIMPSON, C. T. I900. Synopsis of the Najades or Pearly Fresh-water Mussels. Proceedings of the United States National Museum, Vol. XXII, pp. 5II-IO44.

48. SMITH, JAMES PERRIN. I 895. Geologic Study of Migration of Marine Invertebrates. Journal of Geology, Vol. II I, pp. 48I-495.

49. STANTON, TIMOTHY W. I893. The Colorado Formation and its Invertebrate.Fauna. Bulletin of the United States Geological Survey, I06.

5o. STANTON, T. W. 19 10. Palrontologic Evidences of Climatc. Palæontologic Record, pp. 24-27. Reprinted from Popular Science Monthly.

51. THOMSON, WYVILlE. 1873. The Depths of the Sea. An Account of the General Results of the Dredging Cruises of H. M. S. S. Porcupine and Lightning. 
52. UHLIG, VICTOR. I9II. Die Marinen Reiche des Jtra und der Kreide. Mittheilungen der geologischen Gesellschaft in Wien. IV Jahrgang, Heft 3 , pp. 329-448, with map.

53. VAUGHAN, T. WAYLAND. 1910. The Continuity of Development. The Palæontologic Record, pp. 8I-84. Reprinted from Popular Science Monthly.

54. VERRILL, A. E. and SMITH, S. J. 1873. Report upon the Invertebrate Animals of Vineyard Sound and the Adjacent Waters, with an Account of the Physical Characters of the Region. United States Commission of Fish and Fisheries Report, pp. 295-747.

55. WALLACE, ALFRED RUSSELL. 1876. The Geographical Distribution of Animals. London.

56. WALTHER, JOHANNES. 1894. Einleitung in dic Geologie als historische Wissenschaft. I. Bionomie des Mecres. II. Die Lebenweise der Meeresthiere. Jena. Gustav Fischer.

57. WELLER, STUART. r895. A Circum-insular Palæozoic Fatuna. Journal of Geology, Vol. III, pp. 903-927.

58. WELLER, S. I898. The Silurian Fauna Interpreted on the Epicontinental Basis. Journal of Geology, Vol. VI, pp. 692-703.

59. WILLIAMS, HENRY S. I9IO. The Migration and Shifting of Devonian Faunas. Palæontologic Record, pp. 27-34. Reprinted from Popular Science Monthly.

6o. WILLISTON, S. W. 1910. The Birthplace of Man. Palæontologic Reeord, pp. 85-88. Reprinted from Popular Seience Monthly.

61. WOODWARD, S. P. I880. Manual of the Mollusca. 
CHAPTER XXX.

FOSSILS, THEIR CHARACTER AND MODE OF PRESERVATION.

Definition and Limitation of the Term Fossil.

Fossils are the remains of animals and plants, or the direct evidence of their former existence, which have been preserved in the rocks of the earth's crust. By direct evidence is meant the impressions left by animals in transition, the structures built by them, etc. Beds of iron ore and deposits of apatite or of crystalline limestone must be considered indirect and not always reliable evidence of the former existence of organisms, since, in these cases, organisms were only the agents active in their formation. Under remains preserved in the earth's crust must be included those formed in the northern ice fields, for we have seen that these ice masses are to be regarded as a portion of the rocky crust of the earth, though in most respects the least permanent one.

It has been a common custom to limit the term fossil to those remains which were buried prior to the present geologic period. This will be seen from the common text-book definitions of this term. A few of them may be quoted. Fossils: "All remains or traces of plants and animals which have lived before the beginning of the present geological period, and have become preserved in the rocks." (Zittel, Eastman's translation.) "Remains of animals and plants which have existed on the earth in epochs anterior to the present, and which are buried in the crust of the earth, are called fossils." (Bernard's Elements, adapted from the English translation.) "All the natural objects which come to be studied by the palæontologists are termed 'fossils' . . Remains of organisms . . . found . . . in those portions of the earth's crust which we can show by other evidence to have been formed prior to the establishment of the existing terrestrial order . . ." (Nicholson and Lydekker, Manual of Palæntology.) "Of those animals and plants which have inhabited the earth in former times, certain parts, decomposable with difficulty, or not at all, have been 
preserved in the strata of the earth, and these we call fossils, or petrefactions." (Steinmann, Einfiihrung in die Paläontologie, translated.) This definition in terms of past geologic time is an arbitrary one, and is not based on any distinction in character between the remains which were buried before and those which were buried during the present geologic epoch. Thus the marine shells in the post-glacial elevated clays of northern New England and Canada (Leda, Saxicava, etc.) differ in no wise from those of the same species buried in the modern deposits off the present coast. "In the former case the strata have been elevated several hundred feet; while in the latter case they still retain their original position, or, at least, have experienced no appreciable disturbance. In like manner many of the Mliocenic and Pliocenic shells are not only of the same species as those recently buried on neighboring shores, but the changes which they have undergone since burial are frequently not greater than those experienced by shells buried in modern accumulations. The difference in the alteration is merely one of degree, and with proper discrimination specimens can be selected which show all grades of change, from the unaltered state of shells in modern mud-flats to the crystalline condition of an ancient limestone fossil, in which the original structure has been completely lost." (Grabau-13:97, 98.) It is thus seen that it is far more logical to extend the term "fossil" so as to include all remains of animals and plants preserved from the time of the earliest fossiliferous strata to the present. This is the position taken by Lyell, who defines a fossil as: "Any body or the traces of the existence of any body, whether animal or vegetable, which has been buried in the earth by natural causes." In this definition made by the geologist the time element is entirely omitted and in this respect it contrasts markedly with the definitions quoted above from palæontologists. Of the latter, however. D'Orbigny forms an exception, for he considers the term "fossil" to comprise "all bodies or vestiges of bodies of organisms buried naturally in the rocks of the earth and found to-day, except when actually in the living state." (Cours Elémentaire de Paléontologie, Vol. I, p. I3.) Geikie, too, neglects the time element in his definition of a fossil. He says: "The idea of antiquity or relative date is not necessarily involved in this conception of the term. Thus, the bones of a sheep buried under gravel and silt by a modern flood and the obscure crystalline traces of a coral in ancient masses of limestone are equally fossils." (Text-book of Geology, 3d ed., p. 645.) This general definition of a fossil is the one insisted upon by Grabau and Shimer in "North American Index Fossils" (Volume I, page I.) 


\section{Fossilization.}

"Geologic time is continuous, and the development of life is progressive. No break divides the present from the past, and the geologic phenomena of the present epoch are controlled by the same laws which governed those of past time. Fossilization is a mere accident by which some animals and plants are preserved, and it resolves itself into a process of inhumation, neither the nature of the organism nor the time or mode of burial being of primary significance. These are of first importance in determining the degree of preservation which the fossil is to experience, and, consequently, the nature of the record which is to remain; but they do not affect the process of fossilization, which is merely the burial of the dead organism. Thus the idlea of change is not necessarily involved in the concept of a fossil, although it is true that few organisms long remain buried without undergoing some chemical change. Examples of the preservation of organisms in an almost unchanged condition are nevertheless known, the most conspicuous being the nrammoths frozen into the mud and ice of Siberia, and retaining hair, skin, and flesh intact: and the insects and other animals included in the amber of the Baltic, where they have remained unchanged since early Tertiary time. Ordinarily, however, the flesh of the buried animal soon decays, and, consequently, no record of the soft parts is retained. In plants the decay is less rapid, and the buried vegetable remains may be indefinitely preserved in the form of carbonaceous films.

"The hard parts of animals are best preserved as fossils. Such are the shells and other external skeletal structures secreted by a variety of animals, as crustaceans, molluses, echinoderms, corals, and so forth; and the bones, teeth, and other hard structures of the vertebrates. Besides the actual remains of animals and plants. any evidence of their existence, which is preserved, is commonly included under the name of fossil. Thus impressions made by living animals and plants in the unconsolidated rock material, and structures built by animals from inorganic material, are fossils if properly buried. Examples of the first are the footprints of vertebrates; the tracks and trails of jelly-fish, worms, molluses, or Crustacea; the burrows of worms, borings of animals in stones or shells, and the impression made by sea-weeds in motion. Among the second class are worm tubes built of sand grains; foraminiferal shells, built of foreign particles; flint implements and other utensils of primitive man; and the relies of the Swiss Lake dwellers . . . 
(Grabau-1 $3: 98$, 99.) Here belong, further, ancient buried cities, like Pompeii; the Roman coins, weapons, etc., buried in the peat bogs of Flanders and the north of France; and, in fact, all artificial productions of early man or other animals which have been preserved. Finally, coprolites, or the characteristic excrementa of animals, have frequently been preserved, and these constitute a class by themselves. Thus four distinct types or classes of fossils may be recognized, viz.: (Grabau and Shimer-14:3.)

I. Actual remains and their impressions.

2. Tracks, trails, and burrows of organisms.

3. Artificial structures.

4. Coprolites.

These may now be discussed more fully.

Types of FossiLs.

\section{Actual Remains.}

Preservation of Soft Tissues. As has already been noted, a number of cases are known where the fleshy portions of animals have been preserved. The mammoth (Elephas primigenius), and the rhinoceroses frozen into the mud and icc of Siberia are classical examples. Insects, spiders, and myriopods have been preserved in great perfection in the Oligocenic amber of the Baltic provinces. This fossil resin was produced by a species of pine (Pinus succini$f e r)$ and its quantity was so great that the deposits, though they have been worked since very ancient times, have not yet been exhausted.

Remains of man and other animals have been found perfectly preserved in peat-bogs where they had been entombed for hundreds of years. Mummification, or the preservation of the flesh in dried condition, nust also be noted in this connection, for in this manner many remains of the human period have been prescrvecl. Natural mummies have been found in saline soil at Arica in Chili (South America), and they have also been found occasionally in dry caverns and in crypts, notably in Bordeaux, France. In the desert region west of the Peruvian Cordillera in South America climatic and other conditions have proverl particularly favorable to the natural preservation of human remains. "The tombs and graves [of the Incas] are usually found on elevated places outside of the valleys where the extreme dryness of the air 
combines with the nitrous character of the sand, into which moisture has seldom found its way, to desiccate and preserve the bodies of the dead, thus mummifying them naturally. The same factors have caused the clothing and objects placed with the dead to be preserved for many centuries." (Mead-17:8.) Bodies of animals have been similarly mummified, particularly those of household pets, such as $\log s$ and parrots; and foods, such as corn and beans, have been perfectly preserved. In the Atacama desert in Chile, in the Chuquicamata copper mining district, was found the body of a miner who had been caught, while at work, by a cave-in of the roof of a mine in a side hill. "The stone and carth surrounding the mummy were impregnated with anhydrous sulphate of copper (brochantite), and sulphate of copper (blue vitriol). This mineral prevented the organic matter from decomposition." "The skin has not collapsed on the bones, as in the mummies found usually in the region, but the body and limbs preserve nearly their natural form and proportions, except for the crushing . . " which took place on the caving-in of the mine. The age of the mummy is unknown, but it is probably several hundred years old, as indicated by the primitive character of the implements embedded with the body.

Preservation of animal tissue by impregnation with mineral matter also occurs. As an example may be mentioned the wellpreserved body of a negro woman which had been buried for fiftyseven years and was found near Tuskegee, Macon county, Alabana, in I894. The body lay in a sandy soil where the water from a nearby spring kept it continually wet. In this water, silica, lime, and magnesia were held in solution, and silica, lime, and oxide of iron in suspension. About 50 per cent. of the substance of the body had been replaced by mineral matter. Lead was also found present in the body and might have been active in its preservation. (Stedman-23.) All told, however, the complete preservation of the animal body is of rare occurrence, and probably never dates back very far in geologic history. A remarkable exception to this rule is found in the muscle fibers of Devonic and later fish, and in Mesozoic reptiles, which have been so perfectly preserved by a process of replacement that their structure can readily be determined under the microscope. These will be noted again in the discussion of modes of preservation.

Impressions of the soft parts in rocks, or even a carbonaceous film representing them, are foumd under favorable conditions. The most familiar examples of this kind are ferns and other plant remains, but those of animals are not unknown. In the finc litho- 
graphic lutytes of the Solnhofen district in Bavaria have been found the impressions of medusæ and of naked cephalopods with the inkbag still containing the sepia in a solidified state, while the beautiful impressions of insect wings and the membranous wings of pterosauria are among the most noted preservations obtained from this rock.

Even more perfect examples of the preservation of soft parts have recently been obtained by Walcott from the Stephen shale (Cambric) of western Canada (26). Here worms, holothurians, and other soft-bodied aninals occur in a wonderful state of preservation, so that, in many cases, even the internal anatomy can be ascertained. The appendages of trilobites and other organisms are also well preserved. The rock in which these fossils occur is an exceedingly fine-grained sapropellutyte. Other remarkable preservations of soft tissues in rock of this type are known from the Lias of Württemberg, where, at Holzmaden, the impression of the skin of the Ichthyosaurians has been obtained.

Preservation of Hard Structures and of Petrified Remains. The hard parts of animals are best adapted for preservation. This is particularly the case where these parts are either calcareofts or siliceous. Such are the shells of Protozoa; the spicules of sponges; the coral of the coral-polyps; the test of the echinoderm; the shell of brachiopod or mollusc; the calcareous structure of Bryozoa; the exoskeleton of Crustacea; and the bones and teeth of fishes, amphibians, reptiles, birds, and mammals. But hard parts of a purely organic origin are also commonly preserved. These are the structures composed of chitin and conchiolin. Chitin, or entomolin, as it is also called, is the substance of which the elytra and integuments of beetles and other insects are composed, and which, commonly with an admixture of calcium carbonate or phosphate, forms the carpace and other exoskeletal parts of Crustacea, etc. Its composition is probably expressed by the formula $\mathrm{C}_{45} \mathrm{H}_{26} \mathrm{~N}_{2} \mathrm{O}_{10}$. Chitinous structures of other animals are the perisarc of Hydrozoa and the similar network of horny fibers in the Ceratospongix. Conchiolin is the organic matter of shells which, on solution of the lime by acids, remains as a soft mass. The young shells, particularly the protoconch, consist wholly of this material. It is generally strengthened by subsequent deposition of calcium carbonate, but in some cases, as in the nautiloids, it seems to remain in the original chitinous condition, and is occasionally preserved.

These structures, whether of chitin or conchiolin, are preserved either as impressions, or, more generally, as carbonaceous films. 
Sometimes various minerals, as pyrite, or chlorite, or even talc, replace them. The same thing may be said of the cellulose composing the tissues of plants, where decomposition is a slower process than in the fleshy tissues of animals. The cell structure of plants may thus be conserved for a long period, and this is especially the case where there is a nearly complete exclusion of air, as in fine sediments or in peat bogs.

- The first requisite in fossilization is the burial or inlummation of the remains. Even the hard parts of animals will be destroyed if exposed too long to the atmosphere. Thus the bones of the American bison, which, during the process of extinction that this animal was undergoing on the western plains, were abundantly scattered about, are fast disappearing by decay, so that shortly no traces of them will remain except where they have been buried.* This fact must be borne in mind in considering the remains of earlier mammals. Those found can constitlite but a small portion of the skeletons once scattered about but which disintegrated before the slow process of burial by continental waste or by dust saved them. The soft tissues of animals and the tissues of plants decay, of course, rapidly, and even inhumation, except in the cases noted above, will not check the process of decay. Immersion in water likewise results in the decay of organic matter, for bacteria here become an active agent in the dissolution of tissues. Hard structures, such as shells or bones, will also suffer destruction by solution, especially if the waters are rich in carbon dioxide. Thus, as already noted in an earlier chapter, the shells of many Protozoa are dissolved after the death of the animal before they settle down to the abyssal portions of the sea, and hence deposits of these shells are generally absent from the greater deeps, though abundant in regions of lesser deptl. Solution may continue even after burial if the beds are raised above the sea-level, and if they are permeable.

The buried hard parts of animals generally undergo a process of petrifaction, which most commonly is either calcification or silicification, or sometimes the first followed by the second, $i$. $c$., a replacement of the lime by silica, or, more rarely, the reverse. Pyritization, or the replacement of the remains by iron pyrites (or, more frequently, by marcasite) and replacement by iron oxide, sphalerite, barite, vivianite, glauconite, or other minerals, also occurs. The process of replacement differs in different groups of organisms.

* A certain percentage of these bones, however, has been picked up and burned for commercial and other purposes. 


\section{Petrifaction of non-mineral substances.}

(a) Replacement of soft animal tissue. As stated above, the muscle tissues of a number of groups of vertebrates have been known to be preserved in a most remarkable manner. In the upper Devonic shales (Cleveland shales) of Ohio the muscular tissue of cladodont sharks has been mineralized in such a perfect manner that in places "they suggest in color, distinctness, and texture the mummified tissue of recent fish." (Dean-10:274.) Similarly, wellpreserved muscular tissue has been found in fishes of the lithographic stone (Reis-20, pl. II), and in other deposits both finer and coarser. The muscular mass thus preserved is pure mineral, composed of about $80 \%+$ of calcium phosphate. Reis holds that the muscular tissue was in a semi-decomposed condition, that mineralization took place quickly, and that the remains must have been so effectively enclosed that decomposition was checked. The phosphate, he thinks, is derived from the body of the animal and precipitated on contact of the decomposing material with the calcium carbonate of the surrounding sediment. Dean, on the other hand, favors the view that the phosphate was deposited from solution within the undecomposed tissue of the shark, which thus became mineralized before it had time to decompose. The partial replace-. ment of human bodies mentioned above is analogous to the more ancient case here cited.

(b) Petrification of plants. (Roth-22:605.) Aside from the unicellular diatoms, in which the cell walls of the living plant are impregnated with amorphous silica, and the unicellular to multicellular lime-secreting algæe, the tissues of plants may in general be regarded as free from mineral matter. But plants immersed in mineral waters, or buried where such waters have free access, are saturated and completely impregnated with the mineral matter. Colloidal silica is most favorable for the preservation of the delicate cell structures, while calcite or other minerals of high crystallizing power will cause deformation if not disruption and complete destruction of the cell walls.

A mass of wood completely penetrated by and saturated with silica still shows its original form and structure, even to the ornamentation of the cell walls, which, in a properly prepared slide, will not appear very different from the fresh or dried tissues. Even in appearance the impregnated wood resembles the unaltered wood, being fibrous and splintery, and the change is often noticeable only from the difference in weight and hardness. The silica of wood 
thus saturated may be dissolved in concentrated hydrofluoric acid, when the woody tissue will be left belind unattacked. This shows, according to Göppert, a cellular structure which in most cases is sufficient for the generic determination of the wood.

Replacement of the cell walls themselves generally follows impregnation, and thus the wood becomes wholly changed to silica. Under these circumstances the finer structure is often destroyed and the mass becomes uniform and breaks with a conchoidal fracture. Illustrations of this are found in the brilliantly colored. agatized woods of Arizona, fragments of which are hardly distinguishable from agates of wholly inorganic origin.

Opalized woods are not uncommon. Here, as in the case of woods replaced by quartz, the structure of the wood is generally retained, and in some cases the interior has been found to be but slightly impregnated with the opal, or even to be unaltered wood, thus showing the progress of opalization from without inward. (Blum-4:I97.)

Calcified woods are not uncommon, occurring in all formations, from the Devonic up. They have been found in limestones, sanclstones, shales, basaltic conglomerates, volcanic ashes and tuffs, and other deposits. Daubrée found at Bourbonne-les-Bains, in the department of Haute-Marne, France, piles of red beechwood, in places so completely impregnated with transparent calcium carbonate that on solution in hydrochloric acid only 3.1 per cent. of insoluble matter, showing plant structure, remained. The piles supported an ancient Roman canal, and when found were buried about 8 meters below the surface.

Aragonite is also known to have replaced wood. Even gypsum has been found replacing wood in some Tertiary beds, and phosphate, as well as fluorite of lime, is likewise known in this connection. Barite also has replaced wood in some limestones of the Lias, and a talc-like, complex silicate, probably pyrophyllite, has been found replacing fronds of Neuropteris and Pecopteris and the leaves of Annularia in Carbonic rocks in the Piedmont district. Chlorite has been found occurring in a similar manner. So delicate is the replacement that the venation is easily recognizable, although no part of the original organic matter remains. Wood largely replaced by sulphur and devoid of structure has been found in Cesena, Italy, and plant remains replaced by sulphur have also been obtained from the Tertiary beds of Aragon. (Blum-7:I7O.)

In the Carbonic and later coal-bearing horizons wood replaced by siderite, often with considerable iron oxide, or wholly by limonite or hematite, is not uncommon in various parts of the earth; while 
- sphalerite, galenite, and marcasite are also known. Galenite has been reported as replacing the fronds of ferns in some Coal Measures of Saxony. Malachite, azurite, and chalcocite are found in carboniferous marls, probably of Jurassic age, in the district of Angola, West Africa, in the Urals, and in other regions. Even modern cedar wood has been found coated with and, in some cases, largely replaced by malachite, as reported by Dr. A. F. Rogers from Brigham, Utah (2I). From a tuff bed enclosed between basaltic flows below the Limburg (Germany) wood of Prunus nadus (?) replaced by a kaolin-like substance has been obtained in abundance. This still retains the structure and occasionally carbonaceous remnants of the wood occur.

Where the actual plant remains have been removed by decay an impression or mold often remains, in which a cast of the plant may be formed by infiltrating foreign material. Such casts are common in the Carbonic sandstones of the Joggins region of Nova Scotia, in western Scotland and elsewhere. Trunks of Calamites, Sigillaria and Lepidodendra, together with their rootstalks, Stigmaria, are abundant in these strata as sandstone casts, resulting from the filling of the cavities left by the decaying wood.

Decaying wood or other delicate parts of plants may leave a record behind in the rocks in the form of a film of colored mineral matter, precipitated by the decaying organic matter, or by the removal of the coloring matter of that portion of the rock covered by the decaying plant. This process of self-inscription upon the rock by the plant has been termed autophytography (White-28), the first mode producing a positive picture, and the second a negative one.

\section{Petrifaction of mineral structures.}

(a) Protozoa. The shell of the Foraminifera is typically composed of carbonate of lime, either in the form of calcite (vitreous species) or of aragonite (porcellaneous species). The skeletal structures of Radiolaria are mainly of silica, though horny types (of acanthin) also occur. Both types of Protozoa are well adapted for preservation and extensive deposits of them are known, such as the Radiolarian beds of Barbados (Miocenic) and the chalk of western Europe (Cretacic).

(b) Sponges and hydrozoans. These organisms are generally capable of preservation on account of the chitinous material which composes the network of many sponges and forms the perisarc of the Hydrozoa. They are most commonly preserved as carbonaceous 
films, but cases of pyritization among the graptolites are not uncommon. Such pyritized specimens stand out in relief and afford good material for sectioning. (Wiman-27.) Pyrophyllite also has been found replacing these organisms, which thus became outlined in white on the dark shales in which they occurred. (Blum-5: I26; $7: 175.5)$

In a considerable number of sponges siliceous or calcareous spicules occur, frequently uniting into a solid network, and then preserving the form of the sponge. The siliceons spicules of sponges are sometimes replaced by calcite in the process of fossilization.

(c) Silicification of corals. Most corals are composed of calcium carbonate in the form of aragonite, with the exception of the Alcyonaria, which are calcite. Often a small percentage of magnesium carbonate is present. The structure of the corals is frequently very porous, but it is most probable that these pores are first filled by calcium carbonate, and that silicification is a process of replacement pure and simple. While silicified corals preserve the form well, the finer structure is commonly destroyed. The ringed structure, known as Beekite rings and more fully described under the section on moiluscan shells, occurs rarely in corals; the rings seldom occur so abundantly or of such size as in molluscs or brachiopods. Corals are occasionally replaced by other minerals, sphalerite having been most frequently observed.

(d) The brachiopod shell. In a number of inarticulate brachiopods the shell consists chiefly of chitin, and here the preservation is similar to that of other chitinous structures. In Lingula, alternating layers of chitinous and calcareous matter make up the shell. but in the majority of species the shell is wholly composed of calcium carbonate. This is present in the form of calcite. The greater portion of the shell is composed of a layer of fibers or prisms of calcic carbonate which constitutes the inner layer of the shell. Outside of this is a thin lamellar layer of calcic carbonate. covered in turn by the periostractim. or outer corneous film. In a large number of species the shell is traversed by vertical canals or tubules which expand upward and terminate in the lamellar layer, not piercing the periostracum.

Calcification and silicification occur in the brachiopods as in the molluse shells, the tubules. when present, forming additional spaces for the infiltration of lime or silica. Details will be mentioned in the description of molluscs. Nearly all the minerals mentioned under molluses have been found replacing brachiopor shells; $i$. $c$., pyrite, galenite, sphalerite, the various iron oxides, barite, etc. 
(e) Shells of molluscs. These are composed of calcareous salts, either carbonate of lime or mixed carbonate and phosphate of lime, penetrated and bound together by an organic network of conchiolin. In the Pelecypoda the shell consists of three layers: (I) the outer or periostracum, a horny integument without lime; (2) the middle prismatic or porcelancous layer, consisting of slender prisms perpendicular to the surface and closely crowded; and (3) the inner or nacreous layer, which has a finely lamellate structure parallel to the shell surface. Many pelecypod shells consist entirely of aragonite. In Ostrea and Pecten the whole shell is calcite, while in some others (Pinna, Mytilus, Spondylus, etc.) the nacreous layer is aragonite, while the prismatic layer is calcite. In the gastropod and cephalopod shell the inner or nacreous layer is often wanting, while the periostracum is generally present. The structure of the middle layer differs much from that of the pelecypods. The shells are mostly aragonite, except those of a few gastropods (Scalaria and some species of Fusus) and a few cephalopods ( $c . g$., the guard of Belemnites), which are of calcite.

The first process of alteration in the shells is the removal by decay of the horny periostracum covering the shell and of the conchiolin which penetrates the calcareous mass. As a result the shell is rendered porous, which can be proved by applying it to the tongue, when it will be found to be adhesive. This porous condition may be observed in many Miocenic and later shells. The aspect of a shell which has thus undergone the first change is more or less chalky, instead of firm and often shiny, as in the fresh shell. Frequently shells composed of aragonite are entirely destroyed, while in those in which both calcite and aragonite occur the latter is dissolved away while the calcite remains unimpaired. Water carrying salts in solution will enter the pores and there deposit its mineral matter, until the pores are filled. If the matter in solution is carbonate of lime, this process of infiltration will result in the complete calcification of the shell, whereby the finest structural details will be fully preserved. Those portions of the shell which originally were aragonite may be changed to calcite. In some cases, however, the whole shell is converted into crystalline calcite, and then the finer structure is destroyed. At other times grantular limestone replaces the shells. If, however, the infiltrating substance is silica, the process of fossilization does not stop with the filling of the pores, but from the greater insolubility of the silica it becomes the dominating substance and gradually replaces the more soluble lime. This process is frequently most active around certain centers, and is then indicated by the formation of concentric rings of silica 
(Kieselringchen), which have been named beckite rings, after Dr. Beek, sometime Dean of Bristol, who first called attention to them. These rings often form a regular ornamentation of the surface of shells and have been mistaken for original features. According to T. M. McKenny Hughes ( $15: 265$ et seq.), these rings form in a layer $1 / 8$ to $1 / 4$-inch thick, just beneath the outside film of lime. Blum $(4: 190)$ records cases where the calcium carbonate of the shell is still largely retained, while at many places single tubercles of silica project, surrounded each by one or two rings, but seldom more. This was especially noted in brachiopods. In some cases the shell was changed to chert with only scattered rings. A shell of Orthis rectangularis from the Carbonic limestone was wholly silicified, the silica appearing in the form of small spheres which are arranged in place of the former radial striations of the shell. A shell of Gryphæa contained several layers of silica in the form of beekite rings. A Plicatuia armata had its inner surface preserved in compact yellowish-brown chert; while its outer surface, with all its original roughnesses, was composed of beekite rings. Pecten vagans showed the reverse, with a layer of stalactitic quartz between the two layers. Arca had both outer and inner surfaces made up of beekite rings, while between these layers appeared a porous mass of chert. A specimen of Exogyra reniformis from the Oxford Oolite was replaced by beekite rings, while Trigonia costata, to which it adhered, was replaced by chert only. Belemnite guards had their surfaces covered with beekite rings, while the interior was still fibrous calcite. Others had been changed entirely to beekite. The rings here had become concentric cylinders, the axes of which coincided with the original calcite fibers. In other cases the guard was composed of a number of concentric layers or funnels, each of which was composed of beekite rings.

So far as present observation goes, there seems to be no inherent character within the organism or the formation within which it is embedded which determines whether silicification is to be accompanied by the formation of beekite rings or not. Both cases have been found within the same formation at the same locality and within the same genus.

Silicified shells are among the most acceptable fossils, for they will readily weather out in relief or even become entirely free, or they may also be easily separated from the enclosing matrix by the use of weak acid.

A great variety of minerals besides silica replaces the calcium salts of mollusc shells. The chambers of ammonites often contain ankerite (Quenstedt), others again are chiefly filled by stron- 
tianite (Sandberger). In the Zechstein of Altenburg shells of Schizodus have been found replaced by malachite, which fills the space between external and internal mold. Gypsum has also occasionally served as replacing substance of pelecypods and gastropods. Barite is not an uncommon replacing agent of molluscan as well as brachiopod shells and other hard structures. In the Lias of Whitby, England, the ammonites are commonly replaced by barite, colored brownish by bituminous matter. Celestite or anglesite more rarely takes the place of barite. Vivianite not uncommonly replaces the guards of Belemnites in the New Jersey Cretacic, as well as shells of other molluscs. Even wulfenite has been recorded as replacing the shell of an Isocardia. Iron pyrite or marcasite is a common replacing agent of mollusc shells, especially those of ammonites. This strbstance often becomes altered to limonite, and not infrequently disintegrates altogether, where not protected from the air; and thus beautiful fossils are destroyed. Blum records the case of an Avicula in which the outer surface was pyrites and the inner calcite. Sphalerite, and, rarely, smithsonite, galenite, and other metallic salts, replace the shells of pelecypods and gastropods and, more rarely, of cephalopods. In the Côte-d'Or, a Liassic pelecypod has been found completely replaced by specular hematite, while ordinary red hematite is not infrequently found replacing mollusc shells. Chlorite has been found replacing shells in several cases. In the Tertiary beds of Aragon, Spain, Planorbis has been found replaced by native sulphur (Blum- $7: I 7 I, I 76)$; and Tertiary Helix from near Madrid has been reported replaced by meerschaum or sepiolite.

(f) Crustaceans, Merostomes, Insects, etc. As has been noted above, the exoskeleton of Crustacea is composed of chitin impregnated with calcium carbonate and phosphate. Sometimes the chitin carbonizes and a black mass of carbon mixed with lime remains, which is susceptible of a high polish. Again, the organic matter may be entirely removed and replaced by calcium carbonate or other minerals. Thus trilobite tests are sometimes changed entirely to crystalline calcite. Pyrite not infrequently replaces the tests of trilobites, as in the famous specimens of Triarthrus becki from near Rome, New York, discovered by Valient, in which Matthew and Beecher have found the antennæ and legs beautifully preserved, the whole test having become pyritized. The exoskeletons of merostomes correspond closely to those of Crustaceans. The insect body is rarely preserved, except the wings and the elytra of beetles, owing to the absence of mineral matter.

(g) Echinoderms: This class of animals is characterized by the 
possession of calcareous dermal plates wholly composed of calcite, which in many groups form a solid test or enclosure for the main mass of viscera within. The plates are not firmly united with each other, but they have the power to grow and change form during the life of the individual. A characteristic feature of all the skeletal parts is their extreme porosity. This is true of the test and the spines of the sea-urchin as well as of the calyx, arms, and stem of the crinoids. The porosity shows in section, and it is also indicated by the fact that the specific gravity of a recent Cidaris spine, with its pores unfilled by water, is only $\mathrm{I} .46$, while the completely calcified spine has a specific gravity of 2.7. The hollow spaces constitute about 43 per cent. of the spine. (Haidinger. Blum-4:I6I.) During the life of the animal the pores in the calcareous tissue are occupied by organic matter (chitin), which is removed by decay after death. Furthermore (Haidinger), each skeletal element of the echinoderm test is composed of an individual crystal, the crystalline axis of which is coincident with the organic axis; and the new lime which fills the pores crystallizes in continuity with the calcite of the original structures. As a result, perfect cleavage is obtained in the skeletal parts, each plate or spine having virtually become a perfectly cleaving calcite fragment. 'The axis of the crystal coincides with the organic axis of the part. (Hessel, Blum.) In crinoid stems the cleavage often shows a rotation of axis in the successive joints, so that corresponding cleavage planes make an angle with each other. (Blum-4:I6r.) According to investigations carried on by Dr. A. F. Rogers (2I) the twisting is sometimes such as to place the crystals composing the successive joints into a twinning position. At other times it is irregular, and again in some species there is no twisting at all.

Silicification of echinoderms occurs more rarely. When it does occur, beekite rings, while present, are often less pronounced and abundant than in molluses or brachiopods. (Blum-4:192.)

Pyrites occasionally replaces echinoderm structures. Thus pyritized crinoid stems are not uncommon in some formations. Pyritized spines of Cidaris have been recorded from the Oolite of Helgoland. (Blum-4:202.)

Entire specimens of Liassic Pentacrinites are found in the sapropellutytes of Holzmaden, Württemberg, replaced by iron disulphide.

Cerussite (lead carbonate) has been found as a frequent replacing agent of crinoid remains in the lead-bearing formations of the department of Kielce, southwestern Russia. These replaced remains commonly have the aspect of crystals of this mineral, with 
which they occur loose in the gange of the ore-beds. (Blum$4: 209$.)

(h) Vertebrates. The bones of vertebrates contain much calcium phosphate with the calcium carbonate, the whole being bound together by the organic ossein, or bone-cartilage. According to Berzélius, the bones of mammals consist of: bone cartilage 32.17 per cent.; ducts I.I3 per cent.; basic phosphate of lime with a trace of fluoride of calcium, 54.04 per cent. : carbonate of lime, I I.3O per cent.; phosphate of magnesia, I.I6 per cent.; and carbonate of sodium with a trace of the chloride, I.20 per cent. The organic substance is replaced by the mineralizer, which is commonly calcium carbonate. Sometimes complete crystallization takes place. Among the bones found in the gypsum beds of the Paris basin and other regions many had been more or less impregnated with gypsum.

Pyritized skeletons of Ichthyosaurs, Plesiosaurs and other reptiles, as well as higher types, are common. Where marcasite is the replacing agent decomposition readily sets in and, if the matrix is a clay slate (argillutyte), alum efflorescence marks the progress of this decay.

Chalcopyrite is common as a coating of fish remains in Thuringia and Hessia, though seldom wholly replacing them. Bornite occasionally performs the same office. Native copper sometimes results from the alteration of these coatings. Cinnabar sometimes occurs in the same manner as the copper ores, seldom completely replacing the fish remains.

The teeth of mammals are rich in phosphate of lime, 60 per cent. or more of this salt being present. 'To the large proportion of this substance the durability of the teeth is attributable, they being among the most frequently preserved parts of mammals. The enamel of the teeth contains a somewhat larger percentage of phosphate of lime than the dentine, a difference which is expressed in the diverse degrees of preservation of these parts. (D'OrbignyI I :37.)

Eggs of vertebrates have not infrequently been found well preserved. Examples are: the eggs of the Moas of New Zealand, Chelonian eggs from the Tertiary of Auvergne, France, in which the shell was filled with mud which subsequently hardened; the Miocenic egg from South Dakota described by Farrington (12), which was completely silicified, and the fossil egg of Quaternary age from Arizona, described by Morgan and Tallmon (18), in which the shell is perfectly preserved, showing the same structure found in modern hen's eggs, the shell agreeing in composition with that of the egg of the wild goose. The interior with the 
exception of a small space near the periphery was filled solidly with a beautiful crystalline mass of the mineral colemanite. "In several places next the shell a semi-fluid layer of bitumen occurs, which probably represents the original organic matter within the shell."

\section{Excessive silicification.}

In some cases, notably in the Carbonic strata of the Mississippi Valley region, it has happened that silica has been deposited to excess in crinoids, shells or corals, with the result that the original form has been wholly destroyed, the fossil at the same time swelling out enormously. This excessive deposition goes on more particularly along lines of fracture, or, as in the crinoid calices, between the component plates. These become more and more separated as the deposition of silica goes on, and they also become sunken below the level of the network of silica. Eventually they are probably buried in the accumulation of silica which closes over them. Thus from a small fossil in which all the plates are discernible, a large mass of structureless silica is formed, which seldom gives a clue to its origin. (Bassler-I.)

Molds and Casts. Whenever organisms are buried in material of sufficient plasticity to adapt itself to the contours of the buried bodies, molds of the exteriors of these bodies will be made. Such molds may be temporary or they may be persistent ones. Lutaceous material generally furnishes the most perfect molds. Even soft tissues, when encased in a matrix which solidifies rapidly enough, may leave a mold behind after decay. Thus the bodies of human beings buried in the volcanic mud which overwhelmed Herculaneum and Pompeii left behind a perfect mold of their exterior. Again, the calcareous tufa, forming constantly in many portions of the earth, encloses leaves, mosses, or even fish and other animals and covers them with a crust of lime. On the subsequent decay of the enclosed body a perfect mold of its exterior is commonly preserved from which an artificial cast could be made. Viscous lava also may flow around and enclose a foreign body, which, if it is able to withstand the heat of the molten mass, may leave a distinct mold or impression. Impressions of medusa are known from the Cambric of the southeastern United States (IValcott-25). When two valves of a bivalve mollusc become buried in juxtaposition, the space between them is filled with mud and thus an internal mold is produced. The same occurs in gastropods, in cephalopods and in other shelled animals, and may also be found in trilobites and 
other Crustacea. This mold of the interior is commonly spoken of as a "cast," which is wholly erroneous, since the cast reproduces the original in a new substance, whereas the mold is a reverse copy. Between the external and internal mold a cast may be formed by infiltration of mineral matter or by artificial means. Not uncommonly the removal of the sheil by solution is followed by a closing of the cavity between the external and internal mold, owing to the pressure to which the enclosing rocks are constantly subjected. In such cases, the more strongly marked surface features will be impressed upon the smoother surface, or, in general, the features of the exterior will be impressed on the mold of the interior, which thus shows the normal external features, though weakened, together with a reversed impression of the interior. This, as shown by J. B. Woodworth, is illustrated by many Palæozoic mussels, which are represented by internal molds (Stcinkerne). These show the lines of growth and other features of the exterior of the shell, and, on the same specimen, may be seen the mold of the scars marking the former attachment of the mussel.

In the Tampa beds of Florida natural casts of corals occur. The original corals have been removed by solution, but have left behind hollow molds in which afterward geodes of chalcedony were formed, the exterior of which accurately reproduces in silica the form of the corals. On the whole, while natural molds-both external and internal-are common, and characteristic of nearly all porous rocks, natural casts are correspondingly rare. It should, however, be noted that pseudomorphs are closely akin to casts as here defined, since in them the replacement is pari passu with the removal of the original substance of the shell or other hard structure, while in normal casts complete removal of the original substance precedes deposition of the new material.

\section{Tracks, Trails and Burroz's of Animals.}

Tracks. These are made by vertebrates walking or hopping along the soft sand or mud, which will register their footprints. If the mud is very soft the footprint will be closed again by the flowage of the mud, but, if it is viscous, or so nearly dry as to remain permanent, the footprints may readily be preserved. Numerous reptilian footprints are known from the Newark sandstones of the Connecticut Valley and the related district of New Jersey. Lull (I6) believes that these may have been partially hardened by the heat of an underlying lava sheet, which was only recently 
covered by sediments and had not yet cooled completely. This is not necessary, however, since, as shown in an earlier chapter, footprints may be preserved for a long period by mere drying of the mud. Even the delicate impressions of the web membranes of the foot were frequently preserved, which seems to indicate that the arenaceous mud must have been fairly hard and resistant before the next layer of sand was spread over it. This later layer on its under side furnishes accurate impressions in relief of the footprint, which, though rudely reproducing the form of the foot which made the impression, reproduces the impression in reverse. Since the original fossil is the impression (of which there may be many made by one individual) and not the animal's foot, the relief impression of it must be considered a mold and not a cast.

Trails. These are made by animals crawling over the mud and dragging their bodies along. Jelly-fish floating in shallow water may have their tentacles dragging along over the bottom, thus leaving distinct impressions. Plants are not infrequently dragged along over the shallow sea-bottom, with the result that a certain type of trail is made on the mud which may be indistinguishable from similar trails made by floating animals. Even attached plants, like the beach grass on the sand-dunes, may have a very characteristic semi-circular trail when swung about by the wind. Seaweeds partly buried on an uncovered mud flat may be moved by the wind and so produce similar markings. These may, in some instances, be preserved, as appears to have been the case in the structures described as Spirophyton from the Palæozoic rocks of North America and elsewhere.

Burrow's. While tracks and trails are made by animals in transit, burrows are the temporary or permanent abodes of animals. At the end of many trails of molluses or crustacea a mound is found which marks the place where the creature has temporarily buried itself in the sand. This type of burrow is not generally well preserved, though under favorable conditions it may be found. At the end of a peculiar trail on the Potsdam sandstone of New York, known as Clinactichnites. Woodworth (29) has discovered an oval impression which he considers to have been made by the animal in resting. This may possibly represent the collapsed burrow.

The remarkable structures known as Diemonelix which occur in the Miocenic deposits of the Nebraska region and which were first described as sponges and have often been considered as plants. are probably the burrows of some species of burrowing mammal. The strata in which they occur are of the continental type of cle- 
posit and the skeletons of rodents have been found in the expansion at the base of the erect spiral. The material which has filled the burrow has solidified and now forms a solid core or mold of the original burrow. It should, however, be said that sections of the core disclose what appears to be a cellular structure, which has led to the supposition that the Drmonelix is not a burrow but a-plant, which grew around the skeleton and has been preserved in the attitude of growth.

The borings of sponges in shells (Clione) and the excavations made by molluses and echinoderms in wood and stone represent

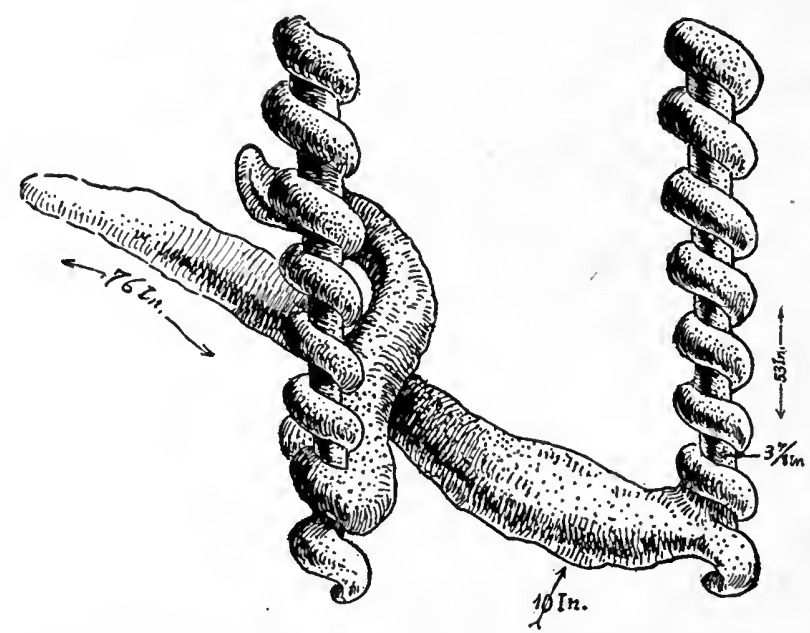

FIG. 26I. Two views of a typical example of Damonclix circumaxilis, from the Miocenic beds of Nebraska. (After Barbour.)

permanent lodgments of the organisms, and are more nearly of the grade of artificial structures than is the case with the burrows before mentioned, which are more transient, and more nearly related to trails made in transit. For illustration of the burrows of echinoids of limestone in Brazil, see Branner (8).

Burrows like the Devil's Corkscrew, above described, if, indeed, they are burrows, and like the borings of aquatic animals, are preserved by reason of the character of the material in which they were excavated. Worm-tubes, on the other hand, so characteristic of the sandy and muddy beaches, are maintained by a lining or cement of mucus, secreted by the animal. These, therefore, carry us a step further into the class of undoubtedly "artificial structures." 


\section{Artificial Structures.}

Beginning with the worm-tubes already mentioned, or even with the excavations made by some animals, we have this type of fossil increasing in importance as we rise in the scale of organic being. Even as far down as the group of rhizopods we find many types building shells by cementing foreign particles with the aid of a secretion. This type of habitation is analogous to the worm-tube already mentioned. Though represented in most classes of animals, it is not until we reach man that these artificial structures assume any great importance.

Thus the implements of stone, shell, bone or metal, the pottery and the copper, bronze and iron vessels; the beads and other ornaments; the coins and the habitations of man from the rude excavation in the rock to the buried cities of historic time, with all their accessories, belong to this type of fossils. This group, therefore, falls largely in the province of Anthropology, or the science which is concerned with man in all his relations, including his palæontology.

\section{Coprolites.}

The excrements of certain animals have a definite and recognizable form, and so become valuable indices to the former presence of such animals. Most important among these are the coprolites of fishes and reptiles, the latter constituting important fossils in the Mesozoic rocks. Very much concerning the food of the animal can often be learned from the remains found within the coprolite. The excrements or "castings" of worms also belong here. They generally consist of cord-like masses of molded sand which have passed through the intestine of the worm and from which the nutrient organic matter has been abstracted. They cover some modern beaches in great quantities, and are not infrequently preserved. Certain echinoderms, particularly holothurians, have recognizable excrements. Rothplotz has found an abundance of calcareous rods in the bottom deposits of Great Salt Lake, which he regards as excrements of Artemia, an abundantly represented crustacean in this body of water. They closely resemble known excrements of Artemia, but are calcareous, since the species of the Salt Lake are supposed to feed on calcareous algæ. 


\section{Mechanical. Deformation of Fossils.}

Wherever rocks containing fossils have been under pressure, or have, through other means, suffered mechanical disturbances, the fossils commonly show a more or less pronounced deformation. Two types of deformation may be considered: (I) that due to the normal desiccation and consequent shrinking of the rocks in otherwise undisturbed regions, and (2) that due to orogenic disturbances. The first type is especially marked in shales, and is due to the vertical pressure exerted by the overlying rock and the vertical shrinking of the shales upon the loss of water. Shells of brachiopods and pelecypods are commonly flattened out, while gastropods, cephalopods and trilobites are most frequently distorted by this vertical pressure. The amount of compression can sometimes be estimated by noting the sagging of the strata on either side of a concretion enclosed by them. Again, it may be estimated from a comparison of the compressed shell with uncompressed examples from the same formation, but preserved in limestone bands or lenses. The latter have suffered little or no vertical compression on account of the fact that the component grains of the rock were already as firmly packed when the rock solidified as they were ever likely to be.

The second group begins with the deformations due to horizontal slipping within a stratum, owing to the pressure of a superincumbent mass. Under such circumstances slickensides are frequently produced within a given formation, and fossils may readily be affected by such movements. Lateral compression of the strata, either slight or sufficient to produce foldings, will distort the fossils embedded in them and not infrequently alter their form so that they are no longer recognizable. A brachiopod, for example, by compression may assume the outline of a pelecypod, and may readily be mistaken for one. When, through strong compression, cleavage is induced in a given stratum, the fossils of that bed may become largely or entirely destroyed. The same is true if metamorphism affects the strata, though occasionally, as in the Palrozoic of Scandinavia, fossils are found in schists and other metamorphic rocks.

\section{INDEX Fossils.}

Fossils which serve to indicate definite geological horizons are called Index Fossils (German, Leitfossilien). The best index fossils for marine formations are furnished by invertebrates, though 
marine vertebrates, when well preserverl, are also good horizon markers. The very detailed knowledge of vertebrate anatomy required, however, to determine the genera and species makes vertebrate remains available only to the trained specialist. Plants furnish good and reliable index fossils for terrestrial or delta formations, although their distribution is nuch more subject to limitations, owing to climatic influence. The same may be said to be true of land vertebrates. The subject is further discussed under correlation, in Chapter XXXIT.

\section{BIBLIOGRAPHY XXX.}

I. BASSLER, R. S. 1908. The Formation of Geodes with remarks on the Silicification of Fossils. Proceedings of the United States National Museum, Vol. XXXV, pp. 133-154.

2. BASSLER, R. S. I9I0. Adequacy of the Paleontologic Record. The Paleontologic Record, pp. 6-9, reprinted from Popular Science Monthly.

3. BERNARD, FÉLIX. I 895 . Éléments de Paléontologie.

4. BLUM, J. REINHARD. I843. Die Pseudomorphosen der Mineralogic, and First Appendix (Erster Nachtrag) I 8+7. Stuttgart.

5. BLUM, J, R. I852. Pseudomorphosen, Second Appendix.

6. BLUM, J. R. 1863. Pseudomorphosen, Third Appendix.

7. BLUM, J. R. 1879. Pseudomorphosen, Fourth Appendix.

8. BRANNER, JOHN C. I I905. Stone Reefs on the Northeast Coast of Brazil. Bulletin of the Geological Society of America, Vol. XVI, pp. I-I 2, pls. I-I I.

9. CALVIN, SAMUEL. 1910. Adequacy of the Paleontologic Record. The Paleontologic Record, pp. 2-6. Reprinted from Popular Science Monthly.

10. DEAN, BASHFORD. I902. The Preservation of Muscle Fibers in Sharks of the Cleveland Shale. American Geologist, Vol. XXX, pp. 273-278, pls. VIII and IX.

I I. D'ORBIGNY, ALCIDE. I 849. Cours Élémentaire de Paléontologie et de Géologie Stratigraphiques. 3 vols. Victor Masson, Paris.

12. FARRINGTON, OLIVER C. I899. A Fossil Egg from South Dakota. Field Columbian Museum. Publication 35, Vol. I, No. 5, Geol. Series pp. 192-200, pls. XX-XXI, figs. I-2.

13. GRABAU, A. W. I 899. Palæontology of Eighteen Mile Creek. Bullctin of the Buffalo Society of Natural Sciences, Vol. VI.

14. GRABAU, A. W. and SHIMER, H. W. 1909. North American Index Fossils, Invertebrates. Vol. I.

15. HUGHES, T. McKENNY. 1889. On the Nanner of Occurrence of Beekite and Its Bearing upon the Origin of Siliceous beds of Palæozoic Age. Mineralogical Magazine, Vol. III, No. to, pp. 265-271.

16. LULL, RICHARD S. 1904. Fossil Footprints of the Jura-Trias of North America. Memoirs of the Boston Socicty of Natural History, Vol. V, 97 pp., I pl.

17. MEAD, CHARLES IV. I907. Peruvian Mummies. American Museum of Natural History. Guide Leaflet No. 24. 
18. MORGAN, WILLIAM C., and TALLMON, MARION C. 1904. A Fossil Egg from Arizona. California University, Department of Geology, Bulletin, Vol. III, pp. 403-4IO, 2 pls.

19. NICHOLSON, H. ALLEYNE, and LYDEKKER, RICHARD. I889. Manual of Palieontology. 2 vols. Third edition.

20. REIS, OTTO M. Die Colacanthinen, mit besonderer Berücksichtigung der im weissen Jura, Bayerns Vorkommenden Arten. Palæontographica XXXV, pp. I-96, pls. I-V.

21. ROGERS, AUSTIN F. Private Communication.

22. ROTH, I. 1879. Allgemeine und chemische Geologie, Vol. I. Especially literature on fossilization of plants.

23. STEDMANN, J. M., and ANDERSON, J. T. 1895. Observations on a so-called petrified man, with a report on chemical analysis by $\mathrm{J}$. T. Anderson. American Naturalist, Vol. XXIX, pp. 326-335.

24. STEINMANN, GUSTAV. 1903. Einführung in die Palæontologie. Wilhelm Engelmann, Leipzig.

25. WALCO'TT, CHARLES D. 1898. Fossil Medusæ. Monograph of the United States Geological Survey. XXX.

26. WALCOT'T, C. D. I9I I. Cambrian Geology and Palæontology. Smithsonian Institution Collections, Vol. 57.

27. WIMAN, C. I895. Ueber die Graptolithen. Geol. Inst. Upsala, Bull., Vol. II, No. 2.

28. WHITE, C. H. 1905. Autophytography: a Process of Plant Fossilization. American Journal of Science, 4th series, Vol. XIX, pp. $23^{1-236}$.

29. WOODWORTH, JAY B. 1903. On the Sedentary Impression of the Animal whose trail is known as Climactichnites. New York State Museum Bulletin 69, pp. 959-966, 2 pls,, 3 figs. 


\title{
G. PRINCIPLES OF CLASSIFICATION AND COR- RELATION OF GEOLOGICAL FORMATIONS.
}

\author{
CHAPTER XXXI. \\ NOMENCLATURE AND CLASSIFICATION OF GEOLOGIC \\ FORMATIONS.
}

\section{Development of Crassifications.}

The history of the earth is written in the strata of the earth's crust. Like all histories, it is a continuous succession of events, but the record of these events is never complete and seldom even unbroken in any given region. It is of the first importance to the chronographer of earth history that he should find a continuous record, in order that he may have a measure by which to judge the partial records of any given region and to discover the breaks and imperfections in the local records thus presented. (Grabau-5.) The question then arises: under what conditions may we expect to obtain a continuous record and how are we to guard against the introduction of errors?

We have, in the first place, to deal with the time element in the history of the earth. In human history the time element is a measurable factor, its duration being recorded in years and centuries. No such precise measurements are possible in earth history, although several attempts have been made to reduce geologic time to units of human chronology. (For methods and results, see beyond.) But while we cannot now, and probably may never, hope to divide geologic time into centuries and millenniums, we can divide it into periods, each of which has its own special significance in the history of the earth. The basis for such subdivision was long ago found in the succession of organic types from relatively simple to highly complex forms. As long as the doctrine of special creation of organic types was held, and with it the belief in successive acts of creation, and more or less complete extinction of the faunas and 
floras preceding, it was a comparatively simple matter to divide the earth's history into periods or eras characterized by these successive changes in the ancient inhabitants of the earth. That there was much apparent justification for this belief in the characters of the faunas and floras found in the strata of the earth cannot be questioned. Thus, trilobites are even to-day unknown from strata later than Palæozoic, nor until recently have strata containing ammonites been recognized as older than the Mesozoic. That sudden disappearances of whole organic assemblages, and the equally sudden appearance of others of a different type occur repeatedly are matters of common observation; but it was not always recognized that such sudden changes are seldom universal in extent, though generally traceable over wide areas. While abrupt changes in organic content of the strata have come to be generally regarded as marking the lines between the greater divisions in the earth's history, they are correlated with, and, in fact, dependent on, widespread physical breaks in the continuity of the strata which compose the earth's crust. Such physical breaks were, indeed, taken as the planes of division by the pioneers in stratigraphy, who considered stratigraphic succession rather than geologic chronology. Thus, about the middle of the I8th Century Lehman, a German miner (II) proposed a threefold division of the rocks of the earth's crust into (I) "Primitive" (Primitiv) or "Urgebirge," including all the igneous and metamorphic rocks in which there was no sign of life and which showed no evidence of having been derived from the ruins of preëxisting rocks, and, therefore, of chemical origin, antedating the creation of life; (2) Secondary, comprising the fossiliferous strata, and largely composed of mechanical deposits, produced after the planet had become the habitation of animals and plants; and (3) Allurial deposits, due to local floods, and the deluge of Noah. Füchsel, a contemporary of Lehmann, recognized that certain groups of strata belonged together and constituted a geologic formation. He held that each formation represented an epoch in the history of the earth, and thus he brought into consideration the time element in the earth's history. Half a century later Werner introduced his "transition formations" between the primitive and secondary rocks, comprising a series of strata, first found in northern Germany, which were intermediate in mineral character between the crystallines and sedimentaries and partook in some degree of the characters of both. This Uebergangsgebirge, or transition formation, consisted principally of clay slates, argillaceous sandstones or graywackes and calcareous beds, which, in the region studied by Werner, were highly inclined and unconformably overlain by the horizontal Secondary 
strata. The latter, including formations up to the top of the chalk, were called by Werner the Flötycbirge formation, on account of their horizontality, and because they were the stratified rocks par excellence. The term Flötz signifies "a level floor," and had been generally used since the time of Agricola for stratified rocks. With the Flötz were included the trap rocks of the Secondary strata, as subordinate members, these being held by WVerner and his followers to be the result of aqueous precipitation. All deposits above the chalk were referred by Werner to alluvial deposits under the designation Angeschwemmtgebirge. Werner's followers later on distinguished a series of strata between the chalk and the alluvium. and applied to this the term Newer Flötz (Neues Flötzgebirge). These are the rocks subsequently named "Tertiary" by Cuvier and Brongniart. In the Wernerian terminology, the characters of the strata themselves rather than their time relations were considered, and Füchsel's term "formation" was applied by Werner and his followers to groups of strata of similar lithic composition. Thus he spoke of limestone formation, sandstone formation, slate formation, etc. The term "transition" strata soon began to take on chronologic meaning, and it was widely applied to rocks older than those designated as Secondary. It was still retained even after it was shown that these strata are not always transitional in mineral character and that strata belonging to the Secondary or even later series had sometimes the mineralogical character of the original Transition rocks.

At the time of Lyell, the strata of the earth's crust were generally divided into Primary, Transition, Secondary, Tertiary and post-Tertiary. It had become recognized that crystalline and metamorphic rocks were not all of one age, but that some were even newer than the Secondary formation. As a chronologic term, Primary had come to be applied by some to the fossiliferous rocks older than the Secondary, while it had become a matter of some question whether any of the crystalline rocks really antedated the oldest fossiliferous deposits. Inyell, to avoid confusion, used the term Primary Fossiliferous formation "because the word primary has hitherto been most generally connected with the irlea of a nonfossiliferous rock." About this time the terms "Palconoic," * "Meso$z o i c$," $\dagger$ and "Conozoic" $\dagger$ were introduced to replace the terms Primary Fossiliferous (the former Transition), Secondary and zoë, life.

* Proposed by Sedgwick, 1838 . From $\pi \alpha \lambda a \iota b s$, palaios, ancient, and $j \omega \eta \dot{\eta}$,

† Proposed by Philips, I 84 I, from $\mu t \tilde{\sigma} \sigma s$, mesos, middle; $\alpha a \iota v b s$, new, recent. The latter was also written Kainozoic. 
Tertiary, but they met at first with little favor. Palæozoic was the first to be adopted, while Secondary and Tertiary were still retained. Later Mesozoic gradually replaced Secondary, but Tertiary has still retained its hold in geologic literature to the present day. To it the Quaternary* has been added, which comprises the formations designated by Lyell as Post-Pliocene, together with his Later Pliocene or Pleistocene. These have frequently been included with the Tertiary under the term Canozoic (=Kainozoic), but they have also been separated under the term Psychozoic, introduced by Le Conte, but limited by him to the most recent formations, which ininclude abundant remains of man.

It is thus seen that the classification at first proposed as a rock classification became a chronologic one, as geologists began to perceive that all kinds of rock may be formed during each period of the earth's history. When the fossils of cach of these four divisions became better known, it was found that each was characterized by its peculiar assemblage of organisms. It was further found that in most regions the strata of each of these larger subdivisions were separated from those above or below by a marked unconformity, so that records of disturbances of widespread occurrence were looked upon as generally marking the dividing lines between the greater subdivisions of the earth's history. The use of unconformities in defining limits of geologic formations was also extended to the further subdivision of the larger units, and, in fact, such breaks have frequently been advocated as the best available criterion. But geologists have pretty generally recognized the fact that a classification based on unconformities is an incomplete one, and that a complete record of geologic time can be expected only in a series resulting from continuous deposition. Such a series is, however, nowhere obtainable, since in no known region of the earth has there been continuous and uniform deposition. Stratigraphers are thus compelled to construct their typical section from fragments of overlapping sections from all parts of the world. Each fragment thus used in the building up of the typical scale must be complete in itself, and its relationship to the next adjoining fragments of the scale must be determined.

\section{Selection of the Type Section.}

What, then, are the criteria which must guide us in the selection of our typical section? First and foremost, the section must show

* Proposed by Morlot in 1854 . 
continuous deposition. No sharp break either lithic or faunal should occur between the members, but all should be transitional. The character and origin of the strata composing the section must be carefully considered, since all rocks are not of equal value as indices of continuous deposition.

Hydroclastic rocks are by far the most reliable indices of deposition, since none other are formed under so uniform an environment. Marine sediments, further, are more reliable than those of fresh water lakes, since the latter are only temporary features of the earth's surface and are preceded and succeeded by conditions which will of necessity destroy the continuity of formation of strata. Thus marine formations alone will serve for the erection of a standard scale, all formations of a continental type, whether of fresh water or of atmo-, anemo-, or pyroclastic origin, must be ruled out of the standard scale. Hence the Old Red Sandstone cf Britain, the non-marine Carbonic formations, the Newark, Potomac, Dakota and Laramie formations of North America, are all to be discarded in the making of a true geologic formation scale. Even among marine strata, there are some which must be ruled out, as not furnishing a reliable account of the progress of rock deposition. Thus sandstones and conglomerates, either as basal members or intercalated between a series of clay or lime rocks, are almost sure to introduce an element of uncertainty, if not error, into the section, even if the gradation above and below is a perfect one. As has been pointed out in an earlier chapter, shore-derived siliceous clastics of coarse grain, when not forming a basal sandstone or conglomerate, can become widespread only by an oscillatory movement of the land, which results in a temporary retreat and readvance of the sea. Such a change involves almost certainly a time interval unrecorded in the section, but represented rather by an unrecognizable break within the terrigenous member itself. An example of such a formation is found in the St. Peter Sandstone of central United States, a formation which in itself represents a disconformity, constantly increasing in magnitude toward the north, where it includes an unrecorded interval clsewhere represented by from 2,000-3,000 feet of limestones. Shore deposits of all kinds should be ruled out in the establishment of a typical section, for they represent local conditions and, therefore, cannot furnish reliable evidence of the general progress of development.

Deposits formed in an enclosed basin, whether marine or continental, are likewise unsatisfactory for purposes of establishing a general scale. Such deposits at present included in the standard scale of North American strata are: the Medina and Salina forma- 
tions of New York, which were formed under local and in part continental conditions, and cannot, therefore, represent a standard by which the more widespread marine conditions existing elsewhere can be measured. Wherever possible, such local formations should be taken out of the standard scale of strata and replaced by formations of purely marine origin. These may, of course, not exist within the limits of the territory for which the scale is made, in which case the old terms, perforce, have to be retained.

The best example of a truly representative classification of the divisions of a larger formation, which has yet been devised, is that of the Triassic system. In no one region of the world is there a complete representation of marine Triassic strata; in fact, the best known divisions of this system are to a large extent non-marine. But, by a careful study of all the widely dissociated marine members and their relation to each other, a standard classification, more nearly perfect than that of most other similar formations, has been devised. By its use the various dissociated marine members of each region, as well as the non-marine members, may be measured and the time relation of each to the others and to all may be ascertained.

\section{Time Scale and Formation Scale.}

While the time scale is thus of primary importance as a standard of comparison, a formation scale is also needed. A formation is a stratigraphic unit, composed in general of similar or closely related strata and characterized by a particular assemblage of organisms (fauna or flora). Sometimes a formation may consist of a single stratum-more frequently it comprises many strata. The rules recently promulgated by the United States Geological Survey for the government geologists in the preparation of the geologic folios of the United States (18:23) make the formation the cartographic unit, and define it among sedimentary rocks as follows: "Each formation shall contain between its upper and lower limits either rocks of uniform character or rocks more or less uniformly varied in character, as, for example, a rapid alternation of shale and limestone." It is further suggested that, "As uniform conditions of deposition were local as well as temporary, it is to be assumed that each formation is limited in horizontal extent. The formation should be recognized and should be called by the same name as far as it can be traced and identified by means of its lithologic character, its stratigraphic association, and its contained fossils." 


\section{Subdivisions of Time and Formation Scales.}

The primary divisions of the geologic time scale are, as we have seen, based on the changes in life, with the result that fossils alone determine whether a formation belongs to one or the other of these great divisions. The primary divisions now generally recognized are as follows:

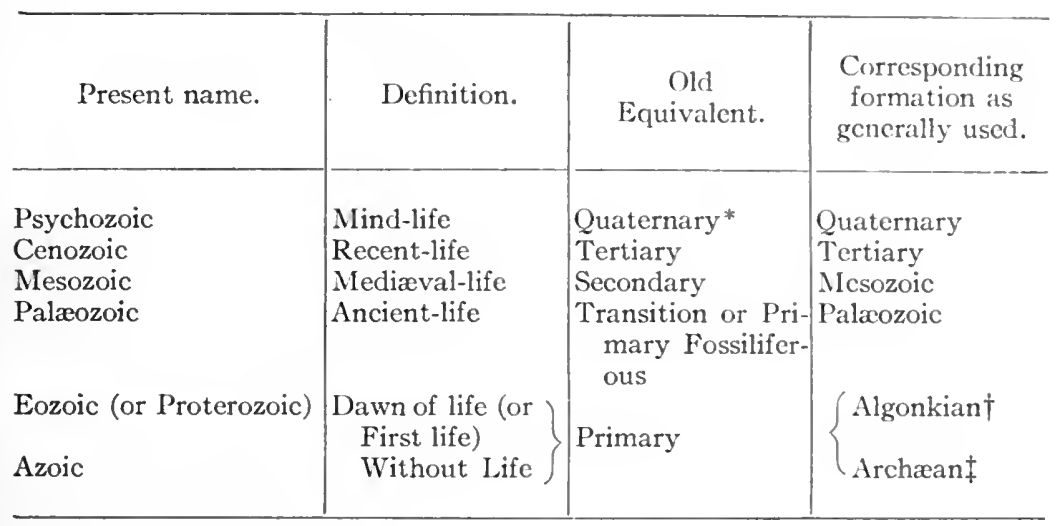

Corresponding to each time division we have a formational division, which represents the rock material accumulated during the continuance of that time. As will be seen from the above table, the formation scale now generally in use is made up partly of the old names in vogue during Lyell's time, partly of the newer names, and in part of distinct names applied to the rocks of these divisions by American geologists and adopted by workers in other countries as well.

A number of terms have been proposed by which the subdivisions of the time and formation scale are to be known, but at present there is no unanimity in the usage of these terms. The following are the most important of the proposals made, the numbering being in the order of magnitude of the categories:

* In many text-books the Quaternary is included with the Tertiary under Cenozoic, which is not the historic sense of the term. Post-Tertiary time is essentially characterized by the presence of man and may be separated as Psychozoic.

$\dagger$ Walcott, 1889. From a tribe of North American Indians.

\pm Proposed by Dana. 
I. International Geological Congress. At the first meeting of the Congress in Paris in 1878 a commission was appointed to frame a plan of procedure for the unification of geologic classification and naming. The recommendations of this Commission, adopted at the Bologna Congress in I88I, as far as they affect the point in question, are as follows. Period-System; (3) Epoch-Series;

(1) Era-Group; (2) Perize No time equivalent for (5) (Assize) was designated.

(4) Age-Stage; (5)

During succeeding Congresses proposed modifications of this scheme were discussed until in 1900 the 8 th Congress, convened in Paris, accepted the following scheme:

Chronologic.

I. Era (Erès).

2. Period (Période).

3. Epoch (Époque).

4. Age (Âge).

5. Phase (Phase).
Stratigraphic.

I. (No stratigraphic term).

2. System (Système).

3. Series (Séries).*

4. Stage (Êtage). $\dagger$

5. Zone (Zone).

Periods, and the corresponding systems, have a worldwide value, and are characterized by the development of the organisms during the period, and their entombment in the strata of the system. Pelagic faunas, where available, are especially characteristic, owing to their wide distribution and independence of local environments. The termination of the names of periods and systems adopted is $i c$, ique (French); isch (German); ico (Spanish, Italian, Portuguese, Roumanian); Ex. Cambric (Cambrique, Kambrisch, Cambrico); Devonic (Devonique, Devonisch, Devonico); also Carbonic (Carbonique, Karbonisch, Carbonico) ; Cretacic (Cretacique, Kretacisch, Kreide Formation), etc.

Periods are generally divisible into three epochs each, which are designated by the prefixes Palco-, Meso-, and Neo-. For Palcothe term Eo may be used, wherever the name is long and the name itself further abbreviated. (Williams-I9.) Thus, while Palæocambric, Mesocambric and Neocambric are used, Eodevon, Mesodevon and Neodevon, or, Eocret, Mesocret and Neocret, may be used for these longer terms. Locally, series are commonly given names derived from typical localities, these ending in ian (ien, Fr., etc.), as the following example will show:

* German, Abtheilung. † German, Stufe; Italian, piano; Spanish, piso. 
Epoch.

Neodevonic............ $\left\{\begin{array}{l}\text { Chautauquan } \\ \text { Senecan }\end{array}\right.$

Mesodevonic.......... $\left\{\begin{array}{l}\text { Erian } \\ \text { Ulsterian }\end{array}\right.$

Eodevonic............ $\left\{\begin{array}{l}\text { Oriskanian } \\ \text { Helderbergian }\end{array}\right.$
Local name of series.

\section{Eastern United States. Western Europe.}

$\left\{\begin{array}{l}\text { Famennien } \\ \text { Frasnien }\end{array}\right.$

$\left\{\begin{array}{l}\text { Givétien } \\ \text { Eifélien }\end{array}\right.$

$\left\{\begin{array}{l}\text { Coblentzien } \\ \text { Taunusien } \\ \text { Gedinien }\end{array}\right.$

The values of these local series are not always uniform nor equivalent. In practice it is often more convenient to speak of Lower, Middle and Upper Siluric, Devonic, etc., series (German: Unterdevon, Mitteldevon, Oberdevon, etc.; French Dćvonicn infórieur, Dévonien moyen, Dévonicn supéricur, etc.). These terms are commonly employed in a general discussion of the strata of a series.

Ages and their corresponding stages receive local names. Stages are relatively restricted in areal distribution and different countries have different stages corresponding to the same age.

Stages end in ian (ien, Fr.; ian, Germ.*: iano, Spanish, Italian, Portuguese, Roumanian). Thus we have Bartonian, Bartonien, etc.; Portlandian, Portlandien, etc., stages.

The stratigraphic division of the fifth order, the zone, is often needed, and this division is named wherever possible after a particular species of organism which characterizes it. Thus we have in the Lias of England the following 17 zones characterized by particular species of ammonites. (Geikie-4:II33.)

Upper Lias or Toarcian $\left\{\begin{array}{l}17 \text { zone of Lytoceras jurense } \\ 16 \text { zone of Dactylioceras commune } \\ 15 \text { zone of Harpoceras serpentinus, etc. } \\ 14 \text { zone of Dactylioceras annulatum }\end{array}\right.$

Middle Lias or Liassian $\left\{\begin{array}{l}13 \text { zone of Paltopleuroceras spinatum } \\ 12 \text { zone of A maltheus margaritatus }\end{array}\right.$

* The German terms are often contracted, instead of Astian Stufc, Astistufe is used. 


Lower Lias or Sinemurian $\left\{\begin{array}{l}\text { I I zone of Liparoceras henleyi, etc. } \\ \text { I } 5 \text { zone of Phylloceres ibex } \\ 9 \text { zone of Algoceras jamesoni } \\ 8 \text { zone of Deroceras armatum } \\ 7 \text { zone of Caloceras raricostatum } \\ 6 \text { zone of Oxynoticeras oxynotum } \\ \text { 5 zone of Arietites obtusus, etc. } \\ 4 \text { zone of Arietites turneri, etc. } \\ 3 \text { zone of Arietites bucklandi } \\ 2 \text { zone of Schlotheimia angulata } \\ \text { I zone of Psiloceras planorbe }\end{array}\right.$

In the Trias, too, a number of distinct zones marked by species of ammonites or other fossils are recognized.

II. Dana's System. In the last edition of his Manual $(3: 406)$, Professor James D. Dana gives the following classification:

Chronologic.

I. Acon (Ex.: Palæozoic).*

2. Era (Ex.: Siluric).

3. Period (Ex.: Palæo-Siluric).

4. Epoch (Ex.: Clinton).
Stratigraphic.

1. Series (Ex: Palæozoic).

2. System (Ex.: Siluric).

3. Group (Ex.: Niagaran). 4. Stage (Ex.: Clinton).

III. United States Geological Survey. The United States Geological Survey in its ruling of IgO3 makes the period the unit of the time scale and correlates with it the system of the formation scale, thus following the usage of the International Congress. The systems recognized are: "Quaternary, Tertiary, Cretaceous, Jurassic, Triassic, Carboniferous, Devonian, Silurian, Ordovician, Cambrian, Algonkian, and Archran." No complete scheme is formulated, only the following terms being used:

Chronologic.

I.

2. Period.

3 .

4. $\ldots \ldots \ldots \ldots \ldots \ldots$
Stratigraphic.

I. ................

2. System.

3 . Serics.

4. Group.

As far as this scheme was developed it is thus seen to correspond to the one promulgated by the International Congress, with the exception that group is used for the division of the fourth order

* Examples added by the author. 
instead of stage. The terminations of the names of the systems are not altered to correspond to that adopted by the Congress.

\section{Unification of Terminology.}

In the development of the classification of the geologic formations, the systems were gradually introduced either by intercalation of a previously unknown system between two well-established ones, as the Devonian between the Silurian and Carboniferous; or by the separation of the new system from an older one with which it was formerly included, as Ordovician from Silurian. No uniform method of derivation of these names was followed, though the majority of names had a geographic origin. Neither was uniformity of termination considered, though among the later-formed names ian was generally selected. This heterogeneous terminology has become so firmly embodied in the framework of stratigraphic classification that it probably will be a long time before we can hope to replace it by a more homogeneous one. Such terms as Carboniferous are. wholly out of harmony with the majority of other terms and ought to be discarded. But the adoption of a uniform termination of these names, as suggested by the Congress, and as is widely practiced, particularly in Europe, will do away with the most objectionable part of this terminology and bring it into harmony with the remaining portion of the scheme. In the table on p. I 108 the systems used in this work are given with the termination used by the International-Congress, and with it the old heterogeneous termination. The author and derivation of each term is given. (See also table on page 22.)

A tendency toward splitting up some of the larger systems and uniting others has been shown by many stratigraphers. The Palæocenic has been introduced in the Cenozoic and united with the Eocenic and Oligocenic as Palæogenic; Miocenic and Pliocenic have been united as Neogenic; and Pleistocenic and Holocenic as Cenogenic. The Liassic has also been separated as a distinct system by some European stratigraphers. Recently this methorl of subdivision has been carried to great extremes in the works of Schuchert and Ulrich, to which the student is referred (14; 17). The subdivisons advocated by Ulrich are more extreme than the facts seem to warrant, and they have not generally been adopted.

Local Stages and Substages. Generally, detailed study of a given region will show the occurrence of numerous local forma- 


\begin{tabular}{|c|c|c|c|c|}
\hline ERAS. & $\begin{array}{l}\text { SYSTEMS } \\
\text { Chiefly accord- } \\
\text { ing to recom- } \\
\text { mendation of } \\
\text { International } \\
\text { Congress. }\end{array}$ & $\begin{array}{l}\text { Syst EMS } \\
\text { Old usage. }\end{array}$ & Founder. & $\begin{array}{l}\text { ORIGIN OR DERIVATION } \\
\text { OF NAME. }\end{array}$ \\
\hline $\begin{array}{l}\text { Psychozoic or } \\
\text { Quaternary }\end{array}$ & $\begin{array}{l}\text { Holocenic } \\
\text { Pleistocenic }\end{array}$ & $\begin{array}{l}\text { Recent } \\
\text { Pleistocene }\end{array}$ & $\begin{array}{l}\text { Portuguese Com- } \\
\text { mittee I.C. ( ( } 885) \\
\text { Lyell (I839) }\end{array}$ & $\begin{array}{l}\text { Wholly recent.* } \\
\text { Most recent.* }\end{array}$ \\
\hline $\begin{array}{l}\text { Cenozoic } \\
\text { or } \\
\text { Tertiary }\end{array}$ & $\begin{array}{l}\text { Pliocenic } \\
\text { Miocenic } \\
\text { Oligocenic } \\
\text { Eocenic }\end{array}$ & $\begin{array}{l}\text { Pliocene } \\
\text { Miocene } \\
\text { Oligocene } \\
\text { Eocene }\end{array}$ & $\begin{array}{l}\text { Lyell (1833) } \\
\text { Lyell (1833) } \\
\text { Beyrich (I 854) } \\
\text { Lyell (1833) }\end{array}$ & $\begin{array}{l}\text { More recent.* } \\
\text { Less or intermediate re- } \\
\text { cent.* } \\
\text { Few recent.* } \\
\text { Dawn of recent.* }\end{array}$ \\
\hline $\begin{array}{l}\text { Mesozoic or } \\
\text { Secondary }\end{array}$ & $\begin{array}{l}\text { Cretacic } \\
\text { Comanchic } \\
\text { Jurassic } \\
\text { Triassic }\end{array}$ & $\begin{array}{l}\text { Cretaceous } \\
\text { Comanchean } \\
\text { Jurassic } \\
\text { Triassic }\end{array}$ & $\begin{array}{l}\text { Omalius d'Halloy } \\
\text { (I822) } \\
\text { R. T. Hill (I 893) } \\
\text { A iexander von } \\
\text { Humboldt (I 795) } \\
\text { F. von Alberti, } \\
(1834)\end{array}$ & $\begin{array}{l}\text { Creta chalk (chalk bear- } \\
\text { ing) } \\
\text { Comanche Indians } \\
\text { Jura Mountains } \\
\text { Original three-fold divi- } \\
\text { sion }\end{array}$ \\
\hline $\begin{array}{l}\text { Palæozoic or } \\
\text { Primary } \\
\text { Fossiliferous }\end{array}$ & $\begin{array}{l}\text { Permic } \\
\text { Carbonic } \\
\text { Mississippic } \\
\text { Devonic } \\
\text { Siluric } \\
\text { Ordovicic } \\
\text { Cambric }\end{array}$ & $\begin{array}{l}\text { Permian } \\
\text { Carboniferous } \\
\text { (Pennsylvanian) } \\
\text { Sub-Carbonifer- } \\
\text { ous (Mississip- } \\
\text { pian) } \\
\text { Devonian } \\
\text { Silurian (Upper } \\
\text { Silurian) } \\
\text { Ordovician } \\
\text { (LowerSilurian) } \\
\text { (Up'r Cambr'n) } \\
\text { Cambrian }\end{array}$ & 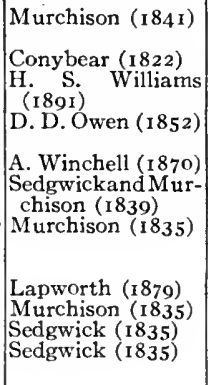 & $\begin{array}{l}\text { Government of Perm, } \\
\text { Russia } \\
\text { Coal-bearing } \\
\text { Pennsylvania } \\
\text { Below the coal-bearing } \\
\text { strata } \\
\text { Mississippi valley } \\
\text { Devonshire, England } \\
\text { Ancient tribe of Silures } \\
\text { inhabitingSouth Wales, } \\
\text { etc. } \\
\text { Ancient tribe of western } \\
\text { England } \\
\text { Old Roman Province of } \\
\text { Cambria, N. Wales }\end{array}$ \\
\hline
\end{tabular}

Thus names were derived, in part, from the age of the formation, in part, from their lithic character and contents, in part from typical localities, and in part from former inhabitants of typical localities.

tions of the value of stages or substages, as in the following case:

Hiatus and disconformity

Detroit River $\left\{\begin{array}{l}\text { Lucas dolomite } \\ \text { Amherstburg limestone } \\ \text { Series, } \\ \text { Anderdon limestone } \\ \text { Flat Rock dolomite }\end{array}\right.$
Hiatus and disconformity

Upper Siluric or Monroan. (Ncosiluric)

Sylvania sandstone

Hiatus and disconformity

$\left\{\begin{array}{c}\text { Bass Island } \\ \text { Series }\end{array}\left\{\begin{array}{l}\text { Raisin River series } \\ \text { Put-in-Bay series } \\ \text { Tymochtee shale } \\ \text { Greenfield dolomite }\end{array}\right.\right.$

* Referring to the percentage of modern organisms present. 
Where fully developed nost formations include several zones. Thus, in Maryland and West Virginia, the Oriskany formation, which belongs to the Oriskany stage of the Lower Devonic series of eastern North America, contains at least two zones, the upper, or Hipparionyx proximus, zone, 258 feet thick, and the lower, 90 feet thick with Anoplotheca flabellites and other fossils. In some cases, however, what has been considered a single formation may represent an aggregation of apparently uniform lithic character, of such great stratigraphic range as not only to transgress the limit of a series, but even that of a system. An example of this is found in the Arbuckle and Wichita sections of Indian Territory and Oklahoma, where the following pre-Mississippic formations were formerly recognized: (Ulrich-16.)

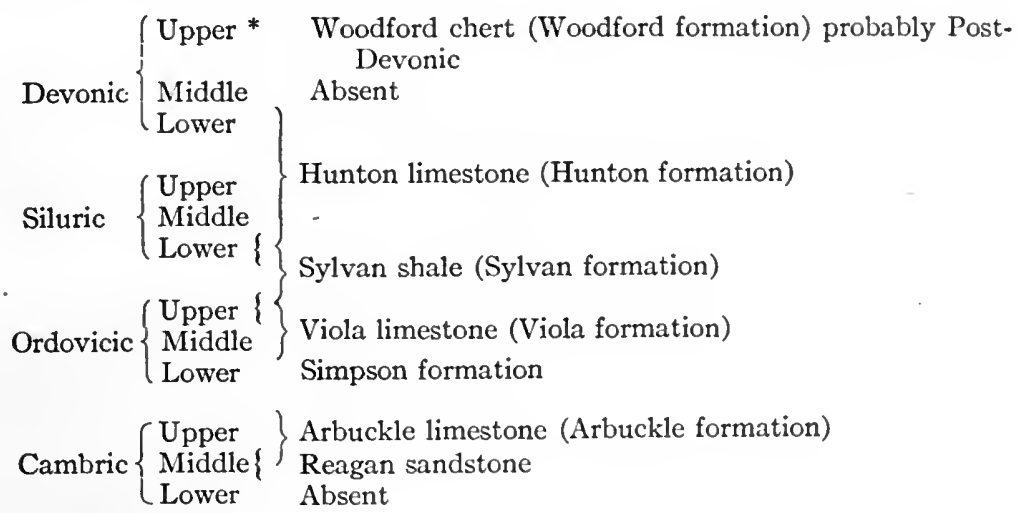

It has since been found that the Hunton formation is not a unit, but represents fragments of several distinct formations separated by large breaks and unrepresented time intervals (I3).

\section{Principles Governing the Naming of Formations.}

A formation may retain its name only so far as its essential unity is retained, though change in lithic character does not necessarily require a change of name. Thus, when a shaly formation in one locality can be traced into, and can be shown to be the exact depositional equivalent of, a limestone formation in another

* The classification is by the author, and is made in harmony with the present classification of the formations supposed to be included in the divisions given. 
locality, both should be called by the same name. Such exact equivalency, however, seldom obtains. The following figures copied from Willis' paper (20) show the case mentioned and the far more common cases in which such depositional equivalency is not complete. In Diagram II the $m$ (shale) formation grades into the $n$ (limestone) formation, but with a prolonged overlap. In this case neither formation is the exact equivalent of the other, and both may occur together. Hence, each should receive a different name. An example of this kind is furnished by the
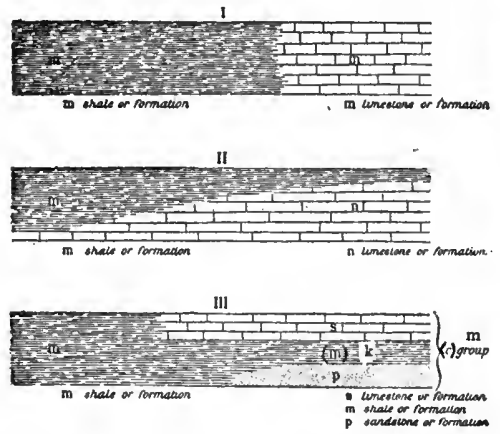

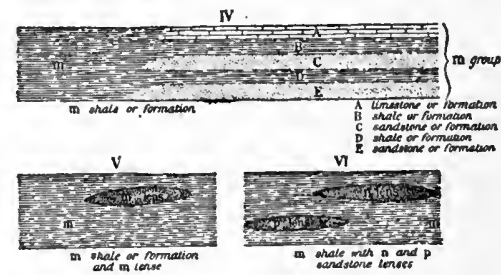

VII

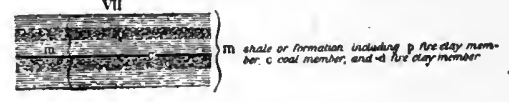

FIG. 262. Diagrams showing horizontal variation in sediments. (After Willis.)

Catskill and Chemung formations, which grade into each other by overlap, the Catskill alone being present in eastern New York and the Chemung alone in western New York, while between these points parts of both are present. In the diagram cited, the near shore overlapping the offshore deposits, the overlap is regressional and a replacing one and due to shoaling of the water. In the Catskill-Chemung case, a continental formation overlaps a marine one.

Diagram III represents three formations on the right equivalent to the shale formation $(m)$ on the left. This shale formation $(m)$ is represented on the right by its middle portion, while the lower is replaced by a sandstone formation and the upper by a limestone formation. Each of the two new formations receives a distinct name, as $p$ sandstone formation and $s$ limestone formation. If the name " $m$ shale" is retained for the middle member, a new name $(x)$ for the entire group $p m s$ must be given, the $x$ group being then equivalent to the $m$ shale of the left hand locality, but including the $m$ shale at the right hand locality. A better method, however, is to give the shale on the right hand a new name $(k)$ and call the group $p k s$ the $m$ group, this being equivalent to the 
$m$ shale. While a difference of opinion exists as to whether or not the name $m$ should be applied in the above case to the middle member, it is generally agreed that, when the shale formation $m$ breaks up into a number of units, as in diagram IV, none of which can absolutely be identified with the original mass $m$, each of the smaller members should receive a distinct name, while collectively they may be called the $m$ group, being the exact equivalent of the $m$ shale. If lenses of sandstone or conglomerate of importance are present in a formation these should receive distinct names, as $n$ and $p$ lenses in $m$ shale. (Diagram VI.) If only one lens is present, however, this may be known by the same name as the enclosing formation, though it may be better to give even a single lens a distinct name. Thus, in the Cattaraugus formation of southwestern New York and adjacent areas in Pennsylvania, three conglomerate lentils occur, the Wolf Creek, near the base, the Salamanca higher up, and the Kilbuck still higher up. In some localities only one of the upper two lentils is present: in others both are absent. The desirability of distinct names, even where only one of these lentils occurs, is apparent.

Where the main mass is of uniform character, but contains thin beds of another character, the whole may be classed as one formation $(m)$, while the minor strata are spoken of as distinct members. (Diagram VII.) Thus the Waldon sandstone formation of the southern Appalachians contains the Sewanee coal member besides shate and other coal members and conglomerate lenses.

Names of sedimentary formations are derived from localities where the formation is best developed or where it was first studied. "The most desirable names are binomial, the first part being geographic and the other lithologic $(e . g$., Dakota sandstone, Trenton limestone, etc.) The geographic term should be the name of a river, town, or other natural or artificial feature at or near which the formation is typically developed. Names consisting of two words should be avoided. Names taken from natural features are generally preferable, because less changeable than those of towns or political divisions. When the formation consists of beds differing in character, so that no single lithologic term is applicable, the word "formation" should be substituted for the lithologic term (e. g., Rockwood formation)." (18:24.)

Selection of N.imes for Sistens, Series and Stages (Groups). These divisions, as already noted, are of much wider distribution than formations. The names of systems are mostly uniform throughout the world, as Deronic, Triassic, Cretacic, etc. American terms have in some cases been proposed where the origi- 
nal European names seemed less desirable. Thus, Taconic has been used for Cambric, Champlainic for Ordovicic, Ontaric for Siluric, Guadaloupic for Permic. Where names proposed originally for series became those of systems, on the raising of tine original series to the rank of a system, they naturally differed in different countries. Thus the original Subcarboniferous is known as the Mississippic in America and is now regarded as a separate system, while in eastern Europe it is the Donjetic and in western Europe the Dinantic. The old Lower Cretacic or Infra-Crétacée * is the Neocomic of Europe, in its broader sense, and the Comanchic of America. The names of series generally differ in different countries, and those of stages in the different sections of the same country. The name in either division is derived from a typical locality and the appropriate ending (ian, ien) is affixed. When the name itself is not adaptable in its original form, the practice generally has been to substitute the Latin form (Turonien from Touraine, Campanien from Champagne and Carentonien from the Charent). Sometimes the name is derived from the original name of the locality, as Cambrian from Cambria, the old Roman name for North Wales, and Cenomanien from Conomanum, the old Latin name of the town of Mans in the Department of Sarthe and Rothomagien from Rothomagus, the Roman name of Rouen.

\section{MAPPING.}

The question is often asked: Should geologic maps express primarily formations or geologic horizons? In other words, should the mapping be based on lithic formations or on time units? The decision generally has been in favor of the mapping of lithic units or formations. Generally the units have been small enough to allow a grouping into systems, and these have then been referred to their proper time period. This method is apparently the most satisfactory, since all mappable features, such as the outcrops themselves, as well as the topography of the region, are the direct consequence of the lithic formations, and have no regard whatever to time relations. The present outcrops show only the present extent of the formations, and give no clue to the former extent of the strata deposited during a given time interval, except in so far as the lithic character of the formation indicates this.

Mapping on Formational Basis. The United States Geological Survey has adopted the formation as its cartographic unit, mapping

* In recent classifications this term is discarded. See Haug Traité, p. I I 7o. 
being hence conducted on a lithic basis. "As uniform conditions of deposition were local as well as temporary it is to be assumed that each formation is limited in horizontal extent. The formation should be recognized and should be called by the same name as far as it can be traced and identified by means of its lithologic character, its stratigraphic association and its contained fossils." (18:73.) In mapping it is often impossible to draw a sharp line when two contiguous formations grade into each other. In such cases the boundary has to be more or less arbitrarily established. An example of this is the Siluro-Devonic boundary of the Helderbergs. Here in some places the Manlius or uppermost Siluric member is found to grade up into the Coeymans or lower Devonic member both lithically and faunally.*

Mapping on Faunal Basis. When two formations of the same lithic character are separable by their faunal content only it is often found practicable to map them separately on a purely faunal basis. In such a case it is frequently necessary to represent the transition portion by a commingling of colors of the two series. Sometimes the faunal change is a horizontal one, where two distinct faunas occupied different portions of the province at the same time, there being no change in lithic character. An example of this is seen in the two Portage faunas of New York, the Ithaca and the Naples, which existed side by side throughout Portage time. This is expressed on the map by two colors, or two shades of the same color, which horizontally pass into each other or overlap along the line of interlocking of the faunas. (Clarke-2.)

Mapping of Discontinuous Formations. It is a matter of common experience that formations change in passing away from the shore line, certain more terrigenous ones (as sandstones, etc.) coming to an end and others of more truly marine origin (such as limestones) appearing. As a result, detailed maps of adjoining areas, not parallel to the old shore line, may exhibit considerable diversity of formations, and it may even happen that quadrangles not so far removed from each other may exhibit scarcely any formations of the same name. Thus the Columbia quadrangle of Central Tennessee (Hayes and Ulrich-9) and the McMinnville quadrangle of eastern Tennessee (Hayes-8) have no formations in common, though they are separated by an interval $\dagger$ of only

* This is not always the case, however, and this close relationship has been denied by Ulrich. But there can be no question of this gradation in the Schoharie region of New York (see Grabau-6).

† The Chattanooga formation which appears on both maps is not of the same age, being younger in the more eastern quadrangle. 
two quadrangles. This distinctness is partly due to the fact that formations represented in one are wanting in the other, owing to discontinuity of sequence (represented by either unconformities or disconformities). It would, however, be just as true if the formations were complete in both. The greater number of subdivisions is found in the more western nearer shore phase of the lower (Ordovicic) system, while the Siluric and Mississippic systems have their nearer shore phase in the eastern sections. The following dia-
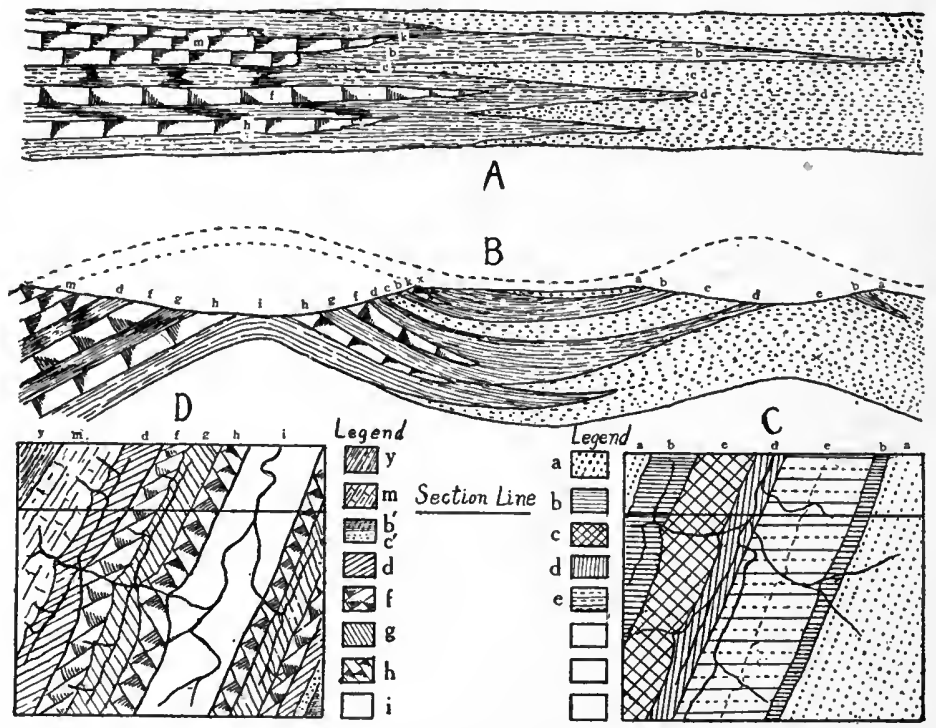

FIG. 263. A. Section showing variation of strata from shore seaward. B. The same section after folding and erosion. $C, D$. Maps of the same region, representing the two end quadrangles which have scarcely any formations in common.

grams (Fig. 263) illustrate the change in formations away from shore, and the resultant differences in the cartographic units of two quadrangles separated by an interval of one quadrangle only. In the eastern portion of the section only sands were deposited, constituting but one formation. Owing to repeated oscillation during the deposition of these sands, a series of intercalations of the more off-shore clays and the still more distant limestones occurred. Two anticlinal folds were formed which subsequently suffered erosion and exposed the succession of beds. The strike of the eroded strata is northeasterly, though the section is due east and west at 
right angles to the original shoreline. The two quadrangles mapped

- have only formations $b, c$, and $d$ (called $b^{1}, c^{1}, d^{1}$ ) in common. Formation $b^{1}$ of the western quadrangle is, however, more nearly equivalent to the upper part of $c$, as it appears in the eastern quadrangle. The bed $c^{1}$ of the western quadrangle is only a part-the lower-of bed $c$ as it appears in the eastern quadrangle, while $d^{2}$ and $d$ are almost exact equivalents. In the eastern quadrangle occur the formations $a$ and $e$, which are not found in the western one, while the latter shows formations $f, g, h, i, m$ and $y$, not found in the eastern quadrangle. In the eastern quadrangle, furthermore, the formations differ on opposite sides of the valley, $b$ being thin on the eastern and thick on the western side, while $c$ and $d$ of the western side are represented by $e$ on the eastern side.

\section{Types of Geological Maps.}

Formation and System Maps. Two kinds of geological maps are in vogue in most countries. These are the formation map and the system map. The first takes account of the geological formations, and is illustrated by the folio sheets of the Geological Atlas of the United States, already referred to. In these each formation is given a distinct color, or pattern, all the formations of a system generally being grouped together under a similar tint, such as pink, brown, etc. For the production of such maps, large scale basemaps are needed, those used by the United States Geological Survey being mostly on the scale of $I$ to 62,500 , or approximately I inch to a mile. As the scale of the map is increased, smaller units can be mapped, and structural details not representable on the smaller scale map may be introduced. The sy'stem map aims to represent in distinctive colors only the geologic systems, each of which receives a distinct color pattern. The new geological map of North America, issued by the United States Geological Survey, may be taken as an example of this type. Here eighteen distinct color shades are used to represent the systems from the Cambric to the Quaternary, though for convenience the boundary in a few cases is not drawn precisely at the dividing line between the systems.

The International Geological Map of Europe is also a system map, though the attempt has there been made to differentiate by distinctive shades the lower, middle and upper portions of some of the systems (e.g., Triassic, Jurassic, etc.).

Intermediate Maps. Maps intermediate between the system and 
formation map are also known. The best examples are the complete maps of New York State, on the scale of 5 miles to I inch, while the map issued with the summary final report of the Second Geological Survey of Pennsylvania may serve as another example. These maps represent series rather than formations, though in many cases the series consist practically of one formation only, such as the Onondaga limestone. In other cases the unit mapped includes what, on a map of larger scale, would be represented as several distinct formations. Such, for example, is the Clinton series which on the New York State map is shown by one color only, while on the map of the Rochester quadrangle it is shown as five distinct formations. The Portage group, represented as a single unit on the State map, is divided into eleven formations on the Canandaigua-Naples map $(1 / 62,500)$, exclusive of the Genesee shale and the Tully limestone.

Notation of Formations on Map. In addition to the color and pattern used in the representation of the formations or larger units, a conventional sign, which may be a letter, or combination of letters, or a number is used. This insures greater ease in identifying the formation on the map. The United States Survey, in its folios, has adopted a group of letters as the symbol, the first letter representing the horizon, the other the name of the formation. Thus, on the Hancock quadrangle, where the Siluric is represented by five formations some of the symbols are: Sc, Clinton shale; Smk, McKenzie formation; Stw, Tonoloway limestone. The $\mathrm{S}$ in each case signifies Siluric (Silurian). In the Geological Map of North America, above referred to, numbers are used to further differentiate the systems from one another.

Legend. In order that the proper superposition of the formation may be ascertained, a legend is added consisting of small rectangles colored to correspond to the color pattern which it represents on the map, and furnished, moreover, with the corresponding symbol and the name of the formation. These rectangles are arranged in the order of superposition or sequence. As a rule, the oldest formation is put at the bottom and the youngest on top. The New York State Survey has, however, adopted in some of its larger maps the reverse arrangement, the oldest being on the top. This is done, apparently, to bring the color pattern of the legend into harmony with that of the map; in which the successive older formations crop out in belts of decreassing age from the north southward. 


\section{Contimuous and Discontinuous Mapping.}

Since rock outcrops are, as a rule, scattered over a consider= able area with intervening portions in which the rock is covered by glacial or other loose soil deposits, two modes of mapping on the same scale have come into usage. 'The first is the mapping of outcrops only, forming what may be called outcrop maps. The intervening covered spaces may be left blank or may be colored for the superficial deposits. The result will be a map very difficult to read and to follow, while the structure of the region is not readily ascertainable from such a map. The practice of printing the pattern, representing the superficial unconsolidated deposit, over the color pattern of the formation is adopted in some quarters, as in the case of the International Geological Map of Europe. American maps, as a rule, represent rock formations only, without the overtint for superficial unconsolidated deposits. These deposits are either entirely omitted or represented on a separate map. It is, of course, understood that in such cases the map does not represent an accurate picture of the surface features of the lithosphere, but is hypothetical so far as the covered portions are concerned. In a region of simple structure no appreciable errors are likely to arise from such a mapping, but in a complicated region this may readily be the case.

\section{Sections.}

Types of Sections. Geological sections are of three kinds: (1) the natural cross-section, (2) the columnar section, and (3) the ideal section. The natural cross-section represents structure (in so far as it is ascertainable) and surface features, and is the one most generally employed in connection with geological representation. It gives the third dimension of the land form, the other two being furnished by the map. Cross-sections should, whenever the scale permits it, be drawn to the natural scale, $i$. e., vertical and horizontal scales should be alike. In some instances this is not possible, owing to the smallness of the scale and the large number of structural features to be represented. In such cases an exaggeration of the vertical over the horizontal scale is necessary, but this should not be over five times, or, in rare cases, ten times, the horizontal. It must be borne in mind that vertical exaggeration of the scale always involves an increase in the steepness of dip of the strata and a corresponding distortion of other characters. 
Columnar sections are designed to show the superposition and relative thickness of the strata of the region which they represent, provided they are drawn to scale. They serve their main purpose in giving a quick and comprehensive view of the stratigraphy of a region and in making comparison with other regions possible. If a uniform set of scales, each a multiple of the others, could be adopted, ready comparisons of published sections for different regions would be possible, and would greatly facilitate the work of correlation.

Ideal sections are attempts to restore the conditions as they were before deformation or erosion has taken place. The term is also sometimes used for generalized cross-sections, but this is better avoided. In so far as structure is eliminated, the columnar section is an ideal section, but sections to which the term is best applicable should show a wider relationship than is possible in a columnar section. Fig. I 52, page 739 and Figs. 157 and 158 , page 743 , are examples of ideal cross-sections.

\section{The Length of Geological Time.}

Various estimates of the actual length of geologic time have been attempted, the basis of most of such estimates being the rate of deposition, ascertainable in modern river systems, or the rate of erosion of river canyons, such as the Niagara, the Yellowstone, Colorado, etc., and the rate of retreat of the Falls of St. Anthony. (See Williams-I9.) If it can be ascertained that the beginnings of erosion have a definite relation to some other event which itself is of definite value in geochronology, a basis for a rational estimate of the actual time duration is furnished. Such a relationship seems to have existed between the beginnings of the Falls of Niagara and of St. Anthony, and the end of the Pleistocenic glacial period. So many questionable factors, however, enter into the problem, that it is scarcely worth while, with our present incomplete knowledge, to attempt much more than the most general estimate. Thus Cambric, Ordovicic and Siluric time has been estimated at I0,000,ooo years; Devonic time at 2,000,000 years; Mississippic to Permic time at 5,000,000 years, making a total of $17,000,000$ years for the Palæozoic. Mesozoic time has been estimated at 7,000,000 years, Cænozoic at 3,000,000 years and Psychozoic at 50,000, marking a total of 27,050,000 years since the beginning of Cambric time. This estimate is conservative, others having made a much larger one. Thus Dana's estimate of the age the earth was at least $48,000,000$ years. Geikie's estimate ranges from $100,000,000$ to $680,000,000$ years, 
while McGee has suggested a possible age of 7,000,000,000 years for our earth. Since we have not as yet ascertained the actual thickness of the stratified rocks of the earth, and since we know so little about the rate of erosion, we must conclude that all such estimates are premature and almost valueless, and that even the estimates of the proportional length of cluration of the various divisions are extremely hypothetical. Geological time was long, very long, as measured in terms of human chronology-long enough to permit the development of the multifarious forms of life upon the earth. Only a part of this time is recorded in the known rocks of the earth's crust-for there are probably many lost intervals, the duration of which we cannot even estimate.

\section{BIBLIOGRAPHY XXXI.}

1. CLARKE, JOHN M. 1896. The Stratigraphic and Faunal Relations of the Oneonta Sandstone and Shales, the Ithaca and Portage Groups in Central New York. New York Geological Survey, Fifteenth Annual Report, pp. 27-82, map.

2. CLARKE, J. M. 1903. The Naples Fauna in Western New York. New York State Museum, Memoir 6, pp. 199-454, 26 pls., I 6 figs.

3. DANA, JAMES D. I 895. Manual of Geology. Fourth Edition. American Book Company, New York.

4. GEIKIE, ARCHIBALD. 1903. Text-book of Geology. Fourth edition. Macmillan and Co., London.

5. GRABAU, A. W. I905. Physical Characters and History of Some New York Formations. Science, N. S., Vol. XXII, pp. 528-535.

6. GRABAU, A. W. I906. Guide to the Geology and Paleontology of the Schoharie Valley in Eastern New York. New York State Museum Bulletin 92 (58th Annual Report, Vol. III); pp. 77-386, 24 pls., 216 figs.

7. GRABAU, A. W., and SHIMER, H. W. 1910. Summary of North American Stratigraphy. North American Index Fossils, Vol. II, pp. 604-663. A. G. Seiler \& Co. New York.

8. HAYES, C. WILlaRD. I 895. McMinnville Folio, Tennessee. United States Geological Survey, Geological Atlas of the United States, Folio 22.

9. HAYES, CHARLES W., and ULRICH, EDWARD O. 1903. Columbia Folio, Tennessec. Geological Atlas of the United States, Folio No. 95. United States Geological Survey.

Io. LE CONTE, JOSEPH. 1902. Elements of Geology. D. Appleton and Co., New York.

I I. LEHMANN, JOHANN G. 1736. Versuch eincr Geschichte von Flötzgebirgen.

12. LYELL, CHARLES. 1856. A Manual of Elementary Geology. Sixth Edition.

13. REEDS, CHESTER A. 1911. The Hunton Formation of Oklahoma. American Journal of Science, $4^{\text {th }}$ series, Vol. XXXII, pp. 256-268.

14. SCHUCHERT, CHARLES. IgIO.. Palcogeography of North Amcrica. Geological Society of America Bulletin, Vol. XX, pp. 427-606, 56 pls. 
15. SINCLAIR, W. J. I9I0. Interdependence of Stratigraphy and Paleontology. The Paleontologic Record, pp. 9-II. Reprinted from Popular Science Monthly.

16. ULRICH, EDWARD O. 1904. In Taff's Preliminary Report on the Geology of the Arbuckle and Wichita Mountains in Indian Territory and Oklahoma. United States Geological Survey, Professional Paper No. 3I, pp. I I $-8 \mathrm{I}$.

I7. ULRICH, E. O. I9II. Revision of the Paleozoic System. Bulletin of the Geological Society of America, Vol. XXII, pp. 28I-68o, pls. 25-29.

18. UNITED STATES GEOLOGICAL SURVEY. I903. Nomenclature and Classification for the Geologic Atlas of the United States. 24th Annual Report.

19. WILLIAMS, HENRY S. I895. Geological Biology. An Introduction to the Geological History of Organisms. New York. Henry Holt \& Co.

19a. WILLIAMS, HENRY S. 1893. The Elements of the Geological Time Scale. Journal of Geology, Vol. I, pp. 283-295.

20. WILLIS, BAILEY. I90I. Individuals of Stratigraphic Classification. Journal of Geology, Vol. IX, pp. 557-569. 


\section{CHAPTER XXXII.}

\section{CORRELATION: ITS CRITERIA AND PRINCIPLES- PALAOGEOGRAPHY.}

\section{Correlation.}

"The fundamental data of geologic history are: (I) local sequences of formations, and (2) the chronologic equivalences of formations in different provinces. Through correlation all formations are referred to a general time scale, of which the units are periods. The formations made during a period are collectively designated a system." (Rule I4, Nomenclature and Classification for the Geologic Atlas of the United States.)

\section{History of Development of Methods of Correlation.}

Correlation of strata, or the establishment of an orderly relationship between the formations of separate regions, has been one of the chief aims of stratigraphers ever since the days of Verner and William Smith. Werner's correlations were based on the lithic character of the strata, but William Smith in England and Cuvier and Brogniart in France made their identifications of strata by means of the organic remains included in them. Each of these workers based his investigation upon the ascertained succession of strata in the region selected by him as typical, and thus the three fundamental criteria of correlative geology: lithic similarity, likeness of fossil content and superposition of strata, were made use of by the pioneers in stratigraphy.

The efforts of these founders of stratigraphy were directed chiefly toward establishing the identity or correspondence of strata between different localities; and, when it was recognized that strata were formed at different periods in the earth's history, the effort was further directed toward establishing the time-equivalency or synchroneity of strata. Before fossils were extensively studied, 
similarity of superposition and lithic identity were taken as the guides to synchroneity, a proceeding which naturally led to many erroneous correlations. Thus McClure and Eaton in their early studies of the rocks of the United States were entirely guided by superposition and lithic and structural character of the rocks, their classification being modeled upon that of Werner. Both McClure and Eaton identified the undisturbed Palæozoic formations of eastern United States with the Secondary or Mesozoic formations of England, being thus influenced in their correlation by another criterion, namely, the relative position of the strata. Lithic similarity caused Eaton to identify the Rochester shale of New York (Lower Siluric) with the Lias of England (Lower Jurassic). Lithic similarity and similarity of superposition led many of the early geologists to identify the Potsdam sandstone and the quartzose sand rock of Vermont as of the same age, though one is Upper and the other Lower Cambric. In the same manner lithic similarity led some of the earlier geologists to identify the Upper Cambric or early Ordovicic, Lake Superior sandstone with the Triassic sandstone of New Jersey and the Connecticut Valley, while the ribbon limestones of Pennsylvania and New Jersey, of Cambric and Lower Ordovicic age, and the Waterlimes of the Hudson River region-of Upper Siluric age-were not so long ago thought to be stratigraphic equivalents, on account of their great similarity in lithic characters. Superposition, sometimes erroneously inferred, similarity of lithic character, and superficial comparison of fossils led Bigsby in 1824 to identify the Rideau sandstone of Kingston, Ontario (Lower Ordovicic), with the Medina of the Niagara and Genesee gorges (Lower Siluric), and both with the Old Red Sandstone of England, on account of lithic resemblance of the two formations, and the apparent similarity of fossils in the limestones overlying them. In his later investigations Eaton, like Bigsby, made use of fossils in correlation, but the comparisons made by both were of the crudest, being chiefly by classes of organisms. Thus the Ordovicic conglomerates opposite Quebec were correlated by Bigsby with the "Carboniferous limestone" of England, because both contain remains of trilobites, "encrinites," "corallites" and other fossils. Another of the early correlations of formations by lithic characters was made in $182 \mathrm{I}$ by Dr. Edwin James. He considered that the sandstone of Sault Ste. Marie (Cambric or early Ordovicic) the Triassic sandstone of the eastern foothills of the Rocky Mountains, the Catskill, Medina and Potsdam sandstones of New York and the Newark sandstone of New Jersey were of the same relative geologic 
age and occupied a place similar to that assigned to the "Old Red Sandstone" by Werner. Geologists, however, were not long in finding out that beds of the same lithic character are not all of the same age, but it has taken them much longer to realize that beds of the same age are not always of the same or even similar lithic character.

With the detailed study of the New York strata by the five geologists and paleontologists on the survey (Nather, Emmons, Vanuxem, Conrad and Hall), correlation by fossils became recognized as the most reliable known method. At first American species were directly identified with European types, and such identification was in many cases not far wrong. Extensive collections of fossils, however, soon showed that the rocks of this country contained an assemblage of organisms largely peculiar to themselves and specifically, if not generically, distinct from that of Europe. Correlation by similarity of faunas was then substituted for correlation by species and so the general correspondence of the strata in the two continents was established. The need of an American standard of comparison was soon felt, and such a need was supplied by the development of the "New York series" of geological formations. The succession of New York strata and the organic remains characterizing them was so thoroughly worked out that "it is and has been for decades a standard of reference for all students of the oider rocks throughout the world." (Clarke-II.) Professor James Hall was one of the first in America to recognize the importance of naming formations from localities in which they were best exposed. In his report to the New York State legislature in 1839 he urges that neither lithic character nor characteristic fossils is a satisfactory source from which to derive the name of the formation, for the first may change while the second is not always ascertainable and may even be absent. He holds that it "becomes a desideratum to distinguish rocks by names which cannot be traduced, and which, when the attendant circumstances are fully understood, will never prove fallacious." Such names can be derived only from localities. It is most fortunate that this principle was recognized before the New York series of formations was fully promulgated in the final reports of the survey. As a result, the majority of formations were named from typical localities, only a relatively small number retaining the lithic or palicontologic names given them by the earlier investigators. Nore recently these, too, have been replaced by names derived from typical localities, of which the following is a partial list : 
Calciferous. ...................... replaced by Beekmantown.

Birdseye.................... replaced by Lowville.

Waterlime (of Buffalo).............. replaced by Bertie.

Coralline..................... replaced by Cobleskill.

Waterlimes (of the Hudson). . . . . . . . . replaced by Rondout \& Rosendale

Tentaculite limestone. . . . . . . . . . . replaced by Manlius.

Lower Pentamerus. ................. replaced by Coeymans.

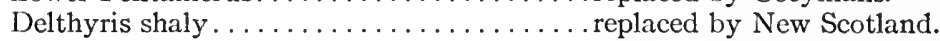

Upper Pentamerus................. replaced by Becraft.

Upper Shaly . . . . . . . . . . . . . . replaced by Port Ewen.

Cauda-Galli.................... replaced by Esopus.

Corniferous.......................

As the Palæozoic formations of other districts of North America were studied, it was found that the correspondence between them and the New York formations was not as close as could have been hoped. Not only did the lithic character of the strata change when traced away from the type locality, but the superposition did not, in many cases, correspond, some formations being absent altogether while others were found to be united in a single unit, often of slight thickness. Even the fossils, which had gradually come to be looked upon as the surest indicators of position in the geologic scale, appeared in horizons not known to contain them in New York. Thus the chain-coral Halysites was universally thought to be characteristic of the Lower Siluric (Niagaran) age, until it was discovered that this coral also occurred in the Ordovicic, in some of the localities west of New York, and in the Anticosti region, while in eastern New York it was found in an Upper Siluric horizon, the Cobleskill, which is stratigraphically many hundred feet above the Niagaran beds. In like manner Tropidoleptus carinatus and some of its associates, believed formerly to be restricted to the Hamilton (Mid-Devonic) formation, were found in south central New York to occur in the Ithaca (Portage) beds and, again, in the Chemung (Upper Devonic).

Recurrent faunas have also been described from the Mississipic. Weller (53) found Devonic elements in the Kinderhook fauna, and Williams and others have described such recurrence of Devonic elements in the Spergen and other Mississippic beds of central North America. Ulrich ( $49: 296)$ has noted the occurrence of the trilobite Triarthrus becki in the Fulton shale, and in the Southgate beds I 50 feet above it.

Chronological Equivalency. Contemporaneous and Homotaxial Formations. Chronological equivalency as one of the fundamental data of geologic history has repeatedly been assailed by eninent scientists. Huxley, indeed, went so far as to question the possi- 
bility of determining in any case the existence of contemporaneous strata, and he coined the term homotaris, signifying similarity of order, to express the correspondence in succession rather than exact time equivalence. Geikie also held that "strict contemporaneity cannot be asserted of any strata merely on the ground of similarity or identity of fossils" (14:608), and H. S. Williams, among American authors, has most strenuousiy insisted on the impossibility of recognizing strict contemporaneity among strata of widely separated regions. Williams would refer formations not to a general time scale, but to a stratigraphic scale, of which not "periods" but systems are units. He advocates the revision of Rule I4 of the U. S. Geological Survey quoted at the beginning of this chapter

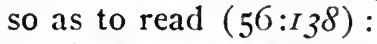

"The fundamental data of geologic history are: (I) the local sequence of formations and (2) the similarity of the fossil faunas of the formation of different prozinces. Through correlation all formations are referred to a standard stratigraphic scale, of which the units are systems."

Contrary to the views of Huxley and other writers, some of whom like Edward Forbes went so far as to assert that similarity of organic content of distant formations is prima facie evidence, not of their similarity, but of their difference of age, most modern stratigraphers have come to believe in the possibility of essential chronological equivalency of formations characterized by the same faunas, recognizing at the same time the fact that such equivalency is not necessarily indieated by the similarity of faunas, and that a given fauna may appear earlier and continue longer in some sections than in others. The rapidity of migration shown by modern faunas indicates that, if the path is open and no barriers exist, widespread migration or dispersal may occur within such short time limits as to be considered almost homochronic.

Contemporaneity of Faunas. That several distinct faunas may exist side by side in not too widely separated districts is a well known fact. The difference of faunas north and south of Cape Cod on the Atlantic Coast may be mentioned as a modern example; also the difference between the Red Sea fauna and that of the Mediterranean, and, finally, the distinct faunas on opposite sides of the Isthmus of Panama. In all of these cases a partial or complete land barrier separated the faumas. In the case of Cape Cod. this barrier is incomplete and, although aided by cold currents from the north, it has not entirely prevented the migration around it of the faunas. The other two barriers were complete, and separated faunas of different provinces, but the transsection in I869 of the 
Suez barrier by the canal has permitted a certain commingling of faunas, a phenomenon predictable for the faunas on opposite sides of the Isthmus of Panama on the completion of the canal.

Contemporaneous faunas existed in North America at various times in its geologic history. The most noted case is that of the Upper Devonic. An indigenous fauna, the Ithaca fauna, derived largely by development from the earlier Hamilton fauna, occupied the eastern area in New York and Pennsylvania, while an immigrant fauna, the Naples fauna, occupied the region to the west of this. At first the two faunas were separated by a land barrier, but this was subsequently submerged. Nevertheless, the two faunas continued in their essential integrity through Portage time, though the area of occupancy of each varied from time to time, but within comparatively narrow limits.

Prenuncial Faunas, Colonies. Prenuncial faunas are the advance invaders of a new territory of members of a foreign host, which subsequently occupies the territory. Such have been noted in some cases, especially in that of the Styliolina limestone of the Upper Devonic of New York, which marks the first invasion of the Naples fauna into this Upper Devonic province.

The term "Colonies" was employed by Barrande to designate the appearance of a fauna normal to a later geological horizon, during a period when an earlier fauna still flourished. Though the examples cited by Barrande have proved to be mostly inadequate to establish his theory, the fact remains that faunas in their ensemble suggestive of a much later period may appear in deposits otherwise marked by the normal fauna of that period. Thus, during the Upper Siluric (Upper Monroan) time, a fauna in large measure suggestive of Middle Devonic time flourished in Michigan, Ohio, and Ontario (Anderdon fauna). In this fauna something over twenty species have exact specific, or closely similar, representatives in the Onondaga or Schoharie formation. This similarity is largely found in the coral, brachiopod, pelecypod, and trilobite elements of the fauna, while the cephalopods and gastropods are of typical Siluric species. The whole fauna is succeeded by a normal Siluric fauna, and is separated by an extensive hiatus from the overlying limestones of Middle Devonic age. The explanation of this commingling of faunas is found in the fact that two faunas, with distinctive characters, existed simultaneously, one of which furnished the faunal elements with Devonic affinities, but did not make much headway against the resident normal Siluric fauna. Continuing to modify in its own center of distribution, the more specialized fauna finally evolved into the normal Middle Devonic fauna of that region, 
some parts of which spread widely over the earth, and, with elements derived from other sources, constituted the local Middle Devonic faunas of eastern North America. (Graban and Sherzer-20a.)

Standard or Type Sections. In general the first section studied is taken as the type section for the country. Often it is not the most complete nor the most perfect section, as in the case of the Devonic section of southern England (Devonshire), which is less perfect than that of the Rhine region; or the Cretacic section of Colorado and Montana, which is less complete than that of Texas and Mexico. In such cases it not infrequently happens that, by a process of natural selection, the poorer section is gradually replaced by the better, as in the case of the Rhenish Devonic, which is now more frequently used for comparison, or the Cambric of Scandinavia, which is more satisfactory than that of Wales. In America the type section for the Palæozoic formations is found in the State of New York. This not only was the first section thoroughly studied in this country, but, what is more significant, it turned out to be in many respects the most complete and most representative of all American Palrozoic sections. So truly representative is this section that, ". . . while other classifications proposed for these rocks, contemporaneously or subsequently, have fallen to the ground, it has withstood all the attacks of time." (Clarke-I I.)

Not a little did the detailed palæontologic work carried on by the State Survey of New York contribute to this prominence of the New York Section. No other American region has had the organic remains of its formations so fully investigated and descriptions and illustrations of them published in such a complete manner. This thoroughness, for which in a large measure James Hall was responsible, has forever made the New York column the foundation on which all other work on Palæozoic Stratigraphy of America must be based.

In spite of this fact, however, the relationships between the various local sections of the State of New York have not yet been fully ascertained, and each year facts are discovered which demand a modification, in details, of these standard sections.

Nor is the New York column as a whole complete and without flaws. Undoubted Middle Cambric appears to be but slightly developed in the state, while the Lower and Upper Cambric also are not fully represented, so far as the sections have been studied. Hence the American type sections for these formations are obtained from other regions: that for the Lower Cambric from northwestern Vermont and that for the Middle Cambric in the Acadian 
provinces of Canada. In the latter region is likewise found a more complete representation of the Upper Cambric formations than has yet been ascertained to exist in the State of New York. It is on this account that the East Canadian names Bretonian, Acadian and Etcheminian ( $c f$. Georgian) have been used for the Upper, Middle and Lower Cambric, respectively. (Grabau-r7.)

Again, a hiatus exists in New York between the Ordovicic and Siluric, the upper part of the Ordovicic not being represented, at least not by fossiliferous formations. The lower Siluric, too, is less satisfactorily represented in New York than elsewhere, for, as currently understood, it begins with a sandstone formation, the Medina, which is a shore formation, where not of non-marine origin. For the Upper Ordovicic and Lower Siluric, then, the New York column has to be pieced out by formations developed elsewhere, the standard selected being the Cincinnati group of the south-central states for the one, and the lower Mississippi region for the other.* Even within the lower Ordovicic there is an incomplete representation of the top of the Beekmantown and of the Chazy formation, this incompleteness being measurable by thousands of feet of limestone in the Mohawk Valley, but by very much less in the Lake Champlain region. The Salina of New York, of Mid-Siluric age, also forms an unsatisfactory member of the standard series, as already pointed out, since it represents abnormal conditions of sedimentation. Aside from these, however, the New York column represents an eminently satisfactory standard of the Palæozoic formation below the Mississippic.

The standard American series for the Mississippic is that of the Mississippi Valley, though that is not itself a complete section. The standard marine sections for the Carbonic and Permic have not yet been fully worked out for this country. The former is found in Kansas, Missouri and Arkansas; the latter in Texas. No American Triassic or Jurassic standards are recognized, the fragmentary development of these formations being referred to foreign standards. The Comanchic and Cretacic, on the other hand, are well represented by formations in Mexico, Texas and the Great Plains region, which localities have furnished the standard sections. The Comanchic is well represented in the southern areas, but the sections of the typical Cretacic in the standard region (Colorado and Montana) are incomplete at the bottom and at the top, where they include non-marine formations, $i$. e., the Dakota sandstone, and the

* The Anticosti section promises to be one of the most perfect North American Lower Siluric (Niagaran) sections, but it is not as yet certain in how far this section belonged to a distinct geographic province. (See Schuchert-39:532.) 
Laramie formation. The standards of the North American marine Eoccnic and Oligocenic are found in the Gulf States, while those of the Miocenic and Pliocenic are found on the Atlantic coast of Maryland and Virginia, the Carolinas and Florida. All these localities together, however, furnish only a partial standard of the American marine Tertiary.

A Double Standard. In some cases it has been found most practicable to have a double standard of formations: one marine, the other non-marine. This has been most fully worked out for the American Tertiary, where the continental deposits of the Great Plains region serve as a standard of comparison for similar deposits of other American regions, while the Gulf and Atlantic Coast deposits serve as our standard of marine formations. In western Europe the Carbonic is represented by the non-marine Westphalian and Stephanian, while the corresponding marine formations of eastern Europe are the Moscovian and Uralian. In America the Pocono-Mauch Chunk formations are the non-marinc equivalents of the Mississippic, and the Pennsylvanic (PottsvilleMonongahela) is the non-marine standard of the Carbonic, the marine standard being still undetermined, though in part represented in the Kansas section. The Laramie, Belly River, Bear River, and Dakota formations form a nearly complete non-marine standard for the American Cretacic, and the Kootanie for the Comanchic.

\section{Methods of Correlation.}

The means by which formations of different localities are correlated may be summarized as follows:

I. Superposition.

2. Stratigraphic continuity.

3. Lithic characters.

4. Organic contents.

5. Unconformities or disconformities.

6. Regional metamorphism.

7. Diastrophism.

I. Superposition.

The basis of all stratigraphic work is the ascertainment of the order of superposition of the strata. No correlation of the strata in any two localities is possible until the exact superposition in 
each has been ascertained. The general law of superposition is: that, of any two strata of sedimentary rocks, the one which was originally the lower is also the older. This does not, of course, apply to intruded igneous rock, for a much later sheet of intrusive material may find its way between strata very much older and so be followed by strata older than itself. In exceptional cases, too, sedimentary rocks may not follow this rule, as in the case of deposits in caverns cut out of older rocks. Here strata may actually form beneath the surface of the lithosphere and hence below an older stratum.

Of course, in regions of faulting and strong folding, the order of the strata may be reversed, so that it becomes necessary, first of all, to demonstrate the original position of the formations.

In the ascertainment of the superposition of strata of a given region great care must be taken to note the existence of stratigraphic breaks. Disconformities of strata are often difficult to recognize, but unless ascertained are sure to introduce an element of error into the geologic columns of the region. Abrupt changes in sedimentation are a useful guide in the location of such disconformities and, in fact, where such sudden changes occur it may be taken as an indication of the possibility of the existence of such a hiatus, though this alone is not sufficient proof of its existence. A good example of a great hiatus indicated only by an abrupt change in the character of the rock is found in the case of the contact of the Black Chattanooga shale with the gray Rockwood clays in eastern Tennessee. Here there seems to be, at times, no other indication, than this sudden change in character, of the absence, between these two formations, of more than the "entire Devonic system of strata. Indication of erosion surfaces, and the inclusion of the fragments of the lower in the upper beds, commonly characterize the disconformity, but give no clue as to the magnitude of the hiatus. The change from one lithic unit to another may be abrupt, without necessarily indicating a disconformity. In such cases, generally, there is some alternation of beds of the two series before the complete disappearance of the lower series.. Thus the Black Shale at the top becomes intercalated with thin bands of the overlying formation, and itself occurs at intervals in the form of thin layers for some time after the extensive development of the overlying series.

Correlation by superposition, however, is a method fraught with grave dangers. Thus a succession of formations from sandstones to shales and limestones in one part of a province is not necessarily the same as a similar series in another part of the same 
province, and most probably not the same as a similar series in another geologic province. Indeed, from a consideration of the phenomena accompanying marine progressive overlap, it becomes apparent that even within the same province the two series are different, unless they are situated along a line parallel to the old shore of the time when the strata accumulated.

\section{Stratigraphic continuity.}

When a formation can be traced, with but slight interruptions, over a wide area, the general assumption is, that it is synchronous in all its outcrops. This is true enough where the tracing of the formation is parallel to the old shore line, or source of supply, but not always true when at an angle with that line. This is especially the case when the formation in question is of terrigenous origin, formed either as a marine or as a fluviatile deposit. A basal sandstone or conglomerate, formed in a transgressing sea, rises in the scale shoreward: in a regressing sea it rises seaward (see Chapter XVIII). The Mahoning sandstone of the Lower Conemaugh of northwestern Pennsylvania had been traced almost contintously around the bituminous coal field and united with the Charleston sandstone of the Kanawha district of West Virginia. It has since been shown, however, that these sandstones are part of a series rising and overlapping northwestward, and that, whereas the Charleston end of the series lies in the Lower Allegheny, the Mahoning sandstone proper forms the westernmost part of the series, lying at the base of the Conemaugh. (Campbell.)

Limestones are, however, much more continuous, and, if traced for moderate distances, are apt to hold their own pretty well. This is especially the case with limestone beds of slight thickness interbedded with shales. Thus the Encrinal limestone has been recognized in all its ontcrops, from Thedford, Ontario, to the Genesee Valley, a distance of over 200 miles, holding its own throughout in lithic character as well as fossil content, though there are other strata which have been mistaken for it farther east. It forms a prominent plane of correlation of the strata, for it seems pretty certain that this limestone in all of its occurrences represents simultaneous, or nearly sinultaneous, accumulation as the result of widespread uniformity of conditions. (Shimer and Grabau-43.)

The Agoniatite limestone of the New York Marcellus has been traced from Buffalo to Schoharie, and southward to Maryland. 
This limestone, intercalated between black shales, indicates a period of widespread uniform conditions, followed by a resumption of the Black Murl sedimentation. It therefore serves as an excellent horizon marker, by which the rocks above and below can be correlated. Still another example is the Cobleskill of New York, which has been traced across the State, chiefly by its fauna, and serves as a datum-plane for the strata above and below it.

\section{Lithic characters.}

Correlation by lithic characters is possible only in very limited areas, and where it can be used in connection with stratigraphic continuity and order of superposition. Under certain conditions, however, the lithic character becomes an important guide in correlation. An example is the St. Peter sandstone, a pure silicarenyte, which has been widely recognized by its lithic character, and its enclosure within pure limestone or dolomytes. The uniformity of grain and composition over thousands of square miles of area is its most remarkable feature. As already outlined, however (Chapter XVIII), the St. Peter, though occupying a definite position in the scale, encloses within itself a hiatus, which constantly widens northward, so that the top of the sandstone is higher in the scale and the bottom is lower in the northern region, as compared with its more southern occurrence. Moreover, there are formations, such as the Sylvania sandstone of Ohio (Upper Siluric), which are, lithically identical with the St. Peter, and might be mistaken for it, if lithic character alone were considered.

An intercalated shore-derived formation between offshore formations can generally be recognized in its various outcrops by its lithic character. Such a formation represents an oscillation of the land during sedimentation, either a shoaling or a total retreat of the sea, followed by a re-advance or a deepening. Lithic character then, when taken in conjunction with superposition, may be a valuable guide in correlation. Intercalated off-shore beds among terrigenous formations may likewise serve a good purpose in correlation. Thus the Ames or Crinoidal limestone, a marine bed, has been widely recognized as an intercalated bed in the non-marine Conemaugh formation of the bituminous coal field. In this case the correlation is confirmed by the contained fauna.

Another way in which lithic character serves a useful purpose in correlation is by the occurrence of what may be called sympathetic changes in sedimentation. Thus two regions, one more dis- 
tant from the shore than the other, may experience a sympathetic change in sedimentation, when simultaneously affected by an oscillatory movement. Thus, when in the near-shore region muds change upward into sands, and still higher into muds again, the corresponding clange in the more distant region may be from limestones to terrigenous muds and higher still to limestones again. Such sympathetic changes seem to have taken place between the New York and Michigan Hamilton deposits.

\section{Organic contents.}

Correlation by organic contents, or Paleontologic correlation, has been found to be the most reliable method, far surpassing in importance any other single method. Nevertheless, there are many pitfalls which must be guarded against, and the sources of error must be recognized and taken into account.

(a) Index fossils. Index fossils have already been defined as species characteristic of definite geologic horizons, and typically occurring only in beds of that horizon (page 1094). Index fossils in order to be efficacious must be of limited vertical but wide horizontal distribution. Thus the brachiopod Hypothyris cuboides characterizes a certain zone in the Upper Devonic of America, Europe and Asia, while the Goniatite Manticoceras intumescens likewise characterizes late Devonic rocks throughout much of the northern hemisphere. Similarly, Spirifer disjunctus has a limited vertical range, combined with a wide horizontal one, being characteristic of the Upper Devonic of many countries. Locally, the type may transgress the normal vertical range, as in the case of the last-mentioned species, which passes up into Lower Mississippic beds in eastern North America, or, as in the case of Tropidoleptus carinatus, a widespread index fossil of the Mid-Devonic, but which locally passes into the Upper Devonic. The best index fossils are those which are capable of wide distribution, and remains of which' will occur in regions where the organisms may never have lived, and in sediments which may differ widely from those forming the normal facies of sea bottom for the type in question. As pointed out in an earlier chapter, epiplanktonic and pseudoplanktonic forms are most likely to produce such index fossils. The shell of Spirula. a dibranchiate cephalopod of the modern fauna, illustrates the wide distribution possible by flotation, though the animal has been found to occur only in a few localities in deep water. Epiplanktonic $\mathrm{Hy}$ drozoa and Bryozoa likewise suffer a wide distribution through the flotation of their liost. 
Among the pseudoplankton the shells of Ammonites should be especially noted as being included, at least to some extent, in sediments of varied character over wide areas.* The genera and species of ammonites as a rule were short-lived cephalopods, different species characterizing different zones. Besides having their shells widely distributed after death, by flotation, living ammonites also seem to have spread rapidly and widely, probably during a meroplanktonic stage.

Holoplanktonic organisms may also suffer a wide distribution and, if they contain parts capable of preservation, these may be entombed in sediments of widely different character. Such cases are seen in the pteropod oozes of various geologic horizons.

The wide distribution of the Ordovicic graptolites was probably due to epiplanktonic as well as holoplanktonic dispersion. Graptolite species were short-lived, hence successive zones are characterized by distinct types over a wide area. Plants whose seeds are widely distributed by winds or other agents produce good index fossils for continental deposits. Here, however, the climatic factor exercises a limiting influence, since plants will only grow where climatic conditions are favorable.

(b) Grade of index fossil. The grade of the index fossil commonly has a very direct relation to the magnitude of the stratigraphic divisions to be correlated. Thus, while the class of trilobites as a whole may serve for the recognition of Palæozoic rocks the world over-none having as yet been found outside of the Palæozoic-smaller subdivisions must be used for the correlation of more restricted stratigraphic divisions. Thus the family Conocoryphida among the trilobites is characteristic of the Cambric, and any member of that family will serve to determine the Cambric age of the strata in which it occurs. The family Olenide is principally restricted to the Cambric, though some members occur in the Ordovicic. The most characteristic types, nevertheless, serve to correlate the Cambric formations in all their occurrences. While any of the more characteristic genera of this family (Olenidæ) will thus serve in correlating Cambric formations as a whole, certain genera of this fanily serve as indices of the three principal sub-

* The pseudoplanktonic dispersal of the shells of Ammonites is strongly advocated by Walther, but questioned by Ortmann (34), Tornquist (46), J. P. Smith and others. Tornquist has urged against such interpretation the observation that in the Jurassic and Cretacic the Ammonites are distributed according to climatic zones. Examples of dispersal by flotation are, however, known, for as shown by Clarke (Naples fauna) the Goniatite fauna of the Styliolina or Genundewah limestone of western New York ("prenuncial intumescens fauna") must be regarded as derived in this manner. (See also Chapter XXIX.) 
divisions. Thus Olcncllus and Holmia characterize the Lower Cambric, Paradoxides the Middle Cambric, and Olemus and Dikellocephalus the Upper Cambric.* Again, the Niddle Cambric may be subdivided into a number of zones, each characterized by a species of Paradoxides. These species are either identical or representative in the corresponding zones of the East American and West European Middle Cambric.

The dendroid graptolite Dictyonema may serve as an example of a genus of more extended range, some of whose species are, nevertheless, good index fossils. The genus itself begins in the transition beds from the Upper Cambric to the Lower Ordovicic, where $D$. Alabclliforme is a characteristic index fossil and is of almost worldwide distribution. Other species characterize the Siluric and still others the Devonic.

(c) Correlation by equivalent stages in development. Among organisms characterized by community of descent corresponding stages in development are sometimes reached in different lines of evolution at about the same time period. Such inomøomorphic representatives (morphological equivalents, see Chapter $\mathrm{XXV}^{\circ}$ ) may thus serve as indices of a given horizon even where intercommunication has not occurred. Thus Goniatites the world over characterize the upper Palaozoic, but Goniatites are derived along different lines of descent. $\dot{\dagger}$ The simpler types along the various lines of descent characterize the Devonic, while those with more complicated sutures greater involution, or marked ornamentation are mostly characteristic of the Mississippic and Carbonic. The Ceratite type, in which the lobes of the sutures are further modified by secondary indentations, while the saddles are entire, are typically developed along the various lines of evolution. in the Trias. Finally, the Ammonite type, in which both lobes and saddles are modified by additional indentations, appears chiefly in the Jurassic, in the various evolutional lines, and continues into the Cretacic. Owing to these facts the orginal idea prevailed that Goniatites constituted one genus, characteristic of the formations from the Devonic to the Carbonic; Ceratites formed another genus characteristic of the Trias; while Ammonites was regarded as a genus characterizing the time from the Jurassic to the Cretacic inclusive.

It is now known, however, that many exceptions to this general rule exist. Genetic series, in which acceleration of development prevailed, reached the Ceratite or even the Ammonite stage in preTriassic time. Thus the genus Prodomites from the Lower Missis-

* For illustrations see Grabau and Shimer, North American Index Fossils Vol. II. † See Chapter XXV, p. 978. † See Chapter XXIV, p. 945. 
sippic (Chouteauan) has advanced into the Ceratite stage, while Waagenoceras of the Permic has already true Ammonite (phylliform) sutures. Sometimes, by retardation, a type remains in a more primitive evolutional stage, one which normally characterizes a lower horizon. The case of the Triassic ammonite Trachyceras, cited by J. P. Smith (45), from the Karnic limestone of California, and referred to in Chapter XXV, belongs here. This had persisted in the more primitive Tirolites stage and so suggested correlation of the beds with those of a lower horizon. The "Pseudoceratites" of the Cretacic (Hyatt-23) form another instructive example. In these types (Protengonoceras, Engonoceras, ${ }^{*}$ etc.) arrestation in development affects the later stages (the earlier stages being accelerated with reference to the corresponding stages of their Jurassic ancestors), so that the adult sutures remain in the ceratite or even goniatite stage. This is a case of heterepistasis, the cessation in development affecting only the sutures. What appears to be a good example of corresponding stages in development in distinct provinces at about the same time period, thus serving for interregional correlation, is seen in the case of Clavilithes of the Parisian Eocenic, and the corresponding morphologic equivalents of the Eocenic of the Gulf States of North America. The American series of species parallels the Parisian to such an extent that they have been regarded as varieties of the Parisian species. There is every reason for believing, however, that they represent an independent development. (Grabau-15.)

The graptolites present other examples of corresponding stages in development reached in distinct genetic series at approximately the same time. Thus, Dichograptus, Tetragraptus, Didymograptus, etc., represent stages in development rather than monophyletic genera, but, since these stages appear simultaneously in the various lines of descent, they may be used as geologic genera, eminently adapted for correlative purposes. (Ruedemann-38.)

(d) Correlation by faunas and floras. Representative species. When the index species themselves are not represented, correlation by means of the sum total of associated organisms must be made. Thus Paradoxides is absent from the Middle Cambric of the Appalachian and Pacific provinces of North America, nor are any of the associated species of the other genera present in these faunas. Representative species, however, occur and the sum total of the Middle Cambric faunas of the various provinces has similarity of expression, which is almost as good as absolute identity. The lower Middle Cambric of the Atlantic Coast and of western Europe

* For illustrations see North American Index Fossils, Vol. II. 
has different species of Paradoxides in the different provinces, but these species are representative, so that they serve to correlate even the zones. The zones with their representative or identical species are as follows:

Eastern North America.

Paradoxides forchhammeri

P. davidis

P. abenacus

P. eteminicus

P. lamellatus
Western Europe.

P. forchhammeri

P. davidis

P. tessini

P. rugulosus

P. œlandicus

Even between provinces as close as New Brunswick and eastern Massachusetts the species are representative rather than identical. Thus Paradoxides harlani, the large Middle Cambric trilobite of eastern Massachusetts, is representative of $P$. ctcminicus of New Brunswick, while Acrothele gamagii of the Massachusetts Middle Cambric is the representative of $A$. matthere $i$ of New Brunswick. The Meekoceras beds of the Lower Trias of the Himalayas, Siberia, California, Idaho and Utah are readily correlated, though no species common to these regions are known. The genera, however, which characterize them are sufficiently short-lived and the species of the different provinces are closely representative. (Smith-45.)

\section{Correlation by unconformities and disconformities.}

Correlation by unconformities has in the past been extensively employed, and some stratigraphers have adrocated the use of unconformities as a primary basis for correlation. A little reflection, however, will show that such a method. when used indiscriminately, is sure to lead to confusion and false correlation, for it is a well-ascertained fact that folding of formations was not simultaneous in different parts of a region, nor in different regions. but may be earlier in some and later in others. Thus. while there was a rather widespread period of folding in later Palreozoic time, both in Europe and North America, this folding began in the Devonic in some sections, and not until the Permic in others. Moreover, the formation next succeeding the unconformity is by no means always the same one, and grave mistakes have been made by assuming this to be the case. Thus in some cases the Triassic beds rest directly upon the folded Palrozoics. while in other cases beds of much later age, even Cretacic or Tertiary, succeed them. 
In the same way the beds resting upon the truncated Ordovicic folds in New York and Pennsylvania vary considerably in age. The conglomerates succeeding the unconformity were originally all classed as basal Siluric. In reality some are of Lower and some are of Middle Siluric age, while in still other cases beds of upper Siluric or even younger age rest directly upon the truncated roots of the old folds.

Nevertheless, with due circumspection it is possible to use great and widespread unconformities for broad correlation of formations. Since there were two periods of widespread, if not universal, disturbance of the earth's crust, besides many minor ones. these at least have a considerable value in correlation. One of these occurred before the beginning of Palæozoic time, and the other came to an end before the beginning of Mesozoic time. Thus everywhere, the world over, the Archæan rocks are separated from the Palæozoic formations by great unconformities. This does not apparently hold for all pre-Cambric rocks, however, since some of the formations commonly referred to the Algonkian are separated from the Cambric only by a disconformity. It may, however, be true, as already pointed out, that the unaltered or but slightly altered rocks, like the Belt terrane, the Uinta sandstone, and others, are not necessarily pre-Palæozoic. They are known to be preCambric, or better, in most cases only pre-Niddle Cambric, and, since they are largely, if not entirely, of non-marine origin, they may, in part at least, represent the continental equivalents of the marine Lower Cambric beds. The unconformity between the Palæozoic and Mesozoic, though widespread, is nevertheless much more restricted than the earlier one mentioned. Moreover, it is of sufficient constancy to make possible this broad correlation, though, as before remarked, there is no guarantee that the beds next succeeding are everywhere of the same age.

Disconformities are, to a certain extent, better criteria for correlation, especially the larger and more extensive ones, which can be interpreted as due to eustatic movements of the sea. Withdrawals or transgressions of the sea, due to change in sea-level, will affect all continents more or less in the same manner, and thus serve as a primary basis for subdivision. The danger with this method lies in the difficulty of distinguishing between the local and the widespread character of the disconformity and the tendency which it induces to multiply the number of breaks in the geologic column by assuming that the minor breaks of one locality are necessarily reproduced elsewhere.

That there are widespread breaks in the geological column, 
which are undoubtedly due to eustatic movements of the sea, becomes more and more apparent. The widespread mid-Jurassic transgression of the sea over Europe is well known and the disconformity (and occasional unconformity) produced by this transgression has been used for widespread correlation. The great Mid-Ordovicic hiatus first observed in North America. (GrabauI6; I8), and the similarly widespread hiatus in the Upper Ordovicic (Weller-52), are now known to be marked in North Europe as well (Bassler-5). In like manner the Mid-Siluric hiatus and disconformity so widespread in North America appear also to be present in the Baltic region of Russia and Sweden and in the Bohemian Palæozoic district. The probabilities are that in MidSiluric time the sea left a large part of the present land area dry. Similar widespread disconformities are recognized in the Mesozoic.

\section{Correlation by regional metamorphism.}

Regional metamorphism has already been defined as an alteration or metamorphism, which affects extensive regions and which is primarily due to tectonic disturbances. Such metamorphism may, of course, occur at any time in the history of the earth, but whenever it does occur it will affect all the formations of the region in which it takes place, though, obviously, some formations may be more strongly affected than others. This being the case, it follows that, wherever unaltered rocks overlie the metamorphosed ones, the age of the former cannot date back of the period of metamorphism, and that, hence, the lower limit of their age is fixed by this period of metamorphism. Evidently there is no guarantee here, however, that the strata of the overlying serics are all of the same age, though within moderate limits this is probably true. One general rule may, perhaps, be formulated, and within certain limits applied, namely, that, of two formations in contact, the more strongly metamorphosed one is the older. Here, however, the same caution is necessary that is required in applying the rule of greater deformation to two deformed formations in contact. Some formations are more subject to metamorphism than others, just as some formations are more subject to deformation.

The method of correlation by metamorphism is, perhaps, the most applicable to the determination of the boundary line between the pre-Palæozoic and later formations, though even here it seems not always to be reliable. This would appear from the fact that extensive sedimentary formations, such as the Belt series of Mon- 
tana, and its continuation into Canada, with a thickness of over $\mathbf{I 2 , 0 0 0}$ feet, and similar formations in Utah (Uinta quartzite) and in the Grand Canyon district (Unkar and Chuar series*) have suffered no appreciable metamorphism, though from their relationship to the overlying Cambric formations they are believed to be of pre-Cambric age. The Torridon sandstone of Scotland is another example of a formation underlying the Olenellus-bearing sandstones (Lower Cambric), the two being separated by a slight unconformity, while the American formations are generally separated from the Cambric only by a disconformity, or at least by an unconformity in which the deformation of the lower beds has been so slight as to appear non-existent. If these formations are really pre-Cambric, and not basal Cambric, they may well represent an earlier system, which, however, still belongs in the Palæozoic; or they may represent a pre-Palæozoic, but still post-Algonkic system, one, the formation of which succeeded the apparently worldwide metamorphism which has affected the Algonkic and earlier formations.

Finally, it must be noted that extensive metamorphism has affected rocks of Palæozoic and even of much later age. The schists and marbles of the New York City area are believed by many to be the altered Cambro-Ordovicics, which, north of the Highlands, appear unmetamorphosed. Berkey, however, holds that they belong to the pre-Cambric (6), a view strongly advocated by Crosby. A similar difference of opinion exists with reference to the metamorphic rocks of New Jersey, especially those in the region about Franklin Furnace.

On the whole, it will be seen that correlation by metamorphism, while serviceable and often very reliable within certain limits, is, nevertheless, a method likely to mislead. We need but recall that the early stratigraphers classed all metamorphic rocks as Primary, and that this included the metamorphosed Palæozoic formations of western Europe, as well as the metamorphosed Mesozoic and later formations of the Alps. Or we may compare the older and newer maps of New England and of the Appalachians, where we shall find that many of the formations formerly classed as preCambric are now placed into the Paleozoic. The international map of Europe also shows many areas of pre-Cambric rock, where more recent study has led the observers to place the metamorphic formations high in the geological column.

* In the Chuar group fossils of Palæozoic character have been found, which suggests that these formations form a pre-Cambric Palæozoic system if they are not actually a part of the Lower Cambric. 


\section{Correlation by diastrophism.}

The recognition of the widespread character of hiatuses or gaps in the sedimentary series, noted in preceding sections, suggests that the causes of these breaks are of more or less universal extent. These causes are diastrophic, or deformative of the earth's crust, for every hiatus signifies a retreat of the sea, followed by a readvance, indicating, thus, a relative rise of the land-mass, which results in the emergence of large tracts, followed by a relative depression, resulting in submergence. If these movements affect individual land blocks only, the regression and transgression are chiefly confined to this block, while, at the same time, as has been shown in Chapter I, a reverse change in relative level of sea and land may be noted on the stationary blocks, this being brought about by the readjustment of the entire sea-level, necessitated by the partial displacement of it in one region. Thus, if one land block rises independently of the others, its shores will suffer a negative or retreatal movement, and its margins will energe. As a result of this, however, there will be a partial elevation of the sea-level as a whole, due to the displaced water, and this will affect all blocks, including the emerging one. In the latter it will tend merely to reduce somewhat the total amount of sea-retreat which the elevation of the block would bring about, but in the stationary blocks there would be a universal advance of the sea over their margins. Thus retreatal movements in one continent would be correlated with transgressive movements in the other, and, since emergence is followed by erosion, and submergence by deposition. base-leveling of one continent would go on, with deposition beyond its margins, at the same time that deposition over the submerged margins of the other continents and a reduction in the erosive activities over the unsubmerged portions of those continents would occur.

If the movement affects the suboceanic crustal block, however, a universal sinking or rising of the sea-level will result, in conformity with the lowering or elevation of this block. This will be manifested in a universal retreat and readvance of the sea along all continental margins, with the production of a widespread hiatus in the succession of formations. If the interval between the two movements is a large one, with comparative stability of the land, the base-leveling processes will tend to wear the country down to a nearly uniform level, while the resultant marginal deposits will tend further to raise the sea-level, and thus set the gravitative movement 
going. The shrinking of the land from invading lower temperatures will likewise tend to reduce the level of the land, and so permit the sea to transgress across it anew.

If erosion is not uniform in amount, owing to variable hardness of formations, or to other causes, the resulting hiatus will vary in magnitude from point to point. For, though the time interval between the retreat and readvance of the sea in two localities might be the same, it is obvious that the missing formations will be more extensive than can be accounted for by non-deposition, since, during the interval of exposure, erosion removes a part of the earlier deposited sediments. The amount thus removed in different sections may vary greatly, and, hence, the gap in the series will vary from place to place.

Chamberlin (9:304) has considered four stages, which must be taken cognizance of in correlation by general diastrophic movements: (I) "the stages of climacteric base-leveling and sea transgression; (2) the stages of retreat, which are the first stages of diastrophic movement after the quiescent period; (3) the stages of climacteric diastrophism and of greatest sea-retreat; and, (4) the stages of early quiescence, progressive degradation, and seaadvance."

(I) The stage where base-leveling and sea transgression have successively reached their climax is especially characterized by diminution in land, a reduction in the amount of solution, oxidation and carbonation of rocks, and, hence, in the abstraction of carbon dioxide from the atmosphere, coupled with the greatest extension of lime deposition and hence the setting free of carbon dioxide. Thus there will be a tendency toward the amelioration of the climatic conditions, and this will aid the great expansional evolution of marine life favored by the broad expansion of the littoral belt and the formation of numerous epicontinental seas. New marine faunas and floras, often of a provincial type, will come into existence, which are likely to arise through parallel evolution from closely related ancestors in the various provinces. Thus a widespread basis for faunal correlation will be inaugurated, such faunas comprising not identical, but rather closely representative, species. Pathways for extensive migration along the littoral belts of the oceans also result, and these tend to produce widespread uniformity of the littoral fauna of the oceans. Such periods of extensive transgression of the sea and corresponding expansional evolution are seen in the late Cambric and early Ordovicic, in the Middle, and early Upper Ordovicic, in the early Siluric, Middle Devonic, early 
Mississippic and in the Middle and early Upper Jurassic (Callovian to Oxfordian), as well as in the early part of the Cretacic.

(2) The stages of initial diastrophism and sea-retreat are marked by the increase in deposition of the material resulting from the deep decomposition of the rock, during the period of baseleveling; the increasing deposition of terrigenous clastics, and the consequent change in the character of the fauna, a turbid water fauna taking the place of the one previously flourishing in the purer waters. The littoral belt is narrowed, the epicontinental seas disappear, and the evolution of shallow-water life and the migration of organisms are restricted.

(3) When the climax of the regression is reached the restriction in the evolution of the shallow water organisms is at its maximum. Clastic deposits predominate and they even encroach upon the continents. Climatic changes are toward a colder period, owing to the locking up of the carbon dioxide in land-vegetation, by solution of limestones, and by carbonation of silicates. Such refrigeration may go so far as to result in glaciation, at least locally, the evidences of such glaciation furnishing an additional basis for correlation. Broad land expansions would in general favor wide distribution of animals and plants, unless the severity of the climate should enter in as a deterrent factor. Should climatic factors be less in evidence, however, the wide expansion of the land might favor a wide distribution of land life. As a result, the struggle for existence would be less intense and modifications would be slower, and more of thie nature of adaptations to slowly changing environment. The littoral region of the sea being, however, much reduced, the survivors of the once widespread marine littoral fauna would be forced into a more restricted area and hence a fierce struggle for existence would be sure to result. This would lead to the rapid extinction of numerous types and to the comparatively rapid modification of the survivors, and would thus produce a comparatively sudden change in the character of the fauna.

(4) The early stages of quiescence and base-leveling which follow and which initiate anew the slow transgressive movement of the sea, will again favor migration of marine faunas. Owing to the effect of the previous restrictions, however, the aspect of the fauna will have been changed to a marked degree, so that the expanding fauna will have a distinct aspect of its own. The great expansion which followed the retreat of the sea in the late Middle or early Upper Cambric time in North America brought with it the spread of a fauna widely different from that which preceded it. The Middle and early Upper Ordovicic expansional faunas (Chazy- 
Trenton) differed, likewise, in a marked degree from the preceding Beekmantown faunas. The Siluric fauna of North America, also an expansional fauna, differed radically from that of the preceding Upper Ordovicic (Weller-52), which was largely exterminated by the late Ordovicic or early Siluric retreat of the sea. The comparative uniformity of expansional faunas, over wide areas, such as that of the Mid-Ordovicic, the early Siluric, the Mid-Devonic, and the later Jurassic and Cretacic, shows that such periods are eminently fitted to furnish a basis for practically worldwide correlation.

Finally, it may here be noted that, if the theory of polar pendulations, as outlined in Chapter XXIII, should prove to have a sound basis in fact, we must modify our conception of movements of the water body, to the extent of recognizing the coincident rising of the sea-level in the region approaching the Equator, and the fall of the sea-level in the regions approaching the poles. Thus movements of the water body would not be uniform over the earth, but compensatory, rising in the equatorial and falling in the polar regions. For an attempt at correlation on such a basis the student is referred to Simroth's book "Die Pendulations-theorie." (44.)

\section{Paleogeography and Paleogeographic Maps.}

"Palæogeography," says Dacqué, "may be compared to a fire which has smoldered long under cover, but which has at last broken forth with all-consuming energy" (I2). Attempts to restore the outlines of continents and seas during former geological periods were essayed by geologists and palæontologists before the middle of the nineteenth century. Since then the subject has smoldered under cover of the detailed investigations carried on in other fields by the students of the earth sciences, until, in recent years, it has burst forth with almost volcanic violence, and palæogeographic maps and palæogeographic discussions have become the order of the day.

The term Palcogeography is credited to Robert Etheridge, and its birth is given as in the year I88I (Schuchert-39), * but palæogeographic maps were made much earlier. Schuchert regards those given by Dana in the first edition of his manual (I863) as the earliest; but earlier maps, though less definite in character, had been published, as, for example, those by Goodwin Austen for England

*Dacqué mentions A. Boué, who in 1875 used the terms paläogeologische Geographie and geologische Paläo-Geographie. (Sitzungsberichte K. K. Akad. Wiss. Wien. Math. Nat. K1. Bd. 7I, I $^{\text {te }}$ Abt., s. 305-405.) 
in 1856 , by B. Crivelli for Italy in 1853 and by Gemmellaro for Sicily in I834. (Dacqué-I2:I92.) The most elaborate recent attempt to map the conditions of land and water at different geologic periods is that of Schuchert, who, in his instructive monograph on the Paleogeography of North America, has published fifty separate maps showing the changes in outlines of North America from Cambric to Pliocenic time.

Types of Palemogegraphic Maps. Palæogeographic maps may be simple of complex, special or generalized. The simple map aims to show the distribution of geographic features, of a particular period in the earth's history, over the surface of the earth, much as a modern geographic map shows this distribution for the present time; a complex map, on the other hand, attempts to show more than this. The simple map need not be confined to the depiction of the hypothetical coastline, but, if the facts available allow it, should represent the ocean currents, the mountains, the rivers, etc. As examples of maps of this type, though very incomplete, especially in so far as the land features are concerned, may be mentioned the Ordovicic map by Ruedemann (38) and those for the same time-period by Grabau (I8); the older Devonic maps of Schuchert, and many others. The excellent maps by De Lapparent (3I) may also be classed here, though on them the areas of continental as well as marine sedimentation are shown. The complex maps nay show, in addition to the deduced geographic conditions, some of the data on which this deduction is based, especially the distribution of the geological formation in question, or of its outcrops. Such a map is in reality a combination of a palæogeographic and a geologic map, and this may prove higllly useful, for the degree of detail depicted upon the map, and the extent to which the map is hypothetical, are at once apparent. Such are the maps issued by Schuchert for North America. A somewhat more complicated type is represented by the Palæogeographic maps issued by Chamberlin and Salisbury (IO) where the attempt is made to represent not only the outcrop, but also the parts believed to exist beneath cover, and the areas from which the formations are believed to be removed by erosion.

The most complex and detailed maps of this type published in America are those issued by Bailey Willis $(57 ; 59)$. In them the attempt is made to represent the oceanic basins, the littoral and the epicontinental waters, the areas which may have been either sea or land-separating those which were more likely sea and those which were more likely land-the lands of the time, the indeterminate areas, and the ocean currents, both polar and equatorial. 
Maps of this kind are more easily read when colors instead of symbols are used. Another type of complex map is that which attempts to show changes in outline of the lands and seas during the period represented. Such are the maps of Frech (13), in which transgressions and regressions of the sea are represented by differences in color. Haug, too (2I), indicates the areas of transgression upon his maps, and, furthermore, outlines the limits of the geosynclines. And, in addition, his maps are facies maps.

Special maps aim to show the outlines of lands and seas at a definite time period, as at the end of the Lower, Middle or Upper Cambric (Fig. $264 \mathrm{a}-\mathrm{c}$ ), or at the beginning of a time period. Such maps may be either simple or complex. Examples of the
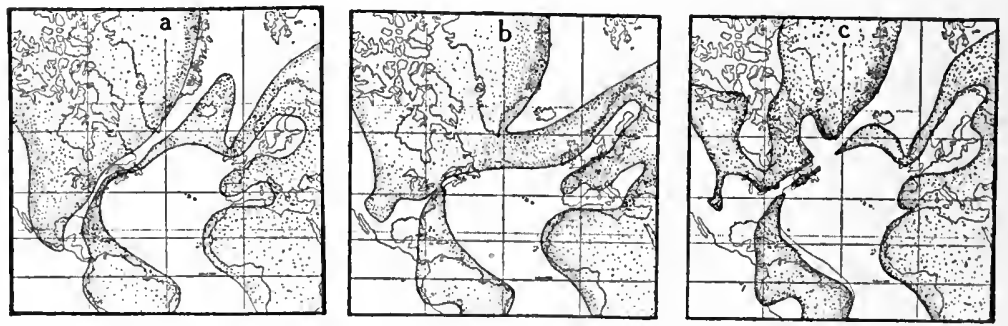

Fig. 264. Maps showing the probable distribution of land and sea around the Atlantic basin in Cambric time. $a$. At end of Lower Cambric. $b$. At end of Middle Cambric. $c$. At end of Dictyonema fabelliforme time. (A. W. Grabau.)

former are the maps published by Grabau (19) for the Cambric (Fig. 264), and for the various stages of the Ordovicic (18). The maps published by Schuchert, Chamberlin and Salisbury, Willis, Haug, De Lapparent, and, indeed, by most authors are general maps to cover a whole time period, though in some cases this period may be very small.

Construction of Paligogegrapiic Maps. In the construction of palæogeographic maps it is first of all necessary to bear in mind that modern geographic maps can at least serve only as a distorted base for such depiction. Thus the Appalachian region of North America, and the region of the Alps in southern Europe are areas where the earth's crust has been greatly foreshortened, and where, hence, localities far apart at an earlier time were brought close together. It is, of course, impossible to allow for such foreshortening, if the localities where certain formations crop out to-day are 
to be brought into the seas in which they were deposited. Thus, as will be seen on the maps for the Lower Cambric (Fig. 264a), the New England land barrier between the Atlantic and the Pacific extension in the Appalachian or Cumberland trough is much too narrow, while the width of that trough is also too small. The same is true for the land-barrier in North Britain, between the Atlantic and Arctic oceans. Since, however, the rocks carrying the faunas of these two seas are found so much nearer together to-day than was the case at the time of the deposition, such faulty construction seems to be unavoidable.

The overlap relations of marine strata are especially significant as aids in determining old shore-lines, for such overlap of a later over an earlier formation indicates, as a rule, that the point of overlap is also a point on the shore-line of the earlier formation. Due attention must here be given to the type of overlap (see Chapter XVIII), and the fact must be borne in nind that minor overlaps may also be developed upon an irregular sea-bottom, where wave activity or current scour is active.

Important factors that must not be overlooked in the construction of palæogeographic maps are the nature of the sediment and its source. Where coarse clastic sediments abound in the formation, a land of sufficient size must have existed to furnish this sediment. This is especially the case when the sediment consists of well-assorted material, such as quartz-sand or pebbles, when it must be remembered that such assorted material may represent only a part. perhaps less than one-fourth, of the original rock which was its source. In general, it may be said that much closer discrimination between marine and non-marine sediments than has generally been the case is necessary; and the conditions of deposition must be borne in mind, as well as the factors of marine and non-marine bionomy, and the effects of topography on currents and of both on deposition, so that we may not again fall into the error of reconstructing the area of former coral-rock formation as an arm of the sea, one-half or one-quarter of a mile in width, and less than ten fathoms in depth.

When the science of Stratigraphy has developed so that its basis is no longer purely or chiefly palæontological, and when the sciences of Lithogenesis, of Orogenesis and of Glyptogenesis, as well as of Biogenesis, are given their due share in the comprehensive investigation of the history of our earth, then we may hope that Palreogeography, the youthful daughter science of Stratigraphy. will have attained unto that stature which will make it the crowning attraction to the student of earth history. 


\section{BIBLIOGRAPHY XXXII.}

I. ARLDT, TH. 1907. Die Entwicklung der Kontinente und ihrer Lebewelt. Ein Beitrag zur Vergleichenden Erdgeschichte. Leipzig.

2. ARLDT, TH. 1909. Palæogeographie und Seismologie. Hettners geographische Zeitschrift. Jahrgang 15, pp. 674-684.

3. ARLDT, TH. I9Io. Methoden und Bedeutung der Palæogeographie. Petermanns geographische Mittheilungen, II, pp. 229-233.

4. ARLDT, TH. I9I2. Palæogeographische Fragen. Geologische Rundschau, Bd. III, Heft 2, pp. 93-I4I (with map).

5. BASSLER, RAY S. I9II. The Early Palæozoic Bryozoa of the Baltic Provinces. United States National Museum, Bulletin 77.

6. BERKEY, CHARLES P. 1907. Structural and Stratigraphic Features of the Basal Gneisses of the Highlands. New York State Museum, Bulletin 107, pp. $36 x-378$.

7. CAMPBELL, M. R. 1903. Variation and Equivalency of the Charleston Sandstone. Journal of Geology, Vol. XI, pp. 459-468.

8. CANU, F. I895. Essai de Paléogéographie. Restauration des contours des mers anciennes en France et dans les pays voisins. Paris. Text and atlas.

9. CHAMBERLIN, THOMAS. 1910. Diastrophism as the Ultimate Basis of Correlation; in Outlines of Geological History, etc., by Willis and Salisbury, Chapter XVI, pp. 298-306.

Io. CHAMBERLIN, THOMAS, and SALISBURY, ROLLIN D. 1906. Geology. Vols. II and III. Henry Holt \& Co.

I I. CLARKE, JOHN M. I904. Nomenclature of the New York Series of Geologic Formations. Proceedings Eighth Annual Conference of New York State Science Teachers' Association. High School Bulletin 25, pp. $495^{-506 .}$

12. DACQUE, E. I9I3. Paläogeographische Karten und die gegen sie zu erhebenden Einwände. Geologische Rundschau, Bd. IV, Heft 3, pp. I 86-206.

13. FRECH, FRITZ. I897-1902. Lethæa Palæozoica. Stuttgart.

14. GEIKIE, ARCHIBALD. I893. Text-book of Geology. 3rd edition. $4^{\text {th }}$ edition, 1903. Macmillan and Co.

5. GRABAU, A. W. 1904. The Phylogeny of Fusus and Its Allies. Smithsonian Micellaneous Collections, Vol. XLIV, pp. I-I 57, I 8 pls., 22 figs.

16. GRABAU, A. W. I906. Types of Sedimentary Overlap. Bulletin of the Geological Society of America, Vol. XVII, pp. 567-636.

17. GRABAU, A. W. I909. A Revised Classification of the North American Lower Palæozoic. Science, N. S., Vol. XXIX, pp. 35I-356.

18. GRABAU, A. W. I909. Physical and Faunal Evolution of North America during Ordovicic, Siluric, and Early Devonic Time. Journal of Geology, Vol. XVII, No. 3, pp. 209-252.

I9. GRABAU, A. W. I9I0. Ueber die Einteilung des nord amerikanischen Silurs. Compte Rendu du XI: Congrès Géologique International, pp. 979-995.

20. GRABAU, A. W. 19I3. Ancient Delta Deposits. Bulletin of the Geological Society of America, Vol. XXIV, pp. 399-528.

20a. GRABAU, A. W., and SHERZER, W. H. I9I0. The Monroe Formation, etc. Geological and Biological Survey of Michigan. Publication 2.

21. HAUG, EMILE, I908-igII. Traité de Géologie, I, II, Les Périodes Géologiques, Paris, Armand Colin. 
22. HULL. 1882. Palæo-geological and geographical maps of the British Islands. Scientific Transactions of the Royal Society of Dublin, Vol. I.

23. HYAT'T, ALPHEUS. I903. Pseudoceratites of the Cretaceous. United States Geological Survey, Monograph XLIV.

24. IHERING, H. Von. 1908. Archhelenis and Archinotis. Gesammelte Beiträge zur Geschichte der neotropischen Region. Leipzig.

25. IHERING, H. Von. I908. Die Umwandlung des amerikanischen Kontinentes während der Tertiärzeit. Neues Jahrbuch für Mincralogie, u. s. w. Beilage Band 32, pp. I34-I 76 .

26. KARPINSKY, A. 1895. Palæogeographic Maps. (Russian title and text.) Bulletin de l'Académie Impériale de Sciences. St. Petersbourg. $5^{\text {me }}$ sér. T. I, pp. I-I9.

27. KNOWLTON, F. H. I9ro. Biologic Principles of Paleogeography. The Paleontologic Record, pp. 2I-23. Reprinted from Popular Science Monthly.

28. KOKEN, E. I893. Die Vorwelt und ihre Entwicklungsgeschichte. Leipzig.

29. KOKEN, E. 1907. Indisches Perm und permische Eiszeit. Neues Jahrbuch für Mineralogie, u.s. w. Fest Band, pp. 446-546. Map.

30. KOSSMAT, F. 1908. Paläogeographie. Geologische Geschichte der Meere und Festlānder. Leipzig.

3I. LAPPARENT, A. DE. I906. Traité de Géologie. First edition, Paris, 1885. Third edition, I 893. Fourth edition, I900. Fifth edition, 1906.

32. LULL, RICHARD S. I904. Fossil Footprints of the Jura Trias of North America. Boston Society of Natural History, Memoirs, Vol. V, pp. 46 I-557, I pl., 34 figs.

33. NEUMAYR, MELCHIOR. I883. Ueber klimatische Zonen während der Jura-und Kreidezeit. Denkschrift der mathematisch-naturwissenschaftliche Klasse der kōniglich-kaiserlichen Akademie der Wissenschaften. Wien. Band XLVII, pp. 227-310.

34. ORTMANN, ARNOLD E. I896. An Examination of the Arguments Given by Neumayr for the Existence of Climatic Zones in Jurassic Times. American Journal of Science, 4 th series, Vol. I, pp. 257 et seq.

35. ORTMANN, A. E. I902. Tertiary Invertebrates. Report of the Princeton University Expedition to Patagonia, Vol. IV, 1896-1899.

36. ORTMANN, A. E. 1902. The Geographical Distribution of Freshwater Decapods and Its Bearing upon Ancient Geography. Proceedings of the American Philosophical Society, Vol. XLI, pp. 250 et seq.

37. OSBORN, HENRY F. I910. The Age of Mammals in Europe, Asia, and North America. New York.

38. RUEDEMANN, RUDOLF. 1904. The Graptolites of New York. Part I. New York State Museum, Memoir 7.

39. SCHUCHERT, CHARLES. I910. Paleogeography of North America Bulletin of the Geological Society of America, Vol. XX, pp. 427-606, pls. 46-Ior.

40. SCHUCHERT, C. 1910. Biologic Principles of Paleogeography. The Paleontologic Record, pp. II-20. Reprinted from Popular Science Monthly.

4I. SEMPER, M. 1896. Das paläothermale Problem, speziell dic klimatischen Verhältnisse des Eocãns in Europa und im Polargebiet. Inaugural Dissertation, Munich. 
42. SEMPER, M. 1908. Die Grundlagen paläogeographischer Untersuchungen. Centralblatt für Mineralogie, usw. Bd. IX, pp. 434-445.

43. SHIMER, HERVEY W., and GRABAU, A. W. 1902. Hamilton Group of Thedford, Ontario. Bulletin of the Geological Society of America, Vol. XIII, pp. 149-186.

44. SIMROTH, HEINRICH. 1907. Die Pendulations-Theorie. Leipzig.

45. SMITH, JAMES PERRIN. I90o. Principles of Paleontologic Correlation. Journal of Geology, Vol. VIII, pp. 673-697.

46. TORNQUIST, A. Oxford Fauna von Metam.

47. TOULA, F. 1908. Das Wandern und Schwanken der Meere. Vorträge des Vereins zur Verbeitung der naturwissenschaftlichen Kenntnisse in Wien. Jahrgang 48, Heft II.

48. UHLIG, V. I9II. Die marinen Reiche des Jura und der Unterkreide. Mittheilungen der geologischen Gesellschaft, Bd. III, pp. 329 et seq.

49. ULRICH, EDWARD O. 19II. Revision of the Paleozoic Systems. Bulletin of the Geological Society of America, Vol. XXII, No. 3, pp. $28 \mathrm{r}-68 \mathrm{o}, 5 \mathrm{pls}$.

50. ULRICH, E. O., and SCHUCHERT, CHARLES. 190r. Paleozoic Seas and Barriers in Eastern North America. Report of the State Paleontologist of New York State Museum, pp. 633-663.

51. UNITED STATES GEOLOGICAL SURVEY. I903. Nomenclature and Classification for the Geologic Atlas of the United States. Twentyfourth Annual Report.

52a. WALTHER, JOHANNES. 1908. Geschichte der Erde und des Lebens.

52. WELLER, STUART. I898. The Silurian Fauna Interpreted on the Epicontinental Basis. Journal of Geology, Vol. VI, pp. 692-703.

53. WELLER, S. 1906-1909. Kinderhook Faunal Studies. IV. The Fauna of the Glen Park Limestone. St. Louis Academy of Science Transactions, Vol. XVI, No. 7, pp. 435-47I, 2 pls. V. The Fauna of the Fern Glen Formation. Geological Society of America Bulletin, Vol. XX, pp. 265-332, 6 pls.

54. WELLER, S. 1907. The pre-Richmond Unconformity in the Mississippi Valley. Journal of Geology, Vol. XV, No. 6, pp. 519-525, I fig.

55. WHITE, D. 1907. Permocarboniferous Climatic Changes in South America. Journal of Geology, Vol. XV, pp. 619 et seq.

56. WILLIAMS, HENRY SHALER. I904. Bearing of Some New Palæontologic Facts on Nomenclature and Classification of Sedimentary Formations. Bulletin of the Geological Society of America, Vol. XVI, pp. 137-I 50.

57. WILLIS, BAILEY. 1909. Paleogeographic Maps of North America. Journal of Geology, Vol. XVII, pp. 203-600.

58. WILLIS, B. Í́ Io. Principles of Paleogeography. Science, N. S., Vol. XXXI, No. 790, Feb. 18, 1910, pp. 246-249.

59. WILLIS, B., and SALISBURY, ROLLIN D. 1910. Outlines of Geologic 1. History with Especial Reference to North America. The University of Chicago Press, Chicago. 


\section{INDEX}

(Consult also the table of contents. Names of genera and species are, with few excepticns, omitted.)

A

Aar, delta of, 6 ro

Aarmassive, 308

Abbe, C., cited, 56

Abbotsham, 223

Ablation, 17,263

Abrasion, 18

Abrolhos Islands, 416

Abu Roasch, 856

Abu Sir, 355

Abyssal district, 983

Abyssinia, 355

Abyssinian Mountains, rainfall in, 68

Abyssolith, 310, 731

Abysso-pelagic district, 983

Acadian, 1128

Acantbin, 457 , 38

Acaustophy tolitbs, 280,467

Acceleration, differential, 964

- illustration of law of, 969, 970

Accordanz, 821

Accretions, 719

Achatinellidx, mutations of, 1043, 1052

Acid, crenic, 37

$$
\text { humic, } 37
$$

, ulmic, 37

Actinic (chemical) rays, 28

Adams, F. D., cited, $92,747,773$

Adams, F. D., and Coker, E. G., cited, 773

Adaptive radiation, 1054

Adirondacks, 834

Adour River, 223,558

Adriatic Sea, 108, 240

$$
\text { - Po delta in, } 584
$$

- surface salinity of, 153

Egean Sea, 240, 334

\section{temperatures of, 18}

Eolian Islands, volcanoes of, 86 ,

Ethoballism, 749, 765

Atna, radial dikes of, 870,87

Afghanistan, habitual fault lines of, 882

Africa, coast of, 235

African deserts, salinas of, 359

Agarica, 406

Agassiz, A., cited, 102, 125, 219, 387, 406, $408,414,416,461,462,469,470,471$, $519,520,685$, 1011, $1021,1024,1026$, 1038,1069

- quoted, 519, 680, 1016, 1019, 1020

Agassiz, L., cited, 143, 462

Agger, 224

Agoniatite limestone, 425, 1131,1132

Agra, 26

Agulhas banks, 218

Agulhas shelf, 103

Ajdin, 54

Aigon, earthquake fissures in 1861 at, 883
Air frost, ${ }^{63}$

Airy, G. B., cited, 265

Ajusco Mountain group, new mountain formed in 1881 in, 863

Alabama, coastal plain of, 839

Aland Islands, 24

Alands deep, temperatures in, 190

Alaska, 263 dredging off coast of, 641,642 , glaciers of, 324 stone glaciers from, 544

, tundra of, 507

Albatross, dredgings by, 519, 676

Albatross, marine habitat of, 985

Alberta, pre-Cambric reefs of, 418

Albert Edward Nyanza Lake, 124, 359

Albert Lake, 118, 119

, composition of, $157,158,159,160$ salinity of, 155

, soda deposits of, 361

Albert Nyanza Lake, 124

Albien, 730

Albuquerque, dune sands from, 553

Alcyonaria, 385, 392, 1083

Aldborough, church at, 225

Alden, W. C., cited, 92

Aldrich, T. H., cited, 916

Aletschhorn, 308

, unconformity in, $\mathbf{8 2 5}, 826$

Aleutian Islands, basaltic lava field in, 867

Al, submarine volcanoes of, 872

Algx, 935

Algion encrustation by silica, 477

Algai Lake, peat of, 498

Algeria, onyx deposits of, 345

Al, salt dome of, 379,758

Algiers, 221, 240

Alhambra formation, 591

- torrential deposits from, 630

Allahabad (Persia), 26

Allan, Dr., cited, 413

Allegheny formation, thickness in Appalachians of, 904

Allegheny Rivcr, gravel tcrraces of, 136

Alten, H. S., cited, 685

Allen, J. A., cited, 921,956

Allocht honous, $298, \$ 67,478$

Allolebod, 355

Allometrons, 961, 970

Allotriomorphic dolomite crystals, 445

Alpena, reefs at, 427,428

Alps, alluvial deposits of, 584

igneous intrusions in, 308

Altenburg, 1086

Amazon River. 248

A. red mud opposite mouth of, 669

Amber, 1075

Amboina Island, 519

Ambulacral areas, 949 
Ames limestone, 1132

Amfila Bay, 355

Amherstburg, 422

Ammonites, 945,978

- minerals in chambers of, 1085 , naming of, 913 wide distribution of shells of, 1022

Ammonoidea, 945

Ammonoids, range of, 945, 946

Amu-darja (Amudaria), see Oxus

Amundsen, R., cited, 327

Amygdaloidal structure, $277^{-}$

Amygdules, 313

Anam, 242

Anamorphism, zone of, 747

Andaman Islands, 109

Andaman Sea, Io9, 393

Anderdon fauna, II 26

Anderdon limestone, 52, 422

Anderdon, Ontario, 423

Anderson, J. G., cited, 543, 578

Anderson, T., cited, 878

Anderson, W. S., cited, 380

Andersson, G., cited, 85

Andersson, J. G., cited, 92

Andes, earthquake fissures in, 883

- , rainfall on, 67

- , snow-line of, 322

Andesites, depth of formation of, 15

Andrée, K., cited, $367,380,644,673,682$, $685,748,773$, I 069

Andresen C. C., cited, 223, 265

Andrussow, N., cited, 338, 35 I, 354, 380, $443,444,462,609,637,666,685$

Ane, quoted, 354

Anegada Straits, 108

Anemoclasts, 285

Angara River, 16

Anglesey, craterlets of, 885

- , sandstone pipes of, 884

Anhydrite, changed to gypsum, 537

Animikie, 385

- Archæocyathidæ of, 417

Anschütz quarry, 420

Antarctic block, 9

Antarctic glacial clay, salt content of, 367

Antarctic Ocean, manganese concretions in, 718

Antedon, development of, 1032

Anthracite coal, 5 Io, 5 II

Anthracolithic period, 511

Anticosti, 418

- , peat beds of, $508,509,514$

Anticyclones, 46

Antigua Salines, onyx marble of, 344

Antilles, decapods in mountains of, 1027

Antilles, Lesser, 233

, pteropod ooze outside of, 456

Apennines, mud volcanoes in, 872

Aphotic region, 982,983

Apo, 771

Apocrenic acid, 173

Apophyses, 304

Appalachian region, basal Cambric sandstones in, 729

- - overlap of marine strata in, 732

Appalachians, disconformities in, 823 , folding of, 903

for eshortening of, 903

revived topography of, 845

, source of Pottsville conglomerate in, $74^{2}$

- spring line in, 26 I

Aptien, 730,850

, overlapping of, 850

Aptychus beds, age of, 459

, origin of, 677

Aquileja, 153
Aquitanien, 454

Arabia, dune area of, 562

Arabian Gulf, temperature in, 187

Arabian Sea, 240

-, miliolitic limestone of, 574

$\longrightarrow$, oölite dunes of, 472

$\longrightarrow$, temperature of, 187,190

Arago, cited, 72

Aragon, Planorbis of, 1086

Aragon, woods replaced by sulphur at, 108I

Aragonite, oölites of, 473

-

recrystallization of, 755

Aral Sea, composition of, 157 dunes of, 561 salinity of, 155

Arbuckle Mountains, Saint Peter standstone in, 739

Arca, in Bermudaite, 573

Arctic climatic period, 506

Arctic Ocean, Lithothamnion in, 470

- mean temperature of 193

Arenaceous texture, 285

Arenig, 315

Arenytes, 285

Argentina, 367

Argentine basin, 105

Argon, 25

Arizona, onyx marble of, 343

- pre-Cambric "reefs" of, 418

Arizona desert, earthquake fissure in, 884

Arkansas, caverns of, 346

-, hot springs of, 201

overlap of marine strata in, 732

Arkansas River, 245

Arkose, 33

Arldt, T., cited, I 148

Armenia, alkaline lakes of, $36 \mathrm{r}$

Armorican Mountains, $71,373,375$

- , elevations of, 374

Arrhenius, S., cited, 22, 29, 92, 757, 758, 773

Arsis, climatic, 82,83

Artemia, excrements of, 1093

Arundel formation, 632

Ascutney Mountain, 302

Ascension Island, 105, 215 cölites of, 336

-, pteropod ooze near, 456

Aseptata, 943

Ashkabad, unbedded eolian deposits at, 554 well-boring near, 592

Ashokan formation, origin of, 635

Asia, connection with America by Behring Sea, 106

Asia Minor, 240, 334

Askja, eruption of, 866

Aspen, dolomitization of limestone at, 761

Astogeny, defined, 973

Astrakhan, rainfall at, 65

Astrakhan desert, salt lakes of, 357, 358

Atacama desert, 32, 364, 365

-, dunes in, 563

- natural mummies in, 1077

- soda niter deposits in, 364

Atlantic climatic period, 506

Atlantic Ocean, manganese concretions in, 718

- - mean temperature of, 193

surface temperature of, 182

temperatures in, 185,187

Atlantosaurus beds, see Como beds

Atmobios, 991, 992

Atmo-biotic realm, 982

Atmoliths, 279

Atmology, 20

Atmometamorphism, 749, 767

Atmoseisma, 88I 
Atmosphere, chemical work of, 34 , circulation of, 42

, composition of, 1, 24

electrical phenomena of, 72

impurities of, 24, 27

mechanical work of, 5 I

optical characters of, 28

- temperature of, 29

Atmospheric pressure, 2 fefs of, $43{ }^{\circ}$

Atwater, cited, 9r5, of, 56

Austen, G., cited, 1144

Australia, 390

, barrier reefs of, 387

Cambric tillites of, 534,535

-, Murée glacial formation of, 536

Autochthonous, 298, 467

Autoclasts, 285

Autophytography, 1082

Autotype, 9 I9

Autun, cannel coal of, 48 r

Auvergne, acid lavas of, 869

$\longrightarrow$, mineral springs of, 179 , petrified chelonian eggs from, !088

pustular lava cones in, 870

volcanic lake basins of, 120

Avolcanoes of, 874

Aves, 954

Avon River, 663

Ayin Musa Springs, entomostracan ooze of,

456
Ayrshire, prismatic jointing in coal seams of, 820

Azores, 152, 205, 218

pteropod ooze near, 456

, transported rocks off the, 452

, volcanic cone in the, 864,865

\section{B}

Bacteria, anaërobic, 338

Baden, Miocenic deposits of, 754

Bader, H., cited, 352,380

Bad land topography, 53

Baffin Bay, 108, 109, 237

Baffin Land, 418

Bahama Banks, 233

Bahama Islands, 398, 41

- foraminiferal sands of, 455

Bahia, 34I

Bahia Blanca, 360

Baie, Bay of, volcano in, 863

Bain, F., cited, 82, 93

Bakalsk, rock streams at, 547

Bakewell Buxton, warm springs of, 201

Bala-jschem, 54

Balbi lagoon, 401

Balch, F. N., cited, 1042, 1069

Balchash Sea, elevation of, 1 I 5

Bald Eagle conglomerate, 636

Ballingtang channel, 237

Baltic, amber of, 1075

Baltic Provinces, cuesta of, 838

Baltic Sea, 109, 110

- osmotic pressure in, 180

_, salinity of, 1044,1045

temperatures of, 190

Baltic stream, 241

Baltzer, A., cited, 307, 308, 320, 825

Raluchistan, desert areas of, 562

Banda, Island of, Spiruia dredged near, 1021

Randa Sea, 107, 186, 242

Ranff, synclinal fold near, 796

Banks, 104

Baraboo ridge, 848
Barbados, dust falls at, 60

, radiolarian ooze of, 458,678

Barbados earth, 458, 1008,1082

Barbour, E. H., cited, 1092

Barca, 153, 240

Barchans, 556,563

Bardarson, G., cited, 92

Baren, G. van, cited, 92

Barent shelf, 103

Barent Straits, 236

Barents Sea, I 12,236

Barnstable, 1041

Barnstable Bay, waves in, 222

Barrande, J., cited, I 126

Barrell, J., cited, 93, $54 \mathrm{I}, 578,619,633$. $634,635,637,662,709,721,740,74$ -, quoted, 604, 621

Barren lands, 133

Barrows, IV. L., cited, 72, 73, 93

Barus, C., cited, 15, 22, 685

Barysphere, I.

Basal bed, formation of, 731

Basalts, depth of formation or, 15

Bascom, F., cited, 772, 773

Basel, 251

Basin, Alabama-Mississippi, 810

- Alleghany, 810

- Brazilian, ro5

- Illinois, 8 ro

- Iowa, 8 10

- James Bay 810 Michigan, 810,846

New York, 810

North African, 105

North Atlantic, 105

Oklahoma, 810

Ottawa, 8 ro

Paris, 846

Quebec, 8 10

St. Lawrence, 8 io

Wisconsin, 810

Baskunchak Lake, 357

Bassler, R. S., cited, $1089,1095,1$ I 39,1148

Bastei, 53

Batavia, 26

Bath, hot springs of, 201

Bather. F. A., cited, 93

Batholith, 303

Bauer, M., cited, 93, 537

Bauermann, cited, 460

Bavaria, Jurassic reefs of, 437

Bay of Bengal, 240

- temperature of, 187

Bay of Biscay, 112, 219

, dune areas of, 557

-, salinity range of, 152

Bay of Cadiz. temperatures of, 189

Bay of Danzig, salinity of, 151

, delta in, 614

Bay of Fundy, 112, 649

Bay tides of, 226

Bay of Morlaix, peat of, 514

Bay of Naples, mud of, 334

Bay of New York, in Tertiary, 984

Bayou la Fourche, 245

Beach cusps, 706

Beardmore, cited. 248, 265

Bear Island solifluction on, 543, 544

Bear Island stream, 236

Bear River, calcium carhonate in, 468

Beaumont. Elic de. cited, 203

Rèche. sec de la Bèche

Bechilite. ${ }^{36} 4$. cited. 752, 774, 906, 908

Beecher, C. E., cited, 979, 1086

Beede, J. WW., cited, 624, 637

Beekite rings. formation of, 1083,1085

Behrens, J. H., cited, 685 
Behring Sea, 108, 242

Beluring Sea, pole migrating toward, 895

- surface freezing of, 181

Behring shelf, 104

Behring Straits, 242 .

Belfast, South Africa, glacial deposit at, 535

Belgica, 185, I87

Belgium, dunes of, $55^{8}$

- Permic climate of, 375 reefs of, 423

Bell, R., cited, 430,462

Belle Isle, Cambric limestone of, 417

Belt of cementation, 17

Belt of weathering, 17

Belt terrane, 334

age of, $1138,1139,1140$

Cryptozoan of, 417

Belvedere gravels, 595

Bengal Gulf, temperature in, 187

Ben Nevis, 32 wind-blown pebble on, 56

Benthos, defined, 991, 996 , sedentary, 996

- vagrant, 996

Benton clay, 261

Berckhemer, F., cited, 438

Berendt, G., cited, 126, 133, 557

Bergschrund, 264

Berkey, C. 'P., cited, 206, 223, 265, 637, $717,721,903,1140,1148$

Berkey, C. P., and Hyde, J. E., cited, 200

Berlepsch salt sliaft, 757

Bermuda, 390, 397, 41 I

, calcareous dunes of, 573

calcareous sand of, 65

, cementation of sands of, 753

, consolidation of sand of, 750

, eolian rocks of, 293, 439

lime-sand dunes of, 343

Lithothamnion at, 471

peat in, 509

-, reefs, 416

Bermudaite, 573

Bernard, F., cited, 956, 1095

- quoted, 1073

Bertie waterlime, 376

Bertin, cited, 217

Bertrand, C. E., cited, 481, 482, 520

Bessarabia, 443

Bessel, cited,

Beyrich, E., cited, I 108

Biarritz, 103,558

Bigelow, H. B., cited, 520, 685

Biggs, Oregon, 53

Bighorn Basin, Eocenic and Oligocenic deposits of, 627

Big Pine, block movement of, 88 ;

Bigsby, J., cited, I 122

Big Soda 'Lake, analysis of, 361

Billings, E., cited, 9 I5

Bilma oasis, 359

Bimana, 956

Bingerloch, 245

Binnewater sandstone, 731, 823

- Lorraine age of, 823

Bioclasts, 285

Biogenesis, importance of, 1147

Bioliths, 384

Bionomic realms, 982

Biometamorphism, 768

Bioseisma, 881

Biosphere, 1, 16

Bird's Eye limestone (see Lowville), 488 , I 24

Birma shelf, 103

Birsig River, 25 I

Bischof, G., cited, $163,350,614,637,760$
Bitter Lakes of Suez, 366

- - deposits of, 352

- intercalated silt layers of, 697

Bitter Spring Laa, sulphate waters of, 168

Bituminous coal, 510,511

Black Hills, 308

Black dome of, 841, 842, 843

Hills dome, dips in, 808

Black Hills, flanking monoclines of, 844

Black Lake, salinity of, 154

Black Prairies, 839

Black Rock Desert, playa lake in, 603

Black Sea, 107, $115,230,240$

-., black mud at bottom of, 1046

- dwarf fauna of, 1067

- evaporation from, 27

- faunal conditions in, 666,667

muds in, 479

optics of, 204

salinity of, I5

salt and gypsum deposits on borders of, 348

D1, surface freezing of, 18

Black shale, 261

, Devonic, origin of, $636,637,850$

. E., cited, 248, 249, 265

Bladderworts, 495

Blake, abyssal deposits dredged by, 676 dredging of Spirula by the, 102

, dredgings of, oft West Indies, 519

Blake, J. F., cited, 685

Blake, W. P., cited, 637

Blake Plateau, 673

Blanck, E., cited, 578

Blanckenhorn, M., cited, 92

Blastoidea, 949

, naming of, 913

Blättermollasse, 630

Bludenz, weather at, 48

Blue Lick Springs, Upper, composition of 168

Blue Ridge, monoclines of, 798

Blum, J. R., cited, $1081,1083,1085,1086$, $1087,1088,1095$

Blytt, A., cited, 506

Bodländer, G., cited, 657,658

Bogdo Lake, salinity of, 154

Bohemia, 336

Devonic reefs of, 423

, overlap relations of Cambric of, 729

Bohemian Mass, 373

Bokkeveld series, Devonic fossils in, 536

Bolivia, 365,360

Bolson plains, 34

Bolsons, 58

Bon Ami, Cape, gliding in limestones of, 782,783

Bonney, T. C., cited, 462,878

Bombay quod, 400

Boracite, 372

Borax Lake, 363

composition of, $: 58$ salinity of, 154

Bordeaux, natural mummies from, 1076

Boreal climatic period, 506

Bornemann, J. G., cited, $284,417,455,520$

Borneo, 242

Borneo-Java shelf, 104

Bornhardt, W., cited, 58,93

Bornholm, 19 I

Borocalcite, 364

Bosnia, 284

Bosphorus, 240

Boss, 303

Boston, sea-breeze at, 44

Boston Basin, drumlins in, 532

Boston Harbor, drumlins of, 265 
Bosworth, T. O., cited, 93

Botany, 20

Bothnian Gulf, 109, $110,111,241$

, salinity of, 1045

Boué, A., cited, 1144

Bound skerries, 222

Bourbonne-les-Bains, petrified wood of, 1081

Bourguignat, J. R., cited, 1064,1069

Bourne, G. C., cited, 392, 462

- quoted, 392

Bournemouth, 215

Boussingault and Lewy, cited, 38

Boussingaultite, 364

Bowland shales, 432

Bowling Green, Ohio, 167

Brachiopoda, 944

, bathymetric distribution of, 1014

, importance of growth lines of, 911

Bradygenesis, defined, 964

Bradyseisms, 88 ?

Brahmaputra delta, 607, 608

, thickness of, 609

Brahmaputra River, alluvial plain of, 585

Branner, J. C., cited, $32,34,38,93,341$, $380,692,693,695,707,721,761,774$, $884,1092,1095$

- quoted, 33, 342, 693, 694

Bräuhäuser, cited, 634

Brayman shale, 261,823 Salina age of, 823

Upper Ordovicic age of, 823

Brazil, 34t

disintegration of rocks in, 33

- fringing reefs of, 390

hydration of rocks of, 38

lime sands of, 416

rainfall of, 67

, range of temperature in, 32

Brazilian basin, ro5

Breccia, limestone, 432, 433

- limestone tuff of Tyrol, 437

Breccias, endolithic, 536

, intra-formational, 529, 779

, fault, 528 .

Breckenridge, cannel coal of, 48

Breisbach, 250

Bretonian, 1128

Brewer, W. H., cited, 656, $68_{5}$

Bridger beds, volcanic dust in, 572

tuff of, 526

Brighton, force of waves at, 222

Brisbane River, Unio in, 1015

British coast, force of waves on, 221

British Columbia, 305

pre-Cambric reefs of, 418

British Isles, mild temperatures of, 234

British shelf, to3

Brock, R. W., cited, 92

Brocken, hornstone of, 766

Brockmann-Jerosch, H., cited, 92

Brögger, W. C., cited, 302

Brongniart, A., cited, 1099

Brooks, W. K., cited, to 017,1038

Brown, T. C., cited, 530, 537, 762, 785, 826

Brown coal, 510,511

Browne, W. R., cited, 685

- quoted, 663

Brückner, E., cited, 71, 92, 93

Brückner cycle, 71

Brunswick, salt domes of, 758

Bryozoa, 385 bathymetric range of, 1014 growing on corals, 428

Buchanan, J. Y., cited, 215, 265, 679, 685

Buchenstein, 435

Buchensteiner formation, 4.34

Buckley, E. R., quoted, 140

Buckmann, S. S., cited, 957, 976, 979
Buenos Ayres, droughts in, 593

Buffalo, fossil earthquake fissure of, 792

- sandstone dike at, 885

Bugula, growing on Laminaria, 995

Bunsen, R. W., cited, 164

Bungted, 169

Bunter sandstein, 71, 225, 436

-, Ceratodus in, 1034

-, Limulus in, 1029

- - origin of, 634

- Rogensteine of, 472,473

, tracks in, 605

transgression on Zechstein, 565 windkanter of, 5

Burlington formation, fossils in, 732

Burma Nountains, rainfall in, 69

Burma Sea, gog

Butte, tepce, 840

Buttes, 57

Bysmalith, 303, 304

Byssus, attachment of Lucina by, 448

\section{C}

Cabot Straits, 113,235

Cader Idris, lavas of, 315

Caithness, 2 ig

Caithness flags, 651

Caithness Old Red sandstone, Palxospondylus in, 1034

Calabria, earthquake in, 883

, earthquake craterlets in, 886

-, Pliocenic foraminiferal deposits of, 454

- torrential deposits in, 59

Calamites, $375,512,939,1004,1082$

Calcaire de Givet, 431

Calcaire de Waulsort, 432

Calcẩire Grossier, 977

Calciferous, I I 24

Calciferous series of Scotland, oil shales in, 479

Calcification, 1079

Calcutta, borings in alluvial deposits at, 586

Caliche, 365

California, basaltic plateau of, 867

- borax lakes of, 363

- earthquakes of, 882,887

- lava of 315

- - ony $x$ marble of, 344

-, sandstone dike of, 88

, valley of, alluvial fans in, 584

Calted, 578

Callao, tripolite near, 460

Callunetum, 503

Calms, equatorial, 43, 67

Calumet and Hecla mine, 14

Calvin, S., cited, 1095

Cambrian, origin of name, 1112

Cambric, brcaks in, 729

Cambric salt deposits, 371

Camiguin volcano, 863

Camillus shales, 376,378

Campanularia, growing on Laminaria, 995

Campbell, M. R., cited, 363, 380, 1131,1149

Campeche bank, 104, 335

Campeche shelf, I0

Campo Bianco pumice-cone, 863

Campos, 68

Canada, old land of, 834

unconformity in Siluric of, 826

Canadian shield, 311

Canary Islands, $244,335,33^{6}$

Canary Islands, dust falis of, 60

- passages between, 680

_ pteropod ooze west of the, 456 
Candolle, C. de, cited, 721

Caney shale, 262

Cannel coal, analyses of, $48 \mathrm{I}$

-

- Carbonic, 479

, organic remains in, 481

- , origin of, 482

Canu, F., cited, II 48

Cape Ann, boulders on, 226

Bojador, dunes on, 558

Breton, Etcheminian at," 729

Canaveral, 234

Cod, 234

$\longrightarrow$, apron plains of, 54,598 difference of faunas on north and south side of, I I 25

- dunes of, 551,559

- - lignite in dunes of, 565

..-, moraine of, 265

- old marshes on, 491

- - sand plains of, 600

strand dunes on, 557

wave work on, 223

-, wind kanter from, 573

Colony, 238

Comorille of, 535

Comorin, 456

Farewell, 234

Finister re, 187

Gata, 152

Hatteras, 226, 652

Hurd, 838

Leeuwin, 239

of Good Hope, 214,238

Palmas, 235

Pedaran, 242

Reykyanaes, 865

St. Roque, 233

'Skagen, 103

Teneriffe, ro 8

-, dredging off, 1024

trough, temperatures in, 187

Verde, dunes on, 558

York, 387 slands, 152, 235

Capps, S. R., cited, 544,578

Carbonation, $17,30,38$

Carbon dioxide, 24, 29 climate affected by, 30 sources of, 25

Carbonization, 25

Carcharadon, teeth of, 684

Caribbean Sea, 107, 239

-. Spirula from, roz

Carinata-quader sandstone, absent near Dresden, 681

Carlsbad Sprudel, 203

- composition of waters of, 168

origin of algous limestone of, 476

pisoliths of, 284,336

- travertine deposits of, 475

Carnallite, $368,37 \mathrm{I}, 372$

Carney, F., cited, 265

Caroline Archipelago, 389, 390, 40 I

Cerpentaria, 394

Carse lands, peat of, 514

Carson River, tufa in, 340

Carter, J. H., cited, 575, 579

Casa Colorado, 57

Casco Bay, relict fauna of, 89

Caspian Sea, $108,356,365,897$

, composition of, 157,159

dwarf fauna of 1067

elevation of, II 5

salinity of, 155,159

Cassian formation, $434,435,437$
Cataclastic, 746

Catinga limestone, 341
Catskill formation, 635

alternation in colors of beds in, $62 y$, 624

overlap relations of, 742

progressive replacement in, 743

red beds of, 636

- variation in thickness of, 683

Caucasus, mud volcanoes in, 872

Cauda-galli, I 124

Caustobioliths, 280,384

- classification of, 486,487

Caustophytoliths, $280,467,478$

Cave Creek, onyx marble of, 344

Caverns, aphotic region of, 983

Cavonne River, delta of, 608

Cayeux, L., cited, $336,380,514,670,671$, 673,685

Cedarburg, fossil reefs of, 419

Celebes, 392

Sea, I07

-

Cementation, 75 1,753 belt of, 747

- substances causing, 754

Cenomanien, 730 , 1112

Center of the earth, density of, 15

C. fusion of rocks at, 15

Centrosphere, 1, 13

Centrum, 883

Cephalochorda, 950

Cephalonia, Sea Mills of, 257

Cephalopoda, naming of, 9 1 3

Ceratopyge limestone, 53

Cesena, wood replaced by sulphur at, 1081

Cette, 348

Cévennes, 133

, winds from, 50

Ceylon, 390

Chagos group, 388, 389, 390, 392, 393, 399

C. nullipores of, $47 \mathrm{I}$

Chaleur, Bay of, roy I

Chalk, chemical precipitation of, 336 Radiolaria of, 1082

Challenger Bank, nullipores on, 471

Challenger, the, 334,410

-, annelids dredged by the, 1024

Anthozoa dredged by the, 1012

blue mud dredged by the, 668

Cirripedia dredged by the, 1026 glauconite dredged by the, 671,672 Ostracods dredged by the, 1026

Plumularians obtained by the, IoII

Radiolaria dredged by the, 1008 Spirula dredged by the, 1021

Challenger Expedition, 147, 184, 45 I, 452, 454

Challenger Exploration, in Marian deep, 457

Challenger narrative, cited, 469

Chama, in Bermudaite, 573

Chamæliths, 281

Chamberlin, R. T., cited, 903, 904, 905, 908

Chamberlin, T. C., cited, 29, 93, 107,265 , $327,418,420,462,990,1038,1148$

, quoted 876,1142

Chamberlin, T. C., and Salisbury, R. D. cited, $2,4,22,59,93,148,206,263$. $265,278,294,297,298,325,326,327$ $579,634,637,675,679,861,878,908$ II $45, \quad$ I 146,1148

II qu, I1 46, 698

Chamisso, A, von, cited, 399, 410

Champlain clays, concretions in, $76_{3}$

Chapeiros, 396

Chapman, F., cited, 575

Cliara, 426, $471,475,495,935$, 1001 analyses of, 478

marls, 494 


\section{INDEX}

Charleston, 234

earthquake craterlets at, 885 sandstone, I 3 I

Charybdis, maelstrom at, 230

Chatard, cited, 362

Chattanooga shale, 823

complex nature of, 549

hiatus indicated in, 1130

origin of, 479,514

Cheirotherium, tracks in Bunter Sandstein, 605

\section{Chelonians, 953}

Chelsea, England, 28

Chemaklia, earthquake at, 885

Chemical (actinic) rays, 28

Chemnitzia, 436

Cliemung, overlap relations of, 742

- progressive overlap of, 744

, Progressive overlap of

variation in thickness of, 683

Cherbourg, 22 I

Cherry county, Nebraska, dune-enclosed lakes in, 562

Chesil Bank, force of waves on, 222

Chile, 369

-

-, earthquake in, 888

_- natural mummies from, 1076

nitrate deposits of, 364

origin of nitrates of 370

Chiltern Ifills, chalk cuesta of, 839

China, loess of, 565

$$
\text { Sea, 237, 240, 242, } 392
$$

atolls and fringing reefs of, 390

Chin-kiang, dust storm at, 59

Chirotype, defined, 919

Chitin, composition of, 1078

Chlorides, 177

Chlorinization, 768

Cholnoky, E. de, cited, 92

Chonolith, 304, 305, 307, 309

Chonos Archipelago, peat in, 509

Chotila Hill, miliolite limestone on, 575

Chouteau limestone, 732

Christmas Island, 393

. radiolarian ooze around, 458

Chronobios, 922

Chronofauna, 922,1043

Chuar series, age of, I140

Chun, C., cited, 460, 999, 1038, 1069

Chunnenugga Ridge, 839

Cluquicamata, natural mummy at, 1077

Cidaroidea, 950

Cincinnati, artesian well at, 168

Cincinnati dome, 808

Circulus, 978

Civitavecchia, 221

Clamshell cave, basaltic jointing of, 318

Clapp, F. C., cited, 143, 600

Clark, W. B., cited, 672, 686, 979

Clarke, F. W., cited, 39, 93, 157, 168, 206. $348,362,363,364,365,369,380,468$, $570,579,614,637,657,671,678$

$169,173,468,668,670,671,677$

Clarke, J. M., cited, 456, 462, 479, 520, 667 $686,1038,1069,1070,1113,1119,1134$, 1148

quoted, 1023, 1123, 1127

Clarke, J. M., and Ruedemann, R., cited, 1030,1038

Clarke Range, 334

Clastation, 17

Clay-galls, 564, 711

Clay iron stones, 719

Claypole, E. W., cited, 903, 908

Cleavage, 769

Clement, J. M., cited, 317, 320
Cleveland shales, tissue of sharks in, 1080

Climate, desert, 77

$\longrightarrow$, interior, 7

, littoral, 75

mountain, 77

oceanic, 75

physical, 74,75

- solar, 74

Climatic belts, 74

provinces, 77

types, 78

zones, Mesozoic, 8 a

Neuniayr's Jurassic, 79

, past, 78

Clino-unconformity, 82

Clinton formation, ballstone reefs of, 446

- iron ore, dyarf fauna of, 1045, 1068 C, origin of, 762

Clinunconformity, 821,824

Cl:one, borings of, 1092

Clitheroe district, carbonic limestones of, 449

C., limestone, 432

Closs, H., cited, 93

Clouds, cirrus, 63

-

, nimbus, 63

stratus, 63

Coal, oxidation of, 37

Coal measure limestones, intraformational breccia in, 530

Coastal plain, 830

- - New York Palicozoic, 834

Cobalt, Huronian tillite from, 534

Cobequid Bay, tides in, 227

Coblenz, 245

Cobleskill limestone, continuity of, 1132

Coccolitlis, $453,454,456,933$

- in Severn muds, 664

Cócliabamba, 365

Cochin China, 242

Cocos Islands, gradual emergence of, 895

- radiolarian ooze around, 458

Cocos-Keeling atoll, 388, 389, 390

Codden Hill beds, 459

Cohn, F., cited, 476,520

Coire Bog, peat in, 505

Cole, G. A. J., and Crook, T., cited, 686

Cole, G. A. J., and Gregory, J. W., cited, $315,316,320$

Colenan, A. P., cited, 81, 92, 93, 534, 537

Colemanite, 364

Colima, dust from, 60

Collet, L. W., cited, 686

Collet, L. W.: and Lee, G. W., eited. 686

Colob formation, dune origin of, $57 \mathrm{r}$

Cologne, brown-coal north of, 513

Colorado, $2 Q^{1}$

, Cretacic dwarf fauna of, 1069

- Palreozoic sandstones of, 310

delta, deposits of lime in, 610

desert, 70

desert, dunes of, 562

River, delta, 6:9

Springs, eolian crosstbedding near, 705

Columbia River, dune area of, 561

Columbian gravels, cementation of, 754

Columbus limestone, $42^{24}$

Commentry basin, coal deposit's of, 518

Cono beds, colors of, 624

Comoro Isles, 388

Concepcion, earthquake waves from, 890 Harbor, earthquake in, 888

Conchiolin, 1078

Concretions, 718,763

Condore Islands, $24^{2}$

Conduction, 30 
Coney Island, sea-breeze at, 45

Confervales, 935

Conformable strata, 826

Congelation, 31,751 .

Conglomerate, edgewise, $530,784,785$

Congo River, 235,248

Congress Spring, chloride waters of, 168

Conidx, poison fangs of, 1020

Conifers, 37.5

Conn, H. W., cited, I 038

Conneautsville, well at, 168

Connecticut River, 131

- Valley, concretions in post-glacial

- - clays of, 719

Conocoryphidæ, as index fossil, II 34

Conodonts, 947, $95 \mathrm{I}$

Conoplains, 830,856

Conrad, T., cited, 915, 1123

Constantinople, 240

Contacts, fault, 309 igneous, 309

-., sedimentary, 309

Continental block, 7, Ioo

- deposits, $70,71,734$ platform, 8

slope, 7

Convection currents, 30, 31

Convergence 979

Conybeare, W., cited, 1108

Coode, Sir J., cited, 222, 266

Cook Inlet, I I

Coon Butte, 861

Cooper Creek, dry delta of, 584

Copal, 5 I 8

Cope, E. D., 964, 1040

Coquina, 260

Coral basin, temperature in, 187

Coralline Crag, faunas of, 89

Corallines, 476

Coral Sea, 108

Corals, growth lines on, 911

- naming of, 913

Cordonan, lighthouse of, 223

Corndon, 307

Corniferous limestone (see Onondaga), 424, I 124

Cornish, V., cited, 215, 265, 286

Corrasion, eolian, 18

- glacial, 18

$\longrightarrow$, river, 18

Corrowd, 51,52

Corrosion, 18

Corsica, 275

Coseguina, volcanic ash from, 60

Cotentin, peat at, 514

Cotidal lines, 228

Cotopaxi, dust from, 60

Cotswold Hills, oölite cuesta of, 839

Cotype, defined, 919

Couvin, Devonic reef near, 431

Covesea, 256

Crabs, production of alkalinity by, 331

Cragin, F. W., cited, 521

-, quoted, 469

Craigellachie, 255

Cramer, F., cited, 753, 774

Crammer, H., cited, 6o1, 602, 637

Crater Lake, "I 20

C., depth of, 116

Craven district, 43

Credner, G. R., cited, 609, 613, 618,637

Credner, H., cited, $317,320,537$

-

Credner, R., cited, 1063, 1064,1070

Credneria beds, absent in vicinity of Dres. den, 681
Creep, 541

"Creeping Joe" dune, 560

Crenic acid, 173

Creodontia, 955

Cretacic clays, pyrite concretions in, 764

Crete, 240, 334

Crinoidea, 421,949

C. naming of, 913

Crivelli, B., cited, I 45

Croatia, lakes of, 125

Crocodiles, marine habitat of, 985

Cromdale, 252

Crosby, W. O., cited, $4,13,15,16,22,38$ $93,143,264,265,266,287,288,298$ $310,315,320,412,462,533,537,600$, $638,726,744,790,821,826,848,857$ quoted, $36,532,621$

Crosby, W. O., and Ballard, H., cited, 265 266

Crosby, W. O., and Crosby, F., cited, 257, 266

Cross, "W., cited, $5 \dot{8}, 82,93,638$

$\longrightarrow$ quoted, 627

Cross, W., Iddings, J. P., Pirsson, L. V. and Washington, $\dot{H}$. S., cited, 273,277 298

Cross-bedding, delta type, 701

, eolian, 702, 703

, in Devonic limestone of Michigan, 429

torrential, 701

ross Fell, peat covering, 504

Croton reservoir, salinity of, 155

Crozet Islands, 40

Crustacea, destruction of limestone by, $4 \mathrm{I}$

Crustal block, lowering and elevation of 1141

C, thickness of, 905

Crustal blocks, 4

Cruzy, sulphate waters of, 168

Cryohydrate, I94

Cuba, 233

Cuesta, 832, 836

Cuestas, Devonic, 838

Mesozoic, 838

Palæozoic, 838

Culbin, dunes of, 256

Cullis, G., cited, 445,462

Culm, cherts from, 459

Culmination circle, 894

Cumings, E. R., cited, 973, 979

Current ripples, 712

Currents, Agulhas Stream, 238

Benguelan, 235, 1050

Brazil, 233, 235, 1050

Cabot, 235

California, 237, 239

Canary, 235, 1050

Cape Horn, 235

East Australian, 237

East Greenland, 234

Equatorial counter, 235, 237, 238

Falkland, 235

Florida, 235

Guiana, 233

Guinea, 235

Irminger, 234

Kuroshiwo drift, 237, 242, 1049

Labrador, 234, 237

Mozambique, 238

North Cape, 236

North Equatorial, 233, 235, 237, 1050

North Pacific west-wind drift, 237

Peruvian, 238, 460, 1050

South equatorial, 233, 237, 238, 1050

South Pacific west-wind drift, 238

West Australian, 239

West Greenland, 237 


\section{INDEX}

Cutch, Miliolite of, 575

Cuttle-fish, 946

Cuvier, G., cited, 1099

Cuxhaven, 229

Cvijic, J., cited, 133, 143

Cyatholiths, 457,933

Cycle of erosion, $137,829,849$

Cyclones, 46

Cypress, 513

Cypris, in playa lakes, 603

Cyprus Island, 153

Cystoidea, 949

$\longrightarrow$, naming of, 913

\section{D}

Dacqué, E., cited, 1145, 1148

D. quoted, I 144

Dadoxylon wood, 941

Dxmonelix, 1091, 1092

Dagö Island, cuesta of, 838

Dakota sandstone, $71,260,642$

- - compound overlap of, 739

Dale, T. Non-marine, 101

Dall, W. H., cited, 92, 1038, 1070 quoted, 1048

Dallas, dunes at, 561

Dalmatia, 240

Dalmatian coast, Karst region of, 882

Daly, R. A., cited, 302, 303, 304, 305, 307, $309,320,331,333,334,338,380,719$, $721,764,774$

, quoted, 333,334

Dana, J. D., cited, 16, 38, 143, 314, 320, $336,380,391,406,408,409,462,520$, $537,761,774,799,878,900,902,908$, $1038,1055,1103,1106,1119,1144$ , quoted, 315, 396, 409, 414, 481, 699. $720,890,1007,1012$

Danish coast, dunes of, 558

Danube, 248, 251, 587 delta, 608 rate of growth of, 609 velocity of, 245

Danzig Bay, temperatures in, 190

Daphnia, in playa lakes, 603

Darcy, cited, 257

Dardanelles, 240

Darwin, C., cited, $335,336,380,386,397$ $398,404,408,413,462,509,520,544$, $579,638,693,694,695,908,1015$, $1018,1026,1038,1055,1070$

quoted, 360, 398, 399, 415, 416, 593, 594,888

Darwin, G. H., cited, 91, 92, 94, 579, 712 , $713,721,897$

Darya, salinas of, 358

Daubrée, A., cited, 226, 266, 294, 295, 298, $686,789,790,826,906,907,1081$

Davenport, C. B., cited, $1038,1042,1070$

- quoted, 1019

David, T. W. E., cited, 81, 94, 393, 462, 535,538

David Island, 397

Davidson, T., cited, 1038

Davis, C. A., cited, 47 I, 49 I, 495, 496, 498, $500,502,516$

quoted $490,491,492$

Davis, W. M., cited, $22,40,43,54,94$ I 6 , I 20, $121,124,126,128,133,134$. 137, 143, 212, $217,218,220,228,266$, $356,409,410,462,487,520,535,538$, $573,579,626,638,816,826,839,842$, $845,852,854,857,858$
Davis, W. M., quoted, 90, 215, 229, 410, $535,536,566,584,585,588,589,839$, $852,853,854,885$

Davison, C., cited, 693, 695, 908

Davis Straits, 186, 234, 237

Dawson, Sir W., cited, 515, 520, 621, 638

Daylighoted, 515, 516,622

diffusion of, 28

Dead Sea, 897

- composition of, 157,159

- coral from, 1013

$\longrightarrow$ elevation of, 115

- leached salt of, 367 salinity of, 154, 159

Dead wood Gulch, 308

Dean, B., cited, 950, 1095

- quoted, 1080

Death Valley, Cal., 27 , soda niter deposits of, 364

- desert, 364

De Candolle, A., cited, $5^{6}$

Decapods, range of, 948

Decarbonation, 39

Deccan Plateau, Cretacic trap forming, 868

Decewville beds, 424

Decomposition, 17

Deep, Nero, to6

, Tuscarora, 106

Deep sea platform, 8

Deflation, $17,51,52,55$

Deformation, endogenetic, 776,777 endolithic, 757 exogenetic, 776

De Groot, H., cited, 363,380

Dehnã Desert, dune area of, 562

Dehydration, 38

De la Beche, Sir Henry T., cited, 269, 299 $576,577,578,865,878$

- quoted, 864

De Lapparent, A., cited, 203, I068, 1070 $1145,1146,1149$ quoted, 6

De Laumy, cited, 203

Delaware Bay, drowned, 832

- River, tides in, 227

Delesse, A., cited, 219, 266, 686

Delta beds, 612

Deltas, coal in fossil, $74 \mathrm{I}$

Delthyris shale, 1124

Demorphism, belt of, 34

Dendrites, 791

Denmark, Chara in lakes of, 471

- coastal erosion of, 224 Straits, 109

- ridge, 188,192

Density of the earth, 12, 15

Denudation, 17

Deposition, 17, 19

Depressed oceanic region, 8

Depth of compensation. 10

Derby, O. A., cited, 38

Desalinification, 748,763 .

De Saussure, H. B., cited, 72

Desert, Hamada, 57

—-, stony, Gobi, material brought from, 566 varnish, 27,57

Deserts, eolian ripplc marks in, 714

Desmids, 935

Deuterogenous, 269

De Vries, H., cited, 962, 963, 979

Dew, 26, 62

D'Halloy, O.. cited, 1108

Diabase, defined, 278

Diadematoidea, $95^{\circ}$

Diagenesis, 748

Diagenetic processes, 750 
Diagenism of cinder cones, 863

Diastrophism, 12, 16

Diatomaceous ooze, salt content of, 367

Diatom ooze, analysis of, 677

Diatoms, 983

Dicotyledons, 941

Diego Garcia, 388, 392, 393

Diener, C., cited, 682

Diener, C., and Arthaber, G., cited, 435, 462

Dietrich, cited, 397

Dikes, clay, 564

- composite, 304 multiple, 304

- , sandstone, 791

Diller, J. S., cited, 72, 299, 885, 908

Dinosauria, 954, 1037

Dippersdorf, 246

Disceras limestone, 438

Discolith, 457, 933

Disconformity, 821, 822, 823, 826

Discordanz, 821, 824

Disintegration, 17

Disko Island, post-glacial deposits of, 87

Dismal Swamp, 120, 500

Distillery quarry, 419

Dittmar, W., cited, 147, 148, 194

Dixon, E. E. L., and Vaughan, A., cited, $459,460,462$

Dnieper River, dunes along, 560

Dodge, R. E., cited, 131, 143

Dogger Bank, 104, 191, 218, 230

Dogger, 459

Dog's Bay, Foraminifera in, 576

Doldrums, 67

Dolerite, 278

of Bombay, 39 of South Staffordshire, 39

Dolgeville, 243

Dolinas, 857

Dolomitization, 761

Domes:

- Adirondack, 810

Black Hills, $841,842,843$

Cincinnati, 810,843

Nashville, 810,843

North Ontario, 810

Ontario, 810

Ozark, 8 10

- Wisconsin, 810

Donetz Valley, dunes in, 56

Donney Lake, 361

D'Ooust, Virlet, cited, 336

D’Orbigny, A., cited, 964, 979, 1088, 1095

$\longrightarrow$, quoted, 1074

Dorpat, 27

Dorset, 838

Dover, 228

Straits, 234

-

Drasche, $\dot{R}$. von, cited, 462

Dreikanter, 54

Treikanter, in basal Cambric of Sweden, 728

Dresden, 651

Dresser, J. A., cited, 92

Drift, englacial, 265

$$
\text { , subglacial, } 265
$$

-, supergiacial, 265

Drigg, fulgurites of, 73

Drumlins, material of Boston, 532

Drummond Island, corals of, 420

Ducie Island, 390

Dufour, L. cited, 196, 206

Dundee limestone, 424,648

Dundelbach, delta of the, 610, 613

Dune deposits, reworked by encroaching sea, 736

Dune Park, height of dunes in, 559
Dunes, slopes of, 563,703

Dunker, G., cited, 915,916

Dunnet Head, Lighthouse of, 210

Dupont, E., cited, $431,462,463$

Durance, Mont Genèvre, 3 I 6

Durham, Magnesian limestone series of, 341

Durham, W., cited, 686

Durness limestone, gaps in, 684

Dust falls, volume of, 60

Dust fogs, 61

Dtorms, 28

Dutton, C. E., cited, 314, 320, 868, 869, 878,908

-. quoted, 869

Dwyka conglomerate, $82,535,536$.

Dybowski, W., cited, 1064,1070

Dysodil, 479

Dysphotic region, 982

E

Earawalla, Isthmus of, foraminiferal deposit of, 576

Earth glacier, 34

Earth's axis, displacement of, go

Earth's crust, characters of, 12

-, defined, 10

$\longrightarrow$, deformation of, 12

materials of 12

specific gravity, 12

thickness of, 10, 11, 12

Earth's intcrior, condition of, 16

$\longrightarrow$, temperature of, 13, 14, 15

East Abyssinian mountains, 355

East China Sea, I o

Easter Ross, peat of, 505

East Greenland, post-glacial fauna of, 88

- Mediterranean, salinity of, 15

- - sea, 109

stream, temperature of, 192

tham, sand plains of, 600

slet, 392

Eaton, Amos, cited, 1122

Ebro River, delta of, 608

Ecca formation, coals of, 536

Eccles, J., cited, 72

Echinodermata, 949

Echinoderms, destruction of limestone by, 415

Echinoidea, naming of, 913

Echinoids, burrows in limestone made by, 1092

Ecuador, earthquake fissures in, $88_{3}$

- position of oscillation poles in, 893

Edentata, 955

Eel grasses, 98

Egleston, T., cited, 54, 94

Egmont Island, 399

Egypt, 369

- alkaline lakes of, 361

- Foraminifera in eastern desert of, 576 , soda lakes of, 362

Ehlers, cited, 1024

Ehrenberg, C. G., cited, 384, 455, 686

Eifel, crinoidal limestone of the, 431

, Maare region of the, 860

reefs of the, $423,430,431$

Tertiary volcanoes of the 874

Eimer, T., cited, 963, 964, 977, 979

Einkanter, 54

Eisenach, 434

Ekman, F. L., cited, 191

Elbe River, 225, 220

Fibrine areas of, 557

Elbriz Lake, 120

Eld cleft, lava from, 866 
Eldgjá, length of, 866

Elgin, Triassic reptiles from, 953

Elgin sandstone, dune origin of, 571

Ellis Island group, 388, 389, 393, 394, 401

El Late Mountains, 308

Elm, Switzerland, rock fall at, 546, 66 I

Elton Lake, 357

$$
\text { composition of, } 157
$$

salinity of, 154,156

Ely River, 662

Embryonic periods, 971

Emerson, B. K., cited, 313, 320

Emmons, E., cited, 1123

Ems delta, 607

Encrinal limestone, continuity of, 684,1131

Encyclopædia Britannica, cited, 24, 348

Endell, K., cited, 463

Endolithic brecciation, 777

Endosmosis, 180

England, Carbonic oölites of, 472 - Jurassic oölites of, 472 origin of chalk of, 850

- transgressing Cretacic of, 730

English Channel, I $12,218,219,234$ tides in, 228

Enterolithic structure, $527,758,778$

Eolation, 51

Eolian cross-bedding, tangency of layers in, 704

Eolian deposits, size of grains of, 56,553

Eophyton sandstone, windkanter from, 573

Epeirogenic movements, 12

Epembryonic periods, 971

Ephebastic, 971

Ephebic stage, 972

Epicenter, 883

Epicontinental sea, provincial fauna of, 984

Epidote, 177

Epiphytes, 1002

Epiplankton, 994

Equatorial currents, 390

Erdmann, E., cited, 372, 373, 380

Erongo, 692

Erosion, 17

Erosion cycle, 137, 829, 849

Eruptions, explosive, 860

, extravasative, 860,865

Erzgebirge, 375

Escambia, 295

Eschscholtz Bay, tundra at, 508

Eskers, 133,257

Esmeralda county, Nev., 363

Esopus grit, 635

Estheria, in playa lakes, 603

Esthonia, 838

Etcheminian, 1128

- thickness of, 729

Etheridge, R., cited, 1144

Etna, volcanic gases from, 203

Eureka black shale, 732

Euryhalinity, 1045

Eurypterida, $377,425,948,950$

- habitat of, $989,1020,1030$

Eurythermal organisms, 8o

Eustatic movements, negative, 3, 4 .

Eutraphent

Evans, J. W., cited, 574, 577, 579

Evaporation, 27

Everding, H., cited, 757, 774

Everglades, 126, 404, 406, 407

Ewing, A. L., cited, 94, 175, 206

Exaration, 17,263

Excretions, 719,720

Exfoliation, concentric, 33

Exomorphic, 765

Exosmosis, 180

\section{$\mathbf{F}$}

Faira Island, 218

Fairchild, IH. L., cited, 126, 127, 137, 143, $264,266,297,299,652,686,707,708$, $721,861,878$

Falb, R., cited, 908

Falkland Islands, glacial deposits of, 82 peat in, 509

Fall, "stone rivers" of. 544

Falls of the Ohio, corals of, 420 reefs of, 426

Farafrah, clalk from, 454

Farlow, W. G., cited, 979

- , quoted, 959,960

Faroe-lccland ridge, 110,188

Faroe Islands, 192, 218, 234

- Tertiary basaltic flows in, 867

Farrington, O. C., cited, 1088, 1095

Fault breccias, 29

Fault scarps, submarine, 890

Favosites, worn heads of, 428

Faxon, W., cited, 1059

Fedden, F. cited, 574, 579

Feldspar, clouding of 33

Fenner, $\mathrm{C}$. $\mathrm{N}$. cited, 312,320

Fermor, L., cited, 94

Ferns, 375, 941

Ferrara, height of channel of Po in, 617

Fetlar, 72

Fife, lava flows of, 313

Fiji basin, temperature in, 187

Islands, 388,4 I 1

- - nullipores on, 471

- - pteropod ooze around, 456

-, raised reers of, 436

- reefs of, 393

Fillmore, gypsum deposit at, 359

Finckb, $A$. E., cited, 394, 463, 471, 520

Fingal's Cave, columnar structure of, 318

- Tertiary basaltic flows forming, 867

Finger Lakes, 123, 127

Finistère, peat deposits of, $5^{\mathrm{I}} 4$

Finland, eskers in, 599

undecomposed granite of, 40

Finlay, G. I., cited, 300

Finnish Gulf, 109, 110, 111

Fire clay, 517

Firn, 279

Fischer, P., cited, 603, 1019, 1038

Fissility, 769,794

Fissures, gases active in, 767

Fissures, solution, 857

Flachsee, 987

Flamborough head, 224

Flammarion, C., cited. 28

Flanders, dunes of, 557

Fleming, J. A., cited, 721

Flints, 764

Flocculation, $654,655,656$

Flores Sea, 186,242

Florida, 233. 405, 411

- cypress swanips of, 500

deposits in lagoons of $4^{2} 4$

fringing reefs of 380,390

muds in lagoons of, 479

peat in cypress swamps of, 509

ripple marks off coast of, 219

sands of, 220,295

Straits, 233, 244

Florida-Texas shelf, 103

Florissant lake, heds of, 291 uud cracks in, 710

volcanic ashes of, 524

volcanic dust in. 572

Flower, Sir William, cited, 989

Flying fish, 988 
Focus, earthquake, $88_{3}$

Foehn, explanation of, 49

Foerste, A. E., cited, 843,858

Fogs, 63

Fol and Sarasin, cited, '205

Folds section of Appalachian, 844

Foraminifera, 942, 1007

Forbes, E., cited, $248,266,686,1070,1125$

Forchhammer, G., cited, 147, 194, 206, 559, $579,686,703,721$

Foredeep, defined, 800

Forel, F. A., cited, 170, 196, 197, 198, 204, 205, 206, 244, 266, 721

Fore-set beds, 702

Forestian, Lower, 506

Fore, Upper, 506

Forest marble, cross-bedding in, 704

Formaldehyde, 24

Forres, 413

Fort Jefferson, 391

Fossa Magna, 882

Fosters Flats, 246

Foureau, F., cited, 604, 638

Fowey Rocks, 406

Fowler G. H., cited, 992

Fox, H, and 'Teall, J. J., cited, 316, 320

Fraas, E., cited, 442, 634, 635, 638

Fraas, O., cited, 456, 463, 7 II, 72 I

Fractoconformity 826

Fracture, zone of, 8 i 9

Fram, $15 \mathrm{I}$

Frank, Canada, rock fall in, 546

Franken, Solnhofen reefs at, 438 , subaquatic gliding at, 782 dolomite, 438, 440

Frankenwald, 375

Frantzen, T., cited, 455,521

Franzensbad, volcanic hill near, 874

Franz Josef fjord, post-glacial fauna of, 88

Franz Josef Land, 236

-, post-glacial fauna of, 88

Frasnien reef. $43 \mathrm{I}$

Frauenthal, stylolites at, 786

Frech, F., cited, 94, 431, 463, 1146,1148

Fredericksburg formation, Dakota sandstone on, 739

Free, E. E, cited, 55, 56, 57, 60, 94, 579

Freeman, W. B., and Bolster, R. H., cited, 356,380

Free-stone, 752

Fresenius, K., cited, 346

Friendly Islands, 386

Friesian Islands, dunes of, 557

Frische Haff, I26

- strand dunes of, 557

Nehrung, dunes of, 559

Fritsch, K. von, cited, 60, 94, 537

Fritting, 766

Frontenac axis, 810

Front Range, Appalachian, 844

- - Rocky Mountain, 260 in, 726

hog-backs of, 841

- - monoclines facing, 798, 844

Frost, 26, 62, 63

torrential deposits of,
591

Fuchs, T., cited, $463,684,1038$, 1 068 , 1070

Fïchsel, cited, 1099

Fucoids, 936

Fulgurites, 72

Fuller, M. L., cited, 5, 22, 142, 143, 257,

Fumarolic action, 768
Funafuti, 388, 426

- atoll, 389, 393, 394, 409, 412, 413, 4 I 5

depth of lagoon of, 393

diagenism in, $76 \mathrm{I}$

Fungi, 933, 937, 1002,1003

Fusulina limestone, 453

Fusulina limestones, asphaltic material in, 485

\section{G}

Gagas River, jet deposits of, 483

Gagatite, 482

Gaisa series, glacial deposits on, 534

Galapagos Islands, 237, 239

Galicia, 443

-., Oligocenic shales of, 485

Galveston, range of tide at, 230

Ganges, 1 27,248

- C, alluvial plain of, 585

- delta, 607

- _ l lignitized wood in, 614

- - overlap in, 74I

- - - remains of river animals in, 615 - thickness of, 609

flood plain, 589

system, hydrographic basin of, 247

Ganoids, sediment of, 247

Gardiner, 951 , 1034

J. S., cited, $463,471,520$

Gardon River, dunes in valley of, 560

Garonne River, 223, 558

Gaspé limestones, enterolithic structure in, 782

- sandstone, Bothryolepis from, 1034

Gavb, dry delta deposit, 635

Gault, 730

-, overlapping of the, 850

Gauss, 185

Gautier, A., cited, 24, 206

- , quoted, 203

Gaylussite, 362

Gaysum Island, calcareous eolian deposits on, 577

Gazelle, observations on the, 204

Gebbing, J., cited, 687

Geer, G. de, cited, 92

Geic acid, I 73

Geikie, A., cited, 175, 206, 266, 304, 318, $320,537,774,796,873,875,878$, I I19, I 148

-, quoted, $219,315,698,770,864,872$, 1074, I105, I106, I1 125

Geikie, J., cited, 505, 506

Gekröse, 757

Gekrösekalk, 759, 785

Gemmellaro, G., cited, II 45

Genepistasis, 964

Generation, alternation of, 938

Genesee glacial lakes, 126 River, 137, 837 shale, origin of, 479

- Protosalvinia in, 718

- Valley, Portage sandstone in, 569

Geneva, foehn of, 47

Genoholotype, 920

Genolectotype, 920

Genosyntype, 920

Genotype, selection of, 920

- - elimination method, 920, 921

Geo-biotic realm, 98 
Geologic genera, 978

Geological time scale, 22

Geology, defined, 19

- subdivided, 20

Georgia Straits, 118

Georgian Bay, 836,837

Geosyncline, 799

-, proposed by Dana, 900

Gephyrean worms, destruetion of corals by, 415

Gerbing, J., cited, 763, 774

Germersheim, 251

Gerontastic, 973

Gerontic stage, defined, 972

Ghadames, 26 .

Giants' Causeway, columnar. structure of, $3 \times 8$

Gibbsite, 177

Gibraltar, limestone breccias of, 547

Straits of, 240

Gilbert, G. K., cited, $119,143,380,705$ $706,707,709,721,861,878,908$

- , quoted, 705, 706, 712, 713, 882,4 463,840 and others, cited, 908

- Islands, 389

Gironde River, 223, 231

Girvan district, oölites of, 471

Girvanella, 283, 474

Givétien, 431

Gjâs, 866

Glabella, 947

Glacial grooves, 264

periods, 30

Glaciation, Cambric, $8 \mathrm{r}$

- Lower Huronian, 81

Permo-Carbonic, 82

Pleistocenic, 80,8

pre-Cambric, 81

Glaciers, ablation of, 642

- alpine, 324

cliff, 324

continental, 325

piedmont, 324

plateau, 325

ravine, 324

valley, 324

Glauberite, 363

Glauconite, $330,45 \mathrm{I}$

Glen Roy, "Parallel Roads" of, 125

Glinka, K., cited, 687

Globigerina ooze, $450-453,675$

- , analysis of, 677

Glossopteris, 481,967

Glyptogenesis, 16, 829, 1147

Glyptoliths, 572

Gneiss, 279, 77

restriction of term, 770

Gneissoid structure, defined, 795

Goat Island, fossiliferous gravels of, 89

Gobi desert, strength of wind in, 56

Goebel, quoted, 357

Goethe, cited, 874

Goldspie, 650

Golfe di Taranto, 113, 608

Golfe du Lion, 113

Gollachy Mill, Old Red conglomerate of, 716

Gondwana formation, reptiles of, 953

- land, 82

Goniatites, 978

Goodchild, J. G., cited, 253, 266

Goodenough Lake, coinposition of, 157,158

$7-$, salinity of, 154

Göppert, cited, 1081
Gorjanovic-Kramberger, K., cited, 92

Gorteen Bay, 576

Cössendorf, 246

(iotan, S., cited, 79, 94

Gotland, $420,421,838$

reefs of, 418,427

Siluric oölites of, 472

Gotthard road, 368

(G̈̈tzinger, G., cited, 543, 579

(;our, 53

Gower, limestones of, 459

Grabau, A. W., cited, 124, 126, 127, 143, $243,257,266,271,283,288,299,355$. $366,377,380,381,418,419,424,425$, $427,446,463,547,579,599,600,635$, $636,637,638,684,687,719,721,723$, $732,739,744,749,758,774,821,827$, $837,858,916,960,964,970,977,979$, $980,981,989,990,992,994,999,1043$. $1052,1066,1070,1095,1097,1113$ $1119,1136, \cdot 1139,1145,1146,1148$

, quoted, $273,282,792,793,1074$, 1075,1076

$\longrightarrow$, and Reed, M., cited, 980

, and Sherzer, W. H., cited, 52, 94, $537,538,1127,1148$

, and Shimer, H. W., cited, 956, 1095, 1119

Graff, cited, quoted, 1074,1076

Grafton, 420

Graham's Island, 864

Grampians, Carex peat of, 505

Gran Canaria, 244, 336

of 753

nks, 234

Grand Canyon, lava flows of, 313

Grand Cayman Island, 108

Grand Puy of Sarconi, lava cone of, 870

Granite, disintegration of, 32

Granite, graphic, 194

Granulites, consoliatation of, 751

Graphite, 510, 511

Graptolites, 243

- wide distribution of, 1134

Gravenzande, destruction of dunes at, 224

Graz, 246

Great Bahama Banks, 104

Great Banks, red algre on, 470

Great Barrier Reef, 387, 389, 390, 39r, 402 , $403,411,413,417$ jteropod ooze near, 456 Orbitolites on, 1007

Great Basin, diatomaceous earth of, 46

Crainfall in, 69

Great Fisher Pank, 191

Great Geyser, siliceous waters of, 168

Grcat Lakes, American, wave crosion on, 606

Great Oölite, worn grains of, 577

Great Pamir Mountains, sands brought from, 561

Great Plains, 260

Great Salt Lake, $70,338,3^{60}$, absence of calcium carbonate in, 476

calcium carbonate in tribu. taries of, 468

change in salinity of, 155 , 156

composition of, 159

dine-forming oölites of, 550 elevation of, 115

excrements of Artemia in. 1093

oulite dunes of, 472,574

oülites of, $467,408,473$

salinity of, 154, 159 
Great Salt Lake, soda deposits of, 361 Great Syrt, dunes on, 559

Grebenau, cited, 251

Greece, 257

Greenalite, 67 I

Greenfield, Triassic extrusives of, 317

Greenland, 236

- Eocenic climate of, 29

glaciers of, 263

ice cap of, 325

- snow-line in, 322

Greenland-Iceland region, migration of pole from, 895

- Sea, temperatures in, 192

Greenly, cited, 884

Green River Beds, fossil mosses from, 938

Gregory, J. W., cited, 22, 8I, 94

Grenada, 1021

Greylock, Mount, 799, 801

Griquatown series, tillite of, 535

Ground water, 4,139

- , depth of, $4,5,142$

Grund, alteration of limestones of, 767

Grundy county, Ill., concretions in carbonic shales of, 764

Guadalquiver River, dunes on bank of, 560

Guam, island of, 2

Guano, 370,461

Guayaquil, 60

Guelb-el-Zerzour, erosion-buttes near, 854

Guelph dolomite, 376,377

Guiana shelf, 103

Guinea current, 187

Gulf of Aden, 113

- temperatures of, 190,192

Akabah, 113

Cadiz, I 3

- - Salinity of, 153

- temperature of, 187,192

California, $112,356,652$

Finland, 24 I, 838

Guinea, I1 3, 195, 235

Jemsa, 576

Lion, II 3

Mexico, 107, 230, 233, 239, 247

Naples, 470

$\overline{\mathrm{Obi}}$, blue mud in, 668

Oman, II 3

Panama, Is 3

Riga, dunes of, 557

St. Lawrence, in 3

Sidra, 240

Suez, 113

Taranto, delta in, 608

Tartary, 242

Gulf Stream, 192, 215, 233, 234, 236, 239, $335,390,405,406,407$

greensand under, 673

velocity of, 680,1050

Gulick, J.' T., cited, to

Gümbel, C. 'W. von, cited, 73, 298, 482, 687,748

Gunnison River, 131

Günther, A. C. L. G., cited, s056, 1070

Günther, S., cited, 13, 22, 23

Guppy, H. B., cited, 59, 94, 248, 411,463

Gürich, G., cited, 956

Gypsum, dehydration of, 765

- , recrystallization of, 756

H

Haeckel, E., "cited, 993, 996, 999, 1039

Haecker, V., cited, $46_{3}$

Hägg, R., cited, 92
Hague, A., cited, 143, 201, 203, 206

Hahn, F. F., cited, 380, 381, 459, 463, 530, $538,758,774,783,784,827,1039$

Haidinger, cited, 1087

Hail, 62,63

Halimeda, 388, 394, 474, 476, 935

Hall, C. W., and Sardeson, F. W., cited, 687

Hall, - , quoted, 672

cited, 900, 902, 101 I, 1123,1127

Halle, J., cited, 82, 94

Halligan, G. H., cițed, 463

Hallock, W., cited, 73

Halobios, $99 \mathrm{I}, 992$

Halo-biotic realm, 982

Halo-pelagic district, 988

Hamburg, cited, 194

Hamilton fauna, 1053

- group, 426

Island, 397

, locofauna of, 922

- sandstone, 636

Hanamann,. J., cited, 166, 206

Handlirsch. A., cited, 949

Hanford Brook, thickness of Etcheminian at, 729

Hankow, dust storm at, 59

Hanksite, 363

Hann, J., cited, 26, 28, 47, 76, 94, 323, 328 quoted, 48,50

Hanover, salt domes of, 758

- county, Va., Greensand marls of, $C_{7} \mathrm{I}$, 672

Hansen, H., and Nansen, F., cited, 236 , 266

Hansen, H. J., quoted, I8

Harder, P., cited, 92 ostracoderms from, 1033

Hardwar, 127

Harker, A., cited, 277, 299, 306, 307, 308,

Harper, R. M., cited, 521

I Iarris, G. D., cited, 380, 381

G. F., cited, 275, 299

Harrisburg, Appalachian folds at, 844, 903 904

Harrison, J. B., and Jukes-Browne, cited, 463

, Williams, J cited, 206

ITarrison beds, loess-like origin of, 568

Hartland Point, 222

Hartsalz, 371

Hartt, C. F., cited, 463

$\overline{\text { Harzz }}$ quoted, 396

Harz, 375

Hatcher

J. B., cited, 538

Eug, cited, 23, 79, 94, 101, 110, 270, $299,643,687,873,901,902,907,908$, $987,1057,1146,1148$

Hawaiian Islands, lava of, 314

-_ - marine erosion of, 875

origin of, 679

pteropod ooze around, 456

_—_, rainfall of, 67 submarine cones of, 872

Hay, O. P., cited, 90, 92, 95

-, R., cited, 908

Hayden, F. V., cited, 36, 202, 342, 824

Hayek, A. von, cited, 92

Hayes, C. W., cited, 95, 176, 206, III3, I 19

Hay, and Ulrich, E. O., cited, I I I3, I1 19

Hay ford, J. F., cited, 10, 11,23 
Heautotype, 919

Heawandoo Pholo, 399

Hebrides, 234

Hecker, O., cited, 58, 95

Hedin, S., cited, $53,92,95$

Hedstrom, H., cited, 420,463

Heidelberg Schloss, erosion of, 58

Heiderich, quoted, 6

Heilprin, A., cited, 870, 878, 1037, 1070

Heim, Albert, cited, i $76,546,579,657$, $687,798,800$

Árnold, cited, 657, 660, 661, 687, 780, 821,827 F., cited, 687

Helderberg escarpment, 837,838

- mountains, 261, 709

Heleoplankton, 998

Helgoland, Island of, 225

Helium, 25

Hellbrun, Nagelfluh of, 602

Hell Gate, narrows at, 22

Hellmann, J. G. G., and Meinardus, W., cited, 95

Hlelman, C. H., cited, 556, 579

Helmert, F. R., cited, 15, 23

Helmsdale, 651

Heluan, 594

Hematite, 35

Henning, K. L., cited, 633,638

Henry Mountains, 308

Hensen, V., cited, 992, 999, 1039

Herculaneum, human bodies presserved at, 525

molds of bodies buried at, 1089

Herero Land, destruction of surface by herds in, 691

Hermansville, peat deposit near, 502

Hernösand, 110

Heroöpolite Gulf, 352

Herrick, C. L., cited, 578, 579

Heterepistasis, 964

illustration of, 1136

Heterocerci, 95

Heterocontez, 934

Hexaseptata, 943

Hibbert-Ware, S., cited, 72, 95

Hieber, V., cited, 443, 463

Hilgard, E. W., cited, 140, 369, 381, 611, 638,705

Hill, R. T., cited, 58, 95, 575, 579, 870, 878,1108

and Vaughan, T. IV., cited, 587,638

Hill, W., and Jukes-Browne, A. J., cited, 463

Hilo, lava flow near, 868

Himalayas, a geosyncline, 902

Eocenic marble of, 773

Meekoceras beds of, 1137

rainfall in, 69

rock fall in 54

Hinde and Fox, cited, 459

Hinds, R. B., cited, 917

Hindu Kush Mountains, sands brought from, 56

Hippopus, in Arabian eolian limestone. 57.5

Hitchcock, C. H., cited, 314, 317, 320, 878

Hjort, J, cited, 205, 206

Hohbs, $W$. H. cited, 328, 547, 590, 629, $630,638,816,827,861,886,878,881$, 908

7 quoted, 862, 866, 885

Hoburgen, reefs of, 421

Hochenburger, cited, 246, 256

Hochstetter, F. V., cited, 336,381

Hoernes R, cited, 595,638, 882, 1064, 1070

Hog-backs, 840,841

Hogoleu, 402

Holland, subsidence of coast of, 224
Hollick, A., cited, 1070

1 Iolmboe, J., cited, 86, 92

Ilolmia, index fossil of Lower Cambric, 912 fauna, 1052

Holocenic, 910

Holocepbali, 95

Holoplankton, 992

[ Ioloplastoty pe, 919

Holothuroidea, 950

Holotype, 9 r 9

Holyoke, trap of, 313

Holy Well, composition of water of, 168

Holzmaden, jet from, 483 , Lias of, 1078

petrifaction of Pentacrinites at, 108

Homceomorpl, 976, 978, $106 \mathrm{I}$

Homœotype, 919

Homozooidal belts, 78 Horgen, subaqueous gliding at, 657,780 ,

Hornblendite, 278

Ilorsepen, brachiopod fauna of, 742

Iloskins, L. M., cited, 906, 908

IIot Lake, composition of water of, 168

Hot Spring, borate waters of, 168

Housatonic River, $13 \mathrm{I}$

Iloutin, sea advance at, 558

Ilove, force of waves at, 222

Hovey, E. O., cited, $861,870,878,883$. 908

Hoted, 862,876

How, J. A.; cited, 827

Howchin. Wi., cited, 81, 535, 538

Howe, M. A., cited, 385, 463, 471, 521 , 545,579

Huang-hai (Yellow) Sea, II

Huang-ho, 248

- alluvial fan of, 584

delta, extent of, 252

, overlap in, $74 \mathrm{I}$

, rate of growth of, 609

- slope of, 904

flood plain, 589

Hubbard, L. L., cited, $38 \mathrm{r}$

Hudson Bay, 109, 241

mean temperature of, 193

, temperatures in, 191

furrow, 104

Highland, northwest thrusting of, 903

River, depth of channel of, 662 beds, 261 drowning of, 136 group, folding of, 851 series, metamorphism of, 772 tides in, 227

Hughes, T. McK.. cited, 1085, 1095

Hugli River, tidal bore of, 227

Hull, cited, I 149

Humber River, 224, 225

Humboldt, $A$. von, cited, 72, 322, 1108

Lake, composition of, 157,158

- - salinity of, 155

Hume, WW. F., cited. 92

Ilumic acid, 173. 174

Il umidity, absolute and relative, 26

II umphreys, A. G., and Abbott, H. L., cited, 247,267

Ilumulith, 28

II umus, 28 i

Hungary, alkaline lakes of, $36 \mathrm{t}$

- dune area of, 562

IIunt, A. R cited, 713,721

Hunt, T. S., cited, $206,347,369,381,672$ 687 quoted, 174

Huntington, E., cited, 82, 83, 84, 95, 381, $555,579,623,638,703,722$ , quoted, 358,359 
Hunton limestone, 684

Huronian, Lower, tillite from, 534

Hurst castle, 222

Hussakof, L., cited, 980

Huxley, T., cited, 1059, 1070, 1125

Hyatt, A., cited, 913, 964, 965, 966, 970, $971,976,980,1136,1149$

Hyde, J. E., cited, 530, 538, 777, 827

Hydration, 17, 37, 765

Hydrargillite, 39

Hydroclasts, 285

Hydrocorallines, $385,418,943$

Hydrogen sulphide, 24

- - , in peat beds, 493

Hydrology, 20

Hydrometamorphism, 748, 749, 766

Hydromicas, 177

Hydroseisma, 88

Hydrosphere, I

- subdivisions of, 99

Hydrothecæ, 943

Hydrozoa, 942

- reefs, 439

Hyolithidæ, 946

Hyphæ, 937

Hypnetum, 486, 487, 500

Hy pocenter, 883

Hypoplastotype, 919

Hypsometric niveau, 444

I

Ice, glacier, 279

snow, 279

caps, Cordilleran, 326

Keewatin, 326

Labradoran, 326

Newfoundland, 326

, Pleistocenic, 325, 326

floes, 198

Iceland, 234

-

hot springs and geysers of, 201

sinter deposits of, 475

Tertiary basaltic flows in, 867

volcanic fissures of, 866

Iceland-Faroe shelf, 103

Icoplastotype, 919

Idaho, Archæan dolomites of, 334

Iddings, J. P., cited, 277, 299, 303, 304, $313,319,320$

Idiotype, 919

Ihering, H. von, cited, 1149

Ile Julia, 864

Illinois River, plankton in, 997

Illye's Lake, salinity of, I 54

Imatra stones, 764

Inclusions, acicular, 716

- irregular, 716

regular, 76

Incretions, 719,720

Indevsk Lake, salinity of, 154

India, earthquake lakes of, 889

- isobars of, 45,46

regur of, 514

- , winds of, 45,46

Indian Ocean, 240

- atolls of, 388

evaporation from, 182,183

fringing reefs in, 386,390

manganese concretions in, 718

mean temperature of, 193

- - surface temperature of, I82, 183

- in, 536 surface temperature of, I82, 183

- Peninsula, 836
Indo-Gangetic delta plain, 584 flood plain, 585

Indus, 248 delta, 607, 608 , deposits or lime in, 616 -, overlap in, 741

River, alluvial plain of, 585

- - mud volcanoes along, 872

Inner Lowland, $83 \mathrm{I}$

Innsbruck, fölin days of, 47

Insectivora, 955

Insects, marine habitat of, 985

Inselberge, 58,853

-, Kalahari, 692

, South Africa, 854, 855

Insolation, Austr

Intercontinental seas, 9

Intercretions, 719

Interformational sheets, 304, 305

Interlaken, delta at, 127

Interstrophe, climatic, 82,83

Intervale, flood plain in, 588,596

Intracontinental seas, 9

Intumescens fauna, 1023

Inyo county, $\mathrm{Ca}$ !, 362

- soda niter deposits in, 364

Ionian Sea, 230, 240

Iquique, guano of, $46 \mathrm{r}$

Iran, desert areas of, 562

Ireland, 374

-

- mild temperatures of, 234

origin of chalk of, 850

- - transgressing Cretacic of, 730

Irish Sea, 112

"Irish Stream," interference in, 229

Irondequoit limestone, ballstone reefs of, 446

Iron Gate, gorge of, cut by Danube, 587

Irvine, R., cited, 194 381,46 381,464

, and Young, G., cited, 38

Irving, A., cited, 774

Island quoted, 766

and of Gran Canaria, 244, 336

Island of Rhodes, 153

Skye, 306, 308

Staffa, 318

Isle of Man, 229

of Wight, ercsion of chalk cliffs of, 225

Isobars, 4

Isostacy, 9

- Penck's illustration of, 9

Isostatic equilibrium, 10

- readjustment, 900

Issyk Kul, composition of, 157

Isthmus of Suez, Bitter lakes of, 352

Italy, 221

, cavern deposits of, 346

-, travertine of, 343

Ithaca, salt well at, 376

- fauna, 1053

\section{$\mathrm{J}$}

Jabor, lagoon at, 44

Jackson, R. T., cited, 980

Jacobitti.: E., cited, $897,898,908$

Jaggar, T. A., cited, $870,872,878$

Jahn, J., cited, 464

Jaluit, lagoon at, 441

Jamaica, foraminiferal limestone of, 455 
James, E., cited, 122

James, U.' P., cited, 917

James Bay, 430

Japan, eartliquake in, 887

explosive eruption in, 86r

New Mountain formed in, 863

, Pliocenic climate of, 89

seismic periods observed in, 891

Sea, ro8, 242

- mean temperature of, 193

Jatulian formation, anthracite in, 478

Java, 390

Sea, 242

Jaxartes delta, 608

. $\frac{}{\mathrm{J}}$, rate of growth of, 609

- River, dunes along, 56I

Jefferson, il. WV., cited, 707

Jeffersonville limestone, 426

Jeffrey, E. C., cited, $482,52 \mathrm{t}$

$\longrightarrow$, quoted, 482

Jena, 252

-, Muschelkalk of, 335

Jensen, A. S., cited, 92

$\longrightarrow$, and Harder, P., cited, 87

Jet, 482,483

, analysis of, 483

Jhelam River, 587

Joggins, South, section at, 515

Johnson, D. W., cited, 135, 143, 228, 267 $706,722,858,874,878,966,980$

$\longrightarrow$, quoted, 707

- Willard $\mathrm{D}_{\text {, }}$, cited, 888, 909

L. and Hobbs, W. H., cited, 909

Johnston, J., cited, 753, 774

Johnston-Lavis. H. J., cited, 879

Jointing, prismatic, in coal, 820

Joints, compression, 789

- tension, 789

- widening of, 79

Joly, J., cited, 687

Jordan, D. S., cited, 1042, 1070

, quoted, 1043

Jordan River, Utah, calcium carbonate in, 468

Jorullo, cinder cone formed in, 863

Josephine bank, 335

Judith Mountains, 306

Juglans, 630

Jukes-Browne, A. J., cited, J04, 387, 464

Julien, A. A., cited, 73, 95, 166, 173, 174 , 206

Jumna River, vertebrate remains in clays of, 586

Junagarb limestone, 455, 574

Juniata shales, 636

Jupiter Serapis, temple of, 3, 887

Jura, formation, 367

origin of oólites of, 455

White of Swabia 44

Mountains, anticlines and synclines of, 847

Jurassic limestone, Alpine, breaks in, 682 Jutland, dunes of, 557

, structure of dunes of, 703

\section{$\mathrm{K}$}

Kainite, 37 I, 372

Kalabari, Inselberge of, 692 desert, 123,124 erosion in, 58,70 leveling of, 854 oölites of lakcs in, 469,473 rainfall of, 63,64
Kalahari desert, salinas of, 359

Kalala oasis, 359

Kalkowsky, E., cited, 469, 472, 473, 521

Kalmar Sund, 838

Kammerbühl, volcanic hill, 874

Kampar River, 509, 510

Kamtchatka,, 86

Kanab formation, dune origin of, 57 I

Kankar, 586,719

Kaolin, 37,177

Kaolinite, 39, 292, 540, 548

Kaolinization, 37

Kapstadt, 452

Karabugas Gulf, 366

$\longrightarrow$, composition of, 157 density of, 180

deposits of, 354

, freezing of, 181

, map of, 353

- - salinity of, 154, 351

- - sulphate of soda deposits in, 360

Kara Kum, dunes of, 551, 561, 565

Kara Sea, 111,241

Straits, 236

Karibib, 692

Karisimbi Mountain, 125

- , height of crater rim of, 866

Karnic Alps, Devonic reefs of, 431

Karnic limestone, ammonoid from, 975

- Trachyceras from, 1136

Karoo formation, Ceratodus in, 1034

Karpial deposits in, 535

Karpinsky, A., cited, 82, 1149

Karst landscape, 133

region, 125, 791, 882

Kashmir, Vale of, 587

Katamorphism, zone of, 747

- depth of, 747

Kathiawar peninsula, foraminiferal (Juna. garh) limestone of, 455,574

Kattegat, 241, 1045

Katwee Lake, 359

Katwijk, 224

Kauar, oasis of, 26

Kayser, E., cited, 247, 267, 434, 442

, and Holzapfel, E., cited, 423,464

Kazan district, dunes in, $56 \mathrm{I}$

Keeling atoll, 397, 398, 399, 416

Keewatin, 311

- Devonic reefs of, 430

Keilhack, K., cited, 252, 267, 287, 299, 805 , 828

Kelheim, 440

- Solnhofen reefs, 438

limestone, 438

Kelley's Island, glacial grooves of, 264

Kelvin, see Thompson

Kemp, J. F., cited, 23, 138, 142, 144. 206, $277,279,299,874$

- quoted, 4

, and Knight, W. C., cited, 879

Kengott, cited, 368

Kenny, Captain, cited, 224

Kent, pipes of sand in chalk at, 698

Kentucky, fossil reefs of, 420

Keokuk anticline, 810

Kerguelen Islands, 40

Kermadcc deep, 3, 896

temperatures in, 187

Islands, pteropod ooze around, 456

Kerr. IV. C, cited, 34, 95

Kertch, pcninsula of, 443

- and Taman, mud volcanoes in, 872

Kettle Point, concretions of, 719,764

K River, 305

Keuper, Ceratodus in, 1034

- marls, loess-like origin of, 568

- $\ldots$, organic remains of, 635 
Keuper sandstone, origin of, 634

Ke, transgression on Muschelkall:, 565

Kew, 28

Keweenawan, lava sheets of, 868

Keyes, sandstone, cementation of, 754

$85,579,858$

"Keys," 404, 406, 407

Key West, 404

, diagenism of limestone of, 761

Khanat Desert, sand ripples in, 556

Khasi Hills, rainfall in, 68

Kielce, petrifaction of crinoids at, 1087

Kieserite, $368,372,757$

Kiev, rainfall at, 65

$\mathrm{Ki}$ Island, 519

Kilauea, 138

- elevation of rim of, 869

- frozen lava surface of, 866,869

Kilnsea, church at, 225

Kinderhook fauna, 732,1124

Kindle, E. M., cited, 641,687

King, C., cited, 15, 23, 626, 638

King, F. H., cited, 258, 267

King, L. V., cited, 747,774

King Charles Land, Jurassic temperature of, 79

Kin Fard post-glacial fauna of, 88

Island, volcanoes of, 877

King River, alluvial fan of, 126

Kingsley, J. S., cited, 1029

Kingston, repetition by faulting near, 817

Kiota, seismic periods observed at, $89 \mathrm{I}$

Kirchoff, A., cited, 1070

Kirk, E., cited, 449, 464, 1031,1039

Kizil Kum, dunes of, 551,561

Klintar of Gotland, 420,430

Knight, C. W., cited, 534, 538

Knop, A., cited, 381

Knorria, 5 i 8

Knowlton, F. H., cited, 92, 1149

Knudsen, cited, 179,180

Kochbrunnen, composition of the, 168

Koken, E., cited, $513,536,538,757,758$, $759,774,784,785,827,897,909,956$ $1058,1070,1149$

Koko-Nor Lake, salinity of, 159

Kola, peninsula of, 86

Konjepruss, 423

- limestones, 431

Köppen, cited, 45,46

Korea, 242

Kormos, T., cited, 92

Kossmat, F., cited, 1149

Köstritz, 433

Kota-Maleri beds, Ceratodus in, 1034

Koto, B., cited, 909

Kotzebue Sound, 508

Krakatoa, 28

- ashes from, 60

dust from, $59,550,572$

explosive eruption of, 875,88 r secondary thalassoseisma from, 890

Kraus, E. H., cited, 537, 538

Kreichgauer, D., cited, 893, 909

Krümmel, O., cited, 2, 3, 6, 8, 23, 99, 105 , $106,107,144,145,147,149,150,151$, $153,165,170,179,180,183,184,193$ $206,231,232,234,236,239,245,267$, $453,458,464,644,657,687$ quoted, 103, 171, 181, 182, 194, 212 , $213,214,216$

Krypton, 25

Ktypeit, 336

oölites changed to, 469

-, rccrystallization of, 755

Kufra, oasis of, 26

Kümmel, H. B., cited, 634, 740, 744

Kupferschiefer, 372, 375, 434
Kupferschiefer, fishes of, $95 \mathrm{I}$

- origin of, 479

Kurische Haff, 126, 1063

strand dunes of, 557

Nehrung, migrating dunes on, 559

Kurland, dunes on coast of, 557

Kuroshiwo, see currents

Kymoclastic, 295

\section{6}

Laacher Sea, 122, 860

$\longrightarrow$, salinity of, 155

Labadie-Cockburn bank, 104

Labrador, 234

Archæocyathidæ of, 417

, lakes of, 199

Labyrinthodonts, 633

Laccadive Islands, 389,390

Laccoliths, 306, 308

Lac de Brenets, 125

Lacertilia, 953

Lachmann, cited, 758

Ladakh, 364

Ladinian, 435

Ladrone (Marian) Islands, 2

Lady Elliott Island, 387

$\mathrm{La}$ Fayette formation, eolian cross-bedding in, 705

Lagarfljöt, 1063

Laggo Maggiore, 116, 124

Lagonite, 364

Lahore, 26

Lake Âgassiz, 126

Agnano, 120

Akiz, 1063

Altai Beisk, soda deposits of, $36 \mathrm{r}$

Averno, 120

Baikal, I 8

- composition of, 161

depth of, 116

drainage of, 116 elevation of, 116

- - salinity of, I 55

Balaton, 122

Biljo, composition of, 157,158

, salinity of, 155

Bonneville 70,121

-, alluvial fans in, 83

-, calcareous deposits of, 338

Bouvé, 126

- sand plains in, 600

Brienz, 127, 610

Champlain, composition of, $16 \mathrm{I}$

-, fulgurites of, 73

salinity of, 155

Charles, 126

Chichen-Kanab, composition of, 157 - gypsum in, 359

-

Como, depth of, 116

Constance, 622

- composition of silt in, 616

, optics of, 205

rock slide at, 546

shells in, 631

Domoshakovo, composition of, 157

, salinity of, 154

- soda deposits of, $36 \mathrm{x}$

Drummond, 120

Frie peat of, 500

Erie, 245, 264

- composition of, 161

- nature of pebbles on shores of, 595 
Lake Erie, salinity of, 155

Ful shale pebbles of, 650

Eulailie, drainage of, 889

Florissant, 125

Geneva, 196, 197, 198

- , aphotic region of, 983

Characea in, 204

subaquatic glidings in, 659

Hachinchama, 363

Huron, composition of, 161

- , cross-section of, 838

elevation of, if 6

, salinity of, 155

Illye's, 122,154

Iroquois, glacial lake, 753

Kisil-Kull, soda deposits of, 361

Kivu, 124, 125

rift-valley of, 866

Koko-Nor, composition of, 157, 158, 159 , salinity of, 155

Ladogra, 85

Lahontan, calcareous deposits of, 338 successors of, 121

- tufa deposits of, 340, 341, 347

Lucerne, 124

Lucrinus, 863

Lugern, delta in, 610,613

Maggiore, depth of, 116

Michigan, composition of, $16 \mathrm{I}$

- dunes on, 559

elevation of, 116

glacial sands of, 553

- nature of pebbles on shores of, 595

-

- shore dunes of, 557

- -, storm terraces on, 606

s of, 231

Nashua, 126

Nemi, 120

Nicaragua, 118

Nyassa, 118

, drainage of, 116

Onega, 478

Ontario, $118,124,218$ , crystallines of, 834

Pangkong, 126

Passaic, 126

Pontchartrain, 121, 1063

, cypress swamps in, 500

Rukwa, figured, 119

St. Laurent, 127

Schunett, soda deposits of, 361

Seyistan, deposits in, 84

Shaler, 126

Superior, 118

$\longrightarrow$, aphotic region of, 983

$\longrightarrow$, composition of, 161

_. depth of, 116

- salinity of, 155

region, Keweenawan lava shcets in, 868 in, 868 sandstone, 648

- hasal arkose of, 548

Tahoe, depth of, 116

Tanganyika, 118, 119,125

Tanganyika, $118,{ }^{119,125}$

_- medusa of, 1009

relict fauna of, 1064

Thaxter, 23

Thun, 127

Tinetz, 351

-, salinity of, 154

Venérn, 1064

Vettern, 1064

Winnipeg, 837
Lake Winnipegasie, 199

Zurich, optics of, 205

Laki, volcano of, 866

Laminaria, 470, 936, 995, 1001

- organisms growing on, 995

Lamination, planes of, 699

Lamplugh, G. W., cited, 92

Lamprecht, cited, 758

Lampreys, 95 I, 1034

Land, area of, 6 , elcvation of surface of, 6 breezes, 45

Lander, red beds from, 633

Landes, 223

Land dunes of, 558

Land lobe, Alleghany, 807. 809

- Cape Breton, 808, 809

- Maine, 808,809

- - Mississippi, 807, 809

, New York, 807, 809

, Rome, 807, 809

Lane, $A$. C., cited, 138, 139, 144, 167, 320 , $376,381,635,1017,1020,1024$

Lang, $A$., cited, 1039

Langenbeck, R., cited, 464

Languedoc, dunes in, 560

Lapilli, 860, 862

Lapland, snow-line in. 322

La Plata, mountains, 308

River and Estuary, 248, 66 1, 662

La Platte sandstone, eolian cross-bedding in, 704

Lapparent, A. de, sec De Lapparcnt

Lapworth, C., cited, 1011,1108

-

Laramie formation, non-marine, 1 101

La Soufrière, dust from, 60

Las Palmas, 336

Laterite, 39, 292, 540, 548

Laterization, 39

Laufer, F., cited, 287, 288

, and Wahnschaffe, F., cited, 299

Laurentian, 311

Lava, nillowy (pahoehoe), 313, 344, 808 ropy, $3 \mathrm{r} 3$

Le rough (aa), 313,3 I6

Le Chenaillet Ridge, 316

Le Conte, J., cited, 247, 267, 386, 387, 388 , $405,407,464,617,639,909,1119$

-, quoted, 890

Lecoq cited, 179

Lectotype, 919

Leda, 88

- clays, 1074

Lehmann, J. G., cited, 1098,119

Leitersdorf, 246

Leith, C. R., cited, 671, 687, 793, 827, 906, 909

Lena delta, 607, 608

Lendenfeld, R. v., cited. 92

Lepidodendracex, geologic range of, 941

Lepidodetidrales, 940

Lepidodendron, $512,940,1004,1082$

Lepidophytes, $5 \mathrm{I} 2$

Lesley, J. P., cited, 903

Lesquereux cited, 708

Leucite IIjills, volcanic nccks of, 874

Leverett, F., cited, 579

Lewiston, Pleistocenic delta near, 6or, 616, 753

Lewistown limestone, 418,422, 423

Leythakalk, 474

Lias of Ireland, 730

Liburnau, J. L. von, cited, 595, 639

Libyan desert, chalk from, 454

L, erosion ncedles in, 856 , fossils in, 642 
Libyan desert, fulgurites in, 73

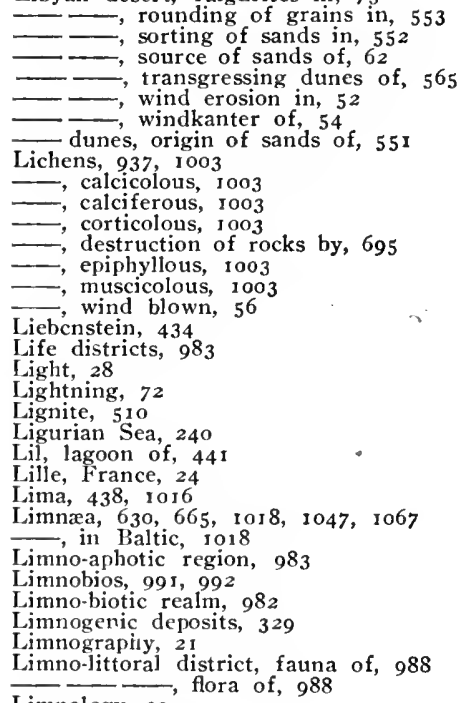

Limnology, 20 , flora of, 988

Limonite, 35, i 77

Limulava, 948,1030

Linck, G., cited, 332, 337, 38I, 464, 469, 473

Lincoln, F. C., cited, 144, 203, 207

Lincoln, New Zealand, rain at, I66

Lindberg, H., cited, 92

Linnæan species, 960,962

Linth, foehn of, 47

Linton, organic remains in cannel coal of, 481

Lipari group, 317,863

Liptobiolith, $28 \mathrm{I}$

Lisbon, tidal wave of, 889,890

Lithification, $748,75^{\circ}$

Lithodomus, 1016

Lithogenesis, I6, 1147

Lithographic beds, fish from, 951

Lithology, 20

Lithophysæ, 277

Lithoseisma, 88

Lithospliere, I

Lithothamnion, 394, 406, 415, 470, 471, 474, $476,649,936$

Little Ararat, fulgurites of, 72

Prairie, earthquake lake near, 888 Rocky Mountains, igneous intrusion in, 308

- Soda Lake, analysis of, 36r

Littoral belt, 100

belts, explosive eruptions on, 863 district, $646,647,983,987,988$

districts, estuarine facies of, 987

- zone, 646,647

Littorina, on mangrove trees, Brazil, 986

Livingston, David, cited, 32

Livonia, 378

- salt shaft, 376

Lizard, greenstone of the, 316

Lizards, Fimer's observations on, 963

Llanos, 68

Lobes, defined, 966

Lob (Lake) Nor, waste-filled basin of, 588
Loch Fyne, concretions in, 679

Loch Lomond, 1063

Lockport, New York, 420

- ballstone reefs of, 446 dolomite, $26 \mathrm{I}$

series, enterolithic structure in, 758

Locobios, 922

Loco fauna, 922, 1043

Locoflora, 922

Lóczy, L. de, cited, 92

Loess, 565

\section{coloring agent of, 622}

concretions in, 701

Mississippi Valley, origin of, 566

Prairie, origin of, 566

vertical tubes in, 566

Loesskindel, 568

Loessmännchen, $568,578,719,764$

Loesspüppchen, 568,701, 718,764

Lofoten Islands, whirlpools of, 230

Logan, Sir W., cited, $782,783,827$

Loirc, the, $25 \mathrm{I}$

Lomas, J., cited, 569, 579

Long Island, apron plains of, 598 coast marshes of 493 , destruction of coast of, 649 dunes on, 557,559 old marshes of, 491

wave work on, 223 Sound, 229

Recf, 406

Longwood shales, 377,636

Loo Choo group, fringing reefs of, 390 Looking Glass Rock, 57

Loomis, F. B., cited, $568,580,980$, 1067, 1070

L-, quoted, 1045

Lop, Great Salt Plain of, 358

Lossie River, 252, 256

Louèche, spring at, 175

Lough Neagh, I 73

Louisiana, deformed salt domes of, 758

Louisville, fossil reefs of, 420

- limestone, 418

Loup River, 259

Loven, S., cited, 990, 1062

- quoted, 987

Low Archipelago, 388, 389, 390, 399, 456

Lowville limestone, origin of, 488

Lucknow, depth of alluvial deposits at, 582

Ludlow, bone bed, 1034

Luksch, J., cited, 189

Lull, R. S., cited, 980, 1090, 1095, I149

Lümfjord, the, 224

Lutaceous texture, 28

Lu-Tschu Islands, 108

Lutytes defined, 285

Luzon, dredgings off coast of, 519

Lycia, jet of, 483

Lycopods, 940

Lydekker, R., cited, 1055, 1062, 1070

Lyell, Sir C., cited, 3, 23, 343, 381, 475 $521,611,615,824,857,1099,1100$ I 08,1119

-, quoted, ro74

Lykens, Lower, Naiadites and "Spirorbis" in, 742

Lyme Regis, black shale of, 483

M

Maare, I22, 860

Macclesfield bank, 391

Mackenzie delta, 607,608

Menzie delta, 607, 
Mackie, W., cited, 252, 253, 254, 255, 256, $267,293,294,299,716,722$ quoted, $254,255,256$,

Mackinac, breccias of, 547,548

Maclear, Captain, cited, 399,400

Macrophytes, 983

Madagascar, 195, 386, 390, 413

Madeira, 235

Madras, fish falls at, 56

Maelstrom, 230

Magdeburg-Halberstadt region, 371

Magnesian limestone of England, 571

, dwarf fauna of, 1069

Magnet Cove, composition of spring near,

Magnetite, oxidation of, 35

Magnolias, in brown-coal, 5 . 3

Mahoning sandstone, continuity of, 1131

Maine coast, sea urchins on, 103 $=1033$

Makaroff, cited, 240

Makatea Island, diagenism in reefs of, 761

Malaspina Glacier, 324

Malaysian Islands, volcanic belt in, 877

Maldive Islands, $386,388,389,390,399$

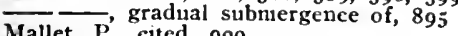

Mallet, P., cited, 909

Malm, 459

Malta, I 53, 240, 454

Mammoth Cavc, organisms in, 1028

Mangrove, 494

floating islands of, 235

partial marine habitat of, 985

Creek, Anthozoa in, sol 3

Manitou, 3 so

Manitou, 310

Manitoulin Islands, 836

Manlius, Stromatopora reefs of, 445

Mannestone, 423,456

Mannheim, 245

Manoluai, 402

Manson, M., cited, 95

Maranhão, 4 I 6

Marcellus muds, 407, 424

shale, origin of, 479,484

Marcou, J., cited, 78

Marian depression, 2, 897 lslands, diatomes near, 460 trench, I05

Mariana Islands, 386

Marin county, 315

Marine clastics, negative characters of, 642 littoral district, depth of, 983

-1 , life of, 984

Marlekor, 719 origin of, 983

Marquesas, 406,441

Marquette, basal sandstone at, 726

buried peat at, 516

Lake Superior sandstone of, 310

district, metamorplism in, 772

Marr, J. E., cited, 432, 433, 464, rozo

, quoted, 432,699

Marsh, O. C., cited, $709,789,827$

Marshall group, 388, 389, 399

Martha's Vineyard, apron plains of, 598 deformation of Tertiary beds of, 785

Martin, L., cited, goo

Martinique, Island of, erosion on, 875,$8 ; 6$

Martonne, E. de, cited, 52, 96

Marzelle, cited, I 49

Masmarhu, 399, 400, 401

Massachisetts, 392

$$
\text { peat deposits of coast of, } 514
$$

-, sea-breeze of, 44

Mastodon, 956

Mather, W. W., cited, I 123
Matilda atoll, 399

Matthew, G. F.. cited, 92, 1086

, W. D., cited, 568,580

Natto Grosso, ants' nests in, 692

Mauch Chunk, 635, 636

Mauna shales, carnotite in, 365

Mauna Loa, $3 \mathrm{I}_{4}$

Mauritiu, elevation of rim of, 869

ius, 386, 390, 399, 402

Maurua, 402

Maury, M. F., eited, 96

Iit quoted, 44

Mauth-Eichdorf, 2.46

Mazon Creek, concretions of, 764

MeClure, W., cited, 1122

MeConnell, R. G., cited, 92, 580

Mcuiee, W. J., cited, 245, 267, 580, 652 , $687,909, \quad 1119$

Mead, C. 'W., cited, 1095

$\longrightarrow$, quoted, 1076, 1077

If can sphere level, 6 , ?

Mecklenhurgian period, 506

Medina "sandstone, beach cusps in, 707

- beach features of, 652

- - colian cross-bedding in, 704, 706

- - fucoid in, 937

, marks 111, 709 $219,240,344,355$

provincial fauna of, 98

temperatures of, 189

Mcditerranean Sea, evaporation from, 27 height of waves of, 210 salinity of, 152

_- subnarine volcanic eruptions of 864

Medlicott, If. B., and Blanford, W. T. cited, 639

Medve quoted, 592

Mrek, F B., cited, 917

Meigen, W., cited, 39, 96

Mclville Sound, i i

Menilite shales, 48,5

Mentawie Islands, $4 ; 6$

Merced River, alluvial fan of, 584

Mler-de-Glace, glacial sand of the, 532

Meriden, earthquake fissures at, 885

Merionthshire, 315

Merjelen Sce, 125

Meroplankton, defined. 993

Merostonata, 948,950

Merriam. J. C., cited, 1071

Merrill, G. P., cited, $38,96,286,287,299$, 344,381

-, quoted, 344, 345

Merseburg, 1029

Nesa, 830

Mesabi Range, greenalite in, 67t

Mesotraphent, 498

Messina, earthquake at, 888

M. Straits of, 230

Netamorphism, 746

contactic, 748

dyllamic, $7+8$

regional, 749

static, 748

Metatype, 919

Meunier, S., cited, 56, 96

Ileuse delta, 607 River, 224 capture of, 134, 136

Mexican lagoons, oólites of, 336

- Sea, temperature of, 190

Mexico, 341

- cinder cones of, 863

, ony $x$ marble of, 344 
Mfumbiro Mountains, 124, 125

- volcanic origin of, 866

Michael Sars, the, 205

Michalski, cited, 443,464

Michigan, Devonic clay boulders of, $7 \mathrm{II}^{1}$ , reefs in Southern Peninsula of, 427 , salt deposits of, 376

- City, dune sands from, 553

Microphytes, 983

$M$ icrospherulites, 277

Mid-Atlantic rise, 105

Milan, weather at, 48

Miliola, in Severn muds, 664

Mliliolitic formation, 574

Mill, H. R., cited, 7,23

Miller, S. A., cited, 957

- W. J., cited, $569,580,621,639,783$ 827

Millstone grit, composition of, 596

Milne, J., cited, 899, 909

Milne-Edwards and Haime, cited, 1013

Milwaukee, 419

Mlindanao, 519

Minnesota, glanconite of, 671,672

Mississippi delta, 608, 611

-_ fine muds of, 850

- - , mud lumps of, 615 passes of, 610 , thickness of, 609

embayment, 984

River, 248

, hack swamp of, 497,589

load of, 247

mud at mouth of, 655

reversal of current of, 889

tree trunks carricd by, 105 l , velocity of, 245

system, discharge of scdiment of, 247 , hydrographic basin of, 247

- Valley, black shale in, 732

Mississippic black shale, Ordovicic fossils iin, 685

Missouri, caverns of, 345

, overlap of marine strata in, 732

- River, Great Falls of, 137

Mittagong, chalybeate waters of, 168

Miodoboren hills, 443

Mjöscn, Biri limestone of, 784

Moas, 1038

$\longrightarrow$, petrified eggs of, 1088

Moencopie beds, 84

- alternation of colors in, 623

Mohave Desert, 70, 364

$\bar{M}$, dunes of, 562

Mohn, H., cited, 96

Mojsisovics, E. von, cited, 435, 464, 474, 521

Mollasse, 591 subaqueous gliding of the, 658

- torrential deposits, 630

Mollusca, importance of shells of, 9 II

Molucca Straits, 237

Nlombas, 404

Nonadnock, $847,848,849$

iona passage, 108

Nönchsberg, Nagelfluh of the, 602

Mlonhegan, Island of, 848

IIono Lake, salinity of, 155

, soda deposits of, 36 I

- Valley, extinct lake of, 340

Monongahela River, gravel terraces of, I 36

Nonroe limestone, 261,422 endolithic brecciation in, 537

- - oölites of, 472

Mons, greensands near, 673

Monsoons, 45, 75

Mont Blanc, fulgurites of, 72
Mont Doré Province, breached lava cones of, 871

Mont Genèvre, 315

Mont Pelée, dust from, 60 , eruption of, 861 , spine of, 870

Montana, Belt terrane of, 334,417

Monte Nuovo, cinder cone of, 863

Monte Somma, 871, 875

Monte Viso, fulgurites of, 72

Montessus de Ballore, F. de, cited, 909

Montgomery county, $O$., peat bed in, 515

Monticules, formation of, $87 \mathrm{r}$

Montreux-Veytaux, subaquatic glidings of, 659

Montrose county, Col., carnotite of, 365

Monument Creek beds, cementation of, 754 , dune origin of, 570

Park, 53 , joints in, 792

-

Moor, Captain, 227

Moore, J. E. S., cited, 119, 125, 144, 761 , $774,879,1064,1071$

Moraines, lateral, 265

$\longrightarrow$, medial, 265

Moray, rivers of Eastern, 252

- Sands on eastern shores of, 226

$\longrightarrow$ Firtl, 256, 650

Morgan, temperatures of, 19

H., cited, 080

W. C., and Tallmon, M. C., cited, 1088,1096

- quoted, 1089

orlot, cited, 1100

Moros Valley, salt dome in, 758

Morphological equivalents, 976,1135

Morrisville, 377

Morse, E. S., cited, 1042,1071

Morse Creek limestone, 684

Morvern, Cenomanien greensands of, $85^{\circ}$

Moscow shale, variation in thickness of, 683

Moselle River, 134

Mosely, meanders of, 137

Mosken, 230

Mosquito bank, 335

Mottez, Admiral, cited, 215

Mt. Adams, 32

Mt. Everest, 5

Mt. Hillers, 308

Mt. Holmes, 308

Mt. Marcellina, 308

Mt. Mica, composition of spring near, 168

Mt. Monadnock, 32

Mt. Shasta, fulgurites of, 72

Mt. Sinai, 33

Mt. Starr-King, 32

IIt. Taylor region, volcanic necks of, 874

Mt. Thielson, fulgurites of, 72

Mt. Washington, Arctic plants and butterflies on, 1066

Mountain Home, hot springs of, 201

-... limestone reefs in, 432

Mozambique, 386

cliannel, 388

Mud cracks, 530

- lumps, 6r1, 615

Muir glacier, 263

Mulder, cited, 173

Mull, Cenomanien greensands of, 850 and Morvern, transgressing Cretacic of, 730

Mullion Island, greenstone of, 316

Mummies, Chile, 1076, 1077

Munthe, H., cited, 420,464

Mur River, 252 


\section{INDEX}

Murchison, Sir R., cited, 222, 1108

Murce glacial formation, 536

Ml urgoci, G., cited, 92

Murray, Sir J., cited, $7,23,63,65,96,165$, $194,207,387,391,408,410,451,452$, $466,678,679,687,688,1071$ , quoted, 6, 66, 164 and Hjort, J., cited, 205, 207 and Lee, G. V., cited, 688 and Philippi, E., cited, 688 and Renard, A. F., cited, 45I, 453, $455,643,644,668,670,688$

- and Renard, M. A., cited, 56, 96

Muschelkalk, 225, 436

cementation of, 335

origin of oölites of, 455

subaquatic gliding in, 782

- Sea, 376

Muskegon, dune near, 559

Mutation of De Vries, 963

- , of Waagen, 912, 960

Mycelium, 937

Myxinoids, 95

\section{$\mathbf{N}$}

Nagasaki, 59

Nagelfuh, 601, 602, 750 , cementation of, 753 delta, 616

Naiadites, in Lower Lykens, 742

Nairn River, 252

Näkkebröd, 719

Namak, 358

Nansen, F., cited, 1 ro, 267

Nantasket, Carbonic lavas of, 315

drumlins of, 532

Nantucket Island, apron plains on, 598

, old marshes on, 491

Naples, Bay of, bradyseisms in, 887

Gulf of, 3

Napoleonite, 275

Narni, travertine deposits of, 343

Natissa River, salt water in, 153

Natron, 362

- Lake, salinity of, 155

Natterer, cited, 332

Nattbeim, reefs near, 439

Natuna Islands, 242

Naumann, C. F., cited, 269, 270, 299, 537

Nautiloidea, 945, 946

Nautilus. 945, 946, 1022

Nauset Lights, 223

Navahoe i peat under

Navigator Islands, 386

Neanastic stage, 973

Neanic stage, 972

Nebraska, 259

- lakes in sandhill region of, 562,564

Nebraska dunes, 122,572$$
\text { lignite in, } 565
$$

origin of sands of, 55

Nebular hypothesis, 92

Neckar, velocity of, 245

Neckar, valley, enterolithic structure in, 758 , 759,785

Nefud desert, 37

- red sands of, 562

Nekton, 991, 996

Neocomien, greensand lenses in, 673

Neon, 25

Neotype, 919

Nepiastic, 973

Nepionic stage, 972

Neritic zone, 643,987

Nero deep, 2, 105, 897
Netherlands, dunes of, 557

Neumayr, M., cited, $78,80,133,144,682$. 1057. 1149

- quoted, 79

Teutraul, C. M., cited, 958, 959, 980

Neutral

Nevada, borax lakes of, $36_{3}$

Név, playa lakes in, 603

Newark sandstonc, arkose character of, 84 - - footprints in, 1090

- $\longrightarrow$ fucoid in, 937

$\longrightarrow$, non-marine, I $10 \mathrm{x}$

- , origin of, 633

- - overlap relations in, 740

Newark, red color of, 625

Newark trap sheets, 312

Newberry, J. S., cited, 708

New Caledonia, 388

New England, color of till of, 532 destruction of coast of, 649

New found eskers in, 599

New foundland, 215,234

Archaocyathida of, 417

, frost work in, 34

banks, $104,218,234,262$

shelf, 103

New Guiuea, 334

New Ilaven. 104

New Hebrides Islands, 38

New Jersey coast, dunes on, 557, 559

New Mexico, marshes of, 493

New Mexico, Cretacic dwarf fauna of, 1060

$\overline{\mathrm{New}} \mathrm{Red}$, dune of gypsum in, 578

New Scotland beds, overthrust of, 817

Newson, J. F.. cited, 885, 909

New South Wales, meduse of, 1009, 101n New World block, 9

New York, beveling of Palxozoic strata in 835

fower Cambric limestones of, 335

thickness of salt beds of Central, 378 type section for the Palazoic, 1127 Western, disconformity in Siluric of.

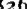

City, age of schists and marbles of, 1140

Aqueduct Commission of, 286

- sinter deposits of, 475

Niagara Falls, amount of water per nin ute, 246

height of, 246

escarpment, 261

gorge, 261

River, 133

changes in bed of, 245, 246

consolidated plains along, 60

- old shore lines of, 654

Niagaran, former extent of the, 379 reefs of the, 431

- Sea, evaporation of, 377

Nicaragua, 335

- colors of soil of, 36, 620

Nicbolson, H. A., cited, 455

- and Etheridge, R., cited, 472

- and Lydckker, R., cited, 956, 1096

Nicobar Islanded,

ands, $109,386,390,456$

Niger delta, 608

Nikitinsky, quoted, 357

Nile delta, $252,607,608$

- deposits of lime in, 6,6

- iron content of 622

- - nature of deposits of, 614 
Nile delta, salines of, 355 saline deposits on, 617

River, 248 flood plain of, 589 overflow of, 68

Nile Valley, angular sands along, 553 caverns in Eocenic limestones of, 346

Niles, W. H., cited, 753,774

Nitrogen, 24,25

Nittany Valley, 175

Nodes, 945

Noë] black shale, 732

Nontronite, 39

Nordmann, V., cited, 92

Normandy, dunes of, 557

North Cape, 236

- Germany, Permic climate of, 375

- Pole, ascertained migration of, 899

- - , hypothetical migration of, 898

- Sea, 112, 218, 234, 236, 239

- height of waves of, 210

subinarine forests of, 224

subsidence of coast of, 223

Siberian shelf, 103

Northwest Australian shelf, 103

Norway, Cambric glacial deposits from, 534

- , concretions in clays of, 763

- dolomites of, 334

Nocent corals of, 392

Norwegian shelf, 103

Novaculite, 755

Nova Scotia, erosion stacks of, 225

-

No, red Mississippic beds of, 622

Nova Zembla, 236

red algæ at, 470

Novorssisk, winds from, 49

Nubian sandstone, 61, 565

- dune origin of, 570

Nullipore, Libyan

Nummulite limestone, 453

Nummulites, 942

Nunatack, 326

Nunda sandstone, see Portage

Nyssetum, 487, 500

\section{O}

Oatka, 377

Oaxaca, volcanic ash deposit of, 60

Obrutschew, cited, 604

Ocean, composition of, 158,159

- mean depth of, 6

Oceanography, 20, 21

Oceanology, 20

Oceans, areas of, 100

Ochsenius, C., cited, 267, 350, 353, 359, $366,369,370,381,38$

O'Connell, M., cited, 989, 990, 1029, 1039

Octapoda, I02I

Octoseptata, 943

Odessa, subaquatic glidings at, 659

Oeningen, deformations at, 784

folding in Miocenic marl of, 780,78

- Mioccnic shell deposits of, 631

Oesel, Island of, cuesta of, 838

Synxiphosurans from, 1029

Ogden quartzite, 817

- River, calcium carbonate in, 468

Ogilvie, I. H., cited, 856,858

Ogilvie-Gorden, M., cited, 435, 464

Ohio, Devonic limestones of, $47 \mathrm{I}$ origin of black shale of, 484 River, 245
Oisan Mountains, 127

Ojen, P. A., cited, 92

Okefenoke Swamp, 500

Oken, L., cited, 917

Okhotsk-Sachalin shelf, 104

- Sea, 108

Oklahoma, 262

$\div$, basal Cambric sandstones in, 729

Öland, Island of, cuesta, 838

Odd Faithful Geyser, siliceous waters of, I 68

Oldham, R. D., cited, 585, 639

- quoted, 586

Old Red sandstone, analyses of sand grains of, 716

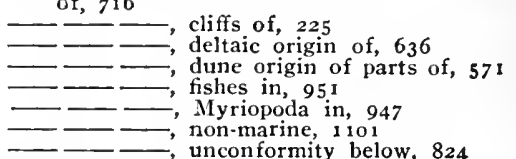

Old World Block,

Olean conglomerate, 252

Olenellus fauna, 1052

Olenidæ, as index fossils, 1134

Olenoides fauna, 1052

Olenus limestones, 53

Oligocenic, pyroclastics of, 526

Oligochrete, 1024

Oligotraphent, 498

Olkusz, fulgurites in, 73

Omori, F., cited, 879

Onchidium, 986

Oneonta, see Portage

- sandstone, 636

Onondaga limestone, $261,407,423,424$, 425,426

Onto-stages, 971

Onto sub-stages, 971

Oölite, Great, 472

- - Inferior, 472 Superior, 472

Oölites, size of phytogenic, 468

Oölitic sands, 422

Oozes, formation of, 996

Opercula, 945

Operculina limestone, 52

Oran, province of, 345

Orange Spring, composition of, 168

Orbitoidal limestone, 453

Ordovicic, black sliale resting on, 732

- - insects from graptolite shales of, 949

-

-- Upper, replacing overlap of, 744 sandstone, marine progressive overlap of, 728

Oregon, basaltic plateau of, 867

Ore Sound, 241

Organ Pipe Reef, 404

Orinoco delta, 608

- River, tree trunks carried by, 1051

Oriskany-Esopus, contact in Helderbergs, 823

Orkney Islands, 112, 218, 230, 234

-, Tertiary dikes in, 867

Orogenesis, 16, 776, 1147

Orogenic movements, 12

Orpiksuit fjord, 87

Orth, cited, 287, 299

Orthoboric acid, 364

Orthogenesis, 963

Ortiz Mountains, conoplains of, 856

Ortmann, A. E., cited, 8o, 96, 647, 688 $995,999,1022,1027,1039,1059,106 \mathrm{I}$ $1062, \quad 1071,1134, \quad 1149$

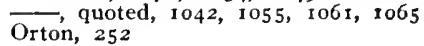


Osage River, boulders in loess on, 567

Osborn, H. F., cited, 920, 956, 957, 961, 970, 980 , 981,1149

- and Grahau, A. W., cited, 958

Oscillation, circle, 894

ripples, 712, 713

Ostrea, in Arabian eolian limestone, 575

Ostwald, quoted, 747

Oswing, Neocomien of, 673

Ottawa River, 334

-, drainage of, 166

Otyipatura River, 692

Owen, D. D., cited, 915,1108

Owens, J. S., cited, 688

Owens Lake, 362 , 369

- change in salinity of, 155

, change in salinity of, 155

salinity of 154,155

soda

Valley, earthquake fissures in, $88_{3}$ earthquake of, 887

Oxford lowland, 839

Oxidation, 17, 25, 35

$\bar{O}$, of organic compounds, 37

Oxus River, 23

- dunes along $56 r$

Oxygen, 24

$$
\text { delta of, } 608
$$

Oy sources of, 25

Oysters, attached to roots of mangroves, 986

Ozark region, basal Cambric sandstones in, 729

Ozone, 72

\section{$\mathbf{P}$}

Pacific Ocean, manganese concretions of, 330,718

-

- surface temperature of, 182,183

Pares of, 185,187

Prnaccordanz, 821, 822

Pahoehoe, Hawaiian Islands, 868

Palzëchinoidea, 950

Palzobotany, 20, 9 to

Palzo-Cordillerans, 70

Palzohypsometric, 444

Palzozoic, diversity of fauna of, 984

- rocks, desert varnish of, 57

Palzozoölogy, 20, 910

Palawan Island, 242

Palgrave, W. G., cited, 562, 580

Palic Lake, composition of, 157,158

Palinity of, 155

Palisades trap, 320

Pallas, cited, 443

Pallas and Humboldt, V., cited, I $_{063}$

Paludina, 631

series, 960

Paluxy sandstone, 729

Pantelleria, 153

Paradoxides, index fossil of Middle Cambric, 912

fauna, 1052

Parallelism, 979 illustration of, 976,977

Parallelkanter, 54

Paraña, carcasses of animals in, 593

Parat tributary of La Plata, 661

Paratype, 919

Para-unconformity, 82

Pâris, Lieutenant, cited, 214

Paris Basin, Eocenic locofauna of, 1043

Paris Basin, Eocenic locofauna , Eocenic shales of, 48 beds of, 779,820
Parks, W. A., cited, 731, 744

Parmas, 808

Parrot fish, destruction of corals by, 4t5

- River, 663

Parry Archipelago, 237

Parsons, A. L., cited, 485, 521

, quoted, 486

Partiot, cited, 231, 267

Parunconformity, 821, 822

Paruschowitz well, 14

Pas-de-Calais, dune areas of, 557

Pass a l'Outre, form of, 514

- rate of growth of, 609

Passarge, S., cited, 58, 196, 359, 382, 580 $692,695,854,855,858$

Patagonia, 239

-

- Salinas of, 360

—, salitrales, 329,360

, shelf, 103

Tertiary volcanic dust deposits of 572

Patapsco formation, 632

Paterson, trap of, 312

Patten, W., cited, 950, 957

Patuxent formation, 632

Paumota Archipelago, see Low, 456

Peach, B. N., and Horne, J., cited, 315 , $321,867,879$

Peat bog, succession of strata in, 499, 506

Pebbles, facetted, 54

Pechuel-Loesche, E., cited, 32, 695

Pedro quoted, 691

Pei-ho, 248

Pelagic district, $101,983,988$

Perganisms, quantity of, 451

Pelew Islands, 388

Pelytes, 285

Penck, A., cited, 2, 3, 5, 6, 7, 8, 9, 23, 100 $125,144,165,248,250,251,257,267$. $541,580,595,602,639,858,1063$ , quoted, 162, 163, $213,246,248,584$ and Brückner, E., citcd, 328, 639 and Supan, A., cited, 23

Pendleside limestone, 432

Peneplain, defined, 847

- transgression over, 731

Penhallow, D. P., cited, 98 I

Pennines, peat of, 504

Penrose, R. A. F., Jr., cited, 370, 382

Pensauken gravels, fulgurite in, 73

Pentland fjord, 230

Permic, position of North Pole in, 897

Permille, defined, 147

Perry, N. W., cited, 701, 709, 712, 722

Persia, onyx deposits of, 345

Persian Gulf, 111,242 , 390

- temperature of, 193. 373

Peru, natural mummies from, 1076, 1077

Peschel, O., cited, 1063 , 1071

Pestalozzi, cited, 251, 267

Peterhead, force of waves at, 221

Petermann, A., cited, 584, 639

Petersen, C. G. J., 92

Petit Codiac River, tidal bore of, 227

Petoskey, reefs of, 429

Petrascheck, cited, 682, 688

Petro-Alexandrovsk, rainfall at, 65

Petten, height of dunes near, 558

Pettersson, S. O., cited, 193, 207

Pfaff, F. W., cited, 96, 175, 759, 774

Phacoliths, 307

Phanerogams, 941

Phit, acquired marine habitat of, 985

Philippi, E., cited, 82, 92, 96, 332, 334, 335 , $382,635,639,644,675,681,688$ 
Philippine Islands, 204, 237, 242

$\longrightarrow$, diatoms near, 460

Philippine Sea, 195

Phillips, J., cited, 224, 267, 1099

- J. A., cited, 37, 96, 294, 299, 639

Phillipsite, 330

Phoca, in fresh water, 1063

Photic region, 982

Phragmitetum, 486, 487, 500

Phyllocarida, 377,948

Phylogerontic stages, 973

Phylum, 912

Physa, in Florissant Lake Basin, 525

Phytogenic deposits, 384

Phytolitharia, marine, in Mississippi mud, 615

Phytoliths, 280

Phytology, 20

Phytosphere, 16, 9ro

Piedmont region, 226

Pierre shales, 447

Pike's Peak, 32, 33, 3 to

Pilgrim, G. E., cited, 92

Pilot, fish, 996

Pine Creek Valley spring, composition of, 168

Pittsford shales, $376,377,1029$

Planetesimal hypothesis, 92, 297

Planetesimals, 907

Plankton, defined, 991, 992

Planoconformity, 826

Planorbis, 1064

- , in Florissant Lake basin, 525

- , in loess, 568

- in Severn deposits, 665

mutations of, 1043

, shell replaced by sulphur, 1086

Plants, chlorophyll-forming, 25

Plasmodium, 933

Plasticity, zone of, 819

Plastotype, 919

Plattenkalke, 438

Playa lake, $77,123,602$

Playa surface, 709

Pleistocenic, beaches of, 654

, location of pole in, 895, 896

Pleistocenic ice sheet, 344

Plesiotype, 919

Plitvicer seas, 125

Plucking, 18

Plum Island, map of, $49 \mathrm{r}$

Plyinouth, force of waves at, 221

$\mathrm{Po}, 248$

- delta, 607, 642

, lignitized wood in, 614 , thickness of, 609

River, alluvial plain built by, 584 , flood plain of, 589

- - , natural levees of, 617

Pocahontas, Pottsville conglomerate at, 742 Pochutla, cinder cone of, 863

Pocono conglomerate, 636

Pandstone, 635

Podolia, 443

Point au Sable, 838

Point Bonita, basic lava of, 3/5

Polar Sea, temperatures of, 193

Pole, migration of, 891,892

Pole, shifting of, 536

Poles, wanderings of, 91,92

Polyhalite, 37 $, 372,374$

Pomerania, brackish ponds of, 126

Pompeckj, J. F., cited, 479, 521, 667, 678, 688

Pompeii, human bodies in volcanic mud at, 525,1089

Pool, R. J., cited, 563,580
Porta do Mangue, diagenism of reefs of, 761

Portage beds, faunas of, 1053

Portage sand'stone, 554, 635, 936

, loess-like origin of, 569 origin of, 479

- Protosalvinia in, 718

Portageville, 127

Port Elizabeth, sea wave at, 875

Port Hudson clays, 6II

Port Jefferson, wave cutting at, 223

Portugal, recent corals of, 392

Posidonia shale, jet from, 483

, organic remains in, 483

Pössneck, origin of, 479

Pössneck, 433

Potamoclastic, 295

Potamogenic deposits, 329

Potamology, 20

Potamoplankton, 998

Potomac formation, colors of beds of, 624 631

ić non-marine, 101

Potonié, H., cited, 280, 330, 382, 480, 482, $510,517,521,578$

Potsdam sandstone, $642,729,856$

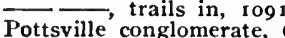

Pottsville conglomerate, 635,742

, extent of, 252, 594

pebbles from, 596

- thickness of, 904

series, westward overlap of members of, 741

Poughkeepsie, 227

Pouillon-Boblage, cited, 267

Pourtales, L. F. von, cited, 406, 464, 673, 688

Pourtales Plateau, ro6, 244, 335, 407, 414

Pozzuoli, 3

sol fatara at, 168

Prather, J. K., cited, 671, 672, 688

Pre-Cambric ocean, lime of, 331

Precipitation, effect of latitude on, $7 \mathbf{r}$

Presque Isle, Lake Superior sandstone of, 726

Pressure, areas of high and low, 4x

$\longrightarrow$, belts of, 43

normal atmospheric, $4{ }^{\circ}$

Prestwich, J., cited, 698

Primates, 956

Prince Edward Island, glacial conglomerate of, 82

Progressive overlap, marine, 740

Prothallus, 938

Protœcium, 973

Protogenous, 269

Protograph, 919

Protolimulus, ro29

Protolog, 919

Protoplastotype, 9 19

Protosalvinia, 718,1004

Prouvot, cited, i 88

Provincetown, dunes of, 557, 559

Provincial faunas, 984

Przhevalsky, N. M., cited, 56, 562, 580

Psammytes, 285

Psephytes, 285

Pseudoplankton, 994

Psilotales, 940

Pteropod ooze, 455, 456

- analysis of, 677

Pteropoda, 946

Pueblo, 27

Pugha, lake plain of, 364

Pulverites, consolidation of, 75

Pumpelly, R. W., cited, 56, 96, 580, 655, 688,690 
Punjab district, 26

Punt salt range of, 592

Punta Robanal, 218

Pupa, in delta beds, 613

$\rightarrow$ in loess, 568

Purgatory chasm, graben of, 815

Put, the, 355

Pyramid Lake, 160, 340 , composition of, 157,158

Pyrenees Mountains, fulgurites of, 72

Pyroclasts, 285

Pyrogeology, 20

Pyrometamorphism, 749, 765

Pyrosphere, 1

limits of, 12

, manifestations of, 13

\section{$\mathbf{Q}$}

Quadrumana, 956

Quahog Bay, 1065

Ouaquaversal dip, 808

Quartz, secondary enlargement of grains, 754

Quartzite, 755

Quebradas, earthquake, 884

Queensland shelf, 104

Queneau, A. L., cited, 319, 32

Quenstedt, A., cited, 438,1085

Quiriquina lsland, earthquake destruction of, 888

\section{$\mathbf{R}$}

Rabaka River, volcanic mud in, 876

Radiation, 30, 31

Radioactivity, 876

Radiolarian ooze, 457

, analysis of, 677

Ragaz, 251

Ragged Keys, 406

Ragged Top Mt., 308

Ragtown, 361

Raibler beds, 437

Rain, 26, 62, 63

Rainberg, Nagelfluh of, 602

Rainfall, amount of, 63,64

- influence of winds on, 66,67

influence of topography on, 66,67

equatorial type of, 68

tropical type of, 68

tropical type of,

Rain-prints, 712

Ramann, E., cited, 499, 503, 52x, 689

, quoted, 486

Ramsay, W., cited, 175, 689

Rann, the, Miliolite of, 575

Rann of Cutch, 111, 348

, salt deposits in, 617

- salt pans of, 354,355

Ransome, F. L., cited, 315, 321

Rantum, 223

Rantum, advance of dunes in, $55^{8}$

Rapakiwi, 275

Raritan Bay, Pleistocenic gravels, 754

Raritan clays, 632

Raritan formation, dune origin of, 570

, lignitic sands of, 365

Raritan sands, fulgurites in, 73

Ratb, G. von, cited, 879

Rauchwacke, 434

Ravenser, 225

Ravenserodd, 225

Raymond, P. E., cited, 72
Reade, T. M., cited, 175, 244, 248, 267, 634,639

Recklinghausen, coal at, 482

Reclus, J. J. E., cited, 127, 144, 175, 879

Recrystalization, 748, 755

Rectigradations, 961,970

Redbank sands, origin of color of, 673

Red beds, $7 \circ$

Red River, lakes along, 127

Red rafts of, 127

Red Sca, 107, 109, 334, 352, 393

, barrier reefs of, 388

, clay boulders from, $7 \mathrm{II}$

, clay galls from. 71 ,

, fringing reefs in, 386,390

mean temperature of, 193 oölites on shores of, 468 , osmotic pressure in, 180

, salinas on borders of, 355

salinity of, 154, 190, 1044

salt and gypsum on borders of, 348

Reemperature of, $189,190,373$

Reed, F. R. C., cited, 1071

Reede of Suez, oölites of, 336

Reeds, C. A., cited, 684, 689, 1119

Reef knolls, 449
Reefs, atoll, 386

- barrier, 386

- bedded, 417

epicontinental, 389

fringing, 386

inter-fringing of, 422 neritic, 380

reanic, 38

Reelfoot Lake, origin of, 88

Regensburg, Jurassic of, 667

Regnard. P., cited, 181, 207

Regressions, 3

Regressive deposits, 734

Regressive movements, 1141

Regressive-transgressive series, 736, 737

Reibisch, P., cited, 892, 909

Rcid, H. F.. cited, $263,267,328,810,811$

Reind others, cited on faults, 827

Reis, O. M., cited, $782,827,1080,1096$

Relicts, 1044, 1054

Renault, cited, 482

Renevier, cited, 643

Replacement, metasomatic, 761

Reptilia, naming of, 913

Retreatal sandstone, 735, 736

Reusch, H., cited, 81, 267

Reuss, foehn of, 47

Revy, J. J., cited, 661,689

Rewa, Anthozoa in harbor of, 1012

Reyer, cited, 203

Rhabdoliths, 456,933

Rhxtic sandstone, destruction of, 247

Rhang-el-Melah, 379

Rhine, foehn of, 47

- Maare region of, 860

Rhine delta, 607, 642

, lime content of, 622 thickness of, 609

Rhine graben, 815

Rhine River, 137, 248, 250, 251

, velocity of, 245

Rhine Valley, loess of, $56 \mathrm{~s}$

Rhizocarps, 941

Rhizopoda, 942

Rhodes' Marsh, 363

Rhombenporphyry, 305

Rhone, foehn of, 47

Rhone delta, cementation of deposits in, 616

- inclination of strata in, 610

rate of growth of, 609

. thickness of, 609, 610 
Rhymney River, 662

Richmond, Va., diatoms beneath, 461, 676, 1002

Richmond formation, reefs of, 418

Richthofen, F. von, cited, 40, 96, 435, 465, 565,580

Richthofen reef, 434

Ridge, Wyville-Thomson, see Wyville-Thomson ridge

- Faroe-Iceland, 106

Ries, H., cited, 533, 538, 622, 639

Riga, salinity of Baltic at, 1045

Rill marks, 708

Ringer, cited, 194

Rio de la Plata, corals at mouth of, IOI2 , estuary of, II3 temperatures of, 195

Rio de los Papagayos, 367

Rio Grande rise, I05

Rio Janciro, 1015

Riparia, dunes at, 561

Ripple marks, 219,712

greatest depth of formation of, 713

in Devonic limestone of Michigan, 429

Rise, Easter Island, 106

- Kerguelen, 106

River Bar, 136

Findhorn, 252

Jordan, salinity of, 156

Mur, 246

Saale, 252

Spey, 252, 255

Rivers, annual rainfall in, 66

- solids in, 163,164

Rivière Blanche, filling of, 861

Roba-el-Khali desert, dune area of, $5_{52}$

Robertson, cited, 689

Robson, H., cited, 689

Roches moutonnées, 264, 265

Rochester shales, 26 :

Rock city, joints in, 791

Rock fracture, zone of, 142

Rockwood clays, 823

Rogensteine, 283, 336, 472, 473

, structure of, 472,473

Rogers, A. F., cited, 1082, 1087,1096

$\longrightarrow$, A. W. cited, $81,92,96,538$

A. W., and Schwartz, E. H. L. cited, 576,580

Rohlfs, cited, 56 . D., 708

Rolland, quoted, 167

Romanche deep, 188

Romieux, A., cited, 7, 23

Romney shale, 424

Rondout waterlimes, mud-cracks in, 709

Roost, the, 230

Rosalind bank, I 88

Rosenbusch, H., cited, 270, 271, 299, 302, 771,775

Rosendale cement, 731

waterlimes, absent at Kingston, 68I

Rossi, M. S. de, cited, 909

Rotalia, in Severn muds, 664

Roth, J., cited, $164,537,1080,1096$

Rothes Burn, origin of sand of the, 716

Rothliegende, windkanter of, 55

Rothliegende desert, 375

Rothpletz, A., cited, 337, 338, 465, 468, $469,472,474,476,521,1093$

- quoted, $468,784,827$

Royal gorge, 587

Rudaceous texture, 285

Rudolph, E., cited, 879, 909

Rudytes, 285

Ruedemann, R., cited, 243, 268, 474, 521,
$808,823,827,928,981,1011,1012$, 1039, I I 36, I1 45,1149

Ruedemann, R., quoted, 243, 244

Ruetschi, G., cited, 580

Rüst, cited, 458,465

Russell, I. C., cited, 36, 38, 40, 96, 119 , $121,144,159,161,163,164,200,201$, $207,268,324,338,339,340,341,359$, $382,517,625,634,639,870,879$ , quoted, 154, 159, 160, 162, 163, 199, 507,508

Russell,'W. J., cited, 28, 96

Russia, unconsolidated Palzozoic sands of, 750

Rut, tchernozom of, 514

Rutot, A,. cited, 92, 689, 724, 745

\section{$\mathbf{S}$}

Saal feld, 434

Sabrina Island, 864, 865

Saco, flood plain of, 588, 596

Saddle Mt., 313

Saddles, defined, 966

Saginaw Bay, 837

Sahara, 359

$\longrightarrow$ dune area of, 562

- migration of dunes from, 558

preservation of tracks in, 604

- , rainfall of, 63,77 spring water of, 167 strength of wind in, 56

St. Anthony, falls of, II 18

St. Augustine, 406

St. Croix, dalles, 23, 648 formation, 648 sandstone, 729 sandstone, Aglaspis in, 1029

St. Giles, ripple marks of, 713

St. Gotthard Pass, weather in, 48

St. Helena, Island, 105

- harbor of, 215

St. Ignace, brecciated limestone of 547

St. Jean-de-Luz, encroachments of sea at, 558

St. John, absence of Lower Cambric at,

St. John's River, tides in, 227

St. Lawrence, furrow, 104 , gulf of, $235,24 x$ river, 133 spring, drownin

St. Louis limestone, cross-bedding of, 577

St. Michaels, 864,865

St. Paul, Island of, $872,873,875$

St. Peter sandstone, 642

, disconformity represented by, 110 dune origin of parts of, 571

hiatus in, 1132

inclusions in, 717

intercalated, 738,739

loess-like origin of portions of, 569

slight cohesion of, 752

- transgression of 565,738

St. Vincent, erosion on Island of, 875,876 Salem, I04I

Salina, endolithic brecciation in, 537

Salina group, 376

Salina salt, $366,73 \mathrm{I}, 756$

Salinas, 603

Salinity, defined, 145

Salisbury, R. D., cited, $25,42,43,45,46$, $59,96,116,125,144,200,207,247$, 268 


\section{INDEX}

Salitrales, 329

Salitre, 341

Salt, efflorescence of, 124

-, Miocenic deposits of, $35 \mathrm{I}$

Salt domes, 758

Saltenfjord, 230

Salton Sink, 355, 356

Saltstrom, 230

Salversen, Captain, cited, 224

Salzburg, foehn of, 47

- Nagelfluh of, 601, 616, 750, 753

Samoan islands, 40

Samuelson, G., cited, 52

-, quoted, 504, 505

San Bernardino, alluvial fans of, 83

borax lakes in county of, 363, 364

pass, 53

soda niter deposits of, 364

Sandberger, F., cited, 1086

Sand grains, dimming of, 6 effective size of, 258

rounding and sorting of, 61, 715

Sands, coating of, 37 desert type of, 37

Sandwich Islands 386

, marine erosion of, 875

San Filippo, travertine of, 343

San Francisco, Bay of, 111

earthquake at, 882

San Joaquin River, 126

San Juan Mts., rock streams in, 545

San Juan River, section on, 848

Sankaty Head, 599

Santa Anna Island, 4I

Santa Fé, 27

Santa Maria, dust from, 60

San Vignone, baths of, 343

Sapping, 18

Saprocollyte, 480

Saprodillyte, 480

Sapropel, 28

Sapropelite, 281,480

Sapropeliths, 478, 479, 480

Sardinia, Archrocyathidx of, 417

Sargasso Sea, 187,236

, temperature of, 187

Sarle, C. J., cited, 465

-, quoted, 446

Sarmatian reefs, 443

Sassolite, 364

Sault Ste. Marie, 1122

Sava de Malha group, 389, 390

Saville-Kent, W. cited, 391, 400, 401, 465

Savu-Savu, chloride waters of, 168

Scandinavia, eskers in, 599

Scania, Cretacic boulder bed of, 651

Schala, The, 603

Schardt, H., cited, 659, 689

Schiaparelli, G. V., cited, 96

Schiefergebirge, theinische, 375

Schimper, A. F. W., cited, 982, 990, 1000 1039

Schire River, 116

Schist, 279, 770

restriction of term, 770

Schistosity, 769, 794

Schladebach bore hole, 14

Schlern dolomite, 435

Schleswig-Holstein, 223

Coastal dunes of, 557,558

Schmelck, cited, 194

Schnaitheim, quarries of, 439

Schneider, K., cited, 203,207

Schoenite, 371, 372

Schoharie grit, 424

Schoharie region, disconformities in, 823

Schott, G., cited, 149, 150, 207

Schott-Mel-Rir, The, 359
Schramberg, Bunter Sandstein of, 634

Schuchert, C., cited, 957, 1107, i119, 1144 , $1145,1146,1149$

Schuchert, C., and Buckmann, S. S., cited, 957

Schucht, F., cited, 689

Schütt, F., cited, 994,999

Schwart 2, E. H. F., cited, 535, 538

Scilla, land slip at, 888

Sclater, P. L., and W. L., cited, 1056, 1071 Scotland, 219,293

- clay boulders on coast of, 711

- fundamental gneiss of, 252

- Ordovicic rocks of, 315

recent corals of, 392

section of peat moor of, 504

Scoves on coast of, 221

Scorpions, 948, 949

Screes, 33

Scrope, P., cited, 879

Scudder, S. H., cited, 525, 538, 917, 957

Sculpturing processes, 16

Sea, bathymetric zones of, 100 regional subdivisions of, 99 salinity of, 145

Sea.breezes, 44

Sea-lobes of Appalachians, 807,809

Sea of Aral, elevation of, 1 is Azov, 240 Marinity of, 153 Marmora, 240

, salinity of, 153

Okhotsk, 242

Searles's Marsh, 363

- , soda niter of, 364

Seas, dependent, 99, 107

epicontinental, 109

funnel, is

independent, 99, 106

intercontinental, 99, 100

intracontinental, 99, 106

- marginal, 99

Sebcha, the, 603

Secca di Benda Palumno, 470

Secca di Gajola, 470

Secretions, 721

Sedgwick, A., cited, 1099, 1108

Sedgwick, A., and Murchison, R., cited, 1108

Sedimentation, eolian, 5

Seeley, A., cited, $530,538,785$

Seiches, 209, 231

Seidlitz, N. von, cited, 382

Seine bank, no sediments on, 680

Seine-Dacia bank, 335

Seine River, meanders of, 137

tidal bore of, 227

Seismic center, 883

Seismic disturbances, baryseismic, 882

-, pyroseismic. 882

Semper, K., cited, 465, 990, 1019, 1025 $1039,1047,1071$

-, quoted, 986, 1047, 1068, 1069

Semper, M., cited, II49, I I50

Senomien, 730

glauconitic chalk of, 850

Sentis Mts., 176

Sepia, wide distribution of shells of, 1022

Septaria, 763

Sernander, R., cited, 92

Serpentine, 177,279

Sett Sass, reef of, 434

Sezern, corals on wreck of, 412

Severn, estuary of. 662

, tidal bore of, 227

Sevier lake, composition of, 157 
Sevier lake, salinity of, I54

, soda deposits of, 361

Sewell, middle Pottsville at, 742

Seychelles Island, 386, 390

Seyistan, alternation of beds in Lake of, 623

Shaler, N. S., cited, 32, 82, 96, 226, 268, $448,473,485,487,489,49 \mathrm{x}, 494,52 \mathrm{I}$ $522,652,689,694,695,8_{51}, 8_{58}$ quoted, 488, 652

Shaliness, 785

Shan-Tung Mts., 585

Sharon conglomerate, 252

Shaw, E. W., cited, I 36,144

Shawangunk conglomerate, $377,596,636$

Sheboygan, $x 67$

Sheik Zayed, 355

Shelden, J. M. A., cited, 719, 722

Shelf, Florida-Carolina, so6

Sheppard limestone, 334

Sherlock, R. L., cited, 465

Sherzer, W. H., and Grabau, A. W., cited, $422,465,553,570,57 \mathrm{I}, 580$

Shetland Islands, 219,236

- force of waves on, 222

Shimek, B., cited, 566, 580

Shimer, H. W., cited, 981, ro67, ro68, 107 I - - quoted, io66

- and Blodgett, M. E., cited, ro69, I 07 I , and Grabau, A. W., cited, I 3 I, I 150 Shinarump, playa surface in, 709

Shoonmaker quarry, 4 Ig

Shore formations, intercalated, 736

Shropshire, 307, 447

Shunett Lake, 360

Siau, cited, 713

Siberia, Archæocyathidx of, $4 \mathrm{Iz}$

- mammoths of, I075

Siboga expedition, $68 \mathrm{I}$

Siccar Point, unconformity at, 824

Sicily, 240, 343

mud volcanoes in, 872

- Pliocenic foraminifera of, 454

Sickenberger, cited, 369

Sieberg, A., cited, 909

Sierra Nevada, gold+bearing slates of, 773

- rivers from, 584

Silicification, 1079

Sills, 304, 305

Siluric abrupt change in sea-level in, 73 I

- hiatus in Appalachians, 823

- , replacing overlap of, 744

Silver Pit, furrow, I04

Simpson, C. T., cited, ro7 I

quoted, ro59

Simpson formation, 739

Simroth, H., cited, 91, 97, 892, 894, 900, 909, I 019, I 039, I I 44, I I 50

Sinai desert, quartz in, $\mathbf{5 5 2}$

- peninsula, hydrometamorphism on, 767

- oölites on, 336,468

Sinclair, W. J., cited, 538, 539, 572, 580, I I 9

, and Granger, W., cited, 639

-

Singapore, fish falls at, 56

Sinj, earthquakes of, 883

Sink holes, I 76

Sirmur group, 59 I

Siwalik formation, 904

- alternation of colors in, 623

, thickness of, $59 \mathrm{I}$

, torrential origin of, 630

Siwalik Hills, 59I

Siyeh limestone, 334

Skagerak. 224, 1045

Skaptar fissure, lava from, 866
Skeats, E. W., cited, 331, 382, 436, 445, $465,761,775$

Skerries, 65

Skerryvore, 221

Skottsberg, C., cited, 92

Slate, restriction of term, 770

Slatiness, 786

Slaty cleavage, 793

Slavonia, Paludina beds of, 958, 959

Slichter, C. S., cited, 4, $23,140,141,142$, $144,258,259,260,268$

Slickensides, formation of, 768

Smith, J. P., cited, 966, 972, 975, 981, I07, 1134, I136, I 137, I 156

Smyth, C. H., Jr., cited, 763,775

Snake River, dune area of, $56 \mathrm{I}$

- , lava plains of, 867

Snakes, in marine habitat, 985

Snow, 26, 62, 63

Snow line, 322

Society Archipelago, 401, 402

Society Islands, barrier reefs of, 388

Soda Lake, 1 20, 361

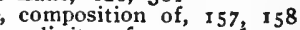

- salinity of, 154,156

Soil, colors of, 36,62 I

Sokolow, N. A., cited, 97, 552, 555, 556, 557,580

, quoted, 56

otora, 456

Soldier Key, 406

Solent, 222

Solfataric action, 768

Sollas, W. J., cited, 662, 689

$\longrightarrow$, quoted, 662,663

Solnhofen, calcilutytes of, 336

- impressions in rock of, 1078

, insects in limestone of, 440

, mud cracks in beds of, 709

reefs of, 437

remains in limestone of, 439

roofing slates of, 786

- solution of limestone of, 175

Solomon Islands, 386, 411

Sombrero, 108

Somerville, drumlins of, 532

Somersetshire oölite, cross-bedding in, 704

Sonora, gold-bearing slates in, 773

Sorby, H. C., cited, 250, 268, 455, 474

Soudan, rainfall of, 68

South African trough, ro5

- temperature in, 187

South Australian shelf, 103

South Brazil shelf, ro3

South China Sea, Io7

South Dakota, artesian basin of, 260

South Pole, migration of, 898

South Tunis, 359

Southern Appalachians, caves in, 346

Spain, monsoons of, 46

, torrential deposits in. 629,630

Spanish Peaks, radiating dikes in, 874

Species, 912,962

Speremberg, bore hole, I3

Sphxrites, consolidation of, $75 \mathrm{I}$

Sphenocon formity, 826

Spirula, wide distribution of shell of, 1022

Spitzbergen, r 92, 236

, postglacial fauna of, 88

- red algæ at, 470

Sponges, 385

Spring, W., cited, 664, 665, 689

Squid, 946, I02 I

Stalactites, 346

Stalagmites, 346

Stamm, K., cited, 580

Stanton, T. W., cited, 1069, 107 I 


\section{INDEX}

Stapff, F. M., cited, 23

Stassfurt, 371

- salts, 350, 372, 374

period of deposition of, 373

Stedman, rings of 355,376

Stedman, J. NI., cited, I077

Steidtmann, Anderson, J. T., cited, 1096.

Steinheim Planorbis of 1043

-, shells in beds at, 631

Steinmann, G., cited, 332, 382, 522, 956, 1074,1096

Stemme, H., cited, 522

Stenohalinity, 1045

Stenothermal organisms, 80

Stephen shale, preservation of organisms in, 1078

Stevenson, J. J., cited, 500, 522

- , quoted, 509, 514, 515, 517, 518

Stevenson, T., cited, $213,218,221,222,268$

$\overline{\text { Stille, }}$, cuoted, 221

Sti.nkkalk, 85

Stinkstein, 434

Stirling Island, 411

Stolle, J., cited, 522

Stone, W., cited, 921,957

Stonesfield slate, 577,1034

Stoneworts, 471,934

Storm King, 1067

Strahan, A., cited, 81, 97, 534, 539

Straits of Bab-el-Mlandeb, 190, 241 Gibraltar, 230, 244 Kertch, 240 salinity of, 152 -, salinity of, 154

Korea, 242

Strand, 647

Stratification, 700, 70

Stratified Rocks, 269

Stratigraphy, I

Stratum, defined, 698,699, 700

Stringocephalus beds, 430

Stromatoliths, 473

Stromatopora, 421, 422, 430, 431 , asphaltic material in, 485

worn heads of, 428

Stromatopora reefs, 423

Stromatoporoids, 385,418

Stromboli, volcano of, 861,871

Stromer, cited, 956

Strophe, climatic, 82, 83

Strutt, cited, 876

Stuben sandstein, origin of, 635

-, reptiles in, 953

Stuttgart, weather at, 48

Styliolina limestone, 456, 1023

Stylolites, $786,787,788$

Subaèrial fans, overlaps of, 740

Subatlantic climatic period, 506

Subarctic climatic period, 506

Sub-mutation, 961,962

Suchier, cited, 250, 268

Suess, E., cited, 3, 138, 201, 202, 203, 207 $595,639,760,775,881,909$

Suez, Bitter Lakes of, 697

$\longrightarrow$, Quaternary oölite near, 469

Suez Canal, date of cutting, 352

- migration through, 1042

Loaf Mountain (Brazil), 32

Sumatra, 390 , oscillation poles in, 893

, peat swamp on, 509,510, 512

Summer Lake, 118

Sunda Islands, 242

Sunderland, coast of, 225

Supan, A., cited, 74, 77, 78, 97, 101, 105 106, 144, 678, 689
Surface features of earth, compared, 13

Susquehanna River, 845

Sussex, chalk from, 454

Sutherland, conglomerate of, 65 s

Sutton, Mass., graben at, 815

Swabian Alp, 442 , cuestas of, 838

- Jurassic reefs of, 438

Swainson, T., cited, 917,918

Sweden, Cambric windkanter of, 573 , coast of, 241

Cretacic boulder beds of, 65

- overlap of basal Cambric of, 728

Swell, Crozet, 106

Swells, 209

Sylt, Island of, 223

, dunes of, 557,558

Sylvania sandstone, 642 cross-bedding in, 570, 571, 704 , dune origin of, 571

hiatus in, 1132

inclusions in, 717

, slight cohesion of, 752

trangression of, 565

Sylvinite, 371,372

Sylvite, 372

Symphrattism, 749

Synchroneity, black shale across planes of, 732

Syntype, 919

Syracuse salt, 376

Syr-darja (Syrdaria), 561, 608

Syria, 240

coast of, 218

- desert areas of, 562

Szovata, 122

\section{$\mathbf{T}$}

Tabasco, volcanic ash deposit of, 60

Tachygenesis, 964

Tahiti, 388, 401, 402, 410

Takyr, 603, 709

Talbot formation, 87

Talc, 177

Talcot, Captain, cited, 609

Talheim, stylolites of, 788

Taltal, 365

Talus, 32

Taman, peninsula of, 443

Tamaracks, 498

, filling of swamps by, 496

Tampa beds, casts of corals in, 1090

Tanfiljef, G. I., cited, 92

Tapachula, volcanic ash deposit of, 60

Tapir, 956

Taramelli, T., cited, 92

Tarapaca desert, 365

二-, soda niter deposits in, 364

Tarawera, eruption of, 60

Tarim River, 588

Tarr, R. S., cited, 642,689

Tasmania shelf, 104

Tasmanian Sea, 112

Taurida, Russia, dunes of, 560

Taylor, F. B., cited, 909

Tay River, peat of, 514

Tectonic, restriction of term, 88

Teisseyre, L., cited, 443,465

Teleosts, 952

Temiscaming syncline, 8 io

Temperature arrangement, dichothermal, 183

3 , heterothermal, 183

homothermal, 183 
Temperature arrangcment, katothermal, 183 Teneriffe, 244

Peak, trade winds of, 44

Tenison-Woods, cited, 1013

Tennessec, Lower Cambric limestone of, 335

Tentaculite limestone, 456, I 124

Tepee buttes, 447,448

Tepetate, 341,586

Teredo, 632, 1016

Terek delta, rate of growth of, 609

Termites, height of nests of, 694

Terra rossa, 40

Terreild, cited, 156

Tetrabranchiata, 946

Tetragraptus, 978

Tetraseptata, 913, 943, 1013

Teuchern, Limulus in brown coal of, 1029

Teutoburger Wald, 673

Texas, deformed salt domes of, 758

Textularia, in Severn muds, 664

Thalassic zone, 987

Thalassogenic deposits, 329

Thalassoseisma, 881

Thallophytes, 935

Thal weg, 258

Thames River, 248

-, currents in, 229

Thenardite, 363

Theobold, cited, 56, 97

Thermonatrite, 362

Thesis, climatic, 82,83

Thet is Sea, 375

Thompson, Sir W., cited, 897, 909

-, quoted, 897,898

Thomson, W., cited, $450,107 \mathbf{x}$

Thon-gallen, 711

Thoroddsen, T., cited, 879

Thorpe, parish of, 225

Thorshaven (Faroe Islands), 31

Thoulet, J., cited, 34, 97, 268, 288, 299, $452,679,689,879$

-, quoted, 55

Thuringia, Kupferschiefer of, 479

, Zechstein reefs in, 433

Thüringer Wald, 252

Thurr, the, 355

Thursday Island, 404

Tian-Shan Mountains, sands brought from, 561

Tiber, cuspate delta of, 608

Tibet, borax deposits of, 364

Tichenor limestone, 684

Tidal bore, 227

Tidal race, 229

Tiddeman, R. H., cited, 432, 449, 465

, quoted, 433

Tides, 227

Tile fish, destruction of, 195

Tillard, Captain, 864

Tillers Ferry, fish falls of, 56

Tillite, 534

Timor, 242

Tirolites stage, preserved in a Tracbyceras, 975

Titanothere, 956

Tizard bank, 391

Todd, J. E., cited, 719,722

Toledo anticlinals, 810

Tolman, C. F., cited, 97, 197, 207

- quoted, 147,148

Toltry, 443

Tomboro, dust from, 60

Tonga deep, 3,896

- temperatures in, 187

Tonkin-Hong-Kong shelf, 104

Topography, karren, 176

$\longrightarrow$, lapiaz, 176
Topotype, 919

Top-set beds, 702

Torell, O., cited, 236

Tornquist, A., cited, $690,1134,1 \times 50$

Torres Strait, 387

Torridon sandstone, 33; 293 , arkose character of, 84

windkanter of, 54,573

Tortugas, 391

- dry, 406

Toula, F., cited, 1150

Tournasien, reefs of the, 432

Toxodontia, 956

Trachyceras, retarded, 975

Trachytes, depths of formation, 15

Transcaspian Desert, see Kara Kum

$\longrightarrow$, dunes in, 563, 564

Transgressions, $3,725,738$, I 14

Transportation, 17,18

Trantance of eolian, 58,59

Trap, 278

Traverse Bay, reefs of, 429

- group, 423, 426

Travertine, 343

Treasury Island, 4I 1

Treitz, P., cited, 92

Trench, Japan, 106

-, Marian, 106

Trenton Falls, deformation in limestones of, 783,784

- limestone, distortion of, 530

- - overlapped by Utitica shales, 743 .

Triassic time, climatic conditions of, 70

Tricyrtida, 458

Trigonodus limestone, stylolite from, 786

Trilobites, 912,947

Trinity formation, 729

Tripoli, diatomaceous earth of, $46 x$

Tripolite, $460,461,676$

Tristan da Cunha, 105, 452

pteropod ooze near, 456

Trona, 362,363

Truckee River, 160

Truro, sands from, 559

- sand plains of, 600

Tschermak, cited, 203

Tschudi, cited, 461

Tsien-Tang River, tidal bore of, 227

Tsunamis, $88 \mathrm{r}, 889$

Tufa, calcarcous, 342 dendritic, 340,341

lithoid, 339

thinolithic; 339

Tulare Lake, 126

Tule Arroyo, onyx marble of, 344

Tully, pyrite layer, fauna of, 1045, 1065

Tultenango, Permic position of North Pole at, 536

Tumlirz, O., cited, 23

Tundra, frozen soil of, 200

Tung lakes of, 121

Sea, 107

Tunis, 240

Turbarian, 506

Turkestan, 358

, earthquake in, 885

"Turks' Heads," 403

'Turks' Island, 412

Turonien, 730,850

Turtle Mountain, rock fall on, 546

-.. stones, 720

Tuscany, 343

- borate deposits of, 364 




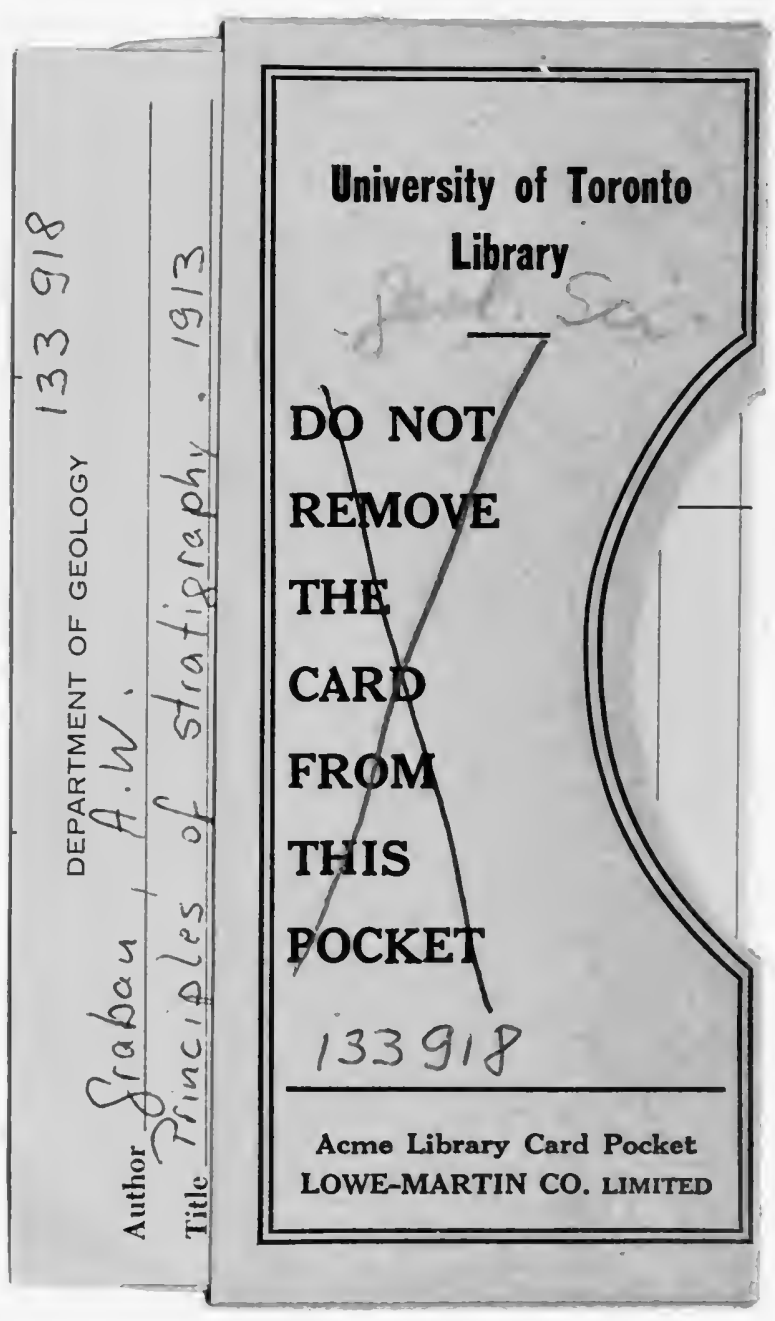


